\title{
§ 2 Die Anfechtungsklage
}

1 Der gutachterlichen Prüfung der Anfechtungsklage liegt die folgende Struktur zugrunde:

A. Zulässigkeit

I. Eröffnung des Verwaltungsrechtswegs (dazu § 1 Rn. 162ff.)

II. Statthafte Klageart (dazu einführend $\S 1 \mathrm{Rn}$. 222ff. sowie ausführlich in diesem $\S$ Rn. 2ff.)

III. Klagebefugnis (dazu Rn. $281 \mathrm{ff}$.)

IV. Vorverfahren (dazu Rn. $301 \mathrm{ff}$.)

V. Klagefrist (dazu Rn. $353 \mathrm{ff}$.)

VI. Beteiligte (dazu Rn. $403 \mathrm{ff}$.)

VII. Zuständiges Gericht (dazu Rn. 462ff.)

VIII. Rechtsschutzbedürfnis (dazu Rn. $476 \mathrm{ff}$.)

B. Begründetheit (zur Struktur der Begründetheitsprüfung einführend Rn. $507 \mathrm{ff}$.)

I. Rechtswidrigkeit des Verwaltungsakts

1. Ermächtigungsgrundlage (dazu einführend Rn. 554 ff.)

2. Formelle Rechtmäßigkeit

a) Zuständigkeit (dazu Rn. 580 ff.)

b) Verfahren (dazu Rn. $621 \mathrm{ff}$.)

c) Form (dazu Rn. 681 ff.)

3. Materielle Rechtmäßigkeit (dazu Rn. 712ff.)

a) Tatbestand der Ermächtigungsgrundlage

b) Rechtsfolge der Ermächtigungsgrundlage

II. Verletzung in subjektiven Rechten (dazu Rn. 828 ff.)

Die Prüfung der klausurrelevanten Ermächtigungsgrundlagen des Allgemeinen Verwaltungsrechts wird in Rn. $832 \mathrm{ff}$., des Polizei- und Ordnungsrechts in Rn. 1000 ff., des Versammlungsrechts in Rn. 1141 ff., des Bauordnungsrechts in Rn. 1222 ff., des Kommunalrechts in Rn. 1252ff. und des Verwaltungsvollstreckungsrechts in Rn. $1292 \mathrm{ff}$. vertieft.

\section{Gliederung}

A. Die Statthaftigkeit der Anfechtungsklage -91

I. Einführung in die Anfechtungsklage (Jens Milker) -92

1. Die Rechtsnatur der Anfechtungsklage — 92

Ә OpenAccess. () 2019 Nikolas Eisentraut, publiziert von De Gruyter. (cc)BY-sA Dieses Werk ist lizenziert unter der Creative Commons Attribution-ShareAlike 4.0. International. 
2. Das Begehren: Aufhebung eines noch nicht erledigten Verwaltungsakts 94

a) Allgemeines -94

b) Einzelfälle (insbesondere Abgrenzung zu anderen Klagearten) - 96

aa) Nebenbestimmungen, Wiederaufgreifen des Verfahrens und Zurückstellung von Baugesuchen -96

bb) Bereits erledigte Verwaltungsakte -97

cc) Nichtige Verwaltungsakte -97

dd) Nicht bekanntgegebene Verwaltungsakte — 98

ee) Rein formelle Verwaltungsakte - 99

3. Überblick über den Gegenstand der Anfechtungsklage

101

a) $\S 79$ I Nr. 1 VwGO als Regelfall — 101

b) Der Abhilfe- oder Widerspruchsbescheid als alleiniger Gegenstand der Anfechtungsklage 102

aa) Isolierte Anfechtung des Abhilfe-/Widerspruchsbescheids bei „erstmaliger Beschwer“ (§ 79 I Nr. 2 VwGO) 102

bb) Isolierte Anfechtung des Widerspruchsbescheids bei „zusätzlicher und selbstständiger Beschwer“ (§ 79 II VwGO) — 104

c) Vorgehen in der Klausur — 106

II. Der Begriff des Verwaltungsakts (Jens Milker) — 106

1. Funktionen des Verwaltungsakts -106

2. Merkmale eines Verwaltungsakts $-\mathbf{1 0 7}$

a) „Verfügung, Entscheidung oder andere hoheitliche Maßnahme“ — 108

aa) Maßnahme - 108

bb) „Hoheitlich“ - 110

b) Maßnahme einer „Behörde“ — 112

c) Maßnahme „auf dem Gebiet des öffentlichen Rechts“ — 116

d) „Regelung“ — 117

aa) Allgemeines 117

bb) Vorgelagerter Verwaltungsakt — 118

cc) Polizeiliche Standardmaßnahmen und Vollstreckungshandlungen — 120

e) Maßnahme „zur Regelung eines Einzelfalls“ — 122
aa) Konkret-individuelle Maßnahmen — 122
bb) Konkret-generelle Maßnahmen — 123
cc) Abstrakt-individuelle Maßnahme 126
dd) Abstrakt-generelle Maßnahme 127

f) Außenwirkung 128

3. Prozessuale Folgen bei Fehlen der Voraussetzungen — 132

III. Die Wirksamkeit des Verwaltungsakts (Tobias Brings-Wiesen) — 133

1. Die Wirksamkeit von Verwaltungsakten i. S.v. § 43 VwVfG 134

a) Die Wirksamkeit von Verwaltungsakten in materieller und persönlicher Hinsicht 135

b) Die Wirksamkeit von Verwaltungsakten in zeitlicher Hinsicht - 139

2. Wirksamwerden von Verwaltungsakten, § 43 I VwVfG - 146

a) Allgemeine Voraussetzungen der Bekanntgabe - 148

aa) Auf Seiten der erklärenden Behörde — 149

bb) Auf Seiten des Empfängers — 152 
b) Ergänzende bzw. abweichende besondere Vorgaben nach Art der Bekanntgabe 157

aa) Einfache individuelle Bekanntgabe - 158

bb) Elektronische Bekanntgabe - 164

cc) Öffentliche Bekanntgabe 168

dd) Die Bekanntgabe von Verwaltungsakten mittels Zustellung

c) Rechtsschutz bei Fehlern im Wirksamwerden eines Verwaltungsakts — 180

3. Das Ende der Wirksamkeit gemäß § 43 II VwVfG 182

a) Konstellationen der Aufhebung eines Verwaltungsakts 183

b) Konstellationen der Erledigung eines Verwaltungsakts (durch Zeitablauf oder auf andere Weise) — 183

c) Rechtsschutz bei Beendigung der Wirksamkeit - 188

4. Unwirksamkeit aufgrund von Nichtigkeit, § 43 III VwVfG — 188

a) Statthaftigkeit der Anfechtungsklage nach § 42 I Var. 1 VwGO bei nichtigen Verwaltungsakten? 190

b) Erhebung eines Widerspruchs gegen den nichtigen Verwaltungsakt gemäß §§ $68 \mathrm{ff}$. VwGO 192

5. Literaturhinweise - 193

IV. Die Anfechtung von Nebenbestimmungen (Christian Kaerkes) — 193

1. Die Nebenbestimmungen im Einzelnen 195

a) Befristung — 195

b) Bedingung — 196

c) Auflage, Abgrenzung und „modifizierende Auflage“ — 198

aa) Auflage - 198

bb) Abgrenzung von Bedingung und Auflage — 199

cc) „Modifizierende Auflage“ und Inhaltsbestimmung 201

d) Widerrufs- und Auflagenvorbehalt -202

e) Keine Nebenbestimmungen -204

2. Zulässigkeit von Nebenbestimmungen - 204

3. Rechtsschutz gegen Nebenbestimmungen — 207

a) Sonderfall - „Modifizierende Auflage“ — 208

b) Echte Nebenbestimmungen — 209

aa) h.M.: Anfechtungsklage 209

bb) a. A.: Verpflichtungsklage -210

cc) a. A.: Unterscheidung nach der Art des Hauptverwaltungsaktes - 211

dd) a. A.: Unterscheidung zwischen den Nebenbestimmungen - 212

ee) Ergebnis — 214

4. Literaturhinweise -214

B. Weitere Zulässigkeitsvoraussetzungen der Anfechtungsklage - 214

I. Die Klagebefugnis (Hendrik Burbach) -215

1. Voraussetzungen des $\S 42 \mathrm{II}$ VwGO 216

a) Möglichkeitstheorie - $\mathbf{2 1 6}$

b) Adressatentheorie - 217

c) Drittanfechtungsklagen $-\mathbf{2 1 8}$

2. Formulierungsvorschlag 219

3. Literaturhinweise -219 
II. Das Vorverfahren (Renana Braun) - 220

1. Erforderlichkeit des Vorverfahrens -221

2. Ordnungsgemäße Einlegung - 223

a) Handlungsfähigkeit (§§79, 11 ff. VwVfG) - 223

b) Einhaltung der Widerspruchsform ( $(70$ I 1 VwG0) — 223

c) Einhaltung der Widerspruchsfrist ( $(70$ I 1 VwGO) — 224
aa) Monatsfrist - 224
bb) Jahresfrist 226
cc) Verstreichen der Widerspruchsfrist -226
dd) Verwirkung 228
d) Richtige Behörde — 229

3. Erfolglosigkeit des Widerspruchs $-\mathbf{2 3 0}$

4. Prüfungsschema Erfolgsaussichten eines Widerspruchs

5. Reformatio in peius („Veränderung ins Schlechte“) - 232

a) Besonderheiten bei der Prüfung der Zulässigkeit der Klage — 232

b) Besonderheiten bei der Prüfung der Begründetheit der Klage — 232
aa) Ermächtigungsgrundlage -233
bb) Formelle Rechtmäßigkeit -234
cc) Materielle Rechtmäßigkeit — 234

6. Literaturhinweise — 235

III. Die Klagefrist (Patrick Stockebrandt) - 236

1. Funktion der Klagefrist und Bestandskraft eines Verwaltungsakts -236

2. Systematik und Bezug zum Vorverfahren - 238

3. Fristberechnung 238

a) Fristende fällt auf einen Sonnabend, Sonn- oder Feiertag - § 222 II ZPO 239

b) Unterbliebene oder fehlerhafte Rechtsbehelfsbelehrung - §58 II VwGO 240

4. Bekanntgabe als fristauslösendes Ereignis und die sog. „Drei-Tages-Fiktion“ — 241

5. Zustellung als fristauslösendes Ereignis und verschiedene Zustellungsarten — 242

a) Zustellung durch die Post mittels Zustellungsurkunde — 242

b) Zustellung durch die Post mittels Einschreiben — 243

aa) Ersatzempfänger beim Einschreiben — 244

bb) Zugang im Falle der Notwendigkeit der Abholung eines Einschreibens bei der Post 244

6. Untätigkeit der Behörde - §75 VwGO 245
a) Zureichender Grund für die Verzögerung — 245
b) Angemessene Frist \& dreimonatige „Sperrfrist“ — 246
c) Zeitliche Begrenzung der Klage - $\mathbf{2 4 6}$

7. Weitere Bereiche -246
a) Wiedereinsetzung in den vorigen Stand - §60 VwGO
247
b) Klageverwirkung -248
8. Literaturhinweise -248

IV. Die Beteiligten (Carola Creemers) - 248

1. Beteiligte, $\S 63$ VwGO 249

2. Passive Prozessführungsbefugnis, § 78 VwGO 250
a) Richtiger Beklagter nach $\S 78$ I VwGO 250
b) Sonderfall: Widerspruchsbescheid als Klagegegenstand — 251
c) Aufbauproblem: Prüfungsstandort des $\S 78$ VwGO 251

Nikolas Eisentraut 
3. Beteiligungsfähigkeit, § $61 \mathrm{VwGO}$ 252

a) Beteiligungsfähigkeit von natürlichen und juristischen Personen

(§ 61 Nr. 1 VwGO) 253

b) Beteiligungsfähigkeit von Vereinigungen ( $(61$ Nr. 2 VwGO) - 255

c) Beteiligungsfähigkeit von Behörden nach Landesrecht (§ $61 \mathrm{Nr} .3$ VwGO)

4. Prozessfähigkeit, § 62 VwGO 256

a) Prozessfähigkeit Geschäftsfähiger (§ 62 I Nr. 1 VwGO) — 257

b) Prozessfähigkeit beschränkt Geschäftsfähiger (§ 62 I Nr. 2 VwGO)

c) Fehlende Prozessfähigkeit -258

d) Vertreter von Vereinigungen und Behörden ( 62 III VwGO) - 258

5. Postulationsfähigkeit und Prozessvertretung, § $67 \mathrm{VwGO}-258$

6. Beiladung, § $65 \mathrm{VwGO} \longrightarrow 259$

a) Einfache (fakultative) Beiladung ( $(65$ I VwG0) -260

b) Notwendige (obligatorische) Beiladung ( $\$ 65$ II VwGO) - 261

7. Subjektive Klagehäufung (Streitgenossenschaft), § 64 VwGO 262

a) Einfache Streitgenossenschaft ( 64 VwGO i. V.m. §§ 59, 60 ZPO) - 263

b) Notwendige Streitgenossenschaft (§ 64 VwGO i.V.m. §§ 62 ZPO) - 264

8. Literaturhinweise - 264

V. Das zuständige Gericht (Katharina Goldberg) — 265

1. Sachliche Zuständigkeit -265

2. Örtliche Zuständigkeit 267

3. Literaturhinweise - 268

VI. Das Rechtsschutzbedürfnis (Dana-Sophia Valentiner) - 268

1. Das Rechtsschutzbedürfnis als allgemeine

Sachentscheidungsvoraussetzung -268

a) Herleitung -268

b) Prüfungsanforderungen und -umfang -269

c) Relevante Fallgruppen $-\mathbf{2 7 1}$

aa) Rechtsschutzziel kann auf einfachere Art und Weise erreicht werden

bb) Rechtsschutz verspricht keinerlei Vorteil für die rechtsschutzsuchende Person 272

cc) Rechtsmissbräuchliche Inanspruchnahme des gerichtlichen Verfahrens 273

(1) Verspätete Geltendmachung — 273

(2) Verwirkung -274

2. Das allgemeine Rechtsschutzbedürfnis als Sachentscheidungsvoraussetzung der Anfechtungsklage $-\mathbf{2 7 4}$

3. Literaturhinweise -275

\section{Begründetheit -275}

I. Die Struktur der Begründetheitsprüfung (Dominik Marek Kowalczyk) -275

1. Einführung in die Struktur der Begründetheitsprüfung von Anfechtungsklagen $-\mathbf{2 7 8}$

2. Rechtswidrigkeit des angefochtenen Verwaltungsakts im Überblick 280
a) Ermächtigungsgrundlage -281
b) Formelle Rechtmäßigkeit 283
c) Materielle Rechtmäßigkeit -283

3. Verletzung subjektiver Rechte des Klägers — 286 
4. Maßgeblicher Zeitpunkt für die Beurteilung der Rechtmäßigkeit des angefochtenen Verwaltungsakts 287

5. Besonderheiten im Falle von Drittanfechtungsklagen 289

6. Literaturhinweise 291

II. Die Prüfung der Rechtmäßigkeit des Verwaltungsakts im Einzelnen (Bernhard Hadank; Sebastian Eickenjäger; Julian Senders; Tristan Lemke; Daniel Benrath) — 292

1. Das Erfordernis einer Ermächtigungsgrundlage (Bernhard Hadank) -292

a) Verfassungsrechtliche Grundlage des Vorbehalts des Gesetzes — 293

b) Umfang des Vorbehalts des Gesetzes — 294

aa) Belastende Maßnahmen der Eingriffsverwaltung — 295

bb) Begünstigende Maßnahmen der Leistungsverwaltung — 296

cc) Verdichtung des Vorbehalts des Gesetzes zum Parlamentsvorbehalt — 299

c) Prüfung der Ermächtigungsgrundlage im Rahmen der Anfechtungsklage — 301

d) Zusammenfassung $\mathbf{3 0 2}$

e) Literaturhinweise — $\mathbf{3 0 3}$

2. Formelle Rechtmäßigkeit des Verwaltungsakts — $\mathbf{3 0 3}$

a) Zuständigkeit (Sebastian Eickenjäger) — $\mathbf{3 0 3}$

aa) Bestimmung der sachlichen Zuständigkeit - 304

(1) Verbandskompetenz -304

(2) Organkompetenz — 307

(a) Bundesverwaltungsaufbau $-\mathbf{3 0 7}$

(b) Landesverwaltungsaufbau $-\mathbf{3 0 8}$

(3) Zuständigkeit im Widerspruchsverfahren - 311

(4) Folgen eines Verstoßes gegen die sachliche Zuständigkeit — 312

bb) Örtliche Zuständigkeit — 313

cc) Literaturhinweise 314

b) Verfahren (Julian Senders) - 315

aa) Überblick: Begriff und Systematik der Verwaltungsverfahren — 317

bb) Das nichtförmliche Verwaltungsverfahren — 318

(1) Insbesondere: Anhörung nach § $28 \mathrm{VwVfG}-320$

(a) Entbehrlichkeit der Anhörung nach § 28 II VwVfG — 320

(b) Unterbleiben der Anhörung nach § $28 \mathrm{III}$ VwVfG 321

(2) Weitere Verfahrensgrundsätze im nichtförmlichen Verfahren - 321

(3) Heilung von Verfahrensfehlern - 324

(4) Unbeachtlichkeit von Verfahrensfehlern - 326

cc) Das förmliche Verfahren — 327

dd) Das Planfeststellungsverfahren - 328

ee) Literaturhinweise -330

c) Form (Tristan Lemke) $\mathbf{3 3 0}$

aa) Schriftform - 331

bb) Elektronische Verwaltungsakte und elektronische Form — 331

cc) Rechtsbehelfsbelehrung - 332

dd) Begründung - 332

ee) Heilung und Unbeachtlichkeit von Formfehlern - 333

(1) Heilung von Formfehlern, § 45 I VwVfG 334

(2) Insbesondere: Nachholen von Gründen, § 45 । Nr. 2 VwVfG — 335

(3) Nachschieben von Gründen — 335 
(4) Unbeachtlichkeit von Formfehlern, § 46 VwVfG 336

ff) Bestimmtheit des Verwaltungsakts

338

gg) Literaturhinweise 339

3. Materielle Rechtmäßigkeit des Verwaltungsakts (Daniel Benrath)

a) Rechtsbindung und Spielräume der Verwaltung

342

aa) Verwaltung zwischen Rechtsbindung und Spielräumen 343

bb) Gebundene Entscheidungen — 346

cc) Ermessen — 346

dd) Weitere Spielräume — 348

ee) Fehlerlehre — 351

(1) Ermessensspielraum - 353

(2) Beurteilungsspielraum und Bewertungsspielraum

b) Inhaltliche Vorgaben an die Rechtmäßigkeit des Verwaltungsakts 357

aa) Verwaltungsaktbefugnis 358

bb) Inhaltliche Vorgaben der Rechtsgrundlage — 359

cc) Allgemeine Grundsätze — $\mathbf{3 6 0}$

(1) Verhältnismäßigkeit -360

(2) Gleichbehandlungsgebot -363

(3) Keine Unmöglichkeit — 365

dd) Sonstige rechtliche Vorgaben - 367

(1) Vorrangiges Recht - 368

(2) EU-Recht - 368

(3) Sonstiges Recht -368

c) Richtiger Adressat 369

d) Spezifische Fehler bei der Inanspruchnahme von Spielräumen 370
aa) Nichtgebrauch 371
bb) Fehlgebrauch 371

e) Der Aufbau der Prüfung der materiellen Rechtmäßigkeit 373

aa) Verhältnis zu anderen Teilen der Prüfung — 374

bb) Dimensionen, Perspektiven und Herausforderungen des Prüfungsaufbaus 374

cc) Schema-Angebote und deren Vor- und Nachteile - 376

f) Maßgeblicher Zeitpunkt der Rechtmäßigkeitsprüfung — 383

g) Literaturhinweise 384

III. Verletzung subjektiver Rechte (Nikolas Eisentraut) - 384

IV. Klausurrelevante Ermächtigungsgrundlagen und ihre Prüfung (Tobias Brings-Wiesen; Nikolas Eisentraut; Sebastian Eickenjäger; Felix Steengrafe; Sebastian Piecha; Mariamo Katharina Ilal) 386

1. Ermächtigungsgrundlagen des Allgemeinen Verwaltungsrechts (Tobias Brings-Wiesen) 386

a) Die behördliche Aufhebung eines Verwaltungsakts gemäß §§ $48 \mathrm{f}$. VwVfG

b) Rücknahme eines Verwaltungsakts nach § $48 \mathrm{VwVfG}-392$

aa) Ermächtigungsgrundlage, § 48 I 1 VwVfG — 393

bb) Formelle Rechtmäßigkeit — 394
(1) Zuständigkeit — 394
(2) Verfahren - 396
(3) Form - 396 
cc) Materielle Rechtmäßigkeit 397

(1) Überblick über die Prüfung des Tatbestands 397

(2) Tatbestandsmerkmal 1: Vorliegen eines Verwaltungsakts

(3) Tatbestandsmerkmal 2: Rechtswidrigkeit des aufzuhebenden Verwaltungsakts 400

(4) Tatbestandsmerkmal 3: Belastender oder begünstigender Verwaltungsakt 403

(5) Besondere Tatbestandsvoraussetzungen bei Rücknahme eines begünstigenden Verwaltungsakts, § 48 II bis IV VwVfG

(a) Leistungsverwaltungsakte, § 48 II VwVfG — 405

(b) Sonstige Verwaltungsakte $-\mathbf{4 1 5}$

(c) Kein Ausschluss aufgrund von Verfristung gemäß § 48 IV VwVfG 416

(6) Rechtsfolge: Ermessen, § 48 I $1 \mathrm{VwVfG}$ 423

(a) Im Falle eines belastenden Verwaltungsakts _ 423

(b) Im Falle eines begünstigenden Verwaltungsakts - 425

(7) Rücknahme von Verwaltungsakten im unionsrechtlichen Kontext

(a) Vollzug von Unionsrecht durch die Verwaltung — 429

(b) Besonderheiten bei der Rücknahme von begünstigenden EU-beihilfenrechtswidrigen Verwaltungsakten 430

(c) Die Rücknahme unionsrechtswidriger Verwaltungsakte im Übrigen -440

dd) Literaturhinweise -443

c) Widerruf eines Verwaltungsakts nach $\S 49 \mathrm{VwVfG}$ 444
aa) Ermächtigungsgrundlage -445
bb) Formelle Rechtmäßigkeit — 445
cc) Materielle Rechtmäßigkeit — 445

(1) Anwendungsbereich - 446

(2) Belastender oder begünstigender Verwaltungsakt — 446
(a) Belastender Verwaltungsakt, § 49 I VwVfG 446
(b) Begünstigender Verwaltungsakt 448

(3) Widerruf von Verwaltungsakten im unionsrechtlichen Kontext 459 dd) Literaturhinweise 460

d) Rücknahme und Widerruf im Rechtsbehelfsverfahren gegen Verwaltungsakte mit Drittwirkung, § 50 VwVfG 461

e) Erstattung, § 49a VwVfG 464

aa) Ermächtigungsgrundlage und formelle Rechtmäßigkeit 465

bb) Materielle Rechtmäßigkeit — 466

f) Die Zusicherung, § 38 VwVfG — 468

Literaturhinweise 469

2. Ermächtigungsgrundlagen des Polizei- und Ordnungsrechts (Nikolas Eisentraut) 469

a) Einführung in das Polizei- und Ordnungsrecht 472

aa) Die Unterscheidung zwischen allgemeinem und besonderem Polizei- und Ordnungsrecht 472

bb) Die Unterscheidung zwischen Landes- und Bundesbehörden 475

cc) Abgrenzung zum Recht der Strafverfolgung — 477 
dd) Abgrenzung zum Recht der Nachrichtendienste und des Verfassungsschutzes 478

ee) Gefahrenabwehr im weiteren Sinne: Gefahrenvorsorge vs. Strafverfolgungsvorsorge 479

b) Prüfungsstruktur im Überblick — 481

c) Ermächtigungsgrundlage -481

aa) Abgrenzung gegenüber Befugnissen des besonderen Gefahrenabwehrrechts 482

(1) Versammlungsrecht $-\mathbf{4 8 2}$

(2) Bauordnungsrecht -484

(3) Weitere Rechtsbereiche - 484

bb) Abgrenzung zwischen Generalklausel(n) und Standardbefugnissen

(1) Die Standardbefugnisse — 485

(a) Gefahrenabwehrmaßnahmen, die auf eine Person oder Sache einwirken 485

(b) Datenerhebung und Datenverarbeitung — 486

(2) Die Generalklausel(n) 490

cc) Die zwangsweise Durchsetzung des allgemeinen Polizei- und Ordnungsrechts 492

d) Formelle Rechtmäßigkeit -492

aa) Zuständigkeit — 492

(1) Sachliche Zuständigkeit -493

(2) Instantielle Zuständigkeit -495

(3) Örtliche Zuständigkeit -495

bb) Verfahren -495

cc) Form -496

e) Materielle Rechtmäßigkeit -497

aa) Die Standardbefugnisse -497

bb) Die Generalklausel — 497

(1) Tatbestandsmerkmale -498
(a) Subsidiarität
498
(b) Öffentliche Sicherheit und Ordnung
498
(c) Gefahr 503
(d) Polizei- und Ordnungspflichtigkeit $\longrightarrow \mathbf{5 0 8}$

(2) Rechtsfolge: Ermessen - $\mathbf{5 1 3}$

f) Literaturhinweise - $\mathbf{5 1 4}$

3. Ermächtigungsgrundlagen des Versammlungsrechts (Sebastian Eickenjäger)

a) Versammlungsrecht in der Klausurbearbeitung — $\mathbf{5 1 6}$

b) Ermächtigungsgrundlagen - $\mathbf{5 1 7}$

aa) Versammlungsbegriffe der Versammlungsgesetze - $\mathbf{5 1 7}$

bb) Öffentliche und nichtöffentliche Versammlungen - $\mathbf{5 1 9}$

cc) Polizeirechtsfestigkeit des Versammlungsrechts - $\mathbf{5 2 1}$

dd) Die einzelnen Ermächtigungsgrundlagen der Versammlungsgesetze 523

c) Formelle Rechtmäßigkeit $-\mathbf{5 2 5}$
aa) Zuständigkeit
525
bb) Verfahren und Form
529 
d) Materielle Rechtmäßigkeit $-\mathbf{5 3 0}$

aa) Versammlungen unter freiem Himmel $-\mathbf{5 3 0}$

(1) VersammlG des Bundes - $\mathbf{5 3 0}$

(2) Landesversammlungsgesetze - 533

bb) Versammlungen in geschlossenen Räumen — 534

(1) VersammlG des Bundes - $\mathbf{5 3 4}$

(a) $\S 5$ - Verbot von Versammlungen in geschlossenen Räumen

(b) $\S 13$ - Auflösung von Versammlungen in geschlossenen Räumen 536

(2) Landesversammlungsgesetze 537

cc) Adressat*innen und Pflichtigkeit im Versammlungsrecht 539

dd) Rechtsfolge: Ermessen - 541

e) Literaturhinweise - $\mathbf{5 4 2}$

4. Ermächtigungsgrundlagen des Bauordnungsrechts (Felix Steengrafe)

a) Einführung in das Baurecht -544

aa) Unterscheidung zwischen Bauplanungs- und Bauordnungsrecht $-\mathbf{5 4 5}$

bb) Verfassungsrechtliche Anknüpfungspunkte des öffentlichen Baurechts 545

b) Die Beseitigungsverfügung 547
aa) Ermächtigungsgrundlagen -547
bb) Formelle Rechtmäßigkeit $-\mathbf{5 4 8}$
cc) Materielle Rechtmäßigkeit $-\mathbf{5 4 8}$
dd) Ermessen - $\mathbf{5 5 0}$

c) Die Nutzungsuntersagung
aa) Ermächtigungsgrundlagen -552
bb) Formelle Rechtmäßigkeit -553
cc) Materielle Rechtmäßigkeit $\mathbf{5 5 3}$

d) Die Stilllegungsverfügung - 553

aa) Ermächtigungsgrundlagen -554

bb) Formelle Rechtmäßigkeit -554

cc) Materielle Rechtmäßigkeit $\longrightarrow 554$

e) Literaturhinweise — $\mathbf{5 5 5}$

5. Ermächtigungsgrundlagen des Kommunalrechts (Sebastian Piecha) 555

a) Einführung in das Kommunalrecht -556

aa) Begriff des Kommunalrechts — 556

bb) Die kommunale Selbstverwaltungsgarantie — $\mathbf{5 5 8}$

cc) Landesrechtliche Ausgestaltung des Kommunalrechts 562

b) Die Anfechtungsklage im Kommunalrecht -563

aa) Maßnahmen der Kommunalaufsicht -564

(1) Ermächtigungsgrundlagen -567

(2) Formelle Rechtmäßigkeit $-\mathbf{5 6 8}$

(3) Materielle Rechtmäßigkeit - $\mathbf{5 6 8}$

bb) Maßnahmen der Kommune gegen Einzelne — 571

(1) Vertretungsverbote Ehrenamtlicher - $\mathbf{5 7 1}$

(2) Sanktionen gegen Ratsmitglieder $\mathbf{5 7 1}$

c) Literaturhinweise — $\mathbf{5 7 2}$ 
6. Ermächtigungsgrundlagen des Verwaltungsvollstreckungsrechts (Mariamo Katharina Ilal) 573

a) Überblick und Einführung in das Verwaltungsvollstreckungsrecht -574

aa) Das Recht zur Selbsttitulierung und Selbstvollstreckung - $\mathbf{5 7 4}$

bb) Normativer Rahmen — $\mathbf{5 7 5}$

cc) Verwaltungszwang - $\mathbf{5 7 6}$

dd) Pflichtiger — $\mathbf{5 7 6}$

b) Das Verwaltungsvollstreckungsrecht in der Klausur 577

aa) Erkennen einer vollstreckungsrechtlichen Konstellation, insbesondere Abgrenzung zu polizeirechtlichen Standardmaßnahmen — 577

bb) Überblick über die typischen Ermächtigungsgrundlagen im Verwaltungsvollstreckungsrecht $-\mathbf{5 7 8}$

cc) Überblick über die Zwangsmittel $\mathbf{5 7 9}$

dd) Typische Rechtsschutzkonstellationen - 581

c) Gestrecktes Verfahren, § 6 I VwVG — $\mathbf{5 8 3}$

aa) Gemeinsame Rechtmäßigkeitsvoraussetzungen von Androhung und Festsetzung - $\mathbf{5 8 4}$

(1) Ermächtigungsgrundlage -584

(2) Formelle Rechtmäßigkeit - $\mathbf{5 8 5}$

(3) Materielle Rechtmäßigkeit: Allgemeine Vollstreckungsvoraussetzungen 585

(a) Wirksamer, bestimmter und vollstreckbarer Grundverwaltungsakt - $\mathbf{5 8 5}$

(aa) Wirksamkeit des Grundverwaltungsakts - $\mathbf{5 8 6}$

(bb) Bestimmtheit des Grundverwaltungsakts - $\mathbf{5 8 7}$

(cc) Vollstreckbarkeit des Grundverwaltungsakts - $\mathbf{5 8 8}$

(b) Richtiges Zwangsmittel — $\mathbf{5 8 8}$

(c) Keine Vollstreckungshindernisse - $\mathbf{5 8 8}$

(d) Ermessen, insbesondere Verhältnismäßigkeit - $\mathbf{5 8 9}$

bb) Besondere Rechtmäßigkeitsvoraussetzungen der Androhung — 589

(1) Besonderheiten innerhalb der formellen Rechtmäßigkeit $-\mathbf{5 9 0}$

(2) Besonderheiten innerhalb der materiellen Rechtmäßigkeit - $\mathbf{5 9 0}$

cc) Besondere Rechtmäßigkeitsvoraussetzungen der Festsetzung — 591

d) Sofortiger Vollzug, § 6 II VwVG -593

aa) Ermächtigungsgrundlage - 594

bb) Formelle Rechtmäßigkeit — 595

cc) Materielle Rechtmäßigkeit - $\mathbf{5 9 5}$

(1) Ohne vorausgehenden Verwaltungsakt - 596

(2) Dringlichkeitstatbestand - 597

(3) Rechtmäßigkeit der hypothetischen Grundverfügung — 599

(4) Zwangsmittel — 599

(5) Ermessen, insbesondere Verhältnismäßigkeit — $\mathbf{6 0 0}$

e) Sekundärebene, insbesondere Kosten — 601

aa) Ermächtigungsgrundlage -602

bb) Formelle Rechtmäßigkeit -603

cc) Materielle Rechtmäßigkeit -603

(1) Rechtmäßige Vollstreckungsmaßnahme 603 
(2) Richtiger Kostenschuldner -604

(3) Richtige Höhe -605

(4) Verhältnismäßigkeit -605

(5) Verjährung - 607

dd) Überblick über die Entschädigungsansprüche - 607

f) Literaturhinweise - $\mathbf{6 0 8}$

V. Der Vollzugsfolgenbeseitigungsanspruch (Jana Himstedt) -608

VI. Die Begründetheitsprüfung bei der Anfechtung von Nebenbestimmungen (Christian Kaerkes) 609

1. Rechtswidrigkeit der Nebenbestimmung - $\mathbf{6 1 0}$

a) Ermächtigungsgrundlage -610

b) Formelle Rechtmäßigkeit $-\mathbf{6 1 0}$

c) Materielle Rechtmäßigkeit -611

aa) Spezialgesetzliche Ermächtigung - 611

bb) Regelfall des § 36 VwVfG — 611

(1) Gebundene Entscheidung — 611

(2) Ermessensentscheidung - 612

(3) Weitere Voraussetzungen -612

2. Verletzung subjektiver Rechte -613

3. Sinnvoller und rechtmäßiger Rest-Verwaltungsakt -613

3. Literaturhinweise -615

\section{A. Die Statthaftigkeit der Anfechtungsklage}

Wurde der Verwaltungsrechtsweg für eröffnet erkannt (s. ausführlich zur Prüfung 2 $\S 1$ Rn. 162ff.), so ist im Rahmen der Zulässigkeit als nächstes die statthafte Klagebzw. Antragsart zu untersuchen. Die Prüfung der statthaften Klage-/Antragsart ist das zentrale Scharnier für die gesamte restliche Klausur. Nach ihr richten sich sowohl die weiteren Zulässigkeitsvoraussetzungen als auch die Struktur der Begründetheitsprüfung. Entsprechend wichtig ist die saubere Prüfung, welche Klage- bzw. Antragsart einschlägig ist (eine erste Übersicht über die Klage- und Antragsarten der VwGO findet sich in $\S 1$ Rn. $222 \mathrm{ff}$.).

Die Anfechtungsklage stellt die in der juristischen Ausbildung am umfas- 3 sendsten behandelte Klageart der VwGO dar, sodass entsprechend umfassende Kenntnisse in Prüfungsarbeiten erwartet werden. Die Anfechtungsklage ist deshalb so bedeutsam, weil sie am engsten mit der in der Ausbildung zentralen Eingriffsverwaltung und der dafür wichtigsten Handlungsform, dem (belastenden) Verwaltungsakt, verknüpft ist. Denn nach § 42 I Var. 1 VwGO kann mittels der Anfechtungsklage die Aufhebung eines Verwaltungsakts begehrt werden.

Nach einer einen ersten Überblick gebenden Einführung in die Anfechtungsklage (Rn. 4ff.) wird der für das gesamte Verwaltungsrecht zentrale Begriff des Verwaltungsakts vertieft (Rn. $38 \mathrm{ff}$.). Ob über den Wortlaut des $\S 42$ I 
Var. 1 VwGO hinaus auch die Wirksamkeit des Verwaltungsakts Voraussetzung für seine Anfechtbarkeit ist, wird ab Rn. 98 behandelt. Als besondere Klausurkonstellation wird abschließend die Statthaftigkeit der Anfechtung von Nebenbestimmungen vertieft dargestellt (Rn. $204 \mathrm{ff}$.).

\section{Einführung in die Anfechtungsklage (Jens Milker)}

4 Die Anfechtungsklage gemäß $§ 42$ I Var. 1 VwGO bietet vornehmlich die prozessuale Möglichkeit, die Wirksamkeit eines nicht erledigten Verwaltungsakts durch dessen „anderweitige“ Aufhebung ${ }^{1}$ gerichtlich zu beseitigen. ${ }^{2}$

$5 \quad$ Zudem kann sie auch bei einem nichtigen ${ }^{3}$ (vgl. dazu Rn. 19) und rein formellen Verwaltungsakt ${ }^{4}$ (vgl. dazu Rn. $21 \mathrm{ff}$.) sowie einem Scheinverwaltungsakt ${ }^{5}$ (dazu Rn. 20) statthaft sein.

Im Folgenden soll zur Verdeutlichung der Stellung der Anfechtungsklage im Rechtschutzsystem der VwGO zunächst allgemein auf ihre Rechtsnatur (Rn. 6 ff.), das für ihre Statthaftigkeit erforderliche Klägerbegehren (Rn. 9 ff.) und schließlich ihren Gegenstand (Rn. $25 \mathrm{ff}$.) eingegangen werden.

\section{Die Rechtsnatur der Anfechtungsklage}

6 Ihrer Art nach ist die Anfechtungsklage eine Gestaltungsklage, ${ }^{6}$ d. h., ihre Wirkungen treten bereits kraft Gesetzes ein und bedürfen keiner Vollstreckungsmaßnahme. ${ }^{7}$ Damit scheidet im Urteil auch der Ausspruch einer vorläufigen

1 Vgl. § 43 II Alt. 3 VwVfG; die Verwaltungsverfahrensgesetze der Länder enthalten insoweit identische oder jedenfalls ähnliche Regelungen. Im Folgenden wird ausschließlich auf das VwVfG des Bundes Bezug genommen.

2 Vgl. BVerwG, Beschl.v. 21.03.1990, Az.: 9 B 276/89 = NVwZ 1990, 774; in der Regel wird es sich dabei um einen belastenden Verwaltungsakt handeln, vgl. dazu etwa Pietzcker, in: Schoch/ Schneider/Bier, VwGO, 36. EL Februar 2019, § 42 I VwGO, Rn. 7 ff.

3 Vgl. BGH, Urt. v. 09.02.1979, Az.: RiZ (R) 6/78 = NJW 1979, 1710; s. auch R. P. Schenke, in: Kopp/ Schenke, VwGO, 25. Aufl. 2019, § 42 VwGO, Rn. 3.

4 Dabei handelt es sich um eine behördliche Handlungsform, die nur nach dem äußeren Anschein einen Verwaltungsakt darstellt, die Voraussetzungen eines Verwaltungsakts in materieller Hinsicht aber nicht erfüllt, vgl. dazu Stelkens, in: Stelkens/Bonk/Sachs, VwVfG, 9. Aufl. 2018, § 35 VwVfG, Rn. 16.

5 Vgl. dazu Blunk/Schroeder, JuS 2005, 602 (603f.); im Ergebnis die Statthaftigkeit der Anfechtungsklage ablehnend: Bickenbach, JA 2015, 481 (487).

6 Pietzcker, in: Schoch/Schneider/Bier, VwGO, 36. EL Februar 2019, § 42 I VwGO, Rn. 2; R. P. Schenke, in: Kopp/Schenke, VwGO, 25. Aufl. 2019, § 42 VwGO, Rn. 2.

7 Pietzcker, in: Schoch/Schneider/Bier, VwGO, 36. EL Februar 2019, § 42 I VwGO, Rn. 2.

Nikolas Eisentraut/Jens Milker 
Vollstreckbarkeit in Bezug auf die Hauptsacheentscheidung konsequenterweise aus, wie daher auch $\S 167$ II VwGO ausdrücklich festlegt. Das Gericht hebt bei Erfolg der Klage im Urteilsausspruch den angegriffenen Verwaltungsakt auf und gestaltet damit - anders als etwa bei Leistungsklagen - unmittelbar die Rechtslage. ${ }^{8}$ Einer Aufhebung durch die Behörde - beispielsweise gemäß §§ 48, 49 VwVfG - bedarf es dann nicht mehr.

Bei nichtigen oder auch rein formellen Verwaltungsakten ist eine insoweit 7 gerichtlich im Tenor ausgesprochene Aufhebung allerdings rein deklaratorisch, da diese Akte von vornherein keine Rechtswirkungen, sondern nur einen Rechtsschein entfalten. ${ }^{9}$ Bei einer Verpflichtungsklage hingegen, die auch an den Begriff des Verwaltungsakts anknüpft (s. dazu ausführlich Rn. $38 \mathrm{ff}$.), wird der Klagegegner zum Erlass eines Verwaltungsakts verpflichtet, den das Gericht nicht selbst erlässt. ${ }^{10}$ Ebenso wie bei der Verurteilung des Klagegegners zur Vornahme eines Realakts im Rahmen der allgemeinen Leistungsklage (s. dazu §5) bedarf es zur Durchsetzung eines Verpflichtungsurteils grundsätzlich einer daran anschließenden Vollstreckungsmaßnahme, wenn der Klagegegner das Urteil nicht freiwillig umsetzt. ${ }^{11}$ Dies ist bei der Anfechtungsklage nicht notwendig. Materiellrechtlich betrachtet, setzt der Kläger mit der Anfechtungsklage schließlich seinen - gesetzlich regelmäßig nicht ausdrücklich formulierten ${ }^{12}$ - Anspruch auf Aufhebung eines rechtswidrigen Verwaltungsakts durch. ${ }^{13}$

Beispiel 1: A erhält für sein Haus eine rechtswidrige Beseitigungsverfügung vom 15. Mai 2018 der zuständigen Bauaufsichtsbehörde. Er geht dagegen mit einem fristgerechten Widerspruch

8 Pietzcker, in: Schoch/Schneider/Bier, VwGO, 36. EL Februar 2019, § 42 I VwGO, Rn. 2.

9 Vgl. zur möglichen (deklaratorischen) Aufhebung bei nichtigen Verwaltungsakten: BFH, Urt. v. 26.03.1985, Az.: VIII R 225/83 = NVwZ 1986, 156 (157), OVG Rheinland-Pfalz, Urt. v. 25.06. 1986, Az.: 8 A 92/85 = NVwZ 1987, 899: „Dabei kann die Nichtigkeit eines Verwaltungsakts auch im Wege der Anfechtungsklage geltend gemacht werden, denn es ist anerkannt, daß auch bei nichtigen Verwaltungsakten aus Gründen der Rechtsklarheit die Aufhebung des nur dem Rechtsschein nach bestehenden Bescheids formell ausgesprochen werden kann"; a. A. Pietzcker, in: Schoch/Schneider/Bier, VwGO, 36. EL Februar 2019, § 42 I VwGO, Rn. 18.

10 Es findet auch keine Fiktion eines Verwaltungsakts statt, wie etwa bei einer Willenserklärung (vgl. § 173 S. 1 VwGO i.V.m. § 894 I ZPO).

11 S. zu den insoweit bestehenden Vollstreckungsmöglichkeiten gegen die öffentliche Hand etwa $\S 172$ VwGO. Besonders aktuell dürfte hier die Frage nach einer möglichen Zwangshaft von hochrangigen Verwaltungsmitarbeitern/Politikern sein, s. dazu BayVGH, Beschl. v. 09.11.2018, Az.: 22 C 18.1718 = BeckRS 2018, 29302).

12 Pietzcker, in: Schoch/Schneider/Bier, VwGO, 36. EL Februar 2019, § 42 I VwGO, Rn. 3: „wird in den Verhaltensnormen ebenso wie in Art. 19 Abs. 4 GG vorausgesetzt“.

13 Vgl. BVerwG, Urt. v. 21.05.1976, Az.: IV C 80/74 -, NJW 1976, 1760 (1761); Pietzcker, in: Schoch/ Schneider/Bier, VwGO, 36. EL Februar 2019, § 42 I VwGO, Rn. 3 m.w. N. 
vor, der allerdings mit Widerspruchsbescheid vom 21. November 2018 zurückgewiesen wird. Seiner zulässigen und begründeten Anfechtungsklage gibt das zuständige Verwaltungsgericht vollumfänglich statt. In der Hauptsache tenoriert das Gericht daher wie folgt: „Der Bescheid des Beklagten vom 15. Mai 2018 in der Gestalt des Widerspruchsbescheids vom 21. November 2018 wird aufgehoben".

\section{Das Begehren: Aufhebung eines noch nicht erledigten Verwaltungsakts}

9 Zentraler Anknüpfungspunkt zur Bestimmung der statthaften Klageart ist das Begehren des Klägers (vgl. § 88 VwGO).

\section{a) Allgemeines}

10 Damit eine Anfechtungsklage statthaft ist, muss sich dem Begehren des Klägers (ggf. durch Auslegung) entnehmen lassen, dass er einen jedenfalls für ihn belastenden ${ }^{14}$ noch nicht erledigten Verwaltungsakt beseitigen möchte. Bei erledigten Verwaltungsakten ist die in $\S 113$ I 4 VwGO geregelte Fortsetzungsfeststellungsklage die richtige Klageart (s. dazu ausführlich §4). Der Begriff des Verwaltungsakts im Rahmen der Statthaftigkeit ist grundsätzlich nach Maßgabe der VwGO zu beurteilen. Da sich in der VwGO keine Legaldefinition findet, ist der Begriff nach dem bundesrechtlichen $\S 35 \mathrm{VwVfG}^{15} \mathrm{zu}$ bestimmen, auch wenn eine Landesbehörde gehandelt hat. ${ }^{16}$ Sind dessen Voraussetzungen erfüllt (dazu noch näher Rn. $38 \mathrm{ff}$.), ist die Anfechtungsklage ohne weiteres statthaft.

11 Gleichwohl erfasst der Verwaltungsaktbegriff der VwGO gegenüber dem des VwVfG weitergehende behördliche Maßnahmen, etwa solche, die nur dem äuBeren Anschein nach einen Verwaltungsakt darstellen (sog. formelle Verwaltungsakte; zu den damit einhergehenden weiteren prozessualen Besonderheiten s. unten Rn. $21 \mathrm{ff}.){ }^{17}$ Ob die Anfechtungsklage statthaft ist, setzt daher Kenntnisse des Verwaltungsaktbegriffs voraus (s. hierzu ausführlich Rn. $42 \mathrm{ff}$.).

14 Die Anfechtung eines Verwaltungsakts durch den insoweit Begünstigten dürfte in der Praxis ausgeschlossen sein. Gleichwohl wäre auch in diesen Fällen die Anfechtungsklage statthaft; üblicherweise dürfte aber dann die Klagebefugnis fehlen; vgl. auch Brenner, in: Sodan/Ziekow, VwGO, 5. Aufl. 2018, § 79, Rn. 26: fehlende „Beschwer“.

15 Dahingehend enthalten $\S 118$ AO bzw. § 31 SGB X denselben Wortlaut und wären im Rahmen ihres Anwendungsbereichs vorzuziehen.

16 Sodan, in: Sodan/Ziekow, VwGO, 5. Aufl. 2018, § 42 VwGO, Rn. 99 m.w. N.; W. R. Schenke, in: Kopp/Schenke, VwGO, 25. Aufl. 2019, Anh § 42 VwGO, Rn. 2; a. A. Stelkens, in: Stelkens/Bonk/ Sachs, VwVfG, 9. Aufl. 2018, §35 VwVfG, Rn. 15: Abstellen auf einen „gemeindeutschen“ Rechtsgedanken; kritisch hingegen Rusteberg, ZJS 2012, 450.

17 Vgl. Ramsauer, in: Kopp/Ramsauer, VwVfG, 19. Aufl. 2018, § 35 VwVfG, Rn. 52; Stelkens, in: Stelkens/Bonk/Sachs, VwVfG, 9. Aufl. 2018, § 35 VwVfG, Rn. 16; eine solche Differenzierung Jens Milker 
Bei einer Verpflichtungsklage als besondere Form der Leistungsklage ${ }^{18}$ begehrt der Kläger hingegen den Erlass eines Verwaltungsakts, wobei die kassatorische Wirkung der Verpflichtungsklage dazu führt, dass ein entgegenstehender Ablehnungsbescheid mit ihr gleichsam (ex nunc) aufgehoben werden kann, ohne dass es einer zusätzlichen Anfechtungsklage bedarf. ${ }^{19}$ Es ist daher in der Klausursituation und auch in der Praxis genau zu untersuchen, ob der Kläger sein Rechtsschutzziel bereits durch reine Aufhebung eines Verwaltungsakts erreichen kann ${ }^{20}$ oder ob darüber hinaus noch der Erlass eines begünstigenden Verwaltungsakts notwendig ist. Dabei ist der Wortlaut des Klageantrags nur ein Anhaltspunkt (vgl. § 88 VwGO). Im Zweifel ist dann das Begehren - besonders bei nicht anwaltlich vertretenen Privatpersonen - im Lichte des Art. 19 IV GG möglichst rechtsschutzintensiv auszulegen. ${ }^{21}$ Die verwaltungsgerichtliche Praxis ist insoweit auch recht großzügig, sodass diese Herangehensweise ebenso bei Klausurbearbeitungen im ersten und zweiten Staatsexamen übernommen werden kann. Insgesamt gilt es, aus dem unter Umständen nicht mit juristischen Fachbegriffen formulierten Vortrag des Klägers dessen tatsächliches Rechtsschutzziel herauszuarbeiten und dann „die Klageart zu wählen, mit der er weder weniger als das Begehrte erreicht, noch auch mehr, als zur Erfüllung seines Begehrens nötig ist". ${ }^{22}$

Beispiel 2: B hat eine Erlaubnis zum Betrieb einer Spielhalle erhalten, einige Zeit später bemerkt die Behörde, dass bei der Erteilung ein Fehler gemacht worden ist und sendet dem $B$ einen „Rücknahmebescheid“ zu. Hier wäre nur die Anfechtungsklage gegen den „Rücknahmebescheid“ statthaft, da dann die (zurückgenommene) Erlaubnis als begünstigender Verwaltungsakt „wieder auflebt“ und B so schon vollumfänglich sein Rechtsschutzziel erreichen würde.

zwischen verfahrens- und prozessrechtlichem Verwaltungsaktbegriff ausdrücklich ablehnend: Pietzcker, in: Schoch/Schneider/Bier, VwGO, 36. EL Februar 2019, § 42 I VwGO, Rn. 23; ebenso jedenfalls nicht ausdrücklich derart differenzierend: BVerwG, Beschl. v. 9. November 1984, Az.: 7 C 5/84, Amtlicher Leitsatz 1: „,anfechtbarer Verwaltungsakt im Sinne des § 35 Satz 1 VwVfG“; in der Tendenz anders allerdings: BVerwG, Beschl. v. 18. Januar 1993, Az.: 6 B 5/92 = NVwZ-RR 1993, 251 (252): „Akt“.

18 Vgl. schon BVerwG, Urt. v. 25.02.1969, Az.: I C 65/67 = VerwRspr 1969, 1006 (1007); s. auch Sodan, in: Sodan/Ziekow, VwGO, 5. Aufl. 2018, § 42 VwGO, Rn. 29 m.w. N.

19 BVerwG, Urt. v. 19.05.1987, Az.: 1 C 13/84 = NVwZ 1987, 893 (894f.): Anders könne die Situation liegen, wenn der Kläger ein besonderes Rechtsschutzinteresse an der Aufhebung (ex tunc) des ablehnenden Bescheides habe; dazu auch Pietzcker, in: Schoch/Schneider/Bier, VwGO, 36. EL Februar 2019, § 42 I VwGO, Rn. 96.

20 Vgl. auch Pietzcker, in: Schoch/Schneider/Bier, VwGO, 36. EL Februar 2019, § 42 I VwGO, Rn. 5.

21 Vgl. dazu näher BVerwG, Urt. v. 27.04.1990, Az. 8 C 70/88 = NJW 1991, 508 (510).

22 Pietzcker, in: Schoch/Schneider/Bier, VwGO, 36. EL Februar 2019, § 42 I VwGO, Rn. 106.

Jens Milker 
Beispiel 3: Die C betreibt einen Auto-Scooter. Sie möchte daher auf das große Volksfest mit mehreren hundert Schaustellerinnen und Schaustellern in der Stadt $M$ und bewirbt sich auf einen Standplatz. Dieser wird ihr allerdings versagt, da das Kontingent erschöpft sei. Sie ist weiter der Ansicht, dass ihr Fahrgeschäft viel attraktiver sei, als das der anderen Schausteller. Wenn die $C$ nun tatsächlich einen Standplatz erhalten möchte und ausdrücklich etwa eine Verpflichtungsklage auf Neubescheidung ( $\$ 113 \mathrm{~V} 2 \mathrm{VwGO}$ ) erhebt, müsste sie hier nicht gleichzeitig eine (Dritt-)Anfechtungsklage gegen die Bescheide gegenüber anderen Schaustellerinnen oder Schaustellern erheben, um sozusagen einen Platz „frei zu räumen“. Aufgrund der hohen Zahl der weiter ansonsten notwendigen Anfechtungsklagen wäre dies wohl für die $C$ unzumutbar. ${ }^{23}$

\section{b) Einzelfälle (insbesondere Abgrenzung zu anderen Klagearten)}

15 Folgende Konstellationen bedürfen regelmäßig einer genaueren Abgrenzung.

\section{aa) Nebenbestimmungen, Wiederaufgreifen des Verfahrens und Zurückstellung von Baugesuchen}

16 Besondere Probleme der Abgrenzung von Anfechtungs- und Verpflichtungsklage ergeben sich bei der (isolierten) Anfechtung von Nebenbestimmungen (s. dazu Rn. 204 ff.). Darüber hinaus kann, wenn der Kläger sich gegen einen belastenden, aber bestandskräftigen (s. dazu Rn. 115) Verwaltungsakt wendet, dessen Begehren dahingehend $\mathrm{zu}$ verstehen sein, dass er die Verpflichtung der Behörde zum Wiederaufgreifen des Verfahrens im Sinne des $\S 51$ VwVfG begehrt. ${ }^{24}$

Beispiel 4: A hat eine Baugenehmigung bei der Stadtverwaltung der kreisfreien Stadt B beantragt. Diese stellt sein Baugesuch gemäß § 15 BauGB rechtswidrig zurück. Nun möchte A gerichtlich erreichen, dass möglichst zügig über seinen Bauantrag entschieden wird. Welcher Antrag wäre statthaft?

Hier könnte A bereits durch Erhebung der Anfechtungsklage sein Rechtsschutzziel erreichen. ${ }^{25}$ Es wird schon alleine mit der Aufhebung der Zurückstellungs-

23 BVerwG, Urt. v. 07.10.1988, Az.: 7 C 65/87 = NJW 1989, 1749 (1750); anders kann die Lage natürlich sein, wenn es nur wenige Konkurrenten gibt.

24 Pietzcker, in: Schoch/Schneider/Bier, VwGO, 36. EL Februar 2019, § 42 I VwGO, Rn. 106.

25 Vgl. NdsOVG, Beschl.v. 28.11.2006, Az.: 1 ME 147/06 = BeckRS 2006, 27262; OVG RP, Beschl.v. 23.05. 2002, Az.: 8 B 10633/02 = NVwZ-RR 2002, 708 (709); anders VGH BW, Beschl.v. 09.08. 2002, Az.: 3 S 1517/02 = NVwZ-RR 2003, 333: Das eigentliche Ziel des Bauherrn sei erst erreicht, wenn er die Baugenehmigung erlangt habe. Für einen isolierten Eilantrag nach $\S 80 \mathrm{~V}$ VwGO fehle daher das erforderliche Rechtsschutzbedürfnis.

Jens Milker 
verfügung der ursprüngliche Zustand dahingehend hergestellt, dass nun im „normalen“ Tempo über den Antrag des A entschieden wird. Es handelt sich bei der Zurückstellung nach §15 I 1 BauGB um eine eigenständige Rechtsbeeinträchtigung durch eine qualifizierte Form der Verfahrensaussetzung. ${ }^{26}$

\section{bb) Bereits erledigte Verwaltungsakte}

Zudem muss schließlich die nicht immer einfache Abgrenzung zur Fortset- 18 zungsfeststellungsklage anhand des Merkmals der „Erledigung“ des Verwaltungsakts gemäß § 113 I 4 VwGO erfolgen (s. dazu ausführlich § 4 Rn. 2ff.).

\section{cc) Nichtige Verwaltungsakte}

$\mathrm{Zu}$ Abgrenzungsproblemen kommt es regelmäßig auch bei nichtigen Verwal- 19 tungsakten (s. dazu auch weiterführend Rn. 197 ff.). Dabei sieht der Gesetzgeber eine spezielle Klageart vor, nämlich die Nichtigkeitsfeststellungsklage gemäß $\S 43$ I Alt. 2 VwGO. Gleichzeitig ergibt sich mittelbar aus § 43 II 2 VwGO, dass die Anfechtungsklage auch bei einem nichtigen Verwaltungsakt statthaft sein kann. ${ }^{27}$ Schließlich ist die Frage, ob ein Verwaltungsakt nichtig oder „nur“ rechtswidrig ist, nicht immer mit hinreichender Sicherheit vor Klageerhebung zu beantworten. ${ }^{28}$ Folglich ist es nur naheliegend, dass beide Klagearten parallel zur Anwendung kommen können. ${ }^{29}$ Denn der Kläger soll nicht das Risiko einer unstatthaften Anfechtungsklage gegen einen nicht bloß rechtswidrigen, sondern nichtigen Verwaltungsakt tragen. ${ }^{30}$ Insgesamt wäre hier daher ein Anfechtungsantrag auch von vornherein nicht etwa von Amts wegen als Nichtigkeitsfeststel-

26 OVG RP, Beschl. v. 23.05.2002, Az.: 8 B 10633/02 = NVwZ-RR 2002, 708 (709); OVG Berlin, Beschl. v. 21.11.1994, Az.: 2 S 28/94 = NVwZ 1995, 399.

27 Vgl. BVerwG, Urt. v. 20.03.1964, Az.: VII C 10/61 = VerwRspr 1964, 938 (939); BFH, Urt. v. 26. 03. 1985, Az.: VIII R 225/83 = NVwZ 1986, 156 (157), OVG Rheinland-Pfalz, Urt.v. 25.06.1986, Az.: 8 A 92/ 85 = NVwZ 1987, 899; Beschl. v. 12.05.1998, Az.: 12 A 12501/97 = NVwZ 1999, 198; Pietzcker, in: Schoch/Schneider/Bier, VwGO, 36. EL Februar 2019, § 42 I VwGO, Rn. 18; a. A. Sodan, in: Sodan/ Ziekow, VwGO, 5. Aufl. 2018, § 42, Rn. 23: Der Kläger müsse, sofern sich die Nichtigkeit des Verwaltungsakts im Laufe des Prozesses herausstelle, seinen Antrag (ggf. nach Hinweis des Vorsitzenden) auf eine Nichtigkeitsfeststellungsklage umstellen.

28 BFH, Urt.v. 26.06.1985, Az.: IV R 62/83 = NVwZ 1987, 359 (360); BGH, Urt.v. 09. 02.1979, Az.: RiZ (R) 6/78 = NJW 1979, 1710; Pietzcker, in: Schoch/Schneider/Bier, VwGO, 36. EL Februar 2019, § 42 I VwGO, Rn. 18.

29 Vgl. für Schein-Verwaltungsakte: Blunk/Schroeder, JuS 2005, 602 (606f.): „Wahlrecht“. 30 Vgl. Sodan, in: Sodan/Ziekow, VwGO, 5. Aufl. 2018, § 42, Rn. 23. 
lungsantrag auszulegen, ${ }^{31}$ da auch grundsätzlich eine deklaratorische Aufhebung ,aus Gründen der Rechtsklarheit““32 im Tenor erfolgen kann. ${ }^{33}$ Dies soll nach wohl überwiegender Ansicht in der Rechtsprechung allerdings nur dann möglich sein, wenn der nichtige Verwaltungsakt noch nicht formell bestandskräftig geworden ist. ${ }^{34}$ Dann wäre allerdings auch die - ggf. auf Hinweis des Vorsitzenden gemäß § 86 III VwGO erfolgende ${ }^{35}$ - Umstellung auf einen Feststellungsantrag (§ 43 I VwGO) nicht als Klageänderung im Sinne des § 173 Satz 1 VwGO i.V. m. § 264 Nr. 2 ZPO anzusehen. ${ }^{36}$

\section{dd) Nicht bekanntgegebene Verwaltungsakte}

20 Eine Sonderstellung nehmen Verwaltungsakte ein, die etwa mangels ordnungsgemäßer Bekanntgabe nicht wirksam und daher von vornherein nicht existent sind (sog. „Scheinverwaltungsakte“337; s. dazu auch noch Rn. 97) bzw. „Nichtakte“338). Dabei handelt es sich nicht um eine Nichtigkeit im Sinne des $§ 44$ VwVfG, ${ }^{39}$ da kein inhaltlicher Fehler vorliegt. ${ }^{40}$ Das Bundesverwaltungsgericht

31 Vgl. BayVGH, Urt. v. 15.09.1983, Az.: 23 B 80 A 861 = NJW 1984, 626: „Die Nichtigkeit des zulässigerweise angefochtenen ,Verwaltungsakts' war deshalb als im Anfechtungsantrag enthaltenes Minus festzustellen“; s. dazu auch Sodan, in: Sodan/Ziekow, VwGO, 5. Aufl. 2018, §42, Rn. 23.

32 OVG Rheinland-Pfalz, Urt. v. 25.06.1986, Az.: 8 A 92/85 = NVwZ 1987, 899.

33 BFH, Urt. v. 26.03.1985, Az.: VIII R 225/83 = NVwZ 1986, 156 (157), OVG Rheinland-Pfalz, Urt. v. 25.06.1986, Az.: 8 A 92/85 = NVwZ 1987, 899: „Dabei kann die Nichtigkeit eines Verwaltungsakts auch im Wege der Anfechtungsklage geltend gemacht werden, denn es ist anerkannt, daß auch bei nichtigen Verwaltungsakten aus Gründen der Rechtsklarheit die Aufhebung des nur dem Rechtsschein nach bestehenden Bescheids formell ausgesprochen werden kann“; Happ, in: Eyermann, VwGO, 15. Aufl. 2019, § 42, Rn. 15; a. A. Pietzcker, in: Schoch/Schneider/Bier, VwGO, 36. EL Februar 2019, § 42 I VwGO, Rn. 18; Sodan, in: Sodan/Ziekow, VwGO, 5. Aufl. 2018, § 42, Rn. 23.

34 Vgl. BVerwG, Urt. v. 30.01.1990, Az.: 1 A 36/86 = NJW 1990, 1804 (1806); BFH, Urt. v. 26.06.1985 Az.: IV R 62/83 = NVwZ 1987, 359 (360); OVG Rheinland-Pfalz, Beschl.v.12.05.1998, Az.:12 A 12501/ 97 = NVwZ 1999, 198; in diesem Sinne auch BT-Drs. 3/55 Anl. 1, S. 32; a. A. BFH, Urt. v. 17.07.1986, Az.: V R 96/85 = NVwZ 1987, 920.

35 Sodan, in: Sodan/Ziekow, VwGO, 5. Aufl. 2018, § 42, Rn. 23.

36 Happ, in: Eyermann, VwGO, 15. Aufl. 2019, § 42, Rn. 15.

37 Vgl. Blunk/Schroeder, JuS 2005, 602 (603f.); Bickenbach, JA 2015, 481 (487) jeweils mit dem Hinweis auf weitere Fallgruppen.

38 BVerwG, Urt. v. 21.11.1986, Az.: 8 C 127/84 = NVwZ 1987, 330.

39 BVerwG, Urt.v. 21.11.1986, Az.: 8 C 127/84 = NVwZ 1987, 330: „Es handelte sich dann um einen rechtlich nicht existent gewordenen Bescheid (Nichtakt), der in seiner rechtlichen Unwirksamkeit einem nichtigen Verwaltungsakt gleicht“; Stelkens, in: Stelkens/Bonk/Sachs, VwVfG, 9. Aufl. 2018, § 41 VwVfG, Rn. 224 m.w. N. auch zur a.A. 
nimmt in den Fällen einer unwirksamen Bekanntgabe an, dass die Feststellung der Nichtigkeit gemäß § 43 I Alt. 1VwGO und nicht im Wege der Nichtigkeitsfeststellungsklage möglich sein soll. ${ }^{41}$ Die Feststellung sei dann darauf gerichtet, dass der Verwaltungsakt nicht wirksam (geworden) sei und deshalb die mit ihm beabsichtigte Regelungswirkung nicht erreicht habe. Gleichwohl wird auch hier alternativ die Anfechtungsklage zur Anwendung kommen können, um einen eventuell bestehenden Rechtsschein durch deklaratorische Aufhebung zu beseitigen. $^{42}$

\section{ee) Rein formelle Verwaltungsakte}

Bei der Anfechtung von rein formellen Verwaltungsakten ist ebenso die An- 2 fechtungsklage statthaft. ${ }^{43}$ Dies sind Verwaltungsakte, die tatsächlich nicht die Voraussetzungen des $\S 35 \mathrm{VwVfG}$ erfüllen, das behördliche Handeln aber nach dem äußeren Erscheinungsbild einen Verwaltungsakt darstellt. ${ }^{44}$ Dies kann beispielsweise durch die Bezeichnung als „Bescheid“ erfolgen oder durch das Anfügen einer Rechtsbehelfsbelehrung, die auf die mögliche Erhebung eines Widerspruchs hinweist. ${ }^{45}$

Eine Maßnahme, die kein Verwaltungsakt im materiellen Sinne ist, wird nicht 22 allein durch ihre äußere Form zu einem solchen Verwaltungsakt. ${ }^{46}$ Die in $\S 35$ Satz 1 VwVfG statuierten Voraussetzungen sind damit keine Elemente der Rechtmäßigkeit, sondern materiell-rechtliche Wesensmerkmale des Verwal-

40 Stelkens, in: Stelkens/Bonk/Sachs, VwVfG, 9. Aufl. 2018, § 41 VwVfG, Rn. 224; Beaucamp, JA 2016, 436 (438f.).

41 BVerwG, Urt. v. 21.11.1986, Az.: 8 C 127/84 = NVwZ 1987, 330.

42 OVG Rheinland-Pfalz, Urt. v. 25.6.1986, Az.: 8 A 92/85 = NVwZ 1987, 899; Blunk/Schroeder, JuS 2005, 602 (606f.): „Wahlrecht“.

43 Vgl. BSG, Urt. v. 5.9. 2006, Az.: B 4 R 71/06 R = BeckRS 2006, 44566, Rn. 16; BVerwG, Beschl.v. 18.1.1993, Az.: 6 B 5/92 = NVwZ-RR 1993, 251 (252); s. ferner BayVGH, Urt. v. 2.8.2016, Az.: 22 B 16.619 = BeckRS 2016, 50120, Rn. 35, 41 ff.; VG Mainz, Urt.v. 3.7.2018, Az.: 1 K 1463/17 = BeckRS 2018, 20916, Rn. 17; a. A. VG Wiesbaden, Urt. v. 5.5.2007, Az.: 7 E 1536/06 = NVwZ-RR 2007, 613: Feststellungsklage; Bickenbach, JA 2015, 481 (486f.).

44 Vgl. Stelkens, in: Stelkens/Bonk/Sachs, VwVfG, 9. Aufl. 2018, § 35 VwVfG, Rn. 16.

45 S. dazu BSG, Urt. v. 5.9.2006, Az.: B 4 R 71/06 R = BeckRS 2006, 44566, Rn. 20; BayVGH, Urt. v. 2.8.2016, Az.: 22 B 16.619 = BeckRS 2016, 50120, Rn. 43; VG Mainz, Urt.v. 3.7.2018, Az.: 1 K 1463/17 = BeckRS 2018, 20916, Rn. 17.

46 Vgl. Stelkens, in: Stelkens/Bonk/Sachs, VwVfG, 9. Aufl. 2018, § 35, Rn. 72; Ramsauer, in: Kopp/ Ramsauer, VwVfG, 19. Aufl. 2018, § 35 VwVfG, Rn. 52; s. auch BVerwG, Beschl. v. 18.1.1993, Az.: 6 B 5/92 = NVwZ-RR 1993, 251 (252): Aufhebung „eines offensichtlich rechtswidrigen Aktes“ (Hervorhebung durch den Verfasser). 
tungsakts. ${ }^{47}$ Hier besteht damit „trotz des äußeren Scheins in Wahrheit kein Verwaltungsakt“. ${ }^{48}$ Gleichwohl gilt auch hier, dass die Anfechtungsklage zulässig sein kann, mit dem Ergebnis, dass der formelle Verwaltungsakt im Tenor deklaratorisch aufgehoben wird (s. für ein Beispiel auch Rn. 51).

\begin{abstract}
Beispiel 5: Der Bürgermeister der Stadt X bestellt beim Versandhandel A Büromaterial für seine Stadtverwaltung. Als zunächst keine Lieferung erfolgt, sendet er ein mit „Bescheid“ überschriebenes Schreiben einschließlich Rechtsbehelfsbelehrung an A und fordert zur unverzüglichen Lieferung auf. Sofern A nun vor dem Verwaltungsgericht (ausschließlich) gegen diesen „Akt “49 vorgehen möchte, wäre die Anfechtungsklage statthaft, obwohl der Bürgermeister ein fiskalisches Hilfsgeschäft getätigt und sich infolgedessen eigentlich im Bereich des Privatrechts bewegt hat..$^{50}$ Insoweit durfte etwa „nur durch bürgerlichrechtliche Willenserklärung“ gehandelt werden. ${ }^{51}$ Überdies könnte möglicherweise auch die Regelungswirkung des „Bescheids“ fraglich sein. ${ }^{52}$ Der A könnte allerdings dennoch „zulässigerweise [...] Anfechtungsklage vor dem VG ${ }^{\text {“53 }}$ gegen den „Bescheid“ erheben, während eine darüber hinausgehende Verpflichtung allerdings nicht mehr auf dem Verwaltungsrechtsweg durchzusetzen wäre. ${ }^{54}$
\end{abstract}

24 Hausarbeitswissen: Ob bei der Anfechtung von formellen Verwaltungsakten auch die in $\$ \S 68 f f$. VwGO vorgesehenen Fristen zur Anwendung kommen ${ }^{55}$ oder dies - mangels Bestandskraftfähigkeit - jedenfalls nicht $z$ wingend ist ${ }^{56}$, ist in Rechtsprechung und Literatur nicht abschließend geklärt. Richtigerweise dürfte anzunehmen sein, dass formelle Verwaltungsakte nicht der Bestandskraft fähig sind, da ansonsten die Behörde in die Lage versetzt würde, insoweit auch solchen Maßnahmen

47 Vgl. Stelkens, in: Stelkens/Bonk/Sachs, VwVfG, 9. Aufl. 2018, § 35, Rn. 17.

48 BVerwG, Beschl.v. 18.1.1993, Az.: 6 B 5/92 = NVwZ-RR 1993, 251 (252); tendenziell anders noch BVerwG, Beschl. v. 9. November 1984, Az.: 7 C 5/84 = NVwZ 1985, 264, Amtlicher Leitsatz 1: ,anfechtbarer Verwaltungsakt im Sinne des $§ 35$ Satz 1 VwVfG“.

49 So BVerwG, Beschl. v. 18.1.1993, Az.: 6 B 5/92 = NVwZ-RR 1993, 251 (252).

50 Vgl. Papier/Shirvani, in: Münchener Kommentar zum BGB, 7. Aufl. 2017, § 839, Rn. 151.

51 BVerwG, Urt. v. 23.1.1990, Az.: 8 C 37/88 = NJW 1990, 2482.

52 Die Regelungswirkung für eine mit Rechtsbehelfsbelehrung ergangene „Zahlungsaufforderung“ im Einzelfall annehmend: HambOVG, Urt. v. 10.4.2003, Az.: 2 Bf 432/99 = NVwZ-RR 2004, 402; zur Abgrenzung von einer bloßen Mitteilung der (vermeintlichen) Rechtslage insoweit auch Stelkens, in: Stelkens/Bonk/Sachs, VwVfG, 9. Aufl. 2018, § 35, Rn. 73a, 82 ff..

53 BVerwG, Beschl. v. 18.1.1993, Az.: 6 B 5/92 = NVwZ-RR 1993, 251 (252).

54 Vgl. BVerwG, Beschl. v. 18.1.1993, Az.: 6 B 5/92 = NVwZ-RR 1993, 251 (252); Urt. v. 23. Januar 1962, Az.: III C 203/60 = NJW 1962, 830; BayVGH, Beschl. v. 14.6.2002, Az.: 7 B 01.2030 = NVwZ 2002, 1392; s. insbesondere auch bei einer fehlenden Regelungs- und Außenwirkung der Maßnahme: BayVGH, Urt. v. 2.8.2016, Az.: 22 B 16.619 = BeckRS 2016, 50120, Rn. 36 ff., $41 \mathrm{ff}$.

55 Ramsauer, in: Kopp/Ramsauer, VwVfG, 19. Aufl. 2018, § 35 VwVfG, Rn. 52: Unter Bezugnahme auf „§§ 42, 68, 113 VwGO“; s. auch die Nachweise bei Stelkens, in: Stelkens/Bonk/Sachs, VwVfG, 9. Aufl. 2018, §35, Rn. 17 (Fn. 74).

56 Vgl. BSG, Urt. v. 5.9.2006, Az.: B 4 R 71/06 R = BeckRS 2006, 44566, Rn. 20; VG Mainz, Urt. v. 03.07.2018, Az.: 1 K 1463/17 = BeckRS 2018, 20916, Rn. 19; Stelkens, in: Stelkens/Bonk/Sachs, VwVfG, 9. Aufl. 2018, § 35, Rn. 17 mit Verweis auf BVerwG, Beschl. v. 18.1.1993, Az.: 6 B 5/92 = NVwZ-RR 1993, 251 (252).

Jens Milker 
außerhalb der (Wesens-)Merkmale des $\S 35$ VwVfG eine (materielle) Verwaltungsaktqualität zuzuweisen, für die der Gesetzgeber dies nicht vorgesehen hat. ${ }^{57}$

\section{3. Überblick über den Gegenstand der Anfechtungsklage}

Der Gesetzgeber sieht im Regelfall Ausgangsverwaltungsakt ${ }^{58}$ und Wider- 25 spruchsbescheid als prozessuale Einheit an (§ 79 I Nr. 1 VwGO), die nur in den gesondert normierten Einzelfällen durchbrochen werden darf (§79 I Nr. 2, II VwGO). ${ }^{59}$ Damit wird eine möglichst ökonomische Verfahrensabwicklung gewährleistet.

\section{a) § 79 I Nr. 1 VwGO als Regelfall}

Gegenstand der Anfechtungsklage ist im Regelfall der Ausgangsverwaltungs- 26 akt in der Gestalt ${ }^{60}$, die er durch den Widerspruchsbescheid gefunden hat (§ $79 \mathrm{I}$ Nr. 1 VwGO), sodass es sich am Ende um eine einheitliche Verwaltungsentscheidung handelt. ${ }^{61}$ Dabei kommt mittelbar zum Ausdruck, dass gerade im Widerspruchsbescheid Formfehler geheilt ${ }^{62}$ (z. B. Nachholen einer Anhörung oder einer Begründung) und auch Ermessenserwägungen ergänzt werden können. ${ }^{63}$ Auch

57 Vgl. Stelkens, in: Stelkens/Bonk/Sachs, VwVfG, 9. Aufl. 2018, § 35, Rn. 17.

58 Das Gesetz spricht vom „ursprünglichen Verwaltungsakt“; § 79 II 1 VwGO; im Folgenden wird hier allerdings der allgemein ebenfalls übliche Begriff „Ausgangsverwaltungsakt“ verwendet; vgl. Pietzcker, in: Schoch/Schneider/Bier, VwGO, 36. EL Februar 2019, § 79 VwGO, Rn. 3.

59 Siehe dazu eingehend etwa auch: Möstl, in: Posser/Wolff, VwGO, 47. Ed., Stand: 1.10.2018, $\S 79$, Rn. 2; Pietzcker, in: Schoch/Schneider/Bier, VwGO, 36. EL Februar 2019, § 79 VwGO, Rn. 3. 60 Bei einer bloßen Bestätigung des Ausgangsbescheids durch Zurückweisung des Widerspruchs nimmt ein Teil in der Literatur der Begrifflichkeit nach keine Gestaltänderung an; vgl. Happ, in: Eyermann, VwGO, 15. Aufl. 2019, § 79, Rn. 5; Brenner, in: Sodan/Ziekow, VwGO, 5. Aufl. 2018, § 79, Rn. 25; a. A. BVerwG, Beschl.v. 30.4.1996, Az.: 6 B 77/95 = NVwZ-RR 1997, 132 (133): „Vom Sinn und Zweck der gesetzlichen Regelung her ist es gerechtfertigt, auch dann von einer ,Gestaltung، des Ausgangsbescheids zu sprechen, wenn dieser von dem Widerspruchsbescheid ohne inhaltliche Änderungen bekräftigt worden ist“.

61 Happ, in: Eyermann, VwGO, 15. Aufl. 2019, § 79, Rn. 5 unter Verweis auf BVerwG, Urt. v. 23.8. 2011, Az: 9 C 2/11 = NVwZ 2012, 506, Rn. 20.

62 Vgl. Kastner, in: Fehling/Kastner/Störmer, Verwaltungsrecht, 4. Aufl. 2016, § 79 VwGO, Rn. 9. 63 Vgl. BVerwG, Beschl.v. 30.4.2010, Az.: 9 B 42/10 = NVwZ-RR 2010, 550; s. auch BVerwG, Urt. v. 18.5.1990, Az.: 8 C 48/88 = NJW-RR 1990, 1351 (1352): „Ob die Behörde eine derartige Änderung mit im Prozeß beachtlicher mängelheilender Wirkung vornehmen, namentlich eine Ermessensentscheidung noch während des Verwaltungsstreitverfahrens ergänzen oder nachholen, darf, ergibt sich in erster Linie aus dem jeweiligen Fachrecht.“

Jens Milker 
der Widerspruchsbescheid stellt seinem Wesen nach einen Verwaltungsakt dar. ${ }^{64}$ Da dies aber einen an sich einheitlichen Sachverhalt unnötig aufteilen würde, betrachtet der Gesetzgeber gemäß § 79 I Nr. 1 VwGO Ausgangs- und Widerspruchsbescheid grundsätzlich als (prozessuale) Einheit. ${ }^{65}$ Er stellt damit klar, dass nicht etwa zwei Klagen gegen den Ausgangs- und den Widerspruchsbescheid erhoben werden müssen. ${ }^{66}$ Natürlich kann aber auch der Ausgangsverwaltungsakt alleiniger Gegenstand der Anfechtungsklage sein, wenn von vornherein kein Widerspruchsverfahren durchzuführen war oder ein Fall des §75 VwGO (sog. Untätigkeitsklage) vorliegt. Dann existiert von Beginn an kein Widerspruchsbescheid, der dem Verwaltungsakt seine finale Gestalt geben konnte. Eine gesonderte ausdrückliche Regelung für diese Fälle hat der Gesetzgeber nicht vorgesehen, sie dürften allerdings ebenfalls unter § 79 I Nr. 1 VwGO fallen.

\section{b) Der Abhilfe- oder Widerspruchsbescheid als alleiniger Gegenstand der Anfechtungsklage}

27 In gesetzlich festgelegten Ausnahmefällen kann auch der Abhilfe- oder Widerspruchsbescheid alleiniger Gegenstand der Anfechtungsklage sein. Denn in bestimmten Konstellationen ist es für den Kläger sinnvoll, ausschließlich gegen den Abhilfe- oder Widerspruchsbescheid vorzugehen.

\section{aa) Isolierte Anfechtung des Abhilfe-/Widerspruchsbescheids bei „erstmaliger Beschwer" (\$ 79 I Nr. 2 VwG0)}

28 Ausweislich dieser Norm ist der Widerspruchs- ( $\$ 73$ VwGO) oder der Abhilfebescheid (§ 72 VwGO) dann alleiniger Gegenstand der Anfechtungsklage, wenn er „erstmalig eine Beschwer enthält“،. Dies kann nur dann der Fall sein, wenn der Ausgangsverwaltungsakt für den Adressaten oder einen Dritten begünstigend ist und im Abhilfe- oder Widerspruchsverfahren zum Nachteil des Begünstigten abgeändert wird. ${ }^{67}$ In dieser Situation wäre es für den Begünstigten unzweckmäßig, auch den Ausgangsverwaltungsakt anzugreifen, da er damit zum einen eine bereits erreichte für ihn günstige Rechtsposition wieder zur Disposition stellen würde und zum anderen eine Anfechtungsklage hinsichtlich des Aus-

64 Vgl. statt vieler: Möstl, in: Posser/Wolff, VwGO, 47. Ed., Stand: 1.10.2018, § 79, Rn. 1.

65 Vgl. BVerwG, Urt. v. 23.08. 2011, Az.: 9 C 2/11 = NVwZ 2012, 506, Rn. 20; Urt. v. 21.10.1964, Az.: V C 14.63 = BeckRS 1964, 30422805; Möstl, in: Posser/Wolff, VwGO, 47. Ed., Stand:1.10.2018, § 79, Rn. 15.

66 Möstl, in: Posser/Wolff, VwGO, 47. Ed., Stand: 1.10.2018, § 79, Rn. 2.

67 Brenner, in: Sodan/Ziekow, VwGO, 5. Aufl. 2018, § 79, Rn. 26.

Jens Milker 
gangsverwaltungsaktes mangels Beschwer (s. näher zur Klagebefugnis Rn. 281ff.) unzulässig wäre. ${ }^{68}$ Daher kann sich in diesen Konstellationen eine Anfechtungsklage nur gegen den Abhilfe- oder Widerspruchsbescheid richten, ein Wahlrecht steht dem Kläger damit schon von vornherein nicht zu. ${ }^{69}$

Erfasst sind daher vor allem die Fälle einer sog. Drittanfechtung bei Ver- 29 waltungsakten mit Doppelwirkung. Dies sind Verwaltungsakte, die für einen Beteiligten begünstigend sind, aber gleichzeitig für einen anderen Beteiligten belastend wirken. ${ }^{70}$ Sie kommen insbesondere in baurechtlichen Nachbarstreitigkeiten vor. Der Begriff der Drittanfechtung folgt daraus, dass der Verwaltungsakt nicht von seinem Adressaten angefochten wird, sondern von einem Dritten. Probleme treten bei dieser Konstellation regelmäßig im Rahmen der Klagebefugnis auf, da dort eine Betroffenheit in eigenen Rechten erforderlich ist. In dieser Situation ist es üblicherweise so, dass die Behörde einen für den Adressaten begünstigenden Verwaltungsakt (z. B. eine Baugenehmigung) erlässt, der aber für Dritte (z. B. die Nachbarn) belastend wirkt (etwa durch Immissionen, die von der baulichen Anlage ausgehen). Erhebt nun ein Nachbar gegen die dem Bauherren erteilte Baugenehmigung Widerspruch und hilft die Ausgangsbehörde diesem ab (§ 72 VwGO) oder gibt die Widerspruchsbehörde dessen Widerspruch statt ( $\$ 73 \mathrm{VwGO}$ ), ist es für den Bauherren möglich, nun isoliert gegen den Abhilfe- oder Widerspruchsbescheid im Wege der Anfechtungsklage vorzugehen. Auf diese Weise bleibt der ursprüngliche für ihn begünstigende (Ausgangs-)Verwaltungsakt unberührt und es muss keine Verpflichtungsklage auf (erneute) Erteilung der Baugenehmigung erhoben werden. Der für den Kläger begünstigende Ausgangsverwaltungsakt lebt dann wieder auf.

Darüber hinaus sind ebenso noch Konstellationen denkbar, in denen die 30 Rechtsstellung eines Dritten durch den Ausgangsverwaltungsakt in keiner Weise berührt wird, die Regelung im Abhilfe- oder Widerspruchsbescheid allerdings in belastender Weise auf ihn wirkt. ${ }^{71}$

68 Vgl. BVerwG, Urt. v. 11.05.1962, Az.: VII C 27/61 = BeckRS 9998, 181335; Brenner, in: Sodan/ Ziekow, VwGO, 5. Aufl. 2018, § 79, Rn. 26.

69 Brenner, in: Sodan/Ziekow, VwGO, 5. Aufl. 2018, § 79, Rn. 26.: „obligatorischer Natur“; FunkeKaiser, in: Bader/Funke-Kaiser/Stuhlfauth/von Albedyll, VwGO, 7. Aufl. 2018, §79, Rn. 8: Anfechtung des Ausgangsbescheids sei hier wegen fehlender Beschwer „undenkbar“; a. A. Happ, in: Eyermann, VwGO, 15. Aufl. 2019, § 79, Rn. 16.

70 Puttler, in: Sodan/Ziekow, VwGO, 5. Aufl. 2018, § 80a, Rn. 25; diese Situation ist nunmehr in $\S 80$ a I, II VwGO umschrieben.

71 Sodan, in: Sodan/Ziekow, VwGO, 5. Aufl. 2018, § 79, Rn. 29: „Von einer solchen Konstellation ist z.B. auszugehen, sobald eine den Nachbarn in seinen Rechten verletzende Baugenehmigung von der Ausgangsbehörde versagt, auf den Widerspruch des Adressaten hin aber von der Wi- 
31 Der erstmalig Beschwerte „soll“72 vor Erlass des Abhilfe- oder Widerspruchsbescheids gemäß $§ 71$ VwGO angehört werden. Eine daher regelmäßig gebotene Anhörung kann insbesondere ausnahmsweise dann unterbleiben, wenn die Fallgruppen des § 28 II, III VwVfG einschlägig sind. ${ }^{73}$ Gemäß § 68 I 2 Nr. 2 VwGO ist gegen den Abhilfe- oder Widerspruchsbescheid kein erneutes Vorverfahren durchzuführen. Dabei ist der vorgenannten Norm der allgemeine Rechtsgedanke zu entnehmen, dass immer nur ein Vorverfahren durchzuführen ist. Es kann demzufolge unmittelbar innerhalb der Frist des §74 I 2 VwGO Klage erhoben werden. Klagegegner wäre dann nach allgemeinen Regeln - bei Abhilfebescheid - die Ausgangs- oder - bei Widerspruchsbescheid - die Widerspruchsbehörde (§ 78 I Nr. 2 VwGO) bzw. deren Rechtsträger (§ 78 I Nr. 1 VwGO). ${ }^{74}$

\section{bb) Isolierte Anfechtung des Widerspruchsbescheids bei „zusätzlicher und selbstständiger Beschwer“ ( $\$ 79$ II VwG0)}

32 Gemäß §79 II 1 VwGO kann der Widerspruchsbescheid auch dann alleiniger Gegenstand der Anfechtungsklage sein, wenn er ,im Vergleich zum ursprünglichen Verwaltungsakt eine zusätzliche, selbstständige Beschwer“ enthält. Im Gegensatz zu § 79 I Nr. 1 VwGO enthält hier schon der Ausgangsbescheid eine Beschwer, sodass dem Kläger insoweit ein Wahlrecht zukommt, ob er im Wege der „Einheitsklage“"75 nach § 79 I Nr. 1 VwGO (Ausgangs- und Widerspruchsbescheid) oder nach $\S 79$ II VwGO (nur Widerspruchsbescheid) vorgeht. ${ }^{76}$ Für den Kläger wird es in der Regel zweckmäßig sein, isoliert den Widerspruchsbescheid anzugreifen, wenn er nur gegen die Verschärfung vorgehen möchte - etwa weil ein weiteres Vorgehen gegen den Ausgangsbescheid aussichtslos erscheint - oder erreichen will, dass die Widerspruchsbehörde ihr Ermessen erneut (fehlerfrei) ausübt. ${ }^{77}$

derspruchsbehörde erteilt wird“; siehe zu weiteren Fallgruppen auch Happ, in: Eyermann, VwGO, 15. Aufl. 2019, § 79, Rn. 14.

72 Damit unterscheidet sich die Rechtsfolge etwa von § 28 I VwVfG und seinen landesrechtlichen Pendants (,ist [...] Gelegenheit zur Äußerung zu geben“).

73 Kastner, in: Fehling/Kastner/Störmer, Verwaltungsrecht, 4. Aufl. 2016, § 71 VwGO, Rn. 5.

$74 \S 79$ II 3 VwGO findet keine Anwendung.

75 Vgl. etwa Möstl, in: Posser/Wolff, VwGO, 47. Ed., Stand: 1.10.2018, § 79, Rn. 15.

76 Pietzcker, in: Schoch/Schneider/Bier, VwGO, 36. EL Februar 2019, § 79 VwGO, Rn. 11; in der Literatur wird § 79 II VwGO in Bezug auf einen Abhilfebescheid für nicht anwendbar gehalten, vgl. Möstl, in: Posser/Wolff, VwGO, 47. Ed., Stand:1.10.2018, § 79, Rn. 20. Dies wird wesentlich durch den Wortlaut (,Widerspruchsbescheid“) und den systematischen Vergleich mit § 79 I Nr. 1 VwGO gestützt.

77 Pietzcker, in: Schoch/Schneider/Bier, VwGO, 36. EL Februar 2019, § 79 VwGO, Rn. 11.

Jens Milker 
Einen Hauptanwendungsfall der Vorschrift stellt die Reformatio in Peius (sog. „Verböserung“) dar (näher dazu Rn. 344 ff.). Gemeint sind damit Situationen, in denen im Rahmen des Widerspruchsverfahrens gegen einen für den Adressaten belastenden Verwaltungsakt dessen Situation verschlechtert wird; die Behörde also eine weitere Belastung ausspricht. ${ }^{78}$ In $\S 79$ II VwGO sind allerdings keine Aussagen zur materiell-rechtlichen Zulässigkeit der Reformatio in Peius getroffen worden; darin wird nur der prozessuale Umgang mit einer derartigen Situation geregelt. ${ }^{79}$

Beispiel 6: Gastwirtin Renate erhält einen Auflagenbescheid gemäß $\S 5$ GastG, dass sie ihre Gaststätte von 01:00 Uhr bis 6:00 Uhr zu schließen hat (Sperrzeit). Dagegen erhebt sie Widerspruch. Die Widerspruchsbehörde verlängert die Sperrzeit um zwei Stunden, sodass die Gaststätte schon um 23:00 Uhr schließen muss. Hier wäre es unter Umständen (aus anwaltlicher Sicht) zweckmäßig, nur gegen den Widerspruchsbescheid vorzugehen, wenn der Ausgangsbescheid mit großer Wahrscheinlichkeit rechtmäßig ist. Aus richterlicher Sicht wäre dann das Begehren der Klägerin auszulegen (§ $88 \mathrm{VwGO}$ ).

In $§ 79$ II 2 VwGO ist zudem ein besonderer Fall der zusätzlichen und selbst- 35 ständigen Beschwer geregelt bzw. fingiert. ${ }^{80}$ Demnach „gilt“ als eine zusätzliche Beschwer auch die Verletzung einer wesentlichen Verfahrensvorschrift, sofern der Widerspruchsbescheid auf dieser Verletzung beruht.

In Rechtsprechung und Literatur ist allgemein anerkannt, dass § 68 I 2 Nr. 236 VwGO auch auf die Fälle des $§ 79$ II VwGO (unmittelbare) Anwendung findet. ${ }^{81}$ Eines Vorverfahrens bedarf es demnach auch hier nicht. Gleichsam ist $\S 71$ VwGO - nach Auffassung in der Literatur - auch in diesen Fällen anzuwenden, ${ }^{82}$ obwohl der Wortlaut eher einen ausschließlichen Bezug zu § 79 I Nr. 2 VwGO nahe legt. Insgesamt kann demnach hier auch innerhalb der Frist des § 74 I 2 VwGO unmittelbar Klage erhoben werden. Der Klagegegner ist gemäß $§ 79$ II 3 i.V.m. $\S 78$ I, II VwGO zu bestimmen.

78 Vgl. dazu Pietzcker, in: Schoch/Schneider/Bier, VwGO, 36. EL Februar 2019, § 79 VwGO, Rn. 13 mit Beispielen aus der Rechtsprechung.

79 Vgl. BVerwG, Urt. v. 12.11.1976, Az.: IV C 34/75 = NJW 1977, 1894; Pietzcker, in: Schoch/ Schneider/Bier, VwGO, 36. EL Februar 2019, § 79 VwGO, Rn. 13.

80 Pietzcker, in: Schoch/Schneider/Bier, VwGO, 36. EL Februar 2019, § 79 VwGO, Rn. 11.

81 Vgl. nur Funke-Kaiser, in: Bader/Funke-Kaiser/Stuhlfauth/von Albedyll, VwGO, 7. Aufl. 2018, $\S 68, \mathrm{Rn} .22$.

82 Vgl. Kastner, in: Fehling/Kastner/Störmer, Verwaltungsrecht, 4. Aufl. 2016, § 71 VwGO, Rn. 4. 


\section{c) Vorgehen in der Klausur}

37 Zusammenfassend bleibt festzuhalten, dass der Gesetzgeber grundsätzlich davon ausgeht, dass Ausgangs- und Widerspruchsbescheid gemeinsam angegriffen werden (müssen). Sollte dieser Regelfall in einer Klausursituation vorliegen, sind Ausführungen zu § 79 I Nr. 1 VwGO üblicherweise nicht erforderlich. Sofern sich aus dem Klagebegehren allerdings ergibt, dass sich die Klage ausschließlich gegen den Widerspruchsbescheid richten soll, dann muss zwingend im Rahmen der Statthaftigkeit eine Auseinandersetzung mit den in $\S 79$ I Nr. 2, II VwGO angelegten Ausnahmekonstellationen erfolgen. ${ }^{83}$

\section{Der Begriff des Verwaltungsakts (Jens Milker)}

38 Der Verwaltungsakt ist die zentrale - aber natürlich nicht die einzige - behördliche Handlungsform. Nachdem überblicksartig auf die Funktionen des Verwaltungsakts eingegangen wurde (1.), werden die Begriffsmerkmale des Verwaltungsakts vertieft erläutert (2.). Abschließend werden die prozessualen Folgen aufgezeigt, wenn Definitionsmerkmale einmal nicht erfüllt sein sollten (3.).

\section{Funktionen des Verwaltungsakts}

39 Mit ihm kann die Behörde Einzelfälle verbindlich einseitig regeln, sodass durch die damit einhergehende behördliche Subsumtion eine Individualisierungs- und Klarstellungsfunktion erfüllt wird. ${ }^{84}$

40 Da ein Verwaltungsakt - ähnlich wie ein Urteil - auch nach Maßgabe des Verwaltungsvollstreckungsrechts vollstreckt werden kann, kommt ihm insbesondere eine sog. Titelfunktion $\mathrm{zu}^{85}$ Gleichzeitig schafft ein Verwaltungsakt für Behörde und Bürger Rechtssicherheit, da er - sofern einmal wirksam erlassen nur unter bestimmten Voraussetzungen vom Bürger (durch Widerspruch und

83 Vgl. in diesem Sinne auch Schildheuer/Kues, Verwaltungsprozessrecht, 4. Aufl. 2018, Rn. 77. 84 Vgl. Stelkens, in: Stelkens/Bonk/Sachs, VwVfG, 9. Aufl. 2018, § 35, Rn. 31; Ramsauer, in: Kopp/ Ramsauer, VwVfG, 19. Aufl. 2018, § 35, Rn. 10: „Konkretisierungs- und Umsetzungsfunktion“. 85 Vgl. Stelkens, in: Stelkens/Bonk/Sachs, VwVfG, 9. Aufl. 2018, § 35, Rn. 39 ff.; Ramsauer, in: Kopp/Ramsauer, VwVfG, 19. Aufl. 2018, §35, Rn. 9, 11f. (mit Ausnahme bei feststellenden Verwaltungsakten).

Jens Milker 
Klage) oder von der Behörde (durch Aufhebung; vgl. insbesondere §§ $48 \mathrm{ff}$. VwVfG, s. dazu ausführlich Rn. $836 \mathrm{ff}$.) beseitigt werden kann. ${ }^{86}$

Schließlich bestimmt sich nach der Einordnung des behördlichen Handelns als Verwaltungsakt auch die statthafte Rechtschutzform (zum verwaltungsaktbezogenen Rechtsschutz bereits näher $\S 1$ Rn. 238; § 2 Rn. 4 ff., $\S 3$ Rn. 2 ff.), ${ }^{87}$ nämlich das „Wie“ des Rechtsschutzes. Ob überhaupt Rechtsschutz gewährt wird, hängt hingegen nicht (mehr) vom Vorliegen eines Verwaltungsakts ab. ${ }^{88}$ Die Frage, ob ein Verwaltungsakt gegenständlich ist, gegen den sich der Kläger wendet oder dessen Erlass der Kläger begehrt, ist dennoch eine zentrale prozessuale Weichenstellung für die Klausurbearbeitung und die Praxis, da damit insbesondere die Einhaltung von Fristen verbunden ist (vgl. §§ 68ff. VwGO). ${ }^{89}$ Der Begriff des Verwaltungsakts ist sowohl in Landes-VwVfG als auch in dem VwVfG des Bundes (legal-)definiert. ${ }^{90}$ Bei der Prüfung der statthaften Klageart ist allerdings insoweit immer - unabhängig davon, ob eine Landes- oder Bundesbehörde gehandelt hat - das VwVfG des Bundes heranzuziehen (s. bereits Rn. 10). ${ }^{91} \mathrm{Im}$ Übrigen sind die Landes-VwVfG und das VwVfG des Bundes in ihrem Anwendungsbereich zu differenzieren (näher dazu § 1 Rn. 95 ff. und § 2 Rn. 621).

\section{Merkmale eines Verwaltungsakts}

Gemäß § 35 Satz 1 VwVfG ist ein Verwaltungsakt jede Verfügung, Entscheidung 42 oder andere hoheitliche Maßnahme, die eine Behörde zur Regelung eines Einzelfalls auf dem Gebiet des öffentlichen Rechts trifft und die auf unmittelbare Rechtswirkung nach außen gerichtet ist. Allgemeinverfügung ist ein Verwaltungsakt, der sich an einen nach allgemeinen Merkmalen bestimmten oder bestimmbaren Personenkreis richtet oder die öffentlich-rechtliche Eigenschaft einer Sache oder ihre Benutzung durch die Allgemeinheit betrifft (§ 35 Satz 2 VwVfG).

86 Vgl. allgemein zur Rechtssicherheit: Stelkens, in: Stelkens/Bonk/Sachs, VwVfG, 9. Aufl. 2018, $\S 35$, Rn. 34 ff.; speziell zur „Rechtsgrundfunktion“: Stelkens, in: Stelkens/Bonk/Sachs, VwVfG, 9. Aufl. 2018, §35, Rn. 42.

87 Ramsauer, in: Kopp/Ramsauer, VwVfG, 19. Aufl. 2018, § 35, Rn. 13.

88 Vgl. zu der insoweit abweichenden früheren Rechtslage: Stelkens, in: Stelkens/Bonk/Sachs, VwVfG, 9. Aufl. 2018, § 35, Rn. 47.

89 Vgl. Ramsauer, in: Kopp/Ramsauer, VwVfG, 19. Aufl. 2018, § 35, Rn. 13.

90 Dabei haben $\S 31$ SGB X und $\S 118$ AO denselben Wortlaut, vgl. Sodan, in: Sodan/Ziekow, VwGO, 5. Aufl. 2018, § 42, Rn. 99.

91 Vgl. Sodan, in: Sodan/Ziekow, VwGO, 5. Aufl. 2018, § 42, Rn. 99 m.w. N.; Stelkens, in: Stelkens/ Bonk/Sachs, VwVfG, 9. Aufl. 2018, § 35, Rn. 48; s. im Ergebnis auch BVerwG, Urt. v. 26.9.1996, Az.: 2 C 39.95 = NJW 1997, 1248 (1249): „Begriff des Verwaltungsakts i.S. des § 42 I VwGO, § 35 S. 1 VwVfG“. 


\section{a) „Verfügung, Entscheidung oder andere hoheitliche Maßnahme“}

43 Den Anfang der Prüfung bildet das Merkmal der „hoheitlichen Maßnahme“. Die Begriffe „Verfügung“ und „Entscheidung“ sind nur spezielle Arten hoheitlicher Handlungsformen und haben keine eigenständige Bedeutung. ${ }^{92}$

\section{aa) Maßnahme}

44 Der Begriff „Maßnahme“ erfasst jedes Handeln mit Erklärungsgehalt. ${ }^{93}$ Sie besteht zunächst aus dem Vorgang der (inneren) Willensbildung in Gestalt eines Entscheidungs- oder Regelungswillens und anschließender Willensäußerung der Behörde (z. B. durch Erstellung eines Bescheids), die schließlich in die Bekanntgabe (§ $41 \mathrm{VwVfG}$ ) mündet (z. B. Übersendung des Bescheids an den Adressaten, s. dazu näher Rn. 120 ff.). ${ }^{94}$ Dahingehend schreibt § 37 II 1 VwVfG vor, dass ein Verwaltungsakt schriftlich, elektronisch, mündlich oder in anderer Weise erlassen werden kann. An die unterschiedlichen Erlassarten knüpfen dann § 39 (Begründung) und §41 VwVfG (Bekanntgabe) unterschiedliche Rechtsfolgen (näher dazu Rn. 157 ff., 638ff.), sodass der Einordnung ein nicht unerhebliches Gewicht in der rechtlichen Prüfung zukommen kann. Regelfall dürfte aber - auch aufgrund der nur langsam voranschreitenden Digitalisierung in der Verwaltung der schriftliche Verwaltungsakt sein. Der „elektronische Verwaltungsakt“ scheint insoweit (noch) eine untergeordnete Rolle spielen. ${ }^{95}$

45 Maßgeblich für die Auslegung behördlichen Verhaltens ist der objektive Erklärungswert, also wie es vor allem der Adressat bei verständiger Würdigung unter Einbeziehung der für ihn erkennbaren Umstände interpretieren musste. ${ }^{96}$ Hier sind die $\S \S 133,157$ BGB in analoger Anwendung maßgeblich. ${ }^{97}$ Dahingehend

92 Vgl. Stelkens, in: Stelkens/Bonk/Sachs, VwVfG, 9. Aufl. 2018, § 35, Rn. 69; von Alemann/ Scheffczyk, in: Bader/Ronellenfitsch, VwVfG, 42. Ed., Stand: 1.1.2019, § 35, Rn. 115 ff.; Müller, in: Huck/Müller, VwVfG, 2. Aufl. 2016, § 35, Rn. 29; W. R. Schenke, in: Kopp/Schenke, VwGO, 25. Aufl. 2019, Anh. § 42, Rn. 13: Sie können allerdings zur näheren Konkretisierung des Merkmals der „hoheitlichen Maßnahme“ genutzt werden.

93 Vgl. Stelkens, in: Stelkens/Bonk/Sachs, VwVfG, 9. Aufl. 2018, § 35, Rn. 69: „verwaltungsrechtliche Willenserklärung“.

94 Stelkens, in: Stelkens/Bonk/Sachs, VwVfG, 9. Aufl. 2018, § 35, Rn. 70.

95 Vgl. zur Ersetzung der gesetzlich vorgeschriebenen Schriftform durch die elektronische Form: Stelkens, in: Stelkens/Bonk/Sachs, VwVfG, 9. Aufl. 2018, § 37, Rn. 117 f.

96 St. Rspr., vgl. etwa BVerwG, Urt. v. 15.6.2016, Az.: 8 C 5/15 = NVwZ 2017, 326, Rn. 20; BVerwG, Urt. v. 22.3.2012, Az.: 1 C 3/11 = NVwZ-RR 2012, 529, Rn. 24 m.w. N.; Stelkens, in: Stelkens/Bonk/ Sachs, VwVfG, 9. Aufl. 2018, § 35, Rn. 71.

97 Vgl. BVerwG, Urt. v. 15.6.2016, Az.: 8 C 5/15 = NVwZ 2017, 326, Rn. 20; Stelkens, in: Stelkens/ Bonk/Sachs, VwVfG, 9. Aufl. 2018, § 35, Rn. 71 m.w. N. aus der Rspr. 
können Unklarheiten nicht durch bloß vernünftig erscheinende Ergebnisse korrigiert werden, ${ }^{98}$ sondern gehen zum Nachteil der Verwaltung. ${ }^{99}$ Die inhaltliche Auslegung eines Verwaltungsakts orientiert sich am Wortlaut seines ,verfügenden Teils“100 (auch als „Tenor“101 , „Spruch“102 oder „Verfügungssatz“103 bezeichnet) ${ }^{104}$ unter ergänzender Heranziehung seiner Begründung. ${ }^{105}$ Insbesondere konkludentes Verhalten kann daher auch einen Verwaltungsakt darstellen, ${ }^{106}$ der „in anderer Weise“ (vgl. § 37 II 1 VwVfG) erlassen wird. ${ }^{107}$

Beispiel: Das Handzeichen eines Polizeibeamten zum Zwecke der Verkehrsregelung. ${ }^{108}$

So können auch etwa Erstattungs- bzw. Rückforderungsbescheide (z. B. in Be- 47 zug auf Subventionen) dahingehend ausgelegt werden, dass sie gleichzeitig konkludent die Aufhebung des früheren Bewilligungsbescheides enthalten, der ansonsten noch einen Rechtsgrund zum Behaltendürfen darstellen würde. ${ }^{109}$ Ebenso kann etwa auch die Auszahlung von Geld eine konkludente Erklärung über die Berechtigung der Zahlung enthalten. ${ }^{110}$ Wesentlich ist dabei, dass dem

98 BayVGH, Urt. v. 22.5.1997, Az.: 22 B 96. 3646 und 3732 = LKV 1998, 67; Stelkens, in: Stelkens/ Bonk/Sachs, VwVfG, 9. Aufl. 2018, § 35, Rn. 71.

99 St. Rspr., vgl. etwa BVerwG, Urt. v. 22.3.2012, Az.: 1 C 3/11 = NVwZ-RR 2012, 529, Rn. 24 m.w. N. 100 Vgl. § 41 IV 1 VwVfG.

101 So etwa von Alemann/Scheffczyk, in: Bader/Ronellenfitsch, VwVfG, 42. Ed., Stand:1.1.2019, $\S 35, \mathrm{Rn} .46$.

102 Vgl. BVerfG, Beschl. v. 9.1.1991, Az.: 1 BvR 207/87 = NJW 1991, 1878.

103 Vgl. BVerwG, Urt. v. 5.11.2009, Az.: 4 C 3/09 = NVwZ 2010, 133.

104 Vgl. insgesamt auch Stelkens, in: Stelkens/Bonk/Sachs, VwVfG, 9. Aufl. 2018, § 35, Rn. 143. 105 Stelkens, in: Stelkens/Bonk/Sachs, VwVfG, 9. Aufl. 2018, § 35, Rn. 76.

106 Vgl. Barczak, JuS 2018, 238 (244); Stelkens, in: Stelkens/Bonk/Sachs, VwVfG, 9. Aufl. 2018, $\S 35$, Rn. 81; Schwarz, in: Fehling/Kastner/Störmer, Verwaltungsrecht, 4. Aufl. 2016, § 35 VwVfG, Rn. 52 m.w. N.; von Alemann/Scheffczyk, in: Bader/Ronellenftisch, VwVfG, 42. Ed., Stand: 1.1. 2019, § 35, Rn. 119.

107 Vgl. HambOVG, Urt. v. 25.7.2017, Az.: 3 Bf 96/15 = BeckRS 2017, 131008, Rn. 39; Barczak, JuS 2018, 238 (244).

108 Ramsauer, in: Kopp/Ramsauer, VwVfG, 19. Aufl. 2018, § 35, Rn. 61.

109 Vgl. BVerwG, Urt. v. 19.3.1992, Az.: 5 C 41/88 = NVwZ-RR 1992, 423 m.w. N.; s. weiter zur stillschweigenden Aufhebung des Bewilligungsbescheids mit Rückforderung der Subvention: BVerwG, Urt. v. 13.12.1984, Az.: 3 C 79/82 = NVwZ 1985, 488 (489); BremOVG, Beschl.v. 18.11.2015, Az.: 2 B 221/15 = BeckRS 2015, 55026, Rn. 15; s. auch mit weiteren Beispielen: Ramsauer, in: Kopp/ Ramsauer, VwVfG, 19. Aufl. 2018, §35, Rn. 61.

110 Vgl. HambOVG, Urt. v. 25.7.2017, Az.: 3 Bf 96/15 = BeckRS 2017, 131008, Rn. 37: „Wird eine Leistung beantragt, und erfolgt daraufhin eine Auszahlung der Leistung, ohne dass zuvor eine ausdrückliche Bewilligung vorgenommen wurde, so kommt es in Betracht, die Zahlung nicht lediglich als einen schlicht-hoheitlichen Realakt, sondern (auch) als konkludenten Verwal- 
Verhalten ein hinreichend bestimmter Erklärungs- bzw. Regelungsgehalt entnommen werden kann und die übrigen Voraussetzungen des $§ 35$ VwVfG erfüllt sind. ${ }^{111}$

Beispiel: A wird am 21. Juni 2018 wegen drohender Obdachlosigkeit für die Dauer von drei Monaten in eine (Privat-)Wohnung durch die zuständige Ordnungsbehörde eingewiesen. Da zwischenzeitlich ein Platz in einer städtischen Obdachlosenunterkunft frei geworden ist, gibt die Behörde dem A am 3. Juli 2018 auf, die „Wohnung zu räumen““ ${ }^{112}$ Hier kann der behördlichen „Räumungsverfügung“ unter Umständen gleichzeitig entnommen werden, dass die zuvor erfolgte (und hier noch wirksame) Einweisung notwendigerweise jedenfalls konkludent mit aufgehoben wird, da diese ansonsten den Aufenthalt des A in der Wohnung formell legalisieren würde und dementsprechend Eingriffsmaßnahmen der Behörde ausschlösse. ${ }^{113}$

\section{bb) „Hoheitlich“}

49 Der Begriff der „hoheitlichen“ Maßnahme hat nach zutreffender Auffassung eine zweifache Bedeutung. ${ }^{114}$ Diese kann sich - schon aufgrund der eigenständigen Erwähnung des Merkmals - nicht in der Bedeutung ,auf dem Gebiet des öffentlichen Rechts“ erschöpfen. ${ }^{115}$ Zunächst kennzeichnet das Merkmal damit insbesondere die Einseitigkeit der Maßnahme in Abgrenzung zum öffentlich-rechtlichen Vertrag, ${ }^{116}$ der zwei korrespondierende Willenserklärungen voraussetzt (vgl. §54ff. VwVfG) und bei dem sich die Beteiligten daher auf Gleichordnungsebene gegenüberstehen. ${ }^{117}$ Als einseitig können demzufolge auch mitwirkungs-

tungsakt anzusehen. Denn die Zahlung schließt dann die Entscheidung ein, ob und in welcher Höhe gezahlt werden soll. Mit ihr wird gleichzeitig festgestellt, dass dem Leistungsempfänger der der Zahlung zugrunde liegende Anspruch zusteht. Dies kann jedenfalls und zumal dann gelten, wenn der Auszahlung [...] eine behördliche Prüfung vorausgeht und dies für den Leistungsempfänger erkennbar ist“ (dazu ausführlich unten Ziffer 2. d) bb)).

111 Barczak, JuS 2018, 238 (244); Stelkens, in: Stelkens/Bonk/Sachs, VwVfG, 9. Aufl. 2018, § 35, Rn. 81; s. dazu auch VGH BW, Urt. v. 25.5.1987, Az.: 11 S 1699/85 = NVwZ 1988, 184 (185).

112 Vgl. Barczak, JuS 2018, 238 (244).

113 Vgl. im Ergebnis auch Barczak, JuS 2018, 238 (244).

114 Stelkens, in: Stelkens/Bonk/Sachs, VwVfG, 9. Aufl. 2018, § 35, Rn. $104 \mathrm{ff.}$

115 Vgl. Windoffer, in: Mann/Sennekamp/Uechtritz, VwVfG, 1. Aufl. 2014, § 35, Rn. 37; Schwarz, in: Fehling/Kastner/Störmer, Verwaltungsrecht, 4. Aufl. 2016, § 35 VwVfG, Rn. 83; a. A. Ramsauer, in: Kopp/Ramsauer, VwVfG, 19. Aufl. 2018, § 35, Rn. 59; Müller, in: Huck/Müller, VwVfG, 2. Aufl. 2016, § 35, Rn. 29.

116 Dies bereits aus den Begriffen „Verfügung, Entscheidung, Maßnahme“ folgernd: Ramsauer, in: Kopp/Ramsauer, VwVfG, 19. Aufl. 2018, § 35, Rn. 59 f.

117 Vgl. W. R. Schenke, in: Kopp/Schenke, VwGO, 25. Aufl. 2019, Anh. § 42, Rn. 14; von Alemann/ Scheffczyk, in: Bader/Ronellenfitsch, VwVfG, 42. Ed., Stand: 1.1.2019, § 35, Rn. 120 ff.; Voßkuhle/ Kaufhold, JuS 2011, 34 (35); Schwarz, in: Fehling/Kastner/Störmer, Verwaltungsrecht, 4. Aufl. 
bedürftige Maßnahmen eingeordnet werden, bei denen der Adressat an dem Verwaltungsverfahren beteiligt werden muss (z. B. durch das Erfordernis einer Antragsstellung), da damit zwar der Erlass verhindert, aber nicht auf den Inhalt Einfluss genommen werden kann. ${ }^{118}$ Es muss sich konsequenterweise auch um eine Maßnahme in einem Über-/Unterordnungsverhältnis handeln, ${ }^{119}$ also grundsätzlich „Ausdruck der ,Andersordnung“ von Staat und Bürger“ sein. ${ }^{120}$ Dann äußert sich die Hoheitlichkeit darin, dass zumindest hinsichtlich der konkreten Maßnahme eine besondere Befugnis der Verwaltung besteht, die dem Adressaten in dieser Form ohne weiteres nicht zustehen kann. ${ }^{121}$ Die Aufrechnung etwa ist mangels hoheitlichem Element daher kein Verwaltungsakt, sondern die Ausübung eines schuldrechtlichen Gestaltungsrechts, das ebenso dem Bürger potentiell zur Verfügung steht.. ${ }^{122}$

Insgesamt ist vor allem dann keine hoheitliche Maßnahme gegeben, wenn 50 eine entsprechende Willenserklärung mit gleichen Wirkungen auch von Privaten abgegeben werden könnte. ${ }^{123}$ Dies ist zum Beispiel der Fall bei privatrechtlichem Handeln oder auch der Kündigung öffentlich-rechtlicher Verträge. ${ }^{124}$ Ein Über-/ Unterordnungsverhältnis fehlt ebenso grundsätzlich bei Maßnahmen zwischen

2016, § 35 VwVfG, Rn. 83; Windoffer, in: Mann/Sennekamp/Uechtritz, VwVfG, 1. Aufl. 2014, § 35, Rn. 37.

118 Voßkuhle/Kaufhold, JuS 2011, 34 (35).

119 Vgl. BSG, Urt. v. 9. Mai 1957, Az.: 4 RJ 228/55 = BeckRS 1957, 00099, Rn. 21; BeckRS 1985, 5642, Rn. 15; Urt. v. 2. 2.1978, Az.: 12 RK 29/77 = BeckRS 1978, 388, Rn. 15; NJW-RR 1994, 788 (790); OVG SH, Urt. v. 22.12.1999, Az.: 2 L 208/98 = BeckRS 2000, 21738, Rn. 38; VG Mainz, Urt. v. 22.2.2018, Az.: 1 K 862/17.MZ = BeckRS 2018, 18583, Rn. 24; Windoffer, in: Mann/Sennekamp/Uechtritz, VwVfG, 1. Aufl. 2014, § 35, Rn. 37; kritisch Emmerich-Fritsche, NVwZ 2006, 762 (763): „Mit einem demokratisch-republikanischen Staatsverständnis, welches die Menschen nicht als Untertanen, sondern als (selbstbestimmte) Bürger wahrnimmt, ist die Subordinationslehre nicht mehr vereinbar".

120 Stelkens, in: Stelkens/Bonk/Sachs, VwVfG, 9. Aufl. 2018, Rn. 104; s. auch Windoffer, in: Mann/Sennekamp/Uechtritz, VwVfG, 1. Aufl. 2014, § 35, Rn. 37: „die Inanspruchnahme von Sonderrecht durch die Behörde“.

121 Stelkens, in: Stelkens/Bonk/Sachs, VwVfG, 9. Aufl. 2018, §35, Rn. 104; von Alemann/ Scheffczyk, in: Bader/Ronellenfitsch, VwVfG, 42. Ed., Stand: 1.1.2019, § 35, Rn. 121; Windoffer, in: Mann/Sennekamp/Uechtritz, VwVfG, 1. Aufl. 2014, § 35, Rn. 37; insoweit auf die Rechtsgrundlage als „öffentliches Sonderrecht“ abstellend: SächsOVG, Beschl.v. 7.3.2014, Az.: 3 A 798/13 = BeckRS 2014, 49259, Rn. 12.

122 Vgl. etwa BVerwG, Urt.v. 27.10.1982, Az.: 3 C 6/82 = NJW 1983, 776; ThürOVG, Urt. v. 24. 2.2004, Az.: 2 KO 434/03 = NVwZ-RR 2004, 781 (782).

123 Stelkens, in: Stelkens/Bonk/Sachs, VwVfG, 9. Aufl. 2018, § 35, Rn. 104 m.w. N.; Windoffer, in: Mann/Sennekamp/Uechtritz, VwVfG, 1. Aufl. 2014, § 35, Rn. 38.

124 Stelkens, in: Stelkens/Bonk/Sachs, VwVfG, 9. Aufl. 2018, § 35, Rn. 104.

Jens Milker 
Hoheitsträgern, die sich prinzipiell auf gleichgeordneter Ebene begegnen; ${ }^{125}$ es sei denn, der Gesetzgeber weist einem Hoheitsträger spezifische einseitige Regelungsbefugnisse zu (z.B. Aufsichtsbefugnisse). ${ }^{126}$ Diese Konstellation kann etwa bei der Geltendmachung von Erstattungsansprüchen im Bereich des Sozialrechts anzutreffen sein (vgl. zum Beispiel §§ 89 ff. SGB VIII, 102ff. SGB X). ${ }^{127}$

Beispiel $^{128}$ : Die Stadt X begehrt die Erstattung von im Rahmen der Jugendhilfe für einen unbegleiteten minderjährigen Ausländer aufgewendeten Kosten nach Maßgabe des §89d SGB VIII von dem Bundesland Y. Dafür wendet sie sich fristgerecht an die zuständige Landesbehörde. Diese sieht die Forderung nur zum Teil als berechtigt an und erlässt daraufhin einen „Kürzungsbescheid“, dem eine Rechtsbehelfsbelehrung mit dem Hinweis auf die Möglichkeit der Erhebung eines Widerspruchs angefügt war. In diesem Fall liegt nur dem äußeren Anschein nach ein Verwaltungsakt vor (ein sog. formeller Verwaltungsakt, s. zum prozessualen Umgang damit bereits Rn. 21ff.). Es fehlt insoweit an dem Über-/Unterordnungsverhältnis zwischen den beiden Behörden, sodass das Merkmal „hoheitlich" nicht erfüllt ist. Hier besteht „trotz des äußeren Scheins in Wahrheit kein Verwaltungsakt“. ${ }^{129}$

\section{b) Maßnahme einer „Behörde“}

52 Weitere Voraussetzung ist, dass es sich um eine Maßnahme einer „Behörde“ handeln muss. Gemäß der Legaldefinition in $\S 1 \mathrm{Abs.} 4 \mathrm{VwVfG}^{130}$ ist eine Behörde jede Stelle, die Aufgaben der öffentlichen Verwaltung wahrnimmt. Damit legt das

125 Vgl. BSG, Urt. vom 9.5.1957, Az.: 4 RJ 228/55 = BeckRS 1957, 00099, Rn. 21: „Wo sich zwei Rechtsträger des öffentlichen Rechts in ihrer Eigenschaft als Hoheitsträger begegnen, ist ein Verwaltungsakt nicht denkbar“; Urt.v. 21.2.1985, Az.: 11 RK 2/84 = BeckRS 1985, 5642, Rn. 15; Urt.v. 2.2.1978, Az.: 12 RK 29/77 = BeckRS 1978, 388, Rn. 15; BSG, Urt. v. 21.4.1993, Az.: 14a RKa 6/92 = NJW-RR 1994, 788 (790); OVG SH, Urt. v. 22.12.1999, Az.: 2 L 208/98 = BeckRS 2000, 21738, Rn. 38; VG Mainz, Urt. v. 22. 2.2018, Az.: 1 K 862/17.MZ = BeckRS 2018, 18583, Rn. 24; unter Verneinung der „Verwaltungsaktbefugnis“: Maslaton/Koch, NVwZ 2003, 1347 (1348); a. A. Stelkens, in: Stelkens/ Bonk/Sachs, VwVfG, 9. Aufl. 2018, § 35, Rn. 185.

126 Vgl. BSG, Urt. v. 21.4.1993, Az.: 14a RKa 6/92 = NJW-RR 1994, 788 (790) m.w. N.; Urt. v. 21. 2. 1985, Az.: 11 RK 2/84 = BeckRS 1985, 5642, Rn. 15; Urt. v. 2.2.1978, Az.: 12 RK 29/77 = BeckRS 1978, 388, Rn. 15; VG Mainz, Urt. v. 22.2.2018, Az.: 1 K 862/17.MZ = BeckRS 2018, 18583, Rn. 24.

127 S. dazu etwa VG Mainz, Urt.v. 22. 2.2018, Az.: 1 K 862/17.MZ = BeckRS 2018, 18583; Urt.v. 15.11. 2018, Az.: 1 K 1434/17.MZ = BeckRS 2018, 36229; Urt.v. 3.7.2018, Az.: 1 K 1463/17.MZ = BeckRS 2018, 20916; Urt. v. 10. 8.2017, Az.: 1 K 1419/16.MZ = BeckRS 2017, 121948; s. ferner OVG SH, Urt. v. 22.12. 1999, Az.: 2 L 208/98 = BeckRS 2000, 21738, Rn. 38.

128 Vgl. dazu unter Anwendung des § 89d Abs. 3 SGB VIII (a. F.): VG Mainz, Urt. v. 22. 2. 2018, Az.: $1 \mathrm{~K}$ 862/17.MZ = BeckRS 2018, 18583.

129 Vgl. BVerwG, Beschl. v. 18. Januar 1993, Az.: 6 B 5/92 = NVwZ-RR 1993, 251 [252].

130 Zur Anwendbarkeit im Rahmen des $\S 35$ Satz 1 VwVfG: BVerwG, Urt. v. 23.8.2011, Az.: 9 C $2.11=$ NVwZ 2012, 506, Rn. 9. 
Verwaltungsverfahrensrecht einen funktionellen Behördenbegriff zu Grunde. ${ }^{131}$ Es kommt demnach immer darauf an, welche Aufgaben im konkreten Fall wahrgenommen werden. So können etwa auch Verfassungsorgane, die grundsätzlich keine Exekutivaufgaben erfüllen (z.B. der Bundestag und seine Untergliederungen als Legislativorgan), „in einem Teilbereich ihrer verfassungsrechtlichen Kompetenzen Verwaltungstätigkeiten ausüben“. ${ }^{132}$

Beispiel: Der Bundestagspräsident kann als Teil des Bundestages neben der Ausübung der Legislativfunktion auch etwa bei der Ausübung der Polizeigewalt nach Art. 40 II 1 GG als Behörde im Sinne der $\S \S 1$ IV, 35 Satz 1 VwVfG einzustufen sein, wenn er etwa eine die Sitzung störende Person aus dem Zuschauerraum des Bundestages verweist. ${ }^{133}$ Gleiches gilt insoweit etwa für die Ausübung des Hausrechts durch den oder die Präsident(-in) eines Gerichts als Teil der Judikative. ${ }^{134}$

Examenswissen: Da eine Behörde nicht selbst handlungsfähig ist, sondern faktisch nur durch die für sie nach außen auftretenden Personen, geht es bei der Prüfung, ob eine Maßnahme einer Behörde vorliegt, schließlich auch um die Frage der Zurechenbarkeit. Sofern die Behörde durch eigene Organwalter handelt, ist die Zurechnung in der Regel wenig problematisch. Dabei entspricht es allgemeiner Verwaltungspraxis, dass der Leiter einer Behörde (z. B. der Bürgermeister) die in deren Zuständigkeit fallenden hoheitlichen Aufgaben nicht persönlich wahrnehmen muss. ${ }^{135}$ Vielmehr können diejenigen Beamten bzw. Angestellten für die Behörde tätig werden, denen nach Maßgabe der behördeninternen Organisationsregelungen die eigenverantwortliche Wahrnehmung der jeweiligen Aufgabe zugewiesen ist. ${ }^{136}$ Dabei ist zwischen Organwaltern im engeren Sinne, also solchen deren Handeln kraft Gesetzes der Behörde zugerechnet wird (,geborene“ Behördenvertreter; z.B. Bürgermeister), und Organwaltern im weiteren Sinne, d.h. sonstigen Bediensteten (Angestellte, Beamte), die ihre Vertretungsmacht schließlich von dem jeweiligen Organwalter im engeren Sinne ableiten (sog. Zeichnungsbefugnis), zu unterscheiden. ${ }^{137}$

Beispiel: In der Stadtverwaltung einer kreisfreien Stadt werden regelmäßig Verwaltungsakte „Im Auftrag“ des Oberbürgermeisters als Behördenleiter von den dort tätigen Mitarbeiterinnen und Mitarbeitern gezeichnet.

131 Vgl. BremOVG, Beschl. v. 7.4.2011, Az.: 1 A 200/09 = NVwZ 2011, 1146 (1147); von Alemann/ Scheffczyk, in: Bader/Ronellenfitsch, VwVfG, 42. Ed., Stand: 1.1.2019, § 35, Rn. 125.

132 OVG NRW, Beschl. v. 23.9.1986, Az.: 15 B 2039/86 = NVwZ 1987, 608 (609).

133 Müller, in: Huck/Müller, VwVfG 2. Aufl. 2016, §1, Rn. 29. Keine Verwaltungstätigkeit wäre hingegen anzunehmen, wenn der Bundestagspräsident die Diensthoheit gegenüber den Bundestagsabgeordneten wahrnimmt (vgl. W. R. Schenke, in: Kopp/Schenke, VwGO, 25. Aufl. 2019, Anh. § 42, Rn. 17).

134 Vgl. BayVGH, Urt. v. 9.7.1980, Az.: 9 CS 80 A. 268 = NJW 1980, 2722; s. zum Hausrecht des Gerichtspräsidenten auch BVerwG, Urt. v. 17.5.2011, Az.: 7 B 17/11 = BVerwG, NJW 2011, 2530.

135 BVerwG, Beschl. v. 26.2.2008, Az.: 2 B 122/07 = NVwZ-RR 2008, 477, Rn. 17.

136 BVerwG, Beschl. v. 26.2.2008, Az.: 2 B 122/07 = NVwZ-RR 2008, 477, Rn. 17.

137 Vgl. Stelkens, in: Stelkens/Bonk/Sachs, VwVfG, 9. Aufl. 2018, § 35, Rn. 56.

Jens Milker 
56 Besonderheiten ergeben sich insoweit regelmäßig bei kommunalen Verpflichtungserklärungen, für die die Gemeindeordnungen der Länder spezielle Anforderungen vorsehen. ${ }^{138}$ So sieht etwa § 49 I 2 GemO RP ${ }^{139}$ vor, dass Erklärungen, durch die die Gemeinde verpflichtet werden soll, nur rechtsverbindlich sind, wenn sie vom Bürgermeister oder dem zur allgemeinen Vertretung berufenen Beigeordneten oder einem ständigen Vertreter unter Beifügung der Amtsbezeichnung handschriftlich unterzeichnet sind. Obwohl der Wortlaut prima facie eine Interpretation als Formvorschrift nahelegt, besteht Einigkeit darüber, dass die Norm aufgrund der insoweit jedenfalls bei privatrechtlichen Verpflichtungserklärungen fehlenden Gesetzgebungskompetenz der Länder als eine Beschränkung der Vertretungsmacht $\mathrm{zu}$ interpretieren ist. ${ }^{140}$ Gleichwohl ist umstritten, ob dies auch für öffentlich-rechtliche Verpflichtungserklärungen gilt. ${ }^{141}$ Schließlich kann die unterschiedliche Interpretation der Vorschrift nach öffentlich-rechtlichen und privatrechtlichen Erklärungen nicht überzeugen, da bei genauer Interpretation des Wortlauts ${ }^{142}$ (,sind nur rechtsverbindlich“) bereits insgesamt das Verständnis als Vertretungsregel vorzugswürdig sein dürfte.

Sofern sich die Behörde zu ihrer Aufgabenerfüllung (privater) Dritter bedient, ist eine vertiefte Prüfung erforderlich, ob ein hinreichender Zurechnungszusammenhang besteht. Auch natürliche ${ }^{143}$ und juristische ${ }^{144}$ Personen des $^{2}$ Privatrechts können selbst als Behörde im Sinne des § 1 IV VwVfG einzuordnen sein. Dies kann durch „Beleihung“ erfolgen. Beliehene sind Privatpersonen, die mit der selbstständigen, hoheitlichen Wahrnehmung bestimmter Verwaltungsaufgaben im eigenen Namen durch ein formelles Gesetz betraut sind. ${ }^{145}$ Während

138 Vgl. dazu im Überblick: Burgi, Kommunalrecht, 3. Aufl. 2010, § 13, Rn. 33ff.; Stelkens, in: Stelkens/Bonk/Sachs, VwVfG, 9. Aufl. 2018, § 35, Rn. 58.

139 S. zu vergleichbaren Regelungen in anderen Bundesländern: Burgi, Kommunalrecht, 3. Aufl. 2010, § 13, Rn. 33.

140 Vgl. OVG RP, Urt. v. 17.12.1997, Az.: 8 A 12998/98 = NVwZ 1998, 655.

141 Insoweit für eine Einordnung als Formvorschrift: OVG RP, Urt. v. 17.12.1997, Az.: 8 A 12998/ 98 = NVwZ 1998, 655; vgl. für eine Einordnung als Vertretungsregel zu den jeweiligen landesrechtlichen Regelungen: OVG NRW, Urt.v. 19.3.2002, Az.: 15 A 4043/00 = NVwZ-RR 2003, 147 (148); HessVGH, Urt. v. 15.2.1996, Az.: 5 UE 2836/95 = NVwZ 1997, 618.

142 So auch Stelkens, in: Stelkens/Bonk/Sachs, VwVfG, 9. Aufl. 2018, § 35, Rn. 58.

143 Z.B. wird der „Luftfahrzeugführer“ (Flugkapitän) gemäß § 12 LuftSiG mit der luftpolizeilichen Hoheitsgewalt betraut, vgl. BVerwG, Beschl. v. 7.6.1984, Az.: 7 B 153/83 = NVwZ 1985, 48; weitere Beispiele etwa bei Kastner, in: Fehling/Kastner/Störmer, Verwaltungsrecht, 4. Aufl. 2016, $\S 1 \mathrm{VwVfG}, \mathrm{Rn} .35$.

144 Z.B. die Deutsche Flugsicherungs GmbH; vgl. Verordnung zur Beauftragung eines Flugsicherungsunternehmens vom 11. November 1992 (BGBl. I S. 1928); s. auch VG Frankfurt a. M., Beschl. v. 22.6.1994, Az.: 9 E 895/94 = NVwZ 1995, 410.

145 Stelkens, NVwZ 2004, 304 (305) m.w. N.

Jens Milker 
der Beliehene selbst Behörde ist, wird etwa der sog. „Verwaltungshelfer“146 unselbstständig für die Behörde tätig, die sich sodann dessen Verhalten (vor allem in Bezug auf Haftungsfragen) zurechnen lassen muss. ${ }^{147}$ Er handelt sozusagen als „als Werkzeug oder verlängerter Arm der Behörde“. ${ }^{148}$ Wie sich aus § 35a VwVfG nunmehr ausdrücklich ergibt, kann ein Verwaltungsakt auch „vollautomatisiert“ erlassen werden, sofern dies durch Rechtsvorschrift zugelassen ist und weder ein Ermessen noch ein Beurteilungsspielraum besteht; auch dann kann es sich demnach um eine der Behörde zurechenbare Maßnahme handeln. ${ }^{149}$ Es gelten dann hinsichtlich der Zurechnung dieselben Grundsätze. ${ }^{150}$

Beispiel: Beauftragt die zuständige Behörde ein privates Abschleppunternehmen, um ein Auto aus dem Haltverbot abschleppen zu lassen, handelt es sich um einen Verwaltungshelfer. Letztlich wird dann das Handeln des Abschleppunternehmens der Behörde zugerechnet. Hier tritt das Abschleppunternehmen auch regelmäßig nicht nach außen auf, sondern liquidiert in der Praxis die Kosten des Abschleppvorgangs zunächst im Innenverhältnis bei der Behörde, die dann wiederum den Falschparker in Regress nimmt.

Dabei gilt das sog. „Prinzip der Selbstorganschaft““. ${ }^{151}$ Behörden dürfen ihre 59 gesetzlich zugewiesenen Aufgaben demnach grundsätzlich nur durch die Organwalter und Bediensteten erfüllen, die ihnen nach Maßgabe der jeweiligen Stellenpläne bzw. Stellenübersichten zugeordnet sind. ${ }^{152}$ Das schließt - soweit (wie üblich) gesetzlich nichts anderes vorgesehen ist - aus, dass die Behörde jedenfalls die Letztentscheidungskompetenz bei in ihren Zuständigkeitsbereich fallenden Aufgaben im hoheitlichen Bereich an Dritte überträgt. ${ }^{153}$ Die ergänzende (unselbstständige) Einschaltung privater Dritter (als Verwaltungshelfer), anderer

146 Vgl. Weber, in: Creifelds, Rechtswörterbuch, 22. Ed., 2016.

147 Vgl. etwa Sodan, in: Sodan/Ziekow, VwGO, 5. Aufl. 2018, § 40, Rn. 365.

148 Schönenbroicher, in: Mann/Sennekamp/Uechtritz, VwVfG, 1. Aufl. 2014, § 1, Rn. 76.

149 S. dazu etwa Stelkens, in: Stelkens/Bonk/Sachs, VwVfG, 9. Aufl. 2018, § 35, Rn. 67 f.: § 35a VwVfG hat nur „klarstellenden Charakter“.

150 Stelkens, in: Stelkens/Bonk/Sachs, VwVfG, 9. Aufl. 2018, § 35, Rn. 67 f.

151 Der Begriff geht zurück auf Hufeld, Vertretung der Behörde, 2003, S. $21 \mathrm{ff}$.; dies übernehmend etwa Stelkens, in: Stelkens/Bonk/Sachs, VwVfG, 9. Aufl. 2018, § 35, Rn. 59; vgl. BVerwG, Urt. v. 23.8.2011, Az.: 9 C 2/11 = NVwZ 2012, 506, Rn. 14: „Grundsatz der Eigenverantwortlichkeit“.

152 Stelkens, in: Stelkens/Bonk/Sachs, VwVfG, 9. Aufl. 2018, § 35, Rn. 59; s. auch BremOVG, Urt. v. 20.3.2018, Az.: 1 LB 55/17 = NordÖR 2018, 230 (231): Verstoß gegen diesen Grundsatz führt zur formellen Rechtswidrigkeit des Verwaltungsakts.

153 Stelkens, in: Stelkens/Bonk/Sachs, VwVfG, 9. Aufl. 2018, § 35, Rn. 59; BVerwG, Beschl.v. 26. 2. 2008, Az.: 2 B 122/07 = NVwZ-RR 2008, 477, Rn. 17: „Der Behördenleiter darf die Wahrnehmung von Behördenzuständigkeiten im hoheitlichen Bereich nur dann auf andere Behörden oder auf nicht seiner Behörde angehörende Personen übertragen, wenn er hierzu durch Rechtssatz ermächtigt ist". 
Behörden (im Wege der Amtshilfe) oder die Automatisierung einzelner Arbeitsschritte (vgl. § 35a VwVfG) ${ }^{154}$ bleibt hingegen zulässig. ${ }^{155}$ Letztlich müssen dabei die wesentlichen Entscheidungen von der zuständigen Behörde selbst getroffen werden. Sofern die Maßnahme keiner Behörde zurechenbar ist, liegt ein sogenannter Scheinverwaltungsakt vor. ${ }^{156}$

60

Beispiel: Anwohnerin A beantragt für ihren Umzug das Aufstellen von Haltverbotsschildern vor ihrem Haus. Die zuständige Behörde teilt ihr mit, dass die betreffenden Schilder auf dem Betriebshof ausgeliehen werden könnten. Gleichzeitig wird darauf hingewiesen, dass die Schilder ausschließlich in dem beantragten Bereich aufgestellt werden dürfen und nur für die dort genannte Dauer Geltung entfalten. In diesem Fall führt A nur die behördliche Anordnung aus, sodass die Aufstellung der Schilder der Behörde (noch) hinreichend zurechenbar ist. ${ }^{157}$

61 Ein fiktiver Verwaltungsakt - wie etwa eine Genehmigungsfiktion (z. B. §42a VwVfG oder §6a I GewO; s. dazu näher Rn. 123) - ist hingegen keine einer bestimmten Behörde zurechenbare Maßnahme, sondern insgesamt kraft Gesetzes ein Verwaltungsakt. ${ }^{158}$ Auch fingierte Verwaltungsakte sind mit den Rechtsbehelfen der VwGO angreifbar, z.B. kommt eine Drittanfechtung der Genehmigungsfiktion in Betracht. ${ }^{159}$ Der Klagegegner ist dann die Behörde bzw. ihr Rechtsträger, für den bzw. die der Verwaltungsakt als erlassen gilt. ${ }^{160}$

\section{c) Maßnahme „auf dem Gebiet des öffentlichen Rechts“}

62 Wann eine Maßnahme auf dem Gebiet des öffentlichen Rechts vorliegt, bestimmt sich nach denselben Kriterien wie bei der Eröffnung des Verwaltungsrechtswegs nach $\S 40$ I 1 VwGO ${ }^{161}$ (dazu bereits ausführlich $\S 1 \mathrm{Rn}$. 162ff.) und ist damit im Regelfall bei einer prozessual eingekleideten Klausur bereits geprüft worden. Bei

154 S. dazu Stelkens, in: Stelkens/Bonk/Sachs, VwVfG, 9. Aufl. 2018, § 35a, Rn. 26 ff.: Anwendung der Grundsätze der automatisierten Willenserklärung.

155 Vgl. Stelkens, in: Stelkens/Bonk/Sachs, VwVfG, 9. Aufl. 2018, § 35, Rn. 59.

156 Vgl. Stelkens, in: Stelkens/Bonk/Sachs, VwVfG, 9. Aufl. 2018, §35, Rn. 56, 62f.; zu den Rechtsfolgen s. Rn. 97.

157 Vgl. BVerwG, Urt. v. 6.4.2016, Az.: 3 C 10/15 = NJW 2016, 2353, Rn. $11 \mathrm{ff}$.

158 Vgl. dazu Barczak, JuS 2018, 238 (244) mit weiteren Beispielen.

159 Vgl. Stelkens, in: Stelkens/Bonk/Sachs, VwVfG, 9. Aufl. 2018, § 42a, Rn. 70 f.

160 Stelkens, in: Stelkens/Bonk/Sachs, VwVfG, 9. Aufl. 2018, § 42a, Rn. 70.

161 Vgl. Schwarz, in: Fehling/Kastner/Störmer, Verwaltungsrecht, 4. Aufl. 2016, § 35 VwVfG, Rn. 101; Voßkuhle/Kaufhold, JuS 2011, 34 (35); s. dazu ausführlich Kapitel Nr. 2.

Jens Milker 
einer verwaltungsgerichtlichen Entscheidung hat das Merkmal daher an dieser Stelle regelmäßig keine eigenständige Bedeutung. ${ }^{162}$

\section{d) „Regelung“}

Zentrales Merkmal eines Verwaltungsakts ist die sog. Regelungswirkung. Das Merkmal dient insbesondere der Abgrenzung zu einem Realakt, also schlichtem Verwaltungshandeln (z. B. (Meinungs-)Äußerungen von Hoheitsträgern ${ }^{163}$ ), das nicht auf das Bewirken einer Rechtsfolge, sondern auf einen tatsächlichen Erfolg gerichtet ist. ${ }^{164}$

\section{aa) Allgemeines}

Eine Maßnahme hat Regelungscharakter, wenn sie nach ihrem Erklärungsgehalt - 64 im Gegensatz zum Realakt - darauf gerichtet ist, eine verbindliche Rechtsfolge zu setzen. ${ }^{165}$ Das ist zunächst dann anzunehmen, wenn Rechte des Betroffenen begründet, geändert oder aufgehoben werden (sog. gestaltender oder befehlender Verwaltungsakt). ${ }^{166}$ Regelungscharakter liegt aber auch dann vor, wenn Rechte mit bindender Wirkung festgestellt oder verneint werden (sog. feststellender Verwaltungsakt). ${ }^{167}$ Schließlich wird mit einem Verwaltungsakt von dem Adressaten ein Tun, Dulden oder Unterlassen gefordert oder diesem ein solches erlaubt bzw. eine derartige Pflicht festgestellt. ${ }^{168}$ Gerade hier gilt das Gebot der „Formenklarheit“, sodass aus dem behördlichen Handeln deutlich werden muss, dass das Verwaltungsverfahren (vgl. §9 VwVfG) durch die Erklärung - bestandskraftfähig - abgeschlossen werden soll. ${ }^{169}$ Nur vorbereitende Handlungen sind damit keine Verwaltungsakte. ${ }^{170}$ Das Merkmal „Regelung“ ist

162 So auch Schwarz, in: Fehling/Kastner/Störmer, Verwaltungsrecht, 4. Aufl. 2016, § 35 VwVfG, Rn. 101.

163 Dazu ausführlich im Überblick Milker, JA 2017, 647.

164 von Alemann/Scheffczyk, in: Bader/Ronellenfitsch, VwVfG, 42. Ed., Stand: 1.1.2019, § 35, Rn. 46; Ramsauer, in: Kopp/Ramsauer, VwVfG, 19. Aufl. 2018, § 35, Rn. 39.

165 BVerwG, Urt. v. 5.11.2009, Az.: 4 C 3/09 = NVwZ 2010, 133, Rn. 15; von Alemann/Scheffczyk, in: Bader/Ronellenfitsch, VwVfG, 42. Ed., Stand: 1.1.2019, §35, Rn. 141.

166 BVerwG, Urt. v. 5.11.2009, Az.: 4 C 3/09 = NVwZ 2010, 133, Rn. 15.

167 BVerwG, Urt. v. 5.11.2009, Az.: 4 C 3/09 = NVwZ 2010, 133, Rn. 15.

168 von Alemann/Scheffczyk, in: Bader/Ronellenfitsch, VwVfG, 42. Ed., Stand: 1.1.2019, §35, Rn. 142.

169 Vgl. Stelkens, in: Stelkens/Bonk/Sachs, VwVfG, 9. Aufl. 2018, § 35, Rn. 73 m.w. N. aus der Rechtsprechung.

170 von Alemann/Scheffczyk, in: VwVfG, 42. Ed., Stand:1.1.2019, § 35, Rn. 171.

Jens Milker 
zudem eng verknüpft mit dem der Außenwirkung. ${ }^{171}$ Problematisch ist die Frage der Regelungswirkung insbesondere in den im Folgenden aufgeführten Fallgruppen.

\section{bb) Vorgelagerter Verwaltungsakt}

65 Viel diskutiert und daher besonders hervorzuheben ist die Frage, ob in bestimmten Fällen behördlichen Realakten ein (unter Umständen auch konkludenter) Verwaltungsakt (jedenfalls gedanklich) vorgelagert ist. Dies nimmt die Rechtsprechung insbesondere in Fällen an, in denen vor Durchführung des Realakts über schwierige Sach- oder Rechtsfragen entschieden (z.B. bei Auskunftserteilung ${ }^{172}$ ) oder eine Auswahlentscheidung getroffen werden muss (z. B. Gewährung von Subventionen $\left.{ }^{173}\right) .{ }^{174}$ Es ist insoweit maßgeblich, ob der Schwerpunkt des behördlichen Verhaltens auf dem Realakt selbst oder der vorgelagerten Entscheidung über dessen Durchführung liegt. ${ }^{175}$ Bei letzterem wird dann durch die Vornahme bzw. Nichtvornahme des Realakts eine Regelung getroffen. ${ }^{176}$ Maßgeblich für die Schwerpunktsetzung sind insbesondere die ausdrückliche Erwähnung der Behördenentscheidung im Gesetz sowie die an sie gestellten rechtlichen Anforderungen. ${ }^{177}$

66 Dies kann insbesondere bei Ansprüchen auf Auskunftserteilung relevant werden. ${ }^{178}$ Dabei ist stets das jeweilige Fachrecht (z.B. das IFG) heranzuziehen und die einschlägigen Bestimmungen für den Informations- bzw. Auskunftsan-

171 Vgl. BVerwG, Urt.v. 20.11.2003, Az.: 3 C 29/02 = NVwZ 2004, 349 (350): „zwar begrifflich, aber kaum sachlich trennbar“.

172 Vgl. BVerwG, Urt. v. 20.2.2013, Az.: 6 A 2/12 = NVwZ 2013, 1006, Rn. 15; NVwZ 2008, 580, Rn. 13; von Alemann/Scheffczyk, in: Bader/Ronellenfitsch,VwVfG, 42. Ed., Stand: 1.1.2019, § 35, Rn. 148.

173 Vgl. BVerwG, Urt. v. 19.11.2009, Az.: 3 C 7.09 = NVwZ 2010, 643.

174 von Alemann/Scheffczyk, in: Bader/Ronellenfitsch,VwVfG, 42. Ed., Stand: 1.1.2019, §35, Rn. 148.

175 Vgl. schon BVerwG, Urt. v. 25.2.1969, Az.: I C 65/67 = NJW 1969, 1131 (1132); s. auch BVerwG, Urt. v. 28.11.2007, Az.: 6 A 2/07 = NVwZ 2008, 580, Rn. 13.

176 Stelkens, in: Stelkens/Bonk/Sachs, VwVfG, 9. Aufl. 2018, §35, Rn. 99; von Alemann/Scheffczyk, in: Bader/Ronellenfitsch,VwVfG, 42. Ed., Stand: 1.1.2019, § 35, Rn. 148; s. auch BVerwG, Urt. v. 25.2.1969, Az.: I C 65/67 = NJW 1969, 1131; BFH, Urt. v. 25.7.1978 Az.: VII R 77/74 = NJW 1979, 735 (736); OVG NRW, Urt. v. 23.5.1995 Az.: 5 A 2875/92 = NJW 1995, 2741.

177 Vgl. BVerwG, Urt. v. 28.11.2007, Az.: 6 A 2/07 = NVwZ 2008, 580.

178 Vgl.von Alemann/Scheffczyk, in: Bader/Ronellenfitsch,VwVfG, 42. Ed., Stand:1.1.2019, § 35, Rn. $148 \mathrm{ff}$.

Jens Milker 
spruch auszulegen. ${ }^{179}$ Insoweit können etwa auch Bestimmungen zur Durchführung eines Widerspruchsverfahrens (z. B. §9 IV IFG) ein wesentliches Indiz dafür sein, dass der Gesetzgeber davon ausgeht, dass sich die Auskunftserteilung schwerpunktmäßig im Rahmen der Entscheidung darüber bewegt. ${ }^{180}$ Die Rechtsprechung nimmt dabei stets den Einzelfall in den Blick. So wird etwa beim presserechtlichen Auskunftsanspruch unmittelbar aus Art. 5 I 2 GG die Leistungsklage für einschlägig gehalten, da der Erteilung der Auskunft keine davon gesonderte und als Verwaltungsakt zu qualifizierende „Entscheidung“ des Behördenleiters oder einer von ihm beauftragten Person vorausgehe, ${ }^{181}$ während diese bei Ansprüchen gemäß § 7 BNDG i.V.m. § 15 BVerfSchG schon im Gesetz ausdrücklich erwähnt sei. ${ }^{182}$

Ähnliches gilt insoweit bei Geldzahlungen. Dabei kann es unter Umständen 67 dem behördlichen Handeln $\mathrm{zu}$ entnehmen sein, dass mit der Auszahlung als Realakt ein Rechtsgrund zum Behaltendürfen geschaffen werden soll bzw. über den Anspruch auf die (Aus-)Zahlung konkludent entschieden wird. ${ }^{183}$ Dies ist dann unproblematisch, wenn etwa das Gesetz einen Festsetzungsbescheid ausdrücklich vorschreibt (z. B. § 49 I 2 VwVfG). In sonstigen Fallkonstellationen dürfte eine Einzelfallbetrachtung geboten und der Schwerpunkt des behördlichen Handelns herauszuarbeiten sein. In Anbetracht der mittlerweile ausufernden Kasuistik, dürften sich Klausuren insbesondere hier nicht zwingend am „richtigen“ Ergebnis, sondern an der nachvollziehbaren argumentativen Herleitung messen lassen.

Als aktuell diskutierter Fall sei noch die Ausübung eines „virtuellen Hausrechts“ durch Hoheitsträger genannt. ${ }^{184}$ Dabei geht die Rechtsprechung bei der Nutzung der Blockierungs- bzw. Sperrfunktion in sozialen Netzwerken durch Hoheitsträger überwiegend davon aus, dass es sich dabei um einen bloßen Realakt handele. ${ }^{185}$ Im Schrifttum wird hingegen überwiegend vom Vorliegen eines jedenfalls konkludenten (vorgelagerten) Verwaltungsakts ausgegangen, da

179 von Alemann/Scheffczyk, in: Bader/Ronellenfitsch,VwVfG, 42. Ed., Stand: 1.1.2019, §35, Rn. 149.

180 Vgl. von Alemann/Scheffczyk, in: Bader/Ronellenfitsch,VwVfG, 42. Ed., Stand:1.1.2019, § 35, Rn. 149; VG Karlsruhe, Urt. v. 5. 8.2011, Az.: 2 K 765/11 = BeckRS 2011, 53817, Rn. 12.

181 BVerwG, Urt. v. 20.2.2013, Az.: 6 A 2/12 = NVwZ 2013, 1006, Rn. 15.

182 BVerwG, Urt. v. 28.11.2007, Az.: 6 A 2/07 = NVwZ 2008, 580, Rn. 13.

183 Vgl. etwa HambOVG, Urt. v. 25.7.2017, Az.: 3 Bf 96/15 = BeckRS 2017, 131008, Rn. 37.

184 Dazu ausführlich etwa Kalscheuer/Jacobsen, NJW 2018, 2358; Milker, NVwZ 2018, 1751.

185 Vgl. VG Mainz, Urt. v. 13.4.2018, Az.: 4 K 762/17.MZ = MMR 2018, 556, Rn. 69; VG München, Urt. v. 27.10. 2017, Az.: M 26 K 16.5928 = MMR 2018, 418, Rn. 14; a. A. wohl VG Düsseldorf, Beschl.v. 28.6.2018, Az.: 15 L 1022/18 = BeckRS 2018, 14305, Rn. 11.

Jens Milker 
der Schwerpunkt des behördlichen Handelns auf der Entscheidung über die Blockierung nach Durchführung einer umfassenden Interessenabwägung liegt. ${ }^{186}$

\section{cc) Polizeiliche Standardmaßnahmen und Vollstreckungshandlungen}

69 Problematisch ist das Vorliegen einer Regelung auch in Bezug auf polizeiliche Standardmaßnahmen (s. auch Rn. 1045ff.) und Vollstreckungshandlungen (s. auch Rn. $1311 \mathrm{ff}$.). Hier ist auf die jeweils durchgeführte Maßnahme im Einzelfall abzustellen. ${ }^{187}$ Nicht jede Maßnahme zur Durchsetzung einer öffentlichrechtlichen Verpflichtung ist notwendig ein Verwaltungsakt.

70 Die dafür erforderliche Regelungswirkung kann nach zutreffender Ansicht etwa bei der Androhung ${ }^{188}$ und Festsetzung ${ }^{189}$ im Verwaltungsvollstreckungsrecht angenommen werden. ${ }^{190}$ Während ein Zwangsgeld alleine durch seine Festsetzung „Vollstreckungswirkung“ entfaltet, ist die Anwendung des Zwangsmittels der Ersatzvornahme (z. B. das Abschleppen eines PKW) ${ }^{191}$ oder des unmittelbaren Zwangs (z. B. Einsatz eines Wasserwerfers) ${ }^{192}$ nach Vollstreckungsrecht bzw. die unmittelbare Ausführung nach Polizeirecht mangels Regelungswirkung kein Verwaltungsakt, da sich diese auf rein tatsächliches Handeln beschränken. ${ }^{193}$

186 Eingehend dazu: Milker, NVwZ 2018, 1751 (1756); so im Ergebnis auch unter allgemeinem Verweis auf behördliche (analoge) Hausverbote: Kalscheuer/Jacobsen, NJW 2018, 2358 (2359); a. A. Libertus, CR 2019, 262 (265).

187 Vgl. Ramsauer, in: Kopp/Ramsauer, VwVfG, 19. Aufl. 2018, § 35, Rn. 114.

188 Vgl. BVerwG, Urt. v. 17.6.2014, Az.: 10 C 7/13 = BeckRS 2014, 54339, Rn. 35; OVG RP, Urt.v. 27.3. 2014, Az.: 7 A 10993/13.0VG = LKRZ 2014, 363; s. auch von Alemann/Scheffczyk, in: Bader/Ronellenfitsch,VwVfG, 42. Ed., Stand: 1.1.2019, § 35, Rn. 154: nicht hingegen die bloße Vollstreckungsankündigung.

189 OVG RP, Urt. v. 22.1.1986, Az.: 8 B 44/85 = NVwZ 1986, 762: „[D]ie Festsetzung der Ersatzvornahme stellt einen belastenden Verwaltungsakt mit - gegenüber der Androhung - eigenständigem Regelungsgehalt dar“.

190 S. zu weiteren Beispielen: von Alemann/Scheffczyk, in: Bader/Ronellenfitsch,VwVfG, 42. Ed., Stand: 1.1.2019, §35, Rn. 154.

191 Vgl. etwa OVG RP, Urt. v. 25.1.2005, Az.: 7 A 11726/04 = NVwZ-RR 2005, 577.

192 Vgl. etwa VG Stuttgart, Urt. v. 18.11.2015, Az.: 5 K 1265/14 = BeckRS 2015, 56039; zur Versiegelung eines Geländes: VG Weimar, Beschl. v. 3.5.1999, Az.: 7 E 964/99 = NVwZ-RR 2000, 478. 193 Vgl. zur unmittelbaren Ausführung: BVerwG, Urt. v. 12.1.2012, Az.: 7 C 5/11 = NVwZ 2012, 1184, Rn. 19ff.; VG Karlsruhe, Urt. v. 5.5.2008, Az.: 11 K 645/08 = BeckRS 2008, 34709, Rn. 29; zur Ersatzvornahme: HessVGH, Urt.v. 30.4.1982, Az.: III TG 119/82 = NVwZ 1982, 514; zum unmittelbaren Zwang: VG Stuttgart, Urt. v. 18.11.2015, Az.: 5 K 1265/14 = BeckRS 2015, 56039. 
Das offenbar immer noch - vor allem in der älteren Rechtsprechung ${ }^{194}$ - 71 verbreitete (Hilfs-)Konstrukt einer konkludenten Duldungsverfügung ${ }^{195}$ ist als realitätsfern abzulehnen, ${ }^{196}$ zumal auch der Grund für dessen „Einführung“ längst weggefallen ist. ${ }^{197}$ Gleichwohl kann die Duldungspflicht im Einzelfall durch einen (ausdrücklichen) Verwaltungsakt („Anordnung“ einer Maßnahme) konkretisiert werden. ${ }^{198}$ Daher kommt es stets auf den Einzelfall an.

Die jedenfalls mittelbar dem Vollstreckungsrecht zuzuordnende Anordnung 72 der sofortigen Vollziehung (§ 80 II 1 Nr. 4 VwGO) hat keine Regelungswirkung, da sie nicht den Abschluss eines (eigenständigen) Verwaltungsverfahrens bezweckt, sondern nur ein Teil einer anderen Verwaltungssache ist, nämlich für die Frage, ob eine bereits getroffene Regelung schon vor ihrer formellen Bestandskraft vollzogen werden kann. ${ }^{199}$

Auch bei der Rechtsnatur von Standardmaßnahmen (s. dazu auch noch 73 Rn. 1004) ist die jeweils durchgeführte Maßnahme in den Blick zu nehmen, sodass sich pauschale Aussagen verbieten. ${ }^{200}$ Beispielsweise ist in einem Platzverweis (z. B. nach $\S 38$ BPolG) ohne weiteres eine Regelungswirkung erkennbar, ${ }^{201}$ während sich dies etwa bei der Ingewahrsamnahme - außer bei der (abzulehnenden)

194 S. dazu VG Frankfurt a.M., Urt. v. 20.1.1993, Az.: V/3 E 1210/90 = NVwZ 1994, 720 (Ingewahrsamnahme); VG Bremen, Urt. v. 5.12.1988, Az.: 4 A 226/86 = NVwZ 1989, 895 (Anfertigung von Videoaufnahmen von einer Versammlung); BayVGH, Urt. v. 16.5.1982, Az.: 21 B 87.02889 = NVwZ 1988, 1055 (Tränengaseinsatz als polizeiliche Zwangsmaßnahme); anschaulich zum Einsatz eines Schlagstocks: Pfeiffer/Buchinger, JA 2006, 102.

195 S. dazu insgesamt von Alemann/Scheffczyk, in: Bader/Ronellenfitsch,VwVfG, 42. Ed., Stand: 1.1.2019, §35, Rn. 150 .

196 So auch von Alemann/Scheffczyk, in: Bader/Ronellenfitsch, VwVfG, 42. Ed., Stand:1.1.2019, $\S 35$, Rn. 151; Finger, JuS 2005, 116 (117 f.); dies auch aus Gründen der fehlenden „Formenklarheit“ ablehnend: Stelkens, in: Stelkens/Bonk/Sachs, VwVfG, 9. Aufl. 2018, § 35, Rn. 95, 98; a. A. OVG RP, Urt. v. 27.3.2014, Az.: 7 A 10993/13.0VG = LKRZ 2014, 363.

197 Schwarz, in: Fehling/Kastner/Störmer, Verwaltungsrecht, 4. Aufl. 2016, § 35 VwVfG, Rn. 94; VG Stuttgart, Urt.v. 18.11.2015, Az.: 5 K 1265/14 = BeckRS 2015, 56039 = BeckRS 2015, 56039; Finger, JuS 2005, 116 (117); s. auch Rachor/Graulich, in: Lisken/Denninger, Handbuch des Polizeirechts 6. Aufl. 2018, Kapitel E, Rn. 35 f.

198 Vgl. BVerwG, Beschl. v. 14.7.2014 Az.: 6 B 2/14 = NVwZ-RR 2014, 848, Rn. 4.

199 OVG RP, Urt. v. 25.11.1987, Az.: 12 B 112/87 = NVwZ 1988, 748; von Alemann/Scheffczyk, in: Bader/Ronellenfitsch,VwVfG, 42. Ed., Stand: 1.1.2019, § 35, Rn. 156.

200 von Alemann/Scheffczyk, in: Bader/Ronellenfitsch,VwVfG, 42. Ed., Stand: 1.1.2019, §35, Rn. 153; Ramsauer, in: Kopp/Ramsauer, VwVfG, 19. Aufl. 2018, § 35, Rn. 114; insoweit auch differenzierend etwa OVG RP, Urt. v. 21.4.2016, Az.: 7 A 11108/14.OVG = NJW 2016, 2820, Rn. 25.

201 Vgl. OVG RP, Urt. v. 27.3.2014, Az.: 7 A 10993/13.OVG = LKRZ 2014, 363; BremOVG, Urt. v. 24.3. 1998, Az.: 1 BA 27/97 = NVwZ 1999, 314 (315); von Alemann/Scheffczyk, in: VwVfG, 42. Ed., Stand: 1.1.2019, § 35, Rn. 153. 
Konstruktion einer konkludenten Duldungsverfügung ${ }^{202}$ - generell nicht annehmen lässt. ${ }^{203}$

\section{e) Maßnahme „zur Regelung eines Einzelfalls“}

74 Das Merkmal der Maßnahme „zur Regelung eines Einzelfalls“ ist nur schwer im herkömmlichen Sinne positiv definierbar. Klassisch meint „Einzelfall“ jedenfalls konkret-individuelle Regelungen (dazu Rn. 76). Es dient (negativ) der Abgrenzung zur Rechtsnorm als abstrakt-generelle Regelung, ${ }^{204}$ die eine unbestimmte Vielzahl von Personen und Sachverhalten erfasst (dazu Rn. 88 ff.). ${ }^{205}$ Dazwischen finden sich Mischkonstellationen, also konkret-generelle (sog. Allgemeinverfügung, dazu Rn. 77 ff.) und abstrakt-individuelle (dazu Rn. 87) Regelungen, die ebenfalls Verwaltungsakte darstellen. Diese vier Konstellationen sollen im Folgenden näher erläutert werden.

75 Examenswissen: Der Behörde kommt grundsätzlich ein Wahlrecht zu, ob sie per Verwaltungsakt oder (materiellem) Gesetz handelt. ${ }^{206}$ Abgrenzungsprobleme treten regelmäßig dann auf, wenn die Maßnahme nicht eindeutig bezeichnet ist und daher die äußere Form als primäres Kriterium keine hinreichenden Rückschlüsse zulässt. ${ }^{207}$

\section{aa) Konkret-individuelle Maßnahmen}

76 Die klassische Konstellation beschreibt Maßnahmen, die sich auf einen bestimmten Adressatenkreis zur Regelung einer konkreten Situation beziehen. ${ }^{208}$ Dies kann etwa der polizeiliche Platzverweis gegenüber einer Person sein, die einen Polizeieinsatz behindert und von einem Polizeibeamten direkt persönlich angesprochen wird. Dabei wird dann der Adressat individualisiert und ihm gleichzeitig in der konkreten Situation des stattfindenden Polizeieinsatzes eine Rechtspflicht auferlegt.

202 So aber VG Frankfurt a.M., Urt. v. 20.1.1993, Az.: V/3 E 1210/90 = NVwZ 1994, 720 (721) ohne dies allerdings näher zu begründen.

203 Vgl. dazu ausführlich: Finger, JuS 2005, 116 (117); Müller, in: Huck/Müller, VwVfG, 2. Aufl. 2016, §35, Rn. 41.

204 Ramsauer, in: Kopp/Ramsauer, VwVfG, 19. Aufl. 2018, § 35, Rn. 118.

205 Schwarz, in: Fehling/Kastner/Störmer, Verwaltungsrecht, 4. Aufl. 2016, § 35 VwVfG, Rn. 97; Ramsauer, in: Kopp/Ramsauer, VwVfG, 19. Aufl. 2018, § 35, Rn. 121.

206 Vgl. Ramsauer, in: Kopp/Ramsauer, VwVfG, 19. Aufl. 2018, § 35, Rn. 119 m.w. N.

207 Vgl. Ramsauer, in: Kopp/Ramsauer, VwVfG, 19. Aufl. 2018, § 35, Rn. 120.

208 Siehe dazu etwa auch Schwarz, in: Fehling/Kastner/Störmer, Verwaltungsrecht, 4. Aufl. 2016, § 35 VwVfG, Rn. 97.

Jens Milker 


\section{bb) Konkret-generelle Maßnahmen}

Eine weitere häufig anzutreffende Variante von Verwaltungsakten sind konkret- 77 generelle ${ }^{209}$ Maßnahmen (sog. Allgemeinverfügungen im Sinne des § 35 Satz 2 VwVfG). Dabei wird nicht - wie soeben in Rn. 76 - von vornherein eine bestimmte Person bzw. ein Personenkreis konkret individualisiert und damit als Adressat festgelegt; vielmehr sind andere Anknüpfungspunkte relevant. Mit der Einordnung als Allgemeinverfügung sind zudem verwaltungsverfahrens- und prozessrechtliche Sonderregelungen verbunden (insbesondere hinsichtlich Bekanntgabe und Anhörung). ${ }^{210}$ Der Gesetzgeber sieht in $\S 35$ Satz 2 VwVfG insgesamt drei Varianten der Allgemeinverfügung vor. Die genaue Zuordnung hat zwar rechtlich keine Auswirkungen, erleichtert aber die Bildung von Fallgruppen und trägt so zum Verständnis der Reichweite des Begriffs der Allgemeinverfügung bei.

Die personenbezogene Allgemeinverfügung (Var. 1) ${ }^{211}$ richtet sich an einen 78 bestimmten oder bestimmbaren Personenkreis. ${ }^{212}$ Es findet keine individuelle Bestimmung des Adressaten (etwa durch persönliches oder namentliches Ansprechen bzw. Anschreiben) statt, diese erfolgt vielmehr anhand allgemeiner Merkmale. ${ }^{213}$ Gleichzeitig wird aber nur ein konkreter Sachverhalt geregelt und dieser nicht etwa anhand von abstrakten Merkmalen beschrieben. Dies unterscheidet schließlich die Allgemeinverfügung von der Rechtsnorm. ${ }^{214}$ Die genaue Zahl der Adressaten muss dabei nicht abschließend feststehen. ${ }^{215}$

Beispiel: Eine Verfügung, mit der alle öffentlichen Versammlungen unter freiem Himmel und 79 Aufzüge für einen Zeitraum von mehreren Tagen untersagt werden und die sich räumlich auf die genau beschriebene Umgebung der Route eines konkret geplanten „Castortransports“ beschränkt, ist als ein präventives Versammlungsverbot im Wege der Allgemeinverfügung ( $\$ 35$

209 Vgl. BremOVG, Beschl. v. 21.10.2011, Az.: 1 B 162/11 = NordÖR 2012, 38.

210 S. dazu Ramsauer, in: Kopp/Ramsauer, VwVfG, 19. Aufl. 2018, § 35, Rn. 159 f.

211 Vgl. von Alemann/Scheffczyk, in: Bader/Ronellenfitsch,VwVfG, 42. Ed., Stand:1.1.2019, § 35, Rn. 255; s. insbesondere mit zahlreichen Fallgruppen und Beispielen: Stelkens, in: Stelkens/ Bonk/Sachs, VwVfG, 9. Aufl. 2018, § 35, Rn $284 \mathrm{ff}$.

212 Vgl. von Alemann/Scheffczyk, in: Bader/Ronellenfitsch,VwVfG, 42. Ed., Stand:1.1.2019, § 35, Rn. 255.

213 Vgl. von Alemann/Scheffczyk, in: Bader/Ronellenfitsch,VwVfG, 42. Ed., Stand:1.1.2019, § 35, Rn. 255; Schwarz, in: Fehling/Kastner/Störmer, Verwaltungsrecht, 4. Aufl. 2016, § 35 VwVfG, Rn. 120: „der Gattung nach bestimmbar“.

214 Vgl. OVG Nds., Urt. v. 29.5.2008, Az.: 11 LC 138/06 = BeckRS 2008, 36232; von Alemann/ Scheffczyk, in: VwVfG, 42. Ed., Stand: 1.1.2019, §35, Rn. 255; Ramsauer, in: Kopp/Ramsauer, VwVfG, 19. Aufl. 2018, § 35, Rn. 161.

215 Stelkens, in: Stelkens/Bonk/Sachs, VwVfG, 9. Aufl. 2018, §35, Rn. 282; von Alemann/ Scheffczyk, in: Bader/Ronellenfitsch,VwVfG, 42. Ed., Stand: 1.1.2019, § 35, Rn. 255.

Jens Milker 
Satz. 2 Var. 1 VwVfG) einzuordnen. ${ }^{216}$ Eine Allgemeinverfügung ist „bei versammlungsbeschränkenden Maßnahmen anzunehmen, wenn sich die Maßnahmen vor dem Hintergrund eines bestimmten Ereignisses oder Anlasses an alle Personen wenden, die zu einem bestimmten Zeitpunkt bzw. innerhalb eines bestimmten Zeitraums an einem bestimmten Ort oder innerhalb eines näher bezeichneten räumlichen Bereichs zu Versammlungen zusammenzukommen beabsichtigen“. ${ }^{217}$

Beispiel: Am 11. Mai findet um 15:30 Uhr das Fußballspiel zwischen dem 1. FSV Mainz 05 und Eintracht Frankfurt statt. Eine polizeiliche Verfügung, in der Linie S8 von Mainz nach Frankfurt am Main (Stadion) am 11. Mai 2019 mit Abfahrtszeiten zwischen 12:00 Uhr und 16:00 Uhr keine Glasflaschen mitzuführen, ließe sich aufgrund des hinreichend konkret umschriebenen Sachverhalts als Allgemeinverfügung einordnen. Eine Rechtsnorm würde hingegen vorliegen, wenn die Regelung dahingehend gefasst wäre, dass anlässlich jeder Begegnung der beiden Vereine in der Zukunft das oben angeführte Glasflaschenverbot am Spieltag greifen soll.

81 Der Behörde steht ein Wahlrecht $\mathrm{zu}$, ob sie eine Allgemeinverfügung oder ein „Bündel von Einzelverfügungen“218 (sog. „Sammelverwaltungsakt““219) erlassen möchte; die Abgrenzung bereitet dahingehend oftmals Schwierigkeiten. ${ }^{220}$ Maßgeblich dürfte es darauf ankommen, ob und inwieweit die individuellen Verhältnisse der Adressaten zu berücksichtigen sind. ${ }^{221}$ Zudem betreffen Sammelverwaltungsakte typischerweise eine bestimmte (nicht nur bestimmbare) und damit von vornherein feststehende Zahl von Personen. ${ }^{222}$

82 Die sachbezogene Allgemeinverfügung (Var. 2) ${ }^{223}$ betrifft die öffentlichrechtliche Eigenschaft einer Sache. Unmittelbarer Bezugspunkt ist schließlich

216 Vgl. VGH BW, Urt. v. 6.11.2013, Az.: 1 S 1640/12 = BeckRS 2013, 58560; OVG Nds., Urt. v. 29. 5. 2008, Az.: 11 LC 138/06 = BeckRS 2008, 36232: „Dies ist bei versammlungsbeschränkenden Maßnahmen der Fall, wenn sich die Maßnahmen vor dem Hintergrund eines bestimmten Ereignisses oder Anlasses an alle Personen wenden, die zu einem bestimmten Zeitpunkt bzw. innerhalb eines bestimmten Zeitraums an einem bestimmten Ort oder innerhalb eines näher bezeichneten räumlichen Bereichs zu Versammlungen zusammenzukommen beabsichtigen“; von Alemann/Scheffczyk, in: Bader/Ronellenfitsch,VwVfG, 42. Ed., Stand: 1.1.2019, § 35, Rn. 261.1.

217 OVG Nds., Urt. v. 29.5.2008, Az.: 11 LC 138/06 = BeckRS 2008, 36232.

218 von Alemann/Scheffczyk, in: Bader/Ronellenfitsch,VwVfG, 42. Ed., Stand: 1.1.2019, §35, Rn. 259.

219 Vgl. von Alemann/Scheffczyk, in: Bader/Ronellenfitsch,VwVfG, 42. Ed., Stand:1.1. 2019, § 35, Rn. 259; Stelkens, in: Stelkens/Bonk/Sachs, VwVfG, 9. Aufl. 2018, § 35, Rn. 277.

220 Vgl. dazu von Alemann/Scheffczyk, in: Bader/Ronellenfitsch,VwVfG, 42. Ed., Stand:1.1.2019, $\S 35$, Rn. 259 f.; Stelkens, in: Stelkens/Bonk/Sachs, VwVfG, 9. Aufl. 2018, § 35, Rn. 277 ff.; Ramsauer, in: Kopp/Ramsauer, VwVfG, 19. Aufl. 2018, § 35, Rn. 163.

221 Vgl. von Alemann/Scheffczyk, in: Bader/Ronellenfitsch,VwVfG, 42. Ed., Stand:1.1.2019, § 35, Rn. 260; dabei auch wesentlich auf die Art des Erlasses abstellend: Stelkens, Rn. 279.

222 Ramsauer, in: Kopp/Ramsauer, VwVfG, 19. Aufl. 2018, § 35, Rn. 163.

223 Vgl. von Alemann/Scheffczyk, in: Bader/Ronellenfitsch,VwVfG, 42. Ed., Stand:1.1.2019, § 35, Rn. 262.

Jens Milker 
eine bestimmte Sache, wobei mittelbar die Rechte und Pflichten von Personen geregelt werden, die mit der Sache in Berührung kommen. ${ }^{224}$ Es handelt sich damit um einen „adressatenlosen“ Verwaltungsakt. ${ }^{225}$ Der Sachbegriff ist verwaltungsrechtlich $\mathrm{zu}$ bestimmen ${ }^{226}$ und erfasst neben Sachen im Sinne des $§ 90$ BGB auch „Sachgesamtheiten“ (z. B. öffentliche Anstalten und Einrichtungen). ${ }^{227}$ Erfasst sind insoweit etwa die Umbenennung einer Straße $\mathrm{e}^{228}$ oder auch die Widmung einer öffentlichen Einrichtung. ${ }^{229}$

Mit der benutzungsregelnden Allgemeinverfügung (Var. 3) ) $^{230}$ wird die 83 Benutzung einer (bereits als solchen gewidmeten) öffentlichen Sache näher ausgestaltet (etwa im Hinblick auf Öffnungszeiten). ${ }^{231}$ Auch hier ist unmittelbarer Bezugspunkt schließlich die bestimmte Sache, während sie gleichzeitig (mittelbar) an einen anhand abstrakter Merkmale bestimmbaren Personenkreis (die „Benutzer“) gerichtet ist. ${ }^{232}$

Beispiel: Die Benutzungsordnung einer Stadthalle mit der etwa die zugelassenen Veranstaltungsarten (insbesondere der Ausschluss politischer Veranstaltungen) festgelegt werden. ${ }^{233}$

224 Vgl. von Alemann/Scheffczyk, in: Bader/Ronellenfitsch,VwVfG, 42. Ed., Stand:1.1.2019, § 35, Rn. 262; s. auch Ramsauer, in: Kopp/Ramsauer, VwVfG, 19. Aufl. 2018, §35, Rn. 164: Aus dem Bezug zur bestimmten Sache folgt die hinreichende Konkretheit der Regelung.

225 Vgl. OVG NRW, Urt. v. 29.10.2007, Az.: 15 B 1517/07 = NVwZ-RR 2008, 487; s. auch BVerwG, Beschl.v. 24.4.1978, Az.: 7 B 111/77 = NJW 1978, 2211: „intransitive Zustandsregelung“.

226 von Alemann/Scheffczyk, in: Bader/Ronellenfitsch,VwVfG, 42. Ed., Stand: 1.1.2019, §35, Rn. 263.

227 von Alemann/Scheffczyk, in: Bader/Ronellenfitsch,VwVfG, 42. Ed., Stand: 1.1.2019, §35, Rn. 263; Stelkens, in: Stelkens/Bonk/Sachs, VwVfG, 9. Aufl. 2018, § 35, Rn. 316.

228 Vgl. OVG NRW, Urt. v. 29.10.2007, Az.: 15 B 1517/07 = NVwZ-RR 2008, 487.

229 Vgl. BayVGH, Urt. v. 31.3.2003, Az.: 4 B 00.2823 = NVwZ-RR 2003, 771 (771); VGH BW, Urt. v. 11.4.1994, Az.: 1 S 1081/93 = NVwZ 1994, 920 (921); Schoch, NVwZ 2016, 257 (260); von Alemann/ Scheffczyk, in: Bader/Ronellenfitsch,VwVfG, 42. Ed., Stand: 1.1.2019, §35, Rn. 263; auf die ausdrückliche Widmung beschränkend: Stelkens, in: Stelkens/Bonk/Sachs, VwVfG, 9. Aufl. 2018, $\S 35$, Rn. 325.

230 von Alemann/Scheffczyk, in: Bader/Ronellenfitsch,VwVfG, 42. Ed., Stand: 1.1.2019, § 35, Rn. 266.

231 von Alemann/Scheffczyk, in: Bader/Ronellenfitsch,VwVfG, 42. Ed., Stand: 1.1.2019, §35, Rn. 266; Stelkens, in: Stelkens/Bonk/Sachs, VwVfG, 9. Aufl. 2018, § 35, Rn. 338; tendenziell auf Var. 2 abstellend: BVerwG, NVwZ 2007, 340, Rn. 7.

232 von Alemann/Scheffczyk, in: Bader/Ronellenfitsch,VwVfG, 42. Ed., Stand: 1.1.2019, §35, Rn. 266.

233 Vgl. etwa VG Bayreuth, Beschl. v. 16.2.2009, Az.: B 2 E 08.1234 = BeckRS 2009, 48133; von Alemann/Scheffczyk, in: Bader/Ronellenfitsch,VwVfG, 42. Ed., Stand: 1.1.2019, § 35, Rn. 267. 
85 Eine Sonderstellung der benutzungsregelnden Allgemeinverfügungen nehmen sofern sie eine Regelung enthalten ${ }^{234}$ - Verkehrszeichen (z.B. Haltverbote) ein. ${ }^{235}$ Deren Adressat sind die Verkehrsteilnehmer, für die das Verkehrszeichen in einer konkreten Verkehrssituation Rechte und Pflichten begründet, ${ }^{236} \mathrm{z}$. B. das Verbot des Parkens in einem bestimmten Straßenabschnitt. ${ }^{237}$ Dabei ergeben sich aufgrund der Bedürfnisse des Straßenverkehrs und der einschlägigen Spezialregelungen der StVO besondere Einzelfragen hinsichtlich der Bekanntgabe und des Wirksamwerdens (s. näher Rn. 117 ff.) sowie der Anfechtungsfrist (s. näher Rn. 166). ${ }^{238}$

86 Hausarbeitswissen: In der älteren Rechtsprechung wurden Verkehrszeichen noch als Rechtsverordnungen angesehen. ${ }^{239}$ Da auch der Gesetzgeber in der amtlichen Begründung zu §35 S. 2 VwVfG davon ausgeht, dass Verkehrszeichen als Verwaltungsakte einzuordnen sind, ${ }^{240}$ und sich die ganz herrschende Meinung ${ }^{241}$ insoweit schon länger gewandelt hat, ${ }^{242}$ muss dieser Streit in einer Klausur nicht mehr zwingend thematisiert werden, kann aber ggf. in Hausarbeiten Erwähnung finden. ${ }^{243}$

\section{cc) Abstrakt-individuelle Maßnahme}

87 Eine abstrakt-individuelle Regelung wird getroffen, wenn für eine unbestimmte Anzahl an Lebenssachverhalten einer bestimmten Person oder einem bestimmten Personenkreis eine bestimmte Handlungspflicht auferlegt wird. ${ }^{244}$ Als Beispiele

234 Vgl. zur Differenzierung der Arten von Verkehrszeichen etwa: Milker, Jura 2017, 271; Kümper, JuS 2017, 731.

235 Vgl. zur Zuordnung zu § 35 Satz 2 Var. 3 VwVfG: von Alemann/Scheffczyk, in: Bader/Ronellenfitsch,VwVfG, 42. Ed., Stand: 1.1.2019, § 35, Rn. 269; Kümper, JuS 2017, 731 (732).

236 Vgl. BVerwG, Urt v. 13.12.1979, Az.: 7 C 46/78 = NJW 1980, 1640: „Entscheidend ist, (...) daß Verkehrszeichen eine konkrete örtliche Verkehrssituation betreffen und eine situationsbezogene Verkehrsregelung zum Inhalt haben. Sie vertreten gleichsam die Stelle von Polizeivollzugsbeamten“; s. dazu auch Milker, Jura 2017, 271 (272f.); Kümper, JuS 2017, 731 (732).

237 Milker, Jura 2017, 271 (273).

238 Vgl. von Alemann/Scheffczyk, in: Bader/Ronellenfitsch,VwVfG, 42. Ed., Stand:1.1.2019, § 35, Rn. 270; s. dazu ausführlich Milker, Jura 2017, 271; Kümper, JuS 2017, 731; aus der Rechtsprechung etwa BVerwG, Urt. v. 6.4.2016, Az.: 3 C 10/15 = NJW 2016, 2353, Rn. 16.

239 Vgl. BayVGH, Urt. v. 21.12.1977, Az.: 141 XI/76 = NJW 1978, 1988; dazu auch Maurer/Waldhoff, Allgemeines Verwaltungsrecht, 19. Aufl. 2017, § 9, Rn. $35 \mathrm{ff}$.

240 BT-Drs.7/910, S. 57; s. auch Milker, Jura 2017, 271 (273); Kümper, JuS 2017, 731 (733).

241 Vgl. auch Kümper, JuS 2017, 731 (732) m.w. N.: „Gegenwärtig werden Verkehrszeichen praktisch einhellig als Verwaltungsakte in Form der Allgemeinverfügung (...) angesehen“.

242 Näher dazu Kümper, JuS 2017, 731 (733) m.w.N.

243 Milker, Jura 2017, 271 (273).

244 Schwarz, in: Fehling/Kastner/Störmer, Verwaltungsrecht, 4. Aufl. 2016, § 35 VwVfG, Rn. 97; von Alemann/Scheffczyk, in: Bader/Ronellenfitsch,VwVfG, 42. Ed., Stand: 1.1.2019, § 35, Rn. 193 (diese Konstruktion aber als überflüssig ansehend). 
werden dazu etwa die „Beseitigung wiederkehrender Verschmutzungen oder das Ergreifen bestimmter Sicherheitsmaßnahmen bei wiederholten Sprengungen“ genannt. ${ }^{245}$ Teilweise wird diese Konstellation als überflüssig angesehen, da es sich um eine „Bündelung konkret-individueller“ Regelungen handele. ${ }^{246}$

\section{dd) Abstrakt-generelle Maßnahme}

Eine abstrakt-generelle Maßnahme bezeichnet schließlich Gesetze bzw. Rechts- 88 normen, die nicht als Verwaltungsakte einzuordnen sind. Abgrenzungsprobleme ergeben sich regelmäßig zur Allgemeinverfügung. ${ }^{247}$ Die Verwaltung hat dabei grundsätzlich die Wahl, ob sie ein (materielles) Gesetz (z. B. eine Gefahrenabwehrverordnung) oder eine Allgemeinverfügung erlässt; anders liegt die Sache hingegen, wenn das Gesetz eine bestimmte Handlungsform zwingend vorschreibt. 248

Beispiel $^{249}$ : Die Stadt M erlässt zur Eindämmung von Lärm und Verunreinigungen eine Gefahrenabwehrverordnung, die u. a. folgenden Inhalt hat:

\section{$\S 2$ Alkoholverbot}

(1) Im Geltungsbereich der Verordnung ist es auf den öffentlich zugänglichen Flächen außerhalb konzessionierter Freisitzflächen verboten:

- alkoholische Getränke jeglicher Art zu konsumieren

- alkoholische Getränke jeglicher Art mit sich zu führen, wenn auf Grund der konkreten Umstände die Absicht erkennbar ist, diese im Geltungsbereich der Verordnung konsumieren zu wollen.

(2) Dieses Verbot gilt in den Nächten von Freitag auf Samstag, Samstag auf Sonntag, Sonntag auf Montag jeweils von 22 bis 6 Uhr. Gleiches gilt für die Zeit von 00:00 bis $6 \mathrm{Uhr}$ morgens an einem gesetzlichen Feiertag und die zwei Stunden davor (d.h. von 22 bis 6 Uhr). Gemäß § 4 I GefahrenabwehrVO kann ein Verstoß gegen dieses Verbot als Ordnungswidrigkeit geahndet werden.

Bei der vorgenannten Gefahrenabwehrverordnung handelt es sich um eine abstrakt-generelle Regelung, weil schon das Gebiet, auf dem das Alkoholverbot gelten soll, abstrakt umschrieben ist, nämlich alle „öffentlich zugänglichen Flächen“ im Geltungsbereich. Zudem spricht hier

245 von Alemann/Scheffczyk, in: Bader/Ronellenfitsch,VwVfG, 42. Ed., Stand: 1.1.2019, §35, Rn. 193; weitere Beispiele bei Heyle, NVwZ 2008, 390.

246 von Alemann/Scheffczyk, in: Bader/Ronellenfitsch,VwVfG, 42. Ed., Stand: 1.1.2019, § 35, Rn. 194; so auch VGH BW, Urt. v. 5.12.2002, Az.: 5 S 2625/01 = NZV 2003, 301: Zur Anordnung gegenüber einem bestimmten Adressaten, mit dem Liegefahrrad Radwege zu benutzen.

247 von Alemann/Scheffczyk, in: Bader/Ronellenfitsch,VwVfG, 42. Ed., Stand: 1.1.2019, §35, Rn. $195 \mathrm{ff}$.

248 von Alemann/Scheffczyk, in: Bader/Ronellenfitsch,VwVfG, 42. Ed., Stand: 1.1.2019, § 35, Rn. 196 m.w. N.

249 Vgl. VGH BW, Urt. v. 28.7.2009, Az.: 1 S 2200/08 = NVwZ-RR 2010, 55. 
auch schon die gewählte Form als Gefahrenabwehrverordnung indiziell für eine abstrakt-generelle Regelung (zur Rechtmäßigkeit von Alkoholverbotsverordnungen näher $\S 7$ Rn. 118). ${ }^{250}$

\section{f) Außenwirkung}

90 Die Maßnahme muss schließlich darauf gerichtet sein, ${ }^{251}$ Rechtswirkungen gegenüber einer Person zu erzeugen, die außerhalb des handelnden Verwaltungsträgers steht. ${ }^{252}$ Sie muss nach ihrem objektiven Sinngehalt dazu bestimmt sein, Außenwirkung zu entfalten, unabhängig davon, wie sie sich im Einzelfall auswirkt. $^{253}$ Von wesentlicher Bedeutung ist dabei, ob der Adressat in seiner Eigenschaft als Teil der Verwaltung oder als selbstständiges Rechtssubjekt angesprochen wird. ${ }^{254}$ Die Außenwirkung ist nur dann als „unmittelbar“ einzuordnen, wenn keine weiteren Umsetzungsmaßnahmen notwendig sind, damit die Rechtsfolgen bei dem Adressaten eintreten. ${ }^{255}$ Schließlich geht es um die Abgrenzung zu rein verwaltungsinternen Vorgängen. ${ }^{256}$ Dazu zählen insbesondere - jedenfalls im Verhältnis zum Bürger - die Zustimmungs- und Genehmigungsakte anderer Behörden bei Erlass von mehrstufigen Verwaltungsakten ${ }^{257}$ (wie etwa die Erteilung des gemeindlichen Einvernehmens nach $\S 36 \mathrm{BauGB}^{258}$ ). ${ }^{259}$ Anders ist die Lage dann, wenn die Entscheidung der mitwirkenden Behörde dem Betroffenen als selbstständiger Verwaltungsakt bekannt gegeben wird. ${ }^{260} \mathrm{Ge}$ meinderatsbeschlüsse haben regelmäßig keine Außenwirkung, da sie grundsätzlich einer Umsetzung durch den Bürgermeister als monokratisches Ausfüh-

250 Vgl. von Alemann/Scheffczyk, in: Bader/Ronellenfitsch,VwVfG, 42. Ed., Stand:1.1.2019, § 35, Rn. 197 f.; Ramsauer, in: Kopp/Ramsauer, VwVfG, 19. Aufl. 2018, § 35, Rn. 120.

251 Vgl. BVerwG, Urt. v. 19.4.2011, Az.: 1 C 2/10 = BeckRS 2011, 52368, Rn. 14: „Indem das Gesetz normiert, dass der Verwaltungsakt auf eine Rechtswirkung ,gerichtet` ist, betont es die Finalität des Verwaltungshandelns in dieser Handlungsform“; Stelkens, in: Stelkens/Bonk/Sachs, VwVfG, 9. Aufl. 2018, § 35, Rn. 147.

252 Vgl. statt vieler Schwarz, in: Fehling/Kastner/Störmer, Verwaltungsrecht, 4. Aufl. 2016, § 35 VwVfG, Rn. 103 m.w. N.

253 BVerwG, Urt. v. 26.4.2012, Az.: 2 C 17/10 = NVwZ 2012, 1483, Rn. 15; Stelkens, in: Stelkens/ Bonk/Sachs, VwVfG, 9. Aufl. 2018, § 35, Rn. 147.

254 Vgl. BVerwG, Urt.v. 2.3. 2006, Az.: 2C 3/05 = NVwZ-RR 2007, 781; von Alemann/Scheffczyk, in: Bader/Ronellenfitsch,VwVfG, 42. Ed., Stand: 1.1.2019, § 35, Rn. 223.

255 von Alemann/Scheffczyk, in: Bader/Ronellenfitsch, VwVfG, 42. Ed., Stand: 1.1.2019, § 35, Rn. 224 m.w. N.; Müller, in: Huck/Müller, VwVfG, 2. Aufl. 2016, § 35, Rn. 45.

256 Vgl. Stelkens, in: Stelkens/Bonk/Sachs, VwVfG, 9. Aufl. 2018, § 35, Rn. 146.

257 Vgl. Ramsauer, in: Kopp/Ramsauer, VwVfG, 19. Aufl. 2018, § 35, Rn. 129.

258 Vgl. etwa BVerwG, NVwZ 1986, 556; Ramsauer, in: Kopp/Ramsauer, VwVfG, 19. Aufl. 2018, $\S 35$, Rn. 129 m.w. N.

259 Ramsauer, in: Kopp/Ramsauer, VwVfG, 19. Aufl. 2018, § 35, Rn. 131.

260 Ramsauer, in: Kopp/Ramsauer, VwVfG, 19. Aufl. 2018, § 35, Rn. 131.

Jens Milker 
rungsorgan bedürfen. ${ }^{261}$ Probleme hinsichtlich der Abgrenzung treten darüber hinaus im Beamtenrecht und bei Maßnahmen zwischen unterschiedlichen Behörden auf.

Bei Maßnahmen des Dienstherrn im öffentlichen Dienstrecht gegen- 91 über Beamten ist - auch nach berechtigter Ablehnung eines grundrechts- und rechtsschutzfreien Raums im Rahmen eines „besonderen Gewaltverhältnisses“262 - weiterhin zwischen dem Grund- und Betriebsverhältnis zur Feststellung der Außenwirkung einer Maßnahme zu unterscheiden. ${ }^{263}$

Hausarbeitswissen: Seit der sog. „Strafgefangenenentscheidung“ des Bundesverfassungsgerichts ${ }^{264}$ ist es in Rechtsprechung und Literatur allgemein anerkannt, dass auch in „Sonderstatusverhältnissen“, also etwa im Beamten- oder Soldatenverhältnis, ${ }^{265}$ kein „,besonderes Gewaltverhältnis“266 besteht, das „als eine eigenständige, implizite Beschränkung der Grundrechte“267 fungieren kann. ${ }^{268}$ Grundrechte gelten damit auch dem Grunde nach im Sonderstatusverhältnis, wobei im Rahmen der Rechtfertigung von Grundrechtseingriffen vor allem bei Beamten aufgrund des Näherverhältnisses zum Staat Besonderheiten gelten (insbesondere Art. 33 Abs. 5 GG). ${ }^{269}$ Insgesamt sind Maßnahmen in Sonderstatusverhältnissen allgemein einer verwaltungsgerichtlichen Kontrolle zugänglich, unabhängig davon, ob sie das Grund- oder Betriebsverhältnis betreffen. ${ }^{270}$

Dem Betriebsverhältnis sind solche Maßnahmen zuzuordnen, die bestimmen, 93 auf welche Art und Weise der Beamte seinen dienstlichen Verrichtungen nachzukommen hat (auch wenn sie - wie etwa die Anpassung der Haartracht - in der

261 Vgl. dazu (mit weiteren Beispielen): Pietzcker, in: Schoch/Schneider/Bier, VwGO, 36. EL Februar 2019, § 42 I, Rn. 60.

262 Vgl. dazu BVerfG, Beschl.v. 14.3.1972, Az.: 2 BvR 41/71 = NJW 1972, 811; Ramsauer, in: Kopp/ Ramsauer, VwVfG, 19. Aufl. 2018, § 35, Rn. 134.

263 Vgl. Ramsauer, in: Kopp/Ramsauer, VwVfG, 19. Aufl. 2018, § 35, Rn. 134f.; von Alemann/ Scheffczyk, in: Bader/Ronellenfitsch, VwVfG, 42. Ed., Stand: 1.1.2019, § 35, Rn. 239; Stelkens, in: Stelkens/Bonk/Sachs, VwVfG, 9. Aufl. 2018, § 35, Rn. 198; diese begriffliche Differenzierung ablehnend: Schwarz, in: Fehling/Kastner/Störmer, Verwaltungsrecht, 4. Aufl. 2016, § 35 VwVfG, Rn. 107.

264 BVerfG, Beschl.v. 14.3.1972, Az.: 2 BvR 41/71 = NJW 1972, 811.

265 S. zu einer ausführlichen Betrachtung weiterer Sonderstatusverhältnisse: Stelkens, in: Stelkens/Bonk/Sachs, VwVfG, 9. Aufl. 2018, § 35, Rn. 198 ff.; die „Sonderstatusverhältnisse“ bzw. „Sonderrechtsverhältnisse“ und damit die Differenzierung zwischen Grund- und Betriebsverhältnis auf das Beamten- und Soldatenverhältnis beschränkend: von Alemann/Scheffczyk, in: Bader/Ronellenfitsch, VwVfG, 42. Ed., Stand: 1.1.2019, § 35, Rn. $236 \mathrm{ff}$.

266 Vgl. zur historischen Entwicklung: v. Kielmansegg, JA 2012, 881.

267 BVerfG, Beschl.v. 14.3.1972, Az.: 2 BvR 41/71 = NJW 1972, 811 (812).

268 Vgl. statt vieler: Ramsauer, in: Kopp/Ramsauer, VwVfG, 19. Aufl. 2018, § 35, Rn. 134.

269 Vgl. dazu v. Kielmansegg, JA 2012, 881.

270 Ramsauer, in: Kopp/Ramsauer, VwVfG, 19. Aufl. 2018, § 35, Rn. 134. 
privaten Lebenssphäre fortwirken). ${ }^{271}$ Es kommt insoweit nicht allgemein auf die faktischen Auswirkungen, sondern auf die Zielrichtung der Maßnahme und deren beabsichtigte unmittelbare Folgen an. ${ }^{272}$ Demgegenüber zählen zum Grundverhältnis nicht nur die Begründung ${ }^{273}$, Beendigung ${ }^{274}$ und wesentliche Änderung ${ }^{275}$ des Sonderstatusverhältnisses, sondern alle Maßnahmen, die unmittelbar auf die Veränderung des individuellen Rechtsstatus des Betroffenen abzielen (z.B. Bewilligung von Urlaub $\left.{ }^{276}\right){ }^{277}$ Dementsprechend werden etwa Umsetzungen ${ }^{278}$ und sonstige dienstliche Weisungen ${ }^{279}$ mangels Außenwirkung regelmäßig nicht als Verwaltungsakte eingeordnet. ${ }^{280}$ Im Gegensatz dazu haben etwa die Ernennung $^{281}$ und die Versetzung ${ }^{282}$ eines Beamten Außenwirkung. ${ }^{283}$ Ebenso wird überwiegend (besonders aktuell!) dem gegenüber einer Beamtin ausge-

271 Vgl. BVerwG, Urt.v. 2.3.2006, Az.: 2C 3/05 = NVwZ-RR 2007, 781 (allerdings ohne Verwendung des Begriffs „Betriebsverhältnis“); BVerwG, Urt. v. 22.5.1980, Az.: 2 C 30/78 = NJW 1981, 67: „Behördeninterne Maßnahmen sind insbesondere (...) die an einen Beamten allein in seiner Eigenschaft als Amtsträger und Glied der Verwaltung gerichteten, auf organisationsinterne Wirkung zielenden Weisungen des Dienstherrn und die auf die Art und Weise der dienstlichen Verrichtung bezogenen innerorganisatorischen Maßnahmen der Behörde, in deren Organisation der Beamte eingegliedert ist“.

272 Stelkens, in: Stelkens/Bonk/Sachs, VwVfG, 9. Aufl. 2018, § 35, Rn. 198 m.w. N.

273 BVerwG, Urt. v. 1.2.1978, Az.: VI C 9/77 = BeckRS 1978, 00835, Rn. 17.

274 BVerwG, Urt. v. 12.4.1978, Az.: VIII C 70/76 = BeckRS 1978, 00897, Rn. 9.

275 z. B. Versetzung und Abordnung vgl. BVerwG, Urt. v. 22.5.1980, Az.: 2 C 30/78 = NJW 1981, 67 (68)).

276 Vgl. BVerwG, Urt. v. 15.3.1973, Az.: II C 7/71 = BVerwG, NJW 1973, 1242.

277 Vgl. BVerwG, Urt. v. 22.5.1980, Az.: 2 C 30/78 = NJW 1981, 67; Ramsauer, in: Kopp/Ramsauer, VwVfG, 19. Aufl. 2018, § 35, Rn. 136; von Alemann/Scheffczyk, in: Bader/Ronellenfitsch,VwVfG, 42. Ed., Stand: 1.1.2019, § 35, Rn. 239.

278 BVerwG, Urt. v. 19.11.2015, Az.: 2 A 6/13 = NVwZ 2016, 460, Rn. 18; BVerwG, Urt. v. 22.5.1980, Az.: 2 C 30/78 = NJW 1981, 67 (68).

279 BVerwG, Urt. v. 26.4.2012, Az.: 2 C 17/10 = NVwZ 2012, 1483, Rn. 15 (zur Anordnung einer ärztlichen Begutachtung); s. auch Ramsauer, in: Kopp/Ramsauer, VwVfG, 19. Aufl. 2018, §35, Rn. 139.

280 Dazu insgesamt auch mit weiteren Beispielen: von Alemann/Scheffczyk, in: Bader/Ronellenfitsch,VwVfG, 42. Ed., Stand:1.1.2019, § 35, Rn. 240.1 ff.; Ramsauer, in: Kopp/Ramsauer, VwVfG, 19. Aufl. 2018, § 35, Rn. 136 ff.; W. R. Schenke, in: Kopp/Schenke, VwGO, 25. Aufl. 2019, Anh. § 42, Rn. 70.

281 BVerwG, Urt. v. 1.2.1978, Az.: VI C 9/77 = BeckRS 1978, 00835, Rn. 17: „Die Ernennung, ein rechtsgestaltender formaler Verwaltungsakt, erlangt - wie andere Verwaltungsakte auch mit der Bekanntgabe - durch die Aushändigung an den Betroffenen äußere Wirksamkeit“.

282 BVerwG, Beschl. v. 18.2.2013, Az.: 2 B 51/12 = NVwZ 2013, 797, Rn. 16.

283 Weitere Beispiele auch bei von Alemann/Scheffczyk, in: Bader/Ronellenfitsch, VwVfG, 42. Ed., Stand: 1.1.2019, § 35, Rn. 240.1 ff. und W. R. Schenke, in: Kopp/Schenke, VwGO, 25. Aufl. 2019, Anh. § 42, Rn. 69. 
sprochenen Verbot des religiös motivierten Tragens eines Kopftuchs Außenwirkung zuerkannt. ${ }^{284}$

Sofern es sich um Maßnahmen zwischen mehreren Behörden handelt, 94 muss differenziert werden. Zunächst ist stets Außenwirkung anzunehmen, soweit die Behörde wie eine Privatperson betroffen ist, also die Maßnahme auf Grundlage einer Norm erfolgt, die die Behörde auch zum Erlass von Verwaltungsakten gegenüber Privatpersonen berechtigt (z.B. Festsetzung von Gebühren ${ }^{285}$ ). ${ }^{286} \mathrm{Im}$ Gegensatz dazu haben (Aufsichts-)Maßnahmen gegenüber Behörden desselben Rechtsträgers keine Außenwirkung. ${ }^{287}$

Bei Aufsichtsmaßnahmen zwischen Behörden unterschiedlicher 95

Rechtsträger sind bei Selbstverwaltungskörperschaften (z. B. Gemeinden, Universitäten oder Rundfunkanstalten) Maßnahmen der Rechts- und Fachaufsicht zu unterscheiden. ${ }^{288}$ Während bei der Fachaufsicht ${ }^{289}$ die beaufsichtigte Behörde in der Regel keine „geschützte Rechtsstellung“ gegenüber der Aufsichtsbehörde innehat und daher wie eine (staatliche) Behörde desselben Rechtsträgers zu behandeln ist, kann insoweit auch grundsätzlich keine Außenwirkung angenommen werden; sie bewegt sich dabei in dem ihr übertragenen (staatlichen) Aufgabenbereich. ${ }^{290}$ Bei der Rechtsaufsicht ${ }^{291}$ hingegen befindet sich die beaufsichtigte

284 Vgl.VGH BW, Urt. v. 14. 3.2008, Az.: 4 S 516/07 = BeckRS 2008, 34909, Rn. 22; W. R. Schenke, in: Kopp/Schenke, VwGO, 25. Aufl. 2019, Anh. § 42, Rn. 69; so wohl auch BayVGH, BeckRS 2018, 7009; a. A. wohl: Windoffer, in: Mann/Sennekamp/Uechtritz, VwVfG, 1. Aufl. 2014, § 35, Rn. 119; s. aktuell zu der Zulässigkeit solcher Verbote für Rechtsreferendarinnen: BVerfG, Beschl. v. 27.6. 2017, Az.: 2 BvR 1333/17 = NJW 2017, 2333.

285 Vgl. BVerwG, Urt. v. 19.1.2000, Az.: 11 C 6/99 = NVwZ 2000, 673 (674).

286 Vgl. Stelkens, in: Stelkens/Bonk/Sachs, VwVfG, 9. Aufl. 2018, § 35, Rn. 189f.; von Alemann/ Scheffczyk, in: Bader/Ronellenfitsch,VwVfG, 42. Ed., Stand: 1.1.2019, § 35, Rn. $233 \mathrm{ff}$.

287 Vgl. zu einer Weisung des Bundesministeriums des Innern gegenüber dem BND: BVerwG, Urt. v. 23.1.2008, Az.: 6 A 1/07 = NJW 2008, 2135 (2136); s. allgemein auch Ramsauer, in: Kopp/ Ramsauer, VwVfG, 19. Aufl. 2018, § 35, Rn. 151.

288 Vgl. von Alemann/Scheffczyk, in: Bader/Ronellenfitsch,VwVfG, 42. Ed., Stand:1.1.2019, § 35, Rn. $228 \mathrm{ff}$.

289 Dabei wird die Recht- und Zweckmäßigkeit überprüft, vgl. von Alemann/Scheffczyk, in: Bader/Ronellenfitsch,VwVfG, 42. Ed., Stand: 1.1.2019, § 35, Rn. 231.

290 Vgl. BVerwG, Beschl. v. 27.2.1978, Az.: 7 B 36/77 = NJW 1978, 1820 (1821); s. auch BVerwG, Urt. v. 14.12.1994, Az.: 11 C 4/94 =NVwZ 1995, 910: Daher kann auch eine fachaufsichtliche Weisung nach § 44 I 2 StVO ihrem objektiven Sinngehalt nach auf Außenwirkung gerichtet und damit Verwaltungsakt sein, wenn ihre Rechtswirkung unter Berücksichtigung des zugrundeliegenden materiellen Rechts nicht im staatlichen Innenbereich verbleibt, sondern auf den rechtlich geschützten Bereich der Gemeinde in Selbstverwaltungsangelegenheiten übergreift und damit Außenwirkung erzeugt“; Ramsauer, in: Kopp/Ramsauer, VwVfG, 19. Aufl. 2018, § 35, Rn. 156; insoweit a. A. Stelkens, in: Stelkens/Bonk/Sachs, VwVfG, 9. Aufl. 2018, § 35, Rn. 181.

Jens Milker 
Stelle in ihrem eigenen Wirkungskreis (z. B. Art. 28 II GG) und hat daher eine geschützte Rechtsposition inne, die sie gleichsam aus dem Verwaltungsaufbau heraushebt und ihr im Verhältnis zur Aufsichtsbehörde eine bürgerähnliche Stellung zuschreibt. ${ }^{292}$ Infolgedessen haben etwa Maßnahmen der Kommunalaufsicht (z. B. die Beanstandung ${ }^{293}$ ) Außenwirkung. ${ }^{294}$

\section{Prozessuale Folgen bei Fehlen der Voraussetzungen}

96 Fehlt zumindest eine der oben dargestellten (Wesens-)Voraussetzungen, liegt jedenfalls kein Verwaltungsakt im materiellen Sinne vor. ${ }^{295}$ Für den prozessualen Umgang mit solchen Handlungen ist allerdings eine differenzierte Betrachtung geboten. Sofern es sich etwa um einen Realakt oder Regelungen ohne Außenwirkung handelt, wäre die allgemeine Leistungsklage (s. $§ 5$ Rn. 2 ff.) oder ggf. die Feststellungsklage statthaft (s. §6 Rn. 2ff.). Ist hingegen eine Rechtsnorm der prüfungs- bzw. Streitgegenstand, wäre die verwaltungsgerichtliche Normenkontrolle in den Blick zu nehmen (§ 47 VwGO; s. näher dazu § 7). Besteht allerdings zumindest formal der Anschein eines Verwaltungsakts, unterscheidet die Rechtsprechung und Literatur im Wesentlichen zwischen „Scheinverwaltungsakten“296 und rein formellen Verwaltungsakten ${ }^{297}{ }^{298}$

97 Ein sog. „Scheinverwaltungsakt“ bzw. „Nichtakt“ ist bei drei Fallgruppen anzunehmen: die unwirksame Bekanntgabe eines Verwaltungsakts (s. dazu Rn. 20), ${ }^{299}$ den fehlenden Willen der Behörde zum Erlass eines Verwaltungsakts ${ }^{300}$ und den Fall, dass die Maßnahme nicht durch eine Behörde erfolgte bzw. die-

291 Dabei wird - vergleichbar mit der gerichtlichen Prüfungsdichte - nur die Recht- und nicht auch die Zweckmäßigkeit geprüft, vgl. Franz, JuS 2004, 937 unter Hinweis auf § 114 VwGO analog. 292 Vgl. im Ergebnis: von Alemann/Scheffczyk, in: Bader/Ronellenfitsch,VwVfG, 42. Ed., Stand: 1.1.2019, § 35, Rn. 232; Schwarz, in: Fehling/Kastner/Störmer, Verwaltungsrecht, 4. Aufl. 2016, § 35 VwVfG, Rn. 106; Ramsauer, in: Kopp/Ramsauer, VwVfG, 19. Aufl. 2018, § 35, Rn. 155.

293 Vgl. OVG NRW, Urt. v. 12.3.2013, Az.: 20 A 1564/10 = ZUR 2013, 547.

294 von Alemann/Scheffczyk, in: Bader/Ronellenfitsch,VwVfG, 42. Ed., Stand: 1.1.2019, § 35, Rn. 232; Ramsauer, in: Kopp/Ramsauer, VwVfG, 19. Aufl. 2018, § 35, Rn. 155.

295 Stelkens, in: Stelkens/Bonk/Sachs, VwVfG, 9. Aufl. 2018, § 35, Rn. 16.

296 Vgl. etwa Barczak, JuS 2018, 238 (244); eingehend auch Blunk/Schroeder, JuS 2005, 602. 297 Stelkens, in: Stelkens/Bonk/Sachs, VwVfG, 9. Aufl. 2018, § 35, Rn. 16; Barczak, JuS 2018, 238 (244): „Verwaltungsakt kraft Form“; Bickenbach, JA 2015, 481 (483).

298 Vgl. zum Ganzen auch Barczak, JuS 2018, 238 (244).

299 Vgl. dazu BVerwG, Urt. v. 21.11.1986, Az.: 8 C 127/84 = NVwZ 1987, 330: „Nichtakt“.

300 Vgl. Bickenbach, JA 2015, 481 (487): ,[E]in Schriftstück wurde für interne Zwecke gefertigt, ist aber aus Versehen verschickt worden und sieht aus wie ein Verwaltungsakt“.

Jens Milker 
ser nicht zugerechnet werden kann ${ }^{301}{ }^{302}$ Gemeint mit dem Begriff des formellen Verwaltungsakts ,sind Maßnahmen, die eine Behörde willentlich in Form eines Verwaltungsakts kleidet, obgleich gesetzliche Merkmale nicht erfüllt sind, die daher ohne die Form keine Verwaltungsakte wären“ (näher dazu schon Rn. $21 \mathrm{ff}$. ). ${ }^{303}$ Als statthafte Klagearten werden insoweit die Anfechtungsklage ${ }^{304}$ und die (negative) Feststellungsklage gemäß § 43 I VwGO ${ }^{305}$ diskutiert (s. näher dazu Rn. 20 ff.), wobei auch ein Nebeneinander beider Klagearten denkbar erscheint. ${ }^{306}$

\section{Die Wirksamkeit des Verwaltungsakts (Tobias Brings-Wiesen)}

Die Anfechtungsklage gemäß § 42 I Var. 1 VwGO ist statthaft, wenn der Kläger 98 gegen einen (ihn belastenden) Verwaltungsakt aufbegehrt (s. zum Klagebegehren Rn. 9 ff.). Dies setzt (zumindest grundsätzlich) nicht nur voraus, dass es sich rechtsförmlich um einen Verwaltungsakt i.S.v. § 35 VwVfG (zum Begriff des Verwaltungsakts Rn. $38 \mathrm{ff}$. und zum Umgang mit sog. „formellen Verwaltungsakten“ Rn. $21 \mathrm{ff}$.) handelt, sondern auch, dass der Verwaltungsakt wirksam i.S.v. § 43 VwVfG ist. Bereits Wortlaut und Systematik der Norm verdeutlichen, dass dafür drei Voraussetzungen erfüllt sein müssen:

- Der Verwaltungsakt muss durch Bekanntgabe überhaupt wirksam geworden sein (§ 43 I VwVfG);

301 Stelkens, in: Stelkens/Bonk/Sachs, VwVfG, 9. Aufl. 2018, § 35, Rn. 56, 62f.; s. auch das Beispiel bei Bickenbach, JA 2015, 481 (487): Eine Privatperson stellt ohne wirksame Beleihung ein in der StVO geregeltes Verkehrsschild auf.

302 Vgl. Blunk/Schroeder, JuS 2005, 602 (603f.); Bickenbach, JA 2015, 481 (487).

303 Bickenbach, JA 2015, 481 (483); Barczak, JuS 2018, 238 (244).

304 Für formelle Verwaltungsakte: BSG, Urt.v. 5.9.2006, Az.: B 4 R 71/06 R = BeckRS 2006, 44566, Rn. 16; BVerwG, Beschl.v. 18.1.1993, Az.: 6 B 5/92 = NVwZ-RR 1993, 251 (252); BayVGH, Urt. v. 2. 8. 2016, Az.: 22 B 16.619 = BeckRS 2016, Rn. 35, 41 ff.; VG Mainz, Urt. v. 3.7.2018, Az.: 1 K 1463/17.MZ = BeckRS 2c018, 20916, Rn. 17; für nicht wirksam bekannt gegebene Verwaltungsakte: OVG RP, Urt.v. 25.6.1986, Az.: 8 A 92/85 = NVwZ 1987, 899; allgemein für Scheinverwaltungsakte: Blunk/Schroeder, JuS 2005, 602 (603).

305 So für Scheinverwaltungsakte und formelle Verwaltungsakte: Bickenbach, JA 2015, 481 (486f.); für formelle Verwaltungsakte: VG Wiesbaden, Urt. v. 5.3.2007, Az.: 7 E 1536/06 = NVwZ-RR 2007, 613; für nicht wirksam bekanntgegebene Verwaltungsakte: BVerwG, Urt. v. 21.11.1986, Az.: 8 C 127/84 = NVwZ 1987, 330.

306 Insoweit bei Scheinverwaltungsakten ein „Wahlrecht“ des Klägers annehmend: Blunk/ Schroeder, JuS 2005, 602 (603). 
- $\quad$ sodann darf er seine Wirksamkeit nicht (von Anfang an oder nachträglich) aufgrund von Nichtigkeit gemäß § 44 VwVfG (§ 43 III VwVfG) oder

- durch spätere Aufhebung oder Erledigung wieder eingebüßt haben (§ 43 II VwVfG). ${ }^{307}$

99 Steht die Wirksamkeit eines Verwaltungsakts in Frage, bieten sich den Betroffenen diverse Möglichkeiten, ein etwaiges Rechtsschutzbegehren zu realisieren. Nach herrschender Meinung bleibt indes gegen nicht wirksam gewordene oder nichtige Verwaltungsakte auch die Anfechtungsklage eine Option (s. auch Rn. 19 ff. sowie näher noch Rn. 174 ff. und 197 ff.).

100 Darüber hinaus gilt es zu bedenken, dass sich die Frage der Wirksamkeit eines Verwaltungsakts vielfach auch inzident im Rahmen der Prüfung anderer Verwaltungsmaßnahmen stellen kann. Ein regelrechter Klausurklassiker ist die Frage der Wirksamkeit einer Grundverfügung im Rahmen der Verwaltungsvollstreckung (für die Vollstreckung im sog. gestreckten Verfahren sowie den folgenden Kostenbescheid; zum Vollstreckungsrecht Rn. $1327 \mathrm{ff}$.). Besonderer Beliebtheit erfreuen sich dabei die Fälle von Vollstreckungsmaßnahmen auf Grundlage von nach einem Verkehrsvorgang (wie dem Parken) aufgestellten mobilen Verkehrsschildern (s. dazu sogleich Rn. 165ff.). Prüfungsrelevant ist zudem die Frage der Wirksamkeit von Nebenbestimmungen im Falle des Widerrufs von Verwaltungsakten (s. dazu näher Rn. 959, 962). Fragen der Nichtigkeit gemäß §44 VwVfG können sich schließlich auch bei der Prüfung subordinationsrechtlicher Verträge gemäß § 54 S. 2 VwVfG stellen (§ 59 II Nr. 1 VwVfG) (s. dazu näher $§ 5$ Rn. 99).

101 Vor diesem Hintergrund ist es elementar, sich mit der Systematik und den Voraussetzungen der Wirksamkeit von Verwaltungsakten eingehend vertraut zu machen.

\section{Die Wirksamkeit von Verwaltungsakten i.S.v. § 43 VwVfG}

102 Ausgangspunkt eines umfassenden Verständnisses der Wirksamkeit von Verwaltungsakten ist \$ 43 VwVfG. Die Vorschrift enthält Vorgaben zu Beginn und Ende der Wirksamkeit, setzt den „Begriff“ der Wirksamkeit damit aber nur voraus, ohne ihn selbst zu definieren. ${ }^{308}$ Auch eine allgemein anerkannte Definition

307 S. für einen guten Überblick auch die Aufbauhilfe für die Prüfung der Wirksamkeit eines Verwaltungsakts des öffentlich-rechtlichen Online-Lernprojekts „Saarheim“ von Grupp und Stelkens, abrufbar unter: http://saarheim.de/Anmerkungen/vawirksamkeit.htm.

308 Ramsauer, in: Kopp/Ramsauer, VwVfG, 20. Aufl. 2019, § 43 Rn. 3; Sachs, in: Stelkens/Bonk/ Sachs, VwVfG, 9. Aufl. 2018, § 43 Rn. 163; Schwarz, in: Fehling/Kastner/Störmer, Verwaltungsrecht, 4. Aufl. 2016, § 43 VwVfG Rn. 1, 6. 
des Begriffs existiert nicht. ${ }^{309}$ Dies ist auch der Tatsache geschuldet, dass sich die hinter dem Begriff verbergende Dogmatik nur schwer in wenige griffige Worte fassen lässt. Stark verallgemeinernd lässt sich festhalten: „Wirksamkeit“ beschreibt den Zustand, währenddessen ein Verwaltungsakt die mit seiner Regelung (zu diesem Merkmal näher Rn. 63 ff.) verfolgten Rechtswirkungen gegenüber einem durch diese Regelung näher bestimmten Personenkreis entfaltet. ${ }^{310}$

Diese Entfaltung von Rechtswirkungen muss in materieller, persönlicher 103 und insbesondere zeitlicher Hinsicht noch weiter konkretisiert werden. ${ }^{311}$ Dies soll hier im Interesse der Verständlichkeit nur überblicksartig geschehen. ${ }^{312}$

\section{a) Die Wirksamkeit von Verwaltungsakten in materieller und persönlicher Hinsicht}

In materieller Hinsicht kommt es auf den Regelungsinhalt des Verwaltungsakts an. Dieser muss gegebenenfalls unter Heranziehung der zugrundeliegenden materiellen Vorschriften näher bestimmt werden. Für den Zeitraum der Wirksamkeit eines Verwaltungsakts besteht insofern eine Bindungswirkung ${ }^{313}$ an die Regelung. Sie ist grundsätzlich auf diesen verfügenden Teil des Verwaltungsakts, den Tenor der Entscheidung, beschränkt und nach dem objektiven Empfängerhorizont zu bestimmen. ${ }^{314}$ Nur in gesetzlich vorgesehenen Fällen kann es über den verfügenden Teil des Verwaltungsakts hinaus zu einer Bindungs-

309 Leisner-Egensperger, in: Mann/Sennekamp/Uechtritz, VwVfG, 2. Aufl. 2019, § 43 Rn. 2.

310 Vgl. auch Maurer/Waldhoff, Allgemeines Verwaltungsrecht, 19. Aufl. 2017, § 10 Rn. 5; Peuker, in: Knack/Henneke, VwVfG, 10. Aufl. 2014, § 43 Rn. 6.

311 Anschaulich auch Leisner-Egensperger, in: Mann/Sennekamp/Uechtritz, VwVfG, 2. Aufl. 2019, § 43 Rn. 3, 5 ff.; vgl. entsprechend Ramsauer, in: Kopp/Ramsauer, VwVfG, 20. Aufl. 2019, § 43 Rn. $3 \mathrm{ff}$.

312 S. zu den Bindungswirkungen ausführlich Randak, JuS 1992, 33; Schroeder, DÖV 2009, 217. 313 Die Terminologie zur Beschreibung der Bindungswirkung - insbesondere in ihren verschiedenen Wirkungsfacetten - divergiert stark, sodass bei ihrer Verwendung und Rezeption stets Vorsicht geboten ist, s. dazu nur Ramsauer, in: Kopp/Ramsauer, VwVfG, 20. Aufl. 2019, § 43 Rn. 14. Im Folgenden werden die Begrifflichkeiten im Anschluss an die gängige Lehrbuchliteratur verwendet, s. nur Maurer/Waldhoff, Allgemeines Verwaltungsrecht, 19. Aufl. 2017, §10 Rn. 18; Detterbeck, Allgemeines Verwaltungsrecht, 17. Aufl. 2019, Rn. 544; Peine/Siegel, Allgemeines Verwaltungsrecht, 12. Aufl. 2018, Rn. 462. Es ist jedoch zu bedenken, dass darüber hinaus auch ganz andere Ausgangspunkte einer Systematisierung gewählt werden, s. bspw. Sachs, in: Stelkens/Bonk/Sachs, VwVfG, 9. Aufl. 2018, § 43 passim (insbesondere Rn. 7f.); so auch Windoffer, JURA 2017, 1274 (1275f.): Terminologischer Ausgangspunkt „Bestandskraft“.

314 Die Begründung des Verwaltungsakts kann nur ergänzend zur Bestimmung des Regelungsinhalts herangezogen werden, BVerwG, Urt. v. 11.12.2014, Az.: 3 C 6.13 = BVerwGE 151, 129 (132, Rn. 18). So auch Ramsauer, in: Kopp/Ramsauer, VwVfG, 20. Aufl. 2019, § 43 Rn. 15. 
wirkung kommen (sog. „Feststellungswirkung“, s. dazu Rn. 110). ${ }^{315}$ Die besondere Schwierigkeit besteht darin, im Einzelfall den Regelungsinhalt genau und abgrenzend $\mathrm{zu}$ bestimmen.

Diese Bindungswirkung besteht grundsätzlich unabhängig von der Rechtskonformität des wirksam gewordenen Verwaltungsakts. ${ }^{316}$ Die „Wirksamkeit“ eines Verwaltungsakts ist entsprechend der gesetzlichen Grundsystematik zwingend von seiner „Rechtmäßigkeit“ abzugrenzen. Diese Abgrenzung ist bereits in § 43 II, III VwVfG angelegt. Die Vorschriften bestimmen eine fortwährende Wirksamkeit, solange und soweit es nicht zu einem aktiven Einwirken Dritter auf eben diese Wirksamkeit (durch Rücknahme, Widerruf oder anderweitige Aufhebung) oder zum Eintritt bestimmter, die Regelungswirkung des Verwaltungsakts tilgender Ereignisse (seiner Erledigung durch Zeitablauf oder auf andere Weise) kommt. Ansonsten ist von einer Unwirksamkeit nur dann auszugehen, wenn ein Verwaltungsakt nichtig ist. ${ }^{317}$ Diese Unterscheidung ist gar einer der zentralen Anreize der Verwaltung, auf das Handlungsinstrument des Verwaltungsakts zurückzugreifen (s. dazu Rn. 40). Im Interesse der Sicherung von Rechtssicherheit und Rechtsfrieden ${ }^{318}$ sowie der Funktionsfähigkeit der Verwaltung tritt der Grundsatz der Gesetzmäßigkeit der Verwaltung (s. dazu $\S 1$ Rn. 13) unter den Bedingungen des $\S 43$ VwVfG in der Abwägung zurück. Dies hat zur Folge, dass auch rechtswidrige Verwaltungsakte bestandskräftig werden können und somit ihre Wirksamkeit grundsätzlich dauerhaft behalten (s. dazu Rn. 115). Nach ganz herrschender Meinung kann die Behörde sie auch trotz ihrer Rechtswidrigkeit im Wege der Verwaltungsvollstreckung durchsetzen (s. dazu § 2 Rn. 1327 f.).

315 Vgl. für den Regelfall beispielhaft BVerwG, Urt. v. 1.9.2011, Az.: 5 C 27.10 = BVerwGE 140, 311 (316, Rn. 20): Durch eine unbefristete Aufenthaltserlaubnis wird nur die Rechtmäßigkeit des dauerhaften Aufenthalts einer Person begründet. Die Identität einer Person muss zwar als Erteilungsvoraussetzung geklärt sein (§ 5 I Nr. 1a AufenthG), sie ist jedoch bloße Vorfrage, sodass deren Richtigkeit nicht Teil des Regelungsinhalts wird. Dem Verwaltungsakt liegt die Tatsachenfeststellung nur zugrunde, sie wird nur implizit festgestellt. Die Identität kann daher im Rahmen eines späteren Einbürgerungsverfahrens uneingeschränkt geprüft werden.

316 S. nur Maurer/Waldhoff, Allgemeines Verwaltungsrecht, 19. Aufl. 2017, § 10 Rn. 6.

317 An der Regelung des $§ 44$ VwVfG - insbesondere wegen der Voraussetzung des „besonders schwerwiegenden Fehlers“ - zeigt sich jedoch, dass zwischen der Rechtmäßigkeit und der Wirksamkeit des wirksam gewordenen Verwaltungsakts durchaus ein sachlicher Zusammenhang besteht; s. dazu noch § 6 Rn. $149 \mathrm{ff}$.

318 Ramsauer, in: Kopp/Ramsauer, VwVfG, 20. Aufl. 2019, § 43 Rn. 1b; Sachs, in: Stelkens/Bonk/ Sachs, VwVfG, 9. Aufl. 2018, § 43 Rn. 9 ff. m.w. N. 
Die Bindungswirkung des Verwaltungsakts kann in persönlicher Hinsicht 106 unterschiedlich ausfallen. Dabei kann grundsätzlich binär zwischen der privaten und der staatlichen Seite unterschieden werden.

Der Kreis der Privatpersonen, für die die Wirksamkeit eines Verwaltungs- 107 akts relevant sein kann, wird in §43 I 1 VwVfG bestimmt. Demnach wird ein Verwaltungsakt gegenüber demjenigen wirksam, für den er bestimmt ist oder der von ihm betroffen wird. ${ }^{319}$ Die Bestimmung ergibt sich dabei maßgeblich aus dem Regelungsinhalt des Verwaltungsakts, wie die Behörde ihn festlegt. ${ }^{320}$ Die so identifizierte Person wird gemeinhin als Adressat des Verwaltungsakts ${ }^{321}$ bezeichnet. Je nach Regelungsinhalt des Verwaltungsakts kann sich darüber hinaus die Frage stellen, ob der Verwaltungsakt auch einen Rechtsnachfolger binden kann. ${ }^{322}$ Dafür bedarf es des Eintretens eines Nachfolgetatbestands und - wichtiger noch - der grundsätzlichen Nachfolgefähigkeit eines Rechts oder einer Pflicht. ${ }^{323}$ Sofern eine Nachfolge nicht bereits ausdrücklich gesetzlich vorgesehen ist, ${ }^{324}$ muss die Nachfolgefähigkeit unter Berücksichtigung der Regelungszwecke eines Verwaltungsakts und des ihm zugrundeliegenden Rechts via Auslegung ermittelt werden. Insbesondere im Falle sog. höchstpersönlicher Verwaltungsak$\mathrm{te}^{325}$ fehlt eine Nachfolgefähigkeit. Von einem Verwaltungsakt sonst betroffen ist die Person, die vom Regelungsinhalt des Verwaltungsakts unter Berücksichtigung der aus dem einschlägigen materiellen Recht resultierenden Rechtsfolgewirkun-

319 Die Begriffe entsprechen weitestgehend denen in §41 I 1 VwVfG mit der zentralen Ausnahme, dass nicht an die Beteiligtenstellung gemäß §13 VwVfG angeknüpft wird. Dies ändert jedoch nichts daran, dass auch ein nicht am Verfahren Beteiligter betroffen sein und ihm der Verwaltungsakt entsprechend bekanntgegeben werden kann, s. dazu noch Rn. 126.

320 Ramsauer, in: Kopp/Ramsauer, VwVfG, 20. Aufl. 2019, § 43 Rn. 10; Leisner-Egensperger, in: Mann/Sennekamp/Uechtritz, VwVfG, 2. Aufl. 2019, § 43 Rn. 29.

321 Wobei der Sprachgebrauch stets auf seinen Sachzusammenhang hin zu prüfen ist; s. nur Stelkens, in: Stelkens/Bonk/Sachs, VwVfG, 9. Aufl. 2018, § 41 Rn. 29, der zu Recht gleich zwischen „materiellem Adressat“, „Inhaltsadressat“ und „Bekanntgabeadressat“ unterscheidet.

322 S. dazu näher Erbguth/Guckelberger, Allgemeines Verwaltungsrecht, 9. Aufl. 2018, § 13 Rn. 14.

323 S. dazu näher Ramsauer, in: Kopp/Ramsauer, VwVfG, 20. Aufl. 2019, § 43 Rn. $13 \mathrm{ff}$.

324 S. dazu insbesondere die verschiedenen Vorschriften zur Nachfolgefähigkeit bauaufsichtlicher Maßnahmen in den Landesbauordnungen, bspw. § 58 III BauO NRW.

325 S. dazu die griffige Definition des OVG Münster, Urt. v. 27.2.2013, Az.: 13 A 2661/11= juris, Rn. 36. Dies sind bspw. solche Verwaltungsakte, die an besondere persönliche Merkmale oder Fähigkeiten gebunden sind, wie die Gaststättenerlaubnis gemäß § 2 I 1 GastG, die die für den Gewerbebetrieb erforderliche Zuverlässigkeit des Antragsstellers voraussetzt (§ 4 I 1 Nr. 1 GastG), oder die Fahrerlaubnis gemäß § 2 I 1 StVG, für die die Befähigung zum Führen von Kraftfahrzeugen in einer theoretischen und praktischen Prüfung nachzuweisen ist (§ 2 II 1 Nr. 5, V StVG). 
gen in ihren rechtlich geschützten Interessen berührt wird. ${ }^{326}$ Diese Personen trifft im Hinblick auf den Regelungsinhalt des ihnen bekanntgegebenen Verwaltungsakts ein Beachtungsgebot.

108

Zumindest expressis verbis blendet die Vorschrift des $§ 43 \mathrm{VwVfG}$ die staatliche

Seite komplett aus. Aus Gründen der Rechtssicherheit und des Vertrauensschutzes der Betroffenen kann der Staat jedoch nicht von jeglicher Bindungswirkung freigestellt werden. Primär ist die Wirksamkeit des Verwaltungsakts für die ihn erlassende Behörde (s. zum Behördenbegriff näher Rn. 52ff.) und ihren Rechtsträger ${ }^{327}$ von Relevanz. Auch sie trifft ein Beachtungsgebot. Darüber hinaus können sie den Verwaltungsakt nur noch unter den Voraussetzungen der §§ $48 \mathrm{ff}$. VwVfG (oder ggf.

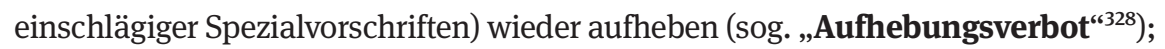
sie können hinsichtlich seines Regelungsgegenstandes auch keine neue abweichende Entscheidung treffen (sog. „Abweichungsverbot“329).

Die Wirkung des Verwaltungsakts kann indes auch über diesen Personenkreis hinausgehen. ${ }^{330}$ Wegen der mit ihm verbundenen sog. „Tatbestandswirkung“331 erlangt er grundsätzlich auch für alle anderen Behörden und Rechtsträger ${ }^{332}$ und sogar die Gerichte ${ }^{333}$ Bedeutung. Soweit der Verwaltungsakt nicht selbst Gegenstand der rechtlichen Überprüfung ist, haben sie ihn ihren Entscheidungen zugrunde zu legen. ${ }^{334}$ Diese Tatbestandwirkung trägt grundsätzlich jeder Verwaltungsakt ohne besondere gesetzliche Anordnung ${ }^{335}$ in sich. ${ }^{336}$

326 Vgl. Leisner-Egensperger, in: Mann/Sennekamp/Uechtritz, VwVfG, 2. Aufl. 2019, § 43 Rn. 30. 327 Ramsauer, in: Kopp/Ramsauer, VwVfG, 20. Aufl. 2019, § 43 Rn. 12; Leisner-Egensperger, in: Mann/Sennekamp/Uechtritz, VwVfG, 2. Aufl. 2019, § 43 Rn. 31; s. zu Fragen der Verwaltungsorganisation ausführlich Rn. $582 \mathrm{ff}$.

328 Ramsauer, in: Kopp/Ramsauer, VwVfG, 20. Aufl. 2019, § 43 Rn. 14c.

329 Ramsauer, in: Kopp/Ramsauer, VwVfG, 20. Aufl. 2019, § 43 Rn. 14d.

330 Ausführlich zu Tatbestands- und Feststellungswirkung Rebler, DVBl 2017, 1279.

331 Der Begriff wird heute weiterhin nicht einheitlich gebraucht, seine Verwendung scheint jedoch von einer erkennbaren Mehrheit in Rechtsprechung und Literatur zumindest akzeptiert, s. nur die Nachweise bei Sachs, in: Stelkens/Bonk/Sachs, VwVfG, 9. Aufl. 2018, § 43 Rn. 140. Bedeutsamer ist vor diesem Hintergrund, die hinter dem Begriff stehende Idee verstanden zu haben. 332 BVerwG, Urt. v. 4.7.1986, Az.: 4 C 31.84 = BVerwGE 74, 315 (320); BVerwG, Beschl.v. 11.2.2016, Az.: 4 B 1.16 = NVwZ-RR 2016, 471.

333 BVerwG, Urt. v. 30.1.2003, Az.: 4 CN 14.01 = BVerwGE 117, 351 (354f.). Dies gilt grundsätzlich auch gegenüber Zivilgerichten, vgl. nur BGH, Urt. v. 4.2.2004, Az.: XII ZR 301/01 = BGHZ 158, 19 (22); Beschl.v. 16.12. 2014, Az.: EnVR 54 /13 = juris, Rn. 19. Ausnahmen hat der BGH jedoch für den wichtigen Bereich des Staatshaftungsrechts angenommen, s. dazu Ramsauer, in: Kopp/Ramsauer, VwVfG, 20. Aufl. 2019, § 43 Rn. 22 m.w. N.; ausführlich Beaucamp, DVBl 2004, 352.

334 BVerwG, Urt. v. 10.10.2006, Az.: 8 C 23.05 = juris, Rn. 22; Maurer/Waldhoff, Allgemeines Verwaltungsrecht, 19. Aufl. 2017, § 10 Rn. 20; Leisner-Egensperger, in: Mann/Sennekamp/Uecht-

Tobias Brings-Wiesen 
Auch die sog. „Feststellungswirkung“ eines Verwaltungsakts geht über den 110 besagten Personenkreis hinaus. Ihre Besonderheit ist jedoch, dass sie in materieller Erweiterung der Tatbestandswirkung über den Regelungsinhalt des Verwaltungsakts hinaus auch die ihm zugrundeliegenden tatsächlichen und rechtlichen Feststellungen erfasst. ${ }^{337}$ Die Feststellungswirkung eines Verwaltungsakts muss daher gesetzlich angeordnet sein. ${ }^{338}$

\section{b) Die Wirksamkeit von Verwaltungsakten in zeitlicher Hinsicht}

Auch in zeitlicher Hinsicht gelingt es dem Begriff der „Wirksamkeit“ allein 111 nicht, den durchaus komplexen und von verschiedenen (äußeren wie inneren) Faktoren beeinflussten Lebenszyklus eines Verwaltungsakts ${ }^{339} \mathrm{zu}$ umschreiben. Es ist dogmatisch wie begrifflich weiter $\mathbf{z u}$ differenzieren $z_{\text {wischen }}{ }^{340}$ seiner rechtlichen Existenz, seiner äußeren Wirksamkeit, seiner inneren Wirksamkeit sowie seiner Bestandskraft. ${ }^{341}$

Gemäß § 43 I 1 VwVfG wird ein Verwaltungsakt gegenüber demjenigen, für 112 den er bestimmt ist oder der von ihm betroffen wird, in dem Zeitpunkt wirksam, indem er ihm bekannt gegeben wird. Zentraler Anknüpfungspunkt des Wirk-

ritz, VwVfG, 2. Aufl. 2019, § 43 Rn. 39f.; s. aber zur Problematik im Straf- und Ordnungswidrigkeitenrecht Leisner-Egensperger, a. a. O., Rn. 42.

335 BVerwG, Urt. v. 23.4.1980, Az.: 8 C 82.79 = BVerwGE 60, 111 (116f.). Der Gesetzgeber kann die Tatbestandswirkung indes auch gesetzlich näher ausgestalten, Leisner-Egensperger, in: Mann/ Sennekamp/Uechtritz, VwVfG, 2. Aufl. 2019, § 43 Rn. 43. Insbesondere kann er sie gesetzlich ausdrücklich anordnen, vgl. bspw. § 6 und $\S 42$ AsylG.

336 Davon abzugrenzen sind Konstellationen sog. „erweiterter besonderer Tatbestandswirkung“, Ramsauer, in: Kopp/Ramsauer, VwVfG, 20. Aufl. 2019, § 43 Rn. 24 f., bzw. sog. „Tatbestandswirkung im engeren Sinne“, Sachs, in: Stelkens/Bonk/Sachs, VwVfG, 9. Aufl. 2018, § 43 Rn. 154, bei denen das Vorliegen eines Verwaltungsakts als Voraussetzung für den Eintritt eine Rechtsfolge bestimmt ist.

337 Maurer/Waldhoff, Allgemeines Verwaltungsrecht, 19. Aufl. 2017, § 10 Rn. 21; Ramsauer, in: Kopp/Ramsauer, VwVfG, 20. Aufl. 2019, § 43 Rn. 26.

338 BVerwG, Urt. v. 27.10.1998, Az.: 1 C 19.97 = NVwZ-RR 1999, 243; Urt. v. 10.10.2006, Az.: 8 C 23.05 = juris, Rn. 22; s. auch Sachs, in: Stelkens/Bonk/Sachs, VwVfG, 9. Aufl. 2018, § 43 Rn. 160, m.w.N.

339 Vgl. zu diesem Bild auch die Ausführungen von Gröpl, JA 1995, 904 und 983, sowie Herrmann, ZJS 2011, 25.

340 Bisweilen wird - insbesondere angesichts des Wortlauts von § 9 VwVfG - die Frage des Zeitpunkts des Erlasses eines Verwaltungsakts diskutiert, s. nur Detterbeck, Allgemeines Verwaltungsrecht, 17. Aufl. 2019, Rn. 540 f., der indes zu Recht darauf hinweist, dass dieser Zeitpunkt zumindest für die Frage der Wirksamkeit des Verwaltungsakts keine Rolle spielt.

341 Vgl. entsprechend Maurer/Waldhoff, Allgemeines Verwaltungsrecht, 19. Aufl. 2017, §10 Rn. 5 ff.; Detterbeck, Allgemeines Verwaltungsrecht, 17. Aufl. 2019, Rn. 537 ff. (insbesondere 548). 
samwerdens eines Verwaltungsakts ist demnach die Bekanntgabe, auf die im Folgenden noch genauer einzugehen sein wird (s. dazu Rn. $117 \mathrm{ff}$.). Diese hat potentiell gegenüber mehreren Personen zu erfolgen (§ 41 I 1 VwVfG). Der Verwaltungsakt erlangt jedoch bereits dann rechtliche Existenz, wenn er der ersten dieser Personen wirksam bekanntgegeben wird. ${ }^{342} \mathrm{Ab}$ dem Zeitpunkt seiner rechtlichen Existenz gilt:

- Der Verwaltungsakt entfaltet seine ersten Bindungswirkungen: Die ihn erlassende Behörde (und deren Rechtsträger) trifft das Aufhebungs- und Abweichungsverbot. Soweit die Wirkungen nicht erst verzögert eintreten soll (s. zur sog. „inneren Wirksamkeit“ sogleich Rn. 114), setzen mit der rechtlichen Existenz des Verwaltungsakts auch seine über den Kreis der Bekanntgabeempfänger hinaus geltenden Tatbestands- sowie Feststellungswirkungen ein. ${ }^{343}$

- In der juristischen Sekunde seines rechtlichen Entstehens kann der Verwaltungsakt gemäß $\S 43$ III VwVfG sogleich aufgrund von Nichtigkeit unwirksam sein.

- Der Verwaltungsakt kann nun grundsätzlich von jeder Person - nicht nur von der Person, der er zuerst bekanntgegeben wurde - mit den verschiedenen statthaften Rechtsbehelfen angegriffen und schließlich aufgehoben werden. ${ }^{344}$

- Der Verwaltungsakt kann sich nun gemäß § 43 II VwVfG durch Fristablauf oder auf andere Weise erledigen.

113 Davon zu unterscheiden ist die sog. äußere Wirksamkeit. Sie hängt - wie von § 43 I 1 VwVfG unmissverständlich verdeutlicht - untrennbar mit der individuellen Bekanntgabe (s. dazu noch Rn. 135ff.; indes zu den Besonderheiten der öffentlichen Bekanntgabe Rn. $154 \mathrm{ff}$.) gegenüber demjenigen, für den er bestimmt ist oder der von ihm betroffen wird, zusammen. Sie tritt daher auch nur gegenüber der Person ein, der der Verwaltungsakt wirksam bekanntgegeben wurde. Die rechtliche Existenz eines Verwaltungsakts ist damit absolut, seine (äußere) Wirksamkeit hingegen relativ (Grundsatz der relativen Wirksamkeit von Verwaltungsak-

342 Detterbeck, Allgemeines Verwaltungsrecht, 17. Aufl. 2019, Rn. 537; Ramsauer, in: Kopp/ Ramsauer, VwVfG, 20. Aufl. 2019, § 43 Rn. 4. Sie fällt dann zeitlich mit dem Eintritt der (mindestens) äußeren Wirksamkeit gegenüber dieser Person zusammen, s. dazu noch Rn. 113.

343 Leisner-Egensperger, in: Mann/Sennekamp/Uechtritz, VwVfG, 2. Aufl. 2019, § 43 Rn. 6.

344 OVG Magdeburg, Beschl. v. 27.5.2008, Az.: 2 M 72/08 = NVwZ-RR 2008, 747; Detterbeck, Allgemeines Verwaltungsrecht, 17. Aufl. 2019, Rn. 537; R. P. Schenke, in: Kopp/Schenke, VwGO, 25. Aufl. 2019, § 42 Rn. 56, 58. 
ten). ${ }^{345} \mathrm{Ab}$ dem Zeitpunkt der äußeren Wirksamkeit gilt: Es beginnt der Lauf der Rechtsbehelfsfristen, selbst dann wenn die innere Wirksamkeit (s. dazu sogleich Rn. 114) noch nicht eingetreten ist. ${ }^{346}$ Deren Beginn ist an die Bekanntgabe geknüpft (§§ 70 I, 74 VwGO, s. dazu genauer Rn. 353 ff.), sodass es im Falle zeitlich versetzter $^{347}$ Bekanntgaben an verschiedene Personen auch $\mathrm{zu}$ verschiedenen Fristläufen und einem entsprechend zeitversetzten Eintritt der (formellen) Bestandskraft (s. dazu sogleich Rn. 115) kommen kann. Wird ein Betroffener gänzlich übergangen, können Rechtsbehelfe gar für unbestimmte Zeit zulässig bleiben. ${ }^{348}$

Die innere Wirksamkeit eines Verwaltungsakts tritt erst dann ein, wenn die $\mathbf{1 1 4}$ in ihm enthaltene Regelung ihre Wirkung entfalten soll. Dies ergibt sich auch aus $\S 43$ I 2 VwVfG, wonach der Verwaltungsakt „mit dem Inhalt wirksam [wird], mit dem er bekannt gegeben wird“. Soweit sich aus dem Verwaltungsakt nichts anderes ergibt, fällt der Zeitpunkt des Eintritts der inneren mit dem der äußeren Wirksamkeit zusammen. ${ }^{349}$ Dies wird regelmäßig der Fall sein. Es kann jedoch auch zu Abweichungen der Zeitpunkte innerer und äußerer Wirksamkeit kommen $^{350}$ - so insbesondere durch die Verbindung des Verwaltungsakts mit aufschiebenden Befristungen oder Bedingungen (s. dazu Rn. $210 \mathrm{ff}$.) oder durch die (gesetzlich vorgesehene) Bestimmung der Rückwirkung eines Verwaltungsakts ${ }^{351}$. Ab dem Zeitpunkt der inneren Wirksamkeit gilt:

- Der Verwaltungsakt entfaltet seine Bindungswirkung vollständig: Der Begünstigte darf von einer Genehmigung Gebrauch machen, der Belastete muss sich einem Gebot oder Verbot fügen. Kehrseitig muss die Behörde die Betroffenen in ihrem Handeln gewähren oder ihnen gar bestimmte Leistungen zukommen lassen.

345 Stelkens, in: Stelkens/Bonk/Sachs, VwVfG, 9. Aufl. 2018, § 35 Rn. 20, § 41 Rn. 229; Sachs, a.a.O., § $43 \mathrm{Rn} .165$.

346 BVerwG, Urt. v. 1.2.1978, Az.: 6 C 9.77 = BVerwGE 55, 212 (215). So auch Ramsauer, in: Kopp/ Ramsauer, VwVfG, 20. Aufl. 2019, § 43 Rn. 5.

347 Oder unter abweichender Einhaltung der Vorgaben zur ordnungsgemäßen Rechtsbehelfsbelehrung, vgl. § 58 VwGO, s. dazu ausführlich Rn. $368 \mathrm{ff}$.

348 Eine zeitliche Grenze wird zumindest dann angenommen, wenn der Betroffene auf anderem Wege von dem Verwaltungsakt Kenntnis erlangt und untätig bleibt. In diesem Fall kann ein von ihm erhobener Rechtsbehelf wegen fehlenden Rechtsschutzbedürfnisses infolge von Verwirkung (als besonderer Form eines Verstoßes den den Rechtsgrundsatz von Treu und Glauben) unzulässig sein, s. dazu ausführlich Rn. 329, $399 \mathrm{ff}$.

349 BVerwG, Urt. v. 21.6.1961, Az.: VIII C 398.59 = BVerwGE 13, 1 (7).

350 BVerwG, Urt. v. 21.6.1961, Az.: VIII C 398.59 = BVerwGE 13, 1 (7); BVerwG, Urt. v. 1.2.1978, Az.: 6 C 9.77 = BVerwGE 55, 212 (215). S. auch Detterbeck, Allgemeines Verwaltungsrecht, 17. Aufl. 2019, Rn. $546 \mathrm{ff}$.

351 BVerwG, Urt. v. 21.6.1961, Az.: VIII C 398.59 = BVerwGE 13, 1 (7); Maurer/Waldhoff, Allgemeines Verwaltungsrecht, 19. Aufl. 2017, § 10 Rn. 11.

Tobias Brings-Wiesen 
- Soweit sein Regelungsinhalt dies ermöglicht (s. zum vollstreckbaren Verwaltungsakt Rn. 1331), wird der Verwaltungsakt grundsätzlich vollstreckbar. ${ }^{352}$ Die Vollziehbarkeit kann jedoch von der Erfüllung weiterer gesetzlicher Voraussetzungen abhängig gemacht werden. ${ }^{353}$ Sie wird durch Erhebung eines Widerspruchs bzw. einer Anfechtungsklage gegen den Verwaltungsakt im Regelfall gehemmt (sehr str.) ${ }^{354}$ (sog. „aufschiebende Wirkung“); ausnahmsweise kann ein Verwaltungsakt jedoch sofort vollziehbar sein, sodass es des Ersuchens nach vorläufigem Rechtsschutz gemäß §§ 80 ff. bedarf (s. dazu ausführlich die $\S \S 8,9) .{ }^{355}$ Die aufschiebende Wirkung hat zur Folge, dass zumindest die staatliche Seite aus dem betroffenen Verwaltungsakt weder rechtliche noch tatsächliche Folgen ableiten darf, bspw. gestützt auf eine Abrissverfügung einen Schwarzbau beseitigen. ${ }^{356}$

- Die innere Wirksamkeit des Verwaltungsakts tritt erst gar nicht ein oder endet, wenn er nichtig ist, zurückgenommen, widerrufen oder anderweitig aufgehoben wird oder sich durch Zeitablauf oder auf andere Weise erledigt.

115 Der (äußerlich) wirksame Verwaltungsakt kann sodann in Bestandskraft erwachsen. $^{357}$ Dabei wird unterschieden zwischen formeller und materieller Be-

352 Peine/Siegel, Allgemeines Verwaltungsrecht, 12. Aufl. 2018, Rn. 459f.; Sachs, in: Stelkens/ Bonk/Sachs, VwVfG, 9. Aufl. 2018, § 43 Rn. 171; Schemmer, in: Bader/Ronellenfitsch, VwVfG, 44. Ed., Stand: 1.7.2019, § 43 Rn. 12.

353 So ist bspw. die Vollstreckung gegen Geldforderungen gemäß § 3 II lit. b), c) BVwVG erst nach Fälligkeit der Leistung und dem Ablauf einer (zusätzlichen) Wochenfrist möglich; die Erzwingung von Handlungen, Duldungen oder Unterlassungen verlangt gemäß § 6 I BVwVG im sog. gestreckten Verfahren die Unanfechtbarkeit des Verwaltungsakts. S. zur Verwaltungsvollstreckung ausführlich Rn. $1292 \mathrm{ff}$.

354 So zumindest nach der wohl h.M. in Rspr. und einem Teil der Lit., s. dazu ausführlich $\S 8$ Rn. 5 sowie Gersdorf, in: Posser/Wolff, VwGO, 50. Ed., Stand: 1.7.2018, § 80 Rn. 24 ff.

355 Verwaltungsakte, die den Antrag einer Person ablehnen (sog. Versagungsbescheide) und denen in der Hauptsache mit einer Verpflichtungsklage gemäß § 42 I Var. 2 VwGO (in Form der sog. Versagungsgegenklage) zu begegnen wäre, tragen keine vollziehbaren Regelungsinhalte mit sich. Besteht die Gefahr, dass sich die Verhältnisse in Folge der Ablehnung zulasten einer Person verändern, bevor diese ihr Klagebegehren in der Hauptsache durchsetzen kann, ist vorläufiger Rechtsschutz über $\S 123$ VwGO zu erreichen, s. dazu ausführlich § 10 .

356 Nach bereits benannter wohl h. M. in Rspr. und einem Teil der Lit. ist von einer Hemmung der Vollziehbarkeit nur die staatliche Seite betroffen; die sog. Wirksamkeitstheorien sowie die (vermittelnde) Position einer sog. „Verwirklichungshemmung“ kommen hingegen zu dem Ergebnis, dass auch die Folge- und Ausnutzungsmaßnahmen Privater untersagt sind, s. nur Gersdorf, in: Posser/Wolff, VwGO, 50. Ed., Stand: 1.7.2018, § 80 Rn. $24 \mathrm{ff.}$

357 S. zum verfassungsrechtlichen Hintergrund der Bestandskraft von Verwaltungsakten grundlegend BVerfG, Beschl. v. 20.4.1982, Az.: 2 BvL 26/81 = BVerfGE 60, 253 (269ff.). S. zur Bestandskraft auch Windoffer, JURA 2017, 1274.

Tobias Brings-Wiesen 
standskraft. Formell bestandskräftig ist ein Verwaltungsakt, soweit er von seinem Empfänger ${ }^{358}$ nicht mehr mit den ordentlichen Rechtsbehelfen (Widerspruch, Anfechtungs- oder Verpflichtungsklage) aufgehoben werden kann - entweder weil diese ausgeschöpft wurden oder weil die einschlägigen Rechtsbehelfsfristen abgelaufen sind. ${ }^{359}$ Als materiell bestandskräftig wird ein Verwaltungsakt bezeichnet, wenn seine Aufhebung auch nicht mehr im Wege des Wiederaufgreifens des Verfahrens gemäß $\S 51$ VwVfG (s. dazu noch $\S 3$ Rn. $98 \mathrm{ff}$.) oder über eine Rücknahme bzw. einen Widerruf gemäß $\S \S 48 \mathrm{f}$. VwVfG (s. dazu noch Rn. $836 \mathrm{ff}$.) erreicht werden kann. ${ }^{360}$

Um den Lebenszyklus eines Verwaltungsakts umfassend und differenziert zu verstehen, bedarf 116 es eines - zugegebenermaßen komplexen - Beispiels:

Die in Nordrhein-Westfalen zuständige Ordnungsbehörde der Stadt Köln bringt am Freitag, den 22.3.2019, die nach § 2 I 1 GastG erforderliche Erlaubnis zum Betrieb eines Gaststättengewerbes ab Mittwoch, den 1.5.2019, im Erdgeschoss des Hauses Zülpicher Straße 40 auf den Postweg zum A. Verbunden ist die Erlaubnis mit der Auflage, an der Decke des Gastraumes noch zusätzliche Schallschutzplatten anzubringen, um den Lärm des Betriebs für die darüber liegende Wohnung zu reduzieren, und einer ordnungsgemäßen Rechtsbehelfsbelehrung. Den A erreicht der Brief am Montag, den 25.3.2019. Als A drei Wochen später am Montag, den 8.4.2019, mit den Renovierungsarbeiten beginnt, werden Nachbar B und Nachbarin $C$ aus dem ersten und zweiten Obergeschoss darauf aufmerksam. Sie erkundigen sich noch am gleichen Tag via E-Mail bei der Ordnungsbehörde. Diese versendet am Freitag, den 12.4.2019, wiederum auf dem Postweg die Erlaubnis für den A auch an den B und die C. B erhält den Brief bereits am Montag, den 15.4.2019. Der Brief an C hingegen landet auf unglückliche Weise in einem Zwischenraum der Posttasche der Briefträgerin und wird von ihr erst am Freitag, den 19.4.2019, wiederentdeckt und bei C eingeworfen. Bei der Durchsicht des Dokuments fällt C auf, dass ihm gar keine Rechtsbehelfsbelehrung beiliegt - dies war bei B anders. Der wird auch umgehend aktiv und erhebt am Freitag, den 26.4.2019, Anfechtungsklage gegen die Erlaubnis beim zuständigen Verwaltungsgericht. Als A die Klage am Montag, den 29.4. 2019, zugestellt wird ${ }^{361}$, ist er verärgert. Er erinnert sich aber bei dieser Gelegenheit auch daran, dass ihm die Auflage zu seiner Erlaubnis gar nicht passte und erhebt noch am gleichen Tag selbst Anfechtungsklage, um deren Aufhebung zu erwirken (zum Rechtsschutz gegen Neben-

358 Die formelle Bestandskraft eines Verwaltungsakts tritt wie seine äußere Wirksamkeit nicht absolut, sondern relativ ein.

359 S. nur Ramsauer, in: Kopp/Ramsauer, VwVfG, 20. Aufl. 2019, § 43 Rn. 29.

360 S. nur Maurer/Waldhoff, Allgemeines Verwaltungsrecht, 19. Aufl. 2017, § 10 Rn. 19; Schemmer, in: Bader/Ronellenfitsch, VwVfG, 44. Ed., Stand:1.7.2019, § 43 Rn. 23 f., der überdies zu Recht darauf hinweist, dass der „materiellen Bestandskraft“ nach diesem Verständnis inhaltlich keine über die Bindungswirkung des Verwaltungsakts hinausgehende Bedeutung zukommt. Der Begriff beschreibt lediglich den Zustand der Bindungswirkung nach Eintritt der formellen Bestandskraft und hat somit in der Sache praktisch keinen Mehrwert.

361 Die Zustellung der Klage an den Beklagten erfolgt auf obligatorische Verfügung des Gerichts hin, § 85 S. 1 VwGO.

Tobias Brings-Wiesen 
bestimmungen ausführlich Rn. 204ff., 1388ff.). Die C kommt erst während eines Termins am Mittwoch, den 5.6.2019, dazu, mit ihrer Rechtsanwältin über den Fall zu sprechen, die für sie am Montag, den 10.6.2019, eine Anfechtungsklage erhebt. Bei Rückkehr von besagtem Termin trifft die $C$ auf den Nachbarn D aus dem dritten Obergeschoss, der von alldem bislang noch überhaupt nichts mitbekommen hatte. $C$ erzählt $D$ von den Klagen und rät ihm, sich anzuschließen. Der ist indes gerade mit anderen Dingen beschäftigt und verdrängt die Angelegenheit. Erst als anderthalb Jahre später im Rahmen der Verfahren eine Ortsbegehung erfolgt, wird er wieder darauf aufmerksam. Er erhebt am Mittwoch, den 9.12.2020, Anfechtungsklage.

- Der Verwaltungsakt der Gaststättenerlaubnis wurde am Freitag, den 22.3.2019, von der Ordnungsbehörde der Stadt Köln erlassen. Er wurde dem A gegenüber am Montag, den 25.3.2019, durch einfache Übermittlung mit der Post bekanntgegeben (§ 41 II 1 VwVfG ${ }^{362}$ ). Folglich wurde er A gegenüber äußerlich wirksam ( $\$ 43$ I 1 VwVfG) und somit zugleich universell rechtlich existent. Seine innere Wirksamkeit wird er jedoch wegen der aufschiebenden Befristung erst ab Mittwoch, den 1.5.2019, entfalten (§ 43 I 2 VwVfG). ${ }^{363}$ Wegen Entbehrlichkeit eines Widerspruchs- bzw. Vorverfahrens ${ }^{364}$ begann mit der Bekanntgabe auch die Frist für die Erhebung der Anfechtungsklage von einem Monat (\$ 74 I 2 VwGO), die gemäß der geltenden Berechnungsregeln (§ 57 II VwGO i.V.m. § 222 ZPO, §§ 187ff. BGB; zur Fristberechnung ausführlich Rn. 361ff.) als Ereignismonatsfrist mit Ablauf des Donnerstags, den 25.4.2019, endete, sodass der Verwaltungsakt (inklusive der Auflage) an diesem Tag für den A auch in (formelle) Bestandskraft erwuchs. Die von A am Montag, den 29.4.2019, erhobene Anfechtungsklage war daher bereits aus diesem Grund unzulässig.

- B erhielt den Brief mit der Erlaubnis am Montag, den 15.4.2019. Mit dieser Bekanntgabe wurde der Verwaltungsakt B gegenüber äußerlich wirksam. Zu diesem Zeitpunkt war der Verwaltungsakt aber - wie dargestellt - bereits erlassen und rechtlich existent. Er hätte auch dem B gegenüber ab dem 1.5.2019 seine innere Wirksamkeit entfaltet. Allerdings erhob der B am Freitag, den 26.4.2019, Anfechtungsklage. Wie dargestellt war der Verwaltungsakt dem A gegenüber zu diesem Zeitpunkt bereits in (formelle) Bestandskraft erwachsen. Wegen der späteren Bekanntgabe an B begann der Lauf der einmonatigen Klagefrist ihm gegenüber jedoch auch erst später. Ihr Ende fiel auf Mittwoch, den 15.5.2019, sodass der Verwaltungsakt am Freitag, den 26.4.2019, dem B gegenüber noch nicht in (formelle) Bestandskraft erwachsen war. Durch die Klageerhebung wurde der Eintritt der Bestandskraft gegenüber B unterbunden. Darüber hinaus kam es bereits durch Erhebung dieser ersten

362 Hier geht die Erlaubnis dem A an dem Tage zu, an dem der Zugang gemäß § 41 II 1 VwVfG auch vermutet wird. S. aber noch ausführlich zur Wirkung dieser besonderen Regelung Rn. $136 \mathrm{ff}$. 363 Anders als die Befristung oder eine Bedingung hat die Auflage bewusst keinen Einfluss auf die Wirkung der Regelung eines Verwaltungsakts - hier die Erlaubnis, die Gaststätte ab dem 1.5. 2019 zu betreiben, s. zur Unterscheidung zwischen Bedingung und Auflage ausführlich Rn. $222 \mathrm{ff}$. 364 Dazu ein vorgreifender, aber notwendiger Hinweis: In vielen Bundesländern - darunter Nordrhein-Westfalen - wurde das Widerspruchsverfahren entsprechend § 68 (II i.V.m.) I 2 Hs. 1 VwGO weitgehend abgeschafft, s. dazu ausführlich Rn. $307 \mathrm{ff}$., dies gilt auch für Fragen des Gaststättenrechts in Nordrhein-Westfalen, vgl. § 68 I 2 VwGO i.V.m. § 110 I 1 JustG NRW.

Tobias Brings-Wiesen 
(zulässigen ${ }^{365}$ ) Anfechtungsklage zur sog. „aufschiebenden Wirkung“ (gemäß § 80 I 2 VwGO bei sog. Verwaltungsakten mit Doppel- bzw. Drittwirkung, s. dazu § 9 Rn. 6ff.), deren Effekt auf die Wirkungen des Verwaltungsakts - wie bereits erwähnt - stark umstritten sind.

- C erhielt den Brief mit der Erlaubnis am Freitag, den 19.4.2019. Mit dieser Bekanntgabe wurde der Verwaltungsakt $C$ gegenüber äußerlich wirksam. Sie kam durch ihre Rechtsanwältin aber leider erst am Montag, den 10.6.2019, dazu, selbst Anfechtungsklage zu erheben. Wegen der bereits von B am Freitag, den 26.4.2019, erhobenen Anfechtungsklage (und der mit ihr eingetretenen aufschiebenden Wirkung) wurde zwar - zumindest vorübergehend - mittelbar auch dem Interesse der C gedient. Zugleich kommt es mit der Klageerhebung durch einen Betroffen jedoch nicht zu einer Unterbrechung des Fristlaufs für die übrigen Betroffenen. Ihr Rechtsschutzbegehren ist grundsätzlich unabhängig zu verfolgen. Insofern könnte die von $C$ in anwaltlicher Vertretung erhobene Anfechtungsklage gemäß § 74 I 2 VwGO bereits verfristet gewesen sein. Dies wäre jedoch nur der Fall, wenn die Frist zu laufen begonnen hätte. Dies erfolgt - bei Entbehrlichkeit eines Widerspruchs bzw. Vorverfahrens - grundsätzlich mit Bekanntgabe des Verwaltungsakts, es sei denn, diesem fehlt es an einer (hinreichenden) Rechtsbehelfsbelehrung gemäß § 58 I VwGO. Ist eine Rechtsbehelfsbelehrung unterblieben oder unrichtig erteilt, so läuft ab Zustellung, Eröffnung oder Verkündung nur die einjährige Ausschlussfrist des § 58 II 1 VwGO, die im Falle von C noch nicht abgelaufen war. (Dies wäre erst am Montag, den 20.4.2020, der Fall, da das Datum des eigentlichen Fristendes am 19.4.2020 auf einen Sonntag fällt, §57 II VwGO i.V.m. § 222 II ZPO.) Sollte die Anfechtungsklage von C die übrigen Sachentscheidungsvoraussetzungen erfüllen, würde das zuständige Verwaltungsgericht die beiden anhängigen Verfahren über den gleichen Gegenstand qua Beschluss gemäß § 93 S. 1 VwGO miteinander verbinden.

- D erfuhr erst am Mittwoch, den 5.6.2019, von der Erlaubnis - allerdings nur aus einem persönlichen Gespräch mit der C. Ihm gegenüber erfolgte jedoch zu keinem Zeitpunkt eine Bekanntgabe seitens der Ordnungsbehörde der Stadt Köln (s. dazu ausführlich Rn. 122). Dies bedeutet, dass der Verwaltungsakt ihm gegenüber gemäß § 43 I 1 VwVfG auch nie äußerlich wirksam wurde. Mangels Bekanntgabe begann weder der Lauf der Klagefrist (§ 74 I 2 VwGO) noch der Lauf der Ausschlussfrist ( $\$ 58$ II 1 VwGO), sodass D auch noch am Mittwoch, den 9.12.2020, gegen den am 25.3.2019 rechtlich entstandenen und seither existenten Verwaltungsakt Anfechtungsklage erheben konnte. Denkbar wäre nur eine Unzulässigkeit der Klage wegen fehlenden Rechtsschutzbedürfnisses infolge von Verwirkung (als besonderer Form eines Verstoßes den Rechtsgrundsatz von Treu und Glauben, s. dazu ausführlich Rn. 329, 399ff.).

365 S. zur Problematik des Eintritts der aufschiebenden Wirkung bei (offensichtlich) unzulässigen Rechtsbehelfen m.w. N. W.-R. Schenke, in: Kopp/Schenke, VwGO, 25. Aufl. 2019, § 80 Rn. 50 f. 


\section{Wirksamwerden von Verwaltungsakten, § 43 I VwVfG}

$117 \S 43$ I VwVfG knüpft den Eintritt der Wirksamkeit - das Wirksamwerden - eines Verwaltungsakts maßgeblich an den Akt der Bekanntgabe. ${ }^{366}$ Abgesehen von der Tatsache, dass sie auch im Interesse der Funktionsfähigkeit der Verwaltung erfolgt, ${ }^{367}$ dient die Bekanntgabe eines Verwaltungsakts insbesondere der Realisierung der verfassungsrechtlich geschützten Interessen der Betroffenen. Sie ist rechtsstaatlich geboten, denn erst die Kenntnisnahme des Inhalts eines Verwaltungsakts versetzt sie in den Stand, die Garantie effektiven Rechtsschutzes gemäß Art. 19 IV 1 GG $^{368}$ und ihren Anspruch auf rechtliches Gehör ${ }^{369} \mathrm{zu}$ verwirklichen und in der Folge effektiven Grundrechtsschutz ${ }^{370} \mathrm{zu}$ erlangen.

118 Soweit die Bekanntgabe nicht spezialgesetzlich geregelt ist, kommt es zentral auf die Vorgaben des $\mathbf{\$} \mathbf{4 1} \mathbf{V w V f G}^{371}$ an. Aus dieser Vorschrift ergeben sich insbesondere die allgemeinen Voraussetzungen der Bekanntgabe. Dabei ist der Wortlaut der Norm wenig ergiebig. Ihr ist weder eine Legaldefinition des Begriffs „Bekanntgabe“ zu entnehmen, noch enthält sie konkrete Merkmale. Die Bestimmung der Voraussetzungen erfolgt vielmehr unter Rückbesinnung auf die allgemeine Rechtsgeschäftslehre. Denn beim Verwaltungsakt handelt es sich der Sache nach um eine rechtliche Willenserklärung der Behörde (s. dazu Rn. 44 ff.). Aus diesem Grund wird - unter notwendiger Berücksichtigung etwaiger Besonderheiten im Staat-Bürger-Verhältnis - maßgeblich auf die aus dem Zivilrecht bekannten Grundsätze betreffend das Wirksamwerden von Willenserklärungen zurückgegriffen. ${ }^{372}$ Vor diesem Hintergrund ist auch für die Bekanntgabe des Verwaltungsakts zwischen zwei Verantwortungssphären zu unterscheiden: der der erklärenden Behörde und der des Empfängers (s. dazu Rn. 121ff.). Ist für einen Verwaltungsakt eine bestimmte Art der Bekanntgabe vorgesehen, sind darüber hinaus ergänzende bzw. abweichende besondere Vorgaben $\mathrm{zu}$ berücksichtigen (s. dazu Rn. 133 ff.).

366 S. zur Bekanntgabe ausführlich auch Erichsen/Hörster, JURA 1997, 659; Schoch, JURA 2011, 23; Beaucamp, JA 2016, 436.

367 Stelkens, in: Stelkens/Bonk/Sachs, VwVfG, 9. Aufl. 2018, § 41 Rn. 2.

368 BVerwG, Urt. v. 27.5.1983, Az.: 4 C 40.81 u. a. = BVerwGE 67, 206 (109); Stelkens, in: Stelkens/ Bonk/Sachs, VwVfG, 9. Aufl. 2018, § 41 Rn. 2; Couzinet/Fröhlich, in: Mann/Sennekamp/Uechtritz, VwVfG, 2. Aufl. 2019, § 41 Rn. 11.

369 BVerwG, Urt. v. 18.4.1997, Az.: 8 C 43.95 = BVerwGE 104, 301 (306); Stelkens, in: Stelkens/ Bonk/Sachs, VwVfG, 9. Aufl. 2018, § 41 Rn. 2.

370 Ramsauer/Tegethoff, in: Kopp/Ramsauer, VwVfG, 20. Aufl. 2019, § 41 Rn. 2; Couzinet/Fröhlich, in: Mann/Sennekamp/Uechtritz, VwVfG, 2. Aufl. 2019, § 41 Rn. 10.

371 Für einen Überblick über die Abweichungen in den entsprechenden Vorschriften des Landesrechts Stelkens, in: Stelkens/Bonk/Sachs, VwVfG, 9. Aufl. 2018, vor der Kommentierung zu § 41. 372 Stelkens, in: Stelkens/Bonk/Sachs, VwVfG, 9. Aufl. 2018, § 41 Rn. 7 f.

Tobias Brings-Wiesen 
In einer Prüfung ist die Bekanntgabe eines Verwaltungsakts überhaupt nur 119 dann zu thematisieren, wenn sich aus dem Sachverhalt diesbezüglich Zweifel ergeben. Sind hinsichtlich einer Bekanntgabe Unzulänglichkeiten erkennbar, stellt sich sodann jedoch die Frage, wie mit diesen umzugehen ist. Im Falle einer (im Rechtssinne) fehlenden Bekanntgabe besteht Einigkeit, dass es nicht zum Eintritt der (äußeren) Wirksamkeit gegenüber dem jeweiligen Empfänger kommt bzw. gegebenenfalls gar kein rechtlich existenter Verwaltungsakt vorliegt. ${ }^{373}$ Dies kann beispielsweise der Fall sein, wenn ein Verwaltungsakt ohne Bekanntgabewillen auf Seiten der Behörde den Empfänger erreicht oder wenn umgekehrt ein von der Behörde willentlich auf den Weg gebrachter Verwaltungsakt niemals in den Machtbereich des Empfängers gelangt (s. zu Einzelheiten noch unten Rn. $121 \mathrm{ff}$.). Umstritten ist hingegen der Umgang mit der fehlerhaften Bekanntgabe. ${ }^{374}$ Dies betrifft Konstellationen, in denen ein Verwaltungsakt willentlich die Verantwortungssphäre der Behörde verlassen hat und einem Empfänger zur Kenntnis gelangt ist - die allgemeinen Voraussetzungen also erfüllt sind -, dabei aber die für eine bestimmte Bekanntgabeart geltenden Voraussetzungen verfehlt wurden. Diesbezüglich werden diverse Grundpositionen verfochten: So wird vertreten, derartige Verstöße verhinderten nie das Wirksamwerden eines Verwaltungsakts; ${ }^{375}$ die Gegenmeinung verneint demgegenüber bei jedem Verstoß gegen zwingende Bekanntgabevorschriften die Wirksamkeit der Bekanntgabe; ${ }^{376}$ eine vermittelnde Auffassung unterscheidet nach dem Schweregrad des jeweiligen Fehlers und verneint bei weniger schweren Fehlern zumindest den Beginn des Laufs der Rechtsbehelfsfristen ${ }^{377}$. Hinzu kommt, dass darüber hinaus eine analoge Anwendung von $\S 8$ VwZG (s. dazu Rn. 172) auch auf Bekanntgabefehler

373 S. nur Detterbeck, Allgemeines Verwaltungsrecht, 17. Aufl. 2019, Rn. 553, 557; Maurer/ Waldhoff, Allgemeines Verwaltungsrecht, 19. Aufl. 2017, § 9 Rn. 71; Erichsen/Hörster, JURA 1997, 659 (663f.); Schoch, JURA 2011, 23 (29); Beaucamp, JA 2016, 436 (438).

374 S. auch die Darstellungen bei Detterbeck, Allgemeines Verwaltungsrecht, 17. Aufl. 2019, Rn. 556f.; Erichsen/Hörster, JURA 1997, 659 (664f.); Beaucamp, JA 2016, 436 (438f.).

375 Detterbeck, Allgemeines Verwaltungsrecht, 17. Aufl. 2019, Rn. 557, für den derartige Rechtsfehler maximal zur Nichtigkeit führen können, aber ansonsten als Frage der formellen Rechtmäßigkeit zu behandeln sind, a.a.O., Rn. 581ff.; wohl auch Erbguth/Guckelberger, Allgemeines Verwaltungsrecht, 9. Aufl. 2018, §13 Rn. 13.

376 Stelkens, in: Stelkens/Bonk/Sachs, VwVfG, 9. Aufl. 2018, § 41 Rn. 222; Couzinet/Fröhlich, in: Mann/Sennekamp/Uechtritz, VwVfG, 2. Aufl. 2019, § 41 Rn. 145; Erichsen/Hörster, JURA 1997, 659 (664f.); Ehlers, Rechtsfragen der Existenz, der Wirksamkeit und der Bestandskraft von Verwaltungsakten, in: Krebs, Liber Amicorum Erichsen, 2004, S. 1 (6); Beaucamp, JA 2016, 436 (438f.); wohl auch Maurer/Waldhoff, Allgemeines Verwaltungsrecht, 19. Aufl. 2017, § 9 Rn. 73; Peine/ Siegel, Allgemeines Verwaltungsrecht, 12. Aufl. 2018, Rn. 451; Ruffert, in: Knack/Henneke, VwVfG, 10. Aufl. 2014, § 41 Rn. 69; Herrmann, ZJS 2011, 25 (27); Schoch, JURA 2011, 23 (29).

377 Ramsauer/Tegethoff, in: Kopp/Ramsauer, VwVfG, 20. Aufl. 2019, § 41 Rn. 23 ff.

Tobias Brings-Wiesen 
außerhalb des Zustellungsrechts starken Zuspruch findet. ${ }^{378}$ In der Rechtsprechung scheint sich - soweit ersichtlich - bislang keine kategorische Antwort auf diese Streitfrage herausgebildet zu haben. Dies ist jedoch nicht verwunderlich, da es - allen damit verbundenen Rechtsunsicherheiten zum Trotz ${ }^{379}$ - tatsächlich überzeugender ist, aufmerksam den einzelnen Bekanntgabefehler in den Fokus zu nehmen. Da nicht jede Bekanntgabevorschrift in gleicher Intensität zum Schutz der Interessen der Empfänger beiträgt, entspricht nur ein differenzierendes Fehlerfolgenregime den - auch der weitgehenden Entkopplung von Wirksamkeit und Rechtmäßigkeit von Verwaltungsakten zugrundeliegenden (s. dazu Rn. 105) - Interessen der Gewährleistung von Rechtssicherheit und der Funktionsfähigkeit der Verwaltung. ${ }^{380}$ Überdies werden die Unterschiede zwischen der Meinung, die für eine Unwirksamkeit bei Verletzung „zwingender“ Bekanntgabevorschriften plädiert, und der, die nach dem Schweregrad des Fehlers urteilt, praktisch nur sehr gering sein. Abzulehnen ist indes die Auffassung, die nur bei Außerachtlassung der allgemeinen Voraussetzungen von einer Unwirksamkeit ausgeht. §43 I 1 VwVfG erhebt die Bekanntgabe allgemein zur Wirksamkeitsvoraussetzung. ${ }^{381}$ Differenzierungen zwischen den verschiedenen Arten der Bekanntgabe sind nur unter den besagten teleologischen Erwägungen geboten.

\section{a) Allgemeine Voraussetzungen der Bekanntgabe}

120 Wie bereits erwähnt sollte die Bekanntgabe eines Verwaltungsakts in einer Prüfung nur dann thematisiert werden, wenn diesbezügliche Probleme im Sachverhalt ersichtlich sind. Die folgenden Ausführungen sollen daher vorrangig eine Checkliste bieten, die im Rahmen der Auswertung eines Sachverhalts zuerst gedanklich durchgegangen werden kann. Die allgemeinen Voraussetzungen sind dabei stets, die besonderen Vorgaben nur bei gebotenem Anlass zu berücksichtigen. Sofern im Rahmen dieser Vorprüfung Zweifel an der Bekanntgabe auf-

378 Stelkens, in: Stelkens/Bonk/Sachs, VwVfG, 9. Aufl. 2018, § 41 Rn. 232; Couzinet/Fröhlich, in: Mann/Sennekamp/Uechtritz, VwVfG, 2. Aufl. 2019, § 41 Rn. 148; Ruffert, in: Knack/Henneke, VwVfG, 10. Aufl. 2014, § 41 Rn. 72; a. A. aber Schoch, JURA 2011, 23 (30); Beaucamp, JA 2016, 436 (439).

379 Dies als Argument gegen die vermittelnde Ansicht vorbringend Beaucamp, JA 2016, 436 (438).

380 Entsprechend differenzierend auch Stuhlfauth, in: Obermayer/Funke-Kaiser, VwVfG, 5. Aufl. 2018, § 41 Rn. 71 ff., wenngleich er zu einzelnen Fehlern sodann zu anderen Ergebnissen kommt. 381 Beaucamp, JA 2016, 436 (438).

Tobias Brings-Wiesen 
kommen, sollten diese in der Prüfung selbst auf die potentiellen Fehler konzentriert thematisiert werden.

\section{aa) Auf Seiten der erklärenden Behörde}

Der Gegenstand der Bekanntgabe ist laut § 41 I 1 VwVfG der „Verwaltungsakt“. 121 Dieser ist für die Zwecke der Bekanntgabe von seinen gesetzlich vorgesehenen Annexen zu unterscheiden, da sich eine fehlerhafte Bekanntgabe insofern unterschiedlich auswirkt. ${ }^{382}$ Die Wirksamkeit eines Verwaltungsakts ist nur von der ordnungsgemäßen Bekanntgabe seines verfügenden Teils - sprich seiner Regelung (s. dazu Rn. 63 ff.) - abhängig. ${ }^{383}$ Dazu gehören auch alle Nebenbestimmungen. ${ }^{384}$ Anders wirken indes Fehler hinsichtlich der Bekanntgabe einer dem Verwaltungsakt gegebenenfalls beizufügenden Begründung (§39 VwVfG) oder Rechtsbehelfsbelehrung ( $§ 37$ VI VwVfG): Bestehen Begründungsdefizite, ist ein Verwaltungsakt lediglich (formell) rechtswidrig und gar einer Heilung zugänglich (dazu speziell §45 I Nr. 2 VwVfG, s. dazu Rn. 662); Rechtsbelehrungsdefizite

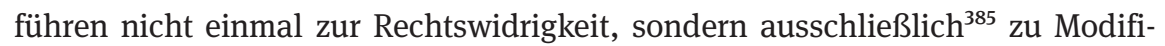
kationen der Rechtsbehelfsfristen nach $\S 58$ VwGO (s. dazu Rn. 368 ff.).

Der Verwaltungsakt muss mit Bekanntgabewillen der den Verwaltungsakt 122 erlassenden Behörde (in amtlicher Eigenschaft ${ }^{386}$ ) in Richtung eines bestimmten Empfängers auf den Weg gebracht werden. ${ }^{387}$ Fehlt dieser, kann ein Verwaltungsakt nicht i.S.v. § 43 I VwVfG wirksam werden. Die Bekanntgabe ist demnach von verschiedenen Möglichkeiten eines bloßen Bekanntwerdens des Verwaltungsakts zu unterscheiden. Die Erlassbehörde muss den Verwaltungsakt zwar

382 Differenzierend auch Stelkens, in: Stelkens/Bonk/Sachs, VwVfG, 9. Aufl. 2018, § 41 Rn. 15f.; Couzinet/Fröhlich, in: Mann/Sennekamp/Uechtritz, VwVfG, 2. Aufl. 2019, § 41 Rn. 24, dort auch zur (analogen) Anwendbarkeit auf Zusicherungen, Anordnungen der sofortigen Vollziehung und behördliche Verfahrensanordungen, a. a.O., Rn. $25 \mathrm{ff}$.

383 Tiedemann, in: Bader/Ronellenfitsch, VwVfG, 44. Ed., Stand: 1.7.2019, § 41 Rn. 6.

384 Sowie eine potentiell damit verbundene Anordnung der sofortigen Vollziehung, so Stelkens, in: Stelkens/Bonk/Sachs, VwVfG, 9. Aufl. 2018, § 41 Rn. 14 f.

385 Die verfahrensrechtlichen Folgen einer unrichtigen oder unterbliebenen Rechtsbehelfsbelehrung sind laut BVerwG in $\S 58$ VwGO abschließend geregelt, Urt. v. 20.4.1994, Az.: 11 C $2.93=$ NVwZ-RR 1995, 50; Urt. v. 15.9.2010, Az.: 8 C 21.09 = BVerwGE 138, 1 (4, Rn. 19).

386 Bezüglich des beim nachbarschaftlichen Grillfest beiläufig mitgeteilten Verwaltungsakts wird es regelmäßig an einem Bekanntgabewillen fehlen.

387 S. nur das BVerwG - bereits vor Erlass des VwVfG - für die Bekanntgabe verallgemeinernd Urt. v. 29.4.1968, Az.: VIII C 19.64 = BVerwGE 29, 321 (323); so bereits konkret zur Zustellung BVerwG, Urt. v. 19.6.1963, Az.: V C 198.62 = BVerwGE 16, 165 (166f.); s. auch speziell zu § 74 VwGO BVerwG, Urt. v. 23.7.1965 - Az.: VII C 175.64 = BVerwGE 22, 14 (15).

Tobias Brings-Wiesen 
nicht selbst bekanntgeben, ${ }^{388}$ die Bekanntgabe aber zumindest willentlich veranlasst haben. ${ }^{389}$ Die ohne oder gar gegen den Willen der Erlassbehörde erfolgende Eröffnung des Verwaltungsakts gegenüber einem Betroffenen durch eine andere Behörde, ${ }^{390}$ einen anderen privaten Betroffenen ${ }^{391}$ oder gar jemand völlig Unbeteiligten $^{392}$ führt nicht $\mathrm{zu}$ einer wirksamen Bekanntgabe. ${ }^{393}$ An einem Bekanntgabewillen kann es noch fehlen, wenn die Behörde eine Erklärung, die zwar ultimativ zum Verwaltungsakt werden soll, vorab bloß informatorisch übermittelt. Besonderer Berücksichtigung bedarf in diesem Zusammenhang die Genehmigungsfiktion gemäß § 42a VwVfG (s. zur Rechtsnatur der Genehmigungsfiktion Rn. 61). ${ }^{394}$ Deren Besonderheit liegt darin, dass ein das Verwaltungsverfahren abschließender Akt der Behörde ausbleibt. Gemäß § 42a I 1 VwVfG gilt eine beantragte Genehmigung jedoch unter bestimmten Voraussetzungen nach Ablauf

388 Vgl. nur das Auseinanderfallen der Zuständigkeit für eine Sachentscheidung und für deren Zustellung bei BVerwG, Beschl.v. 8.3.1984, Az.: 9 B 15204.82 = NVwZ 1984, 521.

389 Maurer/Waldhoff, Allgemeines Verwaltungsrecht, 19. Aufl. 2017, § 9 Rn. 74. Ist dies der Fall, ändert auch die Tatsache, dass eine für die Bekanntgabe unzuständige Behörde gehandelt hat, nichts an der Wirksamkeit des Verwaltungsakts, vgl. BVerwG, Beschl. v. 8.3.1984, Az.: 9 B 15204.82 = NVwZ 1984, 521. - Hier zeigt sich auch die Notwendigkeit eines differenzierten Verständnisses: Soweit eine Bekanntgabe durch die „zuständige Behörde“ gefordert wird, s. bspw. Detterbeck, Allgemeines Verwaltungsrecht, 17. Aufl. 2019, Rn. 552; Maurer/Waldhoff, a.a.O., kann damit nicht die Zuständigkeit für den Erlass des Verwaltungsakts (s. dazu ausführlich Rn. 580 ff.), sondern nur der Bekanntgabewille der Erlassbehörde gemeint sein. Erlässt folglich eine unzuständige Behörde einen Verwaltungsakt und gibt diesen sodann willentlich bekannt, kann dieser grundsätzlich Wirksamkeit erlangen. Er leidet indes wegen fehlender Zuständigkeit an einem formellen Fehler.

390 Bsp.: Die Eröffnung erfolgt durch eine Behörde, die verwaltungsintern vorzeitig über eine Sachentscheidung in Kenntnis gesetzt wurde, obwohl die die Sachentscheidung erlassende Behörde nicht bekanntgeben wollte, BVerwG, Urt. v. 29.4.1968, Az.: VIII C 19.64 = BVerwGE 29, 321 (323).

391 Bsp.: Der Bauherr übergibt seinem Nachbarn eine Kopie seiner Baugenehmigung, die die zuständige Behörde bisher nur ihm gegenüber bekanntgegeben hat.

392 Bsp.: Die Reinigungskraft findet nach Dienstschluss im Papierkorb einer Behördenmitarbeiterin mehrere verschlossene, adressierte Briefumschläge und gibt diese in der irrigen Annahme einer missverständlichen Entsorgung zur Poststelle der Behörde.

393 Nicht abschließend geklärt ist die Frage, wie bei Zweifeln am Bekanntgabewillen der Behörde zu verfahren ist. Zum Teil wird auf das Verständnis eines durchschnittlichen Empfängers abgestellt, Couzinet/Fröhlich, in; Mann/Sennekamp/Uechtritz, VwVfG, 2. Aufl. 2019, § 41 Rn. 18, zum Teil die Ersetzung des Bekanntgabewillens durch dem Zivilrecht entlehnte Rechtsscheinerwägungen gefordert, Stelkens, in: Stelkens/Bonk/Sachs, VwVfG, 9. Aufl. 2018, § 41 Rn. 57 ff., bezüglich derer jedoch angesichts der besonderen Wirkungen des Verwaltungsakts Vorsicht geboten ist.

394 S. rund um die Genehmigungsfiktion ausführlich Guckelberger, DÖV 2010, 109; Weidemann/ Barthel, JA 2011, 221; Kluth, JuS 2011, 1078; Ernst/Pinkl, JURA 2013, 685.

Tobias Brings-Wiesen 
einer für die Entscheidung festgelegten Frist (§ 42a II VwVfG: drei Monate ab Eingang der vollständigen Unterlagen, sofern spezialgesetzlich nichts anderes bestimmt ist) schlicht als erteilt - die Genehmigung wird fingiert ${ }^{395}$, ohne dass es auf einen Bekanntgabeakt oder auch nur einen darauf gerichteten Bekanntgabewillen gemäß $§ 41$ VwVfG ankäme. Insofern kommt es zu einer Modifikation des - gemäß §42a I 2 VwVfG zumindest entsprechend anwendbaren - § 43 I VwVfG. ${ }^{396}$ Mit Ablauf der Frist tritt die (äußere ${ }^{397}$ ) Wirksamkeit ein - allerdings nur gegenüber dem Antragssteller, nicht gegenüber anderen Betroffenen. ${ }^{398}$ Zentrale Voraussetzung des Wirksamwerdens einer solchen fingierten Genehmigung ist, dass sie gemäß § 42a I 1 VwVfG überhaupt durch Rechtsvorschrift angeordnet ist. ${ }^{399} \S 42 \mathrm{a}$ VwVfG selbst ist kein, sondern setzt einen anderweitig bestimmten ${ }^{400}$ Genehmigungstatbestand voraus. Soweit dieser Tatbestand selbst keine Voraussetzungen enthält, ${ }^{401}$ ergeben sich diese aus § 42a VwVfG: Danach bedarf es eines vollständigen wie hinreichend bestimmten Antrags ( $§ 42 \mathrm{a}$ I 1, II 2 VwVfG) an die zuständige Behörde ${ }^{402}$ sowie des Ablaufs der einschlägigen Frist vor Entscheidung der Behörde über den Antrag (§ 42a II VwVfG) ${ }^{403}$. Liegen diese Voraussetzungen vor, wird die fingierte Genehmigung gemäß § 42a I 2 i.V.m. § 43 II VwVfG wie ein regulär bekanntgegebener Verwaltungsakt ohne Rücksicht auf ihre Rechtmäßigkeit wirksam. ${ }^{404}$ Unwirksamkeit aufgrund von Nichtigkeit gemäß

395 Kurz und anschaulich zur Fiktion Kluth, JuS 2011, 1078 (1078f.); ausführlich zur Fiktion von Genehmigungen und zu Bekanntgabefiktionen im Verwaltungsverfahren m. zahlr. Bsp. Jachmann, Die Fiktion im öffentlichen Recht, 1998, S. $281 \mathrm{ff}$. und $442 \mathrm{ff}$.

396 Ramsauer, in: Kopp/Ramsauer, VwVfG, 20. Aufl. 2019, § 42a Rn. 2, 15.

397 Gemäß § 42a I 2 i.V.m. § 43 I 2 VwVfG wird die Genehmigung mit dem beantragten Inhalt wirksam, sodass die innere Wirksamkeit gleichsam erst zu einem späteren Zeitpunkt eintreten kann.

398 Ramsauer, in: Kopp/Ramsauer, VwVfG, 20. Aufl. 2019, § 42a Rn. 3; Kluth, JuS 2011, 1078 (1081); Ernst/Pinkl, JURA 2013, 685 (692). S. aber zu Ansprüchen auf Mitteilung gegenüber Dritten Ramsauer, a.a.O., § 42a Rn. 22, 30.

399 Ramsauer, in: Kopp/Ramsauer, VwVfG, 20. Aufl. 2019, § 42 Rn. 9f.; Ernst/Pinkl, JURA 2013, 685 (686f.).

400 Für das Studium relevante Genehmigungstatbestände finden sich in §6a GewO, § 15 I 5 PBefG und insbesondere in einigen Landesbauordnungen im Hinblick auf das vereinfachte Baugenehmigungsverfahren, vgl. bspw. § 61 III HBauO. Für eine Übersicht über weitere Vorschriften s. Ramsauer, in: Kopp/Ramsauer, VwVfG, 20. Aufl. 2019, § 42a Rn. 10a.

401 S. mit Beispielen zu möglichen Abweichungen oder Ergänzungen Ernst/Pinkl, JURA 2013, 685 (689f.).

402 Ramsauer, in: Kopp/Ramsauer, VwVfG, 20. Aufl. 2019, § 42a Rn. 12a.

403 S. zur Funktionsweise der Fristenregelung in § 42a II VwVfG Ernst/Pinkl, JURA 2013, 685 (688f.).

404 Ramsauer, in: Kopp/Ramsauer, VwVfG, 20. Aufl. 2019, § 42a Rn. 16. 
§ 42a I 2 i.V.m. §§ 43 III, 44 VwVfG ist möglich, sofern der Grund für die Nichtigkeit nicht untrennbar mit Natur oder Verfahren der Genehmigungsfiktion verbunden ist. ${ }^{405}$ Sie kann gemäß $\S \S 48,49$ VwVfG oder aufgrund von spezialgesetzlichen Regelungen aufgehoben und mit den gegenüber Verwaltungsakten statthaften Rechtsbehelfen angegriffen werden. ${ }^{406}$

\section{bb) Auf Seiten des Empfängers}

124 Der Kreis der Empfänger von Verwaltungsakten ist gesetzlich bestimmt. Gemäß $\S 41 \mathrm{I} 1 \mathrm{VwVfG}$ ist ein Verwaltungsakt demjenigen Beteiligten bekannt zu geben, für den er bestimmt ist oder der von ihm betroffen wird. Damit ist der Grundsatz der individuellen Bekanntgabe eines Verwaltungsakts normiert, aus dem der Grundsatz der relativen Wirksamkeit von Verwaltungsakten gemäß § 43 I VwVfG (s. dazu Rn. 113) folgt.

Anders als § 43 I VwVfG knüpft die Vorschrift wörtlich an die Definition der „Beteiligten“ gemäß $\S 13$ VwVfG an. Dabei erfasst sie jedoch in der Sache genauso zwei Gruppen Betroffener: Bestimmt ist der Verwaltungsakt für die Person ${ }^{407}$, die ihn für sich beantragt hat (§ 13 I Nr. 1 Var. 1 VwVfG) oder an die die Behörde den Verwaltungsakt (sonst) richtet (§ 13 I Nr. 1 Var. 2, Nr. 2 VwVfG). ${ }^{408}$ Die Bestimmung ergibt sich - wie bereits dargelegt (s. dazu Rn. 107) - maßgeblich aus dem Regelungsinhalt des Verwaltungsakts, wie die Behörde ihn festlegt ${ }^{409}$ Von einem Verwaltungsakt sonst betroffen ist die Person, die vom Regelungsinhalt des Verwaltungsakts unter Berücksichtigung der aus dem einschlägigen materiellen Recht resultierenden Rechtsfolgewirkungen in ihren rechtlich geschützten Interessen berührt wird ${ }^{410}$ (§ 13 II VwVfG). Damit sind insbesondere die sog. Verwaltungsakte mit Doppel- bzw. Drittwirkung (vgl. dazu § 9 Rn. 6f.) erfasst.

405 Ramsauer, in: Kopp/Ramsauer, VwVfG, 20. Aufl. 2019, § 42a Rn. 16; Ernst/Pinkl, JURA 2013, 685 (691). So sind mangels Schriftlichkeit bzw. Urkunde oder Erlass durch eine Behörde bereits die Anwendungsbereiche von $\S 44$ II Nr. 1 bis 3 VwVfG nicht eröffnet.

406 Ernst/Pinkl, JURA 2013, 685 (691f., 692f.).

407 Dabei ist auch eine Identitätstäuschung irrelevant, BVerwG, Urt. v. 9.9.2014, Az.: 1 C $10.14=$ NVwZ 2014, 1679 (1679f., Rn. 13).

408 Stelkens, in: Stelkens/Bonk/Sachs, VwVfG, 9. Aufl. 2018, § 41 Rn. 29.

409 Ob die Behörde den Verwaltungsakt an die richtige Person gerichtet hat, ist indes eine Frage der materiellen Rechtmäßigkeit, s. dazu allgemein Rn. 790 f., sowie insbesondere in den prüfungsrelevanten Konstellationen des Polizei- und Ordnungsrechts Rn. $1118 \mathrm{ff}$.

410 OVG Münster, Urt.v. 20.6.1991, Az.: 7 A 23/90 = NVwZ 1992, 991; Couzinet/Fröhlich, in: Mann/ Sennekamp/Uechtritz, VwVfG, 2. Aufl. 2019, § 41 Rn. 61; Ruffert, in: Knack/Henneke, VwVfG, 10. Aufl. 2014, § 41 Rn. 19. 
Der Rekurs auf die „Beteiligten“ i.S.v. § 13 VwVfG ist indes nicht überzubewerten. Unterbleibt eine Bekanntgabe gegenüber einem von mehreren gemäß § 41 I 1 VwVfG Betroffenen, ${ }^{411}$ ändert dies gemäß § 43 I VwVfG nichts an der Existenz und Wirksamkeit des Verwaltungsakts gegenüber den anderen, soweit er ihnen wirksam bekanntgegeben wurde. Dem sog. „übergangenen Betroffenen“ gegenüber wird der Verwaltungsakt zwar nicht rechtlich wirksam, er kann jedoch angesichts der gleichwohl drohenden (faktischen) Auswirkungen Rechtsbehelfe gegen einen bereits existenten Verwaltungsakt anstrengen (s. dazu Rn. 112). Mangels Bekanntgabe ist er dabei nicht fristgebunden (§§ 70 I 1, 74 I 2 VwGO); ${ }^{412}$ ein Rechtsbehelf kann jedoch gleichwohl wegen eines Verstoßes gegen die Grundsätze von Treu und Glauben (in Ausprägung der Verwirkung) verspätet sein, wenn der Betroffene von dem Verwaltungsakt Kenntnis erlangt hat oder zumindest hätte erlangen müssen. ${ }^{413}$ Gegenüber Beteiligten, die sich am Ende des Verwaltungsverfahrens doch nicht als Betroffene erweisen, muss keine Bekanntgabe erfolgen. ${ }^{414}$

Besonderheiten gilt es im Falle der Betroffenheit von Personenmehrheiten $^{415}$ und von juristischen Personen ${ }^{416} \mathrm{zu}$ beachten.

Um von dem Verwaltungsakt überhaupt Kenntnis nehmen zu können, muss der Betroffene auch handlungsfähig i.S.v. § 12 VwVfG (s. dazu Rn. 641) sein. ${ }^{417}$ Soweit er i.S.v. § 12 I Nr. 2 VwVfG nur beschränkt geschäftsfähig ist, ist innerhalb des geschäftsfähigen Rechtskreises noch eine persönliche Bekanntgabe mög-

411 Die Frage, ob nur am Verfahren Beteiligte, so Stelkens, in: Stelkens/Bonk/Sachs, VwVfG, 9. Aufl. 2018, § 41 Rn. 33, oder alle materiell Betroffenen, so Couzinet/Fröhlich, in: Mann/Sennekamp/Uechtritz, VwVfG, 2. Aufl. 2019, § 41 Rn. 61 m.w. N., gemeint sind, kann dahinstehen. 412 Vor diesem Hintergrund wird diskutiert, ob sowohl der übergangene Betroffene als auch der von einem Verwaltungsakt mit Drittwirkung Begünstigte gegen die Behörde einen Anspruch auf nachträgliche Bekanntgabe an sich bzw. den belasteten Dritten haben, bejahend Ramsauer/Tegethoff, in: Kopp/Ramsauer, VwVfG, 20. Aufl. 2019, § 41 Rn. 33; Tiedemann, in: Bader/Ronellenfitsch, VwVfG, 44. Ed., Stand: 1.7.2019, § 41 Rn. 58.

413 S. nur BVerwG, Urt. v. 25.1.1974, Az.: IV C 2.72 = BVerwGE 44, 294 (300f.); s. zu diesen Konstellationen ausführlich Rn. 329, $399 \mathrm{ff}$.

414 Stelkens, in: Stelkens/Bonk/Sachs, VwVfG, 9. Aufl. 2018, § 41 Rn. 32; Ruffert, in: Knack/ Henneke, VwVfG, 10. Aufl. 2014, § 41 Rn. 19.

415 S. zur Bekanntgabe an verschiedene Personenmehrheiten Ramsauer/Tegethoff, in: Kopp/ Ramsauer, VwVfG, 20. Aufl. 2019, § 41 Rn. 28 f., 30 ff.; Stelkens, in: Stelkens/Bonk/Sachs, VwVfG, 9. Aufl. 2018, § 44 Rn. 75 ff., 97; Ruffert, in: Knack/Henneke, VwVfG, 10. Aufl. 2014, § 41 Rn. 14 ff. 416 S. dazu Stelkens, in: Stelkens/Bonk/Sachs, VwVfG, 9. Aufl. 2018, § 41 Rn. 48 ff.; Couzinet/ Fröhlich, in: Mann/Sennekamp/Uechtritz, VwVfG, 2. Aufl. 2019, § 41 Rn. 60.

417 Stelkens, in: Stelkens/Bonk/Sachs, VwVfG, 9. Aufl. 2018, § 41 Rn. 50; Couzinet/Fröhlich, in: Mann/Sennekamp/Uechtritz, VwVfG, 2. Aufl. 2019, § 41 Rn. 69. 
lich. ${ }^{418}$ Soweit demgegenüber die Handlungsfähigkeit fehlt, muss die Bekanntgabe gegenüber dem gesetzlichen Vertreter erfolgen - so beispielsweise im Falle eines Minderjährigen ${ }^{419}$ regelmäßig gegenüber seinen Eltern, ${ }^{420}$ im Falle eines Volljährigen gegebenenfalls gegenüber seinem Betreuer. Eine gleichwohl gegenüber dem Handlungsunfähigen erfolgte Bekanntgabe ist unwirksam. ${ }^{421}$ Der gesetzliche Vertreter kann jedoch durch nachträgliche Genehmigung für eine Wirksamkeit sorgen; ebenso kann der Betroffene selbst bei späterer Wiedererlangung der Handlungsfähigkeit Kenntnis über den Verwaltungsakt erlangen. ${ }^{422}$

Gemäß § 41 I 2 VwVfG kann die Bekanntgabe auch einem Bevollmächtigten gegenüber vorgenommen werden. Der persönliche Anwendungsbereich der Vorschrift erstreckt sich nicht nur auf Bevollmächtigte i.S.v. § 14 VwVfG, sondern auch auf Empfangsbevollmächtigte i.S.v. $§ 15$ VwVfG. ${ }^{423}$ Ihnen gegenüber kann die Bekanntgabe indes nur dann wirksam erfolgen, wenn und solange (im Zeitpunkt des Zugangs) eine entsprechende Vollmacht vorliegt. ${ }^{424}$ Umstritten ist die Frage, ob es sich um einen Fehler handelt, wenn die Behörde den Verwaltungsakt einem Betroffenen persönlich bekanntgibt, obwohl dieser einen Bevollmächtigten mit der Wahrnehmung seiner Angelegenheit betraut hat und dies der Behörde auch bekannt ist. ${ }^{425}$ Dies wird von einer Mindermeinung unter Berufung auf $\S 14$ III 1 VwVfG, wonach sich die Behörde im Falle der Bestellung eines Bevoll-

418 Ramsauer/Tegethoff, in: Kopp/Ramsauer, VwVfG, 20. Aufl. 2019, § 44 Rn. 29; Stelkens, in: Stelkens/Bonk/Sachs, VwVfG, 9. Aufl. 2018, § 41 Rn. 50.

419 S. aber zum Sonderfall der Bekanntgabe eines Verwaltungsakts gegenüber minderjährigen Störern im Bereich des Polizei- und Ordnungsrechts Rn. 1121.

420 Die jedoch gemäß § 1629 I 2 Hs. 2 BGB bei Empfang der im Verwaltungsakt enthaltenen Willenserklärung ausnahmsweise jeweils alleinvertretungsberechtigt sind, Couzinet/Fröhlich, in: Mann/Sennekamp/Uechtritz, VwVfG, 2. Aufl. 2019, § 41 Rn. 70 m.w. N.

421 Ramsauer/Tegethoff, in: Kopp/Ramsauer, VwVfG, 20. Aufl. 2019, § 41 Rn. 29; Stelkens, in: Stelkens/Bonk/Sachs, VwVfG, 9. Aufl. 2018, § 41 Rn. 50.

422 Couzinet/Fröhlich, in: Mann/Sennekamp/Uechtritz, VwVfG, 2. Aufl. 2019, § 41 Rn. 71 m.w. N. 423 Die zu diesen Vorschriften geltenden Grundsätze sind entsprechend anzuwenden; insbesondere besteht auch die Möglichkeit einer Anscheins- bzw. Duldungsbevollmächtigung, BVerwG, Urt. v. 25.2.1994, Az.: 8 C 2.92 = NJW-RR 1995, 73 (75); BVerwG, Beschl. v. 20.1. 2017, Az.: 8 B 23.16 = NVwZ-RR 2017, 430 (430 f.); s. dazu auch m.w. N. Couzinet/Fröhlich, in: Mann/Sennekamp/Uechtritz, VwVfG, 2. Aufl. 2019, § 41 Rn. 65.

424 Stelkens, in: Stelkens/Bonk/Sachs, VwVfG, 9. Aufl. 2018, § 41 Rn. 36. Das BVerwG, Urt. v. 25. 2. 1994, Az.: 8 C 2.92 = NJW-RR 1995, 73 (75), hält demgegenüber in einer solchen Konstellation grds. eine Heilung entsprechend $\S 8$ VwZG (s. dazu noch Rn. 172) für möglich, wenn der Betroffene tatsächlich Kenntnis erlangt hat.

425 Davon ausdrücklich abzugrenzen sind Konstellationen der Zustellung an Bevollmächtigte gemäß § 7 VwZG, s. dazu noch Rn. 171.

Tobias Brings-Wiesen 
mächtigten an diesen wenden „soll“, grundsätzlich bejaht. ${ }^{426}$ Die h.M. sieht jedoch in § 41 I 2 VwVfG zu Recht eine Spezialregelung zu § 14 III VwVfG, die es in das Ermessen der Behörde stellt („kann“), wem gegenüber sie den Verwaltungsakt bekanntgibt. ${ }^{427}$ Dieses Auswahlermessen hat sie dann jedoch pflichtgemäß auszuüben, es dürfen ihr keine Ermessensfehler unterlaufen. ${ }^{428}$ Die Rechtsfolge eines Ermessensfehlers ist wiederum umstritten. ${ }^{429}$ Bei dualer Bekanntgabe an den Betroffenen und seinen Bevollmächtigten kommt es auf den zuerst bewirkten Zugang an. ${ }^{430}$

Der Akt der Bekanntgabe wird abgeschlossen mit dem „Zugang“ beim 130 Empfänger. Verlangt ist dafür keine tatsächliche Kenntnisnahme. ${ }^{431}$ Die Rechtsprechung ${ }^{432}$ und die ganz herrschende Meinung in der Literatur ${ }^{433}$ wenden für die Bestimmung des Zugangs der Willenserklärung Verwaltungsakt §130 BGB analog an. ${ }^{434}$ Verlangt ist insofern die derartige Verbringung in den Machtbereich des jeweiligen Empfängers, dass „,bei gewöhnlichem Verlauf und normaler Gestaltung der Verhältnisse des Empfängers mit der Kenntnisnahme durch ihn zu rechnen ist“،. ${ }^{435}$ Es geht demnach nur um die Kenntnisnahmemöglichkeit. Die Anforderungen an diese Kenntnisnahmemöglichkeit richten sich nach der Art der Bekanntgabe und den diesbezüglich existierenden Rechtsvorschriften

426 So noch das VGH Mannheim, Beschl.v. 7.10.1986, Az.: NC 9 S 550/86 = VBlBW 1987, 297; indes später aufgegeben in Urt. v. 19.7.2005, Az.: 9 S 2278/03 = NVwZ-RR 2006, 154.

427 BVerwG, Urt. v. 30.10.1997, Az.: 3 C 35.96 = BVerwGE 105, 288 (292ff.); so auch Ramsauer/ Tegethoff, in: Kopp/Ramsauer, VwVfG, 20. Aufl. 2019, § 41 Rn. 34; Couzinet/Fröhlich, in: Mann/ Sennekamp/Uechtritz, VwVfG, 2. Aufl. 2019, § 41 Rn. 66f. jeweils m.w. N.

428 S. für Beispiele potentieller Ermessensfehler Stelkens, in: Stelkens/Bonk/Sachs, VwVfG, 9. Aufl. 2018, § 41 Rn. 41; Couzinet/Fröhlich, in: Mann/Sennekamp/Uechtritz, VwVfG, 2. Aufl. 2019, $\S 41$ Rn. 67; vgl. auch BFH, Urt. v. 5.10.2000, Az.: VII R 96/99 = NVwZ 2001, 473 (474).

429 Für eine Unwirksamkeit der Bekanntgabe: Stelkens, in: Stelkens/Bonk/Sachs, VwVfG, 9. Aufl. 2018, § 41 Rn. 43; primär für ein Unterbleiben des Fristlaufs (subsidiär indes auch für eine Wiedereinsetzung): Ramsauer/Tegethoff, in: Kopp/Ramsauer, VwVfG, 20. Aufl. 2019, § 41 Rn. 35; für die Möglichkeit einer Wiedereinsetzung in den vorigen Stand: VGH Kassel, Urt. v. 10.8.1992, Az.: 12 UE 2254/89 = NVwZ-RR 1993, 432 (434f.); Couzinet/Fröhlich, in: Mann/Sennekamp/ Uechtritz, VwVfG, 2. Aufl. 2019, § 41 Rn. 68 m.w.N.

430 Couzinet/Fröhlich, in: Mann/Sennekamp/Uechtritz, VwVfG, 2. Aufl. 2019, § 41 Rn. 64.

431 Deswegen ist bspw. irrelevant, ob der Empfänger einen in seinen Machtbereich verbrachten Brief tatsächlich öffnet und liest.

432 S. nur BVerwG, Beschl.v. 22. 2.1994, Az.: 4 B 212.93 = BeckRS 1994, 31246579; Urt. v. 31.5.2012, Az.: 3 C 12.11 = NVwZ-RR 2012, 628 (630, Rn. 18f.); Beschl.v. 21.12.2017, Az.: 6 B 43.17 = NVwZ 2018, 496 (498, Rn. 11).

433 Statt vieler Maurer/Waldhoff, Allgemeines Verwaltungsrecht, 19. Aufl. 2017, § 9 Rn. 75; Peine/ Siegel, Allgemeines Verwaltungsrecht, 12. Aufl. 2018, Rn. 443.

434 So bereits die Gesetzesmaterialien BT-Drucks. 7/910, S. $61 \mathrm{f}$.

435 S. nur BVerwG, Beschl. v. 21.12.2017, Az.: 6 B 43.17 = NVwZ 2018, 496 (498, Rn. 11). 
und Verkehrsanschauungen. ${ }^{436}$ So kommt es beispielsweise im Falle der (fern-) mündlichen Bekanntgabe unter Anwesenden darauf an, dass die Erklärung sinnlich wahrnehmbar ist. ${ }^{437}$ Gemäß $§ 23$ I VwVfG wird sie grundsätzlich in deutscher Sprache erfolgen müssen. ${ }^{438}$ Erfolgt die Bekanntgabe in textlicher Verkörperung unter Abwesenden, wird es besonders auf die Bestimmung des „Machtbereichs“ ankommen: Dazu gehören beispielsweise im Falle des Einwurfs durch die Behörde oder der postalischen Übermittlung ein häuslicher Briefkasten oder ein Postschließfach, ${ }^{439}$ im Falle der Versendung per E-Mail der Posteingang (s. dazu Rn. 144 ff.). Eine Verbringung in den Machtbereich des Empfängers ist auch durch Übermittlung an einen Empfangsboten denkbar, wenn dieser vom Betroffenen bestellt wurde oder nach der Verkehrsanschauung als solcher gewertet wird. ${ }^{440}$

131 Je nach Art der Bekanntgabe und Zugang beim Empfänger differiert auch der rechtlich relevante Zeitpunkt der Bekanntgabe. Dieser bestimmt sich wiederum in entsprechender Anwendung von $\S 130$ BGB - danach, wann bei gewöhnlichem Verlauf und normaler Gestaltung der Verhältnisse des Empfängers mit der Kenntnisnahme zu rechnen ist. ${ }^{441}$ Auch insofern kommt es maßgeblich auf die diesbezüglich existierenden Rechtsvorschriften und Verkehrsanschauungen an. Bereits im Studium sind besonders die Vorgaben in $\S 41$ II VwVfG zu beachten (s. dazu Rn. 136ff.).

132 Kommt es zu einem Zugangsproblem, ist nach dem Ursprung für dieses Problem innerhalb der getrennten Verantwortungssphären von Behörde und Empfänger zu suchen. Dabei ist zu berücksichtigen, dass für den Bürger keine allgemeine Pflicht besteht, Empfangsvorkehrungen zu treffen. ${ }^{442}$ Verschickt die Behörde beispielsweise einen Verwaltungsakt an eine im Melderegister falsch geführte Adresse, mag zwar ein Verstoß gegen Vorschriften des Melderechts

436 S. zu den verschiedenen Möglichkeiten des Zugangs je nach Art der Bekanntgabe ausführlich Stelkens, in: Stelkens/Bonk/Sachs, VwVfG, 9. Aufl. 2018, § 41 Rn. 69ff. m.w. N.

437 Ramsauer/Tegethoff, in: Kopp/Ramsauer, VwVfG, 20. Aufl. 2019, § 41 Rn. 7c.

$438 \mathrm{Zu}$ Recht differenzierend Tiedemann, in: Bader/Ronellenfitsch,VwVfG, 44. Ed., Stand: 1.7. 2019, § 41 Rn. 11f.; rigider Ramsauer/Tegethoff, in: Kopp/Ramsauer, VwVfG, 20. Aufl. 2019, § 41 Rn. 8a; Stelkens, in: Stelkens/Bonk/Sachs, VwVfG, 9. Aufl. 2018, § 41 Rn. 64. Vgl. auch zu anderen Kommunikationsproblemen Tiedemann, a.a.O., Rn. $15 \mathrm{f}$.

439 S. dazu ausführlich m.w. N. Stelkens, in: Stelkens/Bonk/Sachs, VwVfG, 9. Aufl. 2018, § 41 Rn. $69 \mathrm{ff}$.

440 S. dazu ausführlich m.w. N. Stelkens, in: Stelkens/Bonk/Sachs, VwVfG, 9. Aufl. 2018, § 41 Rn. $67 \mathrm{f}$.

441 BVerwG, Beschl. v. 22.2.1994, Az.: 4 B 212.93 = BeckRS 1994, 31246579; Urt. v. 31.5.2012, Az.: 3 C $12.11=$ NVwZ-RR 2012, 628 (630, Rn. 18f.).

442 BVerwG, Urt. v. 29.6.1990, Az.: 8 C 22.89 = BVerwGE 85, 213 (216) m.w. N.

Tobias Brings-Wiesen 
vorliegen - dieser ändert aber nichts daran, dass es in der Risikosphäre der Behörde liegt, die richtige Adresse im Vorfeld sicher zu ermitteln. ${ }^{443}$ Etwas anderes kann sich jedoch daraus ergeben, ${ }^{444}$ dass den Empfänger besondere gesetzliche Pflichten treffen, ${ }^{445}$ er der Behörde eine bestimmte Empfangsmöglichkeit ausdrücklich kommuniziert hat oder es für ihn aus vorangegangenen Vorgängen erkenntlich war, dass er einen Verwaltungsakt erhalten wird. Kommt es in diesen Fällen zu Zugangsproblemen, kann darin eine schuldhafte treuwidrige Vereitelung durch den Empfänger liegen, sodass dieser sich nach den Grundsätzen von Treu und Glauben so behandeln lassen muss, als sei ihm die Erklärung wie im Falle seines pflichtgemäßen Verhaltens zugegangen. ${ }^{446}$

\section{b) Ergänzende bzw. abweichende besondere Vorgaben nach Art der Bekanntgabe}

Ob über die allgemeinen Voraussetzungen hinaus noch weitere bzw. abwei- 133 chende besondere Vorgaben bestehen, richtet sich nach der Art der Bekanntgabe. Wie für den Erlass des Verwaltungsakts (§ 37 II 1 VwVfG; s. dazu Rn. 681) gilt auch für seine Bekanntgabe der „Grundsatz der Formfreiheit“. ${ }^{447}$ Beide Anknüpfungspunkte dürfen jedoch nicht miteinander vermengt werden: Die Art der Bekanntgabe eines Verwaltungsakts ist zwingend von seiner Erlassform (s. dazu Rn. $681 \mathrm{ff}$.) zu unterscheiden, ${ }^{448}$ da diese unterschiedliche Fehlerfolgen nach sich ziehen. Auch wenn die Art $^{449}$ der Bekanntgabe in der Verwaltungspraxis oftmals der Erlassform folgen wird, ${ }^{450}$ hindert eine Verletzung von Formvorschriften nicht ${ }^{451}$ die wirksame Bekanntgabe des Verwaltungsakts. ${ }^{452}$

443 OVG Schleswig, Beschl. v. 28.3.2001, Az.: 1 M 24/00 = NVwZ 2002, 358 (359).

444 S. dazu ausführlich m.w. N. Stelkens, in: Stelkens/Bonk/Sachs, VwVfG, 9. Aufl. 2018, § 41 Rn. $103 \mathrm{ff}$.

445 Vgl. bspw. § 10 I AsylG; zu vergleichbaren Vorschriften des Wehrpflichtgesetzes instruktiv BVerwG, Urt. v. 29.6.1990, Az.: 8 C 22.89 = BVerwGE 85, 213 (215ff.).

446 S. nur BVerwG, Urt. v. 29.6.1990, Az.: 8 C 22.89 = BVerwGE 85, 213 (216). Demgegenüber in rechtsdogmatischer Hinsicht für die Annahme einer Zugangsfiktion Stelkens, in: Stelkens/Bonk/ Sachs, VwVfG, 9. Aufl. 2018, § 41 Rn. 102; dezidiert dagegen Tiedemann, in: Bader/Ronellenfitsch, VwVfG, 44. Ed., Stand: 1.7.2019, § 41 Rn. $32 \mathrm{ff}$.

447 Schwarz, in: Fehling/Kastner/Störmer, Verwaltungsrecht, 4. Aufl. 2016, § 41 VwVfG Rn. 9; Schoch, JURA 2011, 23 (25).

448 S. das Beispiel für die verschiedenen Arten der Bekanntgabe eines schriftlichen Verwaltungsakts bei Detterbeck, Allgemeines Verwaltungsrecht, 17. Aufl. 2019, Rn. 555.

449 Vor diesem Hintergrund ist es sinnvoller, wie hier von „Arten“ anstatt von „Formen“ der Bekanntgabe zu sprechen.

$450 \mathrm{Zu}$ weitgehend Ramsauer/Tegethoff, in: Kopp/Ramsauer, VwVfG, 20. Aufl. 2019, § 41 Rn. 6, die eine „Abhängigkeit“ der Art und Weise der Bekanntgabe von der Erlassform erkennen.

Tobias Brings-Wiesen 
Fehlen Bestimmungen darüber, auf welche Art und Weise ein Verwaltungsakt bekanntzugeben ist, steht die Entscheidung darüber grundsätzlich im Ermessen der Behörde. ${ }^{453}$ Dann bedarf es lediglich der Einhaltung der bereits dargelegten allgemeinen Voraussetzungen einer Bekanntgabe (s. dazu Rn. 120 f.).

\section{aa) Einfache individuelle Bekanntgabe}

135 Soweit gesetzlich keine besondere Art ${ }^{454}$ vorgesehen ist, handelt es sich um eine einfache individuelle Bekanntgabe. Diese kann mündlich in persona oder via Fernkommunikationsmitteln, schriftlich durch persönliche Übergabe, Einwurf eines Behördenmitarbeiters, Übermittlung durch die Post oder Versendung via Fax $^{455}$ oder in völlig anderer Weise - beispielsweise durch Handzeichen oder Piktogramme (s. noch zu Verkehrszeichen Rn. 165) - erfolgen. Für die einfache Bekanntgabe sind zumindest im allgemeinen Verwaltungsrecht keine besonderen Voraussetzungen vorgesehen. Zu berücksichtigen ist jedoch § 41 II 1 und 3 VwVfG.

Entscheidet sich die Behörde für die Bekanntgabe eines schriftlichen Verwaltungsakts via Übermittlung durch die Post im Inland, gilt der Verwaltungsakt gemäß § $41 \mathrm{II} 1 \mathrm{VwVfG}$ als am dritten Tag nach der Aufgabe zur Post als bekannt gegeben. Der Anwendungsbereich der Vorschrift ist begrenzt ${ }^{456}$ : Sie gilt nur für schriftliche (s. dazu Rn. 685f.) Verwaltungsakte; wenn diese durch die „Post“, sprich irgendeinen Erbringer von Postdienstleistungen i.S.v. §4 Nr. 1 Post $\mathrm{G},{ }^{457}$ übermittelt werden; solange dies im Inland, sprich ausschließlich innerhalb des Staatsgebiets der Bundesrepublik Deutschland, geschieht. ${ }^{458}$

451 In Ausnahmefällen mag sie jedoch die Nichtigkeit des Verwaltungsakts begründen, s. dazu noch in $\S 6 \mathrm{Rn} .115 \mathrm{ff}$.

452 Maurer/Waldhoff, Allgemeines Verwaltungsrecht, 19. Aufl. 2017, § 9 Rn. 73; Couzinet/Fröhlich, in: Mann/Sennekamp/Uechtritz, VwVfG, 2. Aufl. 2019, § 41 Rn. 53. A.A. wohl OVG Münster, Beschl. v. 27.10.1995, Az.: 10 B 2720/95 = NWVBl 1996, 222.

453 BVerwG, Beschl. v. 21.12.2017, Az.: 6 B 43.17 = NVwZ 2018, 496 (498, Rn. 11); so auch mit Ausführungen zu entscheidungsleitenden Gesichtspunkten Stelkens, in: Stelkens/Bonk/Sachs, VwVfG, 9. Aufl. 2018, § 41 Rn. 18f.; Couzinet/Fröhlich, in: Mann/Sennekamp/Uechtritz, VwVfG, 2. Aufl. 2019, § 41 Rn. 31f. So auch bereits die Gesetzesmaterialien, BT-Drucks. 7/910, S. 62.

454 Ein davon abgzugrenzender Sonderfall einer „qualifizierten Bekanntgabe“ ist jedoch die Aushändigung sog. konstitutiver Urkunden, vgl. BVerwG, Urt. 1.2.1978, Az.: 6 C 9.77 = BVerwGE 55, 212 (213ff.). S. dazu auch noch die Ausführungen zu § 44 II Nr. 2 VwVfG in § 6 Rn. 125 f.

455 S. dazu ausführlich Stelkens, in: Stelkens/Bonk/Sachs, VwVfG, 9. Aufl. 2018, § 41 Rn. $82 \mathrm{ff}$. 456 Eine analoge Anwendung der Vorschrift auf andere Konstellationen der Bekanntgabe wird von der herrschenden Meinung abgelehnt, s. nur Schwarz, in: Fehling/Kastner/Störmer, Verwaltungsrecht, 4. Aufl. 2016, § 41 VwVfG Rn. 26.

457 Schoch, JURA 2011, 23 (28). Zentral ist nach dieser Definition insbesondere die Gewerbsmäßigkeit der Dienstleistung, sodass eine „Hauspost“ nicht in Frage kommt, vgl. OVG Koblenz,

Tobias Brings-Wiesen 
Auch wenn die rechtsdogmatische Einordnung der Vorschrift umstritten 137 ist, ${ }^{459}$ besteht weitgehend Einigkeit bezüglich ihrer Wirkungen: Die Vorschrift vermutet nicht nur die Bekanntgabe an sich, sondern insbesondere auch den u.a. ${ }^{460}$ - für die Fristberechnung relevanten Zeitpunkt dieser Bekanntgabe. Es handelt sich insofern um eine Spezialvorschrift, die den bereits dargelegten allgemeinen Regeln betreffend den Zugang eines Verwaltungsakts vorgeht.

Soll es tatsächlich zu einem Zugang vor Ablauf dieser Frist gekommen sein, 138 ist entsprechend des Sinn und Zwecks der Vermutung zu differenzieren: Die Vermutung bleibt maßgeblich, den Empfängern ist es jedoch in für sie günstigen Konstellationen möglich, sich unter Darlegung von Beweisen auf diesen früheren Zugang zu berufen. ${ }^{461}$ Der Behörde hingegen ist eine entsprechende Möglichkeit zum Gegenbeweis zulasten der Empfänger nicht eröffnet; insofern gilt die Vermutungswirkung uneingeschränkt. ${ }^{462}$

Soll es indes zu einem Zugang nach Ablauf dieser Frist gekommen oder dieser gar völlig unterblieben sein, greift § 41 II 3 VwVfG: Die Vermutung gilt als widerlegt (Hs. 1) und die Behörde hat den Zugang des Verwaltungsakts und den Zeitpunkt des Zugangs nachzuweisen (Hs. 2). Voraussetzung dessen ist, dass „Zweifel“ am (pünktlichen) Zugang bestehen. Bestehen diese Zweifel auch nach erneuter Sachverhaltsermittlung fort, trägt die Behörde das Risiko der Nichterweislichkeit, sodass letztlich gegebenenfalls der Vortrag des Empfängers zugrunde zu legen ist. ${ }^{463}$ Bis heute ist jedoch stark umstritten, welche Anforderungen an den Widerlegungsvortrag des Empfängers zu stellen sind, sprich wann

Urt.v. 28.6.2002, Az.: 2 A 10667/02 = NVwZ-RR 2003, 4. Kritischer zu bestimmten Postdienstleistern indes zuletzt der BFH, Urt. v. 14.6.2018, Az.: III R 27/17 = NJW 2018, 3606.

458 Ausführlich zu den Voraussetzungen Stelkens, in: Stelkens/Bonk/Sachs, VwVfG, 9. Aufl. 2018, § 41 Rn. $111 \mathrm{ff}$.

459 Das BVerwG sprach zu der vergleichbaren Vorschrift des §4 VwZG a.F. von einer „gesetzlichen Fiktion“ mit „Ausnahmevorschrift“, BVerwG, Urt. v. 23.7.1965, Az.: VII C 170/64 = BVerwGE 22, 11 (12f.); dem folgend Erichsen/Hörster, JURA 1997, 659 (661). Demgegenüber für eine „widerlegbare Vermutung“ m.w. N. Schoch, JURA 2011, 23 (28); für eine differenzierende Betrachtung Stelkens, in: Stelkens/Bonk/Sachs, VwVfG, 9. Aufl. 2018, § 41 Rn. 109.

460 S. für Beispiele zu anderen Bedeutungsdimensionen Stelkens, in: Stelkens/Bonk/Sachs, VwVfG, 9. Aufl. 2018, § 41 Rn. 122, 125.

461 OVG Lüneburg, Urt. v. 23.6.2009, Az.: 12 LC 136/07 = NVwZ-RR 2009, 866 (867); Stelkens, in: Stelkens/Bonk/Sachs, VwVfG, 9. Aufl. 2018, § 41 Rn. 125; a. A. wohl Tiedemann, in: Bader/Ronellenfitsch, VwVfG, 44. Ed., Stand: 1.7.2019, § 41 Rn. 71, der offenbar keinerlei Ausnahme außerhalb von Konstellationen des § 41 II 3 VwVfG zulassen will.

462 Ramsauer/Tegethoff, in: Kopp/Ramsauer, VwVfG, 20. Aufl. 2019, § 41 Rn. 40; Stelkens, in: Stelkens/Bonk/Sachs, VwVfG, 9. Aufl. 2018, § 41 Rn. 121. Vgl. bereits zu § 4 BVwZG a. F. BVerwG, Urt. v. 23.7.1965, Az.: VII C 170/64 = BVerwGE 22, 11 (13f.).

463 Stelkens, in: Stelkens/Bonk/Sachs, VwVfG, 9. Aufl. 2018, § 41 Rn. 127.

Tobias Brings-Wiesen 
dieser wirklich „Zweifel“ sät. Dabei lassen sich heute drei Hauptansätze ausmachen: Eine Ansicht lässt das schlichte Bestreiten des (pünktlichen) Zugangs genügen und verzichtet auf jegliche Substantiierung des Vortrags. ${ }^{464}$ Hingegen lässt die Gegenmeinung nur ein qualifiziertes Bestreiten ${ }^{465}$, sprich den Vortrag und die Glaubhaftmachung von Umständen, die bei objektiver Betrachtung geeignet sind, berechtigte Zweifel am Zugang des Verwaltungsakts zu begründen, ausreichen. ${ }^{466}$ Eine differenzierende Ansicht verlangt eine weitere Substantiierung je nach Lage des Einzelfalls und unterscheidet dabei insbesondere zwischen der Behauptung eines unterbliebenen (= keine weitere Substantiierung) und eines verspäteten Zugangs. ${ }^{467}$ Für ein schlichtes Bestreiten spricht bereits der Wortlaut von § 41 II 3 VwVfG, der gerade der Behörde in Zweifelsfällen (ohne weitere Differenzierung ${ }^{468}$ ) die objektive Beweislast und somit das Risiko der Nichterweislichkeit des Zugangs auferlegt. ${ }^{469}$ Weiterhin wird logisch argumentiert, dass von dem Empfänger nichts Unmögliches verlangt werden dürfe: „Negative Tatsachen“ - wie der unterbliebene oder verspätete Zugang - könnten nicht weiter substantiiert werden. ${ }^{470}$ Auch liegen die Ursachen für einen unterbliebenen oder verspäteten Zugang außerhalb des Einfluss- und Kenntnisbereichs des Empfängers. ${ }^{471}$ Umgekehrt habe es die Behörde selbst in der Hand, Nachweis-

464 Erbguth/Guckelberger, Allgemeines Verwaltungsrecht, 9. Aufl. 2018, § 13 Rn. 9; Stelkens, in: Stelkens/Bonk/Sachs, VwVfG, 9. Aufl. 2018, § 41 Rn. 127 f.; Couzinet/Fröhlich, in: Mann/Sennekamp/Uechtritz, VwVfG, 2. Aufl. 2019, § 41 Rn. 93.

465 Dabei werden an ein solches qualifiziertes Bestreiten überwiegend keine strengen Anforderungen gestellt, s. bspw. das OVG Bautzen, Urt. v. 12.5.2010, Az.: 5 A 203/08 = LKV 2010, 430 (431), das - zumindest im Falle der Behauptung des völligen Unterbleibens eines Zugangs - auch eine plausible schlichte Erklärung ausreichen lassen will.

466 OVG Koblenz, Urt. v. 10.10.1997, Az.: 2 A 13324/96 = juris, Rn. 23; OVG Lüneburg, Beschl.v. 3. 8. 2012, Az.: 12 LA 180/11 = juris, Rn. 6; OVG Bautzen, Urt. v. 12.5.2010, Az.: 5 A 203/08 = LKV 2010, 430 (431); OVG Münster, Beschl. v. 26.11.2014, Az.: 6 A 1784/12 = juris, Rn. 22.

467 Anschaulich Stuhlfauth, in: Obemayer/Funke-Kaiser, VwVfG, 5. Aufl. 2018, § 41 Rn. $37 \mathrm{ff}$. m.w. N. aus der Rspr. Vgl. zu § 122 II AO jüngst auch BVerwG, Urt. v. 15.6.2016, Az.: 9 C $19.15=$ BVerwGE 155, 241 (244f., Rn. 17 f.).

468 Was somit auch gegen die differenzierende Ansicht spreche, Couzinet/Fröhlich, in: Mann/ Sennekamp/Uechtritz, VwVfG, 2. Aufl. 2019, § 41 Rn. 93; Ruffert, in: Knack/Henneke, VwVfG, 10. Aufl. 2014, § 41 Rn. 37.

469 Couzinet/Fröhlich, in: Mann/Sennekamp/Uechtritz, VwVfG, 2. Aufl. 2019, § 41 Rn. 91, 93; in die Richtung auch Stelkens, in: Stelkens/Bonk/Sachs, VwVfG, 9. Aufl. 2018, § 41 Rn. 127; Beaucamp, JA 2016, 436 (437).

470 Schoch, JURA 2011, 23 (29); Beaucamp, JA 2016, 436 (437).

471 Tiedemann, in: Bader/Ronellenfitsch, VwVfG, 44. Ed., Stand: 1.7.2019, § 41 Rn. 81.1; Schoch, JURA 2011, 23 (29); Beaucamp, JA 2016, 436 (437); Stelkens, in: Stelkens/Bonk/Sachs, VwVfG, 9. Aufl. 2018, § 41 Rn. 128, erkennt insofern ein Verwischen der Grenze zwischen der Prüfung der Substantiiertheit und der Beweiswürdigung.

Tobias Brings-Wiesen 
problemen durch die Entscheidung gegen eine einfache postalische Übermittlung und für eine Zustellung vorzubeugen. ${ }^{472}$ Für ein qualifiziertes Bestreiten spricht demgegenüber, dass das Ausreichenlassen eines schlichten Bestreitens praktisch zum Leerlauf der Zugangsvermutung § 41 II 1 VwVfG führte und somit dem Zweck der Vorschrift diametral entgegenstünde. ${ }^{473}$ Zwar sieht sich auch die differenzierende Ansicht der oben dargelegten Kritik ausgesetzt. Ihr ist indes zuzugestehen, dass sie vom Empfänger nur in den Fällen der Verspätung, wo der Verwaltungsakt zumindest zu einem gewissen Zeitpunkt in den Einfluss- und Kenntnisbereich gelangt, einen entsprechenden Vortrag und damit nicht etwas völlig Unmögliches verlangt. Zumindest in den Fällen verspäteten Zugangs gelingt ihr mithin ein zweckgerechterer Ausgleich.

Umstritten ist bis heute gleichsam die Bestimmung des „dritten Tages 140 nach“ der Aufgabe zur Post. Der Streit hat sich in der Praxis weit überwiegend an der Frage entladen, wie das Ende des Drei-Tages-Zeitraumes zu bestimmen ist, wenn der dritte Tag auf einen Sonntag, einen gesetzlichen Feiertag oder einen Sonnabend fällt. Käme in diesem Falle der $§ 31$ III $1 \mathrm{VwVfG}^{474}$ zur Anwendung, so wäre erst der nächstfolgende Werktag maßgeblich.

Die wohl herrschende Ansicht in Rechtsprechung ${ }^{475}$ und Literatur ${ }^{476}$ lehnt 141 die Anwendung der Vorschrift ${ }^{477}$ ab. Bei dem Drei-Tages-Zeitraum gemäß § 41 II 1 VwVfG handele es sich nicht um eine „Frist“ i.S.v. § 31 VwVfG, sondern lediglich um die Fiktion des Zeitpunktes der Bekanntgabe eines Verwaltungsakts ${ }^{478}$ und daher um einen „Termin“ i.S.v. § 31 VwVfG. Die Bestimmung dieses Termins er-

472 Drescher, NVwZ 1987, 771 (772, 774); Hebeler, DÖV 2006, 112 (115f.); Schoch, JURA 2011, 23 (29); Beaucamp, JA 2016, 436 (437f.).

473 OVG Koblenz, Urt. v. 10.10.1997, Az.: 2 A 13324/96 = juris, Rn. 23; OVG Lüneburg, Beschl.v. 3. 8. 2012, Az.: 12 LA 180/11 = juris, Rn. 6; OVG Münster, Beschl.v. 26.11.2014, Az.: 6 A 1784/12 = juris, Rn. 22.

474 Oder eine seiner Parallelvorschriften in den VwVfG der Länder, im Abgaben- (§ 108 III AO) oder Sozialverwaltungsverfahrensrecht (§ 26 III 1 SGB X).

475 S. nur OVG Lüneburg, Beschl. v. 28.2.2011, Az.: 4 LA 44/10 = NJW 2011, 1529 (1530) m.w. N. Vgl. zur Parallelvorschrift im Sozialverwaltungsverfahrensrecht auch BSG, Urt. v. 6.5.2010, Az.: B 14 AS 12/09 R = NJW 2011, 1099 (1100, Rn. 11ff.) m.w. N.

476 S. nur Couzinet/Fröhlich, in: Mann/Sennekamp/Uechtritz, VwVfG, 2. Aufl. 2019, § 41 Rn. 90 m.w.N.

477 Das BSG, Urt. v. 6.5.2010, Az.: B 14 AS 12/09 R = NJW 2011, 1099 (1100, Rn. 11), hat zur Parallelvorschrift im Sozialverwaltungsverfahrensrecht zusätzlich klargestellt, dass sich eine entsprechende Einschränkung auch nicht aus der Vorschrift zur Bekanntgabevermutung selbst ergibt.

478 S. nur OVG Lüneburg, Beschl. v. 28.2.2011, Az.: 4 LA 44/10 = NJW 2011, 1529 (1530). 
folgt zwar in Orientierung am Ablauf eines pauschalierten Zeitraumes ${ }^{479}$, was auf den ersten Blick der Funktionsweise einer „Frist“ ähnelt. § 41 II 1 VwVfG hat jedoch nicht das Telos einer Fristenregelung. Eine „Frist“ sei eine abgegrenzte Zeitspanne, innerhalb der Leistungen erbracht oder Handlungen vorgenommen werden sollen oder können. Ein „Termin“ hingegen sei ein rechtserhebliches Datum, an dem etwas geschehen soll oder eine Rechtswirkung eintritt. ${ }^{480}$ Ein Termin kann auch mit Hilfe des Ablaufs eines Zeitraumes näher bestimmt werden. Der entscheidende Unterschied liegt in der Zweckrichtung der Vorschrift: Innerhalb des Drei-Tages-Zeitraums gemäß § 41 II 1 VwVfG wird von keinem Verfahrensbeteiligten ein Tätigwerden erwartet, die Vorschrift erfüllt allein den Zweck der pauschalierten Vermutung einer Bekanntgabe im Interesse von Rechtssicherheit, Verwaltungsvereinfachung und Sparsamkeit. ${ }^{481}$ Wie der Wortlaut und der systematische Vergleich mit Abs. 1 zeigten, gelte § 31 III VwVfG aber nur für Fristen, nicht für Termine. ${ }^{482}$ Dieses Ergebnis wird auch teleologisch für überzeugend gehalten: Dem genannten Zweck diene am ehesten ein fester Maßstab, nicht aber eine Verschiebung des fingierten Zugangsdatums auf den nächsten Werktag, die gerade die Notwendigkeit einer genaueren Prüfung begründen würde. ${ }^{483}$ Dem sollen umgekehrt auch keine teleologischen Erwägungen im Interesse des Schutzes der Empfänger entgegenstehen, sodass zumindest mangels vergleichbarer Interessenlage ${ }^{484}$ auch keine analoge Anwendung von $\S 31$ III VwVfG in Frage komme. Der „Feiertagsregelung“ liege „in erster Linie die Überlegung zu Grunde, dass die Abgabe einer Erklärung bzw. die Vornahme einer Handlung an diesen Tagen typischerweise Schwierigkeiten bereitet“. ${ }^{485}$ Entsprechende Schwierigkeiten treffen die Empfänger bei der bloßen Fiktion des Zugangs an einem solchen Tag indes nicht. Der allein nachteiligen Konstellation eines die Rechtsbehelfsfirsten verkürzenden Zugangs nach Ablauf des Drei-Tages-Zeitraums könnten die Betroffenen über die Ausnahmeregelung des § 41 II 3 VwVfG

479 OVG Lüneburg, Beschl. v. 26.10.2006, Az.: 7 PA 184/06 = NVwZ-RR 2077, 78; vgl. auch VGH München, Beschl. v. 23.7.1990, Az.: 19 B 88185 = NJW 1991, 1250 (1251).

$480 \mathrm{Zu}$ dieser Differenzierung VGH München, Beschl.v. 23.7.1990, Az.: Gr. S 1/90 - 19 B $88.185=$ NJW 1991, 1250 (1251).

481 Vgl. entsprechend BSG, Urt. v. 6.5.2010, Az.: B 14 AS 12/09 R = NJW 2011, 1099 (1100, Rn. 13); OVG Lüneburg, Beschl.v. 28.2.2011, Az.: 4 LA 44/10 = NJW 2011, 1529 (1530).

482 Vgl. entsprechend VGH München, Beschl. v. 23.7.1990, Az.: Gr. S 1/90 - 19 B $88.185=$ NJW 1991, 1250 (1251).

483 Vgl. entsprechend BSG, Urt. v. 6.5.2010, Az.: B 14 AS 12/09 R = NJW 2011, 1099 (1100, Rn. 13). 484 BSG, Urt. v. 6.5.2010, Az.: B 14 AS 12/09 R = NJW 2011, 1099 (1100, Rn. 13), und OVG Lüneburg, Beschl. v. 28.2.2011, Az.: 4 LA 44/10 = NJW 2011, 1529 (1530), verneinen im sozialverwaltungsverfahrensrechtlichen Kontext bereits das Vorliegen einer planwidrigen Regelungslücke.

485 BSG, Urt. v. 6.5.2010, Az.: B 14 AS 12/09 R = NJW 2011, 1099 (1100, Rn. 14).

Tobias Brings-Wiesen 
(s. dazu Rn. 139) begegnen. ${ }^{486}$ Im Ergebnis akzeptiert diese Ansicht mithin den Eintritt der Vermutung der Bekanntgabe auch an einem Sonntag, einem gesetzlichen Feiertag oder einem Sonnabend.

Die Gegenansicht plädiert hingegen für eine (analoge) Anwendung von 142 $\S 31$ III VwVfG und eine entsprechende Verschiebung des Eintritts der Bekanntgabefiktion auf den nächsten Werktag. ${ }^{487}$ Der Drei-Tages-Zeitraum gemäß § 41 II 1 VwVfG sei als „Frist“ i.S.v. § 31 VwVfG anzusehen. ${ }^{488}$ Der Begriff der „Frist“i.S.d. des BGB, dessen Sprachverständnis auch §31 VwVfG zugrunde liege, bedeute nur einen abgegrenzten Zeitraum. Es handele sich um einen weiten Fristbegriff, für den allein der Ablauf einer bestimmten Zeitspanne entscheidend sei. ${ }^{489}$ Auch regele § 41 II 1 VwVfG nicht allein den fiktiven Zeitpunkt der Bekanntgabe, sondern begründe darüber hinaus die Verpflichtung, bei verspätetem Zugang die Bekanntgabefiktion für den Drei-Tages-Zeitraums zu erschüttern. ${ }^{490}$ Auch die Zwecke der §§ 31 III und 41 II 1 VwVfG sprächen für eine Anwendbarkeit: Die mit der Verschiebung auf den nächsten Werktag erfolgende Berücksichtigung der in Wirtschaft und öffentlicher Verwaltung üblichen Fünf-Tage-Arbeitswoche ermögliche allen Verfahrensbeteiligten eine einfache, leicht nachprüfbare und rechtssichere Weise den vermuteten Bekanntgabetag zu errechnen und vermeide im Interesse des effektiven Rechtsschutzes (Art. 19 IV GG) und der Verwaltungsvereinfachung Schwierigkeiten hinsichtlich der Erschütterung der Bekanntgabevermutung. ${ }^{491}$

486 OVG Lüneburg, Beschl.v. 26.10.2006, Az.: 7 PA 184/06 = NVwZ-RR 2077, 78; vgl. entsprechend BSG, Urt. v. 6.5.2010, Az.: B 14 AS 12/09 R = NJW 2011, 1099 (1100, Rn. 14).

487 Stelkens, in: Stelkens/Bonk/Sachs, VwVfG, 9. Aufl. 2018, § 41 Rn. 133; Ruffert, in: Knack/ Henneke, VwVfG, 10. Aufl. 2014, § 41 Rn. 41. So mittlerweile auch für die abgabenverwaltungsverfahrensrechtliche Parallelvorschriften der $\S \S 108,122$ AO der BFH in st. Rspr. seit Urt. v. 14.10. 2003, Az.: IX R 68/98 = NJW 2004, 94.

488 Vgl. entsprechend BFH, Urt.v. 14.10.2003, Az.: IX R 68/98 = NJW 2004, 94. A.A. aber Stelkens, in: Stelkens/Bonk/Sachs, VwVfG, 9. Aufl. 2018, § 41 Rn. 133, der die Ablehnung einer „Frist“ für „formal korrekt" hält.

489 Vgl. entsprechend BFH, Urt. v. 14.10.2003, Az.: IX R 68/98 = NJW 2004, 94. In Abgrenzug zu dem von der Gegenmeinung zugrundegelegten engen Fristbegriff, gemäß dem innerhalb eines Zeitraums Leistungen erbracht oder Handlungen vorgenommen werden sollen oder können.

490 Vgl. entsprechend BFH, Urt. v. 14.10.2003, Az.: IX R 68/98 = NJW 2004, 94 (94f.).

491 Vgl. in diesem Sinne BFH, Urt. v. 14.10. 2003, Az.: IX R 68/98 = NJW 2004, 94 (95); Stelkens, in: Stelkens/Bonk/Sachs, VwVfG, 9. Aufl. 2018, § 41 Rn. 133. Beachte aber auch das BSG, Urt. v. 6.5. 2010, Az.: B 14 AS 12/09 R = NJW 2011, 1099 (1100f., Rn. 15), das diese Argumentation des BFH, a.a.O., für den abgabenverwaltungsverfahrensrechtlichen Besonderheiten geschuldet hält. 
Für die Fristberechnung ist trotz allem gemäß $\S 31$ I VwVfG - mindestens in analoger Anwendung - auf die $\S \S 187 \mathrm{ff}$. BGB zurückzugreifen, sodass $\S 187$ I und $\S 188$ I BGB heranzuziehen sind.

\section{bb) Elektronische Bekanntgabe}

144 Besonderer Betrachtung bedarf die elektronische Bekanntgabe von Verwaltungsakten, die im Zuge einer sowohl praktischen als auch rechtlichen Hinwendung in Richtung einer Intensivierung des E-Governments ${ }^{492}$ in jüngerer Zeit zunehmend an Bedeutung gewonnen hat. Das allgemeine Verwaltungsrecht regelt heute zwei Arten elektronischer Bekanntgabe ausdrücklich: die elektronische Übermittlung und den Abruf über ein öffentlich zugängliches Netz.

145 Die Bekanntgabevermutung in § 41 II 2 VwVfG setzt die Möglichkeit einer elektronischen Übermittlung voraus, schweigt indes zu deren Zulässigkeit. Diese richtet sich nach $\S 3 \mathrm{a} \mathrm{VwVfG}$, der allgemeine Vorgaben für die elektronische Kommunilkation zwischen Behörde und Bürger trifft. Gemäß § 3a I VwVfG ist die Übermittlung von elektronischen Dokumenten - wie Verwaltungsakten zulässig, soweit der Empfänger hierfür einen Zugang eröffnet. Fehlt eine solche Zugangseröffnung, bleibt eine gleichwohl erfolgte elektronische Bekanntgabe unwirksam. ${ }^{493}$ Welche Anforderungen an eine Zugangseröffnung $\mathrm{zu}$ stellen sind, ist im Einzelnen umstritten. ${ }^{494} \mathrm{Zu}$ Recht wird jedoch angenommen, dass nicht schon dann von einer Zugangseröffnung auszugehen ist, wenn ein privater Empfänger über einen E-Mail-Account verfügt und die E-Mail-Adresse der Behörde bekannt ist. ${ }^{495}$ Die Verkehrsanschauung hinsichtlich der Kommunikation zwischen Bürger und Verwaltung hat sich noch nicht derart gewandelt, dass entsprechend dem Postweg jederzeit mit einer Kontaktaufnahme via E-Mail zu rechnen ist. ${ }^{496} \mathrm{Zu}$ fordern ist daher die ausdrückliche oder zumindest konkludente - beispielsweise durch vorangegangene Korrespondenz - Eröffnung dieses Kommunikationsweges. ${ }^{497}$ Im Falle der Kommunikation mit Geschäftspersonen

492 S. dazu im Überblick Prell, NVwZ 2018, 1255; zu weiteren jüngeren Änderungen des VwVfG Schmitz/Prell, NVwZ 2016, 1273.

493 Stelkens, in: Stelkens/Bonk/Sachs, VwVfG, 9. Aufl. 2018, § 41 Rn. 87; so auch Couzinet/ Fröhlich, in: Mann/Sennekamp/Uechtritz, VwVfG, 2. Aufl. 2019, § 41 Rn. 49, die in diesem Fall eine Heilung für unmöglich erachten.

494 Ausführlich dazu m.w. N. Stelkens, in: Stelkens/Bonk/Sachs, VwVfG, 9. Aufl. 2018, § 41 Rn. $88 \mathrm{ff}$.

495 OVG Münster, Beschl. v. 13.11.2014, Az.: 2 B 1111/14 = NVwZ-RR 2015, 172.

496 Stelkens, in: Stelkens/Bonk/Sachs, VwVfG, 9. Aufl. 2018, § 41 Rn. 88.

497 BVerwG, Urteile v. 7.12.2016, Az.: 6 C 12.15; 6 C 13.15 und 6 C 14.15 = juris, jeweils Rn. 19.

Tobias Brings-Wiesen 
oder Rechtsanwälten ist es grundsätzlich vertretbar, einen reduzierten Maßstab anzulegen. ${ }^{498}$ Hinsichtlich der Regelung in § 41 II 2 und 3 VwVfG gilt das zur Übermittlung des schriftlichen Verwaltungsakts per Post im Inland Gesagte (s. dazu Rn. 136ff.) entsprechend. ${ }^{499}$

Seit Kurzem ${ }^{500}$ kann ein elektronischer Verwaltungsakt $t^{501}$ darüber hinaus 146 auch gemäß § 41 IIa 1 VwVfG dadurch bekannt gegeben werden, dass er vom Beteiligten oder von seinem Bevollmächtigten über ein öffentlich zugängliches Netz abgerufen wird. ${ }^{502}$ Die Besonderheit bei dieser Art der elektronischen Bekanntgabe besteht in der Rolle des Empfängers: Es wird erwartet, dass dieser sich (im Regelfall) den Verwaltungsakt in einem finalen Schritt selber bei der Verwaltung abholt. ${ }^{503} \mathrm{Da}$ also eine finale Verbringung des Verwaltungsakts in den Machtbereich des Empfängers fehlt, handelt es sich nicht um eine elektronische „Übermittlung“ i.S.v. §§ 3a I, 41 II 2 VwVfG. ${ }^{504}$ Die Wirksamkeit der Bekanntgabe gemäß § 41 IIa VwVfG wird an einige besondere Voraussetzungen geknüpft:

Wegen der Verschiebung der Verantwortlichkeit für den Zugang eines Verwaltungsakts zulasten der Empfänger setzt diese Art der Bekanntgabe tatbestandlich die Einwilligung des jeweiligen Beteiligten voraus, die jederzeit widerruflich ist ${ }^{505}$. Fehlt diese, kommt es nicht zu einer wirksamen Bekanntgabe des Verwaltungsakts. Teilweise werden auch an die Einwilligung erhöhte Anforderungen gestellt. ${ }^{506}$ Dem wird jedoch zu Recht das systematisch-teleologische Argument entgegengehalten, dass anders als im Rahmen der elektronischen Übermittlung gemäß § 3a I VwVfG (oder als gemäß der Parallelvorschrift im Ab-

498 Zu weitgehend aber OVG Münster, Beschl.v. 13.11.2014, Az.: 2 B 1111/14 = NVwZ-RR 2015, 172, wonach die bloße Angabe als Kontaktadresse auf der Internetseite ausreichen soll.

499 S. zu den wenigen Besonderheiten Couzinet/Fröhlich, in: Mann/Sennekamp/Uechtritz, VwVfG, 2. Aufl. 2019, § 41 Rn. $95 \mathrm{f}$.

500 Der Absatz wurde eingeführt durch Art. 20 Nr. 4 des Gesetzes zur Modernisierung des Besteuerungsverfahrens v. 18.7.2016, BGBl. I, S. 1679. Ausführlich dazu Schmitz/Prell, NVwZ 2016, 1273 (1277 ff.); Braun Binder, DÖV 2016, 891 (896ff.); Siegel, DVBl 2017, 24 (27f.).

501 Die Frage, ob der Verwaltungsakt in elektronischer Form erlassen werden darf, ist davon abzugrenzen, Stelkens, in: Stelkens/Bonk/Sachs, VwVfG, 9. Aufl. 2018, § 41 Rn. 134c. S. dazu noch Rn. $687 \mathrm{f}$.

$502 \mathrm{Zu}$ den Hintergründen der Vorschrift Stelkens, in: Stelkens/Bonk/Sachs, VwVfG, 9. Aufl. 2018, § 41 Rn. $134 \mathrm{ff}$.

503 Schmitz/Prell, NVwZ 2016, 1273 (1278).

504 In diesem Sinne auch Stelkens, in: Stelkens/Bonk/Sachs, VwVfG, 9. Aufl. 2018, § 41 Rn. 134; Schmitz/Prell, NVwZ 2016, 1273 (1278, Fn. 23).

505 Ramsauer/Tegethoff, in: Kopp/Ramsauer, VwVfG, 20. Aufl. 2019, § 41 Rn. 43c; Tiedemann, in: Bader/Ronellenfitsch, VwVfG, 44. Ed., Stand: 1.7.2019, § 41 Rn. 82b.

506 Braun Binder, DÖV 2016, 891 (896); in diese Richtung bereits Braun Binder, NVwZ 2016, 342 $(345,347)$. 
gabenrecht, §122a AO) keine Bekanntgabevermutung nach drei Tagen eintritt (§ 41 II 2, 3 VwVfG; § 122a IV AO), sondern eine Bekanntgabe schlicht scheitert (§ 41 IIa 4, 5 VwVfG; s. dazu Rn. 149), sodass den Beteiligten in Folge der Annahme einer Einwilligung keine signifikanten Nachteile drohen. ${ }^{507}$ Angesichts dessen werden die Anforderungen an die Einwilligung mehrheitlich abgesenkt: Sie bedürfe keiner besonderen Form; ${ }^{508}$ es bedürfe keiner expliziten (vorherigen) Zustimmung des Empfängers, vielmehr könne erst im Abruf eines gleichwohl bereitgestellten Verwaltungsakts die „Einwilligung“ gesehen werden; ${ }^{509}$ sollte gleichwohl eine vorherige Zustimmung eingeholt werden, könne diese - unter bestimmten Voraussetzungen - auch über die Bekanntgabe eines konkreten Verwaltungsakts als Ergebnis eines konkreten Verwaltungsverfahrens hinausgehen. ${ }^{510}$ Folgt man der letztgenannten Auffassung, hat die Einwilligung als Wirksamkeitsvoraussetzung praktisch kaum noch beschränkenden Charakter. Eine (höchst-)richterliche Klärung der Frage steht jedoch noch aus.

Wurde die Einwilligung erteilt, besteht keine Verpflichtung der Behörde, auch tatsächlich eine Bekanntgabe des Verwaltungsakts durch Abruf über ein öffentlich zugängliches Netz zu bewirken. ${ }^{511}$ Die Entscheidung für eine Bekanntgabe gemäß § 41 IIa VwVfG steht vielmehr im Ermessen der Behörde.

Die Bekanntgabe erfolgt erst mit dem tatsächlichen Abruf durch den Empfänger. ${ }^{512}$ Bis zu diesem Zeitpunkt steht es der Behörde daher auch - trotz willentlicher Einstellung und Benachrichtigung des Empfängers - uneingeschränkt frei, die Bereitstellung zu beenden und den bereitgestellten Verwaltungsakt damit

507 So - beschränkt auf § 122a AO - Stelkens, in: Stelkens/Bonk/Sachs, VwVfG, 9. Aufl. 2018, § 41 Rn. 134h; das Argument ist jedoch auf §§ 3a I, 41 II 2, 3 VwVfG ohne weiteres übertragbar.

508 Ramsauer/Tegethoff, in: Kopp/Ramsauer, VwVfG, 20. Aufl. 2019, § 41 Rn. 43c; so auch Tiedemann, in: Bader/Ronellenfitsch, VwVfG, 44. Ed., Stand:1.7.2019, § 41 Rn. 82b, der dies aus dem Grundsatz der Nichtförmlichkeit des Verwaltungsverfahrens ( $\$ 10 \mathrm{VwVfG})$ ableitet, aber aus Gründen der Rechtssicherheit einen irgendwie gearteten Nachweis empfiehlt.

509 Stelkens, in: Stelkens/Bonk/Sachs, VwVfG, 9. Aufl. 2018, § 41 Rn. 134 h; a. A. aber Ramsauer/ Tegethoff, in: Kopp/Ramsauer, VwVfG, 20. Aufl. 2019, § 41 Rn. 43c; Schmitz/Prell, NVwZ 2016, 1273 (1278); wohl auch Tiedemann, in: Bader/Ronellenfitsch, VwVfG, 44. Ed., Stand: 1.7.2019, § 41 Rn. 82b. Insofern für eine „Heilung“ Couzinet/Fröhlich, in: Mann/Sennekamp/Uechtritz, VwVfG, 2. Aufl. 2019, § 41 Rn. 113.

510 Unter Identifizierung einzelner Grenzen einer solchen generellen Einwilligung Stelkens, in: Stelkens/Bonk/Sachs, VwVfG, 9. Aufl. 2018, § 41 Rn. 134i; Schmitz/Prell, NVwZ 2016, 1273 (1278). 511 Stelkens, in: Stelkens/Bonk/Sachs, VwVfG, 9. Aufl. 2018, § 41 Rn. 134f, 134k; Tiedemann, in: Bader/Ronellenfitsch, VwVfG, 44. Ed., Stand: 1.7.2019, § 41 Rn. 82b.

512 Stelkens, in: Stelkens/Bonk/Sachs, VwVfG, 9. Aufl. 2018, § 41 Rn. 134q; Schmitz/Prell, NVwZ 2016, 1273 (1278). Demgegenüber kommt es im Abgabenrecht auf den Akt der Bereitstellung zum Abruf an, vgl. § 122 I und IV AO. Zu beachten ist, dass keine Pflicht zum Abruf besteht, sodass darin auch keine treuwidrige Vereitelung des Zugangs zu sehen ist.

Tobias Brings-Wiesen 
$\mathrm{zu}$ widerrufen. ${ }^{513}$ Darüber hinausgehend verpflichtet ${ }^{514} \S 41$ IIa 4 VwVfG die Behörde zur Beendigung der Bereitstellung, wenn der Verwaltungsakt nicht innerhalb von zehn Tagen nach Absendung einer Benachrichtigung abgerufen worden ist. Mit der Beendigung der Bereitstellung entfällt auch die Möglichkeit des Abrufs und somit der Bekanntgabe gemäß § 41 IIa 1 VwVfG.

Für Verwirrung sorgt vor diesem Hintergrund die Regelung des § 41 IIa 5 Hs. 1 VwVfG, nach der eine Bekanntgabe ,in diesem Fall [...] nicht bewirkt“ sein soll. Die Vorschrift könnte dahingehend missverstanden werden, dass eine mangels Beendigung der Bereitstellung nach Ablauf besagter zehn Tage gleichwohl durch Abruf erfolgte Bekanntgabe entgegen des Grundsatzes in § 41 IIa 1 VwVfG als rechtlich nicht erfolgt erachtet werden soll. Dem wird zu Recht bereits der Wortlaut entgegengehalten ${ }^{515}$ : „In diesem Fall“ bezieht sich auf Hs. 2 von § 41 IIa 4 VwVfG und somit auf die Beendigung der Bereitstellung, nicht auf den Hs. 1 und den Ablauf der zehn Tage - § 41 IIa 5 Hs. 1 VwVfG weist somit lediglich deklaratorisch auf die bereits mangels Abrufmöglichkeit eintretende Folge des Ausbleibens der Bekanntgabe hin. Auch Sinn und Zweck der Normen verlangen nicht danach. ${ }^{516}$ Folglich kann auch ein verspäteter Abruf noch zu einer wirksamen Bekanntgabe nach § 41 IIa 1 VwVfG führen. ${ }^{517}$ Zugleich bleibt gemäß § 41 IIa 5 Hs. 2 VwVfG die Möglichkeit einer erneuten Bereitstellung zum Abruf oder der Bekanntgabe auf andere Weise unberührt.

Damit dem Empfänger eine Weiterverwendung im Rechtsverkehr möglich ist, 150 ist über den bloßen Abruf hinaus auch die Speicherbarkeit des abgerufenen elektronischen Verwaltungsakts Wirksamkeitsvoraussetzung. ${ }^{518}$

Ohne Auswirkungen auf die Wirksamkeit der Bekanntgabe bleiben eine $\mathbf{1 5 1}$ Verletzung der Verpflichtung zur Gewährleistung des Abrufs nur nach Authenti-

513 Stelkens, in: Stelkens/Bonk/Sachs, VwVfG, 9. Aufl. 2018, § 41 Rn. 134u; Schmitz/Prell, NVwZ 2016, 1273 (1279f.).

514 So wohl auch Ramsauer/Tegethoff, in: Kopp/Ramsauer, VwVfG, 20. Aufl. 2019, § 41 Rn. 43j. A. A. Tiedemann, in: Bader/Ronellenfitsch, VwVfG, 44. Ed., Stand:1.7.2019, § 41 Rn. 82e; Couzinet/ Fröhlich, in: Mann/Sennekamp/Uechtritz, VwVfG, 2. Aufl. 2019, § 41 Rn. 122, die sich demgegenüber für eine teleologische Reduktion auf die Möglichkeit einer Beendigung aussprechen.

515 Stelkens, in: Stelkens/Bonk/Sachs, VwVfG, 9. Aufl. 2018, § 41 Rn. 134v, jedoch ohne nähere Begründung.

516 S. dazu ausführlicher Stelkens, in: Stelkens/Bonk/Sachs, VwVfG, 9. Aufl. 2018, § 41 Rn. 134u; Tiedemann, in: Bader/Ronellenfitsch, VwVfG, 44. Ed., Stand: 1.7.2019, § 41 Rn. 82e.

517 Stelkens, in: Stelkens/Bonk/Sachs, VwVfG, 9. Aufl. 2018, § 41 Rn. 134u; Tiedemann, in: Bader/Ronellenfitsch, VwVfG, 44. Ed., Stand: 1.7.2019, § 41 Rn. 82e.

518 Ramsauer/Tegethoff, in: Kopp/Ramsauer, VwVfG, 20. Aufl. 2019, § 41 Rn. 43h; Couzinet/ Fröhlich, in: Mann/Sennekamp/Uechtritz, VwVfG, 2. Aufl. 2019, § 41 Rn. 115; Schmitz/Prell, NVwZ 2016, 1273 (1278). 
fizierung der berechtigten Person gemäß § 41 IIa 2 Hs. 2 VwVfG sowie das Ausbleiben bzw. die Fehlerhaftigkeit der in § 41 IIa 4 VwVfG vorausgesetzten Benachrichtigung über die Bereitstellung. ${ }^{519}$

Der Zeitpunkt der Bekanntgabe richtet sich nach § 41 IIa 3 VwVfG: Der Verwaltungsakt gilt am Tag nach dem (erstmaligen) Abruf als bekannt gegeben. Die bereits dargestellte Problematik des Fristendes an einem Sonntag, einem gesetzlichen Feiertag oder einem Sonnabend wird bezüglich dieser Norm genauso diskutiert. ${ }^{520}$

153 Tatsächlich beschränkt sich die Möglichkeit der Bereitstellung von Verwaltungsakten über Internetportale jedoch nicht auf die in § 41 IIa VwVfG statuierte Art. Da im Falle des Fehlens von Bestimmungen darüber, auf welche Art und Weise ein Verwaltungsakt bekanntzugeben ist, die Entscheidung darüber grundsätzlich im Ermessen der Behörde steht (s. dazu Rn. 134), hat das Bundesverwaltungsgericht jüngst auch die Bereitstellung einer Klausurbenotung im Internetportal einer Hochschule als wirksame individuelle Bekanntgabe gewertet, da die Note über ein persönliches Konto ähnlich einem Briefkasten in den Machtbereich des Betroffenen gelange und aufgrund der dem Mitgliedschaftsverhältnis zugrundeliegenden Studienordnung, die eine Kommunikation über automatisierte Geschäftsprozesse und Verfahren vorsehe, mit einem regelmäßigen Besuch des Internetportals zu rechnen sei. ${ }^{521}$

\section{cc) Öffentliche Bekanntgabe}

154 „Öffentliche“ Bekanntgabe meint grundsätzlich die Bekanntgabe eines Verwaltungsakts ohne individuell identifizierten oder identifizierbaren Empfänger(-kreis). ${ }^{522}$ Sie ist mithin eine Ergänzung $\mathrm{zu}$ den bisher dargestellten verschiedenen Arten individueller Bekanntgabe. Sie verlangt keinen Zugang, dafür aber eine allgemeine Zugänglichkeit ${ }^{523}$ und insofern eine einhergehende Möglichkeit der Kenntnisnahme. Damit geht sie im Interesse der Funktionsfähigkeit

519 Ramsauer/Tegethoff, in: Kopp/Ramsauer, VwVfG, 20. Aufl. 2019, § 41 Rn. 43h.

520 Stelkens, in: Stelkens/Bonk/Sachs, VwVfG, 9. Aufl. 2018, § 41 Rn. 134s. S. auch Couzinet/ Fröhlich, in: Mann/Sennekamp/Uechtritz, VwVfG, 2. Aufl. 2019, § 41 Rn. $124 \mathrm{ff}$.

521 BVerwG, Beschl. v. 21.12.2017, Az.: 6 B 43.17 = NVwZ 2018, 496 (498, Rn. 12); so bereits in der Vorinstanz OVG Münster, Urt. v. 21.3.2017, Az.: 14 A 1689/16 = BeckRS 2017, 108275 (Rn. 37 ff.); zweifelnd noch VGH München, Beschl. v. 7.11.2012, Az.: 7 C 12.2143 = juris, Rn. 14.

522 Hierin liegt auch der zentrale Unterschied zur öffentlichen Zustellung gemäß § 10 VwZG: In ihrem Falle ist sehr wohl ein individuell identifizierter oder identifizierbarer Empfänger(-kreis) bekannt, eine individuelle Bekanntgabe jedoch aus anderen Gründen nicht möglich, s. dazu noch Rn. 173.

523 Detterbeck, Allgemeines Verwaltungsrecht, 17. Aufl. 2019, Rn. 555.

Tobias Brings-Wiesen 
der Verwaltung ${ }^{524}$ zulasten der mit der Bekanntgabe $\mathrm{zu}$ realisierenden verfassungsrechtlich geschützten Interessen der Betroffenen (s. dazu Rn. 117). Weil sie somit die Wahrscheinlichkeit der tatsächlichen Kenntnisnahme der durch einen Verwaltungsakt Betroffenen reduziert, bildet sie eine praktisch eng begrenzte Ausnahmeerscheinung. Sie ist nur in zwei Konstellationen zulässig: (1) wenn sie durch Rechtsvorschrift zugelassen wird (§ 41 III 1 VwVfG) oder (2) wenn es sich bei dem Verwaltungsakt um eine Allgemeinverfügung gemäß § 35 S. 2 VwVfG (s. dazu Rn. 77 ff.) handelt, deren Bekanntgabe an die Beteiligten untunlich ist (§ 41 III 2 VwVfG).

(1) § 41 III 1 VwVfG enthält selbst keine Ermächtigung der Behörden zur öffentlichen Bekanntgabe, sondern verweist insofern (deklaratorisch) auf andere Rechtsvorschriften. Im Umkehrschluss folgt damit aus der Norm jedoch der Grundsatz der Unzulässigkeit einer öffentlichen Bekanntgabe von Verwaltungsakten. ${ }^{525}$ Darin erschöpft sich indes auch ihr Regelungsgehalt; konkrete Vorgaben zur Zulässigkeit der öffentlichen Bekanntgabe sind den jeweiligen Spezialvorschriften zu entnehmen. Die zu einer öffentlichen Bekanntgabe ermächtigenden Vorschriften, die bereits im Studium bekannt sein sollten, sind insbesondere die $\S \S 36,37$ StVO betreffend die Verkehrszeichen (s. dazu Rn. 165) und Weisungen durch Polizeibeamte und Ampeln, die verschiedenen Vorschriften betreffend die Regelung von Eigenschaften und Nutzung von Straßen (vgl. beispielsweise § 2 VI 4, 5 FStrG; §§ 5 II 2, III 3, 6 I 2, VIII 2, 7 I 3, VI 2, 8 I 2 StrWG NRW) sowie der § 41 III 2 VwVfG. Wird ein Verwaltungsakt öffentlich bekanntgegeben, obwohl eine entsprechende Ermächtigungsgrundlage fehlt, ist dieser unwirksam. $^{526}$

(2) § 41 III 2 VwVfG ist selbst Ermächtigungsgrundlage. ${ }^{527}$ Die Vorschrift 156 ermöglicht es den Behörden, Allgemeinverfügungen i.S.v. § 35 S. 2 VwVfG öffentlich bekanntzugeben, wenn eine individuelle Bekanntgabe an die Beteiligten untunlich ist. Dies verdeutlicht, dass auch für Allgemeinverfügungen eigentlich

524 Diesem Zweck dienen die § 41 III, IV VwVfG, Stelkens, in: Stelkens/Bonk/Sachs, VwVfG, 9. Aufl. 2018, § 41 Rn. 6. Zum verfassungsrechtlich anerkannten Prinzip der Verwaltungseffizienz m.w. N. BVerwG, Urt. v. 27.5.1983, Az.: 4 C 40, 44, 45.81 = BVerwGE 67, 206 (209f.), wo das Gericht überdies auch auf das damit zusammenhängende Interesse der Rechtssicherheit abstellt.

525 Stelkens, in: Stelkens/Bonk/Sachs, VwVfG, 9. Aufl. 2018, § 41 Rn. 148; Tiedemann, in: Bader/ Ronellenfitsch, VwVfG, 44. Ed., Stand: 1.7.2019, § 41 Rn. 100; ähnlich auch Couzinet/Fröhlich, in: Mann/Sennekamp/Uechtritz, VwVfG, 2. Aufl. 2019, § 41 Rn. 129.

526 Stelkens, in: Stelkens/Bonk/Sachs, VwVfG, 9. Aufl. 2018, § 41 Rn. 148; Couzinet/Fröhlich, in: Mann/Sennekamp/Uechtritz, VwVfG, 2. Aufl. 2019, § 41 Rn. 127. A. A. aber Detterbeck, Allgemeines Verwaltungsrecht, 17. Aufl. 2019, Rn. 557.

527 Stelkens, in: Stelkens/Bonk/Sachs, VwVfG, 9. Aufl. 2018, § 41 Rn. 152; Couzinet/Fröhlich, in: Mann/Sennekamp/Uechtritz, VwVfG, 2. Aufl. 2019, § 41 Rn. 128. 
der Grundsatz der individuellen Bekanntgabe gelten soll. Ihre besonderen Charakteristika (s. dazu Rn. 77 ff.) machen es indes unvermeidbar, weitreichendere Ausnahmekonstellationen zuzulassen. Zentrale Voraussetzung ist dabei die „Untunlichkeit“ der individuellen Bekanntgabe. Deren Vorliegen ist unter Berücksichtigung aller Umstände des Einzelfalls mit einer gebotenen Zurückhaltung $\mathrm{zu}$ bewerten. Dabei können verschiedene Faktoren einzeln oder kumulativ für eine Untunlichkeit sprechen. So kann die individuelle Bekanntgabe bereits wegen der Natur der Allgemeinverfügung unmöglich oder mit erheblichen Schwierigkeiten verbunden sein, ${ }^{528}$ beispielsweise weil der Kreis der betroffenen Personen überhaupt nicht abschließend bestimmbar oder zumindest nicht mit letzter Sicherheit ermittelbar ist ${ }^{529}$ - wie regelmäßig im Falle von sachbezogenen und benutzungsregelnden Allgemeinverfügungen gemäß $\S 35$ S. 2 Var. 2 und 3 $\mathrm{VwVfG}^{530}$ oder wie im Falle von personenbezogenen Allgemeinverfügungen gemäß § 35 S. 2 Var. 1 VwVfG, in deren Falle sich anhand allgemeiner Merkmale zwar ein Personenkreis, keineswegs aber jede individuelle Person identifizieren lassen mag, wie bei einem präventiven Versammlungsverbot, ${ }^{531}$ einem Aufenthaltsverbot für bestimmte Gemeindebereiche ${ }^{532}$ oder einem Verbot von Werbung für Sportwetten im Internet ${ }^{533}$. Eine große Anzahl Betroffener kann für die Beurteilung der Erheblichkeit des Verwaltungsaufwands entsprechend indizielle Bedeutung haben, sie wird jedoch mehrheitlich als allein nicht ausreichend erachtet. ${ }^{534}$ Auch personenunabhängige Erwägungen, wie eine besondere Eilbedürftigkeit der

528 S. dazu Ramsauer/Tegethoff, in: Kopp/Ramsauer, VwVfG, 20. Aufl. 2019, § 41 Rn. 46.

529 Vgl. bereits die Begründung zum Entwurf eines VwVfGes, BT-Drucks. 7/910, S. 62; Stelkens, in: Stelkens/Bonk/Sachs, VwVfG, 9. Aufl. 2018, § 41 Rn. 153; zu dinglichen Verwaltungsakten Niehues, DVBl 1982, 317 (317 ff.).

530 Ramsauer/Tegethoff, in: Kopp/Ramsauer, VwVfG, 20. Aufl. 2019, § 41 Rn. 46; Stelkens, in: Stelkens/Bonk/Sachs, VwVfG, 9. Aufl. 2018, § 41 Rn. 153. Nicht aber im Falle einer sog. Schutzbereichsanordnung gemäß § 2 I 1 SchBerG, VGH Mannheim, Urt. v. 15.11.1988, Az.: 10 S 751/88 = NVwZ 1989, 978 (980), oder im Falle von (Ent-)Widmungen, die nur einzelne Personen betreffen, OVG Münster, Urt. v. 27.4.1998, Az.: 7 A 3814/96 = BeckRS 1999, 20219, Rn. 20 ff.

531 VGH Mannheim, Urt. v. 6.11.2013, Az.: 1 S 1640/12 = BeckRS 2013, 58560.

532 VG Darmstadt, Beschl. v. 28.4.2016, Az.: 3 L 642/16.DA = NVwZ 2016, 1344; vgl. auch VGH Mannheim, Beschl. v. 30.9.1996, Az.: 1 S 2531/96 = NVwZ-RR 1997, 225.

533 OVG Münster, Beschl. v. 19.1.2010, Az.: 13 A 841/09 = BeckRS 2010, 46385.

534 Ramsauer/Tegethoff, in: Kopp/Ramsauer, VwVfG, 20. Aufl. 2019, § 41 Rn. 46; so auch Stelkens, in: Stelkens/Bonk/Sachs, VwVfG, 9. Aufl. 2018, § 41 Rn. 154f., der für die Bestimmung der Erheblichkeit des Aufwands Orientierung in den (verworfenen) Vorschriften des VwVfG zu Sammelverfahren sucht; jedenfalls gegen eine schematische Übertragung Couzinet/Fröhlich, in: Mann/Sennekamp/Uechtritz, VwVfG, 2. Aufl. 2019, § 41 Rn. 133.

Tobias Brings-Wiesen 
Bekanntgabe, können - für sich ${ }^{535}$ oder in Kombination mit weiteren Erwägungen $^{536}$ - für eine Untunlichkeit sprechen.

Liegt eine dieser Konstellationen vor, steht es grundsätzlich im Ermessen 157 der zuständigen Behörde, den Verwaltungsakt öffentlichen bekanntzugeben. ${ }^{537}$ Insbesondere kann sie sich auch für eine „kombinierte Bekanntgabe“, sprich eine neben die öffentliche Bekanntgabe tretende individuelle Bekanntgabe an besonders Betroffene, entscheiden. ${ }^{538}$ Dies kann dazu führen, dass sich die Wirkungen eines Verwaltungsakts je nach Art der Bekanntgabe wieder (s. dazu Rn. 164) relativ entfalten.

Ist die öffentliche Bekanntgabe gemäß § 41 III VwVfG zulässig, bedarf es weiterhin der Beachtung ihrer Modalitäten. Für schriftliche und elektronische Verwaltungsakte $^{539}$ wurden in $\S 41$ IV VwVfG allgemeine Vorgaben normiert, die wie gewohnt durch spezialgesetzliche Vorschriften verdrängt oder ergänzt werden können. ${ }^{540}$

Zentral verlangt $\S 41 \mathrm{IV} 1 \mathrm{VwVfG}$ die ortsübliche Bekanntmachung des verfügenden Teils des Verwaltungsakts. Terminologisch wie systematisch zeigt sich, dass § 41 IV VwVfG zwischen öffentlicher Bekanntgabe und ortsüblicher Bekanntmachung unterscheidet: Die Bekanntmachung ist der formalisierte Hinweis auf einen andernorts zur Einsichtnahme bereitgehaltenen Verwaltungsakt (§ 41 IV 2 VwVfG). ${ }^{541}$ Dieser Hinweis muss vorab nur ${ }^{542}$ den verfügenden Teil ${ }^{543}$ des bekanntzugebenden Verwaltungsakts im Wortlaut ${ }^{544}$ sowie die

535 Stelkens, in: Stelkens/Bonk/Sachs, VwVfG, 9. Aufl. 2018, § 41 Rn. 153.

536 Couzinet/Fröhlich, in: Mann/Sennekamp/Uechtritz, VwVfG, 2. Aufl. 2019, § 41 Rn. 133.

537 Stelkens, in: Stelkens/Bonk/Sachs, VwVfG, 9. Aufl. 2018, § 41 Rn. 146; Tiedemann, in: Bader/ Ronellenfitsch, VwVfG, 44. Ed., Stand: 1.7.2019, § 41 Rn. 86.

538 Stelkens, in: Stelkens/Bonk/Sachs, VwVfG, 9. Aufl. 2018, § 41 Rn. 147 m.w. N.

539 S. zur öffentlichen Bekanntgabe mündlicher und in anderer Weise erlassener Verwaltungsakte Stelkens, in: Stelkens/Bonk/Sachs, VwVfG, 9. Aufl. 2018, § 41 Rn. 197 f.

540 Stelkens, in: Stelkens/Bonk/Sachs, VwVfG, 9. Aufl. 2018, § 41 Rn. 150.

541 Stelkens, in: Stelkens/Bonk/Sachs, VwVfG, 9. Aufl. 2018, § 41 Rn. 156.

542 Weitere Informationen, wie sie im Hinblick auf Bekanntmachungen von Verwaltungsentscheidungen im förmlichen oder im Planfeststellungsverfahren verlangt sind (§§ 69 II 4 bis 6, 74 IV 2 und 3,V 2 bis $4 \mathrm{VwVfG}$ ), wie beispielsweise der Zeitraum der Einsichtnahmemöglichkeit, sind bei der „verkürzten Bekanntgabe“ nicht erforderlich, Stelkens, in: Stelkens/Bonk/Sachs, VwVfG, 9. Aufl. 2018, § 41 Rn. 180f.; a.A. aber zu den Geschäftszeiten Tiedemann, in: Bader/Ronellenfitsch, VwVfG, 44. Ed., Stand: 1.7.2019, § 41 Rn. 117.

$543 \mathrm{Zu}$ den verschiedenen denkbaren Bestandteilen dieses „verfügenden Teils“ vgl. nur Stelkens, in: Stelkens/Bonk/Sachs, VwVfG, 9. Aufl. 2018, § 41 Rn. 167 ff. S. dazu bereits Rn. 121.

544 Stelkens, in: Stelkens/Bonk/Sachs, VwVfG, 9. Aufl. 2018, § 41 Rn. 167; Tiedemann, in: Bader/ Ronellenfitsch, VwVfG, 44. Ed., Stand: 1.7.2019, § 41 Rn. 111. Zur Frage einer möglichen Lockerung dieser Anforderung ausführlich m. zahlr. N. Stelkens, a.a.O., Rn. $168 \mathrm{ff}$.

Tobias Brings-Wiesen 
Angabe des Ortes ${ }^{545}$, wo der Verwaltungsakt und seine - gegebenenfalls erforderliche (s. dazu Rn. 690 ff.) - Begründung eingesehen werden können, beinhalten. Fehlt eine dieser Angaben, ist der Verwaltungsakt unwirksam. ${ }^{546}$

159 Examenswissen: Genauerer Betrachtung bedarf im Falle der öffentlichen Bekanntgabe der Umgang mit der Rechtsbehelfsbelehrung gemäß § 37 VI VwVfG, § 58 VwGO. Weitgehende Einigkeit besteht jedenfalls darüber, dass sie dem bekanntzugebenden Verwaltungsakt selbst beizufügen ist - entweder im Rahmen der Einsichtnahme gemäß § 41 IV 2 VwVfG ${ }^{547}$ oder bereits im Rahmen einer vollständigen öffentlichen Bekanntgabe ${ }^{548}$. Umstritten ist hingegen, ob sie im Falle einer „verkürzten“ öffentlichen Bekanntgabe (zusätzlich) bereits der ortsüblichen Bekanntmachung gemäß § 41 IV 1 VwVfG beizufügen ist. ${ }^{549}$ Dagegen sprächen der Wortlaut der Norm und der systematische Vergleich mit anderen Vorschriften zu Bekanntmachungen von Verwaltungsentscheidungen, die eine Bekanntmachung auch der Rechtsbehelfsbelehrung ausdrücklich verlangen (§§ 69 II 4, 74 V 2 VwVfG). ${ }^{550}$ Dafür werden Sinn und Zweck der Rechtsbehelfsbelehrung angeführt: Deren Signalwirkung bleibe aus, wenn sie nicht mit dem ersten öffentlich wahrnehmbaren Mitteilungsakt der Behörde, sondern erst bei einer späteren Einsichtnahme erfolgt. ${ }^{551}$ Verlangt man eine ortsübliche Bekanntmachung auch der Rechtsbehelfsbelehrung, führt deren Ausbleiben zur Modifikation des Laufs der Rechtsbehelfsfristen gemäß $§ 58$ VwGO (s. dazu Rn. 368f.).

160 Die „Ortsüblichkeit“ der Bekanntmachung ist abgestuft zu bestimmen: Fehlen vorrangige spezialgesetzliche Vorgaben ${ }^{552}$, verweist § $41 \mathrm{IV} 1 \mathrm{VwVfG}$ über den Terminus der Ortsüblichkeit auf das für den zuständigen Verwaltungsträger

545 Ein Ort wird regelmäßig ausreichend sein, Stelkens, in: Stelkens/Bonk/Sachs, VwVfG, 9. Aufl. 2018, § 41 Rn. 179.

546 Zu § 41 IV 2 VwVfG VGH München, Beschl.v. 9.7.2001, Az.: 6 B 98.2891 = BeckRS 2001, 25898, Rn. 5; Couzinet/Fröhlich, in: Mann/Sennekamp/Uechtritz, VwVfG, 2. Aufl. 2019, § 41 Rn. 136 m.w. N. Vgl. auch BVerwG, Urt. v. 21.11.1986, Az.: 8 C 127.84 = NVwZ 1987, 230.

547 Stelkens, in: Stelkens/Bonk/Sachs, VwVfG, 9. Aufl. 2018, § 41 Rn. 192; Couzinet/Fröhlich, in: Mann/Sennekamp/Uechtritz, VwVfG, 2. Aufl. 2019, § 41 Rn. 136, jeweils m.w. N.

548 Dafür ausdrücklich Tiedemann, in: Bader/Ronellenfitsch, VwVfG, 44. Ed., Stand: 1.7.2019, $\S 41 \mathrm{Rn} .116$.

549 Dafür Stelkens, in: Stelkens/Bonk/Sachs, VwVfG, 9. Aufl. 2018, § 41 Rn. 193 m.w. N. Dagegen Stuhlfauth, in: Obermayer/Funke-Kaiser, VwVfG, 5. Aufl. 2018, § 41 Rn. 56 m.w. N. Mit Vorsicht zu genießen ist der vielerorts erfolgende Verweis auf BVerwG, Beschl. v. 24.9.1987, Az.: 4 B $93.87=$ NVwZ 1988, 364, dessen Wertungen in einem völlig anderen gesetzessystematischen Zusammenhang erfolgten und nicht ohne weiteres auf § $41 \mathrm{IV}$ VwVfG übertragbar sind, so auch Stelkens, a.a. O., Fn. 462.

550 Tiedemann, in: Bader/Ronellenfitsch, VwVfG, 44. Ed., Stand:1.7.2019, § 41 Rn. 116; Couzinet/ Fröhlich, in: Mann/Sennekamp/Uechtritz, VwVfG, 2. Aufl. 2019, § 41 Rn. 136.

551 In diesem Sinne Stelkens, in: Stelkens/Bonk/Sachs, VwVfG, 9. Aufl. 2018, § 41 Rn. 193; Schwarz, in: Fehling/Kastner/Störmer, Verwaltungsrecht, 4. Aufl. 2016, § 41 VwVfG Rn. 39.

552 Vgl. bspw. die §§ 69 II 4, 74 V 2 VwVfG: „amtliche[s] Veröffentlichungsblatt“, „örtliche[n] Tageszeitungen“.

Tobias Brings-Wiesen 
geltende $\mathrm{e}^{553}$ Organisationsrecht. Dabei ist zu berücksichtigen, dass die Länder vereinzelt - insbesondere für die Gemeindebehörden - allgemeine gesetzliche Vorgaben für die öffentliche Bekanntmachung normiert haben. ${ }^{554}$ So gibt in Nordrhein-Westfalen §4 I 1 BekanntmVO ${ }^{555}$ für gesetzlich vorgeschriebene öffentliche Bekanntmachungen der Gemeinden vier Formen - via Amtsblatt, Zeitung, Aushang oder Internet - vor, aus denen die Gemeinden gemäß § 4 II 1 BekanntmVO die für sie geltende(n) Form(en) ${ }^{556}$ durch Festlegung in ihrer Hauptsatzung zu wählen haben. Fehlen demgegenüber jegliche gesetzliche Vorgaben, ist auf die ortsübliche Behördenpraxis ${ }^{557}$ abzustellen. ${ }^{558}$ Werden die einschlägigen Anforderungen verfehlt, erlangt der Verwaltungsakt keine Wirksamkeit. ${ }^{559}$

Darüber hinaus verlangt § 27a I 1 und 2 VwVfG seit Kurzem, dass die Behörde den Inhalt einer gesetzlich angeordneten öffentlichen oder ortsüblichen Bekanntmachung zusätzlich ${ }^{560}$ im Internet veröffentlichen, sprich auf einer eigenen oder ihrem Verwaltungsträger zugeordneten Internetseite zugänglich machen soll. Entsprechend ist gemäß § 27a II VwVfG in der öffentlichen oder ortsüblichen Bekanntmachung auf die jeweilige Internetseite hinzuweisen. An-

553 OVG Münster, Beschl. v. 19.1.2010, Az.: 13 A 841/09 = BeckRS 2010, 46385; Stelkens, in: Stelkens/Bonk/Sachs, VwVfG, 9. Aufl. 2018, § 41 Rn. 161; Niesler, in: Brandt/Domgörgen, Handbuch Verwaltungsverfahren und Verwaltungsprozess, 4. Aufl. 2018, Rn. 246f. Allgemein ist es hilfreicher, den Terminus „ortsüblich“ i.S.v. „für Veröffentlichungen dieser Behörde üblich“ zu verstehen, so ausdrücklich wie treffend Tiedemann, in: Bader/Ronellenfitsch, VwVfG, 44. Ed., Stand: 1.7.2019, § 41 Rn. 109.

554 S. für einen Überblick die Homepage des öffentlich-rechtlichen Online-Lernprojekts „Saarheim“ von Grupp und Stelkens, abrufbar unter: http://www.saarheim.de/Gesetze_Laender/be kanntmachg-laender.htm.

555 Verordnung über die öffentliche Bekanntmachung von kommunalem Ortsrecht (Bekanntmachungsverordnung - BekanntmVO) v. 26.8.1999 (GV. NRW. S. 516), zuletzt geändert durch Verordnung vom 5. November 2015 (GV. NRW. S. 741).

556 S. zu den Möglichkeiten der Selektion, Kumulation und Hierarchisierung der Formen Tiedemann, in: Bader/Ronellenfitsch, VwVfG, 44. Ed., Stand: 1.7.2019, § 41 Rn. 110 f.

557 OVG Münster, Beschl. v. 19.1.2010, Az.: 13 A 841/09 = BeckRS 2010, 46385; A. A. Tiedemann, in: Bader/Ronellenfitsch, VwVfG, 44. Ed., Stand: 1.7.2019, § 41 Rn. 109f., der die Festlegung der Form der öffentlichen Bekanntmachung durch Rechtssatz für zwingend hält.

558 Fehlt auch eine solche (in Verwaltungsgewohnheitsrecht mündende) Praxis, soll laut Stelkens, in: Stelkens/Bonk/Sachs, VwVfG, 9. Aufl. 2018, § 41 Rn. 160, die öffentliche Bekanntgabe ausgeschlossen sein.

559 Couzinet/Fröhlich, in: Mann/Sennekamp/Uechtritz, VwVfG, 2. Aufl. 2019, § 41 Rn. 134.

560 Damit wird eine allein im Internet erfolgende Bekanntmachung nicht ausgeschlossen, Tiedemann, in: Bader/Ronellenfitsch, VwVfG, 44. Ed., Stand: 1.7.2019, § 41 Rn. 110a; a. A. aber im Hinblick auf schriftliche Verwaltungsakte Stelkens, in: Stelkens/Bonk/Sachs, VwVfG, 9. Aufl. 2018, § 41 Rn. $164 \mathrm{ff}$. 
ders als der Hinweis auf die Einsichtnahmemöglichkeit gemäß § 41 IV 2 VwVfG handelt es sich nicht um eine Wirksamkeitsvoraussetzung. ${ }^{561}$

Dem Hinweis gemäß § 41 IV 2 VwVfG muss die reale Einsichtnahmemöglichkeit für Jedermann ${ }^{562}$ korrespondieren. ${ }^{563}$ Dem muss gerade der für die Einsichtnahme vorgesehene Zeitraum genügen: Dieser darf insgesamt nicht kürzer sein als die in § 41 IV 3 VwVfG vorgesehenen zwei Wochen; ${ }^{564}$ darüber hinaus müssen die (innerhalb der Geschäftszeiten einer Behörde) vorgesehenen einzelnen Zeitfenster für die Einsichtnahme angemessen zahlreich und lang sein ${ }^{565}$.

Werden die Wirksamkeitsvoraussetzungen eingehalten, ist eine öffentliche Bekanntgabe durch öffentliche Bekanntmachung gemäß $§ 41$ IV VwVfG erfolgreich. Daneben steht es der Behörde jedoch auch frei, sich - im Gegensatz zu dieser „verkürzten“ öffentliche Bekanntgabe - für eine vollständige öffentliche Bekanntgabe des in Rede stehenden Verwaltungsakts zu entscheiden. ${ }^{566}$ Tut sie dies, werden die Vorgaben des $§ 41$ IV VwVfG zum Teil hinfällig. ${ }^{567}$

Sind die Voraussetzungen erfüllt, ist der jeweilige Verwaltungsakt mit Wirkung für und gegen jede Person bekanntgegeben und folglich wirksam i.S.v. § 43 I VwVfG. Es wird von einer „Ringsumwirkung“ gesprochen. ${ }^{568}$ Die öffentliche Bekanntgabe wirkt weltweit und zukunftsoffen. ${ }^{569}$ Dies gilt auch unabhängig von einer tatsächlichen Kenntnisnahme oder gar einer Betroffenheit (im Zeitpunkt der Bekanntgabe). ${ }^{570}$ Gemäß § 41 IV 3 VwVfG gilt der Verwaltungsakt zwei Wochen nach der ortsüblichen Bekanntmachung als bekannt gegeben. Die Vorschrift ähnelt § 41 II 1, 2 VwVfG, verfolgt indes einen anderen Zweck: Den potentiell Betroffenen wird mehr Zeit für die Möglichkeit der Kenntnisnahme, insbesondere zur Einsichtnahme gemäß § 41 IV 3 VwVfG, eingeräumt, bevor die Wirksamkeit

561 Stelkens, in: Stelkens/Bonk/Sachs, VwVfG, 9. Aufl. 2018, § 27a Rn. 25f., 69; § 41 Rn. 183a. 562 Weil die Frage der individuellen Betroffenheit sich häufig erst durch Einsichtnahme klären lässt, s. BVerwG, Urt. v. 8.6.1995, Az.: 4 C 4.94 = BVerwGE 98, 339 (360f.).

563 Stelkens, in: Stelkens/Bonk/Sachs, VwVfG, 9. Aufl. 2018, § 41 Rn. 178; Tiedemann, in: Bader/ Ronellenfitsch, VwVfG, 44. Ed., Stand: 1.7.2019, § 41 Rn. 118.

564 Stelkens, in: Stelkens/Bonk/Sachs, VwVfG, 9. Aufl. 2018, § 41 Rn. 180; Tiedemann, in: Bader/ Ronellenfitsch, VwVfG, 44. Ed., Stand: 1.7.2019, § 41 Rn. 120.

565 S. m.w. N. zu verschiedenen Konstellationen nur Stelkens, in: Stelkens/Bonk/Sachs, VwVfG, 9. Aufl. 2018, § 41 Rn. 181.

566 S. dazu - auch terminologisch - Stelkens, in: Stelkens/Bonk/Sachs, VwVfG, 9. Aufl. 2018, § 41 Rn. 157 f.; Tiedemann, in: Bader/Ronellenfitsch, VwVfG, 44. Ed., Stand: 1.7.2019, § 41 Rn. 107.

567 Bspw. bedarf es keines Hinweises mehr auf die Einsichtnahmemöglichkeit, Stelkens, in: Stelkens/Bonk/Sachs, VwVfG, 9. Aufl. 2018, § 41 Rn. 177.

568 Stelkens, in: Stelkens/Bonk/Sachs, VwVfG, 9. Aufl. 2018, § 41 Rn. 137.

569 Stelkens, in: Stelkens/Bonk/Sachs, VwVfG, 9. Aufl. 2018, § 41 Rn. $138 \mathrm{f}$.

570 Stelkens, in: Stelkens/Bonk/Sachs, VwVfG, 9. Aufl. 2018, § 41 Rn. $136 \mathrm{ff}$.

Tobias Brings-Wiesen 
des Verwaltungsakts eintritt und der Lauf der Rechtsbehelfsfristen beginnt. ${ }^{571}$ Gemäß § 41 IV 4 VwVfG kann in einer Allgemeinverfügung selbst - im Interesse einer besonderen Eilbedürftigkeit - ein hiervon abweichender Tag, jedoch frühestens der auf die Bekanntmachung folgende Tag bestimmt werden.

Eine in der juristischen Ausbildung besonders relevante Sonderproblematik 165 offenbart sich im Zusammenhang mit der Bekanntgabe von Straßenverkehrszeichen. ${ }^{572}$ Bei diesen handelt es sich (s. dazu Rn. $85 \mathrm{f}$.) zumindest nach herrschender Ansicht um Allgemeinverfügungen i.S.v. § 35 S. 2 Var. 3 VwVfG. Das Bundesverwaltungsgericht vertritt $\mathrm{zu}$ den Fragen rund um ihre Bekanntgabe ${ }^{573}$ einen differenzierenden Ansatz: Die Bekanntgabe von Straßenverkehrszeichen als besondere Form der öffentlichen Bekanntgabe richtet sich ausschließlich ${ }^{574}$ nach den (bundesrechtlichen) Spezialvorschriften der StraßenverkehrsOrdnung (StVO). Aus den §§ 39 I, 45 IV StVO ergibt sich, dass die Bekanntgabe von Verkehrszeichen grundsätzlich durch deren Aufstellung erfolgt. ${ }^{575}$ In diesem Moment werden sie für jeden Verkehrsteilnehmer wirksam, sofern sie entsprechend des sog. „Sichtbarkeitsgrundsatzes“ so aufgestellt sind, dass „sie ein durchschnittlicher Kraftfahrer bei Einhaltung der nach $\S 1$ StVO erforderlichen Sorgfalt schon ,mit einem raschen und beiläufigen Blick` erfassen kann [...], gleichgültig, ob er das Verkehrszeichen tatsächlich wahrnimmt oder nicht“. ${ }^{576}$ Die „Sichtbarkeit“ ist somit echte Wirksamkeitsvoraussetzung der Allgemeinverfügung Straßenverkehrszeichen. ${ }^{577}$ Die Anforderungen an den Sichtbarkeitsgrundsatz sind dabei stark verkehrssituationsbedingt ${ }^{578}$ : So soll grundsätzlich zwischen Zeichen zur Regelung des ruhenden und des fließenden Straßenverkehrs unterschieden werden; ${ }^{579}$ eine rasche und beiläufige Erkennbarkeit und Erfassbarkeit

571 Hinsichtlich der Fristberechnung gilt das zu § 41 II VwVfG Gesagte entsprechend, s. dazu bereits Rn. 143.

572 S. dazu ausführlich auch Milker, JURA 2017, 271 (274 ff.); Kümper, JuS 2017, 731 (733 ff.); ders., JuS 2017, 833.

573 Zur Entwicklung der Rspr. des BVerwG in dieser Frage m.w. N. Maurer/Waldhoff, Allgemeines Verwaltungsrecht, 19. Aufl. 2017, §9 Rn. 37.

574 Zur Frage einer umfassenden Verdrängung von § 41 VwVfG BVerwG, Urt. v. 13.3.2008, Az.: 3 C 18.07 = BVerwGE 130, 383 (389f., Rn. 24f.); dazu bereits OVG Münster, Urt. v. 12.1.1996, Az.: 25 A 2475/93 = NJW 1996, 3024 (3025).

575 St. Rspr. des BVerwG, Urt. v. 11.12.1996, Az.: 11 C 15.95 = BVerwGE 102, 316 (318); zuletzt Urt.v. 24.5.2018, Az.: 3 C 25.16 = NJW 2018, 2910, Rn. 15.

576 Ausdrücklich seit BVerwG, Urt. v. 11.12.1996, Az.: 11 C 15.95 = BVerwGE 102, 316 (318); zuletzt Urt. v. 24.5.2018, Az.: 3 C 25.16 = NJW 2018, 2910, Rn. 15.

577 BVerwG, Urt. v. 6.4.2016, Az.: 3 C 10.15 = BVerwGE 154, 365 (373, Rn. 22).

578 S. dazu ausführlich Milker, JURA 2017, 271 (275f.); Kümper, JuS 2017, 733 (735f.).

579 BVerwG, Urt. v. 6.4.2016, Az.: 3 C 10.15 = BVerwGE 154, 365 (370 ff., Rn. 17 ff.).

Tobias Brings-Wiesen 
kann im Falle eines „Schilderwaldes“ zu verneinen sein ${ }^{580}$. Die völlige Irrelevanz der tatsächlichen Kenntnisnahme zeigt sich in der Rechtsprechung des Bundesverwaltungsgerichts zu mobilen Straßenverkehrszeichen: Ein mobiles Halteverbotszeichen entfaltet gegenüber dem Halter eines Kraftfahrzeugs selbst dann Rechtswirkungen, wenn es erst nach dem Abstellen eines Fahrzeugs aufgestellt wird und der Halter wegen eines Krankenhausaufenthalts oder eines Urlaubs nicht einmal die Möglichkeit der Kenntnisnahme hatte. ${ }^{581}$ Vor dem Hintergrund des Sichtbarkeitsgrundsatzes ist sodann auch konsequent, dass die innere Wirksamkeit des Verkehrszeichens für den Zeitraum entfällt, während dessen sein Regelungsgehalt - beispielsweise wegen Vandalismus oder Witterungsbedingungen - nicht (mehr) erkennbar ist. ${ }^{582}$

Intensiv umstritten ist vor diesem Hintergrund die Frage des Rechtsschutzes im Hinblick auf die Rechtsbehelfsfristen. Diese beginnen gemäß $\S \S 70$ I 1, 74 I VwGO grundsätzlich mit der Bekanntgabe des Verwaltungsakts (s. dazu Rn. 370 ff.). Nach dem Bundesverwaltungsgericht kann die Aufstellung als besondere Form der öffentlichen Bekanntgabe jedoch in ihrer Wirkung von der Wirkung anderer Formen der öffentlichen Bekanntgabe abweichen. ${ }^{583}$ Vor diesem Hintergrund ${ }^{584}$ entschied es, dass abweichend vom Eintritt der universellen Regelungswirkung (s. dazu Rn. 164) die Rechtsbehelfsfristen individuell erst dann zu laufen beginnen, ,wenn sich der betreffende Verkehrsteilnehmer erstmals der Regelung des Verkehrszeichens gegenübersieht.“585 Jedes andere Verständnis geriete in Konflikt mit der Garantie effektiven Rechtsschutzes gemäß Art. 19 IV 1 GG. ${ }^{586}$ Dies bedeutet, dass mangels Kenntnisnahme für eine Mehrheit an Ver-

580 S. BVerwG, Urt.v. 13.3.2008, Az.: 3 C 18.07 = BVerwGE 130, 383 (386ff., Rn. 13ff.), hinsichtlich eines Verkehrszeichens mit vier Zusatzzeichen.

581 BVerwG, Urt. v. 11.12.1996, Az.: 11 C 15.95 = BVerwGE 102, 316 (318); Urt. v. 24.5.2018, Az.: 3 C 25.16 = NJW 2018, 2910 (Rn. 15).

582 S. dazu nur Kümper, JuS 2017, 731 (736).

583 BVerwG, Urt. v. 23.9.2010, Az.: 3 C 37.09 = BVerwGE 138, 21 (25, Rn. 17).

584 Detterbeck, Allgemeines Verwaltungsrecht, 17. Aufl. 2019, Rn. 562, geht auf diese Differenzierung der Rechtswirkungen in der Rspr. des BVerwG nicht ein. De facto läuft sie nur auf ein differenziertes Verständnis des Aktes der Bekanntgabe in § 43 I VwVfG und §§ 58, 70 I 1, 74 I 2 VwGO hinaus.

585 BVerwG, Urt. v. 23.9.2010, Az.: 3 C 37.09 = BVerwGE 138, 21 (24, Rn. 16); so bereits ohne klarstellende Differenzierung BVerwG, Urt. v. 13.12.1979, Az.: 7 C 46.78 = BVerwGE 59, 221 (226). Krit. zu diesem Ansatz Stelkens, in: Stelkens/Bonk/Sachs, VwVfG, 9. Aufl. 2018, § 35 Rn. 333a m.w. Nw.

586 BVerwG, Urt. v. 23.9.2010, Az.: 3 C 37.09 = BVerwGE 138, 21 (24, Rn. 16). Zustimmend Maurer/ Waldhoff, Allgemeines Verwaltungsrecht, 19. Aufl. 2017, § 9 Rn. 37. In dem vorausgehenden BVerfG(K), Beschl. v. 10.9.2009, Az.: 1 BvR 814/09 = NJW 2009, 3642 (3644), wurde auf die Notwendigkeit der Berücksichtigung von Art. 19 IV 1 GG bei der Bestimmung des Fristbeginns zwar

Tobias Brings-Wiesen 
kehrsteilnehmern nie eine Rechtsbehelfsfrist ausgelöst, der Verwaltungsakt Straßenverkehrszeichen mithin praktisch niemals in formelle Bestandskraft erwachsen wird. Um dem zu begegnen, vertritt eine Gegenansicht - gestützt auf eine konsequente Anwendung des Sichtbarkeitsgrundsatzes - die Meinung, dass auch die Rechtsbehelfsfristen ${ }^{587}$ im Zeitpunkt der Aufstellung ausgelöst werden. ${ }^{588}$ Gegen den Ansatz des Bundesverwaltungsgerichts werden der klare Wortlaut der einschlägigen Fristenregelungen, die ausdrücklich auf die Bekanntgabe abstellen, sowie das Argument fehlender Rechtssicherheit ins Feld geführt. ${ }^{589}$ Außerdem sei ausreichender Rechtsschutz über die Geltendmachung eines Anspruchs auf Wiederaufgreifen des Verfahrens nach § 51 VwVfG oder eines Anspruchs auf ermessensfehlerfreie Entscheidung über eine Aufhebung des Verwaltungsakts nach $\S \S 48,49$ VwVfG zu erreichen. ${ }^{590}$

Obwohl durchaus Wertungsparallelen bestehen, sollte diese Sonderdogmatik der Bekanntgabe von Verkehrszeichen nicht ohne weiteres auf andere Konstellationen der öffentlichen Bekanntgabe, insbesondere von anderen Allgemeinverfügungen, übertragen werden. ${ }^{591}$

\section{dd) Die Bekanntgabe von Verwaltungsakten mittels Zustellung}

Die sog. „Zustellung“ ist eine besonders formalisierte Art der Bekanntgabe ei- 168 nes Verwaltungsakts (s. zum Zusammenhang von Zustellung und Klagefrist Rn. 373ff.). Ihre Existenz wird in $\S 41 \mathrm{~V} \mathrm{VwVfG}$ vorausgesetzt, wobei sich die Vorschrift in der Klarstellung erschöpft, dass die Vorschriften über die Bekanntgabe eines Verwaltungsakts mittels Zustellung unberührt bleiben. Sie verdeutlicht: Diese Vorschriften gehen $\S 41 \mathrm{VwVfG}$ schlicht vor, der weder subsidiär ${ }^{592}$

hingewiesen, jedoch keine Alternativlosigkeit postuliert; s. für einen Überblick über den diesbezüglichen Meinungsstand vor dem Urteil des BVerwG, a.a.O., BVerfG(K), ibid., 2642 (2643). 587 Wobei einhellige Meinung ist, dass mangels ordnungsgemäßer Rechtsbehelfsbelehrung praktisch immer die Ausschlussfrist von $\S 58$ II VwGO relevant sein wird.

588 VGH Mannheim, Beschl. v. 2.3.2009, Az.: 5 S 3047/08 = juris, Rn. 5 ff.; Detterbeck, Allgemeines Verwaltungsrecht, 17. Aufl. 2019, Rn. 562; Stelkens, in: Stelkens/Bonk/Sachs, VwVfG, 9. Aufl. 2018, § 35 Rn. 333f. m.w. N.

589 Ehlers, JZ 2011, 155 (157); Milker, JURA 2017, 271 (278); Kümper, JuS 2017, 833 (835).

590 Detterbeck, Allgemeines Verwaltungsrecht, 17. Aufl. 2019, Rn. 562 m.w. N. Dagegen jedoch Maurer/Waldhoff, Allgemeines Verwaltungsrecht, 19. Aufl. 2017, § 9 Rn. 37.

591 Ausdrücklich ablehnend Stelkens, in: Stelkens/Bonk/Sachs, VwVfG, 9. Aufl. 2018, § 41 Rn. 136.

592 Stelkens, in: Stelkens/Bonk/Sachs, VwVfG, 9. Aufl. 2018, § 41 Rn. 199; Schwarz, in: Fehling/ Kastner/Störmer, Verwaltungsrecht, 4. Aufl. 2016, § 41 VwVfG Rn. 43; Stuhlfauth, in: Obermayer/ Funke-Kaiser, VwVfG, 5. Aufl. 2018, § 41 Rn. 69. 
noch analog ${ }^{593}$ auf Zustellungen anwendbar ist. Die für die Wirksamkeit einer Bekanntgabe dargelegten allgemeinen Voraussetzungen bestehen jedoch der Sache nach auch hinsichtlich der Zustellung. ${ }^{594}$ Besonderheiten ergeben sich vorrangig auf Seiten des Empfängers, insbesondere hinsichtlich des Zugangs. ${ }^{595}$

Die Vorgaben zur Zustellung finden sich allgemein im Verwaltungszustellungsgesetz des Bundes $(V w Z G)^{596}$, das indes unmittelbar nur für die Zustellungsverfahren der Bundesbehörden, der bundesunmittelbaren Körperschaften, Anstalten und Stiftungen des öffentlichen Rechts und der Landesfinanzbehörden gilt (§1 I VwZG). Darüber hinaus sind die Verwaltungszustellungsgesetze der Länder ${ }^{597} \mathrm{zu}$ berücksichtigen, die Vorgaben für die Zustellungsverfahren der übrigen staatlichen Behörden festlegen, ${ }^{598}$ dabei indes inhaltlich weitgehend den Vorgaben des VwZG entsprechen oder sich bisweilen gar in einer Verweisung darauf erschöpfen. Existieren besondere Zustellungsvorschriften, ist zu prüfen, ob und inwieweit diese gegenüber dem allgemeinen Zustellungsrecht Vorrang haben. ${ }^{599}$

Nach der Legaldefinition des § 2 I VwZG ist eine Zustellung die Bekanntgabe eines schriftlichen oder elektronischen Dokuments ${ }^{600}$ in der im VwZG bestimmten Form. Sie erfolgt, soweit dies durch Rechtsvorschrift oder behördliche Anordnung bestimmt ist ( $§ 1$ II VwZG). Die behördliche Anordnung der Zustellung steht im Ermessen der Behörde. ${ }^{601}$ Wählt sie den Weg der Zustellung, muss

593 Ramsauer/Tegethoff, in: Kopp/Ramsauer, VwVfG, 20. Aufl. 2019, § 41 Rn. 56; Tiedemann, in: Bader/Ronellenfitsch, VwVfG, 44. Ed., Stand: 1.7.2019, § 41 Rn. 128.

594 Auf Seiten der Behörde muss jedoch ein spezifischer Zustellungswille bestehen, Schwarz, in: Fehling/Kastner/Störmer, Verwaltungsrecht, 4. Aufl. 2016, § 41 VwVfG Rn. 44.

595 Stelkens, in: Stelkens/Bonk/Sachs, VwVfG, 9. Aufl. 2018, § 41 Rn. 204.

596 Verwaltungszustellungsgesetz vom 12. August 2005 (BGBl. I S. 2354), zuletzt geändert durch Art. 11 Abs. 3 des aIDAS-Durchführungsgesetzes vom 18. Juli 2017 (BGBl. I S. 2745).

597 S. für eine kontinuierlich aktualisierte Auflistung die Homepage des öffentlich-rechtlichen Online-Lernprojekts „Saarheim“ von Grupp und Stelkens, abrufbar unter: http://www.saarheim. de/Gesetze_Laender/vwzg_laender.htm.

598 Selbst im Falle einer kraft Bundesrecht vorgeschriebenen Zustellung, BVerwG, Urt. v. 19.1. 1972, Az.: V C 54.70 = BVerwGE 39, 257 (259); Urt. v. 9.12.1988, Az.: 8 C 38.86 = NVwZ 1989, 648 (649).

599 Vgl. bspw. zum § 10 AsylG Bergmann, in: ders./Dienelt, Ausländerrecht, 12. Aufl. 2018, § 10 AsylG Rn. $10 \mathrm{ff}$.

600 Der Anwendungsbereich ist nicht auf die Bekanntgabe von Verwaltungsakten beschränkt, Stelkens, in: Stelkens/Bonk/Sachs, VwVfG, 9. Aufl. 2018, § 41 Rn. 206.

601 Ramsauer/Tegethoff, in: Kopp/Ramsauer, VwVfG, 20. Aufl. 2019, § 41 Rn. 58; Tiedemann, in: Bader/Ronellenfitsch, VwVfG, 44. Ed., Stand: 1.7.2019, § 41 Rn. 130.

Tobias Brings-Wiesen 
sie sich an dieser Entscheidung festhalten lassen und die Voraussetzungen des Zustellungsrechts erfüllen. ${ }^{602}$

Gemäß § 2 II 1 VwZG erfolgt die Zustellung durch einen Erbringer von 171 Postdienstleistungen (Post), einen nach $\S 17$ des De-Mail-Gesetzes akkreditierten Diensteanbieter oder durch die Behörde selbst. Davon abweichend können gemäß § 2 II 2 VwZG im Rahmen einer Zustellung im Ausland (§ 9 VwZG) oder einer öffentlichen Zustellung ( 10 VwZG) andere Akteure eingebunden werden. Sie erfolgt an den Empfänger ${ }^{603}$ selbst, seinen gesetzlichen Vertreter ( $§ 6$ VwZG) oder seinen Bevollmächtigten (§ 7 VwZG). Anders als nach § 41 I 2 VwVfG ist gemäß $\S 7$ I 2 BVwZG die Zustellung zwingend an den Bevollmächtigten zu richten, wenn dieser eine schriftliche Vollmacht vorgelegt hat, sodass die an eine andere Person erfolgte Zustellung unwirksam ist, ${ }^{604}$ jedoch gemäß $\S 8$ VwZG geheilt werden $\mathrm{kann}^{605}$.

Soweit nicht anders vorgesehen ${ }^{606}$ hat die Behörde gemäß $§ 2$ III 1 VwZG die Wahl zwischen den verschiedenen Arten der Zustellung. Für schriftliche Verwaltungsakte besteht die Wahl zwischen der Zustellung durch die Post mit Zustellungsurkunde ( $§ 3$ VwZG), mittels Einschreiben $(\S 4 \text { VwZG) })^{607}$ oder gegen Empfangsbekenntnis ( $\S 5$ VwZG). Für elektronische Dokumente bietet sich die Möglichkeit der elektronischen Zustellung ( $\$ 5 \mathrm{~V}$ bis VII VwZG), insbesondere gegen Abholbestätigung über De-Mail-Dienste ( $§ 5 \mathrm{a} V w Z G) .{ }^{608}$ Für all diese Arten der Zustellung sind besondere Förmlichkeiten vorgesehen, deren Missachtung zur

602 OVG Lüneburg, Beschl.v. 13.3.2009, Az.: 11 PA 157/09 = NJW 2009, 1834; Ramsauer/Tegethoff, in: Kopp/Ramsauer, VwVfG, 20. Aufl. 2019, § 41 Rn. 58.

603 Besonderheiten ergeben sich wiederum bei Personenmehrheiten Ramsauer/Tegethoff, in: Kopp/Ramsauer, VwVfG, 20. Aufl. 2019, § 41 Rn. 60.

604 BFH, Urt. v. 11.4.2017, Az.: IX R 50/15 = BeckRS 2017, 119902, Rn. 34; OVG Lüneburg, Beschl.v. 13.3.2009, Az.: 11 PA 157/09 = NJW 2009, 1834; Schlatmann, in: Engelhardt/App/Schlatmann, 11. Aufl. 2017, VwVG/VwZG, § 7 VwZG Rn. 8.

605 So bereits zu § 9 VwZG a.F. BVerwG, Urt. v. 15.1.1988, Az.: 8 C 8.86 = NJW 1988, 1612 (1613); Urt. v. 18.4.1997, Az.: 8 C 43.95 = BVerwGE 104, 301 (312ff.). Vgl. auch BFH, Urt. v. 11.4. 2017, Az.: IX R 50/15 = BeckRS 2017, 119902, Rn. 34.

606 So statuiert § 2 III 2 VwZG unmittelbar eine Ausnahme von diesem Grundsatz: Die Behörde ist gemäß § 5 V 2 VwZG verpflichtet, elektronisch zuzustellen, wenn auf Grund einer Rechtsvorschrift ein Verfahren auf Verlangen des Empfängers in elektronischer Form abgewickelt wird.

$\mathbf{6 0 7}$ S. zu diesen beiden Formen noch näher Rn. $374 \mathrm{ff}$.

$608 \mathrm{Zu}$ den einzelnen Zustellungsarten Ramsauer/Tegethoff, in: Kopp/Ramsauer, VwVfG, 20. Aufl. 2019, § 41 Rn. 62ff.; Stelkens, in: Stelkens/Bonk/Sachs, VwVfG, 9. Aufl. 2018, § 41 Rn. 207 ff.; sowie die Kommentierungen zum BVwZG selbst.

Tobias Brings-Wiesen 
Unwirksamkeit der Zustellung führen kann. Dies wird jedoch insbesondere ${ }^{609}$ bei Vorliegen der Voraussetzungen des $\S 8$ VwZG verneint: Danach gilt im Falle des Fehlens eines Nachweises der formgerechten Zustellung oder der Verletzung zwingender Zustellungsvorschriften ein Dokument als in dem Zeitpunkt zugestellt, in dem es dem Empfangsberechtigten tatsächlich zugegangen ist. ${ }^{610}$

Ein davon abzugrenzender Sonderfall ist die öffentliche Zustellung gemäß $\S 10$ VwZG. Mit ihr sollen die in § 10 I 1 VwZG als Voraussetzung ihrer Zulässigkeit $^{611}$ formulierten Hindernisse einer individuellen Zustellung, beispielsweise ein unbekannter Aufenthaltsort des Empfängers, überwunden werden. Die Wirksamkeit einer öffentlichen Zustellung setzt weiterhin die Einhaltung der in § 10 II VwZG vorgesehenen Vorgaben betreffend ihre Modalitäten voraus. Eine Heilung gemäß § 8 VwZG setzt ausdrücklich den Zugang des Dokuments voraus, von dessen Möglichkeit im Falle öffentlicher Zustellung regelmäßig nicht auszugehen ist. Sollte es gleichwohl dazu kommen oder der Empfänger anderweitig vom Inhalt des Verwaltungsakts Kenntnis erlangen ${ }^{612}$, kommt eine Heilung gemäß § 8 VwZG (analog) in Frage. ${ }^{613}$ Gelingt die öffentliche Zustellung wirkt sie anders als die öffentliche Bekanntgabe i.S.v. § 41 III, IV VwVfG (s. dazu Rn. 164) lediglich für die Person, die als Empfänger ausdrücklich identifiziert ist.

\section{c) Rechtsschutz bei Fehlern im Wirksamwerden eines Verwaltungsakts}

174 Wie bereits dargelegt (s. dazu Rn. 100) können sich Fragen des Wirksamkeit (und somit auch des Wirksamwerdens) eines Verwaltungsakts im Rahmen einer Prüfung inzident stellen. Genauso kann ein Verwaltungsakt, dessen Wirksamwerden in Zweifel steht, jedoch selbst Gegenstand eines Rechtsschutzbegehrens sein.

609 Darüber hinaus besteht die Möglichkeit der Unbeachtlichkeit eines Zustellungsfehlers in Konstellationen des „rügelosen Rechtsbehelfs“ und der Verwirkung, s. nur L. Ronellenfitsch, in: Bader/Ronellenfitsch, VwVfG, 44. Ed., Stand: 1.10.2018, § 8 VwZG Rn. $19 \mathrm{ff}$.

610 S. dazu ausführlich L. Ronellenfitsch, in: Bader/Ronellenfitsch, VwVfG, 44. Ed., Stand: 1.10. 2018, § 8 VwZG Rn. $1 \mathrm{ff}$.

611 S. noch zum alten Zustellungsrecht BVerwG, Urt. v. 18.4.1997, Az.: 8 C 43.95 = BVerwGE 104, 301 (306ff.).

612 Bspw. durch Übersendung als Aktenbestandteil an den bestellten Bevollmächtigten VGH Mannheim, Beschl. v. 7.12.1990, Az.: 10 S 2466/90 = NVwZ 1991, 1195 (1196).

613 Schlatmann, in: Engelhardt/App/Schlatmann, VwVG/VwZG, 11. Aufl. 2017, § 10 VwZG Rn. 19; L. Ronellenfitsch, in: Bader/Ronellenfitsch, VwVfG, 44. Ed., Stand: 1.10.2018, § 10 VwZG Rn. $37 \mathrm{f}$. Vgl. auch BFH, Urt. v. 5.3.1985, Az.: VII R 156/82 = BFHE 143, 220 (223).

Tobias Brings-Wiesen 
Aufgrund des Grundsatzes der relativen Wirksamkeit von Verwaltungsakten (s. dazu Rn. 113) ist zwischen zwei Grundkonstellationen zu unterscheiden: ${ }^{614}$ Ist der Verwaltungsakt nur einer Person wirksam bekanntgegeben wor- 175 den, ist er rechtlich existent, sodass er grundsätzlich von jeder Person im Wege des Widerspruchs gemäß § 68 I 1 VwGO bzw. der Anfechtungsklage gemäß § 42 I Var. 1 VwGO angegriffen und schließlich aufgehoben werden kann, wobei sich Unterschiede lediglich hinsichtlich des Laufs der Rechtsbehelfsfristen ergeben (s. Rn. 113, 116).

Ist der Verwaltungsakt niemandem gegenüber wirksam bekanntgegeben 176 worden, handelt es sich schlicht um einen „Nichtakt“615 (s. Rn. 20). Es stellt sich die Frage, ob gegen derartige Nichtakte gleichwohl ein Widerspruch gemäß $\S 68$ I 1 VwGO bzw. eine Anfechtungsklage gemäß § 42 I Var. 1 VwGO ${ }^{616}$ statthaft ist. Dies wird zum Teil ${ }^{617}$ schlicht mit dem Argument der fehlenden Existenz des Verwaltungsakts und dem Verweis auf die Möglichkeit der Beseitigung eines etwaigen Rechtsscheins im Wege der Feststellungsklage (s. Rn. 177) verneint. Auch begründe ein Nichtakt nicht mit gleicher Regelmäßigkeit wie ein nichtiger Verwaltungsakt den Rechtsschein seiner Wirksamkeit, sodass zwischen beiden zu unterscheiden sein soll. ${ }^{618}$ Die Gegenmeinung ${ }^{619}$ möchte demgegenüber eine Anfechtungsklage zulassen. Entsprechend der Argumentation für die Statthaftigkeit einer Anfechtungsklage gegen nichtige Verwaltungsakte (s. dazu noch in

614 So auch Couzinet/Fröhlich, in: Mann/Sennekamp/Uechtritz, VwVfG, 2. Aufl. 2019, § 41 Rn. $157 \mathrm{ff}$.

615 Das BVerwG bezeichnet die somit nicht bekanntgegebene Maßnahme als „Nichtakt“, Urt. v. 21.11.1986, Az.: 8 C 127.84 = NVwZ 1987, 330; Beschl. v. 19.5.2015, Az.: 3 B 6.14 = juris, Rn. 13. Im Falle des Fehlens der Merkmale nach $\S 35$ VwVfG nennt es jedoch mittlerweile den in der Literatur gleichsam gebräuchlichen Begriff des „Scheinverwaltungsaktes“ mit, vgl. nur Urt. v. 22.3.2017, Az.: 5 C 4.16 = BVerwGE 158, 258 (261, Rn. 11).

616 Damit in engem Zusammenhang steht selbstredend die Frage, ob ein Antrag auf vorläufigen Rechtsschutz gemäß $\S \S 8$ ff. VwGO statthaft wäre, s. dazu im Hinblick auf Nichtakte - wie die wohl h.M. - nur W.-R. Schenke, in: Kopp/Schenke, VwGO, 25. Aufl. 2019, § 80 Rn. 16 m.w.N. 617 Gegen die Statthaftigkeit einer Anfechtungsklage - insbesondere im Falle des klägerischen Vorbringens einer unwirksamen Bekanntgabe - VGH Mannheim, Beschl. v. 7.12.1990, Az.: 10 S 2466/90 = NVwZ 1991, 1195 (1195f.); OVG Greifswald, Urt.v. 24.3.2015, Az.: 1 L 313/11 = BeckRS 2015, 46844. So auch Hufen, Verwaltungsprozessrecht, 11. Aufl. 2019, § 14 Rn. 10; R. P. Schenke, in: Kopp/Schenke, VwGO, 25. Aufl. 2019, § 42 Rn. 4; von Albedyll, in: Bader/Funke-Kaiser/Stuhlfauth/ von Albedyll, VwGO, 7. Aufl. 2018, § 42 Rn. 13.

618 S. nur VGH Mannheim, Beschl. v. 7.12.1990, Az.: 10 S 2466/90 = NVwZ 1991, 1195 (1196). 619 Stelkens, in: Stelkens/Bonk/Sachs,VwVfG, 9. Aufl. 2018, § 41 Rn. 226f.; Pietzcker, in: Schoch/ Schneider/Bier, VwGO, 36. EL Februar 2019, § 42 I Rn. 20, jeweils m.w. N.

Tobias Brings-Wiesen 
$\S 6$ Rn. 197 ff. ${ }^{620}$ ) wird maßgeblich auf das Rechtsschutzinteresse des Klägers abgestellt, den in zwischen ihm und der Behörde strittigen Konstellationen bestehenden Rechtsschein eines Verwaltungsakts zu beseitigen. ${ }^{621}$

Anstelle (oder eben neben ${ }^{622}$ ) der Anfechtungsklage kann eine Feststellungsklage gemäß § 43 I Var. 2 VwGO auf Feststellung des Nichtbestehens eines Rechtsverhältnisses (sog. negative Feststellungsklage) ${ }^{623}$ statthaft sein. Das Klagebegehren ist auf die Feststellung gerichtet, dass der Verwaltungsakt nicht wirksam geworden ist und deshalb die mit ihm beabsichtigte Regelung nicht erreicht hat. ${ }^{624}$

\section{Das Ende der Wirksamkeit gemäß § 43 II VwVfG}

178 Neben der Unwirksamkeit auf Grund von Nichtigkeit gemäß § 43 III i.V.m. § 44 VwVfG, auf die noch gesondert einzugehen ist (s. dazu Rn. $189 \mathrm{ff}$. sowie ausführlich § 6 Rn. $115 \mathrm{ff}$.), sind § 43 II VwVfG Anknüpfungspunkte für die Beendigung der Wirksamkeit eines Verwaltungsakts zu entnehmen. Diese lassen sich in zwei Gruppen unterteilen: Das Ende der Wirksamkeit kann zum einen auf einen gezielten nachträglichen Akt, eine sog. Aufhebung, zurückzuführen sein. Sie kann sich zum anderen aber auch schlicht aus dem Verwaltungsakt und dem ihm zugrundeliegenden Recht selbst ergeben, sprich zu seiner Erledigung führen. ${ }^{625}$

620 Wegen der weitgehend vergleichbaren Interessenlage kann grundsätzlich entsprechend auf die umfassenderen Ausführungen zur Statthaftigkeit der Anfechtungsklage gegen nichtige Verwaltungsakte verwiesen werden. Diese sollen zur Vermeidung von Redundanzen an dieser Stelle nicht gespiegelt werden.

621 S. nur Stelkens, in: Stelkens/Bonk/Sachs, VwVfG, 9. Aufl. 2018, § 41 Rn. 227.

622 So zumindest Blunk/Schroeder, JuS 2005, 602 (605).

623 Wie im Zusammenhang mit der Frage der Nichtigkeit eines Verwaltungsakts, s. dazu noch § 6 Rn. 75, kann auch hinsichtlich der übrigen Wirksamkeitsprobleme das Bedürfnis des Betroffenen bestehen, die Wirksamkeit eines Verwaltungsakts im Wege der sog. positiven Feststellungsklage gemäß § 43 I Var. 1 VwGO ausdrücklich bestätigen zu lassen.

624 So ausdrücklich BVerwG, Urt. v. 21.11.1986, Az.: 8 C 127.84 = NVwZ 1987, 330. S. zu den verschiedenen Begehren eines Feststellungsantrags Couzinet/Fröhlich, in: Mann/Sennekamp/ Uechtritz, VwVfG, 2. Aufl. 2019, § 41 Rn. 158. S. zur Feststellungsklage ausführlich noch § 6.

625 Vgl. zu § 43 II VwVfG ähnlich auch das BVerwG, Urt. v. 27.3.1998, Az.: 4 C 11.97 = NVwZ 1998, 729 (730); Urt. v. 19.4.2011, Az.: 1 C 2.10 = BVerwGE 139, 337 (340 f.). 


\section{a) Konstellationen der Aufhebung eines Verwaltungsakts}

Die für die Prüfung relevantesten Konstellationen sind die eines gezielten nach- 179 träglichen Aktes der Beendigung der Wirksamkeit - einer sog. Aufhebung. § 43 II VwVfG rekurriert ausdrücklich nur auf die Möglichkeiten der Rücknahme und des Widerrufs, belässt jedoch Raum für Optionen ,anderweitiger Aufhebung“. Um alle Konstellationen der Aufhebung zu erfassen, ist es hilfreich, in einem ersten Überblick zwischen behördlichen und gerichtlichen Entscheidungen zu differenzieren.

Zur gerichtlichen Aufhebung eines Verwaltungsakts kommt es insbeson- 180 dere im Falle der Begründetheit einer Anfechtungsklage, §§ 42 I Var. 1, 113 I 1 VwGO. Nichts anderes gilt darüber hinaus im Falle der Begründetheit einer Verpflichtungsklage (§§ 42 I Var. 2, $113 \mathrm{~V}$ VwGO) in Form der sog. Versagungsgegenklage, da diese eine Klage gerichtet auf Aufhebung der ablehnenden Entscheidung rechtslogisch einschließt. ${ }^{626}$

Diesen beiden Klagearten vorausgehend kann es bereits im Vorverfahren 181 gemäß $\S 68 \mathrm{ff}$. VwGO zu einer behördlichen Aufhebung eines Verwaltungsakts kommen. Hält die zuständige Behörde den Widerspruch für begründet, so hat sie ihm gemäß $\S 72$ VwGO abzuhelfen. Jederzeit kann die Behörde auch durch Rücknahme oder Widerruf (gemäß §§ 48f. VwVfG oder spezialgesetzlichen Regelungen) die Aufhebung eines Verwaltungsakts ${ }^{627}$ erreichen (s. dazu Rn. $836 \mathrm{ff}$.). Auch der Antrag eines Betroffenen auf Wiederaufgreifen des Verfahrens gemäß $\S 51$ VwVfG kann zur Aufhebung führen (s. dazu § 3 Rn. 98 ff.).

\section{b) Konstellationen der Erledigung eines Verwaltungsakts (durch Zeitablauf oder auf andere Weise)}

Die Wirksamkeit eines Verwaltungsakts kann jedoch auch ohne gezielte nach- 182 trägliche Einwirkung auf eben diese Wirksamkeit enden. Das Gesetz fasst diese Konstellationen unter dem Begriff der „Erledigung“ zusammen. ${ }^{628}$ Das Bundesverwaltungsgericht versteht darunter allgemein, dass ein Verwaltungsakt „nicht

626 S. nur Schenke, Verwaltungsprozessrecht, 16. Aufl. 2019, Rn. 263, 851. S. auch das BVerwG, Urt. v. 17.11.1972, Az.: IV C 21.69 = BVerwGE 41, 178 (182); Urt. v. 21.5.1976, Az.: IV C 80.74 = BVerwGE 51,15 (21).

627 Der selbst Verwaltungsakt ist und somit Gegenstand einer Anfechtungsklage sein kann, sodass sich im Falle der „Aufhebung einer Aufhebung“ die Frage des Wiederauflebens des ursprünglichen Verwaltungsakts stellt, s. dazu ausführlich noch Rn. 839.

628 S. zur Erledigung instruktiv Reimer, Die Verwaltung 2015, 259; Schenke, Die Erledigung eines Verwaltungsakts im Sinne des § 43 II VwVfG, in: Festschrift Peine, 2016, S. 503.

Tobias Brings-Wiesen 
mehr geeignet ist, rechtliche Wirkungen zu erzeugen oder wenn die Steuerungsfunktion, die ihm ursprünglich innewohnte, nachträglich entfallen ist“629. Dieser Definitionsversuch ist nicht nur wegen seiner notwendigen Abstraktionshöhe für die (studentische) Praxis wenig hilfreich. Er ist überdies auch besonders voraussetzungsvoll, da er in seiner Kumulation denkbarer Möglichkeiten der Erledigung eine umfassende Kenntnis verwaltungsrechtlicher Methodik verlangt. Für Prüfungskonstellationen ist darüber hinaus stets zu erinnern, dass die Erledigungsbegriffe in $\S 43$ II VwVfG und $\S 113$ I 4 VwGO (s. dazu § 4 Rn. 11ff.) nicht deckungsgleich sind. ${ }^{630}$

Vergleichsweise leicht verständlich ist die bereits in der Norm ausdrücklich genannte Konstellation der Erledigung „durch Zeitablauf“. Mit ihr wird rekurriert auf eine durch die Verwaltung oder gar bereits den Gesetzgeber gewollte zeitliche Begrenzung der Regelungswirkung eines Verwaltungsakts. Der Verwaltung steht dafür insbesondere das Mittel der Nebenbestimmung (s. dazu Rn. 204 ff.) zur Verfügung. Auf Grundlage einer spezialgesetzlichen Befugnis oder des $\S 36$ VwVfG kann (oder gar muss ${ }^{631}$ ) sie einem Verwaltungsakt eine (einen Wirksamkeitszeitraum oder einen Endzeitpunkt bestimmende) Befristung (§ 36 II Nr. 1 VwVfG) beifügen. Der Gesetzgeber kann diese Entscheidung der Verwaltung durch Festsetzung von Mindest- und Höchstdauern vorprägen. Er kann sie gar durch Bestimmung genauer Wirksamkeitszeiträume vorwegnehmen. ${ }^{632}$ Eine häufig wiederkehrende Ausprägung der gesetzlich angeordneten Erledigung durch Zeitablauf stellt die Fallgruppe des „Erlöschens wegen Untätigkeit“ dar: Machen die Begünstigten eines genehmigenden Verwaltungsakts nicht innerhalb bestimmter Zeiträume von der Genehmigung Gebrauch, erlischt sie ipso iure. ${ }^{633}$

Deutlich schwerer fassbar ist die Auffangkonstellation der Erledigung ,auf andere Weise“. ${ }^{634} \mathrm{Um}$ nicht die grundlegende Systementscheidung des Gesetzgebers „in dubio pro“ Wirksamkeit in ihr Gegenteil zu verkehren, ist der Begriff tendenziell einschränkend auszulegen. ${ }^{635}$ Wichtig ist insbesondere, dass darunter

629 BVerwG, Urt. v. 25.9.2008, Az.: 7 C 5.08 = NVwZ 2009, 122; Urt. v. 19.4.2011, Az.: 1 C $2.10=$ BVerwGE 139, 337 (341); Urt. v. 22.8.2017, Az.: 1 A 3.17 = BVerwGE 159, 296 (299, Rn. 12).

630 S. dazu Reimer, Die Verwaltung 2015, 259.

631 S. dazu bspw. § 18 II 1 Var. 1 StrWG NRW, wonach die Erlaubnis zur Sondernutzung einer Straße nur auf Zeit (oder auf Widerruf) erteilt werden darf.

632 Ein exzellentes Beispiel für all die verschiedenen Optionen findet sich in § 26 I AufenthG. 633 S. bspw. § 75 I BauO NRW, § 75 IV 1 VwVfG, § 18 I BImSchG oder § 8 S. 1 GastG (dazu BVerwG, Beschl. v. 26.5.1987, Az.: 1 B 28.87 = NVwZ 1987, 1081).

634 S. dazu ausführlich Ruffert, BayVBl 2003, 33.

635 BVerwG, Urt. v. 9. 5.2012, Az.: 6 C 3.11 = BVerwGE 143, 87 (91, Rn. 19); Beschl.v. 6.10. 2015, Az.: 3 B 9.15 = NVwZ-RR 2016, 128 (129). So auch Maurer/Waldhoff, Allgemeines Verwaltungsecht, 19. Aufl. 2017, § 10 Rn. 103; Ramsauer, in: Kopp/Ramsauer, VwVfG, 20. Aufl. 2019, § 43 Rn. 41. 
nicht behördliche Entscheidungen subsumiert werden, da es sonst $\mathrm{zu}$ einer Umgehung der Voraussetzungen der $\S \S 48,49$ VwVfG oder entsprechender spezialgesetzlicher Vorschriften käme. ${ }^{636}$ Für eine restriktive Handhabung spricht ebenso die § 51 I Nr. 1 VwVfG zugrundeliegende Wertung, dass eine nachträgliche Änderung der für den Verwaltungsakt maßgeblichen Sach- und Rechtslage grundsätzlich die Möglichkeit des Wiederaufgreifens des Verfahrens nach sich ziehen soll. ${ }^{637}$

Die verschiedenen Möglichkeiten der Erledigung können - sofern dies überhaupt möglich ist - an dieser Stelle nicht abschließend bestimmt werden. Rechtsprechung und Wissenschaft haben verschiedene wiederkehrende Fehlertypen in Fallgruppen zusammengefasst, die zwar Orientierungspunkte bieten, aber aufgrund fehlender Einheitlichkeit hinsichtlich Kategorienbildung und Sprachgebrauch mit einer gebotenen Vorsicht heranzuziehen sind. ${ }^{638}$ In der Prüfungssituation sollte daher der auch vom Bundesverwaltungsgericht fokussierte Grundgedanke des Entfalls der Steuerungsfunktion des Verwaltungsakts (unter besonderer Berücksichtigung des ihm zugrundeliegenden Rechts) Ausgangspunkt einer Prüfung sein. Vor diesem Hintergrund sind folgende Fallgruppen weitgehend akzeptiert:

- In Parallele zur Erledigung durch schlichten Zeitablauf kann die Erledigung auch Resultat des Eintritts ausdrücklich bestimmter Sachumstände sein. Die Verwaltung kann das Erlöschen durch Festsetzung einer auflösenden Bedingung (§36 II Nr. 1 VwVfG) zum Verwaltungsakt ermöglichen. ${ }^{639}$ Der Gesetzgeber kann auch gesetzliche Erlöschenstatbestände ${ }^{640}$ normieren. ${ }^{641}$

- Auch ohne deren ausdrückliche Bestimmung kann der Eintritt von Sachumständen zur Erledigung von Verwaltungsakten führen. Dies ist insbesondere

636 BVerwG, Urt. v. 9.5.2012, Az.: 6 C 3.11 = BVerwGE 143, 87 (91, Rn. 19). Kommt es zum Erlass eines Verwaltungsakts, der sich in inhaltlichen Widerspruch zu einem weiterhin wirksamen Verwaltungsakt setzt, kann darin ggf. eine konkludente Aufhebung gesehen werden, die jedoch sodann die einschlägigen Voraussetzungen erfüllen muss, s. BVerwG, a.a.O. (103ff., Rn. 37 ff.). Die Einzelheiten sind indes umstritten, s. nur Ramsauer, in: Kopp/Ramsauer, VwVfG, 20. Aufl. 2019, § 48 Rn. 29a f.

637 BVerwG, Urt. v. 9.5.2012, Az.: 6 C 3.11 = BVerwGE 143, 87 (94, Rn. 25).

638 S. für beispielshafte Auflistungen nur BVerwG, Urt. v. 9.5. 2012, Az.: 6 C 3.11 = BVerwGE 143, 87 (91ff., Rn. 19ff.); VGH Mannheim, Urt. v. 2.7.2014, Az.: 8 S 1071/13 = NVwZ 2014, 1597 (1598); Ramsauer, in: Kopp/Ramsauer, VwVfG, 20. Aufl. 2019, § 43 Rn. 41 ff.; Sachs, in: Stelkens/Bonk/ Sachs, VwVfG, 9. Aufl. 2018, § 43 Rn. $209 \mathrm{ff}$.

639 Stelkens, in: Stelkens/Bonk/Sachs, VwVfG, 9. Aufl. 2018, § 41 Rn. 207.

640 S. bspw. § 72 AsylG, § 51 I Hs. 1 Nr. 5 bis 8 AufenthG oder § 18 II BImSchG.

641 Ramsauer, in: Kopp/Ramsauer, VwVfG, 20. Aufl. 2019, § 43 Rn. 40d, erachtet diese Konstellation als Unterfall der „Erledigung durch Zeitablauf“. 
dann der Fall, wenn der personelle oder sachliche Bezugspunkt einer (avisierten) Regelung fehlt oder entfällt. Denkbar ist dies beispielsweise im Falle des Todes einer natürlichen oder der Auflösung einer juristischen Person als Berechtigte bzw. Verpflichtete, insbesondere wenn es sich um sog. höchstpersönliche Verwaltungsakte handelt, die an besondere subjektive Voraussetzungen anknüpfen und daher einer Rechtsnachfolge nicht zugänglich sind (s. dazu Rn. 107). ${ }^{642}$ Gleiches gilt, wenn ein Verwaltungsakt konkret auf einen Regelungsgegenstand bezogen gewesen ist, wie beispielsweise im Falle der Baugenehmigung, die mit der Zerstörung eines Gebäudes erlischt. $^{643}$

- Auch darüber hinaus kann es zum Wegfall des Regelungsanlasses kommen. So kann in Ausnahmefällen auch eine nachfolgende behördliche Entscheidung die rechtlichen Voraussetzungen einer Erstentscheidung derart verändern, dass deren Steuerungsfunktion entfällt, so beispielsweise im Falle der Erteilung einer Aufenthaltserlaubnis, die die Ausreisepflicht des Betroffenen (§50 I AufenthG) und somit auch den Regelungsanlass einer Abschiebungsandrohung entfallen lässt, ${ }^{644}$ oder im Falle der Einbürgerung, die den Betroffenen zum deutschen Staatsangehörigen und somit einen Aufenthaltstitel (§4 I 1 AufenthG) überflüssig macht ${ }^{645}$. Eine Änderung der Rechtslage soll zwar - entsprechend der Wertung von § 51 I Nr. 1 VwVfG grundsätzlich nicht zur Erledigung des auf den geänderten Vorschriften beruhenden Verwaltungsakts führen. Etwas anderes soll jedoch dann gelten, wenn die geänderte Rechtslage dazu führt, dass der Verwaltungsakt gegenstandslos wird. Dies kann gesetzlich ausdrücklich bestimmt sein. Zumeist ist es jedoch unter Auslegung von Inhalt und Zweck des Verwaltungsakts, gegebenenfalls im Zusammenhang mit den Vorschriften, auf denen dieser beruht, $\mathrm{zu}$ bestimmen. ${ }^{646} \mathrm{Zu}$ bejahen ist eine Gegenstandslosigkeit jedenfalls dann, wenn eine gesetzliche Genehmigungspflicht vollständig entfällt. ${ }^{647}$

642 So bspw. durch Auslegung der Vorschriften betr. die Bewilligung von Wohngeld BVerwG, Urt. v. 23.1.1990, Az.: 8 C 37.88 = BVerwGE 84, 274 (277); betr. den Aufnahmebescheid für Spätaussiedler, BVerwG, Urt. v. 25.11.2004, Az.: 5 C 47.03 = NVwZ 2005, 818 (819); oder betr. ein an besondere subjektive Voraussetzungen geknüpftes Wegerecht, BVerwG, Urt. v. 29.4.2015, Az.: 6 C 39.13 = NVwZ 2015, 1578 (1579ff., Rn. 14 ff.).

643 OVG Münster, Urt. v. 6.2.2015, Az.: 2 A 1394/13 = BeckRS 2015, 42849.

644 Vgl. zur Erledigung eines Rechtsstreits in der Hauptsache BVerwG, Urt. v. 21.9.1999, Az.: 9 C 12.99 = BVerwGE 109, 305 (313f.)

645 BVerwG, Urt. v. 9.4.2011, Az.: 1 C 2.10 = BVerwGE 139, 337 (341, Rn. 15).

646 BVerwG, Urt. v. 9.5.2012, Az.: 6 C 3.11 = BVerwGE 143, 87 (94, Rn. 25); Ramsauer, in: Kopp/ Ramsauer, VwVfG, 20. Aufl. 2019, § 43 Rn. 42. 
- Denkbar ist auch, dass eine Erledigung auf den Willen der Personen zurückgeht, für die die Regelungswirkung des Verwaltungsakts von Relevanz ist. So kann der Antragssteller vor Unanfechtbarkeit des Verwaltungsakts seinen Antrag zurücknehmen ${ }^{648}$ oder auch später noch auf einen Verwaltungsakt verzichten ${ }^{649}$. Das Bundesverwaltungsgericht hat eine Erledigung auch für den Fall bejaht, dass die an einem Verwaltungsakt Beteiligten durch übereinstimmendes Verhalten dem ursprünglichen Verwaltungsakt keinerlei tatsächliche oder rechtliche Bedeutung mehr beimessen und ihn mithin als erledigt ansehen. ${ }^{650}$ An ein derartiges Verhalten wird man im Einzelfall jedoch hohe Anforderungen stellen müssen. ${ }^{651}$

- Situationen des Gebrauchmachens, der Erfüllung oder der Vollstreckung sind differenziert zu beurteilen. Die Baugenehmigung legalisiert auch nach Abschluss der Bauarbeiten weiterhin das Bauwerk, der Abgabenbescheid bildet auch nach Zahlung des geforderten Betrages deren Rechtsgrund ${ }^{652}$. Vor diesem Hintergrund können auch Konstellationen der Vollstreckung eines Verwaltungsakts nicht anders bewertet werden. Selbst wenn durch einen Vollzug selbst irreversible Tatsachen geschaffen werden, ist vorrangig relevant, ob sich ein Grundverwaltungsakt noch rechtlich auswirkt. ${ }^{653}$ Dies wird beispielsweise mehrheitlich für den Fall bejaht, dass ein Grundverwaltungsakt zugleich die Grundlage für einen Kostenbescheid bildet. ${ }^{654}$

- Die Konsequenzen der sog. ,aufschiebende Wirkung“ gemäß § 80 I VwGO (s. dazu $\S 8$ Rn. 5) für die Wirksamkeit eines Verwaltungsakts sind zwar umstritten, ${ }^{655}$ jedenfalls führt sie nicht zu dessen Erledigung.

647 S. für Beispiele die Nachweise bei Stelkens, in: Stelkens/Bonk/Sachs, VwVfG, 9. Aufl. 2018, $\S 41 \mathrm{Rn} .212 \mathrm{a}$.

648 Ramsauer, in: Kopp/Ramsauer, VwVfG, 20. Aufl. 2019, § 41 Rn. 45.

649 BVerwG, Urt. v. 15.12.1989, Az.: 4 C 36.86 = BVerwGE 84, 209 (211f.); VGH Mannheim, Urt. v. 10.11.1993, Az.: 3 S 1120/92 = NVwZ 1995, 280 (280f.); Maurer/Waldhoff, Allgemeines Verwaltungsrecht, 19. Aufl. 2017, §10 Rn. 104.

650 BVerwG, Urt. v. 27.3.1998, Az.: 4 C 11.97 = NVwZ 1998, 729 (730).

651 S. zum unmissverständlichen Ausdruck des Verzichtswillens VGH Mannheim, Urt. v. 10.11. 1993, Az.: 3 S 1120/92 = NVwZ 1995, 280 (280 f.); zum konsensualen Verhalten BVerwG, Urt. v. 27.3. 1998, Az.: 4 C 11.97 = NVwZ 1998, 729 (730).

652 BVerwG, Urt. v. 3.6.1983, Az.: 8 C 43.81 = NVwZ 1984, 168.

653 BVerwG, Urt. v. 25.9.2008, Az.: 7 C 5.08 = NVwZ 2009, 122.

654 BVerwG, Urt. v. 25.9.2008, Az.: 7 C 5.08 = NVwZ 2009, 122; kritisch dazu Jäckel, NVwZ 2014, 1625, m.w.N. zu den verschiedenen Positionen.

655 S. dazu auch Detterbeck, Allgemeines Verwaltungsrecht, 17. Aufl. 2019, Rn. 1477 f.; Stelkens, in: Stelkens/Bonk/Sachs, VwVfG, 9. Aufl. 2018, § 43 Rn. $227 \mathrm{ff.}$

Tobias Brings-Wiesen 


\section{c) Rechtsschutz bei Beendigung der Wirksamkeit}

186 Auch im Falle der Beendigung der Wirksamkeit eines Verwaltungsakts können Betroffene unter bestimmten Umständen ein Rechtsschutzinteresse haben.

187 Hebt eine Behörde den Verwaltungsakt gemäß §§ 48, 49 oder 51 VwVfG (oder entsprechender spezialgesetzlicher Regelungen) auf, handelt es sich bei ihrer Entscheidung um einen neuen Verwaltungsakt, der wiederum im Wege des Widerspruchs gemäß § 68 I 1 VwGO bzw. der Anfechtungsklage gemäß § 42 I Var. 1 VwGO durch das Verwaltungsgericht aufgehoben werden kann.

188 Erledigt sich ein Verwaltungsakt durch Zeitablauf oder auf andere Weise können Betroffene gleichwohl ein fortbestehendes Interesse an der Klärung seiner Rechtswidrigkeit haben, die sie mit Hilfe der (verlängerten) Fortsetzungsfeststellungsklage gemäß § 113 I 4 VwGO (analog) erreichen können (s. dazu ausführlich § 4).

\section{Unwirksamkeit aufgrund von Nichtigkeit, § 43 III VwVfG}

189 Gemäß § 43 III VwVfG ist ein nichtiger Verwaltungsakt unwirksam. Die Vorschrift verweist somit auf die Regelung in \$ 44 VwVfG und spezialgesetzliche Nichtigkeitsvorschriften.

190 Mit § 43 III VwVfG hat der Gesetzgeber in Umsetzung des Grundsatzes der Gesetzmäßigkeit der Verwaltung (als Element des verfassungsrechtlichen Rechtsstaatsprinzip) ${ }^{656}$ die Wertentscheidung getroffen, bestimmte Rechtsfehler als so relevant zu erachten, dass ihr Vorliegen bereits ipso iure die Wirksamkeit eines Verwaltungsakts zerstört. Der Grundsatz der Gesetzmäßigkeit der Verwaltung überwiegt insofern ausnahmsweise den ebenfalls dem Rechtsstaatsprinzip entspringenden Grundsatz der Rechtssicherheit, der der grundsätzlichen Differenzierung von Wirksamkeit und Rechtmäßigkeit von Verwaltungsakten zugrunde liegt.

191 Zur Erinnerung: Nichtige Verwaltungsakte sind von sog. „Nichtakten“ zu unterscheiden. Während im Falle von Nichtakten bereits das Entstehen eines Verwaltungsakts scheitert, folgt aus $§ 43$ III VwVfG (zumeist bereits) in der juristischen Sekunde ihres Entstehens ihre Unwirksamkeit auf Grund von Nichtigkeit. Auch ,gegenstands- oder funktionslose Verwaltungsakte“ sind von nichtigen Verwaltungsakten abzugrenzen. ${ }^{657}$ Bei diesen Verwaltungsakten fehlt oder entfällt der sachliche Bezugspunkt der avisierten Regelung und es tritt „Erledigung auf andere Weise“ gemäß § 43 II VwVfG (s. dazu Rn. 185) ein.

656 S. dazu ausführlich Detterbeck, Allgemeines Verwaltungsrecht, 17. Aufl. 2019, Rn. 256 ff. 657 Ramsauer, in: Kopp/Ramsauer, VwVfG, 20. Aufl. 2019, § 44, Rn. 2a. 
Ein Verwaltungsakt kann je nach der Natur seines Fehlers von Beginn an 192 nichtig sein oder erst zu einem späteren Zeitpunkt nichtig werden. ${ }^{658}$ Liegen mehrere Fehler vor, sind diese - selbst im Falle der Nichtigkeit aufgrund eines Fehlers - vollständig nebeneinander zu prüfen. Liegt ein Nichtigkeitsgrund vor, sind sowohl eine Heilung als auch eine Unbeachtlichkeit von Verfahrens- und Formfehlern nicht mehr möglich (vgl. §§ 45 I, 46 VwVfG).

Nach den vorangehenden Ausführungen erscheint die Diskussion um einen

Rechtsschutz gegen nichtige Verwaltungsakte - wie im Falle von Nichtakten (s. dazu Rn. 174ff.) - auf den ersten Blick überflüssig: Soweit die Unwirksamkeit eines Verwaltungsakts auf Grund von Nichtigkeit gemäß § 44 i.V.m. § 43 III VwVfG ipso iure eintritt, entfaltet dieser ohne weiteres Zutun weder für die Betroffenen noch für den Staat rechtliche Wirkung. Ziel der vom Gesetzgeber speziell geschaffenen Rechtsbehelfe der behördlichen Feststellung der Nichtigkeit gemäß $\S 44$ V VwVfG und der Nichtigkeitsfeststellungsklage gemäß § 43 I Var. 3 VwGO (s. zu beiden näher $\S 6$ Rn. $73 \mathrm{ff}$. und 166ff.) ist sodann auch nicht die durch Widerspruch und Anfechtungsklage begehrte rechtsgestaltende Aufhebung eines Verwaltungsakts i.S.v. § 43 II VwVfG, sondern die Zerstörung des Rechtsscheins seiner Wirksamkeit durch die verbindliche Feststellung der (teilweisen ${ }^{659}$ ) Nichtigkeit. ${ }^{660}$

Gleichwohl sind die Rechtsschutzmöglichkeiten nicht auf diese beiden Optionen beschränkt. Es bieten sich sowohl auf behördlicher als auch auf gerichtlicher Ebene mehrere Wege, einem nichtigen Verwaltungsakt $\mathrm{zu}$ begegnen. Entsprechend vielgestaltig können auch Prüfungskonstellationen sein, in denen die Nichtigkeit eines Verwaltungsakts eine Rolle spielt.

Auf gerichtlicher Ebene kommt der Frage zentrale Bedeutung zu, ob auch die Anfechtungsklage gemäß § 42 I Var. 1 VwGO gegen nichtige Verwaltungsakte statthaft oder aber ein Kläger ausschließlich auf die Nichtigkeitsfeststellungsklage gemäß § 43 I Var. 3 VwGO zu verweisen ist (s. dazu Rn. 197). Hat die Behörde einen Antrag auf Feststellung der Nichtigkeit gemäß § 44 V VwVfG negativ beschieden, kann sich darüber hinaus die Frage stellen, ob dem Betroffenen die Möglichkeit einer Verpflichtungsklage gemäß § 42 I Var. 2 VwGO zur Durchsetzung

658 Ramsauer, in: Kopp/Ramsauer, VwVfG, 20. Aufl. 2019, § 43 Rn. 47; Schenke, DÖV 1990, 489 (496).

659 So wie ein Verwaltungsakt gerichtlich (s. dazu Rn. 259) und behördlich (s. dazu ausführlich Rn. 841) nur teilweise aufhebbar ist, kann sich sowohl die (behördliche wie gerichtliche) Feststellung der Nichtigkeit entsprechend § 44 IV VwVfG auch nur auf einen Teil des Verwaltungsakts beziehen. Diese Möglichkeit wird im Folgenden nicht wiederholt erwähnt, sondern ist mitzudenken.

660 Will/Rathgeber, JuS 2012, 1057 (1062); Schenke, JuS 2016, 97. 
der behördlichen Nichtigkeitsfeststellung nach §44 V VwVfG zustehen soll (s. dazu unter $\S 3$ Rn. $23 \mathrm{ff}$.).

Auf behördlicher Ebene bietet sich neben der behördlichen Feststellung der Nichtigkeit gemäß § 44 V VwVfG der Weg der Aufhebung des Verwaltungsakts qua Abhilfebescheid im Widerspruchsverfahren gemäß §§ 68 I 1, 72 VwGO (s. dazu Rn. 202) sowie die Aufhebung gemäß §§ 48f. VwVfG (s. dazu Rn. 862).

\section{a) Statthaftigkeit der Anfechtungsklage nach § 42 I Var. 1 VwGO bei nichtigen Verwaltungsakten?}

197 Eine heute ganz herrschende Meinung bejaht die Statthaftigkeit der Anfechtungsklage gemäß $\S 42$ I Var. 1 VwGO auch für den Fall, dass sie gegen einen potentiell nichtigen Verwaltungsakt erhoben wird. ${ }^{661}$

Dem könnte man bei streng dogmatischer Betrachtung entgegenhalten, dass das mit der Anfechtungsklage begehrte Ziel der Aufhebung eines Verwaltungsakts (§§ 42 I Var. 1, 113 I 1 VwGO; § 43 II VwVfG) im Falle eines bereits auf Grund von Nichtigkeit ipso iure eingetretener Unwirksamkeit ( $\$ 43$ III VwVfG) unerreichbar ist. ${ }^{662}$ Die herrschende Meinung legt den prozessrechtlichen Begriff des Verwaltungsakts in $\S 42$ I VwGO jedoch weit aus und fasst im Interesse eines umfassenden Rechtsschutzes auch nichtige Verwaltungsakte darunter. ${ }^{663}$ Dies wird konkret damit begründet, dass die Unterscheidung eines bloß rechtswidrigen und somit aufhebbaren von einem bereits nichtigen Verwaltungsakt schwierig ist und oft erst durch eine gerichtliche Entscheidung beantwortet werden kann. Der Kläger solle aber nicht das Risiko einer unstatthaften Anfechtungsklage tragen. ${ }^{664}$ Bestätigt wird dieses Ergebnis in systematischer Hinsicht: Die in § 43 II 2 VwGO normierte Ausnahme vom Grundsatz der Subsidiarität der Feststellungsklage gegenüber Gestaltungs- und Leistungsklagen setzt deren grundsätzliche Statthaftigkeit denklogisch voraus. ${ }^{665}$ Die Parallelität war vom Gesetzgeber überdies ausdrücklich so beabsichtigt. ${ }^{666}$

661 BVerwG, Urt.v. 20.3.1964, Az.: VII C 10.61 = BVerwGE 18, 154 (155); Maurer/Waldhoff, Allgemeines Verwaltungsrecht, 19. Aufl. 2017, §10 Rn. 93; Schenke, Verwaltungsprozessrecht, 16. Aufl. 2019, Rn. 183; Sodan, in: Sodan/Ziekow, VwGO, 5. Aufl. 2018, § 42 Rn. 23; § 43 Rn. 68, m.w. N. 662 Hufen, Verwaltungsprozessrecht, 11. Aufl. 2019, § 14 Rn. 11.

663 S. nur BVerwG, Urt. v. 20.3.1964, Az.: VII C 10.61 = BVerwGE 18, 154 (155); Schenke, JuS 2016, 97 (99).

664 S. nur Sodan, in: Sodan/Ziekow, VwGO, 5. Aufl. 2018, § 42 Rn. 23.

665 S. nur Schenke, JuS 2016, 97 (99f.).

666 BT-Drucks. 3/55, S. 32.

Tobias Brings-Wiesen 
Examenswissen: Umstritten ist indes die - davon abzugrenzende - Folgefrage von Inhalt und 199

Tenorierung des Urteils durch das Verwaltungsgericht (§ 113 I VwGO) im Falle der Nichtigkeit eines angefochtenen Verwaltungsakts. Diese ist auch insofern von Interesse, als sie das Prüfprogramm in einer Klausur determinieren kann. Je nach Positionierung kann eine Prüfung der Nichtigkeit durch das Gericht dahinstehen und können Ausführungen entsprechend auf die bloße Rechtswidrigkeit konzentriert erfolgen.

So wird einerseits vertreten, das Gericht habe auch im Rahmen der Anfechtungsklage als ein im Anfechtungsbegehren enthaltenes „Minus“, ${ }^{667}$ nach entsprechender Umdeutung (von Amts wegen) ${ }^{668}$ oder nach Umstellung des Klageantrags (auf Hinweis des Gerichts) ${ }^{669}$ - nur die Nichtigkeit des angegriffenen Verwaltungsakts festzustellen. Dafür spreche das - in § 43 II VwVfG auch eine systematische Bestärkung findende - dogmatische Argument, die Aufhebung eines Verwaltungsakts setze dessen Wirksamkeit voraus. ${ }^{670}$

Demgegenüber vertritt die Gegenmeinung, dass auch ein nichtiger Verwaltungsakt vom Gericht aufzuheben sei. ${ }^{671}$ Dafür spreche in systematisch-dogmatischer Hinsicht bereits der allgemeine Charakter der Anfechtungs- als Gestaltungsklage (vgl. §§ 42 I Var. 1, 113 I 1 VwGO). ${ }^{672}$ Wäre eine Aufhebung nicht möglich, hätte das Gericht gemäß § 86 III VwGO gar strenggenommen auf eine Umstellung des Aufhebungs- in einen Feststellungsantrag hinzuwirken, was jedoch aufgrund der damit einhergehenden zeitlichen Verzögerung aus prozessökonomischen Gründen und insofern teleologisch unbefriedigend wäre. ${ }^{673}$ Darüber hinaus gebiete dies eine am Gleichheitssatz des Art. 3 I GG orientierte verfassungskonforme Auslegung: Ein auf die bloße Feststellung der Nichtigkeit beschränktes Urteil hätte - wie alle Feststellungsurteile - lediglich inter partes-Wirkung und bliebe somit in seiner Rechtsschutzintensität hinter der erga omnes-Wirkung eines Gestaltungsurteils, mit dem es zur Aufhebung eines Verwaltungsakts käme, zurück, obwohl im Interesse der Gesetzmäßigkeit der Verwaltung mit der ipso iure eintretenden Unwirksamkeit eines Verwaltungsakts aufgrund von Nichtigkeit ( $\$ 43$ III VwVfG) gerade besonders schweren Rechtsfehlern begegnet werden solle (s. dazu Rn. 190). ${ }^{674}$

667 VGH München, Urt. v. 15.9.1983, Az.: 23 B 80 A.861 = NJW 1984, 626; Maurer/Waldhoff, Allgemeines Verwaltungsrecht, 19. Aufl. 2017, § 10 Rn. 93; auch Möstl, in: Posser/Wolff, VwGO, 50. Ed., Stand: 1.4.2019, § 43 Rn. 38, und Pietzcker, in: Schoch/Schneider/Bier, VwGO, 36. EL Februar 2019, § 42 I Rn. 18; § 43 Rn. 27.

668 Vgl. BSG, Urt. v. 21.6.1960, Az.: 3 RK 72/55 = NJW 1960, 2308 (2309).

669 Schmitt Glaeser/Horn, Verwaltungsprozessrecht, 15. Aufl. 2000, Rn. 139; Sodan, in: Sodan/ Ziekow, VwGO, 5. Aufl. 2018, § 42 Rn. 23, § 43 Rn. 68; letztlich auch Hufen, Verwaltungsprozessrecht, 11. Aufl. 2019, § 14 Rn. 11, § 29 Rn. 11.

670 Hufen, Verwaltungsprozessrecht, 11. Aufl. 2019, § 14 Rn. 11. Dies wird indes zu Recht mit dem grundsätzlichen Einwand gekontert, dass es dem Gesetzgeber konstruktiv freistehe, neben der in $\S 43$ III VwVfG formulierten Rechtsfolge der Unwirksamkeit weitere Rechtsfolgen zu normieren, Ipsen, Allgemeines Verwaltungsrecht, 11. Aufl. 2019, Rn. 696; Schenke, JuS 2016, 97 (101).

671 Schenke, Verwaltungsprozessrecht, 16. Aufl. 2019, Rn. 183; Schmidt-Kötters, in: Posser/Wolff, VwGO, 50. Ed., Stand: 1.7.2017, § 42 Rn. 21, jeweils m.w. N.

672 Schenke, JuS 2016, 97 (100). Unergiebig hinsichtlich des gesetzgeberischen Willens sind demgegenüber - entgegen der Auffassung von Schenke, a.a.O. (100, Fn. 25) - die Gesetzesmaterialien, vgl. BT-Drucks. 3/55, S. 32.

673 Schenke, JuS 2016, 97 (100).

674 Schenke, JuS 2016, 97 (100).

Tobias Brings-Wiesen 
200 Akzeptiert man die Statthaftigkeit der Anfechtungsklage, müssen im Folgenden uneingeschränkt deren Sachentscheidungsvoraussetzungen erfüllt sein. Dies bedeutet insbesondere, dass ein potentiell erforderliches Widerspruchs- bzw. Vorverfahren ( $\S 68 \mathrm{ff}$. VwGO) erfolglos durchgeführt und die Klagefristen ( 74 VwGO) eingehalten ${ }^{675}$ worden sein müssen.

201 Entsprechend umstritten ist auch die Frage einer Anwendbarkeit der Vorschriften über den vorläufigen Rechtsschutz gegenüber Verwaltungsakten (§§ 80 ff. VwGO, s. dazu ausführlich die $\S \S 8$ und 9). Insofern bestehen in argumentativer Hinsicht weitgehende Parallelen zum Streit um die Statthaftigkeit der Anfechtungsklage. Gegen eine Anwendung auf nichtige Verwaltungsakte ${ }^{676}$ wird vorgebracht, dass diese gemäß § 43 III VwVfG keine Wirkung entfalteten und sich daher die Frage der aufschiebenden Wirkung nicht stelle. Der vorläufige Rechtsschutz richte sich vielmehr nach $\S 123$ I VwGO. ${ }^{677}$ Die Gegenmeinung ${ }^{678}$ wendet demgegenüber jedoch ein, dass auch vom nichtigen Verwaltungsakt der Rechtsschein einer hoheitlichen Regelung ausgehe und insbesondere in den schwierigen Fällen der Differenzierung von bloßer Rechtswidrigkeit und Nichtigkeit die Schutzfunktion der ,aufschiebenden Wirkung“ als Interimslösung auch bei einem nichtigen Verwaltungsakt ausgelöst werde. ${ }^{679}$

\section{b) Erhebung eines Widerspruchs gegen den nichtigen Verwaltungsakt gemäß $\S \S 68 \mathrm{ff}$. VwGO}

202 Sofern die Statthaftigkeit der Anfechtungsklage gemäß § 42 I Var. 1 VwGO gegen einen nichtigen Verwaltungsakt bejaht wird, ist konsequenterweise auch die Erhebung eines - soweit gesetzlich vorgesehenen ${ }^{680}$ - Widerspruchs gemäß § 68 I 1 VwGO gegen einen nichtigen Verwaltungsakt zu akzeptieren. Wie hinsichtlich des

675 Hält man die behördliche Rücknahme eines nichtigen Verwaltungsakts gemäß § 48 VwVfG für zulässig, besteht im Falle der Verfristung auch die Möglichkeit einer darauf gerichteten Verpflichtungsklage, Schenke, JuS 2016, 97 (100).

676 Gegen eine Anwendung OVG Münster, Beschl.v. 27.2.1992, Az.: 7 B 2686/92 = NVwZ-RR 1993, 234; Puttler, in: Sodan/Ziekow, VwGO, 5. Aufl. 2018, § 80 Rn. 20; Gersdorf, in: Posser/Wolff, VwGO, 50. Ed., Stand: 1.7.2018, § 80 Rn. 8.

677 OVG Münster, Beschl. v. 27.2.1992, Az.: 7 B 2686/92 = NVwZ-RR 1993, 234.

678 W.-R. Schenke, in: Kopp/Schenke, 25. Aufl. 2019, § 80 Rn. 5, 16; Schoch, in: Schoch/ Schneider/Bier, VwGO, 36. EL Februar 2019, § 80 Rn. 37; Bostedt, in: Fehling/Kastner/Störmer, Verwaltungsrecht, 4. Aufl. 2016, §80 VwGO Rn. 18; Funke-Kaiser, in: Bader/Funke-Kaiser/ Stuhlfauth/von Albedyll, VwGO, 7. Aufl. 2018, § 80 Rn. 8; tendenziell auch VGH Mannheim, Beschl. v. 7.12.1990, Az.: 10 S 2466/90 = NVwZ 1991, 1195 (1195f.).

679 So insbesondere Schoch, in: Schoch/Schneider/Bier, VwGO, 36. EL Februar 2019, § 80 Rn. 37. $680 \mathrm{Zu}$ den in § $68 \mathrm{I} 2 \mathrm{VwGO}$ vorgesehenen Abweichungsbefugnissen ausführlich Rn. $308 \mathrm{ff}$.

Tobias Brings-Wiesen 
Urteils des Verwaltungsgerichts (s. dazu Rn. 199) ist jedoch auch im Hinblick auf den Abhilfebescheid der Widerspruchsbehörde ( $\$ 72$ VwGO) umstritten, ob diese auf die bloße Feststellung der Nichtigkeit beschränkt ist ${ }^{681}$ oder den angegriffenen nichtigen Verwaltungsakt aufhebt ${ }^{682}$.

\section{Literaturhinweise}

Lehrbeiträge: Beaucamp, Rechtsfragen der Bekanntgabe nach §41 VwVfG, JA 203 2016, 436; Blunk/Schröder, Rechtsschutz gegen Scheinverwaltungsakte, JuS 2005, 602; Erichsen/Hörster, Die Bekanntgabe von Verwaltungsakten, JURA 1997, 659; Ernst/Pinkl, Genehmigungsfiktion und Fiktionsbescheinigung nach § 42a VwVfG, JURA 2013, 685; Herrmann, Aus dem Leben eines Verwaltungsaktes, ZJS 2011, 25; Korte, in: Wolff/Bachof/Stober/Kluth, Verwaltungsrecht I, 13. Aufl. 2017, § 48, passim; Kümper, Das Verkehrszeichen als Quelle klassischer Probleme des Verwaltungs- und Verwaltungsprozessrechts, JuS 2017, 731 und 833; Milker, Die Bekanntgabe von Verkehrszeichen, JURA 2017, 271; Reimer, Die Erledigung des Verwaltungsakts, Die Verwaltung 2015, 259; Schoch, Die Bekanntgabe des Verwaltungsakts, JURA 2011, 23; Weber, Die Bedeutung der Bekanntgabe des schriftlichen Verwaltungsaktes, VR 2016, 299; Wolff, in: Wolff/Decker, VwGO/ VwVfG, 3. Aufl. 2012, § 43 VwVfG

Fallbearbeitungen: Grupp/Stelkens, Abgeschleppt und abgezockt?, abrufbar unter http://www.saarheim.de/Faelle/abgeschleppt-fall.htm (Bearbeitungsstand: 2.10.2018); Hong, Altes und Neues zum Abschleppen und zur Bekanntgabe und Anfechtung von Verkehrszeichen, JURA 2012, 473

\section{Die Anfechtung von Nebenbestimmungen (Christian Kaerkes)}

Verwaltungsakte (§35 VwVfG) erlauben der Behörde, bestimmte Rechtsfolgen 204 gegenüber dem Bürger herbeizuführen. Die Behörde kann im Rahmen der Gesetze eine Vielzahl von Handlungen mittels Verwaltungsakts (s. zum Verwaltungsakt Rn. $38 \mathrm{ff}$.) erlauben oder verbieten.

Beispiele: Erlaubnis zur Errichtung eines Gebäudes (Baugenehmigung); Aufstellen von Verkehrszeichen (z.B. Parkverbot); Genehmigung des Verkaufs von alkoholischen Getränken

681 So Hufen, Verwaltungsprozessrecht, 11. Aufl. 2019, § 9 Rn. 9; Schmitt Glaeser/Horn, Verwaltungsprozessrecht, 15. Aufl. 2000, Rn. 218; Geis, in: Sodan/Ziekow, VwGO, 5. Aufl. 2018, § 73 Rn. 36 (Fn. 90).

682 So Schenke, Verwaltungsprozessrecht, 16. Aufl. 2019, Rn. 686; Schenke, JuS 2016, 97 (101). 
(„Schanklizenz“); Einwilligung zur Platzierung von Tischen und Stühlen auf dem Gehweg vor einem Restaurant (Sondernutzungserlaubnis)

205 Diese Verwaltungsakte sind für sich genommen aber reichlich unflexibel. Die Behörde kann die Baugenehmigung erteilen oder nicht. Der Verkauf von alkoholischen Getränken kann nur erlaubt oder abgelehnt werden. Es ist aber einsichtig, dass zumindest im realen Leben eine gewisse Flexibilität notwendig ist. Wenn nur Nebensächlichkeiten an dem Bauvorhaben des Bürgers problematisch sind, dann sollte nicht deswegen die Baugenehmigung abgelehnt werden. Das Gesetz kennt aus diesem Grund die sogenannten Nebenbestimmungen. ${ }^{683}$

206 Nebenbestimmungen sind nach gängiger Definition „einem Verwaltungsakt beigefügte Regelungen, die dessen Inhalt einschränken oder ergänzen“ “. ${ }^{684} \mathrm{Das} \mathrm{Ge}$ setz enthält und definiert bestimmte Nebenbestimmungen in § 36 II VwVfG (und den inhaltsgleichen Länderregelungen ${ }^{685}$ ):

- Befristung,

- Bedingung,

- Widerrufsvorbehalt,

- Auflage und

- Auflagenvorbehalt.

207 Nebenbestimmungen sind Zusätze, die zu einem sogenannten „Hauptverwaltungsakt“ hinzugefügt werden können. Ein kleineres Problem an dem Bauantrag eines Bürgers (z. B. eine fehlende Feuertreppe) muss der Baugenehmigung (als Hauptverwaltungsakt) dann nicht mehr entgegenstehen. Stattdessen ist es der Behörde möglich, die Genehmigung mit dem Zusatz (einer Nebenbestimmung) zu erteilen, noch eine Feuertreppe zu errichten. Nebenbestimmungen ermöglichen Flexibilität. Die Behörde muss nicht mehr „Nein!“ zu dem Antrag des Bürgers sagen, sondern kann mit „Ja, aber!“ antworten. Das liegt regelmäßig auch im Interesse des Antragsstellers:

„Einen begünstigenden Verwaltungsakt unter Beifügung einer Nebenbestimmung zu erteilen, ist vielfach das mildere Mittel gegenüber einer sonst erforderli-

683 Vgl. Brenner, JuS 1996, 281.

684 Statt vieler Axer, Jura 2001, 748.

685 § 36 II LVwVfG BW; Art. 36 II BayVwVfG; § 1 I BlnVwVfG i.V. m. § 36 II VwVfG; § 1 II VwVfGBbg i.V.m. § 36 I VwVfG; § 36 II BremVwVfG; § 36 II HmbVwVfG; § 36 II HVwVfG; § 36 II VwVfG M-V; § 1 I NVwVfG i.V.m. § 36 II VwVfG; § 36 II VwVfG NRW; § 1 I LVwVfG RLP i.V.m. § 36 II VwVfG; § 36 II SVwVfG; § 1 SächsVwVfZG i.V.m. § 36 II VwVfG; § 1 I VwVfG LSA i.V.m. § 36 II VwVfG; § 107 II LVwG SH; § 36 II ThürVwVfG.

\section{Christian Kaerkes}


chen Ablehnung. "686 Die Formulierung des Bundesverwaltungsgerichts bringt klar zum Ausdruck, dass der Bürger ein Interesse an dem Erlass von Nebenbestimmungen hat: Lieber eine Genehmigung mit Nebenbestimmungen, als überhaupt keine Genehmigung. Das gilt natürlich nicht nur für die Baugenehmigung (dem Beispiel, das besonders relevant ist), sondern für alle begünstigenden Verwaltungsakte, die dem Bürger einen Vorteil bieten.

Allerdings stellen Nebenbestimmungen zugleich eine Belastung dar, weil 208 sie den Hauptverwaltungsakt einschränken. Möchte ein Gastwirt dauerhaft Sitzplätze vor seiner Gaststätte anbieten, dann ist die Einschränkung dieser Genehmigung auf einen Monat für ihn ein Problem und unerwünscht. In diesen Fällen muss für den Bürger die Möglichkeit bestehen, sich gegen die Einschränkung seiner Genehmigung zur Wehr zu setzen. Der Rechtsschutz gegen Nebenbestimmungen ist nicht nur der Klausurklassiker, sondern auch in Literatur und Rechtsprechung seit langem umstritten (s. dazu Rn. $249 \mathrm{ff}$.).

\section{Die Nebenbestimmungen im Einzelnen}

Im Folgenden werden die verschiedenen Nebenbestimmungen genauer darge- 209 stellt. Es ist wichtig, dass Nebenbestimmungen im Gutachten erkannt und richtig eingeordnet werden, weil sich die Wirkungen der einzelnen Nebenbestimmungen zum Teil wesentlich voneinander unterscheiden.

\section{a) Befristung}

Die Befristung ist die wohl „einfachste“ Nebenbestimmung, die der Behörde zur 210 Verfügung steht. Gem. § 36 II Nr. 1 VwVfG ist die Befristung eine „Bestimmung, nach der eine Vergünstigung oder Belastung zu einem bestimmten Zeitpunkt beginnt, endet oder für einen bestimmten Zeitraum gilt““ ${ }^{687}$ Der Verwaltungsakt wird demnach in seiner Geltung zeitlich begrenzt, nicht aber inhaltlich verändert.

Beispiele: Gewährung der Sondernutzungserlaubnis bis zum Ende des Jahres; Erteilung der Baugenehmigung ab Beginn des neuen Monats; Parkverbot an einer Straße für die Dauer einer Baustelle

Das Kennzeichen der Befristung ist, dass der Eintritt des angegebenen Zeitpunktes 211 sicher ist. Wenn der Zeitpunkt durch ein Datum festgelegt wird, ist das offen-

686 BVerwG, Urt. v. 9.12.2015, Az.: 6 C 37.14 = BVerwGE 153, 301 = JuS 2016, 959 (m. Anm. Waldhoff) = JA 2016, 799 (m. Anm. Hebeler).

687 Vgl. Wagner, JA 2008, 866. 
sichtlich der Fall. Ausreichend ist aber auch, dass das Datum nur bestimmbar ist. ${ }^{688}$ Die Erlaubnis, die Parkplätze einer Schule nur während der Ferien nutzen zu dürfen, wäre folglich eine zulässige Befristung des Hauptverwaltungsakts. Schließlich kann die Dauer der Ferien kalendermäßig bestimmt werden.

Beispiele: ${ }^{69}$ Erlaubnis zum Aufstellen von Stühlen auf dem Gehweg für die Monate Mai bis Oktober; Erster Prüfungstermin des Jahres; Aufstellung des Imbissstandes nach Ende des Handwerkermarktes

In allen diesen Fällen steht mit Sicherheit fest, dass das „Ereignis“ eintritt. Der Handwerkermarkt wird enden und irgendwann die erste Prüfung stattfinden. In diesen Fällen kann sogar das Datum genauer bestimmt werden. Das ist aber nicht zwingend erforderlich, wenn der Eintritt des Ereignisses zumindest sicher ist.

Beispiel: Monatliche Auszahlung einer Geldsumme bis zum Tod des Leistungsempfängers

Hier ist der Hauptverwaltungsakt auch wirksam befristet, obwohl noch nicht bekannt ist, wann genau der Empfänger der Leistung verstirbt. Der Tod wird aber mit Sicherheit eintreten, weshalb es sich um eine zulässige Befristung handelt. ${ }^{690}$

\section{b) Bedingung}

212 Die Bedingung ist eine „Bestimmung, nach der der Eintritt oder Wegfall einer Vergünstigung oder einer Belastung von dem ungewissen Eintritt eines zukünftigen Ereignisses abhängt“, vgl. §36 II Nr. 2 VwVfG. Die Bedingung unterscheidet sich von der Befristung dadurch, dass der Eintritt des Ereignisses noch im Ungewissen liegt.

Beispiele: Genehmigung zum Betrieb einer Anlage, wenn vorher die Luftfilter erneuert werden; Aufenthaltsgenehmigung für den Fall einer beruflichen Anstellung; Erteilung einer Baugenehmigung, wobei weitere Stellplätze zu schaffen sind

Diese Ereignisse sind noch ungewiss und können deshalb als Bedingung qualifiziert werden. Die Filter können erneuert werden, müssen es aber nicht. Der Arbeitgeber kann die berufliche Anstellung durch eine Kündigung beenden, ist dazu aber nicht gezwungen. Es ist möglich, zusätzliche Stellplätze zu schaffen,

688 Brenner, JuS 1996, 281 (283).

689 Voßkuhle/Kaiser, JuS 2012, 699 (700); Brenner, JuS 1996, 281 (283); Axer, Jura 2001, 748. 690 Erichsen, Jura, 1990, 214 (215). 
aber keine Pflicht. Diese Zusätze können daher als Bedingung verstanden werden (s. zur Abgrenzung von der Auflage Rn. 222ff.).

Weiterhin unterscheidet man drei verschiedene Arten von Bedingungen: ${ }^{691}$

- Aufschiebende Bedingung,

- Auflösende Bedingung und

- Potestativbedingung.

Eine aufschiebende Bedingung liegt dann vor, wenn die Wirksamkeit des 214 Hauptverwaltungsaktes von dem Eintritt des ungewissen Ereignisses abhängig sein soll. Erst mit Eintritt des Ereignisses kann von der Genehmigung Gebrauch gemacht werden. Vorher sind die Wirkungen des Hauptverwaltungsaktes in die Zukunft verschoben.

Beispiel: In dem Beispiel in Rn. 212 darf das Gebäude errichtet werden, sobald die Stellplätze geschaffen worden sind, aber nicht davor.

Um eine auflösende Bedingung handelt es sich hingegen, wenn die rechtlichen Wirkungen des Hauptverwaltungsaktes mit dem Eintritt des ungewissen Ereignisses ihr Ende finden sollen. Dann würde sich die Genehmigung gewissermaßen „in Luft auflösen“ und der Begünstigte kann von dieser Erlaubnis keinen Gebrauch mehr machen.

Beispiel: Erfolgt in dem anderen Beispiel in Rn. 212 die Kündigung des Arbeitnehmers, erlischt die Aufenthaltsgenehmigung.

Die Potestativbedingung zeichnet sich dadurch aus, dass der Eintritt des un- 216 gewissen Ereignisses vom Willen (meist des Begünstigten) abhängt. Weil Menschen handeln können, aber nicht müssen, ist das Ereignis als ungewiss anzusehen. Potestativbedingungen werden deshalb verwendet, weil sie einen Anreiz zu dem in der Bedingung vorgegebenen Verhalten schaffen.

Beispiel: Möchte der Bauherr (in dem Beispiel in Rn. 212) etwa sein Gebäude errichten, dann wird er auch dazu bereit sein, weitere Stellplätze zu schaffen.

Examenswissen: Zum Thema Bedingungen ist unlängst eine Entscheidung des Bundesverwal- 217 tungsgerichts ergangen. ${ }^{692}$ Das Urteil hat zwei Punkte deutlich gemacht:

Ereignisse müssen äußerlich wahrnehmbar sein: Das Gericht hat sich dabei zunächst von

691 Vgl. Detterbeck, Allgemeines Verwaltungsrecht, 17. Aufl. 2019, § 10 Rn. 647 ff. 692 BVerwG, Urt. v. 16.6.2015, Az.: 10 C 15.14 = BVerwGE 152, 211 = ZJS 2015, 532 (m. Anm. Wißmann) $=$ JuS 2016, 187 (m. Anm. Waldhoff). 
dem Prinzip der Rechtssicherheit leiten lassen. Es dürfe nicht sein, dass das Ereignis nur in der „Gedankenwelt“ vorkomme. Die Behörde könne den Hauptverwaltungsakt nicht unter den Vorbehalt einer nur internen Neubewertung stellen. Da mit dem Eintritt des Ereignisses Rechtswirkungen verbunden sind, ist es notwendig, dass das Ereignis durch alle Beteiligten wahrgenommen werden können muss.

„Überprüfungsvorbehalte“ sind keine Bedingungen: Überprüfungsvorbehalte würden es der Behörde erlauben, den Hauptverwaltungsakt einfach zu beseitigen. Durch einen solchen Vorbehalt drohten die Regelungen über den Widerruf und die Rücknahme unterlaufen zu werden. $\S \S 48,49$ VwVfG erfordern immerhin die Einhaltung von Fristen und die Berücksichtigung des schutzwürdigen Vertrauens des Bürgers. An diese Voraussetzungen sollte die Behörde weiterhin gebunden sein.

\section{c) Auflage, Abgrenzung und „modifizierende Auflage“}

218 Eine bedeutsame Nebenbestimmung ist die Auflage. Diese Nebenbestimmung wird immer wieder in Klausuren relevant und muss daher unbedingt beherrscht werden. Schwierigkeiten bereitet dabei vor allem die Abgrenzung zur Bedingung und zur „modifizierenden Auflage“.

\section{aa) Auflage}

219 Die Auflage ist gem. §36 II Nr. 4 VwVfG eine „Bestimmung, durch die dem Begünstigten ein Tun, Dulden oder Unterlassen vorgeschrieben wird“. Kennzeichen der Auflage ist, dass durch sie eine zusätzliche Verpflichtung geschaffen wird, die neben den Hauptverwaltungsakt tritt.

Beispiele: Genehmigung für eine Gaststätte mit der Maßgabe, Maßnahmen zum Lärmschutz zu ergreifen; Fahrerlaubnis mit dem Zusatz, regelmäßig die Abstinenz von Drogen/Alkohol nachzuweisen; Erlaubnis zum Fällen von Bäumen, sofern an anderer Stelle neue Bäume gepflanzt werden

Der Antragssteller erhält in allen diesen Fällen seine Genehmigung, wenn auch mit einer weiteren Verpflichtung. Diese Verpflichtung ist aber akzessorisch, das bedeutet, dass die Verpflichtung vom Hauptverwaltungsakt abhängig ist. ${ }^{693}$ Die Maßnahmen zum Lärmschutz müssen nur dann ergriffen werden, wenn die Genehmigung wirksam ist und genutzt wird. Ohne den Hauptverwaltungsakt hat die Auflage folglich keinerlei Bedeutung.

Beispiele: Wird die Fahrerlaubnis aufgehoben, dann entfällt gleichzeitig auch die Verpflichtung der Auflage, regelmäßig an Drogen- und Alkoholtests teilzunehmen; Beschließt der Begüns-

693 Brenner, JuS 1996, 281 (284).

Christian Kaerkes 
tigte, die Bäume doch nicht zu fällen, dann entfaltet die Auflage keine Wirkung und er muss folglich keine neuen Bäume pflanzen.

Die Auflage ist aber in gewisser Weise doch selbstständig und unterscheidet sich 220 damit insbesondere von der Bedingung. ${ }^{694}$ Was geschieht, wenn die Verpflichtung nicht erfüllt wird? Im Fall einer auflösenden Bedingung erlischt die bisherige Genehmigung. Würde es sich hingegen um eine Auflage handeln, dann bliebe die Genehmigung bestehen, die Verpflichtung könnte aber durch die Behörde erzwungen werden.

Beispiel: Werden keine Maßnahmen zum Lärmschutz ergriffen, dann wird die Genehmigung entweder unwirksam (Bedingung) oder die Genehmigung bleibt wirksam, wobei der Lärmschutz durch die Behörde erzwungen werden kann (Auflage).

Es macht daher für den Bürger einen großen Unterschied, ob es sich um eine Auflage oder Bedingung handelt. Diesen Unterschied hat von Savigny mit seiner bekannten Formulierung „Die Bedingung suspendiert, zwingt aber nicht; der Modus [die Auflage] zwingt, suspendiert aber nicht. “ auf den Punkt gebracht. ${ }^{695}$ In dem einen Fall handelt der Bürger ohne Genehmigung, in dem anderen Fall mit einer Genehmigung, wobei die Auflage durch die Behörde erzwungen werden kann.

Die Auflage kann Gebote oder Verbote enthalten, die nach allgemeinen Re- 221 geln durchsetzbar sind. Die Behörde kann von den Mitteln der Verwaltungsvollstreckung Gebrauch machen und die Einhaltung der Auflage erzwingen (s. zur Verwaltungsvollstreckung Rn. 1292ff.). Grundsätzlich kommen etwa das Zwangsgeld oder die Ersatzvornahme in Betracht. Erweist sich die Verwaltungsvollstreckung einmal nicht als ausreichend, kann die Behörde auch die Genehmigung gem. § 49 II Nr. 2 VwVfG widerrufen und damit den Hauptverwaltungsakt beseitigen.

Beispiel: Sind die Bäume gefällt worden, ohne dass vorher neue Bäume gepflanzt worden sind, kann die Behörde ein Zwangsgeld festsetzen, damit die Auflage doch noch erfüllt wird.

\section{bb) Abgrenzung von Bedingung und Auflage}

Bedingung und Auflage unterscheiden sich in ihren rechtlichen Wirkungen. Die 222 Auflage kann nur durch die Behörde durchgesetzt werden, wohingegen die Bedingung ihre Wirkung automatisch entfaltet und nicht auf das Tätigwerden der

694 Maurer/Waldhoff, Allgemeines Verwaltungsrecht, 19. Aufl. 2017, § 12 Rn. $10 \mathrm{ff}$. 695 V. Savigny, System des heutigen römischen Rechts, Band III, 1840, S. 231.

Christian Kaerkes 
Behörde angewiesen ist. Weil sich Auflage und Bedingung überschneiden können, ist eine Abgrenzung unumgänglich.

Beispiel: Dürfen die Bäume erst gefällt werden, wenn an anderer Stelle neue Bäume gepflanzt wurden (aufschiebende Bedingung), oder schon zuvor, aber mit der späteren Möglichkeit der zwangsweisen Durchsetzung (Auflage)?

223 Es sind grundsätzlich folgende Abgrenzungskriterien anerkannt: ${ }^{696}$

- Wortlaut der Nebenbestimmung,

- Wichtigkeit des Gebots oder Verbots,

- Rechtmäßigkeit des Zusatzes und

- Im Zweifel: Auflage.

224 Zunächst ist von der Formulierung der Nebenbestimmung auszugehen. Spricht diese ausdrücklich von einer Auflage oder Bedingung, ist anzunehmen, dass die Behörde die Nebenbestimmung mit Bedacht gewählt hat. Allerdings kommt dem Wortlaut wohl nur eine Indizwirkung zu. Es ist nicht ausgeschlossen, dass sich die Behörde geirrt oder schlicht nur allgemein von „Nebenbestimmungen“ gesprochen hat. ${ }^{697}$

225 Wichtiger ist daher die Bedeutung der Erfüllung des Gebots oder Verbots (für die Behörde). Es muss danach gefragt werden, ob die Genehmigung mit der Nebenbestimmung „stehen oder fallen“ soll. ${ }^{698}$ Je bedeutsamer die Erfüllung des Gebots oder Verbots ist, desto eher handelt es sich um eine Bedingung und nicht um eine Auflage. Bei der Auflage ist deshalb Vorsicht geboten, weil der Begünstigte von der Genehmigung Gebrauch machen kann.

Beispiel: Baugenehmigung mit dem Zusatz der Behörde, noch ein Gutachten über die Standsicherheit des geplanten Gebäudes vorzulegen

Hier wäre von einer aufschiebenden Bedingung auszugehen. Da das Gutachten dazu dient, Gefahren für Menschen auszuschließen, wäre es verfehlt, wenn mit dem Bau begonnen werden dürfte, obwohl das Gutachten noch nicht vorliegt. Die Genehmigung soll deshalb mit der Verpflichtung „stehen oder fallen“. Das erreicht aber nur die (aufschiebende) Bedingung, weil die Auflage die Wirksamkeit des Hauptverwaltungsaktes unberührt lässt.

696 Voßkuhle/Kaiser, JuS 2012, 699 (701).

697 Brenner, JuS 1996, 281 (282).

698 Wagner, JA 2008, 866 (867).

Christian Kaerkes 
Ein weiteres Kriterium ist schließlich die Zulässigkeit der Nebenbestimmung. 226 Ist zum Beispiel nur die Auflage, nicht aber die Bedingung rechtmäßig, dann spricht dies für eine Auflage. Da die Behörde an das Gesetz gebunden ist, kann davon ausgegangen werden, dass die Behörde auch rechtmäßig handeln wollte.

Verbleiben am Ende noch Zweifel, ob es sich um eine Bedingung oder Auf- 227 lage handelt, ist von einer Auflage auszugehen. Die Auflage ist im Verhältnis zur Bedingung das mildere Mittel, immerhin kann von der Genehmigung schon Gebrauch gemacht werden. ${ }^{69}$ Im Zweifel kann deshalb von einer Auflage ausgegangen werden, weil die durch die Behörde verursachten Unklarheiten nicht zu Lasten des Bürgers gehen sollten.

\section{cc) „Modifizierende Auflage“ und Inhaltsbestimmung}

Die sogenannte modifizierende Auflage ist keine Nebenbestimmung, insbeson- 228 dere keine Auflage im Sinne des § 36 II Nr. 4 VwVfG. Der Begriff „modifizierende Auflage“ ist von Weyreuther geprägt worden ${ }^{700}$ und beschreibt vor allem „eine qualitative Änderung der Gewährung in bezug auf den Antragsgegenstand“. ${ }^{701}$ Diese komplizierte Formulierung beschreibt eine Situation, in der die erteilte Genehmigung von dem Antrag des Bürgers inhaltlich abweicht (,Inhaltsbestimmung“).

Beispiele: Baugenehmigung mit einem Flachdach, anstatt des beantragten Giebeldachs; Baugenehmigung für ein einstöckiges, aber kein mehrstöckiges Gebäude; Sondernutzungserlaubnis für ein religiöses Straßenfest an einem anderen Tag

In diesen Fällen erhält der Bürger zwar eine Genehmigung, allerdings mit einem Inhalt, der in dieser Form nicht von ihm beantragt wurde. De facto ist der ursprüngliche Antrag erst abgelehnt und dann ein veränderter Verwaltungsakt erlassen worden. Ein eingeschossiges Gebäude ist inhaltlich etwas anderes als ein mehrgeschossiges Gebäude. Ein Flachdach kann nicht mit einem Giebeldach verglichen werden. Im Zivilrecht könnte die „modifizierende Auflage“ als ein „Aliud“ verstanden werden. ${ }^{702}$

In der Vergangenheit sind diese inhaltlichen Veränderungen als Auflage be- 229 zeichnet worden. Diese falsche Bezeichnung ändert aber auch nichts daran,

699 Brenner, JuS 1996, 281 (285).

700 Weyreuther, DVBl. 1969, 295 und deutlicher in DVBl. 1984, 365.

701 BVerwG, Urt. v. 8.2.1974, Az.: IV C 73.72 = BVerwG, DÖV 1974, 380 (381).

702 Axer, Jura 2001, 748 (750). 
dass es sich in Wirklichkeit nicht um eine Nebenbestimmung handelt. ${ }^{703}$ Der Bürger erhält keine Baugenehmigung für ein mehrstöckiges Haus mit der Auflage, nur einen Stock zu bauen, sondern die Genehmigung ist von vornherein beschränkt und nur in diesem Umfang erlassen worden.

Das hat erhebliche Bedeutung für den Begünstigten: Errichtet er dennoch ein mehrgeschossiges Gebäude, dann handelt er ohne die erforderliche Genehmigung und sein Bau ist rechtswidrig. Möchte er das Haus in seiner gewünschten Art und Weise errichten, muss zwingend Rechtsschutz vor den Gerichten begehrt werden (Verpflichtungsklage auf Erlass der erweiterten Baugenehmigung).

Die Abgrenzung der „modifizierenden Auflage“ bzw. der Inhaltsbestimmung von einer regulären Auflage ist im Einzelfall schwierig. Es muss sich um eine wesentliche, inhaltliche Abweichung vom Antrag handeln. Dabei kann u.a. auf die folgenden Kriterien abgestellt werden:

- Durchsetzbarkeit der vermeintlichen Auflage,

- Umfang der Abweichung vom Antrag und

- Bedeutung des Elements für das Vorhaben.

231 Grundsätzlich gilt: Desto mehr die Gewährung von dem Antrag abweicht, desto eher handelt es sich um eine Inhaltsbestimmung. Vorhaben werden nämlich durch bestimmte konstitutive Merkmale bestimmt. ${ }^{704}$ Ein Haus ohne Dach ist nicht mehr sinnvoll als Haus zu bezeichnen. Verändert die Behörde das beantragte Dach, spricht dies für eine Inhaltsbestimmung und gegen eine echte Auflage.

232 Schließlich kann auch danach gefragt werden, ob die vermeintliche Auflage zumindest selbstständig durchsetzbar wäre. ${ }^{705}$ Würde das Gebäude mit einem Giebeldach erbaut, wie sollte die Behörde sinnvoll ein Flachdach im Wege der Verwaltungsvollstreckung durchsetzen? Es ist ein Kennzeichen der Auflage, dass diese rechtlich durchsetzbar ist. Ist das nicht möglich, handelt es sich mithin um eine Inhaltsbestimmung und keine Nebenbestimmung.

\section{d) Widerrufs- und Auflagenvorbehalt}

233 Der Vorbehalt des Widerrufs ( $§ 36$ II Nr. 3 VwVfG) ergibt nur im Zusammenspiel mit § 49 II Nr. 1 VwVfG einen Sinn. Danach ist der Widerruf eines rechtmäßigen Verwaltungsakts möglich, wenn dieser „im Verwaltungsakt vorbehalten ist“. Die Ankündigung in der Nebenbestimmung, dass der Verwaltungsakt widerrufen

703 Erichsen, Jura 1990, 214 (216).

704 Vgl. Bumke, in: Festschrift für Battis, 2014, 177 (184).

705 Detterbeck, Allgemeines Verwaltungsrecht, 17. Aufl. 2019, § 10 Rn. 657.

Christian Kaerkes 
werden kann, verhindert die Entstehung schutzwürdigen Vertrauens. ${ }^{706}$ Der Bürger wird gewarnt, dass er seine Genehmigung wieder verlieren könnte.

Beispiele: Baugenehmigung für die Aufstellung von Werbeanlagen mit Widerrufsvorbehalt; Erhalt einer Subvention unter Widerrufsvorbehalt

Konsequenz eines Widerrufsvorbehalts ist auch, dass keine Entschädigung im Falle der Aufhebung des Verwaltungsakts zu zahlen ist, vgl. § 49 VI 1 VwVfG.

Allerdings ist ein Widerruf nicht willkürlich möglich, sondern erfordert 234 die Ausübung pflichtgemäßen Ermessens. ${ }^{707}$ Insbesondere hat sich die Behörde an dem Sinn und Zweck des Gesetzes zu orientieren. Der Widerruf für die Baugenehmigung zur Aufstellung von Werbeanlagen darf nicht deshalb erfolgen, weil der Begünstigte zu schnell mit seinem Auto gefahren ist. Hier besteht kein Zusammenhang zwischen dem vermeintlichen Anlass und dem Baurecht. Die Subvention könnte aber widerrufen werden, wenn Anzeichen dafür bestehen, dass die Gelder nicht wirtschaftlich verwendet werden.

Der Auflagenvorbehalt meint den „,Vorbehalt der nachträglichen Aufnahme, 235 Änderung oder Ergänzung einer Auflage“, vgl. § 36 II Nr. 5 VwVfG. Er hat mit dem Widerrufsvorbehalt gemeinsam, dass die Entstehung von schutzwürdigem Vertrauen grundsätzlich verhindert wird. Auflagenvorbehalt und Widerrufsvorbehalt unterscheiden sich aber dadurch, dass der Auflagenvorbehalt im Vergleich das mildere Mittel darstellt. ${ }^{708}$ Anstatt den Hauptverwaltungsakt vollständig durch einen Widerruf aufzuheben, wird nur eine nachträgliche Auflage erlassen.

Verwendung findet der Auflagenvorbehalt insbesondere bei Unsicherheiten 236 über die zukünftige Entwicklung bestimmter Umstände.

Beispiele: Unklare Lärmbelästigung durch eine neue Gaststätte; Unsicherheit über den Grad der Luftverschmutzung durch eine neue Fabrik

Die Behörde kann in diesen Situationen noch nicht genau wissen, welche Auflagen später im Einzelnen erforderlich sein könnten. Trotzdem sollte es auch unter diesen Umständen im Interesse des Bürgers möglich sein, die entsprechenden Genehmigungen zu erteilen. Der Auflagenvorbehalt erlaubt es nun der Behörde, nachträglich die notwendigen Auflagen zu erlassen. Stellt sich heraus, dass von der Fabrik eine erhebliche Luftverschmutzung ausgeht, könnte der Einbau einer Filteranlage angeordnet werden.

706 Maurer/Waldhoff, Allgemeines Verwaltungsrecht, 19. Aufl. 2017, § 12 Rn. 9.

707 Erichsen, Jura 1990, 214 (216f.).

708 Vgl. Tiedemann, in: Bader/Ronellenfitsch, VwVfG, 44. Ed., Stand: 1.7.2019, § 36 Rn. 68. 


\section{e) Keine Nebenbestimmungen}

237 Es existieren noch zwei weitere scheinbare Nebenbestimmungen, die aber in Wirklichkeit gar keine Nebenbestimmungen darstellen:

- „Hinweise“ auf die Rechtslage und

- „Auflagen“ ohne Hauptverwaltungsakt.

In beiden Fällen handelt es sich selbst dann nicht um Nebenbestimmungen, wenn sie als „Auflagen“ bezeichnet werden: ${ }^{709}$ Hinweise auf die Rechtslage sind deshalb keine Auflagen, weil ihnen keine neue Regelungswirkung zukommt. Das entsprechende Gebot oder Verbot besteht schon kraft Gesetzes, sodass es überhaupt keiner Nebenbestimmung bedarf.

Beispiele: Hinweis, dass die Genehmigung nicht verändert werden darf (Urkundenfälschung); Verpflichtung zur Einhaltung von ohnehin geltenden Sicherheitsvorschriften in einer erteilten Baugenehmigung

238 Nebenbestimmungen sind schließlich nur dann möglich, wenn ein Hauptverwaltungsakt existiert. Relevant ist das im Versammlungsrecht (s. hierzu näher Rn. 1141). Hier erlässt die zuständige Behörde „Auflagen“.

Beispiele: Begrenzung der Teilnehmer auf eine bestimmte Anzahl; Versammlung an einem Ort, anstatt einer Route

Da alle Versammlungen genehmigungsfrei sind (vgl. ausdrücklich Art. 8 I GG) bedarf es offensichtlich keiner Genehmigung. Ohne eine solche Genehmigung gibt es aber auch keinen Hauptverwaltungsakt, zu dem die Nebenbestimmung hinzugefügt werden könnte. Wird die Teilnehmerzahl begrenzt oder die Versammlung anderweitig beschränkt, liegt daher schlicht keine Auflage vor. Es handelt sich vielmehr um einen eigenständigen Verwaltungsakt nach dem Versammlungsgesetz (§ 15 VersG).

\section{Zulässigkeit von Nebenbestimmungen}

239 Rechtsgrundlage für Nebenbestimmungen können entweder das (vorrangige) Fachrecht oder die allgemeine Vorschrift des § 36 VwVfG sein. In einzelnen Fällen sind Nebenbestimmungen aber von vornherein unzulässig (,nebenbestimmungsfeindliche Verwaltungsakte“). Es handelt sich dabei um „Statusentscheidungen“.

709 Hufen/Bickenback, JuS 2004, 867 (869).

Christian Kaerkes 
Beispiele: Einbürgerung; Ärztliche Approbation; Abitur

Darüber hinaus sind Nebenbestimmungen nach $\S 36$ VwVfG möglich. Die Vor- 240 schrift unterscheidet danach, ob der Hauptverwaltungsakt im Ermessen (s. dazu Rn. 729 ff.) der Behörde steht oder nicht.

§ 36 I VwVfG betrifft Verwaltungsakte, auf deren Erlass der Bürger einen Anspruch hat. Eine Nebenbestimmung ist „nur“ zulässig, „wenn sie durch Rechtsvorschrift zugelassen ist oder wenn sie sicherstellen soll, dass die gesetzlichen Voraussetzungen des Verwaltungsakts erfüllt werden“. Aus der Formulierung der Vorschrift („nur“) wird bereits deutlich, dass es sich um eine Ausnahme handelt. Nebenbestimmungen sind grundsätzlich unzulässig, weil der Anspruch des Bürgers beschränkt wird. ${ }^{710}$

Nebenbestimmungen zu gebundenen Entscheidungen sind bürgerfreundlich, weil sie der Behörde erlauben, eine Genehmigung zu erteilen, obwohl eigentlich nicht alle Tatbestandsvoraussetzungen erfüllt sind..$^{711}$

Beispiele: Erteilung einer Baugenehmigung mit dem Zusatz, eine Brandmeldeanlage einzubauen; Leistungen für Eheleute an Verlobte unter der Bedingung eines späteren Heiratsnachweises

Anstatt die Anträge abzulehnen, kann die Behörde als milderes Mittel den Hauptverwaltungsakt mit Nebenbestimmungen erlassen, die sicherstellen, dass die Voraussetzungen erfüllt werden.

Examenswissen: Das Bundesverwaltungsgericht hat unlängst entschieden, dass Nebenbestimmungen unzulässig sind, wenn sichergestellt werden soll, dass die gesetzlichen Voraussetzungen erfüllt bleiben. ${ }^{712}$ Liegen die Voraussetzungen für den Erlass des Verwaltungsakts gegenwärtig vor, ist dieser auch zu erlassen. Dafür spricht vor allem der Wortlaut (,erfüllt werden“) des § 36 I VwVfG.

Grundsätzlich zulässig sind Nebenbestimmungen hingegen dann, wenn der 242 Hauptverwaltungsakt im Ermessen der Behörde steht, vgl. § 36 II VwVfG. Kann die Behörde den Antrag auch ablehnen, so muss es ihr auch möglich sein, den Verwaltungsakt mit Nebenbestimmungen zu erlassen. Genau dieser Fall liegt vor, wenn der Erlass des Hauptverwaltungsaktes im Ermessen der Behörde steht. Allerdings können die Nebenbestimmungen nicht nach Gutdünken der Behörde

710 Axer, Jura 2001, 748 (751).

711 Brenner, JuS 1996, 281 (282).

712 BVerwG, Urt. v. 9.12.2015, Az.: 6 C 37.14 = BVerwGE 153, 301 = JuS 2016, 959 (m. Anm. Waldhoff) = JA 2016, 799 (m. Anm. Hebeler). 
erlassen werden. Die Behörde ist nämlich gehalten, ihr Ermessen ordnungsgemäß auszuüben und insbesondere den Grundsatz der Verhältnismäßigkeit (hierzu Rn. 767 ff.) zu beachten. ${ }^{713}$

243 Gem. §36 III VwVfG „darf [eine Nebenbestimmung] dem Zweck des Verwaltungsakts nicht zuwiderlaufen“. Diese Vorschrift ist weithin unter dem Begriff „Kopplungsverbot“ bekannt. ${ }^{714}$ Das Kopplungsverbot verlangt, dass zwischen der Nebenbestimmung und dem Hauptverwaltungsakt ein sachlicher Zusammenhang besteht. Ein solcher Zusammenhang besteht insbesondere dann nicht, wenn:

- Verwaltungsakte, auf die ein Anspruch besteht, von der Zahlung einer Geldsumme abhängig gemacht werden oder

- „Ressortfremde“ Interessen verfolgt werden.

244 „Ressortfremde“ Interessen sind Ziele, für deren Verwirklichung die handelnde Behörde nicht zuständig ist. Die Straßenbaubehörde darf bei einem Antrag auf Sondernutzung nicht berücksichtigen, dass es möglicherweise ein Problem mit dem Jugendschutz gibt. Für den Jugendschutz ist schlicht eine andere Behörde zuständig. Deshalb darf die Sondernutzungserlaubnis nicht mit Nebenbestimmungen erlassen werden, die den Jugendschutz betreffen. ${ }^{715}$

245 Unzulässig ist es auch, Verwaltungsakte von der Zahlung einer Geldsumme abhängig zu machen.

Beispiele: Baugenehmigung mit der aufschiebenden Bedingung, noch ausstehende Steuern zu bezahlen; Baugenehmigung mit der Auflage, einen Betrag für das städtische Schwimmbad zu „spenden“

In diesen Fällen besteht kein Zusammenhang zwischen der Baugenehmigung und der Forderung. Zulässig wären Nebenbestimmungen, die baurechtliche Zwecke verfolgen. Das ist hier aber gerade nicht der Fall. Die Behörde soll Genehmigungen nicht „verkaufen“.

246 Schließlich gibt es noch weitere Konstellationen, in denen schlicht ein Zusammenhang zwischen Nebenbestimmung und Hauptverwaltungsakt fehlt und daher ein Verstoß gegen das Kopplungsverbot gegeben ist.

Beispiele: Erlaubnis zum Fällen von Bäumen nur gegen Abtretung eines anderen Grundstückes; Gaststättenerlaubnis nur gegen Ermäßigungen für Mitarbeiter der Verwaltung

713 Schachel, Jura 1981, 449 (458f.).

714 Vgl. Breuer, NVwZ 2017, 112 (114).

715 Axer, Jura 2001, 748 (751).

Christian Kaerkes 
Grundsätzlich sind rechtswidrige (d.h. unzulässige) Nebenbestimmungen trotz247 dem wirksam und können wie alle übrigen Verwaltungsakte bestandskräftig (s. dazu Rn. 115ff.) werden. Wenn sie nicht rechtzeitig angefochten werden, müssen unzulässige Nebenbestimmungen beachtet werden. ${ }^{716}$ Aus diesem Grund ist der Rechtsschutz gegen Nebenbestimmungen von besonderer Bedeutung.

Examenswissen: Ausnahmsweise kann eine Nebenbestimmung nichtig sein, vgl. §44 VwVfG (s. dazu $§ 6$ Rn. 115ff.). In einem solchen seltenen Ausnahmefall kann entweder die Aufhebung der nichtigen Nebenbestimmung (Anfechtungsklage) oder die Feststellung der Nichtigkeit der Nebenbestimmung (Nichtigkeitsfeststellungsklage) begehrt werden. ${ }^{717}$

Beispiel: ${ }^{718}$ Willkürliche Auflage, ein Grundstück verkaufen zu müssen

\section{Rechtsschutz gegen Nebenbestimmungen}

Nebenbestimmungen sind oftmals Belastungen zu einem für den Bürger günsti- 249 gen Verwaltungsakt (einer Genehmigung). In diesen Situationen möchte der Bürger zwar die Begünstigung behalten, aber gleichzeitig die Belastung nach Möglichkeit beseitigen.

Beispiele: Baugenehmigung unter der Bedingung zusätzlicher Stellplätze; Gaststättenerlaubnis mit Lärmschutzauflagen

Dabei ist zu beachten, dass Nebenbestimmungen bestandskräftig werden können und dann beachtet werden müssten, selbst wenn sie sich als rechtswidrig erweisen würden. ${ }^{719}$ Der Bürger wird daher gezwungen, rechtzeitig Rechtsschutz vor den Verwaltungsgerichten zu suchen. Dabei bestehen zwei Möglichkeiten:

- Anfechtungsklage gerichtet gegen die Nebenbestimmung oder

- Verpflichtungsklage auf Erlass eines Verwaltungsakts ohne Nebenbestimmung.

Es liegt aber nicht im Interesse des Bürgers, den Hauptverwaltungsakt anzugreifen, weil er im Regelfall den begünstigenden Verwaltungsakt behalten möchte. Er möchte nicht die Baugenehmigung verlieren, sondern nur die Nebenbestimmung beseitigen. Diesem Ziel entspricht allerdings nur die Anfechtungsklage, nicht aber die Verpflichtungsklage. Mit der Verpflichtungsklage kann regelmäßig nur

716 Schwerdtfeger/Schwerdtfeger, Öffentliches Recht, 14. Aufl. 2012, Rn. 168.

717 Vgl. Schenke, JuS 2016, 97 (99f.).

718 Hufen/Bickenbach, JuS 2004, 966 (968).

719 Detterbeck, Allgemeines Verwaltungsrecht, 17. Aufl. 2019, § 10 Rn. 563 ff., 656. 
eine von Grund auf neue Entscheidung über den gesamten Verwaltungsakt herbeigeführt werden.

251 Die Anfechtungsklage (s. zur Anfechtungsklage Rn. 2ff.) ist noch aus weiteren Gründen für den Bürger vorteilhafter: ${ }^{720}$

- Aufschiebende Wirkung der Anfechtungsklage

- $\quad$ Einstweiliger Rechtsschutz über $§ 80$ V VwGO

- Ggf. kostengünstiger als die Verpflichtungsklage

252 Der Streit über den Rechtsschutz gegen Nebenbestimmungen ist ein Streit um die richtige Klageart: Kann und darf der Bürger Anfechtungsklage ausschließlich gegen die belastende Nebenbestimmung erheben (,isolierte Anfechtung“) oder muss er stattdessen Verpflichtungsklage erheben? Diese Frage ist in der Statthaftigkeit der Klageart zu erörtern und ist heftig umstritten.

\section{a) Sonderfall - „Modifizierende Auflage“}

253 Unstrittig ist aber der Rechtsschutz gegen die „modifizierende Auflage“. Gegen diese Bestimmung des Inhalts des Hauptverwaltungsaktes kann nur mit der Verpflichtungsklage vorgegangen werden. ${ }^{721}$ Dafür wird angeführt, dass ein untrennbarer Zusammenhang zwischen der „modifizierenden Auflage“ und dem Hauptverwaltungsakt bestehe. Besser verständlich ist allerdings der Grund, dass mit der Anfechtungsklage kein sinnvolles Ergebnis erzielt werden könnte.

Beispiel: Baugenehmigung mit einem Flachdach statt des beantragten Giebeldachs

254 Würde in diesem Fall die „modifizierende Auflage“ angefochten und durch das Gericht aufgehoben, so bliebe eine Baugenehmigung ohne Dach übrig. ${ }^{722}$ Mit der Anfechtungsklage kann das Rechtsschutzziel des Bürgers (Giebeldach) gar nicht erreicht werden. Die inhaltliche Veränderung der Genehmigung ist nur mit der Verpflichtungsklage möglich.

255 Für den Sonderfall der „modifizierenden Auflage“ - die zwar keine echte Nebenbestimmung ist (s. Rn. $228 \mathrm{ff}$.), aber hier im Zusammenhang behandelt wird - besteht daher weitgehend Einigkeit, dass nur die Verpflichtungsklage statthaft ist.

720 Fricke, DÖV 2019, 48 f.

721 BVerwG, Urt. v. 8.2.1974, Az.: IV C 73.72 = BVerwG, DÖV 1974, 380 (381).

722 Schmidt, VBlBW 2004, 81 (83).

Christian Kaerkes 


\section{b) Echte Nebenbestimmungen}

Heftig umstritten ist hingegen der Rechtsschutz gegen die echten Nebenbestim- 256 mungen. Im Laufe der Zeit haben sich dabei vier unterschiedliche Positionen herausgebildet:

- Grundsätzlich immer Anfechtungsklage,

- Grundsätzlich immer Verpflichtungsklage,

- Unterscheidung nach der Art des Hauptverwaltungsaktes oder

- Unterscheidung zwischen den Nebenbestimmungen.

\section{aa) h.M.: Anfechtungsklage}

Die Position, dass gegen alle Nebenbestimmungen gleichermaßen Anfechtungs- 257 klage erhoben werden kann, entspricht der mittlerweile herrschenden Meinung. Das Bundesverwaltungsgericht hat sich sehr deutlich für diese überzeugende Ansicht ausgesprochen: „Gegen belastende Nebenbestimmungen ist die Anfechtungsklage gegeben. “723

Hierfür sprechen vor allem zwei Überlegungen:

- $\S 113$ I 1 VwGO kennt die Teilaufhebung und

- Teilbarkeit betrifft die Begründetheit.

Gem. § 113 I 1 VwGO ist es möglich, dass der Verwaltungsakt nur teilweise auf- 259 gehoben wird (,soweit der Verwaltungsakt rechtswidrig ist“). ${ }^{724}$ Wird der gesamte Verwaltungsakt angegriffen, kann es demnach sein, dass nur ein Teil des Verwaltungsakts aufgehoben wird. Einen solchen Teil stellt die Nebenbestimmung dar. Das Gesetz selbst sieht demnach die Teilaufhebung vor und erfasst an sich die Aufhebung von rechtswidrigen Nebenbestimmungen.

Entscheidend ist daher, ob Nebenbestimmung und Hauptverwaltungsakt 260 teilbar sind. Wenn beide untrennbar wären, könnte nicht nur ein Teil davon aufgehoben werden. Das ist nach der herrschenden Meinung aber keine Frage der statthaften Klageart, sondern betrifft die Begründetheit der Klage. Weil aber Zulässigkeit und Begründetheit zu unterscheiden sind, ist die Anfechtungsklage selbst dann statthaft, wenn sich Nebenbestimmung und Hauptverwaltungsakt als unteilbar erweisen würden.

723 BVerwG, Urt. v. 10.7.1980, Az.: 3 C 136.79 = BVerwGE 60, 269 (274); bestätigt durch BVerwG, Urt. v. 22.11.2000, Az.: 11 C 2.00 = BVerwGE 112, 221 (224).

724 Schenke, JuS 1983, 182 (184). 
261 Examenswissen: Hiervon wird nur dann eine Ausnahme gemacht, wenn die ,isolierte Aufhebbarkeit offenkundig von vornherein ausscheidet“ “ ${ }^{725}$ Für die Anfechtungsklage soll in diesen Fällen bereits das Rechtsschutzbedürfnis fehlen (s. dazu Rn. 477 ff.). Welche Fallgruppen davon genau erfasst sein sollen, ist jedoch noch nicht eindeutig geklärt. In der Literatur wird vor allem die Inhaltsbestimmung bzw. die „modifizierende Auflage“ als Beispiel angeführt. ${ }^{726}$ Hierbei handelt es sich jedoch schon um keine Nebenbestimmungen (s. bereits Rn. $228 \mathrm{ff}$.).

\section{bb) a. A.: Verpflichtungsklage}

262 Seltener vertreten und gelegentlich unterschätzt wird die Position, dass für den Rechtsschutz gegen Nebenbestimmungen grundsätzlich nur die Verpflichtungsklage in Betracht kommt. ${ }^{727}$ Dafür werden insbesondere zwei Gründe angeführt:

- Aufschiebende Wirkung der Anfechtungsklage und

- Vergleich mit der „klassischen“ Verpflichtungssituation.

263 Gem. §80 I 1 VwGO hat die Anfechtungsklage aufschiebende Wirkung. Rechtsfolge der aufschiebenden Wirkung ist, dass die angegriffene Regelung nicht mehr vollziehbar ist und deshalb nicht beachtet werden muss. ${ }^{728}$ Es sei aber problematisch, wenn sich die aufschiebende Wirkung nur gegen die Nebenbestimmung richten würde. Der Bürger könnte nämlich von dem Hauptverwaltungsakt weiter Gebrauch machen, ohne sich für die Nebenbestimmung interessieren zu müssen. ${ }^{729}$

Beispiel: Anfechtungsklage gegen eine Baugenehmigung mit Lärmschutzauflage führt (vorläufig) zu einer nebenbestimmungsfreien Baugenehmigung

Allerdings kann die Behörde gem. § 80 II Nr. 4 VwGO die sofortige Vollziehung anordnen, mit der Folge, dass der Anfechtungsklage keine aufschiebende Wirkung mehr zukommt. Das „Problem“ lässt sich demnach durch die Behörde beseitigen. Außerdem sollte die aufschiebende Wirkung nicht zu kritisch gesehen werden, weil der Bürger sonst während der (langen) Dauer des Prozesses nicht von der Genehmigung in der von ihm gewünschten Weise profitieren könnte. ${ }^{730}$

Das zweite Argument läuft vor allem darauf hinaus, dass die Gewährung einer Genehmigung mit Nebenbestimmung de facto eine (Teil-)Ablehnung des Antrags

725 BVerwG, Urt. v. 22.11.2000, Az.: 11 C 2.00 = BVerwGE 112, 221 (224).

726 Sproll, NJW 2002, 3221 (3223).

727 Stadie, DVBl. 1991, 613 (614).

728 Hufen, Verwaltungsprozessrecht, 11. Aufl. 2019, § 32 Rn. 1 ff.

729 Stadie, DVBl. 1991, 613 (615).

730 Schmidt, VBlBW 2004, 81 (83).

Christian Kaerkes 
auf eine nebenbestimmungsfreie Genehmigung sei. Der Rechtsschutz müsse nach allgemeinen Regeln durch die Verpflichtungsklage erfolgen. ${ }^{731}$ Hier läge eine „klassische“ Verpflichtungssituation vor, vgl. §42 I Alt. 2VwGO („Erlaß eines abgelehnten [...] Verwaltungsakts“).

Die Verpflichtungsklage ist für den Bürger aber durchaus problematisch, 265 weil regelmäßig nur ein „Bescheidungsurteil“ ergehen wird. Die Behörde muss dann erneut (und ermessensfehlerfrei) über den Antrag entscheiden. Die Verpflichtungsklage kann daher nicht mit der gleichen Effektivität rechtswidrige Nebenbestimmungen beseitigen. ${ }^{732}$ Der Verpflichtungsklage kommt außerdem keine aufschiebende Wirkung zu.

Die Bürger werden durch eine grundsätzliche Verpflichtungsklage im Er- 266 gebnis ohne ausreichende Rechtfertigung schlechter gestellt, weshalb diese Auffassung abzulehnen ist. Gegen diese Position spricht demnach:

- Vorteile der aufschiebenden Wirkung,

- Möglichkeit der Verwaltung, die sofortige Vollziehung anzuordnen und

- Benachteiligung des Bürgers durch die Verpflichtungsklage.

\section{cc) a.A.: Unterscheidung nach der Art des Hauptverwaltungsaktes}

Eine weitere Position unterscheidet danach, ob der Erlass des Verwaltungsakts

im Ermessen der Behörde steht oder nicht. Habe der Bürger einen Anspruch auf den Verwaltungsakt, sei die Anfechtungsklage gegeben, stehe der Verwaltungsakt aber im Ermessen der Behörde, sei die Verpflichtungsklage statthaft. Das entsprach zumindest einer Zeit lang der Rechtsprechung des Bundesverwaltungsgerichts. ${ }^{733}$ Für die Ansicht sprechen zwei Gründe:

- Einheitliche Ermessensentscheidung (,Gewaltenteilung“) und

- Bürger erhielten ansonsten mehr als ihnen zustünde.

Der erste Grund beruht auf der Annahme, dass die Behörde ihr Ermessen nur 268 einheitlich ausübt. Die Behörde würde den Hauptverwaltungsakt (der in ihrem Ermessen steht) nicht ohne die ergänzenden Nebenbestimmungen erlassen haben.

Beispiel: Sondernutzungserlaubnis zum Aufstellen von Stühlen auf dem Gehweg nur mit Befristung, hingegen keinesfalls ohne Befristung

731 Vgl. Labrenz, NVwZ 2007, 161 (164f.).

732 Detterbeck, Allgemeines Verwaltungsrecht, 17. Aufl. 2019, § 10 Rn. 671.

733 BVerwG, Urt. v. 7.7.1978, Az.: 4 C 79.76 = BVerwGE 56, 254 (256). 
269 Würde in einem solchen Fall die Nebenbestimmung aufgehoben, dann würde der Behörde ein Verwaltungsakt „aufgedrängt“, den sie in dieser Form niemals erlassen hätte. Das wäre mit Blick auf die Gewaltenteilung (Abgrenzung von Exekutive und Judikative) tatsächlich nicht unproblematisch. ${ }^{734}$ Die Verpflichtungsklage würde einen „Übergriff“ in die alleinige Kompetenz der Behörde verhindern. Die Nebenbestimmung würde nicht aufgehoben, sondern die Behörde nur zur erneuten Entscheidung verpflichtet.

Indes wird der Behörde kein Verwaltungsakt aufgedrängt, und zwar deshalb, weil die Behörde den Verwaltungsakt beseitigen kann. Ihr stehen die Instrumente des Widerrufs und der Rücknahme zur Verfügung, vgl. §§ 48, 49 VwVfG (näher dazu Rn. 836ff.). ${ }^{735}$ Das Bundesverwaltungsgericht erlaubt zudem auch eine Analogie zu $§ 49$ II Nr. 2 VwVfG. ${ }^{736}$ Die Behörde muss aus diesem Grund nicht durch die Verpflichtungsklage geschützt werden, weil sie sich selbst vor einem „aufgedrängten“ Verwaltungsakt schützen kann.

Der zweite Grund bezieht sich darauf, dass die Anfechtungsklage die Stellung des Bürgers über seinen materiellen Anspruch ausweiten würde. Der Bürger habe keinen Anspruch auf einen Verwaltungsakt ohne Nebenbestimmungen, sondern nur auf eine ermessensfehlerfreie Entscheidung. ${ }^{737}$ Daher solle die Nebenbestimmung auch nicht durch eine Anfechtungsklage aufgehoben werden können. Statthaft sei die Verpflichtungsklage.

272 Allerdings spricht diese Überlegung noch nicht gegen die Anfechtungsklage als solche. Den Bedenken kann nämlich im Rahmen der Begründetheit durchaus Rechnung getragen werden und die Behörde hat immer noch die Möglichkeit, den missliebigen Verwaltungsakt einfach selbst aufzuheben. Daher ist dieser Meinung aus den folgenden Gründen nicht zu folgen:

- „Selbstschutz“ der Behörde durch Widerruf und Rücknahme und

- Bedenken können in der Begründetheit berücksichtigt werden.

\section{dd) a.A.: Unterscheidung zwischen den Nebenbestimmungen}

273 Nach einer weiteren Ansicht kommt es auf die jeweilige Art der Nebenbestimmung an. Auflage und Auflagenvorbehalt seien zwar mit der Anfechtungsklage angreifbar; im Übrigen bleibe aber nur die Verpflichtungsklage. Auch diese Un-

734 Schenke, JuS 1983, 182 (185).

735 Vgl. Hufen/Bickenbach, JuS 2004, 966 (967).

736 BVerwG, Urt. v. 12.3.1982, Az.: 8 C 23.80 = BVerwGE 65, 139 (141).

737 Jahndorf, JA 1999, 676 (677).

Christian Kaerkes 
terscheidung findet sich in der älteren Rechtsprechung des Bundesverwaltungsgerichts wieder. ${ }^{738}$ Dafür wird vor allem ein Grund angeführt:

- Selbstständigkeit bzw. Unselbstständigkeit der Nebenbestimmungen.

Diese Auffassung betrachtet Auflage und Auflagenvorbehalt als „selbstständig“ und Befristung, Bedingung sowie Widerrufsvorbehalt als „unselbstständig“. Unselbstständige Nebenbestimmungen könnten nur als „untrennbare Einheit“ bzw. „integrale Bestandteile“ des Hauptverwaltungsaktes begriffen werden. ${ }^{739}$ Anhaltspunkt für diese Position sei der Wortlaut des $\S 36$ II VwVfG, weil dort zwischen den einzelnen Nebenbestimmungen unterschieden werde (,erlassen mit“ einerseits, „verbunden mit“ andererseits). Letztlich geht es wieder um die Frage, ob Nebenbestimmung und Hauptverwaltungsakt voneinander zu trennen sind.

Indes erscheint die Anknüpfung an den Wortlaut des $\S 36$ II VwVfG als un- 275 zureichend. ${ }^{740}$ Aus diesen sprachlichen Unterschieden folgt nicht zwingend, dass in einem Fall die Anfechtungs- im anderen Fall die Verpflichtungsklage zulässig wäre. Eine solche Unterscheidung überzeugt aber auch deshalb nicht, weil ein sachlicher Grund fehlt, der eine differenzierte Behandlung rechtfertigen würde. Das gilt insbesondere deshalb, weil damit weitere Konsequenzen verbunden sind:

- Aufschiebende Wirkung,

- Einstweiliger Rechtsschutz und

- Anforderungen an die Begründetheit.

Sollte eine Klage gegen die Bedingung keinerlei aufschiebende Wirkung haben, wohl aber gegen eine inhaltsgleiche Auflage? Hierfür dürfte es an einer inhaltlichen Rechtfertigung fehlen. ${ }^{741}$ Vielmehr sollten die Nebenbestimmungen in dieser Hinsicht gleichbehandelt werden.

Daher sprechen zumindest die folgenden Gründe gegen den Vorschlag, zwi- 276 schen den verschiedenen Nebenbestimmungen zu unterscheiden:

- Folgerung aus sprachlichen Unterschieden nicht stichhaltig und

- Fehlende sachliche Rechtfertigung für die unterschiedliche Behandlung.

738 BVerwG, Urt. v. 21.10.1970, Az.: IV C 165.65 = BVerwGE 36, 145 (154).

739 Axer, Jura 2001, 748 (752f.).

740 Bumke, in: Festschrift für Battis, 2014, 177 (185).

741 Vgl. Schmidt, VBlBW 2004, 81 (83). 


\section{ee) Ergebnis}

277 Die besseren Gründe dürften insgesamt für die herrschende Meinung sprechen. Danach sind alle Nebenbestimmungen grundsätzlich mit der Anfechtungsklage angreifbar. Die Teilaufhebung durch die Anfechtungsklage ist in der VwGO vorgesehen. Gleichzeitig können viele Bedenken entkräftet oder in der Begründetheit der Anfechtungsklage berücksichtigt werden. Es besteht danach kein Grund, die Nachteile der Verpflichtungsklage für den Bürger in Kauf zu nehmen.

278 Klausurrelevant: Die herrschende Meinung muss aber die Teilbarkeit von Hauptverwaltungsakt und Nebenbestimmung in der Begründetheit der Anfechtungsklage berücksichtigen. Das führt zu einem besonderen Aufbau der Prüfung (dazu ausführlich Rn. 1388 ff.), der in der Klausur unbedingt bekannt sein muss.

\section{Literaturhinweise}

279 Aufsätze: Voßkuhle/Kaiser, Grundwissen - Öffentliches Recht: Nebenbestimmungen, Jus 2012, 699; Brenner, Der Verwaltungsakt mit Nebenbestimmungen, JuS 1996, 281; Hufen/Bickenbach, Der Rechtsschutz gegen Nebenbestimmungen zum Verwaltungsakt, JuS 2004, 867

Lehrbücher: Detterbeck, Allgemeines Verwaltungsrecht, 17. Aufl. 2019, § 10 Rn. 643 ff.; Maurer/Waldhoff, Allgemeines Verwaltungsrecht, 19. Aufl. 2017, § 12 Rn. $1 \mathrm{ff}$.

Übungsfälle: Fall 2 in: Eisentraut, Fälle zum Verwaltungsrecht, 2020; Ernst/ Kämmerer, Fälle zum Allgemeinen Verwaltungsrecht, 3. Aufl. 2016, Fall 9: „Baustelle ohne Verkehr“; Payandeh, „Übungsfall: Der fragwürdige Widerrufsvorbehalt“, ZJS 2017, 544; Tschentscher, „Zur Übung - Öffentliches Recht: Die religiöse Sondernutzung“, JuS 2003, 345

Lehrvideo: Dobiasch/Schwarz/Schuster, Peer2Peer Lehrvideo Anfechtung von Nebenbestimmungen, abrufbar unter https://youtu.be/2LNM6WkmG0I

\section{B. Weitere Zulässigkeitsvoraussetzungen der Anfechtungsklage}

280 Nach der Prüfung der Eröffnung des Verwaltungsrechtswegs und der Prüfung der statthaften Klageart sind im Falle der Anfechtungsklage regelmäßig die folgenden weiteren Zulässigkeitsvoraussetzungen anzusprechen, wobei es auch hierbei auf problembewusstes Arbeiten ankommt (dazu § 1 Rn. 52, 123). 


\section{Die Klagebefugnis (Hendrik Burbach)}

Die Klagebefugnis nach $\S 42$ II VwGO ist eine der zentralen Voraussetzungen für $\mathbf{2 8 1}$ die Zulässigkeit verwaltungsgerichtlicher Klagen und Anträge. Nach § 42 II VwGO sind Anfechtungs- und Verpflichtungsklagen, soweit gesetzlich nichts anderes bestimmt ist, nur zulässig, wenn der Kläger geltend macht, durch den Verwaltungsakt oder seine Ablehnung oder Unterlassung in seinen Rechten verletzt zu sein. Obgleich der Wortlaut des § 42 II VwGO ausdrücklich nur die Anfechtungsund Verpflichtungsklagen umfasst, ist auch für die übrigen Klagearten die Klagebefugnis des Klägers erforderlich (s. im Einzelnen $\S 3$ Rn. 28, §4 Rn. 33, $\S 5$ Rn. 31, § 6 Rn. 78, § 7 Rn. 36., § 8 Rn. 30, § 9 Rn. 34, § 10 Rn. 11).

Durch das Merkmal der Klagebefugnis soll gewährleistet werden, dass nur Klage erheben kann, wer auch die Verletzung seiner subjektiven Rechte geltend machen kann. Die Verwaltungsgerichtsbarkeit soll hiermit von einer Vielzahl ungerechtfertigter Inanspruchnahmen durch Popularklagen entlastet werden. ${ }^{742}$ Bei diesen erhebt sich der Kläger zum Sachwalter öffentlicher Interessen oder rechtlich geschützter Interessen Dritter. ${ }^{743}$

Examenswissen: Die Klagebefugnis ist dabei nicht mit der Sachlegitimation des Klägers zu verwechseln. Die Sachlegitimation ist die subjektive Seite der Anspruchsberechtigung oder -verpflichtung, die ausschließlich nach dem materiellen Recht zu bestimmen und daher eine Frage der Begründetheit der Klage ist.

Im Rahmen des § 42 II VwGO muss der Kläger substantiiert vortragen, dass er in 284 subjektiven Rechten verletzt ist. Dabei werden an die Voraussetzungen des die Klagebefugnis begründenden Rechts keine hohen Anforderungen gestellt. Ob dieses Recht besteht ist schließlich eine Frage der Begründetheit der Klage. ${ }^{744}$

Examenswissen: Demgegenüber hat der Gesetzgeber gerade im Umwelt- und Naturschutzrecht zur effektiven Durchsetzung des Rechts auch Verbandsklagen zugelassen. Hierbei wird - europarechtlich geprägt ${ }^{745}$ - eine Ausnahme von dem Erfordernis der Verletzung eigener Rechte gemacht. ${ }^{746}$ Insofern spricht man hinlänglich von Interessentenklagen. Diese können Personen erheben, die ein gesetzlich anerkanntes Interesse am Klageausgang haben. ${ }^{77}$ Ist der Anwendungsbereich des $\S 1$ UmwRG eröffnet, sind nach $\S 3$ UmwRG anerkannte Vereinigungen grund-

742 Hufen, Verwaltungsprozessrecht, 11. Aufl. 2019, § 14 Rn. 53.

743 Schenke, Verwaltungsprozessrecht, 16. Aufl. 2019, § 14 I Rn. 490.

744 R. P. Schenke, in: Kopp/Schenke, VwGO, 25. Aufl. 2019, § 42 Rn. 65; Kintz, Öffentliches Recht im Assessorexamen, 10. Aufl., 2018, Rn. 227.

745 Vgl. EuGH, Urt. v. 12.5.2011, Az.: C-115/09 = NVwZ 2011, 801 (mit Anmerkung von Schlacke). 746 Schenke, Verwaltungsprozessrecht, 16. Aufl. 2019, § 14 I Rn. 490a.

747 Peine, Klausurenkurs im Verwaltungsrecht, 6. Aufl. 2016, 1. Teil Rn. 131.

Hendrik Burbach 
sätzlich klagebefugt, ohne dass es einer Darlegung der Verletzung eigener Rechte bedarf, § 2 I 1 UmwRG. ${ }^{748}$ Dies gilt dagegen nicht, wenn die Vereinigung einen Rechtsbehelf gegen eine Entscheidung nach § 1 I Nr. 2a-6 UmwRG einlegt. In diesen Konstellationen sieht § 2 I 2 UmwRG vor, dass die Vereinigung „die Verletzung umweltbezogener Vorschriften geltend machen“ kann. ${ }^{749}$

\section{Voraussetzungen des $\$ 42$ II VwGO}

286 Der Kläger muss nach § 42 II VwGO die Möglichkeit einer Rechtsverletzung geltend machen können. Unzulässig ist die Klage nur, wenn unter Zugrundelegung des Klägervortrags offensichtlich und eindeutig nach keiner Betrachtungsweise subjektive Rechte des Klägers verletzt sein können. ${ }^{750}$

287 Im Rahmen der Fallbearbeitung ist die Möglichkeit der Rechtsverletzung näher zu begründen. Dabei darf allerdings nicht geprüft werden, ob der Kläger durch den Verwaltungsakt tatsächlich in seinen Rechten verletzt ist. Dies ist erst im Rahmen der Begründetheit zu erörtern, § 113 I 1 VwGO. ${ }^{71}$ Zur Begründung der Klagebefugnis genügt daher die Möglichkeit einer Rechtsverletzung. ${ }^{752}$ Diese sollte im Rahmen der Klausur auch kurz dargelegt werden.

288 Die Klagebefugnis folgt bei einer Anfechtungsklage nach § 42 I 1. Alt VwGO zumeist bereits aus der Adressatentheorie. Nach dieser ist der Adressat eines belastenden Verwaltungsakts stets klagebefugt. Dies gilt jedoch nur für den Inhaltsadressat, nicht aber für den Bekanntgabeadressaten. ${ }^{73}$

Bei Drittanfechtungs- oder Nachbarschutzfällen bedarf die Darlegung der Klagebefugnis hingegen einer tiefergehenden Untersuchung. In der Klausur sollte das subjektiv-öffentliche Recht sauber herausgearbeitet werden. Hierbei ist vor allem auch auf den notwendigen Drittschutz der Norm zu achten (vgl. hierzu näher Rn. 296f.).

\section{a) Möglichkeitstheorie}

290 Nach der herrschenden Möglichkeitstheorie genügt zur Begründung der Klagebefugnis, dass die Möglichkeit der vom Kläger behaupteten Rechtsverletzung besteht. ${ }^{754}$ Diese Prüfung folgt dabei einem dreistufigen Aufbau: Es bedarf zunächst

748 Erbguth/Guckelberger, Allgemeines Verwaltungsrecht, 9. Aufl. 2018, §20 Rn. 20.

749 Vertiefend Erbguth/Guckelberger, Allgemeines Verwaltungsrecht, 9. Aufl. 2018, §20 Rn. 20; Schlacke, NVwZ 2017, 905.

750 Kintz, Öffentliches Recht im Assessorexamen, 10. Aufl., 2018, Rn. 227.

751 Detterbeck, Allgemeines Verwaltungsrecht, 17. Aufl. 2019, § 31 Rn. 1351.

752 R. P. Schenke, in: Kopp/Schenke, VwGO, 25. Aufl. 2019, § 42 Rn. 59.

753 Happ, in: Eyermann, VwGO, 15. Aufl. 2019, § 42 Rn. 91.

754 Exemplarisch: R. P. Schenke, in: Kopp/Schenke, VwGO, 25. Aufl. 2019, § 42 Rn. 66.

Hendrik Burbach 
eines Rechts, dieses muss dem Kläger subjektiv zuzuordnen und schließlich auch verletzt sein.

Der Kläger muss zunächst die Verletzung eines Rechts geltend machen. Ein solches liegt insbesondere dann nicht vor, wenn lediglich bloße Interessen, Erwerbschancen, Situationsvorteile oder sonstige Chancen bestehen, die nicht bereits in einer Rechtsposition resultiert sind. ${ }^{755}$ Gleiches gilt für den Fall, dass der Kläger bloß eine obligatorische Rechtsposition innehat. ${ }^{756}$

Beispiel: Dies ist etwa dann der Fall, wenn in einer baurechtlichen Streitigkeit der Mieter eines Objektes klagen möchte. Insoweit gilt der Grundsatz, dass das Grundstück nur einmal gerichtlich repräsentiert werden darf, nämlich durch den Eigentümer; Der Mieter ist insoweit nach ständiger Rechtsprechung des BVerwG nicht klagebefugt. ${ }^{757}$

Weiterhin ist zu untersuchen, ob dem Kläger das geltend gemachte Recht auch subjektiv zugeordnet werden kann. Dies ist nach der sog. Schutznormtheorie insbesondere dann der Fall, wenn die Norm zumindest auch den Individualinteressen des Klägers zu dienen bestimmt ist. ${ }^{758}$ Nach dieser genügt zur Begründung der Klagebefugnis jedes von der Rechtsordnung als schutzwürdig anerkannte Individualinteresse. ${ }^{759}$ Hierunter fallen alle geschriebenen oder ungeschriebenen Rechtsnormen des öffentlichen Rechts. Relevant ist dies vor allem in Fällen der Drittanfechtung.

Als subjektive Rechte des Klägers kommen dabei nicht nur materielle Rechte, 293 sondern auch Verfahrensrechte in Betracht. ${ }^{760}$

\section{b) Adressatentheorie}

In vielen Fällen kann im Rahmen einer Anfechtungsklage die Adressatentheorie 294 herangezogen werden. Nach dieser ist der Adressat eines belastenden Verwaltungsakts, der ihm ein Handeln, Dulden oder Unterlassen gebietet, stets möglicherweise in seinen eigenen Rechten verletzt. ${ }^{761}$ Der belastende Verwaltungsakt

755 Gersdorf, Verwaltungsprozessrecht, 6. Aufl. 2019, Rn. 30; Hufen, Verwaltungsprozessrecht, 11. Aufl. 2019, § 14 Rn. $61 \mathrm{ff}$.

756 Hufen, Verwaltungsprozessrecht, 11. Aufl. 2019, § 14 Rn. 67.

757 BVerwG, Urt. v. 18.11.1985, Az. 8 C 43.83 = BVerwGE 72, 226; BVerwG, Urt. v. 06.03.1987, Az. 8 C 1.85 = NJW 1987, 2829; BVerwG, Urt. v. 05.04.1993, Az. 4 NB 3.91 = NJW 1994, 1233; s. auch Schmidt-Preuß, NJW 1995, 27 (28).

758 Schaks/Friedrich, JuS 2018, 860 (864).

759 R. P. Schenke, in: Kopp/Schenke, VwGO, 25. Aufl. 2019, § 42 Rn. 78.

760 Schenke, Verwaltungsprozessrecht, 16. Aufl. 2019, § 14 I Rn. 489.

761 Detterbeck, Allgemeines Verwaltungsrecht, 17. Aufl. 2019, § 31 Rn. 1352.

Hendrik Burbach 
beeinträchtigt den Kläger zumindest in dem ihm von Art. 2 I GG gewährten Schutz seiner Freiheitssphäre. ${ }^{762}$

295 Die Adressatentheorie kann also grundsätzlich immer dann in der Klausur angewendet werden, wenn der Kläger gegen einen ihn belastenden Verwaltungsakt vorgehen möchte. An dieser Stelle sollte aber nicht nur pauschal auf die Adressatentheorie verwiesen werden, sondern gleichfalls unter Rückgriff auf Art. 2 I GG eine kurze Begründung für die Rechtsverletzung gegeben werden.

\section{c) Drittanfechtungsklagen}

296 Geht der Kläger gegen einen Verwaltungsakt vor, der einen Dritten begünstigt und ihn belastet, liegt ein sog. begünstigender Verwaltungsakt mit belastender Drittwirkung vor. In diesem Fall kann der Kläger seine Klagebefugnis nicht mit der Adressatentheorie begründen. Hauptanwendungsfälle für diese Konstellation folgen aus Nachbarklagen im Bau- und Umweltrecht, bei beamtenrechtlichen und wirtschaftsverfassungsrechtlichen Konkurrentenklagen sowie bei Konkurrentenklagen im Subventionsbereich. ${ }^{763}$ Auch im In diesen Konstellationen führt der Kläger zwar den Prozess gegen die Verwaltung, in der Sache geht es allerdings um eine Entscheidung über konkurrierenden Privatinteressen. ${ }^{764}$

297 Auch in diesen Fällen muss der Kläger die Verletzung eigener subjektiver Rechte geltend machen können. Er muss daher zur Begründung seiner Klagebefugnis vortragen, dass der angegriffene, einen anderen begünstigende und ihn belastende Verwaltungsakt eine Norm verletzt, die zumindest auch seinem Schutz dient. ${ }^{765}$ Dies ist stets dann der Fall, wenn der Norm drittschützende Wirkung zukommt. Ob dies der Fall ist, bestimmt sich u. a. durch die Schutznormtheorie. Nach der Schutznormtheorie ist ein Recht drittschützend, wenn es nicht nur ausschließlich dem Interesse der Allgemeinheit dient, sondern vielmehr auch dem Schutz individueller Rechte dient, die einem abgrenzbaren Kreis von Begünstigten zustehen (s. dazu auch Rn. 828 und beispielhaft Fall 3 in: Eisentraut, Fälle zum Verwaltungsrecht, 2020).

762 R. P. Schenke, in: Kopp/Schenke, VwGO, 25. Aufl. 2019, § 42 Rn. 69.

763 Württemberger/Heckmann, Verwaltungsprozessrecht, 4. Aufl. 2018, § 21 Rn. 334.

764 Schmidt-Preuß, Kollidierende Privatinteressen im Verwaltungsrecht, 2. Auflage 2005, S. 17 ff.; s. auch Schmidt-Aßmann/Schenk in: Schoch/Schneider/Bier, VwGO, 36. EL Februar 2019, Einleitung Rn. $192 \mathrm{ff}$.

765 Württemberger/Heckmann, Verwaltungsprozessrecht, 4. Aufl. 2018, § 21 Rn. 334.

Hendrik Burbach 
Beispiele für drittschützende Normen: ${ }^{766}$

- Ordnungsrechtliche Generalklauseln (Polizei- und Ordnungsrecht)

- Baurechtliche Gebot der Rücksichtnahme, hergeleitet u. a. aus § 15 I BauNVO, § 31 II BauGB, § 34 I BauGB, § 34 II BauGB, § 35I, II i.V.m. § 35 III BauGB (s. dazu beispielhaft Fall 3 in: Eisentraut, Fälle zum Verwaltungsrecht, 2020)

- Festsetzungen des Bebauungsplans zur Art der baulichen Nutzung

- Im Rahmen der wirtschaftlichen Konkurrentenklage kann aus dem Besonderen Verwaltungsrecht (z.B. GewO) möglicherweise Drittschutz vermittelt werden. ${ }^{767}$ In Ausnahmefällen kann auch Art. 12 GG drittschützend wirken, wenn der Wettbewerb empfindlich beeinflusst wurde.

- Vorschriften des BImSchG (z.B. \& 5 I Nr. 1 BImSchG)

\section{Formulierungsvorschlag}

In klassischen Adressatenanfechtungskonstellationen kann wie folgt formu- 298 liert werden: „Der Kläger müsste nach $\S 42$ II VwGO klagebefugt sein. Er ist Adressat eines ihn belastenden Verwaltungsakts und kann mithin geltend machen, im Sinne der Adressatentheorie zumindest in seinem Grundrecht der Allgemeinen Handlungsfreiheit nach Art. 2 I GG verletzt zu sein. Folglich ist der Kläger klagebefugt."

In Drittanfechtungskonstellationen kann hingegen wie folgt die Prüfung eingeleitet werden: „Der Kläger müsste klagebefugt sein. Dies ist bei einer Anfechtungsklage nach $\S 42$ II VwGO der Fall, wenn der Kläger geltend machen kann, durch den Verwaltungsakt in seinen Rechten verletzt zu sein. Diesbezüglich genügt es, wenn die Möglichkeit der Verletzung in eigenen Rechten durch den Verwaltungsakt besteht. Allerdings wurde der vorliegend angegriffene Verwaltungsakt nicht dem Kläger persönlich, sondern (...) erteilt. Die Adressatentheorie ist in diesem Fall unanwendbar. Vielmehr ist anhand der Schutznormtheorie zu untersuchen, ob durch den erteilten Verwaltungsakt eine Verletzung gerade dem Schutz des Klägers dienender Rechtspositionen möglich erscheint. Nach der Schutznormtheorie ist ein Recht drittschützend, wenn es nicht nur ausschließlich dem Interesse der Allgemeinheit dient, sondern vielmehr auch dem Schutz individueller Rechte, die einem abgrenzbaren Kreis von Begünstigten zusteht.“

\section{Literaturhinweise}

Detterbeck, Allgemeines Verwaltungsrecht, 17. Aufl. 2019, § 31 Rn. 1351-1353 und 300 Rn. 1382-1383; Gersdorf, Verwaltungsprozessrecht, 6. Aufl. 2019, Rn. 27 ff; Hufen,

766 Vgl. weiterführend Gersdorf, Verwaltungsprozessrecht, 6. Aufl. 2019, Rn. 31. 767 Gersdorf, Verwaltungsprozessrecht, 6. Aufl. 2019, Rn. 31. 
Verwaltungsprozessrecht, 11. Aufl. 2019, § 14 Rn. 53ff.; Schaks/Friedrich, Verwaltungsaktbezogener Rechtsschutz: Die Zulässigkeitsprüfung, JuS 2018, 860

\section{Das Vorverfahren (Renana Braun)}

301 Das Widerspruchsverfahren (auch: Vorverfahren) eröffnet der Verwaltung die Möglichkeit, nach dem Erlass eines Verwaltungsakts die von der Ausgangsbehörde in der Sache getroffene Entscheidung verwaltungsintern zu überdenken. Im Rechtsstreit um die Rechtmäßigkeit von Verwaltungsakten stellt es eine Sachentscheidungsvoraussetzung für die Klageerhebung dar.

Das Vorverfahren bezweckt auf der einen Seite die Stärkung der Selbstkontrolle der Verwaltung verbunden mit einer Filterfunktion zur Entlastung der Verwaltungsgerichte. ${ }^{768}$ Auf der anderen Seite erweitert es den Rechtsschutz der Adressaten von Verwaltungsakten um eine kostengünstige und aus diesem Grunde risikoarme Form, die die Ausübung des Ermessens insgesamt in den Blick nimmt und nicht nur auf Ermessensfehler überprüft. ${ }^{769}$ Damit steht das Vorverfahren als Zwitter zwischen Verwaltungs- und Gerichtsverfahren.

Besondere Bedeutung entfaltet der Widerspruch im Hinblick auf die formelle Bestandskraft, bei deren Eintritt die Anfechtbarkeit durch den Betroffenen entfällt und der Verwaltungsakt nur noch unter den engmaschigen Voraussetzungen einer Wiederaufnahme des Verfahrens nach $\S 51$ VwVfG (näher dazu $\S 3$ Rn. 108 ff.) bzw. durch Rücknahme oder Widerruf nach §§ $48 \mathrm{ff}$. VwVfG (näher dazu Rn. 844 ff. und $941 \mathrm{ff}$.) behördlich aufgehoben werden kann: Nach § 80 I VwGO entfaltet die Einlegung eines Widerspruchs aufschiebende Wirkung (Suspensiveffekt). Diese hält so lange an, bis im Rahmen eines Widerspruchsbescheides über den Widerspruch entschieden wird. Die Hemmung des Eintritts der formellen Bestandskraft des Verwaltungsakts sperrt die Vollstreckbarkeit des Verwaltungsakts, sofern nicht dessen sofortige Vollziehung gesetzlich oder behördlich angeordnet worden ist (vgl. § 6 I VwVG, § 80 II 1 VwGO).

Das Vorverfahren richtet sich in erster Linie nach $\S \S 68-73$ VwGO und den Ausführungsgesetzen der Bundesländer. Es beginnt mit der Einlegung des außergerichtlichen Rechtsbehelfs und endet mit dem Abhilfe- oder Widerspruchs-

768 Vgl. Schenke, Verwaltungsprozessrecht, 15. Aufl. 2017, Rn. 646.

769 Vgl. Erbguth/Guckelberger, Allgemeines Verwaltungsrecht mit Verwaltungsprozessrecht und Staatshaftungsrecht, 9. Aufl. 2018, § 20 Rn. 2; Maurer/Waldhoff, Allgemeines Verwaltungsrecht, 19. Aufl. 2017, Teil 3 Rn. 75; Brühl, Verwaltungsrecht für die Fallbearbeitung - Anleitungen zum Erwerb prüfungs- und praxisrelevanter Kenntnisse und Fertigkeiten, 9. Aufl. 2018, Rn. 602; Würtenberger/Heckmann, Verwaltungsprozessrecht - Ein Studienbuch, 4. Aufl. 2018, Rn. 410 ff. 
bescheid. Da dieser selbst in Form eines Verwaltungsakts im Sinne des § 35 VwVfG ergeht, sind nachrangig (vgl. § 79 VwVfG) die Vorschriften des VwVfG einschlägig.

Abhilfeverfahren

Hält die Ausgangsbehörde den Widerspruch für zulässig und begründet, hilft sie ihm ab (§ 72 VwGO), indem sie den Verwaltungsakt aufhebt oder ändert.
Widerspruchsverfahren (i.e.S.)

Hält die Ausgangsbehörde den Widerspruch für unzulässig oder unbegründet, hilft sie nicht ab und legt ihn stattdessen der Widerspruchsbehörde vor (§ 73 I 1 VwGO). Diese erlässt einen Widerspruchsbescheid, in dem sie den Widerspruch als unzulässig verwirft, als unbegründet zurückweist oder diesem stattgibt.

Als Zulässigkeitsvoraussetzung der Anfechtungsklage muss der Kläger in der 306 Regel vor Klageerhebung form- und fristgerecht, aber erfolglos Widerspruch eingelegt haben.

\section{Erforderlichkeit des Vorverfahrens}

Das Vorverfahren ist als Sachentscheidungsvoraussetzung im Rahmen eines Klageverfahrens erforderlich, wenn der Widerspruch statthaft und nicht entbehrlich ist.

Statthaft ist der Widerspruch für die Erhebung der Anfechtungsklage gemäß $\S 68$ I 1 VwGO.

Nach § 68 I 2 Hs. 1 VwGO ist das Vorverfahren entbehrlich, wenn ein Ge- 308 setz dies bestimmt. Entsprechende Ausschlüsse des Vorverfahrens sind sowohl in Bundes-, als auch in Landesgesetzen vorgesehen. In einigen Bundesländern wie Niedersachsen und Nordrhein-Westfalen wurde das Vorverfahren grundsätzlich, in anderen für bestimmte Bereiche oder Behörden abgeschafft. Als Gründe hierfür werden Vereinfachungsbestrebungen, die Ersparnis von Verwaltungskosten, die Beschleunigung des Rechtsschutzes und die geringe Erfolgsquote des Widerspruchsverfahrens genannt. ${ }^{770}$

770 Vgl. Erbguth/Guckelberger, Allgemeines Verwaltungsrecht mit Verwaltungsprozessrecht und Staatshaftungsrecht, 9. Aufl. 2018, § 20 Rn. 2; Maurer/Waldhoff, Allgemeines Verwaltungsrecht, 19. Aufl. 2017, Teil 3 Rn. 75; krit. Würtenberger/Heckmann, Verwaltungsprozessrecht - Ein Studienbuch, 4. Aufl. 2018, Rn. 408. 
309 Examenswissen: Ausnahmen auf Bundesebene finden sich beispielsweise in §§ 74 I 2, 70 VwVfG, § 74 VI 3 VwVfG, § 17b I FStrG, § 11 AsylG, § 83 II AufenthG, § 25 IV 2 JuSchG, § 54 II 3 BeamtStG und $\S 20$ VI BDSG.

Beispiele für Sondervorschriften auf Länderebene liefern § 15 BWAGVwGO, § 15 II BayAGVwGO, § 4 II AGVwGO Bln, § 93 I LBG Bln, § 6 II HbgAGVwGO, § 16a I HessAGVwGO, § 13b AGGStrG $M-V, \S 13 a$ GerStrukGAG M-V, \&8a I NdsAGVwGO, §110 JustG NRW und §8a SachsAnhAGVwGO.

310 Darüber hinaus ist das Vorverfahren gegen Entscheidungen einer obersten Bundes- oder Landesbehörde entbehrlich (\$ 68 I 2 Nr. 1 VwG0). ${ }^{771}$ Da es in diesen Fällen an einer nächsthöheren Behörde fehlt und die Ministerialebene von Widerspruchsverfahren freigehalten werden soll, ${ }^{772}$ kann das Verwaltungsgericht hier unmittelbar angerufen werden.

311 Schließlich ist das Vorverfahren auch dann entbehrlich, wenn der Abhilfeoder Widerspruchsbescheid erstmalig eine Beschwer enthält (§ 68 I 2 Nr. 2 VwGO). Von der „erstmaligen“ Beschwer ist auch die „zusätzliche“ Beschwer i.S.d. § 79 II VwGO erfasst.

312 Über die gesetzlich normierten Ausnahmen hinaus erkennt die Rechtsprechung auch dann die Entbehrlichkeit des Widerspruchsverfahrens an, wenn seine Zwecke bereits auf andere Weise erreicht worden sind oder nicht länger erreicht werden können. ${ }^{773}$ Angenommen wird dies zum Beispiel, wenn sich die Widerpruchsbehörde vorgerichtlich endgültig auf die Ablehnung des Rechtsschutzbegehrens festgelegt hat und dies $\mathrm{zu}$ erkennen gibt ${ }^{774}$ oder den anzugreifenden Verwaltungsakt selbst aufgrund bindender Weisung der Aufsichtsbehörde erlassen hat ${ }^{775}$. Dazu zählt auch der Fall, dass sich die Widerspruchsbehörde unter Verzicht auf die Durchführung des Vorverfahrens auf die Klage einlässt; anders ist indes der Fall zu beurteilen, in dem sich die Widerspruchsbehörde nur „hilfsweise“ zur Sache einlässt. ${ }^{776}$

771 Beachte die Sonderregelungen nach § 126 III BBG und § 54 III BeamtStG.

772 Vgl. Uerpmann-Wittzack, Examens-Repetitorium - Allgemeines Verwaltungsrecht mit Verwaltungsprozessrecht, 5. Aufl. 2018, § 5 Rn. 87a.

773 BVerwG, Urt. v. 15.9.2010, Az.: 8 C 21.09 = BVerwGE 138, 1 mit ausführlicher Begründung.

774 BVerwG, Urt. v. 30.10.2013, Az.: 2 C 23.12 = BVerwGE 148, 217.

775 BVerwG, Urt. v. 15.9.2010, Az.: 8 C 21.09 = BVerwGE 138, 1.

776 Hüttenbrink, in: Posser/Wolff, VwGO, 49. Ed., (Stand: 1.4. 2018), § 68 Rn. 23; VGH BW, Urt. v. 23.9.1991, Az.: 1 S 1746/91 Rn. 17 = NVwZ-RR 1992, 184; OVG NRW, Urt. v. 18.4.2013, Az.: 1 A 155/11 Rn. 66 = BeckRS 2013, 50411. 


\section{Ordnungsgemäße Einlegung}

Der Widerspruch muss nicht als solcher bezeichnet werden. ${ }^{777}$ Vielmehr genügt 313 es, wenn die Willenserklärung des Klägers nach § 133 BGB analog erkennen lässt, dass dieser gegen einen erlassenen Verwaltungsakt bzw. die Nichtvornahme eines Verwaltungsakts vorgehen möchte. ${ }^{778}$

\section{a) Handlungsfähigkeit (§§ 79, 11ff. VwVfG)}

Der Widerspruchsführer muss handlungsfähig i.S.d. $\S \S 79,11 \mathrm{ff}$. VwVfG sein. Die 314 an die Handlungsfähigkeit nach $\S 12$ VwVfG gestellten Anforderungen entsprechen im Wesentlichen denjenigen der Prozessfähigkeit nach § 62 VwGO (näher dazu Rn. 433 ff.). ${ }^{779}$ Bei gewillkürter Vertretung muss wie im Rahmen des $§ 67$ VwGO eine entsprechende Vollmacht vorliegen (§§ 14, 79 VwVfG).

\section{b) Einhaltung der Widerspruchsform ( $\$ 70$ I 1 VwG0)}

$\S 70$ I 1 VwGO sieht vor, dass der Widerspruch schriftlich, in elektronischer Form 315 nach § 3 a II VwVfG oder zur Niederschrift zu erheben ist.

Grundsätzlich verlangt die schriftliche Einlegung des Widerspruchs eine eigenständige Unterschrift des Widerspruchsführers oder seines Bevollmächtigten. ${ }^{780}$ Das Schriftformerfordernis ist allerdings nicht streng i.S. d. § 126 BGB zu verstehen. Vielmehr genügt es, wenn aus dem Widerspruchsschreiben klar hervorgeht, wer dessen Urheber ist und dass es zur Erhebung des Widerspruchs willentlich in Verkehr gebracht wurde. ${ }^{781}$

Die elektronische Einlegung setzt voraus, dass die Behörde hierzu den $\mathrm{Zu}-317$ gang eröffnet (§ 3a I VwVfG). Sie ist auf die in § 3a II VwVfG genannten Verfahren beschränkt. Die Versendung einer einfachen E-Mail ohne Signatur erfüllt diese Voraussetzungen nicht. $^{782}$

777 Schenke, Verwaltungsprozessrecht, 16. Aufl. 2019, Rn. 653.

778 Brühl, Verwaltungsrecht für die Fallbearbeitung - Anleitungen zum Erwerb prüfungs- und praxisrelevanter Kenntnisse und Fertigkeiten, 9. Aufl. 2018, Rn. 607.

779 Detterbeck, Allgemeines Verwaltungsrecht mit Verwaltungsprozessrecht, 17. Aufl. 2019, Rn. 1366; Erbguth/Guckelberger, Allgemeines Verwaltungsrecht mit Verwaltungsprozessrecht und Staatshaftungsrecht, 9. Aufl. 2018, § 20 Rn. 9.

780 Würtenberger/Heckmann, Verwaltungsprozessrecht - Ein Studienbuch, 4. Aufl. 2018, Rn. 355.

781 BVerwG, Urt. v. 17.10.1968, Az.: II C 112.65 = BVerwGE 30, 274; Brühl, Verwaltungsrecht für die Fallbearbeitung - Anleitungen zum Erwerb prüfungs- und praxisrelevanter Kenntnisse und Fertigkeiten, 9. Aufl. 2018, Rn. 627 m.w. N.

782 Vgl. Hufen, Verwaltungsprozessrecht, 11. Aufl. 2019, § 6 Rn. 23. 
Die Einlegung des Widerspruchs zur Niederschrift verlangt demgegenüber die mündliche Abgabe der Widerspruchserklärung gegenüber einem zuständigen Behördenmitarbeiter, der hierüber eine Niederschrift anfertigt. Hierzu muss der Widerspruchsführer persönlich anwesend sein. ${ }^{783}$ Ein Telefonat genügt insoweit nicht.

\section{c) Einhaltung der Widerspruchsfrist ( $\$ 70$ I 1 VwG0)}

319 Neben den Vorgaben für die Form regelt § 70 I 1 VwGO auch die Frist, innerhalb derer der Widerspruch einzulegen ist.

\section{aa) Monatsfrist}

320 Die Frist zur Einlegung des Widerspruchs beträgt nach $\S 70$ I 1 VwGO einen Monat ab Bekanntgabe des Ausgangsbescheides. Bekanntgabe ist die amtlich veranlasste Kenntnisnahme eines Verwaltungsakts i.S.d. $§ 41 \mathrm{VwVfG}^{784}$

Für den Zeitpunkt der Bekanntgabe des Verwaltungsakts kann § 41 II VwVfG heranzuziehen sein, wonach ein im Inland durch die Post übermittelter schriftlicher Verwaltungsakt am dritten Tag nach der Aufgabe zur Post und ein elektronisch übermittelter Verwaltungsakt am dritten Tag nach der Absendung als bekannt gegeben gelten, wenn der Verwaltungsakt nicht überhaupt nicht oder zu einem späteren Zeitpunkt zugeht. Hierbei handelt es sich um eine unwiderlegbare Fiktion. ${ }^{785}$ Ein tatsächlich früher erfolgender Zugang ist folglich unschädlich, auch wenn dieser nachweisbar ist. Da mit der Vorschrift nicht das Ende einer Frist bestimmt wird, ist § 193 BGB nicht anwendbar. ${ }^{786}$ Eine entsprechende Regelung für die förmliche Bekanntgabe von Verwaltungsakten im Wege der Zustellung trifft § 4 II 2 VwZG. Ein elektronischer Verwaltungsakt, der durch den Abruf über öffentlich zugängliche Netze bekanntgegeben wird, gilt am Tag nach dem Abruf als bekannt gegeben (\$ 41 IIa VwVfG). Als zugestellt gilt ein elektronisches Dokument gemäß § 5 VII 2 und $\mathbf{3}$ VwZG am dritten Tag nach der Absendung an den vom Empfänger hierfür eröffneten Zugang, wenn der Empfänger nicht nachweist, dass ihm das Dokument nicht oder zu einem späteren Zeitpunkt zugegangen ist.

783 Brühl, Verwaltungsrecht für die Fallbearbeitung - Anleitungen zum Erwerb prüfungs- und praxisrelevanter Kenntnisse und Fertigkeiten, 9. Aufl. 2018, Rn. 629.

784 Würtenberger/Heckmann, Verwaltungsprozessrecht - Ein Studienbuch, 4. Aufl. 2018, Rn. 356.

785 Eine abweichende Regelung trifft $\S 7$ VwVfGBbg.

786 Hierzu ausführlich Brühl, Verwaltungsrecht für die Fallbearbeitung - Anleitungen zum Erwerb prüfungs- und praxisrelevanter Kenntnisse und Fertigkeiten, 9. Aufl. 2018, Rn. 636.

Renana Braun 
Für die Berechnung der Monatsfrist stehen sich die verwaltungsprozessuale 321 Lösung über §57 II VwGO i.V.m. § 222 I ZPO i.V.m. §§ $187 \mathrm{ff}$. BGB und die verwaltungsverfahrensrechtliche Lösung ${ }^{787}$ über $\S 79$ i.V.m. §31 I VwVfG i.V.m. $\S \S 187 \mathrm{ff}$. BGB gegenüber. In einer Klausur braucht der Streit nicht entschieden zu werden, da letztlich beide Lösungen zur Anwendung der zivilrechtlichen Vorschriften zur Fristberechnung führen und § 222 II ZPO und § 31 III VwVfG inhaltsgleiche Regelungen enthalten, sodass die unterschiedlichen Lösungswege insofern keine Auswirkung auf das Ergebnis nehmen. ${ }^{788}$

Hausarbeitswissen: Als Argumente für die verwaltungsprozessuale Lösung können der in $\S 79$ VwVfG verankerte Vorrang der VwGO, die Regelung des Widerspruchs innerhalb der VwGO sowie seine Rechtsnatur als Rechtsbehelf angeführt werden. Für die verwaltungsverfahrensrechtliche Lösung spricht demgegenüber zum einen, dass das Vorverfahren der Selbstkontrolle der Behörde dient und in erster Linie als internes Verwaltungs- und nicht als gerichtliches Verfahren konzipiert ist. Zum anderen markieren die §§ 68ff. VwGO für das Widerspruchsverfahren erkennbar Ausnahmebestimmungen, weshalb beispielsweise § 70 II VwGO auf andere Vorschriften der VwGO verweist. Dieser Verweis erstreckt sich aber nicht auch auf § 57 II VwGO.

Insofern ist für den Fristbeginn $\S 187$ I BGB maßgeblich. Danach beginnt die Widerspruchsfrist mit dem Tag, der auf die Bekanntgabe der Frist folgt, zu laufen. Für das Fristende gelten $\S 188$ BGB und $\S 222$ II ZPO nach verwaltungsprozessualer Lösung bzw. § 31 III VwVfG nach verwaltungsverfahrensrechtlicher Lösung. Im Grundsatz endet die Widerspruchsfrist damit mit Ablauf desjenigen Tages des Folgemonats, der in seiner Ziffer dem Tag der Bekanntgabe entspricht. Ausnahmen bestehen, wenn im Folgemonat der für den Ablauf maßgebende Tag fehlt (vgl. § 188 BGB) oder das Fristende auf einen Samstag, Sonntag oder Feiertag fällt (vgl. § 222 II ZPO bzw. § 31 III VwVfG). Im ersten Fall endet die Frist mit dem Ablauf des letzten Tages des Monats, im zweiten Fall mit dem nächsten Werktag.

Da für die Sachentscheidungsvoraussetzungen der Anfechtungsklage auf $\mathbf{3 2 3}$ den Zeitpunkt der letzten mündlichen Verhandlung des Verwaltungsgerichts abzustellen ist, ist $\mathrm{zu}$ berücksichtigen, dass ein fehlendes, aber erforderliches Vorverfahren nach Klageerhebung nachgeholt werden kann, sofern die Widerspruchsfrist noch nicht abgelaufen ist. ${ }^{789}$

787 Erbguth/Guckelberger, Allgemeines Verwaltungsrecht mit Verwaltungsprozessrecht und Staatshaftungsrecht, 9. Aufl. 2018, § 20 Rn. 9.

788 Vgl. Detterbeck, Allgemeines Verwaltungsrecht mit Verwaltungsprozessrecht, 17. Aufl. 2019, Rn. 1356.

789 Detterbeck, Allgemeines Verwaltungsrecht mit Verwaltungsprozessrecht, 17. Aufl. 2019, Rn. 1354 m.w. N.; Schenke, Verwaltungsprozessrecht, 16. Aufl. 2019, Rn. 642 m.w. N.

Renana Braun 


\section{bb) Jahresfrist}

324 Bei unterbliebener oder unrichtiger Rechtsbehelfsbelehrung beträgt die Widerspruchsfrist gemäß $§ 70$ II i.V.m. § 58 II VwGO statt einem Monat ein Jahr. Für die Berechnung der Jahresfrist gelten dieselben Vorschriften wie für die Monatsfrist. Eine ordnungsgemäße Rechtsbehelfsbelehrung setzt Angaben über den Rechtsbehelf, die Behörde, an die der Widerspruch zu richten ist, deren Sitz und die einzuhaltende Frist voraus (vgl. §37 VI 1 VwVfG). Zur Unrichtigkeit der Rechtsbehelfsbelehrung führen sämtliche Angaben, die geeignet sind, den Betroffenen durch einen hervorgerufenen Irrtum von einer ordnungsgemäßen Widerspruchseinlegung abzuhalten. ${ }^{790}$ Hierzu genügen beispielsweise die Angabe einer Frist von vier Wochen anstelle der gesetzlichen Monatsfrist, eine fehlerhafte Behördenanschrift oder die Angabe, die Widerspruchsfrist beginne mit dem Zugang statt mit der Bekanntmachung zu laufen. Angaben zur Form der Widerspruchseinlegung bedarf es nicht. Verlangt die Rechtsbehelfsbelehrung allerdings die schriftliche Einlegung, macht der fehlende Hinweis auf die Alternativen zur schriftlichen Einlegung in Form der elektronischen Einlegung und der Einlegung zur Niederschrift diese unrichtig. ${ }^{791}$

\section{cc) Verstreichen der Widerspruchsfrist}

325 Bei verstrichener Widerspruchsfrist kann dem Widerspruchsführer Wiedereinsetzung in den vorigen Stand zu gewähren sein. Dies bestimmt sich nach $\S 70$ II i.V.m. §60 I bis IV VwGO und setzt voraus, dass der Widerspruchsführer ohne Verschulden daran gehindert war, die Widerspruchsfrist einzuhalten. Der Antrag auf Wiedereinsetzung ist binnen zwei Wochen ab Wegfall des Hindernisses und innerhalb eines Jahres nach Ende der versäumten Frist zu stellen und die Tatsachen zu seiner Begründung vom Antragsteller glaubhaft zu machen (§ 173 VwGO i.V.m. § 294 ZPO). Die Einlegung des Widerspruchs ist innerhalb der zweiwöchigen Antragsfrist nachzuholen. Ist dies geschehen, kann die Wiedereinsetzung auch ohne Antrag gewährt werden. „Ohne Verschulden“ wird die Frist versäumt, wenn der Widerspruchsführer die erforderliche Sorgfalt walten lässt, die in seiner Situation für einen gewissenhaften Beteiligten geboten und zumutbar erscheint. ${ }^{792}$

790 Brühl, Verwaltungsrecht für die Fallbearbeitung - Anleitungen zum Erwerb prüfungs- und praxisrelevanter Kenntnisse und Fertigkeiten, 9. Aufl. 2018, Rn. 659.

791 Brühl, Verwaltungsrecht für die Fallbearbeitung - Anleitungen zum Erwerb prüfungs- und praxisrelevanter Kenntnisse und Fertigkeiten, 9. Aufl. 2018, Rn. 659f.

792 Erbguth/Guckelberger, Allgemeines Verwaltungsrecht mit Verwaltungsprozessrecht und Staatshaftungsrecht, 9. Aufl. 2018, § 20 Rn. 9.

Renana Braun 
Nach der Rechtsprechung des Bundesverwaltungsgerichts ${ }^{793}$ kann auch ein 326 verfristeter Widerspruch sachlich beschieden werden. Für die Zulässigkeitsprüfung im Rahmen der Anfechtungsklage bedeutet dies, dass auch dann vom Vorliegen der Sachentscheidungsvoraussetzung eines erfolglos durchgeführten Vorverfahrens auszugehen ist, wenn ein Widerspruchsbescheid ergeht, gleichwohl die Widerspruchsfrist versäumt worden ist. Dies ist Ausfluss der ständigen Rechtsprechung, wonach eine sachliche Bescheidung des Widerspruchs die Klagemöglichkeit unabhängig davon eröffnet, ob die Widerspruchsbehörde zu seiner Bescheidung verpflichtet war oder nicht. ${ }^{794}$ Damit kommt der Widerspruchsbehörde die Dispositionsfreiheit $\mathrm{zu}$, die behördlichen und gerichtlichen Rechtsschutzmöglichkeiten des Widerspruchsführers nach Ablauf der Widerspruchsfrist wiederherzustellen.

Examenswissen: Ein Teil der Literatur kritisiert die Rspr. zur Heilung der Verfristung eines Widerspruchs mittels einer in der Sache ergehenden Entscheidung der Widerspruchsbehörde, weil sie im Widerspruch zu Rechtssicherheit und Bestandsschutz steht, die u. a. die Inanspruchnahme der Verwaltungsgerichte begrenzen. ${ }^{795}$ Denn mit der behördlichen Heilung der Verfristung des Widerspruchs wird auch die Befassung der Verwaltungsgerichtsbarkeit in das Ermessen der Widerspruchsbehörde gestellt. Weder die Argumentation, wonach die Widerspruchsbehörde die Sachherrschaft behalten und „Herrin des Streitstoffs“ bleiben solle, ${ }^{796}$ noch ein Abstellen darauf, dass die Widerspruchsfrist in erster Linie den Schutz des Rechtsträgers der Ausgangs- bzw. Widerspruchsbehörde bezwecke, ${ }^{797}$ vermögen diese Bedenken auszuräumen. Schließlich beschränkt sich die Sachherrschaft bei fristgemäßer Einlegung eines Widerspruchs darauf, über den Widerspruch zu entscheiden, und erstreckt sich nicht auch auf die Frage der Zulässigkeit einer Klage, soweit für den Fall einer ausbleibenden Entscheidung § 75 VwGO den Klageweg ebnet. Bei $\S 70$ I 1 VwGO handelt es sich auch nicht um eine verfahrensrechtliche Schutzvorschrift allein zugunsten des Rechtsträgers der Ausgangs- bzw. Widerspruchsbehörde, auf deren Schutz diese verzichten kann. Dies gilt zum einen mit Blick auf etwaig betroffene Dritte (etwa beim Nachbarwiderspruch) und zum anderen bei einer reformatio in peius für den Widerspruchsführer selbst. Die Norm ist vielmehr als Teil des Geflechts von Verfahrensvorschriften zu betrachten, das die Bestandskraft von Verwaltungsakten regelt. Hierin ist eine Durchbrechung der Bestandskraft in den Ausnahmefällen der Wiedereinsetzung in den vorigen Stand, des Wiederaufgreifens des Verfahrens nach $\S 51$ VwVfG sowie der Aufhebung von Verwaltungsakten nach §§ $48 \mathrm{ff}$. VwVfG

793 BVerwG, Urt. v. 28.10.1982, Az.: 2 C 4.80 = NVwZ 1983, 608; BVerwG, Urt. v. 18.11.2010, Az.: 3 C 42.09 = BVerwGE 138, 159 (Rn. 13).

794 Vgl. BVerwG, Urt. v. 21.3.1979, Az.: 6 C 10.78 = BVerwGE 57, 342 (344f.) m.w. N.; BVerwG, Urt.v. 28.10.1982, Az.: 2 C 4.80 = NVwZ 1983, 608.

795 Brühl, Verwaltungsrecht für die Fallbearbeitung - Anleitungen zum Erwerb prüfungs- und praxisrelevanter Kenntnisse und Fertigkeiten, 9. Aufl. 2018, Rn. 663.

796 Würtenberger/Heckmann, Verwaltungsprozessrecht - Ein Studienbuch, 4. Aufl. 2018, Rn. 361 m.w. N.

797 Jäde, Verwaltungsverfahren Widerspruchsverfahren Verwaltungsprozess - Problemschwerpunkte zur Vorbereitung auf die Zweite Juristische Staatsprüfung, 6. Aufl. 2011, Rn. 142f.

Renana Braun 
vorgesehen. Gemein ist diesen Ausnahmen, dass sie die betroffenen Interessen in der jeweiligen Konstellation gegeneinander abwiegen und der Behörde nicht gemeinhin ohne weitere Voraussetzungen ermöglichen, die Bestandskraft des Verwaltungsakts anzurühren. Insofern steht die verwaltungsprozessuale Ausgestaltung der Bestandskraft zum Zwecke der Rechtssicherheit einer Ausweitung der behördlichen Gestaltungsmacht, wonach die Widerspruchsbehörde den nach dem Prozessrecht bereits geschlossenen Zugang zum gerichtlichen Rechtsschutz nach eigenem Ermessen erneut eröffnen könnte, entgegen.

In einer Klausur ist der Streit nur zu diskutieren, wenn zu einem verfristeten Widerspruch eine Sachentscheidung der Behörde ergeht. Wer sich gegen die Rspr. entscheidet, muss hilfsgutachterlich weiterprüfen (dazu §1 Rn. 139).

Abweichend begründet die Verfristung des Widerspruchs ungeachtet einer sachlichen Bescheidung durch die Widerspruchsbehörde unstrittig die Unzulässigkeit einer sich anschließenden Klage, wenn der Widerspruchsbescheid die Interessen eines Dritten berührt, der durch die mit Fristablauf eingetretene Bestandskraft des Verwaltungsakts bereits eine gesicherte Rechtsposition erlangt hatte. ${ }^{798}$ Denn auch die von der herrschenden Meinung angenommene behördliche Sachherrschaft geht nicht so weit, als dass die Widerspruchsbehörde über geschützte Interessen Dritter disponieren dürfte. ${ }^{799}$

\section{dd) Verwirkung}

329 Hat die Widerspruchsfrist in Ermangelung einer Bekanntgabe (beispielsweise im Falle des Nachbarwiderspruchs gegen einen Verwaltungsakt, der nur dem Adressaten, nicht aber dem Widerspruch einlegenden Nachbarn bekannt gegeben wurde) ${ }^{800}$ nicht zu laufen begonnen, kann im Rahmen des allgemeinen Rechtsschutzbedürfnisses $\mathrm{zu}$ prüfen sein, ob der Widerspruchsführer den Rechtsbehelf möglicherweise verwirkt hat. Denn auch die Ausübung des Widerspruchsrechts unterliegt dem allgemeinen Rechtsgrundsatz von Treu und Glauben (§ 242 BGB analog). Hiernach kann sich der Widerspruchsführer nicht darauf berufen, dass ihm der Verwaltungsakt nicht bekanntgegeben worden sei,

798 Detterbeck, Allgemeines Verwaltungsrecht mit Verwaltungsprozessrecht, 17. Aufl. 2019, Rn. 1357; Schenke in: Kopp/Schenke, VwGO, 25. Aufl. 2019, § 70 Rn. 9.

799 BVerwG, Urt. v. 29.10.1968, Az.: IV B 7.68G = DÖV 1969, 142 (142f.); Würtenberger/Heckmann, Verwaltungsprozessrecht - Ein Studienbuch, 4. Aufl. 2018, Rn. 361 m.w. N.

800 S. hierzu Erbguth/Guckelberger, Allgemeines Verwaltungsrecht mit Verwaltungsprozessrecht und Staatshaftungsrecht, 9. Aufl. 2018, § 20 Rn. 9 m.w. N.

Renana Braun 
wenn er sichere Kenntnis von diesem erhalten hat ${ }^{801}$ und zu dem Zeitmoment ein Umstandsmoment hinzutritt (s. zur Verwirkung auch Rn. 399f.). ${ }^{802}$

\section{d) Richtige Behörde}

Die Widerspruchsfrist wird nur bei Einlegung des Widerspruchs bei der richti- 330 gen Behörde gewahrt. Dies ist nach § 70 I 1 VwGO grundsätzlich die Ausgangsbehörde. Nach $\S 70$ I 2 VwGO wird die Frist aber auch dann eingehalten, wenn der Widerspruch bei der Behörde, die den Widerspruchsbescheid zu erlassen hat, eingelegt wird.

Widerspruchsbehörde ist gemäß $§ 73$ I 2 Nr. 1 VwGO die nächsthöhere Be- 331 hörde, wenn nicht aufgrund sondergesetzlicher Bestimmung die Behörde, die den Verwaltungsakt erlassen hat, auch für die Entscheidung über den Widerspruch zuständig ist (§ 73 I 3 VwGO). Ist die nächsthöhere Behörde eine oberste Bundesoder oberste Landesbehörde, ist die Behörde, die den Verwaltungsakt erlassen hat, auch Widerspruchsbehörde (§ 73 I 2 Nr. 2 VwGO). Dies dient - wie $§ 68$ I 2 Nr. 1 VwGO - der Entlastung der Ministerialebene. ${ }^{803}$ In Selbstverwaltungsangelegenheiten ist die Selbstverwaltungsbehörde für die Entscheidung über den Widerspruch zuständig, soweit nicht durch Gesetz etwas anderes bestimmt ist (§ 73 I 2 Nr. 3 VwGO).

Examenswissen: Wird ein Widerspruch bei einer unzuständigen Behörde eingelegt, ist diese grundsätzlich verpflichtet, den Widerspruch weiterzuleiten. ${ }^{804}$ Unterlässt sie dies, kann das Konstrukt der Einheit der Verwaltung bewirken, dass der Widerspruch als rechtzeitig erhoben angesehen werden muss. Gelangt der Widerspruch allerdings trotz unverzüglicher Weiterleitung zu spät an die zuständige Behörde, bewirkt die Einlegung bei der falschen Behörde nicht etwa eine Fristwahrung kraft Einheit der Verwaltung. Dasselbe gilt, wenn die Verfristung auch bei einer unverzüglichen Weiterleitung eingetreten wäre. Die Zulässigkeit des Widerspruchs hängt demnach bei Einlegung bei einer falschen Behörde davon ab, ob diese den Widerspruch noch rechtzeitig innerhalb der Widerspruchsfrist an die zuständige Behörde weiterleiten kann.

801 Würtenberger/Heckmann, Verwaltungsprozessrecht - Ein Studienbuch, 4. Aufl. 2018, Rn. 362.

802 Näher zur Verwirkung Detterbeck, Allgemeines Verwaltungsrecht mit Verwaltungsprozessrecht, 17. Aufl. 2019, Rn. 561.

803 Vgl. Uerpmann-Wittzack, Examens-Repetitorium - Allgemeines Verwaltungsrecht mit Verwaltungsprozessrecht, 5. Aufl. 2018, §5 Rn. 87a.

804 Detterbeck, Allgemeines Verwaltungsrecht mit Verwaltungsprozessrecht, 17. Aufl. 2019, Rn. 1367. 


\section{Erfolglosigkeit des Widerspruchs}

333 Erfolglos ist der Widerspruch, soweit dem Begehren des Widerspruchsführers nicht im Rahmen eines Abhilfebescheides vollumfänglich abgeholfen wird.

Wird über den Widerspruch ohne zureichenden Grund nicht innerhalb einer angemessenen Frist entschieden, ist die Anfechtungsklage nach §75 1 VwGO auch ohne Beendigung des Vorverfahrens durch einen Widerspruchsbescheid als sogenannte Untätigkeitsklage zulässig (s. hierzu Rn. 384 ff.). Die Angemessenheit der Frist ist je nach den Umständen des Einzelfalls zu bestimmen, deckt sich aber regelmäßig mit der Sperrfrist von drei Monaten aus $§ 752$ VwGO. Ein nach Ablauf der Frist ergehender versagender Bescheid lässt das Erfordernis eines Vorverfahrens nicht wieder aufleben, da eine einmal zulässige Klage nicht durch einseitiges Handeln der Verwaltung unzulässig werden darf. Da der Ablauf der Frist erst zum Zeitpunkt der Entscheidung des Gerichts eingetreten sein muss, kann die Untätigkeitsklage auch schon vor deren Ablauf erhoben werden. In diesem Fall ist sie im Zeitpunkt der Erhebung unzulässig, wird aber mit Ablauf der Frist (Heilung des Mangels) zulässig. Ein der Untätigkeitsklage entgegenstehender besonderer Grund kann sich beispielsweise aus den besonderen Schwierigkeiten des Falles oder der Notwendigkeit der Beteiligung Dritter ergeben, nicht aber allein aus Gründen der Arbeitsüberlastung oder aus einer fehlenden Vorauszahlung von Gebühren.

\section{Prüfungsschema Erfolgsaussichten eines Widerspruchs}

335 In einigen Klausurkonstellationen wird nicht nach den Erfolgsaussichten einer Klage, sondern nach denen eines Widerspruchs gefragt. Das Prüfungsschema richtet sich dann nach Zulässigkeit und Begründetheit des Widerspruchs: ${ }^{805}$

\section{A. Zulässigkeit}

I. Verwaltungsrechtsweg (\$ 40 I 1 VwGO analog): Die Eröffnung des Verwaltungsrechtswegs ist ausführlich in $\S 1 \mathrm{Rn}$. $162 \mathrm{ff}$. dargestellt.

II. Statthaftigkeit des Widerspruchs: Statthaft ist der Widerspruch nur für Situationen, für die das Widerspruchsverfahren ausdrücklich angeordnet

805 Ausführlich bei Brühl, Verwaltungsrecht für die Fallbearbeitung - Anleitungen zum Erwerb prüfungs- und praxisrelevanter Kenntnisse und Fertigkeiten, 9. Aufl. 2018, Rn. 606 ff.; Detterbeck, Allgemeines Verwaltungsrecht mit Verwaltungsprozessrecht, 17. Aufl. 2019, Rn. 1360 ff.; Erbguth/ Guckelberger, Allgemeines Verwaltungsrecht mit Verwaltungsprozessrecht und Staatshaftungsrecht, 9. Aufl. 2018, § 20 Rn. 6 ff.; Würtenberger/Heckmann, Verwaltungsprozessrecht - Ein Studienbuch, 4. Aufl. 2018, Rn. 421ff.; s. auch Schenke, Verwaltungsprozessrecht, 16. Aufl. 2019, Rn. $648 \mathrm{ff}$. 
ist, so bei Anfechtungs- (§ 68 I 1 i.V.m. § 42 I Alt. 1 VwGO) und Verpflichtungskonstellationen (in der Variante der Versagungsgegenklage gemäß § 68 II i.V.m. § 42 I Alt. 2 VwGO), soweit es nicht durch abweichende Vorschriften ausdrücklich ausgeschlossen ist, und in bestimmten Fällen, in denen die allgemeine Leistungs- oder Feststellungsklage statthafte Klageart ist (vgl. § 54 II 1 BeamtStG, § 126 II 1 BBG).

III. Widerspruchsbefugnis (\$ 42 II VwGO analog): Der Widerspruchsführer muss die Verletzung eigener subjektiv-öffentlicher Rechte geltend machen. Dies ergibt sich aus $\S 70$ I VwGO, nach dem nur „der Beschwerte“ Widerspruch einlegen kann.

Besonderheit: Es genügt, dass der Betroffene geltend macht, der beeinträchtigende Verwaltungsakt sei nicht zweckmäßig (vgl. § 68 I 1 VwGO). Im Falle des Anfechtungswiderspruchs kann auf die Adressatentheorie (s. Rn. 294 f.) zurückgegriffen werden.

IV. Ordnungsgemäße Einlegung (insbes. Wahrung Form und Frist): Dazu 339 bereits Rn. $315 \mathrm{ff}$.

V. Allgemeines Rechtsschutzbedürfnis: Der Widerspruch muss Vorteile $\mathbf{3 4 0}$ bezwecken, die nicht allein darin bestehen, anderen $\mathrm{zu}$ schaden, und darf auch nicht auf sonstige Weise offensichtlich rechtsmissbräuchlich sein. ${ }^{806}$ Bei einem Verpflichtungswiderspruch muss außerdem zuvor ein Antrag auf Vornahme des begehrten Verwaltungsakts von der zuständigen Behörde abgelehnt worden sein.

\section{B. Begründetheit}

Ein Anfechtungswiderspruch (§ 68 I VwGO) ist begründet, soweit der angegriffene 341 Verwaltungsakt rechtswidrig und der Widerspruchsführer dadurch in seinen Rechten verletzt ist oder der Verwaltungsakt zweckwidrig und der Widerspruchsführer dadurch in seinen Rechten beeinträchtigt ist (§ 68 I i.V.m. § 113 I 1 VwGO analog).

Ein Verpflichtungswiderspruch (§ 68 II VwGO) ist begründet, soweit die Ab- 342 lehnung des Verwaltungsakts rechtswidrig und der Widerspruchsführer dadurch in seinen Rechten verletzt ist oder die Ablehnung zweckwidrig und der Widerspruchsführer dadurch in seinen Rechten beeinträchtigt ist (§ 68 II i.V.m. § 113 V 1 VwGO analog).

806 Erbguth/Guckelberger, Allgemeines Verwaltungsrecht mit Verwaltungsprozessrecht und Staatshaftungsrecht, 9. Aufl. 2018, § 20 Rn. 10. 
343 Examenswissen: Spezialgesetzliche Regelungen können die Widerspruchsbehörde darauf begrenzen, den Widerspruch nur auf seine Rechtmäßigkeit, nicht aber auf seine Zweckmäßigkeit zu überprüfen. Dies ist der Fall, wenn entgegen § 73 I Nr. 3 VwGO in Selbstverwaltungsangelegenheiten nicht die Selbstverwaltungsbehörde, sondern aufgrund von Landesrecht eine andere Behörde über den Widerspruch entscheidet (vgl. § 8 I BWAGVwGO). ${ }^{807}$ Hebt die Widerspruchsbehörde den Bescheid dennoch wegen Zweckwidrigkeit auf, verletzt sie damit das Selbstverwaltungsrecht der Ausgangsbehörde. Die betroffene Selbstverwaltungskörperschaft kann in diesem Fall als erstmalig beschwerter Dritter i.S.d. § 79 I Nr. 2 VwGO Klage gegen den Widerspruchsbescheid erheben.

\section{Reformatio in peius (,Veränderung ins Schlechte“)}

344 Im Rahmen der Entscheidung über einen Widerspruch kann sich unter dem Stichwort der reformatio in peius die Frage stellen, ob die Widerspruchsbehörde den Verwaltungsakt zu Lasten des Widerspruchsführers ändern kann. In einer Klausur zeitigt eine solche Verböserung im Widerspruchsverfahren Auswirkungen auf verschiedenen Ebenen des Prüfungsschemas, die im Folgenden besprochen werden.

345 Gänzlich von der Konstellation einer reformatio in peius zu unterscheiden ist der Fall, dass ein begünstigender Verwaltungsakt auf den Widerspruch eines belasteten Dritten zu Lasten des Begünstigten verschärft wird. ${ }^{808}$

\section{a) Besonderheiten bei der Prüfung der Zulässigkeit der Klage}

346 Da der Widerspruchsführer im Umfang der Verböserung durch den Widerspruchsbescheid zusätzlich beschwert ist, kann er den Klagegegenstand gemäß $\S 79$ II 1 VwGO hierauf beschränken. Richtiger Klagegegner ist dann die Widerspruchsbehörde bzw. deren Träger (§ 78 II VwGO). ${ }^{809}$

\section{b) Besonderheiten bei der Prüfung der Begründetheit der Klage}

347 Im Rahmen der Begründetheit zeitigt die reformatio in peius auf den Ebenen der Ermächtigungsgrundlage, der formellen sowie der materiellen Rechtmäßigkeit Diskussionsbedarf.

807 Vgl. Detterbeck, Allgemeines Verwaltungsrecht mit Verwaltungsprozessrecht, 17. Aufl. 2019, Rn. 1371.

$808 \mathrm{Zu}$ weiteren Abgrenzungen s. Hufen, Verwaltungsprozessrecht, 11. Aufl. 2019, § 9 Rn. 15. 809 Vgl. Hufen, Verwaltungsprozessrecht, 11. Aufl. 2019, § 9 Rn. 22. 


\section{aa) Ermächtigungsgrundlage}

Es ist umstritten, ob eine reformatio in peius überhaupt zulässig ist. ${ }^{810}$ Die 348 grundsätzliche Möglichkeit zur Verböserung im Laufe des Widerspruchsverfahrens wird durch die VwGO zwar vorausgesetzt. Die Vorschriften der $\S \S 68$ I 2 Nr. 2, 78 II und 79 I Nr. 2, II 1 VwGO lassen jedoch auch eine Lesart zu, der zufolge eine Verschlechterung im Widerspruchsverfahren möglich, aber nicht zwangsläufig auch rechtmäßig sein kann. ${ }^{811}$ Die besseren Gründe sprechen jedoch für die Zulässigkeit der reformatio in peius: Dafür spricht zunächst $§ 71 \mathrm{VwGO}$, der eine Anhörung verlangt, wenn die Aufhebung oder Änderung eines Verwaltungsakts im Widerspruchsverfahren erstmalig mit einer Beschwer verbunden ist. Denn anderenfalls liefe der Schutzzweck der erforderlichen Anhörung ins Leere und wäre die formelle Rechtmäßigkeitsanforderung nicht sachgerecht. Für eine Gestattung der reformatio in peius im Allgemeinen spricht außerdem die Verpflichtung der Widerspruchsbehörde zu einer umfassenden Rechts- und Zweckmäßigkeitskontrolle im Rahmen des Vorverfahrens. ${ }^{812}$ Weiterhin wird der Grundsatz der Gesetzmäßigkeit der Verwaltung zur Begründung ihrer Zulässigkeit ins Feld geführt. ${ }^{813}$

Neben der generellen Gestattung, einen angegriffenen Verwaltungsakt im Widerspruchsverfahren zu Lasten des Widerspruchsführers abzuändern, verlangt der Vorbehalt des Gesetzes (Art. 20 III GG) eine materiell-rechtliche Ermächtigung der Verwaltung, die belastende Regelung zu erlassen. ${ }^{814}$ Hierfür lassen sich die $\S \$ 48 \mathrm{ff}$. VwVfG sowie die Ermächtigungsgrundlage fruchtbar machen, die dem Ausgangsbescheid zugrunde lag. ${ }^{815}$ Damit die im Widerspruchsbescheid getroffene Entscheidung auf diese Rechtsgrundlagen gestützt werden kann, muss sie zum einen für die Beseitigung der im Ausgangsbescheid getroffenen Regelung die Grundsätze über die Aufhebung von Verwaltungsakten beachten und zum anderen die Anwendungsgrenzen der ursprünglichen Rechtsgrundlage einhalten. ${ }^{816}$ Dies ist wiederum im Rahmen der formellen und materiellen Rechtmäßigkeit zu prüfen.

810 Kritisch Hufen, Verwaltungsprozessrecht, 11. Aufl. 2019, § 9 Rn. $15 \mathrm{ff}$.

811 Vgl. Detterbeck, Allgemeines Verwaltungsrecht mit Verwaltungsprozessrecht, 17. Aufl. 2019, Rn. 1373; Ipsen, Allgemeines Verwaltungsrecht, 11. Aufl. 2019, Rn. 1080b.

812 Vgl. Würtenberger/Heckmann, Verwaltungsprozessrecht - Ein Studienbuch, 4. Aufl. 2018, Rn. 435.

813 Detterbeck, Allgemeines Verwaltungsrecht mit Verwaltungsprozessrecht, 17. Aufl. 2019, Rn. 1373.

814 Vgl. Hufen, Verwaltungsprozessrecht, 11. Aufl. 2019, § 9 Rn. 18.

815 S. hierzu Schenke, Verwaltungsprozessrecht, 16. Aufl. 2019, Rn. $693 \mathrm{f}$.

816 Weber in Brandt/Domgörgen, Handbuch Verwaltungsverfahren und Verwaltungsprozess, 4. Aufl. 2018, S. 316 f. Rn. 164. 


\section{bb) Formelle Rechtmäßigkeit}

349 Die Widerspruchsbehörde muss außerdem als Teil ihrer sachlichen Zuständigkeit selbst über die erforderliche Kompetenz für die verbösernde Regelung verfügen. Unproblematisch der Fall ist dies, wenn Ausgangs- und Widerspruchsbehörde identisch sind. Außerdem ist die Widerspruchsbehörde verfahrensrechtlich zur Verböserung befugt, wenn sie im Rahmen ihres Rechts zum Selbsteintritt im Widerspruchsverfahren vollumfänglich an die Stelle der Ausgangsbehörde tritt oder sie die Fachaufsicht über die Ausgangsbehörde innehat. ${ }^{817}$

$\S 71$ VwGO verlangt darüber hinaus die Anhörung des Widerpruchsführers zu der behördlich geplanten Änderung. ${ }^{818}$

\section{cc) Materielle Rechtmäßigkeit}

351 Nach ständiger Rechtsprechung des BVerwG sind im Rahmen der materiellen Rechtmäßigkeit die in \$\$ $\mathbf{4 8 f f . ~ V w V f G ~ n i e d e r g e l e g t e n ~ G r u n d s a ̈ t z e ~ u ̈ b e r ~ d e n ~}$ Vertrauensschutz bei Rücknahme und Widerruf von Verwaltungsakten zu beachten.${ }^{819}$ Denn der Austausch des belastenden Ausgangsbescheides gegen einen noch stärker belastenden Widerspruchsbescheid ist aus Sicht des Adressaten der Aufhebung eines begünstigenden Verwaltungsakts vergleichbar. ${ }^{820}$ Dabei ist zu berücksichtigen, dass der Widerspruchsführer mit Einlegung des Widerspruchs grundsätzlich mit der Verschlechterung seiner Position zu rechnen hat, da der angegriffene Verwaltungsakt nicht länger Grundlage für ein zu schützendes Vertrauen sein kann. ${ }^{821}$ Für die Annahme eines entsprechenden Vertrauens müssen insoweit besondere Umstände hinzutreten. ${ }^{822}$ Eine Ausnahme ist nach

817 Vgl. Erbguth/Guckelberger, Allgemeines Verwaltungsrecht mit Verwaltungsprozessrecht und Staatshaftungsrecht, 9. Aufl. 2018, § 20 Rn. 15; Groscurth, Examenskurs VwGO für Studenten und Referendare, 2014, Rn. 316; Würtenberger/Heckmann, Verwaltungsprozessrecht - Ein Studienbuch, 4. Aufl. 2018, Rn. 436 m.w. N.

818 Hierzu Hufen, Verwaltungsprozessrecht, 11. Aufl. 2019, § 9 Rn. 20; Weber in Brandt/Domgörgen, Handbuch Verwaltungsverfahren und Verwaltungsprozess, 4. Aufl. 2018, S. 317 f. Rn. 168. 819 S. bspw. BVerwG, Urt. v. 13.9.2006, Az.: 6 C 10.06 = NVwZ-RR 2007, 192 m.w. N.; krit. Groscurth, Examenskurs VwGO für Studenten und Referendare, 2014, Rn. 316.

820 Vgl. Detterbeck, Allgemeines Verwaltungsrecht mit Verwaltungsprozessrecht, 17. Aufl. 2019, Rn. 1374; Erbguth/Guckelberger, Allgemeines Verwaltungsrecht mit Verwaltungsprozessrecht und Staatshaftungsrecht, 9. Aufl. 2018, § 20 Rn. 15.

821 Brühl, Verwaltungsrecht für die Fallbearbeitung - Anleitungen zum Erwerb prüfungs- und praxisrelevanter Kenntnisse und Fertigkeiten, 9. Aufl. 2018, Rn. 685; krit. hierzu Ipsen, Allgemeines Verwaltungsrecht, 11. Aufl. 2019, Rn. 1080c.

822 BVerwG, Urt. v. 15.4.1983, Az.: 8 C 170.81 = BVerwGE 67, 129. 
der Rechtsprechung dann anzunehmen, wenn die Verböserung anderenfalls zu „untragbaren Zuständen“ führte. ${ }^{823}$

\section{Literaturhinweise}

Zum Widerspruch im Allgemeinen: Brandt in Brandt/Domgörgen, Handbuch 352 Verwaltungsverfahren und Verwaltungsprozess, 4. Aufl. 2018, S. 319-354; Brühl, Verwaltungsrecht für die Fallbearbeitung - Anleitungen zum Erwerb prüfungsund praxisrelevanter Kenntnisse und Fertigkeiten, 9. Aufl. 2018, Rn. 602-729; Detterbeck, Allgemeines Verwaltungsrecht mit Verwaltungsprozessrecht, 17. Aufl. 2019, Rn. 1359-1375; Erbguth/Guckelberger, Allgemeines Verwaltungsrecht mit Verwaltungsprozessrecht und Staatshaftungsrecht, 9. Aufl. 2018, § 20 Rn. 1-16; Groscurth, Examenskurs VwGO für Studenten und Referendare, 2014, Rn. 276 333; Hufen, Verwaltungsprozessrecht, 11. Aufl. 2019, Teil 2 Das Widerspruchsverfahren; Schenke, Verwaltungsprozessrecht, 16. Aufl. 2019, Rn. 639-696; Weber, in: Brandt/Domgörgen, Handbuch Verwaltungsverfahren und Verwaltungsprozess, 4. Aufl. 2018, S. 276 ff.; Würtenberger/Heckmann, Verwaltungsprozessrecht - Ein Studienbuch, 4. Aufl. 2018, Rn. 407-437

Zum Widerspruch im Rahmen der Anfechtungsklage: Brühl, Verwaltungsrecht für die Fallbearbeitung - Anleitungen zum Erwerb prüfungs- und praxisrelevanter Kenntnisse und Fertigkeiten, 9. Aufl. 2018, Rn. 759f.; Detterbeck, Allgemeines Verwaltungsrecht mit Verwaltungsprozessrecht, 17. Aufl. 2019, Rn. 1354-1358; Ipsen, Allgemeines Verwaltungsrecht, 11. Aufl. 2019, Rn. 1061-1080; Sauer, Klausurtraining - Allgemeines Verwaltungsrecht und Verwaltungsprozessrecht, 2018, Rn. 80 - 82; Würtenberger/Heckmann, Verwaltungsprozessrecht - Ein Studienbuch, 4. Aufl. 2018, Rn. 353-363

Übungsfälle: Saarheimer Fälle: „Ausgehöhlt!“, „Dr. Eisenbart“, „Feuer und Flamme“, „Nicht ohne meine Hose“, „Sammy im Saarheimer See“, abrufbar unter http://saarheim.de/; Kurzfälle bei Uerpmann-Wittzack, Examens-Repetitorium Allgemeines Verwaltungsrecht mit Verwaltungsprozessrecht, 5. Aufl. 2018, Fälle $35-37$

Lehrvideo: Brink/Kölle/Weigel, Peer2Peer Lehrvideo Reformatio in peius, abrufbar unter https://youtu.be/04 h4nPGxqT0

823 S. bspw. BVerwG, Urt. v. 13.9.2006, Az.: 6 C 10.06 = NVwZ-RR 2007, 192 m.w. N. 


\section{Die Klagefrist (Patrick Stockebrandt)}

353 Die Einhaltung der Klagefrist des $\S 74$ VwGO gehört zu den zwingenden Sachentscheidungsvoraussetzungen ${ }^{824}$ und ist eine der Prozessvoraussetzungen sowohl für die Anfechtungs- und Verpflichtungsklage als auch für weitere Klagebzw. Antragsarten. ${ }^{825}$ Dies hat zur Folge, dass der gerichtliche Rechtsschutz, der dem Einzelnen gemäß Artikel 19 IV GG verfassungsrechtlich gewährt wird, auch von der Einhaltung der Fristbestimmungen abhängig ist. Es bestehen jedoch keine Zweifel an der Verfassungsmäßigkeit solcher Fristen, da auch im Rechtsstaat ein legitimes, erhebliches Interesse daran besteht, einen Rechtsstreit in angemessener Zeit klären zu können und damit Rechtssicherheit und vor allem auch Rechtsfrieden zu ermöglichen. ${ }^{826}$

354 Die Fristenproblematik ist in der öffentlich-rechtlichen Klausur häufig vorzufinden und es wird erwartet, dass die Klagefrist berechnet werden kann. ${ }^{827}$ Jedoch ist nur auf solche Aspekte einzugehen, die im Sachverhalt auch problematisiert werden. Schweigt der Sachverhalt zu einzelnen Aspekten, ist davon auszugehen, dass die entsprechenden Voraussetzungen im vorliegenden Fall eingehalten wurden.

355 Nachfolgend werden zunächst die Funktion der Klagefrist und die Bestandskraft eines Verwaltungsakts (1.) und sodann die grundlegende Systematik und der Bezug zum Vorverfahren (2.) erläutert. Daran anschließend wird die eigentliche Berechnung beschrieben (3.) und typische Problemfelder im Einzelnen besprochen (4. - 7.).

\section{Funktion der Klagefrist und Bestandskraft eines Verwaltungsakts}

356 Die zentrale Funktion der Klagefrist ist die Sicherung der Bestandskraft eines Verwaltungsakts. ${ }^{828}$ Dieser hat dann Bestandskraft, wenn er mit ordentlichen Rechtsbehelfen (z. B. Widerspruch und Anfechtungsklage) nicht mehr angefochten werden kann. ${ }^{829}$

824 Kintz, Öffentliches Recht im Assessorexamen, 10. Aufl. 2018, Rn. 271; Schenke, in: Kopp/ Schenke, VwGO, 25. Aufl. 2019, Vor § 40 Rn. 17.

825 Schenke, in: Kopp/Schenke, VwGO, 25. Aufl. 2019, § 74 Rn. 1 sowie Rn. 4.

826 Schenke, in: Kopp/Schenke, VwGO, 25. Aufl. 2019, § 74 Rn. 1.

827 Kintz, Öffentliches Recht im Assessorexamen, 10. Aufl. 2018, Rn. 271.

828 Schenke, in: Kopp/Schenke, VwGO, 25. Aufl. 2019, § 74 Rn. 2.

829 Maurer/Waldhoff, Allgemeines Verwaltungsrecht, 19. Aufl. 2017, § 10 Rn. 16; Ramsauer, in: Kopp/Ramsauer, VwVfG, 19. Aufl. 2018, § 43 Rn. 29. Dies wird auch „formelle“ Bestandskraft ge- 
Die „Bestandskraft“ eines Verwaltungsakts ist klar von seiner „Wirksam- 357 keit“ und der möglichen „Rechtswidrigkeit“ zu trennen. Ein Verwaltungsakt wird gemäß § 43 I 1 VwVfG gegenüber demjenigen, für den er bestimmt ist oder der von ihm betroffen wird, in dem Zeitpunkt wirksam, in dem er ihm bekannt gegeben wird. ${ }^{830} \S 43$ II VwVfG nennt die Fälle, in denen die Wirksamkeit eines Verwaltungsakts endet. ${ }^{831}$ Der Umstand, dass ein Verwaltungsakt rechtswidrig ist, ändert zunächst nichts an seiner Wirksamkeit. ${ }^{832}$ Dies hat zur Konsequenz, dass ein rechtswidriger, aber wirksamer Verwaltungsakt grundsätzlich beachtet werden muss. ${ }^{833}$

Der Betroffene kann sich gegen einen rechtswidrigen Verwaltungsakt jedoch mit den dafür vorgesehenen Rechtsbehelfen - z. B. mit Widerspruch und Anfechtungsklage - wehren. Wenn er dies allerdings unterlässt oder z.B. die entsprechenden Fristen nicht einhält, tritt die Bestandskraft - trotz der Rechtswidrigkeit - des Verwaltungsakts ein. ${ }^{834}$ Ein etwaiger Rechtsbehelf hätte dann keine Aussicht auf Erfolg.

Soweit ein Verwaltungsakt bestandskräftig geworden ist, sind vor allem 358 noch zwei Wege der Aufhebung denkbar: über das Wiederaufgreifen des Verfahrens gemäß $\S 51$ VwVfG und vor allem über Rücknahme und Widerruf des Verwaltungsakts gemäß §§ 48, 49 VwVfG (s. dazu Rn. 836ff.). ${ }^{835}$ Im Hinblick auf den äußerst seltenen Fall eines nichtigen Verwaltungsakts gemäß §44 VwVfG (s. dazu $\S 6$ Rn. 115ff.) ist zu beachten, dass ein solcher Verwaltungsakt unwirksam ist ${ }^{836}$ und insofern auch keine Bestandskraft eintreten kann. Auf die Möglichkeit der Wiedereinsetzung in den vorigen Stand wird später einzugehen sein (s. sogleich Rn. 394 ff.).

nannt; s. hierzu insgesamt Maurer/Waldhoff, Allgemeines Verwaltungsrecht, 19. Aufl. 2017, § 10 Rn. 12 ff., insbesondere Rn. 16-19.

830 S. auch Maurer/Waldhoff, Allgemeines Verwaltungsrecht, 19. Aufl. 2017, § 9 Rn. 40 sowie § 10 Rn. 7.

831 S. auch Maurer/Waldhoff, Allgemeines Verwaltungsrecht, 19. Aufl. 2017, § 10 Rn. 8.

832 Maurer/Waldhoff, Allgemeines Verwaltungsrecht, 19. Aufl. 2017, § 9 Rn. 40 sowie § 10 Rn. 6. 833 Ramsauer, in: Kopp/Ramsauer, VwVfG, 19. Aufl. 2018, § 43 Rn. $14 \mathrm{f}$.

834 Maurer/Waldhoff, Allgemeines Verwaltungsrecht, 19. Aufl. 2017, § 9 Rn. 40; Kopp, in: Kopp/ Ramsauer, VwVfG, 19. Aufl. 2018, § 43 Rn. 8.

835 Ramsauer, in: Kopp/Ramsauer, VwVfG, 19. Aufl. 2018, § 43 Rn. 31.

836 Maurer/Waldhoff, Allgemeines Verwaltungsrecht, 19. Aufl. 2017, § 10 Rn. 7. S. hierzu auch Maurer/Waldhoff, Allgemeines Verwaltungsrecht, 19. Aufl. 2017, § 10 Rn. $85 \mathrm{ff}$.

Patrick Stockebrandt 


\section{Systematik und Bezug zum Vorverfahren}

359 Die Klagefrist des $\S 74$ VwGO gehört zum 8. Abschnitt und damit zu den besonderen Vorschriften für die Anfechtungs- und Verpflichtungsklage. Die Vorschrift knüpft dabei grundsätzlich an das Vorverfahren gemäß §§ $68 \mathrm{ff}$. VwGO (s. hierzu Rn. $301 \mathrm{ff}$.$) an, denn die „Grundregel“ des § 74$ I 1 VwGO bezieht sich auf den Widerspruchsbescheid und damit auf den Abschluss des Vorverfahrens. Insoweit ein Widerspruchsbescheid nach $\S 68$ VwGO nicht erforderlich ist (s. hierzu Rn. 308f.), bezieht sich die Klagefrist gemäß § 74 I 2 VwGO auf den „Ausgangsverwaltungsakt“; also den Verwaltungsakt, der den Einzelnen ursprünglich zu einem Handeln im weitesten Sinne veranlasst hat.

360 Gemäß der Systematik des § 74 I VwGO muss zunächst das fristauslösende Ereignis identifiziert werden. Denn $\S 74$ VwGO knüpft an unterschiedliche Bezugspunkte an: Soweit ein Widerspruchsbescheid erforderlich ist, muss die Anfechtungsklage innerhalb eines Monats nach dessen „Zustellung“ (§ 74 I 1 VwGO) und nur soweit kein Widerspruchsbescheid erforderlich ist, innerhalb eines Monats nach „Bekanntgabe“ des Ausgangsverwaltungsakts (§ 74 I 2 VwGO) erhoben werden.

\section{Fristberechnung}

361 Im Hinblick auf die konkrete Fristberechnung sind gemäß § 57 II VwGO ${ }^{837}$ i.V.m. $\S 222$ ZPO die entsprechenden Regeln des BGB (§§ 187ff. BGB) heranzuziehen. ${ }^{838}$ Die zentralen Vorschriften zur Berechnung sind §187 BGB und §188 BGB. Besonderheiten ergeben sich aus § 222 II ZPO und § 58 II VwGO.

362 Die Anfechtungsklage muss innerhalb eines Monats nach ordnungsgemäßer Zustellung des Widerspruchsbescheids (§ 74 I 1 VwGO) bzw. innerhalb eines Monats nach ordnungsgemäßer Bekanntgabe des Ausgangsverwaltungsakts (§ 74 I 2 VwGO) erhoben werden. Der Umstand, dass beispielsweise die Zustellung „ordnungsgemäß“ erfolgt sein muss, kann durchaus relevant sein, da bei einer unwirksamen Zustellung die Klagefrist nicht zu laufen beginnt. ${ }^{839}$

363 Bei der Fristberechnung wird gemäß $§ 187$ I BGB der Tag der Zustellung bzw. der Bekanntgabe nicht mitgerechnet. ${ }^{840}$ Insofern ist der auf dieses „Ereignis“

837 Schenke, in: Kopp/Schenke, VwGO, 25. Aufl. 2019, § 57 Rn. 1.

838 Schenke, in: Kopp/Schenke, VwGO, 25. Aufl. 2019, § 57 Rn. 1 sowie Rn. 10a.

839 Kintz, Öffentliches Recht im Assessorexamen, 10. Aufl. 2018, Rn. 280; Schenke, in: Kopp/ Schenke, VwGO, 25. Aufl. 2019, §57 Rn. 16f.

840 Schenke, in: Kopp/Schenke, VwGO, 25. Aufl. 2019, § 57 Rn. 10 sowie Rn. 10a; Schenke, Verwaltungsprozessrecht, 16. Aufl. 2019, Rn. 711.

Patrick Stockebrandt 
(die Zustellung oder die Bekanntgabe) folgende Tag maßgebend, auch wenn dieser ein Samstag, Sonn- oder Feiertag ist. ${ }^{841}$

Beispiel: Der Widerspruchsbescheid wurde am 16.07. zugestellt. Die Klagefrist beginnt sodann am Folgetag, den 17.07., um 00:00 Uhr.

Im Hinblick auf das Fristende bestimmt $§ 188$ II BGB: „Eine Frist, die (...) nach 364 Monaten (...) bestimmt ist, endigt im Falle des $\S 187$ I mit dem Ablauf desjenigen Tages (...) des letzten Monats, welcher durch (...) seine Zahl dem Tage entspricht, in den das Ereignis (...) fällt (...).“

Insofern endet die Klagefrist mit Ablauf desjenigen Tages des Folgemonats, der durch seine Zahl dem Tag entspricht, in dem das „Ereignis“, also die Zustellung oder die Bekanntgabe, fällt. ${ }^{842}$

Beispiel (Fortführung aus Rn. 363): Die Zustellung (das „Ereignis“) ist am 16.07. erfolgt und die Frist beträgt einen Monat. Folglich endet die Frist mit Ablauf des Monatstages „16“ im Folgemonat, also am 16.08. um 24:00 Uhr. ${ }^{843}$

Insbesondere wenn der Folgemonat der Februar ist, ist $\mathrm{zu}$ beachten, dass es $\mathbf{3 6 5}$ vorkommen kann, dass es den entsprechenden Monatstag (z. B. den „31.“) nicht gibt. Gemäß $§ 188$ III BGB ist sodann der letzte Tag dieses Monats maßgebend. ${ }^{844}$

Beispiel: Die Zustellung erfolgt am 31.01. eines Jahres, so dass die Frist mit Ablauf des 28.02. ${ }^{845}$ endet.

\section{a) Fristende fällt auf einen Sonnabend, Sonn- oder Feiertag - § 222 II ZPO}

Soweit das Fristende auf einen Sonnabend (d.h. einen Samstag), einen Sonntag 366 oder einen allgemeinen Feiertag fällt, ist die Vorschrift des § 222 II ZPO zu beachten. Demnach endet die Klagefrist dann nämlich nicht an dem entsprechenden Samstag, Sonntag oder Feiertag, sondern erst mit Ablauf des nächsten Werktages. ${ }^{846}$

841 Schenke, in: Kopp/Schenke, VwGO, 25. Aufl. 2019, § 57 Rn. 10a.

842 Schenke, in: Kopp/Schenke, VwGO, 25. Aufl. 2019, § 57 Rn. 10a.

843 S. hierzu auch Schenke, in: Kopp/Schenke, VwGO, 25. Aufl. 2019, § 57 Rn. 10a.

844 Schenke, in: Kopp/Schenke, VwGO, 25. Aufl. 2019, § 57 Rn. 10a; Schenke, Verwaltungsprozessrecht, 16. Aufl. 2019, Rn. 712.

845 Bzw. 29.02. in Schaltjahren.

846 Schenke, in: Kopp/Schenke, VwGO, 25. Aufl. 2019, § 57 Rn. 10a. 
Beispiel: Die Klagefrist endet nach § 188 II BGB rechnerisch am Samstag, den 31.05. eines Jahres und fällt damit auf einen Sonnabend. Gemäß § 222 II ZPO ist Fristende sodann Montag, der 02.06., um 24:00 Uhr.

367 Allgemeine Feiertage i. S.d. § 222 II ZPO sind nur gesetzlich bestimmte Feiertage, d. h. vor allem auch, dass der 24.12. und der 31.12. keine Feiertage i. S. d. Vorschrift sind. ${ }^{847}$ Soweit ein Tag nur in einzelnen Bundesländern gesetzlich zum Feiertag erklärt worden ist, kommt es auf das Recht am Ort des Gerichtes an, bei dem die Frist zu wahren ist. ${ }^{848}$

\section{b) Unterbliebene oder fehlerhafte Rechtsbehelfsbelehrung - §58 II VwGO}

368 Soweit in einer Klausur keine Angaben gemacht werden, ist davon auszugehen, dass die Rechtsbehelfsbelehrung ordnungsgemäß erfolgt ist. Sollte sie aber erwähnt oder sogar abgedruckt sein, ist zu prüfen, ob sie fehlerhaft ist. Denn soweit die Belehrung unterblieben ist oder unrichtig erteilt wurde, ${ }^{849}$ ist die Einlegung des Rechtsbehelfs, vorliegend relevant vor allem der Widerspruch und die Klage, ${ }^{850}$ gemäß $§ 58$ II VwGO grundsätzlich innerhalb eines Jahres möglich. Dies ist als Ausschlussfrist zu verstehen. ${ }^{851}$ Bitte hier einen Absatz ergänzen, um die „Anmerkungen zur Falllösung“ graphisch besser abzusetzen.

\section{Anmerkungen zur Falllösung:}

- Der Obersatz zur Fristberechnung könnte demnach lauten: „Die Klage ist fristgerecht zu erheben. Fraglich ist, ob die Klagefrist des $\S 74$ I VwGO eingehalten wurde."

- Ein „Klausurklassiker“ ist der fehlerhafte Hinweis in der Rechtsbehelfsbelehrung, dass die Klagefrist 4 Wochen (und nicht 1 Monat) betrage. Vom Klausurbearbeiter wird sodann erwartet, $\S 58$ II VwGO zu kennen und anzuwenden.

847 Schenke, in: Kopp/Schenke, VwGO, 25. Aufl. 2019, § 57 Rn. 10a.

848 Schenke, in: Kopp/Schenke, VwGO, 25. Aufl. 2019, § 57 Rn. 10a.

849 S. zu den obligatorischen Bestandteilen der Rechtsbehelfsbelehrung: Kintz, Öffentliches Recht im Assessorexamen, 10. Aufl. 2018, Rn. $281 \mathrm{ff}$. sowie Schenke, in: Kopp/Schenke, VwGO, 25. Aufl. 2019, §58 Rn. $10 \mathrm{ff}$.

850 Schenke, in: Kopp/Schenke, VwGO, 25. Aufl. 2019, § 58 Rn. 4.

851 Schenke, in: Kopp/Schenke, VwGO, 25. Aufl. 2019, § 58 Rn. 16.

Patrick Stockebrandt 


\section{Bekanntgabe als fristauslösendes Ereignis und die sog. „Drei-Tages-Fiktion“}

Soweit kein Widerspruchsbescheid nach $\S 68$ VwGO erforderlich ist, knüpft § 74 I 2370 VwGO an die Bekanntgabe des Ausgangsverwaltungsakts als fristauslösendes Ereignis an. Grundsätzlich ist ein Verwaltungsakt dann „bekanntgegeben“, wenn die zuständige Behörde wissentlich und willentlich den Inhalt des Verwaltungsakts gegenüber dem Betroffenen eröffnet (s. zur Bekanntgabe ausführlich Rn. 117 ff.). ${ }^{852}$ Dabei ist der Verwaltungsakt gemäß § 41 I 1 VwVfG demjenigen Beteiligten bekannt zu geben, für den er bestimmt ist oder der von ihm betroffen ist. Sofern gesetzlich keine besonderen Anforderungen an die Bekanntgabe eines Verwaltungsakts bestehen, kann diese auf jede geeignete Weise erfolgen. ${ }^{853}$

Ein mündlicher Verwaltungsakt kann nur unter Anwesenden bekannt $\mathbf{3 7 1}$ gegeben werden, da er eine empfangsbedürftige Willenserklärung darstellt. ${ }^{854}$ Ein schriftlicher Verwaltungsakt muss in den Machtbereich des Adressaten gelangt sein, z. B. durch Einwurf in den Briefkasten. ${ }^{855}$ Soweit beispielsweise demnach ein schriftlicher Verwaltungsakt durch einen behördlichen Boten in den Briefkasten des Adressaten gelangt, ist die Bekanntgabe dann erfolgt, wenn bei gewöhnlichem Verlauf mit der Kenntnisnahme durch den Empfänger zu rechnen ist und zwar grundsätzlich unabhängig von der tatsächlichen Kenntnisnahme. ${ }^{856}$

Soweit ein schriftlicher Verwaltungsakt durch die Post übermittelt wird, 372 ist die sog. Drei-Tages-Fiktion des § 41 II VwVfG zu beachten: Demnach gilt ein solcher Verwaltungsakt am dritten Tag nach Aufgabe zur Post als bekannt gegeben, es sei denn, er ist nicht oder zu einem späteren Zeitpunkt zugegangen. Soweit der einfache Brief dem Empfänger tatsächlich früher zugegangen ist, gilt die DreiTages-Fiktion. ${ }^{857}$

Dies gilt ausnahmsweise dann nicht, wenn der Verwaltungsakt nicht oder später zugegangen ist, denn dann kommt es auf den, insoweit späteren, tatsächlichen Zugangszeitpunkt an. ${ }^{858}$

852 Sodan/Ziekow, Grundkurs Öffentliches Recht, 8. Aufl. 2018, § 79 Rn. 13.

853 Sodan/Ziekow, Grundkurs Öffentliches Recht, 8. Aufl. 2018, § 70 Rn. 14.

854 Sodan/Ziekow, Grundkurs Öffentliches Recht, 8. Aufl. 2018, § 79 Rn. 14.

855 Sodan/Ziekow, Grundkurs Öffentliches Recht, 8. Aufl. 2018, § 79 Rn. 14.

856 Sodan/Ziekow, Grundkurs Öffentliches Recht, 8. Aufl. 2018, § 79 Rn. 14; Ramsauer, in: Kopp/ Ramsauer, VwVfG, 19. Aufl. 2018, § 41 Rn. 7c.

857 Sodan/Ziekow, Grundkurs Öffentliches Recht, 8. Aufl. 2018, § 79 Rn. 14. 858 Sodan/Ziekow, Grundkurs Öffentliches Recht, 8. Aufl. 2018, § 79 Rn. 14.

Patrick Stockebrandt 
Beispiel: Ein einfacher Brief wird per Post am 5. des Monats versendet. Die Bekanntgabe erfolgt nach der Drei-Tages-Fiktion sodann am 8. des Monats - also drei Tage nach Aufgabe zur Post.

\section{Zustellung als fristauslösendes Ereignis und verschiedene Zustellungsarten}

Soweit ein Widerspruchsbescheid nach $\S 68 \mathrm{VwGO}$ erforderlich ist, knüpft $\S 74$ I 1 VwGO an die (ordnungsgemäße) ${ }^{859}$ Zustellung des Widerspruchsbescheids als fristauslösendes Ereignis an (zur Zustellung von Verwaltungsakten s. auch Rn. $168 \mathrm{ff}$.). Der Widerspruchsbescheid ist aufgrund der Regelungen in $\S 73$ III 1 VwGO und § 73 III 2 VwGO von Amts wegen nach den Vorschriften des VwZG des Bundes zuzustellen. ${ }^{860}$

„Zustellung“ ist demnach eine besondere Form der Bekanntgabe ${ }^{861}$, die sodann nach § 2 I VwZG durch ein schriftliches oder elektronisches Dokument in der im VwZG bestimmten Form erfolgt. Dabei liegt die Auswahl der Zustellungsart im Ermessen der Behörde. ${ }^{862}$ Relevante Zustellungsarten (s. §§ 3-5a VwZG) sind vor allem die Zustellung durch die Post mittels Zustellungsurkunde ( 3 VwZG) und die Zustellung durch die Post mittels Einschreiben (§ 4 VwZG). ${ }^{863}$ Die Zustellung ist dann notwendig, wenn dies durch eine Rechtsvorschrift oder eine behördliche Anordnung vorgesehen ist (§ $1 \mathrm{II}$ VwZG). Für den Widerspruchsbescheid ordnet dies $\S 73$ III 1 VwGO an. Zustellungsmängel können im Rahmen des $\S 8$ VwZG geheilt werden. ${ }^{864}$

\section{a) Zustellung durch die Post mittels Zustellungsurkunde}

375 Die praktisch meistgenutzte Zustellungsart ist die Zustellung durch die Post mit Zustellungsurkunde (§ 3 VwZG) ${ }^{865}$ Mit „Post“ ist dabei ein Erbringer von Postdienstleistungen i.S.d. § 2 II 1 VwZG und § 5 PostG gemeint. ${ }^{866}$

Bei dieser Form der Zustellung übergibt die Behörde gemäß § 3 I VwZG der Post den Zustellungsauftrag, das zuzustellende Dokument in einem verschlosse-

859 Bei einer unwirksamen Zustellung beginnt die Klagefrist nicht zu laufen; Kintz, Öffentliches Recht im Assessorexamen, 10. Aufl. 2018, Rn. 280; Schenke, in: Kopp/Schenke, VwGO, 25. Aufl. 2019, § 57 Rn. 16f.

860 Schenke, in: Kopp/Schenke, VwGO, 25. Aufl. 2019, § 73 Rn. 22a.

861 Sodan/Ziekow, Grundkurs Öffentliches Recht, 8. Aufl. 2018, § 79 Rn. 15.

862 Schenke, in: Kopp/Schenke, VwGO, 25. Aufl. 2019, § 73 Rn. 22b.

863 Sodan/Ziekow, Grundkurs Öffentliches Recht, 8. Aufl. 2018, § 79 Rn. 15.

864 Dieser wird im Rahmen der Rechtsprechung über den Wortlaut hinaus ausgelegt, s. dazu Schenke, in: Kopp/Schenke, VwGO, 25. Aufl. 2019, § 73 Rn. 23a.

865 Schenke, in: Kopp/Schenke, VwGO, 25. Aufl. 2019, § 73 Rn. 22b.

866 Schenke, in: Kopp/Schenke, VwGO, 25. Aufl. 2019, § 73 Rn. 22b, s. dort Fn. 36.

Patrick Stockebrandt 
nen Umschlag und den Vordruck einer Zustellungsurkunde. Im Regelfall wird der Postbedienstete das Schriftstück vor Ort übergeben, die Zustellung beurkunden und die Urkunde an die Behörde zurückschicken. ${ }^{867}$

Der Vorteil dieser Zustellungsart gegenüber dem Einschreiben ist, dass die $\mathbf{3 7 7}$ Möglichkeit der Ersatzzustellung nach § 3 II 1 VwZG i.V.m. §§ 177-182 ZPO besteht. ${ }^{868}$ Das bedeutet, dass eine Zustellung insbesondere auch in den Fällen der unberechtigten verweigerten Annahme $(\S 179 \mathrm{ZPO})^{869}$ und durch das Einlegen in den Briefkasten (§ $180 \mathrm{ZPO})^{870}$ erfolgen kann.

\section{b) Zustellung durch die Post mittels Einschreiben}

Der Widerspruchsbescheid kann nach $\S 4$ VwZG durch die Post mittels Ein- 378 schreiben zugestellt werden. Zu beachten ist zunächst, dass gemäß § 4 I VwZG nur das Übergabe-Einschreiben sowie das Einschreiben mit Rückschein zulässig sind. Das einfache Einwurf-Einschreiben durch die Post reicht mangels Übergabe nicht aus. ${ }^{871}$

Hat die Verwaltung in einer Klausur per Einschreiben zugestellt, so handelt $\mathbf{3 7 9}$ es sich grundsätzlich um ein Übergabe-Einschreiben, da ein Einschreiben mit Rückschein nur vorliegt, wenn es ausdrücklich im Sachverhalt erwähnt wird. ${ }^{872}$

Beim Übergabe-Einschreiben wird das Dokument, sofern nicht das Merk- 380 mal „eigenhändig“ ausgewählt wurde ${ }^{873}$, dem Zustellungsadressaten oder dem Ersatzempfänger ausgehändigt. Soweit dies nicht möglich ist, wird der Adressat mittels Benachrichtigungszettel aufgefordert, das Dokument selbst abzuholen. ${ }^{874}$ Dabei erfolgt die Zustellung nicht schon durch Zugang des Benachrichtigungszettels, sondern erst, wenn die Sendung abgeholt wird. ${ }^{875} \mathrm{Im}$ Übrigen gilt die Zugangsvermutung des § 4 II 2 VwZG. Nur soweit diese Vermutung substantiiert bestritten wird, ist der Zugang und dessen Zeitpunkt gemäß § 4 II 3 VwZG von der Behörde $\mathrm{zu}$ beweisen. ${ }^{876}$

867 Pietzner/Ronellenfitsch, Das Assessorexamen im Öffentlichen Recht, 14. Aufl. 2019, Rn. 1358. 868 Kues/Schildheuer, Verwaltungsprozessrecht, 4. Aufl. 2018, 66.

869 Schenke, in: Kopp/Schenke, VwGO, 25. Aufl. 2019, § 73 Rn. 22b sowie § 56 Rn. 33.

870 Schenke, in: Kopp/Schenke, VwGO, 25. Aufl. 2019, § 73 Rn. 22b sowie § 56 Rn. 34.

871 Schenke, in: Kopp/Schenke, VwGO, 25. Aufl. 2019, §73 Rn. 22b; Sodan/Ziekow, Grundkurs Öffentliches Recht, 8. Aufl. 2018, § 79 Rn. 15.

872 Kues/Schildheuer, Verwaltungsprozessrecht, 4. Aufl. 2018, 68.

873 Die Auswahl der Zustellungsart liegt im Ermessen der Behörde, s. Schenke, in: Kopp/ Schenke, VwGO, 25. Aufl. 2019, § 73 Rn. 22b.

874 Schenke, in: Kopp/Schenke, VwGO, 25. Aufl. 2019, § 73 Rn. 22b.

875 Schenke, in: Kopp/Schenke, VwGO, 25. Aufl. 2019, § 73 Rn. 22b.

876 Schenke, in: Kopp/Schenke, VwGO, 25. Aufl. 2019, § 73 Rn. 22b.

Patrick Stockebrandt 
Beim Einschreiben mit Rückschein genügt gemäß § 4 II 1 VwZG der Rückschein als Nachweis der Zustellung. Insofern gilt das Datum auf dem Rückschein als Tag der Zustellung und die Zugangsvermutung des § 4 II 2 VwZG ist nur noch heranzuziehen, wenn der Rückschein verloren gegangen oder unbrauchbar ist. ${ }^{877}$ Auch eine Zustellung an ein vom Empfänger unterhaltenes Postfach ist möglich. ${ }^{878}$

\section{aa) Ersatzempfänger beim Einschreiben}

382 Die Frage der Möglichkeit der Übergabe an einen Ersatzempfänger, z. B. einen Familienangehörigen, richtet sich bei der Zustellung mittels Einschreiben nicht nach den gesetzlichen Vorschriften, sondern nach den allgemeinen Geschäftsbedingungen des Postdienstleisters. ${ }^{879}$ Ersatzempfänger sind z.B. der Ehepartner, der Lebenspartner oder ein Familienmitglied des Empfängers. ${ }^{880}$ Wenn das Dokument nur dem Adressaten ausgehändigt werden darf, muss insoweit das Merkmal „eigenhändig“ ausgewählt werden. ${ }^{881}$

\section{bb) Zugang im Falle der Notwendigkeit der Abholung eines Einschreibens bei der Post}

383 Soweit der Adressat das Dokument selbst abholen muss, hat dies zur Konsequenz, dass der Zugang grundsätzlich erst dann erfolgt, wenn der Empfänger es tatsächlich abholt, selbst wenn er dies bewusst verzögert. ${ }^{882}$ Insoweit das Dokument nicht abgeholt wird, ist es auch nicht zugegangen. ${ }^{883}$ Die Grenze ist hier in den seltenen Fällen zu sehen, in denen der Empfänger die Zustellung gegen Treu und Glauben verzögert oder vereitelt, in dem er beispielsweise den Namen an seinem Briefkasten entfernt. ${ }^{884}$ Sodann muss er sich behandeln lassen, als sei die $\mathbf{Z u}$ stellung in dem Zeitpunkt erfolgt, in dem er bei pflichtgemäßen Verhalten das Dokument erhalten hätte. ${ }^{885}$

877 BT-Drucks. 15/5216, 12; Schenke, in: Kopp/Schenke, VwGO, 25. Aufl. 2019, § 73 Rn. 22b.

878 Schenke, in: Kopp/Schenke, VwGO, 25. Aufl. 2019, § 73 Rn. 22b.

879 Schenke, in: Kopp/Schenke, VwGO, 25. Aufl. 2019, § 73 Rn. 22b.

880 Ramsauer, in: Kopp/Ramsauer, VwVfG, 19. Aufl. 2018, § 41 Rn. 72; Pietzner/Ronellenfitsch, Das Assessorexamen im Öffentlichen Recht, 14. Aufl. 2019, Rn. 1362.

881 Schenke, in: Kopp/Schenke, VwGO, 25. Aufl. 2019, § 73 Rn. 22b; Kues/Schildheuer, Verwaltungsprozessrecht, 4. Aufl. 2018, 67.

882 Pietzner/Ronellenfitsch, Das Assessorexamen im Öffentlichen Recht, 14. Aufl. 2019, Rn. 1363.

883 Kues/Schildheuer, Verwaltungsprozessrecht, 4. Aufl. 2018, 67.

884 Ramsauer, in: Kopp/Ramsauer, VwVfG, 19. Aufl. 2018, § 41 Rn. 72 sowie Rn. 19.

885 S. Kues/Schildheuer, Verwaltungsprozessrecht, 4. Aufl. 2018, 67.

Patrick Stockebrandt 


\section{Untätigkeit der Behörde - $\$ 75$ VwGO}

Soweit eine Behörde über einen Widerspruch oder über einen Antrag auf Vor- 384 nahme eines Verwaltungsakts ohne zureichenden Grund in angemessener Frist sachlich nicht entscheidet, ordnet $\S 751$ VwGO an, dass die Klage abweichend von $\S 68$ VwGO zulässig ist. Durch diese Vorschrift wird auch der Grundsatz aus Art. 19 IV GG geschützt, da die Verwaltung nicht durch ihre Untätigkeit einen Betroffenen von der Möglichkeit der Klage abhalten können soll. ${ }^{886}$

Die Vorschrift des $\S 75$ VwGO hat zur Konsequenz, dass der Klageweg ab- 385 weichend von den Vorschriften der $\S 68 \mathrm{ff}$. und $\S 74 \mathrm{VwGO}$ unmittelbar begangen werden kann und die Klage in einem solchen Fall ohne vorherigen Abschluss bzw. ohne vorherige Durchführung eines Vorverfahrens - unter Beachtung der dreimonatigen Sperrfrist des $\S 752$ VwGO - zulässig ist. ${ }^{887}$

\section{a) Zureichender Grund für die Verzögerung}

Ob und inwieweit ein zureichender Grund besteht, ist nach objektiven Gesichts- 386 punkten $\mathrm{zu}$ beurteilen. ${ }^{888}$ Die Rechtsprechung hat hierzu eine Fülle an Entscheidungen in unterschiedlichen Bereichen erlassen. ${ }^{889}$

Im Hinblick auf das in gewisser Regelmäßigkeit vorgetragene Argument der 387 „Überlastung“ muss unterschieden werden: Die vorübergehende Überlastung einer Behörde infolge einer Gesetzesänderung oder die vorübergehende besondere Geschäftsbelastung der Behörde aus anderen Gründen, soweit nicht ein strukturelles Defizit vorliegt, kann ein zureichender Grund für eine Verzögerung sein. ${ }^{890}$ Bei länger andauernder Überlastung muss die Verwaltung jedoch für Ausgleich sorgen. ${ }^{891}$ Kein zureichender Grund ist dagegen Urlaub, Krankheit oder Arbeitsüberlastung einzelner Sachbearbeiter, da die Verwaltung in solchen Fällen für ausreichende Vertretung sorgen muss. ${ }^{892}$

Liegt ein zureichender Grund für die Verzögerung vor, so setzt das Gericht 388 das Verfahren gemäß $\S 753$ VwGO bis zum Ablauf einer von ihm bestimmten Frist aus. ${ }^{893}$

886 Schenke, in: Kopp/Schenke, VwGO, 25. Aufl. 2019, § 75 Rn. 1.

887 Schenke, in: Kopp/Schenke, VwGO, 25. Aufl. 2019, § 75 Rn. 1; Schenke, Verwaltungsprozessrecht, 16. Aufl. 2019, Rn. 715.

888 Schenke, in: Kopp/Schenke, VwGO, 25. Aufl. 2019, § 75 Rn. 13.

889 S. hierzu Schenke, in: Kopp/Schenke, VwGO, 25. Aufl. 2019, § 75 Rn. 13 ff.

890 Schenke, in: Kopp/Schenke, VwGO, 25. Aufl. 2019, § 75 Rn. 13.

891 Schenke, in: Kopp/Schenke, VwGO, 25. Aufl. 2019, § 75 Rn. 13, dort Fn. 16.

892 Schenke, in: Kopp/Schenke, VwGO, 25. Aufl. 2019, § 75 Rn. 13.

893 S. hierzu Brink, in: Posser/Wolff, VwGO, 49. Ed., Stand: 1.4. 2019, § 75 Rn. 14 ff. 


\section{b) Angemessene Frist \& dreimonatige „Sperrfrist“}

389 Die Verwaltung ist grundsätzlich dazu verpflichtet, über Antrag und Widerspruch so rasch wie möglich zu entscheiden. ${ }^{894} \mathrm{Zu}$ beachten ist jedoch, dass die Klage gemäß $§ 752$ VwGO grundsätzlich nicht vor Ablauf von drei Monaten (sog. „Sperrfrist“) seit der Einlegung des Widerspruchs oder dem Antrag auf Vornahme des Verwaltungsakts erhoben werden kann und eine Klage insoweit - im Regelfall - unzulässig ist. ${ }^{895}$

390 Nur soweit besondere Umstände vorliegen, kann eine kürzere Frist geboten sein. ${ }^{896}$ Dies ist beispielsweise dann der Fall, wenn der Kläger ohne eine alsbaldige Entscheidung einen schweren und irreparablen Nachteil erleiden würde. ${ }^{897}$

\section{c) Zeitliche Begrenzung der Klage}

391 Die Vorschrift des $\S 75$ VwGO regelt nicht, wie lange eine Klage in einer solchen Situation erhoben werden kann. Da die frühere gesetzliche Regelung in $\S 76 \mathrm{VwGO}$ aufgehoben wurde, die im Regelfall eine Jahresfrist vorgesehen hatte, kann die Klage grundsätzlich ohne zeitliche Befristung erhoben werden. ${ }^{898}$

392 Jedoch kann sich aus dem Grundsatz der Verwirkung etwas Anderes ergeben, sodass das prozessuale Recht zur Klage nach den allgemeinen Grundsätzen verwirkt (s. näher Rn. 399 ff.) wird ${ }^{899}$ Allerdings kann aufgrund der Aufhebung des $\S 76$ VwGO nicht davon ausgegangen werden, dass die Verwirkung regelmäßig nach Ablauf eines Jahres eintritt, da dies dem gesetzgeberischen Willen zuwiderlaufen würde. ${ }^{900}$

\section{Weitere Bereiche}

393 Über die bereits genannten Bereiche hinaus können im Rahmen einer Klausur weitere Fragen aufgeworfen werden. Hierzu zählen die Möglichkeit der Wiedereinsetzung in den vorigen Stand und der Aspekt der Verwirkung.

894 Schenke, in: Kopp/Schenke, VwGO, 25. Aufl. 2019, § 75 Rn. 8.

895 Schenke, in: Kopp/Schenke, VwGO, 25. Aufl. 2019, § 75 Rn. 8.

896 S. hierzu Schenke, in: Kopp/Schenke, VwGO, 25. Aufl. 2019, § 75 Rn. 12.

897 Schenke, Verwaltungsprozessrecht, 16. Aufl. 2019, Rn. 715.

898 Schenke, Verwaltungsprozessrecht, 16. Aufl. 2019, Rn. 720.

899 Schenke, in: Kopp/Schenke, VwGO, 25. Aufl. 2019, § 76 Rn. 2.

900 Schenke, Verwaltungsprozessrecht, 16. Aufl. 2019, Rn. 721; Schenke, in: Kopp/Schenke, VwGO, 25. Aufl. 2019, § 76 Rn. 2. 


\section{a) Wiedereinsetzung in den vorigen Stand - $\$ 60$ VwGO}

Soweit der Kläger die Monatsfrist des $\S 74$ VwGO nicht eingehalten und es auch 394 keine fehlerhafte Rechtsbehelfsbelehrung gegeben hat, kommt die Wiedereinsetzung in den vorigen Stand gemäß $\S 60 \mathrm{VwGO}$ in Betracht.

Die Wiedereinsetzung ist eine gerichtliche Entscheidung und stellt eine 395 Wiederherstellung der Zulässigkeit für eine versäumte Prozesshandlung dar. ${ }^{901}$ Dies kann u. a. zur Folge haben, dass beispielsweise die eingetretene Bestandskraft eines Verwaltungsakts nachträglich wieder entfällt und somit auch der Weg zur Sachentscheidung hierüber wieder eröffnet ist. ${ }^{902}$

Voraussetzung für die Wiedereinsetzung gemäß $\S 60$ I VwGO ist, dass eine 396 gesetzliche Frist schuldlos versäumt wurde. ${ }^{903}$ Eine gesetzliche Frist ist die Frist, deren Dauer durch das Gesetz bestimmt ist und die ohne besondere Festsetzung - sondern kraft Gesetzes - aufgrund eines bestimmten Ereignisses, z. B. die Zustellung, zu laufen beginnt. ${ }^{904}$ So ist beispielsweise auch die Klagefrist des $\S 74$ VwGO eine gesetzliche Frist. ${ }^{905}$ Ausgeschlossen ist die Anwendbarkeit des $\S 60$ VwGO hingegen auf sogenannte Ausschlussfristen, wie sie beispielsweise in $\S 60$ III VwGO und § 47 II 1 VwGO vorzufinden sind. ${ }^{906}$ Lediglich bei höherer Gewalt $^{907}$ gewährt $§ 60$ III 2. Hs. VwGO hiervon eine Ausnahme.

Insoweit der Betroffene eine gesetzliche Frist versäumt hat, ist die Frage des Verschuldens zu erörtern. Ein Verschulden im Sinne der Vorschrift liegt vor, wenn der Betroffene hinsichtlich der Wahrung der Frist diejenige Sorgfalt außer Acht gelassen hat, die für einen gewissenhaften, sachgemäß agierenden Prozessführenden geboten ist und ihm die Fristwahrung in der Gesamtschau des Einzelfalls auch zuzumuten war. ${ }^{908}$

Bei der Betrachtung der Anforderungen an die Sorgfaltspflicht muss auf die 398 Verhältnisse des Betroffenen abgestellt werden. ${ }^{909}$ So sind bei einem Rechtsanwalt beispielsweise grundsätzlich höhere Anforderungen zu stellen, als bei einem juristischen Laien. ${ }^{910}$ Darüber hinaus kommt es im Wesentlichen auch auf die konkreten Umstände des Einzelfalles an. ${ }^{911}$

901 Schenke, in: Kopp/Schenke, VwGO, 25. Aufl. 2019, § 60 Rn. 1.

902 Schenke, in: Kopp/Schenke, VwGO, 25. Aufl. 2019, § 60 Rn. 1.

903 Schenke, in: Kopp/Schenke, VwGO, 25. Aufl. 2019, § 60 Rn. 6.

904 Schenke, in: Kopp/Schenke, VwGO, 25. Aufl. 2019, § 57 Rn. 3.

905 Schenke, in: Kopp/Schenke, VwGO, 25. Aufl. 2019, §60 Rn. 3. Davon abzugrenzen sind richterliche Fristen, s. Schenke, in: Kopp/Schenke, VwGO, 25. Aufl. 2019, § 60 Rn. 3.

906 Schenke, in: Kopp/Schenke, VwGO, 25. Aufl. 2019, § 60 Rn. 4.

907 Zum Begriff s. Schenke, in: Kopp/Schenke, VwGO, 25. Aufl. 2019, § 58 Rn. 20.

908 Schenke, in: Kopp/Schenke, VwGO, 25. Aufl. 2019, § 60 Rn. 9.

909 Schenke, in: Kopp/Schenke, VwGO, 25. Aufl. 2019, § 60 Rn. 9.

910 Schenke, in: Kopp/Schenke, VwGO, 25. Aufl. 2019, § 60 Rn. 9.

Patrick Stockebrandt 


\section{b) Klageverwirkung}

399 In seltenen Fällen besteht die Möglichkeit, dass ein Kläger sein Klagerecht dadurch verwirkt hat, dass er die Klageerhebung unredlich verzögert hat und seine Klage damit dann nicht mehr zulässig ist. ${ }^{912}$ Voraussetzung ist, dass die späte Klageerhebung gegen Treu und Glauben verstößt. ${ }^{913}$

400 Dies kann insbesondere dann angenommen werden, wenn der Kläger bereits seit längerer Zeit Kenntnis vom Klagegrund hat oder hätte haben müssen und die Klage trotzdem erst zu einem Zeitpunkt erhebt, in dem der Beklagte oder sonstige Beteiligte nach den Umständen des Falles nicht mehr mit einer Klage rechnen mussten. ${ }^{914}$

401 Eine Klageverwirkung kann kaum vor der in der VwGO mehrfach erwähnten Jahresfrist ${ }^{915}$ eintreten, die insofern als allgemeiner Rechtsgedanke angesehen werden muss. ${ }^{916}$ Maßgeblich sind jedoch die Umstände des konkreten Einzelfalls. ${ }^{917}$

\section{Literaturhinweise}

402 Hufen, Verwaltungsprozessrecht, 11. Aufl. 2019, § 14 Rn. 114 ff.; Kintz, Öffentliches Recht im Assessorexamen, 10. Aufl. 2018, S. 118ff.; Kues/Schildheuer, Verwaltungsprozessrecht, 4. Aufl. 2018, S. 65 ff.; Schenke, Wolf-Rüdiger, Verwaltungsprozessrecht, 16. Aufl. 2019, Rn. 700 ff.; Schmitz, Klagefrist und Fristversäumnis bei der Anfechtungsklage, JuS 2015, 895

\section{Die Beteiligten (Carola Creemers)}

403 Ein verwaltungsgerichtlicher Rechtsstreit kann nur zwischen tauglichen Beteiligten geführt werden. Obwohl die Prüfung der Beteiligten in der verwaltungsrechtlichen Klausur meist unproblematisch ist, wird stets erwartet, dass die ent-

911 Schenke, in: Kopp/Schenke, VwGO, 25. Aufl. 2019, § 60 Rn. 9. Eine Betrachtung von Einzelfällen ist zu finden bei Schenke, in: Kopp/Schenke, VwGO, 25. Aufl. 2019, § 60 Rn. $10 \mathrm{ff}$.

912 Schenke, in: Kopp/Schenke, VwGO, 25. Aufl. 2019, § 74 Rn. 18.

913 Schenke, in: Kopp/Schenke, VwGO, 25. Aufl. 2019, § 74 Rn. 19.

914 Schenke, Verwaltungsprozessrecht, 16. Aufl. 2019, Rn. 590; Schenke, in: Kopp/Schenke, VwGO, 25. Aufl. 2019, § 74 Rn. 19. Insofern ist insbesondere auch zu beachten, ob es sich um einen Verwaltungsakt mit Drittwirkung handelt, s. hierzu Schenke, in: Kopp/Schenke, VwGO, 25. Aufl. 2019, § 74 Rn. 19.

915 S. z.B. § 58 II VwGO und § 60 III VwGO.

916 Schenke, in: Kopp/Schenke, VwGO, 25. Aufl. 2019, § 74 Rn. 20.

917 Schenke, in: Kopp/Schenke, VwGO, 25. Aufl. 2019, § 74 Rn. 20.

Patrick Stockebrandt/Carola Creemers 
sprechenden Normen bekannt sind und sauber geprüft und angewendet werden können. Zudem treten bestimmte Probleme im Rahmen der Beteiligten in verwaltungsrechtlichen Klausuren immer wieder auf, die jedoch nur bei entsprechenden Anhaltspunkten im Sachverhalt anzusprechen sind.

Die VwGO verwendet den Begriff der Beteiligten in den $\S \S 61,63$ VwGO als Teil 404 der allgemeinen Verfahrensvorschriften des 7. Abschnitts.

\section{Beteiligte, $§ 63$ VwGO}

$\S 63$ VwGO regelt abschließend wer zu den Prozessbeteiligten zählt: Der Klä- 405 ger (Nr. 1), der Beklagte (Nr. 2), der Beigeladene nach § 65 VwGO (Nr. 3) und der Vertreter des Bundesinteresses beim Bundesverwaltungsgericht ( $\$ 35$ VwGO) oder der Vertreter des öffentlichen Interesses ( $§ 36$ VwGO), falls er von seiner Beteiligungsbefugnis Gebrauch macht (Nr. 4). Kläger und Beklagter (bzw. Antragssteller und Antragsgegner im Normenkontrollverfahren sowie im einstweiligen Rechtsschutz) sind die Hauptbeteiligten im Verwaltungsprozess. Nebenbeteiligte können der Beigeladene sowie der Vertreter des Bundesinteresses beim BVerwG oder der Vertreter des öffentlichen Interesses sein, wobei die Nebenbeteiligten nicht automatisch am Verfahren beteiligt sind. ${ }^{918}$ Der Beigeladene erlangt die Stellung eines Beteiligten durch Zustellung des Beiladungsbeschlusses und der Vertreter des Bundesinteresses beim BVerwG oder der Vertreter des öffentlichen Interesses durch einseitige Erklärung, dass sie sich beteiligen. ${ }^{919}$

Nur die nach $\S 63$ VwGO am verwaltungsgerichtlichen Verfahren Beteilig- 406 ten haben eigene Verfahrensrechte und können wirksame Prozesshandlungen vornehmen. ${ }^{920}$ Zudem bindet ein rechtskräftiges Urteil gem. § 121 Nr. 1 VwGO die Beteiligten. Folglich erstreckt sich die Rechtskraft des Urteils auf die Beteiligten i.S.d. § 63 VwGO und es tritt für sie eine Bindungswirkung im Umfang des Streitgegenstandes ein. ${ }^{921}$ Insbesondere ist eine erneute Klage über den gleichen Streitgegenstand zwischen denselben Beteiligten unzulässig. ${ }^{922}$ Daher ist bei entsprechenden Anhaltspunkten im Sachverhalt neben der Prüfung der Hauptbeteiligten insbesondere an die Beiladung zu denken (s. zur Beiladung Rn. $445 \mathrm{ff}$.).

918 Schenke, Verwaltungsprozessrecht, 16. Aufl. 2019, Rn. 453-454.

919 Kintz, in: Posser/Wolff, VwGO, 50. Ed., Stand: 1.4.2019, § 63 Rn. 5, 6.

920 Hoppe, in: Eyermann, VwGO, 15. Aufl. 2019, § 63 Rn. 4; Schenke, in: Kopp/Schenke, VwGO, 25. Aufl. 2019, § 63 Rn. 1.

921 Clausing, in: Schoch/Schneider/Bier, VwGO, 36. EL Februar 2019, §121 Rn. 95; Schenke, Verwaltungsprozessrecht, 16. Aufl. 2019, Rn. 619, 631.

922 Lindner, in: Posser/Wolff, VwGO, 50. Ed., Stand: 1.7.2019, § 121 Rn. 16. 
Die formelle Beteiligteneigenschaft des $\S 63 \mathrm{VwGO}$ ist von der Beteiligungsfähigkeit des $\S 61 \mathrm{VwGO}$ zu unterscheiden. Denn zulässig sind verwaltungsrechtliche Klagen nur, wenn die Prozessbeteiligten auch beteiligungsfähig i. S.d. § 61 VwGO und prozessfähig i. S.d. § 62 VwGO sind.

Anmerkung zur Falllösung: Die Nennung der Beteiligten i.S.d. § 63 VwGO ist zwar nicht Teil der Zulässigkeitsprüfung, ${ }^{923}$ jedoch kann $\S 63$ VwGO als Ausgangspunkt der Ausführungen zu den Beteiligten genommen werden, indem festgestellt wird, wer am Verfahren beteiligt ist und ob diese Personen auch beteiligungs- und prozessfähig sind. Zulässigkeitsvoraussetzung sind die Beteiligungs- und die Prozessfähigkeit (s. ausführlich Rn. 419 ff., 430 ff.).

\section{Passive Prozessführungsbefugnis, $\$ 78$ VwGO}

$409 \S 78$ VwGO bestimmt gegen wen Anfechtungs- und Verpflichtungsklagen zu richten sind, d. h. wer richtiger Beklagter ist.

410 Anmerkung zur Falllösung: Der Beklagte zählt nach § 63 Nr. 2 VwGO zu den Prozessbeteiligten. Es empfiehlt sich bereits vor der Prüfung der Beteiligungs- und der Prozessfähigkeit, den richtigen Beklagten zu bestimmen, da auch der richtige Beklagte beteiligungs- und prozessfähig sein muss.

411 Formulierungsvorschlag: „Die Anfechtungsklage muss gegen den richtigen Beklagten gerichtet werden. Gem. \& 78 I Nr. 1 VwGO ist die Anfechtungsklage grundsätzlich gegen die Körperschaft zu richten, deren Behörde den angefochtenen Verwaltungsakt erlassen hat.“924

\section{a) Richtiger Beklagter nach $§ 78$ I VwGO}

412 Nach $\S 78$ I Nr. 1 VwGO ist die Klage gegen den Bund, das Land oder die Körperschaft, deren Behörde den angefochtenen Verwaltungsakt erlassen oder den beantragten Verwaltungsakt unterlassen hat, $\mathrm{zu}$ richten, d.h. richtiger Klagegegner ist der Rechtsträger der handelnden Behörde (Rechtsträgerprinzip). Wer Rechtsträger der handelnden Behörde ist, bestimmt sich nach dem insoweit maßgeblichen Bundes- oder Landesorganisationsrecht. ${ }^{925}$

413 Abweichend vom Rechtsträgerprinzip ermächtigt §78 I Nr. 2 VwGO den Landesgesetzgeber zu bestimmen, dass die Anfechtungs- oder Verpflichtungs-

923 Hufen, Verwaltungsprozessrecht, 11. Aufl. 2019, § 12 Rn. 1.

924 Vgl. Darstellung verschiedener Einzelprobleme bei der Anwendung von $\S 78$ VwGO bei Hufen, Verwaltungsprozessrecht, 11. Aufl. 2019, § 12 Rn. $33 \mathrm{ff}$.

925 Kintz, in: Posser/Wolff, VwGO, 50. Ed., Stand: 1.4.2019, § 78 Rn. 17. 
klage gegen die Behörde selbst $\mathrm{zu}$ richten ist (Behördenprinzip). ${ }^{926}$ Besteht eine solche landesrechtliche Regelung, geht diese $\S 78$ I Nr. 1 VwGO vor. $\S 78$ I Nr. 2 VwGO ist damit eine gesetzliche Ausnahme vom Rechtsträgerprinzip und ein Fall einer gesetzlich geregelten Prozessstandschaft. ${ }^{927}$

\section{b) Sonderfall: Widerspruchsbescheid als Klagegegenstand}

Nach § 79 I Nr. 1 VwGO ist Gegenstand der Anfechtungsklage der ursprüngliche 414 Verwaltungsakt in der Gestalt, die er durch den Widerspruchsbescheid gefunden hat, sodass die Klage grundsätzlich gegen den Rechtsträger der Ausgangsbehörde (§ 78 I Nr. 1 VwGO) oder gegen die Ausgangsbehörde selbst (§ 78 I Nr. 2 VwGO i.V.m. Landesrecht) $\mathrm{zu}$ richten ist.

Bei isolierter Anfechtung des Widerspruchsbescheids, wenn dieser erstmalig 415 oder eine zusätzliche selbständige Beschwer erhält, ist die Klage ausnahmsweise gegen den Rechtsträger der Widerspruchsbehörde zu richten (§ 78 II VwGO bzw. $\S 79$ II i.V.m. § 78 II VwGO) bzw. falls § 78 I Nr. 2 VwGO Anwendung findet gegen die Widerspruchsbehörde selbst. ${ }^{928}$

\section{c) Aufbauproblem: Prüfungsstandort des $\S 78$ VwGO}

$\S 78$ VwGO regelt die passive Prozessführungsbefugnis. ${ }^{929}$ Die passive Pro- 416 zessführungsbefugnis ist die Befugnis des Beklagten, über die vom Kläger behauptete Verpflichtung im eigenen Namen den Prozess zu führen. ${ }^{930}$ Sie wird innerhalb der Zulässigkeit geprüft.

926 Von der Ermächtigung Gebrauch gemacht haben Brandenburg (§ 8 II VwGG), MecklenburgVorpommern (§14 II AGGerStrG) und das Saarland (§19 II AGVwGO) für Behörden allgemein sowie Niedersachsen (§ 8 II AGVwGO), Schleswig-Holstein (§ 6 AGVwGO) und Sachsen-Anhalt (§ 8 AGVwGO LSA) für Landesbehörden.

927 Hufen, Verwaltungsprozessrecht, 11. Aufl. 2019, § 12 Rn. 32; Schenke, Verwaltungsprozessrecht, 16. Aufl. 2019, Rn. 550.

928 Hufen, Verwaltungsprozessrecht, 11. Aufl. 2019, § 12 Rn. 40; Meissner/Schenk, in: Schoch/ Schneider/Bier, VwGO, 36. EL Februar 2019, § 78 Rn. 48.

929 Schenke, in: Kopp/Schenke, VwGO, 25. Aufl. 2019, § 78 Rn. 1; Schenke, Verwaltungsprozessrecht, 16. Aufl. 2019, Rn. 545 f.; Ehlers, in: Festschrift für Christian-Friedrich Menger, 1985, 379 (383); Hufen, Verwaltungsprozessrecht, 11. Aufl. 2019, § 12 Rn. 29 ff. m.w. N.

930 Rozek, JuS 2007, 601 (601). Die aktive Prozessführungsbefugnis ist die Befugnis des Klägers, im eigenen Namen über das streitige Recht einen Prozess zu führen. Die aktive Prozessführungsbefugnis ist im Verwaltungsrecht mit der Klagebefugnis in § 42 II VwGO geregelt, s. Rn. $281 \mathrm{ff}$. 
417 Examenswissen: Die Gegenansicht prüft $\S 78$ VwGO als Passivlegitimation zu Beginn der Begründetheitsprüfung des Rechtsbehelfs. ${ }^{931}$ Die Passivlegitimation ist das materielle Gegenstück zur passiven Prozessführungsbefugnis, denn passivlegitimiert ist derjenige, der durch das materielle Recht tatsächlich verpflichtet ist. ${ }^{932}$ Passivlegitimation und passive Prozessführungsbefugnis haben die gleichen Voraussetzungen und folgen dem Rechtsträgerprinzip..$^{933}$

Im Fall des Behördenprinzips nach $\S 78$ I Nr. 2 VwGO handelt es sich in jedem Fall um eine Regelung der passiven Prozessführungsbefugnis, sodass § 78 I Nr. 2 VwGO stets innerhalb der Zulässigkeit zu prüfen ist. ${ }^{934}$

Im Übrigen sprechen gegen das Verständnis des § 78 I Nr. 1 VwGO als Passivlegitimation sowohl der Wortlaut des $\S 78$ VwGO (,Die Klage ist zu richten“) als auch die systematische Stellung im 8. Abschnitt der VwGO, der die besonderen Zulässigkeitsvoraussetzungen der Anfechtungs- und Verpflichtungsklage regelt. Demzufolge ist $\S 78 \mathrm{VwGO}$ eine Normierung der passiven Prozessführungsbefugnis.

418 Anmerkung zur Falllösung: Der Streit, ob $\S 78$ VwGO die passive Prozessführungsbefugnis oder die Passivlegitimation regelt, hat Auswirkungen auf den Klausuraufbau. Bei § 78 VwGO sollte sich ohne Darstellung des Meinungsstreits für eine Ansicht entschieden und die Falllösung dementsprechend aufgebaut werden, d.h. die Vorschrift sollte entweder kurz als Regelung der passiven Prozessführungsbefugnis im Rahmen der Zulässigkeit oder aber § 78 VwGO als Passivlegitimation erst in der Begründetheit geprüft werden. In jedem Fall sollte der Behördenaufbau auf Bundes- und Landesebene beherrscht werden (s. zu den Zuständigkeiten im Einzelnen Rn. 580 ff.), sodass das Rechtsträgerprinzip sicher angewendet werden kann.

\section{Beteiligungsfähigkeit, $\S 61 \mathrm{VwGO}$}

$419 \S 61$ VwGO regelt die Beteiligungsfähigkeit als Zulässigkeitsvoraussetzung im Verwaltungsprozess. Unter Beteiligungsfähigkeit versteht man die Fähigkeit, als Subjekt eines Prozessrechtsverhältnisses, d.h. als Kläger, Beklagter, Beigela-

931 BVerwG, Urt.v. 3.3.1989, Az.: 8 C 98/85 = NVwZ-RR 1990, 44; BVerwG, Beschl.v. 9.1.1999, Az.: 11 C 8 - 97 = NVwZ 1999, 196; BVerwG, Urt. v. 22.6.2011, Az.: 1 C 5/10 = NVwZ 2011, 1340, Rn. 9; VGH Mannheim, Urt. v. 2.8.2017, Az.: 1 S 542/17 = NVwZ-RR 2018, 358, 359, Rn. 19 ff.; Happ, in: Eyermann, VwGO, 15. Aufl. 2019, § 78 Rn. 1; Brenner, in: Sodan/Ziekow, VwGO, 5. Aufl. 2018, § 78 Rn. 3f., Rozek, JuS 2007, 601 (602f.).

932 Meissner/Schenk, in: Schoch/Schneider/Bier, VwGO, 36. EL Februar 2019, § 78 Rn. 11.

933 Hufen, Verwaltungsprozessrecht, 11. Aufl. 2019, § 12 Rn. 29.

934 Brenner, in: Sodan/Ziekow, VwGO, 5. Aufl. 2018, § 78 Rn. 5; a. A. Happ, in: Eyermann, VwGO, 15. Aufl. 2019, § 78 Rn. 4; Pietzner/Ronellenfitsch, Das Assessorexamen im Öffentlichen Recht, 14. Aufl. 2019, Rn. 252. 
dener oder sonstiger Beteiligter ( $(63$ VwGO), an einem Verwaltungsgerichtsverfahren teilnehmen zu können. ${ }^{935}$

Anmerkungen zur Falllösung: Die Prüfung der Beteiligungsfähigkeit kann in der Klausur grundsätzlich kurz ausfallen. Ausführlichere Ausführungen können erforderlich sein, wenn der Kläger keine natürliche Person ist. Fehlt die Beteiligungsfähigkeit beim Kläger oder Beklagten, ist die Klage unzulässig; fehlt sie beim Beigeladenen, erstreckt sich die Bindungswirkung des Urteils (§ 121 VwGO) nicht auf ihn und bei notwendiger Beiladung (§ 65 II VwGO) erwächst das Urteil nicht in materielle Rechtskraft. ${ }^{936}$

Teilweise wird die Beteiligungsfähigkeit auch als Beteiligtenfähigkeit bezeichnet.937 Beide Begriffe werden synonym verwendet. Empfehlenswert ist, sich für eine Begriffsvariante zu entscheiden und diese einheitlich in der Klausur anzuwenden, d.h. entweder Beteiligungsfähigkeit und beteiligungsfähig oder Beteiligtenfähigkeit und beteiligtenfähig zu verwenden.

Formulierungsvorschlag: „Kläger und Beklagter müssen nach $\S 61$ VwGO be- 421 teiligungsfähig sein.“

\section{a) Beteiligungsfähigkeit von natürlichen und juristischen Personen (§ $61 \mathrm{Nr} .1 \mathrm{VwGO})$}

Nach § 61 Nr. 1 VwGO sind natürliche und juristische Personen beteiligungs- 422 fähig.

Ist der Kläger eine natürliche Person, ist er unproblematisch beteiligungsfähig. ${ }^{938} \S 61$ Nr. 1 VwGO erfasst jedoch nicht die Fälle, in denen eine natürliche Person lediglich als Organwalter um Rechte dieses Organs streitet. ${ }^{939}$

935 Schenke, Verwaltungsprozessrecht, 16. Aufl. 2019, Rn. 455.

936 Schenke, in: Kopp/Schenke, VwGO, 25. Aufl. 2019, § 61 Rn. 2.

937 Vgl. u. a. Hufen, Verwaltungsprozessrecht, 11. Aufl. 2019, § 12 Rn. 18.

938 Umstritten ist die Beteiligungsfähigkeit des nasciturus (Leibesfrucht): Bejahend für eigene Rechte des nasciturus in entsprechender Anwendung der zivilrechtlichen Grundsätze der Rechtsfähigkeit Schenke, in: Kopp/Schenke, VwGO, 25. Aufl. 2019, § 61 Rn. 5; a. A. im Rahmen der Endlagerung radioaktiver Abfälle BVerwG, Beschl. v. 5.2.1992, Az.: 7 B 13/92 = NJW 1992, 1524 (1524).

939 Schenke, in: Kopp/Schenke, VwGO, 25. Aufl. 2019, § 61 Rn. 5; Schoch, JuS 1987, 783 (786); Dolde, in: Festschrift für Christian-Friedrich Menger, 1985, 423 (427 f.); Schenke, Verwaltungsprozessrecht, 16. Aufl. 2019, Rn. 457 m.w.N. 
423 Examenswissen: Umstritten ist die Beteiligungsfähigkeit des nasciturus (Leibesfrucht; bereits gezeugtes, aber noch ungeborenes Kind). Der nasciturus kann soweit er in entsprechender Anwendung der zivilrechtlichen Grundsätze als rechtsfähig behandelt wird oder ihm nach öffentlichem Recht eigene Rechte zustehen beteiligungsfähig nach $\S 61 \mathrm{Nr} .1$ VwGO sein. ${ }^{940}$ Im verwaltungsgerichtlichen Verfahren auf Einstellung des Betriebs eines Endlagers für radioaktive Abfälle ist der nasciturus jedoch nicht beteiligungsfähig. ${ }^{941}$

424 Juristische Personen i.S.d. § 61 Nr. 1 VwGO sind alle juristischen Personen des Privatrechts und des öffentlichen Rechts.

425 Juristische Personen des Privatrechts sind die Kapitalgesellschaften, eingetragene Genossenschaften sowie rechtsfähige Vereine oder Stiftungen des Privatrechts. Auch wenn es sich nicht um juristische Personen des Privatrechts, sondern um Personengesellschaften handelt, sind die OHG und die KG, die GbR, der „nichtrechtsfähige Verein“ (§ 54 BGB), religiöse Vereinigungen nach Art. 4 GG (sofern nicht bereits Körperschaft des öffentlichen Rechts) und politische Parteien (auch Gebietsverbände der höchsten Stufe, § 3 PartG) ebenfalls beteiligungsfähig i.S.v. § 61 Nr. 1 VwGO. ${ }^{942}$

426 Examenswissen: Bei ausländischen juristischen Personen des Privatrechts ist maßgeblich, ob deren Rechtsfähigkeit von der deutschen Rechtsordnung anerkannt wird. ${ }^{943}$ Dabei ist zwischen Fällen innerhalb und außerhalb der EU zu unterscheiden: Innerhalb der EU kommt es für die nationale Zuordnung und rechtliche Beurteilung einer juristischen Person auf das Gründungsland an (sog. Gründungstheorie). ${ }^{944}$ Ist die im EU-Ausland gegründete juristische Person nach dortigem Recht rechtsfähig, ist dies auch in der deutschen Rechtsordnung anzuerkennen. Außerhalb der EU gilt grundsätzlich die Sitztheorie, also das Recht des Staates, in dem die juristische Person ihren tatsächlichen Verwaltungssitz hat. ${ }^{945}$

427 Juristische Personen des öffentlichen Rechts sind die Gebietskörperschaften (Bund, Länder, Gemeinden), sonstige rechtsfähige Körperschaften des öffentli-

940 Schenke, in: Kopp/Schenke, VwGO, 25. Aufl. 2019, §61 Rn. 5; Dolde, in: Festschrift für Christian-Friedrich Menger, 1985, 423 (427); a. A. Hoppe, in: Eyermann, VwGO, 15. Aufl. 2019, § 61 Rn. 5.

941 BVerwG, Beschl. v. 5.2.1992, Az.: 7 B 13/92 = NJW 1992, 1524 (1524).

942 Kintz, in: Posser/Wolff, VwGO, 50. Ed., Stand: 1.4.2019, § 61 Rn. 1.1, 5; Schenke, in: Kopp/ Schenke, VwGO, 25. Aufl. 2019, § 61 Rn. 6; BGH, Urt. v. 29.1.2001, Az.: II ZR 331/00 = NJW 2001, 1056 (1056).

943 Behm, DVBl 2009, 94 (95); Decker, in: Wolff/Decker, VwGO, 3. Aufl. 2012, § 61 Rn. 7.

944 EuGH (Plenum), Urt. v. 5.11.2002, Rs.: C-208/00 („Überseering BV“) = NJW 2002, 3614; BGH, Urt. v. 12.7.2011, Az.: II ZR 28/10 = NJW 2003, 1461 (1461); Kintz, Öffentliches Recht im Assessorexamen, 10. Aufl. 2018, Rn. 289.

945 Bier/Steinbeiß-Winkelmann, in: Schoch/Schneider/Bier, VwGO, 36. EL Februar 2019, § 61 Rn. 4; anders bei abweichender völkerrechtlicher Regelung: BGH, Urt. v. 29.1.2003, Az.: VIII ZR 155/02 = NJW 2003, 1607 (1607).

\section{Carola Creemers}


chen Rechts (z. B. Industrie- und Handelskammern (§ 3 I IHKG), Rechtsanwaltskammern (§ 62 I BRAO), Ärztekammern, anerkannte Religionsgemeinschaften (Art. 4 GG), Universitäten (§ 5 I HRG)), rechtsfähige Anstalten des öffentlichen Rechts sowie Stiftungen des öffentlichen Rechts.

\section{b) Beteiligungsfähigkeit von Vereinigungen ( $\$ 61 \mathrm{Nr} .2$ VwG0)}

Nach § 61 Nr. 2 VwG0 sind Vereinigungen beteiligungsfähig, soweit ihnen 428 ein Recht zustehen kann. Eine Vereinigung ist dann gegeben, wenn ein Mindestmaß an innerer Organisation vorliegt. ${ }^{946} \S 61 \mathrm{Nr} .2$ VwGO stellt nicht auf die Rechtsfähigkeit, sondern auf die Zuordnung einzelner subjektiv-öffentlicher Rechte ab. Die Vereinigung muss folglich Zuordnungssubjekt eines Rechtssatzes sein, durch welchen für sie Rechte oder Pflichten begründet werden, wobei sogar innerorganisatorische Rechte und Pflichten genügen. ${ }^{947} \mathrm{Ob}$ der Vereinigung das Recht tatsächlich zusteht, ist sodann keine Frage der Beteiligungsfähigkeit, sondern des materiellen Rechts und damit der Begründetheit. Beteiligungsfähig nach § 61 Nr. 2 VwGO können z.B. Organe und Teilorgane einer Gemeinde im Kommunalverfassungsstreit, Organe der Hochschulen oder ein ausländischer Verein sein. ${ }^{948}$

\section{c) Beteiligungsfähigkeit von Behörden nach Landesrecht ( $\$ 61 \mathrm{Nr} .3$ VwG0)} Nach § 61 Nr. 3 VwGO sind Behörden beteiligungsfähig, sofern das Landes- 429 recht dies bestimmt. Behörden sind unselbständige Teile ihres jeweiligen Rechtsträgers, sodass sie grundsätzlich nicht beteiligungsfähig sind. Daher sieht § 61 Nr. 3 VwGO vor, dass das Landesrecht die Beteiligungsfähigkeit von Landesbehörden bestimmen kann. ${ }^{949}$ Die betreffenden Landesbehörden machen im Prozess keine eigenen Rechte geltend, sondern werden nur in Prozessstandschaft für ihren Rechtsträger, die Körperschaft, der sie angehören, tätig. ${ }^{950}$ Die Er-

946 BVerwG, Beschl. v. 21.1.2004, Az.: 6 A 1/04 = NVwZ 2004, 887 (887).

947 Schenke, Verwaltungsprozessrecht, 16. Aufl. 2019, Rn. $461 \mathrm{f}$.

948 Hufen, Verwaltungsprozessrecht, 11. Aufl. 2019, § 12 Rn. 21 mit weiteren Beispielen; Schenke, in: Kopp/Schenke, VwGO, 25. Aufl. 2019, § 61 Rn. 9 ff. m.w. N.; zur Beteiligungsfähigkeit des ausländischen Vereins BVerwG, Beschl. v. 21.1.2004, Az.: 6 A 1/04 = NVwZ 2004, 887 (887) Ls. 1. 949 Von der Ermächtigung Gebrauch gemacht haben Brandenburg (§ 8 I VwGG), MecklenburgVorpommern (§ 14 I AGGerStrG), Niedersachsen (§ 79 I NJG), Saarland (§ 19 I AGVwGO), SchleswigHolstein (§ 6 AGVwGO), Sachsen-Anhalt ( 8 AGVwGO LSA) und Rheinland-Pfalz (für die Bezirksregierung im Fall der Beanstandungsklage, § 17 II AGVwGO).

950 Kintz, in: Posser/Wolff, VwGO, 50. Ed., Stand: 1.4.2019, § 61 Rn. 16; Schenke, Verwaltungsprozessrecht, 16. Aufl. 2019, Rn. 463. 
mächtigung des $\S 61$ Nr. 3 VwGO bezieht sich nur auf Landesbehörden. ${ }^{951}$ Durch Bundesrecht kann jedoch aus der allgemeinen Kompetenz des Art. 74 I Nr. 1 GG Behörden ebenfalls die Beteiligungsfähigkeit zuerkannt werden. ${ }^{952}$

\section{Prozessfähigkeit, $§ 62$ VwG0}

430 Von der Beteiligungsfähigkeit ist die Prozessfähigkeit zu unterscheiden, denn nicht jeder Beteiligungsfähige ist auch prozessfähig.

431 Anmerkung zur Falllösung: Die Prüfung der Prozessfähigkeit kann in der Klausur grundsätzlich kurz ausfallen. Ausführlicher sollte auf die Prozessfähigkeit eingegangen werden, sofern es sich um einen minderjährigen Kläger handelt. Zudem sollte kurz auf die entsprechende Vertretungsbefugnis von Vereinigungen und Behörden eingegangen werden. Regelmäßig können die Beteiligungs- und Prozessfähigkeit innerhalb eines Prüfungspunktes kurz zusammengeprüft werden.

432 Formulierungsvorschlag: „Zudem muss die Prozessfähigkeit nach § 62 VwGO vorliegen."

$433 \S 62$ VwGO regelt die Fähigkeit, selbst oder durch einen Prozessbevollmächtigten (§ 173 VwGO i.V.m. §51 ZPO) wirksam Prozesshandlungen (z. B. Klageerhebung, Antragstellung) vorzunehmen. Prozessfähig sind gem. § 62 I Nr. 1 VwGo die nach bürgerlichem Recht Geschäftsfähigen und nach § 62 I Nr. 2 VwG0 die nach bürgerlichem Recht in der Geschäftsfähigkeit Beschränkten (vgl. $\S \S 2,104$ ff. BGB), soweit sie durch Vorschriften des bürgerlichen oder öffentlichen Rechts für den Gegenstand des Verfahrens als geschäftsfähig anerkannt sind. Wer nicht selbst prozessfähig ist, muss sich vertreten lassen. ${ }^{953}$ Dabei beurteilt sich nach materiellem Recht, wer gesetzlicher Vertreter ist und wie weit die entsprechende Vertretungsmacht reicht. ${ }^{954}$

951 Kintz, in: Posser/Wolff, VwGO, 48. Ed., Stand: 1.4.2019, § 61 Rn. 19; Schenke, in Kopp/ Schenke, VwGO, 25. Aufl. 2019, § 61 Rn. 13; a. A. Hufen, Verwaltungsprozessrecht, 11. Aufl. 2019, $\S 12$ Rn. 22.

952 So z. B. in § 47 II 1 VwGO für den Normenkontrollantrag; Bier/Steinbeiß-Winkelmann, in: Schoch/Schneider/Bier, VwGO, 36. EL Februar 2019, § 61 Rn. 8.

953 Detterbeck, Allgemeines Verwaltungsrecht mit Verwaltungsprozessrecht, 17. Aufl. 2019, Rn. 1347.

954 Kintz, in: Posser/Wolff, VwGO, 50. Ed., Stand: 1.4.2019, § 62 Rn. 13. 


\section{a) Prozessfähigkeit Geschäftsfähiger ( $\$ 62$ I Nr. 1 VwG0)}

Unbeschränkt prozessfähig sind gem. § 61 I Nr. 1 VwGO die nach bürgerlichem 434 Recht voll Geschäftsfähigen. Das sind grundsätzlich alle natürlichen Personen, die das 18. Lebensjahr vollendet haben (§ 2 BGB) und deren Geistesfähigkeit nicht dauerhaft gestört ist (§ 104 Nr. 2 BGB).

\section{b) Prozessfähigkeit beschränkt Geschäftsfähiger ( 62 I Nr. 2 VwG0)}

Beschränkt (partiell) prozessfähig gem. § 62 I Nr. 2 VwGO können Minder-

jährige über sieben Jahre (§ 106 BGB) nach Maßgabe der $\S \S 107 \mathrm{ff}$. BGB oder nach öffentlich-rechtlichen Vorschriften sein. Eine beschränkte Prozessfähigkeit i.S.d. §62 I Nr. 2 VwGO ergibt sich zivilrechtlich insbesondere aus §112 BGB oder $\S 113$ BGB. Im öffentlichen Recht ergibt sich eine beschränkte Prozessfähigkeit u. a. für Minderjährige nach Vollendung des 14. Lebensjahres bei religiösen Entscheidungen aus §5 S. 1 des Gesetzes über die religiöse Kindererziehung i.V.m. Art. $4 \mathrm{GG}^{955}$, für Minderjährige ab 15 oder 16 Jahren im Verfahren auf Erteilung einer Fahrerlaubnis gem. § 10 I, III i.V.m. §§ 4, 5 FeV, für Sozialleistungen ab 15 Jahren (§ 36 I SGB I) oder ab 16 Jahren im Melderecht nach § 17 III BMG.

Hausarbeitswissen: Für minderjährige Ausländer gelten grundsätzlich $\S 12$ AsylG und $\S 80$ AufenthG, wonach die Fähigkeit zur Vornahme von Verfahrenshandlungen vom Eintritt der Volljährigkeit abhängig ist. Im Übrigen beurteilt sich die Prozessfähigkeit eines Ausländers nach ungeschriebenem deutschem Verfahrenskollisionsrecht grundsätzlich nach dem Prozessrecht seines Heimatstaates. ${ }^{956}$

Darüber hinaus können Minderjährige beschränkt prozessfähig sein, sofern

höchstpersönliche Rechte, insbesondere Grundrechte, betroffen sind und der minderjährige Kläger hinreichend einsichtsfähig und grundrechtsmündig ist. ${ }^{957}$ Im Zweifel ist durch Auslegung der Norm zu ermitteln, ob der Minderjährige im konkreten Fall als beschränkt prozessfähig anzusehen ist.

Ist der beschränkt Geschäftsfähige unter den Voraussetzungen des § 62 I Nr. 2438 VwGO selbst für das konkrete Verfahren prozessfähig, kann statt oder neben ihm

955 BVerwG, Urt. v. 30.11.2011, Az.: 6 C 20/10 = NVwZ 2012, 162 (163) Rn. 15.

956 Hoppe, in: Eyermann, VwGO, 15. Aufl. 2019, § 62 Rn. 8; Bier/Steinbeiß-Winkelmann, in: Schoch/Schneider/Bier, VwGO, 36. EL Februar 2019, § 62 Rn. 15, 10; Kintz, in: Posser/Wolff, VwGO, 50. Ed., Stand: 1.4.2019, § 62 Rn. 7.

957 Schenke, in: Kopp/Schenke, VwGO, 25. Aufl. 2019, § 62 Rn. 6 m.w.N.; insbesondere zur Grundrechtsmündigkeit Schenke, Verwaltungsprozessrecht, 16. Aufl. 2019, Rn. 480.

Carola Creemers 
auch sein gesetzlicher Vertreter zum Handeln befugt sein, wenn durch Gesetz nichts anderes bestimmt ist. ${ }^{958}$

\section{c) Fehlende Prozessfähigkeit}

439 Kinder unter sieben Jahren (§104 Nr. 1 BGB) und dauerhaft Geistesgestörte (§ 104 Nr. 2 BGB) sind geschäftsunfähig und damit prozessunfähig.

440 Fehlt die Prozessfähigkeit muss sich der Betroffene durch den oder die gesetzlichen Vertreter (z.B. für Minderjährige die Eltern gem. §§ 1626, 1629 BGB) vertreten lassen. Ansonsten ist die Klage bei fehlender Prozessfähigkeit unzulässig. Prozesshandlungen durch oder gegenüber einem Prozessunfähigen sind unwirksam (s. zur vergleichbaren Problematik im Verwaltungsverfahren auch Rn. 641). Dies kann aber durch Genehmigung des gesetzlichen Vertreters geheilt werden. Eine nachträgliche Genehmigung wirkt auf den Zeitpunkt der Prozesshandlungen zurück, sofern die Genehmigung vor Rechtskraft des Urteils erfolgt. 959

\section{d) Vertreter von Vereinigungen und Behörden ( $\$ 62$ III VwG0)}

441 Gem. § 62 III VwG0 handeln für Vereinigungen sowie für Behörden ihre gesetzlichen Vertreter und Vorstände. §62 III VwGO erfasst mit dem Merkmal „Vereinigungen“ sowohl juristische Personen des öffentlichen Rechts und des Privatrechts ( $\S 61$ Nr. 1 VwGO) als auch beteiligungsfähige Personenvereinigungen i.S.d. § 61 Nr. 2 VwGO, wobei sie alle ebenfalls wie Behörden als solche nicht prozessfähig sind, sondern durch ihre gesetzlichen Vertreter und Vorstände handeln. ${ }^{960}$ Wer gesetzlicher Vertreter ist und wie weit die jeweilige Vertretungsmacht reicht, ergibt sich aus dem materiellen Recht. ${ }^{961}$

\section{Postulationsfähigkeit und Prozessvertretung, $\S 67$ VwGO}

442 Anmerkung zur Falllösung: In der Klausur ist regelmäßig ausreichend, wenn die Norm des $\S 67$ VwGO bekannt ist sowie auf die Postulationsfähigkeit und die

958 Bier/Steinbeiß-Winkelmann, in: Schoch/Schneider/Bier, VwGO, 36. EL Februar 2019, § 62 Rn. 10; Schenke, in: Kopp/Schenke, VwGO, 25. Aufl. 2019, § 62 Rn. 9.

959 Schenke, in: Kopp/Schenke, VwGO, 25. Aufl. 2019, § 62 Rn. 17.

960 Bier/Steinbeiß-Winkelmann, in: Schoch/Schneider/Bier, VwGO, 36. EL Februar 2019, § 62 Rn. 17; Kintz, in: Posser/Wolff, VwGO, 50. Ed., Stand: 1.4.2019, § 62 Rn. 14.

961 So z.B. aus GG, Geschäftsordnungen, Landesverfassung, Gemeindeordnung, Verwaltungsvorschriften, BGB, HGB, GmbHG, AktG usw. 
Prozessvertretung nur bei entsprechenden Anhaltspunkten im Sachverhalt eingegangen wird.

Grundsätzlich ist jeder Prozessfähige im Verwaltungsprozess auch postulationsfähig, d.h. fähig Anträge zu stellen und selbst Prozesshandlungen vorzunehmen. ${ }^{962}$

Gem. § 67 I VwGO besteht vor dem Verwaltungsgericht kein Vertretungs- 444 zwang, sodass sich jeder Beteiligte selbst vertreten kann. Lassen Beteiligte sich jedoch vertreten, sind nur die in $\S 67$ II VwGO abschließend aufgezählten Prozessvertreter vertretungsbefugt. Zudem besteht vor dem BVerwG und OVG nach $\S 67$ IV VwGO Vertretungszwang. Treten die Beteiligten dennoch ohne tauglichen Vertreter auf, fehlt ihnen die Postulationsfähigkeit und sie können keine wirksamen Prozesshandlungen vornehmen. ${ }^{963}$

\section{Beiladung, $\S 65$ VwGO}

Nach $\S 63$ Nr. 3 VwGO zählt auch der Beigeladene nach § 65 VwGO zu den Betei- 445 ligten im Verwaltungsprozess, wobei die einfache (fakultative) Beiladung nach § 65 I VwGO sowie die notwendige (obligatorische) Beiladung gem. § 65 II VwGO zu unterscheiden sind. Bei der einfachen Beiladung (§ 65 I VwGO) kann das Gericht Dritte beiladen und bei der notwendigen Beiladung (§ 65 II VwGO) muss das Gericht bei Vorliegen der Voraussetzungen Dritte beiladen. Beigeladen werden können nur Dritte, die nach $\S 61$ VwGO beteiligungsfähig sind, aber nicht selbst Partei des Rechtsstreits, d.h. Kläger oder Beklagter sind. ${ }^{964}$

Zweck der Beiladung ist, Dritte am Rechtsstreit zu beteiligen, wenn ihre $\mathbf{4 4 6}$ rechtlichen Interessen durch den Streit berührt werden. Zudem soll durch die Rechtskrafterstreckung ( $§ 121$ Nr. 1 i.V.m. $§ 63$ Nr. 3 VwGO) aus Gründen der Prozessökonomie etwaigen weiteren Rechtsstreitigkeiten über dieselbe Sache vorgebeugt werden (Rechtsschutz und Rechtssicherheit für den Beigeladenen). ${ }^{965}$ Die Beiladung kommt bei allen Verfahrensarten in Betracht; nach § 47 II 4 VwGO auch im Normenkontrollverfahren. Beiladungsfähig ist jeder Beteiligungsfähige. ${ }^{966}$

962 Hufen, Verwaltungsprozessrecht, 11. Aufl. 2019, § 12 Rn. 27; Schenke, Verwaltungsprozessrecht, 16. Aufl. 2019, Rn. 483.

963 Schenk, in: Schoch/Schneider/Bier, VwGO, 36. EL Februar 2019, § 67 Rn. 73; Hoppe, in: Eyermann, VwGO, 15. Aufl. 2019, § 67 Rn. 20.

964 Bier, in: Schoch/Schneider/Bier, VwGO, 36. EL Februar 2019, § 65 Rn. 9 f.; Schenke, in: Kopp/ Schenke, VwGO, 25. Aufl. 2019, § 65 Rn. 5.

965 Kintz, in: Posser/Wolff, VwGO, 50. Ed., Stand: 1.4.2019, § 65 Rn. 1; Hufen, Verwaltungsprozessrecht, 11. Aufl.2019, § 12 Rn. 4; ausführlich zur Beiladung Guckelberger, JuS 2007, $436 \mathrm{ff.}$ 966 Schenke, Verwaltungsprozessrecht, 16. Aufl. 2019, Rn. 464. 
Der Beigeladene ist kein Hauptbeteiligter, sondern er beteiligt sich als Nebenbeteiligter an einem ursprünglich fremden Rechtsstreit. ${ }^{967} \mathrm{Gem}$. § 65 IV VwGO ist der Beiladungsbeschluss allen Beteiligten zuzustellen. Der Beigeladene erhält die Rechtsstellung eines Beteiligten ( $\$ 63$ Nr. 3 VwGO) erst mit der Zustellung des Beiladungsbeschlusses oder bei Anwesenheit in der mündlichen Verhandlung mit dessen Verkündung. ${ }^{968}$ Zulässig ist die Beiladung nur, solange das Verfahren noch nicht rechtskräftig abgeschlossen ist (§65 I VwGO). Die Rechte des Beigeladenen ergeben sich aus $\S 66$ VwGO: Der Beigeladene kann innerhalb der Anträge eines Beteiligten selbständig Angriffs- und Verteidigungsmittel geltend machen und alle Verfahrenshandlungen wirksam vornehmen. Abweichende Sachanträge kann er nur stellen, sofern eine notwendige Beiladung vorliegt.

\section{a) Einfache (fakultative) Beiladung ( $\$ 65$ I VwG0)}

447 Bei der einfachen (fakultativen) Beiladung nach § 65 I VwG0 können nach dem Ermessen des Gerichts von Amts wegen oder auf Antrag Dritte beigeladen werden, sofern die Entscheidung rechtliche Interessen des Dritten berührt. Eine solche Berührung rechtlicher Interessen liegt vor, wenn die Möglichkeit besteht, dass sich die Rechtsposition des Dritten durch den Prozessausgang jedenfalls faktisch verbessern oder verschlechtern könnte. ${ }^{969}$ Nicht ausreichend sind allerdings rein ideelle, soziale oder wirtschaftliche Interessen. ${ }^{970}$

448 So kann regelmäßig der Grundstücksnachbar bei der Anfechtungsklage des Bauherrn gegen die Rücknahme eines Bauvorbescheids ${ }^{971}$ oder bei der Verpflichtungsklage des Bauherrn auf Erteilung einer Baugenehmigung unter den Voraussetzungen des $\S 65$ I VwGO einfach beigeladen werden. ${ }^{972}$

967 Czybulka/Kluckert, in: Sodan/Ziekow, VwGO, 5. Aufl. 2018, § 66 Rn. 3; Hufen, Verwaltungsprozessrecht, 11. Aufl. 2019, § 12 Rn. 16; Guckelberger, JuS 2007, 436 (436); Stober, in: Festschrift für Christian-Friedrich Menger, 1985, 401 (401).

968 Kintz, in: Posser/Wolff, VwGO, 50. Ed., Stand: 1.4.2019, § 66 Rn. 1.

969 BVerwG, Urt. v. 16.9.1981, Az.: 8 C 1/81 = NJW 1982, 951 (952); BVerwG, Beschl. v. 19.11.1998, Az.: 11 A 50/97 = NVwZ-RR 1999, 276, 276; Erbguth/Guckelberger, Allgemeines Verwaltungsrecht, 9. Aufl. 2018, § 20 Rn. 33.

970 Hoppe, in: Eyermann, VwGO, 15. Aufl. 2019, § 65 Rn. 9; Schenke, in: Kopp/Schenke, VwGO, 25. Aufl. 2019, § 65 Rn. 12.

971 OVG Koblenz, Beschl. v. 14.5.2013, Az.: 8 A 10043/13 = NVwZ-RR 2013, 747 (749); Hoppe, in: Eyermann, VwGO, 15. Aufl. 2019, § 65 Rn. 13.

972 BVerwG, Beschl. v. 21.6.1973, Az.: IV B 38.73 = DÖV 1975, 99 (99). Weitere Beispielsfälle einfacher Beiladung bei Kintz, Posser/Wolff, VwGO, 49. Ed., Stand: 1.4.2019, § 65 Rn. 9 f. 
Examenswissen: Das Unterbleiben der einfachen Beiladung nach $\S 65$ I VwGO hat keine unmittelbaren Folgen: Es handelt sich um keinen Verfahrensmangel, aber das Urteil entfaltet gegenüber dem Nicht-Beigeladenen auch keine Bindungswirkungen nach $\S 121$ VwGO. ${ }^{973}$ Für die Wirksamkeit der Gerichtsentscheidung im Verhältnis zwischen Kläger und Beklagtem hat die fehlerhaft unterbliebene einfache Beiladung grundsätzlich keine Konsequenzen. ${ }^{974}$

\section{b) Notwendige (obligatorische) Beiladung ( $\$ 65$ II VwG0)}

Die notwendige (obligatorische) Beiladung setzt gem. § 65 II VwGO voraus, 450 dass Dritte an dem streitigen Rechtsverhältnis derart beteiligt sind, dass die gerichtliche Entscheidung auch ihnen gegenüber nur einheitlich ergehen kann. Das ist dann der Fall, wenn mit dem Urteil gleichzeitig unmittelbar und zwangsläufig in Rechte der Dritten eingegriffen wird, d.h. ihre Rechte gestaltet, bestätigt, festgestellt, verändert oder aufgehoben werden, sodass aus Rechtsgründen die Entscheidung den Hauptbeteiligten und dem Beigeladenen gegenüber nur einheitlich ergehen kann. ${ }^{975}$ Die Rechte des Dritten müssen durch die Entscheidung unmittelbar berührt werden.

Um Fälle notwendiger Beiladung ${ }^{976}$ handelt es sich insbesondere bei An451 fechtungsklagen gegen Verwaltungsakte mit Drittwirkung, d.h. Verwaltungsakte, die für eine Person begünstigend und für eine andere Person belastend wirken (vgl. dazu den Fall 3 in: Eisentraut, Fälle zum Verwaltungsrecht, 2020).

Examenswissen: Eine unterbliebene notwendige Beiladung stellt grundsätzlich einen wesentlichen Verfahrensfehler dar (Verletzung von Art. 103 GG), der im Rechtsmittelverfahren zur Aufhebung des Urteils und zur Zurückverweisung der Sache führt. ${ }^{977} \S 142$ I 2 VwGO lässt allerdings notwendige Beiladungen in der Revisionsinstanz zu. Damit soll eine Zurückverweisung der Sache im Interesse unnötiger Verfahrensverzögerungen vermieden werden, wenn der Beizuladende ein berechtigtes Interesse an der Zurückverweisung nicht haben kann, da weitere Tatsachenfeststellungen nicht notwendig sind. ${ }^{978}$ Unschädlich ist der Verfahrensmangel der unterbliebenen notwendigen Beiladung auch dann, wenn der Beizuladende durch die ergangene

973 Bier, in: Schoch/Schneider/Bier, VwGO, 36. EL Februar 2019, § 65 Rn. 38; Pietzner/Ronellenfitsch, Das Assessorexamen im Öffentlichen Recht, 14. Aufl. 2019, Rn. 223.

974 Guckelberger, JuS 2007, 436 (441).

975 Schenke, in: Kopp/Schenke, VwGO, 25. Aufl. 2019, § 65 Rn. 14; BVerwG, Beschl. v. 13.6. 2007, Az.: 6 VR 5/07 = NVwZ 2007, 1207 (1207) Rn. 6; BVerwG; Beschl. v. 9.1.1999, Az.: 11 C 8/97 = NVwZ 1999, 296 (296).

976 Auflistung wichtiger Fälle notwendiger Beiladung bei Hufen, Verwaltungsprozessrecht, 11. Aufl. 2019, § 12 Rn. 8.

977 Schenke, in: Kopp/Schenke, VwGO, 25. Aufl. 2019, § 65 Rn. 42; Kintz, in: Posser/Wolff, VwGO, 50. Ed., Stand: 1.4.2019, § 65 Rn. $31 \mathrm{f}$.

978 BVerwG, Beschl. v. 20.10.2000, Az.: 7 B 58/00 = NVwZ 2001, 202 (202). 
Entscheidung nicht in seinen Rechten berührt wird. ${ }^{979}$ Sofern der Verfahrensfehler nicht im Revisionsverfahren behoben wird, ist ein Gestaltungsurteil (z. B. Aufhebung eines Verwaltungsakts) bei fehlerhaft unterlassener notwendiger Beiladung absolut unwirksam, d.h. auch im Verhältnis zwischen den Hauptbeteiligten. ${ }^{980}$ Hingegen bleibt ein Verpflichtungsurteil gegenüber den Hauptbeteiligten wirksam, da der eigentlich beizuladende Dritte, den aufgrund dieses Urteils ergehenden Verwaltungsakt anfechten kann. ${ }^{981}$

453 Anmerkung zur Falllösung: Das Unterbleiben der Beiladung führt sowohl bei der einfachen als auch bei der notwendigen Beiladung nicht zur Unzulässigkeit einer Klage, sondern zu anderen prozessrechtlichen Folgen (vgl. Rn. 449, 452). ${ }^{982} \mathrm{Zu}$ den Zulässigkeitsvoraussetzungen der Klage gehört daher nicht, ob ein Dritter zum Rechtsstreit beizuladen ist oder rechtmäßig beigeladen wurde. ${ }^{983}$ Folglich handelt es sich bei der Beiladung nicht um eine „echte“ Zulässigkeitsvoraussetzung, sodass es sich empfiehlt, die Beiladung zwischen Zulässigkeit und Begründetheit zu prüfen (empfohlener Prüfungsaufbau: A. Zulässigkeit, B. Beiladung, C. Begründetheit; s. dazu $\S 1$ Rn. 63 ff. sowie Fall 3, Fall 4 und Fall 5 sowie den Fall 15 in: Eisentraut, Fälle zum Verwaltungsrecht, 2020). Sofern die Beiladung dennoch im Rahmen der Zulässigkeit geprüft wird, ist zu beachten, dass das Fehlen der Voraussetzungen bzw. das Unterbleiben der Beiladung nicht zur Unzulässigkeit der Klage führt, sondern nur Auswirkungen auf die Rechtskrafterstreckung des Urteils hat.

454 Die Voraussetzungen der Beiladung sind nur bei entsprechenden Anhaltspunkten im Sachverhalt zu prüfen. Im Fall der Drittanfechtungsklage sollte immer an die Prüfung der notwendigen Beiladung gedacht werden; wobei stets die Bearbeitervermerke zu berücksichtigen sind.

\section{Subjektive Klagehäufung (Streitgenossenschaft), § 64 VwGO}

455 Bei der subjektiven Klagehäufung treten mehrere Personen als Streitgenossen auf der Klägerseite (aktive Streitgenossenschaft) oder auf der Beklagtenseite (passive Streitgenossenschaft) auf. Mit Hilfe der subjektiven Klagehäufung kön-

979 Kintz, in: Posser/Wolff, VwGO, 50. Ed., Stand: 1.4.2019, § 65 Rn. 31; BVerwG, Beschl. v. 30.7. 1990, Az.: 7 B 71/90 = NVwZ 1991, 470 (471) m.w.N.

980 Guckelberger, JuS 2007, 436 (441); Czybulka/Kluckert, in: Sodan/Ziekow, VwGO, 5. Aufl. 2018, $\S 65 \mathrm{Rn} .191$.

981 BVerwG, Urt. v. 20.3.1997, Az.: 7 A 1/96 = VIZ 1997, 415 (416); Schmidt, in: Eyermann, VwGO, 15. Aufl. 2019, § 65 Rn. 19.

982 Schenke, Verwaltungsprozessrecht, 16. Aufl. 2019, Rn. 465.

983 Guckelberger, JuS 2007, 436 (441); Decker, in: Wolff/Decker, VwGO, 3. Aufl. 2012, § 65 Rn. 3.

Carola Creemers 
nen somit mehrere Klagen zur gemeinsamen Entscheidung und Verhandlung miteinander verbunden werden.

Nach $\S 64$ VwGO sind im Verwaltungsprozess die Vorschriften der $\S 59$ bis 456 63 ZPO über die Streitgenossenschaft entsprechend anzuwenden. Gem. § 59 ZPO besteht Streitgenossenschaft, wenn mehrere Beteiligte hinsichtlich des Streitgegenstandes in Rechtsgemeinschaft stehen oder wenn sie aus demselben tatsächlichen und rechtlichen Grund berechtigt oder verpflichtet sind oder nach $\S 60 \mathrm{ZPO}$, wenn gleichartige und auf einem im Wesentlichen gleichartigen tatsächlichen und rechtlichen Grund beruhende Ansprüche oder Verpflichtungen den Gegenstand des Rechtsstreits bilden. Anders als Beigeladene sind die Streitgenossen als Kläger oder Beklagte immer Hauptbeteiligte des Verfahrens.

Im Verwaltungsprozess handelt es sich in der Regel um aktive Streitgenos- 457 senschaft, d.h. um eine Mehrheit von Klägern. Für jeden Streitgenossen müssen gesondert die Zulässigkeitsvoraussetzungen seiner Klage gegeben sein. ${ }^{984}$ Wie bei der Beiladung unterscheidet man auch hier zwischen einfacher (fakultativer) Streitgenossenschaft gem. §64 VwGO i.V.m. §§59, 60 ZPO und notwendiger (obligatorischer) Streitgenossenschaft nach § 64 VwGO i.V.m. § 62 ZPO.

\section{a) Einfache Streitgenossenschaft ( $\$ 64$ VwGO i.V.m. $\S \S 59,60$ ZPO)} Die einfache Streitgenossenschaft nach § 64 VwGO i.V.m. §§ 59, 60 ZPO 458 ist nur die organisatorische Verbindung mehrerer Klagen (Prozessrechtsverhältnisse) zu einem Verfahren, d.h. die Entscheidung kann einheitlich ergehen, muss es aber nicht. ${ }^{985}$ Die einzelnen Streitgenossen bleiben hinsichtlich ihrer Prozesse selbständig und sind an Erklärungen und sonstige Prozesshandlungen der übrigen Streitgenossen nicht gebunden. ${ }^{986}$ Sofern die Voraussetzungen der einfachen Streitgenossenschaft nicht vorliegen, muss das Gericht die Verfahren gem. §93 S. 2 VwGO trennen. ${ }^{987}$ Um eine einfache subjektive Klagehäufung handelt es sich zum Beispiel bei mehreren Nachbarklagen gegen eine Baugenehmigung.

\footnotetext{
984 Hufen, Verwaltungsprozessrecht, 11. Aufl.2019, § 12 Rn. 16; Kintz, in: Posser/Wolff, VwGO, 50. Ed., Stand: 1.4.2019, § 64 Rn. 14.

985 Hufen, Verwaltungsprozessrecht, 11. Aufl.2019, § 12 Rn. 17.

986 Schenke, in: Kopp/Schenke, VwGO, 25. Aufl. 2019, § 64 Rn. 10.

987 Kintz, in: Posser/Wolff, VwGO, 50. Ed., Stand: 1.4.2019, § 64 Rn. 7; Schenke, in: Kopp/ Schenke, VwGO, 25. Aufl. 2019, § 64 Rn. 4 a.E.
} 


\section{b) Notwendige Streitgenossenschaft ( $\$ 64$ VwGO i.V.m. $\S \S 62$ ZP0)}

459 Eine notwendige Streitgenossenschaft liegt nach § 64 VwGO i.V.m. § 62 ZPO vor, wenn eine Sachentscheidung des Gerichts einheitlich ausfallen muss, sodass sich die Rechtskraft des Urteils auch auf die anderen Streitgenossen erstreckt. Hier wird nochmals zwischen unechter (uneigentlicher bzw. prozessualer) und echter (eigentlicher bzw. materiell-rechtlicher) notwendiger Streitgenossenschaft differenziert. Die unechte notwendige Streitgenossenschaft (§ 62 I Alt. 1 ZPO) liegt vor, wenn mehrere Kläger derart miteinander verbunden sind, dass zwar eine gesonderte Klage einzelner möglich ist, andererseits aber, wenn sie gemeinschaftlich klagen, die Sachentscheidung für alle identisch sein muss (z. B. wenn alle Miteigentümer gemeinsam auf die Erteilung einer Baugenehmigung klagen). ${ }^{988}$ Bei der echten notwendigen Streitgenossenschaft (§ 62 I Alt. 2 ZPO) sind nur alle Kläger gemeinsam klagebefugt und Klagen Einzelner nicht möglich (z. B. bei einer Klage von Ehegatten auf Änderung des Familiennamens oder gegen eine Namensänderung). ${ }^{989}$ Der Zwang zur gemeinschaftlichen Klage ergibt sich hier aus dem materiellen Recht ${ }^{990}$ - es kann materiell-rechtlich nur eine einheitliche Entscheidung ergehen.

460 Anmerkung zur Falllösung: Bei der subjektiven Klagehäufung handelt es grundsätzlich nicht um eine „echte“ Zulässigkeitsvoraussetzung, sodass es sich empfiehlt die subjektive Klagehäufung zwischen Zulässigkeit und Begründetheit zu prüfen (empfohlener Prüfungsaufbau: A. Zulässigkeit, B. Subjektive Klagehäufung, C. Begründetheit). Eine Ausnahme hiervon bildet die echte notwendige Streitgenossenschaft: Diese muss bereits im Rahmen der Klagebefugnis angesprochen werden, da nur alle Kläger gemeinsam klagebefugt sind. Auf die subjektive Klagehäufung ist jedoch nur dann einzugehen, sofern der Sachverhalt entsprechende Anhaltspunkte enthält.

\section{Literaturhinweise}

461 Ehlers, Der Beklagte im Verwaltungsprozess, in: Festschrift für Christian-Friedrich Menger zum 70. Geburtstag, 1985, 379; Guckelberger, Die Beiladung im Verwaltungsprozess, JuS 2007, 436; Hufen, Verwaltungsprozessrecht, 11. Aufl. 2019, § 12 (Die Beteiligten und die auf sie bezogenen Zulässigkeitsvoraussetzungen); Pietz-

\footnotetext{
988 Schenke, Verwaltungsprozessrecht, 16. Aufl. 2019, Rn. 474a; Bier, in: Schoch/Schneider/Bier, VwGO, 36. EL Februar 2019, § 64 Rn. 13.

989 Kintz, in: Posser/Wolff, VwGO, 50. Ed., Stand: 1.4.2019, § 64 Rn. 12; Schenke, in: Kopp/ Schenke, VwGO, 25. Aufl. 2019, § 64 Rn. 7; BVerwG, Urt. v. 29.11.1982, Az.: 7 C 34/80 = NJW 1983, 1133 (1133).
}

990 Bier, in: Schoch/Schneider/Bier, VwGO, 36. EL Februar 2019, § 64 Rn. 17. 
ner/Ronellenfitsch, Das Assessorexamen im Öffentlichen Recht, 14. Aufl. 2019, $\S 7$ (Beteiligtenbezogene Sachurteilsvoraussetzungen); Rozek, Verwirrspiel um $\S 78$ VwGO? - Richtiger Klagegegner, passive Prozessführungsbefugnis und Passivlegitimation, JuS 2007, 601; Schenke, Verwaltungsprozessrecht, 16. Aufl. 20197, $\S 12$ (Die Beteiligungsfähigkeit), Rn. 446 ff., § 13 (Prozessfähigkeit, Prozessvertretung, Postulationsfähigkeit), Rn. 477 ff., §15 (Die Prozessführungsbefugnis), Rn. $538 \mathrm{ff}$.

\section{Das zuständige Gericht (Katharina Goldberg)}

Bei der Frage des zuständigen Gerichts liegt häufig kein Schwerpunkt der Klau- 462 surlösung. Dennoch müssen die sachliche und örtliche Zuständigkeit in jeder Klausur zumindest angesprochen und die relevanten Normen benannt werden.

Formulierungsvorschlag Obersatz: „Das Verwaltungsgericht müsste sachlich 463 gem. $\S 45$ VwGO und örtlich gem. $\S 52$ VwGO zuständig sein.“

Hausarbeitswissen: Die Vorschriften über die Zuständigkeit eines Gerichts sind Ausfluss des Gebots 464 des gesetzlichen Richters (Art. 101 GG). Sie dienen dazu, dass sich Parteien ihre Richter nicht aussuchen können, sondern diese zuvor gesetzlich bestimmt wurden. ${ }^{991}$ Grundsätzlich ist nach $\S 45$ VwGO das Verwaltungsgericht das Eingangsgericht (das erste Gericht, das sich mit einer Rechtssache beschäftigt).

\section{Sachliche Zuständigkeit}

Das Verwaltungsgericht ist sachlich in der ersten Instanz für alle Streitigkei- 465 ten zuständig, für die der Verwaltungsrechtsweg gem. §40 VwGO eröffnet ist, § 45 VwG0. ${ }^{992}$

In wenigen geregelten Ausnahmefällen kann auch das Oberverwaltungs- 466 gericht (in Bayern, Baden- Württemberg und Hessen: Verwaltungsgerichtshof, vgl. § 184 VwGO) oder das Bundesverwaltungsgericht das Eingangsgericht sein. Die erstinstanzliche Zuständigkeit der Oberverwaltungsgerichte/Verwaltungsgerichtshöfe richtet sich nach den $\S \S 47$ und 48 VwGO. § 47 VwGO bestimmt die Zuständigkeit für Normenkontrollverfahren (s. hierzu § 7 Rn. 49). § 48 VwGO bestimmt eine konkrete erstinstanzliche Zuständigkeit der Oberverwaltungsgerichte/Verwaltungsgerichtshöfe für bestimmte Bereiche: Streitigkeiten im Bereich der Kernenergieanlagen, Kraftwerke, Abfallverbrennungsanlagen und Flughäfen und

991 Morgenthaler, in: Epping/Hillgruber, GG, 41. Ed., Stand: 15.02.2019, § 101 Rn. 15. 992 Berstermann, in: Posser/Wolf, VwGO, 49. Ed., Stand: 1.10.2018, § 45 Rn. 2. 
bei Planfeststellungsverfahren im Energiewirtschaftsbereich, bei Windenergieanlagen auf See, Bahnstrecken, Bundesfernstraßen, Bundeswasserstraßen und im Küsten- und Hochwasserschutz (§ 48 I Nr. 1-10 VWGO) sowie für Vereinsverbote (§ 48 II VwGO).

467 Das Bundesverwaltungsgericht ist in erster Instanz zuständig in den in $\S 50$ VwGO aufgezählten Fällen: bei öffentlich-rechtlichen Streitigkeiten nichtverfassungsrechtlicher Art zwischen dem Bund und den Ländern oder zwischen verschiedenen Ländern, bei bestimmten Vereinsverboten, bei bestimmten Abschiebeanordnungen, bei Bundesnachrichtendienst-Angelegenheiten, in bestimmten Fällen des Abgeordnetengesetzes und in sämtlichen Streitigkeiten über bestimmte Planfeststellungs- und Plangenehmigungsverfahren (§50 I Nr. 1-6 VwGO).

Wenn sich das angerufene Verwaltungsgericht für örtlich oder sachlich unzuständig hält, muss es die Sache von Amts wegen gem. § 83 VwGO an das zuständige Gericht verweisen. Dies geschieht entsprechend der §§ 17a, 17b GVG (s. dazu bereits $\S 1$ Rn. 49, 163). ${ }^{993}$

469 Examenswissen: Die instanzielle Zuständigkeit regelt, ob ein Gericht im Instanzenzug als Berufungs-, Revisions- oder Beschwerdegericht zuständig ist. So sind die Oberverwaltungsgerichte/ Verwaltungsgerichtshöfe zuständig für Berufungen gegen Urteile und Beschwerden gegen andere Entscheidungen des Verwaltungsgerichts (§ $46 \mathrm{Nr}$. 1 und 2 VwGO) und das Bundesverwaltungsgericht gem. § 49 VwGO für Revisionen gegen Entscheidungen der OVG/VerwGH (§132 VwGO) oder Sprungrevisionen bzw. Revisionen bei Ausschluss der Berufung (§§ 134, 135 VwGO). In der Klausur wird dies in den seltensten Fällen Relevanz haben.

470 Hausarbeitswissen: In einigen Fällen kann es dazu kommen, dass die gleiche Rechtsfrage von unterschiedlichen Bundesgerichten (BGH, BFH, BVerwG, BSG, BAG) beantwortet werden muss. Dies kommt z.B. im Steuerrecht gelegentlich vor, wenn ein Sachverhalt vom BGH aus gesellschaftsrechtlicher Perspektive und dann vom BFH aus steuerrechtlicher Perspektive entschieden wird. Um hier eine einheitliche Rechtsprechung zu gewährleisten besteht die Möglichkeit, dass das Bundesgericht, das einen Fall derzeit verhandelt und eine Entscheidung in einer Sache anstrebt, die entgegen einer bereits ergangenen Entscheidung eines anderen Bundesgerichts lauten würde, vor seiner Entscheidung den Gemeinsamen Senat der obersten Gerichtshöfe des Bundes anruft. Dieser trifft in der speziellen Rechtsfrage eine Entscheidung, damit diese dann in der Zukunft einheitlich gehandhabt werden kann. Der Gemeinsame Senat der obersten Gerichtshöfe des Bundes kann jedoch nicht von einem Kläger selbst angerufen werden.

471 Hausarbeitswissen: Die Arbeitsweise der Verwaltungsgerichte wird in einem sog. Geschäftsverteilungsplan geregelt. Dieser legt fest, welcher Richter über welche Rechtssachen entscheidet. Mit dem Geschäftsverteilungsplan wird dem Gebot des gesetzlichen Richters (Art. 101 GG) nachge-

993 Weitergehend hierzu Schenke, Verwaltungsprozessrecht, 16. Aufl. 2019, Rn. 444; Hufen, Verwaltungsprozessrecht, 11. Aufl. 2019, Rn. 87.

Katharina Goldberg 
kommen: Dadurch, dass bereits vor Anhängigkeit einer Rechtssache diese einem bestimmten Richter zugeordnet ist kann sich weder dieser seine Fälle noch der Kläger sich seinen Richter aussuchen.

\section{2. Örtliche Zuständigkeit}

Die örtliche Zuständigkeit richtet sich bei allen Klagearten nach $\$ \mathbf{5 2}$ VwGO. 472

Sie muss bestimmt werden, wenn verschiedene Gerichte sachlich zuständig sind. In den meisten Klausuren wird die örtliche Zuständigkeit durch den Klausursteller vorgegeben. Wenn dies nicht der Fall ist müssen die einzelnen Nummern des § 52 VwGO gründlich gelesen werden. Sie geben eine Reihenfolge vor, nach der die örtliche Zuständigkeit bestimmt werden muss.

Bei Anfechtungsklagen gilt zunächst $§ 52$ Nr. 1 VwGO, nach dem bei Strei- 473 tigkeiten, die sich auf unbewegliches Vermögen oder ein ortsgebundenes Recht oder Rechtsverhältnis beziehen nur das Verwaltungsgericht örtlich zuständig ist, in dessen Bezirk das Vermögen oder der Ort liegt.

Weiterhin ist gem. \$ $\mathbf{5 2} \mathbf{~ N r . ~} \mathbf{4}$ VwGO das Gericht zuständig, in dem der Kläger seinen dienstlichen Wohnsitz bzw. in Ermangelung dessen seinen Wohnsitz hat, wenn es sich um Anfechtungsklagen aus dem Beamten-, Richter-, Wehrpflicht-, Wehrdienst-, oder Zivildienstverhältnis handelt.

§ 52 Nr. 2 VwGO enthält dann eine besondere örtliche Zuständigkeit für Anfechtungsklagen gegen Bundesbehörden, bundesunmittelbare Körperschaften, Stiftungen des öffentlichen Rechts, für Streitigkeiten nach dem Asylgesetz und für Klagen gegen den Bund in Gebieten, die in die Zuständigkeit der diplomatischen und konsularischen Auslandsvertretungen fallen.

Nach § 52 Nr. 3 VwGO ist dann bei allen anderen Anfechtungsklagen das Verwaltungsgericht örtlich zuständig, in dessen Bezirk der Verwaltungsakt erlassen wurde.

Als Auffangregelung greift der $\$ \mathbf{5 2}$ Nr. $\mathbf{5}$ VwGO für alle anderen Fälle, in denen das Verwaltungsgericht zuständig ist, in dessen Bezirk der Beklagte seinen Sitz, Wohnsitz oder in Ermangelung dessen seinen Aufenthalt hat bzw. seinen letzten Wohnsitz oder Aufenthalt hatte. §52 Nr. 5 VwGO hat bei der Anfechtungsklage jedoch keinen Anwendungsbereich, da $\S 52$ Nr. 3 bereits alle möglichen Konstellationen auffängt.

In der Klausur ist die Bestimmung der örtlichen Zuständigkeit des Gerichts in 474 den Stadtstaaten Hamburg, Berlin und Bremen einfach, da sie jeweils nur ein Verwaltungsgericht haben. 


\section{Literaturhinweise}

475 Hufen, Verwaltungsprozessrecht, 11. Aufl. 2019, Rn. 77-87; Schenke, Verwaltungsprozessrecht, 16. Aufl. 2019, Rn. 437-437; Würtenberger/Heckmann, Verwaltungsprozessrecht, 4. Aufl. 2018, Rn. 255-262

\section{Das Rechtsschutzbedürfnis (Dana-Sophia Valentiner)}

476 Die Inanspruchnahme gerichtlichen Rechtsschutzes im Wege der Anfechtungsklage setzt voraus, dass die rechtsschutzsuchende Person ein von der Rechtsordnung anzuerkennendes Interesse hat. Dieses Interesse wird als allgemeines Rechtsschutzbedürfnis bezeichnet.

\section{Das Rechtsschutzbedürfnis als allgemeine Sachentscheidungsvoraussetzung}

477 Wer gerichtlichen Rechtsschutz begehrt, muss ein berechtigtes Interesse an der avisierten Entscheidung des Gerichts haben, also des Rechtsschutzes bedürfen. Die Sachentscheidungsvoraussetzung des Rechtsschutzbedürfnisses, auch als Rechtsschutzinteresse bezeichnet, sichert diesen Grundsatz für alle Verfahrensarten verwaltungsprozessual ab. ${ }^{994}$

478 Das Rechtsschutzbedürfnis wird in der VwGO an keiner Stelle ausdrücklich genannt. Lediglich für die Feststellungklage und die Fortsetzungsfeststellungsklage verlangen $\S \S 43,113$ I 4 VwGO das Vorliegen eines „berechtigten Interesses“, das als besonderes Rechtsschutzbedürfnis qualifiziert wird.

\section{a) Herleitung}

479 Dogmatisch hergeleitet wird das allgemeine Rechtsschutzbedürfnis aus dem allgemeinen Rechtsgedanken ${ }^{995}$, der in $\S \S 43,113$ I 4 VwGO zum Ausdruck kommt, aus dem Grundsatz der Prozessökonomie ${ }^{996}$, dem für die Gerichte geltenden Grundsatz der Effizienz staatlichen Handelns ${ }^{997}$ sowie dem Gebot

994 Vgl. BVerfG, Beschl. v. 19.10.1982, Az.: 1 BvL 34/80, 1 BvL 55/80 = BVerfGE 61, 126 (135); BVerfG, Beschl. v. 14.12.2004, Az.: 2 BvR 1451/04 = NJW 2005, 1855 (1856).

995 BVerwG, Urt. v. 17.1.1989, Az.: 9 C 44/87 = BVerwGE 81, 164 (165f.).

996 Mann/Wahrendorf, Verwaltungsprozessrecht, 4. Aufl. 2015, § 13 Rn. 163.

997 BVerfG, Beschl.v. 14.12.2004, Az.: 2 BvR 1451/04 = NJW 2005, 1855 (1856); BVerwG, Beschl.v. 11.02.2019, Az.: 4 B 28/18, juris Rn. 7.

Katharina Goldberg/Dana-Sophia Valentiner 
von Treu und Glauben ${ }^{998}$, welches einen Missbrauch prozessualer Rechte verbietet. $^{999}$

Hausarbeitswissen: Das allgemeine Rechtsschutzbedürfnis wird in der Literatur zutreffend als 480 verfassungsimmanente Schranke der Rechtsschutzgarantie beschrieben. ${ }^{1000}$ Es bewegt sich in einer Spannungslage zwischen den vorgenannten Grundsätzen und dem verfassungsrechtlich garantierten Anspruch auf Rechtsschutz aus Art. 19 IV GG. Die Sachentscheidungsvoraussetzung des allgemeinen Rechtsschutzbedürfnisses begrenzt den allgemeinen Justizgewährleistungsanspruch. Nur wer ein berechtigtes Interesse mit der angestrengten gerichtlichen Entscheidung verfolgt, hat einen Anspruch auf die sachliche Entscheidung. Fehlt das Rechtsschutzbedürfnis, ist der Antrag bzw. die Klage unzulässig und wird auf prozessualer Ebene abgewiesen. Vereinzelt wird die Sachentscheidungsvoraussetzung des allgemeinen Rechtsschutzbedürfnisses dafür kritisiert, dass sie auf diese Weise Prozessentscheidungen hervorbringe, sachliche Entscheidungen sperre und überdies ein „Einfallstor außerrechtlicher Wertungen“ öffne. ${ }^{1001}$

\section{b) Prüfungsanforderungen und -umfang}

Examenswissen: Das Bundesverfassungsgericht hat festgestellt, dass es mit dem Gebot des effektiven Rechtsschutzes aus Art. 19 IV 1 GG vereinbar sei, die Gewährung gerichtlichen Rechtsschutzes von einem Rechtsschutzinteresse abhängig zu machen. ${ }^{1002}$ Um die Spannungslage zwischen allgemeinen Rechtsschutzbedürfnis und Rechtsschutzgarantie aus Art. 19 IV GG in verhältnismäßiger Weise aufzulösen, werden geringe Anforderungen an die Prüfung des Vorliegens des allgemeinen Rechtsschutzbedürfnisses gestellt. Das allgemeine Rechtsschutzbedürfnis liegt vor, „solange der Rechtsschutzsuchende gegenwärtig betroffen ist und mit seinem Rechtsmittel ein konkretes praktisches Ziel erreichen kann “. ${ }^{1003}$ Nur ausnahmsweise fehlt das allgemeine Rechtsschutzbedürfnis.

Der Grundsatz effektiven Rechtsschutzes verlangt, dass die rechtschutzsuchende 482 Person ihr Rechtsschutzbedürfnis grundsätzlich nicht positiv nachweisen muss. Deshalb formuliert die für die Klausurpraxis entwickelte Merkformel „K-E-S-E“ negative Voraussetzungen zur Prüfung des allgemeinen Rechtsschutzbedürfnisses: Das Rechtsschutzbedürfnis fehlt nur dann, wenn das Rechtsschutzziel auf

998 Würtenberger/Heckmann, Verwaltungsprozessrecht, 4. Aufl. 2018, § 20 Rn. 305.

999 Grundlegend zu dogmatischer Herleitung und Geltungsgrund des Rechtsschutzbedürfnisses: Stein, Die Sachentscheidungsvoraussetzung des allgemeinen Rechtsschutzbedürfnisses im Verwaltungsprozeß, 2000, $34 \mathrm{ff}$.; aus der älteren Literatur Stephan, Das Rechtsschutzbedürfnis, $1967,19 \mathrm{ff}$.

1000 Würtenberger/Heckmann, Verwaltungsprozessrecht, 4. Aufl. 2018, § 20 Rn. 305.

1001 Vgl. aus zivilprozessualer Perspektive: Schumann, in: Festschrift Fasching, 1988, 439 (441 f., 445).

1002 Vgl. BVerfG, Beschl. v. 5.12.2001, Az.: 2 BvR 527/99, 2 BvR 1337, 1777/00 = BVerfGE 104, 220 (232).

1003 BVerfG, Beschl.v. 5.12. 2001, Az.: 2 BvR 527/99, 2 BvR 1337, 1777/00 = BVerfGE 104, 220 (232). 
einem kostengünstigeren, einfacheren, schnelleren oder effektiveren Weg verfolgt werden kann. ${ }^{1004}$

Bei Gestaltungs- und Leistungsklagen folgt das allgemeine Rechtsschutzbedürfnis bereits aus dem Umstand, dass die klagende bzw. antragstellende Person einen auf Leistung an sich selbst gerichteten, bislang nicht erfüllten Anspruch geltend macht. ${ }^{1005}$ Das Bundesverwaltungsgericht postulierte insoweit den Grundsatz, dass die Rechtsordnung immer dann, wenn sie ein materielles Recht gewährt, in aller Regel auch das Interesse desjenigen, der sich als der Inhaber dieses Rechtes sieht, am gerichtlichen Schutze dieses Rechtes anerkennt. ${ }^{1006}$

Für Feststellungsklagen wird ein besonderes (auch: qualifiziertes) Rechtsschutzbedürfnis verlangt. § 43 I VwGO setzt für die Feststellungsklage ein „,berechtigtes Interesse an der baldigen Feststellung“, § 113 I 4 VwGO für die Fortsetzungsfeststellungsklage ein „berechtigtes Interesse“ an der Feststellung der Rechtswidrigkeit eines zurückgenommenen oder anders erledigten Verwaltungsakts voraus. Anders als bei Leistungs- und Gestaltungsklagen, bei denen grundsätzlich davon ausgegangen werden darf, dass die Person, die sich eines materiellen Rechts berühmt, auch ein berechtigtes Interesse auf gerichtlichen Schutz dieses Rechts hat, ist das besondere Rechtsschutzbedürfnis bei Feststellungsklagen stets zu begründen (s. hierzu § 4 Rn. 51 sowie $\S 6$ Rn. 96).

Abzugrenzen ist das allgemeine Rechtsschutzbedürfnis von der Klage- bzw. Antragsbefugnis, (analog) § 42 II VwGO. Die Klage- bzw. Antragsbefugnis verlangt als Ausdruck des subjektiven Rechtsschutzes die Geltendmachung einer Rechtsverletzung, während das allgemeine Rechtsschutzbedürfnis das Vorliegen schutzwürdiger Interessen beurteilt. ${ }^{1007}$ Das allgemeine Rechtsschutzbedürfnis zielt im Unterschied zu der Klage- bzw. Antragsbefugnis darauf zu prüfen, ob die Rechtsverfolgung des begehrten gerichtlichen Rechtsschutzes bedarf. ${ }^{1008}$

In der Klausur ist darauf zu achten, bei der Sachentscheidungsvoraussetzung des allgemeinen Rechtsschutzbedürfnisses das Vorliegen eines berechtigten Interesses an der Rechtsverfolgung zu prüfen, nicht jedoch das Bestehen eines materiellen Anspruchs, welches einschließlich der Sachlegitimation in der Begründetheit der Klage bzw. des Antrags geprüft wird.

Das allgemeine Rechtsschutzbedürfnis ist in der Klausur in unproblematischen Fällen nicht anzusprechen, weil es - jedenfalls bei Leistungs- und Gestal-

1004 Gersdorf, Verwaltungsprozessrecht, 6. Aufl. 2019, Rn. 49; Mann/Wahrendorf, Verwaltungsprozessrecht, 4. Aufl. 2015, § 13 Rn. 164.

1005 BVerwG, Urt. v. 17.1.1989, Az.: 9 C 44/87 = BVerwGE 81, 164 (165f.).

1006 BVerwG, Urt. v. 17.1.1989, Az.: 9 C 44/87 = BVerwGE 81, 164 (165f.).

1007 Ehlers, in: Schoch/Schneider/Bier, VwGO, 36. EL Februar 2019, Vorbem. § 40 Rn. 77.

1008 Brüning, JuS 2004, 882 (884).

Dana-Sophia Valentiner 
tungsklagen - regelmäßig vorliegt. Eine ausführlichere Prüfung ist nur in atypischen Konstellationen erforderlich, wenn der Sachverhalt besondere Umstände schildert, die einen Ausnahmetatbestand nahelegen. ${ }^{1009}$

\section{c) Relevante Fallgruppen}

Es lassen sich verschiedene Konstellationen unterscheiden, in denen das allge- 488 meine Rechtsschutzbedürfnis nicht vorliegt.

\section{aa) Rechtsschutzziel kann auf einfachere Art und Weise erreicht werden}

Das Rechtsschutzbedürfnis fehlt, wenn die rechtsschutzsuchende Person ihr Ziel kostengünstiger, einfacher, schneller oder effektiver erreichen kann.

Beispiel: Das Rechtsschutzziel kann außergerichtlich verfolgt werden, z.B. durch eine Antragstellung gegenüber der Verwaltung.

Eine vorherige Antragstellung ist dem Bürger aber nur zumutbar, wenn sie pro490 zessrechtlich vorgesehen ist. ${ }^{1010}$

Das Rechtsschutzbedürfnis eines Verwaltungsträgers fehlt insbesondere, 491 wenn bereits ein vollstreckbarer Titel in Form eines Verwaltungsakts besteht. ${ }^{1011}$

Examenswissen: Kann eine Behörde einen Verwaltungsakt erlassen, hat dies aber noch nicht getan, nimmt die Rechtsprechung teilweise eine Wahlmöglichkeit der Behörde zwischen dem Erlass eines Verwaltungsakts und der Erhebung einer allgemeinen Leistungsklage an. ${ }^{1012}$ Für diese Möglichkeit spricht der Grundsatz der Verfahrenseffizienz, insbesondere wenn bei Erlass eines Verwaltungsakts ohnehin mit einer gerichtlichen Auseinandersetzung des Rechtsstreits zu rechnen ist. Dagegen wird die Aufgabenverteilung zwischen Judikative und Exekutive ins Feld geführt. ${ }^{1013}$ Die Verwaltung dürfe erst dann gerichtlichen Rechtsschutz in Anspruch nehmen, wenn sie die eigenen Handlungsmöglichkeiten ausgeschöpft hat. ${ }^{1014}$ Außerdem können dem Betroffenen Rechtsschutzmöglichkeiten abgeschnitten werden, die ihm beispielsweise im Widerspruchsverfahren offen stehen würden.

1009 Vgl. Ipsen, Allgemeines Verwaltungsrecht, 11. Aufl. 2019, Rn. 1174.

1010 Ehlers, in: Schoch/Schneider/Bier, VwGO, 36. EL Februar 2019, Vorbem. § 40 Rn. 82.

1011 BVerwG, Urt. v. 12.12.1974, Az.: V C 25.74, juris Rn. 5.

1012 Vgl. BVerwG, Urt. v. 24.11.1966, Az.: II C 27/64 = NJW 1967, 946 (948).

1013 Ehlers, in: Schoch/Schneider/Bier, VwGO, 36. EL Februar 2019, Vorbem. § 40 Rn. 85.

1014 Würtenberger/Heckmann, Verwaltungsprozessrecht, 4. Aufl. 2018, § 20 Rn. 309. 
493 Das Rechtsschutzbedürfnis fehlt außerdem, wenn der rechtsschutzsuchenden Person ein einfacheres gerichtliches Verfahren oder eine rechtschutzintensivere Rechtsschutzform zur Verfügung steht.

Beispiel: Die Klägerin begehrt Aufhebung eines Verwaltungsakts mittels Verpflichtungsklage.

In diesem Fall fehlt das allgemeine Rechtsschutzbedürfnis, weil die Anfechtungsklage als Gestaltungsklage die effektivere Rechtsschutzform darstellt. In der Klausur wird dies in der Regel bereits bei der statthaften Klageart angesprochen.

494 Hausarbeitswissen: Es existieren einige (gesetzliche) Konkurrenzregelungen, die den Fall betreffen, dass das begehrte Rechtsschutzziel mit verschiedenen Verfahren erreicht werden könnte. Solche Verfahrenskonkurrenzregelungen sehen beispielsweise § 43 II 1 VwGO (s. dazu § 6 Rn. 63ff.) und $\S 44 a$ VwGO vor. ${ }^{1015}$ Diese Vorschriften können als gesetzliche Ausprägung eines Unterfalls des allgemeinen Rechtsschutzbedürfnisses verstanden werden. ${ }^{1016}$ In der Literatur wird hingegen auch vertreten, diese Konkurrenzregeln nicht im Rahmen des Rechtsschutzbedürfnisses zu prüfen, weil sie nicht zwingend Ausdruck mangelnden rechtsschutzwürdigen Interesses, sondern einer verfahrenseffizienten Entscheidung des Gesetzgebers seien (s. auch die Ausführungen zur Statthaftigkeit der Leistungsklage $\$ 5$ Rn. 2ff. sowie zur rechtsschützenden Funktion der Subsidiarität der Feststellungsklage $§ 6 \mathrm{Rn}$. 63ff.). ${ }^{1017}$

\section{bb) Rechtsschutz verspricht keinerlei Vorteil für die rechtsschutzsuchende Person}

Das Rechtsschutzbedürfnis fehlt außerdem, wenn das gerichtliche Verfahren keinerlei Vorteile rechtlicher oder tatsächlicher Art mit sich brächte.

Beispiel: Der Kläger begehrt die Verbesserung einer Note, der jedoch keinerlei praktische Bedeutung mehr zukommt. ${ }^{1018}$

Beispiel: Begehrt wird die Festsetzung eines über den gesetzlichen Mindestwert hinausgehenden Gegenstandswertes für eine Verfassungsbeschwerde, die jedoch nicht zur Entscheidung angenommen wurde. ${ }^{1019}$

1015 Schenke, Verwaltungsprozessrecht, 16. Aufl. 2019, Rn. 566.

1016 Hufen, Verwaltungsprozessrecht, 10. Aufl. 2016, § 23 Rn. 20; Mann/Wahrendorf, Verwaltungsprozessrecht, 4. Aufl. 2015, § 13 Rn. 163.

1017 Schenke, Verwaltungsprozessrecht, 16. Aufl. 2019, Rn. 564 f.

1018 Detterbeck, Allgemeines Verwaltungsrecht mit Verwaltungsprozessrecht, 17. Aufl. 2019, Rn. 1349.

1019 BVerfG, Beschl. v. 19.1.2019, Az.: 1 BvR 3165/15, juris Rn. 2. 
Die Rechtsstellung der rechtsschutzsuchenden Person verbessert sich auch dann 496 nicht dergestalt, dass ein Rechtsschutzbedürfnis angenommen werden könnte, wenn die Wiederherstellung der aufschiebenden Wirkung eines bereits vollzogenen Verwaltungsakts verlangt wird. ${ }^{1020}$

Das Rechtsschutzbedürfnis kann auch während des gerichtlichen Verfahrens 497 entfallen.

Beispiel: Die Klägerin begehrt die Erteilung einer Aufenthaltsgenehmigung, die zwischenzeitlich durch die Behörde erteilt wird. ${ }^{1021}$

\section{cc) Rechtsmissbräuchliche Inanspruchnahme des gerichtlichen Verfahrens}

Das Rechtsschutzbedürfnis ist zu verneinen, wenn die Inanspruchnahme des 498 gerichtlichen Rechtsschutzes nicht in Einklang mit der Rechtsordnung steht, insbesondere wenn sie gegen das Gebot von Treu und Glauben verstößt ${ }^{1022}$. Von einem Missbrauch ist auszugehen, wenn das gerichtliche Verfahren ausschließlich angestrengt wird, um die gegnerische Partei oder Dritte zu schädigen, ${ }^{1023}$ wobei nicht zwingenderweise Umstände vorliegen müssen, die im materiellen Recht einen Verstoß gegen das Schikaneverbot aus § 226 BGB bedeuten würden. ${ }^{1024}$

Examenswissen: Zweifel an dem Vorliegen des allgemeinen Rechtsschutzbedürfnisses können sich auch ergeben, wenn ein sogenanntes Sperrgrundstück ausschließlich mit dem Ziel der Bekämpfung einer planerischen Entscheidung erworben wird. Diese Problematik ist regelmäßig bereits bei der Klage- bzw. Antragsbefugnis zu erörtern. ${ }^{1025}$ Der Eigentumsschutz kann in solchen Fällen mit Blick auf die Rechtsschutzgarantie aus Art. 19 IV GG nicht pauschal versagt werden. ${ }^{1026}$ Die fehlende oder nur geringe wirtschaftliche Nutzung des Grundstücks ist vielmehr im Rahmen der materiellen Prüfung zu berücksichtigen.

\section{(1) Verspätete Geltendmachung}

Das Rechtsschutzbedürfnis kann insbesondere entfallen, wenn die verspätete $\mathbf{5 0 0}$ Geltendmachung eines Anspruchs gegen Treu und Glauben verstößt. Das Bundesverfassungsgericht geht von einem fehlenden Rechtsschutzbedürfnis aus,

1020 Ehlers, in: Schoch/Schneider/Bier, VwGO, 36. EL Februar 2019, Vorbem. § 40 Rn. 94. 1021 Mann/Wahrendorf, Verwaltungsprozessrecht, 4. Aufl. 2015, § 13 Rn. 165.

1022 BVerwG, Beschl. v. 11.02.2019, Az.: 4 B 28/18, juris Rn. 7.

1023 Hufen, Verwaltungsprozessrecht, 10. Aufl. 2016, § 23 Rn. 16.

1024 Ehlers, in: Schoch/Schneider/Bier, VwGO, 36. EL Februar 2019, Vorbem. § 40 Rn. 98.

1025 So BVerwG, Urt. v. 27.10.2000, Az.: 4 A 10/99 = NVwZ 2001, 427 (428).

1026 Vgl. BVerwG, Urt. v. 9.7.2008, Az.: 9 A 14/07 = NVwZ 2009, 302 (304). 
wenn die rechtsschutzsuchende Person sich verspätet auf ihr Recht beruft und unter Verhältnissen untätig bleibt, „unter denen vernünftigerweise etwas zur Wahrung des Rechts unternommen zu werden pflegt “.${ }^{1027}$ Das öffentliche Interesse an der Wahrung des Rechtsfriedens könne in derartigen Fällen verlangen, die Anrufung des Gerichts nach langer Zeit untätigen Zuwartens als unzulässig anzusehen. Von einer solchen rechtsmissbräuchlichen verspäteten Antragstellung wird jedoch nur ausnahmsweise ausgegangen.

Beispiel: Der Antragsteller hat mehrere ihm zur Verfügung stehende Zeitpunkte verstreichen lassen, um den von ihm vorgebrachten Wiederaufgreifensgrund überhaupt im behördlichen Verfahren geltend machen zu können. ${ }^{1028}$

\section{(2) Verwirkung}

501 Die rechtsschutzsuchende Person kann ihren Rechtsschutz auch durch ihr vorangegangenes Verhalten verwirkt haben. Von einer prozessualen Verwirkung ist auszugehen, wenn der Klage- bzw. Antragsgegner infolge eines bestimmten Verhaltens der Klägerin bzw. Antragstellerin darauf vertrauen durfte, dass das in Rede stehende Recht nicht mehr geltend gemacht wird, und darauf tatsächlich vertraut hat, sodass ihm durch die verspätete Durchsetzung unzumutbare Nachteile entstehen. ${ }^{1029}$

\section{Das allgemeine Rechtsschutzbedürfnis als Sachentscheidungsvoraussetzung der Anfechtungsklage}

502 Bei der Prüfung der Anfechtungsklage sind regelmäßig keine Ausführungen zum allgemeinen Rechtsschutzbedürfnis erforderlich.

503 Das allgemeine Rechtsschutzbedürfnis fehlt, wenn die Anfechtungsklage keinerlei Vorteil für die rechtsschutzsuchende Person verspricht. Deshalb liegt für die mit der Anfechtungsklage begehrte Aufhebung eines Verwaltungsakts kein Rechtsschutzbedürfnis vor, wenn sich der Verwaltungsakt ex nunc erledigt hat und mit der Aufhebung für den Zeitraum vor Eintritt der Erledigung keinerlei Vorteil verbunden wäre. ${ }^{1030}$ Der Kläger wäre in diesem Fall vielmehr auf die Fortsetzungsfeststellungsklage zu verweisen (s. § 4 Rn. 9 ff.).

1027 BVerfG, Beschl. v. 14.12.2004, Az.: 2 BvR 1451/04 = NJW 2005, 1855 (1856); vgl. BVerfG, Beschl. v. 16.1.1972, Az.: 2 BvR 255/67 = BVerfGE 32, 305 (308f.).

1028 BVerfG, Beschl. v. 17.1.2019, Az.: 2 BvQ 1/19, juris Rn. 31.

1029 Ehlers, in: Schoch/Schneider/Bier, VwGO, 36. EL Februar 2019, Vorbem. § 40 Rn. 103.

1030 Schenke, Verwaltungsprozessrecht, 16. Aufl. 2019, Rn. 588.

Dana-Sophia Valentiner 
Examenswissen: Umstritten ist das Vorliegen des Rechtsschutzbedürfnisses bei der isolierten

Anfechtungsklage, die gegen einen Versagungsbescheid gerichtet wird, ohne zugleich die Verpflichtung zum Erlass des begünstigenden Verwaltungsakts zu begehren. In der Rechtsprechung wurde für die Zulässigkeit der isolierten Anfechtungsklage jedenfalls gegen den Bund, die Länder oder andere öffentlich-rechtliche Körperschaften angeführt, dass es sich um Beklagte handele, von denen angesichts ihrer verfassungsmäßig verankerten Bindung an Recht und Gesetz die Respektierung von gerichtlichen Entscheidungen auch ohne dahinterstehenden Vollstreckungsdruck erwarten werden dürfe. ${ }^{1031}$ Gegen das Vorliegen des Rechtsschutzbedürfnisses spricht, dass die Verpflichtungsklage weitergehenden Rechtsschutz gegen die Ablehnung eines begehrten Verwaltungsakts bietet. ${ }^{1032}$ In der Literatur wird diese Frage bereits bei der statthaften Klageart unter dem Aspekt des Spezialitätsverhältnisses der Versagungsgegenklage gegenüber der isolierten Anfechtungsklage erörtert. ${ }^{1033}$

\section{Literaturhinweise}

Ehlers, in: Schoch/Schneider/Bier, VwGO, 36. EL Februar 2019, Vorbem. § 40; 505 Schenke, Verwaltungsprozessrecht, 16. Aufl. 2019, § 16: Das Rechtsschutzbedürfnis; Würtenberger/Heckmann, Verwaltungsprozessrecht, 4. Aufl. 2018, § 20: Allgemeines Rechtsschutzbedürfnis

\section{Begründetheit}

Ist die Anfechtungsklage zulässig, ist in einem zweiten Schritt zu prüfen, ob sie $\mathbf{5 0 6}$ auch begründet ist.

\section{Die Struktur der Begründetheitsprüfung (Dominik Marek Kowalczyk)}

Im Rahmen der Begründetheitsprüfung der Anfechtungsklage stellt sich zu aller $\mathbf{5 0 7}$ erst die Frage nach der richtigen Einstiegsnorm. Die Anfechtungsklage war im Rahmen der Zulässigkeit nach § 42 I 1 Alt. 1 VwGO statthaft, soweit die Aufhebung eines Verwaltungsakts begehrt wird (s. Rn. 10). Einschlägig ist daher die Norm, welche dem Gericht aufträgt, den Verwaltungsakt aufzuheben. So stößt man unweigerlich auf § 113 I 1 VwG0, der die Aufhebung des Verwaltungsakts anordnet („hebt das Gericht den Verwaltungsakt [...] auf“). Die Norm für die Begründetheitsprüfung der Anfechtungsklage - wie auch sonst für alle anderen

1031 BVerwG, Urt. v. 30.4.1971, Az.: VI C 35/68 = NJW 1971, 2004 (2005).

1032 Vgl. BVerwG, Urt. v. 21.11.1986, Az.: 8 C 127/84 = NVwZ 1987, 330.

1033 Vgl. Schaks/Friedrich, JuS 2018, 860 (867).

Dana-Sophia Valentiner/Dominik Marek Kowalczyk 
verwaltungsgerichtlichen Klagen - muss also in der Rechtsfolge das Begehren des Klägers (vgl. §§ 86 III, 88 VwGO) mitumfassen.

$\S 113$ I 1 VwGO formuliert dabei die Tatbestandsvoraussetzungen, bei deren Vorliegen die Anfechtungsklage „begründet“ ist. Angesprochen wird damit die materielle Rechtslage und damit die Frage, ob das vorgebrachte Recht auch inhaltlich besteht. Dies begründet abermals den Prüfungsstandort im Rahmen der Begründetheit und nicht der Zulässigkeit. ${ }^{1034}$

$\S 113$ I 1 VwGO normiert, dass das Gericht den Verwaltungsakt (und den etwaigen Widerspruchsbescheid) aufhebt, soweit der Verwaltungsakt rechtswidrig und der Kläger dadurch in seinen Rechten verletzt ist. ${ }^{1035}$

Im Rahmen der Anfechtungsklage ist somit unter dem Prüfungspunkt „Begründetheit" der nachfolgende Obersatz zu bilden. ${ }^{1036}$

Formulierungsvorschlag: „Die Anfechtungsklage ist nach § 113 I 1 VwGO begründet, soweit ... (der angefochtene Verwaltungsakt) rechtswidrig und ... (der Kläger) dadurch in seinen Rechten verletzt ist. “1037

\section{Dieser Obersatz legt einen zweistufigen Prüfungsaufbau nahe:}

I. Prüfung der Rechtswidrigkeit des streitgegenständlichen Verwaltungsakts

II. Prüfung der Verletzung subjektiver Rechte des Klägers durch den rechtswidrigen Verwaltungsakt

509 Sofern man - anders als hier vertreten - der Ansicht ist, dass § 78 VwGO als Passivlegitimation im Rahmen der Begründetheit und nicht als passive Prozessführungsbefugnis im Rahmen der Zulässigkeit zu prüfen ist (s. zum Streit Rn. 416f.) wäre hingegen der nachfolgende Obersatz zu bilden.

Formulierungsvorschlag: „Die Anfechtungsklage ist nach \&113 I 1 VwGO begründet, soweit sie sich gegen ... (den Klagegegner) als richtigen Beklagten richtet,

1034 Dabei ist in Erinnerung zu rufen, worum es bei einer Klage eigentlich geht: Sie dient der Durchsetzung eines Rechts. Die Zulässigkeit beantwortet dabei die Frage, ob und in welcher Form sich das Gericht mit dem klägerischen Begehren inhaltlich auseinandersetzen wird, betrifft damit das „Wie“ der Rechtsdurchsetzung. Die Begründetheit betrifft hingegen die materielle Rechtslage und fragt danach, „ob“ dieses bestimmte Recht auch inhaltlich besteht.

1035 Da eine Rechtsverletzung immer Rechtswidrigkeit voraussetzt, birgt sich in diesem Satz beim bloßen Lesen die Gefahr einer tautologischen Wiederholung. Warum dem nicht so ist, zeigt Ehlers, Jura 2004, 176f. wunderbar auf.

1036 Zur Begründetheit der Anfechtungsklage anschaulich Graf von Kielmansegg, JuS 2013, 312ff. Sehr empfehlenswert ist der Beitrag von Gödde, DVP 2016, 317 ff. zu abstrakten Formulierungshilfen und Erläuterungen bei der gutachterlichen Prüfung einer Anfechtungsklage.

1037 Ungenau ist es hingegen im Obersatz abstrakt und ohne Subsumtion von Verwaltungsakt und Kläger zu sprechen. 
... (der angefochtene Verwaltungsakt) rechtswidrig und ... (der Kläger) dadurch in seinen Rechten verletzt ist.“

Dieser Obersatz legt dann aber - anders als hier vertreten - einen dreistufigen Prüfungsaufbau nahe:

I. Prüfung der Passivlegitimation,

II. Prüfung der Rechtswidrigkeit des Verwaltungsakts und

III. Prüfung der Verletzung subjektiver Rechte des Klägers.

Examenswissen: Anhänger der überzeugenden Ansicht, die § 78 VwGO in der Zulässigkeit als passive Prozessführungsbefugnis unter dem Prüfungspunkt des „richtigen Beklagten“ prüfen (s. Rn. 409 ff.), sprechen die Passivlegitimation teilweise noch zusätzlich am Anfang der Begründetheit unter „I. Passivlegitimation“ an (so vertreten in $\S 5$ Rn. 52 f. und $\S 8$ Rn. 52). Die Norm des $\S 78$ VwGO darf dabei allerdings nicht mehr fallen, da sie zur Bestimmung der passiven Prozessführungsbefugnis verwendet und somit „verbraucht“ worden ist. § 78 VwGO regelt entweder die passive Prozessführungsbefugnis in der Zulässigkeit oder die Passivlegitimation in der Begründetheit. Denkbar ist daher lediglich die bloße Feststellung, dass der Beklagte auch passivlegitimiert ist, ohne dabei eine Norm zu nennen. Da passive Prozessführungsbefugnis und Passivlegitimation die gleichen Voraussetzungen mitbringen (s. Rn. 417), decken sie sich inhaltlich in der Regel immer. Aus diesem Grund kann in dieser Konstellation aber auch auf die Feststellung der Passivlegitimation verzichtet werden. Sofern die Feststellung dennoch getroffen werden soll, könnte in der Begründetheit unter „I. Passivlegitimation“ wie folgt formuliert werden: „Weil die Passivlegitimation der passiven Prozessführungsbefugnis aus $\S 78 \mathrm{VwGO}$ folgt, ist (der Beklagte) auch passivlegitimiert.“

Teilweise wird im Obersatz anstelle des „soweit“ ein „wenn“ verwendet. ${ }^{1038}$ Zwar 511 sind die Formulierungen vergleichbar, bedeuten im Ergebnis aber nicht dasselbe. Der entscheidende Unterschied besteht darin, dass „wenn“ ein EntwederOder, also ein Ganz-oder-gar-Nicht bezeichnet, wohingegen ein „soweit“ Teillösungen zulässt. Eine Anfechtungsklage kann aber auch nur teilweise begründet sein: Ein Beispiel hierfür bildet die (isolierte) Anfechtbarkeit von Nebenbestimmungen nach $\S 36$ VwVfG (s. dazu Rn. 259). Eine Formulierung mit „wenn“ ist deshalb ungenau. ${ }^{1039}$ Letztendlich gibt es auch keinen ersichtlichen Grund von dem Wortlaut des § 113 I 1 VwGO abzuweichen, der ganz eindeutig ,soweit“ formuliert. Damit ist im Ergebnis eine „soweit“-Formulierung vorzugswürdig. ${ }^{1040}$

1038 So beispielsweise Gersdorf, Verwaltungsprozessrecht, 6. Aufl. 2019, Rn. 51.

1039 So auch Gödde, DVP 2016, 317 Fn. 4.

1040 Auch wenn beide Formulierungen vertretbar sind, so muss dabei auf eine einheitliche Handhabung geachtet werden. Hier lassen Lösungsvorschläge oftmals eine durchgehende stringente Formulierungsweise vermissen.

Dominik Marek Kowalczyk 


\section{Einführung in die Struktur der Begründetheitsprüfung von Anfechtungsklagen}

512 Nachdem mit Hilfe des Obersatzes der Rahmen der Begründetheitsprüfung von Anfechtungsklagen unter Zugrundelegung des § 113 I 1 VwGO gesetzt worden ist, gilt es nun die einzelnen Tatbestandsmerkmale herauszuarbeiten. Der Tatbestand des § 113 I 1 VwGO normiert hier, dass ,der Verwaltungsakt rechtswidrig und der Kläger dadurch in seinen Rechten verletzt ist.“ Der zweite Halbsatz „hebt das Gericht den Verwaltungsakt und den etwaigen Widerspruchsbescheid auf" normiert nicht den Tatbestand, sondern die Rechtsfolge der Norm. ${ }^{1041}$

513 Prüfungsaufbau: Begründetheit einer Anfechtungsklage nach § 113 I 1 VwG0

I. Passivlegitimation (falls nicht bereits im Rahmen der Zulässigkeit geprüft)

II. Rechtswidrigkeit des angefochtenen Verwaltungsakts

III. Verletzung subjektiver Rechte des Klägers

514 Als erstes Tatbestandsmerkmal wird - als Herzstück einer jeden Begründetheitsprüfung - die Rechtswidrigkeit des Verwaltungsakts (,der Verwaltungsakt rechtswidrig“) genannt. Es muss also im ersten Schritt geprüft werden, ob der angefochtene Verwaltungsakt rechtswidrig ist. Dies erfolgt dadurch, dass man nach der Rechtmäßigkeit des Verwaltungsakts fragt (s. Rn. $518 \mathrm{ff}$.).

Als zweites Tatbestandsmerkmal wird die Verletzung subjektiver Rechte des Klägers durch die Rechtswidrigkeit des Verwaltungsakts verlangt (,der Kläger dadurch in seinen Rechten verletzt ist“). Es muss also in einem zweiten Schritt untersucht werden, ob der Kläger durch den rechtswidrigen Verwaltungsakt in seinen subjektiven Rechten verletzt ist (s. Rn. $536 \mathrm{ff}$. und Rn. $828 \mathrm{ff}$.).

Anders als es die getrennte Prüfung der beiden Tatbestandsvoraussetzungen (Rechtswidrigkeit des Verwaltungsakts und Verletzung subjektiver Rechte) vermuten lässt, stehen die beiden Prüfungspunkte nicht beziehungslos nebeneinander:

Es besteht kein Anspruch des Klägers, dass der von ihm angefochtene Verwaltungsakt anhand des gesamten objektiven Rechts überprüft wird. Ein Anspruch auf allgemeine Rechtmäßigkeitskontrolle scheidet aus. ${ }^{1042}$ Vielmehr kann er eine gerichtliche Überprüfung nur insoweit verlangen, als es um die Verletzung seiner eigenen subjektiven Rechte geht. Ob diese als dem Kläger subjektiv zugehörig gelten, wird dabei aber bereits regelmäßig beim Prüfungspunkt der

1041 Bzgl. detaillierter Aufbaufragen der Begründetheitsprüfung vertiefend Ehlers, Jura 2004, 176 (177f.).

1042 Gersdorf, Verwaltungsprozessrecht, 6. Aufl. 2019, Rn. 51.

Dominik Marek Kowalczyk 
Klagebefugnis (§ 42 II VwGO) im Rahmen der Zulässigkeit festgestellt. Deshalb prüft das Verwaltungsgericht den Verwaltungsakt im Rahmen der Begründetheit unter dem Prüfungspunkt „Rechtswidrigkeit des angefochtenen Verwaltungsakts“ nur anhand solcher Vorschriften, die dem Kläger auch subjektive Rechte zugestehen. Andere Rechte werden der Rechtmäßigkeitsprüfung nicht zugrunde gelegt. ${ }^{1043}$ Der Prüfungspunkt der Verletzung subjektiver Rechte hat letztendlich nur noch die Aufgabe, die in der Klagebefugnis im Rahmen der Zulässigkeit aufgestellte These durch eine tatsächliche Verletzung subjektiver Rechte zu bestätigen. Die Rechtswidrigkeit des angefochtenen Verwaltungsakts indiziert dabei regelmäßig die tatsächliche Verletzung subjektiver Rechte des Klägers (s. Rn. 537).

Schließlich ist in § 113 I 1 VwGO auf die Formulierung „dadurch“ zu achten. Die Rechtsverletzung muss gerade auf der Rechtswidrigkeit beruhen (sog. Rechtswidrigkeitszusammenhang). ${ }^{1044}$

Aufbauhinweis: Der Aufbau der Begründetheit einer Anfechtungsklage ist $\mathbf{5 1 7}$ in seinen Grundzügen fest etabliert. Streit besteht aber darüber, an welcher Stelle $\S 46$ VwVfG im Rahmen der Falllösung zu prüfen ist. ${ }^{1045}$ Vertretbar ist es, dies innerhalb der formellen Rechtmäßigkeit, ${ }^{1046}$ der Verletzung subjektiver Rechte des Klägers ${ }^{1047}$ oder auch als eigenständigen dritten Prüfungspunkt „kein Aus-

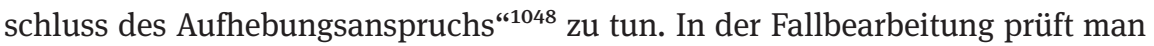
$\S 46$ VwVfG am besten im Rahmen der formellen Rechtmäßigkeit, ohne auf die Frage des Standorts einzugehen. Dies hat den klausurtaktischen Vorteil, dass die Prüfung nicht auseinandergerissen wird. ${ }^{1049}$

1043 Die Klagebefugnis fungiert hier als eine Art „Türsteher“, die nur dem Kläger als subjektiv zugehörige Rechte zur Rechtmäßigkeitsprüfung des Verwaltungsakts im Rahmen der Begründetheit „hindurchlässt“.

1044 Decker, in: Posser/Wolff, VwGO, 49. Ed., Stand: 1.4.2019, § 113 Rn. 18.

1045 Anschaulich hierzu Ehlers, Jura 2004, 176 (177f.).

1046 Statt vieler Graf von Kielmansegg, JuS 2013, 312 (314).

1047 BVerwG, Urt.v. 3.5.1982, Az.: 6 C 60.79 = BVerwGE 65, 287 (289f.); Gödde, DVP 2016, 317 (320 Fn. 48); Ehlers, Jura 2004, 176 (178).

1048 Emmenegger, in: Fehling/Kastner/Störmer, Verwaltungsrecht, 4. Aufl. 2016, § 113 VwGO Rn. 4; Wolff, in: Wolff/Decker, VwGO/VwVfG, Studienkommentar, 3. Aufl. 2012, § 46 VwVfG Rn. 16; Pünder, Jura 2015, 1307 (1315).

1049 Ganz die Fallbearbeitung im Auge so auch Graf von Kielmansegg, JuS 2013, 312 (314). Dennoch sprechen teils überzeugende Argumente für einen anderen Prüfungsstandort. Der Studierende muss jedenfalls zu diesem dogmatischen Standortstreit in der Fallbearbeitung keine Stellung beziehen, sich lediglich einfach entscheiden. 
Ungeachtet dessen kann es bei Vorliegen des § 46 VwVfG - gerade im Hinblick auf die Offensichtlichkeit - an der Klagebefugnis nach § 42 II VwGO fehlen. Darauf ist in der Fallbearbeitung zu achten.

\section{Rechtswidrigkeit des angefochtenen Verwaltungsakts im Überblick}

$518 \S 113$ I 1 VwGO verlangt weiter, dass der angefochtene Verwaltungsakt rechtswidrig ist. ${ }^{1050}$ Rechtswidrigkeit liegt vor, wenn er mit dem geltenden Recht nicht in Einklang steht. ${ }^{1051}$ Der in Art. 20 III GG verankerte Grundsatz der Gesetzmäßigkeit der Verwaltung - der zugleich eine Ausformung des Rechtsstaatsprinzip darstellt - verbietet zum einen aufgrund des Gesetzesvorbehalts ein Handeln ohne Gesetz, d.h. ohne eine Ermächtigungsgrundlage ${ }^{1052}$, und zum anderen nach dem Gesetzesvorrang auch ein Handeln gegen das Gesetz (näher dazu Rn. $554 \mathrm{ff}$.). Die Gesetze im öffentlichen Verwaltungsrecht erlauben einerseits positiv kodifiziert verwaltungsrechtliches Handeln und tragen der Verwaltung bestimmte Handlungsweisen auf, begrenzen es aber andererseits genau dadurch, dass diese Gesetze einen Rahmen für verwaltungsrechtliches Handeln setzen, der nicht überschritten werden darf. Dieser Rahmen wird zum einen durch das Rechtsstaatsprinzip entscheidend mitbeeinflusst, beispielsweise durch das Bestimmtheitsgebot, das Rückwirkungsverbot und vor allem dem Verhältnismäßigkeitsgrundsatz. ${ }^{1053}$ Zum anderen kennzeichnet ihn aber auch die gängige Systematisierung nach formellen und materiellen Anforderungen. Erstere beziehen sich auf die Art und Weise des Zustandekommens und die äußere Form, also auf das „Drumherum“ der materiell inhaltlich ergangenen Verwaltungsentscheidung, letztere betreffen dagegen die Einhaltung der inhaltlichen Vorgaben, die die Rechtsordnung an den Verwaltungsakt stellt. ${ }^{1054}$ Zweck der Zweiteilung ist es, etwaige leichter feststellbare Fehler von Verwaltungsakten zunächst kenntlich zu machen, um so gegebenenfalls eine umfangreiche inhaltliche Prüfung zu vermeiden. ${ }^{1055}$ Überschreitet nun ein Verwaltungshandeln den Rahmen, so verstößt

1050 In der Praxis ist die Rechtswidrigkeit eines Verwaltungsakts der Ausnahmefall. Ganz im Gegenteil werden täglich tausende Verwaltungsakte erlassen, die unzweifelhaft rechtmäßig sind. Jedoch haben sich Juristen - wie auch Mediziner - hauptsächlich um die pathologischen Fälle zu kümmern, Maurer/Waldhoff, Allgemeines Verwaltungsrecht, 19. Aufl. 2017, § 10 Rn. 1.

1051 Erbguth/Guckelberger, Allgemeines Verwaltungsrecht, 9. Aufl. 2018, § 14 Rn. 1.

1052 Hufen, Verwaltungsprozessrecht, 11. Aufl. 2019, § 25 Rn. 3 plädiert hingegen für den Begriff der „Eingriffsgrundlage“.

1053 Stober, in: Wolff/Bachof/Stober/Kluth, Verwaltungsrecht I, 13. Aufl. 2017, § 18 Rn. 23/24. 1054 Graf von Kielmansegg, JuS 2013, 312 (313); Maurer/Waldhoff, Allgemeines Verwaltungsrecht, 19. Aufl. 2017, § 10 Rn. 37 und 47.

1055 Korte, in: Wolff/Bachof/Stober/Kluth, Verwaltungsrecht I, 13. Aufl. 2017, § 48 Rn. 44. 
es gegen das Gesetz, ist damit also rechtswidrig. Hält sich die Verwaltung dagegen an die strikten Vorgaben der Gesetze, bewegt sie sich also im Rahmen dessen, was die Rechtsordnung ihr erlaubt und aufträgt, so verstößt sie eben nicht gegen Gesetze, sodass ihr Handeln nicht rechtswidrig, sondern rechtmäßig ist. Die Rechtswidrigkeit ist somit gleichsam das „negative Spiegelbild“1056 der positiv kodifizierten Rechtmäßigkeit vom Verwaltungshandeln. Spiegelverkehrt wird hier also terminologisch in der weiteren gutachterlichen Lösung nicht die Rechtswidrigkeit, sondern die Rechtmäßigkeit des angefochtenen Verwaltungsakts geprüft. $^{1057}$

Innerhalb der Begründetheit kann somit unter dem Prüfungspunkt „Rechtswidrigkeit des angefochtenen Verwaltungsakts“ der nachfolgende Obersatz gebildet werden: ${ }^{1058}$

Formulierungsvorschlag: „Der ... (angefochtene Verwaltungsakt) müsste rechtswidrig sein. Er ist hingegen rechtmäßig, wenn er auf einer Ermächtigungsgrundlage basiert sowie die formellen und materiellen Voraussetzungen erfüllt.“

Dieser Obersatz legt einen dreistufigen Prüfungsaufbau nahe:

1. Prüfung der Ermächtigungsgrundlage

2. Prüfung der formellen Rechtmäßigkeitsvoraussetzungen

3. Prüfung der materiellen Rechtmäßigkeitsvoraussetzungen

\section{a) Ermächtigungsgrundlage}

Soweit der Vorbehalt des Gesetzes (Art. 20 III GG) eine Ermächtigungsgrundlage 519 verlangt, so muss der Verwaltungsakt auch auf einer solchen beruhen. Diese ermächtigt und begrenzt zugleich das verwaltungsrechtliche Handeln. Die potentielle Ermächtigungsgrundlage bestimmt damit im Wesentlichen die konkreten Anforderungen der formellen und materiellen Rechtmäßigkeitsvoraussetzungen. Daher muss sie auch am Anfang der Prüfung stehen. ${ }^{1059} \mathrm{Zu}$ finden sind diese im

1056 So ausdrücklich Maurer/Waldhoff, Allgemeines Verwaltungsrecht, 19. Aufl. 2017, § 10 Rn. 3. 1057 So mit vergleichbarer Begründung auch Gödde, DVP 2016, 317 (320 Fn. 50).

1058 Gliederungsprobleme entstehen dann, wenn der angefochtene Verwaltungsakt im Ergebnis rechtmäßig ist, weil es dann bereits an der ersten Voraussetzung von § 113 I 1 VwGO fehlt, die Klage also bereits dann unbegründet ist und eine zweite Gliederungsebene nicht mehr erforderlich ist. Empfehlenswert ist es daher in Klausuren und Hausarbeiten eine Lösungsskizze zu entwerfen, um so formale Gliederungsfehler zu vermeiden. Alternativ kann man auch die entfallende Gliederungsebene auch für ein Zwischenergebnis nutzen.

1059 Hufen, Verwaltungsprozessrecht, 11. Aufl. 2019, § 25 Rn. 3; Korte, in: Wolff/Bachof/Stober/ Kluth, Verwaltungsrecht I, 13. Aufl. 2017, § 48 Rn. 45. 
Allgemeinen - insbesondere in den $\S \S 48,49 \mathrm{VwVfG}$-, vor allem aber auch im Besonderen Verwaltungsrecht, beispielsweise im besonders prüfungsrelevanten Polizei- und Ordnungs-, Bau- und Kommunalrecht (näher dazu Rn. 832ff.).

Problematisch kann hier insbesondere die Verfassungsmäßigkeit der Ermächtigungsgrundlage sein..$^{1060}$

521 An dieser Stelle genügt es, nur eine Norm zu nennen, die als Ermächtigungsgrundlage aufgrund passender Rechtsfolge und möglicher Erfüllung der Tatbestandsmerkmale in Betracht kommt. Diese wird anhand der Rechtsfolge ermittelt. Es wird also nach einer Norm gesucht, deren Rechtsfolge das behördliche Handeln erlaubt bzw. anordnet. Ob sie tatsächlich einschlägig ist, ergibt sich regelmäßig erst im Rahmen der Prüfung der materiellen Rechtmäßigkeit. An dieser Stelle des Gutachtens geht es lediglich darum, zu prüfen, ob die in Frage stehende Ermächtigungsgrundlage derartige Verwaltungsakte deckt.

Die Bestimmung der richtigen Ermächtigungsgrundlage kann im Einzelfall Schwierigkeiten bereiten. Auf zwei Dinge ist hier in der Falllösung besonders zu achten:

Die Suche nach der richtigen Norm beginnt nach Maßgabe des Anwendungsvorrangs bei untergesetzlichen Rechtsnormen (Rechtsverordnungen und Satzungen), geht bei formellen Gesetzen weiter und endet schließlich im Verfassungs- und Europarecht. ${ }^{1061}$

Schließlich ist der Grundsatz des lex specialis zu beachten. Spezielle Ermächtigungsgrundlagen sind stets vor Generalklauseln zu prüfen. So gehen beispielsweise solche aus dem Versammlungsrecht als besonderes Polizei- und Ordnungsrecht den Standardbefugnissen des allgemeinen Polizei- und Ordnungsrechts vor, diese finden aber wiederrum vor der polizei- und ordnungsrechtlichen Generalklausel Anwendung (näher zur Ermächtigungsgrundlage Rn. 554 ff.).

1060 Hinsichtlich des Prüfungsstandorts ist man sich uneinig. Zum einen wird eine Prüfung zu Beginn der Prüfung der materiellen Rechtmäßigkeit des Verwaltungsakts vorgeschlagen, so etwa Detterbeck, Allgemeines Verwaltungsrecht, 17. Aufl. 2019, Rn. 610, zum anderen aber auch erst nach der Tatbestandsprüfung, so etwa Bull/Mehde, Allgemeines Verwaltungsrecht mit Verwaltungslehre, 9. Aufl. 2015, Rn. 1245. Dem Studierenden ist der hier vorgeschlagene Prüfungsstandort zu empfehlen, ebenso etwa Peine/Siegel, Allgemeines Verwaltungsrecht, 12. Aufl. 2018, Rn. 540, um so eine klare Abschichtung auf Gesetzes- und Anwendungsebene zu ermöglichen. Auf die Frage nach dem Standort ist in der Fallbearbeitung selbstredend nicht einzugehen. Letztendlich sollte sich der Aufbau aber nach den besonderen Anforderungen des Falles richten. Sofern der Verwaltungsakt von der Ermächtigungsgrundlage erkennbar nicht gedeckt ist, so wäre es verfehlt, vorher in aller Ausführlichkeit dessen Verfassungsmäßigkeit zu prüfen.

1061 Erbguth/Guckelberger, Allgemeines Verwaltungsrecht, 9. Aufl. 2018, § 14 Rn. 5. 


\section{b) Formelle Rechtmäßigkeit}

Indem die einschlägige Ermächtigungsgrundlage benannt worden ist, lassen sich $\mathbf{5 2 3}$ nun die formellen Rechtmäßigkeitsvoraussetzungen bestimmen. Diese beinhalten - in der Prüfungsreihenfolge - Zuständigkeit, Verfahren und Form. ${ }^{1062} \mathrm{Um}$ den Erfordernissen des Rechtsstaatsprinzips gerecht zu werden, die u.a. zum einen Rechtssicherheit bzw. Transparenz für den Bürger verlangen und zum anderen die Ausübung staatlicher Gewalt zu begrenzen versuchen, müssen Verwaltungsentscheidungen auf Grundlage klarer und eindeutiger Zuständigkeitsund Verfahrensregelungen ergehen. ${ }^{1063}$ Es geht hier also vordergründig um das Zustandekommen des Verwaltungsakts, ${ }^{1064}$ also das „Drumherum“ der materiell inhaltlich ergangenen Verwaltungsentscheidung. Diese ergeben sich oftmals aus dem VwVfG. Nicht vergessen werden darf dabei die Subsidiarität des VwVfG, sodass speziellere, abweichende oder ergänzende Normen vorrangig sind. ${ }^{1065}$

Besondere Bedeutung erlangt hierbei die Anhörung nach § 28 VwVfG innerhalb des Verfahrens (näher dazu Rn. 631 ff.) und die Begründung nach § 39 VwVfG innerhalb der Form (näher dazu Rn. 690 ff.). Problematisch können auch die Fehlerfolgen bei Nichteinhaltung von formellen Rechtmäßigkeitsvoraussetzungen sein, die unter Umständen nach § 45 VwVfG geheilt (näher dazu Rn. 696 ff.) oder nach § 46 VwVfG für unbeachtlich erklärt (näher dazu Rn. 700 ff.) werden können.

Gerade weil das Rechtsstaatsprinzip formelle Voraussetzungen verlangt, finden sich die Prüfungspunkte Zuständigkeit, Verfahren und Form vom Grundsatz her im gesamten öffentlichen Recht wieder; so beispielsweise auch bei der Prüfung der formellen Verfassungsmäßigkeit. Es geht im gesamten Recht oftmals immer wieder um gleiche, grundlegende Strukturfragen (näher zur formellen Rechtmäßigkeit Rn. 579 ff.).

\section{c) Materielle Rechtmäßigkeit}

Schließlich ist aufgrund des Gesetzesvorrangs (Art. 20 III GG) der Inhalt des $\mathbf{5 2 6}$ Verwaltungsakts, also die materiellen Rechtmäßigkeitsvoraussetzungen - als Herzstück der gesamten Prüfung - zu untersuchen. ${ }^{1066}$ Dies ist umso bedeutender,

1062 Maurer/Waldhoff, Allgemeines Verwaltungsrecht, 19. Aufl. 2017, § 10 Rn. 37. 1063 Ähnlich Graf von Kielmansegg, JuS 2013312 (313).

1064 Maurer/Waldhoff, Allgemeines Verwaltungsrecht, 19. Aufl. 2017, § 10 Rn. 37.

1065 Peine/Siegel, Allgemeines Verwaltungsrecht, 12. Aufl. 2018, Rn. $104 \mathrm{f}$.

1066 Maurer/Waldhoff, Allgemeines Verwaltungsrecht, 19. Aufl. 2017, § 10 Rn. 47. 
da Gesetze ${ }^{1067}$ gegenüber dem Verwaltungshandeln in Form des Verwaltungsakts normativ höherrangig sind und damit gegen sie nicht verstoßen werden darf. Maßstab sind in erster Linie die Vorgaben der Ermächtigungsgrundlage. Diese setzen sich idealtypisch aus Tatbestand (,wenn ...“) und Rechtsfolge (,dann ...“) zusammen. Hinsichtlich der Normstruktur gilt hier also nichts anderes als bei einer Anspruchsnorm des Privatrechts. Dazu treten unter Umständen weitere Voraussetzungen der Spezialgesetze, dem die Ermächtigungsgrundlage entnommen ist.

527 Der Tatbestand kann aber eine Besonderheit dahingehend aufweisen, dass er einen unbestimmten Rechtsbegriff („öffentliches Interesse“, „Zuverlässigkeit“, „Gemeinwohl“, „[...]“) formuliert. Probleme können sich dann hinsichtlich der gerichtlichen Überprüfbarkeit der Verwaltungsentscheidung ergeben. Grundsätzlich bleiben dabei unbestimmte Rechtsbegriffe gerichtlich vollständig überprüfbar, der Behörde wird nur im Ausnahmefall ein eigener Beurteilungsspielraum eingeräumt. Dann ist dem Verwaltungsgericht nur das Überprüfen von Beurteilungsfehlern erlaubt (näher dazu Rn. 735f. und 746ff.).

528 Nachdem in einem ersten Schritt all diese Tatbestandsvoraussetzungen untersucht worden sind, ist in einem zweiten Schritt zu fragen, ob eine zulässige Rechtsfolge eingetreten ist. In der „zulässigen“ Rechtsfolge liegt der entscheidende Unterschied zum Privatrecht. Unterteilt werden muss in gebundene Entscheidungen (,ist zu erteilen, [...]“) und Ermessensentscheidungen („kann“, „darf“, „,ist befugt/berechtigt, [...]“) der Verwaltung. Bei letzterem kann das Verwaltungsgericht die Verwaltungsentscheidung lediglich nach Ermessensfehlern überprüfen, ist in seinem Entscheidungsspielraum also beschränkt (näher dazu Rn. $729 \mathrm{ff}$. und $744 \mathrm{ff}$.).

529 Schließlich verlangt der Gesetzesvorrang (Art. 20 III GG) auch, dass der Verwaltungsakt mit der gesamten Rechtsordnung in Einklang steht, somit also auch mit allgemeinen Rechtsgrundsätzen und höherrangigem Recht. Zu erwähnen ist hier das in besonderem Maße prüfungsrelevante Verhältnismäßigkeitsprinzip und die Prüfung eines möglichen Grundrechtsverstoßes.

530 Probleme bereitet neben dem Tatbestand regelmäßig das Ermessen, bei welchem das Verhältnismäßigkeitsprinzip praktisch immer und die Wahrung der Grundrechte immer öfter zu erörtern sind (s. näher dazu Rn. 729ff. und Rn. 745).

531 Der Prüfungspunkt Tatbestand bildet somit das Einfallstor für das materielle besondere Verwaltungsrecht. An diesem Prüfungspunkt ist also regelmäßig das Wissen des materiellen Rechts zu erörtern. Klar machen muss man sich, dass der

1067 Darunter fallen neben dem Grundgesetz auch formelle Gesetze, Rechtsverordnungen sowie Satzungen.

Dominik Marek Kowalczyk 
Prüfungsaufbau hinsichtlich der Rechtmäßigkeit eines Verwaltungsakts auf dem Gebiet des besonderen Verwaltungsrechtes kein anderes sein kann. Dahingehend wird einzig und allein der Prüfungspunkt Tatbestand durch die einzelnen Tatbestandsvoraussetzungen ausgetauscht. Verwirren darf sich der Leser dann nicht von anders aufbauenden, aber inhaltlich gleichlautenden Prüfungsschemata anderer Lehrbücher.

Die Übereinstimmung mit allgemeinen Rechtsgrundsätzen und höherrangi- 532 gem Recht wird dagegen regelmäßig im Rahmen des Ermessens in Form einer Ermessensüberschreitung geprüft. ${ }^{1068}$ Dies ist insofern überzeugend, als ein Verstoß gegen höherrangiges Recht zwangsläufig eine Ermessensüberschreitung zu Folge hat und es somit dem Grunde nach in diesem Punkt keine Ermessensfehlerfreiheit geben kann. Gleichzeitig ergibt sich daraus, dass dieser Prüfungspunkt das Einfallstor für die Prüfung des gesamten Verfassungsrechts - also auch einer Grundrechtsprüfung - darstellt.

Die materielle Rechtmäßigkeit bildet damit regelmäßig den Schwerpunkt einer jeden Klausur (näher zur materiellen Rechtmäßigkeit Rn. 712ff.).

\section{Prüfungsaufbau: Rechtmäßigkeit eines Verwaltungsakts}

1. Ermächtigungsgrundlage

a) Vorhandensein einer Ermächtigungsgrundlage

b) ggf. Verfassungsmäßigkeit der Ermächtigungsgrundlage

2. Formelle Rechtmäßigkeit

a) Zuständigkeit

b) Verfahren

c) Form

- $\quad$ ggf. Heilung formeller Fehler (§ $45 \mathrm{VwVfG}$ )

- ggf. Unbeachtlichkeit formeller Fehler (§ $46 \mathrm{VwVfG}$ )

3. Materielle Rechtmäßigkeit

a) Tatbestandsvoraussetzungen der Ermächtigungsgrundlage

- ggf. unbestimmter Rechtsbegriff $\rightarrow$ Beurteilungsspielraum

b) zulässige Rechtsfolge:

- gebundene Entscheidung oder

- Ermessensentscheidung $\rightarrow$ keine Ermessensfehler

c) Übereinstimmung mit allg. Rechtsgrundsätzen und höherrangigem Recht

- insbes. Verhältnismäßigkeitsgrundsatz (falls nicht unter 3. b) als Ermessensfehler geprüft)

- $\quad$ insbes. Grundrechte (falls nicht unter 3. b) als Ermessensfehler geprüft)

1068 Erbguth/Guckelberger, Allgemeines Verwaltungsrecht, 9. Aufl. 2018, § 14 Rn. 47. 
534 Aufbauhinweis: Der Prüfungsaufbau der Rechtmäßigkeit eines Verwaltungsakts ist auch hier in seinen Grundzügen fest etabliert. Hinsichtlich mancher Prüfungspunkte sind jedoch unterschiedliche Varianten und Geschmäcker in der Diskussion. Dabei gibt es nicht den einen „richtigen“ Prüfungsaufbau, da in diesem verfassungsrechtliche und systematische Grundentscheidungen des Autors umgesetzt werden, deren Verständnis für Herleitung und Anwendung ihres Prüfungsaufbaus wichtig ist. Entscheidend ist, dass der Inhalt in einer dogmatisch stringenten Weise umgesetzt wird. Es kann also vielmehr nur darum gehen, eine zuverlässige Orientierung in dem meist unbekannten Sachverhalt zu ermöglichen. ${ }^{1069}$

535 Folgendes ist im Gesamtzusammenhang für das Verständnis noch wichtig: Auch ein rechtswidriger Verwaltungsakt bleibt - mit Ausnahme der Nichtigkeit nach § 43 III i.V.m. § 44 VwVfG - zunächst wirksam. § 43 II VwVfG bestimmt die Wirksamkeit eines rechtswidrigen Verwaltungsakts u.a. bis zum Zeitpunkt der Rücknahme nach §48 VwVfG oder einer anderweitigen Aufhebung. Letzteres umfasst auch eine gerichtliche Aufhebung nach § 113 I 1 VwGO, sodass sich der Kläger zur Beseitigung des rechtswidrigen Verwaltungsakts der Anfechtungsklage bedienen muss. Für den Kläger besteht dabei die Gefahr der formellen Bestandskraft des rechtswidrigen Verwaltungsakts, indem die Frist zur Einlegung des Rechtsmittels verstrichen worden ist und er somit den rechtswidrigen Verwaltungsakt eigenständig nicht mehr aus der Welt schaffen kann (s. Rn. 357 f.) Auf die obige Rechtmäßigkeitsprüfung kommt es dann nicht mehr an.

\section{Verletzung subjektiver Rechte des Klägers}

536 Als letztes zu prüfendes Tatbestandsmerkmal der Begründetheitsprüfung ist die Verletzung subjektiver Rechte des Klägers zu untersuchen. Hierbei wird auf das im Rahmen der Zulässigkeit zur Klagebefugnis nach § 42 II VwGO Gesagte Bezug genommen, doch erst an dieser Stelle die tatsächliche Verletzung subjektiver Rechte des Klägers festgestellt (s. näher Rn. $828 \mathrm{ff}$.). ${ }^{1070}$

537 Für den Fall der Rechtswidrigkeit des angefochtenen Verwaltungsakts wird dabei die Verletzung subjektiver Rechte des Klägers indiziert: Ein rechtswidriger Eingriff in das subjektiv-öffentliche Recht - welches bereits im Rahmen der Klagebefugnis bestimmt und bejaht worden ist - hat zwangsläufig dessen Verletzung zur Folge.

1069 Mit vergleichbarer Argumentation auch Graf von Kielmansegg, JuS 2013, 312.

1070 Im Rahmen der Klagebefugnis nach § 42 II VwGO macht der Kläger eine Verletzung subjektiver Rechte lediglich „geltend“, sodass dort nur die bloße Möglichkeit - nicht das Bestehen einer solchen Verletzung festgestellt werden darf, s. Rn. 284. 
Insofern genügt in aller Regel die knappe Feststellung, dass der Kläger durch $\mathbf{5 3 8}$ den rechtswidrigen Verwaltungsakt in seinen subjektiven Rechten verletzt ist. Empfehlenswert ist es, die in der Klagebefugnis genannten Rechte zu benennen. Je nachdem, ob dabei auf die Möglichkeits- oder die Adressatentheorie abgestellt worden ist, können folgende Sätze gebildet werden.

Formulierungsvorschlag (Anwendung Möglichkeitstheorie): „Durch ... (den angefochtenen Verwaltungsakt) wird ... (der Kläger) damit [nicht] in seinem Recht aus ... (das in der Klagebefugnis benannte Recht) verletzt.“

Formulierungsvorschlag (Anwendung Adressatentheorie): „Durch ... (den angefochtene Verwaltungsakt) wird ... (der Kläger) damit zumindest in seiner grundrechtlich geschützten allgemeinen Handlungsfreiheit aus Art. 2 I GG verletzt.“

\section{Maßgeblicher Zeitpunkt für die Beurteilung der Rechtmäßigkeit des angefochtenen Verwaltungsakts}

Das Verwaltungsgericht überprüft die Rechtmäßigkeit des angefochtenen Ver- 539 waltungsakts anhand der materiellen Rechtslage. Probleme entstehen dann, wenn sich im Laufe des gerichtlichen Verfahrens zwischen dem Erlass des Verwaltungsakts und der gerichtlichen Entscheidung die Sach- und Rechtslage ändert und fortan die Frage im Raum steht, auf welchen Zeitpunkt für die Beurteilung der Rechtmäßigkeit des Verwaltungsakts abzustellen ist. Über den maßgeblichen Zeitpunkt der Sach- und Rechtslage ${ }^{1071}$ herrscht Streit. Zwei Zeitpunkte kommen grundsätzlich in Betracht. ${ }^{1072}$

Eine Ansicht stellt auf den Zeitpunkt der letzten mündlichen Verhandlung des Gerichtsprozesses ab. Angeführt wird vor allem, dass der Wortlaut des $\S 113$ I 1 VwGO keinen Anhaltspunkt für eine prozessrechtliche Differenzierung hinsichtlich des Begriffs der Rechtswidrigkeit und der Rechtsverletzung biete. ${ }^{1073}$

Die überwiegende Ansicht legt hingegen den Zeitpunkt der letzten Behördenentscheidung - die hier regelmäßig im Widerspruchsbescheid liegen wird zugrunde. ${ }^{1074}$ Hierfür spricht, dass grundsätzlich das materielle Recht darüber

\footnotetext{
1071 Der Begriff „maßgeblicher Zeitpunkt der Sach- und Rechtslage“ ist etwas ungenau, weil „maßgeblich“ immer das Recht zum Zeitpunkt der Urteilsfindung ist. Nur dieses Recht kann (konkludent) verlangen, dass für die Aufhebung des Verwaltungsakts noch das alte Recht und nicht das geänderte Recht heranzuziehen ist, Wolff, in: Wolff/Decker, VwGO/VwVfG, Studienkommentar, 3. Aufl. 2012, § 113 VwGO Rn. 37.

1072 Zum maßgeblichen Zeitpunkt für die Beurteilung der Rechtmäßigkeit des angefochtenen Verwaltungsakts anschaulich und prägnant auch Polzin, JuS 2004, $211 \mathrm{ff}$.

1073 W.-R. Schenke/R.P. Schenke, in: Kopp/Schenke, VwGO, 25. Aufl. 2019, § 113 Rn. 39.

1074 Stellvertretend Gersdorf, Verwaltungsprozessrecht, 6. Aufl. 2019, Rn. 52 m.w.N.
} 
entscheidet, ob eine Rechts- oder Tatsachenänderung seit der Behördenentscheidung für die Frage der Rechtmäßigkeit zu berücksichtigen ist (vgl. § 49 II 1 Nr. 3 und 4 sowie $§ 51$ I Nr. 1 VwVfG). ${ }^{1075}$

Die letztgenannte Ansicht überzeugt, da bei der Anfechtungsklage die Überprüfung der Verwaltungsentscheidung im Vordergrund steht. ${ }^{1076}$ Daraus folgt der Grundsatz, dass bei Anfechtungsklagen für die maßgebliche Sach- und Rechtslage in der Regel der Zeitpunkt der letzten Behördenentscheidung maßgeblich ist. ${ }^{1077}$

540 Von diesem Grundsatz gibt es jedoch zwei Ausnahmen, bei denen die Sachund Rechtslage doch im Zeitpunkt der letzten mündlichen Verhandlung des Gerichtsprozesses maßgeblich ist.

541 In einer ersten Fallgruppe sind die Dauerverwaltungsakte zu nennen. Diese erschöpfen sich nicht nur in einer einmaligen Entscheidung der Behörde, sondern werden gleichsam laufend neu getroffen und wiederholen sich damit gewissermaßen immer wieder. ${ }^{1078}$ Sie können daher stets aufgrund einer Änderung der Sach- und Rechtslage rechtswidrig werden und müssen daher auch nach der jeweils aktuellen Sach- und Rechtslage beurteilt werden. Beispiele sind Verkehrszeichen oder eine Anordnung zum Anschluss- und Benutzungszwang. ${ }^{1079}$

542 Die zweite Fallgruppe verlangt die Beurteilung nach dem gegenwärtigen Zeitpunkt - also der letzten mündlichen Verhandlung -, sofern Gründe des Vertrauensschutzes und der Billigkeit dies erfordern. Dies gilt vor allem für noch nicht vollzogene Verwaltungsakte, bei denen die Vollstreckung sofort wieder zurückgenommen bzw. eine entsprechende Erlaubnis sogleich wieder erteilt werden müsste. Beispiele sind hier die Ausweisung eines Ausländers, obwohl ihm zwischenzeitlich ein Aufenthaltsrecht zusteht oder die Beseitigungsanordnung zu einem Haus, das durch einen zwischenzeitlich in Kraft getretenen Bebauungsplan genehmigungsfähig wäre. ${ }^{1080}$

543 In der Falllösung ist die Problematik der maßgeblichen Sach- und Rechtslage dort zu thematisieren, wo es erforderlich ist. Dies kann sowohl bei Tatbestandsmerkmalen der formellen sowie auch der materiellen Rechtmäßigkeitsprüfung

1075 Erbguth/Guckelberger, Allgemeines Verwaltungsrecht, 9. Aufl. 2018, § 20 Rn. 34.

1076 Hufen, Verwaltungsprozessrecht, 10. Aufl. 2016, § 24 Rn. 8.

1077 Letztlich führen beide Ansichten aufgrund der Ausnahmen oftmals zu ähnlichen Ergebnissen.

1078 Detterbeck, Allgemeines Verwaltungsrecht, 17. Aufl. 2019, Rn. 516.

1079 Hiervon ist wiederrum eine Rückausnahme zu machen, wenn das materielle Recht eindeutig einen anderen Zeitpunkt zu Grunde legt, vgl. z. B. § 35 VI GewO.

1080 Anschaulich zu den Ausnahmen Hufen, Verwaltungsprozessrecht, 11. Aufl. 2019, § 24 Rn. $9 \mathrm{ff}$.

\section{Dominik Marek Kowalczyk}


der Fall sein. ${ }^{1081}$ Vorkommen kann es in der Falllösung darüber hinaus auch als Zusatzfrage. ${ }^{1082}$

Formulierungsvorschlag: „Anhand ... (der eintretenden Umstände) wird deutlich, dass sich ... (die konkrete Sach- oder Rechtslage) maßgeblich verändert hat. Es stellt sich dabei die Frage, auf welchen Beurteilungszeitpunkt abzustellen ist.“

Letztendlich verliert der Meinungsstreit aufgrund der Ausnahmen der überzeugenden Ansicht in der Falllösung an praktischer Bedeutung, da die Meinungen dann zu gleichen Ergebnissen führen und so ein Streitentscheid oftmals nicht entschieden werden muss.

\section{Besonderheiten im Falle von Drittanfechtungsklagen}

Einen Sonderfall stellen die Drittanfechtungsklagen dar. Hierbei geht es um $\mathbf{5 4 4}$ Konstellationen, in denen der aufzuhebende Verwaltungsakt von einem Dritten angefochten wird, der nicht selbst Adressat ist, sondern von dem Verwaltungsakt lediglich mittelbar in irgendeiner Weise nachteilig betroffen ist (sog. Verwaltungsakt mit Doppelwirkung). ${ }^{1083}$

Hauptanwendungsfälle sind die Nachbarklage und die Konkurrentenklage: 545 Erstere erlangt vor allem im Baurecht, ${ }^{1084}$ aber auch bei Planfeststellungen, Anlagengenehmigungen nach dem BImSchG und im Gaststättenrecht Bedeutung. Ein Nachbar wendet sich dabei gegen die Genehmigung zur Errichtung eines Wohnhauses, einer Industrieanlage, zum Bau einer Straße, zur Eröffnung einer Gaststätte und ähnliches, und macht geltend, durch das Vorhaben aufgrund von Lärm, Schadstoffemissionen und ähnlichem in seinen Rechten verletzt zu sein. ${ }^{1085}$

Die zweite bedeutende Fallgruppe besteht in den Konkurrentenklagen, die $\mathbf{5 4 6}$ vor allem im Beamten- und Gewerberecht vorkommen. Dabei wendet sich zum Beispiel ein Beamter gegen die (drohende) Beförderung/Einstellung eines Mitbewerbers oder ein Gewerbetreibender bekämpft die Genehmigungserteilung oder Subventionsgewährung an einen Konkurrenten. ${ }^{1086}$

1081 Ein Fallbeispiel bietet Wißmann/Holzner/Steiniger, ZJS 2009, 675 (682f.).

1082 Ein Fallbeispiel hierfür bildet Kaiser/Städele, Jura 2017, 95 (106f.).

1083 Mann/Wahrendorf, Verwaltungsprozessrecht, 4. Aufl. 2015, Rn. 205; Ipsen, Allgemeines Verwaltungsrecht, 11. Aufl. 2019, Rn. 412ff. Früher war auch der Begriff des Verwaltungsakts mit Drittwirkung geläufig, der jedoch heute von Gesetzes wegen überholt ist, vgl. § 80 I 2 VwGO.

1084 Vgl. beispielsweise bei Stollmann/Beaucamp, Öffentliches Baurecht, 11. Aufl. 2017, $\S 21$ Rn. $15 \mathrm{ff}$.

1085 Ausführlich hierzu Schlette, Jura 2004, 90 (93f.).

1086 Ausführlich hierzu Schlette, Jura 200490 (94f.). 
Dabei bleibt es grundsätzlich bei der bereits bekannten „klassischen“ Begründetheitsprüfung.

548 Examenswissen: Hängt die Begründetheit der Anfechtungsklage allein entscheidend von der Rechtsverletzung ab, so stellen Autoren teilweise die Frage, warum nicht von vornherein hierauf abgestellt wird. Teilweise wird daher bei Drittanfechtungsklagen - im Gegensatz zu dem hier vertretenen klassischen Aufbau - auch ein subjektiv-rechtlich orientierter Aufbau vorgeschlagen, bei dem von vornherein nur die Verletzung der drittschützenden Normen in Rede steht. Danach sei eine Rechtsverletzung i.S.d. § 113 I 1 VwGO gegeben, wenn der Kläger - ähnlich wie etwa bei einer Verpflichtungs- oder allgemeinen Leistungsklage - einen Anspruch auf Aufhebung des Verwaltungsakts hat. Der Obersatz zur Begründetheit könnte dann beispielsweise lauten: „Nach 113 I 1 VwGO ist die Anfechtungsklage begründet, soweit ... (der Verwaltungsakt) rechtswidrig und ... (der Kläger) dadurch in seinen Rechten verletzt ist. Dies ist dann der Fall, wenn der ... (der Kläger) einen Anspruch auf Aufhebung ... (des Verwaltungsakts) hat. “1087. Ein solches Vorgehen verkompliziert jedoch nur die Lösung des Falles, da die bewährte Prüfungsstruktur verlassen werden müsste und kann somit nicht empfohlen werden. § 113 I 1 VwGO ist auf ein solches Modell nicht angelegt. Ganz gängige Praxis ist es daher, das klassische Aufbauschema zu verwenden, woran sich insbesondere die Studierenden in der Klausur halten sollten.

549 Besonderheiten bestehen im klassischen Aufbau unter dem Prüfungspunkt „Verletzung subjektiver Rechte des Klägers“. Hierbei genügt keinesfalls eine knappe Feststellung der Verletzung, vielmehr muss grundsätzlich anhand der Schutznormtheorie für jede Vorschrift einzeln geprüft werden, ob diese Vorschrift einen drittschützenden Charakter aufweist, der Kläger unter den Schutzbereich der Norm fällt und mithin seine subjektiven Rechte verletzt werden (näher dazu Rn. 292 und 297). Der Begründungsaufwand ist also höher.

Regelmäßig wird der Schwerpunkt der die Drittanfechtungsklagen betreffenden Ausführungen bereits bei der Klagebefugnis nach § 42 II VwGO liegen. Dort wird dann über den drittschützenden Charakter der streitentscheidenden Normen entschieden. In der Falllösung ist dann hier grundsätzlich nur noch auf alle in der Regel bereits in der Klagebefugnis genannten einzelnen Vorschriften einzugehen und deren drittschützender Charakter zu bejahen bzw. zu verneinen. Dabei kann dann in der Falllösung auf die Ausführungen zur Klagebefugnis verwiesen werden (s. Rn. 296f.). Bedeutung erlangt der Prüfungsschritt vor allem dann, wenn Normen geprüft werden, die noch nicht in der Klagebefugnis genannt worden sind. ${ }^{1088}$

Formulierungsvorschlag: „Wie bereits im Rahmen der Klagebefugnis dargelegt, weist ... (die drittschützende Norm) einen drittschützenden Charakter auf,

1087 Ausführlich zu diesem sog. subjektiv-rechtlich orientierten Aufbau Ehlers, Jura 2004, 176 (178).

1088 Ein Fallbeispiel bietet Kühling/Bäuml, Jura 2013, 728 (741). 
sodass ... (der Kläger) durch ... (den Norminhalt) in seinen subjektiven Rechten verletzt ist. [ggf. zweite/dritte/... Norm].

Regelmäßig ist im Falle von Drittanfechtungsklagen eine Beiladung nach $\mathbf{5 5 1}$ $\S 65$ II VwGO auszusprechen. Diese wird dann in der Falllösung unter „B. Beiladung“ zwischen „A. Zulässigkeit“ und „C. Begründetheit“ angesprochen (näher dazu Rn. 445 ff.). ${ }^{1089}$

\section{Literaturhinweise}

Zur gutachterlichen Prüfung: Beyerbach, Gutachten, Hilfsgutachten und Gut- 552 achtenstil - Bemerkungen zur juristischen Fallbearbeitung, JA 2014, 813; Gödde, Abstrakte Formulierungshilfen und Erläuterungen bei der gutachterlichen Prüfung einer Anfechtungsklage, DVP 2016, 317; Lagodny, Gesetzestexte suchen, verstehen und in der Klausur anwenden, eine praxisorientierte Anleitung für rechtswissenschaftliches Arbeiten im Strafrecht, Öffentlichen Recht, Zivilrecht, 2. Aufl. 2012.

Zur Begründetheitsprüfung von Anfechtungsklagen: Ehlers, Die verwaltungsgerichtliche Anfechtungsklage (Teil II), Jura 2004, 176; stellvertretend für eine Vielzahl von Lehrbüchern Gersdorf, Verwaltungsprozessrecht, 6. Aufl. 2019, Rn. 51ff.; Kielmansegg, Die Begründetheitsprüfung bei der Anfechtungsklage, JuS 2013, 312.

Zur Rechtswidrigkeit des Verwaltungsakts: stellvertretend für eine Vielzahl von Lehrbüchern Maurer/Waldhoff, Allgemeines Verwaltungsrecht, 19. Aufl. 2017, $\S 10$ Rn. $22 \mathrm{ff}$.

Zur Verletzung subjektiver Rechte des Klägers: stellvertretend für eine Vielzahl von Lehrbüchern Bull/Mehde, Allgemeines Verwaltungsrecht mit Verwaltungslehre, 9. Aufl., 2015, Rn. $142 \mathrm{ff}$.

Zum maßgeblichen Zeitpunkt für die Beurteilung der Rechtmäßigkeit des Verwaltungsakts: Baumeister, Der maßgebliche Zeitpunkt im Verwaltungsrecht und Verwaltungsprozessrecht, Jura 2005, 655; Ehlers, Die verwaltungsgerichtliche Anfechtungsklage(Teil II), Jura 2004, 176 (179f.); Gärditz/Orth, Der maßgebliche Zeitpunkt für die Beurteilung der Sach- und Rechtslage im Verwaltungsprozess, Jura 2013, 1100; Polzin, Der maßgebliche Zeitpunkt im Verwaltungsprozess, JuS 2004, 211.

Zu Drittanfechtungsklagen: Albedyll, in: Bader/Funke-Kaiser/Stuhlfauth/Albedyll, Verwaltungsgerichtsordnung. 6. Aufl. 2014, § 42 Rn. $78 \mathrm{ff}$. mit zahlreichen Beispielen; Bosch/Schmidt/Vondung/Vondung: Praktische Einführung in das

1089 Ein anschauliches Beispiel aus der Praxis bietet Koehl, JuS 2016, 133. 
verwaltungsgerichtliche Verfahren, 9. Aufl., 2012, Rn. 563ff.; Hufen, Verwaltungsprozessrecht, 10. Aufl. 2016, § 25 Rn. 43; Mann/Wahrendorf, Verwaltungsprozessrecht, 4. Aufl. 2015, Rn. 205ff.; Stollmann/Beaucamp, Öffentliches Baurecht, 11. Aufl. 2017, Rn. $29 \mathrm{ff}$.

\section{Die Prüfung der Rechtmäßigkeit des Verwaltungsakts im Einzelnen (Bernhard Hadank; Sebastian Eickenjäger; Julian Senders; Tristan Lemke; Daniel Benrath)}

553 Die vorstehend aufgezeigte Struktur der Begründetheitsprüfung der Anfechtungsklage bedarf aufgrund ihrer Klausurrelevanz der Vertiefung. Sowohl hinter dem Erfordernis des Vorliegens einer Ermächtigungsgrundlage (dazu Rn. 554 ff.) als auch bei der Prüfung der formellen (dazu Rn. 579 ff.) und materiellen Rechtmäßigkeit des Verwaltungsakts (dazu Rn. 712ff.) können sich spezifische Probleme ergeben, deren Darstellung in Prüfungsarbeiten beherrscht werden muss.

\section{Das Erfordernis einer Ermächtigungsgrundlage (Bernhard Hadank)}

554 In der verwaltungsrechtlichen Klausur beginnt die Prüfung der Begründetheit der Anfechtungsklage obligatorisch mit der Bestimmung einer tauglichen Ermächtigungsgrundlage. Es wird überprüft, ob die Verwaltung ihre Entscheidungen autonom treffen konnte oder hierfür eine gesetzliche Grundlage notwendig ist. Wenn Entscheidungen der Verwaltung in bestimmten Bereichen durch ein Gesetz legitimiert werden müssen, ${ }^{1090}$ steht ihr Handeln, Tun oder Unterlassen unter dem Vorbehalt des Gesetzes.

In den meisten Klausuren muss an dieser Stelle lediglich die einschlägige Ermächtigungsgrundlage festgestellt werden. Ausführungen zum Vorbehalt des Gesetzes erübrigen sich in der Regel. Ein Blick auf die Dogmatik der Vorbehaltslehre lohnt sich dennoch, weil der Vorbehalt des Gesetzes wegen seiner unsteten Terminologie, der fehlenden einheitlichen Kodifikation in der Verfassung ${ }^{1091}$ und seinem strittigen Anwendungsbereich ${ }^{1092} \mathrm{zu}$ Schwierigkeiten führen kann. Dieser einführende Beitrag soll zunächst einen groben Überblick über die verfassungsrechtlichen Grundlagen des Vorbehalts des Gesetzes (s. Rn. 555 ff.)

1090 BVerfG, Urt. v. 14.7.1998, Az.: 1 BvR 1640/97 = BVerfGE 98, 218 (251).

1091 Grzeszick, in: Maunz/Dürig, GG, Art. 20 III Rn. 80 (Stand: August 2018).

1092 Sodan/Ziekow, Grundkurs Öffentliches Recht, 8. Aufl. 2018, § 7 Rn. 28; Huster/Rux, in: Epping/Hillgruber, GG, Art. 20 Rn. 174 (Stand: November 2018). 
und dessen Umfang (s. Rn. 558 ff.) geben, bevor erläutert wird, inwiefern er bei der Prüfung der Anfechtungsklage relevant wird (s. Rn. 573 ff.)

\section{a) Verfassungsrechtliche Grundlage des Vorbehalts des Gesetzes}

Seine verfassungsrechtliche Fundierung findet der Vorbehalt des Gesetzes in $\mathbf{5 5 5}$ zweierlei Hinsicht. Zunächst ist er anerkanntermaßen ein Element des Rechtsstaatsprinzips. ${ }^{1093}$ Die rechtsstaatliche Komponente spiegelt sich gleich mehrfach in den Funktionen des Vorbehalts des Gesetzes wider: Zum einen schafft er Transparenz und Vorhersehbarkeit exekutiver Entscheidungen und knüpft daher an die Bindung der Verwaltung an „Recht und Gesetz“ nach Art. 20 III Hs. 2 GG $\mathrm{an}^{1094}$; er ist in der Gesetzesbindung der Verwaltung sozusagen „impliziert“1095. Zum anderen grenzt der Vorbehalt des Gesetzes die Befugnisse von Exekutive und Legislative ab und leistet auf diese Weise einen Beitrag für die im Rechtsstaatsprinzip angelegte Gewaltenteilung. ${ }^{1096}$

Darüber hinaus enthält der Vorbehalt des Gesetzes eine demokratische Komponente: Er trägt dem Umstand Rechnung, dass der parlamentarische Gesetzgeber das einzige unmittelbar demokratisch legitimierte Staatsorgan ist, dem die besondere Aufgabe und Verantwortung zukommt, die grundlegenden Entscheidungen für das Gemeinwesen zu treffen. Der Vorbehalt des Gesetzes findet insoweit eine zusätzliche Verankerung im demokratischen Prinzip. ${ }^{1097}$

Verwechslungsgefahr bietet die uneinheitliche Terminologie, die den allge- 557 meinen Vorbehalt des Gesetzes und die spezifischen Gesetzesvorbehalte der Grundrechte nicht trennscharf voneinander abgrenzt. Einige Autoren erkennen einen qualitativen Unterschied dahingehend, dass die grundrechtlichen Gesetzesvorbehalte dem Gesetzgeber die Erlaubnis vermitteln, ein Grundrecht wirksam

1093 Vgl. Schulze-Fielitz, in: Dreier, GG, Kommentar, Band II, 3. Aufl. 2015, Art. 20 (Rechtsstaat) Rn. 105.

1094 Huster/Rux, in: Epping/Hillgruber, GG, Art. 20 Rn. 173 (Stand: November 2018).

1095 BVerfG, Beschl.v. 28.10.1975, Az.: 2 BvR 883/73 = BVerfGE 40, 237 (248); Beschl.v. 8. 8.1978, Az.: 2 BvL 8/77 = BVerfGE 49, 89 (126); Beschl. v. 10.5.1988, Az.: 1 BvR 482/84 = BVerfGE 78, 179 (197); vgl. auch Sachs, in: Sachs, GG, 8. Aufl. 2018, Art. 20 Rn. 114. S. auch Sodan/Ziekow, Grundkurs Öffentliches Recht, 8. Aufl. 2018, §7 Rn. 25. Eine unmittelbare Verankerung in Art. 20 III GG kann dagegen nicht begründet werden, s. hierzu Huster/Rux, in: Epping/Hillgruber, GG, Art. 20 Rn. 173.1 (Stand: November 2018).

1096 Grzeszick, in: Maunz/Dürig, GG, Art. 20 III Rn. 86 (Stand: August 2018); Ossenbühl, in: Isensee/Kirchhof, Handbuch des Staatsrechts für die Bundesrepublik Deutschland, Band V, 3. Aufl. 2007, §101 Rn. $11 \mathrm{f}$.

1097 Ossenbühl, in: Isensee/Kirchhof, Handbuch des Staatsrechts für die Bundesrepublik Deutschland, Band V, 3. Aufl. 2007, § 101 Rn. $49 \mathrm{ff}$. 
durch oder auf Grund eines (einfachen oder qualifizierten) Gesetzes zu beschränken, während der allgemeine Vorbehalt des Gesetzes der Verwaltung das Verbot auferlegt, ohne gesetzliche Grundlage überhaupt tätig zu werden. ${ }^{1098}$ Nichts desto trotz verfolgen der allgemeine Vorbehalt des Gesetzes sowie die grundrechtlichen Gesetzesvorhalte dieselbe Zielrichtung, indem sie staatliches (grundrechtsbeschränkendes) Handeln unter den Vorbehalt einer gesetzlichen Ermächtigung stellen. Die konsequente Abgrenzung der Begriffe hat deshalb eher akademische Relevanz. Auch in der neueren Rechtsprechung des BVerfG werden die Begriffe „Vorbehalt des Gesetzes“ und „Gesetzesvorbehalt“ häufig synonym verwandt. ${ }^{1099}$ Dennoch ist eine terminologische Abgrenzung sinnvoll. Zum einen, um Verwechslungen zu vermeiden; zum anderen kann so vermittelt werden, die Differenzierung der unterschiedlichen Vorbehalte erkannt und verstanden zu haben.

\section{b) Umfang des Vorbehalts des Gesetzes}

558 Aus der verfassungsrechtlichen Ableitung sind keine Erkenntnisse darüber zu gewinnen, in welchem Umfang der Vorbehalt des Gesetzes zur Anwendung gelangt. Deshalb sollten die hierzu vertretenen Auffassungen, die nachfolgend skizziert werden, im Wesentlichen bekannt sein.

559 Hausarbeitswissen: Insbesondere in verwaltungsrechtlichen Hausarbeiten kann bereits ein kurzer rechtshistorischer Umriss der Vorbehaltslehre Licht ins Dunkle bringen. Seine Ursprünge hat der Vorbehalt des Gesetzes in der konstitutionellen Ordnung des 19. Jahrhunderts. ${ }^{1100}$ Er war einerseits als Instrument zur bürgerlichen Mitbestimmung in Bereichen, die vormals der Monarchie vorbehalten waren und andererseits zur Verfestigung des parlamentarischen Gesetzes in der konstitutionellen Monarchie konzipiert. Der Vorbehalt des Gesetzes war somit ein Instrument zur Schaffung demokratischer Legitimation in der von der Monarchie beherrschten Exekutive. ${ }^{1101}$ Gegenstand des Vorbehalts waren die Freiheit und das Eigentum als konstitutive Elemente der persönlichen Individualsphäre. ${ }^{1102}$ Eingriffe in diese zentralen Positionen erforderten ein Gesetz als rechtsstaatlich

1098 So etwa Sachs, in: Sachs, GG, 8. Aufl. 2018, Art. 20 Rn. 113.

1099 BVerfG, Beschl.v. 26.6.2002, Az.: 1 BvR 670/91 = BVerfGE 105, 279 (303ff.); Urt. v. 14. 2. 2012, Az.: 2 BvL 4/10 = BVerfGE 130, 263 (299); Beschl.v. 17.12. 2013, Az.: 1 BvL 6/10 = BVerfGE 135, 48 (78); Beschl.v. 21.4.2015, Az.: 2 BvR 1322/12 = BVerfGE 139, 19 (47); Beschl.v. 17.2.2016, Az.: 1 BvL 8/10 = BVerfGE 141, 143 (164).

1100 Grzeszick, in: Maunz/Dürig, GG, Art. 20 III Rn. 77 (Stand: August 2018).

1101 Lerche, in: Merten/Papier, Handbuch der Grundrechte, Band III, 2009, §62 Rn. 22ff.; Grzeszick, in: Maunz/Dürig, GG, Art. 20 III Rn. 77 (Stand: August 2018).

1102 Ossenbühl, in: Isensee/Kirchhof, Handbuch des Staatsrechts für die Bundesrepublik Deutschland, Band V, 3. Aufl. 2007, § 101 Rn. 18. Vgl. auch Lerche, in: Merten/Papier, Handbuch 
allgemeine und demokratisch-parlamentarisch legitimierte Regelung. ${ }^{1103}$ Diese Formel von Freiheit und Eigentum implizierte allerdings ein weites Verständnis dieser Rechtsgüter: Die Freiheit wurde als umfassende allgemeine Handlungsfreiheit verstanden, das Eigentum erstreckte sich auf sämtliche vermögenswerte Rechte. ${ }^{1104}$

Mit tiefgreifenden Änderungen der Staatsstruktur durch den Übergang in die parlamentarische Demokratie und der verfassungsrechtlichen Kodifikation der Grundrechte durch die Weimarer Reichsverfassung hat sich die Anknüpfung des allgemeinen Vorbehalts des Gesetzes an Freiheit und Eigentum gewissermaßen überholt. Für Eingriffe in diese, gleichwohl weit verstandenen, Rechte sehen die Grundrechte spezifische Gesetzesvorbehalte vor. Die Herstellung demokratischer Legitimation der Exekutive erfolgt nunmehr auch in personeller Hinsicht. Damit bleibt die Frage offen, in welchen Bereichen für den allgemeinen Vorbehalt des Gesetzes mit der Anknüpfung an Freiheit und Eigentum überhaupt noch Raum verbleibt. ${ }^{1105}$

\section{aa) Belastende Maßnahmen der Eingriffsverwaltung}

Einer Anknüpfung an Freiheit und Eigentum bedarf es heute nicht mehr, weil $\mathbf{5 6 0}$ unter Bezugnahme auf die Wesentlichkeitstheorie (s. hierzu Rn. $567 \mathrm{ff}$.) von einem umfassenden Eingriffsvorbehalt für jedes staatliche Eingriffshandeln ausgegangen wird: Jedes staatliche Handeln, das einen Grundrechtseingriff nach sich zieht, bedarf einer gesetzlichen Ermächtigung. ${ }^{1106}$ Maßnahmen der Verwaltung, die dem Bürger ein bestimmtes Handeln, Tun oder Unterlassen durch Aufstellung eines Ge- oder Verbotes gebieten, bedürfen daher einer gesetzlichen Grundlage. ${ }^{1107}$ Dementsprechend beginnt die Prüfung der Begründetheit einer Anfechtungsklage gegen einen belastenden Verwaltungsakt obligatorisch mit der Ermittlung einer tauglichen Ermächtigungsgrundlage des angegriffenen Verwaltungsakts (näher sogleich Rn. 573).

Neben formellen Gesetzen genügen allerdings auch untergesetzliche 561 Rechtsnormen, etwa Rechtsverordnungen, dem Vorbehalt des Gesetzes, sofern diese auf einer hinreichend bestimmten formell-gesetzlichen Ermächtigung gründen. Das Erfordernis der Bestimmtheit der formell-gesetzlichen Ermächtigung ${ }^{1108}$ stellt somit eine notwendige Ergänzung und Konkretisierung des Vor-

der Grundrechte, Band III, 2009, § 62 Rn. 24; Grzeszick, in: Maunz/Dürig, GG, Art. 20 III Rn. 78 (Stand: August 2018).

1103 So etwa Schulze-Fielitz, in: Dreier, GG, Band II, 3. Aufl. 2015, Art. 20 (Rechtsstaat) Rn. 107. 1104 Grzeszick, in: Maunz/Dürig, GG, Art. 20 III Rn. 77 (Stand: August 2018).

1105 Dazu auch Ossenbühl, in: Isensee/Kirchhof, Handbuch des Staatsrechts für die Bundesrepublik Deutschland, Band V, 3. Aufl. 2007, § 101 Rn. 21.

1106 Grzeszick, in: Maunz/Dürig, GG, Art. 20 III Rn. 111 (Stand: August 2018).

1107 Sachs, in: ders., GG, 8. Aufl. 2018, Art. 20 Rn. 114; vgl. auch Degenhart, Staatrecht I. Staatsorganisationsrecht, 34. Aufl. 2018, Rn. $314 \mathrm{ff}$.

$1108 \mathrm{Zu}$ den konkreten Bestimmtheitsanforderungen nach Art. 80 I 2 GG siehe Sodan/Ziekow, Grundkurs Öffentliches Recht, 8. Aufl. 2018, § 17 Rn. 43 f. 
behalts des Gesetzes dar. ${ }^{1109}$ Ebenso stehen Ermessens- (s. Rn. 729 ff.) oder Beurteilungsspielräume (s. Rn. 735) dem Vorbehalt des Gesetzes nicht entgegen, solange sich die Kriterien für die Ausfüllung dieser Spielräume aus dem Gesetz hinreichend ergeben. ${ }^{1110}$

\section{bb) Begünstigende Maßnahmen der Leistungsverwaltung}

562 In der Rechtsprechung des BVerfG ist bereits früh die Frage aufgeworfen worden, ob in Anbetracht der Abkehr von den tradierten Vorstellungen der konstitutionellen Monarchie hin zu einer egalitär-sozialstaatlichen Denkweise und der damit verbundenen Veränderung des Verhältnisses zwischen Staat und Bürger die Ausweitung des Vorbehalts des Gesetzes über Eingriffe in Freiheit und Eigentum hinaus geboten ist. ${ }^{1111}$ Angesprochen ist hiermit vor allem die Idee, den Vorbehalt des Gesetzes generell auf begünstigende Maßnahmen der Leistungsverwaltung auszuweiten. Hierdurch wäre ein weites Feld durch die Vorbehaltslehre erschlossen. Die Leistungsverwaltung umfasst nämlich nicht nur die Begünstigung Einzelner (etwa durch Gewährung von Subventionen oder Sozialleistungen), sondern auch die Aufgaben der Daseinsvorsorge, die die Bereitstellung öffentlicher Infrastruktur (beispielsweise Straßen, Universitäten) sowie die öffentliche Versorgung mit Gütern und Dienstleistungen einschließen. ${ }^{1112}$

Ob die Ausweitung des Vorbehalts des Gesetzes auf die Leistungsverwaltung sinnvoll oder gar geboten ist, ist fraglich. Sicherlich ist nicht von der Hand zu weisen, dass auch Entscheidungen der Leistungsverwaltung freiheitsbeschränkend sein können, etwa wenn die Teilhabe an staatlichen Leistungen vorenthalten wird. ${ }^{1113}$ Unter dieser Prämisse überrascht die Erwägung nicht, den Vorbehalt des Gesetzes auch auf sämtliche Maßnahmen der Leistungsverwaltung auszudehnen, um auch diese Bereiche staatlichen Handelns rechtsstaatlich und demokratisch zu disziplinieren. ${ }^{1114}$

1109 BVerfG, Beschl.v. 27.1.1976, Az.:1 BvR 2325/73 = BVerfGE 41, 251 (265f.); Beschl.v. 19.4.1978, Az.: 2 BvL 2/75 = BVerfGE 48, 210 (221 ff.); Beschl.v. 20.10.1981, Az.: 1 BvR 640/80 = BVerfGE 58, 257 (278); Beschl. v. 21.4.2015, Az.: 2 BvR 1322/12 = BVerfGE 139, 19 (47); Ossenbühl, in: Isensee/ Kirchhof, Handbuch des Staatsrechts für die Bundesrepublik Deutschland, Band V, 3. Aufl. 2007, $\S 101$ Rn. 30; vgl. auch Sachs, in: ders., GG, 8. Aufl. 2018, Art. 20 Rn. 118; Sodan/Ziekow, Grundkurs Öffentliches Recht, 8. Aufl. 2018, § 7 Rn. 26.

1110 Sachs, in: Sachs, GG, 8. Aufl. 2018, Art. 20 Rn. 115.

1111 S. etwa BVerfG, Beschl. v. 6.5.1958, Az.: 2 BvL 37/56 = BVerfGE 8, 155 (167).

1112 Peine/Siegel, Allgemeines Verwaltungsrecht, 12. Aufl. 2018, § 2 Rn. 21; Ehlers, in: Ehlers/ Pünder, Allgemeines Verwaltungsrecht, 15. Aufl. 2015, §1 Rn. 55.

1113 Grzeszick, in: Maunz/Dürig, GG, Art. 20 III Rn. 117 (Stand: August 2018).

1114 Vgl. dazu Schulze-Fielitz, in: Dreier, GG, Band II, 3. Aufl. 2015, Art. 20 (Rechtsstaat) Rn. 108. 
$\mathrm{Zu}$ Recht hat sich diese Lehre vom Totalvorbehalt nicht durchsetzen können. ${ }^{1115}$ Die an sich nachvollziehbare Idee, den Bürgern mithilfe eines Totalvorbehalts gesetzlich klar beschriebene Teilhaberechte zu verschaffen ${ }^{1116}$, kann sich unter Umständen sogar nachteilig für die Bürger auswirken. Zwar schafft der Vorbehalt des Gesetzes aus rechtsstaatlicher Perspektive Klarheit im Hinblick auf die Vergabe von Leistungen. Er engt die Leistungsverwaltung allerdings erheblich ein, nimmt ihr die notwendige Flexibilität, um bedarfsgerecht zu entscheiden und verwehrt dem Bürger die Chance, Leistungen zu erhalten, die bislang nicht ausdrücklich gesetzlich ausgeformt sind. ${ }^{1117}$ Aus demokratischer Sicht ist der Verzicht auf einen Totalvorbehalt verkraftbar, weil auch die Verwaltung demokratisch legitimiert ist, wenngleich die personelle Legitimation erst über Legitimationsketten gewährleistet wird. ${ }^{1118}$

Hausarbeitswissen: Die Entbehrlichkeit eines verfassungsrechtlich begründeten umfassenden Totalvorbehalts für die Leistungsverwaltung wird noch deutlicher, wenn man sich vergegenwärtigt, dass es dem parlamentarischen Gesetzgeber selbstverständlich jederzeit offensteht, normative Vorgaben für die Leistungsverwaltung aufzustellen. In der ausnormierten Leistungsverwaltung darf die Leistungsbewilligung nur nach den gesetzlichen Vorgaben erfolgen. ${ }^{1119}$ Ein gutes Beispiel hierfür ist die Vorbehaltsregelung in § 31 SGB I [,Vorbehalt des Gesetzes"], die besagt, dass Rechte und Pflichten in sämtlichen Sozialleistungsbereichen nur begründet, festgestellt, geändert oder aufgehoben werden dürfen, soweit ein Gesetz dies vorschreibt oder zulässt. Insoweit ist die Einordnung des $\S 31$ SGB I als sozialversicherungsrechtlicher „Totalvorbehalt“ durchaus treffend. ${ }^{1120}$

Obwohl ein umfassender Totalvorbehalt für die Leistungsverwaltung überwie- $\mathbf{5 6 6}$ gend verneint wird (s. bereits Rn. $564 \mathrm{ff}$.), wird dennoch in einigen Bereichen der Leistungsverwaltung ein legitimierendes Element für die Begünstigung gefordert. Dies betrifft vor allem die Bewilligung von Subventionen und Beihilfen, die deshalb in der verwaltungsrechtlichen Klausur immer wieder relevant werden. Nach heute mehrheitlich vertretener Auffassung bedarf es zwar keiner formellgesetzlichen Rechtsgrundlage, sondern es wird vielmehr auf die legitimierende

1115 Zur Ablehnung eines Totalvorbehalts grundlegend BVerfG, Urt. v. 18.12.1984, Az.: 2 BvE 13/ 83 = BVerfGE 68, 1 (109) - Nato-Doppelbeschluss.

1116 Ossenbühl, in: Isensee/Kirchhof, Handbuch des Staatsrechts für die Bundesrepublik Deutschland, Band V, 3. Aufl. 2007, § 101 Rn. 25.

1117 Degenhart, Staatrecht I. Staatsorganisationsrecht, 34. Aufl. 2018, Rn. 325; Ossenbühl, in: Isensee/Kirchhof, Handbuch des Staatsrechts für die Bundesrepublik Deutschland, Band V, 3. Aufl. 2007, § 101 Rn. 25; Sodan/Ziekow, Grundkurs Öffentliches Recht, 8. Aufl. 2018, § 7 Rn. 29. 1118 von Arnim, DVBl. 1986, 1241 (1242).

1119 Sodan/Ziekow, Grundkurs Öffentliches Recht, 8. Aufl. 2018, § 7 Rn. 30.

1120 Spellbrink, in: Kasseler Kommentar Sozialversicherungsrecht, §31 SGB I Rn. 2 (Stand: September 2018). 
Wirkung der etatmäßigen Bereitstellung der Begünstigung im Haushaltsplan abgestellt. Auf eine formelle Rechtsgrundlage kann im Subventionsbereich mithin verzichtet werden, wenn

- im Haushaltsplan als Bestandteil des förmlichen Haushaltsgesetzes der Parlamente Fördermittel bereitgestellt werden,

- deren Verwendungszweck im Rahmen des Haushaltsplans ausreichend umrissen ist und

- durch den Erlass von Richtlinien die Verteilung von Fördermitteln denjenigen Stellen vorenthalten bleibt, die kraft der Verfassung hierzu berufen sind. ${ }^{1121}$

Die legitimierende Wirkung des Parlamentsgesetzes tritt somit mittelbar über den Haushaltsplan ein. Angesichts der vagen Ziel- und Zwecksetzungen, die sich aus dem Haushaltsplan für die Verwaltung ergeben, ist diese Konstruktion allerdings $\mathrm{zu}$ hinterfragen. ${ }^{1122}$ In besonders grundrechtssensiblen Fällen hat die Rechtsprechung eine formell-gesetzliche Ermächtigung für die Zuwendung verlangt, weil den Staat hier eine besondere Neutralitätspflicht treffe. ${ }^{1123}$ Eine solche an den Grundrechten orientierte Differenzierung ist in der Klausur allerdings schwierig. Mit dem treffenden Argument, dass sich eine für den Bürger vorteilhafte budgetäre Flexibilität der Leistungsverwaltung nur durch Steuerung über den Haushaltsplan und nicht durch starre Gesetzgebung erreichen lässt ${ }^{1124}$, kann die formellgesetzliche Ermächtigung für die Subventionsvergabe gut begründet verneint werden.

1121 Grundlegend dazu BVerwG, Urt.v. 26.4.1979, Az.: 3 C 111/79 = BVerwGE 58, 45 (48). S. hierzu Ruthig/Storr, Öffentliches Wirtschaftsrecht, 4. Aufl. 2015, § 9 Rn. 785 ff.; Ossenbühl, in: Isensee/ Kirchhof, Handbuch des Staatsrechts für die Bundesrepublik Deutschland, Band V, 3. Aufl. 2007, $\S 101 \mathrm{Rn}$. 26f. Ein ausführliches Modell zur Bestimmung der möglichen Regelungsinhalte des Haushaltsplans bei Etatzuwendungen bietet Kluckert, Zuwendung und Gesetz, 2018, S. 458 ff.

1122 Ablehnend von Arnim, DVBl. 1987, 1241 (1246f.); bejahend Stober, Allgemeines Wirtschaftsverwaltungsrecht, 17. Aufl. 2011, S. 52. Vgl. dazu Ossenbühl, in: Isensee/Kirchhof, Handbuch des Staatsrechts für die Bundesrepublik Deutschland, Band V, 3. Aufl. 2007, § 101 Rn. 27. 1123 s. etwa zur Förderung von Religionsgemeinschaften BVerwG, Urt. v. 27.3.1992, Az.: 7 C 21/ 90 = BVerwGE 90, 112 (Rn. 40); OVG Münster, Urt. v. 23.3.1990, Az.: 5 A 584/86 = NVwZ 1991, 174 (175). Vgl. auch Degenhart, Staatsrecht I. Staatsorganisationsrecht, 34. Aufl. 2018, Rn. 326.

1124 So auch Stober, Allgemeines Wirtschaftsverwaltungsrecht, 17. Aufl. 2011, S. 52. 


\section{cc) Verdichtung des Vorbehalts des Gesetzes zum Parlamentsvorbehalt}

Der allgemeine Vorbehalt des Gesetzes kann sich bei Betonung der demokrati- 567 schen Komponente ${ }^{1125} \mathrm{zu}$ einem Parlamentsvorbehalt verdichten. Insbesondere das BVerfG hat dies in seiner Rechtsprechung immer wieder getan, indem es die Pflicht des parlamentarischen Gesetzgebers hervorhebt, in grundlegenden normativen Bereichen alle wesentlichen Entscheidungen selbst $\mathrm{zu}$ treffen. ${ }^{1126}$ Über diese als „Wesentlichkeitstheorie“ bekannte Doktrin des BVerfG lässt sich der Vorbehalt des Gesetzes zwar bereichsspezifisch näher ausformen. ${ }^{1127}$ Allerdings bleibt stets klärungsbedürftig, welche Entscheidungen als wesentlich einzustufen sind. ${ }^{1128}$ Das Fehlen schärferer Konturen dürfte die größte Schwäche dieses ansonsten geeigneten Ansatzes für die bereichsspezifische Ausformung der Vorbehaltslehre sein.

Als grobe Orientierung für die „Wesentlichkeit“ dient die Grundrechtsrelevanz einer staatlichen Entscheidung. Im grundrechtsrelevanten Bereich soll alles „wesentlich“ sein, was „für die Verwirklichung der Grundrechte wesentlich“ ist $^{1129}$, wobei die Annahme des Vorbehalts des Gesetzes „mit großer Behutsamkeit“ vorzunehmen ist, um einer „weitgehende[n] Vergesetzlichung“ entgegen zu wirken ${ }^{1130}$.

Examenswissen: Die Wesentlichkeitstheorie ist vor allem dazu genutzt worden, den Vorbehalt des Gesetzes auf die früheren „besonderen Gewaltverhältnisse“, heute als Sonderstatusverhältnisse ${ }^{1131}$ bezeichnet, auszudehnen. ${ }^{1132}$ Dies betraf insbesondere das Schulverhältnis ${ }^{1133}$ sowie den

$1125 \mathrm{Zu}$ deren Betonung in der gewandelten Auffassung des Staatsrechts BVerfG, Beschl. v. 8. 8. 1978, Az.: 2 BvL 8/77 = BVerfGE 49, 89 (126). Vgl. auch Lerche, in: Merten/Papier, Handbuch der Grundrechte, Band III, 2009, § 62 Rn. 25.

1126 BVerfG, Urt. v. 6.12.1972, Az.: 1 BvR 230/70 = BVerfGE 34, 165 (192f.); Beschl. v. 28.10.1975, Az.: 2 BvR 883/73 = BVerfGE 40, 237 (249f.); Beschl. v. 8. 8.1978, Az.: 2 BvL 8/77 = BVerfGE 49, 89 (126f.); Beschl.v. 29.10.1987, Az.: 2 BvR 624/83 = BVerfGE 77, 170 (230 f.); Urt.v. 14.7.1998, Az.: 1 BvR 1640/97 = BVerfGE 98, 218 (251f.); Urt. v. 6.7.1999, Az.: 2 BvF 3/90 = BVerfGE 101, 1 (34); Urt. v. 24.9. 2003, Az.: 2 BvR 1436/02 = BVerfGE 108, 282 (312).

1127 Zum Erfordernis bereichsspezifischer Konkretisierungen Grzeszick, in: Maunz/Dürig, GG, Art. 20 III Rn. 104 (Stand: Dezember 2007).

1128 Sommermann, in: von Mangold/Klein/Starck, GG, 7. Aufl. 2018, Art. 20 III Rn. 275.

1129 BVerfG, Beschl.v. 21.12.1977, Az.: 1 BvL 1/75 = BVerfGE 47, 46 (79); Beschl. v. 27.11.1990, Az.: 1 BvR 402/87 = BVerfGE 83, 130 (142).

1130 BVerfG, Beschl. v. 21.12.1977, Az.: 1 BvL 1/75 = BVerfGE 47, 46 (79).

1131 S. zu den Sonderstatusverhältnissen unter dem Grundgesetz ausführlich Peine, in: Merten/ Papier, Handbuch der Grundrechte, Band III, 2009, § 65 Rn. 30 ff.

1132 Lerche, in: Merten/Papier, Handbuch der Grundrechte, Band III, 2009, § 62 Rn. $54 \mathrm{f}$.

1133 Vgl. BVerfG, Urt. v. 6.12.1972, Az.: 1 BvR 230/70 = BVerfGE 34, 165 (192f.); Beschl.v. 27.1.1976, Az.: 1 BvR 2325/73 = BVerfGE 41, 251 (259f.); Beschl.v. 22.6.1977, Az.:1 BvR 799/76 = BVerfGE 45, 400 
Strafvollzug ${ }^{1134}$; mithin Bereiche mit hoher Grundrechtsrelevanz, in denen der Exekutive allerdings nach tradierten Vorstellungen weite Entscheidungsspielräume zur Verfügung standen.

570 Mehr als eine vage Leitlinie kann aus der Wesentlichkeitsdoktrin nicht gewonnen werden, sodass die Wesentlichkeit doch im Einzelfall mit „Blick auf den jeweiligen Sachbereich und auf die Eigenart des betroffenen Regelungsgegenstandes“ ermittelt werden muss. Die Wesentlichkeit ist dabei nicht nur an der Bedeutung des betroffenen Rechtsgutes, sondern auch nach dem Grad der Betroffenheit dieses Rechtsgutes zu bestimmen. ${ }^{1135}$ Auf keinen Fall lässt sich die Wesentlichkeit aber mit der bloßen politischen Relevanz begründen. ${ }^{1136}$ Einschränkend betont das BVerfG allerdings die in Art. 20 II GG normierte organisatorische und funktionelle Unterscheidung und Trennung der Gewalten, die darauf abzielt, dass „staatliche Entscheidungen möglichst richtig, d.h. von den Organen getroffen werden, die dafür nach ihrer Organisation, Zusammensetzung, Funktion und Verfahrensweise über die besten Voraussetzungen verfügen. Dieses Ziel darf nicht durch einen Gewaltenmonismus in Form eines umfassenden Parlamentsvorbehalts unterlaufen werden““ ${ }^{1137}$

571 Die Wesentlichkeitstheorie gibt nicht nur Aufschluss über die Frage, ob überhaupt eine formell-gesetzliche Rechtsgrundlage erforderlich ist, sondern kann auch zur Klärung der erforderlichen Regelungsdichte herangezogen werden. Wenn der parlamentarische Gesetzgeber alle wesentlichen Entscheidungen selbst treffen muss, hat dies ein Delegationsverbot für die als wesentlich eingestuften Bereiche zur Folge. ${ }^{1138}$

(417f.); Beschl.v. 21.12.1977, Az.: 1 BvL 1/75 = BVerfGE 47, 46 (79); Beschl.v. 20.10.1981, Az.: 1 BvR 640/80 = BVerfGE 58, 257 (268ff.).

1134 BVerfG, Beschl. v. 21.10.1981, Az.: 1 BvR 52/81 = BVerfGE 58, 358 (366f.).

1135 So etwa Sommermann, in: von Mangold/Klein/Starck, GG, 7. Aufl. 2018, Art. 20 III Rn. 279 unter Bezugnahme auf den Facharzt-Beschluss des BVerfG v. 9.5.1972, Az.: 1 BvR 518/62 = BVerfGE 33, 125 (160).

1136 BVerfG, Urt. v. 14.7.1998, Az.: 1 BvR 1640/97 = BVerfGE 98, 218 (251); S. auch Sodan/Ziekow, Grundkurs Öffentliches Recht, 8. Aufl. 2018, § 24 Rn. 28.

1137 BVerfG, Urt. v. 14.7.1998, Az.: 1 BvR 1640/97 = BVerfGE 98, 218 (251f.); Beschl. v. 21.4.2015, Az.: 2 BvR 1322/12 = BVerfGE 139, 19 (46) - jeweils ohne die Hervorhebung.

1138 BVerfG, Beschl. v. 21.4.2015, Az.: 2 BvR 1322/12 = BVerfGE 139, 19 (47); Sodan/Ziekow, Grundkurs Öffentliches Recht, 8. Aufl. 2018, § 24 Rn. 29; Ossenbühl, in: Isensee/Kirchhof, Handbuch des Staatsrechts für die Bundesrepublik Deutschland, Band V, 3. Aufl. 2007, § 101 Rn. 30. Vgl. auch Grzeszick, in: Maunz/Dürig, GG, Art. 20 III Rn. 75 (Stand: August 2018). Zur praktischen Bedeutung des Delegationsverbotes für die untergesetzliche Normsetzung durch den Gemeinsamen Bundesausschuss s. Sodan/Hadank, NZS 2018, $804 \mathrm{f}$. 
Terminologisch ist der Parlamentsvorbehalt allerdings vom allgemeinen $\mathbf{5 7 2}$ Vorbehalt des Gesetzes zu unterscheiden. Der Parlamentsvorbehalt erfasst nicht zwingend normative Regelungen, sondern auch Entscheidungen in konkreten Einzelfällen. ${ }^{1139}$ Er ist somit begrifflich weiter gefasst als der Vorbehalt des Gesetzes.

\section{c) Prüfung der Ermächtigungsgrundlage im Rahmen der Anfechtungsklage}

Soweit mit der Anfechtungsklage belastende Verwaltungsakte angegriffen $\mathbf{5 7 3}$ werden, handelt es sich bei dem Klagegegenstand um eine Maßnahme der Eingriffsverwaltung, die grundsätzlich einer gesetzlichen Ermächtigung bedarf (zu diesem umfassenden Eingriffsvorbehalt bereits Rn. 560f.). Die Ermittlung einer tauglichen Ermächtigungsgrundlage bildet dann obligatorisch den ersten Schritt der Begründetheitsprüfung, wobei sich Ausführungen zur Frage, $o b$ eine gesetzliche Ermächtigung benötigt wird, erübrigen. Es ist vielmehr festzustellen, auf welche gesetzliche Ermächtigung sich die Verwaltung zur Legitimierung ihres Eingriffshandelns berufen kann. Werden begünstigende Verwaltungsakte der Leistungsverwaltung von Dritten, soweit sie hierzu klagebefugt sind, angefochten, kann die Frage, ob es überhaupt einer gesetzlichen Ermächtigung bedarf, allerdings virulent werden.

In der Prüfungsstruktur steht die Ermittlung der tauglichen Ermächtigungs- $\mathbf{5 7 4}$ grundlage an erster Stelle noch vor der formellen Rechtmäßigkeit; die dezidierten Voraussetzungen der Ermächtigungsgrundlage auf der Tatbestands- und Rechtsfolgenseite werden erst anschließend im Rahmen der materiellen Rechtmäßigkeit untersucht (vgl. Rn. 832ff.). Diese gewissermaßen vorweggenommene Prüfung der Ermächtigungsgrundlage ist erforderlich, da eine rechtliche Würdigung der formellen und materiellen Rechtmäßigkeit des angegriffenen Verwaltungsakts nur anhand einer konkreten Ermächtigungsgrundlage gelingen kann. ${ }^{1140}$ Wenn aber die einzelnen Voraussetzungen der Ermächtigungsgrundlage erst im Verlauf der weiteren Prüfung thematisiert werden, verbleibt für den ersten Prüfungsschritt der Begründetheit eine überschaubare Prüfungstiefe, die sich auf folgende zwei Kernfragen erstreckt:

- Es muss erstens festgestellt werden, dass überhaupt eine hinreichend bestimmte und ihrerseits rechtmäßige Ermächtigungsgrundlage besteht,

- die zweitens die konkret angegriffene Entscheidung der Verwaltung deckt. ${ }^{1141}$

1139 Ossenbühl, in: Isensee/Kirchhof, Handbuch des Staatsrechts für die Bundesrepublik Deutschland, Band V, 3. Aufl. 2007, § 101 Rn. 14.

1140 Ehlers, in: Ehlers/Schoch, Rechtsschutz im Öffentlichen Recht, 2009, § 22 Rn. 71.

1141 So auch Hufen, Verwaltungsprozessrecht, 11. Aufl. 2019, § 25 Rn. 12. 
Soweit die einschlägige Ermächtigungsgrundlage bereits offenkundig erkennbar ist (oder durch die Aufgabensteller im Sachverhalt vorgegeben wird), kann dieser Prüfungsschritt mit verhältnismäßig knappen Ausführungen abgehandelt werden. Kommen mehrere Vorschriften als taugliche Ermächtigungsgrundlage in Betracht, muss die am besten passende Norm lokalisiert werden. Die Kriterien für die Auswahl derjenigen Ermächtigungsgrundlage, die den erlassenen Verwaltungsakt am besten deckt, sind überschaubar. Insbesondere sind speziellere Vorschriften allgemeinen Regelungen vorzuziehen (zu dieser Problematik im Polizei- und Ordnungsrecht s. Rn. 1030 ff.). ${ }^{1142}$

Aufwändiger kann die Prüfung der Rechtsgrundlage dagegen sein, wenn zweifelhaft ist, ob die Rechtsgrundlage ihrerseits mit höherrangigem Recht vereinbar ist. Denn im Zuge der Anfechtungsklage prüft das Verwaltungsgericht nicht nur, ob der Verwaltungsakt mit der Ermächtigungsgrundlage, auf die er gestützt ist, in Einklang steht, sondern auch inzident die Vereinbarkeit der Ermächtigungsgrundlage mit höherrangigem Recht. ${ }^{1143} \mathrm{Ob}$ die Vereinbarkeit mit höherrangigem Recht bereits im Prüfungsschritt der Ermächtigungsgrundlage oder erst im Rahmen der materiellen Rechtmäßigkeit zu thematisieren ist, wird je nach Einzelfall unterschiedlich $\mathrm{zu}$ bewerten sein. ${ }^{1144}$ Es bietet sich allerdings eine Prüfung bereits bei der Feststellung der tauglichen Ermächtigungsgrundlage an: Sofern die Prüfung zu dem Ergebnis gelangt, dass die untergesetzliche Norm nicht mit höherrangigem Recht vereinbar ist, scheidet sie bereits als taugliche Ermächtigungsgrundlage aus, sodass sich die Folgeprüfung erübrigt und die Klausur im Hilfsgutachten fortzusetzen ist.

\section{d) Zusammenfassung}

577 Zusammenfassend kann somit festgehalten werden:

- Immer dann, wenn die Verwaltung durch ihr Handeln, Tun oder Unterlassen in Grundrechte eingreift, bedarf sie hierfür einer gesetzlichen Ermächtigung. Soweit es sich um eine untergesetzliche Rechtsgrundlage handelt, muss diese auf einer hinreichend bestimmten Ermächtigung gründen.

- Werden begünstigende Verwaltungsakte der Leistungsverwaltung durch Dritte angefochten, wird die Frage virulent, ob der Vorbehalt des Gesetzes greift. In der Leistungsverwaltung ist dies umstritten. Ein umfassender Totalvorbehalt wird nach herrschender Auffassung abgelehnt. Für den Bereich

1142 Hufen, Verwaltungsprozessrecht, 11. Aufl. 2019, § 25 Rn. 13.

1143 Decker, in: Posser/Wolff, VwGO, 49. Ed., Stand: 1.4. 2019, § 113 Rn. 13. Vgl. dazu auch Wolff, in: Sodan/Ziekow, VwGO, Kommentar, 5. Aufl. 2018, § 113 Rn. 28.

1144 Ehlers, in: Ehlers/Schoch, Rechtsschutz im Öffentlichen Recht, 2009, § 22 Rn. 71. 
der Subventionen gibt sich die Rechtsprechung mit der Legitimation der Verwaltung über die Ausweisungen des Haushaltsplans zufrieden.

- Bei der (vorweggenommenen) Prüfung der Ermächtigungsgrundlage genügt regelmäßig die kursorische Feststellung, ob die Ermächtigungsgrundlage den Erlass des angegriffenen Verwaltungsakts abdeckt.

\section{e) Literaturhinweise}

Jarass, Der Vorbehalt des Gesetzes bei Subventionen, NVwZ 1984, 473 ff.; Lerche, 578 in: Merten/Papier (Hrsg.), Handbuch der Grundrechte, Band III, 2009, § 62; Ossenbühl, in: Isensee/Kirchhof (Hrsg.), Handbuch des Staatsrechts für die Bundesrepublik Deutschland, Band V, 3. Aufl. 2007, § 101; Sodan/Ziekow, Grundkurs Öffentliches Recht, 8. Aufl. 2018, § 24 Rn. 27 ff.; § 7 Rn. 25ff.; Voßkuhle, Grundwissen - Öffentliches Recht: Der Grundsatz des Vorbehalts des Gesetzes, JuS 2007, 118

\section{Formelle Rechtmäßigkeit des Verwaltungsakts}

Im Anschluss an die Bestimmung der einschlägigen Ermächtigungsgrundlage ist 579 zu untersuchen, ob der Verwaltungsakt formell rechtmäßig ist. Die Prüfung wird regelmäßig in drei Schritten vorgenommen: Zuständigkeit, Verfahren, Form.

\section{a) Zuständigkeit (Sebastian Eickenjäger)}

Die Prüfung der Zuständigkeit betrifft zunächst die Frage, welcher Verwaltungs- 580 träger (Bund oder Länder) im Sinne der Verbandskompetenz zuständig ist. Maßgeblich sind hierbei die Regelungen des GG zur Verwaltungskompetenzverteilung (Art. 83 ff. GG). In der verwaltungsrechtlichen Klausur sind Probleme in diesem Bereich jedoch eher unüblich, da Streitigkeiten bzgl. der Kompetenzverteilung zwischen Bund und Ländern regelmäßig im verfassungsrechtlichen BundLänder-Streit gemäß Art. 93 I Nr. 3 GG ausgetragen werden. Dementsprechend soll in der Folge der Fokus auf die Frage der sogenannten Organkompetenz, d. h. die Frage, welche Behörde auf der Ebene des Bundes und in den einzelnen Bundesländern zuständig ist, gelegt werden.

Abgesehen von der Verbands- und Organkompetenz werden in der Litera- $\mathbf{5 8 1}$

tur noch die instanzielle und die funktionelle Zuständigkeit unterschieden. Die funktionelle Zuständigkeit betrifft nach wohl h.M. die behördeninterne Ver- 
teilung von Zuständigkeiten (in diesem Sinne: behördeninterne Zuständigkeit). ${ }^{1145}$ Von der instanziellen Zuständigkeit ist dann die Rede, wenn ausnahmsweise eine höhere Behörde eine Aufgabe wahrnimmt, die eigentlich einer unteren Behörde zugeteilt ist, mithin eine andere „Instanz“ zuständig wird. ${ }^{1146}$ Dies ist etwa der Fall, wenn eine höhere Behörde von einem gesetzlich geregelten Selbsteintrittsrecht Gebrauch macht oder wenn die nächsthöhere Behörde im Rahmen des Widerspruchsverfahrens als Widerspruchsbehörde tätig wird (s. hierzu Rn. 611ff.). ${ }^{1147}$

582 In der verwaltungsrechtlichen Klausur sind Kenntnisse zur Verteilung der Zuständigkeiten erforderlich, um die jeweils zuständige Behörde zu bestimmen (insbesondere dann, wenn dies im Sachverhalt nicht bereits eindeutig erfolgt ist) oder eventuelle Unzuständigkeiten und die Rechtsfolgen (Rechtswidrigkeit, Nichtigkeit und Heilung) herauszuarbeiten. Genaue Kenntnisse im Verwaltungsorganisationsrecht sind zudem für die Bestimmung des richtigen Klagegegners (s. hierzu Rn. 412f.) und im Rahmen der Prüfung des Widerspruchsverfahrens (s. hierzu Rn. $611 \mathrm{ff}$.) von Bedeutung.

583 Im Folgenden wird zunächst die Verteilung der Verwaltungskompetenzen zwischen Ländern und Bund im Sinne der Verbandskompetenz dargestellt. Im Anschluss daran werden in einem ersten Schritt die zur Bestimmung der sachlich zuständigen Behörden erforderlichen Grundlagen der Verwaltungsorganisation auf Bundes- und Landesebene sowie die Folgen eines Verstoßes gegen Zuständigkeitsbestimmungen vorgestellt. In einem zweiten Schritt werden sodann die Regelungen zur Bestimmung der örtlichen Zuständigkeit und die Folgen eines Verstoßes gegen ebendiese dargestellt.

\section{aa) Bestimmung der sachlichen Zuständigkeit}

584 Im vorliegenden Abschnitt wird auf die Verbandskompetenz (1), die Organkompetenz (2), die Zuständigkeit im Widerspruchsverfahren (3) und die Folgen eines Verstoßes gegen Bestimmungen der sachlichen Zuständigkeit (4) eingegangen.

\section{(1) Verbandskompetenz}

585 Die Verteilung der Verwaltungskompetenzen zwischen Bund und Ländern (Verbandskompetenz) ist im GG umfassend geregelt. Art. 30 GG fungiert zunächst

1145 Collin/Fügemann, JuS 2005, 694 (699), m.w. N.

1146 Collin/Fügemann, JuS 2005, 694 (698f.).

1147 Collin/Fügemann, JuS 2005, 694 (699), m.w. N.

Sebastian Eickenjäger 
als Generalklausel der Kompetenzverteilung ${ }^{1148}$ und bestimmt, dass die Ausübung staatlicher Befugnisse und die Erfüllung staatlicher Aufgaben zunächst Ländersache ist, soweit nicht das Grundgesetz andere Regelungen trifft oder zulässt. Die Art. 83ff. GG stellen ,andere Regelungen“ im Sinne des Art. 30 GG dar und sind für die Frage der Verwaltungskompetenzen in Bezug auf Bundesgeset$z^{1149}$ lex specialis. Da sich im GG „,andere Regelungen“ bezüglich der Verwaltung von Landesgesetzen nicht finden, liegt die Kompetenz für den Vollzug von Landesgesetzen gemäß Art. 30 GG bei den Ländern. Die Verwaltung von Landesgesetzen durch den Bund ist mithin unzulässig. ${ }^{1150}$ Dies betrifft in der Klausur besonders relevante Bereiche des besonderen Verwaltungsrechts, wie das Polizeirecht, das Bauordnungsrecht und mittlerweile in den Ländern, die eigene Versammlungsgesetze erlassen haben (also Bayern, Niedersachsen, Sachsen, Sachsen-Anhalt und Schleswig-Holstein), auch das Versammlungsrecht.

Bzgl. der Verwaltung der Bundesgesetze regelt Art. 83 GG, dass die Länder die Bundesgesetze als eigene Angelegenheit ausführen, soweit das GG nichts anderes bestimmt oder zulässt. Die Länder sind danach zunächst für die Verwaltung der Bundesgesetze zuständig und laut BVerfG auch verpflichtet, die Bundesgesetze auszuführen. ${ }^{1151}$ Die Verwaltung von Bundesrecht durch die Länder erfolgt zum einen im Wege der landeseigenen Verwaltung nach Art. 84 GG und zum anderen im Wege der Bundesauftragsverwaltung nach Art. 85 GG. Die landeseigene Verwaltung gemäß Art. 84 GG stellt dabei den Regeltypus des Vollzugs von Bundesgesetzen dar.

Im Bereich der landeseigenen Verwaltung gilt die Formel, dass der Bund zwar mit den Bundesgesetzen den Verwaltungsgegenstand (das „Was“) der Verwaltung bestimmt. Allerdings sind die Länder grds. gemäß Art. 84 I 1 GG frei in der Gestaltung der Organisation der Verwaltung (,Wer“) und der Gestaltung des Verwaltungsverfahrens („Wie“). ${ }^{1152}$ Diese grds. bestehenden Freiheiten werden in Art. 84 GG durch verschiedene Einflussmöglichkeiten des Bundes beschränkt.

1148 Erbguth, in: Sachs, GG, 8. Aufl. 2018, Art. 30, Rn. 7, m.w. N.

1149 Als Bundesgesetze im Sinne der Art. 83 ff. gelten das GG selbst, Gesetze im formellen Sinne, Rechtsverordnungen sowie unmittelbar geltende Normen des Rechts der Europäischen Union, auf die die Art. 83 ff. GG analog angewendet werden, Pieroth, in: Jarass/Pieroth, GG, 15. Aufl. 2018, Art. 83, Rn. 5.

1150 BVerfG, Urt. v. 28.02.1961, Az.: 2 BvG 1/60, 2 BvG 2/60 = BVerfGE 12, 205 (221); BVerfG, Beschl. v. 11.4.1967, Az.: 2 BvG 1/62 = BVerfGE 21, 312 (325ff.).

1151 BVerfG, Urt. v. 10.12.1980, Az.: 2 BvF 3/77 = BVerfGE 55, 274 (318); s. auch BVerfG, Beschl.v. 25.06.1974, Az.: 2 BvF 2/73, 2 BvF 3/73 = BVerfGE 37, 363 (385); BVerfG, Beschl. v. 08.04.1987, Az.: 2 BvR 909/82 u.a. = BVerfGE 75, 108 (150).

1152 Ipsen, Staatsrecht I, Staatsorganisationsrecht, 22. Aufl., 2010, Rn. 616. 
Das GG sieht eine abschließende Aufzählung der Bereiche vor, in denen die Länder im Wege der Auftragsverwaltung nach Art. 85 GG tätig werden (Enumerationsprinzip). Es unterscheidet dabei Bereiche der obligatorischen ${ }^{1153}$ Auftragsverwaltung, in denen eine Verwaltung durch die Länder zwingend vorgegeben ist und Bereiche der fakultativen ${ }^{1154}$ Auftragsverwaltung, in denen es dem Bund offensteht, den Ländern einen Verwaltungsbereich zur Auftragsverwaltung zuzuweisen. Der Begriff „Auftragsverwaltung“ könnte so verstanden werden, dass die Länder in diesem Bereich des Vollzugs von Bundesrecht im Namen des Bundes handeln würden. Tatsächlich ist die Auftragsverwaltung jedoch ebenso eine Form der Landesverwaltung, denn die Länder üben auch hier Landesstaatsgewalt aus. ${ }^{1155}$ Sie (bzw. ihre Behörden) handeln als Landesorgane und nicht als Bundesorgane.

589 Examenswissen: Im Vergleich zur landeseigenen Verwaltung nach Art. 84 GG bestehen im Bereich der Bundesauftragsverwaltung für den Bund weitergehende Einwirkungsmöglichkeiten (durch die Gesetzgebung des Bundes gemäß Abs. 1, der Bundesregierung nach Abs. 2 und 4 S. 2 sowie der obersten Bundesbehörden gemäß Abs. 2, 3 und 4 S. 1).

590 Zuletzt gibt es Bereiche, in denen Bundesrecht vom Bund verwaltet wird. Bei den Verwaltungskompetenzzuweisungen an den Bund handelt es sich insbesondere um die Regelungen zur bundeseigenen Verwaltung gemäß der Art. 86 ff. GG. ${ }^{1156}$

591 Examenswissen: Die Verwaltungszuständigkeit wird in den Art. 86 ff. GG nur insoweit dem Bund übertragen, als es das GG ausdrücklich vorsieht oder zulässt. Es gilt also - ebenso wie bei der Auftragsverwaltung nach Art. 85 GG - grundsätzlich das Enumerationsprinzip. Die Regelzuständigkeit der Länder wird nach den Art. 86 ff. GG entweder obligatorisch ${ }^{1157}$ oder fakultativ ${ }^{1158}$ an den Bund übergeben. Das bedeutet, dass der Bund entweder zur bundeseigenen Verwaltung verpflichtet ist (obligatorisch), oder ihm die Übernahme der Verwaltungszuständigkeit offensteht (fakultativ).

1153 Vgl. Art. 90 II GG, Art 104a III 2 GG und Art 108 II 1 GG.

1154 Vgl. Art 87b II 1 GG, Art 87c GG, Art 87d II GG, Art 89 II 3 und 4 GG sowie Art 120a I 1 GG. 1155 BVerfG, Urt. v. 22.05.1990, Az.: 2 BvG 1/88 = BVerfGE 81, 310 (331).

1156 Darüber hinaus sind hierzu die Regelungen zur Länderverwaltung im Zusammenwirken mit dem Bund (Art. 91a - 91e GG) und zur alleinigen Verwaltung durch die Gemeinden (Art. 91e II GG) zu zählen.

1157 Z. B. Art. 87 I 1 GG, Art. 87 I 1 GG oder auch Art. 87 d I 1 GG.

1158 Z.B. Art. 87 I 2 GG oder Art. 87 b I 3 und II 1 GG. 


\section{(2) Organkompetenz}

Im vorliegenden Abschnitt soll ein Überblick über den Verwaltungsaufbau auf der $\mathbf{5 9 2}$ Ebene des Bundes (a) und der Länder (b) gegeben werden.

\section{(a) Bundesverwaltungsaufbau}

Im Gegensatz zu den Ländern hat der Bund keine allgemeinen Verwaltungsbe- 593 hörden, sondern nur Sonderverwaltungsbehörden. ${ }^{1159}$ Bei der Bundesverwaltung ist zunächst zu unterscheiden, ob der Bund in mittelbarer oder unmittelbarer Staatsverwaltung tätig wird.

Um einen Fall unmittelbarer Staatsverwaltung handelt es sich, wenn Or- 594 gane des Staates dessen Aufgaben selbst erfüllen. Man spricht also von unmittelbarer Staatsverwaltung, wenn Landes- oder Bundesbehörden (unmittelbar) für das betreffende Land oder den Bund deren Aufgaben wahrnehmen.

Ein Fall der mittelbaren Staatsverwaltung liegt dagegen vor, wenn der $\mathbf{5 9 5}$ Bund oder die Länder nicht durch eigene Behörden tätig werden, sondern auf öffentlich-rechtliche Körperschaften, Anstalten oder Stiftungen sowie Beliehene zurückgreifen, die Länder insbesondere auf die Gemeinden als Gebietskörperschaften.

Examenswissen: Die Gemeinden und Gemeindeverbände nehmen aufgrund ihrer besonderen verfassungsrechtlichen Stellung (Art. 28 II GG) im Gegensatz zu anderen öffentlich-rechtl. Körperschaften eine Sonderstellung ein, da sie einen umfassenden Aufgabenkreis haben, Gebietshoheit besitzen und aufgrund ihrer unmittelbar gewählten Volksvertretung - und damit kraft demokratischer Legitimation - zu eigener Willensbildung befähigt sind. ${ }^{1160}$

Soweit der Bund im Rahmen der unmittelbaren Staatsverwaltung tätig wird, 597 sind die Bundesministerien als Spitze der Verwaltung oberste Bundesbehörden. Den obersten Bundesbehörden unmittelbar nachgeordnet sind sogenannte Bundesoberbehörden, welche - als Sonderverwaltungsbehörden sachlich für einen bestimmten Verwaltungsbereich und örtlich für das gesamte Bundesgebiet zuständig sind, weshalb sie auch i.d. R. keinen Unterbau besitzen. Ein prominentes Beispiel hierfür ist das Bundesamt für Migration und Flüchtlinge

1159 Maurer/Waldhoff, Allgemeines Verwaltungsrecht, 19. Aufl. 2017, § 22, Rn. 35.

1160 Maurer/Waldhoff, Allgemeines Verwaltungsrecht, 19. Aufl. 2017, § 21, Rn. 9. Zur Gewährleistung kommunaler Selbstverwaltung im Allgemeinen s. Hellermann, in: Epping/Hillgruber, GG, 39. Ed., Stand:15.11.2018, Art. 28, Rn. 20 ff.; Schwarz, in: v. Mangoldt/Klein/Starck, GG, 7. Aufl. 2018, Art. 28, Rn. 126 ff.; Löwer, in: v. Münch/Kunig, GG, 6. Aufl. 2012, Art. 28, Rn. 35 ff. 
(BAMF), das dem Bundesinnenministerium untergeordnet ist. ${ }^{1161}$ Insofern ist die Verwaltung in diesen Fällen grundsätzlich zweistufig aufgebaut. Bereiche. Auch hier bilden die Ministerien die oberste Stufe, die mittlere Stufe stellen für den jeweiligen Zuständigkeitsbereich spezialisierte Bundesbehörden (Bundesmittelbehörden) dar. Die untere Stufe bilden abschließend insbesondere Standortverwaltungseinheiten.

Ein Beispiel ist die Bundeswehrverwaltung gemäß Art. 87b I1 GG. Hier steht auf oberster Stufe das Bundesverteidigungsministerium, auf mittlerer Stufe die Wehrbereichsverwaltung. Die Karrierecenter sowie Standortverwaltungen etc. bilden als Unterbehörden die untere Stufe. Das $B A M F$ hingegen ist eine Bundesoberbehörde, die nicht mit Mittel- oder Unterbehörden, sondern mit unselbstständigen Außenstellen in den einzelnen Bundesländern ausgestattet ist. ${ }^{1162}$

599 Soweit der Bund im Rahmen der mittelbaren Staatsverwaltung tätig wird, bedient er sich öffentlich-rechtlicher Körperschaften, Stiftungen und Anstalten des Bundes sowie Beliehener. ${ }^{1163}$ Soweit ein Fall der Bundesverwaltung vorliegt, regelt der Bund auch die Frage der Zuständigkeit.

Das AsylG beispielsweise regelt in $\S 5$ AsylG den Aufgabenbereich des BAMF, in Abs. 1 S. 1 insbesondere die Zuständigkeit für die Entscheidung über Asylanträge.

\section{(b) Landesverwaltungsaufbau}

600 Wie die Länder ihre Verwaltung organisieren, ist ihnen grundsätzlich selbst überlassen. Die Verwaltungsorganisation in den Ländern ist traditionell dreistufig aufgebaut, wobei auch hier zwischen der Oberstufe, der Mittelstufe und der Unterstufe unterschieden werden kann.

601 Examenswissen: Es ist jedoch darauf hinzuweisen, dass derzeit eine Tendenz zum zweistufigen Aufbau besteht. ${ }^{1164}$ Nur Hessen, Baden-Württemberg, Bayern, Nordrhein-Westfalen, Sachsen,

1161 Weitere Beispiele sind etwa das Bundesverwaltungsamt und das Bundeskartellamt.

1162 Clodius, in: Hofmann, Kommentar Ausländerrecht, 2. Aufl. 2016, § 5 AsylG, Rn. 1.

1163 Auch bundesunmittelbare Körperschaften, Anstalten und Stiftungen des öffentlichen Rechts genannt, vgl. Bull/Mehde, Allgemeines Verwaltungsrecht mit Verwaltungslehre, 9. Aufl. 2015, § 3, Rn. 114. Beispielsweise angeführt werden können die in Art. 87 II GG genannten Sozialversicherungsträger (als Körperschaften).

1164 Zur praktischen Sichtweise hinsichtlich der Notwendigkeit der Mittelinstanzen in Flächenstaaten s. Twenhoven, Die Mittelinstanz im Verwaltungsaufbau, in: Ipsen, Verwaltungsorganisation in Flächenstaaten - 18. Bad Iburger Gespräche, 2008, der sich hierzu positiv ausspricht. 
Sachsen-Anhalt und Thüringen weisen noch einen dreistufigen Verwaltungsaufbau auf. ${ }^{1165}$ Dass der dreistufige Verwaltungsaufbau als Grundmodell angesehen wird, hat vor allem auch historische Gründe, denn die Mittelinstanz war wesentlicher Bestandteil des preußischen Verwaltungsaufbaus (Regierungsbezirke) und hat sich zunächst auch nach 1945 in den meisten Flächenländern durchgesetzt.

Die Oberste Stufe bilden die obersten Landesbehörden, d.h. die einzelnen Mi602 nisterpräsident ${ }^{\star}$ innen und ihre jeweiligen Ministerien (bzw. in Berlin die Senatsverwaltungen, in Bremen die senatorischen Behörden sowie in Hamburg die Senats- und Fachbehörden).

Auch auf Landesebene gibt es zudem spezielle obere Landesbehörden bzw.

Landesoberbehörden, welche sachlich für einen bestimmten Bereich und örtlich für das gesamte Landesgebiet zuständig sind und den Ministerien unmittelbar unterstehen. Soweit Landesoberbehörden eingerichtet sind, ist der Verwaltungsaufbau auf Landesebene grundsätzlich zweistufig. ${ }^{1166}$

Handelt es sich um einen dreistufigen Aufbau, finden sich auf der Mittel- 604 stufe zunächst die Bezirksregierungen oder die Regierungspräsident`innen (Regierungspräsidium). Diese fungieren als allgemeine Verwaltungsbehörden, so dass die Zuständigkeit dieser Einheiten durch Sonderverwaltungsbehörden verdrängt werden kann. Den Mittelbehörden kommt im Wesentlichen die Aufgabe $\mathrm{zu}$, zwischen den obersten Landesbehörden und der Unterstufe zu vermitteln und $\mathrm{zu}$ koordinieren. ${ }^{1167}$

Auf der Unterstufe bestehen nur wenige Landesbehörden (Sonderverwal- $\mathbf{6 0 5}$ tungsbehörden), denn im Bereich der allgemeinen Verwaltung stellen die Gemeinden und Gemeindeverbände dem Staat (also den Ländern) ihre Behörden zu Verfügung. ${ }^{1168}$

Examenswissen: Es können dabei zwei Modelle der unteren allgemeinen Verwaltungsbehörde $\mathbf{6 0 6}$ unterschieden werden: Auf der einen Seite steht ein Modell, bei dem die untere Verwaltungsbe-

1165 Thüringen, Sachsen und Sachsen-Anhalt haben indes keine dezentrale Struktur, sondern ein landesweit zuständiges „Landesverwaltungsamt“. Ähnliche zentrale Strukturen finden sich in Rheinland-Pfalz und dem Saarland, wobei hier die zentralen Einheiten auf der Oberebene angesiedelt sind. S. zu alledem Burgi, Verwaltungsorganisationsrecht, in: Ehlers/Pünder, Allgemeines Verwaltungsrecht, 15. Aufl. 2016, §9, Rn. 16 m.w. N.

1166 Im Gegensatz zu den Bundesoberbehörden können die Landesoberbehörden jedoch über „untere Sonderbehörden“ verfügen, s. Burgi, Verwaltungsorganisationsrecht, in: Ehlers/Pünder, Allgemeines Verwaltungsrecht, 15. Aufl. 2016, § 9, Rn. 15.

1167 Bull/Mehde, Allgemeines Verwaltungsrecht mit Verwaltungslehre, 9. Aufl. 2015, § 3, Rn. 117. 1168 Bull/Mehde, Allgemeines Verwaltungsrecht mit Verwaltungslehre, 9. Aufl. 2015, § 3, Rn. 119; Burgi, Verwaltungsorganisationsrecht, in: Ehlers/Pünder, Allgemeines Verwaltungsrecht, 15. Aufl. 2016, § 9, Rn. 17. 
hörde vollständig kommunalisiert ist, d.h. es findet eine Verwaltung auf der Ebene der mittelbaren Staatsverwaltung statt. Die Aufgaben werden hier übertragen auf die kreisfreien Städte, ${ }^{1169}$ die Landkreise ${ }^{1170}$ oder auf die Kommunen selbst. ${ }^{1171}$ Auf der anderen Seite steht ein Modell, in dem die Landrät`innen ${ }^{1172}$ (jeweils als Organ des Verwaltungsträgers Landkreis) außerhalb der kreisfreien Städte als untere Verwaltungsbehörde auftreten. Den Landrät`innen kommt hierbei eine Doppelstellung zu: Staatsverwaltung und kommunale Selbstverwaltung werden verknüpft, indem Landrät*innen zum einen kommunale Angelegenheiten wahrnehmen und zum anderen staatliche Aufgaben im Wege der Organleihe (der Landkreis leiht dem Staat sein Organ). ${ }^{1173}$

607 Auf Landesebene ist bzgl. der Frage, welche Behörde zuständig ist, danach zu unterscheiden, ob das Land Gesetze des Bundes (im Wege der landeseigenen Verwaltung gemäß Art. 84 GG oder der Bundesauftragsverwaltung nach Art. 85 GG) oder eigenes Landesrecht vollzieht. Da die Länder im Rahmen der Verwaltung von Bundesrecht im Hinblick auf die Gestaltung der behördlichen Verwaltung ${ }^{1174}$ nach Art. 84 und 85 GG grds. frei sind, kann der Bund die Zuständigkeit auf Landesebene grds. nicht bestimmen.

608 Examenswissen: Art. 84 I und 85 I GG sehen zwar die Möglichkeit vor, dass der Bund Einfluss auf die Organisation nimmt. Hierbei handelt es sich jedoch in der Praxis um eine Ausnahme. Auch die Befugnisse in Art. 84 II und V GG ermöglichen es der Bundesregierung, Vorgaben hinsichtlich Organisations- und Verfahrensfragen zu treffen, wobei die Gebrauchnahme von dieser Kompetenz in der Praxis ebenfalls sehr selten ist. Die VwV-StVO fordert z. B. in Nr. I bis V VwV-StVO zu § 44 StVO von den Ländern, Unfalluntersuchungen durchzuführen und Unfallkommissionen einzurichten.

609 Aus diesem Grund erlassen die Länder für die Verwaltung von Bundesgesetzen die Zuständigkeit regelnde Ausführungsgesetze oder Zuständigkeitsverordnun-

1169 Die kreisfreien Städte sind keinem Kreis zugeordnet und haben staatliche und kommunale Aufgaben wahrzunehmen. Zur der Sonderstellung der großen Kreisstädte s. Maurer/Waldhoff, Allgemeines Verwaltungsrecht, 19. Aufl. 2017, § 22, Rn. 27.

1170 Landkreise sind Gemeindeverbände im Sinne des Art. 28 II 2 GG (Mitglieder sind die kreisangehörigen Gemeinden) und als solche Gebietskörperschaften (insofern sind Mitglieder nicht die kreisangehörigen Gemeinden, sondern die Bewohner des Kreises), welchen generell die Aufgabe zukommt, die Gemeinden bei der Erledigung ihrer Aufgaben von überörtlicher Bedeutung zu unterstützen.

1171 Sog. Vollkommunalisierung.

1172 Landrät*innen sind die Hauptorgane und Hauptverwaltungsbeamt*innen der Landkreise. 1173 Maurer/Waldhoff, Allgemeines Verwaltungsrecht, 19. Aufl. 2017, § 22, Rn. 23f.; Burgi, Verwaltungsorganisationsrecht, in: Ehlers/Pünder, Allgemeines Verwaltungsrecht, 15. Aufl. 2016, § 9 , Rn. 17.

1174 Gemäß Art. 83 GG führen sie die Bundesgesetze in diesem Sinne ,als eigene Angelegenheit aus“.

\section{Sebastian Eickenjäger}


gen. ${ }^{1175}$ Wenn es um den Vollzug von Landesrecht geht, finden sich Zuständigkeitsbestimmungen hingegen regelmäßig unmittelbar in den Landesgesetzen, wie z. B. den Landesbauordnungen (näher Rn. 1227 ff.) oder den Landespolizeigesetzen (näher Rn. 1000 ff.).

Examenswissen: Zur Verdeutlichung soll auf die Frage der Bestimmung der zuständigen Behörden im Versammlungsrecht verwiesen werden: Im Bereich des Versammlungsrechts haben bisher nicht alle Bundesländer von der 2006 auf die Länder übergegangenen Gesetzeskompetenz Gebrauch gemacht. Das Versammlungsrecht war bis zur Föderalismusreform (2006) Gegenstand der konkurrierenden Gesetzgebung (Art. 74 I Nr. 3 GG a. F.) und ist nunmehr Gegenstand der ausschließlichen Gesetzgebungskompetenz der Länder. Bis alle Bundesländer eigene Versammlungsgesetze erlassen haben, gilt gemäß der Übergangsvorschrift des Art. 125a I GG, dass das Bundesversammlungsgesetz (als Bundesrecht) fort gilt, bis es durch die Länder durch Landesrecht ersetzt wird. Während das Niedersächsische Versammlungsgesetz (NdsVersG) in § 24 NdsVersG die Frage der sachlichen Zuständigkeit regelt, finden sich in Nordrhein-Westfalen, das bisher kein eigenes Versammlungsgesetz erlassen hat, entsprechende Zuständigkeitsregelungen in der Verordnung über Zuständigkeiten nach dem Versammlungsgesetz ${ }^{1176}$ (also dem Bundesversammlungsgesetz) (näher dazu Rn. 1174) ${ }^{1177}$. Gemäß § 24 I 1 NdsVersG ist zuständige Behörde vor Versammlungsbeginn die untere Versammlungsbehörde und nach Versammlungsbeginn die Polizei. Laut § 24 I 2 NdsVersG nehmen die Aufgaben der unteren Versammlungsbehörde die Landkreise, kreisfreien Städte, großen selbständigen Städte und selbständigen Gemeinden wahr, auf dem Gebiet der Landeshauptstadt Hannover die Polizeidirektion Hannover.

\section{(3) Zuständigkeit im Widerspruchsverfahren}

Soweit ein Vorverfahren statthaft ist, ist $\S 73$ I 2 VwGO für die Bestimmung der zuständigen Widerspruchsbehörde maßgeblich. Danach erlässt den Widerspruchsbescheid zunächst gemäß § 73 I 2 Nr. 1 VwGO die nächsthöhere Behörde, soweit nicht durch Gesetz eine andere höhere Behörde bestimmt wird. In dreistufig aufgebauten Ländern ist die Widerspruchsbehörde damit regelmäßig auf der Mittelstufe zu finden. Soweit das betreffende Bundesland einen zweistufigen Verwaltungsbau aufweist, ist es in der Regel so, dass eine untere Verwaltungsbehörde als Ausgangsbehörde den streitigen Verwaltungsakt erlassen hat und es sich bei der nächsthöheren Behörde um eine oberste Landesbehörde handelt. In diesen Fällen ist §73 I 2 Nr. 2 VwGO zu beachten. Dieser bestimmt, dass ausnahmsweise die Behörde, die den Verwaltungsakt erlassen hat zuständig ist,

1175 Collin/Fügemann, JuS 2005, 694 (698).

1176 v. 2.2.1987 (GV. NRW. S. 62), zuletzt geändert durch Verordnung v. 9.9.2014 (GV. NRW. S. 500).

$1177 \S 1$ der Verordnung ermächtigt im Hinblick auf die meisten Eingriffsbefugnisse die Kreispolizeibehörden. 
wenn die nächsthöhere Behörde eine oberste Bundes- oder oberste Landesbehörde ist.

612 Handeln Selbstverwaltungsbehörden, ${ }^{1178}$ ist für die Bestimmung der zuständigen Widerspruchsbehörde zudem § 73 I 2 Nr. 3 VwGO zu beachten. Hiernach ist in Selbstverwaltungsangelegenheiten die Selbstverwaltungsbehörde zuständig, soweit nicht durch Gesetz anderes bestimmt wird. Sofern die Selbstverwaltungsbehörde jedoch in Auftragsangelegenheiten ${ }^{1179}$ tätig wird, ist $§ 73$ I 2 Nr. 3 VwGO nicht anwendbar.

613 Examenswissen: Selbstverwaltungsangelegenheiten auf kommunaler Ebene sind Angelegenheiten der örtlichen Gemeinschaft bzw. „diejenigen Bedürfnisse und Interessen, die in der örtlichen Gemeinschaft wurzeln oder auf sie einen spezifischen Bezug haben $\{. .$.$\} , die also den Gemein-$ deeinwohnern gerade als solchen gemeinsam sind, indem sie das Zusammenleben und -wohnen der Menschen in der (politischen) Gemeinde betreffen". ${ }^{1180}$ Unterschieden werden können die freiwillige Aufgaben und Pflichtaufgaben: Freiwillige Aufgaben sind z.B. kommunale Einrichtungen wie Spielplätze, Sportplätze oder Schwimmbäder. Pflichtaufgaben sind z. B. die Bauleitplanung und die Feuerwehr.

$614 \mathrm{Zu}$ beachten ist, dass gemäß § 185 II VwGO die Länder Berlin, Brandenburg, Bremen, Hamburg, Mecklenburg-Vorpommern, Saarland und Schleswig-Holstein Abweichungen von § 73 I 2 VwGO zulassen können. ${ }^{1181}$ Gemäß § 73 I 3 VwGO kann zudem abweichend von $\S 73$ I 2 Nr. 1 VwGO durch Gesetz bestimmt werden, dass die Behörde, die den Verwaltungsakt erlassen hat, auch für die Entscheidung über den Widerspruch zuständig ist.

\section{(4) Folgen eines Verstoßes gegen die sachliche Zuständigkeit}

615 Ein Verstoß gegen die Vorgaben zur sachlichen Zuständigkeit führt zur Rechtswidrigkeit. Eine Heilung gemäß § 45 VwVfG kommt bei Zuständigkeitsfehlern

1178 Also Gemeinden, Kreise, sonstige kommunale Selbstverwaltungskörperschaften, sonstige kommunale Zweckverbände, Handwerkskammern, Industrie- und Handelskammern, die berufsständischen Kammern für Ärzt`innen, Apotheker^innen, Rechtsanwältinnen, Architektinnen, Universitäten und sonstige selbstverwaltete Körperschaften, Hüttenbrink, in: Posser/Wolff, VwGO, 49. Ed., Stand: 1.4.2018, §73, Rn. 5.

1179 Auftragsangelegenheiten sind staatliche Aufgaben, die den Gemeinden zur Erledigung übertragen worden sind, wie z.B. das Pass- und Meldewesen und die Bauaufsicht, Maurer/ Waldhoff, Allgemeines Verwaltungsrecht, 19. Aufl. 2017, § 23, Rn. 19.

1180 BVerfG, Beschl. v. 23.11.1988, Az.: 2 BvR 1619, 1628/83 = BVerfGE 79, 127 (151f.); so auch BVerwG, Urt. v. 14.12.1990, Az.: 7 C 37.89 = BVerwGE 87, 228 (231f.).

1181 Von §73 I 2 VwGO abweichende Regelungen getroffen haben Bremen (Art. 9 BremAGVwGO), Hamburg ( 77 HmbAGVwGO) und das Saarland (§§ 7 bis 17 SaarlAGVwGO). 
nicht in Betracht. ${ }^{1182} \mathrm{Ob}$ darüber hinaus ein Verstoß zur Nichtigkeit führt, ist am Maßstab des § 44 I VwVfG zu bestimmen. Wenn im Einzelfall die gegenständliche Angelegenheit unter keinem sachlichen Gesichtspunkt Bezug zum Aufgabenbereich der handelnden Behörde aufweist und dies zudem auch offensichtlich ist, spricht dies nach § 44 I VwVfG für die Nichtigkeit (s. § 6 Rn. 156). ${ }^{1183}$

Ein Verstoß im Hinblick auf die verschiedenen Hierarchiestufen der Behördenorganisation führt zwar zur Rechtswidrigkeit - z. B. wenn eine Aufsichtsbehörde ohne Rechtsgrundlage selbst gehandelt und nicht etwa die untere Behörde angewiesen hat - allerdings regelmäßig nicht zur Nichtigkeit eines Verwaltungsakts, da einem solchen Verstoß „kein entsprechend hoher Rechtswert zukommt, der einen besonders schwerwiegenden Fehler begründen könnte“. ${ }^{1184}$

Die Unbeachtlichkeit eines Verstoßes gegen die sachliche Zuständigkeit $\mathbf{6 1 7}$ kommt aufgrund des eindeutigen Wortlautes des $§ 46$ VwVfG, der ausdrücklich nur Verstöße gegen die die „örtliche“ Zuständigkeit umfasst, nicht in Betracht. ${ }^{1185}$ $\mathrm{Zu}$ beachten ist hierbei jedoch, dass durch spezialgesetzliche Regelungen die Unbeachtlichkeit einer Verletzung von Vorschriften über die sachliche Zuständigkeit vorgesehen sein kann. ${ }^{1186}$

\section{bb) Örtliche Zuständigkeit}

Sofern nicht die Verwaltungsverfahrensgesetze der Länder (s. zu deren Anwendungsbereich näher Rn. 621$)^{1187}$ oder Spezialgesetze ${ }^{1188}$ Anwendung finden, er-

1182 Hufen, Verwaltungsprozessrecht, 10. Aufl. 2016, § 25, Rn. 4.

1183 Schemmer, in: Bader/Ronellenfitsch, VwVfG, 43. Ed., Stand: 1.4.2019, §44, Rn. 25 mit Verweis auf BVerwG, Urt. v. 22.3. 1974, Az.: IV C 42/73 = NJW NJW 1974, 1961 (1963); OVG Münster, Urt. v. 27.06.2014, Az.: 16 D 31/13.AK = BeckRS 2014, 53467.

1184 Schemmer, in: Bader/Ronellenfitsch, VwVfG, 43. Ed., Stand: 1.4.2019, §44, Rn. 25 mit Verweis auf BVerwG, Urt. v. 14.11.1975, Az.: IV C 2.74 = BVerwGE 49, 365 (371).

1185 Sachs, in: Stelkens/Bonk/Sachs, VwVfG, 9. Aufl. 2018, § 46, Rn. 43; Schemmer, in: Bader/ Ronellenfitsch, VwVfG, 43. Ed., Stand: 1.4. 2019, § 46, Rn. 32.

1186 BVerwG, Urt.v. 29.9.1982, Az.: 8 C 138.81 = BVerwGE 66, 178 (183). Eine entsprechende Norm stellt beispielsweise Art. 53 II 5 BayBO dar.

1187 Die Länder Berlin, Brandenburg, Niedersachsen, Sachsen, Sachsen-Anhalt und RheinlandPfalz verweisen in ihren Verwaltungsverfahrensgesetzen auf das VwVfG des Bundes (,Verweisungsgesetze“). In den folgenden Ländern finden sich ausformulierte Verwaltungsverfahrensgesetze (,Vollgesetze“) und entsprechend eigene Bestimmungen zur örtlichen Zuständigkeit: Baden-Württemberg ( $\$ 3$ LVwVfG), Bayern (Art. 3 BayVwVfG), Bremen ( 33 BremVwVfG), Hamburg ( 33 HmbVwVfG), Hessen (§ 3 HVwVfG), Mecklenburg-Vorpommern ( 3 VwVfG M-V), NordrheinWestfalen (§ 3 VwVfG NRW), Saarland (§ 3 SVwVfG), Schleswig-Holstein ( $\S 29$ bis 31 LVwG) und Thüringen (§ 3 ThürVwVfG). 
gibt sich die örtliche Zuständigkeit aus § 3 VwVfG. §3 I VwVfG regelt die unterschiedlichen Anknüpfungspunkte für die Bestimmung der örtlichen Zuständigkeit. Die in Abs. 1 aufgeführten Zuständigkeitstatbestände schließen sich wechselseitig aus und sind in der vorgegebenen Reihenfolge zu prüfen. ${ }^{1189} \S 3$ II VwVfG regelt sodann den Fall der Mehrfachzuständigkeit, § 3 III VwVfG den Zuständigkeitswechsel und § 3 IV VwVfG schließlich die örtliche Zuständigkeit bei Gefahr im Verzug.

619 Verstöße gegen $\S 3$ VwVfG führen an sich zunächst einmal zur Rechtswidrigkeit des behördlichen Handelns. In einem zweiten Schritt stellt sich sodann die Frage, ob mit der Rechtswidrigkeit auch eine Nichtigkeit einhergeht. Dies ist gemäß § 44 II Nr. 3 VwVfG nur im Falle eines Verstoßes gegen § 3 I Nr. 1 VwVfG ${ }^{1190}$ der Fall (s. näher § 6 Rn. 127 ff.). In den übrigen Fällen des § 3 VwVfG ist ein Verstoß nach $\S 46$ VwVfG unbeachtlich, wenn offensichtlich ist, dass die Verletzung die Entscheidung in der Sache nicht beeinflusst hat (näher dazu Rn. 664).

\section{cc) Literaturhinweise}

620 Allgemein zur Zuständigkeit: Bull/Mehde, Allgemeines Verwaltungsrecht mit Verwaltungslehre, 9. Aufl. 2015, §3; Burgi, Verwaltungsorganisationsrecht, in: Ehlers/Pünder, Allgemeines Verwaltungsrecht, 15. Aufl. 2016, §§ 7 bis 10; Collin/ Fügemann, Zuständigkeit - eine Einführung zu einem Grundelement des Verwaltungsorganisationsrechts, JuS 2005, 694; Detterbeck, Allgemeines Verwaltungsrecht mit Verwaltungsprozessrecht, 17. Aufl. 2019, § 5; Frenzel, Grundfälle zu den Art. 83 ff. GG, JuS 2012, 1082; Maurer/Waldhoff, Allgemeines Verwaltungsrecht, 19. Aufl. 2017, § 21 bis 23; Voßkuhle/Kaiser, Die Ausführung von Bundesgesetzen - Verwaltungskompetenzen, JuS 2017, 316

$\mathrm{Zu}$ den Besonderheiten der Verwaltungsorganisation in den einzelnen Bundesländern s. insbesondere folgende Beiträge: Baden-Württemberg: Kenntner, Öffentliches Recht in Baden-Württemberg, 2. Aufl. 2017, 100 ff.; Bayern: Kempen, Verfassungsrecht, in: Becker/Heckmann/Kempen/Manssen, Öffentliches Recht in Bayern, 6. Aufl. 2015, 1 ff. (42ff.); Brandenburg: Hebeler, Verwaltungsorganisationsrecht, in: Bauer/Peine, Studienbuch Landesrecht Brandenburg, 3. Aufl. 2017, S. $78 \mathrm{ff}$.; Berlin: Waldhoff/Holland, Verfassungs- und Organisationsrecht, in Sie-

1188 Klausurrelevant sind insbesondere die besonderen Bestimmungen in den Landespolizeigesetzen.

1189 Ronellenfitsch, in: Bader/Ronellenfitsch, VwVfG, 43. Ed., Stand: 1.4.2019, § 3, Rn. 5.

1190 Hiernach ist in Angelegenheiten, die sich auf unbewegliches Vermögen oder ein ortsgebundenes Recht oder Rechtsverhältnis beziehen, die Behörde örtlich zuständig, in deren Bezirk das Vermögen oder der Ort liegt.

Sebastian Eickenjäger 
gel/Waldhoff, Öffentliches Recht in Berlin, 1. Aufl. 2015, 1ff. (107ff.); Bremen: Eickenjäger, Grundlagen der Verwaltungsorganisation und des Verwaltungshandelns, in: Fischer-Lescano/Sperlich, Studienbuch Landesrecht Bremen, 1. Aufl. 2018, S. 35 ff.; Hamburg: Bull, Recht der Verwaltungsorganisation und des Verwaltungshandelns, in: Hoffmann-Riem/Koch, Hamburgisches Staats- und Verwaltungsrecht, 1. Aufl. 2006, S. 89 ff. ; Hessen: Hermes, Allgemeines Landesverwaltungsrecht, in: Hermes/Reimer, Studienbuch Landesrecht Hessen, 9. Aufl. 2019, S. 70 ff.; Mecklenburg-Vorpommern: Wallerath, Verwaltungsorganisation, Verwaltungsverfahren, in: Schütz/Classen, Studienbuch Landesrecht Mecklenburg-Vorpommern, 3. Aufl. 2014, S. 70 ff.; Niedersachsen: Mehde, Verwaltungsorganisation, in: Hartmann/Mann/Mehde, Studienbuch Landesrecht Niedersachsen, 2. Aufl. 2018, S. 56 ff.; Nordrhein-Westfalen: Sydow, Verwaltungsrecht, in: Schlacke/Wittreck, Studienbuch Landesrecht Nordrhein-Westfalen, 1. Aufl. 2017, S. 79 ff.; Rheinland-Pfalz: Schröder, Grundlagen der Verwaltungsorganisation und des Verwaltungshandelns, in: Hufen/Jutzi/Proelß, Studienbuch Landesrecht Rheinland-Pfalz, 8. Aufl. 2018, S. 83 ff.; Saarland: Gröpl, Allgemeines Verwaltungsrecht und Verwaltungsprozessrecht, in: Gröpl/Guckelberger/Wohlfarth, Studienbuch Landesrecht Saarland, 3. Aufl. 2017, S. 98ff.; Sachsen: Goerlich/ Hegele, Verwaltungsorganisation und Verwaltungsverfahren, in: Stober, Handbuch des Sächsischen Staats- und Verwaltungsrechts, 1. Aufl. 1996, 123 ff.; Sachsen-Anhalt: Kluth, in: Verfassungsrecht Sachsen-Anhalt, in: Kluth, Studienbuch Landesrecht Sachsen-Anhalt, 2. Aufl. 2010, 19 ff. (40 ff.); Schleswig-Holstein: Brüning/Decker, Öffentliches Recht in Schleswig-Holstein, 1. Aufl. 2014, S. 51, 128 ff.; Thüringen: Schneider, Verwaltungsorganisation und allgemeines Verwaltungsrecht, in: Baldus/Knauff, Studienbuch Landesrecht Thüringen, 1. Aufl. 2019, S. $76 \mathrm{ff}$.

\section{b) Verfahren (Julian Senders)}

Im Dreierkanon der formellen Rechtmäßigkeit wird stets als Zweites geprüft, ob der Verwaltungsakt im ordnungsgemäßen Verwaltungsverfahren erlassen wurde. In Klausur und Hausarbeit heißt das: Der Sachverhalt muss auf bestimmte Fehler „bei der Entstehung“ des Verwaltungsakts durchgesehen werden.

Für das Verwaltungsverfahren stellen die Verwaltungsverfahrensgesetze (VwVfG) des Bundes und der Länder jeweils die zentrale Vorschrift dar. Entsprechend wichtig ist es, genau zu unterscheiden, ob das VwVfG des Bundes oder das jeweilige VwVfG des Landes zur Anwendung kommt. 
Hausarbeitswissen: Anders als verwaltungsrechtliche Spezialmaterien wie etwa das Gewerberecht ${ }^{1191}$, das Bauplanungs ${ }^{1192}$ und Bauordnungsrecht ${ }^{1193}$ (welche früher als Untergebiete des Polizei- und Ordnungsrechts angesehen wurden ${ }^{1194}$ ) oder auch das Wasserrecht ${ }^{1195}$ blieb das allgemeine Verwaltungsrecht und damit auch das Verwaltungsverfahrensrecht bis zum Jahr 1977 ohne Kodifikation. ${ }^{1196}$ Der Wunsch nach Rechtsvereinheitlichung und damit auch Rechtsvereinfachung führte schließlich zum Entstehen des VwVfG, ${ }^{1197}$ welches zum 01. 01.1977 in Kraft trat. Dabei wurden wesentliche bestehende, aber zuvor nicht kodifizierte Grundsätze des Verwaltungsrechts erstmals normiert. ${ }^{1198}$

Der Anwendungsbereich des VwVfG des Bundes ist in $\S \S 1,2 \mathrm{VwVfG}$ wie folgt festgelegt: Es findet Anwendung auf die öffentlich-rechtliche Tätigkeit der Behörden, womit das gesamte privatrechtliche Handeln der Verwaltung herausfällt. Im föderalen Staat kann das VwVfG des Bundes aufgrund der Kompetenzverteilung zwischen Bund und Ländern nur Anwendung finden, soweit es um den Vollzug von Bundesgesetzen geht. Landesgesetze können damit nur nach den Landes-VwVfG vollzogen werden. Vollziehen dagegen Bundesbehörden die Bundesgesetze, so findet für sie das Bundes-VwVfG Anwendung.

Für den Vollzug von Bundesrecht durch Landesbehörden gelten grundsätzlich $\S 1$ Abs. 1 Nr. 2, Abs. 2 VwVfG, wo zwischen der Bundesauftragsverwaltung (Art. 85 GG), sowie der - regelmäßigen - Ausführung als eigene Angelegenheit (Art. 84 GG) differenziert wird. Allerdings ordnet $\S 1$ Abs. 3 VwVfG an, dass das VwVfG des Bundes auf die Tätigkeit der Landesbehörden nicht anwendbar ist, wenn ein Landes-VwVfG besteht. Dies ist in allen Bundesländern der Fall, sodass für den Vollzug der Bundesgesetze durch die Landesbehörden die LandesVwVfG Anwendung finden.

1191 Reichsgewerbeordnung vom 21. Juni 1869 (BGBl. des Norddt. Bundes, 1869, S. 245).

1192 Bundesbaugesetz vom 23.06.1960 (BGBl. I 1960, S. 341).

1193 Vgl. etwa die „Bau-Ordnung für die Stadt Berlin“ vom 02.06.1871.

1194 Nicht umsonst hat sich der Begriff der „Baupolizei“ bzw. des „baupolizeilichen Verbots“ oder der „gewerbepolizeilichen Verfügung“ in Deutschland teils bis in die zweite Hälfte des 20. Jahrhunderts hinein erhalten und wird in Österreich nach wie vor offiziell verwendet.

1195 Wasserhaushaltsgesetz vom 27.07.1957 (BGBl. I 1957, S. 1110, 1386).

1196 Dagegen existierte für das Verfahren der Steuerbehörden mit der Reichsabgabenordnung vom 13.12.1919 (RGBl. S. 1993) bereits sehr früh eine eigene Kodifikation des Steuerverwaltungsverfahrens, die 1977 reformiert und an die Systematik des VwVfG angepasst wurde.

1197 Bundes-Verwaltungsverfahrensgesetz vom 25.05.1976, heutzutage in der Fassung der Bekanntmachung vom 23.01.2003 (BGBl. I 2003, S. 202) und zuletzt geändert durch Gesetz vom 18.07.2017 (BGBl. I 2017, 1745).

1198 Peine/Siegel, Allgemeines Verwaltungsrecht, 12. Aufl. 2018, § 4, Rn. 102.

Julian Senders 
Dabei haben die meisten Länder entweder eigene, mit dem Bundes-VwVfG inhaltsgleiche oder fast inhaltsgleiche Gesetze erlassen (sog. Vollgesetze) ${ }^{1199}$ oder sehr kurze Regelungen mit einigen Ausnahmevorschriften geschaffen und im Übrigen auf das Bundes-VwVfG verwiesen (sog. Verweisungsgesetze) ${ }^{1200}$. Schleswig-Holstein und Mecklenburg-Vorpommern haben Verwaltungsverfahrensgesetze mit eigener Regelungssystematik erlassen, in welche die Verwaltungsverfahrensvorschriften integriert wurden (sog. integrierte Gesetze).

In einer Klausur, in der Landesbehörden tätig werden und somit - wie soeben dargestellt - die Landes-VwVfG Anwendung finden, ist es wichtig, dass dies auch in der Gesetzeszitierung kenntlich wird. Das bedeutet: Spielt die Klausur in einem Bundesland, in welchem ein Vollgesetz oder ein integriertes Gesetz gilt, so ist die Vorschrift des Landes-VwVfG zu zitieren. Geht es dagegen um ein Bundesland mit einem Verweisungsgesetz, so muss die gesamte Verweisungskette zitiert werden (zum Beispiel: „Es müsste eine Anhörung gemäß § 1 Abs. 1 VwVfG Bln i.V.m. § 28 VwVfG stattgefunden haben.“). Allerdings liegt es auf der Hand, dass für eine solche Schreibarbeit die ohnehin knapp bemessene Klausurzeit nicht ausreichen wird. Daher sollte am Anfang der Klausur mit einer Fußnote mitgeteilt werden, dass sämtliche Vorschriften des (Bundes-)VwVfG stets in Verbindung mit der jeweiligen Verweisungsnorm (z. B. § 1 Abs. 1 VwVfG Bln) Anwendung finden (s. auch $\S 1$ Rn. 96f. und beispielhaft Fall 14 in: Eisentraut, Fälle zum Verwaltungsrecht, 2020).

$\S 1$ Abs. 1 VwVfG a. E. ordnet zudem eine generelle Subsidiarität des VwVfG an, d.h. das VwVfG findet nur Anwendung, wenn und soweit Spezialregelungen nicht bestehen. Es hat insoweit lückenfüllende Funktion. ${ }^{1201}$ In $\S 2$ VwVfG finden sich spezifische Bereichsausnahmen.

Entgegen seinem Namen enthält das VwVfG nicht nur formelle Vorschriften, sondern auch einige wichtige materielle Anforderungen, so etwa in $\S \S 37$ I, 40, 48f. VwVfG. ${ }^{1202}$

\section{aa) Überblick: Begriff und Systematik der Verwaltungsverfahren}

Das Verwaltungsverfahren ist in § 9 Hs. 1 VwVfG legaldefiniert als jede nach außen 622 gerichtete behördliche Tätigkeit, die auf die Prüfung der Voraussetzungen, die

1199 Baden-Württemberg, Bayern, Hessen, Thüringen, Sachsen, Hamburg, Bremen, NordrheinWestfalen, Saarland.

1200 Berlin, Brandenburg, Sachsen-Anhalt, Niedersachsen, Rheinland-Pfalz.

1201 Peine/Siegel, Allgemeines Verwaltungsrecht, 12. Aufl. 2018, §4, Rn. 104.

1202 Erbguth/Guckelberger, 9. Aufl. 2018, § 14, Rn. 13.

Julian Senders 
Vorbereitung und den Erlass eines Verwaltungsakts (oder auf den Abschluss eines öffentlich-rechtlichen Vertrags) gerichtet ist.

623 Das VwVfG kennt grundsätzlich drei Verfahrensarten: Das nichtförmliche Verfahren, das förmliche Verfahren und das Planfeststellungsverfahren (§§ 72ff.VwVfG), wobei die letzteren beiden oftmals als „die förmlichen Verfahren“ in Abgrenzung zum einfachen, nichtförmlichen Verfahren zusammengefasst werden:

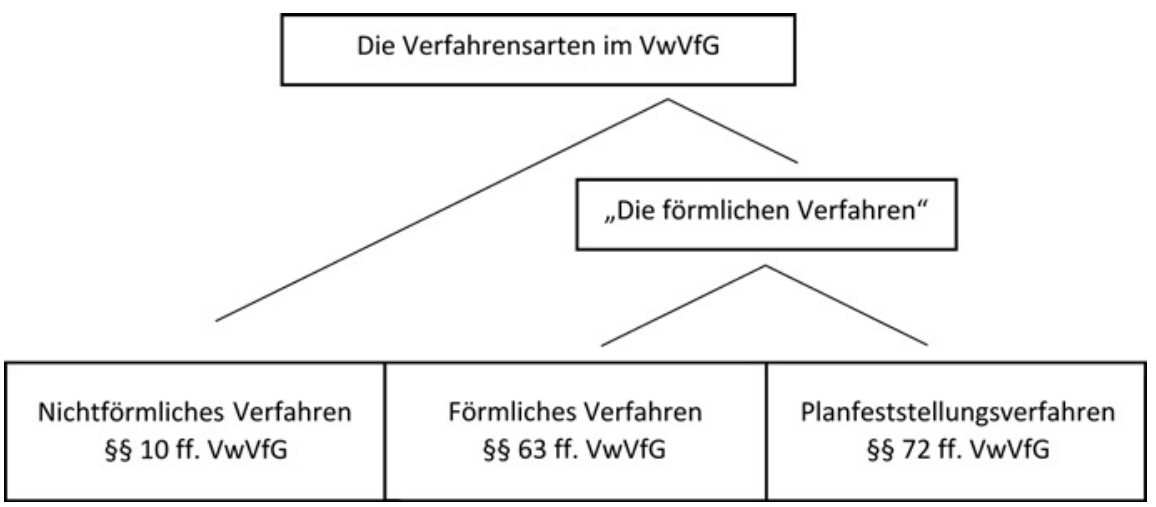

Das VwVfG folgt dem aus anderen Gesetzen (wie z.B. dem BGB) bekannten Klammerprinzip: Soweit die $\S \S 63 \mathrm{ff}$. und $\S \S 72 \mathrm{ff}$. VwVfG jeweils keine spezielle Regelung vorsehen, gelten die allgemeinen Vorschriften und damit diejenigen des nichtförmlichen Verfahrens (vgl. §§ 63 II, 72 I Hs. 1 VwVfG).

625 Dabei gibt es im besonderen Verwaltungsrecht Verfahrensvorschriften, die ihrerseits punktuell oder komplett das VwVfG verdrängen. §1 I VwVfG ordnet diese Subsidiarität gegenüber Normen wie z. B. dem Enteignungsverfahren nach §§ 104-122 BauGB an (s. dazu auch die Rn. 621).

\section{bb) Das nichtförmliche Verwaltungsverfahren}

626 Gemäß $\S 10$ VwVfG ist das Verwaltungsverfahren „an bestimmte Formen nicht gebunden, soweit keine besonderen Rechtsvorschriften für die Form des Verfahrens bestehen. “ Dieses sog. nichtförmliche Verfahren ist damit grundsätzlich ${ }^{1203}$ formfrei. Das VwVfG macht das nichtförmliche Verfahren zur Regel. Auch im

1203 Einzelne Vorschriften des besonderen Verwaltungsrechts (Bauordnungsrecht, Immissionsschutzrecht) stellen punktuell Formerfordernisse auf, fordern etwa die Schriftform für Anträge oder Bescheide.

Julian Senders 
Klausur- und Hausarbeitssachverhalt ist ein nichtförmliches Verfahren der absolute Regelfall.

§§ 11-30 VwVfG normieren die allgemeinen Verfahrensgrundsätze. $\mathrm{Zu}$ erwähnen sind hier

- die Regelungen über die Beteiligten- und Handlungsfähigkeit und die Parteien eines Verwaltungsverfahrens nach $\S \S 11-13$ VwVfG,

- $\quad$ die Notwendigkeit des Handelns der „richtigen“ Amtsträger gemäß §§ 20, 21 VwVfG,

- das Erfordernis vollständiger Sachaufklärung bzw. der sog. Untersuchungsgrundsatz, wonach die Behörde den Sachverhalt von Amts wegen zu ermitteln hat, § 24 I 1 VwVfG,

- die Pflicht der Behörde zur Anhörung Beteiligter nach § 28 I VwVfG

- das Recht auf Akteneinsicht nach § 29 VwVfG

Ein Verstoß gegen diese Verfahrensgrundsätze stellt einen Verfahrensfehler $\mathbf{6 2 8}$ dar, macht den Verwaltungsakt also grundsätzlich formell rechtswidrig. Einen „ungeschriebenen“ Verfahrensfehler stellt die Wahl der falschen Verfahrensart dar. $^{1204}$

In der Klausur kommen - abgesehen von der Anhörung nach § 28 VwVfG spezifische Fragen des Verwaltungsverfahrens und Verfahrensfehler generell sehr selten vor. Zumeist dürfen sich der Bearbeiter und Korrektor mit einem Satz wie: „Verfahrensfehler sind nicht ersichtlich“ begnügen.

Falls aber ein Verfahrensfehler doch aufkommt, ist es sehr wichtig, System- 630 verständnis zu zeigen. Dieses System der Prüfung und Behandlung von Verfahrensfehlern gibt das VwVfG in $\S \S 44-46 \mathrm{VwVfG}$ selbst vor:

1. Prüfung, ob ein Verfahrensfehler vorliegt, anhand der jeweiligen Verfahrensvorschrift.

2. Prüfung, ob dieser Verfahrensfehler den Verwaltungsakt schon nach $\S 44$ VwVfG nichtig macht.

3. Wenn nicht nichtig, dann: Verfahrensfehler geheilt nach § 45 VwVfG?

4. Wenn nicht geheilt, dann: Verfahrensfehler ausnahmsweise unbeachtlich nach $\S 46$ VwVfG?

1204 Peine, Klausurenkurs im Verwaltungsrecht, 6. Aufl. 2016, Rn. 183. 


\section{(1) Insbesondere: Anhörung nach § 28 VwVfG}

631 Verhältnismäßig häufig zu thematisieren ist im Rahmen des Verfahrens die Anhörung. Das Gesetz definiert die Anhörung im \$ 28 I VwVfG als Gelegenheit, sich zu den für die Entscheidung erheblichen Tatsachen zu äußern. Diese hat nach $\S 28$ I VwVfG vor Erlass eines Verwaltungsakts stattzufinden, der in die Rechte eines Beteiligten eingreift. Es bedarf also eines belastenden Verwaltungsakts (zur Frage der Anwendbarkeit in der Verpflichtungssituation $\S 3$ Rn. 89).

632 In der Situation der Anfechtungsklage wird der Verwaltungsakt immer in die Rechte eines Beteiligten, nämlich des Adressaten bzw. Klägers eingreifen. Daher ist prinzipiell immer eine Anhörung durchzuführen, sofern keine Ausnahme gemäß $\S 28$ II bzw. $§ 28$ III VwVfG gegeben ist: Hat keine Anhörung stattgefunden, obwohl § 28 I VwVfG grundsätzlich zu bejahen und damit eine Anhörungspflicht besteht, kann die Anhörung nach § 28 II VwVfG entbehrlich oder nach § 28 III VwVfG untunlich gewesen sein.

\section{(a) Entbehrlichkeit der Anhörung nach § 28 II VwVfG}

633 Nach § 28 II VwVfG kann von der Anhörung abgesehen werden, wenn sie nach den Umständen des Einzelfalls nicht geboten ist. Dabei sieht § 28 II VwVfG fünf Regelbeispiele (,insbesondere“) vor. Diese knüpfen an den Gesichtspunkt des Zeitablaufs bzw. der Gefahr im Verzug (§ 28 II Nr. 1, Nr. 2, Nr. 5 VwVfG) sowie des fehlenden Interesses bzw. der geringen Bedeutung für den Betroffenen (§ 28 II Nr. 3, Nr. 4 VwVfG) an.

634 So wurde Gefahr im Verzug bzw. ein sonstiges öffentliches Interesse nach $\S 28$ II Nr. 1 VwVfG etwa angenommen bei Sicherstellungsmaßnahmen nach einem Vereinsverbot ${ }^{1205}$, der Gefahr des Beiseiteschaffens von Vermögen ${ }^{1206}$ oder bei Maßnahmen zur Sicherung des Straßenverkehrs ${ }^{1207}$.

$635 \mathrm{Zu}$ beachten ist, dass es sich um Regelbeispiele handelt: Fälle, die ähnlich gelagert sind wie die Regelbeispiele, können nach wertender Beurteilung im Rahmen der Subsumtion des Einzelfalls ebenso unter den Ausnahmetatbestand fallen.

$636 \mathrm{Zu}$ beachten ist, dass Vollstreckungsmaßnahmen i.S.v. § 28 II Nr. 5 VwVfG nicht mit der Anordnung der sofortigen Vollziehung des Verwaltungsakts verwechselt werden dürfen: Die in einem solchen Fall zu führende Diskussion, ob

1205 BVerwG, Beschl. v. 29.1.2013, Az.: 6 B 40/12 = NVwZ 2013, 521, Rn. 22.

1206 BVerwG, Urt. v. 18.10.1988, Az.: 1 A 89/83 = BVerwGE 80, 299 = NJW 1989, 993; Urt. v. 13.04. 1999, Az.: 1 A 3/94 = NVwZ-RR 2000, 70.

1207 VG Braunschweig, Urt.v. 06.11.2002, Az.: 6 A 22/02 = NZV 2003, 208; VG Bremen, B.v. 15.05. 2013, Az.: 5 V 1986/12 = BeckRS 2013, 51135. 
eine Anhörung vor der Anordnung der sofortigen Vollziehung des Verwaltungsakts gemäß oder analog § 28 I VwVfG notwendig war (s. dazu § 8 Rn. 63-65), darf also nicht mit dem Hinweis offen gelassen werden, die Anhörung sei ohnehin wegen $\S 28$ II Nr. 5 VwVfG entbehrlich gewesen.

\section{(b) Unterbleiben der Anhörung nach § 28 III VwVfG}

Fälle des § 28 III VwVfG, in denen die Anhörung explizit nicht durchzuführen

ist, sind solche, in denen der Anhörung zwingende öffentliche Interessen entgegenstehen. Die Gesetzesbegründung nennt etwa eine Bedrohung der Sicherheit der Bundesrepublik als Beispiel. ${ }^{1208}$ Hieraus wird das Wohl des Bundes oder eines Bundeslandes abgeleitet, nicht jedoch rein fiskalische Interessen. ${ }^{1209}$ Es muss sich mithin um sehr gewichtige staatliche Belange mit einem qualifizierten Geheimhaltungsinteresse oder mit erheblichen drohenden Gefahren - etwa Naturkatastrophen - handeln. ${ }^{1210}$

Hat die Anhörung nicht stattgefunden und war sie auch nicht entbehrlich, liegt zunächst ein Verfahrensfehler vor. Dies heißt allerdings nicht, dass damit zwangsläufig der Verwaltungsakt formell rechtswidrig ist und die Prüfung an dieser Stelle aufhört bzw. im Hilfsgutachten weitergeht. Denn oftmals wird eine Heilung des Verfahrensfehlers wegen eines durchgeführten Widerspruchsverfahrens eintreten (vgl. den sogleich folgenden Abschnitt zur Heilung, Rn. 652ff.).

Wichtiger Klausurtipp: Bei der formellen Rechtmäßigkeit hören nur wenige 639 Klausuren auf; Klausuren sind in aller Regel so konzipiert, dass sie vollständig ohne Hilfsgutachten angefertigt werden können und dennoch die Bearbeitungszeit füllen. Im Umkehrschluss heißt dies: Ein so frühes Ende der Klausurlösung kann ein Hinweis auf einen Fehler im Lösungsweg sein, der zur erneuten Nachprüfung des eigenen Lösungswegs veranlassen sollte (allgemein zu Hilfsgutachten $\S 1$ Rn. 137 f.).

\section{(2) Weitere Verfahrensgrundsätze im nichtförmlichen Verfahren}

Auf die allgemeinen Verfahrensgrundsätze der §§ 11-34 soll, mit Ausnahme der $\mathbf{6 4 0}$ bereits vorab behandelten Anhörung, nun etwas näher eingegangen werden.

Aus $\S \S 11,12$ VwVfG folgt, wer beteiligungs- und handlungsfähig ist. Der 641 Unterschied zwischen Beteiligungs- und Handlungsfähigkeit wird deutlich,

1208 BT-Drs. 7/910, S. 52.

1209 Kopp/Ramsauer, VwVfG, 19. Aufl. 2018, § 28 VwVfG, Rn. 76.

1210 Kallerhoff/Mayen, in: Stelkens/Bonk/Sachs, VwVfG, 9. Aufl. 2018, § 28 Rn. 65.

Julian Senders 
wenn z. B. ein sechsjähriges Kind Adressat eines Verwaltungsakts wird: Nach $\S 11$ I Nr. 1 Alt. 1 VwVfG ist dessen Beteiligungsfähigkeit gegeben, wegen $\S 12$ I Nr. 1 VwVfG i.V.m. §§ 106, 2 BGB aber nicht die Geschäftsfähigkeit und damit auch nicht die Handlungsfähigkeit. Es muss von den gesetzlichen Vertretern im Verwaltungsverfahren vertreten werden.

642 Für eine Klausur oder Hausarbeit können vor allem \$§ 20, 21 VwVfG relevant werden, die die Unparteilichkeit der öffentlichen Verwaltung sicherstellen sollen:

$\S 20$ VwVfG listet vom Verwaltungsverfahren ausgeschlossene Personen auf. Solche dürfen nicht aufseiten der Behörde in einem Verwaltungsverfahren tätig werden. Hierunter sind: Beteiligte i.S.v. §13 VwVfG, Angehörige von Beteiligten, Vertreter von Beteiligten, Angehörige von Beteiligtenvertretern und bei Beteiligten entgeltlich Beschäftigte bzw. solche Personen, die im Vorstand, Aufsichtsrat oder gleichartigen Organ einer Beteiligten tätig sind. Wer als Angehöriger anzusehen ist, ist in $\S 20$ Abs. 5 VwVfG geregelt.

644 Wurde eine dieser Personen dennoch tätig, liegt ein Verfahrensfehler vor. Hier ist in der Klausur eine saubere Prüfung gefordert, die nicht mit der Feststellung eines Verfahrensfehlers enden darf. Die Befassung einer der in $\S 20$ I 1 Nr. 2 bis 6 VwVfG genannten Personen führt gemäß § 44 III Nr. 2 VwVfG nämlich gerade nicht ohne weiteres zur Nichtigkeit des Verwaltungsakts. Damit sind §§ 45, 46 VwVfG zu berücksichtigen (hierzu vgl. Rn. 652ff.).

645 Während § 20 VwVfG bestimmte Personenkreise von vornherein ausnimmt, regelt § 21 VwVfG allgemeiner die Besorgnis der Befangenheit, d.h. die Sorge um die parteiische Amtsausübung. Die Vorschrift sieht vor, dass - nach Mitteilung entweder des betroffenen Amtswalters oder nach der Behauptung eines anderen Beteiligten - eine behördeninterne Überprüfung erfolgen muss, ob die Besorgnis der Befangenheit tatsächlich besteht. ${ }^{1211}$ Der vorgetragene Grund muss dabei geeignet sein, Misstrauen gegen eine unparteiische Amtsausübung zu rechtfertigen. Erfolgt diese behördeninterne Überprüfung nicht, liegt darin allerdings nur dann ein Verfahrensfehler, wenn die Besorgnis der Befangenheit in der Sache gegeben war. ${ }^{1212}$

646 Der Behördenleiter bzw. eine von ihm beauftragte Person ist zu informieren und auf dessen Anordnung die weitere Mitwirkung des betroffenen Amtswalters zu unterlassen.

647 Anders als man denken könnte, findet sich ein Verstoß gegen $\S \S 20,21$ VwVfG nicht bei den zwingenden Nichtigkeitsgründen des § 44 II VwVfG. Da diese aber

1211 Heßhaus, in: Bader/Ronellenfitsch, VwVfG, 41. Ed., Stand: 01.10.2018, § 21 Rn. 7. 1212 Schmitz, in: Stelkens/Bonk/Sachs, VwVfG, 9. Aufl. 2018, § 21 Rn. 26.

Julian Senders 
nur Regelbeispiele darstellen, kann sich nach Prüfung des Einzelfalls dennoch eine Nichtigkeit gemäß § 44 I VwVfG ergeben.

§ 24 VwVfG normiert den Untersuchungsgrundsatz. Die Behörde hat $\mathbf{6 4 8}$ hiernach alle relevanten Informationen von Amts wegen zu ermitteln.

In § 26 I VwVfG sind mögliche Ermittlungsmethoden der Behörde aufgelistet. 649 Nach § 26 II VwVfG „sollen“ die Beteiligten an der Aufklärung des Sachverhalts mitzuwirken. Diese Pflicht ist allerdings nicht sanktionsbewehrt, d. h. die unterlassene Mitwirkung führt nach dem VwVfG zu keinen Konsequenzen. Zu beachten ist aber, dass Spezialvorschriften im Einzelfall eine Ablehnung des Antrags vorsehen, wenn der Antragsteller seinen Mitwirkungspflichten nicht nachkommt (vgl. z. B. § 20 II 2 der 9. BImSchV).

Zuletzt ist noch das Akteneinsichtsrecht nach § 29 I VwVfG zu erwähnen.

Das Akteneinsichtsrecht steht aber nur Beteiligten am Verwaltungsverfahren offen und einen Anspruch auf Akteneinsicht gibt es aufgrund der systematischen Stellung des §29 VwVfG nur während des laufenden Verwaltungsverfahrens, welches, wie sich aus §9 I VwVfG ergibt, mit Erlass des Verwaltungsakts endet. Allerdings wird auch nach Verfahrensabschluss eine Gewährung der Akteneinsicht nach pflichtgemäßem Ermessen von der Rechtsprechung anerkannt. ${ }^{1213}$ Die Beteiligten müssen darlegen, dass die Akteneinsicht zur Geltendmachung oder Verteidigung ihrer rechtlichen Interessen notwendig ist, die Behörde kann ihnen wiederum die in § 29 II VwVfG genannten Gründe gegen eine Akteneinsicht entgegenhalten.

Hausarbeitswissen: Das Verwaltungsrecht kennt auch andere, weiter gehende Einsichtsrechte, und zwar gemäß \& 3 I Umweltinformationsgesetz (UIG) zur Verwirklichung des Staatsziels Umwelt (Art. 20a GG) sowie einen allgemeinen Informationsanspruch gemäß \& 1 I Informationsfreiheitsgesetz (IFG), der grundrechtlich auf die Informationsfreiheit nach Art. 5 I 1 Alt. 2 GG gestützt ist. Der Anspruch auf Umweltinformationen ist eine Errungenschaft aus dem europäischen Recht (Art. 3 der RL 2003/4/EG - Umweltinformations-RL) Beide Rechte sind weder an die Person des Antragstellers noch an ein rechtliches Interesse geknüpft. ${ }^{1214}$

1213 BVerwG, Urt. v. 01.07.1983, Az.: 2 C 42/82 = NVwZ 1984, 445, 446; OVG Koblenz, Urt. v. 02.10. 1991, Az.: 7 A 10880/91 = NVwZ 1992, 384.

1214 Vgl. zum besonders relevanten Anspruch auf Umweltinformationen die Kommentierung von Reidt/Schiller, in: Landmann/Rohmer, Umweltrecht, 88. EL Sept. 2018, § 3 UIG; außerdem vgl. zur Missbräuchlichkeit von Informationsanfragen und zum Schutz von Betriebsgeheimnissen Schnabel, ZUR 2019, 74. 


\section{(3) Heilung von Verfahrensfehlern}

652 Ein Verfahrensfehler kann nach § 45 I VwVfG geheilt, d. h. ein zunächst formell rechtswidriger Verwaltungsakt im Nachhinein wieder formell rechtmäßig werden. Gerade in der Situation der Anfechtungsklage wird oftmals eine Heilung des Verfahrensfehlers gegeben sein wird. Die Heilung von Verfahrensfehlern ist bei Klausurerstellern „außerordentlich beliebt“1215. Dabei gibt §45 I VwVfG die sachliche, § 45 II VwVfG die zeitliche Grenze für die Heilung vor.

$\S 45$ I VwVfG zählt die Heilungstatbestände abschließend auf. Hieraus ergibt sich eine sachliche Beschränkung der Heilungsmöglichkeit auf das Antragserfordernis (Nr. 1), auf die Begründung des Verwaltungsakts (Nr. 2), auf die Anhörung der Beteiligten (Nr. 3) und auf die Beteiligung bzw. Mitwirkung von Ausschüssen (Nr. 4) und anderen Verwaltungsbehörden (Nr. 5).

654 Dies kommt der Rechtssicherheit aufseiten des vom Verwaltungsakt Betroffenen zugute: Die Behörde kann auf keinen allgemeinen Heilungstatbestand zurückgreifen, sondern muss unter die § 45 I Nr. 1 bis Nr. 5 VwVfG subsumieren.

655 Zeitlich gesehen ist das Gesetz großzügig gegenüber der Behörde: Nach $\S 45 \mathrm{II} \mathrm{VwVfG} \mathrm{hat} \mathrm{die} \mathrm{Behörde} \mathrm{für} \mathrm{das} \mathrm{Nachholen} \mathrm{der} \mathrm{nach} \mathrm{§} 45 \mathrm{I}$ VwVfG versäumten Handlung bis zum Abschluss der letzten Tatsacheninstanz eines verwaltungsgerichtlichen Verfahrens Zeit. Dies meint in der Tat den Zeitpunkt der letzten Entscheidung, bis zu der noch Tatsachenvortrag möglich ist. ${ }^{1216}$ Damit ist in der Eingangsinstanz und ggf. in der Berufungsinstanz (das OVG, welches nach $\S 128$ Satz 1 VwGO im gleichen Umfang prüft wie das VG, niemals aber das BVerwG) noch Möglichkeit zur Heilung des Verwaltungsakts gegeben.

656 Examenswissen: Eine weitere zeitliche Grenze ergibt sich daraus, dass der Verwaltungsakt bei Nachholung nicht erledigt sein darf. Denn in einem solchen Fall wäre die Nachholung des Verfahrensschritts eine sinnentleerte Formalie und würde den Zweck, dem Entscheidungsprozess der Behörde zu dienen, nicht mehr erfüllen können. ${ }^{1217}$

657 Besonders klausurrelevant ist die Nachholung der Anhörung, deren Fehlen so oftmals geheilt wird: Denn die Anfechtungsklage sieht grundsätzlich ein erfolgloses Vorverfahren bzw. Widerspruchsverfahren vor. Der Adressat muss also Widerspruch nach § 68 I VwGO erhoben haben, sofern dies nicht nach § 68 II VwGO entbehrlich ist. Der Widerspruch setzt ein erneutes Verwaltungsverfahren in Gang, der die zuständige Behörde zur Befassung mit dem Vorgang und nunmehr auch zur Befassung mit den Argumenten des Widerspruchsführers zwingt.

1215 Peine, Klausurenkurs im Verwaltungsrecht, 6. Aufl. 2016, Rn. 185.

1216 Sachs, in Stelkens/Bonk/Sachs, VwVfG, 9. Aufl. 2018, § 45 VwVfG, Rn. 108.

1217 BVerwG, Urt. v. 22.3.2012, Az.: 3 C 16/11 = BVerwGE 142, 205, 210.

Julian Senders 
Schon durch den erhobenen Widerspruch wird grds. nach einer vor allem in $\mathbf{6 5 8}$ der Rechtsprechung verbreiteten Auffassung ${ }^{1218}$ die Anhörung i.S.v. § 45 I Nr. 3 VwVfG nachgeholt, sodass die formelle Rechtswidrigkeit durch Heilung entfällt und die Prüfung fortgesetzt wird. Ein Teil der Literatur widerspricht dem mit dem zutreffenden teleologischen Argument, dass das Anhörungserfordernis auf diese Weise leer liefe. ${ }^{1219}$ Dem wird zwar entgegengehalten, dass die Behörde nach Art. 20 III GG zur Beachtung der Anhörungspflicht verpflichtet ist. ${ }^{1220}$ Allerdings ist fraglich, ob dieses verfassungsrechtliche Argument alleine dem faktischen Leerlaufen der Anhörungspflicht entgegenwirken kann, wenn die Behörde im Ergebnis stets davon ausgehen kann, nach Heilung des Verfahrensfehlers rechtmäßig gehandelt zu haben.

Deswegen kann allein nach Erhebung des Widerspruchs noch nicht von einer Heilung ausgegangen werden. Schematische Lösungen verbieten sich. Stattdessen kommt es - ausgehend vom Sinn und Zweck des § 28 VwVfG - darauf an, dass durch die Nachholung der Zweck der Anhörung erreicht wird. ${ }^{1221}$

Dies kann dann nicht mehr der Fall sein, wenn der Widerspruchsbescheid $\mathbf{6 6 0}$ neue Tatsachen zugrunde legt, die dem Betroffenen bislang nicht bekannt waren, zu denen er sich also nicht äußern konnte oder wenn die Widerspruchsbehörde aufgrund besonderer gesetzlicher Bestimmung nur auf die Rechtskontrolle beschränkt ist (z. B. in bestimmten Selbstverwaltungsangelegenheiten, vgl. $\S 73$ I 2 Nr. 3 VwGO) und deshalb keine eigene Anhörung durchführen kann. ${ }^{1222}$

Jedenfalls durch die Durchführung des Widerspruchsverfahrens, in dem sich die Behörde mit den Einwänden des Betroffenen befasst, kann abgesehen von den genannten Fällen davon ausgegangen werden, dass der Zweck der Anhörung erreicht wurde. Dies ist - da sich schematische Lösungen an dieser Stelle verbieten - im Einzelfall zu prüfen.

Geht es um die Nachholung der Begründung (§ 45 I Nr. 2 VwVfG), so ist dies 662 stets vom „Nachschieben von Gründen“ im Verwaltungsprozess zu unterscheiden: Die Nachholung der Begründung nach § 45 I Nr. 2 VwVfG ist dann einschlägig, wenn der Verwaltungsakt zuvor über keine dem § 39 VwVfG genügende Begründung verfügte. Das Nachschieben von Gründen im Prozess hingegen bezieht sich auf einen Verwaltungsakt, der zwar eine Begründung nach $§ 39$ VwVfG aufweist,

1218 BVerwG, Urt. v. 17.08.1982, Az.: 1 C 22/81 = BVerwGE 66, 111, 114; OVG Münster, Urt. v. 20. 06. 1983, Az.: 1 A 1480/81 = NVwZ 1985, 133; Kopp/Ramsauer, VwVfG, 19. Aufl. 2018, § 45 VwVfG, Rn. 43. 1219 Peine/Siegel, Allgemeines Verwaltungsrecht, 12. Aufl. 2018, §14, Rn. 576; Hufen/Siegel, Fehler im Verwaltungsverfahren, 6. Aufl. 2018, Rn. 956; Pünder, Jura 2015, 1307, 1310.

1220 Erbguth/Guckelberger, Allgemeines Verwaltungsrecht, 9. Aufl. 2018, § 15, Rn. 17.

1221 Erbguth/Guckelberger, Allgemeines Verwaltungsrecht, 9. Aufl. 2018, § 15, Rn. 17.

1222 BVerwG, Urt. v. 17.08.1982, Az.: 1 C 22/81 = BVerwGE 66, 111, 115.

Julian Senders 
welche aber in der Sache (und nicht etwa formal) unzureichend oder unzutreffend ist: Die Nachholung der Begründung ist immer Sache der formellen, das Nachschieben von Gründen im Verwaltungsprozess hingegen eine Frage der materiellen Rechtmäßigkeit. ${ }^{1223}$

663

In der Klausur stellt sich aber für den Klausurbearbeiter das Problem, dass er ggf. einen Verwaltungsakt prüft, der formell rechtswidrig ist, weil die Behörde die zur Heilung notwendige Handlung nach dem Sachverhalt noch nicht nachgeholt hat, aber - da noch in der ersten Instanz - auf jeden Fall noch nachholen könnte. In einem solchen Fall liegt zwar strenggenommen ein ,schwebend rechtswidriger" Verwaltungsakt vor. Klausurtaktisch gedacht ist ein Abbruch der Prüfung an dieser Stelle nicht gewünscht und wird auch nicht belohnt - ganz im Gegenteil. Daher sollte an dieser Stelle eine kurze Darstellung der Heilungsproblematik erfolgen und nach einer Feststellung der noch bestehenden Heilungsmöglichkeit mit der weiteren Prüfung fortgefahren werden.

\section{(4) Unbeachtlichkeit von Verfahrensfehlern}

664 Nach § 46 VwVfG kann der Verfahrensfehler unbeachtlich sein: Die Aufhebung eines Verwaltungsakts kann bei gewissen Fehlern nicht beansprucht werden, wenn offensichtlich ist, dass der Fehler die Entscheidung in der Sache nicht beeinflusst hat. § 46 VwVfG zählt diese Fehler abschließend auf: Unbeachtlich kann demnach nur eine Verletzung der Vorschriften über die örtliche Zuständigkeit (§ 3 VwVfG), über das Verfahren und über die Form sein.

665 Dies bedeutet, dass sich der Betroffene unter Umständen trotz fehlender Heilung nach § 45 VwVfG nicht erfolgreich gegen den Verwaltungsakt zur Wehr setzen kann.

666 Die Formulierung der Norm bringt auch schon zum Ausdruck, dass ein solcher Verwaltungsakt nicht durch die Unbeachtlichkeit rechtmäßig wird, sondern nach wie vor als rechtswidrig anzusehen ist. Lediglich seine Aufhebung kann nach § 113 I 1 VwGO nicht begehrt werden. In der Klausur muss auf diese Feinheit geachtet werden.

667 Voraussetzung für die Unbeachtlichkeit ist der offensichtlich fehlende kausale Einfluss des (Verfahrens-)Fehlers auf die Entscheidung in der Sache.

668 Ein offensichtlich fehlender kausaler Einfluss auf die Entscheidung wird regelmäßig gegeben sein, wenn in der Sache eine gebundene Entscheidung vorliegt. Dies leuchtet ein: Wenn zwar der Betroffene nicht angehört wurde, aber auch mit

1223 Maurer/Waldhoff, Allgemeines Verwaltungsrecht, 19. Aufl. 2017, 3. Teil, Rn. 64. Julian Senders 
Anhörung derselbe Bescheid ergehen müsste, ergibt eine Neubescheidung durch die Behörde schon verfahrensökonomisch keinen Sinn.

Dabei muss immer beachtet werden, dass die Behörde nach dem Gesetz den Sachverhalt unabhängig von der Anhörung schon zuvor nach § 24 VwVfG von Amts wegen ermittelt haben muss, sodass die Anhörung systematisch gesehen nicht der reinen Sachverhaltsermittlung dienen kann. Der Betroffene kann daher regelmäßig nicht argumentieren, bei seiner Anhörung wäre der Sachverhalt anders ermittelt und daher eine andere Entscheidung gefällt worden.

Die frühere Fassung von $\S 46$ VwVfG war explizit auf gebundene Entschei- 670 dungen beschränkt. Doch der Gesetzgeber hat die Formulierung ausgedehnt, um mit der Unbeachtlichkeit auch im Einzelfall Ermessensverwaltungsakte zu erfassen. Grundsätzlich wird es sich so verhalten, dass bei Ermessensverwaltungsakten sowie Verwaltungsakten mit tatbestandlichem Beurteilungs- bzw. Abwägungsspielraum ein kausaler Einfluss z. B. der fehlenden Anhörung auf die Entscheidung nicht offensichtlich fehlen und damit keine Unbeachtlichkeit gegeben sein wird. ${ }^{1224}$ Es bedarf dennoch einer Prüfung im Einzelfall. Zudem: Ist das Ermessen der Behörde etwa auf Null reduziert, ist keine andere Behandlung als beim gebundenen Verwaltungsakt angezeigt und § $46 \mathrm{VwVfG}$ wird einschlägig sein.

An dieser Stelle stellt sich die Frage nach dem Prüfungsstandort in der $\mathbf{6 7 1}$ Klausur: Die Norm ist prozessual formuliert, kann also nach Abschluss der Prüfung der materiellen Rechtmäßigkeit des Verwaltungsakts unter dem Punkt „Rechtsverletzung“ geprüft werden. Dies kann sich dann empfehlen, wenn die Ermächtigungsgrundlage für den Verwaltungsakt bzw. eine Ermessensreduzierung auf Null nicht eindeutig ist und daher sonst ein Teil der materiellen Prüfung in die formelle Rechtmäßigkeit gezogen würde. Bei einfach gelagerten Fällen, etwa Ermächtigungsgrundlagen, die zu gebundenen Entscheidungen der Behörde führen, sollte eine Prüfung aber schon im Rahmen der formellen Rechtmäßigkeit erfolgen.

\section{cc) Das förmliche Verfahren}

Das förmliche Verfahren ist gemäß $\S 63$ I VwVfG zu prüfen, wenn es durch 672 Rechtsvorschrift angeordnet wird. Eine solche Vorschrift findet sich etwa in $\S 36$ BBergG. Eher in einer fortgeschrittenen Klausur denkbar sind Vorschriften

1224 Peine/Siegel, Allgemeines Verwaltungsrecht, 12. Aufl. 2018, §14, Rn. 583; Erbguth/Guckelberger, Allgemeines Verwaltungsrecht, 9. Aufl. 2018, § 15, Rn. 20. 
des Landesrechts, etwa $\S 1$ FörmVfVO Bln: Nach dieser Vorschrift ist u.a. für die Gewerbeuntersagung nach $\S 35$ GewO und die Rücknahme/den Widerruf der Gaststättenerlaubnis nach $\S 15$ GastG das förmliche Verfahren durchzuführen. Zu beachten ist in jedem Fall auch hier, dass schon auf Ebene der Anwendbarkeit des VwVfG gemäß § 1 I VwVfG a.E. das förmliche Verfahren gegenüber besonderen Verwaltungsverfahren, etwa dem Enteignungsverfahren nach $\S \S 103 \mathrm{ff}$. BauGB, subsidiär ist.

In der Klausur wird die Einschlägigkeit des förmlichen Verfahrens in aller Regel zu keinen Abweichungen vom Prüfprogramm führen. Es reicht dann die Feststellung aus, dass das förmliche Verfahren durchzuführen ist.

674 Das Verfahren über eine einheitliche Stelle nach §§ 71aff. VwVfG wird demgegenüber nicht als eigenes Verfahren gesehen, ${ }^{1225}$ sondern dient der Beschleunigung aller Verfahrensarten, auch wenn dies aus seiner systematischen Stellung im Gesetz zwischen förmlichem und Planfeststellungsverfahren nicht ohne Weiteres ersichtlich ist. Allerdings ist hier praktisch keine Klausur- oder Examensrelevanz gegeben.

\section{dd) Das Planfeststellungsverfahren}

675 Ein Planfeststellungsverfahren ist ein gesteigert förmliches Verfahren. Es kommt bei der Zulassung großer, raumbedeutsamer Vorhaben zum Tragen, etwa bei großen Fernstraßen ( $§ 17$ FStrG) oder Flughäfen ( $\S \S 8$ ff. LuftVG). Es muss durch besondere Rechtsvorschriften angeordnet sein, § 72 I 1 Hs. 1 VwVfG. Die Komplexität des Verfahrens ergibt sich vor allem durch das Zusammenwirken mehrerer Behörden (Planfeststellungsbehörde, Anhörungsbehörde, Fachbehörden) und ggf. mehrerer Gemeinden.

676 Der maßgebliche Verwaltungsakt am Ende des Planfeststellungsverfahrens ist der sog. Planfeststellungsbeschluss. Das Planfeststellungsverfahren zeichnet sich durch den Ablauf der folgenden, fest vorgegebenen Schritte aus:

- Einleitung des Verfahrens durch einen Plan, der vom öffentlichen oder privaten Vorhabenträger bei der Anhörungsbehörde einzureichen ist, $\S 73$ I 1 VwVfG

- Aufforderung der in ihrem Zuständigkeitsbereich betroffenen Behörden zur Stellungnahme binnen eines Monats nach Zugang des vollständigen Plans durch die Anhörungsbehörde, § 73 II Hs. 1 VwVfG

1225 Erbguth/Guckelberger, Allgemeines Verwaltungsrecht, 9. Aufl. 2018, § 14, Rn. 16. Julian Senders 
- Stellungnahme der aufgeforderten Behörden innerhalb einer von der Anhörungsbehörde gesetzten Frist von höchstens drei Monaten, §73 IIIa 1, 2 VwVfG

- Veranlassung der öffentlichen Auslegung des Plans in den betroffenen Gemeinden binnen eines Monats nach Zugang des vollständigen Plans durch die Anhörungsbehörde, § 73 II Hs. 2 VwVfG

- Binnen drei Wochen nach Zugang: Öffentliche Bekanntmachung des Plans, $\S 73$ V VwVfG, und Auslegung des Plans durch die betroffenen Gemeinden für einen Zeitraum von einem Monat (Auslagefrist), § 73 III 1 VwVfG

- Ggf. Einwendungen aller Art gegen das Projekt, zu erheben innerhalb der Einwendungsfrist

- Einwendungsfrist: 2 Wochen nach Ablauf der Auslagefrist, §73 IV 1 VwVfG

- Einwendungen richten sich auf Veränderung oder Verhinderung des Vorhabens

- Rechtsbetroffenheit des Einwenders nicht erforderlich

- Binnen drei Monaten nach Ablauf der Einwendungsfrist: Behandlung des Vorhabens mit dem Projektträger, den beteiligten Behörden und den Einwendern, § 73 VI 1, 7 VwVfG

- Anfertigung einer Stellungnahme durch die Anhörungsbehörde und Weiterleitung mit dem Plan an die Planfeststellungsbehörde, § 73 IX VwVfG

- Verfahrensabschluss durch Planfeststellungsbeschluss

Werden diese Schritte nicht oder nicht fristgemäß eingehalten, ist wiederum ein $\mathbf{6 7 7}$ Verfahrensfehler gegeben. Für die Heilung bzw. Unbeachtlichkeit von Verfahrensfehlern sind $\S \S 45,46 \mathrm{VwVfG}$ anwendbar, soweit sie den betreffenden Fehler erfassen. Ansonsten sieht das Planfeststellungsrecht bei Verfahrensfehlern eine Planergänzung nach § 76 Ia Satz 2 VwVfG vor, die wiederum ein eigenes Verfahren darstellt und nach Abschluss mit dem ursprünglichen Planfeststellungsverfahren eine Einheit darstellt. ${ }^{1226}$

Dieser Planfeststellungsbeschluss weist gemäß §§ 74, 75 I 1 Hs. 2 VwVfG ei- 678 ne sog. Konzentrationswirkung auf, d.h. er umfasst gleichzeitig alle anderen behördlichen Genehmigungen, welche sonst alle einzeln zu beantragen wären etwa Baugenehmigungen, immissionsschutz- und wasserrechtliche Genehmigungen.

In Klausur und Hausarbeit ist das Planfeststellungsverfahren kaum bis gar 679 nicht relevant. Die Prüfungsordnungen der Bundesländer schließen oftmals das

1226 Kämper, in: Bader/Ronellenfitsch, VwVfG, 43. Ed., Stand: 1.4.2019, § 75 VwVfG, Rn. 34. 
formelle Verfahren vom Examensstoff aus. ${ }^{1227}$ Eine große Rolle spielt es in der Praxis bei Anlagenzulassungen, etwa bei Abfalldeponien und Kraftwerken.

\section{ee) Literaturhinweise}

680 Eine systematische und übersichtliche Darstellung des Verwaltungsverfahrens bietet insbesondere Erbguth/Guckelberger, Allgemeines Verwaltungsrecht, 9. Aufl. 2018, § 14, Abschnitt I. 2; Zu Verfahrensfehlerfolgen bieten sich insbesondere die folgenden Quellen aus Lehrbuch- und Aufsatzliteratur an: Peine/ Siegel, Allgemeines Verwaltungsrecht, 12. Aufl. 2018, § 14, Rn. 542ff.; Erbguth/ Guckelberger, Allgemeines Verwaltungsrecht, 9. Aufl. 2018, §15; Beaucamp, Heilung und Unbeachtlichkeit von formellen Fehlern im Verwaltungsverfahren, JA 2007, 117; Stelkens, Der Eigenwert des Verfahrens im Verwaltungsrecht, DVBl 2010, 1078

\section{c) Form (Tristan Lemke)}

681 Grundsätzlich kann ein Verwaltungsakt in jeder denkbaren Form ergehen. Dieser Grundsatz der Formfreiheit ergibt sich aus § 37 II 1 VwVfG. Der Verwaltungsakt kann somit u.a. schriftlich, mündlich, elektronisch, telefonisch, als Telefax oder auch nur durch Handzeichen ergehen. Beispielsweise handelt es sich auch bei den Gesten eines Polizisten, der den Verkehr lenkt, um Verwaltungsakte. ${ }^{1228}$

682 Dieser Grundsatz wird vom Gesetz in einigen besonders bedeutsamen Bereichen dadurch gebrochen, dass eine bestimmte Form vorgeschrieben wird.

Beispiele: Die Baugenehmigung bedarf nach $\S 2$ V BauVerfV der Schriftform und die Beamtenernennung der Aushändigung einer Urkunde (§ 8 II BeamtStG, §§ 10 II, 12 II 1 BBG).

683 Auch jenseits besonderer gesetzlicher Bestimmungen ist es jedoch aus Praktikabilitätsgründen ${ }^{1229}$ üblich, Verwaltungsakte schriftlich $\mathrm{zu}$ erlassen. Hierdurch besteht für die Betroffenen und die Behörde Klarheit hinsichtlich des Wortlautes des Verwaltungsakts.

684 Folgenden Formerfordernissen muss in Klausuren regelmäßig erhöhte Aufmerksamkeit gewidmet werden:

1227 So etwa § 3 IV Nr. 3 Buchst. b) BlnJAO; § 3 IV Nr. 3 Buchst. b) BbgJAO; § 14 III Nr. 8 Buchst. b) SächsJAPO.

1228 Maurer/Waldhoff, Allgemeines Verwaltungsrecht, 19. Aufl. 2017, § 10 Rn. 41.

1229 Schönenbroicher, in: Mann/Sennekamp/Uechtritz, VwVfG, 2. Aufl. 2019, § 37 Rn. 115.

Julian Senders/Tristan Lemke 


\section{aa) Schriftform}

Wenn Verwaltungsakte schriftlich (oder elektronisch) ergehen, müssen sie den

Anforderungen des § 37 III 1 VwVfG entsprechen. Sie müssen die erlassende Behörde erkennen lassen und die Unterschrift oder die Namenswiedergabe des Behördenleiters, seines Vertreters oder seines Beauftragten enthalten. Das ist unabhängig davon, ob sich die Behörde freiwillig zur Verwendung der Schriftform entschlossen hat oder hierzu durch eine gesetzliche Ausnahme vom Grundsatz der Formfreiheit verpflichtet wurde.

Wenn der Verwaltungsakt entgegen $\S 37$ III 1 VwVfG nicht die erlassende

Behörde erkennen lässt, ist er gem. § 44 II Nr. 1 VwVfG nichtig (s. näher $\S 6$ Rn. 122ff.). Sollten hingegen die Unterschrift oder die Namenswiedergabe des Behördenleiters nicht enthalten sein, ist der Verwaltungsakt lediglich rechtswidrig. Sinn dieser Anforderung ist es, zu gewährleisten, dass nicht versehentlich ein Entwurf versendet wurde, sondern es sich um eine gewollte Erklärung handelt, für die der Behördenleiter die Verantwortung übernimmt. ${ }^{1230}$ Eine Unterschrift ist die eigenhändige Unterzeichnung durch eine natürliche Person mit ihrem eigenen Namen. ${ }^{1231}$ Die Namenswiedergabe verlangt nicht mehr als beispielsweise maschinenschriftlich - den Namen des Behördenleiters wiederzugeben. $^{1232}$

\section{bb) Elektronische Verwaltungsakte und elektronische Form}

Examenswissen: Ein Verwaltungsakt, für den die Schriftform durch Rechtsvorschrift vorgeschrieben ist (z.B. § 2 V BauVerfV), kann gem. §§ 3a II 1, 37 III 2 und 3 VwVfG auch in elektronischer Form ergehen. Hierfür muss gem. § 3 a II 3 VwVfG eine qualifizierte elektronische Signatur im Sinne des $\S 2$ Nr. 1 SigG verwendet werden. Reguläre Emails enthalten diese nicht, so dass in diesem Fall dem Formerfordernis nicht entsprochen wird und der Verwaltungsakt formell rechtswidrig ist. § 3a II 4 und 5 VwVfG nennen weitere Möglichkeiten, das Schriftformerfordernis zu ersetzen. Diese sind jedoch deutlich weniger klausurrelevant.

Examenswissen: Jegliche Verwaltungsakte, die auf elektronischem Wege erlassen werden 688 (elektronische Verwaltungsakte), müssen wie schriftliche Verwaltungsakte ebenfalls § 39 I 1 VwVfG (s. Rn. 690) entsprechen. Darüber hinaus ist für ihr Wirksamwerden erforderlich, dass die Voraussetzungen des §37 III 1 VwVfG (s. dazu Rn. 685f.) und § 3a I VwVfG gewahrt werden. Letzterer verlangt, dass der Empfänger einen Zugang zur Übermittlung elektronischer Dokumente eröffnet hat (s. ausführlich Rn. 144ff.). Hiernach muss in objektiver Hinsicht bei dem Empfänger

1230 BVerwG, Urt. v. 5.6.1974, Az.: VIII C 1.74 = BVerwGE 45, 189 (195).

1231 Ramsauer, in: Kopp/Ramsauer, VwVfG, 20. Aufl. 2019, § 37 Rn. 33.

1232 OVG Magdeburg, Beschl. v. 24.8.2012, Az.: 1 L 20/12 = NVwZ-RR 2013, 131; ausführlich Stelkens, in: Stelkens/Bonk/Sachs, VwVfG, 9. Aufl. 2018, § 37 Rn. 104 f. 
eine entsprechende Kommunikationseinrichtung bestehen (beispielsweise ein Account bei einem Email-Provider) und diese subjektiv der elektronischen Kommunikation gewidmet werden. ${ }^{1233}$ Diese Widmung durch den Empfänger verlangt, dass dem Kommunikationspartner die Bereitschaft signalisiert wird, elektronische Kommunikationsmittel entgegenzunehmen; in der Regel ist das erst mit der ausdrücklichen Mitteilung eines Bürgers an die Behörde der Fall. ${ }^{1234}$ Die Widmung kann jedoch auch konkludent erfolgen; im Geschäftsverkehr, zu dem u.a. Firmen, Behörden, Gerichte und Anwälte gehören, sind hieran geringere Anforderungen zu stellen als bei privaten Nutzern. ${ }^{1235}$ Die Voraussetzungen des §3a I VwVfG sind auch zu wahren, wenn ein Bürger elektronisch mit einer Behörde kommunizieren möchte (beispielsweise durch Erhebung eines Widerspruchs, s. Rn. 317).

\section{cc) Rechtsbehelfsbelehrung}

689 Examenswissen: Aus §37 VI VwVfG ergibt sich die Pflicht der Behörde, belastenden Verwaltungsakten eine Rechtsbehelfsbelehrung beizufügen, wenn sie in schriftlicher oder elektronischer Form ergehen. Das Fehlen oder die Unrichtigkeit der Belehrung wirkt sich jedoch nicht auf die Rechtmäßigkeit des Verwaltungsakts aus, weil sie der eigentlichen Entscheidung nur beigefügt wird. ${ }^{1236} \mathrm{Gem}$. § $58 \mathrm{II}$ VwGO verlängern sich jedoch in diesem Fall die Rechtsbehelfsfristen (daher zu dieser Problematik bereits ausführlich Rn. 368).

\section{dd) Begründung}

690 Schriftliche und elektronische Verwaltungsakte müssen gem. §39 I VwVfG mit einer Begründung versehen werden. Hierbei ist nicht entscheidend, ob die Begründung gelungen ist, also Überlegungen enthält, die den Verwaltungsakt rechtlich tragen können. Stattdessen müssen lediglich die Gründe genannt werden, die für die Behörde maßgeblich waren. ${ }^{1237}$ Somit wird beispielsweise $\S 39$ I VwVfG entsprochen, wenn die Behörde von einem unzutreffenden Sachverhalt ausgeht und diesen in der Begründung darstellt; der belastende Verwaltungsakt ist formell rechtmäßig. Seine materielle Rechtswidrigkeit ergibt sich jedoch daraus, dass die Tatbestandsvoraussetzungen der Ermächtigungsgrundlage nicht vorliegen.

691 Aus der Begründung muss ersichtlich sein, von welchem Sachverhalt die Behörde ausgegangen ist und warum nach Auffassung der Behörde die Tatbe-

1233 BVerwG, Urt. v. 7.12.2016, Az. 6 C 12/15 = BayVBl 2017, 568; Erbguth/Guckelberger, Allgemeines Verwaltungsrecht, 9. Aufl. 2018, § 14 Rn. 22.

1234 Ausführlich Schulz, in Mann/Sennekamp/Uechtritz, VwVfG, 2. Aufl. 2019, § 3a Rn. 55 ff.

1235 Ausführlich Kastner, in: Fehling/Kastner/Störmer, Verwaltungsrecht, 4. Aufl. 2016, § 3a VwVfG Rn. $10 \mathrm{ff}$.

1236 BR-Drucks. 171/12, S. 29.

1237 Maurer/Waldhoff, Allgemeines Verwaltungsrecht, 19. Aufl. 2017, § 10 Rn. 43.

Tristan Lemke 
standsvoraussetzungen der Rechtsgrundlage (nicht) erfüllt sind. ${ }^{1238}$ Ermessensentscheidungen sind darüber hinaus gem. § 39 I 3 VwVfG so zu begründen, dass überprüft werden kann, ob ein Ermessensfehler vorliegt. ${ }^{1239}$ In jedem Fall muss die Begründung am Einzelfall orientiert sein.

Examenswissen: Die Pflicht der Behörde, ihre Entscheidung zu begründen, ist verfassungsrechtlich verankert. ${ }^{1240}$ Art. 19 IV GG räumt dem Bürger einen Anspruch auf effektiven gerichtlichen Rechtsschutz ein. Die Verwaltung ist als Kehrseite hiervon verpflichtet, diesen Rechtsschutz nicht zu vereiteln. Das täte sie jedoch, wenn sie ihre Gründe nicht offenlegte: Der Betroffene könnte die Erfolgsaussichten gerichtlichen Rechtsschutzes nicht abschätzen und würde dadurch davon abgehalten, diesen zu ersuchen. Selbst wenn er diesen Schritt ginge, wäre ihm die Verteidigung seiner Rechte erschwert, weil er die Erwägungen der Verwaltung nicht kennt. Schließlich wäre sogar das Gericht daran gehindert, eine Ermessensentscheidung effektiv zu überprüfen, wenn keinerlei Ermessenserwägungen offengelegt werden. Neben dieser Bedeutung für den Rechtsschutz sichert die Begründungspflicht den Subjektcharakter des Einzelnen im Verwaltungsverfahren. Wenn der Betroffene die Erwägungen nachvollziehen kann, die zum Erlass eines Verwaltungsakts geführt haben, fühlt er sich nicht als bloßes Objekt einer staatlichen Regelung. Hierdurch wird die Akzeptanz der Verwaltungsentscheidung gesteigert. Ferner dient die Begründungspflicht der Selbstkontrolle der Behörde. Diese wird zu sorgfältigen Ermittlungen und zur Auseinandersetzung mit dem Vorbringen des Beteiligten motiviert.

\section{ee) Heilung und Unbeachtlichkeit von Formfehlern}

Verstöße gegen Formvorschriften (und Verfahrensvorschriften, s. dazu bereits

Rn. 652) führen dazu, dass der Verwaltungsakt formell rechtswidrig ist, sofern er nicht nach § 44 VwVfG nichtig (s. Rn. 189ff.) ist. Das bedeutet jedoch nicht, dass der Verwaltungsakt auch unter sachlichen Mängeln leidet - er entspricht möglicherweise vollumfänglich dem materiellen Recht.

Beispiel: Eine Beseitigungsanordnung nach § 80 S. 1 BauO Bln oder eine Gewerbeuntersagung wegen Unzuverlässigkeit nach $\S 35$ I 1 GewO kann inhaltlich zutreffend sein, obwohl die erforderliche Begründung fehlt.

Den Verwaltungsakt aufzuheben und unter Beachtung der Formvorschrift neu zu

erlassen bedeutete einen erheblichen Aufwand. Unter den Voraussetzungen der $\S \S 45,46 \mathrm{VwVfG}$ ist das jedoch nicht notwendig.

1238 Vgl. Weiß, in: Mann/Sennekamp/Uechtritz, VwVfG, 2. Aufl. 2019, § 39 Rn. 29 ff.

$1239 \mathrm{Zu}$ den wenigen Ausnahmen aufgrund der Gesetzesformulierung als „Soll“-Vorschrift: Stelkens, in: Stelkens/Bonk/Sachs, VwVfG, 9. Aufl. 2018, § 39 Rn. 65 ff.

1240 S. hierzu mit Rechtsprechungsnachweisen und unter zusätzlichem Verweis auf Grundrechte als Verfahrensrechte, das Rechtsstaats- und das Demokratieprinzip Ramsauer, in: Kopp/ Ramsauer, VwVfG, 20. Aufl. 2019, § 39 Rn. 5a. 
695 Examenswissen: Die Vorschriften dienen somit der Verfahrensökonomie. Aus ihnen wird ferner deutlich, dass dem Verwaltungsverfahrensrecht eine dienende Funktion zukommt: Das Verwaltungsverfahrensrecht ist kein „Wert an sich“, sondern soll zum Erlass materiell rechtmäßiger und zweckmäßiger Verwaltungsakte beitragen. ${ }^{1241}$

\section{(1) Heilung von Formfehlern, § 45 I VwVfG}

696 Nur die in §45 I aufgezählten Formfehler können durch die jeweils genannte Handlung nachgeholt werden. Der vormals rechtswidrige Verwaltungsakt wird dadurch formell rechtmäßig. § 45 VwVfG ist daher in Klausuren unmittelbar im Anschluss an einen festgestellten Verstoß gegen eine Formvorschrift zu prüfen. Die Heilung ist gem. § 45 II VwVfG bis zum Abschluss der letzten Tatsacheninstanz möglich. Das ist im Berufungsverfahren das OVG. In jedem Fall ist zu beachten, dass der Betroffene durch die Heilung so gestellt werden muss, wie er ohne den Formfehler stünde. ${ }^{1242}$ Mit anderen Worten darf es für den Betroffenen keinen Nachteil bedeuten, dass die fehlerhafte oder unterbliebene Formvorschrift später als vorgesehen beachtet wurde. In Klausuren ist es deswegen erforderlich, den Telos von § 45 I Nr. 2 und Nr. 3 VwVfG zu kennen (s. Rn. 692, Rn. 687 und Rn. 659ff.). An diesem sollte sich die Argumentation daran orientieren, ob der Betroffene so gestellt wird, wie er bei Beachtung der Form- bzw. Verfahrensvorschrift stünde.

697 Hausarbeitswissen: Die erforderliche Handlung kann von bzw. vor der Ausgangsbehörde als auch grundsätzlich von bzw. vor der Widerspruchsbehörde nachgeholt werden. ${ }^{1243}$ Bezüglich der nachträglichen Anhörung ist jedoch umstritten, ob die Widerspruchsbehörde hierfür zuständig ist. ${ }^{124}$ Das wird teilweise verneint: Ermessenskontrolle sei nicht notwendig gleichbedeutend mit Ermessensausübung. Wenn die Widerspruchsbehörde mit der Zurückweisung des Widerspruchs bestätige, dass das Ermessen zweckmäßig ausgeübt worden sei, so schließe das nicht aus, dass sie nicht auch eine andere, dem Betroffenen günstigere Ermessenausübung gebilligt hätte. Es sei also nicht auszuschließen, dass in Fällen vorheriger Anhörung eine für den Betroffenen günstigere Entscheidung ergeht, wie er sie im Widerspruchsverfahren nicht mehr erreichen kann. Diese Argumentation verkennt jedoch den Sinn und Zweck der Anhörung. Diese soll nicht sicherstellen, dass gerade die Ausgangsbehörde (und nicht die Widerspruchsbehörde) die Argumente des Beteiligten würdigt. Mit der Anhörung wird vielmehr gewährleistet, dass der Beteiligte überhaupt seine Sicht der Dinge vortragen kann und damit Einfluss auf die Entscheidung nehmen kann. ${ }^{1245}$ Dieses Ziel wird jedoch

1241 BVerfG, Beschl. v. 20.2.2002, Az.: 1 BvL 19/97 = NVwZ 2002, 1101 (1102).

1242 Hufen/Siegel, Fehler im Verwaltungsverfahren, 6. Aufl. 2018, Rn. 960.

1243 Kopp/Ramsauer, VwVfG, 20. Aufl. 2019, § 45 Rn. 41.

1244 Ablehnend 3. Senat BVerwG, Urt. v. 14.10.1982, Az.: 3 C 46/81 = BVerwGE 66, 184 (187); Bejahend: 1. Senat BVerwG, Urt.v. 18.10.1983, Az.:1 C 13/81 = NVwZ 1984, 578; Sachs, in: Stelkens/ Bonk/Sachs, VwVfG, 9. Aufl. 2018, Rn. 78.

1245 OVG Münster, Urt. v. 7.9.2010, Az.: 6 A 2077/08 = DVBl 2010, 1572.

Tristan Lemke 
auch vollumfänglich erreicht, wenn die Anhörung von einer Widerspruchsbehörde nachgeholt wird, die die Zweckmäßigkeit umfassend überprüft, mit anderen Worten also eine eigene Ermessensentscheidung trifft. ${ }^{1246}$

\section{(2) Insbesondere: Nachholen von Gründen, § 45 I Nr. 2 VwVfG}

Wenn die nach §39 I 1 VwVfG erforderliche Begründung ganz oder teilweise 698 fehlt, kann sie gem. § 45 I Nr. 2 VwVfG nachgeholt werden. Dadurch wird die formelle Rechtswidrigkeit des Verwaltungsakts geheilt. Auf eine etwaige materielle Rechtswidrigkeit hat dies keinen Einfluss. Mit anderen Worten ermöglicht es die Vorschrift nicht, eine Begründung nachzubessern, die zwar den Anforderungen des §39 I 1 VwVfG entspricht, den Verwaltungsakt sachlich jedoch nicht zu tragen vermag.

Beispiel: Die zuständige Behörde erlässt einen auf die polizeiliche Generalklausel (s. näher Rn. 1032) gestützten Verwaltungsakt, der den Adressaten dazu verpflichtet, einen instabilen Baum von der Grundstücksgrenze zu entfernen, weil dieser auf die Straße stürzen könnte. Fehlt dieser Verfügung die Begründung, kann dieser Mangel über § 45 I Nr. 2 VwVfG geheilt werden. Anders verhält es sich, wenn eine Begründung vorhanden ist, diese jedoch auf die Ermessensfehlerhaftigkeit des Verwaltungsakts schließen lässt. In diesem Fall ist $\S 39$ I VwVfG entsprochen, der Verwaltungsakt aber materiell rechtswidrig. § 45 I Nr. 2 VwVfG ermöglicht keine Heilung.

\section{(3) Nachschieben von Gründen}

Examenswissen: Keine Frage der Formerfordernisse ist es, wenn ein materiell rechtswidriger Verwaltungsakt dadurch geheilt werden soll, dass Gründe nachgeschoben werden. Während die Nachholung der Begründung gem. § 45 I Nr. 2 VwVfG die formelle Rechtswidrigkeit aufgrund eines Verstoßes gegen § 39 I 1 VwVfG betrifft, geht es beim Nachschieben von Gründen darum, die materielle Rechtswidrigkeit zu korrigieren, die sich aus einer in der Sache unzureichenden Begründung ergibt. §114 S. 2 VwGO stellt klar, dass dies auch noch während des gerichtlichen Verfahrens zulässig ist. Sofern eine gebundene Entscheidung vorliegt, ist das Nachschieben von Gründen uneingeschränkt zulässig, weil nach § 86 I VwGO das Gericht sowieso Umstände berücksichtigt, die nicht in der ursprünglichen Begründung vorhanden waren. Bei Entscheidungen mit Gestaltungsspielraum, also Ermessens- und Beurteilungsspielraum (s. Rn. 721), sind zwei Kriterien zu beachten: Durch die nachgeschobenen Gründe darf das Wesen des Verwaltungsakts nicht verändert werden und die Rechtsverteidigung des Klägers darf nicht beeinträchtigt werden. ${ }^{1247}$ Aus diesen ergibt sich, dass keine Ermessenserwägungen nachgeschoben werden können, die nicht bereits zum Erlasszeitpunkt vorlagen. Die Behörde darf also nicht zuerst einen

1246 Das ist nicht der Fall, wenn die Widerspruchsbehörde lediglich die Rechtmäßigkeit überprüft; s. hierzu Dolde/Porsch, in: Schoch/Schneider/Bier, VwGO, 36. EL Februar 2019, § 68 Rn. 37. 1247 S. mit Rechtsprechungsnachweisen Decker, in: Posser/Wolff, VwGO, Stand 1.1.2019, § 114 Rn. $42 \mathrm{ff}$. 
Verwaltungsakt erlassen und zu dessen Recht- und Zweckmäßigkeit erst im Nachhinein Erwägungen anstellen. Genauso wenig dürfen die tragenden Gründe ausgetauscht werden oder völlig neue Argumentationsstrukturen hinzugefügt werden. Als Faustformel gilt, dass die Ermessenserwägungen „verfeinert“ werden dürfen, um einen knapp rechtswidrigen Verwaltungsakt auf die Seite der Rechtmäßigkeit zu ziehen. Durch nachgeschobene Gründe können jedoch keine schweren Ermessensfehler, wie beispielsweise der Ermessensausfall, kompensiert werden.

\section{(4) Unbeachtlichkeit von Formfehlern, § 46 VwVfG}

700 Im Rahmen von §45 I VwVfG wird der Verfahrens- oder Formfehler dadurch ausgeglichen, dass die entsprechende Handlung nachgeholt wird und ihre volle Wirkung entfalten kann. Beispielsweise verschafft die nachgeholte Anhörung dem Beteiligten die Gelegenheit, mit seinen Argumenten Einfluss auf die Sachentscheidung zu nehmen (s. Rn. 687 und Rn. 659ff.) Bei §46 VwVfG geht es hingegen um Verstöße, die gar keinen Einfluss auf die Sachentscheidung haben konnten. Trotz der daraus resultierenden formellen Rechtswidrigkeit wird der Verwaltungsakt in diesen Fällen nicht vom Gericht nach § 113 I 1 VwGO aufgehoben. Es wäre ineffizient, einen sachlich richtigen Verwaltungsakt aufzuheben, weil eine Vorschrift verletzt wurde, die in diesem Fall offensichtlich keinerlei Auswirkungen hatte. Auch dem Betroffenen wäre nicht geholfen: Der formell rechtwidrige Verwaltungsakt würde sofort erneut mit identischem Inhalt ergehen, dieses Mal unter Berücksichtigung der entsprechenden Norm. Verfahrensund Formgebote allein ihrer selbst wegen zu berücksichtigen bewirkte demnach nichts außer der Verschwendung knapper staatlicher Ressourcen (s. auch Rn. 695). Das bedeutet jedoch keineswegs, dass $§ 46$ VwVfG die Exekutive davon freistellt, Form- und Verfahrensvorschriften zu beachten: Der Tatbestand ist nur erfüllt, wenn „offensichtlich ist, dass die Verletzung die Entscheidung in der Sache nicht beeinflusst hat".

701 Von § 46 VwVfG werden nur Verstöße gegen die Form, das Verfahren oder die örtliche Zuständigkeit erfasst. Verletzungen der Vorschriften über die sachliche-, instanzielle oder Verbandszuständigkeit sind damit niemals unbeachtlich. ${ }^{1248}$ In Klausuren ist insbesondere denkbar, dass $\S 46$ aufgrund einer unterlassenen Anhörung nach § 28 VwVfG oder einer Verletzung von Befangenheitsvorschriften nach $\S 20$ I Nr. 1 bis 6 VwVfG zu prüfen ist. Grundsätzlich kommen jedoch alle Verfahrens- und Formvorschriften - auch außerhalb des VwVfG - in Betracht.

702 Hausarbeitswissen: Ausgenommen sind Vorschriften, deren Verletzung keinen Aufhebungsanspruch begründete. Denn wenn aus dem Normverstoß kein Aufhebungsanspruch folgt, vermag $\S 46$

1248 Ausführliche Rechtsprechungsnachweise bei Schwarz, in: Fehling/Kastner/Störmer, Verwaltungsrecht, 4. Aufl. 2016, § 46 VwVfG Rn. 20.

Tristan Lemke 
VwVfG diesen auch nicht auszuschließen. Das kann u.a. in Drittanfechtungskonstellationen (s. Rn. 544ff.) problematisch sein. ${ }^{1249}$ Darüber hinaus schließt $\S 46$ VwVfG nicht den Aufhebungsanspruch aus, der sich aus der Verletzung absoluter Verfahrensrechte ergibt. ${ }^{1250}$ Bei diesen handelt es sich um Normen, die dem Beteiligten eine selbstständig durchsetzbare Verfahrensposition unabhängig vom materiellen Recht einräumen. Hierzu gehört beispielsweise das gemeindliche Einvernehmen gem. $\S 36$ BauGB. Dieses Beteiligungsrecht ist von so großer Bedeutung für die gemeindliche Planungshoheit, dass seine Verletzung unabhängig von den Auswirkungen auf die materiell rechtliche Position zur Aufhebung der Baugenehmigung führt.

Dieser Fehler darf die Entscheidung in der Sache offensichtlich nicht beein- 703 flusst haben. Der Verstoß darf also nicht kausal für die Sachentscheidung gewesen sein. Das Ergebnis würde sich nicht ändern, wenn der Verstoß weggedacht würde, die geforderte Handlung also vorgenommen worden wäre. Bei gebundenen Entscheidungen ist das unproblematisch zu bejahen, weil der Fehler keine Auswirkungen auf die Entscheidung gehabt haben kann. Bei Entscheidungen mit Gestaltungsspielraum (Ermessen und Beurteilungsspielraum) bedarf es hingegen einer genauen Prüfung des Einzelfalls, sofern keine Ermessensreduzierung auf null vorliegt. Jeglicher Zweifel daran, dass die Behörde ohne den Verfahrensfehler genauso entschieden hätte, muss ausgeschlossen sein. ${ }^{1251}$ Das ist nicht der Fall, wenn intensive Nachforschungen erforderlich sind, um zu ermitteln, wie die Behörde hypothetisch entschieden hätte: Die Nichtbeeinflussung muss offensichtlich sein. Daraus und aus dem Charakter des §46 VwVfG als Ausnahmevorschrift ergeben sich die hohen Anforderungen, die erfüllt sein müssen, damit ein Verstoß unbeachtlich ist.

Anders als bei der Heilung von Verfahrens- und Formfehlern lässt § 46 VwVfG 704 nach herrschender Meinung die Rechtswidrigkeit des Verwaltungsakts unberührt; die Norm wirkt sich nur auf den prozessualen Aufhebungsanspruch aus, der in $\S 113$ I 1 VwGO geregelt ist. ${ }^{1252}$

Aufbauhinweis: §46 VwVfG kann an mehreren Stellen geprüft werden. 705 Empfehlenswert ist es, die Norm unmittelbar im Anschluss an die formelle Rechtswidrigkeit zu prüfen und festzustellen, dass der Verwaltungsakt zwar formell rechtswidrig ist, der Aufhebungsanspruch jedoch aufgrund von § 46 VwVfG nicht hierauf gestützt werden kann, so dass auch die materielle Rechtmäßigkeit $\mathrm{zu}$ prüfen ist.

1249 Hierzu Emmenegger, in: Mann/Sennekamp/Uechtritz, VwVfG, 2. Aufl. 2019, § 46 Rn. 34 ff. 1250 Ausführlich Emmenegger, in: Mann/Sennekamp/Uechtritz, VwVfG, 2. Aufl. 2019, § 46 Rn. $102 \mathrm{ff}$.

1251 BVerwG, Urt. v. 24.6.2010, Az.: 3 C 14/09 = KommJur 2011, 97 (102).

1252 BVerwG, Urt. v. 24.6.2010, Az.: 3 C 14/09 = KommJur 2011, 97 (98); Hufen/Siegel, Fehler im Verwaltungsverfahren, 6. Aufl. 2018, Rn. 989.

Tristan Lemke 


\section{ff) Bestimmtheit des Verwaltungsakts}

706 Verwaltungsakte müssen gem. § 37 I VwVfG hinreichend bestimmt sein. Der verfügende Teil des Verwaltungsakts muss so klar und eindeutig formuliert sein, dass der Adressat sein Verhalten danach ausrichten kann. Das ist nicht der Fall, wenn die Regelung missverständlich bzw. widersprüchlich ist oder der Adressat noch einmal Rücksprache mit der Behörde halten muss, bevor er zur Tat schreiten kann.

Beispiel: Der Adressat wird verpflichtet, seine Anlage leise zu betreiben oder durch bauliche Maßnahmen sicherzustellen, dass die zulässigen Lärmwerte eingehalten werden ${ }^{1253}$. In beiden Fällen ist für den Adressaten nicht ersichtlich, was von ihm verlangt wird.

707 Bei sachbezogenen Allgemeinverfügungen nach § 35 S. 2 Var. 2 VwVfG - wie der Entwidmung einer Straße - muss eindeutig erkennbar sein, auf welche Sache sich der Verwaltungsakt bezieht; ist beispielsweise die Straße nicht eindeutig identifizierbar, ist der Verwaltungsakt zu unbestimmt. Neben der Regelung des Verwaltungsakts müssen der Adressat des Verwaltungsakts und die die Verwaltungsakt erlassene Behörde eindeutig erkennbar sein. Unbestimmtheit ist in jedem Fall erst anzunehmen, wenn die Unklarheiten auch durch Auslegung nicht beseitigt werden können. ${ }^{1254}$

708 Examenswissen: §37 I VwVfG ist eine einfachgesetzliche Ausprägung des Rechtsstaatsprinzips. Das Bestimmtheitserfordernis für Verwaltungsakte dient der Rechtsklarheit und Rechtssicherheit: ${ }^{1255}$ Der Bürger wird davor bewahrt, dass ein Verwaltungsakt, der ihn betrifft, unverständlich und unklar ist. Nur wenn dieser rechtsstaatlichen Mindestanforderung entsprochen wird, kann die Rechtsordnung das Verhalten der Bürger steuern: § 37 I VwVfG stellt sicher, dass das abstrakt-generelle Gesetz durch den Verwaltungsakt auf den Einzelfall ausreichend präzise konkretisiert wird.

709 Aufbauhinweis: §37 I VwVfG steht in systematischer Nähe zu §§ 37 II bis V, 39 VwVfG, die Aspekte der formellen Rechtswidrigkeit des Verwaltungsakts regeln. Daher wird teilweise angenommen, ein Verstoß gegen § 37 I VwVfG begründe die formelle Rechtswidrigkeit des Verwaltungsakts. ${ }^{1256}$ Die herrschende Meinung geht hingegen davon aus, dass die Bestimmtheit der materiellen Rechtmäßigkeit

1253 OVG Münster, Urt. v. 22.3.1961, Az.: IV A 398/60 = OVGE MüLü 16, 263-271; BVerwG, Urt. v. 5.11.1968, Az.: I C 29.67 = BVerwGE 31, 15.

1254 BVerwG, Beschl. v. 25.3.1996, Az.: 8 B 48/96 = DVBl 1996, 1061.

1255 BVerwG, Urt. v. 27.6.2012, Az.: 9 C 7/11 = BVerwGE 143, 222.

1256 OVG Berlin-Brandenburg, Urt. v. 23.11.2006, Az.: OVG 5 B 11.05 = OVGE BE 27, 287.

Tristan Lemke 
zuzurechnen ist. ${ }^{1257}$ Das ist überzeugend, weil die Bestimmtheit das Wesen, also den „Körper“ des Verwaltungsakts prägt und nicht lediglich seine Erscheinung, sein „Kleid“ betrifft. In Klausuren bedarf dieser Streit regelmäßig keiner Erläuterung. Die Bestimmtheit ist kommentarlos entweder im Rahmen der formellen Rechtmäßigkeit oder im Rahmen der materiellen Rechtmäßigkeit zu prüfen. Ist sie unproblematisch zu bejahen muss sie nicht zwingend im Gutachten erwähnt werden.

Ein Verstoß gegen $\S 37$ I VwVfG kann nicht nur zur Rechtswidrigkeit des 710 Verwaltungsakts führen, sondern sogar seine Nichtigkeit nach § 44 I VwVfG begründen (s. zur Nichtigkeit von Verwaltungsakten näher Rn. 189 ff.). ${ }^{1258}$ Dafür erforderlich ist, dass die Unbestimmtheit offensichtlich ist. Der aufgrund mangelnder Bestimmtheit materiell rechtswidrige Verwaltungsakt kann dadurch ex tunc geheilt werden, dass die Unklarheit oder Widersprüchlichkeit durch Klarstellungen der Behörde beseitigt wird. ${ }^{1259}$

\section{gg) Literaturhinweise}

Pünder, Die Folgen von Fehlern im Verwaltungsverfahren, JURA 2015, 1307 - 1318; 711 Lysander, Formelle Fehler des Verwaltungsakts und ihre Folgen, JA 2012, 844; Beaucamp, Heilung und Unbeachtlichkeit von formellen Fehlern im Verwaltungsverfahren, JA 2007, 117; Erbguth/Guckelberger, Allgemeines Verwaltungsrecht, 9. Aufl. 2018, § 14 Rn. 22-24 und § 15 Rn. 14-18; Maurer/Waldhoff, Allgemeines Verwaltungsrecht, 19. Aufl. 2017, § 10 Rn. 41-46 und § 10 Rn. 57-71

Zur Vertiefung: Lindner/Jahr, Der unzureichend begründete Verwaltungsakt, JuS 2013, 673; Guckelberger, Anhörungsfehler bei Verwaltungsakten, JuS 2011, 577

\section{Materielle Rechtmäßigkeit des Verwaltungsakts (Daniel Benrath)}

Die Prüfung der materiellen Rechtmäßigkeit bzw. Rechtswidrigkeit eines Ver- 712 waltungsakts betrifft dessen inhaltliche Seite, also ob sein Inhalt (auch in Bezug auf die inhaltlichen Grundlagen der behördlichen Entscheidung) mit dem geltenden Recht vereinbar ist. Gegenstand der materiellen Rechtmäßigkeitsprüfung ist der hoheitliche Befehl als Kern des Verwaltungsakts (also der Tenor), nicht hingegen weitere Ausführungen wie die Begründung (wobei die Begründung im Hinblick auf die inhaltlichen Grundlagen zu berücksichtigen sein und sogar im

1257 BVerwG, Urt. v. 29.3.1968, Az.: IV C 27/67 = NJW 1968, 1842; BVerwG, Urt. v.12.12.1996, Az.: 4 C 17/95 = NVwZ 1997, 902; Stelkens in Stelkens/Bonk/Sachs, VwVfG, 9. Aufl. 2018, § 37 Rn. 1. 1258 OVG Weimar, Beschl. v. 28.1.2005, Az.: 4 ZKO 360/04 = LKV 2006, 281.

1259 BVerwG, Urt. v. 20.4.2005, Az.: 4 C 18/03 = NVwZ 2005, 933 (938).

Tristan Lemke/Daniel Benrath 
Vordergrund der Prüfung stehen kann). Im deutschen Verwaltungsrecht stellt die Prüfung der materiellen Rechtsmäßigkeit, auch vor dem Hintergrund vielfältiger Regelungen zur Heilung und zur Unbeachtlichkeit im Rahmen der formellen Rechtmäßigkeit (dazu Rn. 693ff.), oftmals den Kern der Rechtskontrolle dar.

Ein Verwaltungsakt ist materiell rechtmäßig, wenn er den materiell-rechtlichen Vorgaben der Rechtsgrundlage entspricht und nicht gegen anderweitige rechtlichen Vorgaben verstößt. Ist der Verwaltungsakt mit Spielräumen der erlassenden Behörde verknüpft, ist der rechtliche Kontrollmaßstab hinsichtlich des Inhalts des Verwaltungsakts zurückgenommen, allerdings ist insoweit die Inanspruchnahme des Spielraums auf eigenständige Fehler zu überprüfen.

In der materiellen Rechtmäßigkeitsprüfung können also viele verschiedene rechtliche Aspekte zu erfassen und aufeinander zu beziehen sein, die zudem wesentlich von dem jeweiligen Rechtsgebiet abhängen. Diese erheblichen Herausforderungen sind jedoch durch ein gutes Verständnis der materiellen Grundlagen des Verwaltungsrechts sowie ein strukturiertes und reflektiertes Vorgehen in der Prüfung sicher zu beherrschen.

Zur Beherrschung der materiellen Rechtmäßigkeitsprüfung wird eine Vielzahl von Aufbauschemata angeboten. Während sich in der Literatur zum allgemeinen Verwaltungsrecht schnell der Eindruck einer gewissen Einförmigkeit des Prüfungsaufbaus ergeben kann, wird schon bei einem kurzen Blick in die Prüfungsschemata des besonderen Verwaltungsrechts und des Verwaltungsvollstreckungsrechts deutlich, wie unterschiedlich die Prüfung der materiellen Rechtmäßigkeit eines Verwaltungsakts ausgestaltet werden kann. Zudem werden weitere Prüfungsschemata in Ausbildung und Praxis angeboten, die in der Literatur keinen oder wenig Widerhall gefunden haben. Grob - aber nicht abschließend - prägen zwei Unterscheidungsebenen die verschiedenen Schemata. Eine Gruppe von Schemata knüpft an die grundlegende Trennung zwischen den Voraussetzungen des Erlasses des Verwaltungsakts und den Rechtsfolgen, also der konkreten Ausgestaltung des Verwaltungsakts (im Tenor und hinsichtlich der auf die Rechtsfolgen gerichteten Spielräume), an. Diese Gruppe findet sich vor allem in Lehrbüchern gerade zum allgemeinen Verwaltungsrecht (sowie in der allgemeinen Übersicht zur Rechtmäßigkeitsprüfung in Rn. $526 \mathrm{ff}$.) und knüpft an vergleichbare Gliederungsebenen in Teilen der zivilrechtlichen Lehrliteratur an. Auch den Falllösungen im das Lehrbuch begleitenden Fallrepetitorium „Fälle zum Verwaltungsrecht“ liegt dieser Aufbau im Wesentlichen zugrunde.

Jedenfalls aus der Kontrollperspektive der Gerichte (und des üblichen Klausurgutachtens) ist eine Trennung zwischen Voraussetzungen und Rechtsfolgen jedoch nicht zwingend. Gegenstand ist allein der konkrete Verwaltungsakt und dieser ist bei jedem materiellen Verstoß gegen gesetzliche Vorgaben rechtswidrig, unabhängig davon, ob die gesetzlichen Vorgaben sich auf die Voraussetzungen 
oder die Rechtsfolgen beziehen. Viele gängige Schemata verzichten daher auf diese Unterscheidung. Stattdessen wird oftmals auf die Unterscheidung zwischen inhaltlichen Vorgaben, die den möglichen Inhalt eines Verwaltungsakts einschränken, und spezifischen Fehlern bei der Inanspruchnahme von Verwaltungsspielräumen zurückgegriffen. Alle angebotenen Schemata haben sich bewährt, sind insofern gleichwertig und weisen ihre jeweils eigenen Stärken (und Schwächen) auf. Die strikte Einhaltung eines bestimmten Schemas ist für eine Prüfung nicht entscheidend. Vielmehr ist ein gelungener Aufbau der materiellen Rechtmäßigkeitsprüfung von der konkreten Rechtsfrage, den Problemen des Falles, dem individuellen Zugang des Anwenders und nicht zuletzt dem jeweiligen Rechtsgebiet im besonderen Verwaltungsrecht abhängig.

Examenswissen: Eine Quelle von Missverständnissen und Fehlern für Studierende und auch 716 fortgeschrittene Anwender ist hingegen die unreflektierte Anwendung eines Prüfungsschemas. Missverständnisse können sich insbesondere ergeben, wenn sich ein Anwender mit einem ihm unbekannten Aufbau konfrontiert sieht und die entsprechenden Abweichungen nicht einordnen kann. Wird dann versucht, die Abweichungen allzu schematisch in den bekannten Aufbau zu integrieren, kommt es schnell zu versteckten Redundanzen und Widersprüchen. Zudem können sich hartnäckige Missverständnisse entwickeln, wenn bloße Prüfungspunkte oder Strukturen des Prüfungsaufbaus unzutreffend als Kategorien des materiellen Verwaltungsrechts eingeordnet werden. Dies gilt insbesondere für Abgrenzungen, die allein die Prüfung ordnen bzw. das Verständnis erleichtern sollen, für den rechtlichen Ausgang der Prüfung selbst jedoch unerheblich sind (wie etwa zwischen Voraussetzungen und Rechtsfolge oder zwischen verschiedenen Fallgruppen von Ermessensfehlern).

Entscheidend sind also vornehmlich ein gutes systematisches Verständnis 717 der rechtlichen Grundlagen, auf die sich die Prüfung der materiellen Rechtmäßigkeit bezieht, und ein reflektierter Umgang mit den vielfältigen Aufbauvarianten. Dementsprechend ist der weiteren Darstellung der klausurmäßigen Prüfung eine abstrakte Besprechung zu den Grundlagen der materiellen Rechtmäßigkeitsprüfung (Rechtsbindung und Spielräume der Verwaltung) vorangestellt (Rn. 719ff.), während am Ende Grundüberlegungen zum Prüfungsaufbau und verschiedene Aufbaualternativen vorgestellt und reflektiert werden (Rn. $803 \mathrm{ff}$.).

Der hier zur Gewährleistung einer klaren Orientierung in der Klausurprüfung 718 zur Anfechtungsklage zu Grunde gelegte Prüfungsaufbau hat sich nach meiner Erfahrung in Rechtsanwendung und (insbesondere) Lehre als allgemeine Basis der materiellen Rechtmäßigkeitsprüfung besonders bewährt. Er folgt der grundlegenden Trennung zwischen inhaltlichen Vorgaben und spezifischen Fehlern bei der Inanspruchnahme von Spielräumen und zeichnet sich dadurch aus, dass er einzelne Prüfungspunkte eher isoliert betrachtet und auf übergeordnete Strukturen weitgehend verzichtet. Insbesondere die Unterscheidung zwischen inhaltlichen Vorgaben der Rechtsgrundlage, der allgemeinen Grundsätze und des 
sonstigen Rechts soll nur eine grobe Ordnung vermitteln, ohne dass es auf eine Zuordnung einzelner Prüfungspunkte (z. B. der Verhältnismäßigkeit) ankommt; in der Prüfung sind diese Gliederungsebenen ohne Weiteres verzichtbar.

Materielle Rechtmäßigkeit:

a) Inhaltliche Vorgaben (Rn. $756 \mathrm{ff}$.)

aa) Verwaltungsaktbefugnis (Rn. 760)

bb) Inhaltliche Vorgaben der Rechtsgrundlage (Rn. $761 \mathrm{ff}$.)

cc) Allgemeine Grundsätze (Rn. 767 ff.)

dd) Sonstige rechtliche Vorgaben (Rn. 782ff.)

b) Richtiger Adressat (Rn. 790f.)

c) Spezifische Fehler bei der Inanspruchnahme von Spielräumen (Rn. $792 \mathrm{ff}$.)

Durch diesen Aufbau wird eine Prüfung nah am Gesetz erleichtert und relativ wenig auf inhaltlich unnötige Abgrenzungen abgestellt. Vor allem ist dieser Aufbau anschlussfähig für Eigenheiten des besonderen Verwaltungsrechts, atypische Prüfungspunkte und alternative Herangehensweisen. Anfänger, die sich diesen Aufbau sicher aneignen, können alternative Herangehensweisen und unbekannte Prüfungspunkte relativ einfach zuordnen. Fortgeschrittene, die sich anhand dieses Aufbaus wiederholend mit der materiellen Rechtmäßigkeitsprüfung auseinandersetzen, können ihr Verständnis auch im Rahmen des von ihnen favorisierten Aufbaus schärfen. D.h. natürlich mitnichten, dass andere Aufbauvarianten hinsichtlich mancher Aspekte und bestimmter Konstellationen nicht vorteilhafter sind, sie können sich in bestimmten Prüfungssituationen sogar aufdrängen. Im Rahmen der weiteren Darstellung wird an den entsprechenden Stellen darauf hingewiesen, wie die Prüfungspunkte in anderen typischen Aufbauvarianten in Bezug genommen werden können.

\section{a) Rechtsbindung und Spielräume der Verwaltung}

719 Anders als Private sind hoheitlich handelnde Behörden umfassend an die Vorgaben des Rechtsstaats gebunden. Für die Überprüfung der materiellen Rechtmäßigkeit eines Verwaltungsakts wird also nicht bloß geprüft, ob das konkrete Verwaltungshandeln einen bestimmten (Verletzungs-)Tatbestand erfüllt (wie etwa im Deliktsrecht oder im Strafrecht), vielmehr muss der Verwaltungsakt insgesamt den vielfältigen gesetzlichen Bindungen inhaltlich entsprechen. Der Rechtsbindung der Verwaltung entspricht es, dass die materielle Rechtmäßigkeit eines Verwaltungsakts positiv festgestellt werden muss. D.h. jedoch nicht notwendigerweise, dass die juristische Prüfung der materiellen Rechtmäßigkeit die behördliche Entscheidung entlang der gesetzlichen Vorgaben vollständig nach- 
vollzieht. Soweit die handelnde Behörde einen eigenständigen Spielraum bei der Umsetzung der gesetzlichen Vorgaben hat, bleibt die materielle Rechtmäßigkeitsprüfung auf eine Kontrolle hinsichtlich zur Rechtswidrigkeit führender Fehler beschränkt.

\section{aa) Verwaltung zwischen Rechtsbindung und Spielräumen}

In einem Rechtsstaat bedarf jedes staatliche Handeln einer rechtlichen Grundlage $\mathbf{7 2 0}$ (s. dazu näher Rn. 554 ff.). ${ }^{1260}$ Dementsprechend ist nach Art. 20 III GG die vollziehende Gewalt an Gesetz und Recht gebunden. Für die Eingriffsverwaltung verlangen die Grundrechte zudem eine konkrete rechtliche Grundlage. Und selbst im Rahmen der gesetzesfreien Leistungsverwaltung wird, bei allen Streitfragen im Detail, eine rechtliche Anknüpfung verlangt. ${ }^{1261}$ Die Verwaltung unterliegt also einer umfassenden rechtlichen Bindung. Gleichzeitig braucht eine Verwaltung, die flexibel und angemessen handeln soll, in vielen Bereichen eigenständige Spielräume, die über die bloße innere Organisation hinausgehen und auch das Außenverhältnis zu den Bürgern (und anderen) betreffen. ${ }^{1262}$ Insbesondere für den Umgang mit komplexen Fällen, die auf der abstrakten gesetzlichen Ebene kaum oder nur unzureichend erfassbar sind, als Reaktion auf unvorhersehbare Entwicklungen und zur Bewältigung einer Vielzahl unterschiedlicher konkreter Einzelfälle vor dem Hintergrund begrenzter Ressourcen und faktischer Möglichkeiten wird den Behörden häufig ein eigenständiger Spielraum eingeräumt.

Insbesondere für die Prüfung der materiellen Rechtmäßigkeit wird zwischen

gebundenen Entscheidungen und Entscheidungen mit Spielräumen (ungebundene Entscheidungen) unterschieden. Gebundene Entscheidungen sind in Anwendung der gesetzlichen Normen eindeutig vorgegeben. Die Behörde setzt in entsprechenden Verwaltungsakten die gesetzlichen Vorgaben nur konkretisierend um. Bei Entscheidungen mit Spielraum bestehen zwar auch gesetzliche Vorgaben zu den Voraussetzungen und den Inhalten des staatlichen Handelns. Jedoch sind hier die Rechtsfolgen aus den Voraussetzungen nicht eindeutig determiniert, vielmehr wird der Behörde ein eigenständiger Spielraum zur Gestaltung ihres Handelns eingeräumt. ${ }^{1263}$ Auch innerhalb dieses Spielraums handelt die Behörde jedoch nicht ohne rechtliche Bindung. ${ }^{1264}$ Zum einen unterliegt sie den weiterhin bestehenden inhaltlichen rechtlichen Bindungen als äußere

1260 Grzeszick, in: Maunz/Dürig, GG, 87. EL 2019, Art. 20 VI. Rn. 26.

1261 Detterbeck, Allgemeines Verwaltungsrecht, 17. Aufl. 2019, Rn. 285 ff. m.w. N.

1262 Detterbeck, Allgemeines Verwaltungsrecht, 17. Aufl. 2019, Rn. 307.

1263 Instruktiv u.a. Kment/Vorwalter, JuS 2015, 193.

1264 Maurer/Waldhoff, Allgemeines Verwaltungsrecht, 19. Aufl. 2017, § 7 Rn. 7, 17.

Daniel Benrath 
Grenze ihres Spielraums. Zum anderen hat sie (auch wenn der konkrete Inhalt der Entscheidung nicht vorgegeben ist) rechtliche Vorgaben dazu, wie sie ihren Spielraum nutzt, als innere Grenzen des Spielraums zu beachten. Die Gegenüberstellung beider Arten von Grenzen ist für das Verständnis des Verwaltungsspielraum ausgesprochen hilfreich und insbesondere im Zusammenhang mit der gerichtlichen Kontrolle (Stichwort: Ermessensfehlerlehre) relevant. In der juristischen Prüfung kommt es jedoch auf eine Abgrenzung nicht an und auch in der Literaturdiskussion ist die Abgrenzung im Detail weder scharf noch einheitlich.

722 Die äußeren Grenzen des Spielraums beziehen sich (nach dem hier zu Grunde gelegten Verständnis) auf den regelnden Inhalt des Verwaltungsakts. Ein Verwaltungsakt, der die äußeren Grenzen des Spielraums überschreitet, darf so nicht erlassen werden. Ein Spielraum besteht nur innerhalb seiner äußeren Grenzen. Dies betrifft das Überschreiten eines Entscheidungskorridors (Beispiel: Es wird ein Zwangsgeld angedroht, dass über dem gesetzlichen Maximum liegt) ebenso wie Verletzungen rechtlicher Vorgaben gerade durch den konkreten Inhalt des Verwaltungsakts (Beispiel: Die konkrete polizeiliche Maßnahme ist in dieser Situation unverhältnismäßig). Die äußeren Grenzen werden im Rahmen der Ermessensfehlerlehre im Wesentlichen bei der Ermessensüberschreitung angesprochen, können aber auf alle „harten“ inhaltlichen Vorgaben (einschließlich der Tatbestandsmerkmale der Rechtsgrundlage einer Ermessensentscheidung) bezogen werden.

723 Die inneren Grenzen hingegen beziehen sich nicht auf den konkreten Inhalt des Verwaltungsakts, sondern auf die inhaltliche Grundlage des Zustandekommens der konkreten Entscheidung (Beispiele: Berücksichtigung des zu Grunde liegenden Sachverhalts, maßgebliche Gründe, Gewichtung von Interessen). Sie sprechen sozusagen die subjektive Seite der Verwaltungsentscheidung an. Die inneren Grenzen sind strukturell von inhaltlichen gesetzlichen Vorgaben verschieden und die mit ihnen verbundenen spielraumspezifischen Prüfungsschritte sind nur im Rahmen von Entscheidungen mit Spielraum relevant. Diese spielraumspezifische Prüfung ist vor allem im Hinblick auf Fehler sinnvoll erfassbar, insbesondere im Rahmen des Ermessensfehlgebrauchs. Auch wenn sich die inneren Grenzen auf das Zustandekommen des Verwaltungsakts beziehen, sind sie nicht mit den verfahrensrechtlichen Vorgaben gleichzusetzen, die die Abfolge von Verfahrensschritten regeln (und eben nicht die inhaltlichen Grundlagen der Entscheidung).

724 Examenswissen: Die Einräumung von Spielraum für die Behörden unterliegt verfassungsrechtlichen Grenzen. Rechtsstaatlichkeit und demokratische Legitimation stehen einer Ausuferung von Verwaltungsspielräumen entgegen. Auch wenn die Behörden durch die hierarchische Unterordnung unter ihre politisch besetzten Spitzen in die demokratische Legitimationskette

\section{Daniel Benrath}


integriert sind, ${ }^{1265}$ muss sichergestellt bleiben, dass die wesentlichen politischen Entscheidungen auf abstrakter Gesetzesebene getroffen werden ${ }^{1266}$ und die Bürger auf Grund der gesetzlichen Vorgaben das behördliche Verhalten im Voraus abschätzen können ${ }^{1267}$. Und das Grundrecht auf gerichtliche Kontrolle aus Art. 19 IV GG darf nicht durch eine Überdehnung nicht justiziabler Spielräume ausgehöhlt werden. Diese verfassungsrechtlichen Grenzen sind bei der materiellen Prüfung zu berücksichtigen. Verstößt die Einräumung eines Spielraums gegen die verfassungsrechtlichen Vorgaben, ist das entsprechende Gesetz nichtig und der entsprechende Verwaltungsakt mangels Rechtsgrundlage rechtswidrig. Vor allem aber sind die verfassungsrechtlichen Grenzen bei der Auslegung der entsprechenden einen Spielraum einräumenden Regelungen zu berücksichtigen: Der Anwendungsbereich des Spielraums und die rechtlichen Bindungen dieses Spielraums sind vor dem Hintergrund der verfassungsrechtlichen Grenzen auszulegen, insbesondere bei der Betrachtung von bei der Rechtsetzung unerwarteten Entwicklungen oder Einzelfällen. Würde also die Anwendung des Spielraums auf einen neuen Fall wesentliche politische Fragen berühren und letztlich die verfassungsrechtlichen Grenzen überschreiten, ist gegebenenfalls eine Auslegung geboten, die die Anwendung ausschließt. Und insbesondere bei der Einräumung eines weiten Spielraums gilt es, die gesetzlichen Bindungen des Spielraums besonders intensiv zu kontrollieren.

Die im deutschen Verwaltungsrecht gebräuchlichste und für die juristische Aus- $\mathbf{7 2 5}$ bildung relevanteste Form des Verwaltungsspielraums ist der Ermessensspielraum. Das Ermessen bezieht sich auf die Rechtsfolgenseite, also für den Verwaltungsakt auf dessen anordnenden Inhalt. Ist also der Behörde beim Erlass eines Verwaltungsakts Ermessen eingeräumt, kann sie unter den Voraussetzungen und in den sonstigen Grenzen der rechtlichen Vorgaben selbst entscheiden, was genau sie anordnet. Neben dem allgemeinen Ermessen bestehen noch spezielle Ausformungen oder andere Formen des Spielraums, insbesondere der Beurteilungsspielraum, der den Behörden (auf der Tatbestandsseite) einen Spielraum bei der Beurteilung und Einordnung des Sachverhalts gewährt.

Während gebundene Entscheidungen vollständig der gerichtlichen Kon- 726 trolle zugänglich sind, das Verwaltungsgericht also die behördliche Entscheidung anhand des von ihm ermittelten Sachverhalts und der rechtlichen Vorgaben vollständig nachvollzieht, unterliegt die Inanspruchnahme von Spielräumen durch die Behörden nur einer reduzierten gerichtlichen Kontrolle. Das bedeutet jedoch nicht, dass die Eröffnung eines Spielraums direkt jede gerichtliche Kontrolle ausschließt. Neben den voll überprüfbaren gesetzlichen Vorgaben der äußeren Grenze sind die Vorgaben zu den inneren Grenzen des Spielraums im Rahmen der sog. (Ermessens-)Fehlerlehre zu kontrollieren. Den Gerichten entzogen bleibt insofern jedoch die Frage der sachlichen Richtigkeit oder Zweck-

1265 Grzeszick, in: Maunz/Dürig, GG, 87. EL 2019, Art. 20 I. Rn. 139.

1266 Detterbeck, Allgemeines Verwaltungsrecht, 17. Aufl. 2019, Rn. $264 \mathrm{ff}$.

1267 BVerwG, Urt. v. 16.10.2013, Az.: 8 CN 1/12 = BVerwGE 148, 133 (Rn. 21).

Daniel Benrath 
mäßigkeit der konkreten Entscheidung. ${ }^{1268}$ Diese Frage soll ja gerade die Behörde im Rahmen des ihr eingeräumten Spielraums eigenständig beantworten. Die unabhängigen Gerichte können und dürfen sich insoweit nicht an die Stelle der Verwaltung stellen; sie verwalten nicht.

\section{bb) Gebundene Entscheidungen}

727 Die gebundenen Entscheidungen der Verwaltung sind gesetzlich programmiert. Liegen also die gesetzlichen Voraussetzungen vor, sind die gesetzlichen Rechtsfolgen durch die Behörde anzuordnen. Es gibt also nur eine richtige Entscheidung. Der gebundene Verwaltungsakt ist dann materiell rechtswidrig, wenn die gesetzlichen Voraussetzungen nicht erfüllt sind oder die Entscheidung der gesetzlich vorgesehenen Rechtsfolge nicht entspricht. Andersherum ist der Verwaltungsakt materiell rechtmäßig, wenn er hinsichtlich der Voraussetzungen und hinsichtlich der Rechtsfolgen den gesetzlichen Vorgaben entspricht (und zwar auch dann, wenn die Behörde subjektiv Fehler gemacht hat). ${ }^{1269}$ Das Gericht überprüft also auf Grund des selbst ermittelten Sachverhalts, ob der Verwaltungsakt genau so richtig ergangen ist.

728 Für gebundene Entscheidungen gilt der Anspruch, dass die gesetzlichen Regelungen die maßgeblichen Aspekte des Sachverhalts und mögliche Wertungskonflikte vollständig erfasst und aufeinander bezieht. Weder die handelnde Behörde noch das kontrollierende Gericht muss insofern eigenständige Entscheidungen treffen.

\section{cc) Ermessen}

729 Hat die Behörde einen eigenständigen Spielraum hinsichtlich des Inhalts ihrer Entscheidung, spricht man von Ermessen. Dabei wird zwischen Entschließungsund Auswahlermessen unterschieden. ${ }^{1270}$ Das Entschließungsermessen bezieht sich darauf, ob die Behörde überhaupt tätig werden will. Das Auswahlermessen bezieht sich darauf, wie die Behörde tätig werden will. Dies betrifft sowohl die Form des behördlichen Handelns als auch den Inhalt des konkreten Verwaltungsakts. Daneben kann der Ermessensspielraum sich auch auf Aspekte beziehen, die sich nicht ohne weiteres in diese beiden Kategorien einordnen lassen,

1268 Detterbeck, Allgemeines Verwaltungsrecht, 17. Aufl. 2019, Rn. 326.

1269 Vgl. Riese, in: Schoch/Schneider/Bier, VwGO, 36. EL Februar 2019, § 113 Rn. 34.

1270 Detterbeck, Allgemeines Verwaltungsrecht, 17. Aufl. 2019, Rn. $314 \mathrm{f}$. 
sowie bei der Auswahl eines Adressaten, wenn mehrere Adressaten in Betracht kommen.

Ob die gesetzliche Grundlage einen Ermessensspielraum gewährt, ist durch $\mathbf{7 3 0}$ Auslegung zu bestimmten. Häufig geschieht dies ausdrücklich (Beispiel: § 17 II 1 SGB XII zu Art und Maß der Sozialhilfe) oder auf Grund einer deutlichen Markierung als „Kann“- oder „Soll“-Vorschrift, seltener auch als „Darf“-Vorschrift (s. z.B. zu den Generalklauseln im Polizei- und Ordnungsrecht Rn. 1053f.). Manchmal ergibt sich die Einräumung eines Ermessensspielraums auch nur durch den systematischen und teleologischen Kontext und muss dementsprechend durch eine Auslegung der entsprechenden Normen bestimmt werden (so etwa bei der aus der Perspektive des Straßenverkehrsteilnehmers formulierten Vorladung zum Verkehrsunterricht nach § 48 StVO). ${ }^{1271}$

Ermessen ist stets gebundenes Ermessen. Ermessen darf zunächst nur aus- 731 geübt werden, wenn die Voraussetzungen der Ermessensausübung, insbesondere die Tatbestandsvoraussetzungen der Rechtsgrundlage, gegeben sind. Auch die Ermessensausübung selbst unterliegt gesetzlichen Bindungen, die in § 40 VwVfG und entsprechenden Regelungen des Landesrechts verdeutlicht werden: „Ist die Behörde ermächtigt, nach ihrem Ermessen zu handeln, hat sie ihr Ermessen entsprechend dem Zweck der Ermächtigung auszuüben und die gesetzlichen Grenzen des Ermessens einzuhalten.“ Die Verwaltung ist also an die äußeren Grenzen, die das Gesetz den möglichen Rechtsfolgen abstrakt und für den Einzelfall setzt, gebunden und muss das Ermessen entsprechend dem gewährten Spielraum und dessen Zweck tatsächlich ausüben. Darüber hinaus ist der Gesetzgeber frei, die Behörden in ihrem Spielraum durch weitere Vorgaben zur Ausübung des Ermessens einzuschränken. Die gerichtliche Kontrolle von Ermessensentscheidungen erstreckt sich auf die voll überprüfbaren gesetzlichen Voraussetzungen und daneben hinsichtlich der Rechtsfolgen nach § 114 Satz 1 VwGO auf die Ermessensfehler (hierzu unten Rn. 739 ff.).

Examenswissen: Eine besondere Form der Beschränkung des Ermessens stellt das sogenannte

intendierte Ermessen dar. Von intendiertem Ermessen wird gesprochen, wenn ein bestimmtes Verhalten der Behörde gesetzlich „intendiert“ ist und ihr ein darüberhinausgehender Ermessensspielraum nur zur Bewältigung ungewöhnlicher Einzelfälle eingeräumt wird. Dies wird in der Regel als „Soll“-Vorschrift verdeutlicht, kann sich aber auch, insbesondere für bestimmte Teilkonstellationen einer breiteren Ermessensvorschrift, aus Telos und Systematik ergeben. So hat die Bauaufsichtsbehörde regelmäßig, auch durch Abrissverfügungen, gegen dauerhafte baurechtswidrige Zustände vorzugehen. ${ }^{1272}$ Umfang und Folgen intendierten Ermessens sind im Detail

1271 Detterbeck, Allgemeines Verwaltungsrecht, 17. Aufl. 2019, Rn. 318.

1272 OVG Lüneburg, Urt. v. 9.3.2012, Az.: 1 LA 352/07 (Rn. 70). 
streitig. ${ }^{1273}$ Jedoch ergeben sich hieraus sowohl in Bezug auf die Ermessensfehler als auch in Bezug auf die Begründungspflichten Besonderheiten. So reicht es, wenn die Behörde dem intendierten Ermessen folgen will, im Rahmen der Ermessensausübung in der Regel aus, wenn sich die Behörde mit dem Vorliegen eines besonderen Einzelfalls auseinandersetzt und diesen verneint; auch die Begründung muss hierüber nicht hinausgehen. ${ }^{1274}$ Das intendierte Ermessen erleichtert also vor allem die Begründung. ${ }^{1275}$ Demgegenüber stellt es einen Gewichtungsfehler dar, wenn die Behörde das intendierte Verhalten gleichrangig neben andere Verhaltensalternativen stellt.

733 Examenswissen: Die Begrenzung des Spielraums kann so weit gehen, dass trotz eingeräumten Ermessens nur eine behördliche Entscheidung fehlerfrei ergehen kann. Man spricht in diesem Fall von einer Ermessensreduzierung auf Null. In der Anfechtungsklage hat eine solche Konstellation in der Regel keine Konsequenzen, da die materielle Rechtswidrigkeit der konkreten Ermessensentscheidung unabhängig von der Diskussion möglicher Alternativen festgestellt werden kann. Allenfalls für den Fall, dass die Ermessensentscheidung trotz Fehlern dem einzig möglichen fehlerfreien Verwaltungsakt entspricht, werden Konsequenzen für die Begründetheit der Klage diskutiert; sei es, weil parallel zur gebundenen Entscheidung die Rechtswidrigkeit entfie$\mathrm{le}^{1276}$ oder weil (überzeugender) mangels rechtmäßiger Alternativen trotz Rechtswidrigkeit des Verwaltungsakts die Rechtsverletzung zu verneinen sei. Für die Verpflichtungsklage andererseits kann die Ermessensreduzierung auf Null entscheidend dafür sein, ob statt eines regelmäßigen Bescheidungsurteils nach $\S 113$ V 2 VwGO ausnahmsweise auch ein Vornahmeurteil nach $\S 113$ V 1 VwGO in Betracht kommt (s. näher § 3 Rn. 67). ${ }^{1277}$

\section{dd) Weitere Spielräume}

734 Der Gesetzgeber kann auch an anderen Stellen als dem rechtsfolgenbezogenen Ermessen ansetzen, um der Verwaltung eigenständige Handlungsspielräume zu überlassen. Auch hierbei sind jedoch die verfassungsrechtlichen Grenzen für die Einräumung von Spielräumen zu beachten. Die wesentliche Vorformung des hoheitlichen Handelns durch die Gesetzgebung darf durch solche Spielräume ebenso wenig hintertrieben werden wie die grundrechtlich gebotene Möglichkeit gerichtlichen Rechtsschutzes. Dabei kann die Einräumung von Spielraum durch klare äußere wie innere Grenzen kompensiert werden.

1273 Bull/Mehde, Allgemeines Verwaltungsrecht, 9. Aufl. 2015, Rn. 600; Detterbeck, Allgemeines Verwaltungsrecht, 17. Aufl. 2019, Rn. 322f.; Peine/Siegel, Allgemeines Verwaltungsrecht, 12. Aufl. 2018, Rn. 220.

1274 BVerwG, Urt. v. 23.5.1996, Az.: 3 C 13/94, Rn. 51; BVerwG, Urt. v. 16.6.1997, 3 C 22/96 = BVerwGE 105, 55, Rn. 14; Detterbeck, Allgemeines Verwaltungsrecht, 17. Aufl. 2019, Rn. 323.

1275 Kluth, in: Wolff/Bachof u. a., Verwaltungsrecht I, 13. Aufl. 2017, § 31 Rn. 43.

1276 Brenndörfer/Trockels, in: Schweickhardt/Vondung, Allgemeines Verwaltungsrecht, 10. Aufl. 2018, Rn. 205.

1277 BVerwG, Urt. v. 18.12.2014, Az.: 4 C 36/13 = BVerwGE 151, 138, Rn. 40.

\section{Daniel Benrath}


Insbesondere der Beurteilungsspielraum ist $\mathrm{zu}$ erwähnen. Der Beurtei- $\mathbf{7 3 5}$ lungsspielraum wird den Behörden im Hinblick auf die Subsumtion unter ein Tatbestandsmerkmal eröffnet. Auch Tatsachen können sich im Hinblick auf die wertende Subsumtion einer klaren und eindeutigen Betrachtung durch die Rechtsanwender und insbesondere die Gerichte entziehen. Gerade für komplexe Beurteilungen der Wirklichkeit stehen verschiedene Blickwinkel und fachwissenschaftliche Methoden zur Auswahl, die zu unterschiedlichen Ergebnissen führen können, ohne dass ohne Weiteres allein eine als richtig und alle anderen als falsch zu identifizieren sind. Der Beurteilungsspielraum ermöglicht es den Behörden, ihre Entscheidung auf die eigene Beurteilung der Fakten zu stützen, die dann auch in der gerichtlichen Kontrolle vorauszusetzen ist. Im deutschen Verwaltungsrecht sind Beurteilungsspielräume, nicht zuletzt wegen der möglichen Gefahren im Hinblick auf gerichtliche Kontrolle und Umgehung rechtlicher Vorgaben, ${ }^{1278}$ die von einem direkten Zugriff der Verwaltung auf den ihrer Kontrolle zu Grunde liegenden Sachverhalt ausgehen können, selten. Ob ein Beurteilungsspielraum vorliegt, ist durch Auslegung zu bestimmen, ${ }^{1279}$ wobei der Wortlaut in der Regel nicht weiterhilft. Insbesondere für komplexe fachwissenschaftliche Fragestellungen im Wirtschafts- und Umweltrecht ${ }^{1280}$ sowie für Entscheidungen weisungsunabhängiger plural besetzter Gremien und Ausschüsse ${ }^{1281}$ werden Beurteilungsspielräume ins Gespräch gebracht. Jedenfalls sind Beurteilungsspielräume, insbesondere wenn sie sich nicht ausdrücklich aus dem Wortlaut ergeben, durch entsprechend enge Anforderungen an die Ausübung der Beurteilung als innere Grenzen des Beurteilungsspielraums zu kompensieren. ${ }^{1282}$ Gegebenenfalls treten in diesen Kontexten auch Aspekte der formellen Rechtmäßigkeit stärker in den Vordergrund. Dem entspricht auch, wenn Einflüsse anderer Rechtsordnungen und insbesondere des Europarechts, die keine der deutschen Verwaltungsrechtslehre entsprechenden Vorbehalte gegenüber Beurteilungsspielräumen haben ${ }^{1283}$, dafür aber Aspekte der formellen Kontrolle stärker

1278 Maurer/Waldhoff, Allgemeines Verwaltungsrecht, 19. Aufl. 2017, § 7 Rn. 34.

1279 Jacob/Lau, NVwZ 2015, 241 (242f.).

1280 Detterbeck, Allgemeines Verwaltungsrecht, 17. Aufl. 2019, Rn. 376; Jacob/Lau, NVwZ 2015, 241 (243ff.). Vgl. hierzu Hwang, VerwArch 103, 356; Winkler, DVBl 2013, 156.

1281 BVerwG, Urt. v. 26.11.1992, Az.: 7 C 20/92 = BVerwGE 91, 211; BVerwG, Urt. v. 16.5.2007, Az.: 3 C 8/06 = BVerwGE 129, 27 (Rn. 27) m.w. N.; Kluth, in: Wolff/Bachof u.a., Verwaltungsrecht I, 13. Aufl. 2017, § 31 Rn. 26.

1282 Vgl. BVerwG, Urt. v. 16.5.2007, Az.: 3 C 8/06 = BVerwGE 129, 27 (Rn. 26) m.w. N.

1283 Jestaedt, in: Ehlers/Pünder, Allgemeines Verwaltungsrecht, 15. Aufl. 2016, § 11 Rn. 28. 
in den Vordergrund stellen, das deutsche Verwaltungsrecht für Beurteilungsspielräume öffnen. ${ }^{1284}$

736 Examenswissen: Eine weitere Form des Spielraums findet sich als Bewertungsspielraum im Rahmen von Prüfungen und prüfungsähnlichen Entscheidungen oder etwa beamtenrechtlichen Beurteilungen. Dieser Spielraum ist dadurch geprägt, dass die Bewertung des Sachverhalts und der Inhalt des behördlichen Handelns (insbesondere die Benotung einer Prüfungsleistung) in eins gehen und nicht sinnvoll voneinander getrennt werden können. Die wertende Betrachtung des Sachverhalts dient also nicht nur als tatbestandliche Anknüpfung der behördlichen Entscheidung, sondern fließt unmittelbar in sie ein. Insofern geht der Bewertungsspielraum über einen bloßen Beurteilungsspielraum hinaus, auch wenn er oft als Fallgruppe des Beurteilungsspielraums eingeordnet wird ${ }^{1285}$. Auch für den Bewertungsspielraum sind rechtliche Vorgaben als äußere Grenzen zu beachten (wie etwa die Notenskala oder Notenberechnungsregeln), diese sind jedoch in der Regel materiell nebensächlich. Der verfassungsrechtliche Hintergrund, insbesondere Art. 12 GG bei Prüfungen für Berufszulassungen und Art. 33 II, V GG in beamtenrechtlichen Kontexten, verlangt jedoch entgegen der (langlebigen) vorkonstitutionellen Vorstellung auch für Bewertungsspielräume eine klare rechtliche Eingrenzung ${ }^{1286}$, weshalb die verfahrensrechtliche Einbindung und insbesondere die inneren rechtlichen Grenzen zum Zustandekommen der Bewertung den Mangel an äußeren Grenzen kompensieren. Insofern sind gerade im Bereich von Bewertungen die rechtlichen Vorgaben an die Entstehung bzw. Grundlagen der Entscheidung herauszuarbeiten und anzuwenden, was leider in der Praxis vereinzelt nach wie vor übersehen wird. Diese inneren Grenzen sind im Rahmen der Fehlerlehre gerichtlich voll überprüfbar (hierzu sogleich). Der gerichtlich nicht überprüfbare Bewertungsspielraum beschränkt sich insoweit auf die prüfungs- bzw. bewertungsspezifischen Aspekte. ${ }^{1287}$

737 Examenswissen: Zwischen verschiedenen Formen des Spielraums sind zudem Kopplungen denkbar, etwa wenn eine Vorschrift mit Beurteilungsspielraum hinsichtlich des Tatbestands mit einem Ermessen auf der Rechtsfolgenseite verbunden ist. ${ }^{1288}$ Die Folgen dieser Kopplungen für die Rechtslage und die rechtliche Prüfung sind für die jeweilige Konstellation zu bestimmen.

738 Hausarbeitswissen: Weitere eigenständig diskutierte Formen des Spielraums sind zudem insbesondere das Planungs- und das Regulierungsermessen. Das Planungsermessen bezieht sich auf die umfassend abwägenden Entscheidungen im Planungsrecht. ${ }^{1289}$ Das Regulierungsermessen bezieht sich auf die spezifischen Regulierungsentscheidungen der Regulierungsbehörden, die durch komplexe wirtschaftliche Sachverhalte und ein hohes Maß an (oftmals europarechtlich vorgegebe-

1284 Vgl. BVerwG, Urt. v. 16.5.2007, Az.: 3 C 8/06 = BVerwGE 129, 27 (Rn. 29ff., 34).

1285 Detterbeck, Allgemeines Verwaltungsrecht, 17. Aufl. 2019, Rn. 362ff.; Kluth, in: Wolff/ Bachof u. a., Allgemeines Verwaltungsrecht, 13. Aufl. 2017, § 31 Rn. $23 \mathrm{ff}$.

1286 BVerfG, Beschl. v. 17.4.1991, Az.: 1 BvR 419/81 = BVerfGE 84, 34 (Rn. 55).

1287 BVerfG, Beschl. v. 17.4.1991, Az.: 1 BvR 419/81 = BVerfGE 84, 34 (Rn. 55).

1288 Hierzu etwa Maurer/Waldhoff, Allgemeines Verwaltungsrecht, 19. Aufl. 2017, § 7 Rn. 48 ff.; Peine/Siegel, Allgemeines Verwaltungsrecht, 12. Aufl. 2018, Rn. $225 \mathrm{ff}$.

1289 Hierzu etwa Bull/Mehde, Allgemeines Verwaltungsrecht, 9. Aufl. 2015, Rn. $601 \mathrm{ff}$.; Maurer/ Waldhoff, Allgemeines Verwaltungsrecht, 19. Aufl. 2017, § 7 Rn. 63 Peine/Siegel, Allgemeines Verwaltungsrecht, 12. Aufl. 2018, Rn. 222f.

Daniel Benrath 
ner) Unabhängigkeit der Behörde gekennzeichnet sind. ${ }^{1290} \mathrm{Ob}$ es sich hierbei um eigenständige Spielraumkategorien oder bloße Fallgruppen der traditionellen Kategorien mit ausgeprägten Besonderheiten handelt, kann in der Regel offengelassen werden. Ein weiterer Spielraum ergibt sich im Rahmen der exekutiven Rechtsetzung durch Verordnungen und Satzungen ${ }^{1291}$, der jedoch sehr speziell ausgeprägt ist und daher in der Regel trotz mancher Parallelen unabhängig diskutiert wird; für die Anfechtungsklage gegen Verwaltungsakte ist dieser Spielraum kaum relevant.

\section{ee) Fehlerlehre}

Soweit den Behörden Spielräume beim Erlass eines Verwaltungsakts zustehen, 739 sind diese auch in der gerichtlichen Kontrolle zu berücksichtigen. Geht man schon konzeptionell nicht (anders als bei gebundenen Verwaltungsakten) von nur einer rechtmäßigen Entscheidung aus, kann sich die gerichtliche Kontrolle nicht auf den Nachvollzug der Richtigkeit dieser Entscheidung beschränken. Da die Behörden jedoch auch im Rahmen ihrer Spielräume rechtlichen Bindungen unterliegen, müssen diese gerichtlich überprüfbar sein (vgl. Art. 19 IV GG). An dieser Stelle greift die (Ermessens-)Fehlerlehre: Nicht das Ergebnis des Verwaltungshandelns wird auf seine Richtigkeit hin überprüft, sondern die rechtlichen Bindungen im Rahmen des Spielraums auf eine Verletzung, also einen Fehler. Dies kommt in § 114 Satz 1 VwGO zum Ausdruck, der die Rechtmäßigkeitsprüfung für Ermessensentscheidungen auch auf Fehler bei der Ermessensausübung erstreckt.

Sowie Verwaltungsspielräume an verschiedenen Punkten ansetzen können $\mathbf{7 4 0}$ und zwischen verschiedenen Spielraumtypen unterschieden wird, kann auch zwischen verschiedenen Fehlerlehren unterschieden werden. Die Grundzüge der Prüfungssituation und der Prüfung bleiben zwar die gleichen, jedoch ergeben sich wichtige Unterschiede in Details und Schwerpunkten. Entsprechend der praktischen Bedeutung, steht oftmals der Ermessensspielraum im Zentrum der Betrachtung. An ihm wurde und wird die Fehlerlehre maßgeblich entwickelt.

Wichtig für das Verständnis der Fehlerlehre (nicht aber für ihre Anwendung in $\mathbf{7 4 1}$ der Fallprüfung) ist die grundlegende Unterscheidung zwischen inneren und äußeren Spielraumgrenzen (hierzu oben Rn. $721 \mathrm{ff}$.). Äußere Grenzen geben den inhaltlichen Rahmen vor, innerhalb derer sich der Verwaltungsakt bewegen muss. Auch wenn die äußeren Grenzen einen Spielraum belassen, sind sie als Grenze strikt. Werden sie überschritten, ist der Verwaltungsakt rechtswidrig. Werden sie nicht überschritten, liegt kein entsprechender Fehler vor. Strukturell werden sie

1290 Hierzu etwa Bull/Mehde, Allgemeines Verwaltungsrecht, 9. Aufl. 2015, Rn. 608a; Maurer/ Waldhoff, Allgemeines Verwaltungsrecht, 19. Aufl. 2017, § 7 Rn. 64 ff.; Peine/Siegel, Allgemeines Verwaltungsrecht, 12. Aufl. 2018, Rn. 224.

1291 Detterbeck, Allgemeines Verwaltungsrecht, 17. Aufl. 2019, Rn. 387; Peine/Siegel, Allgemeines Verwaltungsrecht, 12. Aufl. 2018, Rn. 221. 
wie Vorgaben zu gebundenen Entscheidungen geprüft. Die inneren Spielraumgrenzen beziehen sich auf die Entscheidungsfindung durch die Behörde, etwa im Hinblick auf die Berücksichtigung bestimmter Aspekte, die Ermittlung zutreffender Tatsachen oder die gedankliche Umsetzung zur endgültigen Entscheidung. Fehler im Hinblick auf innere Spielraumgrenzen liegen unabhängig vom konkreten Inhalt des Verwaltungsakts vor: Eine Behörde, die auf Grund der Verletzung einer inneren Spielraumgrenze zu einer bestimmten Entscheidung gekommen ist, die damit rechtswidrig ist, kann bei Wiederholung der Entscheidung ohne entsprechenden Fehler zu genau der gleichen Entscheidung kommen, die dann aber rechtmäßig ist. Insofern handelt es sich in Bezug auf die inneren Grenzen um spezifische (Ermessens-)Fehler bei der Inanspruchnahme von Verwaltungsspielräumen.

742 Examenswissen: Die Fehlerlehre bezieht sich im Wesentlichen auf den Umfang der gerichtlichen Kontrolle gegenüber einem Verwaltungsspielraum. Sie ersetzt die gerichtliche Vollkontrolle hinsichtlich des Inhalts. Diese besondere Form der gerichtlichen Kontrolle beschränkt sich jedoch allein auf den Spielraum der Verwaltung. Außerhalb des Spielraums (und damit auch in Bezug auf die äußeren Grenzen des Ermessens) bleibt es bei der vollen Kontrolle. Auch im Rahmen der Fehlerkontrolle selbst unterliegen die jeweiligen rechtlichen Bindungen uneingeschränktem richterlichem Zugriff, so etwa im Hinblick auf die tatsächlichen Grundlagen der Entscheidung.

743 Examenswissen: Dem Umfang der gerichtlichen Kontrolle entspricht die Begründungspflicht, wie sie in $\S 39$ VwVfG ausgestaltet ist. Die Begründung des Verwaltungsakts soll den Rechtsschutz gegen den Verwaltungsakt ermöglichen. ${ }^{1292}$ Dementsprechend muss die Begründung so angelegt sein, dass die wesentlichen der gerichtlichen Kontrolle zugänglichen Aspekte auch tatsächlichen gerichtlich überprüfbar sind. Bei Entscheidungen mit Spielraum, die der Fehlerkontrolle unterliegen, bedarf es also entsprechender Ausführungen zu den inneren Grenzen des Spielraums, da eine inhaltliche Kontrolle anhand des Tenors insoweit ausgeschlossen ist. ${ }^{1293}$ Als Faustformel lässt sich sagen, dass ein weiter Spielraum mit einer intensiveren spezifischen Fehlerkontrolle verbunden ist und eingehenderer Begründungen bedarf. Ist eine umfassende gerichtliche Prüfung anhand der Begründung nicht möglich, liegt ein heilbarer Formfehler vor, der (vorerst) zur Rechtswidrigkeit des Verwaltungsakts führt. Besonders plastisch wird dies im Prüfungsrecht und gerade bei besonders komplexen juristischen Prüfungen: Der weitgehende Prüfungsspielraum der Prüfer unterliegt vielfältigen inneren Grenzen (hierzu Rn. 751 ff.), deren Einhaltung durch das Bewertungsgutachten als Begründung voll überprüfbar sein muss; die damit einhergehenden Anforderungen an das Gutachten lassen sich tatsächlich im Alltagsbetrieb kaum flächendeckend erfüllen, so dass dem Überdenkungsverfahren zur Gewährleistung auch formell rechtmäßiger Prüfungsentscheidungen eine herausgehobene Bedeutung zukommt, was dann allerdings auch in der entsprechenden Kostenentscheidung zum entsprechenden Widerspruch zu berücksichtigen ist.

1292 Bull/Mehde, Allgemeines Verwaltungsrecht, 9. Aufl. 2015, Rn. 650; Peine/Siegel, Allgemeines Verwaltungsrecht, 12. Aufl. 2018, Rn. 513.

1293 Schwarz, in: Fehling/Kastner/Störmer, Verwaltungsrecht, 4. Aufl. 2016, § 39 VwVfG Rn. 29. 


\section{(1) Ermessensspielraum}

Die Fehlerlehre findet allein für den Ermessensspielraum allgemeine gesetzliche 744 Anknüpfungspunkte. In § 114 Satz 1 VwGO heißt es: „Soweit die Verwaltungsbehörde ermächtigt ist, nach ihrem Ermessen zu handeln, prüft das Gericht auch, ob der Verwaltungsakt oder die Ablehnung oder Unterlassung des Verwaltungsakts rechtswidrig ist, weil die gesetzlichen Grenzen des Ermessens überschritten sind oder von dem Ermessen in einer dem Zweck der Ermächtigung nicht entsprechenden Weise Gebrauch gemacht ist.“ Ferner führt § 40 VwVfG aus: „Ist die Behörde ermächtigt, nach ihrem Ermessen zu handeln, hat sie ihr Ermessen entsprechend dem Zweck der Ermächtigung auszuüben und die gesetzlichen Grenzen des Ermessens einzuhalten." Diese Anknüpfungen bleiben jedoch vage, insbesondere der Verweis auf die gesetzlichen Grenzen erfasst umfassend und somit ohne Trennschärfe jede Art von Ermessensfehler. Demgegenüber ist der Verweis auf die Zweckverfehlung eine bloße Klarstellung, die die besondere Bedeutung der von der Verwaltung verfolgten Zwecke betont.

Angelehnt an die gesetzlichen Anknüpfungspunkte werden verschiedene

Fallgruppen von Fehlern unterschieden. Diese Fallgruppen sind weder abschließend noch - entsprechend der Vagheit der gesetzlichen Anknüpfungspunkte - trennscharf. Die unterschiedlichen Definitionen und Ausgestaltungen der verschiedenen Fallgruppen in der Literatur sind kein Ausdruck einer inhaltlichen Debatte, sondern entsprechen lediglich unterschiedlichen Vorstellungen zur sinnvollen Kommunikation der wesentlichen Aspekte der Ermessensfehlerlehre. Trotz der markanten Unterschiede im Detail, besteht große Einigkeit hinsichtlich des Kernbestands von Fallgruppen und des Umfangs möglicher Fehler.

- Ermessensnichtgebrauch: Unter Ermessensnichtgebrauch (oder Ermessensunterschreitung) versteht man den Fall, dass die Behörde trotz Einräumung eines Ermessensspielraum auf eine eigenständige Entscheidung hinsichtlich der Rechtsfolgen verzichtet, insbesondere weil sie nicht erkennt, dass ihr ein Entscheidungsspielraum verbleibt, und stattdessen von einer gebundenen Entscheidung ausgeht. Liegt ein Ermessensnichtgebrauch vor, kann die Behörde nicht die inneren Bindungen der Ermessensausübung beachten; insofern handelt es sich um einen Unterfall des Ermessensfehlgebrauchs, der jedoch auf Grund seiner faktischen Bedeutung und der besonderen konzeptionellen Herausforderungen sinnvoll als eigene Fallgruppe behandelt werden kann. Von Ermessensnichtgebrauch kann auch dann gesprochen werden, wenn nur Teile des Spielraums verkannt wurden, im Übrigen aber Ermessen ausgeübt wurde. Das Gegenstück, also die Ausübung von Ermessen trotz insoweit gesetzlicher Bindung, stellt keinen Ermessensfehler dar: Hier kommt es allein auf die inhaltliche Richtigkeit des Ergebnisses an. 
- Ermessensfehlgebrauch: Im Kern verweist der Ermessensfehlgebrauch darauf, dass das Ermessen nicht im Sinne seines Zwecks ausgeübt wird. Neben einem echten Ermessensmissbrauch, bei dem ein sachfremder Zweck verfolgt wird (Beispiel: Der Bürgermeister erlässt eine Nutzungsuntersagung gegenüber einer formell baurechtswidrigen Nutzung eines Gebäudes, weil die Stadt das Gebäude selbst nutzen will), fallen hierunter auch Fälle, in denen neben zweckgemäßen Zielen auch einzelne Ziele verfolgt werden, die nicht dem Ermessenszweck entsprechen, oder in denen ein Zweck nicht verfolgt wurde, obwohl er in die Ermessensausübung einzustellen gewesen wäre (Beispiel: Bei der Erlaubnis einer Straßensondernutzung in der Fußgängerzone wird allein die Beeinträchtigung des Verkehrsflusses, nicht aber die Beeinträchtigung des Verkehrsraums als Kommunikations- und Begegnungsraums berücksichtigt). Darüber hinaus soll hier unter Ermessensfehlgebrauch jede Verletzung der inneren Grenzen des Ermessens verstanden werden. Hierzu fallen dann auch Fehler in der Ermittlung des zu Grunde liegenden Sachverhalts (einschließlich einer nicht ausreichenden Ermittlung der maßgeblichen Umstände), die Nichtberücksichtigung zu berücksichtigender Aspekte (Abwägungsdefizit), oder Gewichtungsfehler (Beispiele: Die Behörde hält den Abriss eines baurechtswidrigen Gebäudes entgegen des intendierten Ermessens für eine besonders begründungsbedürftige Ausnahmemaßnahme; im Rahmen einer polizeilichen Maßnahme geht die Polizei davon aus, dass von der Berufsfreiheit geschützte geschäftliche Interessen gegenüber der freien Meinungsäußerung stets zurückzutreten hätten bzw. vorrangig zu berücksichtigen seien). Zur Erinnerung: Die Zweckmäßigkeit des Verwaltungsakts als solches ist nicht als Ermessensfehlgebrauch zu prüfen, da insoweit die Verwaltung ihren Spielraum in Anspruch nimmt und gerichtlich nicht überprüft wird.

- Ermessensüberschreitung: Unter Ermessensüberschreitung versteht man Entscheidungen, die über den gesetzlichen Ermessensrahmen hinausgehen. Hier soll unter Ermessensüberschreitung die Verletzung äußerer Ermessensgrenzen verstanden werden. Insofern handelt es sich bei Fällen der Ermessensüberschreitung nicht um spezifische Ermessensfehler. Vielmehr wird der konkrete Verwaltungsakt von den gesetzlichen Vorgaben inhaltlich nicht gedeckt. So verstanden, unterliegt die Ermessensüberschreitung der vollen gerichtlichen Kontrolle. Diese liegt insbesondere vor, wenn der gesetzliche Rahmen möglicher Rechtsfolgen überschritten wird, aber auch wenn bei Abwägung der verschiedenen Interessen im Einzelfall eine Position unverhältnismäßig belastet wird. Die allgemeinen Grundsätze und insbesondere die Verhältnismäßigkeit können als äußere Ermessensgrenze im Rahmen der Ermessensüberschreitung geprüft werden sowie (entsprechend 
dem hier gewählten Aufbau) alle Aspekte der Ermessensüberschreitung als eigenständige Prüfungspunkte außerhalb des Ermessens angesprochen werden können.

\section{(2) Beurteilungsspielraum und Bewertungsspielraum}

Für die Beurteilungsfehlerlehre fehlt eine vergleichbare allgemeine gesetzliche $\mathbf{7 4 6}$ Anknüpfung. Die Grundsituation entspricht jedoch für Sachverhaltseinschätzungen im Rahmen eines Beurteilungsspielraums der des Ermessens. Dementsprechend lassen sich die Grundzüge der Ermessensfehlerlehre einschließlich der Fallgruppen auf Beurteilungsspielräume übertragen. Ein Beurteilungsnichtgebrauch liegt demnach vor, wenn die Verwaltung nicht erkennt, dass ihr ein Beurteilungsspielraum zusteht und sie demensprechend ohne eigene Beurteilung von einem bestimmten Sachverhalt ausgeht. Ein Beurteilungsfehlgebrauch liegt vor, wenn die inneren Grenzen des Beurteilungsspielraums verletzt werden, also die Grundlage der Beurteilung fehlerhaft ist. Von einer Beurteilungsüberschreitung kann gesprochen werden, wenn die äußeren Grenzen des Beurteilungsspielraums überschritten werden und eine rechtlich nicht zulässige Beurteilung gewählt wird.

Gleichwohl führt die eigenständige Konstellation des Beurteilungsspielraums 747 zu deutlichen Besonderheiten gegenüber der Ermessensfehlerlehre. So spielt die Verletzung äußerer Grenzen im Rahmen der Sachverhaltsbeurteilung eine allenfalls untergeordnete Rolle, während die inneren Grenzen in Bezug auf das $\mathrm{Zu}$ standekommen der Beurteilung in den Vordergrund rücken und eigene Schwerpunkte bilden.

Durch die Spielräume bei der Beurteilung des Sachverhalts sind insbesondere 748 an die Ermittlung und Beurteilung des Sachverhalts besondere Anforderungen gerichtet. Die Verwaltung muss auch beim Beurteilungsspielraum den der Beurteilung zu Grunde liegenden (und damit dem Spielraum entzogenen) Sachverhalt zutreffend und angemessen gründlich ermitteln.

Die Beurteilung dieses Sachverhalts muss sich dann einer nachvollziehbaren 749 und vertretbaren Methodik bedienen. Fehler bei der Bildung oder bei der Anwendung der Beurteilungsmethodik stehen häufig im Zentrum der Kontrolle (während Fragen der Methodik im Rahmen des Ermessens in der Regel keine Rolle spielen). Insbesondere dürfen auch bei der Inanspruchnahme des Beurteilungsspielraums keine sachfremden Erwägungen einbezogen werden.

Zudem können gerade in Beurteilungskonstellationen Verfahrensfragen jen- 750 seits der formellen Rechtmäßigkeit relevant werden und als Beurteilungsfehlgebrauch durchschlagen: Soweit das Verfahren die Perspektive der Verwaltung ausrichtet, die Fairness der Beurteilung sicherstellen soll oder gar die Berücksichtigung 
besonderer fachlicher Kompetenz oder pluraler Entscheidungsfindung orchestriert, können Fehler im Verfahren nicht nur (heilbare) Verfahrensfehler, sondern auch materielle Beurteilungsfehler sein, da sie die inhaltlichen Grundlagen der Entscheidung prägen.

751 Examenswissen: Auch zum Bewertungsspielraum fehlt es an allgemeinen gesetzlichen Anknüpfungspunkten zur Fehlerlehre, sind aber die Grundzüge der Ermessensfehlerlehre mit Anpassungen übertragbar. Da der Bewertungsspielraum sowohl Sachverhaltsaspekte als auch Rechtsfolgen erfasst, erscheint die Bewertungsfehlerlehre in vielerlei Hinsicht als Mischung zwischen Ermessens- und Beurteilungsfehlerlehre, weist aber auch eigenständige Schwerpunkte auf. Ähnlich wie bei Beurteilungsspielräumen steht der Bewertungsfehlgebrauch im Hinblick auf innere Grenzen des Bewertungsspielraums im Vordergrund der Kontrolle. Ein Bewertungsnichtgebrauch kommt allenfalls in Betracht, wenn die Verwaltung irrig davon ausgeht, dass ihr Bewertungsrahmen beschränkt ist (Beispiel: Ein Prüfer geht davon aus, dass ein bestimmter Fehler ohne Rücksicht auf die weitere Prüfung zu einem Nichtbestehen führen muss), was aber regelmäßig auch im Rahmen der Bewertungsgrundsätze angesprochen werden kann. Die Verletzung äußerer Grenzen ist im Hinblick auf die Rechtsfolgen möglich, spielt aber in der Regel keine Rolle (Beispiel: Ein Prüfer geht von einer falschen Notenskala aus und vergibt eine nicht vorgesehene Note).

752 Examenswissen: Im Rahmen des Bewertungsfehlgebrauchs sind insbesondere Fehler in der Ermittlung des der Bewertung zu Grunde liegenden Sachverhalts zu berücksichtigen. Eine Sachverhaltsermittlung ist schon dann fehlerhaft, wenn nicht alle zur Bewertung maßgeblichen Aspekte erfasst werden (Beispiel: Ein Dienstzeugnis nimmt trotz häufiger Auswärtstätigkeit nur das Verhalten im Büro in den Blick). Zudem ist gerade im Rahmen von Prüfungsentscheidungen zwischen den fachlichen Beurteilungen, die nicht in den Bewertungsspielraum fallen und (gegebenenfalls durch die Hinzuziehung von Sachverständigen) vollumfänglich gerichtlich überprüfbar sind, und deren prüfungsspezifischen Bewertungen zu unterscheiden. ${ }^{1294}$

753 Examenswissen: Ähnlich wie bei Beurteilungsfehlern die Methodik sind im Rahmen des Bewertungsfehlgebrauchs ferner die Bewertungsgrundsätze in den Blick zu nehmen. Zwar lassen sich für im Kern subjektive Bewertungen keine vergleichbaren Fachmethodiken entwickeln (und überprüfen), aber auch das Vorgehen der Verwaltung bei Bewertungen muss systematisch, in sich schlüssig und dem Bewertungszweck angemessen sein. Ein Verstoß gegen allgemeine Bewertungsgrundsätze oder ein widersprüchlicher Zugang zur Bewertung sind daher Bewertungsfehler. Eng damit verbunden ist es zudem der Verwaltung verboten, sachfremde Erwägungen in die Bewertung einfließen zu lassen, wobei im schulischen Bereich eine Vielzahl pädagogischer Aspekte mitberücksichtigt werden kann ${ }^{1295}$. Im Hinblick auf den Bewertungszweck, muss das Vorgehen der Verwaltung geeignet sein, einigermaßen sicher den mit der Bewertung verfolgten Zweck auch tatsächlich zu erreichen (Beispiel: Eine Prüfungsfrage ist so missverständlich gestellt, dass nur zufällig die „richtige“ Aufgabe bearbeitet wird, so dass die Bearbeitung wenig über die geprüfte Kompetenz aussagen kann). ${ }^{1296}$ Hierzu ist auch notwendig, dass die Verwaltung den

1294 Vgl. BVerfG, Beschl. v. 17.4.1991, Az.: 1 BvR 419/81 = BVerfGE 84, 34 (Rn. 54, 58).

1295 OVG Lüneburg, Beschl. v. 20.3.2008, Az.: 2 ME 83/08 (Rn. 16).

1296 Vgl. Niehues/Fischer/Jeremias, Prüfungsrecht, 7. Aufl. 2018, Rn. 374 ff.

Daniel Benrath 
verfolgten Zweck entsprechend der gesetzlichen Vorgaben in ihre Bewertung einfließen lässt; gelingt es schon nicht, die gesetzlichen Vorgaben richtig zu erfassen und in Beziehung zu setzen, handelt es sich um einen Gewichtungsfehler.

Examenswissen: Auch beim Bewertungsfehlgebrauch können zudem Verfahrensfehler als materielle Bewertungsfehler durchschlagen. Soweit das Verfahren eine einheitliche und aussagekräftige Bewertungssituation und -perspektive sicherstellen soll, schlagen Verstöße unmittelbar auf die durch die subjektive Perspektive geprägte Bewertung durch (wobei im Prüfungsrecht im Hinblick auf Verfahrensfehler oftmals Rügeobliegenheiten bestehen, die eine nachträgliche Geltendmachung ausschließen ${ }^{1297}$ ). Bewertungsfehler ergeben sich auch daraus, dass die Verwaltung ihr Verfahren nach sachwidrigen Kriterien ausgestaltet (Beispiel: Die Prüfer kürzen eine mündliche Prüfung massiv ab, da sie schon aus anderen Prüfungsabschnitten ein abschließendes Bild zu den Fähigkeiten gewonnen zu haben glauben).

Examenswissen: Im Prüfungsrecht entspricht der weite Bewertungsspielraum der Prüfer einem 755 engmaschigen Netz innerer Grenzen. Dabei sind diese keine vernachlässigbaren Formalismen, sondern stellen den Grundrechtsschutz der Geprüften und vor allem die Zweckerreichung des Prüfungsverfahrens sicher. Der vielfältigen inneren Grenzen ihres Spielraums sind sich die Prüfer, die sich in erster Linie durch ihre fachliche Kompetenz und Erfahrung auszeichnen, jedoch nicht immer vollumfänglich bewusst. Gerade in einem System der Laienprüfer, wie es sich etwa in den juristischen Staatsprüfungen wiederfindet, besteht oftmals eine deutliche Lücke zwischen den rechtlichen Anforderungen an die Prüfung und den diesbezüglichen Kompetenzen der Prüfer; insbesondere werden oftmals der Umfang des prüfungsspezifischen Spielraums im Hinblick auf Fachfragen über- und die Bedeutung eines stringent an den gesetzlichen Vorgaben ausgerichteten Bewertungssystems unterschätzt. Dies ist bis zu einem gewissen Grad auch gewünscht und sachgerecht, da man die fachliche Expertise und gewollt subjektive Einschätzung nicht durch prüfungsbezogene Instruktionen überformen möchte. Der damit einhergehenden gesteigerten Verantwortung in der vorgerichtlichen Rechtskontrolle von Prüfungen werden jedoch ausgerechnet manche Justizprüfungsämter nicht immer gerecht.

\section{b) Inhaltliche Vorgaben an die Rechtmäßigkeit des Verwaltungsakts}

Jeder Verwaltungsakt muss inhaltlich den gesetzlichen Bestimmungen entspre- 756 chen. Gebundene Entscheidungen müssen den gesetzlichen Vorgaben entsprechen und Verwaltungsakte mit Spielraum müssen sich inhaltlich im Rahmen der äußeren Grenzen des gesetzlichen Spielraums halten. Für gebundene Entscheidungen erfolgt diese Prüfung also in gleicher Weise wie für Entscheidungen mit Spielraum.

In der Struktur der Prüfung ergeben sich für die inhaltlichen Vorgaben keine Unterschiede. Sowohl hinsichtlich der Tatbestandsmerkmale als auch hinsichtlich inhaltlicher Vorgaben an die Rechtsfolgen, insbesondere bezüglich der äußeren Grenzen des Ermessens, ist zu überprüfen, ob der Verwaltungsakt

1297 Niehues/Fischer/Jeremias, Prüfungsrecht, 7. Aufl. 2018, Rn. 214. 
inhaltlich den jeweiligen Vorgaben entspricht. Es handelt sich insofern um eine klassische Subsumtion. Jedenfalls in der Perspektive der Anfechtungsklage bedarf es insoweit keiner weiteren Abgrenzung. Gleichwohl bleibt es jedem Rechtsanwender unbenommen, zur Ordnung des eigenen Gedankengangs weitere Kategorien einzuführen.

Auch wenn die Prüfung der inhaltlichen Vorgaben strukturell simpel ist, ist die konkrete Prüfung der inhaltlichen Vorgaben weder sonderlich formalistisch noch trivial. Die gesetzlichen Vorgaben bedürfen der mitunter anspruchsvollen und wertenden Auslegung. Dies betrifft insbesondere sog. unbestimmte Rechtsbegriffe. Unbestimmte Rechtsbegriffe (Beispiele: Unzuverlässigkeit nach § 35 I GewO, konkrete Gefahr im Polizei- und Ordnungsrecht) zeichnen sich durch ihre unscharfe, oft stark auf Wertungen abstellende Ausgestaltung aus. Ihre Auslegung und gerade ihre Anwendung sind dementsprechend von großer Unsicherheit und wertender Abwägung geprägt. Gleichwohl eröffnen sie nach heute allgemeiner Ansicht nicht ohne weiteres Spielräume der Verwaltung. ${ }^{1298}$ Die Behörde ist im Rahmen ihrer gesetzlichen Bindung - sowohl bei gebundenen Entscheidungen als auch Entscheidungen mit Spielraum - angehalten, die unbestimmten Rechtsbegriffe richtig auszulegen und anzuwenden, und unterliegt diesbezüglich der vollen Kontrolle durch die Verwaltungsgerichte. Auch die systematische Einbettung ist zu berücksichtigen und gegebenenfalls sind teleologische Reduktionen und andere Korrekturen im Einzelfall vorzunehmen.

759 Zudem ist bei der Prüfung der inhaltlichen Voraussetzungen ggf. ein Beurteilungsspielraum der Verwaltung zu berücksichtigen. Soweit der Verwaltung ein Beurteilungsspielraum zusteht, was durch eine entsprechende Auslegung zu bestimmen ist, ist bei der Subsumtion unter die entsprechenden inhaltlichen Vorgaben (innerhalb der gesetzlichen Grenzen) die Beurteilung des Sachverhalts durch die Verwaltung zu Grunde zu legen. Dann aber können sich bei der Inanspruchnahme des Beurteilungsspielraums spezifische Fehler hinsichtlich der inneren Grenzen des Beurteilungsspielraums ergeben, die an der entsprechenden Stelle eigenständig zu prüfen sind.

\section{aa) Verwaltungsaktbefugnis}

760 Im Rahmen einer Anfechtungsklage muss dem angegriffenen Verwaltungsakt eine sogenannte Verwaltungsaktbefugnis zu Grunde liegen. Ein Verwaltungsakt kann nicht rechtmäßig sein, wenn die Behörde gar nicht die Befugnis hat, einen Verwaltungsakt als eigenständig vollstreckbaren hoheitlichen Befehl zu erlassen.

1298 Detterbeck, Allgemeines Verwaltungsrecht, 17. Aufl. 2019, Rn. 354. 
In der Regel wird die Verwaltungsaktbefugnis ausdrücklich gewährt oder ergibt sich deutlich aus dem Zusammenhang, insbesondere wenn die Rechtsgrundlage allgemein Maßnahmen zulässt und erkennbar (zumindest auch) auf Verwaltungsakte ausgerichtet ist. Eine eigenständige Erwähnung ist in typischen Konstellationen regelmäßig verzichtbar. Eingehendere Prüfungen können jedoch im Einzelfall geboten sein, insbesondere wenn sich der Sachverhalt im Grenzbereich zu privat-rechtlichem Handeln der Behörde bewegt (z. B. Verträge, Zahlungsansprüche gegenüber Beamten, Rückforderung eines privat-rechtlich ausgestalteten Darlehens). ${ }^{1299}$ Die Verwaltungsaktbefugnis kann auch bereits im Rahmen der Rechtsgrundlage angesprochen werden und bedarf dann insoweit keiner weiteren Erwähnung im Rahmen der materiellen Rechtmäßigkeit (s. Rn. 520).

\section{bb) Inhaltliche Vorgaben der Rechtsgrundlage}

Die konkrete Rechtsgrundlage des Verwaltungsakts ist (in der Regel) der zentrale $\mathbf{7 6 1}$ Anknüpfungspunkt der materiellen Rechtmäßigkeitsprüfung. Die Rechtsgrundlage gibt sowohl die Voraussetzungen des staatlichen Handelns als auch den geforderten bzw. möglichen Inhalt vor, also Tatbestandsmerkmale und inhaltliche Vorgaben zur Rechtsfolge. Insofern ist die Rechtsgrundlage auszulegen. Gegebenenfalls können sich aus der (insbesondere systematischen) Auslegung auch ungeschriebene Vorgaben zur konkreten Rechtsgrundlage ergeben. Soweit inhaltliche Vorgaben der Rechtsgrundlage schon im Rahmen der Auswahl der Rechtsgrundlage abschließend angesprochen wurden, sind sie an dieser Stelle nicht wieder aufzugreifen.

Die konkrete Rechtsgrundlage ist hierbei weit zu verstehen. Sie umfasst ne- $\mathbf{7 6 2}$ ben der konkreten Norm mit ihrem Tatbestand und ihrer Rechtsfolgenanordnung auch allgemeine Vorgaben des entsprechenden Gesetzes. So ist der Anwendungsbereich des Gesetzes grundsätzlich für jede einzelne Maßnahme zu berücksichtigen, auch wenn er nur allgemein geregelt wird. Aber auch darüber hinaus können allgemeine Regelungen Voraussetzungen postulieren oder die Rechtsfolge beschränken.

Typischerweise können die konkreten gesetzlichen Vorgaben neben speziel- $\mathbf{7 6 3}$ len Tatbestandsmerkmalen und inhaltlichen Vorgaben zur Rechtsfolge den Anwendungsbereich des Gesetzes bzw. des Rechtsbereichs erfassen. Zudem sind, soweit diese anders als hier nicht als eigenständige Prüfungspunkte angesprochen werden, Vorgaben zur Handlungsform und zu den Adressaten zu beachten.

1299 Maurer/Waldhoff, Allgemeines Verwaltungsrecht, 19. Aufl. 2017, § 10 Rn. 32ff. Zurückhaltender Korte, in: Wolff/Bachof u. a., Verwaltungsrecht I, 13. Aufl. 2017, § 45 Rn. $15 \mathrm{ff}$. 
Für gebundene Entscheidungen sind die Vorgaben der Rechtsgrundlage sowohl auf Tatbestands- als auch auf Rechtsfolgenseite in der Regel der Kern der Prüfung. Weitere inhaltliche Vorgaben sind demgegenüber typischerweise eher am Rande relevant. Auch für Verwaltungsakte mit Spielraum hat die Prüfung der konkreten Rechtsgrundlage eine herausgehobene Bedeutung, jedoch spielen hier öfter auch sonstige Vorgaben eine größere Rolle.

\section{cc) Allgemeine Grundsätze}

765 Neben den Vorgaben der Rechtsgrundlage sind allgemeine Grundsätze zu berücksichtigen, die insbesondere im Rahmen von Ermessensentscheidungen regelmäßig relevant werden. Sie stellen keine positiv zu bejahenden Voraussetzungen eines rechtmäßigen Verwaltungsakts dar und sind daher nur anzusprechen, wenn ein Verstoß gegen die Grundsätze in Betracht kommt.

766 Mitunter sind die hier genannten Rechtsgedanken auch speziell normiert. In diesem Fall sind die entsprechenden gesetzlichen Vorgaben zwingend zu prüfen. Es bedarf dann aber üblicherweise keiner eigenständigen Prüfung des allgemeinen Grundsatzes.

\section{(1) Verhältnismäßigkeit}

767 Die Verhältnismäßigkeit kann in der Prüfung in unterschiedlichen Kontexten aufgeworfen werden. Zunächst wird aus dem Rechtsstaatsprinzip der allgemeine Verhältnismäßigkeitsgrundsatz hergeleitet, ${ }^{1300}$ der eine verhältnismäßige Relation zwischen dem Zweck und den Mitteln staatlichen Handelns verlangt und in der konkreten Prüfung über den verfassungsrechtlichen Rahmen hinaus durch die spezifische gesetzliche Ausgestaltung der Zweck-Mittel-Relation (etwa im Hinblick auf Ermessen und Ermessenszweck) inhaltlich geformt wird. Zudem ist bei grundrechtlichen Eingriffen, die in der Regel zumindest im Hinblick auf die allgemeine Handlungsfreiheit aus Art. 2 I GG vorliegen, zu prüfen, ob die Rechtfertigung des Grundrechtseingriffs im Rahmen der Schranken-Schranken der Verhältnismäßigkeit genügt. Schließlich kann das Verhältnismäßigkeitsgebot einfachgesetzlich angeordnet und ausgestaltet sein.

In der Regel reicht es aus, im Rahmen der verwaltungsrechtlichen materiellen Rechtmäßigkeitsprüfung nur einmal die Verhältnismäßigkeit anzusprechen. Ein positiviertes Verhältnismäßigkeitsgebot ist grundsätzlich vorrangig zu prüfen, wobei die anderen Kontexte der Verhältnismäßigkeit, also allgemeiner Verhält-

1300 Maurer/Waldhoff, Allgemeines Verwaltungsrecht, 19. Aufl. 2017, § 10 Rn. 50.

Daniel Benrath 
nismäßigkeitsgrundsatz und Rechtfertigung eines Grundrechtseingriffs, in diese Prüfung zu integrieren sind. Auch wenn das Verhältnismäßigkeitsgebot nicht positiviert ist, reicht es oftmals aus, nur den allgemeinen Verhältnismäßigkeitsgrundsatz anzusprechen und die grundrechtlichen Aspekte im Rahmen dieser Prüfung zu berücksichtigen. Insbesondere bei Ermessensentscheidungen gibt der Zweck des Spielraums einen sinnvollen Anknüpfungspunkt der Prüfung des Verhältnismäßigkeitsgrundsatzes im Einzelnen vor, ohne die Berücksichtigung von Grundrechtseingriffen zu sperren. Allerdings kann es insbesondere im Verhältnis zum allgemeinen Verhältnismäßigkeitsgrundsatz auch sinnvoller sein, die Prüfung spezifischer Grundrechte in den Vordergrund zu stellen. Zwar lässt sich in einer Grundrechtsprüfung der allgemeine Verhältnismäßigkeitsgrundsatz kaum einbinden. Steht aber die mögliche Verletzung eines oder mehrerer bestimmter Grundrechte im Vordergrund, kann die spezifische Prüfung im Hinblick auf diese Grundrechte deutlich konturierter und zielführender sein. Für eine darüberhinausgehende Prüfung des allgemeinen Verhältnismäßigkeitsgrundsatzes besteht dann oftmals kein weiterer Anlass. Der Aufbau der Prüfung ist insofern nicht allgemein vorgegeben.

Auch für die Verortung der Verhältnismäßigkeit innerhalb des Prüfungsauf- 769 baus bestehen mehrere Alternativen, was gerade bei Anfängern zu erheblichen Verwirrungen führen kann. Während hier die Verhältnismäßigkeit im Rahmen der inhaltlichen Vorgaben (insbesondere als äußere Grenze des Ermessens) angesprochen wird, lässt sich die Verhältnismäßigkeit bei einer eigenständigen Prüfung von Ermessenfehlern als Fall der Ermessensüberschreitung ansprechen. Möglich ist schließlich sogar, die Verhältnismäßigkeit erst nach den Ermessensfehlern anzusprechen, jedoch sollten in diesem Fall aus Gründen der Stringenz und Nachvollziehbarkeit in der gutachterlichen Entwicklung deutlich werden, dass die Verhältnismäßigkeit nicht schon im Rahmen des Ermessens angesprochen wird. Inhaltlich ergeben sich aus der Verortung der Prüfung keine Konsequenzen.

Ein Verwaltungsakt ist rechtswidrig, wenn er unverhältnismäßig ist; sei es $\mathbf{7 7 0}$ wegen eines Verstoßes gegen den allgemeinen Verhältnismäßigkeitsgrundsatz, wegen der Verletzung eines Grundrechts oder wegen des Überschreitens des gesetzlichen Rahmens. Die Prüfung der Verhältnismäßigkeit folgt dabei in jedem Fall grob dem aus der Grundrechtsdogmatik bekannten Schema: (1) Verfolgung eines legitimen Zwecks, (2) Geeignetheit des eingesetzten Mittels zur Erreichung des Zwecks, (3) Erforderlichkeit des eingesetzten Mittels in dem Sinne, dass kein gleich wirksames (oder nicht anderweitig nachteiliges) alternatives Mittel zur Verfügung steht, dass weniger belastend ist, und (4) keine Unange- 
messenheit im Hinblick auf die Zweck-Mittel-Relation. ${ }^{1301}$ Die Ausgestaltung der Prüfung im Einzelnen hängt von dem jeweiligen rechtlichen Anknüpfungspunkt und dem jeweiligen Prüfungskontext ab. So ist der legitime Zweck zum Zeitpunkt der Prüfung der Verhältnismäßigkeit oft bereits gesichert und bedarf keiner eigenständigen Erörterung. Und positivierte Verhältnismäßigkeitsgebote geben der Prüfung oft einen eigenen Rahmen, mitunter mit Modifikationen des allgemeinen Schemas. Zudem ist zu berücksichtigen, dass der Verwaltung nicht die gleiche Einschätzungsprärogative zu Geeignetheit und Erforderlichkeit zukommt wie dem Gesetzgeber, vielmehr sind hier die entsprechenden Vorgaben des Gesetzgebers nachzuvollziehen.

771 Hausarbeitswissen: Zur Verhältnismäßigkeit bei gebundenen Entscheidungen hat sich eine eigentümliche verwaltungsrechtswissenschaftliche Diskussion entwickelt. ${ }^{1302}$ Während Teile von Literatur und Rechtsprechung die Verhältnismäßigkeit der konkreten Entscheidung auch im Rahmen gebundener Entscheidungen prüfen wollen, ${ }^{1303}$ trifft diese Position auf entschiedene Kritik verschiedener Literaturstimmen. Die kritischen Stimmen halten eine Prüfung der Verhältnismäßigkeit bei fehlendem Ermessensspielraum für verfehlt, da (im Wesentlichen) eine Verhältnismäßigkeitsprüfung im Einzelfall der gesetzlichen Grundentscheidung für eine gebundene Entscheidung entgegenstünde und bei fehlender Verhältnismäßigkeit schon die gesetzliche Grundlage verfassungswidrig sei. ${ }^{1304}$ Auch wenn dieser Streit für die Rechtswidrigkeit des entsprechenden Verwaltungsakts unerheblich ist, hat er erhebliche prozessuale Folgen in der Anfechtungsklage: Die Verfassungswidrigkeit der gesetzlichen Grundlage kann das Fachgericht nicht ohne weiteres feststellen, sondern muss gemäß Art. 100 I GG das Gesetz zur konkreten Normenkontrolle dem BVerfG vorlegen, während die Unverhältnismäßigkeit bloß des konkreten Verwaltungsakts keine Vorlage verlangt. ${ }^{1305}$ Rein dogmatisch kann der Ausschluss der Verhältnismäßigkeitsprüfung im Einzelfall für gebundene Entscheidungen nicht überzeugen. Denn nicht jeder (zufällige) Konflikt im Einzelfall zwischen einer gesetzlichen Norm wie der Rechtsgrundlage und einer Verfassungsnorm wie dem Rechtsstaatsprinzip oder den Grundrechten führt zur Nichtigkeit der gesamten gesetzlichen Norm. ${ }^{1306}$ Vielmehr kann es sich um einen bloßen Normenkonflikt handeln, der zu Gunsten des Verfassungsrechts aufgelöst wird (lex superior derogat lex inferiori, Art. 1 III GG). Ein einfaches Gesetz ist nur insgesamt

1301 Statt aller Maurer/Waldhoff, Allgemeines Verwaltungsrecht, 19. Aufl. 2017, § 10 Rn. 51.

1302 Hierzu Barczak, VerwArch 105, 142; Mehde, DÖV 2014, 541; Naumann, DÖV 2011, 96; Westerhoff, Die Prüfung der Verhältnismäßigkeit im Rahmen gebundener Entscheidungen, 2016. 1303 BVerfG, Beschl.v. 10. 8.2007, Az.: 2 BvR 535/06 = NVwZ 2007, 1300 (Rn. 19); BVerwG, Urt. v. 21.3.2012, Az.: 6 C 19/11 = NVwZ 2012, 1188; Maurer/Waldhoff, Allgemeines Verwaltungsrecht, 19. Aufl. 2017, § 10 Rn. 50.

1304 Barczak, VerwArch 105, 142; Bull/Mehde, Allgemeines Verwaltungsrecht, 9. Aufl. 2015, Rn. 152a; Detterbeck, Allgemeines Verwaltungsrecht, 17. Aufl. 2019, Rn. 606.

1305 Vgl. Barczak, VerwArch 105, 142 (174, 179).

1306 Vgl. mit entgegenstehenden Schlussfolgerungen Barczak, in: Mülder/Drechsler u.a., Richterliche Abhängigkeit, 2018, 333 (350 ff.). 
nichtig, wenn es auch auf abstrakter Ebene gegen die Verfassung verstößt. ${ }^{1307}$ Dementsprechend wird auch in der grundrechtlichen Prüfung einer staatlichen Maßnahme im Einzelfall zwischen der Grundrechtsverletzung der Rechtsgrundlage und der Grundrechtsverletzung im Einzelfall unterschieden. Ein Spielraum der Verwaltung oder gar der Gerichte ist damit nicht eröffnet: Nur wenn der gebundene Verwaltungsakt im Einzelfall wegen Unverhältnismäßigkeit verfassungswidrig ist, ist er rechtswidrig; einen verhältnismäßigen gebundenen Verwaltungsakt muss die Verwaltung erlassen. Gleichwohl ist die grundsätzliche Stoßrichtung der Kritik bedenkenswert. Für eine Prüfung des Verhältnismäßigkeitsgrundsatzes bei gebundenen Entscheidungen bleibt nur wenig Raum, da die Zweck-Mittel-Relation gesetzlich vorgegeben ist und eine eklatante Abweichung im Einzelfall von der gesetzlich vorgesehenen Zweck-Mittel-Relation, die erst eine Unverhältnismäßigkeit im Einzelfall trotz verhältnismäßiger Rechtsgrundlage möglich erscheinen lässt, in der Regel bereits auf Auslegungsebene (ohne Blick auf die verfassungsrechtlichen Vorgaben) eine teleologische Reduktion erfordert. Allenfalls im Hinblick auf einzelne Grundrechte bleibt die Verhältnismäßigkeitsprüfung für gebundene Entscheidungen praktisch relevant. Und auch in diesen Fällen bedarf es einer genauen Prüfung, ob der konkrete grundrechtliche Konflikt nicht bereits auf der abstrakten Ebene angelegt ist und zur Verfassungswidrigkeit der gesetzlichen Grundlage führt ${ }^{1308}$; jedenfalls wäre es verfehlt, wenn die unabhängigen Fachgerichte mit einem lapidaren Verweis auf die Prüfung des Einzelfalls die gesetzlichen Wertungen aushöhlen und den für die Gewaltenteilung des Grundgesetzes wesentlichen „Ohrfeigenvorbehalt“ des BVerfG gegenüber dem Gesetzgeber umgehen würden.

\section{(2) Gleichbehandlungsgebot}

Art. 3 I GG verlangt nicht nur die Berücksichtigung der Gleichheit der Menschen 772 im Gesetz, sondern auch die Gleichbehandlung der Menschen durch die Behörden bei der Anwendung der Gesetze. Gerade bei Ermessensentscheidungen, die auf die Vielfalt möglicher Einzelfälle reagieren und nicht selten auch von der persönlichen Einschätzung und Entscheidung des handelnden Beamten geprägt werden, kann das Gleichbehandlungsgebot zu berücksichtigen sein. Das Gleichbehandlungsgebot verlangt von den Behörden, vergleichbare Fälle vergleichbar zu behandeln, also ihr Verhalten nicht nach sachwidrigen Kriterien zu differenzieren. Tut eine Behörde dies doch, verstößt der entsprechende Verwaltungsakt gegen das Gleichbehandlungsgebot aus Art. 3 I GG und ist rechtswidrig. Eine Ungleichbehandlung kann dabei auch darin liegen, dass maßgebliche Unterschiede nicht richtig erfasst werden. Daher lässt sich plakativ auf das Gebot abstellen, Gleiches gleich und Ungleiches ungleich $\mathrm{zu}$ behandeln. ${ }^{1309}$

1307 Vgl. BVerfG, Beschl. v. 10.8.2007, Az.: 2 BvR 535/06 = NVwZ 2007, 1300 (Rn. 18); BVerwG, Urt. v. 21.3.2012, Az.: 6 C 19/11 = NVwZ 2012, 1188, Rn. $20 \mathrm{ff}$.

1308 So im Wesentlichen bereits z.B. BVerfG, Beschl. v. 10.8.2007, Az.: 2 BvR 535/06 = NVwZ 2007, 1300, Rn. 18; BVerwG, Urt. v. 21.3.2012, Az.: 6 C 19/11 = NVwZ 2012, 1188, Rn. 20 ff.

1309 BVerfG, Beschl. v. 21.6.2006, Az.: 2 BvL 2/99 = BVerfGE 116, 164, Rn. 69; Bull/Mehde, Allgemeines Verwaltungsrecht, 9. Aufl. 2015, Rn. 141. 
Dies rückt den Vergleich und die Vergleichbarkeit von Fällen ins Zentrum der Betrachtung. Der Vergleich von Fällen macht die Bildung von Vergleichsgruppen notwendig. Die Vergleichbarkeit von Fällen ist eine normativ geprägte Frage, für deren Beantwortung neben verfassungsrechtlichen Grundsatzentscheidungen auch die Abgrenzungskriterien und Zwecke des maßgeblichen Gesetzes heranzuziehen sind.

774 Examenswissen: Die mit der Vergleichbarkeit verbundenen Fragen sind im Einzelnen herausfordernd und unüberschaubar und entziehen sich oftmals einer abschließenden abstrakten Beantwortung. So stellt sich die Frage, auf welche handelnden Teile der staatlichen Verwaltung abzustellen ist. Teilweise ist nur auf die konkrete Behörde abzustellen, weshalb Zuständigkeitsfragen auch wichtige materielle Folgen haben können. Teilweise kann es auf den hoheitlich handelnden Staat insgesamt ankommen, etwa wenn mit einer Ungleichbehandlung besondere Gefahren verbunden sind oder relevante Vergleichsgruppen sinnvoll nur in einem weiteren Rahmen zu bilden sind. Andererseits kann es auch auf die handelnden Beamten ankommen, insbesondere wenn ein Spielraum eine Differenzierung anhand der handelnden Personen zulässt: Polizisten handeln in Gefahrensituationen situationsbezogen aufgrund ihrer individuellen Erfahrung, so dass es auf unterschiedliche Reaktionen unterschiedlicher Polizisten nicht immer ankommen kann; Prüfer in staatlichen Prüfungen genießen einen weiten Bewertungsspielraum, in dem sie ihre persönlichen Einschätzungen wiedergeben, die unterschiedlich ausfallen können (und können sollen). Und selbst bestimmte Beamte sind keine Maschinen, die sich immer gleich verhalten, ohne dass dies zu einem Verstoß gegen das Gleichbehandlungsgebot führt. Die Prüfung des Gleichbehandlungsgebots muss all dem Rechnung tragen, ohne das Gebot als ein zentrales Element des Grundrechtsstaates faktisch auszuhebeln. Maßgeblich ist letztlich die materielle Programmierung durch Art. 3 I GG unter den tatsächlichen und rechtlichen Umständen der jeweiligen Konstellation.

775 Examenswissen: Eine besondere Rolle im Rahmen der Prüfung des Gleichbehandlungsgebots spielt die Selbstbindung der Verwaltung. Hat sich eine einheitliche Behandlung bestimmter Fälle faktisch oder insbesondere durch geplante Koordinierung (etwa durch Verwaltungsvorschriften) in einer Behörde etabliert, ist auch jeder vergleichbare Einzelfall entsprechend zu behandeln. ${ }^{1310}$ Weicht die Behörde hiervon ab, führt dies zu einer rechtswidrigen Ungleichbehandlung. Ausreichend kann bereits sein, wenn nur ein Teil vergleichbarer Fälle einheitlich behandelt wird, um eine entsprechende Selbstbindung zu etablieren. Andererseits darf die Selbstbindung auch nicht überzogen werden. Der Behörde steht es in der Regel frei, ihre Verwaltungsübung zu ändern; die relevante Vergleichsgruppe stellt sich dann aus den neu zu regelnden Fällen zusammen. ${ }^{1311}$ Sie muss dann aber gegebenenfalls die Änderung ankündigen, um eine Verletzung des Vertrauens und eine Ungleichbehandlung gerade durch den Überraschungseffekt zu verhindern. ${ }^{1312}$ Die Behörde kann sogar den konkreten Einzelfall zum Anlass

1310 Hierzu etwa Bull/Mehde, Allgemeines Verwaltungsrecht, 9. Aufl. 2015, Rn. 233 ff.; Sachs, in: Stelkens/Bonk/Sachs, VwVfG, 9. Aufl. 2018, § 40 Rn. $103 \mathrm{ff}$.

1311 Vgl. Aschke, in: Bader/Ronellenfitsch, VwVfG, 42. Ed., 2019, § 40 Rn. $66 \mathrm{ff}$.

1312 Aschke, in: Bader/Ronellenfitsch, VwVfG, 44. Ed., Stand: 1.7.2019, § 40 Rn. 68. 
nehmen, ihre Übung anzupassen, ohne dass dies zu einer Ungleichbehandlung führen muss, soweit sie diesbezüglich konsequent ist.

Examenswissen: Das Gleichbehandlungsgebot verlangt nicht, eine rechtswidrige Praxis - ins- 776 besondere im Rahmen der Selbstbindung - auch auf andere Fälle anzuwenden: keine Gleichheit im Unrecht. ${ }^{1313}$ Allenfalls in besonderen Situationen, in denen die Ungleichbehandlung mit zusätzlichen eigenständigen Belastungen verbunden ist, die anderweitig nicht beseitigt werden können, lässt sich darüber diskutieren, dass das Gleichbehandlungsgebot an rechtswidriges Verhalten gegenüber Dritten anknüpft. Dementsprechend spielt das Gleichbehandlungsgebot für gebundene Entscheidungen regelmäßig keine Rolle.

\section{(3) Keine Unmöglichkeit}

Es gilt als allgemeiner Grundsatz, dass von niemandem etwas rechtlich ver- 777 langt werden kann, dass ihm unmöglich ist (ultra posse nemo obligatur). Dieser Grundsatz ist logisch keineswegs zwingend, da auch an eine vorhersehbare Pflichtverletzung Rechtsfolgen geknüpft werden können (vgl. § 311a I BGB), ergibt sich aber im Rahmen von Verwaltungsakten jedenfalls aus dem Verhältnismäßigkeitsgrundsatz, da eine Verpflichtung, die nicht eingehalten werden kann, zumindest ungeeignet ist. Da das Verbot Unmögliches zu verlangen aber auch andere Aspekte ansprechen kann (vgl. § 44 II Nr. 4, 5 VwVfG) und mit eigenen Problemstellungen verbunden ist, wird es in der Regel als eigenständiger Prüfungspunkt im Rahmen der materiellen Rechtmäßigkeit angesprochen. Als Bündel verschiedener Aspekte der Verhältnismäßigkeit und anderer rechtlicher Vorgaben, kann es dabei im Detail unterschiedlich ausgestaltet sein. Eine Ausdifferenzierung des Bündels ist nur sinnvoll, soweit es auf eine Differenzierung der unterschiedlichen rechtlichen Maßstäbe ankommt.

Für das Verbot, durch einen Verwaltungsakt Unmögliches zu verlangen, be- 778 steht gleichwohl ein einheitlicher Kern, der stets zu berücksichtigen ist: Ein Verwaltungsakt ist rechtswidrig, soweit er von dem Adressaten ein Verhalten verlangt, dass diesem aus tatsächlichen oder rechtlichen Gründen nicht möglich bzw. verboten ist. Dabei ist insbesondere der zeitliche Rahmen, auf den sich der hoheitliche Befehl bezieht, zu berücksichtigen. Verlangt ein Verwaltungsakt beispielsweise von A die Herausgabe einer Sache, die nicht in As Besitz ist, so ist die Herausgabe zwar derzeit nicht möglich. Allerdings kann sich A gegebenenfalls die Sache verschaffen, um sie dann auch herauszugeben. Dementsprechend wäre dann ein Verwaltungsakt, der die sofortige Herausgabe verlangt, rechtswidrig, nicht jedoch eine entsprechende Verpflichtung ohne zeitlichen Rahmen. Der Bezug zum zeitlichen Rahmen ist insbesondere dann zu beachten, wenn im

1313 Sachs, in: Stelkens/Bonk/Sachs, VwVfG, 9. Aufl. 2018, § 40 Rn. 119. 
Rahmen eines Verwaltungsverfahrens unterschiedliche Zeitrahmen relevant werden, etwa wenn bei einem zeitlich nicht klar umrissenen Grundverwaltungsakt in der Verwaltungsvollstreckung bestimmte Fristen gesetzt werden.

Man kann zwischen rechtlicher und tatsächlicher sowie zwischen objektiver und subjektiver Unmöglichkeit unterscheiden. Rechtlich unmöglich ist die Befolgung eines Verwaltungsakts, wenn vorrangige rechtliche Vorgaben die verlangte Rechtshandlung nicht vorsehen oder das verlangte Verhalten verbieten. ${ }^{1314}$ Subjektiv unmöglich ist ein Verhalten, dass dem Adressaten unmöglich ist, während sich objektive Unmöglichkeit auf ein Verhalten bezieht, das niemandem möglich ist. Hingegen nicht (auch nicht subjektiv) unmöglich ist eine vertretbare Handlung (so kann natürlich kein Bauherr eigenhändig ein größeres Gebäude in einer angemessenen Zeit abreißen). ${ }^{1315}$ Für die materielle Rechtswidrigkeit des Verwaltungsakts kommt es auf die Differenzierungen nicht an, sie können jedoch im Rahmen der Fehlerfolgen relevant werden (vgl. § 44 II Nr. 4 und $5 \mathrm{VwVfG})$.

780 Examenswissen: Keinen Fall der Unmöglichkeit stellen Fälle der wirtschaftlichen oder persönlichen Unzumutbarkeit dar, wie sie für das Zivilrecht in § 275 II, III BGB geregelt sind. Derartige Konstellationen werden im Verwaltungsrecht für öffentlich-rechtliche Pflichten besser durch die Prüfung der Verhältnismäßigkeit erfasst. Zivilrechtliche Pflichten machen die Befolgung des hoheitlichen Befehls daher in der Regel nicht unmöglich. Zwar sind auch zivilrechtliche Pflichten und Verbote im Rahmen der rechtlichen Unmöglichkeit zu berücksichtigen $^{1316}$, jedoch besteht häufig (zumindest mit entsprechendem Vorlauf) die Möglichkeit, sich durch Verhandlungen und Rechtsgeschäfte von diesen Pflichten und Verboten zu lösen. Der Aufwand zur Lösung von den zivilrechtlichen Vorgaben bzw. die damit verbundenen Eingriffe in die Privatautonomie der Adressaten ist dann aber im besonderen Maße im Hinblick auf ihre Verhältnismäßigkeit zu überprüfen, insbesondere wenn der öffentlich-rechtliche Druck durch den Verwaltungsakt den Abschluss eines wirtschaftlichen Geschäfts erschwert oder gar unmöglich macht.

781 Examenswissen: Missverständnisse zum Verbot, Unmögliches zu verlangen, entstehen insbesondere in der Ausbildung durch einen unscharfen und undifferenzierten Verweis auf den Topos durch die Literatur und teilweise auch durch die Rechtsprechung. Die gebotenen Differenzierungen werden dann oftmals durch nicht weiter begründete Abgrenzungslinien nachvollzogen, was den Zugriff auf die rechtlichen Maßstäbe weiter verunklart. Anschaulich ist insofern die Behandlung von bauaufsichtlichen Nutzungsuntersagungen an Vermieter. Die Pflichten aus dem Mietvertrag (und die besonderen Anforderungen an eine gerichtliche Durchsetzung der Räu-

1314 Brenndörfer/Trockels, in: Schweickhardt/Vondung, Allgemeines Verwaltungsrecht, 10. Aufl. 2018, Rn. 198f.

1315 Brenndörfer/Trockels, in: Schweickhardt/Vondung, Allgemeines Verwaltungsrecht, 10. Aufl. 2018, Rn. 196.

1316 Brenndörfer/Trockels, in: Schweickhardt/Vondung, Allgemeines Verwaltungsrecht, 10. Aufl. 2018, Rn. 198. 
mung) stehen einer Durchsetzung der Nutzungsuntersagung durch den Vermieter entgegen. ${ }^{1317}$ Gleichwohl ist es dem Vermieter nicht von vorneherein unmöglich, die weitere Nutzung zu unterbinden, insbesondere indem er auf die Vertragsauflösung hinwirkt und auf eine Neuvermietung verzichtet. ${ }^{1318}$ Vor diesem Hintergrund ist eine ausdifferenzierte und uneinheitliche Rechtsprechung zu Nutzungsuntersagungen an den Vermieter im Verhältnis zu Nutzungsuntersagungen an den Mieter entstanden, die dazu noch mitunter zwischen Grundverwaltungsakt und Vollstreckung unterscheidet. ${ }^{1319}$ Der Versuch, diese Rechtsprechung allein aus der rechtlichen Unmöglichkeit der Kündigung der Mieter zu rekonstruieren, kann diese in sich stringenten Rechtsprechungslinien, die wiederum mit den jeweiligen örtlichen Verwaltungspraktiken interagieren, nicht nachvollziehen. Vielmehr bedarf es einer differenzierten Betrachtung der unterschiedlichen Zeithorizonte der Verwaltungsakte und der rechtlichen und tatsächlichen Folgen der materiellen Gebote im Hinblick auf die Verhältnismäßigkeit. Insbesondere in der Verwaltungsvollstreckung kommt es dabei regelmäßig nicht darauf an, ob die Mieter sich tatsächlich einer Vertragsauflösung bedingungslos widersetzen und die Durchsetzung der Nutzungsuntersagung so dem Vermieter unmöglich machen oder aber der externe Druck durch die Vollstreckung den Vermieter in eine unzumutbare und damit unverhältnismäßige Verhandlungssituation gegenüber dem Mieter bringt. Jedenfalls bedarf es einer Prüfung der maßgeblichen rechtlichen Maßstäbe im Einzelfall, ohne unmotiviert auf die Unmöglichkeit und deren Fallgruppen abzustellen.

\section{dd) Sonstige rechtliche Vorgaben}

Die Verwaltung ist in allem, was sie tut, an das Recht gebunden (Art. 20 III GG). 782 Sie muss also nicht nur die Voraussetzungen der Rechtsgrundlage erfüllen, sondern auch alle anderen anwendbaren gesetzlichen Vorgaben berücksichtigen. Dabei kann es nötig sein, das Verhältnis zwischen den speziellen Vorgaben der Rechtsgrundlage und in Betracht kommenden sonstigen rechtlichen Grundlagen zu bestimmen.

Sonstige rechtliche Vorgaben sind eher bei Verwaltungsakten mit Spielraum als bei gebundenen Verwaltungsakten relevant. Üblicherweise erfasst die entsprechend auszulegende Rechtsgrundlage für gebundene Entscheidungen auch das Verhältnis zu sonstigen Regelungsbereichen. Für einzelne Rechtsgrundlagen für gebundene Verwaltungsakte, für bestimmte Fallgruppen und in besonderen Konstellationen des Einzelfalls kann aber auch für gebundene Verwaltungsakte der Blick auf sonstige rechtliche Vorgaben zentraler Prüfungsbestandteil sein.

1317 Maurer/Waldhoff, Allgemeines Verwaltungsrecht, 19. Aufl. 2017, § 10 Rn. 53.

1318 Vgl. OVG Schleswig, Beschl. v. 17.11.2015, Az.: 1 MB 25/15, Rn. 20; VG Saarlouis, Urt. v. 19.11. 2014, Az.: 5 K 451/13, Rn. 43 f.

1319 U.a. VGH München, Beschl. v. 18.9.2017, Az.: 15 CS 17.1675; OVG Münster, Beschl. v. 24.11. 1988, Az.: 7 B 2677/88; OVG Saarlouis, Beschl.v. 10.5.1999, Az.: 2 W 3/99; OVG Schleswig, Beschl.v. 17.11.2015, Az.: 1 MB 25/15. 


\section{(1) Vorrangiges Recht}

784 Eine besondere Rolle spielt im Rahmen der sonstigen rechtlichen Vorgaben das vorrangige Recht, auf das die Rechtsgrundlage nicht zugreifen kann. Hierzu zählen insbesondere die verfassungsrechtlichen Grenzen des Grundgesetzes, also neben den Grundrechten, die aber im Rahmen der Verhältnismäßigkeitsprüfung erfasst werden können und daher oftmals nicht mehr eigenständig geprüft werden, die Staatsstrukturprinzipien.

785 Bei landesrechtlichen Rechtsgrundlagen ist zudem der Vorrang des Bundesrechts zu berücksichtigen sowie das Landesverfassungsrecht.

786 Verstöße gegen vorrangiges Recht sind im Rahmen der materiellen Rechtmäßigkeitsprüfung nur im Einzelfall relevant. Liegt ein struktureller Verstoß der Rechtsgrundlage gegen das höherrangige Recht vor, führt dies bereits - jedenfalls grundsätzlich - zur Nichtigkeit der Rechtsgrundlage (vgl. Rn. 576). Dementsprechend bleiben solche Konstellationen die Ausnahme.

\section{(2) EU-Recht}

787 Für das Recht der EU gilt kein Geltungsvorrang, sondern ein bloßer Anwendungsvorrang im Einzelfall. Das bedeutet, dass die Rechtsgrundlage nicht wegen Verstoßes gegen EU-Recht nichtig sein kann, gleichwohl ist ein Verwaltungsakt, der gegen EU-Recht verstößt, stets rechtswidrig. Da auch eine strukturelle Unvereinbarkeit mit dem Recht der EU nicht die Nichtigkeit der Rechtsgrundlage verursacht und zudem die Struktur des EU-Rechts eher zu Konflikten mit dem nationalen Recht führen kann, bedürfen mögliche Verstöße gegen das EU-Recht im Rahmen dessen Anwendungsbereichs besonderer Aufmerksamkeit. Nicht zuletzt deshalb müssen Juristen im öffentlichen Recht stets die Implikationen des EU-Rechts mitbedenken und können schwerlich ohne die in ihrem jeweiligen Arbeitsbereich relevanten Grundkenntnisse zum Recht der Union auskommen.

\section{(3) Sonstiges Recht}

788 Steht ein Verstoß des Verwaltungsakts gegen eine gesetzliche Vorgabe, die gegenüber der Rechtsgrundlage gleich- oder gar nachrangig ist, im Raum, bedarf es einer genauen Untersuchung des Verhältnisses zwischen der Rechtsgrundlage und der sonstigen Rechtsvorgabe. Dabei kann sich eine schier unüberschaubare Vielzahl von Konstellationen ergeben. Im einfachsten und grundsätzlichen Fall, stehen die gesetzlichen Vorgaben parallel nebeneinander und sind gleichermaßen zu beachten, so dass ein Verstoß gegen jede der Normen den Verwaltungsakt bereits materiell rechtswidrig macht. Weniger einfach, aber sicher handhabbar sind ausdrückliche Regelungen zur Anwendbarkeit von gesetzlichen Vorschriften 
für bestimmte sich gegenseitig ausschließende Regelungsbereiche. Zudem können vollständige, teilweise oder weitere differenzierte Spezialitätsverhältnisse bestehen. Mitunter wird die Anwendbarkeit der Normen auch im Hinblick auf bestimmte Entscheidungen ausdrücklich oder implizit eingeschränkt, etwa wenn fachbehördliche Genehmigungen nur am Maßstab des Fachrechts zu messen (und in ihrer Reichweite entsprechend begrenzt) sind und die Prüfung anderer Regelungen anderen Behörden überlassen wird. Bei Nachrangigkeit der sonstigen Regelung ist zu untersuchen, ob die Rechtsgrundlage diese Regelung verdrängt, sich dieser gegenüber öffnet oder durch gleich- oder vorrangige Regelungen in eine Öffnung gezwungen wird. Einzelheiten, wie etwa zum Verhältnis zwischen polizeilicher Gefahrenabwehr und anderweitigem Behördenhandeln ${ }^{1320}$, lassen sich nur im Rahmen klar umrissener Regelungsbereiche des besonderen Verwaltungsrechts sinnvoll ordnen und darstellen.

Als sonstiges Recht kann insbesondere anderes öffentliches Recht relevant 789 werden. Auch straf- und privatrechtliche gesetzliche Vorgaben sind (wenn sie nicht ohnehin schon im Rahmen der Unmöglichkeit durchschlagen) von der Verwaltung zu berücksichtigen, wobei insoweit besonderes Augenmerk auf die Bindungsrichtung zu werfen ist: Die Verwaltung ist nicht an die privatrechtlichen Rechte und Pflichten zwischen den Bürgern gebunden und kann insbesondere nicht durch einen Vertrag unter Dritten von der Erfüllung ihrer gesetzlichen Aufgaben abgehalten werden. Auch die Rechtskraft von Urteilen ist insofern von der Verwaltung $\mathrm{zu}$ beachten. ${ }^{1321}$

\section{c) Richtiger Adressat}

Im Regelfall werden Verwaltungsakte gegenüber einer bestimmten Person oder 790 einem klar umrissenen Personenkreis erlassen. Für diesen Fall lassen sich auch Regeln für die rechtlich zulässigen Adressaten finden oder herleiten (s. zum Polizei- und Ordnungsrecht Rn. 1118ff.). Ein Verwaltungsakt gegenüber einer bestimmten Person, muss diesen Vorgaben entsprechen. Soweit der Verwaltung hinsichtlich der Adressatenauswahl ein Spielraum zukommt, sind zudem (ggf. unter einem eigenen Prüfungspunkt oder im Rahmen der spezifischen Fehler bei der Inanspruchnahme von Spielräumen) diesbezügliche (Ermessens-)Grenzen zu beachten.

Soweit ein Verwaltungsakt ohne einen klaren Adressaten erlassen wurde, ist $\mathbf{7 9 1}$ zu prüfen, ob dies der Verwaltung überhaupt gestattet war.

1320 Vgl. u. a. Gusy, Polizei- und Ordnungsrecht, 10. Aufl. 2017, Rn. 134 ff.

1321 Erbguth/Guckelberger, Allgemeines Verwaltungsrecht, 9. Aufl. 2018, § 14 Rn. 55.

Daniel Benrath 


\section{d) Spezifische Fehler bei der Inanspruchnahme von Spielräumen}

792 Soweit der Verwaltungsakt mit Spielräumen verbunden ist, ist im Rahmen des hier zu Grunde gelegten Prüfungsaufbaus nach der Prüfung der inhaltlichen Vorgaben zu prüfen, ob durch die Überschreitung der inneren Grenzen spezifische Fehler bei der Inanspruchnahme der Spielräume vorliegen. Dieser Prüfungspunkt umfasst Fehler hinsichtlich aller möglichen Spielräume, also neben Ermessensfehlern insbesondere auch Beurteilungs- und Bewertungsfehler. Bei gebundenen Verwaltungsakten entfällt er. Im Rahmen dieses Prüfungspunkts ist also stets zu prüfen bzw. festzustellen, dass und inwieweit der Verwaltung ein Spielraum beim Erlass des Verwaltungsakts zustand.

793 Im Rahmen der spezifischen Fehler kann entsprechend der Fallgruppen der Fehlerlehre zunächst der Nichtgebrauch des Spielraums und dann der Fehlgebrauch in seinen vielfältigen Formen angesprochen werden.

794 Ob die Verwaltung tatsächlich die inneren Grenzen des Spielraums verletzt hat, ist eine Tatsachenfrage, die sich nicht aus dem im Tenor zum Ausdruck kommenden Inhalt des Verwaltungsakts beantworten lässt. Wesentlicher Anknüpfungspunkt ist dabei in erster Linie die Begründung des Verwaltungsakts. Weitergehende Untersuchungen sind in der Klausur nur in Ausnahmefällen, die in der Regel klar markiert sind, geboten; auch in der gerichtlichen Praxis bleiben sie Ausnahmen. Stellt sich heraus, dass die Begründung unvollständig war, da sie nicht alle Gründe enthält, die die Behörde zu ihrer Entscheidung bewogen hat, kann dies nachträglich mit heilender Wirkung korrigiert werden (Formfehler).

795 Examenswissen: Spezifische Fehler bei der Ausübung des Spielraums können nachträglich auch noch während der Anfechtungsklage beseitigt werden, indem die Verwaltung Gründe nachschiebt. Dies ergibt sich aus prozessualer Sicht aus §114 Satz 2 VwGO. Inwieweit die Behörde hierzu berechtigt ist, ergibt sich aus dem jeweiligen Verwaltungsverfahrensrecht. ${ }^{1322}$ Beim Nachschieben von Gründen (s. hierzu schon Rn. 699) handelt es sich nicht nur um eine bloße Korrektur der Begründung, sondern um eine echte materielle Ergänzung hinsichtlich der Inanspruchnahme des Spielraums. Es geht also nicht um eine formelle Heilungsmöglichkeit, vielmehr dient diese prozessuale Regelung allein der Verfahrensbeschleunigung (und damit letztlich auch dem effektiven Rechtsschutz), um trotz der (im Ergebnis ggf. unerheblichen) Korrektur des Verwaltungsakts nicht das gesamte Verfahren neu aufrollen zu müssen, wenn es beim Streit bleibt. ${ }^{1323}$ Dementsprechend kann ein Nachschieben von Gründen nur zur Rechtmäßigkeit des Verwaltungsakts führen, wenn der Spielraum auf Grund der nachgeschobenen Gründe auch erneut und unvoreingenommen in Anspruch genommen wurde; ansonsten liegt schon allein diesbezüglich ein eigenständiger Fehler vor. Zudem wird - bei vielfältigen offenen Detailfragen - die Möglichkeit der Fehlerkorrektur durch Nachschieben beschränkt: Insbesondere eine Wesensveränderung der Entscheidung oder gar das Auswechseln der maßgeblichen Abwägungsgründe soll

1322 Gerhardt, in: Schoch/Schneider/Bier, VwGO, 36. EL Februar 2019, § 114 Rn. 12c. 1323 Vgl. Gerhardt, in: Schoch/Schneider/Bier, VwGO, 36. EL Februar 2019, § 114 Rn. 12a. 
nicht als bloße „Ergänzung“ gelten. ${ }^{1324}$ Erklärt der Kläger das Verfahren auf Grund der nachgeschobenen Gründe für erledigt (und war die Anfechtungsklage ursprünglich wegen der Fehler begründet), kann er immerhin der Kostenlast entgehen (vgl. § 161 VwGO). ${ }^{1325}$

\section{aa) Nichtgebrauch}

Kann das Vorliegen eines Spielraums bejaht werden, muss die Behörde diesen 796 Spielraum auch durch eine eigenständige Entscheidung in Anspruch nehmen. $\mathrm{Ob}$ die Verwaltung dies getan hat, ist insbesondere durch die Auslegung der Begründung zu bestimmen, wobei auch anderweitige Äußerungen der handelnden Beamten und gegebenenfalls Zeugenaussagen zu berücksichtigen sein können. Auf einen Fehler hinsichtlich des Nichtgebrauchs eines Spielraums deuten insbesondere Formulierungen hin, die darauf hinweisen, dass die Behörde sich rechtlich gebunden sah. Nicht hingegen führen gleich alle Formulierungen, die eine für die Verwaltung klare Entscheidung verdeutlichen, gleich zur Fehlerhaftigkeit des Verwaltungsakts. Eine häufige Fehlerquelle sind verwaltungsinterne Vorgaben, etwa durch Verwaltungsvorschriften, die den Spielraum des konkret handelnden Beamten praktisch ausschließen, ohne dass die handelnde Behörde als solche rechtlich gebunden würde; vielmehr sind diese Vorgaben Ausdruck der eigenständigen Entscheidung der Verwaltung, die dann aber im konkreten Fall auch nachvollzogen werden muss.

Examenswissen: Auch im Falle des intendierten Ermessen, muss die Behörde Ermessen ausüben und kommt ein Ermessensnichtgebrauch in Betracht. Allerdings reicht nach der Rechtsprechung insofern aus, dass über das Vorliegen eines Regelfalls entschieden wird, und es bedarf dann keiner weiteren Ausführungen in der Begründung. ${ }^{1326}$ Bei einer Ermessensreduzierung auf Null fehlt es letztlich an einem Spielraum, den die Verwaltung in Anspruch nehmen kann; ein Ermessensnichtgebrauch ist insofern ausgeschlossen.

\section{bb) Fehlgebrauch}

Auch hinsichtlich eines Spielraums sind die gesetzlichen Vorgaben zu berück- 798 sichtigen. Aus der gesetzlichen Grundlage ergibt sich nicht nur, ob überhaupt ein Spielraum eingeräumt wird. Vielmehr formt die gesetzliche Grundlage, insbesondere im Hinblick auf den Zweck, den Spielraum aus und gibt die wesentlichen inneren Grenzen der Spielrauminanspruchnahme vor. Dabei kann der Gesetzgeber die Inanspruchnahme des Spielraums auf vielfältige Weise lenken und ein-

1324 Decker, in: Posser/Wolff, VwGO, 50. Ed., Stand: 1.7.2019, § 114 Rn. 41 ff. m.w. N. 1325 Gerhardt, in: Schoch/Schneider/Bier, VwGO, 36. EL Februar 2019, § 114 Rn. $12 \mathrm{f}$. 1326 BVerwG, Urt. v. 23.5.1996, Az.: 3 C 13/94, Rn. 51; BVerwG, Urt. v. 16.6.1997, 3 C 22/96 = BVerwGE 105, 55, Rn. 14; Detterbeck, Allgemeines Verwaltungsrecht, 17. Aufl. 2019, Rn. 323. 
engen. Zudem können allgemeine rechtliche Wertungen wie insbesondere die Grundrechte und Staatsziele bei der Inanspruchnahme von Spielräumen zu berücksichtigen sein.

Die vielfältigen Fehler, die sich im Rahmen des Fehlgebrauchs ergeben, sind nicht abstrakt im Rahmen eines Prüfungsschemas abzuprüfen. Vielmehr sind Fehler hinsichtlich des Fehlgebrauchs nur anzusprechen, soweit sich hierfür konkrete Anhaltspunkte finden. Eine schematische Kontrolle aller möglichen Fehler würde die Prüfung schnell und ohne Ertrag überfordern. Allenfalls im besonderen Verwaltungsrecht können sich in bestimmten Konstellationen typische Ermessensfehlgebräuche ergeben, deren schematische Erfassung sinnvoll sein kann. Für die Prüfung von Fehlern hinsichtlich des Fehlgebrauchs ergeben sich also drei Herausforderungen: Zunächst sind Anhaltspunkte für mögliche Fehler zu identifizieren, dann sind die entsprechenden rechtlichen inneren Grenzen des Spielraums zu bestimmen und schließlich ist zu prüfen, ob diese inneren Grenzen auch tatsächlich verletzt wurden.

800 Soweit sich aus dem besonderen Verwaltungsrecht keine typischen Fehlerkonstellationen ergeben, die sinnvoll angesprochen werden können, finden sich in der Klausursituation häufig Anmerkungen oder Parteivorträge, die auf spezifische Fehler hindeuten. Aber auch darüber hinaus müssen in der Klausurprüfung und insbesondere in der praktischen Rechtsanwendung mögliche rechtliche Spannungen hinsichtlich der rechtlichen Vorgaben und des Verwaltungshandeln im Blick behalten werden. Weicht der von der Verwaltung dargestellte Sachverhalt vom tatsächlichen ab oder ist auffällig grob und pauschalisierend? Entsprechen die von der Verwaltung dargestellten Entscheidungsgründe den gesetzlichen Vorgaben, könnten wichtige Aspekte fehlen, Gründe unsachlich sein, werden besondere Gewichtungen vorausgesetzt? Gibt es Auffälligkeiten im Entscheidungsprozess? Eine Durchdringung der entsprechenden Rechtsmaterie (in Klausursituationen durch den Prüfungsstoff begrenzt) ist hierfür oftmals unerlässlich.

801 Verwertbare Vorgaben zu den inneren Grenzen des Spielraums sind oftmals nur durch eine anspruchsvolle systematisch-teleologische Auslegung zu erkennen. Eine besondere Rolle spielen hierbei Regelungen zu den Gesetzeszwecken, die sich im besonderen Verwaltungsrecht häufig ausdrücklich finden (z. B. §1 EnWG) oder aus bestimmten Normen herleiten lassen (z. B. § 9 BauGB).

$\mathrm{Ob}$ und inwieweit die inneren Grenzen eingehalten wurden, ergibt sich im Regelfall aus der Begründung des Verwaltungsakts. Dessen Angaben sind also, soweit sich keine anderweitigen Anhaltspunkte geben, unter die inneren Grenzen zu subsumieren. Ist dies mangels entsprechender Angaben in der Begründung nicht möglich, so ist die Begründung unvollständig und der Verwaltungsakt schon formell rechtswidrig (s. Rn. 743). Allerdings kann die Begründung auch 
ausdrücklich oder implizit auf den gesetzlichen Hintergrund verweisen, der dann ebenfalls miteinzubeziehen ist; insbesondere bei intendiertem Ermessen sind die Anforderungen an die Begründung nicht zu überspannen (s. Rn. 732).

\section{e) Der Aufbau der Prüfung der materiellen Rechtmäßigkeit}

Der Aufbau einer juristischen Prüfung muss zwar das juristische Prüfungsprogramm vollständig abdecken, ist in diesem Rahmen jedoch ausgesprochen flexibel und vielgestaltig. Die Freiheit und Vielfalt der Aufbaumöglichkeiten ist gerade im Bereich der materiellen Rechtmäßigkeitsprüfung eines Verwaltungsakts besonders ausgeprägt. Die Vielfalt betrifft nicht nur die Struktur und Reihenfolge der Prüfung, sondern auch den Umfang der unter die materielle Rechtmäßigkeit gefassten Prüfung.

Examenswissen: Maßgeblich für den Aufbau der Prüfung der materiellen Rechtmäßigkeit ist, dass sie alle rechtlichen Aspekte erfasst und in sich stimmig und ohne Widerspruch ist. Dementsprechend sollte das Prüfungsschema auch die grundlegende Unterscheidung der rechtlichen Kontrollmaßstäbe (vgl. § 114 Satz 1 VwGO) abbilden. Zudem sollen die Schemata sinnvoll für die Aneignung in der Ausbildung und praktikabel in der tatsächlichen Anwendung sein. Ein gutes Schema spiegelt die Grundstrukturen des Prüfungsgegenstands wider, ist einfach zu erlernen und verzichtet in der Anwendung auf künstliche Unterscheidungen, unnötige Abgrenzungen oder sinnlose Wiederholungen. Die Diskussion abstrakter Prüfungsschemata im Rahmen des allgemeinen Verwaltungsrechts ist dabei notwendigerweise grob; sie dient allenfalls als Grundlage für die Weiterentwicklung des Prüfungsaufbaus im besonderen Verwaltungsrecht oder als Anknüpfungspunkt für die Entwicklung eines Prüfungsaufbaus in unbekannten Rechtsbereichen oder Prüfungssituationen.

Examenswissen: Erfahrungsgemäß ergeben sich aus der Auseinandersetzung mit den üblichen Schemata für die materielle Rechtmäßigkeitsprüfung der äußerlich weitgehend einheitlichen Lehrbuchliteratur zum allgemeinen Verwaltungsrecht vielfältige Unsicherheiten und Missverständnisse bei Studierenden und darüber hinaus, die bis auf das materielle Verständnis des Verwaltungsrechts durchschlagen können. Insbesondere kleinere Variationen in der Definition einzelner Prüfungspunkte können deutliche Folgen für den Aufbau haben, ohne dass dies immer klar wird. Gerade für fortgeschrittene Studierende des Verwaltungsrechts bedarf es daher einer fundierten Reflexion zum Aufbau der materiellen Rechtmäßigkeitsprüfung und seines rechtlichen und tatsächlichen Rahmens. Nur wer den Prüfungsaufbau in seinen Varianten kritisch nachvollziehen kann, kann sich Schemata informiert aneignen, aus diesen in der Prüfung die wesentlichen rechtlichen Maßstäbe entnehmen und eigenständig für eine konkrete Prüfung einen praktikablen Aufbau wählen. Die weiteren Ausführungen zum Prüfungsaufbau an dieser Stelle sind in diesem Sinne bei weitem nicht umfassend, haben aber den Anspruch, ausreichend erkenntnisreich zu sein, um eine eigenständige Arbeit mit dem Prüfungsaufbau zu unterstützen. 


\section{aa) Verhältnis zu anderen Teilen der Prüfung}

806 Schon der Umfang der Prüfung der materiellen Rechtmäßigkeit ist mangels legaldefinierter Abgrenzung nicht klar und variiert in unterschiedlichen Ansätzen zum Aufbau. Da gleichwohl der Umfang der gesamten Rechtmäßigkeitsprüfung rechtlich vorgegeben ist, ergeben sich aus diesen Variationen unterschiedliche Verhältnisse $\mathrm{zu}$ anderen Prüfungspunkten. Bei der Auswahl eines Prüfungsschemas ist auch insofern auf Stringenz zu achten; Redundanzen und Lücken sind $\mathrm{zu}$ vermeiden. Insbesondere das Verhältnis der Prüfung der materiellen Rechtmäßigkeit zur Prüfung der Rechtsgrundlage kann sehr unterschiedlich ausgestaltet werden. So sind alle Tatbestandsmerkmale und rechtsfolgenseitigen Vorgaben, die im Rahmen der Rechtsgrundlage zur Abgrenzung bereits geprüft wurden (s. Rn. 521, $573 \mathrm{ff}$.), im Rahmen der materiellen Rechtmäßigkeit nicht wieder aufzugreifen. Andersherum können Aspekte der Rechtsgrundlage eigenständig in die Prüfung der materiellen Rechtmäßigkeit integriert werden. ${ }^{1327}$ Die Bestimmtheit eines Verwaltungsakts (s. Rn. 706ff.) wird mitunter als allgemeiner Grundsatz im Rahmen der materiellen Rechtmäßigkeit geprüft, ${ }^{1328}$ während die Prüfung von Ermessensfehlern teilweise als eigener Punkt außerhalb der materiellen Rechtmäßigkeitsprüfung angesprochen wird.

\section{bb) Dimensionen, Perspektiven und Herausforderungen des Prüfungsaufbaus}

807 Abgesehen von den rechtlichen Vorgaben und deren Verhältnis zueinander, sind bei der Entwicklung und Auswahl eines angemessenen Prüfungsaufbaus verschiedene Aspekte zu berücksichtigen. So stellt sich zunächst die Frage, nach welchen Dimensionen sich die verschiedenen Prüfungspunkte überhaupt ordnen lassen. Zudem ist zu berücksichtigen, welche Fallfrage aus welcher Perspektive bearbeitet wird und wie sich die materielle Rechtmäßigkeitsprüfung hierein einbettet. Entscheidend für einen sinnvollen Aufbau ist nicht zuletzt, welche Ziele das Prüfungsschema verfolgen soll, wie es zur Erreichung dieser Ziele beitragen kann und welche konkreten Herausforderungen in der Prüfung es durch das Schema zu bewältigen gilt.

1327 So etwa Detterbeck, Allgemeines Verwaltungsrecht, 17. Aufl. 2019, Rn. 588 ff.; ZimmermannKreher/Büchner, in: Schweickhardt/Vondung, Allgemeines Verwaltungsrecht, 10. Aufl. 2018, Rn. 353.

1328 So etwa Detterbeck, Allgemeines Verwaltungsrecht, 17. Aufl. 2019, Rn. 607; Erbguth/Guckelberger, Allgemeines Verwaltungsrecht, 9. Aufl. 2018, § 14 Rn. 56; Korte, in: Wolff/Bachof u.a., Verwaltungsrecht I, 13. Aufl. 2017, § 48 Rn. 74ff.; Maurer/Waldhoff, Allgemeines Verwaltungsrecht, 19. Aufl. 2017, § 10 Rn. 52; Zimmermann-Kreher/Büchner, in: Schweickhardt/Vondung, Allgemeines Verwaltungsrecht, 10. Aufl. 2018, Rn. 353. 
Examenswissen: Jeder Versuch, alle möglichen Ordnungsdimensionen der materiellen Rechtmäßigkeitsprüfung in ihren vielfältigen Verästelungen im besonderen Verwaltungsrecht zu erfassen, ist zum Scheitern verurteilt. Gleichwohl lassen sich zentrale Aspekte nennen, die eine besondere Rolle bei der Strukturierung des Aufbaus spielen können. Zunächst lässt sich auch für den Prüfungsaufbau zwischen der grundlegenden Unterscheidung zwischen Gesetzesbindung und Verwaltungsspielraum anknüpfen: Während sich bei gebundenen Entscheidungen hieraus naturgemäß keine Ordnung ergibt, kann man bei Entscheidungen mit Spielraum einerseits zwischen den gesetzlichen Vorgaben außerhalb des Spielraums (also etwa den Tatbestandsvoraussetzungen beim Ermessen) und den Fehlern bei der Inanspruchnahme des Spielraums und andererseits zwischen den äußeren Grenzen und den inneren Grenzen (also den spezifischen Ermessens-, Beurteilungs- und Bewertungsfehlern) des Spielraums unterscheiden. Auf einer ganz anderen Ebene lässt sich an die Allgemeinheit der Prüfungspunkte anknüpfen: Die allgemeinen Grundsätze, die ohne Blick auf das jeweilige Rechtsgebiet stets oder regelmäßig zu berücksichtigen sind, lassen sich mit vielfältigen Zwischenstufen von allgemeinen Vorgaben des jeweiligen Rechtsgebiets oder Verwaltungsakttyps und den besonderen Vorgaben der Rechtsgrundlage für die spezielle Maßnahme unterscheiden, während sonstige gesetzliche Vorgaben je nach Situation eher den allgemeinen oder den besonderen Prüfungspunkten nahestehen können. Eine grundlegende Unterscheidung lässt sich auch zwischen den Tatbestandsvoraussetzungen und der Rechtsfolge machen (vgl. Rn. 553, 715). Daneben finden sich weitere thematisch abgrenzbare Bereiche, so etwa die Betrachtung der Adressatenauswahl in Abgrenzung zum Inhalt der Maßnahme. Keine dieser Ordnungsdimensionen ist zwingend relevant oder hilfreich, mitunter kann eine Abgrenzung schwerfallen oder sich der Trennschärfe entziehen.

Examenswissen: Ein sinnvoller Aufbau kann zudem von der übergeordneten Fallfrage abhängen. Dabei ist insbesondere zwischen den verschiedenen Prüfungsperspektiven zu unterscheiden. Die klassische juristische Prüfungsperspektive ist die Perspektive der kontrollierenden Instanz. Diese Perspektive blickt allein auf die Rechtmäßigkeit der konkreten Maßnahme. Insbesondere das Verwaltungsgericht in der Anfechtungsklage nimmt diese Perspektive ein, aber auch die Widerspruchsbehörde oder die Verwaltung bei der letzten Rechtskontrolle vor Erlass des konkreten Verwaltungsakts. Eine andere Perspektive blickt auf die erreichbaren Ziele in Bezug auf den Verwaltungsakt, so etwa aus der Sicht eines beratenden Anwalts. Diese Folgenperspektive blickt auf die materielle Rechtmäßigkeit des Verwaltungsakts nicht als Selbstzweck, sondern zur Erreichung anderweitiger Ziele. Auch wenn die Rechtmäßigkeit auch insoweit oftmals entscheidend ist, kann diese Perspektive weitergehende Differenzierungen, die im Hinblick auf weitere Folgen relevant sind, verlangen oder aber auf genauere Abgrenzungen verzichten, wenn diese für die Rechtmäßigkeit, nicht aber für die Zielerreichung relevant sind. Eine weitere wichtige Perspektive ist die Auswahlperspektive. Dies ist insbesondere die Perspektive der Verwaltung, die einen Verwaltungsakt erlassen möchte. Aus dieser Perspektive grenzt die Rechtmäßigkeitsprüfung den möglichen Handlungsspielraum ein, während der konkrete erlassene Verwaltungsakt als Bezugspunkt der Prüfung ausfällt.

Examenswissen: Zudem stellt sich die Frage, welche Ziele der Aufbau erreichen und welche Herausforderungen er konkret bewältigen soll. Die unterschiedlichen Aufbaumöglichkeiten sprechen die Ziele und Herausforderungen in unterschiedlicher Weise an. Je nachdem, welche Ziele für den jeweiligen Rechtsanwender im Vordergrund stehen und welche speziellen Probleme gerade zu bewältigen sind, kann der Aufbau der Prüfung also sehr unterschiedlich ausfallen. Bei der Prüfung der materiellen Rechtmäßigkeit sind dabei neben allgemeinen Zielen jeder Schemabildung (klare, leicht zu erlernende Struktur mit deutlichen Hinweisen auf die Prüfungsin- 
halte; Bezug zu den maßgeblichen gesetzlichen Vorgaben; Informationsgehalt und Flexibilität des Schemas) und den Besonderheiten des jeweiligen Rechtsgebiets auch übergreifende Herausforderungen des Verwaltungsrechts zu berücksichtigen, insbesondere das Verhältnis zwischen den Ermessensgrenzen und anderen rechtlichen Bindungen und deren mitunter klare Abgrenzung sowie die Vielfalt möglicher Anknüpfungspunkte für die Prüfung von (Ermessens-) Fehlern. Insbesondere im Rahmen der Ausbildung sollten Schemata vermieden werden, die Missverständnisse hinsichtlich der Struktur der materiellen Rechtsmäßigkeit eines Verwaltungsakts und seiner Rechtskontrolle fördern.

\section{cc) Schema-Angebote und deren Vor- und Nachteile}

811 Um die Verortung einzelner rechtlicher Vorgaben im Prüfungsaufbau zu verorten, sich die Vielfalt der Aufbaumöglichkeiten vor Augen zu führen und die Unterschiede reflektieren zu können, ist es sinnvoll verschiede Schema-Angebote zu vergleichen. Während Anfänger im Verwaltungsrecht in Prüfungsschemata im Wesentlichen Anleitungen zur Ordnung des Gelernten und seiner Anwendung in einem stringenten gutachterlichen Gedankengang suchen, müssen geübte Rechtsanwender ihren Prüfungsaufbau reflektieren können, um ihn sinnvoll zu entwickeln und an den Fall anzupassen. Selbst wenn für Anfänger eine breite Auseinandersetzung mit unterschiedlichen Aufbauansätzen eher verwirrend und kontraproduktiv sein kann, ist auch für sie das Wissen um unterschiedliche Aufbaumöglichkeiten wichtig, da sonst bloße Variationen im Aufbau, auf die sie unvermeidbar treffen, schnell als widersprüchlich oder gänzlich neue Lernmasse missverstanden werden.

812 Vor diesem Hintergrund werden hier als Alternativen zum hier zu Grunde gelegten Aufbau einige typische Aufbauschemata für die Prüfung der materiellen Rechtmäßigkeit dargestellt, einschließlich kurzer Reflexionen zu den Vorteilen, Nachteilen und Gefahren bei der Verwendung gerade dieser Strukturierungen. Nicht hingegen sollen die folgenden Darstellungen eine klare Orientierung anhand klarer Vorgaben vermitteln; bei einer Auseinandersetzung mit diesem Ziel hätten die folgenden Ausführungen wohl eher (kontraproduktiv) erschlagende Wirkung. ${ }^{1329}$ Angesichts des Variantenreichtums gerade im Hinblick auf das besondere Verwaltungsrecht kann diese Darstellung natürlich nicht vollständig sein. Aus Gründen der Übersichtlichkeit wird auf alle Schemata verzichtet, die die Grenze der materiellen Rechtmäßigkeit anders ziehen (weder die Bestimmtheit noch die gesetzliche Grundlage werden daher hier erfasst, während die Ermessensfehler in die materielle Rechtmäßigkeitsprüfung integriert sind). Ein beson-

1329 Für eine klare Orientierung lässt sich besser an den hier zu Grunde gelegten Aufbau oder an die vielfältigen anderweitigen Angebot anknüpfen. 
deres Augenmerk liegt dabei auf der Verortung der Verhältnismäßigkeit, der Fehlerlehre und der Verwaltungsaktbefugnis, mit der viele Rechtsanwender besondere Schwierigkeiten haben.

Die Vorstellung der Aufbauvarianten folgt dabei den grundsätzlichen Unterscheidungen zwischen Voraussetzung und Rechtsfolge einerseits und zwischen inhaltlichen Vorgaben und spezifischen Fehlern andererseits. In der ersten Gruppe, die zwischen den Voraussetzungen des Erlasses des Verwaltungsakts und den Rechtsfolgen trennt, wird dabei mit Blick auf § 114 Satz 1 VwGO die Ermessensfehlerlehre den Rechtsfolgen zugeordnet.

Wird die Trennung zwischen Voraussetzungen und Rechtsfolgen dem Aufbau zu Grunde gelegt, bedarf es keiner Abgrenzung zwischen verschiedenen Arten von Ermessensfehlern, was die Prüfung entlastet. Auch die Verhältnismäßigkeitsprüfung ist den Rechtsfolgen zuzuordnen, da sie nur mit Blick auf den konkreten Inhalt des Verwaltungsakts erfolgen kann. Andererseits verlangen entsprechende Ansätze die Abgrenzung zwischen Tatbestandsmerkmalen und rechtsfolgenbezogenen Regelungen, was mit eigenen Schwierigkeiten verbunden sein kann und vor dem Hintergrund anderweitiger Abgrenzungsbedürfnisse und Ordnungsüberlegungen nicht immer übersichtlich und mitunter auch nicht völlig stringent umzusetzen ist. Aus der (Auswahl-)Perspektive der Verwaltung ist ein solcher Ansatz insbesondere im Zusammenhang mit Ermessensspielräumen geboten, da für sie die Prüfung der Erlassvoraussetzungen und die Betrachtung der Grenzen möglicher Ausgestaltungen des Verwaltungsakts gänzlich unterschiedliche Operationen sind.

Materielle Rechtmäßigkeit:

a) Voraussetzungen (inkl. Tatbestandsmerkmale, weitere Vorgaben)

b) Rechtsfolgen (inkl. Verwaltungsaktbefugnis, Ermessensfehler, weitere Vorgaben)

Die einfachste Art, die Trennung zwischen Voraussetzungen und Rechtsfolgen in einem Prüfungsschema umzusetzen, ist die Gliederung allein nach Voraussetzungen und Rechtsfolgen, wobei alle zu prüfenden Prüfungspunkte einem der beiden Gliederungspunkte zuzuordnen sind. In die Voraussetzungen fallen dann die Tatbestandsmerkmale der Rechtsgrundlage sowie alle weiteren Prüfungspunkte, die den Erlass des Verwaltungsakts betreffen. Den Rechtsfolgen sind neben den gesetzlich angeordneten Rechtsfolgen bzw. den Ermessensfehlern weitere gesetzliche Vorgaben, die die konkrete Rechtsfolge betreffen, zuzuordnen. Der Vorteil dieses Schemas ist offensichtlich seine klare Struktur. Weitere Anpassungen lassen sich dann für spezielle Rechtsgebiete und Maßnahmen vornehmen. Der Nachteil ist offensichtlich, dass es kaum zusätzliche Strukturen oder 
Informationen vermittelt. Zudem ist - insbesondere im Hinblick auf die außerhalb der Rechtsgrundlage liegenden rechtlichen Vorgaben - nicht immer klar, ob einzelne Prüfungspunkte zu den Voraussetzungen oder den Rechtsfolgen gehören; die entsprechenden Abgrenzungen und Zuordnungen können daher trotz geringen Gewinns sehr aufwendig sein bzw. willkürlich erscheinen.

816 Materielle Rechtmäßigkeit:

a) Tatbestand

b) Rechtsfolgen (inkl. Verwaltungsaktbefugnis, Ermessensfehler)

c) Sonstiges Recht

Statt allein zwischen Voraussetzungen und Rechtsfolgen $\mathrm{zu}$ trennen, lassen sich zunächst der Tatbestand und die Rechtsfolge der Rechtsgrundlage prüfen, bevor weitere rechtliche Vorgaben in den Blick genommen werden. Auch dieses Grundschema hat eine klare Struktur, die zudem stärker an den rechtlichen Regelungen orientiert ist. Gleichzeitig bedarf es nicht der Zuordnung sonstiger rechtlicher Vorgaben zu Voraussetzungen oder Rechtsfolgen. Nicht umsonst ist diese Aufbauvariante sehr verbreitet (vgl. Rn. 533). Allerdings bleiben Abgrenzungs- bzw. Zuordnungsprobleme bestehen. Denn nicht bei allen Prüfungspunkten liegt eine Zuordnung zu den Vorgaben der Rechtsgrundlage und dem sonstigen Recht auf der Hand. Insbesondere allgemeine Grundsätze, lassen sich mitunter als (ggf. ungeschriebener) Teilaspekt der Rechtsgrundlage oder aber als sonstiges Recht verstehen. Eine spezialgesetzliche Positivierung der Verhältnismäßigkeit (wie etwa im Polizei- und Ordnungsrecht) erscheint eher als Regelung der Rechtsfolge, während das Aufgreifen von Grundrechten in der Verhältnismäßigkeitsprüfung eher auf das sonstige Recht verweist, ohne dass eine Differenzierung hinsichtlich des Prüfungsaufbaus gewinnbringend erscheint. Ferner ist es möglich, die Verhältnismäßigkeit im Rahmen der Ermessensüberschreitung zu prüfen. Zudem ergibt sich ein Stringenzproblem, wenn im Rahmen der Rechtsfolgen die Ermessensüberschreitung abschließend geprüft wird, äußere Grenzen des Ermessens sich aber auch aus dem sonstigen Recht ergeben können. Insgesamt lädt dieser Aufbau im Detail zu manchen Missverständnissen und Verwirrungen ein, gerade bei Studierenden, die gerade beginnen, sich vertieft mit dem Verwaltungsrecht auseinanderzusetzen. Und schließlich bleibt gerade der klare Aufbau so generell, dass in ihm wichtige Prüfungspunkte, insbesondere wenn sie weder klar den Tatbestandsmerkmalen noch den sonstigen Vorgaben zuzuordnen sind, leicht vergessen werden. 
Materielle Rechtmäßigkeit:

a) Tatbestand

b) Sonstiges Recht

c) Rechtsfolgen (inkl. Verwaltungsaktbefugnis, Ermessensfehler)

Zum Teil lassen sich die Probleme der letzten Aufbauvariante beheben, indem das sonstige Recht noch vor den Rechtsfolgen der Rechtsgrundlage angesprochen wird. Zuvorderst wird die Stringenz der Prüfung unterstützt, wenn im Rahmen der Ermessensüberschreitung nur noch Punkte angesprochen werden müssen, die nicht bereits im Rahmen des sonstigen Rechts abschließend geprüft wurden bzw. die Prüfung der Ermessensfehler auf alle noch ausstehenden äußeren und inneren Grenzen ausgedehnt werden kann, um die Prüfung umfassend abschließen zu können. Dieser Aufbau spiegelt die dogmatische Struktur der Prüfung auch deutlich besser wider. Das Vorgehen ist in der praktischen Prüfung jedoch oftmals mit erheblichen Nachteilen verbunden, während der Gewinn an Stringenz kaum Vorteile in der Prüfungspraxis vermittelt: Tatbestand und Rechtsfolge der Rechtsgrundlage sind häufig eng miteinander verzahnt und die Prüfung der Rechtsfolge ist regelmäßig auf enge inhaltliche Verweise auf die Prüfung des Tatbestands angewiesen. Die Prüfung des sonstigen Rechts zwischen Tatbestand und Rechtsfolge bricht diesen engen Zusammenhang sowohl in der Darstellung als auch der zu Grunde liegenden Gedankenführung auf, was zu Verwirrungen und einem Qualitätsverlust in der rechtlichen Argumentation führen kann.

Materielle Rechtmäßigkeit:

a) Tatbestand

b) Rechtsfolgen in Bezug auf äußere Grenzen (inkl. Verwaltungsaktbefugnis, Ermessensüberschreitung, weitere Vorgaben)

c) Rechtsfolgen in Bezug auf innere Grenzen (inkl. Ermessensnichtgebrauch, Ermessensfehlgebrauch)

Eine weitere Variation der Untergliederung in Voraussetzungen und Rechtsfolgen ist die Trennung zwischen Tatbestand der Rechtsgrundlage, den äußeren Grenzen des Ermessens und den inneren Grenzen des Ermessens. Erlassvoraussetzungen, die nicht dem Tatbestand zuzuordnen sind, können in diesem Schema als äußere Grenze des Ermessens geprüft werden. Innerhalb der Prüfung der äußeren Ermessensgrenzen können die einzelnen Prüfungsaspekte jenseits des Tatbestands flexibel geordnet werden. Dieser Aufbau folgt relativ klaren Abgrenzungslinien, ohne dass Abgrenzungsfehler schwerwiegende Folgen zeitigen oder Missverständnisse provozieren. Gleichzeitig spiegelt er auch überzeugend die unterschiedlichen Kontrollstufen wider. Der aus theoretischer Sicht sinnvolle Aufbau, 
ist in der praktischen Anwendung jedoch unnötig kompliziert. Jedenfalls aus Kontrollsicht erscheinen die Abgrenzungen zwischen den verschiedenen Gliederungspunkten unnötig. Und innerhalb der Gliederungspunkte kann der Aufbau die Prüfung nicht weiter anleiten. Gerade für Anfänger scheint der Ansatz auch weniger geeignet, weil er bereits ein vertieftes Verständnis der dogmatischen Struktur der materiellen Rechtmäßigkeitsprüfung voraussetzt.

819 Materielle Rechtmäßigkeit:

a) Verwaltungsaktbefugnis

b) Tatbestand

c) Adressat

d) Rechtsfolgen (inkl. Ermessensfehler)

e) Sonstiges Recht (inkl. allgemeine Grundsätze)

Dem geringen Informationsgehalt der groben Schemata kann entgegengewirkt werden, indem einzelne Punkte aus den allgemeineren Prüfungspunkten ausgegliedert werden bzw. einzelne Punkte schon im Schema fest bestimmten Gliederungspunkten zugeordnet werden. Die Prüfung gewinnt an Ordnung und der Aufbau sichert ab, dass wesentliche Punkte auch erfasst werden. Dementsprechend folgen die meisten üblichen Schema-Angebote (für die hier nur ein Beispiel angegeben wird) diesem Pfad. Der Gewinn an Kontur ist jedoch auch mit Gefahren verbunden: Je mehr Punkte im Schema explizit angesprochen werden, desto eher werden ungenannte (seltene) Punkte in der Prüfung übersehen; wird ein detailliertes Schema angewandt, ohne es inhaltlich zu verstehen, können die entsprechenden Missverständnisse schnell auf das inhaltliche Verständnis durchschlagen (etwa wenn die klare Zuordnung der Verhältnismäßigkeit in der Gliederung als materielle Einordnung verstanden wird); der Aufwand für die Aneignung erhöht sich; die Flexibilität insbesondere im Hinblick auf die besonderen Anforderungen bestimmter Rechtsgebiete nimmt ab, was dann die zusätzliche Aneignung weitere Ausnahmen und Spezialfälle verlangt. Und schließlich ist jede Entscheidung für die Gliederung des Schemas im Detail mit den gleichen Problemen wie die entsprechende Grobgliederung verbunden.

820 Schemata, die die Differenzierung zwischen inhaltlichen Vorgaben und spezifischen Fehlern bei der Inanspruchnahme von Verwaltungsspielräumen in den Vordergrund rücken, können alle äußeren Grenzen des Verwaltungsakts einheitlich behandeln, während eine Abgrenzung zwischen (Ermessens-)Spielraumüberschreitungen und spezifischen Fehlern nötig wird. Der Wegfall der Unterscheidung zwischen Voraussetzungen und Rechtsfolgen entlastet die Prüfung hinsichtlich der Abgrenzung einschließlich möglicher Abgrenzungsfehler und Missverständnisse. So lässt sich die Verhältnismäßigkeit umstandslos ei- 
genständig prüfen, ohne dass ein Bedürfnis nach einer verwirrenden Zuordnung besteht. Zudem wird die Prüfung direkt flexibler und erlaubt es situationsbezogen bestimmte Prüfungspunkte zusammenzustellen oder zu differenzieren; nicht zuletzt deshalb liegt ein entsprechender Ansatz gerade vielen Prüfungsschemata im besonderen Verwaltungsrecht zu Grunde. Die klare Ausrichtung am Kontrollmaßstab entspricht außerdem der dogmatischen Struktur der Rechtmäßigkeitsprüfung. Für die Auswahlperspektive der Verwaltung ist dieser Aufbauansatz hingegen ungeeignet, da es das Vorgehen der Behörde nicht vernünftig abbilden kann. Schon allein deshalb sind entsprechende Schemata unpassend, wenn man einen einheitlichen Aufbau für unterschiedliche Perspektiven vorzieht.

Materielle Rechtmäßigkeit:

a) Themenkomplex $\mathrm{A}$

aa) Inhaltliche Vorgaben

bb) Spezifische Ermessensfehler

b) Themenkomplex B (z.B. Adressaten)

aa) Inhaltliche Vorgaben

bb) Spezifische Ermessensfehler

Die Flexibilität eines Aufbaus ohne grundlegende Unterscheidung zwischen Voraussetzungen und Rechtsfolgen wird deutlich, wenn die Struktur auf der ersten Gliederungsebene bestimmten Themenkomplexen folgt und erst hierunter zwischen der Prüfung der inhaltlichen Vorgaben und den spezifischen Fehlern bei der Inanspruchnahme eines Spielraums unterschieden wird. Die so möglichen thematischen Bündelungen erlauben es, die Prüfung der spezifischen Fehler eng auf die damit verbundenen inhaltlichen Prüfungspunkte zu beziehen. Die Vorteile eines solchen Vorgehens werden etwa im Hinblick auf die Adressatenauswahl deutlich; die Prüfung möglicher Fehler bei der Adressatenauswahl künstlich zwischen rechtlichen Vorgaben zur Adressatenauswahl und möglichen Fehlern beim Ermessen aufzuteilen erscheint aufwendig und eher verwirrend. Eine thematische Gliederung ist jedoch nicht immer sinnvoll. Und es ist auch überdeutlich, dass dieses sehr abstrakte Schema kaum mit weiterer Kontur oder eigenen Lerneffekten verbunden ist. Als Schema erscheint dieser Aufbau weniger geeignet; er erscheint vielmehr als abstrakter Rahmen zur Schemabildung (etwa im besonderen Verwaltungsrecht).

Materielle Rechtmäßigkeit:

a) Allgemeine Vorgaben des Gesetzes

b) Spezielle Vorgaben der Rechtsgrundlage

c) Allgemeine Grundsätze und sonstiges Recht

d) Spezifische Ermessensfehler 
Ein anderer Ausdruck der Flexibilität, der sich daraus ergibt, die Unterscheidung zwischen Voraussetzungen und Rechtsfolgen nicht in den Vordergrund des Aufbaus zu stellen, ist die konsequente Entwicklung des Aufbaus entlang der Allgemeinheit der rechtlichen Vorgaben. Dabei kann grob - und im Detail flexibel variierbar - zwischen den speziellen inhaltlichen Vorgaben der jeweiligen Rechtsgrundlage, den allgemeinen Vorgaben zum jeweiligen Rechtsgebiet (also insbesondere des allgemeinen Teils des entsprechenden Gesetzes) sowie den allgemeinen Grundsätzen und sonstigen rechtlichen Vorgaben unterschieden werden. Dabei können sich die inhaltlichen Vorgaben jeweils sowohl auf den Tatbestand bzw. die Erlassvoraussetzungen als auch die äußeren Grenzen des Ermessens richten. Dieser Aufbau ermöglicht es, für bestimmte Rechtsgebiete einen einheitlichen Aufbautorso zu entwickeln, der für die konkrete Rechtsgrundlage ergänzt wird, gleichzeitig aber auch sonstige rechtliche Regelungen und insbesondere die allgemeinen Rechtsgrundsätze umstandslos integrieren kann. Die Prüfung spezifischer Fehler lässt sich dann am Schluss mit beliebigem Bezug zu den vorherigen Prüfungen für die verschiedenen Spielräume nacheinander durchführen. Auch dieser Aufbau bleibt jedoch ohne konkreten Bezug zu einem konkreten Rechtsgebiet sehr abstrakt und stellt wenige Informationen zu konkreten Prüfungspunkten zur Verfügung; er stellt also ebenfalls eher einen Rahmen zur Schemabildung als ein eigenes Schema dar.

Wie bei der grundsätzlichen Gliederung nach Voraussetzungen und Rechtsfolge, kann auch ein Aufbau ohne diese Unterscheidung im weiten Umfang einzelne Punkte besonders betonen oder eigenständig ansprechen; dem folgt auch der hier zu Grunde gelegte Aufbau. Da eine sinnvolle Gliederung jedoch wesentlich von den konkreten Umständen der Prüfungssituation und insbesondere dem jeweiligen Rechtsgebiet des besonderen Verwaltungsrechts abhängt, ist auf der allgemeinen Ebene kaum ein universell überzeugendes Schema zu entwickeln. Wichtiger ist es, ein grundlegendes Prüfungsschema zu finden, dessen Grundlage man auch dogmatisch nachvollziehen kann und das dabei einerseits so offen formuliert ist, dass es für speziellere Situationen weiterentwickelt werden kann, und andererseits wesentliche Prüfungspunkte, die sonst leicht übersehen werden könnten, betont. Wichtiger noch als ein sinnvolles und gut erlernbares Prüfungsschema bleibt ohnehin, die einzelnen Prüfungspunkte sauber aus den rechtlichen Vorgaben $\mathrm{zu}$ entwickeln und stringent aufeinander $\mathrm{zu}$ beziehen. Insbesondere in Bezug auf die Verhältnismäßigkeitsprüfung ist weniger die Verortung (in den allgemeinen Grundsätzen, den Ermessensgrenzen, dem Tatbestand etc.) als vielmehr die saubere, strukturierte Prüfung mit klarem Bezug zur rechtlichen Grundlage ausschlaggebend.

824

Besonders herausfordernd wird der Prüfungsaufbau, wenn auch ein Beurteilungsspielraum (oder gar ein Bewertungsspielraum) mitzuberücksichtigen Daniel Benrath 
ist. Insbesondere auf Grundlage eines Schemas, das die Voraussetzungen von den Rechtsfolgen trennt, ist hier erhöhte Wachsamkeit geboten. Denn während die Fehlerprüfung hier im Normalfall im Rahmen der Rechtsfolgen erfolgt, bezieht sich die Beurteilung und damit auch mögliche Beurteilungsfehler auf die Voraussetzungen. Dies lässt sich dadurch auffangen, dass mögliche Beurteilungsfehler im Rahmen des jeweiligen Tatbestandsmerkmals angesprochen werden (das bei Beurteilungsfehlern eben nicht der weiteren Prüfung zu Grunde gelegt werden kann). Dieses Vorgehen führt jedoch zu einer komplizierten Inzidentprüfung und ist nur schwer stringent $\mathrm{zu}$ formulieren. Alternativ lässt sich die Beurteilung bei der Prüfung des Tatbestands voraussetzen, um etwaige Beurteilungsfehler eigenständig zu einem späteren Zeitpunkt (insbesondere nach der Prüfung der Rechtsfolgen) zu prüfen. Dieser Aufbau sichert Stringenz und Übersichtlichkeit, erscheint aber kontraintuitiv. Verzichtet man auf die Trennung zwischen Voraussetzungen und Rechtsfolgen, mildert dies die Schwierigkeiten im Aufbau ab. Die Prüfung von Beurteilungsfehlern im Rahmen des Tatbestandsmerkmals ist ebenso möglich wie als eigenständiger spezifischer Fehler (wie hier).

\section{f) Maßgeblicher Zeitpunkt der Rechtmäßigkeitsprüfung}

Verwaltung und Rechtsprechung sind an das geltende Recht gebunden. Es ist also 825 stets das zum Zeitpunkt der jeweiligen Entscheidung geltende Recht anzuwenden. Aus der Verwaltungsperspektive ist die maßgebliche Entscheidung der Erlass des Verwaltungsakts. In der Anfechtungsklage ist für die Beurteilung der Sach- und Rechtslage der Zeitpunkt des verwaltungsgerichtlichen Urteils (grundsätzlich also das Ende der letzten mündlichen Verhandlung, vgl. §§ 101, 116 VwGO) maßgeblich. ${ }^{1330}$

Davon zu unterscheiden ist die Frage, auf welche Sach- und Rechtslage sich die

gerichtliche Rechtskontrolle bezieht (s. hierzu ausführlicher Rn. $539 \mathrm{ff}$.). ${ }^{1331}$ Dies ist eine inhaltliche Rechtsfrage, die gegebenenfalls durch Auslegung aus dem geltenden materiellen Recht herzuleiten ist. ${ }^{1332}$ Da die Gerichte die behördliche Tätigkeit kontrollieren, kommt es zur Beurteilung der materiellen Rechtmäßigkeit des Verwaltungsakts regelmäßig auf das maßgebliche Recht zum Zeitpunkt der letzten behördlichen Entscheidung (bei einem Vorverfahren also auf die Bekanntgabe des

1330 Riese, in: Schoch/Schneider/Bier, VwGO, 36. EL Februar 2019, § 113 Rn. 236.

1331 Instruktiv Baumeister, Jura 2005, 655; Gärditz/Orth, Jura 2013, 1100.

1332 BVerwG, Urt. v. 31.3.2004, Az.: 8 C 5/03 = BVerwGE 120, 246, Rn. 35 m.w. N.; Decker, in: Posser/Wolff, VwGO, 50. Ed., Stand: 1.7.2019, § 113 Rn. 21 m.w. N. Kritisch hierzu Hufen, Verwaltungsprozessrecht, 11. Aufl. 2019, § 24 Rn. 7. 
Widerspruchs) an. ${ }^{1333}$ Hierzu können sich jedoch Ausnahmen ergeben, insbesondere wenn nachträgliche Gesetze eine Rückwirkung anordnen, vermögensrechtliche Zuordnungen durch das aktuelle Gesetz abschließend geklärt werden sollen ${ }^{1334}$ oder wenn sich ein Verwaltungsakt auf die Gestaltung von Rechtsbeziehungen (auch) in der Zukunft richtete (insbesondere Dauerverwaltungsakte ${ }^{1335}$ ) und diese Ausgestaltung durch erhebliche Veränderungen nachträglich rechtswidrig wurde.

\section{g) Literaturhinweise}

827 Bull/Mehde, Allgemeines Verwaltungsrecht mit Verwaltungslehre, 9. Aufl. 2015, $\S \S 4,16,29$; Detterbeck, Allgemeines Verwaltungsrecht mit Verwaltungsprozessrecht, 17. Aufl. 2019, §§ 6, 8, 10; Erbguth/Guckelberger, Allgemeines Verwaltungsrecht mit Verwaltungsprozess- und Staatshaftungsrecht, 9. Aufl. 2018, § 14; Peine/Siegel, Allgemeines Verwaltungsrecht: Lehrbuch, Entscheidungen, Gesetzestexte, 12. Aufl. 2018, §§ 7, 8, 13

Lehrvideo: Fannipour/Schmidt/Schneider, Peer2Peer-Lehrvideo Ermessen: Ausübung und Fehler, abrufbar unter https://youtu.be/iF51NQInEew

\section{Verletzung subjektiver Rechte (Nikolas Eisentraut)}

828 Sollte sich der Verwaltungsakt als rechtswidrig herausstellen, muss nach § 113 I 1 VwGO abschließend noch untersucht werden, ob der Kläger durch die Rechtswidrigkeit des Verwaltungsakts auch in seinen subjektiven Rechten verletzt ist. Als „materielles Gegenstück ${ }^{\text {“1336 }}$ der Klagebefugnis ist hier nicht mehr nur die Möglichkeit einer Rechtsverletzung zu prüfen, diese muss an dieser Stelle auch tatsächlich bejaht werden können. Auch in § 113 I 1 VwGO findet der Gedanke Ausdruck, dass rechtswidriges Handeln nicht von jedem Bürger gerügt werden darf, sondern nur durch denjenigen, der auch in seinen subjektiven Rechten verletzt ist. ${ }^{1337}$

Examenswissen: Dieser Gedanke hat eine verfassungsrechtliche Wurzel: Art. 19 IV 1 GG zwingt zur Eröffnung eines Rechtswegs nur dann, wenn jemand durch die öffentliche Gewalt in seinen Rechten verletzt ist. Dieses Recht ist einfach-rechtlich als Begrenzung des Zugangs zu den Ge-

1333 Decker, in: Posser/Wolff, VwGO, 50. Ed., Stand: 1.7.2019, § 113 Rn. 22 m.w. N. 1334 Vgl. BVerwG, Urt. v. 31.3.2004, Az.: 8 C 5/03 = BVerwGE 120, 246, Rn. $36 \mathrm{ff}$.

1335 Decker, in: Posser/Wolff, VwGO, 50. Ed., Stand:1.7.2019, § 113 Rn. 22.9 m.w. N.

1336 Hufen, Verwaltungsprozessrecht, 11. Aufl. 2019, § 25 Rn. 41.

1337 Decker, in: Posser/Wolff, VwGO, 50. Ed., Stand:1.7.2019, § 113 Rn. 16.

Daniel Benrath/Nikolas Eisentraut 
richten in § 42 II, 113 I 1 VwGO ausgestaltet worden. ${ }^{1338}$ Der deutschen Rechtsordnung liegt damit das sog. Prinzip der Verletztenklage zugrunde; in anderen Mitgliedstaaten der Europäischen Union reicht bereits ein (nicht notwendig rechtliches) „berechtigtes Interesse“. ${ }^{1339}$

Art. 19 IV 1 GG setzt das Bestehen subjektiver Rechte voraus und begründet diese nicht. ${ }^{1340}$ Wann dem Bürger ein sog. subjektives öffentliches Recht zusteht, ist eine im Verwaltungsrecht intensiv diskutierte Frage, weil die Verwaltung zunächst einmal im öffentlichen Interesse und nicht im Interesse Einzelner tätig wird. ${ }^{1341}$ Mit der herrschenden Schutznormtheorie ist danach zu fragen, ob eine Norm auch dem Interesse des einzelnen Bürgers zu dienen bestimmt ist; der Interessenschutz muss dabei gesetzlich bezweckt worden sein. ${ }^{1342}$ Neben Grundrechten kommen als subjektive öffentliche Rechte auch Normen des einfachen und des administrativen Rechts in Betracht. ${ }^{1343}$ In abwehrrechtlichen Konstellationen kommt Art. 2 I GG zentrale Bedeutung $\mathrm{zu}$, denn diese Norm vermittelt ein subjektives Recht darauf, nicht Adressat rechtswidrigen, in die Handlungsfreiheit eingreifenden Verwaltungshandelns zu werden (Adressatentheorie). In Leistungskonstellationen ist der Begründungsaufwand hingegen höher, weil die Grundrechte jedenfalls nicht typischerweise auch Leistungsansprüche begründen. ${ }^{1344}$ Hier ist mit der Schutznormtheorie zu untersuchen, ob die streitentscheidenden Normen auch als Anspruchsgrundlagen taugen (näher zu den Anspruchsgrundlagen bei der Verpflichtungsklage § 3 Rn. $62 \mathrm{ff}$. und bei der allgemeinen Leistungsklage $\S 5 \mathrm{Rn}$. $55 \mathrm{ff}$.).

In Fällen, in denen die Adressatentheorie Anwendung findet (dazu bereits Rn. 294f.), ist die Bejahung der Verletzung subjektiver Rechte im Rahmen der Anfechtungsklage mit einem Satz abzuhandeln. Die Rechtswidrigkeit des Verwaltungsakts führt hier dazu, dass der Adressat des belastenden, rechtswidrigen Verwaltungsakts in seinem subjektiven Recht aus Art. 2 I GG verletzt ist. ${ }^{1345}$

Eines besonderen Begründungsaufwands bedarf es hingegen in Drittan-

fechtungskonstellationen. Bereits in der Klagebefugnis bei Drittanfechtungsklagen ist der Begründungsaufwand erhöht, weil die Adressatentheorie leer läuft. Dort muss die Möglichkeit eines subjektiven Rechts ausführlich begründet werden (s. dazu Rn. 296f.). Dieser Aufwand muss sich beim Prüfungspunkt „Verletzung subjektiver Rechte“ spiegeln. Hier muss dargelegt werden, dass die zur Rechtswidrigkeit des Verwaltungsakts führende Norm auch wirklich gerade die

1338 Maurer/Waldhoff, Allgemeines Verwaltungsrecht, 19. Aufl. 2017, § 8 Rn. 5.

1339 Peine/Seigel, Allgemeines Verwaltungsrecht, 12. Aufl. 2018, Rn. 236.

1340 Maurer/Waldhoff, Allgemeines Verwaltungsrecht, 19. Aufl. 2017, § 8 Rn. 10.

1341 S. zur Frage des subjektiven öffentlichen Rechts ausführlich Scherzberg, in: Ehlers/Pünder, Allgemeines Verwaltungsrecht, 15. Aufl. 2016, § 12; Maurer/Waldhoff, Allgemeines Verwaltungsrecht, 19. Aufl. 2017, § 8 Rn. 1ff.; Peine/Seigel, Allgemeines Verwaltungsrecht, 12. Aufl. 2018, Rn. $233 \mathrm{ff}$.

1342 Peine/Seigel, Allgemeines Verwaltungsrecht, 12. Aufl. 2018, Rn. 239.

1343 Peine/Seigel, Allgemeines Verwaltungsrecht, 12. Aufl. 2018, Rn. $241 \mathrm{ff}$.

1344 Näher Maurer/Waldhoff, Allgemeines Verwaltungsrecht, 19. Aufl. 2017, § 8 Rn. 14.

1345 Hufen, Verwaltungsprozessrecht, 11. Aufl. 2019, § 25 Rn. 42.

Nikolas Eisentraut 
Rechte des Dritten schützt (s. beispielhaft den Fall 3 in: Eisentraut, Fälle zum Verwaltungsrecht, 2020). Ist der Verwaltungsakt aufgrund einer Norm rechtswidrig, die nicht dem Schutz der Rechte des klagenden Dritten dient, ist der Verwaltungsakt zwar rechtswidrig, aber die Klage dennoch unbegründet. ${ }^{1346}$ Teilweise werden Drittanfechtungsklagen deshalb auch nur aus dem Blickwinkel der drittschützenden Norm geprüft (dazu näher Rn. 548).

831 Hausarbeitswissen: Entsprechend zu den Ausführungen in der Klagebefugnis (s. Rn. 285) ist bei der Verbandsklage auch keine Verletzung subjektiver Rechte erforderlich. ${ }^{1347}$ Hintergrund ist das Europäische Unionsrecht, das den deutschen Gesetzgeber teilweise zu einer Abkehr von dem Prinzip der Verletztenklage gezwungen hat. ${ }^{1348}$

\section{Klausurrelevante Ermächtigungsgrundlagen und ihre Prüfung (Tobias Brings-Wiesen; Nikolas Eisentraut; Sebastian Eickenjäger; Felix Steengrafe; Sebastian Piecha; Mariamo Katharina Ilal)}

Die Prüfung bestimmter Ermächtigungsgrundlagen muss in Prüfungssituationen regelmäßig beherrscht werden. Dazu zählen insbesondere die Ermächtigungsgrundlagen des Allgemeinen Verwaltungsrechts (Rn. 832ff.), des Polizeiund Ordnungsrechts (Rn. $1000 \mathrm{ff}$.), des Versammlungsrechts (Rn. 1141ff.), des Bauordnungsrechts (Rn. 1222ff.), des Kommunalrechts (Rn. 1252ff.) sowie des Verwaltungsvollstreckungsrechts (Rn. 1292ff.).

\section{Ermächtigungsgrundlagen des Allgemeinen Verwaltungsrechts (Tobias Brings-Wiesen)}

832 Die Anfechtungsklage gemäß § 42 I Var. 1 VwGO ist das „schärfste Schwert“ des rechtsschutzbegehrenden Bürgers gegen einen Verwaltungsakt, der ihn in seinen subjektiven Rechten verletzt. Zum einen ist das Aufhebungsurteil des Gerichts unmittelbar rechtsgestaltend und beendet die Wirksamkeit eines Verwaltungsakts i.S.v. § 43 II VwVfG, ohne dass es eines erneuten Tätigwerdens der Verwaltung bedürfte (s. dazu Rn. 6). Zum anderen kann es in Rechtskraft erwachsen ${ }^{1349}$ und somit im Regelfall endgültig für Rechtssicherheit und Rechtsfrieden sorgen. ${ }^{1350}$

1346 Hufen, Verwaltungsprozessrecht, 11. Aufl. 2019, § 25 Rn. 43. 1347 Hufen, Verwaltungsprozessrecht, 11. Aufl. 2019, § 25 Rn. 49.

1348 Näher Maurer/Waldhoff, Allgemeines Verwaltungsrecht, 19. Aufl. 2017, § 8 Rn. 16.

1349 S. zur Rechtskraft Schenke, Verwaltungsprozessrecht, 16. Aufl. 2019, Rn. 615 ff.; Würtenberger/Heckmann, Verwaltungsprozessrecht, 4. Aufl. 2018, Rn. $294 \mathrm{ff}$.

Nikolas Eisentraut/Tobias Brings-Wiesen 
Für Prüfungssituationen ist die Anfechtungsklage reizvoll, weil sie mit dem Verwaltungsakt die geläufigste Handlungsform zum Gegenstand hat. Sie erlaubt es dem Prüfer, in vielerlei Hinsicht verwaltungsrechtliches Grundverständnis abzufragen.

Da die maßgeblichen materiellen Vorgaben für Verwaltungshandeln sich ganz überwiegend aus dem sachnäheren Fachrecht ergeben, kennt das allgemeine Verwaltungsrecht selbst nur sehr wenige Ermächtigungsgrundlagen. Dies sollte jedoch keineswegs zu dem Trugschluss verleiten, diese seien nicht oder auch nur weniger prüfungsrelevant. Da in ihnen die vormals ungeschriebenen allgemeinen Grundsätze des Verwaltungsrechts eine Normierung gefunden haben, sind sie Ausgangspunkt eines Grundverständnisses für die systematischen Zusammenhänge des Verwaltungsrechts. Selbst soweit sie nicht unmittelbar anwendbar sind, können die in ihnen zum Ausdruck kommenden Wertungen im Rahmen der Prüfung von Spezialnormen des besonderen Verwaltungsrechts Orientierung bieten.

Vor diesem Hintergrund ist es elementar, die für Prüfungen mit Abstand relevantesten Konstellationen der Anfechtungsklagen im allgemeinen Verwaltungsrecht $\mathrm{zu}$ verinnerlichen. Die folgenden Ausführungen widmen sich daher dem gesamten Themenkomplex der behördlichen Aufhebung von Verwaltungsakten gemäß §§ 48 ff. VwVfG sowie - in der gebotenen Kürze - der Anfechtungsklage gegen die Zusicherung auf Erlass eines Verwaltungsakts mit Drittwirkung.

\section{a) Die behördliche Aufhebung eines Verwaltungsakts gemäß $\S 48 f$. VwVfG}

Die Prüfung der Aufhebung von Verwaltungsakten gemäß §§ 48f. VwVfG ist einer 836 der Prüfungsklassiker. Ihr sollte daher in der Prüfungsvorbereitung besondere Aufmerksamkeit zuteilwerden. Die folgenden Ausführungen beschränken sich zwar expressis verbis auf die $\S \S 48 \mathrm{f}$. VwVfG. Sie behalten jedoch wegen der weit überwiegend bestehenden Wortgleichheit auch für die VwVfGe der Länder ihre Gültigkeit. ${ }^{1351}$

1350 Auch die Aufhebung eines Verwaltungsakts gemäß $\S 38$ ff. VwVfG ist dann nur noch in begrenzten Ausnahmefällen denkbar, vgl. nur VGH Mannheim, Urt. v. 18.6.2008, Az.: 13 S 2809/ 07 = BeckRS 2008, 37311, Rn. 33ff.; s. auch J. Müller, in: Bader/Ronellenfitsch, VwVfG, 44. Ed., Stand: 1.1.2019, § 48 Rn. 37.

1351 Vgl. dazu nur die überschaubaren Hinweise auf abweichendes Landesrecht vor den Kommentierungen zu den §§ 48f. VwVfG bei Sachs, in: Stelkens/Bonk/Sachs, VwVfG, 9. Aufl. 2018. 

eines Verwaltungsakts i. S.v. § 43 II VwVfG (s. bereits Rn. 181). Davon abzugrenzen sind:

- die behördliche Aufhebung eines Verwaltungsakts am Ende eines Vorverfahrens ( $§ 72 \mathrm{VwGO}$ ), das sich ausschließlich nach den $\S \S 68 \mathrm{ff}$. VwGO richtet (s. dazu Rn. $301 \mathrm{ff}$ );

- (zumindest nach herrschender Meinung) die behördliche Aufhebung eines Verwaltungsakts in Folge des Wiederaufgreifens des Verfahrens gemäß $§ 51$ VwVfG (s. dazu § 3 Rn. 120), sowie

- die gerichtliche Aufhebung eines Verwaltungsakts im Wege der Anfechtungsklage (§§ 42 I Var. 1, 113 I 1 VwGO) sowie der Verpflichtungsklage (§§ 42 I Var. 2, 113 V VwGO, in Form der Versagungsgegenklage).

838 Die behördliche Aufhebung gemäß $\S ~ 48 \mathrm{f}$. VwVfG wird wesentlich von zwei widerstreitenden Grundinteressen gelenkt, deren Ausgleich bereits der Gesetzgeber in der Ausformulierung der Vorschriften zu erreichen gesucht hat und die auch die Entscheidungen der Behörde über die Aufhebung im Einzelfall leiten: dem (schutzwürdigen) Vertrauen der Betroffenen auf den Bestand des aufzuhebenden Verwaltungsakts bzw. das objektive Interesse der Rechtssicherheit daran einerseits und dem öffentlichen Interesse an der Herstellung rechtmäßiger Zustände entsprechend dem Grundsatz der Gesetzmäßigkeit der Verwaltung andererseits (s. dazu $§ 1 \mathrm{Rn}$. 13). Diese gegenläufigen Interessen sind je nach Aufhebungskonstellation in Verbindung mit den gesetzlichen Vorgaben unter Berücksichtigung verschiedener Vorprägungen miteinander in Einklang zu bringen.

Behördliche Aufhebungen erfüllen alle Merkmale des § 35 S. 1 VwVfG (s. dazu Rn. 42 ff.) und sind daher selbst Verwaltungsakte. ${ }^{1352}$ Ihre Regelungswirkung besteht darin, die Wirksamkeit des vorangegangenen Verwaltungsakts zu beenden (§ 43 II VwVfG). Daraus folgt sowohl, dass sie den allgemeinen rechtlichen Vorgaben für Verwaltungsakte nach dem $\mathrm{VwVfG}$ zu genügen haben, als auch, dass bei Rechtsfehlern über den Widerspruch (§68 I 1 VwGO) bzw. die Anfechtungsklage (§ 42 I Var. 1 VwGO) ihre (behördliche bzw. gerichtliche) Aufhebung ersucht werden kann. Kommt es dabei zu einer „Aufhebung der Aufhebung“, hat diese das Wiederaufleben der Wirksamkeit des ursprünglichen Verwaltungsakts ex tunc zur Folge. ${ }^{1353}$

1352 So auch Maurer/Waldhoff, Allgemeines Verwaltungsrecht, 19. Aufl. 2017, §11 Rn. 20; ausführlich Sachs, in: Stelkens/Bonk/Sachs, VwVfG, 9. Aufl. 2018, § 48 Rn. $242 \mathrm{ff.}$

1353 Maurer/Waldhoff, Allgemeines Verwaltungsrecht, 19. Aufl. 2017, § 11 Rn. 20; Detterbeck, Allgemeines Verwaltungsrecht, 17. Aufl. 2019, Rn. 738; Ipsen, Allgemeines Verwaltungsrecht, 11. Aufl. 2019, Rn. 722. 
Vor diesem Hintergrund kann die Erhebung einer Anfechtungsklage gegen 840 die Aufhebungsentscheidung einer Behörde in zwei Konstellationen dem Klagebegehren entsprechen: (1) Die Behörde hat sich eigeninitiativ für die Aufhebung eines Verwaltungsakts entschieden, was zulasten eines - insbesondere bislang begünstigten - Adressaten geht; (2) die Behörde hat sich eigeninitiativ oder auf Antrag für die Aufhebung eines Verwaltungsakts mit Drittwirkung entschieden, was zwar zugunsten eines zugleich aber zulasten eines anderen Betroffenen geht. In beiden Fällen wird es regelmäßig dem Wunsch der von der Aufhebungsentscheidung belasteten Personen entsprechen, schlicht die Aufhebung aus der Welt zu schaffen, damit der sie ursprünglich begünstigende Verwaltungsakt wiederauflebt. ${ }^{1354}$

Für ein besseres Verständnis der $\S \S 48 \mathrm{f}$. VwVfG und als „Checkliste“ für 841 die Vorüberlegungen in der Prüfung sollte berücksichtigt werden, dass die beiden Vorschriften grundsätzlich fünf Differenzierungsmerkmale enthalten, die die Prüfung an verschiedenen Stellen lenken.

- Die Grundunterscheidung zwischen Rücknahme und Widerruf wird anhand der Rechtswidrigkeit bzw. der Rechtmäßigkeit ihres Bezugsobjekts, dem aufzuhebenden Verwaltungsakt, getroffen. Zumindest ausdrücklich ${ }^{1355}$ steht für die Aufhebung eines rechtswidrigen Verwaltungsakts das Mittel der Rücknahme gemäß § 48 VwVfG, für die Aufhebung eines rechtmäßigen Verwaltungsakts das Mittel des Widerrufs gemäß § 49 VwVfG zur Verfügung.

- Das schutzwürdige Vertrauen der Betroffenen auf den Bestand eines aufzuhebenden Verwaltungsakts wiegt umso schwerer, je positiver die Auswirkungen dieses Verwaltungsakts für sie sind. Daher knüpft der Gesetzgeber sowohl die Rücknahme als auch den Widerruf begünstigender Verwaltungsakte zusätzlich an die Erfüllung besonderer Tatbestandsvoraussetzungen (§ 48 I 2, II bis IV, § 49 II, III VwVfG), während die Aufhebung belastender Verwaltungsakte im ordnungsgemäßen Ermessen der Behörden steht (§ 48 I 1, § 49 I VwVfG).

- Unter den begünstigenden Verwaltungsakten kommt denen, die eine einmalige oder laufende Geldleistung oder teilbare Sachleistung (zur Erfüllung eines bestimmten Zwecks) gewähren oder hierfür Voraussetzung sind, nochmals eine Sonderstellung zu. Da es bei ihnen materiell meist ausschließlich um fiskalische Interessen geht, hält der Gesetzgeber es für

1354 Von mindestens gleicher Prüfungsrelevanz sind indes die Konstellationen, in denen Betroffene (nach Eintritt der Bestandskraft) den Erlass einer behördlichen Aufhebungsentscheidung gemäß §§ $48 \mathrm{f}$. VwVfG begehren, s. dazu noch unter $§ 3$ Rn. $96 \mathrm{ff}$.

1355 S. zur Erweiterung des Anwendungsbereichs von $\S 49$ VwVfG über eine „teleologische Erweiterung“ des Tatbestands noch Rn. 948. 
leichter erträglich, ihre Wirkung aufrecht $\mathrm{zu}$ erhalten. Aus diesem Grund knüpft er ihre Rücknahme (§ 48 II, IV VwVfG) bzw. ihren Widerruf (mit Wirkung für die Vergangenheit $§ 49$ III VwVfG) im Interesse der Vertrauensschutzes an die Einhaltung besonders strikter Tatbestandsvoraussetzungen. Die sonstigen Verwaltungsakte können hingegen grundsätzlich unter weniger strengen Anforderungen aufgehoben werden.

- Ein Verwaltungsakt kann nur ausschnittsweise Anlass für eine Aufhebung bieten. Wie die gerichtliche Aufhebung im Rahmen der Anfechtungsklage (vgl. § 113 I 1 VwGO: ,soweit“) können auch Rücknahme und Widerruf nicht nur zur vollständigen, sondern auch zur bloß partiellen Aufhebung eines Verwaltungsakts führen (vgl. § 48 I 1, § 49 I, II 1, III 1 VwVfG: „ganz oder teilweise“). Die Rechtmäßigkeit dieses Vorgehens kann bereits auf Tatbestandsebene zu thematisieren sein (vgl. § 48 II 1 VwVfG: „soweit“), sie wird jedoch insbesondere im Rahmen der ordnungsgemäßen Ermessensausübung der Behörde relevant werden.

- Die Frage einer nur begrenzten Aufhebung stellt sich jedoch nicht nur in sachlicher, sondern insbesondere auch in zeitlicher Hinsicht. Die Gründe für die Aufhebung eines Verwaltungsakts bestehen in der überwiegenden Zahl der Fälle bereits lange vor der behördlichen Entscheidung darüber. Sie können bereits im Zeitpunkt seines Erlasses vorliegen oder erst später eintreten. Wird die Behörde ihrer erst später gewahr, stellt sich die wichtige Frage einer potentiellen Rückwirkung der Aufhebung (ex tunc). § 48 VwVfG verlangt bereits im Tatbestand nach einer zeitlichen Differenzierung (§ 48 II 1 VwVfG: „soweit“; § 48 II 2 VwVfG: „wenn der Begünstigte gewährte Leistungen verbraucht oder eine Vermögensdisposition getroffen hat"), stellt die Entscheidung ansonsten aber ins Ermessen der Behörde (§ 48 I 1 VwVfG: „mit Wirkung für die Zukunft oder für die Vergangenheit"). § 49 VwVfG erlaubt einen Widerruf grundsätzlich nur mit Wirkung für die Zukunft (§ 49 I, II 1 VwVfG), nur in den Ausnahmefällen von Abs. 3 auch mit Wirkung für die Vergangenheit.

842 Bei aller hinlänglich bekannten Prüfungsrelevanz der $\S \S 48 \mathrm{f}$. VwVfG sollte nie vergessen werden, dass ihre Anwendbarkeit ausgeschlossen sein kann. Dies kann bereits der Tatsache geschuldet sein, dass entsprechend § 2 VwVfG bestimmte Sachgebiete in Gänze aus dem Anwendungsbereich des VwVfG ausgenommen sind. ${ }^{1356}$ So gelten für Verfahren nach der Abgabenordnung (§ 2 II Nr. 1 VwVfG) die $\S \S 130,172$ ff. AO; für Verfahren nach dem Sozialgesetzbuch (§ 2 II

1356 Sachs, in: Stelkens/Bonk/Sachs, VwVfG, 9. Aufl. 2018, § 48 Rn. 3; Suerbaum, in: Mann/ Sennekamp/Uechtritz, VwVfG, 2. Aufl. 2019, § 48 Rn. 13 ff.

Tobias Brings-Wiesen 
Nr. 4 VwVfG) die $§ \S 44$ ff. SGBX. Fehlen in Folge dieser Ausnahme gesetzliche Vorgaben, kann gar ein Rückgriff auf allgemeine Grundsätze des Verwaltungsrechts erforderlich sein. ${ }^{1357}$ Eine Anwendbarkeit der $\S \S 48 \mathrm{f}$. VwVfG ist jedoch auch im Anwendungsbereich des VwVfG insoweit ausgeschlossen, als sie durch spezialgesetzliche Ermächtigungsgrundlagen überlagert werden. ${ }^{1358}$ Bereits im Studium bekannt sein sollten insbesondere: § 15 GastG, § 45 WaffG $^{1359}$, § 35 StAG und - angesichts der in den letzten Jahren gestiegenen Bedeutung des Migrationsrechts - auch die $\S \S 73 \mathrm{ff}$. AsylG und der $\S 52$ AufenthG. Diese Spezialnormen können die §§ 48f. VwVfG vollständig verdrängen, soweit sie beabsichtigen, die Möglichkeiten der Aufhebung eines Verwaltungsakts für einen bestimmten Sachbereich abschließend zu regeln. Bestehen hingegen Rechtslücken, können die $\S \S 48 \mathrm{f}$. VwVfG weiterhin subsidiär herangezogen werden. Das Verhältnis von Spezialvorschriften zu den $\S \S 48 \mathrm{f}$. VwVfG ist im Einzelfall im Wege der Auslegung zu ermitteln. ${ }^{1360}$

Bereits an dieser Stelle sei darauf verwiesen, dass in einer Klausur nicht außer $\mathbf{8 4 3}$ Acht gelassen werden sollte, dass die Aufhebung eines „Leistungsverwaltungsaktes“ (gemäß § 48 II bzw. § 49 III VwVfG) gerne mit der unmittelbaren Rückforderung einer (auf Grundlage des aufgehobenen Verwaltungsakts erteilten) Leistung gemäß § 49a VwVfG verbunden wird. Diese Erstattung wird in Prüfungen meist noch im Anschluss an die Aufhebung zu prüfen sein (s. dazu Rn. 989 ff.). Dies entspricht dem praktischen Vorgehen im Rahmen des Rechtsschutzbegehrens: Es bedarf zuerst der gerichtlichen „Aufhebung der Aufhebung“, um der Erstattung die zentrale Tatbestandsvoraussetzung $\mathrm{zu}$ entziehen (vgl. § 49a I 1 VwVfG) ${ }^{1361}$. Da der Aufgabenstellung in der Prüfung jedoch keine Grenzen gesetzt sind, besteht auch die Möglichkeit, die isolierte Prüfung des Erstattungsbescheids

1357 Sachs, in: Stelkens/Bonk/Sachs, VwVfG, 9. Aufl. 2018, § 48 Rn. 3.

1358 S. dazu am Beispiel des Gaststättenrechts die Fallbearbeitung bei Broscheit, JA 2016, 840 (841); am Beispiel des Gewerberechts die Fallbearbeitung bei Klafki, JURA 2018, 1019 (1020 f.). 1359 S. dazu die Fallbearbeitung bei Knappe/Thelen, JURA 2018, 829.

1360 So regelt bspw. der erwähnte $\S 52$ AufenthG nur den Widerruf von Aufenthaltstiteln, während die Rücknahme sich nach $\S 48$ VwVfG richtet (vgl. nur die Allgemeine Verwaltungsvorschrift zum Aufenthaltsgesetz v. 26.10.2009, Zu §52, Punkt 52.0.3); § 15 I GastG erfasst nur einen bestimmten Fall der Rücknahme und verlangt von der Behörde eine gebundene Entscheidung, während ansonsten eine Rücknahme über § 48 VwVfG möglich ist (vgl. nur Schönleiter, GastG, 2012, § 15 Rn. 1). Im Einzelfall mag das Verhältnis komplizierter sein, vgl. bspw. zu § 73 AsylG nur Bergmann, in: ders./Dienelt, Ausländerrecht, 12. Aufl. 2018, §73 AsylG Rn. 3, 21; s. dazu beispielhaft auch die Fallbearbeitung bei Knappe/Thelen, JURA 2018, 829 (834f.).

1361 In den Kategorien des Bereicherungsrechts gemäß §§ 812ff. BGB gedacht: Ohne „Aufhebung der Aufhebung“ besteht der Rechtsgrund für eine Leistung fort.

Tobias Brings-Wiesen 
$\mathrm{zu}$ verlangen, sodass in diesen Fällen eine umfängliche Inzidentprüfung der §§ 48f. VwVfG innerhalb des Tatbestands von § 49a VwVfG erfolgen muss.

\section{b) Rücknahme eines Verwaltungsakts nach $\S 48$ VwVfG}

844 Die folgende Darstellung orientiert sich - wie die späteren Ausführungen zu den $\S \S 49$ bis 51 VwVfG - weitgehend am Prüfungsschema der Vorschrift. Grundlegendere Ausführungen zum Verhältnis der Normen untereinander finden sich soweit sie nicht bereits erfolgt sind - an den für die Prüfung relevanten Stellen, um dort zu einem systematischen Verständnis für Struktur und Inhalt der Vorschriften beizutragen.

\section{Prüfungsschema zu § 48 VwVfG:}

I. Einheitliche Ermächtigungsgrundlage: § 48 I 1 VwVfG

II. Formelle Rechtmäßigkeit

1. Zuständigkeit (Beachte: $\S 48 \mathrm{~V}$ VwVfG)

2. Verfahren (Insbesondere: $\S 28 \mathrm{I}$ VwVfG)

3. Form (Beachte: actus contrarius-Gedanke)

III. Materielle Rechtmäßigkeit

1. Tatbestand

a) Vorliegens eines Verwaltungsakts (als Gegenstand der Aufhebung)

b) Rechtswidrigkeit des aufzuhebenden Verwaltungsakts (grds. im Zeitpunkt seines Erlasses)

c) Ggf. weitere tatbestandliche Voraussetzungen gemäß §48 II bis IV VwVfG im Falle des Vorliegens eines rechtswidrigen begünstigenden Verwaltungsakts gemäß § 48 I 2 VwVfG

aa) Ggf. weitere tatbestandliche Voraussetzungen gemäß §48 II VwVfG im Falle des Vorliegens eines Verwaltungsakts, der eine einmalige oder laufende Geldleistung oder teilbare Sachleistung gewährt oder hierfür Voraussetzung ist (,Leistungsverwaltungsakt")

(1) Tatsächliches Vertrauen

(2) Schutzwürdigkeit dieses Vertrauens

(a) Ausschluss der Schutzwürdigkeit bei Vorliegen eines der Gründe in $\S 48$ II 3 VwVfG

(b) Regelvermutung zugunsten einer Schutzwürdigkeit im Falle des Verbrauchs einer Leistung oder einer Vermögensdisposition (,Vertrauensbetätigung“) gemäß § 48 II 2 VwVfG 
(c) Abwägung des Vertrauens auf den Bestand des Verwaltungsakts mit dem öffentlichen Interesse an einer Rücknahme

bb) Kein Ausschluss der Rücknahme aufgrund von Verfristung gemäß $\S 48 \mathrm{IV}$ VwVfG

2. Rechtsfolge: Ordnungsgemäße Ermessensausübung gemäß § 48 I 1 VwVfG (Beachte: „ganz oder teilweise mit Wirkung für die Zukunft oder für die Vergangenheit")

\section{aa) Ermächtigungsgrundlage, § 48 I 1 VwVfG}

$\S 48$ I 1 VwVfG bildet die für Rücknahmen nach dem allgemeinen Verwaltungs- 846 recht einheitliche Ermächtigungsgrundlage. ${ }^{1362}$ In der Ausbildungsliteratur zur Fallbearbeitung werden verschiedene Varianten des Prüfungsaufbaus zur Ermächtigungsgrundlage vertreten. So erfolgt vielerorts bereits innerhalb dieses Gliederungspunktes eine ausführliche Prüfung der Rechtswidrigkeit des aufzuhebenden Verwaltungsakts. ${ }^{1363}$ Andernorts wird anfänglich global auf die $\S 48$ und/oder § 49 VwVfG als Ermächtigungsgrundlagen für die Aufhebung eines Verwaltungsakts rekurriert, während die weitere Präzisierung der Ermächtigungsgrundlage mit fortschreitender Prüfung erfolgt. ${ }^{1364}$ Um nicht vom gewohnten - und regelmäßig zu Recht erwarteten - Vorgehen zu diesem Prüfungspunkt (s. Rn. 574f.) abzuweichen, ist demgegenüber vorzugswürdig, auch innerhalb der §§ 48f. VwVfG präzise eine (potentiell) einschlägige Ermächtigungsgrundlage zu identifizieren, deren Voraussetzungen - also u.a. die Rechtswidrigkeit bzw. Rechtmäßigkeit des aufzuhebenden Verwaltungsakts (s. dazu näher Rn. 865 ff.) sodann im Rahmen der materiellen Rechtmäßigkeit genauer zu prüfen sind. ${ }^{1365}$

1362 Suerbaum, in: Mann/Sennekamp/Uechtritz, VwVfG, 2. Aufl. 2019, § 48 Rn. 34; so auch Sachs, in: Stelkens/Bonk/Sachs, VwVfG, 9. Aufl. 2018, § 48 Rn. 37; Kastner, in: Fehling/Kastner/ Störmer, Verwaltungsrecht, 4. Aufl. 2016, § 48 VwVfG Rn. 11; Erichsen/Brügge, JURA 1999, 155 (156).

1363 So Ernst/Kämmerer, Fälle zum Allgemeinen Verwaltungsrecht, 3. Aufl. 2016, Fall 11, S. 158 (162f.); Kahl/Hilbert, JURA 2011, 948 (952ff.); Faßbender, JuS 2016, 538 (541f.). Teilweise erfolgt die Bestimmung der Ermächtigungsgrundlage auch am Anfang der Prüfung der materiellen Rechtmäßigkeit, Greim-Diroll, JURA 2018, 740 (743).

1364 So Martini, JuS 2003, 266 (267f.); Funke/Waidhas, JA 2014, 439 (442); Broscheit, JA 2016, 840 (841); Klafki, JURA 2018, 1019 (1020 f.).

1365 So auch Klement, JuS 2010, 1088 (1090); Staufer/Steinebach, JURA 2012, 883 (887); Ingold, JuS 2014, 40 (41); Haltern/Manthey, JuS 2016, 344 (346); Kruse, ZJS 2017, 212 (214f.); Payandeh, ZJS 2017, 544 (550); Wormit, JURA 2018, 87; (89); Linke, JuS 2018, 259 (261); Edenharter, JuS 2018, 456 (458); Winter-Peter, JURA 2018, 508 (509f.); auch Pünder, JA 2004, 467 (469). 
Angesichts des differenzierten Meinungsbildes wird man jedoch jede Aufbauvariante für vertretbar erachten müssen. Wichtig ist, sich konsequent für einen Weg $\mathrm{zu}$ entscheiden und diese reine Aufbaufrage in der Prüfung nicht $\mathrm{zu}$ thematisieren. Ist indes das Verhältnis zu einer spezialgesetzlichen Ermächtigungsgrundlage zu erörtern (s. näher Rn. 842), ist die Ermächtigungsgrundlage notwendigerweise genau $\mathrm{zu}$ bestimmen. ${ }^{1366}$

847 Verfassungsrechtliche Bedenken bezüglich § 48 VwVfG bestehen grundsätzlich nicht. ${ }^{1367}$ In der Prüfung sollte daher auf diese Problematik nur dann eingegangen werden, wenn deutliche Hinweise im Sachverhalt den Schluss auf den Wunsch des Prüfenden erlauben, diese Problematisierung sehen zu wollen. ${ }^{1368}$

\section{bb) Formelle Rechtmäßigkeit}

848 Wie bereits dargelegt (s. Rn. 839) handelt es sich bei der Rücknahme selbst um einen Verwaltungsakt, der in einem neuen, selbstständigen Verwaltungsverfahren erlassen wird. ${ }^{1369}$ Aus diesem Grund gelten die allgemeinen rechtlichen Vorgaben für Verwaltungsakte nach dem VwVfG, inklusive der Vorschriften über Zuständigkeit, Verfahren und Form. Insofern kann an dieser Stelle auch grundsätzlich auf die allgemeinen Ausführungen zur formellen Rechtmäßigkeit verwiesen werden (s. dazu Rn. 579 ff.). Die folgenden Darstellungen konzentrieren sich auf die Ausnahmefälle und Besonderheiten der Prüfung der formellen Rechtmäßigkeit im Rahmen der §§ 48f. VwVfG ${ }^{1370}$.

\section{(1) Zuständigkeit}

849 Soweit das Fachrecht zur örtlichen Zuständigkeit schweigt, ist diese nach $\S 3$ VwVfG zu bestimmen. Nach Eintritt der Bestandskraft des zurückzunehmenden

1366 S. dazu die Fallbearbeitung bei Edenharter, JuS 2018, 456 (458).

1367 Vgl. dazu nur BVerwG, Beschl. v. 20.10.2006, Az.: 6 B 67.06 = juris, Rn. 4 ff., unter Verweis auf BVerfG, Urt. v. 24.5.2006, Az.: 2 BvR 669/04 = BVerfGE 116, 24 (54ff.), wo nur für Ausnahmekonstellationen eine Verfassungswidrigkeit für möglich gehalten wird, a.a. O., 59f. - S. aber auch die Meinung der Senatsminderheit, a.a. $0 ., 60 \mathrm{ff}$.

1368 S. dazu bspw. die Fallbearbeitung bei von Weschpfennig, JURA 2014, 1055 (1059).

1369 Vgl. nur BVerwG, Urt. v. 20.12.1999, Az.: 7 C 42.98 = BVerwGE 110, 226 (230 ff.); Ramsauer, in: Kopp/Ramsauer, VwVfG, 20. Aufl. 2019, § 48 Rn. 162.

1370 Da hinsichtlich § 49 VwVfG praktisch keine nennenswerten Unterschiede gelten, können die Ausführungen seiner bezüglich bereits hier mitgedacht werden.

Tobias Brings-Wiesen 
Verwaltungsakts ${ }^{1371}$ sollte in der Prüfung auch auf den $\S 48$ V VwVfG rekurriert werden. Dieser stellt (fast) nur klar, ${ }^{1372}$ was bereits nach den anderweitig einschlägigen Vorschriften gilt: Nach Unanfechtbarkeit entscheidet über die Rücknahme des Verwaltungsakts die nach §3 VwVfG zuständige Behörde und dies selbst dann, wenn der zurückzunehmende Verwaltungsakt von einer anderen Behörde erlassen wurde, sprich es zu einem Wechsel der örtlichen Zuständigkeit gekommen ist.

Examenswissen: Nur im Hinblick auf die Vorschrift des § 3 III VwVfG ist § 48 V VwVfG eine eigene rechtliche Wirkung zu entnehmen. Danach kann die bisher zuständige Behörde das Verwaltungsverfahren auch im Falle von Änderungen der die Zuständigkeit begründenden Umstände in dessen Lauf fortführen, wenn dies unter Wahrung der Interessen der Beteiligten der einfachen und zweckmäßigen Durchführung des Verfahrens dient und die nunmehr zuständige Behörde zustimmt. § 3 III VwVfG ist somit eigentlich beschränkt auf Änderungen in laufenden Verfahren. Angesichts der eindeutigen Verweisung wird man die Vorschrift jedoch auch auf das neue Rücknahmeverfahren entsprechend anzuwenden haben. ${ }^{1373}$

Für die sachliche Zuständigkeit ist keinesfalls auf § 48 V VwVfG abzustellen. Die Vorschrift regelt lediglich Fragen der örtlichen Zuständigkeit. ${ }^{1374}$ Dies ist indes verständlich. Dem VwVfG sind allgemein keine Vorgaben zur sachlichen Zuständigkeit zu entnehmen, weil „eine Einheitlichkeit der Vorschriften über die sachliche Zuständigkeit niemals bestanden hat und bei der Verschiedenartigkeit der Behördenorganisation auch nicht bestehen kann“1375. Maßgeblich sind für die Bestimmung der sachlichen Zuständigkeit auch im Falle der Rücknahme die Zuständigkeitsregeln des jeweils anzuwenden Fachrechts. ${ }^{1376}$

Hat eine unzuständige Behörde den zurückzunehmenden Verwaltungsakt erlassen, ist die Zuständigkeit für die Rücknahme gleichwohl nach dem jeweils einschlägigen Fachrecht bzw. den allgemeinen Vorgaben des Verwaltungsver-

1371 Und - in Anbetracht des klaren Wortlauts - auch nur dann, J. Müller, in: Bader/Ronellenfitsch, VwVfG, 44. Ed., Stand: 1.1.2019, § 48 Rn. 124.

1372 Ramsauer, in: Kopp/Ramsauer, VwVfG, 20. Aufl. 2019, § 48 Rn. 162; Suerbaum, in: Mann/ Sennekamp/Uechtritz, VwVfG, 2. Aufl. 2019, § 48 Rn. 217, 226.

1373 Ramsauer, in: Kopp/Ramsauer, VwVfG, 20. Aufl. 2019, § 48 Rn. 163; Sachs, in: Stelkens/ Bonk/Sachs, VwVfG, 9. Aufl. 2018, § 48 Rn. 256. A.A. J. Müller, in: Bader/Ronellenfitsch, VwVfG, 44. Ed., Stand: 1.1.2019, § 48 Rn. 124; Kastner, in: Fehling/Kastner/Störmer, Verwaltungsrecht, 4. Aufl. 2016, § 48 VwVfG Rn. 68.

1374 S. nur BVerwG, Urt. v. 20.12.1999, Az.: 7 C 42.98 = BVerwGE 110, 226 (230).

1375 BVerwG, Urt. v. 20.12.1999, Az.: 7 C 42.98 = BVerwGE 110, 226 (230), unter Rekurs auf den Musterentwurf eines Verwaltungsverfahrensgesetzes, 2. Aufl. 1968, S. 82.

1376 S. nur BVerwG, Urt. v. 20.12.1999, Az.: 7 C 42.98 = BVerwGE 110, 226 (230), mit dem zusätzlichen Hinweis, dass bei deren Unergiebigkeit allgemeine verwaltungsverfahrensrechtliche Grundsätze greifen. 
fahrensrechts zu bestimmen, sodass die Behörde zuständig ist, die zum Zeitpunkt der Rücknahmeentscheidung für den Erlass des aufzuhebenden Verwaltungsakts zuständig ist. ${ }^{1377}$

Nach alldem wird zwar im Ergebnis regelmäßig sowohl in örtlicher als auch in sachlicher Hinsicht die Behörde für die Rücknahme zuständig sein, die bereits den ursprünglichen Verwaltungsakt erlassen hat bzw. diejenige, die diesen hätte erlassen müssen. In der Prüfung sollte jedoch gleichwohl sauber dargelegt werden, warum dies so ist.

854 Während der Anhängigkeit eines Vorverfahrens (bis zum Eintritt der Bestandskraft des Widerspruchsbescheids) erstreckt sich die Zuständigkeit darüber hinaus auf die Widerspruchsbehörde. ${ }^{1378}$

\section{(2) Verfahren}

855 Für ein ordnungsgemäßes Verfahren ist unter den Bedingungen des § 28 VwVfG insbesondere eine Anhörung erforderlich. ${ }^{1379}$ Insbesondere im Falle der Rücknahme eines begünstigenden Verwaltungsakts wird in die aktuelle Rechtsstellung des durch den Verwaltungsakt Begünstigten als Beteiligter nach § 13 I Nr. 2 VwVfG eingegriffen. ${ }^{1380}$ Auch im Falle der Rücknahme eines belastenden Verwaltungsakts ist dies jedoch nicht per se ausgeschlossen. Im Falle der Rücknahme eines Verwaltungsakts mit Drittwirkung besteht die Pflicht zur Anhörung des Drittbetroffenen erst nach dessen Hinzuziehung gemäß §13 II VwVfG, auf die indes ein Anspruch bestehen kann. ${ }^{1381}$

\section{(3) Form}

856 Soweit dem Fachrecht keine speziellen Formvorgaben zu entnehmen sind, würde auch für den Verwaltungsakt der Rücknahme eigentlich der Grundsatz der Formfreiheit gemäß § 37 II 1 VwVfG gelten (s. dazu Rn. 681). Aus der individu-

1377 Für einen Fall örtlicher Unzuständigkeit BVerwG, Beschl. v. 25.8.1995, Az.: 5 B $141.95=$ NVwZ-RR 1995, 538; für einen Fall sachlicher Unzuständigkeit BVerwG, Urt. v. 20.12.1999, Az.: 7 C 42.98 = BVerwGE 110, 226 (229ff.).

1378 S. dazu und zum Verhältnis zur Ausgangsbehörde allgemein Ramsauer, in: Kopp/Ramsauer, VwVfG, 20. Aufl. 2019, § 48 Rn. $164 \mathrm{ff.}$

1379 S. dazu anschaulich OVG Münster, Urt. v. 10.12.1984, Az.: 16 A 3086/83 = NVwZ 1985, 661 (662).

1380 Vgl. BVerwG, Urt. v. 14.10.1982, Az.: 3 C 46.81 = BVerwGE 66, 184 (186).

1381 Dazu jeweils m.w. N. Ramsauer, in: Kopp/Ramsauer, VwVfG, 20. Aufl. 2019, § 28 Rn. 22 f; Kallerhoff/Mayen, in: Stelkens/Bonk/Sachs, VwVfG, 9. Aufl. 2018, § 28 Rn. 33; Schwarz, in: Fehling/Kastner/Störmer, Verwaltungsrecht, 4. Aufl. 2016, § 28 VwVfG Rn. 21 f. 
alschutzorientierten Fortführung des actus contrarius-Gedankens kann sich jedoch ergeben, dass für die Rücknahme die Form einzuhalten ist, in der der zurückzunehmende Verwaltungsakt (entsprechend der für ihn geltenden Vorgaben) erteilt wurde. ${ }^{1382}$ Insofern ist die Entscheidung über die Rücknahme, insbesondere im Hinblick auf die ihr zugrundeliegenden Ermessenserwägungen, ${ }^{1383}$ auch gemäß § 39 VwVfG zu begründen (s. dazu Rn. 690 ff.). ${ }^{1384}$

\section{cc) Materielle Rechtmäßigkeit}

Während Ausführungen zur Ermächtigungsgrundlage und zur formellen Rechtmäßigkeit regelmäßig „,reine Formsache“ sein werden bzw. nur allgemein bekannte Probleme aufgreifen, wird der Schwerpunkt der Prüfungen von Rücknahmen gemäß § 48 VwVfG praktisch immer auf der materiellen Rechtmäßigkeit liegen.

\section{(1) Überblick über die Prüfung des Tatbestands}

Die Tatbestandsprüfung fällt je nach Vorliegen der von § 48 VwVfG besonders hervorgehobenen Charakteristika eines Verwaltungsakts unterschiedlich umfänglich aus. Stets festzustellen ist, dass sich die Entscheidung der Behörde auf einen rechtswidrigen Verwaltungsakt bezieht.

Ist dieser Verwaltungsakt belastend, ist die Tatbestandsprüfung zu beenden und abschließend gemäß § 48 I 1 VwVfG die ordnungsgemäße Ermessensausübung der Behörde bei der Entscheidung über die Rücknahme zu beurteilen.

Ist der Verwaltungsakt indes i.S.v. § 48 I 2 VwVfG begünstigend, sind die 860 zusätzlichen Tatbestandsvoraussetzungen der Abs. 2 bis $4 \mathrm{zu}$ prüfen. Innerhalb dieser wird indes nochmals unterschieden zwischen Verwaltungsakten, die eine einmalige oder laufende Geldleistung oder teilbare Sachleistung gewähren oder hierfür Voraussetzung sind (im Folgenden: „Leistungsverwaltungsakte“), und sonstigen Verwaltungsakten. Für beide ist ein möglicher Ausschluss der Rücknahme aufgrund von Verfristung gemäß § 48 IV VwVfG zu prüfen. Nur für die Erstgenannten sieht $\S 48$ II VwVfG darüber hinaus weitere besondere Tatbestandserwägungen vor.

1382 So i. E. auch Sachs, in: Stelkens/Bonk/Sachs, VwVfG, 9. Aufl. 2018, § 48 Rn. 242; Kastner, in: Fehling/Kastner/Störmer, Verwaltungsrecht, 4. Aufl. 2016, § 48 VwVfG Rn. 72; Ehlers/Kallerhoff, JURA 2009, 823 (834).

1383 Wobei das Begründungserfordernis im Falle von § 48 II 4 VwVfG reduziert sein kann, s. nur BVerwG, Urt. v. 16.6.1997, Az.: 3 C 22.96 = BVerwGE 105, 55 (57).

1384 Ramsauer, in: Kopp/Ramsauer, VwVfG, 20. Aufl. 2019, § 48 Rn. 171; Sachs, in: Stelkens/ Bonk/Sachs, VwVfG, 9. Aufl. 2018, § 48 Rn. 253. 


\section{(2) Tatbestandsmerkmal 1: Vorliegen eines Verwaltungsakts}

861 Bezugsobjekt der Rücknahme (zum Widerruf s. Rn. $941 \mathrm{ff}$.) ist ein Verwaltungsakt. Im Rahmen von Prüfungen wird diesem Tatbestandsmerkmal selten besondere Aufmerksamkeit zuteil. Dies ist in der weit überwiegenden Zahl der Sachverhalte auch vertretbar. Stets sollte jedoch zumindest in der gebotenen Kürze das Vorliegen der Merkmale des § 35 VwVfG (s. Rn. 42ff.) und der Eintritt der rechtlichen Existenz eines Verwaltungsakts (s. Rn. 117 ff.) dargelegt werden (soweit dies bei verwaltungsprozessualer Einbettung noch nicht bei der Erläuterung der statthaften Klageart erfolgt ist, sodass entsprechend verwiesen werden könnte).

862 Examenswissen: Diese kurze Vergewisserung des Vorliegens eines Verwaltungsakts ist auch der Tatsache geschuldet, dass die Möglichkeit der Aufhebung von bloß „formellen Verwaltungsakten“ (s. dazu Rn. 21 ff.), „Nichtakten“ (s. dazu Rn. 20) und nichtigen Verwaltungsakten (s. dazu Rn. 19, 197 ff.) umstritten ist.

Besonders intensiv diskutiert wird die Anwendbarkeit von $\S 48$ VwVfG auf nichtige Verwaltungsakte.

Gegen eine Anwendung ${ }^{1385}$ wird insbesondere die Systematik des VwVfG ins Feld geführt. Die behördliche Aufhebung ziele auf die Beseitigung der Wirksamkeit, setze diese folglich voraus. Die Aufhebung eines nichtigen Verwaltungsakts gehe daher ins Leere. ${ }^{1386}$ Die Anwendung von $\S 48$ VwVfG würde die - in § 43 II, III VwVfG angelegte - Unterscheidung zwischen bloßer Rechtswidrigkeit und Nichtigkeit verwischen. ${ }^{1387}$ Insbesondere sei für eine analoge Anwendung kein Raum, da angesichts der Möglichkeit behördlicher Feststellung gemäß § 44 V VwVfG bereits keine Regelungslücke bestehe. ${ }^{1388}$ Die nötige Klarheit wider den Rechtsschein eines nichtigen Verwaltungsakts könne auch über die speziell dafür vorgesehenen Rechtsbehelfe erreicht werden. ${ }^{1389}$ Da sich behördliche Nichtigkeitsfeststellung und Aufhebung sowohl nach den Voraussetzungen als auch nach den Rechtsfolgen unterschieden, könne keine Parallele zur gerichtlichen Aufhebung eines nichtigen Verwaltungsakts (s. dazu Rn. 197 ff.) gezogen werden. ${ }^{1390}$

1385 Detterbeck, Allgemeines Verwaltungsrecht, 17. Aufl. 2019, Rn. 684; Maurer/Waldhoff, Allgemeines Verwaltungsrecht, 19. Aufl. 2017, § 11 Rn. 7; Suerbaum, in: Mann/Sennekamp/Uechtritz, VwVfG, 2. Aufl. 2019, § 48 Rn. 40; Erichsen/Brügge, JURA 1999, 155 (156); Schladebach, VerwArch 2013, 188 (203f.); Mehde, JURA 2017, 783 (786).

1386 S. nur Maurer/Waldhoff, Allgemeines Verwaltungsrecht, 19. Aufl. 2017, § 11 Rn. 7. Im Interesse dogmatischer Konsistenz wird daher vermittelnd auch vertreten, dass § 48 VwVfG zwar anwendbar, die Aufhebung jedoch nur deklaratorischer Natur sei, J. Müller, in: Bader/Ronellenfitsch, VwVfG, 44. Ed., Stand: 1.1.2019, § 48 Rn. 8.

1387 Kastner, in: Fehling/Kastner/Störmer, Verwaltungsrecht, 4. Aufl. 2016, § 48 VwVfG Rn. 23. 1388 Schladebach, VerwArch 2013, 188 (203); wohl auch Detterbeck, Allgemeines Verwaltungsrecht, 17. Aufl. 2019, Rn. 684.

1389 Maurer/Waldhoff, Allgemeines Verwaltungsrecht, 19. Aufl. 2017, §11 Rn. 7; Kastner, in: Fehling/Kastner/Störmer, Verwaltungsrecht, 4. Aufl. 2016, § 48 VwVfG Rn. 23; Schladebach, VerwArch 2013, 188 (203f.).

1390 Maurer/Waldhoff, Allgemeines Verwaltungsrecht, 19. Aufl. 2017, § 11 Rn. 7. Soweit demgegenüber die Möglichkeit einer Anfechtungsklage befürwortet wird, wird auch auf den dies indi-

Tobias Brings-Wiesen 
Die herrschende Meinung spricht sich demgegenüber für eine - zumindest analoge ${ }^{1391}$ Anwendung aus. ${ }^{1392}$ Dafür spreche - wie im Verwaltungsgerichtsprozess (s. Rn. 197 ff.) - der Grundsatz der Verfahrensökonomie: Durch die Möglichkeit der Aufhebung erübrige sich für die Behörde die schwierige - und oftmals umstrittene - Entscheidung, ob der Verwaltungsakt nichtig oder bloß rechtswidrig sei. ${ }^{1393}$ Sie sei somit vor allem in Grenz- und Zweifelsfällen vielfach der einfachere Weg. ${ }^{1394}$ Außerdem bestehe mangels Vergleichbarkeit von Feststellungs- und Aufhebungsentscheidung sehr wohl eine Regelungslücke und demnach ein Interesse an der Anwendbarkeit: Endgültig beseitigt werde der Rechtsschein erst durch Aufhebung des den Rechtsschein erzeugenden Aktes. ${ }^{1395}$ Demgegenüber sei die Unterscheidung von bloßer Rechtswidrigkeit und Nichtigkeit im Hinblick auf $\S 48$ VwVfG systematisch nicht zwingend: Weder schaffe § 43 II VwVfG einen untrennbaren Zusammenhang zwischen Aufhebung und Wirksamkeit, noch sei es dem Gesetzgeber per se untersagt, auch die Aufhebung eines unwirksamen Verwaltungsakts vorzusehen. ${ }^{1396}$ Bejaht man eine Anwendbarkeit, ist für den Fall, dass die Behörde oder ein Betroffener diesen Weg wählen, eine Prüfung der Nichtigkeit entbehrlich. ${ }^{1397}$ Es gelten die Voraussetzungen des $\S 48$ VwVfG. ${ }^{1398}$

Das Bundesverwaltungsgericht hat zuletzt zu erkennen gegeben, dass es die Argumentation, dass ein aufgrund von Erledigung bereits unwirksamer Verwaltungsakt zwar nicht mehr rechtsgestaltend aufgehoben, sehr wohl aber der mit ihm verbundene Rechtsschein durch eine Aufhebung beseitigt werden könnte, hinsichtlich aller Konstellationen der Unwirksamkeit für überzeugend hält. ${ }^{1399}$ Angesichts der fortbestehenden Kontroverse um diese Position ${ }^{1400}$ sollte in

zierenden Wortlaut von § 43 II 2 VwGO abgestellt, Detterbeck, Allgemeines Verwaltungsrecht, 17. Aufl. 2019, Rn. 684 (Fn. 315).

1391 Ramsauer, in: Kopp/Ramsauer, VwVfG, 20. Aufl. 2019, § 44 Rn. 70; § 48 Rn. 18, verneint eine unmittelbare Anwendung mit der Begründung, die Rücknahme sei gemäß § 43 II VwVfG auf wirksame Verwaltungsakte bezogen; so wohl auch Ehlers/Kallerhoff, JURA 2009, 823 (825); dagegen jedoch Schenke, JuS 2016, 97 (100, Fn. 27).

1392 OVG Münster, Urt. v. 3.12.2009, Az.: 18 A 1787/06 = NVwZ-RR 2010, 411 (412); Peine/Siegel, Allgemeines Verwaltungsrecht, 12. Aufl. 2018, Rn. 603; Sachs, in: Stelkens/Bonk/Sachs, VwVfG, 9. Aufl. 2018, § 44 Rn. 199; § 48 Rn. 57 m.w. N. Zustimmend wohl auch BVerwG, Urt. v. 17.11.2016, Az.: 6 C 36.15 = BVerwGE 156, 283 (285, Rn. 12).

1393 So zu § 44 SGB X BSG, Urt. v. 23.02.1989, Az.: 11/7 RAr 103/87 = NVwZ 1989, 902 (903). 1394 Ramsauer, in: Kopp/Ramsauer, VwVfG, 20. Aufl. 2019, § 44 Rn. 70; § 48 Rn. 18; Schenke, JuS 2016, 97 (100).

1395 Ehlers/Kallerhoff, JURA 2009, 823 (25).

1396 Schenke, JuS 2016, 97 (101).

1397 Schenke, JuS 2016, 97 (103).

1398 S. aber zur wichtigen Frage eines Ermessens der Behörde im Falle der Nichtigkeit ausführlich Schenke, JuS 2016, 97 (102f.).

1399 BVerwG, Urt. v. 17.11.2016, Az.: 6 C 36.15 = BVerwGE 156, 283 (285, Rn. 12), im Zusammenhang mit dem Widerruf eines Verwaltungsakts nach dessen Erledigung „auf andere Weise“ durch Verzicht.

1400 Aus der Lehrbuchliteratur dagegen Maurer/Waldhoff, Allgemeines Verwaltungsrecht, 19. Aufl. 2017, § 11 Rn. 7; Detterbeck, Allgemeines Verwaltungsrecht, 17. Aufl. 2019, Rn. 684 (zum nichtigen Verwaltungsakt); Ruffert, in: Ehlers/Pünder, Allgemeines Verwaltungsrecht, 15. Aufl. 2016, § 24 Rn. 7; dafür Peine/Siegel, Allgemeines Verwaltungsrecht, 12. Aufl. 2018, Rn. 603. 
einer Klausur jedoch im Falle von bloß formellen Verwaltungsakten, Nichtakten und nichtigen Verwaltungsakten unbedingt auf das Problem eingegangen werden. In diesem Zusammenhang können dann auch tiefergehende Ausführungen zu Verwaltungsaktqualität und Wirksamkeit erforderlich werden.

863 Weitgehend bedeutungslos ${ }^{1401}$ ist demgegenüber die Frage seiner Bestandskraft, wie sich bereits am Wortlaut von § 48 I 1 VwVfG (,auch nachdem er unanfechtbar geworden ist“) verdeutlicht. Dies eröffnet insbesondere die Möglichkeit der Betroffenen, die Aufhebung eines Verwaltungsakts auch über das Ende der Klagefrist hinaus zu beantragen. Die Anhängigkeit eines Widerspruchs- oder Gerichtsverfahrens steht einer Aufhebung gemäß §§ 48f. VwVfG grundsätzlich nicht im Wege, hat jedoch gemäß $§ 0$ VwVfG Auswirkungen auf deren materielle Rechtmäßigkeitsmaßstäbe (s. dazu Rn. 979ff.). Die Rechtskraft aufgrund gerichtlicher Bestätigung eines Verwaltungsakts wird der Aufhebung hingegen regelmäßig entgegenstehen. ${ }^{1402}$

864 Objekt einer Rücknahme nach § 48 VwVfG können auch Abhilfe- (§ 72 VwGO) oder Widerspruchsbescheide $(\S 73 \mathrm{VwGO})^{1403}$ sowie Aufhebungsbescheide gemäß §§ 48f. VwVfG selbst sein. Auf Genehmigungsfiktionen ist § $48 \mathrm{VwVfG}$ gemäß § 42a I 2 VwVfG entsprechend anwendbar.

\section{(3) Tatbestandsmerkmal 2: Rechtswidrigkeit des aufzuhebenden Verwaltungsakts}

865 Ein Schwerpunkt von Prüfungen am Maßstab von $\S 48$ VwVfG wird meist in der Inzidentprüfung der Rechtskonformität des aufzuhebenden Verwaltungsakts liegen. Dabei bestehen in der Sache keine Besonderheiten: Ein Verwaltungsakt ist rechtswidrig, wenn er nicht auf einer eigentlich erforderlichen Ermächtigungsgrundlage beruht oder in formeller ${ }^{1404}$ oder materieller Hinsicht gegen einschlägige Rechtsvorschriften (auch und insbesondere Unionsrecht ${ }^{1405}$ ) verstößt.

1401 Gestritten wird jedoch um die Fragen der Interessenabwägung gemäß § 48 II VwVfG und der Ermessensausübung im Falle der Rücknahme eines noch nicht bestandskräftigen Verwaltungsakts, s. dazu noch Rn. 925.

1402 S. nur J. Müller, in: Bader/Ronellenfitsch, VwVfG, 44. Ed., Stand: 1.1.2019, § 48 Rn. 37, m.w.N.

1403 S. dazu ausführlich Rn. $301 \mathrm{ff}$. Soweit ein Widerspruchsbescheid ergangen ist, so ist regelmäßig dessen Rechtswidrigkeit zu beurteilen, Ramsauer, in: Kopp/Ramsauer, VwVfG, 20. Aufl. 2019, § 48 Rn. 50.

1404 S. aber zu den (vor allem) formelle Rechtsfehler betreffenden $\S \S 45 \mathrm{ff}$. VwVfG noch Rn. 652. 1405 S. zu den daraus resultierenden besonderen Konsequenzen noch Rn. $929 \mathrm{ff}$. 
Steht am Ende dieser Prüfung fest, dass der Verwaltungsakt rechtmäßig war, hätte er ausschließlich nach $\S 49$ VwVfG widerrufen werden dürfen. ${ }^{1406}$

War er demgegenüber rechtswidrig, legt zwar der Wortlaut der §§ 48, 49866 VwVfG nahe, dass nur eine Rücknahme in Frage kommt. Die ganz herrschende Meinung hält jedoch auch den Widerruf eines rechtswidrigen Verwaltungsakts gemäß § 49 VwVfG für möglich (s. dazu Rn. 948).

Für die Prüfung bedeutet dies: Soweit sich aus einem Sachverhalt hinrei- 867 chende Anhaltspunkte für einen Widerruf ergeben, sollte die Bearbeitung mit $\S 49$ VwVfG beginnen. Unter dem Prüfungspunkt „Rechtmäßigkeit des Verwaltungsakts“ sollte dann - zumeist in der gebotenen Kürze - auf die Möglichkeit des Widerrufs rechtswidriger Verwaltungsakte eingegangen werden. In der Konsequenz kann dann die Entscheidung über die Rechtmäßigkeit (vorerst) dahinstehen. ${ }^{1407}$ Sollte jedoch sodann wegen Rechtswidrigkeit des Widerrufs oder schlicht ergänzend noch § 48 VwVfG geprüft werden, ist zwingend eine Entscheidung zu treffen. Auch sollten Ausführungen dort nicht unterbleiben, wo sie je nach Sachverhaltsgestaltung ersichtlich erwartet werden. ${ }^{1408}$

Wie im Fall der Anfechtungsklage (§§ 42 I Var. 1, 113 I 1 VwGO) ergibt sich aus 868

Wortlaut und Systematik der §§ 48f. VwVfG, dass ein Verwaltungsakt auch nur teilweise aufgehoben werden kann.

Zuletzt gilt es in zeitlicher Hinsicht einige Besonderheiten $\mathrm{zu}$ beachten. 869 Maßgeblicher Beurteilungszeitpunkt der Rechtskonformität des aufzuhebenden Verwaltungsakts ${ }^{1409}$ ist der Zeitpunkt seines Erlasses. ${ }^{1410}$ Spätere Änderungen der Sach- und - insbesondere auch der - Rechtslage bleiben grundsätzlich unberücksichtigt. ${ }^{1411}$

1406 Maurer/Waldhoff, Allgemeines Verwaltungsrecht, 19. Aufl. 2017, § 11 Rn. 17. Es besteht indes unter bestimmten Voraussetzungen die Möglichkeit zur Auslegung der behördlichen Entscheidung.

1407 Detterbeck, Allgemeines Verwaltungsrecht, 17. Aufl. 2019, Rn. 685; Peine/Siegel, Allgemeines Verwaltungsrecht, 12. Aufl. 2018, Rn. 603; Manssen/Greim, JuS 2010, 429 (432).

1408 So zu Recht Faßbender, JuS 2016, 538 (Fn. 2).

1409 Anderes gilt im Falle der Aufhebung eines Widerspruchsbescheids nach §73 VwGO, Detterbeck, Allgemeines Verwaltungsrecht, 17. Aufl. 2019, § 10 Fn. 302.

1410 Maurer/Waldhoff, Allgemeines Verwaltungsrecht, 19. Aufl. 2017, §11 Rn. 18; Detterbeck, Allgemeines Verwaltungsrecht, 17. Aufl. 2019, Rn. 680; Ramsauer, in: Kopp/Ramsauer, VwVfG, 20. Aufl. 2019, § 48 Rn. 57; Sachs, in: Stelkens/Bonk/Sachs, VwVfG, 9. Aufl. 2018, § 48 Rn. 49. 1411 Vgl. nur die Beispiele bei Ramsauer, in: Kopp/Ramsauer, VwVfG, 20. Aufl. 2019, § 48 Rn. $58 \mathrm{ff}$. 
870 Examenswissen: Prüfungsrelevant weil zum Teil stark umstritten sind indes die folgenden Ausnahmen:

Keine nachträgliche Änderung der Rechtslage liegt im Falle der gerichtlichen Nichtigerklärung einer Vorschrift wegen Unvereinbarkeit mit höherrangigem Recht (vgl. §§ 78, 95 III 1 BVerfGG; §§ 49, 61 III 1 VGHG NRW; § 47 V 2 Hs. 1 VwGO) vor. Die verschiedenen Gerichte treffen dabei jeweils eine allgemeinverbindliche Feststellungsentscheidung, keine rechtsgestaltende Aufhebungsentscheidung. Die Vorschriften waren objektiv bereits vorher rechtswidrig und damit nichtig. Daraus folgt, dass auch die auf den betroffenen Vorschriften beruhenden Verwaltungsakte mangels wirksamer Rechtsgrundlage als von Anfang $a n^{1412}$ rechtswidrig $^{1413} \mathrm{zu}$ erachten sind. ${ }^{1414}$ Gleiches gilt für die Konstellation, dass die einen ursprünglich rechtmäßigen Verwaltungsakt betreffenden Vorschriften vom Gesetzgeber mit Rückwirkung geändert werden. ${ }^{1415}$ Gleiches kann sich ergeben, wenn die nachträgliche Änderung einer Verwaltungsentscheidung mit Rückwirkung erfolgt. ${ }^{1416}$

Umstritten ist der Umgang mit ursprünglich rechtmäßigen, - aufgrund von Änderungen der Sach- oder Rechtslage - nachträglich rechtswidrig ${ }^{1417}$ gewordenen „Dauerverwaltungsakten“ (s. dazu Rn. 541). Das Bundesverwaltungsgericht geht in ständiger Rechtsprechung ${ }^{1418}$ davon aus, dass ihre Aufhebung für den Zeitraum ab dem Eintritt der Rechtswidrigkeit als Rücknahme nach $\S 48$ VwVfG und nicht als Widerruf nach § 49 VwVfG zu bewerten ist. Die Gegenmeinung ${ }^{1419}$ hält dem insbesondere das systematische Argument entgegen, dass Konstellationen nachträgli-

1412 Dies soll laut Ramsauer, in: Kopp/Ramsauer, VwVfG, 20. Aufl. 2018, § 48 Rn. 56, nicht gelten, wenn trotz Rechtswidrigkeit eine vorläufige Fortgeltung anerkannt bzw. angeordnet wird. Dies wird jedoch höchstens nach den Umständen der Entscheidung in Frage kommen können. 1413 S. zur Rechtswidrigkeit aufgrund fehlender oder mangelhafter Ermächtigungsgrundlage ausführlich Rn. 554 ff. Sie führt jedoch keineswegs automatisch zur Unwirksamkeit des Verwaltungsakts (wegen Erledigung oder Nichtigkeit), s. dazu ausführlich Rn. 185 sowie in § 6 Rn. 153. 1414 BVerwG, Urt. v. 25.10.2012, Az.: 2 C 59.11 = BVerwGE 145, 14 (16, Rn. 10); Detterbeck, Allgemeines Verwaltungsrecht, 17. Aufl. 2019, Rn. 683; Ramsauer, in: Kopp/Ramsauer, VwVfG, 20. Aufl. 2019, § 48 Rn. 56. S. zur weiteren Berücksichtigung der Nichtigkeit für die Rücknahmeentscheidung BVerwG, Urt. v. 24.2.2011, Az.. 2 C 50.09 = NVwZ 2011, 888 (889f.); dazu auch Detterbeck, a.a.O.

1415 Maurer/Waldhoff, Allgemeines Verwaltungsrecht, 19. Aufl. 2017, § 11 Rn. 19; Detterbeck, Allgemeines Verwaltungsrecht, 17. Aufl. 2019, Rn. 681; Ramsauer, in: Kopp/Ramsauer, VwVfG, 20. Aufl. 2019, § 48 Rn. 15a.

1416 Vgl. BVerwG, Urt. v. 16.11.1989, Az.: 2 C 43.87 = BVerwGE 84, 111 (113), dort durch gerichtliche Aufhebung eines Verwaltungsakts, was auch auf die Beurteilung eines in sachlichem Zusammenhang stehenden Verwaltungsakts zurückwirkte.

1417 Zum umgekehrten Fall des nachträglichen Rechtmäßigwerdens rechtswidriger Verwaltungsakte Schenke, NVwZ 2015, 1341.

1418 BVerwG, Urt. v. 2.11.1989, Az.: 2 C 43.87 = BVerwGE 84, 111 (113f.); Urt. v. 28.6.2012, Az.: 2 C 13.11 = BVerwGE 143, 230 (233, Rn. 15); anders aber für den Planfeststellungsbeschluss BVerwG, Urt. v. 29.4.2016, Az.: 4 A 2.15 = BVerwGE 155, 81 (86, Rn. 28). So auch mit ausführlicher Begründung Schenke, DVBl 1989, 433.

1419 S. nur Maurer/Waldhoff, Allgemeines Verwaltungsrecht, 19. Aufl. 2017, § 11 Rn. 19; Detterbeck, Allgemeines Verwaltungsrecht, 17. Aufl. 2019, Rn. 682; Ruffert, in: Ehlers/Pünder, Allgemeines Verwaltungsrecht, 15. Aufl. 2016, § 24 Rn. 6; Ehlers/Kallerhoff, JURA 2009, 823 (825).

Tobias Brings-Wiesen 
cher Veränderung der Sach- oder Rechtslage entsprechend § 49 II 1 Nr. 3, 4 VwVfG eindeutig der Aufhebung durch Widerruf zugewiesen sind.

Da auch formelle Rechtsfehler zur Rechtswidrigkeit des aufzuhebenden Verwaltungsakts führen können, ${ }^{1420}$ sind auch die Fehlerfolgenregelungen der $§ \S 45 \mathrm{f}$. VwVfG besonders zu berücksichtigen: Während weitestgehend Einigkeit ${ }^{1421}$ darüber besteht, dass ein ursprünglich rechtswidriger Verwaltungsakt rückwirkend rechtmäßig wird, wenn ein Verfahrens- oder Formfehler gemäß § 45 VwVfG (s. dazu Rn. 652ff.) durch Nachholung der entsprechenden Handlung nachträglich geheilt wird, ${ }^{1422}$ ist die Frage einer Rücknahme im Falle von Unbeachtlichkeit gemäß $§ 46 \mathrm{VwVfG}$ umstritten ${ }^{1423}$.

Umstritten ist auch der Umgang mit Konstellationen, in denen der Verwaltungsakt gemäß $\S 47 \mathrm{VwVfG}$ durch die Behörde bereits umgedeutet wurde bzw. noch werden kann. ${ }^{1424}$

\section{(4) Tatbestandsmerkmal 3: Belastender oder begünstigender Verwaltungsakt}

Handelt es sich um einen rechtswidrigen Verwaltungsakt, so ist eine Rücknahme nach §48 VwVfG möglich. Für die Klärung der Frage, welche weiteren Voraussetzungen erfüllt sein müssen, ist sodann zu prüfen, ob der zurückzunehmende Verwaltungsakt eine belastende oder begünstigende Wirkung hat. Was unter einem begünstigenden Verwaltungsakt zu verstehen ist, ist in § 48 I 2 VwVfG legaldefiniert als Verwaltungsakt, der ein Recht oder einen rechtlich erheblichen Vorteil begründet oder bestätigt hat. Handelt es sich um einen solchen begünstigenden Verwaltungsakt, kann seine Rücknahme nur unter den zusätzlichen Voraussetzungen der Abs. 2 bis 4 erfolgen. Andernfalls steht die Rücknahme entsprechend dem „Grundsatz der freien Rücknehmbarkeit“ gemäß §48 I 1 VwVfG im Ermessen der Behörde.

Für die Beantwortung der Frage, ob ein Verwaltungsakt ein Recht oder einen $\mathbf{8 7 2}$ rechtlich erheblichen Vorteil begründet oder bestätigt, ist die Wirkung des aufzuhebenden Verwaltungsakts an sich in den Fokus zu nehmen. Treffend formuliert Ramsauer, dass die Vorschrift Rechte im engeren Sinne und rechtlich geschützte Interessen, d.h. alle von der Rechtsordnung durch Sätze des öffentlichen Rechts als schutzwürdig anerkannten und rechtlich geschützten Vorteile,

1420 Ramsauer, in: Kopp/Ramsauer, VwVfG, 20. Aufl. 2019, § 48 Rn. 52.

1421 S. dazu nur Ramsauer, in: Kopp/Ramsauer, VwVfG, 20. Aufl. 2019, § 45 Rn. 14; Sachs, in: Stelkens/Bonk/Sachs, VwVfG, 9. Aufl. 2018, § 45 Rn. 21f., jeweils m.w. N.

1422 OVG Münster, Beschl. v. 23.6.1987, Az.: 13 B 826/87 = NVwZ 1988, 740 (741); Sachs, in: Stelkens/Bonk/Sachs, VwVfG, 9. Aufl. 2018, § 45 Rn. 21, 23; § 48 Rn. 56; Ehlers/Kallerhoff, JURA 2009, 823 (825).

1423 S. dazu m.w. N. nur Sachs, in: Stelkens/Bonk/Sachs, VwVfG, 9. Aufl. 2018, § 46 Rn. 12.

1424 Dafür Maurer/Waldhoff, Allgemeines Verwaltungsrecht, 19. Aufl. 2017, § 11 Rn. 16; Peuker, in: Knack/Henneke, VwVfG, 10. Aufl. 2014, § 48 Rn. 46; Ehlers/Kallerhoff, JURA 2009, 823 (825); a. A. aber Sachs, in: Stelkens/Bonk/Sachs, VwVfG, 9. Aufl. 2018, § 48 Rn. 58. 
die aus dem Verwaltungsakt erwuchsen, umfasse. ${ }^{1425}$ Diese müssen durch den Verwaltungsakt begründet, bestätigt oder festgestellt werden. Begünstigend ist ein Verwaltungsakt jedoch auch dann, wenn die Rechtsordnung an seinen an sich neutralen Regelungsinhalt begünstigende Rechtsfolgen knüpft. So wurde beispielsweise die Feststellung der Zivildienstunfähigkeit (§ 8 ZDG) als begünstigend gewertet, weil in der Folge die mit dem Zivildienst verbundenen gesetzlichen Pflichten entfielen. ${ }^{1426} \mathrm{Zu}$ verneinen ist eine Begünstigung hingegen, wenn sie wie im Falle der Umnummerierung von Grundstücken im öffentlichen Interesse liegt und höchstens reflexhaft tatsächliche Auswirkungen für die Betroffenen hat. ${ }^{1427}$

Teilweise wird für die Bestimmung einer Begünstigung oder Belastung auf die Wirkung der Aufhebung abgestellt, sodass die Aufhebung einer Belastung zulasten des Betroffenen nach den Maßstäben für begünstigende Verwaltungsakte behandelt werden soll. ${ }^{1428}$ Dieses Vorgehen wird indes von der herrschenden Meinung und der Rechtsprechung nicht geteilt. ${ }^{1429}$ Bei Verwaltungsakten, die zugleich belastend und begünstigend sind, kommt es vorrangig auf die Teilbarkeit an, ansonsten sind sie wie begünstigende Verwaltungsakte zu behandeln. ${ }^{1430}$ Bei Verwaltungsakten mit Drittwirkung kommt es stets auf die Perspektive des „Adressaten“ - d.h. die Person, für die ein Verwaltungsakt i.S.v. § 41 I 1, § 43 I 1 VwVfG bestimmt ist (s. dazu Rn. 107) - an. ${ }^{1431}$

874 Ein begünstigender Verwaltungsakt darf nur unter den Einschränkungen der Abs. 2 bis 4 zurückgenommen werden. Entgegen vereinzelt vertretener Ansicht ${ }^{1432}$ handelt es sich um weitere Tatbestandsvoraussetzungen deren Vorliegen gerichtlich voll überprüfbar ist und die je nach Vorliegen eine Rücknahme ausschließen. ${ }^{1433}$

1425 Ramsauer, in: Kopp/Ramsauer, VwVfG, 20. Aufl. 2019, § 48 Rn. 66; auch mit Negativbeispielen, a.a.O., Rn. 65.

1426 BVerwG, Urt. v. 25.6.1982, Az.: 8 C 122.81 = BVerwGE 66, 61 (62).

1427 OVG Münster, Beschl. v. 29.2.2012, Az.: 5 A 353/11 = NVwZ-RR 2012, 541 (541f.).

1428 S. nur Maurer/Waldhoff, Allgemeines Verwaltungsrecht, 19. Aufl. 2017, § 11 Rn. 13; Detterbeck, Allgemeines Verwaltungsrecht, 17. Aufl. 2019, Rn. $686 \mathrm{f}$.

1429 S. dazu nur das Beispiel bei Ramsauer, in Kopp/Ramsauer, VwVfG, 20. Aufl. 2019, § 48 Rn. 69 m.w. N.

1430 Ramsauer, in: Kopp/Ramsauer, VwVfG, 20. Aufl. 2019, § 48 Rn. 72; Ehlers/Kallerhoff, JURA 2009, 823 (827).

1431 Vgl. dazu nur BVerwG, Urt. v. 9.5.2012 Az.: 6 C 3.11 = BVerwGE 143, 87 (106ff., Rn. 46 f.). a. A. dagegen m.w. N. Ehlers/Kallerhoff, JURA 2009, 823 (827).

1432 Peuker, in: Knack/Henneke, VwVfG, 10. Aufl. 2014, § 48 Rn. 66; Ziekow, VwVfG, 3. Aufl. 2013, $\S 48 \mathrm{Rn} .14$.

1433 OVG Münster, Urt. v. 25.11.1996, Az.: 25 A 1950/96 = NVwZ-RR 1997, 585 (585f.); Maurer/ Waldhoff, Allgemeines Verwaltungsrecht, 19. Aufl. 2017, §11 Rn. 29; Detterbeck, Allgemeines

Tobias Brings-Wiesen 
Handelt es sich hingegen um einen belastenden Verwaltungsakt, findet die Tatbestandsprüfung hier ihren Abschluss, sodass zum Ermessen (s. dazu Rn. $921 \mathrm{ff}$.) überzugehen ist.

\section{(5) Besondere Tatbestandsvoraussetzungen bei Rücknahme eines begünstigenden Verwaltungsakts, $\$ 48$ II bis IV VwVfG}

Handelt es sich um einen rechtswidrigen, aber begünstigenden Verwaltungsakt, 875 bedarf es der Prüfung der weiteren besonderen Tatbestandsvoraussetzungen des $§ 48$ II bis IV VwVfG.

Auch insofern bedarf es jedoch einer weiteren Differenzierung zwischen 876 zwei Kategorien begünstigender Verwaltungsakte. Während die in § 48 IV VwVfG vorgesehene Fristenregelung auf beide Kategorien anzuwenden ist (s. dazu Rn. 905 ff.), sieht § 48 II VwVfG nur für Verwaltungsakte, die eine einmalige oder laufende Geldleistung oder teilbare Sachleistung gewähren oder hierfür Voraussetzung sind, näher ausdifferenzierte Tatbestandsvoraussetzungen zum Ausgleich der widerstreitenden Interessen vor. Für alle sonstigen Verwaltungsakte ist nach der Prüfung von § 48 IV VwVfG unmittelbar zum Ermessen überzugehen. ${ }^{1434}$

\section{(a) Leistungsverwaltungsakte, § 48 II VwVfG}

Für „Leitungsverwaltungsalkte“ hat der Gesetzgeber in § 48 II VwVfG die Be- 877 rücksichtigung des schutzwürdigen Vertrauens bereits weitgehend tatbestandlich ausgestaltet. Gemäß § 48 II 1 VwVfG ist eine Rücknahme ausgeschlossen, soweit der Begünstigte auf den Bestand des Verwaltungsakts vertraut hat und sein Vertrauen unter Abwägung mit dem öffentlichen Interesse an einer Rücknahme schutzwürdig ist. Diese Abwägung wird wiederum vorgeprägt durch die die Schutzwürdigkeit konkretisierenden Vorgaben in § 48 II 2 und 3 VwVfG. ${ }^{1435}$

\section{Begriffsbestimmung}

Die Anwendbarkeit von § 48 II VwVfG setzt voraus, dass es sich um einen Leis- 878 tungsverwaltungsakt handelt. Wesentlich für die Abgrenzung zu Abs. 3 ist, dass aus dem Verwaltungsakt vorrangig eine finanzielle Belastung für die öffentliche Hand resultieren muss. ${ }^{1436}$ Der Gesetzgeber ging davon aus, dass die „sonstigen

Verwaltungsrecht, 17. Aufl. 2019, Rn. 703; Ramsauer, in: Kopp/Ramsauer, VwVfG, 20. Aufl. 2019, $\S 48$ Rn. 84, 127.

1434 S. zu den diesbezüglich geltenden Besonderheiten aber noch Rn. 928.

1435 Ramsauer, in: Kopp/Ramsauer, VwVfG, 20. Aufl. 2019, § 48 Rn. 94.

1436 Ramsauer, in: Kopp/Ramsauer, VwVfG, 20. Aufl. 2019, § 48 Rn. 88.

Tobias Brings-Wiesen 
Verwaltungsakte“ stärker staatsbezogen sind und es daher schwerer erträglich ist, einen rechtswidrigen Zustand aufrechtzuerhalten, als wenn es nur um fiskalische Interessen geht. ${ }^{1437}$

Ein Verwaltungsakt gewährt eine Leistung, wenn er eine Regelung enthält, die unmittelbar zu einer Vermehrung des Vermögens des Begünstigten führt. ${ }^{1438}$ Diese kann in der unmittelbaren Anspruchsbegründung, aber auch im Verzicht auf eine eigentlich bestehende Forderung, wie im Falle einer Steuerbefreiung, liegen ${ }^{1439}$. Sachleistungen umfassen zumindest alle körperlichen Gegenstände i.S.d. §90 BGB, ${ }^{1440}$ selbst dann wenn nur der Gebrauch an ihnen überlassen wird $^{1441}$. Vor diesem Hintergrund ist auch die Teilbarkeit zu verstehen: Sie ist in sachlicher wie zeitlicher Hinsicht denkbar. ${ }^{1442}$

Es genügt indes auch, dass der Verwaltungsakt bloß Voraussetzung für eine einmalige oder laufende Geldleistung oder teilbare Sachleistung ist. Dies ist der Fall, wenn durch den Verwaltungsakt rechtliche Voraussetzungen festgestellt werden, die sich unmittelbar in Richtung einer Leistung auswirken, wie beispielsweise bei der Festsetzung des Besoldungsdienstalters. ${ }^{1443}$ Umstritten war dies lange Zeit für statusfeststellende Bescheide mit Tatbestandswirkung gegenüber allen anderen Behörden (wie im Rahmen des Staatsangehörigen- oder Asylrechts), die die Grundlage für die Gewährung weiterer Geld- oder Sachleistungen bilden. Hier scheint das Bundesverwaltungsgericht jedoch mittlerweile durchweg zwischen dem eigentlichen Statusbescheid und den an diesen anknüpfenden Bescheiden zu unterscheiden. ${ }^{1444}$

Alle anderen Verwaltungsakte, insbesondere solche die eine nicht monetäre Rechtsstellung gestalten oder feststellen ${ }^{1445}$ oder ein bestimmtes Verhalten erlauben (s. dazu Rn. 64), unterfallen § 48 III VwVfG. Dazu gehören beispielsweise die Feststellung der Asylberechtigung gemäß $\S 31$ AsylG, die Gaststättenerlaubnis gemäß § 2 I GastG oder die Baugenehmigung auf Grundlage der einschlägigen landesbauordnungsrechtlichen Vorschriften.

1437 BT-Drucks. 7/910, S. 71. Darauf rekurrierend auch das BVerwG, Urt. v. 28.5.2015, Az.: 1 C 24.14 = BVerwGE 152, 164 (174, Rn. 29).

1438 Erichsen/Brügge, JURA 1999, 155 (158f.); Ehlers/Kallerhoff, JURA 2009, 823 (829). So für Geldleistungen BVerwG, Urt. v. 22.3.2017, Az.: 5 C 4.16 = BVerwGE 158, 258 (265, Rn. 23).

1439 S. zu weiteren Beispielen Ramsauer, in: Kopp/Ramsauer, VwVfG, 20. Aufl. 2019, § 48 Rn. 87. 1440 Suerbaum, in: Mann/Sennekamp/Uechtritz, VwVfG, 2. Aufl. 2019, § 48 Rn. 120.

1441 Ramsauer, in: Kopp/Ramsauer, VwVfG, 20. Aufl. 2019, § 48 Rn. 88.

1442 Sachs, in: Stelkens/Bonk/Sachs, VwVfG, 9. Aufl. 2018, § 48 Rn. 130.

1443 Ramsauer, in: Kopp/Ramsauer, VwVfG, 20. Aufl. 2019, § 48 Rn. 91.

1444 S. dazu nur BVerwG, Urt. v. 28.5.2015, Az.: 1 C 24.14 = BVerwGE 152, 164 (174f., Rn. 30) m.w. N.

1445 BVerwG, Urt. v. 28.5.2015, Az.: 1 C 24.14 = BVerwGE 152, 164 (174, Rn. 29). 


\section{Tatsächliches Vertrauen}

Als Grundvoraussetzung der sodann vorzunehmenden Abwägung gemäß § 48 II 1 VwVfG wird verlangt, dass auf Seiten des Begünstigten tatsächliches Vertrauen in den (Fort-)Bestand des Verwaltungsakts vorlag. Dies wird in Prüfungen selten ein Problem darstellen und höchstens dann von Interesse sein, wenn gegenteilig klar ersichtlich ist, dass der Betroffene eben nicht vertraut hat, beispielsweise weil er den Verwaltungsakt gar nicht kannte ${ }^{1446}$ oder bereits sicher von einer Aufhebung ausging ${ }^{1447}$. Wie $§ 48$ II 2 VwVfG verdeutlicht muss der Betroffene sein Vertrauen aber noch nicht „betätigt“ haben. ${ }^{1448}$

Besteht schon kein Vertrauen, kann die Prüfung von § 48 II VwVfG bereits an dieser Stelle beendet werden - es bedarf dann nur noch der Prüfung eines möglichen Rücknahmeausschlusses aufgrund von Verfristung gemäß § 48 IV VwVfG sowie der ordnungsgemäßen Ermessensausübung gemäß § 48 I 1 VwVfG.

\section{Ausschluss der Schutzwürdigkeit des Vertrauens gemäß § 48 II 3 VwVfG}

Soweit hingegen tatsächliches Vertrauen besteht, kann dessen Berücksichtigung für die Abwägung gleichwohl gemäß § 48 II 3 VwVfG von vornherein ausgeschlossen $^{1449}$ sein, wenn einer der dort genannten Tatbestände erfüllt ist.

Dies ist der Fall, wenn der Verwaltungsakt durch arglistige Täuschung, 885 Drohung oder Bestechung erwirkt wurde (Nr. 1). ${ }^{1450}$

Eine arglistige Täuschung liegt laut Bundesverwaltungsgericht vor, wenn $\mathbf{8 8 6}$ der Täuschende weiß und will, dass die Behörde durch insbesondere die Vorspiegelung falscher Tatsachen zum Erlass eines Verwaltungsakts veranlasst wird, den sie andernfalls nicht oder nicht mit diesem Inhalt erlassen hätte. ${ }^{1451}$ Er muss zumindest mit bedingtem Vorsatz tätig werden. ${ }^{1452}$ Sie kann durch gezielte An-

1446 Maurer/Waldhoff, Allgemeines Verwaltungsrecht, 19. Aufl. 2017, § 11 Rn. 35; Ramsauer, in: Kopp/Ramsauer, VwVfG, 20. Aufl. 2019, § 48 Rn. 97.

1447 Detterbeck, Allgemeines Verwaltungsrecht, 17. Aufl. 2019, Rn. 697.

1448 So zutreffend Ramsauer, in: Kopp/Ramsauer, VwVfG, 20. Aufl. 2019, § 48 Rn. 96; Ehlers/ Kallerhoff, JURA 2009, 823 (830); a. A. aber Sachs, in: Stelkens/Bonk/Sachs, VwVfG, 9. Aufl. 2018, § 48 Rn. 136; J. Müller, in: Bader/Ronellenfitsch, VwVfG, 44. Ed., Stand: 1.1.2019, § 48 Rn. 56.

1449 So auch Detterbeck, Allgemeines Verwaltungsrecht, 17. Aufl. 2019, Rn. 698 (,,ausnahmslos und ohne Wertungsmöglichkeit“); Peine/Siegel, Allgemeines Verwaltungsrecht, 12. Aufl. 2018, Rn. 731; Ramsauer, in Kopp/Ramsauer, VwVfG, 20. Aufl. 2019, § 48 Rn. 103; Sachs, in: Stelkens/ Bonk/Sachs, VwVfG, 9. Aufl. 2018, § 48 Rn. 148.

1450 Die Tatbestände in $\S 48$ II 3 Nr. 1 und 2 VwVfG sind verfassungsrechtlich nicht zu beanstanden, vgl. BVerfG, Beschl. v. 16.12.1981, Az.: 1 BvR 898/79 u. a. = BVerfGE 59, 128 (171).

1451 BVerwG, Urt. v. 22.3.2017, Az.: 5 C 4.16 = BVerwGE 158, 258 (265, Rn. 25); ähnlich bereits BVerwG, Urt. v. 9.9.2013, Az.: 1 C 6.03 = BVerwGE 119, 17 (22): „bewusste Täuschung“. 1452 Suerbaum, in: Mann/Sennekamp/Uechtritz, VwVfG, 2. Aufl. 2019, § 48 Rn. 134. 
gaben oder ein Verschweigen erfolgen. ${ }^{1453}$ Selbst beständige Zweifel auf Seiten der Behörde schließen eine Täuschung nicht aus. ${ }^{1454}$

Um eine Drohung handelt es sich, wenn einer Person ein zukünftiges Übel in Aussicht gestellt wird, um von ihr im Wege psychischen Zwangs eine bestimmte Handlung, Duldung oder Unterlassung zu erwirken. Hier kann eine Orientierung an den Begriffen des Strafrechts erfolgen, ${ }^{1455}$ die Verwirklichung eines Straftatbestands ist jedoch nicht erforderlich.

888 Um eine Bestechung handelt es sich insbesondere dann, wenn der Tatbestand des $\S 334$ I 1 StGB erfüllt ist. ${ }^{1456}$ Dies ist der Fall, wenn der Begünstigte einem für die zuständige Behörde tätigen Amtswalter einen Vorteil für diesen oder einen Dritten als Gegenleistung dafür gewährt (hat), dass jener eine Diensthandlung vorgenommen und dadurch seine Dienstpflichten verletzt hat. Eine Bestechung i.S.v. § 48 II 3 Nr. 1 VwVfG muss jedoch nicht zwingend diesen Straftatbestand erfüllen. Es genügt bereits eine Vorteilsgewährung i.S.v. § $333 \mathrm{StGB}^{1457}$ und jede andere versprochene oder erfolgte Vorteilsgewährung als Gegenleistung für einen entsprechenden verfahrenslenkenden Eingriff ${ }^{1458}$. Von Bedeutung sind insofern also nicht bloß Bestechungen von Amtswaltern, sondern auch von Zeugen. ${ }^{1459}$ Amtswalter müssen darüber hinaus die Rechtswidrigkeit des von ihnen erlassenen Verwaltungsakts nicht erkannt haben. ${ }^{1460}$

Der Begriff des Erwirkens verdeutlicht, dass die drei erfassten Handlungen für den Erlass des Verwaltungsakts zumindest objektiv mitursächlich gewesen sein müssen. ${ }^{1461}$ Wie bereits erwähnt müssen die Einwirkungen nicht zwingend gegenüber dem entscheidenden Amtswalter erfolgen. Bereits denklogisch verlangen alle Handlungen das Vorliegen von Vorsatz. Um ein Erwirken kann es sich auch dann handeln, wenn der Begünstigte die Handlungen nicht selbst vorge-

1453 Peuker, in: Knack/Henneke, VwVfG, 10. Aufl. 2014, § 48 Rn. 120.

1454 VGH Mannheim, Beschl. v. 9.5.1990, Az.: 13 S 2666/89 = NVwZ 1990, 1198 (1199)

1455 Kastner, in: Fehling/Kastner/Störmer, Verwaltungsrecht, 4. Aufl. 2016, § 48 VwVfG Rn. 46 1456 BVerwG, Urt. v. 22.3.2017, Az.: 5 C 4.16 = BVerwGE 158, 258 (265, Rn. 25).

1457 So zu Recht Ramsauer, in: Kopp/Ramsauer, VwVfG, 20. Aufl. 2019, § 48 Rn. 112; Kastner, in: Kastner/Fehling/Störmer, Verwaltungsrecht, 4. Aufl. 2016, § 48 VwVfG Rn. 46; Suerbaum, in: Mann/Sennekamp/Uechtritz, VwVfG, 2. Aufl. 2019, § 48 Rn. 134.

1458 J. Müller, in: Bader/Ronellenfitsch, VwVfG, 44. Ed., Stand: 1.1.2019, § 48 Rn. 70.

1459 BVerwG, Beschl.v. 27.10.2004, Az.: 4 B 74.04 = juris, Rn. 8.

1460 BVerwG, Beschl.v. 27.10.2004, Az.: 4 B 74.04 = juris, Rn. 8; Urt. v. 22.3.2017, Az.: 5 C $4.16=$ BVerwGE 158, 258 (265, Rn. 25).

1461 BVerwG, Beschl.v. 27.10.2004, Az.: 4 B 74.04 = juris, Rn. 8; Urt. v. 22.3.2017, Az.: 5 C $4.16=$ BVerwGE 158, 258 (265, Rn. 25).

Tobias Brings-Wiesen 
nommen, sondern im Wege der Anstiftung oder Beihilfe mit realisiert hat. ${ }^{1462}$ Das Handeln eines (gesetzlichen) Vertreters kann zugerechnet werden. ${ }^{1463}$

Darüber hinaus soll sich der Begünstigte nicht auf sein Vertrauen berufen können, wenn der den Verwaltungsakt durch Angaben erwirkt hat, die in wesentlicher Beziehung unrichtig oder unvollständig waren (Nr. 2).

Unrichtig sind Angaben, wenn sie schlicht nicht die objektive Tatsachenlage 891 wiedergeben. Unvollständig sind sie, wenn sie nicht dem von der Behörde erkennbar erwarteten Umfang entsprechen. ${ }^{1464}$ Entsprechende Erwartungen können bereits aus einer gesetzlichen Mitwirkungspflicht resultieren, sie können indes auch auf einen von der Behörde ausdrücklich geäußerten oder zumindest kontextual klar erkennbaren Willen zurückzuführen sein. ${ }^{1465}$ Wie hinsichtlich des Ausschlusstatbestands unter Nr. 1 wird verlangt, dass die Angaben für den Erlass des begünstigenden Verwaltungsakts mitursächlich waren. Demgegenüber ist ein Verschulden für die Anwendung des Ausschlusstatbestands unter Nr. 2 keine Voraussetzung. ${ }^{1466}$ Daher ist nicht von Bedeutung, ob der Begünstigte die Unrichtigkeit oder Unvollständigkeit kannte oder hätte kennen müssen. Wie sich auch der Gesetzesbegründung ergibt, ${ }^{1467}$ liegt der Vorschrift vielmehr die Idee einer Aufteilung von Risikosphären zugrunde. ${ }^{1468}$ So ist im Falle der Unvollstän-

1462 So bereits die Gesetzesmaterialien, BT-Drucks. 7/910, S. 70; Ramsauer, in: Kopp/Ramsauer, VwVfG, 20. Aufl. 2019, § 48 Rn. 111; Sachs, in: Stelkens/Bonk/Sachs, VwVfG, 9. Aufl. 2018, § 48 Rn. 151.

1463 BVerwG, Urt. v. 9.9.2003, Az.: 1 C 6.03 = BVerwGE 119, 17 (24): Verhalten eines Elternteils; Urt. v. 22.3.2017, Az.: 5 C 4.16 = BVerwGE 158, 258 (266, Rn. 28): Verhalten des Ehepartners. So auch Ramsauer, in: Kopp/Ramsauer, VwVfG, 20. Aufl. 2019, § 48 Rn. 114; Sachs, in: Stelkens/Bonk/ Sachs, VwVfG, 9. Aufl. 2018, § 48 Rn. 151.

1464 Ehlers/Kallerhoff, JURA 2009, 823 (830).

1465 Ehlers/Kallerhoff, JURA 2009, 823 (830). Vgl. zu einer Mitteilungspflicht auch BVerwG, Urt. v. 28.6.2012, Az.: 2 C 13.11 = BVerwGE 143, 230 (234, Rn. 18), hier indes hinsichtlich des Unterlassens der Mitteilung einer veränderten Sachlage, die zum Rechtswidrigwerden eines Dauerverwaltungsaktes geführt hat, und mangels „Erwirkens“ zu einer Berücksichtigung der Wertungen des § 48 II 3 Nr. 2 VwVfG im Rahmen der nach § 48 II 1 VwVfG erforderlichen Abwägung.

1466 BVerwG, Urt. v. 14.8.1986, Az.: 3 C 9.85 = BVerwGE 74, 357 (364); Urt. v. 20.10.1987, Az.: 9 C 255.86 = BVerwGE 78, 139 (142f.).

1467 BT-Drucks. 7/910, S. 70.

1468 Vgl. für ein besseres Verständnis des Konzepts den Sachverhalt bei BVerwG, Urt. v. 20.10. 1987, Az.: 9 C 255.86 = BVerwGE 78, 139 (142f.), für einen Fall, in dem eine Betroffene unbekannterweise unrichtige Urkunden einreichte. Hier handelt es sich insofern um ein gutes Beispiel dafür, warum ein Verschulden nicht verlangt werden kann, weil sonst die Risikoverteilung entgegen des gesetzgeberischen Willens zu stark zulasten der Behörde ginge. Dafür spricht in systematischer Hinsicht auch die Existenz von § 49a II 2 VwVfG, der gar nicht nötig wäre, wenn ein Verschulden bereits hier erfasst wäre, vgl. BVerwG, a. a. O. 
digkeit - wie bereits oben angedeutet - gegebenenfalls doch korrigierend nach Wertungsgesichtspunkten zu entscheiden, ob der Betroffene die Relevanz der Angaben erkennen konnte. ${ }^{1469}$ Die Angaben sind in wesentlicher Beziehung fehlerhaft, wenn sie für die Subsumtion unter den Tatbestand und eine gegebenenfalls erforderliche Ermessenserwägung relevant sind. ${ }^{1470}$

Zuletzt soll sich der Begünstigte nicht auf sein Vertrauen berufen können, wenn er die Rechtswidrigkeit des Verwaltungsakts kannte oder infolge grober Fahrlässigkeit nicht kannte (Nr. 3). Bezugspunkt der Kenntnis ist die Rechtswidrigkeit des Verwaltungsakts, nicht bloß die Kenntnis der Tatsachen, die diese Rechtswidrigkeit begründen. ${ }^{1471}$ Dementsprechend können die Voraussetzungen des Tatbestands auch erst zu einem späteren Zeitpunkt eintreten. ${ }^{1472}$ Wenige Schwierigkeiten wird regelmäßig die Feststellung der positiven Kenntnis der Rechtswidrigkeit bereiten. Sie wird jedoch zugleich entsprechend selten in Erscheinung treten. Relevanter sind die Konstellationen grob fahrlässiger Unkenntnis. Grobe Fahrlässigkeit liegt vor, wenn der Begünstigte die erforderliche Sorgfalt in besonders schwerem Maße verletzt hat. ${ }^{1473}$ Hinsichtlich der erforderlichen Sorgfalt gilt ein konkret-individueller Maßstab in Ansehen der konkret betroffenen Person ${ }^{1474}$ und der sonstigen Umstände des Sachverhalts. Insofern lässt sich grob abstufen: Fehlen besondere Anhaltspunkte im Sachverhalt, ist im Rahmen einer „Parallelwertung in der Laiensphäre“1475 auf das durchschnittliche Rechtsverständnis eines Normalbürgers abzustellen. ${ }^{1476}$ Da dieser grundsätzlich auf ein rechtmäßiges Handeln der Behörde vertrauen darf, wird man ihm nur im Falle offensichtlicher, sich aufdrängender Zweifel an der Rechtmäßigkeit die Pflicht auferlegen können, einen Verwaltungsakt unter Verwendung zusätzlicher Erkenntnismittel oder gar einer Erkundigung bei der Behörde zu überprüfen. ${ }^{1477}$

1469 S. dazu BVerwG, Urt. v. 6.6.1991, Az.: 3 C 46.86 = BVerwGE 88, 278 (285), unter Verweis BVerwG, Urt. v. 25.10.1978, Az.: 8 C 55.75 = BVerwGE 56, 354 (358), wo die Behörde den Mangel eines Antragsformulars gegen sich gelten lassen musste.

1470 Sachs, in: Stelkens/Bonk/Sachs, VwVfG, 9. Aufl. 2018, § 48 Rn. 154.

1471 Ramsauer, in: Kopp/Ramsauer, VwVfG, 20. Aufl. 2019, § 48 Rn. 122; Kastner, in: Fehling/ Kastner/Störmer, Verwaltungsrecht, 4. Aufl. 2016, § 48 VwVfG Rn. 48.

1472 Ramsauer, in: Kopp/Ramsauer, VwVfG, 20. Aufl. 2019, § 48 Rn. 121; Sachs, in: Stelkens/ Bonk/Sachs, VwVfG, 9. Aufl. 2018, § 48 Rn. 159.

1473 BVerwG, Urt. v. 17.2.1993, Az.: 11 C 47.92 = BVerwGE 92, 81 (84); so auch Ramsauer, in: Kopp/ Ramsauer, VwVfG, 20. Aufl. 2019, § 48 Rn. 124; Sachs, in: Stelkens/Bonk/Sachs, VwVfG, 9. Aufl. 2018, § 48 Rn. 161.

1474 So bereits die Gesetzesmaterialien, BT-Drucks. 7/910, S. 70.

1475 Ramsauer, in: Kopp/Ramsauer, VwVfG, 20. Aufl. 2019, § 48 Rn. 122.

1476 Sachs, in: Stelkens/Bonk/Sachs, VwVfG, 9. Aufl. 2018, § 48 Rn. 162.

1477 Vgl. OVG Lüneburg, Beschl. v. 31.3.2010, Az.: 4 LC 281/08 = NJW 2010, 2061 (2062).

Tobias Brings-Wiesen 
Die individuellen Kenntnisse und Fähigkeiten des Begünstigten (oder seines Vertreters ${ }^{1478}$ ) und die besonderen Umstände des Einzelfalls können jedoch die Sorgfaltsanforderungen erhöhen, so insbesondere im Falle von Unternehmen mit eigenen Rechtsabteilungen, Personen mit juristischer Vorbildung ${ }^{1479}$ oder auch Beamten ${ }^{1480}$. Es besteht jedoch auch in diesem Fall keine generelle, anlasslose Nachforschungspflicht. ${ }^{1481}$

Greift einer dieser drei Tatbestände, kann die Prüfung von § 48 II VwVfG an dieser Stelle beendet werden: Da der Begünstigte sich gemäß § 48 II 3 VwVfG nicht auf sein Vertrauen berufen kann, überwiegt gemäß § 48 II 1 VwVfG zwangsläufig das öffentliche Interesse an der Rücknahme des Verwaltungsakts. ${ }^{1482}$ Wiederum bedarf es dann nur noch der Prüfung eines möglichen Rücknahmeausschlusses aufgrund von Verfristung gemäß § 48 IV VwVfG sowie der ordnungsgemäßen Ermessensausübung gemäß § 48 I 1 VwVfG. Dabei sind jedoch sodann zwei Besonderheiten $\mathrm{zu}$ berücksichtigen: Sofern von einer Erwirkung des Verwaltungsakts durch arglistige Täuschung, Drohung oder Bestechung (§ 48 II 3 Nr. 1 VwVfG) ausgegangen wird, ist die Anwendung der Fristenregelung gemäß § 48 IV 2 VwVfG ausgeschlossen (s. dazu Rn. 906). Wird nur einer der Ausschlusstatbestände bejaht, bestimmt § 48 II 4 VwVfG, dass der Verwaltungsakt in der Regel mit Wirkung für die Vergangenheit zurückzunehmen ist (s. dazu Rn. 927).

\section{Regelvermutung des \$ 48 II 2 VwVfG}

Greift indes keiner der Ausschlusstatbestände, kann nun § 48 II 2 VwVfG umge894 kehrt zum Vorteil des Begünstigten wirken. Danach ist sein Vertrauen in der Regel schutzwürdig, wenn er die gewährte Leistung verbraucht oder eine Vermögensdisposition getroffen hat, die er nicht mehr oder nur unter unzumutbaren Nachteilen rückgängig machen kann. An dieser Stelle wird die Vertrauensbetätigung relevant. Bereits der Wortlaut (,in der Regel“) verdeutlicht, dass damit die nach § 48 II 1 VwVfG eigentlich erforderliche Abwägung keineswegs vorweggenommen wird. Sie wird jedoch entscheidend vorgeprägt (s. dazu Rn. 899).

1478 Ramsauer, in: Kopp/Ramsauer, VwVfG, 20. Aufl. 2019, § 48 Rn. 123.

1479 Ramsauer, in: Kopp/Ramsauer, VwVfG, 20. Aufl. 2019, § 48 Rn. 125.

1480 BVerwG, Urt. v. 13.11.1986, Az.: 2 C 29.84 = NVwZ 1987, 500, betr. einen Ruhestandsbeamten. 1481 Vgl. dazu im beihilferechtlichen Kontext BVerwG, Urt. v. 17.2.1993, Az.: 11 C $47.92=$ BVerwGE 92, 81 (84), allerdings noch zur alten Rechtslage, bevor mit der ersten einschlägigen Mitteilung der Kommission (ABl. EG Nr. C 318 v. 24.11.1983, S. 3) allgemein auf die Möglichkeit einer Rückforderung bei fehlender Notifikation gemäß dem - heutigen - Art. 108 III AEUV hingewiesen wurde. S. zu diesem Themenkomplex noch Rn. 935.

1482 So auch Ehlers/Kallerhoff, JURA 2009, 823 (830). 
Die gewährten Leistungen sind verbraucht, wenn sie sich bei wirtschaftlicher Betrachtung nicht mehr im Vermögen des Begünstigten befinden. Dabei sind laut Bundesverwaltungsgericht die zivilrechtlichen Grundsätze zum Umfang des Bereicherungsanspruchs nach § 818 BGB heranzuziehen. ${ }^{1483}$ Entsprechend § 818 III BGB ist somit insbesondere eine mögliche Entreicherung zu prüfen, die jedoch dann nicht gegeben ist, wenn eine (Geld-)Leistung verwendet wurde, um Anschaffungen vorzunehmen, die sich wertmäßig noch im Vermögen des Begünstigten befinden ${ }^{1484}$ oder nur Ausgaben erspart wurden, die auch sonst bestanden hätten, ${ }^{1485}$ insbesondere im Falle der Schuldentilgung ${ }^{1486}$. Handelte es sich dagegen um (nur geringfügig gesteigerte ${ }^{1487}$ ) Ausgaben des täglichen Lebens, ${ }^{1488}$ denen insbesondere die Leistungsgewährung auch dienen soll, ${ }^{1489}$ ist von einer Entreicherung auszugehen.

896 Der Begriff der Vermögensdispositionen wird weit ausgelegt. Dazu gehören all jene Verhaltensweisen des Begünstigten, die im Vertrauen auf den begünstigenden Verwaltungsakt erfolgt sind und Auswirkungen auf seine Vermögenssituation haben. ${ }^{1490}$ Der Ursachenzusammenhang ist dabei von besonderer Bedeutung. ${ }^{1491}$ Dies ist insbesondere mit Blick auf § 48 III VwVfG von Relevanz, für den sowohl hinsichtlich des Entschädigungsanspruchs ${ }^{1492}$ als auch hinsichtlich der Ermessensausübung (s. dazu Rn. 928) auf (die Wertungen des) § 48 II VwVfG zurückzugreifen ist. So kann beispielsweise im kostenpflichtigen Erstellenlassen von Bauplänen im Vertrauen auf eine Baugenehmigung ${ }^{1493}$ oder im Inverkehrbringen von BSE-belastetem Fleisch im Vertrauen auf eine Genusstauglichkeitsbescheinigung, weil sich der Hersteller möglichen Ersatzansprüchen seiner Abnehmer aussetzt, eine Vermögensdisposition liegen. ${ }^{1494}$ Hinzukommen muss jedoch, dass die Disposition nicht mehr oder nur unter unzumutbaren

1483 BVerwG, Urt. v. 28.1.1993, Az.: 2 C 15.91 = NVwZ-RR 1994, 32 (33).

1484 S. dazu BVerwG, Urt. v. 28.1.1993, Az.: 2 C 15.91 = NVwZ-RR 1994, 32 (33).

1485 VGH München, Beschl. v. 24.9.2002, Az.: 19 B 98.945 = BeckRS 2003, 20336.

1486 BVerwG, Urt. v. 28.1.1993, Az.: 2 C 15.91 = NVwZ-RR 1994, 32 (33).

1487 BVerwG, Urt. v. 28.1.1993, Az.: 2 C 15.91 = NVwZ-RR 1994, 32 (33).

1488 Ehlers/Kallerhoff, JURA 2009, 823 (831).

1489 Vgl. Maurer/Waldhoff, Allgemeines Verwaltungsrecht, 19. Aufl. 2017, § 11 Rn. 37: „Besoldungsbezüge, Renten, Stipendien“.

1490 Ramsauer, in: Kopp/Ramsauer, VwVfG, 20. Aufl. 2019, § 48 Rn. 109; OVG Münster, Urt. v. 9. 5. 2011, Az.: 1 A 88/08 = BeckRS 2011, 51124.

1491 OVG Münster, Urt. v. 9.5.2011, Az.: 1 A 88/08 = BeckRS 2011, 51124.

1492 BVerwG, Urt. v. 28.1.2010, Az.: 3 C 17.09 = BVerwGE 136, 43 (45f., Rn. 12).

1493 Ramsauer, in: Kopp/Ramsauer, VwVfG, 20. Aufl. 2019, § 48 Rn. 109.

1494 BVerwG, Urt. v. 28.1.2010, Az.: 3 C 17.09 = BVerwGE 136, 43 (46f., Rn. 16)

Tobias Brings-Wiesen 
Nachteilen rückgängig ${ }^{1495} \mathrm{zu}$ machen ist. Sie können bereits aus tatsächlichen Gründen irreversibel sein - so wie in den genannten Beispielen der Bauplan als Werkleistung nicht einfach wieder verschwinden, das Inverkehrbringen nicht ungeschehen gemacht werden kann. Denkbar ist aber auch, dass Rückabwicklungen von Rechts wegen unmöglich sind. ${ }^{1496}$ Die Unzumutbarkeit einer Rückabwicklung ist indes nach den individuellen Verhältnissen des Betroffenen zu beurteilen. ${ }^{1497}$

\section{Abschließende Abwägung zwischen schutzwürdigem Vertrauen und öf- fentlichem Interesse gemäß § 48 II 1 VwVfG}

Nach Abschluss der drei vorstehenden Prüfungspunkte darf die nach § 48 II 1897 VwVfG erforderliche Abwägung als Ausgangspunkt dieses Prüfungsabschnitts nicht unterschlagen werden. Es ist zu prüfen, ob das Vertrauen des Begünstigten auf den Bestand des Verwaltungsakts unter Abwägung mit dem öffentlichen Interesse an einer Rücknahme schutzwürdig ist. Es muss ,eine wertende Abwägung der Gesichtspunkte, die für eine Aufrechterhaltung des begünstigenden Hoheitsaktes sprechen, gegen das öffentliche Interesse an der Herstellung des an sich nach den maßgeblichen Rechtsvorschriften gebotenen Rechtszustandes“ erfolgen. ${ }^{1498}$

Auf Seiten der Behörde steht das dem Grundsatz der Gesetzmäßigkeit der 898 Verwaltung entspringende Interesse an der Wiederherstellung rechtmäßiger Zustände. Die dem einschlägigen Fachrecht zugrundeliegenden Regulierungsinteressen können dieses allgemeine Interesse im Einzelfall verstärken. Daneben tritt im Falle von Leistungsverwaltungsakten auch das fiskalische Interesse des Staates an der Vermeidung ungerechtfertigter Ausgaben ${ }^{1499}$ und deren Rückführung in den Haushalt ${ }^{1500}$. Handelt es sich um auf einem Dauerverwaltungsakt

1495 Detterbeck, Allgemeines Verwaltungsrecht, 17. Aufl. 2019, Rn. 700, plädiert im Interesse des Gleichlaufs darüber hinaus für eine entsprechende Anwendung der zivilrechtlichen Grundsätze des Bereicherungsrechts auch auf Vermögensdispositionen.

1496 OVG Münster, Urt. v. 9.5.2011, Az.: 1 A 88/08 = BeckRS 2011, 51124.

1497 J. Müller, in: Bader/Ronellenfitsch, VwVfG, 44. Ed., Stand: 1.1.2019, § 48 Rn. 67.

1498 Vgl. BVerwG, Urt. v. 31.8. 2006, Az.: 7 C 16.05 = juris, Rn. 24; Urt. v. 19. 2.2009, Az.: 8 C 4.08 = juris, Rn. 45; VGH München, Urt. v. 9.3.1999, Az.: 9 B 96.1786 = juris, Rn. 27; OVG Bautzen, Urt. v. 19.2.2008, Az.: 1 B 538/06 = juris, Rn. 24; Ramsauer, in: Kopp/Ramsauer, VwVfG, 20. Aufl. 2019, $\S 48$ Rn. 98.

1499 BVerwG, Beschl. v. 25.6.1986, Az.: 1 WB 166.84 = BVerwGE 83, 195 (199); Urt. v. 31.8.2006, Az.: 7 C 16.05 = juris, Rn. 25.

1500 Ramsauer, in: Kopp/Ramsauer, VwVfG, 20. Aufl. 2019, § 48 Rn. 99. 
beruhende, regelmäßig wiederkehrende Leistungen wird für die Zukunft häufig ein erhebliches fiskalisches Interesse daran bestehen, dass diese Leistungen nicht weitergezahlt werden. ${ }^{1501}$ Eine derartige Differenzierung in zeitlicher Hinsicht (Vergangenheit - Zukunft) ist ausweislich des Wortlauts („soweit“) genauso möglich wie ein bloß sachlich anteiliger Vertrauensschutz.

Auf Seiten des Begünstigten sind alle im unmittelbaren Zusammenhang mit seinem Vertrauen auf den Bestand des Verwaltungsakts stehenden Erwägungen zu berücksichtigen. Vorrangig ist zu beachten, dass im Falle einer Vertrauensbetätigung gemäß $\S 48$ II 2 VwVfG das öffentliche Interesse an der Wiederherstellung gesetzmäßiger Verhältnisse nur noch in Ausnahmefällen überwiegen soll. ${ }^{1502}$ Zusätzlich sind die das Vertrauen erzeugenden oder vernichtenden Umstände in die Betrachtung einzubeziehen, soweit sie nicht bereits durch $\S 48$ II 2, 3 VwVfG Berücksichtigung gefunden haben: Ein Fehlen jeglicher Mitverantwortung des Begünstigten für die Fehlerhaftigkeit, eine besondere Förmlichkeit des Verfahrens oder ein besonders langer Zeitraum seit Erlass des Verwaltungsakts können für die Schutzwürdigkeit sprechen; ein Widerrufsvorbehalt oder eine aus sonstigen Gründen bestehende Erwartung der Aufhebung können dagegen sprechen. ${ }^{1503}$ Der Schutz des Vertrauens soll jedoch kein Selbstzweck sein, sondern gerade die dahinterstehenden materiellen Rechte des Begünstigten in den Blick nehmen. ${ }^{1504}$ Entsprechend sind auch die Folgen der Rücknahme und ihre Verhältnismäßigkeit im Hinblick auf die Rechtsgüter des Begünstigten zu berücksichtigen. ${ }^{1505} \mathrm{Zu}$ weit geht es jedoch, bereits im Tatbestand die schutzwürdigen Interessen aller Betroffenen zu berücksichtigen. ${ }^{1506}$ Dagegen spricht bereits der Wortlaut der Norm, der klar auf das Vertrauen des Begünstigten abstellt. Dies ist vielmehr eine Frage der ordnungsgemäßen Ermessensausübung (s. Rn. 927).

1501 BVerwG, Urt.v. 28.10.2004, Az.: 2 C 13.03 = NVwZ-RR 2005, 341 (342). Dieses muss aber nicht zwingend immer zur Rücknahme führen, vgl. die Umstände in BVerwG, Urt. v. 26.9.1991, Az.: 5 C 14.87 = NVwZ-RR 1992, 485 (486).

1502 Ramsauer, in: Kopp/Ramsauer, VwVfG, 20. Aufl. 2019, § 48 Rn. 103.

1503 J. Müller, in: Bader/Ronellenfitsch, VwVfG, 44. Ed., Stand: 1.1.2019, § 48 Rn. 60. S. dazu auch Peuker, in: Knack/Henneke, VwVfG, 10. Aufl. 2014, § 48 Rn. $111 \mathrm{ff}$.

1504 Vgl. VG Oldenburg, Urt. v. 23.5.2001, Az.: 2 A 790/99 = NVwZ 2002, 119 (121); J. Müller, in: Bader/Ronellenfitsch, VwVfG, 44. Ed., Stand:1.1.2019, § 48 Rn. 60.

1505 Maurer/Waldhoff, Allgemeines Verwaltungsrecht, 19. Aufl. 2017, §11 Rn. 38. Vgl. auch BVerwG, Urt. v. 11.2.1982, Az.: 2 C 9.81 = BeckRS 1982, 31268995.

1506 So aber Ramsauer, in: Kopp/Ramsauer, VwVfG, 20. Aufl. 2019, § 48 Rn. 101; wohl auch Maurer/Waldhoff, Allgemeines Verwaltungsrecht, 19. Aufl. 2017, § 11 Rn. 38. 


\section{(b) Sonstige Verwaltungsakte}

Für die Rücknahme sonstiger Verwaltungsakte enthält §48 III VwVfG zwar 900 keine zusätzlichen Tatbestandsvoraussetzungen.

Die Norm enthält aber einen eigenen Entschädigungsanspruch zugunsten 901 des Betroffenen. Bereits diese Unterscheidung ist elementar: Wird die Rücknahmeentscheidung der Behörde geprüft, ist § 48 III VwVfG im Tatbestand unter keinen Umständen näher zu prüfen. Alles andere zeugte von fehlendem Systemverständnis. Sehr wohl Erwähnung finden kann er allerdings im Rahmen der Prüfung der ordnungsgemäßen Ermessensausübung, dies jedoch - wie noch zu zeigen sein wird (s. dazu Rn. 928) - nur in zweierlei Hinsicht: Das schutzwürdige Vertrauen des Begünstigten ist - nach richtiger Auffassung - unter Berücksichtigung der Wertungen, die in § 48 II VwVfG ihren Ausdruck gefunden haben, ${ }^{1507}$ sowie unter Berücksichtigung der Möglichkeit, dieses im Wege des Entschädigungsanspruchs nach § 48 III VwVfG zu realisieren, in die Ermessensausübung einzubeziehen. ${ }^{1508}$

Der Entschädigungsanspruch an sich kommt ausweislich § 48 III 1 VwVfG 902 erst in Frage, wenn eine wirksame Rücknahmeentscheidung der Behörde vorliegt. Auch hieran zeigt sich noch einmal, dass zwischen beiden Fragestellungen zwingend zu trennen ist. Der Ausgleich des ihm entstandenen Vermögensnachteils erfolgt nur auf Antrag des Betroffenen und wird von der Behörde gemäß $\S 48$ III 4 VwVfG durch Verwaltungsakt festgesetzt. Kommt es also zu einer Ablehnung des Antrags, kann der Betroffene Festsetzung der Entschädigung im Wege des Widerspruchs (§68 II VwGO) bzw. im Wege der Verpflichtungsklage (§ 42 I Var. 2 VwGO, in Form der Versagungsgegenklage) erzwingen. ${ }^{1509}$ Entsprechend ist er wegen der öffentlich-rechtlichen Natur des Entschädigungsanspruchs auf dem Verwaltungsrechtsweg geltend zu machen. ${ }^{1510}$

In der Prüfung sollte wie folgt vorgegangen werden: ${ }^{1511}$ Anspruchsgrundlage 903 ist $§ 48$ III 1 VwVfG. In formeller Hinsicht bedarf es gemäß § 48 III 1 VwVfG des Antrags bei der Behörde, die den Verwaltungsakt zurückgenommen hat. In materieller Hinsicht muss (1) ein rechtswidriger begünstigender Verwaltungsakt

1507 Unter Rekurs auf diese „Wertungen“ wird kenntlich, dass die Vorschrift keineswegs unmittelbar angewandt wird.

1508 S. dazu nur Ehlers/Kallerhoff, JURA 2009, 823 (832).

1509 Ramsauer, in: Kopp/Ramsauer, VwVfG, 20. Aufl. 2019, § 48 Rn. 144.

1510 Maurer/Waldhoff, Allgemeines Verwaltungsrecht, 19. Aufl. 2017, § 11 Rn. 52.

1511 S. dazu m.w. N. nur Maurer/Waldhoff, Allgemeines Verwaltungsrecht, 19. Aufl. 2017, § 11 Rn. $49 \mathrm{ff}$. 
i.S.v. § 48 I 2, III VwVfG (2) wirksam ${ }^{1512}$ zurückgenommen worden sein, wodurch (3) dem Antragssteller ein Vermögensnachteil entstanden ist, der (4) darauf zurückgeht, dass er auf den Bestand des Verwaltungsakts vertraut hat, soweit sein Vertrauen unter Abwägung mit dem öffentlichen Interesse schutzwürdig ist (was entgegen der Beschränkung des Verweises in § 48 III 2 VwVfG auf § 48 II 3 VwVfG jedoch unter entsprechender Berücksichtigung der Wertungen des § 48 II VwVfG insgesamt $\mathrm{zu}$ erfolgen hat ${ }^{1513}$ ). Zuletzt (5) darf der Anspruch insbesondere nicht gemäß § 48 III 5 VwVfG verfristet sein, wobei die Frist erst nach einem entsprechenden Hinweis der Behörde zu laufen beginnt.

Gerichtet ist der Anspruch auf den Ausgleich des durch die Rücknahme entstandenen Vertrauensschadens, wobei jedoch ein Mitverschulden des Betroffenen entsprechend reduzierend berücksichtigt werden kann ${ }^{1514}$.

\section{(c) Kein Ausschluss aufgrund von Verfristung gemäß § 48 IV VwVfG}

905 Gemäß § 48 IV 1 VwVfG kann die Rücknahme eines begünstigenden Verwaltungsakts $^{1515}$ ausnahmsweise ${ }^{1516}$ ausgeschlossen ${ }^{1517}$ sein, wenn die zuständige Behörde diese nicht innerhalb eines Jahres, nachdem sie von Tatsachen Kenntnis erlangt hat, welche die Rücknahme rechtfertigen, bekanntgibt ${ }^{1518}$. Die Vorschrift ist das letzte Glied der Kette von dem Vertrauensschutz des Begünstigten dienenden Vorgaben in $\S 48$ VwVfG. Sie kann spezialgesetzlich verdrängt oder ergänzt werden. ${ }^{1519}$ Gemäß $§ § 49$ II 2, III 2 VwVfG gilt sie entsprechend für den Widerruf von begünstigenden Verwaltungsakten. Ihre Anwendung zwischen Verwaltungsträgern ist umstritten. ${ }^{1520}$

1512 Maßgeblich wird insbesondere eine etwaige Nichtigkeit sein, vgl. dazu OVG Münster, Urt. v. 12.7.2012, Az.: 10 A 1769/10 = NVwZ-RR 2012, 953 (954).

1513 S. nur BVerwG, Urt. v. 28.1.2010, Az.: 3 C 17.09 = BVerwGE 136, 43 (45f., Rn. 12).

1514 Ramsauer, in: Kopp/Ramsauer, VwVfG, 20. Aufl. 2019, § 48 Rn. 142.

1515 Der Ausschlusstatbestand gilt angesichts des klaren Wortlauts von § 48 I 2 VwVfG nicht für belastende Verwaltungsakte, Ramsauer, in: Kopp/Ramsauer, VwVfG, 20. Aufl. 2019, § 48 Rn. 150; Sachs, in: Stelkens/Bonk/Sachs, VwVfG, 9. Aufl. 2018, § 48 Rn. 199.

1516 Das zeitlich unbeschränkte Rücknahmerecht bleibt die Regel, während sein Ausschluss die Ausnahme bildet, Sachs, in: Stelkens/Bonk/Sachs, VwVfG, 9. Aufl. 2018, § 48 Rn. 203.

1517 Es handelt sich um eine Ausschlussfrist, Sachs, in: Stelkens/Bonk/Sachs, VwVfG, 9. Aufl. 2018, § 48 Rn. 204.

1518 Dies ist jedoch umstritten, dazu ausführlich Broscheit, DVBl 2017, 1274. Ebenso auf den Zeitpunkt der Bekanntgabe abstellend Ramsauer, in: Kopp/Ramsauer, VwVfG, 20. Aufl. 2019, § 48 Rn. 152; J. Müller, in: Bader/Ronellenfitsch, VwVfG, 44. Ed., Stand: 1.1.2019, § 48 Rn. 117.2.

1519 Sachs, in: Stelkens/Bonk/Sachs, VwVfG, 9. Aufl. 2018, § 48 Rn. 203.

1520 Gegen eine Anwendbarkeit Sachs, in: Stelkens/Bonk/Sachs, VwVfG, 9. Aufl. 2018, § 48 Rn. 202, m.w. N. auch zur Gegenansicht.

Tobias Brings-Wiesen 
Der Ausschlusstatbestand ist gemäß § 48 IV 2 VwVfG nicht anwendbar, 906 wenn der Begünstigte den Verwaltungsakt gemäß § 48 II 3 Nr. 1 VwVfG durch arglistige Täuschung, Drohung oder Bestechung erwirkt hat. Obgleich nicht klar ersichtlich gilt dies auch für Verwaltungsakte, die gemäß § 48 III VwVfG zurückzunehmen sind, ${ }^{1521}$ obwohl für sie die Ausschlusstatbestände des $§ 48$ II 3 VwVfG sonst höchstens im Rahmen des Ermessens Berücksichtigung finden (s. dazu Rn. 901). Diese Verwaltungsakte sind zeitlich unbeschränkt rücknehmbar. ${ }^{1522}$

Bei § 48 IV 1 VwVfG handelt es sich sodann um eine der meistdiskutier- 907 ten Vorschriften des allgemeinen Verwaltungsrechts. Die zahlreichen, über mehrere Jahrzehnte unter Auseinandersetzung mit verschiedenen Entwicklungen in der Rechtsprechung vertretenen Ansätze zu ihrer Auslegung können und sollen an dieser Stelle nicht umfassend - schon gar nicht unter Berücksichtigung all ihrer Nuancierungen - dargestellt werden. Wichtig ist jedoch, zumindest die drei zentralen Problemkomplexe und die sie betreffenden Grundpositionen richtig zu erfassen. Sie sind beständig wiederkehrende Probleme verwaltungsrechtlicher Prüfungen.

(1) Umstritten ist zunächst, was i.S.d. Vorschrift unter „Tatsachen [...], 908 welche die Rücknahme eines rechtswidrigen Verwaltungsakts rechtfertigen“, zu verstehen ist. Von diesem Verständnis hängt nicht nur der Fristbeginn ${ }^{1523}$, sondern maßgeblich bereits der Anwendungsbereich der Vorschrift ab. Um die Kontroverse um die Auslegung zu verstehen, ist es hilfreich, sich vorab vor Augen $\mathrm{zu}$ führen, dass der Erlass eines bereits ursprünglich rechtswidrigen Verwaltungsakts auf Fehler zurückzuführen sein kann, die zwei unterschiedlichen Fehlerkreisen entspringen: Entweder ist die Behörde bereits von einem unvollständigen oder falschen Sachverhalt ausgegangen oder sie hat bei umfassender und richtiger Erfassung der Faktenlage nur das einschlägige Recht falsch angewendet. Fehler aus beiden Kreisen können letztlich die Rechtswidrigkeit eines Verwaltungsakts begründen, ${ }^{1524}$ bei Letzteren handelt es sich jedoch um reine ${ }^{1525}$

1521 Vgl. nur BVerwG, Urt.v. 23.5.1995, Az.: 1 C 3.94 = BVerwGE 98, 298 (312); Sachs, in: Stelkens/ Bonk/Sachs, VwVfG, 9. Aufl. 2018, § 48 Rn. 209.

1522 Sachs, in: Stelkens/Bonk/Sachs, VwVfG, 9. Aufl. 2018, § 48 Rn. 201.

1523 Die Frist beginnt anders als bspw. nach $\S 45$ III SGB X nicht mit der Bekanntgabe des zurückzunehmenden Verwaltungsakts.

1524 So auch der Große Senat des BVerwG, Beschl. v. 19.12.1984, Az.: BVerwG Gr. Sen. 1 und 2.84 = BVerwGE 70, 356 (358).

1525 Hierin liegt der zentrale Unterschied. Auch das Zugrundelegen eines unvollständigen oder unrichtigen Sachverhalts führt im Ergebnis zu einer falschen Rechtsanwendung, deren Ursprung liegt jedoch in einer falschen Vorstellung von der Wirklichkeit und nicht in einer falschen Vorstellung vom Recht begründet. 
Rechtsanwendungsfehler. Umstritten ist nun, ob beide Fehlerkreise auch von $\S 48$ IV VwVfG erfasst werden.

909 So wird vertreten, dass mit „Tatsachen [...], welche die Rücknahme eines rechtswidrigen Verwaltungsakts rechtfertigen“, ausschließlich die tatsächlichen Umstände des dem Verwaltungsakt zugrundeliegenden Sachverhalts gemeint sind. Daraus werden sodann wiederum zwei unterschiedliche Schlussfolgerungen abgeleitet: Eine Ansicht ${ }^{1526}$ schließt daraus, dass erst später erkannte Rechtsanwendungsfehler für den Fristbeginn unerheblich sind. Ist der Sachverhalt zum Zeitpunkt der Entscheidung ${ }^{1527}$ ausermittelt, beginnt deren Lauf folglich bereits mit dem Erlass des Verwaltungsakts, ${ }^{1528}$ sodass eine danach eintretende positive Kenntnis der Behörde von ihrem Rechtsanwendungsfehler irrelevant sein soll. Eine andere Ansicht ${ }^{1529}$ schließt daraus hingegen, dass die Ausschlussfrist auf Rechtsanwendungsfehler schlicht nicht anwendbar ist, was wiederum eine unbefristete Rücknahme ermöglicht.

Die Gegenansicht, die insbesondere vom Bundesverwaltungsgericht ${ }^{1530}$ vertreten wird, wendet § 48 IV VwVfG indes auch auf besagte reine Rechtsanwendungsfehler an, sprich „Fälle, in denen die Behörde bei voller Kenntnis des entscheidungserheblichen Sachverhalts unrichtig entschieden hat"1531 und dies nachträglich erkennt. Zwar verlangt die Norm nach „Tatsachen“, dieser Terminus soll jedoch in seinem sprachlichen Zusammenhang verstanden werden: Verlangt sind eben „Tatsachen“, die eine Rücknahme „rechtfertigen“. Wie dargelegt kann der Grund für eine Rücknahme jedoch auch in einem Rechtsanwendungsfehler liegen, ohne dass die Vorschrift näher zwischen beiden Fehlerkreisen unterscheiden würde. ${ }^{1532}$ Dies soll auch vor dem Hintergrund überzeugen, dass sich beide Kreise nicht nur schwer voneinander abgrenzen lassen, sondern bisweilen

1526 So noch BVerwG, Urt.v. 25. 6.1982, Az.: 8 C 122.81 = BVerwGE 66, 61 (63ff.); OVG Berlin, Urt.v. 29.10.1982, Az.: OVG 2 B 153/80 = NJW 1983, 2156.

1527 Der Anwendungsbereich der Vorschrift ist nicht beschränkt auf Fälle nachträglicher Kenntnisnahme, BVerwG, Urt. v. 25.6.1982, Az.: 8 C 122.81 = BVerwGE 66, 61 (63).

1528 Nicht aber bereits zu einem tatsächlich denkbaren früheren Zeitpunkt, da die Rücknahme denklogisch erst nach dem Erlass möglich wird, BVerwG, Urt. v. 25.6.1982, Az.: 8 C $122.81=$ BVerwGE 66, 61 (64f.).

1529 So noch VGH München, Urt. v. 20.5.1983, Az.: 23 B 81 A.1968 = DVBl 1983, 946 (947f.); OVG Münster, Urt. v. 24.7.1984, Az.: 13 A 1910/83 = NVwZ 1984, 734.

1530 Grundlegend Großer Senat des BVerwG, Beschl. v. 19.12.1984, Az.: BVerwG Gr. Sen. 1 und 2.84 = BVerwGE 70, 356 (357 ff.); zuletzt ausdrücklich aufrechterhalten in Beschl.v. 29. 8. 2014, Az.: 4 B 1.14 = juris, Rn. 4 ff. Zum Meinungsstand vor dem Beschluss des Großen Senats, a.a.O., s. Hendler, JuS 1985, 947 (947 ff.).

1531 BVerwG, Beschl. v. 19.12.1984, Az.: BVerwG Gr. Sen. 1 und 2.84 = BVerwGE 70, 356 (357). 1532 BVerwG, Beschl. v. 19.12.1984, Az.: BVerwG Gr. Sen. 1 und 2.84 = BVerwGE 70, 356 (358f.). 
ununterscheidbar überlagern. ${ }^{1533}$ In systematischer Hinsicht wird zusätzlich auf den Ausnahmetatbestand des §48 IV 2 VwVfG verwiesen, der durch die Inbezugnahme von § 48 II 3 Nr. 1 VwVfG auch Konstellationen der Drohung oder Bestechung erfasse, bei denen die Rechtswidrigkeit des Verwaltungsakts (regelmäßig) nur auf reinen Rechtsanwendungsfehlern beruht und der folglich deren Subsumtion unter § 48 IV 1 VwVfG voraussetze, um nicht mehrheitlich überflüssig zu sein. ${ }^{1534}$ Dies soll zuletzt auch der Telos der Norm bestätigen: Soll im Interesse der Gesetzmäßigkeit der Verwaltung die grundsätzliche Möglichkeit der Rücknahme bei Rechtswidrigkeit bestehen, ist nicht ersichtlich, warum die beiden Fehlerkreise unterschiedlich behandelt werden sollten. ${ }^{1535}$ Den beiden genannten Gegenansichten (s. dazu Rn. 909) gelinge es nicht auf die gleiche Art und Weise die widerstreitenden Interessen (Gesetzmäßigkeit der Verwaltung; Rechtssicherheit und Vertrauensschutz) in Ausgleich zu bringen. Angesichts all dessen ${ }^{1536}$ überzeugt die Position des Bundesverwaltungsgerichts. ${ }^{1537}$

(2) Daran anknüpfend stellt sich sodann die Frage, wann im Sinne der Vorschrift „Kenntnis“ vorliegt und somit die Jahresfrist zu laufen beginnt. Diesbezüglich werden im Wesentlichen zwei Positionen vertreten, die die Frist des $\S 48$ IV 1 VwVfG entweder im Sinne einer „Bearbeitungsfrist“ oder im Sinne einer „Entscheidungsfrist“ interpretieren.

Eine starke Ansicht in der Literatur erkennt eine Bearbeitungsfrist. ${ }^{1538}$ Der 912 Fristlauf soll in dem Moment beginnen, in dem die Behörde Kenntnis von der Tatsache erlangt, die die Rechtswidrigkeit des Verwaltungsakts und somit dessen Rücknehmbarkeit begründet. Insbesondere das Bundesverwaltungsgericht sieht in § 48 IV 1 VwVfG jedoch eine Entscheidungsfrist: Neben der Rechtswidrigkeit des Verwaltungsakts müssten die für die Rücknahme außerdem erhebli-

1533 BVerwG, Beschl. v. 19.12.1984, Az.: BVerwG Gr. Sen. 1 und 2.84 = BVerwGE 70, 356 (360f.). 1534 BVerwG, Beschl. v. 19.12.1984, Az.: BVerwG Gr. Sen. 1 und 2.84 = BVerwGE 70, 356 (359). 1535 BVerwG, Beschl. v. 19.12.1984, Az.: BVerwG Gr. Sen. 1 und 2.84 = BVerwGE 70, 356 (359f.). 1536 Der Große Senat des BVerwG, Beschl. v. 19.12.1984, Az.: BVerwG Gr. Sen. 1 und $2.84=$ BVerwGE 70, 356 (361f.), findet zuletzt auch Bestätigung in den Gesetzesmaterialien, die jedoch mindestens wenig ergiebig scheinen, so auch Weides, DÖV 1985, 431 (433f.); noch kritischer Pieroth, NVwZ 1984, 681 (686); Kopp, DVBl 1985, 525 (525f.); Schoch, NVwZ 1985, 880 (883).

1537 A.A. aber u.a. Sachs, in: Stelkens/Bonk/Sachs, VwVfG, 9. Aufl. 2018, § 48 Rn. 223 ff.; J. Müller, in: Bader/Ronellenfitsch, VwVfG, 44. Ed., Stand: 1.1.2019, § 48 Rn. 110.1; Pieroth, NVwZ 1984, 681 (685f.); Kopp, DVBl 1985, 525 (525f.); Schoch, NVwZ 1985, 880 (883f.); Ehlers/ Kallerhoff, JURA 2009, 823 (834).

1538 Maurer/Waldhoff, Allgemeines Verwaltungsrecht, 19. Aufl. 2017, §11 Rn. 44; Detterbeck, Allgemeines Verwaltungsrecht, 17. Aufl. 2019, Rn. 713; Peine/Siegel, Allgemeines Verwaltungsrecht, 12. Aufl. 2018, Rn. 628; Suerbaum, in: Mann/Sennekamp/Uechtritz, VwVfG, 2. Aufl. 2019, $\S 48$ Rn. 196f. m.w.N. 
chen Tatsachen, insbesondere die für die nach § 48 II VwVfG erforderliche Abwägung und die Ermessensausübung relevanten Umstände, vollständig bekannt sein. Die Frist beginne daher erst zu laufen, wenn die Behörde ohne weitere Sachaufklärung objektiv in der Lage sei, zu entscheiden. ${ }^{1539}$

Wortlaut und Genese der Vorschrift sind für die Beantwortung dieser Streitfrage unergiebig - sie lassen sich in beide Richtungen interpretieren. ${ }^{1540}$ Somit rückt insbesondere ihr Telos in den Vordergrund. Das Bundesverwaltungsgericht argumentiert, der Zweck der Vorschrift, mit Ablauf der Frist den Rücknahmefall unter Herstellung eines gesetzmäßigen Zustands abgeschlossen zu haben, könne nur unvollkommen erfüllt werden, wenn die Behörde bereits vor Entscheidungsreife gezwungen wäre, zu entscheiden. ${ }^{1541}$ Dem wird jedoch zu Recht entgegengehalten, dass bei Annahme einer „Entscheidungsfrist“ der gleichsam zu beachtende Zweck der Schaffung von Rechtssicherheit durch praktische Entwertung der Fristenregelung verfehlt wird. ${ }^{1542}$ Darüber hinaus wird auch nicht recht ersichtlich, warum die Behörde nach Entscheidungsreife noch ein ganzes Jahr Zeit haben sollte, nur um die Entscheidung bekanntzugeben. Dies erscheint noch weniger plausibel, wenn in systematischer Hinsicht andere dem Interesse der Rechtssicherheit dienende Fristen (vgl. nur §§ 70, 74, 75 VwGO) in den Blick genommen werden, denen keine vergleichbare Gewichtung zugunsten des Interesses der Gesetzmäßigkeit der Verwaltung zugrunde liegt. ${ }^{1543}$

Davon entschieden abzugrenzen ist die Konstellation, dass eine Behörde von die Rücknahme rechtfertigenden Tatsachen Kenntnis erlangt, auf deren Grundlage sie eine Entscheidung über die Rücknahme trifft, bei der ihr dann ein Rechtsanwendungsfehler unterläuft. Auf diesem Wege kommt es nicht zu einem Neubeginn der Frist. ${ }^{1544}$

(3) Gleichsam umstritten ist zuletzt, wessen Kenntnis entscheidend ist. Ausdrücklich stellt die Norm nur auf die „Behörde“ ab. Bereits in systematischer

1539 BVerwG, Beschl.v. 19.12.1984, Az.: BVerwG Gr. Sen. 1 und 2.84 = BVerwGE 70, 356 (362f.); zuletzt ausdrücklich aufrechterhalten in Beschl. v. 10.1.2018, Az.: 3 B 59.16 = LKV 2018, 124 (125). Zustimmend Ziekow, VwVfG, 3. Aufl. 2013, § 48 Rn. 54. Der Gesetzgeber hat diese Interpretation hingenommen, vgl. BT-Drucks. 10/6283, S. 5; so auch BVerwG, Beschl.v. 5.5.1988, Az.: 7 B $8.88=$ NJW 1988, 2911 (2912).

1540 Satt vieler Stadie, DÖV 1992, 247 (250).

1541 BVerwG, Beschl. v. 19.12.1984, Az.: BVerwG Gr. Sen. 1 und 2.84 = BVerwGE 70, 356 (363f.). S. aber zur Lösung dieses Problems Stadie, DÖV 1992, 247 (250).

1542 S. nur Maurer/Waldhoff, Allgemeines Verwaltungsrecht, 19. Aufl. 2017, § 11 Rn. 44.

1543 S. nur Peuker, in: Knack/Henneke, VwVfG, 10. Aufl. 2014, § 48 Rn. 99; Stadie, DÖV 1992, 247 (251).

1544 Vgl. dazu BVerwG, Urt. v. 22.10.1987, Az.: 3 C 27.86 = NVwZ 1988, 349 (350); so auch Sachs, in: Stelkens/Bonk/Sachs, VwVfG, 9. Aufl. 2018, § 48 Rn. 227 m.w. N. 
Hinsicht kann dies nur die für die Rücknahme zuständige Behörde sein, sodass die Kenntnis anderer Behörden ${ }^{1545}$ ohne Bedeutung bleibt. Nur dies entspricht dem Zweck der Vorschrift, eben der zuständigen Behörde eine hinreichend lange Zeit für eine erneute Prüfung einzuräumen. ${ }^{1546}$

Umstritten ist jedoch, auf wessen Kenntnis es behördenintern ankommt. ${ }^{1547}$ Auch insofern hat das Bundesverwaltungsgericht eine rücknahmefreundliche Interpretation vertreten: Es komme nur darauf an, dass der nach der innerbehördlichen Geschäftsverteilung zur Rücknahme des Verwaltungsakts berufene Amtswalter oder ein sonst innerbehördlich zur rechtlichen Überprüfung des Verwaltungsakts berufener Amtswalter ${ }^{1548}$ die die Rücknahme des Verwaltungsakts rechtfertigenden Tatsachen feststelle. ${ }^{1549}$ Dafür spreche, dass eine „Behörde“ als rechtsorganisatorische Einheit nicht zu einer „Kenntnis“ fähig sei, es vielmehr stets auf das Wissen der für sie handelnden Amtswalter ankomme. ${ }^{1550}$

Die Gegenmeinung ${ }^{1551}$ will demgegenüber auf die Kenntnis der Organisationseinheit „Behörde“ abstellen. Dafür spreche bereits der Wortlaut, aus dem sich weder ergebe, dass ein anderer als der in § 1 IV VwVfG definierte Behördenbegriff zugrunde gelegt werde, noch dass es auf einen einzelnen Amtswalter ankommen könnte. ${ }^{1552}$ Überdies trete die Behörde im Verhältnis zum Bürger als Einheit auf und müsse innerhalb ihrer Organisationsverantwortung dafür sorgen, dass der

1545 Dies gilt auch für den Fall, dass der zurückzunehmende Verwaltungsakt von einer unzuständigen Behörde erlassen wurde, BVerwG, Urt. v. 20.12.1999, Az.: 7 C 42.98 = BVerwGE 110, 226 (234). S. aber zur Situation des zwischenzeitlichen Zuständigkeitswechsels Ramsauer, in: Kopp/ Ramsauer, VwVfG, 20. Aufl. 2019, § 48 Rn. 159.

1546 BVerwG, Urt.v. 20.12.1999, Az.: 7 C 42.98 = BVerwGE 110, 226 (234); Beschl.v. 10.1.2018, Az.: 3 B 59.16 = LKV 2018, 124 (125).

1547 Zu Recht weist Detterbeck, Allgemeines Verwaltungsrecht, 17. Aufl. 2019, Rn. 713, darauf hin, dass dieser dritte Problemkomplex der Sache nach weitgehend obsolet wird, wenn man der Ansicht folgt, dass es sich um eine „Entscheidungsfrist“ handelt.

1548 Ein einzelne Fachfragen begutachtender Mitarbeiter soll nicht genügen, BVerwG, Urt. v. 24.5.2012, Az.: 5 C 17.11 = BVerwGE 143, 161 (165f., Rn. 19).

1549 BVerwG, Beschl. v. 19.12.1984, Az.: BVerwG Gr. Sen. 1 und 2.84 = BVerwGE 70, 356 (364); Urt.v. 24.5. 2012, Az.: 5 C 17.11 = BVerwGE 143, 161 (165, Rn. 19f.).Vgl. auch BSG, Urt.v. 8. 2.1996, Az.: 13 RJ 35/94 = BeckRS 1996, 30759854.

1550 J. Müller, in: Bader/Ronellenfitsch, VwVfG, 44. Ed., Stand: 1.1.2019, § 48 Rn. 111; so auch Sachs, in: Stelkens/Bonk/Sachs, VwVfG, 9. Aufl. 2018, § 48 Rn. 214, der jedoch sodann zu einer anderen Lösung kommt.

1551 OVG Berlin, Urt. v. 29.10.1982, Az.: OVG 2 B 153/80 = NJW 1983, 2156 (2156f.); Ruffert, in: Ehlers/Pünder, Allgemeines Verwaltungsrecht, 15. Auf. 2016, § 24 Rn. 23; Pieroth, NVwZ 1984, 681 (684f.); Schoch, NVwZ 1985, 880 (885).

1552 Peuker, in: Knack/Henneke, VwVfG, 10. Aufl. 2014, § 48 Rn. 101; Schoch, NVwZ 1985, 880 (885). 
Informationsfluss funktioniere. ${ }^{1553}$ Der Bürger selbst könne die behördeninterne Zuständigkeitsverteilung nicht beurteilen und hätte selbst bei Befassung der zuständigen Behörde keine Rechtssicherheit. ${ }^{1554}$

Daneben sind zu Recht vermittelnde Ansichten getreten, die die Umstände des Einzelfalls in den Blick nehmen. ${ }^{1555}$ Diese blicken grundsätzlich auf die Behörde als rechtsorganisatorische Einheit, fokussieren jedoch im Sinne eines Organisationsverschuldens ${ }^{1556}$ sodann die behördeninternen Verhältnisse. Von Kenntnis der „Behörde“ ist ab dem Zeitpunkt auszugehen, zu dem im Falle eines ordnungsgemäßen Geschäftsgangs der zuständige Amtswalter durch Weitergabe der Informationen Kenntnis erlangt hätte. Davon wird beispielsweise dann nicht auszugehen sein, wenn nur ein sachlich völlig unzuständiger Amtswalter Kenntnis erlangt ${ }^{1557}$ oder die interne Weitergabe von Informationen aus datenschutzrechtlichen Gründen unzulässig ist ${ }^{1558}$. Nur diese Ansicht vermag es im Interesse des Zwecks der Vorschrift, der Behörde in vollständiger Kenntnis der eine Rücknahme potentiell rechtfertigenden Tatsachen noch einmal Zeit für eine Entscheidung zu geben, realistische Ergebnisse zu erzeugen: Zweifelsohne muss bereits sinnlogisch auf die Kenntnis eines Menschen abgestellt werden, dies kann indes nicht jede mit einem Verfahrensvorgang nicht vertraute Person sein. Ein von der internen Organisation abhängiger Informationsfluss innerhalb der Behörde kann nur dort erwartet werden, wo dafür hinreichender Anlass besteht und die rechtlichen Vorgaben ihn erlauben.

919 Es bedarf positiver Kenntnis, schuldhafte Unkenntnis genügt nicht. ${ }^{1559}$ Insofern genügt beispielsweise die bloße Aktenkundigkeit nicht, ${ }^{1560}$ vielmehr muss ein Bewusstsein für die Relevanz der Tatsachen bestehen.

1553 S. nur Maurer/Waldhoff, Allgemeines Verwaltungsrecht, 19. Aufl. 2017, § 11 Rn. 44.

1554 OVG Berlin, Urt. v. 29.10.1982, Az.: OVG 2 B 153/80 = NJW 1983, 2156 (2157); Peuker, in: Knack/Henneke, VwVfG, 10. Aufl. 2014, § 48 Rn. 101.

1555 Vgl. dazu jeweils m.w. N. - insbesondere aus der finanzgerichtlichen Rspr. - Ramsauer, in: Kopp/Ramsauer, VwVfG, 20. Aufl. 2019, § 48 Rn. 158; Kastner, in: Fehling/Kastner/Störmer, Verwaltungsrecht, 4. Aufl. 2016, § 48 VwVfG Rn. 65; Suerbaum, in: Mann/Sennekamp/Uechtritz, VwVfG, 2. Aufl. 2019, § 48 Rn. 205; ähnlich auch Sachs, in: Stelkens/Bonk/Sachs, VwVfG, 9. Aufl. 2018, § 48 Rn. $214 \mathrm{f}$.

1556 Ramsauer, in: Kopp/Ramsauer, VwVfG, 20. Aufl. 2019, § 48 Rn. 158; Suerbaum, in: Mann/ Sennekamp/Uechtritz, VwVfG, 2. Aufl. 2019, § 48 Rn. 205.

1557 Sachs, in: Stelkens/Bonk/Sachs, VwVfG, 9. Aufl. 2018, § 48 Rn. 215.

1558 Sachs, in: Stelkens/Bonk/Sachs, VwVfG, 9. Aufl. 2018, § 48 Rn. 215; Kastner, in: Fehling/ Kastner/Störmer, Verwaltungsrecht, 4. Aufl. 2016, § 48 VwVfG Rn. 65.

1559 BVerwG, Urt. v. 24.1.2001, Az.: 8 C 8.00 = BVerwGE 112, 360 (363).

1560 BVerwG, Urt. v. 24.1.2001, Az.: 8 C 8.00 = BVerwGE 112, 360 (363); so auch Ramsauer, in: Kopp/Ramsauer, VwVfG, 20. Aufl. 2019, § 48 Rn. 153. 
Für die Berechnung der Frist gilt $\S 31 \mathrm{VwVfG}$, der auch auf die Vorschriften 920 der $\S 187$ ff. BGB verweist. Die „Kenntnis“ der Behörde ist das gemäß § 187 I BGB für den Fristbeginn relevante Ereignis, dessen Ende sodann gemäß § 188 II Hs. 2 BGB zu bestimmen ist. ${ }^{1561}$

\section{(6) Rechtsfolge: Ermessen, § 48 I 1 VwVfG}

Die Entscheidung der Behörde über die Rücknahme eines Verwaltungsakts 921 steht gemäß § 48 I 1 VwVfG in ihrem Ermessen. (s. zum Ermessen ausführlich Rn. $729 \mathrm{ff}$., $739 \mathrm{ff}$.) Sie kann entscheiden, ob sie ihn überhaupt zurücknimmt (Entschließungsermessen), und falls ja, ob dies zum einen ganz oder teilweise, zum anderen mit Wirkung für die Zukunft oder für die Vergangenheit geschieht (Auswahlermessen). In zeitlicher Hinsicht ist der Behörde insbesondere die Möglichkeit geboten, sehr variabel auf Vertrauensschutzerwägungen zu reagieren, die sich erst nach dem Erlass ergeben.

Grundsätzlich gelten die allgemeinen Vorgaben betreffend Ermessensent- 922 scheidungen. Dabei sind im Zusammenhang mit § 48 VwVfG indes folgende Besonderheiten zu berücksichtigen, die sich je nach für die Rücknahme einschlägigem Absatz der Norm ergeben.

\section{(a) Im Falle eines belastenden Verwaltungsakts}

Im Falle der Rücknahme eines rechtswidrigen belastenden Verwaltungsakts stehen sich allgemein der Grundsatz der Gesetzmäßigkeit der Verwaltung und das Interesse der Schaffung von Rechtssicherheit und Rechtsfrieden durch eine einmal getroffene Entscheidung gegenüber. ${ }^{1562}$ Bereits die Tatsache, dass der Gesetzgeber ein solches Ermessen vorgesehen hat, verdeutlicht, dass allein die Rechtswidrigkeit nicht eine Rücknahme nach sich zieht. Vielmehr sollen beide Interessen grundsätzlich gleichberechtigt nebeneinanderstehen. ${ }^{1563}$

Gleichwohl ergibt sich laut Bundesverwaltungsgericht ein besonderes Be- 924 gründungserfordernis für die Annahme eines Überwiegens der materiellen Einzelfallgerechtigkeit. Dies ist keineswegs überraschend. Wie der Vertrauensschutz hat das mit ihm verwandte Interesse der Rechtssicherheit für sich

1561 S. für ein Berechnungsbeispiel Ramsauer, in: Kopp/Ramsauer, VwVfG, 20. Aufl. 2019, § 48 Rn. 152.

1562 Maurer/Waldhoff, Allgemeines Verwaltungsrecht, 19. Aufl. 2017, § 11 Rn. 72.

1563 BVerwG, Urt. v. 24. 2. 2011, Az.: 2 C 50.09 = NVwZ 2011, 888 (889, Rn. 11); Urt. v. 20.11.2018, Az.: 1 C 23.17 = NVwZ-RR 2019, 170 (172f., Rn. 26); auch bereits Beschl. v. 7.7.2004, Az.: 6 C $24.03=$ BVerwGE 121, 226 (229f.). 
genommen keine weitergehenden materiellen Gehalte, sprich: Für das Interesse der Rechtssicherheit spricht oftmals allein, dass es sich um „ein wesentliches Element der Rechtsstaatlichkeit und damit ein[es] Konstitutionsprinzip[s] des Grundgesetzes“ handelt. ${ }^{1564}$ Dieses gewichtet das Bundesverwaltungsgericht indes so stark, dass selbst ein Verwaltungsakt, der auf einer verfassungswidrigen Norm basiert, nicht ohne weiteres zurückgenommen werden darf. ${ }^{1565}$ Ausnahmsweise wird jedoch ein Anspruch auf Rücknahme - gar eines bestandskräftigen Verwaltungsakts - angenommen, wenn dessen Aufrechterhaltung „schlechthin unerträglich“ ist. ${ }^{1566}$ Dies geschieht vor dem Hintergrund der Annahme, dass bei einer allzu starken Abweichung von rechtlichen Vorgaben der mit der Rechtssicherheit in Verbindung stehende Rechtsfrieden nicht erreicht werden kann. ${ }^{1567} \mathrm{Ob}$ eine derartige Unerträglichkeit vorliegt, hängt von den Umständen des Einzelfalls und deren Abwägung gegeneinander ab. ${ }^{1568}$ Dies ist in der Rechtsprechung des Bundesverwaltungsgerichts insbesondere in vier anerkannten Fallgruppen denkbar ${ }^{1569}$ : (1) Bei Verstoß gegen den Grundsatz der Selbstbindung der Verwaltung gemäß Art. 3 I GG (s. dazu Rn. 772ff.), (2) bei Verstoß gegen die guten Sitten oder gegen Treu und Glauben, (3) im Falle einer offensichtlichen Rechtswidrigkeit des Verwaltungsakts ${ }^{1570}$ sowie (4) unter Berücksichtigung der Wertungen und Intentionen des dem Verwaltungsakt zugrundeliegenden Fachrechts ${ }^{1571}$ (da $§ 48$ VwVfG selbst keine materiellen Gesichtspunkte zu entnehmen sind). ${ }^{1572}$ Insofern ist die Behörde jedoch zugleich in sachlicher Hinsicht beschränkt: Ermessenserwägungen, die dem Fachrecht nicht zugrundeliegen, sind sachfremd. Zuletzt können auch im Falle eines belastenden Verwaltungsakts auf Seiten der Betroffenen Vertrauensschutzerwägungen (unter Berücksichtigung aller Umstände des Einzelfalls, s. dazu Rn. 899) für eine Aufrechterhaltung des Verwaltungsakts streiten.

1564 BVerwG, Beschl. v. 7.7.2004, Az.: 6 C 24.03 = BVerwGE 121, 226 (230).

1565 Vgl. BVerwG, Urt. v. 24.2.2011, Az.: 2 C 50.09 = NVwZ 2011, 888 (889, Rn. 14f.).

1566 BVerwG, Beschl.v. 7.7.2004, Az.: 6 C 24.03 = BVerwGE 121, 226 (230); Urt. v. 24. 2.2011, Az.: 2 C 50.09 = NVwZ 2011, 888 (889, Rn. 11), jeweils m.w. N.

1567 Vgl. BVerwG, Urt. v. 27.1.1994, Az.: 2 C 12.92 = BVerwGE 95, 86 (92).

1568 BVerwG, Urt. v. 24. 2.2011, Az.: 2 C 50.09 = NVwZ 2011, 888 (889, Rn. 11).

1569 S. dazu die Fallbearbeitung bei Ludwigs, JURA 2009, 226 (230f.).

1570 Vgl. dazu BVerwG, Urt. v. 17.1.2007, Az.: 6 C 32.06 = MMR 2007, 365 (366): Es kann auf die Maßstäbe zu §44 I VwVfG zurückgegriffen werden, ohne dass es jedoch einer besonderen Schwere bedürfte. So auch Ludwigs, NVwZ 2007, 549 (551); Ludwigs, JURA 2009, 226 (231).

1571 BVerwG, Beschl. v. 7.7.2004, Az.: 6 C 24.03 = BVerwGE 121, 226 (231); Urt. v. 24.2.2011, Az.: 2 C 50.09 = NVwZ 2011, 888 (889, Rn. 16).

1572 S. nur BVerwG, Beschl. v. 7.7.2004, Az.: 6 C 24.03 = BVerwGE 121, 226 (231).

Tobias Brings-Wiesen 
Vor diesem Hintergrund besteht Streit um die Ermessensausübung vor 925 Eintritt der Bestandskraft eines Verwaltungsakts. Eine Ansicht geht für diesen Fall von einer Ermessensreduktion auf Null zugunsten einer Rücknahme aus. ${ }^{1573}$ Angesichts von Rechtswidrigkeit und noch bestehender Anfechtbarkeit bestehe schlicht kein abwägungsrelevantes Interesse am Fortbestand des Verwaltungsakts. ${ }^{1574}$ Auch bestehe wegen des vielfachen Ausschlusses des Vorverfahrens auf Grundlage von § 68 I 2 VwGO ein praktisches Bedürfnis dem Bürger einen strikten Rechtsanspruch zuzusprechen. ${ }^{1575}$ Die Gegenansicht ${ }^{1576}$ hält dem den klaren Wortlaut des §48 I 1 VwVfG, der Ermessen ausdrücklich auch für noch nicht bestandskräftige gewordene Verwaltungsakte vorsieht, entgegen. Darüber hinaus bestehe kein Bedürfnis nach einem Rechtsanspruch, da der Bürger sein Ziel selbst bei Ausschluss des Vorverfahrens noch mit der Anfechtungsklage erreichen könne. ${ }^{1577}$

\section{(b) Im Falle eines begünstigenden Verwaltungsakts}

Die Normstruktur von § 48 I 1 und 2 VwVfG verdeutlicht, dass der Behörde auch im Falle der Rücknahme von begünstigenden Verwaltungsakten ein Ermessen zusteht. ${ }^{1578}$ Im Hinblick auf die Besonderheiten der Ermessensausübung ist indes wiederum zwischen Leistungsverwaltungsakten und sonstigen Verwaltungsakten zu unterscheiden.

Handelt es sich um die Rücknahme eines begünstigenden Leistungsver- 927 waltungsaktes i.S.v. §48 II VwVfG ist zu berücksichtigen, dass wesentliche rechtliche Bewertungen bereits im Tatbestand, insbesondere im Rahmen der Abwägung zwischen dem schutzwürdigen Vertrauen auf den Bestand des Verwaltungsakts und dem öffentlichen Interesse an einer Rücknahme, vorzunehmen waren. Dies führt zwar grundsätzlich ${ }^{1579}$ nicht $\mathrm{zu}$ einer rechtlich zwingenden Engführung des Ermessensspielraums im Sinne eines „intendierten Ermessens“ (s. zu diesem Begriff ausführlich Rn. 732). Rein faktisch verdichtet die Systematik

1573 S. nur Detterbeck, Allgemeines Verwaltungsrecht, 17. Aufl. 2019, Rn. 692, m.w. N.; wohl auch Ramsauer, in: Kopp/Ramsauer, VwVfG, 20. Aufl. 2019, § 48 Rn. 80.

1574 Detterbeck, Allgemeines Verwaltungsrecht, 17. Aufl. 2019, Rn. 692.

1575 Detterbeck, Allgemeines Verwaltungsrecht, 17. Aufl. 2019, Rn. 692.

1576 S. nur Maurer/Waldhoff, Allgemeines Verwaltungsrecht, 19. Aufl. 2017, § 11 Rn. 74; Sachs, in: Stelkens/Bonk/Sachs, VwVfG, 9. Aufl. 2018, § 48 Rn. 48; Peuker, in: Knack/Henneke, VwVfG, 10. Aufl. 2014, § $48 \mathrm{Rn} .77$.

1577 Maurer/Waldhoff, Allgemeines Verwaltungsrecht, 19. Aufl. 2017, § 11 Rn. 74.

1578 Ramsauer, in: Kopp/Ramsauer, VwVfG, 20. Aufl. 2019, § 48 Rn. 127; Suerbaum, in: Mann/ Sennekamp/Uechtritz, VwVfG, 2. Aufl. 2019, § 48 Rn. 143.

1579 Eine Ausnahme bildet die sogleich zu thematisierende Vorschrift des § 48 II 4 VwVfG. 
der Vorschrift jedoch den verbleibenden Ermessensspielraum. Für ein besseres Verständnis ist zwischen verschiedenen Entwicklungen innerhalb einer Prüfung zu unterscheiden: ${ }^{1580}$

- Gelangt man im Rahmen von § 48 II 1 VwVfG zu dem Ergebnis, dass das schutzwürdige Vertrauen (insbesondere auf Grundlage der Regelvermutung des § 48 II 2 VwVfG) das öffentliche Interesse überwiegt, darf bereits aus diesem Grund nicht zurückgenommen werden. Die Frage der ordnungsgemäßen Ermessensausübung stellt sich überhaupt nicht. ${ }^{1581}$

- Ist das Vertrauen gemäß § 48 II 3 VwVfG ausgeschlossen, entfällt die Abwägung gemäß § 48 II 1 VwVfG. In der Folge begrenzt § 48 II 4 VwVfG auch die Ermessensausübung dahingehend, dass der Verwaltungsakt in der Regel mit Wirkung für die Vergangenheit zurückzunehmen ist. Damit wird zwar wörtlich verdeutlicht, dass noch Raum für Ermessen besteht. ${ }^{1582}$ Dieses ist jedoch bereits rechtlich stark beschränkt. Laut Bundesverwaltungsgericht müssen im Einzelfall besondere Gründe, gar außergewöhnliche Umstände vorliegen, wenn eine Rücknahme nur für die Zukunft angeordnet oder überhaupt von der Rücknahme abgesehen werden soll. ${ }^{1583}$ Derartige Fälle sind jedoch in der Praxis erwartungsgemäß selten. ${ }^{1584}$

- In allen übrigen Konstellationen ist man im Rahmen von § 48 II 1 VwVfG zu dem Ergebnis gelangt, dass das öffentliche Interesse das schutzwürdige Vertrauen (gegebenenfalls gar entgegen der Regelvermutung des § 48 II 2 VwVfG) überwiegt. Bei der sodann folgenden Prüfung der Ermessensausübung können bestimmte Ermessensfehler - wie ein Ermessensausfall ${ }^{1585}$ oder ein Ermessensmissbrauch aufgrund sachfremder Erwägungen - unproblematisch $\mathrm{zu}$ bejahen sein. Vorsicht ist jedoch geboten hinsichtlich des schutzwürdigen Vertrauens (und der damit unmittelbar zusammenhän-

1580 Zum Folgenden Suerbaum, in: Mann/Sennekamp/Uechtritz, VwVfG, 2. Aufl. 2019, § 48 Rn. 143 ff.; so auch Ramsauer, in: Kopp/Ramsauer, VwVfG, 20. Aufl. 2019, § 48 Rn. 127 ff.

1581 Sollte, weil dies verlangt ist, hilfsgutachtlich weiter geprüft werden, müsste im Rahmen des Ermessens konsequent auf das schutzwürdige Vertrauen verwiesen werden. Darüber hinaus wären - je nach gegebenem Anlass - die übrigen Ermessenserwägungen in die Prüfung einzubeziehen.

1582 S. dazu auch BVerwG, Urt. v. 9.9.2013, Az.: 1 C 6.03 = BVerwGE 119, 17 (22f., 25).

1583 BVerwG, Urt. v. 23.5.1996, Az.: 3 C 13.94 = juris, Rn. 51; Urt. v. 16.6.1997, Az.: 3 C $22.96=$ BVerwGE 105, 55 (57 f.); Urt. v. 22.3.2017, Az.: 5 C 4.16 = BVerwGE 158, 258 (270f., Rn. 40 f.).

1584 Ramsauer, in: Kopp/Ramsauer, VwVfG, 20. Aufl. 2019, § 48 Rn. 127c, nennt beispielhaft die Zurechnung des absprachewidrigen Verhaltens eines Vertreters (s. dazu indes auch BVerwG, Urt.v. 22.3.2017, Az.: 5 C 4.16 = BVerwGE 158, 258 [270f., Rn. $40 \mathrm{f}$.]) oder das Befinden in einer Zwangslage.

1585 Suerbaum, in: Mann/Sennekamp/Uechtritz, VwVfG, 2. Aufl. 2019, § 48 Rn. 149.

Tobias Brings-Wiesen 
genden rechtlichen Erwägungen, s. dazu Rn. 899): Dieses wurde bereits erschöpfend in der Abwägung gemäß § 48 II 1 VwVfG berücksichtigt, ohne dass es ihm allein gelungen wäre, das öffentliche Interesse zu überwiegen. ${ }^{1586}$ Gegen eine Rücknahme müssen daher andere, darüberhinausgehende Ermessenserwägungen sprechen, wie beispielsweise gleichheitsrechtliche Erwägungen gemäß Art. 3 I GG (insbesondere bei Konstellationen der Selbstbindung der Verwaltung ${ }^{1587}$ oder freiheitsrechtliche Aspekte unter besonderer Berücksichtigung von Verhältnismäßigkeitsgesichtspunkten (auch und insbesondere im Hinblick auf die Interessen Dritter).

Auch die Rücknahme eines sonstigen begünstigenden Verwaltungsakts ge- 928 mäß § 48 III VwVfG steht gemäß § 48 I 1 VwVfG im Ermessen der Behörde. Mangels Vorprägung durch Beurteilungen innerhalb des Tatbestands kann das Ermessen hier uneingeschränkt geprüft werden. Besonders umstritten ist jedoch die Frage, ob und inwieweit im Rahmen der Ermessensausübung auch Vertrauensschutzerwägungen zu berücksichtigen sind. ${ }^{1588}$ Dagegen könnte in systematischer Hinsicht sprechen, dass der Vertrauensschutz im Rahmen von § 48 III VwVfG nur durch den Ausgleichsanspruch in Form von Vermögensschutz, nicht aber in Form von Bestandsschutz zu gewähren sein soll. In diese Richtung deuten auch die Gesetzesmaterialien. ${ }^{1589}$ Die wohl herrschende Meinung ${ }^{1590}$ stellt jedoch zu Recht auf den Wortlaut ab, der ein Ermessen uneingeschränkt ermöglicht. Zudem wird geltend gemacht, dass eine völlige Ausblendung von Vertrauensschutzerwägungen vor dem Hintergrund des Rechtsstaatsprinzips verfassungsrechtlich unzulässig wäre - dies insbesondere in den Fällen, in denen ein immaterieller Schaden nicht im Wege des durch §48 III VwVfG gewährleisteten Vermögensschutzes kompensiert werden könnte. ${ }^{1591}$ Grundsätzlich sind damit Vertrauensschutzerwägungen auch in die Prüfung des Ermessens gemäß § 48 I 1, III VwVfG einzu-

1586 Kastner, in: Fehling/Kastner/Störmer, Verwaltungsrecht, 4. Aufl. 2016, § 48 VwVfG Rn. 53; Ehlers/Kallerhoff, JURA 2009, 823 (834).

1587 Suerbaum, in: Mann/Sennekamp/Uechtritz, VwVfG, 2. Aufl. 2019, § 48 Rn. 149; Ehlers/ Kallerhoff, JURA 2009, 823 (834).

1588 S. dazu mit Darstellung der unterschiedlichen Meinungen innerhalb des BVerwG Struzina/ Lindner, NVwZ 2016, 1295. Für eine Fallbearbeitung zu dieser Fragestellung von Weschpfennig, JURA 2014, 1055 (1064f.).

1589 So die Gesetzesmaterialien, BT-Drucks. 7/910, S. 71.

1590 Detterbeck, Allgemeines Verwaltungsrecht, 17. Aufl. 2019, Rn. 705; Ehlers/Kallerhoff, JURA 2009, 823 (832). So auch ohne nähere Begründung das BVerwG, Beschl. v 7.11.2000, Az.: 8 B 137.00 = NVwZ-RR 2001, 198 (199); Urt. v. 24.5.2012, Az.: 5 C 17.11 = BVerwGE 143, 161 (168f., Rn. $27 \mathrm{f}$.$) .$

1591 Ramsauer, in: Kopp/Ramsauer, VwVfG, 20. Aufl 2019, § 48 Rn. 137. 
beziehen. Nicht abschließend geklärt scheint indes, inwieweit dies zu erfolgen hat. So wird vertreten, dass die Möglichkeit des Ausgleichs von Vermögensnachteilen nur einen unter mehreren Gesichtspunkten darstelle. ${ }^{1592}$ Jedenfalls insoweit über diesen Anspruch keinerlei Vertrauensschutz effektuiert werden kann (wie beispielsweise in bereits genannten Fällen ausschließlich immaterieller Schäden), wird man Vertrauensschutzerwägungen im Rahmen des Ermessens berücksichtigen müssen. Dafür kann dann maßstabsbildend auf die in § 48 II 2, 3 VwVfG zum Ausdruck gekommenen Wertungen zurückgegriffen werden. ${ }^{1593}$

\section{(7) Rücknahme von Verwaltungsakten im unionsrechtlichen Kontext}

929 Zum Teil erhebliche Modifikationen der bislang dargestellten Grundsätze ergeben sich im Falle der Rücknahme von unionsrechtswidrigen Verwaltungsakten (s. zum Widerruf Rn. 978). ${ }^{1594}$ Insofern bietet § 48 VwVfG eines (s. zum unionrechtlichen Staatshaftungsanspruch $\S 11 \mathrm{Rn}$. 31ff.) der idealen Einfallstore für das Abrufen von Wissen und Systemverständnis zum Problemfeld der „Europäisierung des Verwaltungsrechts“1595. Besondere Praxis- wie Prüfungsrelevanz haben dabei die einen Empfänger begünstigenden unionsrechtswidrigen Beihilfenbewilligungsbescheide, die als „Leistungsverwaltungsakte“ gemäß §48 II VwVfG zurückzunehmen sind und für die beachtliche Sondermaßstäbe gelten (s. dazu Rn. 932ff.). Davon strikt zu unterscheiden ist die Rücknahme unionsrechtswidriger Verwaltungsakte im Übrigen (s. dazu Rn. 937 ff.), die in der Prüfungspraxis zwar nur eine untergeordnete Rolle spielt, aber nicht minder kompliziert ist.

1592 Ramsauer, in: Kopp/Ramsauer, VwVfG, 20. Aufl. 2019, § 48 Rn. 137; wohl auch Peine/Siegel, Allgemeines Verwaltungsrecht, 12. Aufl. 2018, Rn. 621. A.A. aber wohl Sachs, in: Stelkens/Bonk/ Sachs, VwVfG, 9. Aufl. 2018, § 48 Rn. $180 \mathrm{ff}$.

1593 BVerwG, Beschl. v. 14.4.2010, Az.: 8 B 88.09 = juris, Rn. 9; Detterbeck, Allgemeines Verwaltungsrecht, 17. Aufl. 2019, Rn. 706; Ramsauer, in: Kopp/Ramsauer, VwVfG, 20. Aufl. 2019, § 48 Rn. 136f.; Ehlers/Kallerhoff, JURA 2009, 823 (832).

1594 S. dazu ausführlich auch Maurer/Waldhoff, Allgemeines Verwaltungsrecht, 19. Aufl. 2017, $\S 11$ Rn. 53ff.; Detterbeck, Allgemeines Verwaltungsrecht, 16. Aufl. 2018, Rn. 749ff.; Erbguth/ Guckelberger, Allgemeines Verwaltungsrecht, 9. Aufl. 2018, §16 Rn. $33 \mathrm{f}$.

1595 S. dazu im Überblick Voßkuhle/Schemmel, JuS 2019, 347; Kahl, NVwZ 2011, 449; ausführlich die Kommentierung von Stelkens, in: Stelkens/Bonk/Sachs, VwVfG, 9. Aufl. 2018, Europäisches Verwaltungsrecht, Europäisierung des Verwaltungsrechts und Internationales Verwaltungsrecht, passim.

Tobias Brings-Wiesen 
Im Interesse des besseren Verständnisses dieser durchaus komplexen Pro- 930 blematik ist im Folgenden vorab überblicksartig auf den Vollzug von Unionsrecht (s. Rn. 931) durch die deutsche Verwaltung sowie auf die Grundzüge des EU-Beihilfenrechts (s. Rn. 934) einzugehen.

\section{(a) Vollzug von Unionsrecht durch die Verwaltung}

Um die sogleich darzustellende Problematik zu erfassen, ist in der gebotenen 931 Kürze daran zu erinnern, wie Unionsrecht vollzogen wird. ${ }^{1596}$ Grundsätzlich ist zwischen dem unionseigenen (oder sog. „direkten“) und dem mitgliedstaatlichen (oder sog. „indirekten“) Vollzug zu unterscheiden, sprich dem Vollzug durch eigene Organe der Europäischen Union und dem Vollzug durch mitgliedstaatliche Institutionen. $\mathrm{Zu}$ einer ,unionsrechtlichen Überformung“1597 des deutschen Verwaltungsrechts kann es überhaupt nur kommen, wenn es sich um einen Fall mitgliedstaatlichen bzw. indirekten Vollzugs von Unionsrecht handelt. Im Rahmen der ihnen übertragenen Kompetenzen können die zuständigen Organe der Europäischen Union diesen Vollzug materiellen Unionsrechts durch die mitgliedstaatlichen Institutionen auch durch besondere verwaltungsorganisations- und -verfahrensrechtliche Vorgaben flankieren. Soweit derartige konkrete unionsrechtliche Vorgaben fehlen, gilt der Grundsatz der Verfahrensautonomie $^{1598}$ der Mitgliedstaaten ${ }^{1599}$, sodass die Vorschriften des mitgliedstaatlichen Verwaltungsrechts Anwendung finden. Der Vollzug von Unionsrecht hat dabei jedoch unter Beachtung des Grundsatzes der loyalen Zusammenarbeit gemäß Art. 4 III EUV, konkreter unter Beachtung von Äquivalenz- und Effektivitätsgrundsatz zu erfolgen. ${ }^{1600}$ Danach dürfen nationale Vorgaben für den Vollzug von Unionsrecht weder ungünstiger sein als bei rein nationalrechtlich determinierten Sachverhalten, noch dessen Verwirklichung praktisch unmöglich machen oder übermäßig erschweren. ${ }^{1601}$

1596 S. dazu im Überblick Maurer/Waldhoff, Allgemeines Verwaltungsrecht, 19. Aufl. 2017, § 2 Rn. 51ff.; § 22 Rn. 11; ausführlicher Ehlers, in: ders./Pünder, Allgemeines Verwaltungsrecht, 15. Aufl. 2016, § 5 Rn. $34 \mathrm{ff}$.

1597 So terminologisch Korte, JURA 2017, 656 (661).

1598 Dessen Anwendungsbereich indes nicht auf das „Verwaltungsverfahrensrecht“ nach deutschem Verständnis beschränkt ist, Ludwigs, NVwZ 2018, 1147 (1147f.).

1599 Dazu grundlegend - und zu der im Folgenden dargestellten Rspr. krit. - Krönke, Die Verfahrensautonomie der Mitgliedstaaten der Europäischen Union, 2013, passim; s. jüngst auch Ludwigs, NVwZ 2018, 1147.

1600 S. nur jüngst EuGH, Urt. v. 26.6.2019, Az.: C-407/18 - Addiko Bank, Rn. 46. So auch das BVerwG, Urt. v. 16.12.2010, Az.: 3 C 44.09 = BVerwGE 138, 322 (325f., Rn. 14).

1601 So in gebotener (terminologischer) Weite Ludwigs, NVwZ 2018, 1417 (1418).

Tobias Brings-Wiesen 


\section{(b) Besonderheiten bei der Rücknahme von begünstigenden EU-beihilfenrechtswidrigen Verwaltungsakten}

932 Vor besondere Herausforderungen stellt die Student`innen das überaus komplexe wie prüfungsrelevante Themenfeld der Rückabwicklung unionsrechtswidriger Beihilfen im Verhältnis zwischen Mitgliedstaat und Beihilfeempfänger. Diese Rückabwicklung erfolgt im Regelfall im mitgliedstaatlichen bzw. indirekten Vollzug, ohne dass auf besondere verwaltungsorganisations- und -verfahrensrechtliche Vorgaben zu rekurrieren wäre. ${ }^{1602}$ Rechtlicher Ausgangspunkt sind (bei Fehlen spezialgesetzlicher Vorschriften) die Vorschriften der §§ $48 \mathrm{ff}$. VwVfG, die jedoch unionsrechtlich stark überformt werden. Die Spannungslagen dieses Themenfeldes in ihren Nuancen zu erfassen, setzt ein Grundverständnis der zugrundeliegenden subventionsrechtlichen ${ }^{1603}$ Vorgaben voraus, auf die im Folgenden in der gebotenen Kürze ${ }^{1604}$ einzugehen ist.

Vorab ist zu berücksichtigen, dass eine Rückabwicklung unionsrechtswidriger Beihilfen keineswegs ausschließlich auf Grundlage der §§ $48 \mathrm{ff}$. VwVfG erfolgen muss. Obgleich derartige Sachverhaltskonstellationen in der juristischen Ausbildung mit Abstand die größte Aufmerksamkeit genießen dürften, hängt die Anwendbarkeit besagter Vorschriften - und in der Konsequenz der korrekte Prüfungsaufbau - maßgeblich von der Art der Gewähr der Beihilfe ab. ${ }^{1605}$ Ausgehend vom Grundsatz der Formenwahlfreiheit ${ }^{1606}$ kann die Verwaltung ihre Rechtsbeziehungen zu den Beihilfeempfängern einstufig oder zweistufig regeln und sich dabei der Formen des öffentlichen oder des privaten Rechts bedienen. ${ }^{1607}$ Eine Rückabwicklung über Verwaltungsakte auf Grundlage der §§ $48 \mathrm{ff}$. VwVfG ist daher regelmäßig nur dann möglich, wenn die Beihilfe selbst durch Verwal-

1602 Mangels umfassender oder auch nur sektorieller unionsrechtlicher Rücknahme- bzw. Widerrufsregelung ist dies selbst bei auf Grundlage von Unionsrecht gewährten und aus Unionsmitteln kofinanzierten Zuwendungen die Regel, BVerwG, Urt.v. 10.12.2003, Az.: 3 C 22.02 = NVwZRR 2004, 413 (413f.); VGH Mannheim, Urt. v. 22.5.2014, Az.: 10 S 1719/13 = juris, Rn. 27.

1603 „Subventionsrecht“ wird hier als Oberbegriff für die einschlägigen nationalen und unionalen Normen verwendet, so auch Korte, JURA 2017, 656.

1604 S. zur Schnittstelle des nationalen Subventions- und unionalen Beihilferechts ausführlich Ziekow, Öffentliches Wirtschaftsrecht, 4. Aufl. 2016, § 6, passim; Bungenberg/Motzkus, GewArch Beil. WiVerw 2/2013, 76; in einem auch für Anfänger^innen gut zugänglichen Überblick Ehlers, DVBl 2014, 1; zu den jüngsten Reformen Hilbert, JURA 2017, 1150.

1605 Finck/Gurlit, JURA 2011, 87 (89); Korte, JURA 2017, 656 (659ff.).

1606 BVerwG, Urt.v. 11.2.1993, Az.: 4 C 18.91 = BVerwGE 92, 56 (64); dazu ausführlich Detterbeck, Allgemeines Verwaltungsrecht, 17. Aufl. 2019, Rn. $903 \mathrm{ff}$.

1607 S. dazu Detterbeck, Allgemeines Verwaltungsrecht, 17. Aufl. 2019, Rn. 911 ff.; dazu auch die anschauliche Prüfung des BVerwG, Urt. v. 31.5.2012, Az.: 3 C 12.11 = NVwZ-RR 2012, 628 (629f., Rn. 14 ff.).

Tobias Brings-Wiesen 
tungsakt gewährt wurde. ${ }^{1608}$ Diese abgrenzende Prüfung kann je nach Aufgabenstellung an verschiedenen Stellen eines Gutachtens erforderlich werden. Steht fest, dass die Beihilfe im Wege eines Bewilligungsbescheids, der die Merkmale des $\S 35$ S. 1 VwVfG erfüllt, gewährt wurde, wird es sich (regelmäßig) auch um einen begünstigenden Verwaltungsakt i.S.v. § $48 \mathrm{I}_{2} \mathrm{VwVfG}^{1609}$ und in der Folge um einen Leistungsverwaltungsakt i. S.v. § 48 II $1 \mathrm{VwVfG}^{1610}$ handeln. Dies macht eine Prüfung am Maßstab von § 48 I 2, II, IV VwVfG erforderlich (s. dazu Rn. 935 f.).

Examenswissen: Handelt es sich um einen öffentlich-rechtlichen Vertrag i.S.d. §§ $54 \mathrm{ff}$. VwVfG sind jedoch gleichsam Besonderheiten zu berücksichtigen, s. dazu noch § 5 Rn. 117, 124.

Erst in einer fortgeschrittenen Phase des juristischen Studiums steht zu erwarten, 934 dass innerhalb dieser Prüfung auch eine umfassendere Bewertung der Rechtslage am Maßstab des unionalen Beihilfenrechts zu leisten ist. Doch bereits um die Quellen der Unionsrechtswidrigkeit einer Beihilfegewähr präzise identifizieren und in der Folge deren Relevanz für die mitgliedstaatliche Aufhebungsentscheidung bestimmen zu können, bedarf es einer Grundkenntnis des unionalen Beihilfenrechts. Dabei ist maßgeblich zwischen materiellen und prozeduralen Vorgaben zu unterscheiden:

In materieller Hinsicht: Gemäß Art. 107 I AEUV sind staatliche oder aus staatlichen Mitteln gewährte Beihilfen gleich welcher Art, die durch die Begünstigung bestimmter Unternehmen oder Produktionszweige den Wettbewerb verfälschen oder zu verfälschen drohen, mit dem Binnenmarkt unvereinbar, soweit sie den Handel zwischen Mitgliedstaaten beeinträchtigen (und soweit in den Verträgen nichts anderes bestimmt ist). ${ }^{1611}$ Die Erfüllung dieser Voraussetzungen bedeutet indes noch nicht die Unionsrechtswidrigkeit einer Beihilfe. Das unionale Beihilfenrecht kennt diverse Ausnahmetatbestände: (1) Art. 107 II AEUV bestimmt, dass Beihilfen, die den dort identifizierten Zwecken dienen, bereits qua legem mit dem Binnenmarkt vereinbar sind. (2) Gemäß Art. 106 II AEUV sollen die Vorschriften der Verträge, insbesondere die Wettbewerbsregeln, für Unternehmen, die mit Dienstleistungen von allgemeinem wirtschaftlichem Interesse (DAWI) betraut sind, nicht gelten, soweit sie die Erfüllung der übertragenen DAWI (im

1608 Statt vieler Finck/Gurlit, JURA 2011, 87 (89), m.w. N., auch zur Gegenansicht.

1609 Der Bewilligungsbescheid begründet ein Recht, nämlich den Anspruch des Adressaten aus Auszahlung der bewilligten Beihilfe.

1610 Die vielfältigen Formen staatlicher Beihilfen, s. nur Cremer, in: Calliess/Ruffert, EUV/AEUV, 5. Aufl. 2016, Art. 107 AEUV Rn. 40 f., werden regelmäßig als Gewährung einer einmaligen oder laufenden Geldleistung gewertet werden können.

1611 Zum Beihilfenbegriff im Überblick Ehlers, DVBl 2014, 1 (2f.). 
Einzelfall) rechtlich oder tatsächlich verhindern. (3) Art. 107 III AEUV stellt die Entscheidung über die Binnenmarktvereinbarkeit von Beihilfen, die wieder anderen bestimmten Zwecken dienen, in das Ermessen der Kommission (z.T. unter Zusammenwirken mit dem Rat). (4) Aufgrund „außergewöhnlicher Umstände“ kann der Rat ${ }^{1612}$ (auf Antrag eines Mitgliedstaats) gemäß Art. 108 II Uabs. 3 AEUV im Einzelfall in Abweichung von Art. 107 AEUV oder von den nach Art. 109 AEUV erlassenen Verordnungen beschließen, dass eine Beihilfe als mit dem Binnenmarkt vereinbar gilt.

In prozeduraler Hinsicht: Nicht minder wichtig sind die prozeduralen Vorgaben des unionalen Beihilfenrechts. Sie dienen dem Zweck der Sicherung der Verfahrenshoheit der Kommission bei der Überwachung der Einhaltung der materiellen Vorgaben im Interesse der einheitlichen Durchsetzung der EU-Wettbewerbsordnung. Ihre Beurteilung der Vereinbarkeit von Beihilfemaßnahmen mit dem Binnenmarkt ist schlussendlich maßgeblich. ${ }^{1613}$ Um diese Prüfung effektiv zu ermöglichen, verlangt Art. 108 III 1 AEUV nicht nur, dass die Kommission von jeder beabsichtigten Einführung oder Umgestaltung von Beihilfen durch die Mitgliedstaaten unterrichtet wird (sog. Notifikationspflicht). Gemäß Art. 108 III 3 AEUV ist überdies festgelegt, dass die beabsichtigte Maßnahme nicht durchgeführt werden darf, bevor die Kommission nicht einen abschließenden Beschluss erlassen hat (sog. Durchführungsverbot). Ein diesen Vorgaben zuwiderlaufender Bewilligungsbescheid ist bereits formell unionsrechtswidrig.

Examenswissen: Das Beihilfeverfahren ist ausgefeilter als es Art. 108 AEUV auf den ersten Blick vermuten lässt. Dessen Einzelheiten regelt die auf Grundlage von Art. 109 AEUV erlassene Beihilfeverfahrensverordnung (BeihilfeVVO) ${ }^{1614}$. Darin sind drei verschiedene Wege der Initiierung einer vorbeugenden Prüfung der beabsichtigten Einführung oder Umgestaltung von Beihilfen (sog. „,neue Beihilfen“, Art. 1 lit. c) BeihilfeVVO) gemäß Art. 108 III AEUV vorgesehen:

(1) Der unionsrechtliche Normalfall ist die gemäß Art. 108 III 1 AEUV, Art. 2 BeihilfeVVO erforderliche Anmeldung durch die Mitgliedstaaten. Art. 109 Var. 3 AEUV ermächtigt ${ }^{1615}$ darüber

1612 Bei dreimonatiger Untätigkeit des Rates die Kommission, Art. 108 II Uabs. 4 AEUV.

1613 Dabei unterliegt sie der Kontrolle der Unionsgerichte, während die nationalen Gerichte bis zur endgültigen Entscheidung der Kommission nur über die Wahrung der Rechte der Einzelnen bei eventuellen Verstößen der mitgliedstaatlichen Behörden gegen Art. 108 III AEUV wachen, EuGH, Urt. v. 21.11.2013, Az.: C-284/12 - Deutsche Lufthansa, Rn. 28.

1614 Verordnung (EU) 2015/1589 des Rates vom 13. Juli 2015 über besondere Vorschriften für die Anwendung von Artikel 108 des Vertrags über die Arbeitsweise der Europäischen Union, ABl. EU Nr. L 248 v. 24.9. 2015 , S. 9.

1615 S. insofern auch die sog. „Ermächtigungsverordnung“, Verordnung (EU) 2015/1588 des Rates vom 13. Juli 2015 über die Anwendung der Artikel 107 und 108 des Vertrags über die Arbeitsweise der Europäischen Union auf bestimmte Gruppen horizontaler Beihilfen, ABl. EU Nr. L 248 v. 24.9. 2015, S. 1. 
hinaus zum Erlass von Durchführungsverordnungen, die Beihilfen bestimmen, die von dem Verfahren nach Art. 108 III AEUV ausgenommen sind. Dem sind die zuständigen Organe durch Erlass der allgemeinen ${ }^{1616}$ De-minimis-Beihilfen-Verordnung ${ }^{1617}$ sowie der allgemeinen Gruppenfreistellungsverordnung ${ }^{1618}$ nachgekommen. ${ }^{1619}$

(2) Darüber hinaus kann jeder Beteiligte (vgl. die weite Legaldefinition in Art. 1 lit. h) BeihilfeVVO) gemäß Art. 24 II BeihilfeVVO eine förmliche Beschwerde einlegen, um die Kommission über mutmaßliche rechtswidrige Beihilfen zu informieren.

(3) Zuletzt kann die Kommission gemäß Art. 12 BeihilfeVVO auch von Amts wegen alle Auskünfte über mutmaßliche rechtswidrige Beihilfen prüfen.

Im unionsrechtlichen Normalfall der Anmeldung führt die Kommission innerhalb einer Frist von regelmäßig zwei Monaten (Art. 4 V BeihilfeVVO) eine vorläufige Prüfung durch, die mit einem positiven Beschluss i.S.v. Art. 4 II oder III BeihilfeVVO oder einem Beschluss über die Eröffnung des förmlichen Prüfverfahrens gemäß Art. 108 III 2 AEUV, Art. 4 IV BeihilfeVVO endet. Unterbleibt der Beschluss, gilt die Beihilfe als genehmigt und kann nach erneuter Notifikation durchgeführt werden (Art. 4 VI BeihilfeVVO). Das förmliche Prüfverfahren erfolgt auf Grundlage der Art. $6 \mathrm{ff}$. BeihilfeVVO. Es endet innerhalb von regelmäßig 18 Monaten (Art. 9 VI, VII BeihilfeVVO) wiederum mit einem Beschluss der Kommission (Art. 9 I BeihilfeVVO): Diese kann bereits das Vorliegen einer Beihilfe verneinen (Art. 9 II BeihilfeVVO), deren uneingeschränkte Vereinbarkeit mit dem Binnenmarkt beschließen (sog. „Positivbeschluss“, Art. 9 III BeihilfeVVO) oder diese unter Bedingungen und Auflagen stellen (sog. „mit Bedingungen und Auflagen verbundener Beschluss“, Art. 9 IV BeihilfeVVO). Ist die Beihilfe hingegen mit dem Binnenmarkt unvereinbar, so beschließt die Kommission, dass diese Beihilfe nicht eingeführt werden darf (sog. „Negativbeschluss“, Art. 108 II Uabs. 1 AEUV, Art. 9 V BeihilfeVVO). Wurde die Beihilfemaßnahme bereits durchgeführt, ergeht mit dem Negativbeschluss ein sog. „Rückforderungsbeschluss“ gemäß Art. 16 BeihilfeVVO, der auch Zinsen umfasst. Gemäß Art. 108 III 3 AEUV, Art. 3 BeihilfeVVO darf der be-

1616 Sonderregelungen gibt es bspw. im Agrarsektor, Verordnung (EU) Nr. 1408/2013 der Kommission vom 18. Dezember 2013 über die Anwendung der Artikel 107 und 108 des Vertrags über die Arbeitsweise der Europäischen Union auf De-minimis-Beihilfen im Agrarsektor, ABl. EU Nr. L 352 v. 24.12.2013, S. 9.

1617 Verordnung (EU) Nr. 1407/2013 der Kommission vom 18. Dezember 2013 über die Anwendung der Artikel 107 und 108 des Vertrags über die Arbeitsweise der Europäischen Union auf Deminimis-Beihilfen, ABl. EU Nr. L 352 v. 24.12.2013, S. 1. Eine Subsumtion unter die De-minimisVerordnung führt dazu, dass bereits der Beihilfentatbestand gemäß Art. 107 I AEUV nicht erfüllt ist, Koenig/Paul, in: Streinz, EUV/AEUV, 3. Aufl. 2018, Art. 109 AEUV Rn. 17.

1618 Verordnung (EU) Nr. 651/2014 der Kommission vom 17. Juni 2014 zur Feststellung der Vereinbarkeit bestimmter Gruppen von Beihilfen mit dem Binnenmarkt in Anwendung der Artikel 107 und 108 des Vertrags über die Arbeitsweise der Europäischen Union, ABl. EU Nr. L 187 v. 26.6. 2014, S. 1, zuletzt geändert durch Verordnung (EU) Nr. 2017/1084 der Kommission vom 14. Juni 2017 ABl. EU Nr. L 156 v. 20.6.2017, S. 1. Gemäß Art. 3 der Verordnung sind Beihilfen bei Erfüllen der Voraussetzungen auch mit dem Binnenmarkt vereinbar, Cremer, in: Calliess/Ruffert, EUV/AEUV, 5. Aufl. 2016, Art. 107 AEUV Rn. 66.

1619 Soweit Leistungen unter einen dieser Ausnahmetatbestände fallen, gelten die im Folgenden geschilderten Sondermaßstäbe nicht, vgl. die Fallbearbeitung bei Grupp/Stelkens, Nichts für viel Lärm, abrufbar unter: http://www.saarheim.de/Faelle/laerm-fall.htm (Bearbeitungsstand: 29.9.2019). 
treffende Mitgliedstaat die beabsichtigte Beihilfemaßnahme nicht durchführen, bevor die Kommission einen ihm günstigen Beschluss erlassen hat (oder die Maßnahme als genehmigt gilt); während des gesamten Prüfverfahrens besteht demnach ein Durchführungsverbot. Missachtet der Mitgliedstaat dieses Verbot, kann die Kommission gemäß Art. 13 BeihilfeVVO eine Anordnung zur Aussetzung oder einstweiligen Rückforderung der Beihilfe erlassen. In ihrer Funktion erfüllt die Kommission darüber hinaus entsprechend der BeihilfeVVO auch andere fortlaufende Aufgaben. ${ }^{1620}$

935 Vor diesem Hintergrund sind mehrere Konstellationen der Rückabwicklung von durch Verwaltungsakt bewilligten unionsrechtswidrigen Beihilfen denkbar. Die in der Ausbildung relevanteste Konstellation dürfte die Rückabwicklung nach Negativbeschluss der Kommission gemäß Art. 108 II Uabs. 1 AEUV, Art. 9 V BeihilfeVVO (in Verbindung mit einem Rückforderungsbeschluss gemäß Art. 16 BeihilfeVVO) sein. ${ }^{1621}$ Mit diesem Beschluss wird die materielle Unionsrechtswidrigkeit des Bewilligungsbescheides abschließend ${ }^{1622}$ festgestellt. Damit gehen im Falle der Begehr einer Rückabwicklung bereits sinnlogisch ein Verstoß gegen das Durchführungsverbot sowie regelmäßig eine Verletzung der Notifikationspflicht einher, sodass oftmals zugleich auch die formelle Unionsrechtswidrigkeit des Bescheids in Rede steht. Davon ausgehend sind im Rahmen der Prüfung von $\S 48$ I 1 und 2, II, IV VwVfG weiterhin ${ }^{1623}$ folgende Besonderheiten zu berücksichtigen:

- Im Rahmen der Prüfung der Verwaltungsaktqualität ist - spätestens ${ }^{1624}$ auf die Art der Beihilfengewähr einzugehen (s. dazu Rn. 933).

- Bei der Prüfung der Rechtswidrigkeit des zurückzunehmen Verwaltungsaktes haben Ausführungen zur formellen wie materiellen Unionsrechtswidrigkeit $\mathrm{zu}$ erfolgen. Dabei ist vorab $\mathrm{zu}$ berücksichtigen, dass

1620 Zum einen überprüft sie gemäß Art. 108 I AEUV fortlaufend die in den Mitgliedstaaten bestehenden Beihilferegelungen (und unterbreitet ggf. zweckdienliche Vorschläge zu deren Fortentwicklung; vgl. dazu auch die Art. $21 \mathrm{ff}$. BeihilfeVVO), zum anderen kontrolliert sie gemäß Art. 108 II Uabs. 1 Var. 2 AEUV (auch nach Beschwerde, Art. 24 II BeihilfeVVO) die missbräuchliche Anwendung gewährter Beihilfen.

1621 S. zu dieser Konstellation zentral EuGH, Urt. v. 20.3.1997, Az.: C-24/95 - Land RheinlandPfalz/Alcan Deutschland.

1622 Unbenommen ist es den verschiedenen Betroffenen, gegen den Beschluss Nichtigkeitsklage gemäß Art. 263 AEUV zu erheben, Cremer, in: Calliess/Ruffert, EUV/AEUV, 5. Aufl. 2016, Art. 108 AEUV Rn. 23.

1623 S. zur Subsumtion unter die Tatbestandsmerkmale „Verwaltungsakt“, „,begünstigender Verwaltungsakt“ und „Leistungsverwaltungsakt“ bereits Rn. 933.

1624 Vorstellbar ist, dass diesbezügliche Ausführungen je nach Aufgabenstellung bereits im Rahmen der Prüfung der Zulässigkeit einer Klage erfolgen müssen.

Tobias Brings-Wiesen 
grundsätzlich weder eine formelle ${ }^{1625}$ noch eine materielle ${ }^{1626}$ Unionsrechtswidrigkeit zu einer Nichtigkeit des Bescheids gemäß § 44 VwVfG führt. ${ }^{1627}$ Bei einer Verletzung der Notifikationspflicht liegt ein Verfahrensfehler vor, bezüglich dessen sich die Frage stellt, ob er gemäß § 45 I Nr. 5, II VwVfG („Mitwirkung einer anderen Behörde“) durch Nachholung ${ }^{1628}$ geheilt werden kann. Dem steht jedoch insbesondere ${ }^{1629}$ das teleologische Argument entgegen, dass - wie im Falle eines späteren Positivbeschlusses der Kommission (s. dazu noch Rn. 936) - die Annahme einer Heilung die unmittelbare Wirkung dieser Vorschrift beeinträchtigen, ihre Missachtung begünstigen und somit ihre praktische Wirksamkeit nehmen würde. ${ }^{1630}$ Die materielle Unionsrechtswidrigkeit wird meist nicht gesondert zu prüfen sein: Mit Eintritt der Bestandskraft des Negativbeschlusses steht sie ohnehin fest. ${ }^{1631}$ Doch auch vorher steht es den mitgliedstaatlichen Institutionen aufgrund der ausschließlichen Kompetenz der Kommission nicht frei, vom Beschluss der Kommission abzuweichen. Die materielle Unionsrechtswidrigkeit kann daher im Rahmen der Prüfung zumeist ohne nähere Ausführungen unter Rekurs auf den Negativbeschluss vorausgesetzt werden. ${ }^{1632}$

- Die Unionsrechtswidrigkeit der Beihilfe wirkt sich insbesondere auf die Schutzwürdigkeit des Vertrauens des Beihilfeempfängers gemäß §48 II VwVfG aus. Der EuGH hat in der maßgeblichen Rechtssache „Land Rheinland-Pfalz/Alcan Deutschland“ geurteilt, dass berechtigtes Vertrauen auf die Ordnungsmäßigkeit einer Beihilfe nur dann bestehen kann, wenn diese unter Einhaltung des - mittlerweile - in Art. 108 AEUV vorgesehenen Verfahrens

1625 BVerwG, Urt.v. 16.12.2010, Az.: 3 C 44.09 = BVerwGE 138, 322 (326f., Rn. 16). So auch Kokott, DVBl 1993, 1235 (1237) (unter Rekurs auf § 44 III Nr. 4 VwVfG); Finck/Gurlit, JURA 2011, 87 (91) (unter Rekurs auf die zumeist fehlende Offensichtlichkeit).

1626 BVerwG, Beschl. v. 11.5.2000, Az.: 11 B 26.00 = NVwZ 2000, 1039 (1040).

1627 Der Streit um die Anwendbarkeit der Vorschrift auf nichtige Verwaltungsakte, s. dazu Rn. 862, ist mithin im Regelfall nicht zu diskutieren.

1628 So Finck/Gurlit, JURA 2011, 87 (91); Gurlit, ZJS 2011, 368 (370), die indes noch weiter gehen und in der schlichten „Positiventscheidung“ der Kommission den Anknüpfungspunkt für die Heilung sehen.

1629 Zu weiteren Argumenten s. Korte, JURA 2017, 656 (660).

1630 So i. E. auch Korte, JURA 2017, 656 (660). Vgl. aus der Rspr. des EuGH nur Urt. v. 12. 2. 2008, Az.: C-199/06 - CELF und ministre de la Culture und de la Communication, Rn. 40. Finck/Gurlit, JURA 2011, 87 (91), plädieren daher - unabhängig vom allgemeinen Streit um die zeitliche Dimension der Heilung (s. dazu bereits Rn. 862) - hier für eine bloße ex nunc-Wirkung.

1631 Detterbeck, Allgemeines Verwaltungsrecht, 17. Aufl. 2019, Rn. 753.

1632 Etwas anderes gilt insbesondere dann, wenn die Aufgabenstellung oder die Angaben im Sachverhalt die Prüfung erwarten lassen. 
gewährt wurde. ${ }^{1633}$ Aus der Verfahrenshoheit der Kommission resultieren mithin speziell für den beihilfenrechtlichen Kontext geltende Sondermaßstäbe. Weitgehend offen blieb dabei naturgemäß die Frage der Einordnung dieser Rechtsprechung in die Systematik von § 48 II VwVfG: Grundsätzlich denkbar ist bereits die Annahme eines Ausschlusses der Schutzwürdigkeit gemäß § 48 II 3 Nr. 3 VwVfG aufgrund grob fahrlässiger Unkenntnis der formellen und/oder materiellen Unionsrechtswidrigkeit des Verwaltungsaktes. Unter Berücksichtigung des konkret-individuellen Maßstabs wird im Hinblick auf die Einhaltung der formellen Vorgaben des Art. 108 III AEUV argumentiert, dass von einem sorgfältigen Durchschnittsbeihilfeempfänger regelmäßig zu erwarten sei, sich der ordnungsgemäßen Durchführung des Prüfverfahrens zu vergewissern. ${ }^{1634}$ Vorzugswürdig ist jedoch, in der Prüfung weiterhin die Umstände des Einzelfalls, wie Umfang und Marktrelevanz einer Beihilfe sowie Größe und Beihilfeerfahrenheit des empfangenden Unternehmens (mit oder ohne eigene Rechtsabteilung), zu berücksichtigen und nicht stets pauschal auf einen Ausschluss der Schutzwürdigkeit abzustellen. ${ }^{1635}$ Jedenfalls aber hat das Vertrauensschutzinteresse - selbst für den Fall, dass die Regelvermutung des § 48 II 2 VwVfG zugunsten des Beihilfeempfängers greift - in der Abwägung nach § 48 II 1 VwVfG wegen dem besonderen unionsrechtlichen Interesse an der effektiven Durchsetzung der unionalen Wettbewerbsordnung ${ }^{1636}$, das auf Seiten des öffentlichen Rücknahmeinteresses neben das Interesse an der Gesetzmäßigkeit der Verwaltung und das fiskalische Interesse tritt, in der Regel zurückzustehen. Auch im Falle einer überwiegenden Verantwortlichkeit ${ }^{1637}$ oder auch vorherigen Abstimmung ${ }^{1638}$ mit der für die Bewilligung zuständigen Behörde soll deren rechtswidriges Verhalten kein schutzwürdiges Vertrauen begründen können, wenn die Vorgaben des Art. 108 III AEUV missachtet wurden. Die gleichsam unionsrechtlich geschützten Grundsätze von Rechtssicherheit und Vertrau-

1633 EuGH, Urt. v. 20.3.1997, Az.: C-24/95 - Land Rheinland-Pfalz/Alcan Deutschland, Rn. 25, $30 \mathrm{f}$.

1634 Für eine Nachforschungspflicht bereits der EuGH, Urt. v. 20.9.1990, Az.: C-5/89 - Kommission/Deutschland, Rn. 14; Urt. v. 20.3.1997, Az.: C-24/95 - Land Rheinland-Pfalz/Alcan Deutschland, Rn. 25; a.A. jedoch Detterbeck, Allgemeines Verwaltungsrecht, 17. Aufl. 2019, Rn. 754; Triantafyllou, NVwZ 1992, 436 (439).

1635 Suerbaum, in: Mann/Sennekamp/Uechtritz, VwVfG, 2. Aufl. 2019, § 48 Rn. 153.

1636 So bereits BVerwG, Urt. v. 17.2.1993, Az.: 11 C 47.92 = BVerwGE 92, 81 (86).

1637 EuGH, Urt. v. 20.3.1997, Az.: C-24/95 - Land Rheinland-Pfalz/Alcan Deutschland, Rn. 41 ff.; BVerwG, Urt. v. 23.4.1998, Az.: 3 C 15.97 = BVerwGE 106, 328 (338): Kein Verstoß gegen den Grundsatz von Treu und Glauben.

1638 BVerwG, Urt. v. 24.7.2014, Az.: 3 C 23.13 = NVwZ-RR 2015, 21 (22). 
ensschutz sollen laut EuGH lediglich bei Vorliegen - bis heute kaum näher bestimmter - „außergewöhnlicher Umstände“ überwiegen. ${ }^{1639}$

- In der Konsequenz kommt es sodann zu einem harten dogmatischen Bruch im Hinblick auf die Prüfung eines möglichen Ausschlusses der Rücknahme aufgrund von Verfristung gemäß § 48 IV VwVfG. Insofern verlangt der EuGH selbst für den Fall, dass die Jahresfrist des § 48 IV 1 VwVfG verstrichen ist, die Rücknahme des Bewilligungsbescheids. Die Anwendbarkeit von §48 IV VwVfG wird im Interesse der Effektivität des Unionsrechts schlicht ausgesetzt. $^{1640}$

- Zuletzt verlangt die Berücksichtigung der unionsrechtlichen Wertungen im Falle eines Negativbeschlusses der Kommission eine konsequente Reduktion des Rücknahmeermessens gemäß § 48 I 1 VwVfG auf Null. ${ }^{1641}$

- Zusätzlich steht die Unionsrechtswidrigkeit der Beihilfe später im Rahmen der Prüfung der Erstattung (s. dazu noch Rn. 989 ff.) dem Einwand der Entreicherung gemäß § 49a II i.V.m. §§ 812ff. BGB entgegen.

Examenswissen: Die Unionsrechtswidrigkeit wirkt sich darüber hinaus (im Interesse des Effektivitätsgrundsatzes) auch vollstreckungs- und verwaltungsprozessrechtlich auf den Erstattungsbescheid aus: Verbunden mit einem Negativbeschluss gemäß Art. 108 II Uabs. 1 AEUV, Art. 9 I, V BeihilfeVVO ergeht gemäß Art. 16 I BeihilfeVVO grundsätzlich ein Rückforderungsbeschluss, infolgedessen der Mitgliedstaat alle notwendigen Maßnahmen zu ergreifen hat, um die Beihilfe vom Empfänger zurückzufordern. Gemäß Art. 16 III BeihilfeVVO „erfolgt die Rückforderung unverzüglich und nach den Verfahren des betreffenden Mitgliedstaats, sofern hierdurch die sofortige und tatsächliche Vollstreckung des Beschlusses der Kommission ermöglicht wird." Daraus folgt zunächst, dass die zuständige Behörde den Erstattungsbescheid für sofort vollziehbar zu erklären hat, und sodann, dass weder Behörden die Aussetzung der Vollziehung gemäß § 80 IV 1 VwGO anordnen, noch Gerichte die aufschiebende Wirkung eines Widerspruchs bzw. einer Anfechtungsklage gemäß § $80 \mathrm{~V} 1 \mathrm{VwGO}$ wiederherstellen dürfen. ${ }^{1642}$

Examenswissen: Davon strikt abzugrenzen sind Konstellationen bloß formell unionrechtswidriger Beihilfen. ${ }^{1643}$ Die mit ihnen verbundenen Rechtsprobleme unterscheiden sich danach, in welchem Stadium des Prüfverfahrens der Kommission ihre Rückabwicklung in Rede steht. ${ }^{1644}$

1639 EuGH, Urt. v. 11.3.2010, Az.: C-1/09 - CELF und Ministre de la Culture et de la Communication, Rn. 42f.; so auch Urt. v. 20.9.1990, Az.: C-5/89 - Kommission/Deutschland, Rn. 16.

1640 EuGH, Urt. v. 20.3.1997, Az.: C-24/95 - Land Rheinland-Pfalz/Alcan Deutschland, Rn. 31 ff.; BVerwG, Urt. v. 23.4.1998, Az.: 3 C 15.97 = BVerwGE 106, 328 (336ff.).

1641 EuGH, Urt. v. 20.3.1997, Az.: C-24/95 - Land Rheinland-Pfalz/Alcan Deutschland, Rn. 34; Detterbeck, Allgemeines Verwaltungsrecht, 17. Aufl. 2019, Rn. 756; Ruffert, in: Ehlers/Pünder, Allgemeines Verwaltungsrecht, 15. Aufl. 2016, § 24 Rn. 33.

1642 Detterbeck, Allgemeines Verwaltungsrecht, 17. Aufl. 2019, Rn. 758.

1643 Dazu auch Detterbeck, Allgemeines Verwaltungsrecht, 17. Aufl. 2019, Rn. 759 ff.; ausführlich auch zu anderen Konstellationen der Beihilfegewähr Finck/Gurlit, JURA 2011, 87.

1644 S. auch Korte, JURA 2017, 656 (662f.). 
In den verschiedenen Konstellationen sind im Rahmen der Prüfung von § 48 I 1 und 2, II, IV VwVfG wiederum beihilfenrechtlich bedingte Sondermaßstäbe zu berücksichtigen:

- Mit einem für den Mitgliedstaat günstigen Beschluss gemäß Art. 108 II Uabs. 1 AEUV stellt die Kommission abschließend fest, dass die Bewilligung einer Leistung - regelmäßig von Beginn an - mit dem materiellen Beihilfenrecht vereinbar gewesen ist. ${ }^{1645}$ Die nationalen Behörden sind dann nicht verpflichtet, die Beihilfegewähr aufgrund materieller Unionsrechtswidrigkeit unter Berücksichtigung der bereits geschilderten Modifikationen rückabzuwickeln. Der günstige Beschluss ändert indes nichts an einer bereits erfolgten Verletzung der formellen Vorgaben: Verstöße gegen die Notifikationspflicht gemäß Art. 108 III 1 AEUV und/ oder gegen das Durchführungsverbot gemäß Art. 108 III 3 AEUV werden dadurch nicht rückwirkend geheilt oder legitimiert. ${ }^{1646}$ Gleichwohl hat der EuGH entschieden, dass das Unionsrecht (auch außerhalb von Konstellationen „außergewöhnlicher Umstände“) nicht die Rückzahlung der gesamten rechtswidrigen Beihilfe verlangt. Begründet wird dies mit dem nur vorläufigen Charakter des Zwecks des Durchführungsverbots, den gemeinsamen Markt und andere Marktteilnehmer vor unzulässigen Wettbewerbsverzerrungen zu schützen. ${ }^{1647} \mathrm{Im}$ Interesse von dessen effektiver Durchsetzung verlangt der EuGH jedoch zumindest eine Abschöpfung der Zinsen, die der Beihilfeempfänger gezahlt hätte, wenn er sich den gewährten Beihilfebetrag bis zum Erlass des Beschlusses auf dem Markt hätte leihen müssen. ${ }^{1648}$ Wird der Beschluss der Kommission vor den Unionsgerichten angegriffen, kann sich der relevante Zeitraum bis zur endgültigen gerichtlichen Entscheidung ${ }^{1649}$ und gar darüber hinaus verlängern, ohne dass sich der Empfänger auf ein berechtigtes Vertrauen berufen könnte ${ }^{1650}$. Erfolgte die Beihilfegewähr unter Verletzung des Durchführungsverbots ausschließlich auf Grundlage eines Bewilligungsbescheids, hat die Rückabwicklung wie gewohnt auf Grundlage von § 48 I 1

1645 S. zu dieser Konstellation zentral EuGH, Urt.v. 12.2.2008, Az.: C-199/06 - CELF und Ministre de la Culture et de la Communication; Urt. v. 11.3.2010, Az.: C-1/09 - CELF und Ministre de la Culture et de la Communication. Dazu auch Detterbeck, Allgemeines Verwaltungsrecht, 17. Aufl. 2019, Rn. 762; Decker, in: Wolff/Decker, VwGO/VwVfG, 3. Aufl. 2012, § 48 VwVfG Rn. 54 ff.

1646 EuGH, Urt. v. 21.11.1991, Az.: C-354/90 - Fédération nationale du commerce extérieur des produits alimentaires u. a./Frankreich, Rn. 16; Urt.v. 12.2.2008, Az.: C-199/06 - CELF und ministre de la Culture und de la Communication, Rn. 40.

1647 EuGH, Urt. v. 12.2.2008, Az.: C-199/06 - CELF und Ministre de la Culture et de la Communication, Rn. 46 ff. Die Möglichkeit einer derartigen Anordnung nach nationalem Recht, schließt der EuGH zwar nicht aus, a.a.O., Rn. 53, sie wird indes bei Anwendung des Verhältnismäßigkeitsgrundsatzes hinter der bloßen Abschöpfung gezogener Vorteile zurückstehen, Finck/Gurlit, JURA 2011, 87 (92).

1648 EuGH, Urt. v. 12.2.2008, Az.: C-199/06 - CELF und Ministre de la Culture et de la Communication, Rn. 50 ff. Daran anknüpfend EuGH, Urt. v. 18.12.2008, Az.: C-384/07 - Wienstrom, Rn. 28 ff.; Urt. v. 5.3.2019, Az.: C-349/17 - Eesti Pagar, Rn. $131 \mathrm{ff.}$

1649 EuGH, Urt. v. 12.2.2008, Az.: C-199/06 - CELF und Ministre de la Culture et de la Communication, Rn. $56 \mathrm{ff}$.

1650 Der EuGH, Urt. v. 11.3.2010, Az.: C-1/09 - CELF und Ministre de la Culture et de la Communication, Rn. 41 ff., verneinte mangels Eintritts der Bestandskraft des Kommissionsbeschlusses gar für den Sonderfall des Aufeinanderfolgens von drei Nichtigkeitsklagen das Vorliegen „außergewöhnlicher Umstände“.

Tobias Brings-Wiesen 
und 2, II, IV und § 49a VwVfG zu erfolgen. ${ }^{1651}$ Dabei ist - neben den bereits dargelegten Besonderheiten betreffend die formelle Unionsrechtswidrigkeit (s. dazu Rn. 938) - zu berücksichtigen, dass eine Rücknahme des Bescheids entsprechend des bloß vorläufigen Sicherungszwecks des Durchführungsverbots ausschließlich mit Wirkung für die Vergangenheit und bis zum endgültigen Beschluss der Kommission erfolgt. In der Folge sind die Zinsvorteile als „bereits erbrachte Leistungen“ auf Grundlage von § 49a I 1 VwVfG zurückzufordern, wobei ein etwaiger Entreicherungseinwand gemäß § 49a II 2 VwVfG wiederum unionsrechtlich bedingt unbeachtet zu bleiben hat.

- Davon zu unterscheiden sind Konstellationen, in denen eine (zumindest vorläufige) Rückabwicklung während eines noch laufenden Prüfverfahrens begehrt wird. Wird eine Beihilfemaßnahme unter Verstoß gegen das Durchführungsverbot durchgeführt, haben die mitgliedstaatlichen Institutionen im Interesse des vorläufigen Sicherungszwecks des Art. 108 III AEUV Maßnahmen anzuordnen, die geeignet sind, die Rechtswidrigkeit der Durchführung zu beseitigen, damit der Empfänger in der bis zum Beschluss der Kommission noch zu verbleibenden Zeit nicht weiterhin frei über sie verfügen kann. ${ }^{1652}$ Auch insofern hat die Rückabwicklung auf Grundlage von § 48 I 1 und 2, II, IV und § 49a VwVfG zu erfolgen, wobei sich Rücknahme und Erstattung unter der auflösenden Bedingung eines günstigen Beschlusses der Kommission anbieten. ${ }^{1653}$ Vor Eröffnung des formellen Prüfverfahrens trifft sie dabei die Pflicht, die Voraussetzungen von Notifikationspflicht und Durchführungsverbot selbst zu prüfen; nach dessen Eröffnung sollen sie laut EuGH an den Beschluss der Kommission gebunden $\operatorname{sein}^{1654}{ }^{1655}$ Vor diesem Hintergrund liegt zumindest nahe, die bereits geschilderte weitgehende unionsrechtliche Überformung von § 48 I 1 und 2, II, IV und § 49a VwVfG auch in diesen Konstellationen anzunehmen - abschließend geklärt sind diese Fragen indes noch nicht. ${ }^{1656}$ Von einer strikten unionsrechtlichen Bindung wird man zumindest im Falle einer Anordnung der Kommission gemäß Art. 13 BeihilfeVVO auszugehen haben. ${ }^{1657}$

- Wettbewerber des Beihilfeempfängers ${ }^{1658}$ können sich in beiden Fällen im Wege von Anfechtungsklage und Vollzugsfolgenbeseitigungsklage gemäß § 113 I 1 und 2 VwGO (s. dazu näher Rn. 1387) gegen den Bewilligungsbescheid und die bereits erfolgte Durchführung der Beihilfemaßnahme wenden. ${ }^{1659}$ Art. 108 III 3 AEUV entfaltet nicht nur unmittelbare Wirkung, sondern zugunsten der Wettbewerber auch drittschützenden Charakter. ${ }^{1660}$

1651 BVerwG, Urt. v. 16.12. 2010, Az.: 3 C 44.09 = BVerwGE 138, 322 (325f., Rn. 14f.); Finck/Gurlit, JURA 2011, 87 (91f.).

1652 EuGH, Urt. v. 11.3.2010, Az.: C-1/09 - CELF und Ministre de la Culture et de la Communication, Rn. 29f.; Urt. v. 21.11.2013, Az.: C-284/12 - Deutsche Lufthansa, Rn. 30 f.

1653 Detterbeck, Allgemeines Verwaltungsrecht, 17. Aufl. 2019, Rn. 761.

1654 S. dazu Martin-Ehlers, EuZW 2014, 247; Berrisch, EuZW 2014, 253; Rennert, DVBl 2014, 669. 1655 EuGH, Urt. v. 21.11.2013, Az.: C-284/12 - Deutsche Lufthansa, Rn. 33 ff. Keine derartige Bindung gilt indes im Falle eines Beschlusses der Kommission gemäß Art. 4 III BeihilfeVVO, BVerwG, Urt. v. 26.10.2016, Az.: 10 C 3.15 = EuZW 2017, 355 (357 ff., Rn. 18 ff.).

1656 Detterbeck, Allgemeines Verwaltungsrecht, 17. Aufl. 2019, Rn. 760.

1657 Detterbeck, Allgemeines Verwaltungsrecht, 17. Aufl. 2019, Rn. 761.

1658 S. zu beihilferechtlichen Konkurrentenklagen Rennert, EuZW 2011, 576.

1659 Detterbeck, Allgemeines Verwaltungsrecht, 17. Aufl. 2019, Rn. 760; Rennert, EuZW 2011, 576 (578). 


\section{(c) Die Rücknahme unionsrechtswidriger Verwaltungsakte im Übrigen}

937 Examenswissen: Wie bereits mehrfach angemerkt handelt es sich bei dem Voranstehenden um Sondermaßstäbe, die vom EuGH speziell für EU-beihilfenrechtlich relevante Sachverhalte statuiert und entsprechend von der deutschen Rechtsprechung rezipiert wurden. Auf den Regelfall der Rücknahme anderweitig unionsrechtswidriger Verwaltungsakte sind sie nicht übertragbar. Die mitgliedstaatlichen Institutionen sind aber bei Anwendung des § 48 VwVfG in unionsrechtlich determinierten Sachverhalten weiterhin mindestens an die Grundsätze von Äquivalenz und Effektivität (als Ausprägungen des Grundsatzes der loyalen Zusammenarbeit gemäß Art. 4 III EUV, s. bereits Rn. 931) gebunden.

938 Dies hat in der Vergangenheit vermehrt zu der Frage geführt, ob eine mitgliedstaatliche Behörde wegen ihrer Bindung an den Effektivitätsgrundsatz die Pflicht treffen kann, eine bereits bestandskräftige Entscheidung zurückzunehmen, wenn sich durch ein späteres Urteil des EuGH deren Unionsrechtswidrigkeit offenbart. ${ }^{1661}$ Ausschlaggebend war der der Rechtssache „Kühne \& Heitz“ zugrundeliegende Sachverhalt ${ }^{1662}$ : Das niederländisches Unternehmen Kühne \& Heitz NV hatte von Dezember 1986 bis Dezember 1987 Geflügelteile in Drittstaaten exportiert und dafür gemäß EU-sekundärrechtlicher Vorgaben ursprünglich eine Ausfuhrerstattung erhalten. Bei einer nachträglichen Überprüfung dieses Vorgangs ordnete die zuständige niederländische Behörde die Geflügelteile einer neuen Tarifposition zu, die eine Erstattung nicht vorsah. In der Folge verlangte sie eine Rückzahlung in Höhe der Erstattung von Kühne \& Heitz NV, wogegen das Unternehmen erfolglos den Rechtsweg beschritt. Jahre später entschied der EuGH, dass die Zuordnung der Geflügelteile zur ursprünglichen Tarifposition korrekt war. ${ }^{1663}$ Das um Vorabentscheidung (gemäß Art. 267 AEUV) ersuchende niederländische Gericht erwog, unter den Umständen des Falles verpflichtet $\mathrm{zu}$ sein, einen bereits bestandskräftigen Bescheid zurückzunehmen, um die volle Wirksamkeit des Unionsrechts sicherzustellen. Eine derartige Verpflichtung verneinte der EuGH indes für den Regelfall: Unter Berücksichtigung des auch im Unionsrecht geltenden Grundsatzes der Rechtssicherheit seien mitgliedstaatliche Behörden grundsätzlich nicht verpflichtet, eine (nach Ablauf einer angemessenen Klagefrist oder Erschöpfung des Rechtswegs) bestandskräftige Verwaltungsentscheidung zurückzunehmen. ${ }^{1664}$ Vor diesem Hintergrund erachtete er in einem späteren Vorabentscheidungsverfahren insbesondere auch die deutsche Rechtslage für mit dem Effektivitätsgrundsatz vereinbar. ${ }^{1665}$ Wegen der besonderen Umstände des Falles „Kühne \&Heitz“ erkannte der EuGH jedoch ausnahmsweise auf eine Pflicht zur „Überprüfung“:

1660 BVerwG, Urt. v. 16.12.2010, Az.: 3 C 44.09 = BVerwGE 138, 322 (324f., Rn. 13); Urt. v. 26.10. 2016, Az.: 10 C 3.15 = EuZW 2017, 355 (356f., Rn. 13, 20).

1661 S. dazu auch die Fallbearbeitung bei Musil/Burchard, Klausurenkurs im Europarecht, 4. Aufl. 2016, Fall 14, S. 256.

1662 EuGH, Urt. v. 13.1.2004, Az.: C-453/00 - Kühne \& Heitz, Rn. $26 \mathrm{ff}$.

1663 EuGH, Urt. v. 5.10.1994, Az.: C-151/93 - Voogd Vleesimport en -export.

1664 EuGH, Urt. v. 13.1.2004, Az.: C-453/00 - Kühne \& Heitz, Rn. 24; zuletzt Urt.v. 20.12. 2017, Az.: C-492/16 - Incyte, Rn. 46. Darauf rekurrierend BVerwG, Urt. v. 22.10.2009, Az.: 1 C $26.08=$ BVerwGE 135, 137 (146, Rn. 20).

1665 EuGH, Urt. v. 19.9.2006, Az.: C-392/04 und C-422/04 - i-21 Germany und Arcor, Rn. 58 ff. 
- Die Behörde war nach nationalem Recht grundsätzlich befugt, die bestandskräftige Entscheidung zurückzunehmen.

- Die Entscheidung war infolge eines Urteils eines in letzter Instanz entscheidenden nationalen Gerichts bestandskräftig geworden, der nationale Rechtsweg mithin erschöpft gewesen.

- Dieses letztinstanzliche Urteil beruhte, wie eine nach seinem Erlass ergangene Entscheidung des Gerichtshofs zeigte, auf einer unrichtigen Auslegung des Unionsrechts, die erfolgt war, ohne dass der Gerichtshof um Vorabentscheidung ersucht wurde, obwohl der Tatbestand des Art. 267 III AEUV erfüllt war. ${ }^{1666}$

- Der Betroffene hatte sich, unmittelbar nachdem er Kenntnis von der besagten Entscheidung des Gerichtshofs erlangt hatte, an die Behörde gewandt. ${ }^{1667}$

An dieser Rechtsprechung hat der EuGH bis heute grundsätzlich festgehalten, ${ }^{1668}$ dabei jedoch zugleich immer wieder ihren Ausnahmecharakter demonstriert: Er verneinte ihre Anwendbarkeit mangels Erschöpfung des nationalen Rechtswegs ${ }^{1669}$ oder mangels gesetzlich vorgesehener Befugnis zur Durchbrechung der Vorgaben zur Gewährleistung von Rechtssicherheit ${ }^{1670}$. Zugleich hat der EuGH zaghaft andere „besondere Umstände“ erkannt, unter denen im Interesse der Sicherstellung der Unionsrechtmäßigkeit eine Verpflichtung der Überprüfung einer Verwaltungsentscheidung unter Durchbrechung ihrer Bestandskraft besteht: In „Byankov“ urteilte der EuGH, dass die Unmöglichkeit der erneuten Überprüfung eines offensichtlich rechtswidrigen bestandskräftigen Ausreiseverbots nach bulgarischem Recht wegen seines fundamentalen Widerspruchs zum Recht auf Freizügigkeit von Unionsbürgern gemäß Art. 21 I AEUV gegen den Effektivitätsgrundsatz verstößt. ${ }^{1671}$ In „Incyte“ schloß der EuGH insbesondere aus der Zielsetzung des zugrundeliegenden Sekundärrechts darauf, dass die Korrektur der bestandskräftig bestimmten, aber rechtswidrigen Laufzeit eines Patents möglich sein muss. ${ }^{1672}$ Obgleich der EuGH sich mit dem Rekurs auf mögliche „besondere Umstände“ eine Hintertür offenhält, zeigt sich unverkennbar der Ausnahmecharakter einer durch den Effektivitätsgrundsatz bedingten Verpflichtung zur Überprüfung eines Verwaltungsaktes unter Durchbrechung der Bestandskraft.

Liegt keine dieser Ausnahmekonstellationen vor, verlangt der Äquivalenzgrundsatz lediglich, dass bei Anwendung der nationalen Vorschriften nicht ohne sachliche Rechtfertigung zwischen unionsrechtlich und rein nationalrechtlich determinierten Sachverhalten unterschie-

1666 Dabei muss sich der Betroffene vor den nationalen Gerichten nicht auf Unionsrecht berufen haben, soweit diese verpflichtet sind, Unionsrecht von Amts wegen zu berücksichtigen, EuGH, Urt. v. 12.2.2008, Az.: C-2/06 - Kempter, Rn. 34ff. Die deutschen Verwaltungsgerichte trifft im Regelfall eine derartige Pflicht; s. aber zur besonderen Ausnahme hinsichtlich des Antrags auf Zulassung der Berufung gemäß §124a VwGO BVerwG, Urt. v. 22.10.2009, Az.: 1 C 15/08 = BVerwGE 135, 121 (133, Rn. 32).

1667 S. zur „Unmittelbarkeit“ näher EuGH, Urt. v. 12.2.2008, Az.: C-2/06 - Kempter, Rn. 54 ff. 1668 Zuletzt EuGH, Urt. v. 20.12.2017, Az.: C-492/16 - Incyte, Rn. 47.

1669 EuGH, Urt. v. 19.9.2006, Az.: C-392/04 und C-422/04 - i-21 Germany und Arcor, Rn. 53; Urt.v. 4.10.2012, Az.: C-249/11 - Byankov, Rn. 51.

1670 Vgl. entsprechend zur Durchbrechung der Rechtskraft EuGH, Urt. v. 16.3.2006, Az.: C-234/ 04 - Kapferer, Rn. 23.

1671 EuGH, Urt. v. 4.10.2012, Az.: C-249/11 - Byankov, Rn. 77 ff.

1672 EuGH, Urt. v. 20.12.2017, Az.: C-492/16 - Incyte, Rn. 45 ff.

Tobias Brings-Wiesen 
den wird. ${ }^{1673}$ Dies bedeutet bei bestandskräftigen Verwaltungsakten insbesondere, dass auch im Falle ihrer Unionsrechtswidrigkeit nur bei Vorliegen einer der vom Bundesverwaltungsgericht etablierten Fallgruppen der Unerträglichkeit der Aufrechterhaltung der Bestandskraft eine Ermessensreduktion auf Null erfolgt (s. dazu Rn. 924).

940 Für die Prüfungspraxis bedeutet dies: Die Bewertung der Rücknahme unionsrechtswidriger Verwaltungsakte außerhalb des geschilderten beihilfenrechtlichen Kontexts erfolgt - auch wegen des Äquivalenzgrundsatzes - im Regelfall ohne besondere unionsrechtliche Überformung am Maßstab von § 48 VwVfG. Besonderheiten werden sich dann höchstens im Rahmen der Prüfung der Rechtswidrigkeit des zurückzunehmenden Verwaltungsaktes ergeben, soweit diese unter Berücksichtigung unionalen Primär- oder Sekundärrechts zu erfolgen hat. ${ }^{1674}$ Anderes gilt in den wenigen geschilderten Ausnahmekonstellationen, die in der Prüfungspraxis zwar nur eine untergeordnete Rolle spielen dürften, aber wegen ihrer Feinheiten gleichwohl bekannt sein sollten: Die im Interesse des Effektivitätsgrundsatz erforderliche unionsrechtliche Überformung ist je nach Anwendungsfall des $§ 48$ VwVfG an verschiedenen Stellen der Prüfung denkbar. In der derzeit praktisch ${ }^{1675}$ allein relevanten Konstellation der Rücknahme eines belastenden Verwaltungsaktes gemäß § 48 I 1 VwVfG spielt sie sich ganz wesentlich im Rahmen der Prüfung des Ermessens als Frage einer unionsrechtlich bedingten Ermessensreduktion auf Null ab. Die den Rechtssachen „Bankyo“ und „Incyte“ zugrundeliegenden Sachverhaltskonstellationen lassen sich dabei bereits problemlos den vom Bundesverwaltungsgericht etablierten Fallgruppen zuordnen (Bankyo: „offensichtliche Rechtswidrigkeit“; Incyte: Berücksichtigung der Wertungen und Intentionen des zugrundeliegenden Fachrechts). Die besonderen Umstände der Rechtssache „Kühne \& Heitz“ sind demgegenüber als besondere unionsrechtliche Fallgruppe zu betrachten. ${ }^{1676}$ Weitere Ausnahmekonstellationen sollten in der Prüfung nur mit extremer Zurückhaltung überhaupt erwogen werden. Handelt es sich um eine dieser Ausnahmekonstellationen, ist abschließend auf den Streit einzugehen, ob der EuGH in diesen Fällen mit der Pflicht zur „Überprüfung“ tatsächlich eine Pflicht zur Rücknahme verbindet ${ }^{1677}$ oder lediglich ein Wiederaufgreifen des Verfahrens fordert ${ }^{1678}$. Von Letzterem wird man zumindest dann ausgehen müssen,

1673 Maurer/Waldhoff, Allgemeines Verwaltungsrecht, 19. Aufl. 2017, §11 Rn. 73. S. dazu die Prüfung des EuGH, Urt. v. 19.9.2006, Az.: C-392/04 und C-422/04 - i-21 Germany und Arcor, Rn. 62ff.; daran anknüpfend BVerwG, Urt. v. 17.1.2007, Az.: 6 C 32.06 = NVwZ 2007, 709 (711f., Rn. 16 ff.); zust. Detterbeck, Allgemeines Verwaltungsrecht, 17. Aufl. 2019, Rn. 764. S. dazu auch die Fallbearbeitung bei Ludwigs, JURA 2009, 226 (232)

1674 S. zu den prüfungsrelevanten Grundfreiheiten Sauer, JuS 2017, 310. S. auch die Fallbearbeitung bei Staufer/Steinebach, JURA 2012, 883.

1675 Rücknahmen unionsrechtswidriger begünstigender Verwaltungsakte gemäß § 48 I 2, II bis IV VwVfG sind zwar theoretisch denkbar, spielten in der Praxis jedoch - wie die dargestellte Rechtsprechung zeigt - bislang (außerhalb des Subventionsrechts) keine Rolle.

1676 So auch Ludwigs, JURA 2009, 226 (229ff.), der abgrenzend auf die verschiedenen Konstellationen der Ermessensreduktion auf Null aufgrund nationalen und unionalen Rechts eingeht. 1677 So Maurer/Waldhoff, Allgemeines Verwaltungsrecht, 19. Aufl. 2017, §11 Rn. 73; Ruffert, in: Ehlers/Pünder, Allgemeines Verwaltungsrecht, 15. Aufl. 2016, § 24 Rn. 17 f.; Frenz, DVBl 2004, 375; Kanitz/Wendel, EuZW 2008, 231 (235). Zumindest in bipolaren Rechtsverhältnissen Rennert, DVBl 2007, 401 (408); Ludwigs, JZ 2008, 466 (468f.).

1678 EuGH, Urt. v. 19.9.2006, Az.: C-392/04 und C-422/04 - i-21 Germany und Arcor, Rn. 52 (sehr deutlich: „,eventuell zurückzunehmen“); wohl auch das BVerwG, Urt.v. 22.10.2009, Az.:1 C 15/08 = 
wenn in multipolaren Rechtsverhältnissen die Belange betroffener Dritter zu berücksichtigen sind. ${ }^{1679}$ Sind diese Fragestellungen in die Prüfung eines Anspruchs auf Wiederaufgreifen des Verfahrens (s. dazu in $\S 3$ Rn. 98 ff.) eingebettet, hat dieser ultimativ am Maßstab von $\S 51$ V i.V.m. $\S 48$ I 1 VwVfG zu erfolgen, da nach der zutreffenden herrschenden Meinung ${ }^{1680}$ auch der Effektivitätsgrundsatz kein Abweichen vom Verständnis des Tatbestands der Änderung der Rechtslage gemäß § 51 I Nr. 1 VwVfG verlangt.

\section{dd) Literaturhinweise}

Lehrbeiträge: Britz/Richter, Die Aufhebung eines gemeinschaftsrechtswidrigen nicht begünstigenden Verwaltungsakts, JuS 2005, 198; Brügge/Erichsen, Die Rücknahme von Verwaltungsakten nach $\S 48$ VwVfG, JURA 1999, 155; Bungenberg/Motzkus, Die Praxis des Subventions- und Beihilfenrechts in Deutschland, GewArch Beil. WiVerw 2/2013, 76; Ehlers, Rechtsfragen des Subventionsrechts, DVBl 2014, 1; Ehlers/Kallerhoff, Die Rücknahme von Verwaltungsakten, JURA 2009, 823; Finck/Gurlit, Die Rückabwicklung formell unionsrechtswidriger Beihilfen, JURA 2011, 87; Hilbert, Die reformierte europäische Beihilfeaufsicht, JURA 2017, 1150; Korte, Grundlagen des Subventionsrechts, JURA 2017, 656; Krausnick, Grundfälle zu §§ 48, 49 VwVfG, JuS 2010, 594, 681 und 778; Martini, Die Aufhebung von Verwaltungsakten nach $\S \$ 48$ ff. VwVfG, JA 2012, 762; JA 2013, 442; JA 2016, 830 und JA 2017, 838; Struzina/Lindner, Vertrauensschutz bei der Rücknahme von Verwaltungsakten nach § 48 III VwVfG, NVwZ 2016, 1295

Fallbearbeitungen: Broscheit, „Der findige Gaststättenbetreiber“, JA 2016, 840; Funke/Waidhas, „Subventioniertes Freibad“, JA 2014, 439; Gurlit, Übungsklausur: Gau-Wackenheimer Streit um Weinbau, ZJS 2011, 368; Kahl/Hilbert, Das nachträglich zerronnene Subventionsglück, JURA 2011, 948; Knappe/Tehlen, „Rocker ohne Knarre und Kutte“, JURA 2018, 829; Ludwigs, Jus vigilantibus scriptum, JURA 2009, 226; Musil/Burchard, Fall 14 - Bestandskraft als Europarechtsproblem, in: Klausurenkurs im Europarecht, 4. Aufl. 2016, S. 256; Peters, Der rechtswidrig gewährte Zuschuss, VR 2018, 62; Staufer/Steinebach, Recht auf Freizügigkeit und Hochschulzulassung, JURA 2012, 883; Vrhovac/Sprungmann,

BVerwGE 135, 121 (132f., Rn. 30, 33); Urt. v. 22.10.2009, Az.: 1 C 26/08 = BVerwGE 135, 137 (146f., Rn. 20, 23); so auch Britz/Richter, JuS 2005, 198 (199ff.); Krönke, Die Verfahrensautonomie der Mitgliedstaaten der Europäischen Union, 2013, S. 238.

1679 Detterbeck, Allgemeines Verwaltungsrecht, 17. Aufl. 2019, Rn. 765; Britz/Richter, JuS 2005, 198 (199); Ludwigs, DVBl 2008, 1164 (1169). Vgl. bereits EuGH, Urt. v. 13.1.2004, Az.: C-453/00 Kühne \& Heitz, Rn. 27.

1680 BVerwG, Urt.v. 22.10. 2009, Az.: 1 C 15/08 = BVerwGE 135, 121 (128, Rn. 21); Urt.v. 22.10. 2009, Az.: 1 C 26/08 = BVerwGE 135, 137 (143f., Rn. 16); Detterbeck, Allgemeines Verwaltungsrecht, 17. Aufl. 2019, Rn. 763; Britz/Richter, JuS 2005, 198 (201); Rennert, DVBl 2007, 400 (408); Kanitz/ Wendel, JuS 2008, 58 (63); Ludwigs, DVBl 2008, 1164 (1172). A.A. Lenze, VerwArch 2006, 49 (56 ff.). 
„Wash and go - auch am Heiligen Sonntag?“, JA 2018, 927; von Weschpfennig, „Doktor Ade“, JURA 2014, 1055

\section{c) Widerruf eines Verwaltungsakts nach $\S 49$ VwVfG}

941 Die folgende Darstellung zum Widerruf eines Verwaltungsakts gemäß § 49 VwVfG orientiert sich wiederum weitgehend am Prüfungsschema der Vorschrift, während sich grundlegendere Ausführungen an den für die Prüfung relevanten Stellen finden.

\section{Prüfungsschema zu § 49 VwVfG}

I. Ermächtigungsgrundlage: § 49 I, II oder III VwVfG (s. im Einzelnen Rn. 943)

II. Formelle Rechtmäßigkeit

1. Zuständigkeit (Beachte: $\S 49 \mathrm{~V} \mathrm{VwVfG)}$

2. Verfahren (Insbesondere: $\S 28 \mathrm{I}$ VwVfG)

3. Form (Beachte: actus contrarius-Gedanke)

III. Materielle Rechtmäßigkeit

1. Tatbestand

a) Vorliegens eines Verwaltungsakts (als Gegenstand der Aufhebung)

b) Rechtmäßigkeit des aufzuhebenden Verwaltungsakts (im Zeitpunkt seines Erlasses) (Beachte: „Erst-recht-Schluss“ hinsichtlich rechtswidriger Verwaltungsakte)

c) Kein Ausschluss des Widerrufs, weil ein Verwaltungsakt gleichen Inhalts erneut erlassen werden müsste oder aus anderen Gründen ein Widerruf unzulässig ist (§ 49 I VwVfG)

d) Ggf. weitere tatbestandliche Voraussetzungen gemäß § 49 II oder III VwVfG im Falle des Vorliegens eines rechtmäßigen begünstigenden Verwaltungsakts

aa) Tatbestandliche Voraussetzungen gemäß § 49 III VwVfG (als lex specialis)

(1) Vorliegen eines Verwaltungsakts, der eine einmalige oder laufende Geldleistung oder teilbare Sachleistung zur Erfüllung eines bestimmten Zwecks gewährt oder hierfür Voraussetzung ist („Leistungsverwaltungsakt“)

(2) Vorliegen eines Widerrufsgrundes gemäß § 49 III 1 VwVfG

bb) Tatbestandliche Voraussetzungen gemäß § 49 II VwVfG

(1) Vorliegen eines sonstigen Verwaltungsakts

(2) Vorliegen eines Widerrufsgrundes gemäß § 49 II 1 VwVfG 
cc) Kein Ausschluss des Widerrufs aufgrund von Verfristung gemäß $\S 49$ II 2 bzw. III 2 i.V.m. § 48 IV VwVfG

2. Rechtsfolge: Ordnungsgemäße Ermessensausübung (Beachte: Zeitliche Ermessensbegrenzungen in § 49 I und II VwVfG [nur „mit Wirkung für die Zukunft“]; Ausnahme: Widerruf „mit Wirkung für die Vergangenheit“ gemäß § 49 III VwVfG)

\section{aa) Ermächtigungsgrundlage}

Anders als im Rahmen von $\S 48$ VwVfG besteht keine einheitliche Ermächti- 943 gungsgrundlage, sodass im Rahmen einer Prüfung jeweils auf den im Folgenden näher $\mathrm{zu}$ begutachtenden Absatz zu rekurrieren ist. Rechtmäßige belastende Verwaltungsakte sind gemäß § 49 I VwVfG zu widerrufen. Im Falle von rechtmäßigen begünstigenden Verwaltungsakten ist $\mathrm{zu}$ unterscheiden zwischen Verwaltungsakten, die eine einmalige oder laufende Geldleistung oder teilbare Sachleistung zur Erfüllung eines bestimmten Zwecks gewähren oder hierfür Voraussetzung sind und gemäß § 49 III VwVfG - auch mit Wirkung für die Vergangenheit - widerrufen werden können -, und sonstigen Verwaltungsakten, die gemäß § 49 II VwVfG widerrufen werden können. Wie im Rahmen von § 48 VwVfG (s. dazu Rn. 846) sollte eine dieser Ermächtigungsgrundlagen zu Beginn der Rechtmäßigkeitsprüfung präzise bestimmt, deren Voraussetzungen jedoch sodann erst im Rahmen der materiellen Rechtmäßigkeit ausführlich geprüft werden.

\section{bb) Formelle Rechtmäßigkeit}

Da auch der Widerruf eines Verwaltungsakts selbst ein Verwaltungsakt ist, 944 gelten die bereits zu § 48 VwVfG erfolgten Darstellungen entsprechend. ${ }^{1681} \S 49 \mathrm{~V}$ VwVfG entspricht dabei der Zuständigkeitsregelung des § 48 V VwVfG.

\section{cc) Materielle Rechtmäßigkeit}

Da auch der Widerruf im Ermessen der Behörde steht, ist im Rahmen der Prüfung 945 der materiellen Rechtmäßigkeit wiederum zwischen Tatbestand und Rechtsfolge zu unterteilen. Im Interesse der Darstellung werden diese Prüfungsebenen im Folgenden für die jeweiligen Absätze zusammen behandelt.

1681 S. zur besonderen Regelung des § 49 IV VwVfG nur Ramsauer, in: Kopp/Ramsauer, VwVfG, 20. Aufl. 2019, § 49 Rn. 75 ff. 
946

Wie im Rahmen von § 48 VwVfG und entsprechend der jeweils gewählten Ermächtigungsgrundlage sind im Tatbestand unterschiedliche Voraussetzungen zu prüfen.

\section{(1) Anwendungsbereich}

$947 \mathrm{Zu}$ Beginn ist wie bei $\S 48 \mathrm{VwVfG}$ die Anwendbarkeit der Vorschrift zu prüfen: Der Widerruf ist zumindest bei rein wörtlich-systematischer Betrachtung die Aufhebung eines rechtmäßigen Verwaltungsakts. Insofern kann auf die zu $\S 48$ VwVfG erfolgten Darstellungen (s. dazu Rn. $865 \mathrm{ff}$.) entsprechend verwiesen werden.

948 Die wesentliche Besonderheit liegt jedoch darin, dass die Vorschrift nach herrschender Meinung über ihren klaren Wortlaut hinaus auch auf rechtswidrige Verwaltungsakte anwendbar ist. ${ }^{1682}$ Dies wird in teleologischer Hinsicht wesentlich auf einen „Erst-recht-Schluss“ gestützt: Wenn bereits ursprünglich rechtmäßige Verwaltungsakte nach $\S 49 \mathrm{VwVfG}$ widerrufen werden dürfen, müsse dies erst recht für Verwaltungsakte gelten, die bereits ursprünglich rechtswidrig gewesen sind und somit schon immer dem Grundsatz der Gesetzmäßigkeit der Verwaltung widersprochen haben.

\section{(2) Belastender oder begünstigender Verwaltungsakt}

949 Die Unterscheidung zwischen rechtmäßigen belastenden und begünstigenden Verwaltungsakten erfolgt wiederum nach der Legaldefinition in § 48 I 2 VwVfG. Handelt es sich um einen belastenden Verwaltungsakt, richtet sich der Widerruf nach § 49 I VwVfG. Für begünstigende Verwaltungsakte gilt § 49 II und III VwVfG.

\section{(a) Belastender Verwaltungsakt, § 49 I VwVfG}

950 Der Widerruf rechtmäßiger belastender Verwaltungsakte ist gemäß §49 I VwVfG ausgeschlossen, wenn ein Verwaltungsakt gleichen Inhalts erneut erlassen werden müsste oder aus anderen Gründen ein Widerruf unzulässig ist.

1682 S. dazu nur Ramsauer, in: Kopp/Ramsauer, VwVfG, 20. Aufl. 2019, § 49 Rn. 12 m.w. N.; dagegen aber bspw. Ehlers/Schröder, JURA 2010, 503 (506) m.w. N.; ausführlich zur Problematik Kiefer, NVwZ 2013, 1257; Struzina, DÖV 2017, 906, jeweils m.w. N. zu den versch. Ansichten und Argumenten. 
Neben den bereits dargestellten positiven Merkmalen handelt es sich um 951 zwei negative Tatbestandsmerkmale. ${ }^{1683}$ Dabei ist das erste Merkmal vor dem Hintergrund des Zwecks der §§ 48f. VwVfG selbsterklärend: Der Behörde soll über den Widerruf nicht ermöglicht werden, die rechtlichen Vorgaben zu umgehen, die für sie hinsichtlich des Erlasses des Verwaltungsakts gelten. ${ }^{1684}$ Es kommt im Wege einer hypothetischen Betrachtung darauf an, ob sie bei Aufhebung des Verwaltungsakts rechtlich verpflichtet wäre, diesen mit dem identischen Regelungsgehalt umgehend wieder zu erlassen. Dies ist der Fall, wenn die Behörde bei Erlass des ursprünglichen Verwaltungsakts gebunden war und weiterhin alle Tatbestandsvoraussetzungen vorliegen. ${ }^{1685}$ Davon wird man regelmäßig dann nicht ausgehen können, wenn eine gemäß § 36 I Var. 2 VwVfG beigefügte Auflage nicht erfüllt wurde oder sich die Sach- oder Rechtslage verändert hat. Stand die ursprüngliche Entscheidung hingegen im Ermessen der Behörde, wird nur eine Ermessensreduktion auf Null den Widerruf von vornherein sperren können. ${ }^{1686}$ Aus anderen Gründen kann ein Widerruf unzulässig sein, wenn ausdrückliche gesetzliche Bestimmungen, der Zweck des zugrundeliegenden Rechts, allgemeine Rechtsgrundsätze oder der Grundsatz der Selbstbindung der Verwaltung dem entgegenstehen. ${ }^{1687}$ Von diesen Beispielen dürfte insbesondere das letztgenannte wirkliche Prüfungsrelevanz haben.

Liegt keiner der Ausschlussgründe vor, steht die Entscheidung über den 952 Widerruf im Ermessen der Behörde, die darin lediglich in zeitlicher Hinsicht begrenzt ist: Wegen der in der Vergangenheit bestehenden Rechtmäßigkeit des Verwaltungsakts kann dessen Widerruf nur mit Wirkung für die Zukunft erfolgen. Wie im Rahmen von § 48 I 1 VwVfG können die verschiedenen Ermessenserwägungen des Einzelfalls uneingeschränkt Berücksichtigung finden. Dabei kann auch auf die § 49 II, III VwVfG zugrundeliegenden Wertungen abgestellt werden. Im Falle der nachträglichen Änderung der Sach- oder Rechtslage sprechen sowohl der Grundsatz der Gesetzmäßigkeit der Verwaltung als auch die Grundrechte des Belasteten regelmäßig für einen Widerruf eines Dauerverwaltungsaktes (mit

1683 Suerbaum, in: Mann/Sennekamp/Uechtritz, VwVfG, 2. Aufl. 2019, § 49 Rn. 60 ff.; wohl auch Kastner, in: Fehling/Kastner/Störmer, Verwaltungsrecht, 4. Aufl. 2016, § 49 VwVfG Rn. 20.

1684 Ramsauer, in: Kopp/Ramsauer, VwVfG, 20. Aufl. 2019, § 49 Rn. 21a.

1685 Maurer/Waldhoff, Allgemeines Verwaltungsrecht, 19. Aufl. 2017, § 11 Rn. 76.

1686 Ramsauer, in: Kopp/Ramsauer, VwVfG, 20. Aufl. 2019, § 49 Rn. 21b; Sachs, in: Stelkens/ Bonk/Sachs, VwVfG, 9. Aufl. 2018, § 49 Rn. 23; Suerbaum, in: Mann/Sennekamp/Uechtritz,VwVfG, 2. Aufl. 2019, § 49 Rn. 61.

1687 S. nur Ramsauer, in: Kopp/Ramsauer, VwVfG, 20. Aufl. 2019, § 49 Rn. 22. 
Wirkung für die Zukunft). ${ }^{1688}$ Etwas anderes kann dann gelten, wenn ein Antrag auf Wiederaufgreifen des Verfahrens gemäß §51 I Nr. 1 VwVfG innerhalb der vorgegebenen Frist versäumt wurde. ${ }^{1689}$

\section{(b) Begünstigender Verwaltungsakt}

953 Der Widerruf rechtmäßiger begünstigender Verwaltungsakte ist demgegenüber tatbestandlich stärker beschränkt: Zulässig ist er nur, soweit einer der in $\S 49$ II, III VwVfG normierten besonderen Widerrufsgründe vorliegt und der Widerruf nicht aufgrund von Verfristung gemäß § 49 II 2 bzw. § 49 III 2 i.V.m. § 48 IV VwVfG ausgeschlossen ist. Über den Wortlaut hinaus sind aus teleologisch-systematischen Erwägungen auch die in § 49 I VwVfG normierten Ausschlussgründe (s. dazu Rn. 951) zu berücksichtigen.

\section{Der Unterschied zwischen Abs. 2 und 3}

954 Der besondere Unterschied zwischen Abs. 2 und 3 liegt in der zeitlichen Ermessensbegrenzung: Während § 49 II VwVfG lediglich einen Widerruf mit Wirkung für die Zukunft zulässt, eröffnet § 49 III VwVfG die Möglichkeit, Leistungsverwaltungsakte (zur Begriffsbestimmung s. Rn. $878 \mathrm{ff}$.) unter den genannten Voraussetzungen auch mit Wirkung für die Vergangenheit zu widerrufen. Dabei kommt es jedoch nicht zu einer systematischen Trennung zwischen Leistungsund sonstigen Verwaltungsakten, sondern nur zu einer zeitlichen Erweiterung der Widerrufsmöglichkeit im Hinblick auf Leistungsverwaltungsakte. Dies bedeutet, dass der Widerruf von Leistungsverwaltungsakten, sofern er nur mit Wirkung für die Zukunft erfolgen soll, genauso auf die Widerrufsgründe des § 49 II VwVfG gestützt werden kann. ${ }^{1690}$ Da $§ 49$ III 1 VwVfG spezieller ist, ist er jedoch zumindest vorrangig anzuwenden. ${ }^{1691}$

\section{Der Widerruf nach \$ 49 II VwVfG}

955 Ein Schwerpunkt der Prüfung des Widerrufs eines rechtmäßigen begünstigenden Verwaltungsakts wird regelmäßig auf den Widerrufsgründen des § 49 II 1 VwVfG liegen, auf die im Folgenden näher einzugehen sein wird. Darüber hinaus sind

1688 BVerwG, Urt. v. 17.8.2011, Az.: 6 C 9.10 = BVerwGE 140, 221 (243f., Rn. 55); Maurer/Waldhoff, Allgemeines Verwaltungsrecht, 19. Aufl. 2017, § 11 Rn. 77; Detterbeck, Allgemeines Verwaltungsrecht, 17. Aufl. 2019, Rn. 716.

1689 So zu Recht Detterbeck, Allgemeines Verwaltungsrecht, 17. Aufl. 2019, Rn. 716.

1690 Ramsauer, in: Kopp/Ramsauer, VwVfG, 20. Aufl. 2019, § 49 Rn. 62; Sachs, in: Stelkens/ Bonk/Sachs, VwVfG, 9. Aufl. 2018, § 49 Rn. 107.

1691 Detterbeck, Allgemeines Verwaltungsrecht, 17. Aufl. 2019, Rn. 726.

Tobias Brings-Wiesen 
tatbestandlich die Ausschlussgründe gemäß § 49 I VwVfG (dazu Rn. 951) und $\S 49$ II 2 i.V.m. § 48 IV VwVfG (dazu Rn. 905 ff.) zu berücksichtigen, bezüglich derer die bereits erfolgten Ausführungen entsprechend gelten. Abschließend ist die ordnungsgemäße Ermessensausübung der Behörde zu prüfen.

\section{Gesetzlich oder durch Vorbehalt zugelassener Widerruf, Abs. II 1 Nr. 1}

Gemäß § 49 II 1 Nr. 1 VwVfG kann ein rechtmäßiger begünstigender Verwal- 956 tungsakt widerrufen werden, wenn der Widerruf durch Rechtsvorschrift zugelassen oder im Verwaltungsakt vorbehalten ist.

Var. 1 dieses Widerrufsgrundes unterfallen alle Konstellationen, in denen die Möglichkeit eines Widerrufs bereits gesetzlich vorgesehen ist. Für die Prüfung ist jedoch zu differenzieren: Ist der Widerruf spezialgesetzlich bereits abschließend geregelt, hat $§ 49$ VwVfG keine Bedeutung mehr - die Prüfung erfolgt vielmehr am Maßstab der Spezialnorm. ${ }^{1692}$ Nur soweit diese Spezialnorm (ausdrücklich oder nach Auslegung) Lücken aufweist, kann § 49 VwVfG ergänzend herangezogen werden. ${ }^{1693}$

Var. 2 dieses Widerrufsgrundes hat aus verschiedenen Gründen eine größere Prüfungsrelevanz. ${ }^{1694}$ Ein Widerruf ist zulässig, wenn er auf einen dem Verwaltungsakt als Nebenbestimmung beigefügten Widerrufsvorbehalt i.S.v. § 36 II Nr. 3 VwVfG gestützt werden kann. Dieser Anknüpfung macht es - in jedem Fall ${ }^{1695}$ - erforderlich, inzident die Rechtmäßigkeit des in Rede stehenden Widerrufsvorbehalts (s. dazu Rn. 233f.) umfassend zu prüfen. ${ }^{1696}$

Vor Eintritt der Bestandskraft schließt die Rechtswidrigkeit des Vorbehalts einen auf ihn gestützten Widerruf aus. ${ }^{1697}$ Nach Eintritt der Bestandskraft ist die Bewertung rechtswidriger Widerrufsvorbehalte umstritten.

1692 Ramsauer, in: Kopp/Ramsauer, VwVfG, 20. Aufl. 2019, § 49 Rn. 32; Sachs, in: Stelkens/ Bonk/Sachs, VwVfG, 9. Aufl. 2018, § 49 Rn. 44; Abel, in: Bader/Ronellenfitsch, VwVfG, 44. Ed., Stand: 1.7.2019, § 49 Rn. 30.

1693 Dies wird sogar umfassend geschehen müssen, wenn gesetzlich nur allgemein eine Widerrufbarkeit vorgesehen ist, Sachs, in: Stelkens/Bonk/Sachs, VwVfG, 9. Aufl. 2018, § 49 Rn. 45. 1694 S. dazu die Fallbearbeitung bei Winter-Peter, JURA 2018, 508.

1695 Je nach Entscheidung für oder gegen die Berücksichtigung der Rechtswidrigkeit auf Tatbestandsebene (s. dazu sogleich Rn. 959) kann jedoch die Verortung im Prüfungsaufbau (im Tatbestand oder im Ermessen) unterschiedlich ausfallen.

1696 Vgl. für Beispiele der Rechtswidrigkeit eines Widerrufsvorbehalts Sachs, in: Stelkens/Bonk/ Sachs, VwVfG, 9. Aufl. 2018, § 49 Rn. 41; Abel, in: Bader/Ronellenfitsch, VwVfG, 44. Ed., Stand:1.7. 2019, § 49 Rn. 32.

1697 Dann wird man insbesondere im Vorgehen gegen den Widerruf auch ein Vorgehen gegen den Widerrufsvorbehalt erblicken können, Ramsauer, in: Kopp/Ramsauer, VwVfG, 20. Aufl. 2019, $\S 49$ Rn. 37a; Ehlers/Schröder, JURA 2010, 503 (509). 
Die herrschende Ansicht, die insbesondere auch vom Bundesverwaltungsgericht vertreten wird, ${ }^{1698}$ verlangt lediglich die Wirksamkeit ${ }^{1699}$ des Widerrufsvorbehaltes. Sie stellt maßgeblich darauf ab, dass dieser als Nebenbestimmung an der Bestandskraft des Verwaltungsakts teilhat. Habe der Begünstigte von den ihm eröffneten Rechtsschutzmöglichkeiten ${ }^{1700}$ keinen Gebrauch gemacht, müsse er sich die Bestandskraft auch insoweit entgegenhalten lassen. Damit soll die Rechtswidrigkeit jedoch nicht irrelevant sein. Anhänger dieser Ansicht sprechen sich mehrheitlich dafür aus, die Rechtswidrigkeit als Erwägung in die Ermessensentscheidung einzustellen. ${ }^{1701}$ Dabei wird ihr jedoch unterschiedliches Gewicht beigemessen. ${ }^{1702}$

Die Gegenansicht ${ }^{1703}$ plädiert indes für eine bereits tatbestandliche Berücksichtigung der Rechtswidrigkeit auch nach Eintritt der Bestandskraft. Dafür spreche nicht nur der gesetzgeberische Wille, ${ }^{1704}$ sondern auch der der Vorschrift zugrundeliegende Interessenausgleich: Vor dem Hintergrund des Grundsatzes der Gesetzmäßigkeit der Verwaltung sei die Aufhebung rechtmäßiger Verwaltungsakte prinzipiell nicht geboten. ${ }^{1705}$ Auch wenn das Entstehen subjektiven Vertrauens auf den Bestand des Verwaltungsakts durch Beifügung des Widerrufsvorbehalts verhindert sein mag, dürfe nicht außer Acht gelassen werden, dass

1698 BVerwG, Urt. v. 21.11.1986, Az.: 8 C 33.84 = NVwZ 1987, 498 (499); Urt. v. 22.11.2018, Az.: 7 C 11.17 = juris, Rn. 32. Zust. Ruffert, in: Ehlers/Pünder, Allgemeines Verwaltungsrecht, 15. Aufl. 2016, § 25 Rn. 7; Ehlers/Schröder, JURA 2010, 503 (509), jeweils m.w. N.

1699 Vor diesem Hintergrund bietet es sich in Prüfungen an, Anhaltspunkte für die mögliche Nichtigkeit eines Widerrufsvorbehalts einzubauen. Zur Nichtigkeit ausführlich in § 6 Rn. 115 ff.; s. zur Nichtigkeit allein von Nebenbestimmungen auch den Fall 12 in Eisentraut, Fälle zum Verwaltungsrecht, 2020.

1700 S. zur isolierten Anfechtung von Nebenbestimmungen ausführlich Rn. $204 \mathrm{ff}$.

1701 A.A. hingegen Ziekow, VwVfG, 3. Aufl. 2013, § 49 Rn. 12, der auch eine Berücksichtigung im Rahmen der Ermessensausübung ablehnt.

1702 Jedenfalls bei „offensichtlicher Rechtswidrigkeit“, BVerwG, Beschl. v. 19.5.1994, Az.: 1 B 104.94 = NVwZ-RR 1994, 580; noch offengelassen in Urt. v. 12.1989, Az.: 3 C 30.87 = NJW 1991, 766 (767). Rechtswidrigkeit führt „in der Regel“ zur Ermessensfehlerhaftigkeit, Ehlers/Schröder, JURA 2010, 503 (509); noch weitgehender wohl Sachs, in: Stelkens/Bonk/Sachs, VwVfG, 9. Aufl. 2018, § 49 Rn. 40. Für eine offene Ermessensausübung indes Ramsauer, in: Kopp/Ramsauer, VwVfG, 20. Aufl. 2019, § 49 Rn. 37a.

1703 Maurer/Waldhoff, Allgemeines Verwaltungsrecht, 19. Aufl. 2017, § 11 Rn. 62; Peuker, in: Knack/Henneke, VwVfG, 10. Aufl. 2014, § 49 Rn. 52; Krausnick, JuS 2010, 778 (780); so auch, wenngleich weiter differenzierend Decker, in: Wolff/Decker, VwGO/VwVfG, 3. Aufl. 2012, § 49 Rn. 11. S. dazu auch die Fallbearbeitung bei Winter-Peter, JURA 2018, 508 (510).

1704 S. dazu bereits die Gesetzesmaterialien, BT-Drucks. 7/910, S. 72.

1705 Krausnick, JuS 2010, 778 (780); für den Widerruf rechtswidriger Verwaltungsakte daher anders Decker, in: Wolff/Decker, VwGO/VwVfG, 3. Aufl. 2012, § 49 Rn. 11. 
objektiv betrachtet ein rechtmäßiger Hauptverwaltungsakt besteht, der überdies selbst in Bestandskraft erwachsen ist. Angesichts dessen scheint es tatsächlich nicht plausibel, die Behörde aus eigenem Fehlverhalten auch noch Vorteile für die Zukunft ziehen zu lassen. ${ }^{1706}$

Insbesondere wenn hinsichtlich des Widerrufsvorbehalts keine rechtlichen $\mathbf{9 6 0}$ Bedenken bestehen, bedarf es darüber hinaus der Prüfung der für den Widerruf angeführten Gründe. Diese Gründe können im Vorbehalt selbst näher konkretisiert sein, sodass sie als Voraussetzungen des Widerrufs einzuhalten sind. ${ }^{1707}$ Ihre Konkretisierung kann jedoch auch bereits in dem den Widerrufsvorbehalt erlaubenden Gesetz erfolgt sein. Fehlen konkrete Vorgaben, sind diese durch Auslegung des den Widerrufsvorbehalt erlaubenden Gesetzes zu ermitteln. Der Widerruf muss dann durch sachliche Erwägungen gerechtfertigt sein, die den Zwecksetzungen des einschlägigen Fachrechts entsprechen. ${ }^{1708}$ Die letztgenannte Konstellation ist Bestandteil der Ermessensausübung der Behörde, sodass im Falle eines Verstoßes ein Ermessensfehler vorliegt. ${ }^{1709}$

\section{Unterbleiben der (fristgemäßen) Erfüllung einer Auflage, Abs. II 1 Nr. 2}

Gemäß § 49 II 1 Nr. 2 VwVfG kann ein rechtmäßiger begünstigender Verwal- 961 tungsakt widerrufen werden, wenn mit dem Verwaltungsakt eine Auflage verbunden ist und der Begünstigte diese nicht oder nicht innerhalb einer ihm gesetzten Frist erfüllt hat.

Auch hier macht es die Verknüpfung des Widerrufs mit der Auflage i.S.v. 962 $\S 36$ II Nr. 4 VwVfG - in jedem Fall ${ }^{1710}$ - erforderlich, inzident die Rechtmäßigkeit der in Rede stehenden Auflage (s. dazu ausführlich Rn. 218ff.) umfassend zu prüfen. ${ }^{1711}$ Im Einzelfall kann vorab auch die Abgrenzung der mit dem Verwaltungsakt verbundenen ${ }^{1712}$ Auflage von einer beschränkenden Inhaltsbestim-

1706 So Maurer/Waldhoff, Allgemeines Verwaltungsrecht, 19. Aufl. 2017, § 11 Rn. 62.

1707 Suerbaum, in: Mann/Sennekamp/Uechtritz, VwVfG, 2. Aufl. 2019, § 49 Rn. 78 m.w. N. (auch aus der Rspr.).

1708 Ramsauer, in: Kopp/Ramsauer, VwVfG, 20. Aufl. 2019, § 49 Rn. 35. S. für ein anschauliches Beispiel Maurer/Waldhoff, Allgemeines Verwaltungsrecht, 19. Aufl. 2017, § 11 Rn. 63.

1709 So auch Detterbeck, Allgemeines Verwaltungsrecht, 17. Aufl. 2019, Rn. 719.

1710 Je nach Entscheidung für oder gegen die Berücksichtigung der Rechtswidrigkeit auf Tatbestandsebene kann jedoch auch hier die Verortung im Prüfungsaufbau unterschiedlich ausfallen.

1711 S. dazu die Fallbearbeitung bei Klement, JuS 2010, 1088.

1712 Es muss eine rechtliche, keine verkörperte Verbindung bestehen. So kann sich eine Auflage vorab auch aus einem öffentlich-rechtlichen Vertrag ergeben, indem sich die Behörde nur zum Erlass eines Verwaltungsakts verpflichtet, BVerwG, Urt. v. 10.12.2003, Az.: 3 C 22.02 = NVwZRR 2003, 413 (414f.). 
mung ${ }^{1713}$ und einer auflösenden Bedingung ${ }^{1714}$ erforderlich (s. dazu Rn. 222ff.). Wie hinsichtlich des Widerrufsvorbehaltes wird um die Frage der Berücksichtigung der Rechtswidrigkeit einer Auflage nach Eintritt der Bestandskraft gerungen. Insofern gelten die bereits dargestellten Überlegungen (s. dazu Rn. 959) entsprechend. Auch hier verlangt die herrschende Ansicht lediglich Wirksamkeit der Auflage. ${ }^{1715}$ Vielerorts wird jedoch, obgleich es sich eigentlich um eine Voraussetzung der (materiellen) Rechtmäßigkeit handelt (§37 I VwVfG; s. zur vergleichbaren Problematik im Rahmen der Verwaltungsvollstreckung Rn. 1329f.), die hinreichende Bestimmtheit der Auflage auch im Zusammenhang mit dem Widerruf verlangt. ${ }^{1716}$

963 Der Begünstigte darf dem in der Auflage enthaltenen Gebot oder Verbot (auch nur teilweise ${ }^{1717}$ ) nicht oder nicht innerhalb einer ihm gesetzten Frist nachgekommen sein. Ob dies der Fall ist, bedarf der Beurteilung im Einzelfall. Die aufschiebende Wirkung von Widerspruch und Anfechtungsklage gegen die Auflage führt dazu, dass ein Widerruf zumindest während des Verfahrens nicht möglich ist. ${ }^{1718}$ Das Bundesverwaltungsgericht hat angedeutet, die isolierte Aufhebung einer Auflage deren Nichterfüllung gleichstellen zu wollen. ${ }^{1719}$ Dies ist jedoch weder mit dem Wortlaut, noch mit Sinn und Zweck des § 49 II 1 Nr. 2 VwVfG in Einklang zu bringen. ${ }^{1720}$ Es genügt die objektive Nichterfüllung der Auflage, die Vorschrift verlangt kein Verschulden des Begünstigten. ${ }^{1721}$ Dieses ist jedoch im Rahmen der Ermessensausübung zu berücksichtigen. Dabei kann auch das

1713 Auch auf beschränkende Inhaltsbestimmungen ist die Vorschrift nach h.M. nicht anwendbar, s. nur Ramsauer, in: Kopp/Ramsauer, VwVfG, 20. Aufl. 2019, § 49 Rn. 38 m.w. N.

1714 Krausnick, JuS 2010, 778 (780f.).

1715 OVG Münster, Urt. v. 20.4.2012, Az.: 4 A 1055/09 = NVwZ-RR 2012, 671 (675); s. sonst nur Ramsauer, in: Kopp/Ramsauer, VwVfG, 20. Aufl. 2019, § 49 Rn. 38a m.w. N.

1716 Ruffert, in: Ehlers/Pünder, Allgemeines Verwaltungsrecht, 15. Aufl. 2016, § 25 Rn. 8; Abel, in: Bader/Ronellenfitsch, VwVfG, 44. Ed., Stand: 1.7.2019, § 49 Rn. 37; Suerbaum, in: Mann/Sennekamp/Uechtritz, VwVfG, 2. Aufl. 2019, § 49 Rn. 79; a. A. aber Ziekow, VwVfG, 3. Aufl. 2013, § 49 Rn. 14.

1717 Ehlers/Schröder, JURA 2010, 503 (510).

1718 S. dazu Sachs, in: Stelkens/Bonk/Sachs, VwVfG, 9. Aufl. 2018, § 49 Rn. 52.

1719 BVerwG, Urt. v. 12.3.1982, Az.: 8 C 23.80 = BVerwGE 65, 139 (141).

1720 Überzeugend m.w. N. nur Suerbaum, in: Mann/Sennekamp/Uechtritz, VwVfG, 2. Aufl. 2019, $\S 49$ Rn. $84 \mathrm{f}$.

1721 S. nur Peine/Siegel, Allgemeines Verwaltungsrecht, 12. Aufl. 2018, Rn. 638; Ruffert, in: Ehlers/Pünder, Allgemeines Verwaltungsrecht, 15. Aufl. 2016, § 25 Rn. 8; Sachs, in: Stelkens/ Bonk/Sachs, VwVfG, 9. Aufl. 2018, § 49 Rn. 50. Vgl. auch BVerwG, Urt. v. 6.9.1995, Az.: 4 B $198.95=$ NVwZ-RR 1996, 193.

Tobias Brings-Wiesen 
Handeln Dritter dem Verantwortungsbereich des Begünstigten zuzurechnen sein. ${ }^{1722}$

Die Anforderungen im Tatbestand werden im Einzelfall zumeist gut hand- 964 habbar sein. Im Fokus der Prüfung eines Widerrufs auf Grundlage von § 49 II 1 Nr. 2 VwVfG steht jedoch überwiegend die ordnungsgemäße Ermessensausübung der Behörde. In deren Rahmen bedarf es einer besonderen Berücksichtigung von Verhältnismäßigkeitserwägungen. ${ }^{1723}$ Folgende Gesichtspunkte können im Einzelfall mit unterschiedlichem Gewicht in die Prüfung eingestellt werden: das Maß an Verschulden des Begünstigten, ${ }^{1724}$ die Wesentlichkeit der durch die Auflage gesicherten Rechtspflicht ${ }^{1725}$ und der Grad der Abweichung vom Gewollten. ${ }^{1726}$ Je nach Lage des Sachverhalts kann es erforderlich bzw. angemessen sein, den Begünstigten vor dem Widerruf abzumahnen ${ }^{1727}$ oder die Auflage im Wege der Verwaltungsvollstreckung zwangsweise durchzusetzen ${ }^{1728}$.

\section{Nachträgliche Änderung der Sachlage, Abs. II 1 Nr. 3}

Gemäß § 49 II 1 Nr. 3 VwVfG kann ein rechtmäßiger begünstigender Verwal- 965 tungsakt widerrufen werden, wenn die Behörde auf Grund nachträglich eingetretener Tatsachen berechtigt wäre, den Verwaltungsakt nicht zu erlassen, und wenn ohne den Widerruf das öffentliche Interesse gefährdet würde. Beide Voraussetzungen müssen kumulativ erfüllt sein.

Hinsichtlich der ersten Voraussetzung ist zunächst $\mathrm{zu}$ fragen, ob i.S.d. 966 Vorschrift nachträglich Tatsachen eingetreten sind. ${ }^{1729}$ Verlangt ist eine Veränderung der Sachlage, auf der die gesamte rechtliche Bewertung basiert, deren

1722 OVG Münster, Urt. v. 2.5.1994, Az.: 8 A 3885/93 = NVwZ 1996, 610 (612); VGH Mannheim, Urt. v. 7.4.2011, Az.: 10 S 2545/09 = BeckRS 2011, 50482.

1723 So auch Maurer/Waldhoff, Allgemeines Verwaltungsrecht, 19. Aufl. 2017, §11 Rn. 64; Detterbeck, Allgemeines Verwaltungsrecht, 17. Aufl. 2019, Rn. 720.

1724 Ruffert, in: Ehlers/Pünder, Allgemeines Verwaltungsrecht, 15. Aufl. 2016, § 25 Rn. 8; Ehlers/ Schröder, JURA 2010, 503 (510).

1725 Maurer/Waldhoff, Allgemeines Verwaltungsrecht, 19. Aufl. 2017, §11 Rn. 64; Detterbeck, Allgemeines Verwaltungsrecht, 17. Aufl. 2019, Rn. 720.

1726 Sachs, in: Stelkens/Bonk/Sachs, VwVfG, 9. Aufl. 2018, § 49 Rn. 57.

1727 Ramsauer, in: Kopp/Ramsauer, VwVfG, 20. Aufl. 2019, § 49 Rn. 39; Sachs, in: Stelkens/ Bonk/Sachs, VwVfG, 9. Aufl. 2018, § 49 Rn. 56; vgl. auch BVerwG, Beschl.v. 6.9.1991, Az.: 1 B 97.91 = NVwZ 1992, 167 (167 f.); Kastner, in: Fehling/Kastner/Störmer, Verwaltungsrecht, 4. Aufl. 2016, § 49 VwVfG Rn. 34.

1728 Maurer/Waldhoff, Allgemeines Verwaltungsrecht, 19. Aufl. 2017, § 11 Rn. 64; Kastner, in: Fehling/Kastner/Störmer, Verwaltungsrecht, 4. Aufl. 2016, § 49 VwVfG Rn. 33; Ehlers/Schröder, JURA 2010, 503 (510); Krausnick, JuS 2010, 778 (781).

1729 Für bestimmte Verwaltungsakte kann eine Anwendbarkeit der Vorschrift ausgeschlossen sein, s. Ramsauer, in: Kopp/Ramsauer, VwVfG, 20. Aufl. 2019, § 49 Rn. 42.

Tobias Brings-Wiesen 
Ergebnis der konkrete Verwaltungsakt ist. Dabei können die entscheidungserheblichen Elemente je nach dem zugrundeliegenden Recht sowohl in einem Verhalten von Beteiligten oder Betroffenen als auch in äußeren Umständen liegen. ${ }^{1730}$ Die Tatsachen müssen nachträglich eintreten. Dem nicht gleichgestellt ist die Situation, dass die Behörde erst zu einem späteren Zeitpunkt von ihnen erfährt ${ }^{1731}$ oder diese erst später anders beurteilt ${ }^{1732}$. Dementsprechend ist auch eine Änderung der Rechtsprechung keine nachträglich eingetretene Tatsache. ${ }^{1733}$ Für all diese Konstellationen kommt vielmehr eine Rücknahme gemäß § 48 VwVfG in Frage. Die wissenschaftliche Neubewertung einer Sachlage kann hingegen von Bedeutung sein. ${ }^{1734}$

Im nächsten Schritt ist im Rahmen einer Inzidentprüfung zu klären, ob die nachträglich eingetretene Tatsache von einer derartigen rechtlichen Relevanz ist, dass die Behörde berechtigt wäre, den ursprünglichen Verwaltungsakt nicht zu erlassen. Dies ist der Fall, wenn eine entsprechend veränderte Sachlage im Zeitpunkt der ursprünglichen Entscheidung hypothetisch dazu geführt hätte, dass die Behörde den Erlass des Verwaltungsakts mangels Vorliegens von Tatbestandsvoraussetzungen oder im Rahmen einer fehlerfreien Ermessensausübung hätte ablehnen müssen bzw. können. ${ }^{1735}$

Zuletzt muss geklärt werden, ob ohne den Widerruf das öffentliche Interesse gefährdet würde. Im „öffentlichen Interesse“ steht der Schutz des Staates, der Allgemeinheit und wichtiger Gemeinschaftsgüter. ${ }^{1736}$ Ob im konkreten Einzelfall wichtige Gemeinschaftsgüter in Rede stehen und welche dies sind, ist unter Berücksichtigung des Regelungsgehalts des Verwaltungsakts und dem ihm

1730 So ausdrücklich BVerwG, Urt. v. 11.12.1990, Az.: 6 C 33.88 = NVwZ 1991, 577 (578). S. für Beispiele nur Ramsauer, in: Kopp/Ramsauer, VwVfG, 20. Aufl. 2019, § 49 Rn. 44f.; Sachs, in: Sachs/Stelkens/Bonk/Sachs, VwVfG, 9. Aufl. 2018, § 49 Rn. 59 ff.

1731 BVerwG, Urt. v. 19.9.2018, Az.: 8 C 16.17 = juris, Rn. 21.

1732 BVerwG, Urt. v. 11.12.1990, Az.: 6 C 33.88 = NVwZ 1991, 577 (578).

1733 Detterbeck, Allgemeines Verwaltungsrecht, 17. Aufl. 2019, Rn. 721; Ramsauer, in: Kopp/ Ramsauer, VwVfG, 20. Aufl. 2019, § 49 Rn. 46.

1734 BVerwG, Beschl. v. 16.7.1982, Az.: 7 B 190.81 = NVwZ 1984, 102 (103); so auch Ruffert, in: Ehlers/Pünder, Allgemeines Verwaltungsrecht, 15. Aufl. 2016, § 25 Rn. 10; Ramsauer, in: Kopp/ Ramsauer, VwVfG, 20. Aufl. 2019, § 49 Rn. 45; Ehlers/Schröder, JURA 2010, 503 (510). Es muss sich jedoch um eine allgemein anerkannte Neubewertung handeln, vgl. BVerwG, Beschl. v. 27.5. 2015, Az.: 3 B 5.15 = NVwZ 2016, 323 (325, Rn. 12); Urt. v. 28.4. 2016, Az.: 4 A 2.15 = BVerwGE 155, 81 (88f.; Rn. 36).

1735 S. nur Suerbaum, in: Mann/Sennekamp/Uechtritz, VwVfG, 2. Aufl. 2019, § 49 Rn. 90 ff.

1736 BVerwG, Beschl. v. 16.7.1982, Az.: 7 B 190.81 = NVwZ 1984, 102 (103); Urt. v. 24.1.1992, Az.: 7 C 38.90 = NVwZ 1992, 565 (566); VGH Mannheim, Urt. v. 20.6.2013, Az.: 9 S 2883/11 = NVwZRR 2014, 43 (47), m. zahlr. w. N. 
zugrundeliegenden Fachrecht zu ermitteln. ${ }^{1737}$ Daraus ergibt sich, dass die für den Widerruf zuständige Behörde nur das „öffentliche Interesse“ zu berücksichtigen hat, dessen Wahrung Teil ihres Aufgabenbereichs ist. ${ }^{1738}$ Das bloße Interesse an der Wiederherstellung eines rechtmäßigen Zustands genügt nicht. ${ }^{1739}$ Auch bloße Individualinteressen sind grundsätzlich nicht berücksichtigungsfähig. ${ }^{1740}$ Ein so näher identifiziertes öffentliches Interesse muss gefährdet sein. Dies setzt bereits denklogisch voraus, dass die Gefährdung des öffentlichen Interesses eine Konsequenz der nachträglich eingetretenen Tatsachen ist, insofern also Kausalität besteht. ${ }^{1741}$ Für eine Gefährdung genügt nicht, dass der Widerruf schlicht im öffentlichen Interesse liegt. Anders als bei § 49 II 1 Nr. 5 VwVfG bedarf es aber auch keines „schweren Nachteils“. Erforderlich ist vielmehr, dass der Widerruf zur Beseitigung oder Verhinderung eines sonst drohenden Schadens geboten ist. ${ }^{1742}$ Dabei setzt die Vorschrift voraus, dass der Widerruf zumindest geeignet ist, die Gefährdung zu beenden. Diese Feststellung genügt jedoch an dieser Stelle auch. Es bedarf noch keiner Abwägung mit den widerstreitenden Interessen auf Seiten des Begünstigten. Fragen der Erforderlichkeit und Angemessenheit sind vielmehr Bestandteile der nachfolgenden Prüfung der Ermessensausübung. ${ }^{1743}$ Obwohl in § 49 II 1 Nr. 3 VwVfG nicht ausdrücklich ausgewiesen, soll darin auch Berücksichtigung finden, ob und inwiefern von der Begünstigung bereits Gebrauch gemacht wurde. ${ }^{1744}$

1737 Vgl. für Beispiele Sachs, in: Stelkens/Bonk/Sachs, VwVfG, 9. Aufl. 2018, § 49 Rn. 70; Abel, in: Bader/Ronellenfitsch, VwVfG, 44. Ed., Stand: 1.7.2019, § 49 Rn. 57.

1738 Peine/Siegel, Allgemeines Verwaltungsrecht, 12. Aufl. 2018, Rn. 640; Ramsauer, in: Kopp/ Ramsauer, VwVfG, 20. Aufl. 2019, § 49 Rn. 48; Sachs, in: Stelkens/Bonk/Sachs, VwVfG, 9. Aufl. 2018, § 49 Rn. 72.

1739 VGH Mannheim, Urt. v. 20.6.2013, Az.: 9 S 2883/11 = NVwZ-RR 2014, 43 (47).

1740 S. BVerwG, Urt. v. 29.10.1998, Az.: 4 C 9.97 = NVwZ 1999, 417 (419), wo das Gericht indes andeutete, dass der Sachverhalt im Falle einer Gesundheitsgefahr anders zu beurteilen sein könnte.

1741 Peine/Siegel, Allgemeines Verwaltungsrecht, 12. Aufl. 2018, Rn. 640; Sachs, in: Stelkens/ Bonk/Sachs, VwVfG, 9. Aufl. 2018, § 49 Rn. 71; Abel, in: Bader/Ronellenfitsch, VwVfG, 44. Ed., Stand: 1.7.2019, § 49 Rn. 58.

1742 So ausdrücklich das BVerwG, Urt. v. 24.1.1992, Az.: 7 C 38.90 = NVwZ 1992, 565 (565f.). 1743 Es erschließt sich insbesondere nicht, warum die vielerorts scheinbar als Tatbestandsmerkmal genannte „Erforderlichkeit“, s. nur Sachs, in: Stelkens/Bonk/Sachs, VwVfG, 9. Aufl. 2018, § 49 Rn. 70, m.w. N., bereits hins. der Bewertung am Maßstab von § 49 II 1 Nr. 3 VwVfG vorliegen müsste.

1744 Sachs, in: Stelkens/Bonk/Sachs, VwVfG, 9. Aufl. 2018, § 49 Rn. 73; Abel, in: Bader/Ronellenfitsch, VwVfG, 44. Ed., Stand:1.7.2019, § 49 Rn. 56; Suerbaum, in Mann/Sennekamp/Uechtritz, VwVfG, 2. Aufl. 2019, § 49 Rn. 96. 


\section{Nachträgliche Änderung von Rechtsvorschriften, Abs. II 1 Nr. 4}

969 Gemäß § 49 II 1 Nr. 4 VwVfG kann ein rechtmäßiger begünstigender Verwaltungsakt widerrufen werden, wenn die Behörde auf Grund einer geänderten Rechtsvorschrift berechtigt wäre, den Verwaltungsakt nicht zu erlassen, soweit der Begünstigte von der Vergünstigung noch keinen Gebrauch gemacht oder auf Grund des Verwaltungsakts noch keine Leistungen empfangen hat und wenn ohne den Widerruf das öffentliche Interesse gefährdet würde. ${ }^{1745}$

Für die Vorschrift gelten überwiegend die bereits zu § 49 II 1 Nr. 3 VwVfG erfolgten Ausführungen entsprechend. Der erste wesentliche Unterschied liegt in der Ursache für die Neubewertung des Verwaltungsakterlasses: Es muss zu einer Änderung des Rechts ${ }^{1746}$ gekommen sein. Wenngleich der Wortlaut eine „geänderte Rechtsvorschrift“ verlangt, ist weitergehend jede Änderung des für die Beurteilung des Verwaltungsakts relevanten materiellen Rechts ${ }^{1747}$, sprich auch der Neuerlass oder die Aufhebung von Vorschriften, von Bedeutung. ${ }^{1748}$ Grundsätzlich nicht $\mathrm{zu}$ berücksichtigen sind Änderungen von Verwaltungsvorschriften $^{1749}$ oder der Rechtsprechung ${ }^{1750}$. Rückwirkende Änderungen der Rechtslage können zur Rechtswidrigkeit des Verwaltungsakts zum Zeitpunkt seines Erlasses führen; die Nichtigerklärung einer Vorschrift ist rein deklaratorisch und erstreckt sich regelmäßig auf die Vergangenheit ${ }^{1751}$. Auf diese Konstellationen ist $\S 48$ VwVfG anwendbar (s. dazu Rn. 870).

971 Der zweite wesentliche Unterschied liegt darin, dass § 49 II 1 Nr. 4 VwVfG einen Widerruf nur erlaubt, soweit der Begünstigte von der Vergünstigung noch keinen Gebrauch gemacht oder auf Grund des Verwaltungsakts noch keine Leistungen empfangen hat. Ein „Gebrauchmachen“ verlangt laut Bundesver-

1745 S. dazu die Fallbearbeitung bei Pernice-Warnke, ZJS 2018, 590 (596f.).

1746 Es wird vertreten, den Begriff „Rechtsvorschriften“ von dem Begriff der „Rechtslage“ in $\S 51$ I Nr. 1 VwVfG (s. dazu noch in $§ 3$ Rn. 116) abzugrenzen, s. nur Sachs, in: Stelkens/Bonk/Sachs, VwVfG, 9. Aufl. 2018, § 49 Rn. 79; dies mutet angesichts der sprachlichen Abweichung zwar plausibel an, bislang lassen sich jedoch - soweit ersichtlich - weder Rechtsprechung, noch Literatur Abgrenzungskriterien entnehmen.

1747 S. dazu Ramsauer, in: Kopp/Ramsauer, VwVfG, 20. Aufl. 2019, § 49 Rn. 50.

1748 Detterbeck, Allgemeines Verwaltungsrecht, 17. Aufl. 2019, Rn. 722.

1749 BVerwG, Urt. v. 11.12.1990, Az.: 6 C 33.88 = NVwZ 1991, 577 (579). Zu berücksichtigen sind jedoch ausnahmsweise Verwaltungsvorschriften mit Außenwirkung, Ruffert, in: Ehlers/Pünder, Allgemeines Verwaltungsrecht, 15. Aufl. 2016, § 25 Rn. 12; Ehlers/Schröder, JURA 2010, 824 (825). 1750 A.A. aber zu Änderungen der Rspr. Abel, in: Bader/Ronellenfitsch, VwVfG, 44. Ed., Stand: 1.7.2019, § 49 Rn. 60 f.

1751 Dazu anschaulich m.w. N. Suerbaum, in: Mann/Sennekamp/Uechtritz, VwVfG, 2. Aufl. 2019, § 49 Rn. $103 \mathrm{f}$.

Tobias Brings-Wiesen 
waltungsgericht ein „Inswerksetzen“ ${ }^{1752}$ Aus dem Sachverhalt muss sich ergeben, dass der Begünstigte in irgendeiner Art und Weise auf Grundlage der in einem Verwaltungsakt enthaltenen Regelung ${ }^{1753}$ tätig geworden ist. Umstritten ist, wie intensiv der Zusammenhang zwischen „Vergünstigung“ und „Gebrauchmachen“ sein muss. Einigkeit besteht über die Einbeziehung unmittelbarer Umsetzungen von Regelungsinhalten, beispielsweise dem Bau eines Hauses auf Grundlage einer Baugenehmigung. Unterschiedlich bewertet werden hingegen lediglich mittelbare Umsetzungen, wie beispielsweise Vorbereitungshandlungen oder Investitionen im Vertrauen auf einen Verwaltungsakt. ${ }^{1754}$ Derartige Umsetzungen werden jedoch spätestens im Rahmen der Ermessensausübung zu berücksichtigen sein. ${ }^{1755}$ Bei Leistungen jedweder Art kommt es allein auf den Empfang an, diese muss endgültig in das Vermögen des Begünstigten übergehen ${ }^{1756}$. Nicht verlangt sind ein Verbrauch oder eine Vermögensdisposition. ${ }^{1757}$

\section{Zur Verhütung oder Beseitigung schwerer Nachteile für das Gemeinwohl,}

\section{Abs. II 1 Nr. 5}

Gemäß § 49 II 1 Nr. 5 VwVfG kann ein rechtmäßiger begünstigender Verwal- 972 tungsakt widerrufen werden, um schwere Nachteile für das Gemeinwohl zu verhüten oder zu beseitigen. Es handelt sich um eine Art Auffangklausel, die der Behörde in besonderen Ausnahmekonstellationen den Widerruf ermöglichen soll. Dabei ist sie jedoch - anders als der Wortlaut suggeriert - nicht auf die Berücksichtigung von Allgemeininteressen beschränkt, sondern lässt auch die Einbeziehung hochrangiger Individualrechtsgüter $\mathrm{zu}^{1758}$ Gleichwohl ist ihre Praxis- wie Prüfungsrelevanz gering. ${ }^{1759}$ Die Anforderungen, die an die Schwere

1752 BVerwG, Urt. v. 24.1.1992, Az.: 7 C 38.90 = NVwZ 1992, 565 (566).

1753 Auch bei feststellenden Verwaltungsakten wird man daher grundsätzlich von der Möglichkeit eines „Inswerksetzens“ ausgehen können, Sachs, in: Stelkens/Bonk/Sachs, VwVfG, 9. Aufl. 2018, § 49 Rn. 77; Abel, in: Bader/Ronellenfitsch, VwVfG, 44. Ed., Stand: 1.7.2019, § 49 Rn. 62.1.

1754 Dafür Peuker, in: Knack/Henneke, VwVfG, 10. Aufl. 2014, § 49 Rn. 69; Kastner, in: Fehling/ Kastner/Störmer, Verwaltungsrecht, 4. Aufl. 2016, § 49 VwVfG Rn. 43; Suerbaum, in: Mann/Sennekamp/Uechtritz, VwVfG, 2. Aufl. 2019, § 49 Rn. 106; z.T. auch Ramsauer, in: Kopp/Ramsauer, VwVfG, 20. Aufl. 2019, § 49 Rn. 52.

1755 Sachs, in: Stelkens/Bonk/Sachs, VwVfG, 9. Aufl. 2018, § 49 Rn. 77; Abel, in: Bader/Ronellenfitsch, VwVfG, 44. Ed., Stand: 1.7.2019, § 49 Rn. 62.

1756 Kastner, in: Fehling/Kastner/Störmer, Verwaltungsrecht, 4. Aufl. 2016, § 49 VwVfG Rn. 43. 1757 Ruffert, in: Ehlers/Pünder, Allgemeines Verwaltungsrecht, 15. Aufl. 2016, § 25 Rn. 13; Sachs, in: Stelkens/Bonk/Sachs, VwVfG, 9. Aufl. 2018, § 49 Rn. 75.

1758 BVerwG, Urt. v. 21.5.1997, Az.: 11 C 1.96 = BVerwGE 105, 6 (15).

1759 So auch Ehlers/Schröder, JURA 2010, 824 (826).

Tobias Brings-Wiesen 
des Nachteils für das Gemeinwohl zu stellen sind, sind hoch. ${ }^{1760}$ Dementsprechend sollte auch in der Prüfung nur sehr restriktiv mit dem Tatbestand umgegangen werden.

\section{Exkurs: Entschädigungsanspruch gemäß § 49 VI VwVfG}

973 Ähnlich dem § 48 III VwVfG enthält auch § 49 VI VwVfG einen Entschädigungsanspruch. Sofern ein begünstigender Verwaltungsakt in den Fällen des Abs. II 1 Nr. 3 bis 5 widerrufen wird, hat die Behörde den Betroffenen auf Antrag für den Vermögensnachteil zu entschädigen, den dieser dadurch erleidet, dass er auf den Bestand des Verwaltungsakts vertraut hat, soweit sein Vertrauen schutzwürdig ist. $\S 48$ III 3 bis 5 soll entsprechend gelten. Insofern kann weitgehend auf die Ausführungen zu § 48 III VwVfG verwiesen werden. Ein wesentlicher Unterschied besteht indes darin, dass für Streitigkeiten über die Entschädigung gemäß § 49 VI VwVfG der ordentliche Rechtsweg zu beschreiten ist.

\section{Der Widerruf nach \$ 49 III VwVfG}

$974 \S 49$ III VwVfG ${ }^{1761}$ gilt - wie § 48 II VwVfG - für Verwaltungsakte, die eine einmalige oder laufende Geldleistung oder teilbare Sachleistung gewähren oder hierfür Voraussetzung sind, sodass insofern auf die bereits erfolgten Darstellungen verwiesen werden kann („Leistungsverwaltungsakte“). ${ }^{1762}$ Hinzukommen muss jedoch, dass die Leistung ultimativ zur Erfüllung eines bestimmten Zwecks dient. Davon zwingend zu unterscheiden sind Leistungsverwaltungsakte, bei denen bereits der Erlass selbst den vom Gesetz avisierten Zweck verwirklicht dazu gehören beispielsweise allgemeine Dienstbezüge von Beamten oder auch die Grundleistungen im Rahmen von Sozialleistungen. ${ }^{1763}$ Diese Leistungen dienen keinem bestimmten Zweck, sondern der allgemeinen Lebensführung. Die konkrete Zweckbindung muss aus dem Bescheid selbst mit hinreichender Bestimmtheit und Deutlichkeit hervorgehen. ${ }^{1764}$

975 Die so bestimmte Leistung kann wegen zweier Gründe widerrufen werden: entweder weil die Leistung nicht, nicht alsbald nach der Erbringung oder nicht

1760 S. nur Abel, in: Bader/Ronellenfitsch, VwVfG, 44. Ed., Stand. 1.7.2019, § 49 Rn. 64 ff.; Ehlers/ Schröder, JURA 2010, 824 (826).

1761 S. zu diesen Konstellationen instruktiv Folnovic/Hellriegel, NVwZ 2016, 638.

1762 Ramsauer, in: Kopp/Ramsauer, VwVfG, 20. Aufl. 2019, § 49 Rn. 64. S. dazu Rn. 878 ff

1763 Sachs, in: Stelkens/Bonk/Sachs, VwVfG, 9. Aufl. 2018, § 49 Rn. 92; Suerbaum, in: Mann/ Sennekamp/Uechtritz, VwVfG, 2. Aufl. 2019, § 49 Rn. 128.

1764 OVG Münster, Urt. v. 13.6.2002, Az.: 12 A 693/99 = NVwZ-RR 2003, 803 (804); Ramsauer, in: Kopp/Ramsauer, VwVfG, 20. Aufl. 2019, § 49 Rn. 65; Sachs, in: Stelkens/Bonk/Sachs, VwVfG, 9. Aufl. 2018, § 49 Rn. $94 \mathrm{f}$. 
mehr für den in dem Verwaltungsakt bestimmten Zweck verwendet wird (Nr. 1) oder weil eine mit dem Verwaltungsakt verbundene Auflage nicht oder nicht innerhalb einer gesetzten Frist erfüllt wurde (Nr. 2) ${ }^{1765} \cdot{ }^{1766}$ Ein Verschulden des Begünstigten ist nicht von Belang. Die Vorschriften zielen nur darauf ab, die zweckentsprechende Leistungsverwendung sicherzustellen. Ein fehlendes Verschulden ist jedoch wiederum im Rahmen der Ermessensausübung zu berücksichtigen.

Auch hier sind tatbestandlich die Ausschlussgründe gemäß § 49 I VwVfG (dazu Rn. 951) und § 49 III 2 i.V.m. § 48 IV VwVfG (dazu Rn. 905 ff.) zu berücksichtigen, bezüglich derer die bereits erfolgten Ausführungen gleichsam entsprechend gelten.

Abschließend ist die ordnungsgemäße Ermessensausübung der Behörde zu prüfen: Gemäß §49 III 1 Hs. 1 VwVfG kann ein rechtmäßiger begünstigender Leistungsverwaltungsakt widerrufen werden. Anders als §49 I oder II VwVfG kennt § 49 III VwVfG auch keine Ermessensbegrenzung in zeitlicher Hinsicht: Der Widerruf ist grundsätzlich auch mit Wirkung für die Vergangenheit zulässig. Dies macht seinen besonderen Reiz aus. Die Vorschrift dient der Sicherung einer dem Zweck der Gewährung entsprechenden Verwendung öffentlicher Mittel und insofern den haushaltsrechtlichen Grundsätzen der Wirtschaftlichkeit und Sparsamkeit. ${ }^{1767}$ Entgegen des klaren Wortlauts hat das Bundesverwaltungsgericht wegen der Relevanz dieser Grundsätze im Falle des § 49 III 1 Nr. 1 VwVfG ein „intendiertes Ermessen“ angenommen, ${ }^{1768}$ sodass besondere Gründe für eine Abweichung vorliegen müssen.

\section{(3) Widerruf von Verwaltungsakten im unionsrechtlichen Kontext}

Auch im Falle des Widerrufs von nachträglich unionsrechtswidrig gewordenen 978

Verwaltungsakten ergeben sich Besonderheiten. ${ }^{1769}$ Besonderes Augenmerk fiel

1765 Zur Auflage gilt das zu § 49 II 1 Nr. 1 und 2 VwVfG Dargelegte entsprechend: Nach h.M. soll es nicht auf deren Wirksamkeit ankommen, s. dazu Rn. $956 \mathrm{ff}$.

1766 Vgl. dazu die Beispielsfälle bei Ehlers/Schröder, JURA 2010, 824 (826ff.); s. auch die Fallbearbeitungen bei Haltern/Manthey, JuS 2016, 344, sowie bei Ernst/Kämmerer, Fälle zum Allgemeinen Verwaltungsrecht, 3. Aufl. 2016, Fall 11, S. 158 (165f.).

1767 So treffend Ramsauer, in: Kopp/Ramsauer, VwVfG, 20. Aufl. 2019, § 49 Rn. 73.

1768 BVerwG, Urt. v. 16.6.1997, Az.: 3 C 22.96 = BVerwGE 105, 55 (57 f.); Urt. v. 26.2.2015, Az.: 3 C 8.14 = BVerwGE 151, 302 (307, Rn. 17).

1769 S. dazu auch Peine/Siegel, Allgemeines Verwaltungsrecht, 12. Aufl. 2018, Rn. 655; Erbguth/ Guckelberger, Allgemeines Verwaltungsrecht, 9. Aufl. 2018, § 16 Rn. 35.

Tobias Brings-Wiesen 
zuletzt auf das Urteil des EuGH in der Rechtssache „Stadt Papenburg“, ${ }^{1770}$ in dessen Folge die unionsrechtliche Überformung des § 49 II VwVfG diskutiert wurde. ${ }^{1771}$ Denkbar ist darüber hinaus auch, dass es zum Widerruf einer ursprünglich unionsrechtmäßig gewährten Beihilfe (s. dazu Rn. $937 \mathrm{ff}$.) auf Grundlage von § 49 VwVfG kommt. Dies kommt im Falle einer „missbräuchlichen Anwendung von Beihilfen“ i.S.v. Art. 1 lit. g) BeihilfeVVO in Frage, deren Kontrolle der Kommission gemäß Art. 108 II Uabs. 1 AEUV, Art. 20 BeihilfeVVO obliegt. Eine Verwendung von Beihilfen entgegen den Beschlüssen der Kommission gemäß Art. 4 III und Art. 9 III BeihilfeVVO findet ihre Entsprechung im Widerrufsgrund nach § 49 III 1 Nr. 1 Var. 2 VwVfG ${ }^{1772}$; eine Verwendung von Beihilfen unter Verstoß gegen Auflagen zu einem Beschluss gemäß Art. 9 IV BeihilfeVVO findet ihre Entsprechung im Widerrufsgrund nach $\S 49$ III 1 Nr. 2 VwVfG ${ }^{1773}$. Erlässt die Kommission zum Abschluss eines (neuen) formellen Prüfverfahrens sodann einen Negativbeschluss gemäß Art. 20 i.V.m. Art. 9 V BeihilfeVVO ist von einer den bereits dargestellten Konstellationen entsprechenden unionsrechtlichen Überformung der Entscheidung über den Widerruf des Bewilligungsbescheids und die Erstattung der bereits erbrachten Leistungen auszugehen.

\section{dd) Literaturhinweise}

Lehrbeiträge: Brügge/Erichsen, Der Widerruf von Verwaltungsakten nach §49 VwVfG und der öffentlich-rechtliche Erstattungsanspruch nach § 49a VwVfG, JURA 1999, 496; Ehlers/Schröder, Der Widerruf von Verwaltungsakten (Teil I), JURA 2010, 503; Ehlers/Schröder, Der Widerruf von Verwaltungsakten (Teil II), JURA 2010, 824; Kiefer, Können rechtswidrige Verwaltungsakte widerrufen werden?, NVwZ 2013, 1257; Struzina, Die Prüfung von Rücknahme und Widerruf, DÖV 2017, 906 (s. darüber hinaus auch bereits unter Rn. 939)

Fallbearbeitungen: Edenharter, Fortgeschrittenenklausur - Öffentliches Recht: Allgemeines Verwaltungsrecht - Explosive Biogasanlage, JuS 2018, 456;

1770 EuGH, Urt. v. 14.1.2010, Az.: C-226/08 - Stadt Papenburg. S. dazu auch Hecker, Europäisierung der Widerrufsdogmatik? - Zum „Papenburg“-Urteil des Europäischen Gerichtshofs, in: Festschrift Peine, 2016, S. 663.

1771 S. dazu Suerbaum, in: Mann/Sennekamp/Uechtritz, VwVfG, 2. Aufl. 2019, § 49 Rn. 30 ff.; Ehlers/Schröder, JURA 2010, 824 (825f.); Kahl, NVwZ 2011, 449 (453).

1772 Es ist davon auszugehen, dass der der einschlägigen Ausnahmevorschrift des AEUV zugrundeliegende Zweck in der Folge als „bestimmter Zweck“ auch der Leistungsgewähr i.S.v. $\S 49$ III 1 Nr. 1 Var. 2 VwVfG zugrunde zu legen ist. Der subsidiär anwendbare § 49 II 1 Nr. 5 VwVfG würde zumindest unter normalen Umständen keinen Widerruf für die Vergangenheit legitimieren. 1773 So auch Korte, JURA 2017, 656 (663).

Tobias Brings-Wiesen 
Ernst/Kämmerer, Fall 11 - Für Subventionen keine Subventionen, in: Fälle zum Allgemeinen Verwaltungsrecht, 3. Aufl. 2016, S. 158; Faßbender, (Original-)Referendarexamensklausur - Öffentliches Recht: Allgemeines Verwaltungsrecht und Europarecht - Subvention für ökologische Landwirtschaft, JuS 2016, 538; GreimDiroll, Blumige Aussichten, JURA 2018, 740; Haltern/Manthey, (Original-)Referendarexamensklausur - Öffentliche Recht: Verwaltungsrecht - Rechtsnachfolge und Verwaltungsaktbefugnis im Subventionsrecht, JuS 2016, 344; Klafki, „Die reisende Kristallkugel“ Eine Tour d'Horizon durch das Gewerberecht, JURA 2018, 1019; Klement, Referendarexamensklausur - Öffentliches Recht: Allgemeines Verwaltungsrecht - Ellingers Traum aus Kindertagen, JuS 2018, 1088; Kühn, Politische Bildung auf dem Oktoberfest, JURA 2017, 1214; Manssen/Greim, Referendarexamensklausur - Öffentliches Recht: Rückforderung von Subventionen „Biofleisch, nein danke“, JuS 2010, 429; Payandeh, Übungsfall: Der fragwürdige Widerrufsvorbehalt, ZJS 2017, 544; Polzin/Doll, Der Gesichtsschleier in der Schule, JURA 2017, 1436; Winter-Peter, Widerruf einer Genehmigung, JURA 2018, 508; Wormit, Ein unheiliger Weihnachtsabend, JURA 2018, 87

\section{d) Rücknahme und Widerruf im Rechtsbehelfsverfahren gegen Verwaltungsakte mit Drittwirkung, §50 VwVfG}

Gemäß $\S 50$ VwVfG gelten $\S 48$ I 2, II bis IV sowie $\S 49$ II bis IV und VI nicht, 979 wenn ein begünstigender Verwaltungsakt, der von einem Dritten angefochten worden ist, während des Vorverfahrens oder während des verwaltungsgerichtlichen Verfahrens aufgehoben wird, soweit dadurch dem Widerspruch oder der Klage abgeholfen wird. Die Vorschrift hat zwar nun einen sehr begrenzten Anwendungsbereich, sollte allerdings wegen ihrer Komplexität nicht in der „Lernlücke“ verschwinden. ${ }^{1774}$

Der Anwendungsbereich von $\S 50$ VwVfG ist doppelt beschränkt: ${ }^{1775}$ In 980 sachlich-persönlicher Hinsicht gilt die Vorschrift nur im Falle der Erhebung eines Widerspruchs gemäß §68 I 1 VwGO bzw. einer Anfechtungsklage gemäß $\S 42$ I Var. 1 VwGO gegen einen den Adressaten begünstigenden Verwaltungsakt

1774 S. dazu ausführlich Remmert, VerwArch 2000, 209; Horn, Die Aufhebung des der Drittanfechtung unterliegenden Verwaltungsakts, 1989; Klostermann, Die Aufhebung des Verwaltungsakts mit Doppelwirkung im Verwaltungsverfahren, 1992. S. auch Gassner, JuS 1997, 794.

1775 S. zum Anwendungsbereich näher Ramsauer, in: Kopp/Ramsauer, VwVfG, 20. Aufl. 2019, $\S 50$ Rn. 3f., 12. 
mit Drittwirkung ${ }^{1776}$ durch den belasteten Dritten. In zeitlicher Hinsicht gilt die Vorschrift sodann nur für die Dauer des jeweiligen Verfahrens.

Entgegen des leicht widersprüchlichen Wortlauts soll eine Aufhebung des durch den Dritten angegriffenen begünstigenden Verwaltungsakts während der Verfahren nicht ausgeschlossen sein. ${ }^{1777}$ Die Norm modifiziert auch nicht die Voraussetzungen einer Aufhebung innerhalb des laufenden Rechtsbehelfsverfahrens. ${ }^{1778}$ Auch Abhilfe- oder Widerspruchsbehörde können den Verwaltungsakt ohne jegliche Berücksichtigung von $\S \S 48 \mathrm{f}$. VwVfG im Vorverfahren aufheben. ${ }^{1779}$ Die Vorschrift bewirkt vielmehr eine Modifikation der Voraussetzungen, die die zuständige Behörde außerhalb eines laufenden Rechtsbehelfsverfahrens einzuhalten hat, wenn sie der widerspruchsbehördlichen oder gerichtlichen Entscheidung durch Aufhebung gemäß \$§ $48 \mathrm{f}$. VwVfG ${ }^{1780}$ vorgreifen will. Im Vorverfahren steht die Entscheidung der Widerspruchsbehörde über den Weg der Aufhebung in ihrem Ermessen. ${ }^{1781}$

Die Wirkung von $\S 50$ VwVfG greift nur bei Vorliegen der folgenden Voraussetzungen, die im Einzelnen in verschiedener Hinsicht strittig diskutiert werden, worauf an dieser Stelle jedoch nicht en detail eingegangen werden soll $^{1782}$ :

(1) Der Anwendungsbereich der Vorschrift muss überhaupt eröffnet sein. Dies ist nur dann der Fall, wenn es sich um einen Verwaltungsakt mit Drittwirkung handelt, gegen den der belastete Dritte einen Widerspruch gemäß § 68 I 1 VwGO bzw. eine Anfechtungsklage gemäß § 42 I Var. 1 VwGO erhoben hat.

(2) Das somit anhängig gewordene Rechtsbehelfsverfahren muss noch andauern.

1776 S. dazu ausführlich bereits Rn. 296f. S. auch die Darstellungen bei Sachs, in: Stelkens/ Bonk/Sachs, VwVfG, 9. Aufl. 2018, § 50 Rn. 8 ff.

1777 Detterbeck, Allgemeines Verwaltungsrecht, 17. Aufl. 2019, Rn. 744; Ramsauer, in: Kopp/ Ramsauer, VwVfG, 20. Aufl. 2019, §50 Rn. 6. S. zur dogmatischen Frage der Ermächtigungsgrundlage für den Widerruf rechtmäßiger begünstigender Verwaltungsakte Remmert, VerwArch 2000, 209 (211) m.w. Nw.

1778 Maurer/Waldhoff, Allgemeines Verwaltungsrecht, 19. Aufl. 2017, § 11 Rn. 95.

1779 Ramsauer, in: Kopp/Ramsauer, VwVfG, 19. Aufl. 2018, § 50 Rn. 10.

1780 Oder gegebenenfalls aufgrund entsprechender Vorschriften des Fachrechts, für die eine analoge Anwendung diskutiert wird, s. nur Ramsauer, in: Kopp/Ramsauer, VwVfG, 20. Aufl. 2019, $\S 50$ Rn. 5; Sachs, in: Stelkens/Bonk/Sachs, VwVfG, 9. Aufl. 2018, § 50 Rn. 1, jeweils m.w. N.

1781 BVerwG, Urt. v. 18.4.1996, Az.: 4 C 6.95 = BVerwGE 101, 64 (69f.); vgl. zust. nur Sachs, in: Stelkens/Bonk/Sachs, VwVfG, 9. Aufl. 2018, §50 Rn. 5 m.w. Nw. Dagegen jedoch ausführlich Cornils, Die Verwaltung 2000, 485.

1782 S. für eine gut zugängliche Darstellung einzelner Probleme Remmert, VerwArch 2000, 209. S. für einen Überblick über die zu den Erfolgsaussichten des Rechtsbehelfs existierenden Positionen nur Sachs, in: Stelkens/Bonk/Sachs, VwVfG, 9. Aufl. 2018, § 50 Rn. 99. 
(3) Der Rechtsbehelf muss zulässig sein. ${ }^{1783}$

(4) Umstritten ist insbesondere, ob und falls ja, inwiefern das anhängige 986 Rechtsbehelfsverfahren in der Sache erfolgreich sein muss. $\mathrm{Zu}$ dieser Frage existieren verschiedene nuancierende Positionen, wesentlich lassen sich jedoch drei Hauptansätze identifizieren. Eine Ansicht verzichtet völlig auf eine Prüfung der Erfolgsaussichten des Rechtsbehelfs in der Sache. ${ }^{1784}$ Eine vermittelnde Ansicht verlangt lediglich, dass der Rechtsbehelf nicht offensichtlich unbegrün$\operatorname{det}^{1785}$ sein darf. ${ }^{1786}$ Die letzte Ansicht fordert hingegen, dass der Rechtsbehelf begründet sein muss. ${ }^{1787}$ Unabhängig davon, welcher Meinung man folgt, wird man jedenfalls bei Zulässigkeit und Begründetheit eines Rechtsbehelfs konsequenterweise eine Ermessensreduktion auf Null im Hinblick auf die Aufhebungsentscheidung annehmen müssen. ${ }^{1788}$

(5) Die Aufhebung gemäß §§ 48f. VwVfG muss dem eingelegten Rechtsbehelf 987 tatsächlich „abhelfen“, sprich das Begehren des Verfahrensführers verwirklichen.

Liegen diese Voraussetzungen vor, entfällt für die Behörde im Rahmen der 988 Aufhebung gemäß §§ 48f. VwVfG zumindest die Notwendigkeit der Beachtung der Vorschriften, die tatbestandlich das schutzwürdige Vertrauen des Begünstigten absichern sollen. Ziel der Vorschrift ist es, eine (weitgehende) Annäherung an die materiellen Beurteilungsmaßstäbe im Rechtsbehelfsverfahren, in dem Vertrauensschutzerwägungen mangels Bestandskraft maximal eine untergeordnete Bedeutung haben, zu erwirken. Hat man das Vorliegen der Voraussetzungen

1783 Dies scheint heute der ganz h.M. zu entsprechen, s. nur BVerwG, Urt. v. 13.11.1997, Az.: 3 C 33.96 = BVerwGE 105, 354 (360 f.); Urt. v. 4.4. 2012, Az.: 8 C 9.11 = juris, Rn. 38. S. dazu überdies die Nachweise - auch zu vereinzelt vertretenen Gegenmeinungen - bei Suerbaum, in: Mann/ Sennekamp/Uechtritz, VwVfG, 2. Aufl. 2019, § 50 Rn. 22.

1784 So bspw. OVG Münster, Urt. v. 25.4.1988, Az.: 13 A 464/87 = NVwZ 1989, 72 (73); Falkenbach, in: Bader/Ronellenfitsch, VwVfG, 44. Ed., Stand:1.7.2019, § 50 Rn. 7; Ziekow, VwVfG, 3. Aufl. 2013, $\S 50$ Rn. 9; Krausnick, JuS 2010, 594 (598).

1785 Für das VGH München, Urt. v. 10.12.1996, Az.: 20 B 95.3349 = NVwZ 1997, 701 (703), ist dies dann der Fall, wenn Gründe für den Erfolg des Rechtsbehelfs zu sprechen vermögen, ohne dass es aus einer ex-post-Perspektive darauf ankommt, ob sich diese Gründe auch tatsächlich durchzusetzen vermögen.

1786 Peine/Siegel, Allgemeines Verwaltungsrecht, 12. Aufl. 2018, Rn. 658; Ehlers/Kallerhoff, JURA 2009, 823 (828).

1787 S. nur Sachs, in: Stelkens/Bonk/Sachs, VwVfG, 9. Aufl. 2018, § 50 Rn. 93, m.w. N.; wohl auch das BVerwG, Urt. v. 24.2.2000, Az.: 4 C 12.98 = BVerwGE 110, 355 (362).

1788 So das BVerwG, Urt. v. 8.11.2001, Az.: 4 C 18.00 = NVwZ 2002, 730 (732f.). A.A. aber Ramsauer, in: Kopp/Ramsauer, VwVfG, 20. Aufl. 2019, § 50 Rn. 24. 
des $\S 50$ VwVfG bejaht, kann daher im Folgenden eine Prüfung der Tatbestandsvoraussetzungen gemäß § 48 I 2, II bis IV und § 49 II, III VwVfG unterbleiben. ${ }^{1789}$ Wurde es hingegen verneint, sind die $\S \S 48 \mathrm{f}$. VwVfG uneingeschränkt zu prüfen. Umstritten ist, ob darüber hinaus jeglicher Vertrauensschutz ausgeschlossen sein soll, also insbesondere auch die Pflicht der Behörde entfällt, Vertrauensschutzerwägungen im Rahmen der Ausübung ihres Ermessens zu berücksichtigen. ${ }^{1790}$ Dies wird jedoch nur dann überhaupt ein Problem sein, wenn mangels Erforderlichkeit von Begründetheit noch Raum für eine Ermessensausübung verbleibt. Hier zeigt sich wiederum die besondere dogmatische Komplexität der Vorschrift, deren Auslegung je nach Positionierung in bestimmten interdependenten Streitfragen differiert.

\section{e) Erstattung, § 49a VwVfG}

989 Gemäß § 49a VwVfG sind bereits erbrachte Leistungen zu erstatten, soweit ein Verwaltungsakt mit Wirkung für die Vergangenheit zurückgenommen oder widerrufen worden oder infolge Eintritts einer auflösenden Bedingung unwirksam geworden ist. Die Vorschrift ist eine besonders normierte Ausprägung (s. zum allgemeinen öffentlich-rechtlichen Erstattungsanspruch ausführlich unter $\S 5$ Rn. 189ff.) des öffentlich-rechtlichen Erstattungsanspruchs zugunsten der Behörde und dient als Ermächtigungsgrundlage für die Rückforderung bestimmter rechtsgrundlos erbrachter Leistungen. Entsprechend bestimmt § 49a I 2 VwVfG ausdrücklich, dass die zu erstattende Leistung durch Verwaltungsakt festzusetzen ist. ${ }^{1791}$ Die Rückforderung basiert zwar zum Teil auf der Aufhebung eines Verwaltungsakts mit Wirkung für die Vergangenheit (§ 49a I 1 Var. 1 und 2 VwVfG), sie ist jedoch ein rechtlich davon zu unterscheidender Verwaltungsakt, dessen Aufhebung im Wege des Widerspruchs (§ 68 I 1 VwGO) bzw. der Anfechtungsklage (§ 42 I Var. 1 VwGO) eigenständig zu begehren ist.

990 In Prüfungen erfolgt die Rückforderung von Leistungen überwiegend in Verbindung mit der Aufhebungsentscheidung. Dies ist vor dem Hintergrund, dass die Rückforderung gemäß § 49a I 1 VwVfG u. a. nur im Falle der Aufhebung (Var. 1 und 2) zulässig ist, verständlich. Aus dem Sachverhalt wird sich regelmäßig klar ergeben, dass die Behörde es begehrt, zwei verschiedene Regelungen vorzunehmen. Davon ist im Wege der Auslegung selbst dann auszugehen, wenn diese in

1789 S. dafür ausführlich zu verschiedenen Positionen Sachs, in: Stelkens/Bonk/Sachs, VwVfG, 9. Aufl. 2018, §50 Rn. $71 \mathrm{ff}$.

1790 S. dazu Ramsauer, in: Kopp/Ramsauer, VwVfG, 20. Aufl. 2019, § 50 Rn. 8.

1791 Es handelt sich um eine der seltenen ausdrücklichen Verwaltungsaktbefugnisse, s. dazu Rn. 760.

Tobias Brings-Wiesen 
einem Bescheid zusammengefasst sind. ${ }^{1792}$ Unter Umständen kann durch Auslegung gar einem bloßen Rückforderungsbescheid die vorgeschaltete Aufhebung eines Verwaltungsakts entnommen werden. Je nach Aufgabenstellung kann es zwar vereinzelt erforderlich sein, die Aufhebungsentscheidung der Behörde im Rahmen von § 49a I 1 VwVfG inzident umfassend zu prüfen. Da die Rückforderung jedoch nur von der Wirksamkeit der Aufhebung abhängig ist, wird sie in der überwiegenden Zahl der Fälle sinnvoll nur in unmittelbarer Kombination mit der Beurteilung der Wirksamkeit des einer Leistung zugrundeliegenden Verwaltungsakts zu prüfen sein. Dabei wird sie praktisch immer dessen Überprüfung nachfolgen. Die klassische Prüfungskonstellation ist die Erhebung zweier (in objektiver Klagehäufung gemäß §44 VwGO - s. dazu unter §1 Rn. 64, $231 \mathrm{ff}$., 252ff. - miteinander verbundener) Anfechtungsklagen gegen die Aufhebung eines Verwaltungsakts und die darauf beruhende Rückforderung bereits erbrachter Leistungen gemäß § 49a I 1 VwVfG. In diesem Fall sollte besonders darauf geachtet werden, dass im Zeitstress zum Ende der Prüfung die Rückforderung nicht unterschlagen wird.

\section{aa) Ermächtigungsgrundlage und formelle Rechtmäßigkeit}

Wie bereits dargelegt ist $\S 49$ a I 1 VwVfG Ermächtigungsgrundlage des Rück- 991 forderungsbescheids.

Da es sich bei dem Rückforderungsbescheid um einen Verwaltungsakt han- 992 delt, gelten wiederum die allgemeinen rechtlichen Vorgaben für Verwaltungsakte nach dem VwVfG. Daher kann auch an dieser Stelle grundsätzlich auf die allgemeinen Ausführungen zur formellen Rechtmäßigkeit verwiesen werden (s. dazu Rn. 579 ff.). Folgende Besonderheiten sind zu berücksichtigen: Die Zuständigkeit für die Rückforderung liegt nach herrschender Meinung entweder bei der Behörde, die auch für die Aufhebung des leistungsbegründenden Verwaltungsakts (Var. 1 und 2) zuständig gewesen ist, oder im Falle des Eintritts einer auflösenden Bedingung bei der Behörde, die den Hauptverwaltungsakt erlassen hat. ${ }^{1793}$ Da der Rückforderungsbescheid durch die Begründung einer Leistungspflicht in die Rechte des durch die Leistung Begünstigten eingreift, ist auch seiner bezüglich

1792 So auch Maurer/Waldhoff, Allgemeines Verwaltungsrecht, 19. Aufl 2017, § 11 Rn. 48. 1793 Sachs, in: Stelkens/Bonk/Sachs, VwVfG, 9. Aufl. 2018, § 49a Rn. 34; Kastner, in: Fehling/ Kastner/Störmer, Verwaltungsrecht, 4. Aufl. 2016, § 49a VwVfG Rn. 8; Suerbaum, in: Mann/Sennekamp/Uechtritz,VwVfG, 2. Aufl. 2019, § 49a Rn. 50; Peuker, in: Knack/Henneke, VwVfG, 10. Aufl. 2014, § 49a Rn. 28; Gröpl, VerwArch 1997, 23 (43f.). 
eine Anhörung gemäß § 28 I VwVfG erforderlich. Zuletzt ist zu beachten, dass der Rückforderungsbescheid gemäß § 49a I 2 VwVfG schriftlich ergehen muss.

\section{bb) Materielle Rechtmäßigkeit}

993 Die Rückforderung durch die Behörde auf Grundlage von § 49a VwVfG erfolgt rechtmäßig, soweit sie die folgenden Voraussetzungen erfüllt: ${ }^{1794}$

(1) Ausdrücklich ist der Anwendungsbereich der Vorschrift auf drei Konstellationen beschränkt: die Rücknahme, den Widerruf oder die Erledigung eines Verwaltungsakts infolge Eintritts einer auflösenden Bedingung. Gemein ist den drei Konstellationen, dass die Unwirksamkeit mit Wirkung für die Vergangenheit eintreten muss. Soweit in einer Prüfung bereits vorab die Aufhebung eines Verwaltungsakts geprüft wurde, kann an dieser Stelle nach oben verwiesen werden. Dabei ist irrelevant, ob die Prüfung am Maßstab spezialgesetzlicher Aufhebungstatbestände oder der §§ 48f. VwVfG erfolgte. ${ }^{1795}$ Dies kann insbesondere auch dazu führen, dass die Prüfung mangels rechtmäßiger Aufhebung zumindest mit Wirkung für die Vergangenheit - sofort $\mathrm{zu}$ beenden ist. Eine analoge Anwendbarkeit der Vorschrift auf andere Konstellationen der Unwirksamkeit mit Wirkung für die Vergangenheit wird unter Rekurs auf den klaren Wortlaut und die Entstehungsgeschichte der Norm nahezu einheitlich abgelehnt. ${ }^{1796}$ Nichts anderes gilt grundsätzlich für Aufhebungen mit Wirkung für die Zukunft. ${ }^{1797}$ Zum Teil wird jedoch mit der Begründung, die Aufhebung mit Wirkung für die Zukunft lasse den Rechtsgrund für das Behalten der empfangenen Leistung entfallen, für eine analoge Anwendung plädiert. ${ }^{1798}$ Dies ist abzulehnen. ${ }^{1799}$ In all diesen Konstellationen ist die Behörde vielmehr auf den allgemeinen öffentlich-rechtlichen Erstattungsanspruch verwiesen. Soweit es nur zu einem anteiligen Entfall des Rechtsgrundes für eine Leistung kommt, ist die Erstattung darauf beschränkt. ${ }^{1800}$

1794 S. für einen Prüfungsaufbau auch Kastner, in: Fehling/Kastner/Störmer, Verwaltungsrecht, 4. Aufl. 2016, § 49a VwVfG Rn. 3.

1795 Ramsauer, in: Kopp/Ramsauer, VwVfG, 20. Aufl. 2019, § 49a Rn. 3.

1796 S. nur Ramsauer, in: Kopp/Ramsauer, VwVfG, 20. Aufl. 2019, § 49a Rn. 3f. m.w. N.

1797 Detterbeck, Allgemeines Verwaltungsrecht, 17. Aufl. 2019, Rn. 731; Ramsauer, in: Kopp/ Ramsauer, VwVfG, 20. Aufl. 2019, § 49a Rn. 8; Ehlers/Schröder, JURA 2010, 824 (831).

1798 Dafür Sachs, in: Stelkens/Bonk/Sachs, VwVfG, 9. Aufl. 2018, § 49a Rn. 9, 16, 19; Falkenbach, in: Bader/Ronellenfitsch, VwVfG, 44. Ed., Stand: 1.7.2019, § 49a Rn. 5 f.

1799 S. dazu mit überzeugender Begründung nur Folnovic/Hellriegel, NVwZ 2016, 638 (641 f). 1800 Maurer/Waldhoff, Allgemeines Verwaltungsrecht, 19. Aufl. 2017, § 11 Rn. 48. 
(2) Der Bescheid muss gegen den richtigen Adressaten, nämlich den 995 Schuldner des Erstattungsanspruchs, gerichtet sein. Dies ist regelmäßig die im ursprünglichen Verwaltungsakt als Empfänger der Leistung ausgewiesene Person. ${ }^{1801}$ Nur unter besonderen Umständen können von der Behörde auch Dritte in Anspruch genommen werden. ${ }^{1802}$

(3) Der Erstattungsanspruch der Behörde darf noch nicht verjährt sein. Dies 996 ist im Einklang mit der herrschenden Meinung nach §195 i.V.m. §199 I BGB analog zu bestimmen. ${ }^{1803}$ Danach beträgt die regelmäßige Verjährungsfrist drei Jahre und beginnt mit dem Schluss des Jahres, in dem der Anspruch entstanden ist und der Gläubiger von den Anspruch begründenden Umständen Kenntnis erlangt hat oder ohne grobe Fahrlässigkeit hätte erlangen müssen. Eine Hemmung nach $\S \S 203 \mathrm{ff}$. BGB analog ist möglich. ${ }^{1804}$

(4) Die von der Behörde vorgenommene Festsetzung muss sich innerhalb des gesetzlich zulässigen Umfangs der Erstattung bewegen. Dies richtet sich nach § 49a II bis IV VwVfG. Hinsichtlich der erbrachten Leistung ordnet §49a II 1 VwVfG die entsprechende Geltung der Vorschriften des Bürgerlichen Gesetzbuchs über die Herausgabe einer ungerechtfertigten Bereicherung ( $\S 812 \mathrm{ff}$. BGB) an. Da der Rechtsgrund für die Erstattung jedoch abschließend in §49a I 1 VwVfG geregelt ist, handelt es sich dabei nur um eine Rechtsfolgenverweisung auf die $\S \S 818 \mathrm{ff}$. BGB $^{1805}$ Dies bedeutet insbesondere, ${ }^{1806}$ dass der Begünstigte sich gemäß $§ 818$ III BGB auf den Wegfall der Bereicherung berufen kann - dies allerdings gemäß (des als lex specialis zu § 819 I BGB anwendbaren ${ }^{1807}$ ) §49a II 2 VwVfG nur, soweit er nicht die Umstände kannte oder infolge grober Fahrlässigkeit nicht kannte, die zur Rücknahme, zum Widerruf oder zur Unwirksamkeit des Verwaltungsakts geführt haben. Anders als im Rahmen von § 48 II 3 Nr. 3 VwVfG (s. dazu Rn. 892) soll sich die Kenntnis oder grob fahrlässige Unkenntnis hier nur

1801 Falkenbach, in: Bader/Ronellenfitsch, VwVfG, 44. Ed., Stand: 1.7.2019, § 49a Rn. 16; Ramsauer, in: Kopp/Ramsauer, VwVfG, 20. Aufl. 2019, § 49a Rn. 10.

1802 S. dazu Falkenbach, in: Bader/Ronellenfitsch, VwVfG, 44. Ed., Stand: 1.7.2019, § 49a Rn. 16 ff.; Ramsauer, in: Kopp/Ramsauer, VwVfG, 20. Aufl. 2019, § 49a Rn. 10a.

1803 Vgl. dazu - im subventionsrechtlichen Kontext - nur Scherer-Leydecker/Laboranowitsch, NVwZ 2017, 1837, m. ausf. Darstellung des aktuellen Streitstands; s. auch die überzeugende Begründung des BVerwG, Urt. v. 15.3.2017, Az.: 10 C 3.16 = BVerwGE 158, 199 (203f., Rn. 19).

1804 BVerwG, Urt. v. 15.3.2017, Az.: 10 C 3.16 = BVerwGE 158, 199 (206f., Rn. 24).

1805 Sachs, in: Stelkens/Bonk/Sachs, VwVfG, 9. Aufl. 2018, § 49a Rn. 42.

1806 Für eine anschauliche Darstellung der sonstigen Folgen Sachs, in: Stelkens/Bonk/Sachs, VwVfG, 9. Aufl. 2018, § 49a Rn. $43 \mathrm{ff}$.

1807 Maurer/Waldhoff, Allgemeines Verwaltungsrecht, 19. Aufl. 2017, § 11 Rn. 48. 
auf die tatsächlichen Voraussetzungen der die Aufhebung begründenden Rechtswidrigkeit beziehen, nicht indes auf die Rechtswidrigkeit selbst. ${ }^{1808}$

Bei der Entscheidung über die Rückforderung gewährt § 49a I 1 VwVfG der Behörde im Hinblick auf die erbrachte Leistung selbst kein Ermessen. Sie muss diese vielmehr zurückfordern. Die Forderung von Zinsen gemäß §49a III, IV VwVfG hingegen steht im Ermessen der Behörde.

\section{f) Die Zusicherung, § 38 VwVfG}

999 Besonderer Berücksichtigung bedarf auch die Möglichkeit einer Anfechtungsklage gemäß § 42 I Var. 1 VwG0 gegen die Zusicherung auf Erlass eines Verwaltungsakts mit Drittwirkung gemäß $\S 38$ VwVfG. ${ }^{1809}$ Dabei handelt es sich um einen gesetzlich ausdrücklich normierten Unterfall der Zusage: Ausweislich der Legaldefinition in § 38 I 1 VwVfG handelt es sich um die behördliche Zusage, einen bestimmten Verwaltungsakt später zu erlassen oder zu unterlassen. Obgleich die Rechtsqualität der Zusicherung weiterhin lebhaft umstritten ist, geht zumindest die wohl herrschende Meinung davon aus, dass es sich bei ihr um einen Verwaltungsakt handelt. ${ }^{1810}$ Daraus folgt, dass in multipolaren Rechtsverhältnissen das Begehren eines belasteten Dritten bei Verletzung seiner Rechte durch die dem Begünstigten gegenüber ausgesprochene Zusicherung darauf gerichtet sein kann, diesen Verwaltungsakt aufheben zu lassen. Die Erhebung von Rechtsbehelfen ist erforderlich, um die - zumindest gemäß § 38 II VwVfG - unabhängig von einer etwaigen Rechtswidrigkeit eintretende Wirksamkeit der Zusicherung zu beenden und dem Begünstigten so die Anspruchsgrundlage für den Erlass eines Verwaltungsakts zu nehmen (s. dazu in $\S 3$ Rn. 71, 79). Im Rahmen der Prüfung der Begründetheit ist sodann zu berücksichtigen, dass § 38 VwVfG einige Besonderheiten betreffend Wirksamkeits- und Rechtsmäßigkeitsvoraussetzungen der Zusicherung bereithält. ${ }^{1811} \mathrm{Da}$ - zumindest gemäß § 38 II VwVfG - die §§ $48 \mathrm{f}$. VwVfG entsprechend anwendbar sind, kann eine rechtswidrige Zusicherung auch gemäß § 48 VwVfG zurückgenommen werden. Kommt es schließlich zum Erlass

\footnotetext{
1808 BVerwG, Urt. v. 13.11.1997, Az.: 3 C 33.96 = BVerwGE 105, 354 (362).

1809 Maurer/Waldhoff, Allgemeines Verwaltungsrecht, 19. Aufl. 2017, § 9 Rn. 61. S. dazu Stelkens, in: Stelkens/Bonk/Sachs, VwVfG, 9. Aufl. 2018, § 38 Rn. 119ff.; für einen gut zugänglichen Überblick zu den Rechtsproblemen rund um die Zusicherung Hebeler/Schäfer, JURA 2010, 881; Kingler/Krebs, JuS 2010, 1059. S. dazu auch die Fallbearbeitung bei Pünder, JA 2004, 467. 1810 S. dazu nur Stelkens, in: Stelkens/Bonk/Sachs, VwVfG, 9. Aufl. 2018, § 38 Rn. 29 ff. m. zahlr. N. Da sich der Streit auf das Rechtsschutzbegehren auswirkt, wird er in einer Klausur regelmäßig $\mathrm{zu}$ entscheiden sein.
}

1811 S. dazu Kingler/Krebs, JuS 2010, 1059 (1060 ff.). 
des Verwaltungsakts auf Grundlage der Zusicherung, ist eine gegen diesen gerichtete Anfechtungsklage am Maßstab der Zusicherung und insofern unter Begutachtung ihrer Wirksamkeit zu prüfen. ${ }^{1812}$

\section{Literaturhinweise}

Lehrbeiträge: Guckelberger, Behördliche Zusicherungen und Zusagen, DÖV 2004, 357; Hebeler/Schäfer, „Versprechungen“ der Verwaltung - Zusagen, Zusicherungen und ähnliche behördliche Erklärungen, JURA 2010, 881; Kellner, Vertrauensschutz in kleiner Münze - Staatshaftungsrechtliche Aspekte der Zusicherung nach § 38 VwVfG, NVwZ 2013, 482; Kingler/Krebs, Die Zusicherung, § 38 VwVfG, JuS 2010, 1059

Fallbearbeitungen: Diederichsen, Referendarexamensklausur - Öffentliches Recht: Zoff um eine Zusage, JuS 2006, 60; Ernst/Kämmerer, Fall 10 - Ein dilettantischer Gastwirt, in: Fälle zum Allgemeinen Verwaltungsrecht, 3. Aufl. 2016, S. 139; Grupp/Stelkens, Wahlverwandtschaften, abrufbar unter: http://www.saarheim.de/ Faelle/wahlverwandtschaften-fall.htm (Bearbeitungsstand: 1.6.2018); Pünder, Die voreilige Subventionszusage, JA 2004, 467

Lehrvideos: Mayer/Breidenbach, Peer2Peer-Lehrvideo Rücknahme und Widerruf eines Verwaltungsakts, Teil 1 abrufbar unter https://youtu.be/y1QqFT_ YGGQ und Teil 2 abrufbar unter https://youtu.be/ojoOPLYW_Ik

\section{Ermächtigungsgrundlagen des Polizei- und Ordnungsrechts (Nikolas Eisentraut)}

Ein zentrales Anwendungsfeld für die Anfechtungsklage bietet das allgemeine 1000

Polizei- und Ordnungsrecht. Die Anfechtungsklage spielt im allgemeinen Polizei- und Ordnungsrecht deshalb eine bedeutende Rolle, weil die Polizei- und Ordnungsbehörden bei der Gefahrenabwehr häufig auf die Handlungsform des Verwaltungsakts zurückgreifen. ${ }^{1813}$

Aber Achtung: Nicht gegen jede polizei- oder ordnungsbehördliche Maß- 1001 nahme ist die Anfechtungsklage statthaft. Die Ermächtigungsgrundlagen der Polizei- und Ordnungsgesetze der Länder sprechen häufig nur von den durch die Polizei- oder Ordnungsbehörden zu ergreifenden „Maßnahmen“. ${ }^{1814}$ Nur dann,

1812 Stelkens, in: Stelkens/Bonk/Sachs, VwVfG, 9. Aufl. 2018, § 38 Rn. 122.

1813 Schenke, Polizei- und Ordnungsrecht, 10. Aufl. 2018, Rn. 482.

1814 Schenke, Polizei- und Ordnungsrecht, 10. Aufl. 2018, Rn. 482. 
wenn es sich bei der Maßnahme auch um einen Verwaltungsakt handelt, den der Kläger aufgehoben wissen will, ist die Anfechtungsklage statthaft.

1002

Auch bei Klausuren im Polizei- und Ordnungsrecht stellt sich daher regelmäßig unter dem Prüfungspunkt „Statthafte Klageart“ (s. dazu einleitend $\S 1$ Rn. 222ff.) die Frage, ob die zu prüfende Maßnahme als Verwaltungsakt zu qualifizieren ist (grundlegend zum Begriff des Verwaltungsakts Rn. $38 \mathrm{ff}$.).

1003 Nicht als Verwaltungsakt qualifiziert, sondern dem Realbereich des Handelns der Verwaltung (Realakt, s. dazu näher $§ 5$ Rn. 6 ff.) zugeordnet werden Warnungen (etwa die Gefährderansprache bzw. das Gefährderanschreiben ${ }^{1815}$ ), Datenerhebung und -verarbeitung, heimliche informationelle Eingriffe und die unmittelbare Ausführung von Maßnahmen, ${ }^{1816}$ aber auch polizeiliche Streifengänge, Beobachtungen und Ermahnungen. ${ }^{1817}$ Mangels Regelungswirkung sind gegen Realakte nur die Rechtsschutzformen der allgemeinen Leistungsklage (insbesondere in Form der Unterlassungsklage, s. zur allgemeinen Leistungsklage im Polizei- und Ordnungsrecht $\S 5$ Rn. 223ff.) sowie im Falle bereits erledigter Realakte die Feststellungsklage statthaft (s. zur Feststellungsklage im Polizei- und Ordnungsrecht $§ 6$ Rn. $181 \mathrm{ff}.)^{1818}$

1004 In der Regel gelingt die Abgrenzung mittels einer sauberen Subsumtion unter die Tatbestandsmerkmale des Verwaltungsaktbegriffs. Insbesondere im Falle ausdrücklicher Anordnungen durch die handelnden Behörden kann der Regelungscharakter typischerweise bejaht werden. ${ }^{1819}$ Fehlt eine solche ausdrückliche Anordnung, ist die Qualifikation als Verwaltungsakt jedoch zweifelhaft, insbesondere, wenn es um Standardbefugnisse geht, die zu einem tatsächlichen Handeln ermächtigen. Dem entsprechend ist die Qualifikation als Verwaltungsakt für einige Standardmaßnahmen umstritten, sodass hier ein besonderes Problembewusstsein nicht schaden kann. Dies gilt insbesondere für den Gewahrsam, die Durchsuchung, die Sicherstellung sowie für die erkennungsdienstliche Behandlung. ${ }^{1820}$ Zwar ist die faktische Durchführung der Maßnahmen dem Realbereich des Verwaltungshandelns zuzuordnen; nach klassischer Sichtweise enthält die Durchführung aber zugleich die Regelung, dass der Betroffene die Maßnahme dulden muss. ${ }^{1821}$ Danach wären die Maßnahmen also

1815 Götz/Geis, Allgemeines Polizei- und Ordnungsrecht, 16. Aufl. 2017, § 12 Rn. 5; Schoch, in: Schoch, Besonderes Verwaltungsrecht, 2018, Kapitel 1 Rn. 229.

1816 Götz/Geis, Allgemeines Polizei- und Ordnungsrecht, 16. Aufl. 2017, § 12 Rn. 1.

1817 Schenke, Polizei- und Ordnungsrecht, 10. Aufl. 2018, Rn. 484.

1818 Schenke, Polizei- und Ordnungsrecht, 10. Aufl. 2018, Rn. 663 und 667.

1819 Möstl, JURA 2011, 811 (848).

1820 Götz/Geis, Allgemeines Polizei- und Ordnungsrecht, 16. Aufl. 2017, § 12 Rn. 9.

1821 Götz/Geis, Allgemeines Polizei- und Ordnungsrecht, 16. Aufl. 2017, § 12 Rn. 11.

Nikolas Eisentraut 
als Verwaltungsakt zu qualifizieren. ${ }^{1822}$ Nach wohl überwiegender Auffassung soll es sich hingegen um Realakte handeln, weil die klassische Sichtweise konstruiert und in der Praxis überflüssig sei. ${ }^{1823}$

Die Qualifikation der streitgegenständlichen Maßnahme als Verwaltungs- 1005 akt reicht noch nicht aus, um die Statthaftigkeit der Anfechtungsklage zu bejahen. Der Verwaltungsakt muss weiterhin wirksam sein (zu diesem Erfordernis näher Rn. 98 ff.). Im Polizei- und Ordnungsrecht kommt es jedoch nicht selten vor, dass sich der Verwaltungsakt bereits erledigt hat. Ist bereits Erledigung eingetreten, kann der Kläger nur noch die Feststellung der Rechtswidrigkeit der Ordnungsverfügung mittels der Fortsetzungsfeststellungsklage verfolgen (s. zur Fortsetzungsfeststellungsklage im Polizei- und Ordnungsrecht näher $\S 4$ Rn. 62 ff.).

Zudem wird für ordnungsbehördliche Verwaltungsakte häufig die sofortige 1006 Vollziehbarkeit angeordnet (§ 80 II 1 Nr. 4 VwGO) oder sie besteht bereits qua Gesetz für „unaufschiebbare Anordnungen und Maßnahmen von Polizeivollzugsbeamten“ (§ 80 II 1 Nr. 2 VwGO). In diesen Fällen wird der Antragsteller einstweiligen Rechtsschutz nach \$ 80 Abs. 5 VwGO begehren (s. zum Antrag nach $\S 80$ V VwGO im Polizei- und Ordnungsrecht näher $\S 8$ Rn. 79f.).

Ebenfalls nicht als Verwaltungsakt zu qualifizieren sind die sog. Gefahren- 1007 abwehrverordnungen. Die Polizei- und Ordnungsgesetze der Länder sehen die Möglichkeit vor, dass abstrakte Gefahren mittels Gefahrenabwehrverordnungen abgewehrt werden können. Gefahrenabwehrverordnungen gelten jedoch nicht konkret-individuell, sondern generell-abstrakt, formulieren ihre Ge- und Verbote also für eine unbestimmte Zahl von Fällen und für eine unbestimmte Zahl von Personen. Soweit im Landesrecht davon Gebrauch gemacht wurde, kann die Rechtmäßigkeit einer solchen Verordnung mittels der verwaltungsgerichtlichen Normenkontrolle nach § 47 I Nr. 2 VwGO überprüft werden (zum Normenkontrollverfahren im Polizei- und Ordnungsrecht näher $\S 7$ Rn. $106 \mathrm{ff}$.). Ansonsten kann ihre Rechtmäßigkeit inzident im Rahmen des Angriffs eines Vollzugsakts zu überprüfen sein (s. näher Rn. 1035 und Rn. 1091) sowie mittels der Feststellungsklage (s. § 6 Rn. 26 ff.). ${ }^{1824}$

1822 So auch weiterhin Götz/Geis, Allgemeines Polizei- und Ordnungsrecht, 16. Aufl. 2017, § 12 Rn. 11.

1823 M.w.N. zu dieser Ansicht Götz/Geis, Allgemeines Polizei- und Ordnungsrecht, 16. Aufl. 2017, $\S 12$ Rn. 11.

1824 Siegel, in: Siegel/Waldhoff, Öffentliches Recht für Berlin, 2. Aufl. 2017, § 2 Rn. 273. 
Examenswissen: Öffentlich-rechtliche Verträge werden im Polizei- und Ordnungsrecht hingegen nur selten geschlossen (näher zum öffentlich-rechtlichen Vertrag als Handlungsinstrument der Verwaltung $\S 5$ Rn. 65 ff.). ${ }^{1825}$

\section{a) Einführung in das Polizei- und Ordnungsrecht}

1008 Der Begriff des Polizei- und Ordnungsrechts umfasst alle Rechtsgrundlagen, die die Gefahrenabwehr durch die Verwaltung regeln. ${ }^{1826}$ Gefahrenabwehr meint dabei klassischer Weise (s. aber sogleich noch Rn. 1024f.) die Abwehr konkreter Gefahren für die polizeilichen Schutzgüter. ${ }^{1827}$ Darüber hinaus können die Gefahrenabwehrbehörden zudem im Bereich abstrakter Gefahren tätig werden, indem sie Gefahrenabwehrverordnungen erlassen (dazu §7 Rn. 107) und Gefahrenvorsorge betreiben. ${ }^{1828}$

1009 Hausarbeitswissen: Die Gefahrenabwehr wird als Staatsaufgabe qualifiziert. ${ }^{1829}$ Als „staatliche Kernaufgabe“ steht sie einer Privatisierung nur in engen Grenzen offen. ${ }^{1830}$

\section{aa) Die Unterscheidung zwischen allgemeinem und besonderem Polizei- und Ordnungsrecht}

1010 Innerhalb des Rechts der Gefahrenabwehr wird unterschieden zwischen allgemeinem und besonderem Ordnungsrecht. ${ }^{1831}$ Da der Bund im Bereich der Gefahrenabwehr nur einzelne, bereichsspezifische Gesetzgebungskompetenzen besitzt, ${ }^{1832}$ ist die Regelung des allgemeinen Polizei- und Ordnungsrechts der Gesetzgebungskompetenz der Länder zugewiesen (Art. 70 GG). ${ }^{1833}$ Ihrer Kom-

1825 Dazu Schenke, Polizei- und Ordnungsrecht, 10. Aufl. 2018, Rn. $656 \mathrm{ff}$.

1826 Schenke, Polizei- und Ordnungsrecht, 10. Aufl. 2018, Rn. 20; Schoch, in: Schoch, Besonderes Verwaltungsrecht, 2018, Kapitel 1 Rn. 1; zur Geschichte des Polizei- und Ordnungsrechts Kingreen/Poscher, Polizei- und Ordnungsrecht mit Versammlungsrecht, 10. Aufl. 2018, § 1 Rn. $1 \mathrm{ff}$. 1827 Schoch, in: Schoch, Besonderes Verwaltungsrecht, 2018, Kapitel 1 Rn. 10; zur Gefahrenabwehr als staatliche Aufgabe Schoch, in: Schoch, Besonderes Verwaltungsrecht, 2018, Kapitel 1 Rn. 65 ff.; zur Gefahrenabwehr durch Private Schoch, in: Schoch, Besonderes Verwaltungsrecht, 2018, Kapitel 1 Rn. $130 \mathrm{ff}$.

1828 Kingreen/Poscher, Polizei- und Ordnungsrecht mit Versammlungsrecht, 10. Aufl. 2018, § 8 Rn. 19.

1829 Näher dazu Schoch, in: Schoch, Besonderes Verwaltungsrecht, 2018, Kapitel 1 Rn. 65 ff. 1830 Siegel, in: Siegel/Waldhoff, Öffentliches Recht für Berlin, 2. Aufl. 2017, § 2 Rn. 4.

1831 Schenke, Polizei- und Ordnungsrecht, 10. Aufl. 2018, Rn. 20.

1832 Schoch, in: Schoch, Besonderes Verwaltungsrecht, 2018, Kapitel 1 Rn. 87 f.; Aufzählung bei Kingreen/Poscher, Polizei- und Ordnungsrecht mit Versammlungsrecht, 10. Aufl. 2018, § 2 Rn. $34 \mathrm{f}$. 1833 Schenke, Polizei- und Ordnungsrecht, 10. Aufl. 2018, Rn. 23; Schoch, in: Schoch, Besonderes Verwaltungsrecht, 2018, Kapitel 1 Rn. 90.

Nikolas Eisentraut 
petenz entsprechend haben die Länder allgemeine Polizei- und Ordnungsgesetze erlassen.

Hausarbeitswissen: Eine Vereinheitlichung der Regelungen ist zuletzt wieder in die Diskussion geraten, als die Innenministerkonferenz im Juni 2017 die Erarbeitung eines neuen Musterpolizeigesetzes beschlossen hat. ${ }^{1834}$ Einem Musterpolizeigesetz käme aufgrund der weiterhin bestehenden Länderkompetenz jedoch nur eine nicht bindende „Vorbildwirkung“ $z u$.

Folgende allgemeine Polizei- und Ordnungsgesetze existieren in den Bundesländern: ${ }^{1835}$

\begin{tabular}{ll}
\hline Bundesland & Polizei- und Ordnungsgesetz \\
\hline Baden-Württemberg & Polizeigesetz (BWPolG) \\
\hline Bayern & $\begin{array}{l}\text { 1. Gesetz über die Aufgaben und Befugnisse der Bayerischen } \\
\text { Staatlichen Polizei (Polizeiaufgabengesetz - BayPAG) } \\
\text { 2. Gesetz über das Landesstrafrecht und das Verordnungsrecht auf } \\
\text { dem Gebiet der öffentlichen Sicherheit und Ordnung (BayLStVG) }\end{array}$ \\
\hline Berlin & $\begin{array}{l}\text { Allgemeines Gesetz zum Schutz der öffentlichen Sicherheit und } \\
\text { Ordnung (ASOG Bln) }\end{array}$ \\
\hline Brandenburg & $\begin{array}{l}\text { 1. Gesetz über Aufbau und Befugnisse der Ordnungsbehörden } \\
\text { (Ordnungsbehördengesetz - BbgOBG) }\end{array}$ \\
$\begin{array}{l}\text { 2. Gesetz über die Aufgaben, Befugnisse, Organisation und Zu- } \\
\text { ständigkeit der Polizei im Land Brandenburg (Polizeigesetz - Bbg- } \\
\text { PolG) }\end{array}$ \\
\hline Bremisches Polizeigesetz (BremPolG) \\
\hline Hamburg & $\begin{array}{l}\text { 1. Gesetz zum Schutz der öffentlichen Sicherheit und Ordnung } \\
\text { (HambSOG) } \\
\text { 2. Gesetz über die Datenverarbeitung der Polizei (HambPolEDVG) }\end{array}$ \\
\hline Hessisches Gesetz über die öffentliche Sicherheit und Ordnung \\
(HSOG)
\end{tabular}

1834 Schoch, in: Schoch, Besonderes Verwaltungsrecht, 2018, Kapitel 1 Rn. 91; zur Thematik näher Kaiser/Struzina, Vereinheitlichung des Polizeirechts? - Vom Beruf unserer Zeit zur Mustergesetzgebung, ZG 2018, 111; generell zu Zentralisierungstendenzen Kingreen/Poscher, Polizeiund Ordnungsrecht mit Versammlungsrecht, 10. Aufl. 2018, §1 Rn. $33 \mathrm{ff}$.

1835 Näher zu den einzelnen Gesetzen Kingreen/Poscher, Polizei- und Ordnungsrecht mit Versammlungsrecht, 10. Aufl. 2018, § 3 Rn. 9 ff. 
Fortsetzung

\begin{tabular}{|c|c|}
\hline Bundesland & Polizei- und Ordnungsgesetz \\
\hline Nordrhein-Westfalen & $\begin{array}{l}\text { 1. Polizeigesetz (PolG NRW) } \\
\text { 2. Gesetz über die Organisation und die Zuständigkeit der Polizei } \\
\text { (Polizeiorganisationsgesetz - NWPOG) } \\
\text { 3. Gesetz über die Aufbau und Befugnisse der Ordnungsbehörden } \\
\text { (Ordnungsbehördengesetz - NWOBG) }\end{array}$ \\
\hline Rheinland-Pfalz & Polizei- und Ordnungsbehördengesetz (PhPfPOG) \\
\hline Saarland & Saarländisches Polizeigesetz (SPolG) \\
\hline Sachsen & $\begin{array}{l}\text { 1. Polizeigesetz des Freistaates Sachsen (SächsPolG) } \\
\text { 2. Gesetz über die Sächsische Sicherheitswacht (Sicherheitswacht- } \\
\text { gesetz - SächsSWG) }\end{array}$ \\
\hline Sachsen-Anhalt & $\begin{array}{l}\text { Gesetz über die öffentliche Sicherheit und Ordnung des Landes } \\
\text { Sachsen-Anhalt (SOG LSA) }\end{array}$ \\
\hline Schleswig-Holstein & $\begin{array}{l}\text { 1. Allgemeines Verwaltungsgesetz für das Land Schleswig-Holstein } \\
\text { (Landesverwaltungsgesetz - SchlHLVwG) } \\
\text { 2. Gesetz über die Organisation der Polizei in Schleswig-Holstein } \\
\text { (Polizeiorganisationsgesetz - SchlHPOG) }\end{array}$ \\
\hline Thüringen & $\begin{array}{l}\text { 1. Gesetz über die Aufgaben und Befugnisse der Polizei (Polizei- } \\
\text { aufgabengesetz - ThürPAG) } \\
\text { 2. Gesetz über die Aufgaben und Befugnisse der Ordnungsbehörden } \\
\text { (Ordnungsbehördengesetz - ThürOBG) } \\
\text { 3. Gesetz über die Organisation der Polizei des Landes Thüringen } \\
\text { (Polizeiorganisationsgesetz - ThürPOG) }\end{array}$ \\
\hline
\end{tabular}

Examenswissen: Die Polizei- und Ordnungsgesetze sind zuletzt in mehreren Ländern Gegenstand von Reformen gewesen, die insbesondere der Erweiterung der polizei- und ordnungsbehördlichen Befugnisse dienten (zur Gefahr einer „Entgrenzung“ des Polizeirechts s. Rn. 1025). In Bayern ist etwa erstmals der Begriff der „drohenden Gefahr“ (dazu noch Rn. 1116) eingeführt worden. ${ }^{1836}$ Auch in Brandenburg sind Befugnisse erweitert worden. ${ }^{1837}$ Gleiches gilt für Mecklenburg-Vorpommern, ${ }^{1838}$ Hessen, ${ }^{1839}$ Nordrhein-Westfalen, ${ }^{1840}$ Niedersachsen, ${ }^{1841}$ Sachsen-Anhalt ${ }^{1842}$ und

1836 Gegenstand der Auseinandersetzungen ist das Gesetz zur effektiveren Überwachung gefährlicher Personen, GVBl. 2017, 388; näher dazu Schmid/Wenner, BayVBl. 2019, 109; Weinrich, NVwZ 2018, 1680; Waechter, NVwZ 2018, 458; Möstl, BayVBl. 2018, 156; Müller, BayVBl. 2018, 109. 1837 Zwölftes Gesetz zur Änderung des Brandenburgischen Polizeigesetzes v. 1.4. 2019, GVBl. I 2019, Nr. 3.

1838 Sechstes Gesetz zur Änderung des Sicherheits- und Ordnungsgesetzes v. 22.3.2018, GVBl. S. 114 .

1839 Art. 3 des Gesetzes zur Neuausrichtung des Verfassungsschutzes in Hessen. v. 25.6.2018, GVBl. S. 302.

\section{Nikolas Eisentraut}


Sachsen ${ }^{1843}$, wo u.a. Body-Cams (dazu Rn. 1048) sowie die automatische Erfassung von Autokennzeichnen (dazu Rn. 1048) eingeführt wurden; Eine Kennzeichnungspflicht für Polizisten (dazu Rn. 1026) wurde hingegen nicht eingeführt. ${ }^{1844}$

Neben diesen allgemeinen Gesetzen bestehen spezielle Vorschriften, die das 1013 Recht der Gefahrenabwehr nur für einen bestimmten Sektor regeln. Sie werden als besonderes Gefahrenabwehrrecht bezeichnet. ${ }^{1845}$ Die Unterscheidung spielt aufgrund des Vorrangs spezieller Ermächtigungsgrundlagen vor den Ermächtigungsgrundlagen des allgemeinen Polizei- und Ordnungsrechts eine noch unter „Ermächtigungsgrundlage“ (s. Rn. 1036) zu vertiefende Rolle.

Zum prüfungsrelevanten besonderen Gefahrenabwehrrecht zählt insbeson- 1014 dere das Versammlungsrecht (s. näher Rn. 1037 ff.) und das Bauordnungsrecht (s. näher Rn. 1042).

Examenswissen: Dem besonderen Gefahrenabwehrrecht wird darüber hinaus eine Vielzahl an Verwaltungsbereichen zugeordnet, die zwar in den Ausbildungsordnungen nicht zum Prüfungsgegenstand gemacht werden. Da in Prüfungsarbeiten aber auch unbekannte Normen eine Rolle spielen können (s. § 1 Rn. 19), ist es nicht schädlich, einen Überblick zu haben. Insbesondere dem Gewerberecht ${ }^{1846}$ kommt Bedeutung als besonderes Gefahrenabwehrrecht zu. Aber beispielsweise auch im Luftrecht spielt Gefahrenabwehr eine Rolle. ${ }^{1847}$

\section{bb) Die Unterscheidung zwischen Landes- und Bundesbehörden}

Das allgemeine Polizei- und Ordnungsrecht wird von den Polizei- und Ord- 1016 nungsbehörden der Länder vollzogen. ${ }^{1848}$ Auch die in Klausuren relevanten Bereiche des besonderen Polizei- und Ordnungsrechts wie das Versammlungs-

1840 Gesetz zur Stärkung der Sicherheit in Nordrhein-Westfalen - Sechstes Gesetz zur Änderung des Polizeigesetzes des Landes Nordrhein-Westfalen v. 13.12.2018, GV. NRW. S. 638; näher dazu Coelln/Pernice-Warnke/Pützer/Reisch, NWVBl. 2019, 89; Ullrich/Walter/Zimmermann, NWVBl. 2019, 98; Thiel, NWVBl. 2018, 50.

1841 Gesetz zur Änderung des Niedersächsischen Gesetzes über die öffentliche Sicherheit und Ordnung und anderer Gesetze v. 20.5.2019, GVBl. S. 88.

1842 Siebentes Gesetz zur Änderung des Gesetzes über die öffentliche Sicherheit und Ordnung des Landes Sachsen-Anhalt v. 18.10.2018, GVBl. S. 376 (kein Onlineangebot).

1843 Gesetz zur Neustrukturierung des Polizeirechtes des Freistaates Sachsen v. 11. Mai 2019, SächsGVBl. S. 358.

1844 Bereits der Referentenentwurf war Gegenstand von Kritik, so u.a. in einer Stellungnahme von Amnesty International v. 8.11.2018.

1845 Schenke, Polizei- und Ordnungsrecht, 10. Aufl. 2018, Rn. 21.

1846 Näher dazu Schenke, Polizei- und Ordnungsrecht, 10. Aufl. 2018, Rn. 21.

1847 Dazu Kaienburg, JA 2019, 119.

1848 Schenke, Polizei- und Ordnungsrecht, 10. Aufl. 2018, Rn. 437; Kingreen/Poscher, Polizeiund Ordnungsrecht mit Versammlungsrecht, 10. Aufl. 2018, § 2 Rn. 33. 
und Bauordnungsrecht werden durch die Landesbehörden vollzogen. Dies gilt im Grundsatz auch dann, wenn es sich um Bundesrecht handelt (etwa das Versammlungsgesetz des Bundes), s. Art. 83 GG. ${ }^{1849} 12$ Bundesländer haben dafür das sog. Trennungssystem realisiert (s. näher Rn. 1066): Polizeibehörden ${ }^{1850}$ und Ordnungsbehörden ${ }^{1851}$ sind danach organisatorisch getrennt (sog. „Entpolizeilichung“1852). Während die Polizei Gefahrenabwehr „am Ort des Geschehens“ betreibt, ist die Tätigkeit der Ordnungsbehörden durch die Tätigkeit „am Schreibtisch“ gekennzeichnet. ${ }^{1853} 4$ Bundesländer (Baden-Württemberg, Bremen, Saarland und Sachsen) haben hingegen das sog. Einheitssystem realisiert (s. auch Rn. 1067): Hier sind die Polizeibehörden den Behörden der allgemeinen Landesverwaltung zugeordnet; Indes wird auch in diesen Ländern zwischen Polizeivollzugsdienst und allgemeinen Polizeibehörden unterschieden. ${ }^{1854}$

1017 Hausarbeitswissen: Daneben nehmen auch Bundesbehörden auf Grundlage der bereichsspezifischen Gesetzgebungskompetenzen des Bundes Aufgaben der Gefahrenabwehr wahr. Dazu zählt zunächst die Bundespolizei, die auf Grundlage des BPolG handelt. ${ }^{1855}$ Weiterhin nimmt das Bundeskriminalamt, das auf Grundlage des BKA-Gesetzes tätig wird, wichtige Aufgaben der Gefahrenabwehr im Bereich des internationalen Terrorismus wahr. ${ }^{1856}$ Auf europäischer Ebene entstehen darüber hinaus zunehmend Strukturen der Zusammenarbeit bei der (grenzüberschreitenden) Gefahrenabwehr. ${ }^{1857}$ Insgesamt lassen sich „Zentralisierungstendenzen“ beobachten, wonach Kompetenzen auf immer höhere Ebenen verlagert werden (sollen). ${ }^{1858}$ Eine absolute Grenze dieser

1849 Kingreen/Poscher, Polizei- und Ordnungsrecht mit Versammlungsrecht, 10. Aufl. 2018, § 2 Rn. 36.

1850 Einen Überblick über die Polizeibehörden der einzelnen Bundesländer findet sich bei Götz/ Geis, Allgemeines Polizei- und Ordnungsrecht, 16. Aufl. 2017, § 20 Rn. 8.

1851 Einen Überblick über die allgemeinen Behörden der Gefahrenabwehr der einzelnen Bundesländer findet sich bei Götz/Geis, Allgemeines Polizei- und Ordnungsrecht, 16. Aufl. 2017, § 20 Rn. 17; zum „Ordnungsrecht“ als selbstständiges Rechtsgebiet Peters/Rind, LKV 2017, 251.

1852 Schenke, Polizei- und Ordnungsrecht, 10. Aufl. 2018, Rn. 449.

1853 Kingreen/Poscher, Polizei- und Ordnungsrecht mit Versammlungsrecht, 10. Aufl. 2018, § 2 Rn. 25.

1854 Götz/Geis, Allgemeines Polizei- und Ordnungsrecht, 16. Aufl. 2017, § 20 Rn. 14; zum Einheitssystem auch näher Schenke, Polizei- und Ordnungsrecht, 10. Aufl. 2018, Rn. 447 f.

1855 Näher Schoch, in: Schoch, Besonderes Verwaltungsrecht, 2018, Kapitel 1 Rn. $94 \mathrm{ff}$.

1856 Näher Schoch, in: Schoch, Besonderes Verwaltungsrecht, 2018, Kapitel 1 Rn. $98 \mathrm{ff}$.; Rn. $102 \mathrm{ff}$. auch zu den weiteren Verwaltungskompetenzen des Bundes.

1857 Näher Schoch, in: Schoch, Besonderes Verwaltungsrecht, 2018, Kapitel 1 Rn. $155 \mathrm{ff}$;; Rn. $181 \mathrm{ff}$. auch zur Internationalisierung; zur „Europäisierungs- und Inernationalisierungstendenz" auch Kingreen/Poscher, Polizei- und Ordnungsrecht mit Versammlungsrecht, 10. Aufl. 2018, § 1 Rn. 35f.

1858 Kingreen/Poscher, Polizei- und Ordnungsrecht mit Versammlungsrecht, 10. Aufl. 2018, § 1 Rn. 33.

\section{Nikolas Eisentraut}


Zentralisierung wird im Verbot der Schaffung einer allgemeinen Bundespolizei gesehen. ${ }^{1859}$ Aufgrund der Klausurrelevanz konzentriert sich die folgende Darstellung jedoch auf die Gefahrenabwehr durch Landesbehörden nach den jeweiligen allgemeinen Polizei- und Ordnungsgesetzen.

\section{cc) Abgrenzung zum Recht der Strafverfolgung}

Die Gefahrenabwehr ist abzugrenzen von der Strafverfolgung. ${ }^{1860}$ Während das 1018 Gefahrenabwehrrecht präventiv auf die Verhinderung einer Gefahr ausgerichtet ist, regelt das Strafverfolgungsrecht das repressive, sich an eine bereits geschehene Straftat anschließende polizeiliche Handeln. ${ }^{1861}$ Der Unterscheidung kommt in der Klausur bereits bei der Frage der Eröffnung des Verwaltungsrechtswegs zentrale Bedeutung zu (s. § 1 Rn. 218), denn die gerichtliche Kontrolle repressiver polizeilicher Maßnahmen ist nicht den Verwaltungsgerichten, sondern der ordentlichen Gerichtsbarkeit zugewiesen (§ 23 EGGVG). In der Klausur ist daher bereits bei der Frage der Eröffnung des Verwaltungsrechtswegs zu problematisieren, ob die streitgegenständliche Maßnahme repressiven (dann: abdrängende Sonderzuweisung an die ordentlichen Gerichte) oder präventiven Charakter (dann: keine abdrängende Sonderzuweisung) hat.

Eine besondere Problematik in diesem Kontext stellen die sog. „doppel- 1019 funktionalen Maßnahmen“1862 dar. Bei diesen Maßnahmen kommt es zu einer Überschneidung zwischen Gefahrenabwehr- und Strafverfolgungsmaßnahme.

Beispiel: Dies wäre etwa der Fall, wenn eine bei einem Straftäter durchgeführte Identitätsfeststellung sowohl auf die Verfolgung der bereits begangenen Straftat als auch auf die Abwehr künftiger Straftatbegehungen gerichtet wäre.

Mit der wohl überwiegenden Auffassung ist in einem solchen Fall auf den Schwerpunkt der Maßnahme abzustellen; falls ein solcher nicht erkennbar ist, soll dem Gefahrenabwehrrecht Vorrang einzuräumen sein. ${ }^{1863}$

1859 Kingreen/Poscher, Polizei- und Ordnungsrecht mit Versammlungsrecht, 10. Aufl. 2018, § 2 Rn. 40.

1860 Näher Kingreen/Poscher, Polizei- und Ordnungsrecht mit Versammlungsrecht, 10. Aufl. 2018, § 2 Rn. 5 ff.

1861 Schoch, in: Schoch, Besonderes Verwaltungsrecht, 2018, Kapitel 1 Rn. 15f.; „der Anfangsverdacht markiert den Beginn der Strafverfolgung (§152 II StPO)“, Schoch, in: Schoch, Besonderes Verwaltungsrecht, 2018, Kapitel 1 Rn. 20.

1862 Übergreifend zur Thematik doppelfunktionaler Maßnahmen in der öffentlich-rechtlichen Klausur Danne, JuS 2018, 434.

1863 Schoch, in: Schoch, Besonderes Verwaltungsrecht, 2018, Kapitel 1 Rn. 20; Kingreen/Poscher, Polizei- und Ordnungsrecht mit Versammlungsrecht, 10. Aufl. 2018, § 2 Rn. 14.

Nikolas Eisentraut 
1020 Examenswissen: Das Meinungsbild ist vielschichtig. Teilweise wird bei doppelfunktionalen Maßnahmen auch ein Nebeneinander beider Ermächtigungsgrundlagen und damit auch der Rechtswege (§ 17 II 1 GVG) für möglich gehalten; es genüge, wenn die Voraussetzungen einer Ermächtigungsgrundlage erfüllt seien. ${ }^{1864} \mathrm{Nach}$ a.A. müssen bei „echten“ doppelfunktionalen Maßnahmen (also solchen, die nicht in mehrere, jeweils für sich zu beurteilende Maßnahmen aufgespalten werden können ${ }^{1865}$ ) hingegen die Voraussetzungen beider Ermächtigungsgrundlagen vorliegen. ${ }^{1866}$

1021 Darüber hinaus ist die Unterscheidung deshalb wichtig, weil die Gesetzgebungskompetenz im Bereich der Strafverfolgung der konkurrierenden Gesetzgebungskompetenz und damit im Wesentlichen dem Bund zu gewiesen ist, Art. 74 I Nr. 1 GG. ${ }^{1867}$ In diesen Bereichen bleibt den Ländern daher nur dann noch eine Regelungsbefugnis, wenn der Bund keine abschließenden Regelungen getroffen hat (näher zu dieser Problematik im Bereich der Strafverfolgungsvorsorge Rn. 1027).

\section{dd) Abgrenzung zum Recht der Nachrichtendienste und des Verfassungsschutzes}

1022 Der präventiven Tätigkeit der Gefahrenabwehrbehörden vorgelagert ist die Tätigkeit der Nachrichtendienste und Verfassungsschutzbehörden, da sie insbesondere Informationen im Vorfeld konkreter Gefahrenlagen beschaffen. ${ }^{1868}$

1023 Hausarbeitswissen: Indes sind Tendenzen einer „Entgrenzung“ des Rechts der Nachrichtendienste erkennbar (zu diesem Begriff sogleich noch Rn. 1024f.), ${ }^{1869}$ die zu einer Ausdehnung des Rechts der Nachrichtendienste in Bereiche polizei- und ordnungsbehördlicher Befugnisse führt. Eine verfassungsrechtliche Grenze zwischen Nachrichtendiensten und Polizei- bzw. Ordnungsbehörden wird teilweise im sog. Trennungsgebot gesehen. ${ }^{1870}$

1864 M.w.N. zu dieser Ansicht Kingreen/Poscher, Polizei- und Ordnungsrecht mit Versammlungsrecht, 10. Aufl. 2018, § 2 Rn. 14.

1865 Näher Schoch, in: Schoch, Besonderes Verwaltungsrecht, 2018, Kapitel 1 Rn. 21.

1866 Schoch, in: Schoch, Besonderes Verwaltungsrecht, 2018, Kapitel 1 Rn. 21.

1867 S. auch Schoch, in: Schoch, Besonderes Verwaltungsrecht, 2018, Kapitel 1 Rn. 17.

1868 Näher zu den Nachrichtendiensten und zum Trennungsprinzip Schoch, in: Schoch, Besonderes Verwaltungsrecht, 2018, Kapitel 1 Rn. 30 ff.; s. auch Kingreen/Poscher, Polizei- und Ordnungsrecht mit Versammlungsrecht, 10. Aufl. 2018, § 2 Rn. $15 \mathrm{ff}$.

1869 So sorgte zuletzt ein Referentenentwurf des Bundesinnenministeriums zur Harmonisierung des Verfassungsschutzrechts für Kontroversen, in dem eine Kompetenzausweitung des Bundesnachrichtendienstes vorgesehen war; der Entwurf wurde auf netzpolitik.org veröffentlicht.

1870 Dazu Schoch, in: Schoch, Besonderes Verwaltungsrecht, 2018, Kapitel 1 Rn. 31 f.

\section{Nikolas Eisentraut}




\section{ee) Gefahrenabwehr im weiteren Sinne: Gefahrenvorsorge vs. Strafverfolgungsvorsorge}

Gefahrenabwehr bildet den Ausgangspunkt jeden polizei- und ordnungsbehördlichen Handelns. ${ }^{1871}$ Dabei bildet die konkrete Gefahr die „traditionelle Eingriffsschwelle im Polizeirecht“"1872. Gefahrenabwehr findet jedoch teilweise bereits im Vorfeld konkreter Gefahren statt: mit der sog. Gefahrenvorsorge soll bereits das Eintreten einer konkreten Gefahrensituation verhindert werden. ${ }^{1873}$ Zur Gefahrenvorsorge zählen Maßnahmen zur Verhütung von Straftaten, wozu insbesondere Überwachungsmaßnahmen (sog. Gefahrerforschungseingriffe) zählen. Darüber hinaus können die im bayerischen Polizeirecht realisierten Eingriffstatbestände bei sog. „drohender Gefahr“ (dazu noch näher Rn. 1116) aber auch zu Präventivhaft führen.

Examenswissen: Diese voranschreitende „Entgrenzung“ des Gefahrenabwehrrechts bedarf 1025 unter rechtsstaatlichen Gesichtspunkten einer kritischen Begleitung. ${ }^{1874}$ Die Entgrenzung des Gefahrenabwehrrechts ist nur im Rahmen des rechtsstaatlichen Korsetts möglich, das sich aus Vorrang und Vorbehalt des Gesetzes speist. ${ }^{1875}$ Die Staatsaufgabe der Gewährleistung von Sicherheit (s. bereits Rn. 1009) bewegt sich deshalb stets in einer Spannungslage zu den verfassungsrechtlichen Grenzen eines staatlichen Zugriffs auf persönliche Freiheiten. ${ }^{1876}$ Über das einfache Recht hinaus berühren eingreifende Maßnahmen der Polizei- und Ordnungsbehörden neben der allgemeinen Handlungsfreiheit eine Vielzahl spezieller Grundrechte, die die Auslegung des einfachen Rechts beeinflussen und in verwaltungsrechtlichen Prüfungsarbeiten insbesondere im Rahmen der Verhältnismäßigkeit polizeilicher Maßnahmen eine Rolle spielen können.

Beispiele: Die Durchsuchung von Wohnraum berührt das Grundrecht auf die Unverletzlichkeit der Wohnung aus Art. 13 GG; Freiheitsentziehende Maßnahmen berühren das grundrechts-

1871 Kingreen/Poscher, Polizei- und Ordnungsrecht mit Versammlungsrecht, 10. Aufl. 2018, § 3 Rn. $11 \mathrm{f}$.

1872 Trurnit, JURA 2019, 258 (262).

1873 Schoch, in: Schoch, Besonderes Verwaltungsrecht, 2018, Kapitel 1 Rn. 11; Kingreen/Poscher, Polizei- und Ordnungsrecht mit Versammlungsrecht, 10. Aufl. 2018, §1 Rn. 32; BVerwG, Urt. v. 25.1.2012, Az.: 6 C 9.11 = BVerwGE 141, 329 = NVwZ 2012, 757; dazu Siegel, NVwZ 2012, 738 und Waldhoff, JuS 2013, 94.

1874 Zum Begriff der Entgrenzung grundlegend Thiel, Die „Entgrenzung“ der Gefahrenabwehr, 2011; m.w. N. Schoch, in: Schoch, Besonderes Verwaltungsrecht, 2018, Kapitel 1 Rn. 13; Baldus, Die Verw 47 (2014), 1; Gutachten des Wissenschaftlichen Dienstes des Bundestages WD 33000 226/18 v. 27.7.2018: „Ausweitung polizeilicher Befugnisse in Deutschland und Europa“.

1875 Schoch, in: Schoch, Besonderes Verwaltungsrecht, 2018, Kapitel 1 Rn. 187 f.; umfassend zu den rechtsstaatlichen und demokratischen Grundlagen der Polizeiarbeit Denninger, in: Lisken/ Denninger, Handbuch des Polizeirechts, 6. Aufl. 2018, B., Rn. $24 \mathrm{ff}$.

1876 Becker, NVwZ 2015, 1335. 
gleiche Recht aus Art. 104 GG; ${ }^{1877}$ Überwachungsmaßnahmen berühren das Recht auf informationelle Selbstbestimmung (Art. 2 I i. V.m. Art. 1 I GG), das Fernmeldegeheimnis aus Art. 10 GG und das Grundrecht auf Gewährleistung der Vertraulichkeit und Integrität informationstechnischer Systeme. ${ }^{1878}$

1026 Hausarbeitswissen: Darüber hinaus werden auch ganz konkrete Maßnahmen diskutiert, um die Rechtsstaatlichkeit polizeilichen Handelns sicherzustellen. Gegenstand fortwährenden Streits ist die Frage, ob Polizeivollzugsbeamte einer Kennzeichnungspflicht unterliegen sollten. ${ }^{1879}$ Der damit einhergehende Eingriff in das Recht der Polizisten auf informationelle Selbstbestimmung wird vom BVerwG als gerechtfertigt angesehen. ${ }^{1880}$ Auch die Nutzung von sozialen Netzwerken durch Polizeiund Ordnungsbehörden wird in Hinblick auf ihre Grenzen untersucht. ${ }^{1881}$

1027 Zum Bereich der vorbeugenden Bekämpfung von Straftaten wird einerseits die Verhütung von Straftaten gezählt, andererseits die sog. Strafverfolgungsvorsorge. ${ }^{1882}$ Die Verhütung zielt darauf ab, dass Straftaten schon gar nicht passieren; Die Vorsorge dient hingegen dazu, im Falle trotzdem passierender Straftaten die Strafverfolgung zu vereinfachen. ${ }^{1883}$ Während die Verhütung der Gefahrenabwehr zugerechnet wird und damit in die Länderkompetenz fällt, wird die Strafverfolgungsvorsorge der Bundeskompetenz nach Art. 74 I Nr. 1 GG zugerechnet. ${ }^{1884}$

Examenswissen: Dies führt im Einzelfall zu schwierigen Abgrenzungsfragen. So musste sich das BVerwG etwa mit der Frage auseinandersetzen, ob die landesgesetzlich angeordnete Videobeobachtung auf der Hamburger Reeperbahn als Maßnahme der Gefahrenvorsorge (Verhütung von Straftaten) oder als Strafverfolgungsvorsorge zu qualifizieren sei. Da die Videoüberwachung beide Varianten erfülle, handele es sich um eine doppelfunktionale Maßnahme. Indes ergebe sich aus der konkurrierenden Bundeskompetenz für die Strafverfolgungsvorsorge keine Sperrwirkung in Bereichen, in denen der Bund keine abschließende Regelung erlassen habe. ${ }^{1885}$

1877 Beispiele nach Siegel, in: Siegel/Waldhoff, Öffentliches Recht für Berlin, 2. Aufl. 2017, § 2 Rn. 10.

1878 Näher Becker, NVwZ 2015, 1335; Zu den Auswirkungen des BKAG-Urteils des BVerfG auf das allgemeine Persönlichkeitsrecht Dürr, JA 2019, 432.

1879 Dazu näher Guckelberger, DÖV 2018, 421 und Daimagüler, NVwZ 2018, 1530; Knaust, DVBl 2017, 876.

1880 So für die Kennzeichnungspflicht für Polizeivollzugsbeamte in Brandenburg BVerwG, Urt.v. 26.9.2019, Az.: BVerwG 2 C 32.18.

1881 Näher Milker, NVwZ 2018, 1751; Ingold, VerwArch 2017, 240.

1882 Näher dazu Schoch, in: Schoch, Besonderes Verwaltungsrecht, 2018, Kapitel 1 Rn. 23 ff. 1883 Kingreen/Poscher, Polizei- und Ordnungsrecht mit Versammlungsrecht, 10. Aufl. 2018, § 2 Rn. 4.

1884 Kingreen/Poscher, Polizei- und Ordnungsrecht mit Versammlungsrecht, 10. Aufl. 2018, § 2 Rn. 5.

1885 BVerwG, Urt. v. 25.1.2012, Az.: 6 C 9.11 = BVerwGE 141, 329 = NVwZ 2012, 757; dazu Siegel, NVwZ 2012, 738 und Waldhoff, JuS 2013, 94.

\section{Nikolas Eisentraut}




\section{b) Prüfungsstruktur im Überblick}

Die Prüfung der Rechtmäßigkeit einer Ordnungsverfügung im Rahmen der An- 1028 fechtungsklage richtet sich nach dem klassischen Prüfungsschema für Verwaltungsakte (s. bereits Rn. 518ff.). Ein erster Schwerpunkt liegt auf der Ermittlung der einschlägigen Ermächtigungsgrundlage (s. näher sogleich Rn. 1029). Im Rahmen der formellen Rechtmäßigkeit sind die Prüfungspunkte Zuständigkeit, Verfahren und Form zu behandeln (s. näher sogleich Rn. 1062ff.). Im Rahmen der materiellen Rechtmäßigkeit sind die materiellen Voraussetzungen der einschlägigen Ermächtigungsgrundlage zu prüfen und die Rechtsfolge der Ermächtigungsgrundlage zu thematisieren (s. näher sogleich Rn. 1079).

\section{c) Ermächtigungsgrundlage}

Aufgrund des Vorbehalts des Gesetzes erfordern in Grundrechte eingreifende 1029 Gefahrenabwehrmaßnahmen stets das Vorliegen einer Ermächtigungsgrundlage (näher zum Erfordernis einer Ermächtigungsgrundlage Rn. 554 ff.). ${ }^{1886}$ Es reicht also nicht, dass die Polizei- und Ordnungsbehörden generell für die Aufgabe der Gefahrenabwehr zuständig sind. ${ }^{1887}$ Die konkrete Maßnahme muss auch auf Grundlage und unter Einhaltung der Voraussetzungen der jeweils einschlägigen Ermächtigungsgrundlage (auch Befugnisnorm genannt) vorgenommen werden.

In polizeirechtlichen Klausuren besteht neben der prozessualen Einklei- 1030 dung eine zentrale Aufgabe darin, die in Betracht kommenden Ermächtigungsgrundlagen zu erkennen und ordnungsgemäß zu prüfen.

Bevor auf die Ermächtigungsgrundlagen der allgemeinen Polizei- und Ord- 1031 nungsgesetze eingegangen werden kann, ist zunächst zu untersuchen, ob es spezialgesetzliche Befugnisse gibt, die die Ermächtigungsgrundlagen des allgemeinen Polizei- und Ordnungsrechts verdrängen können. ${ }^{1888}$

Findet sich keine spezialgesetzliche Befugnis, können die Ermächtigungs- 1032 grundlagen der allgemeinen Polizei- und Ordnungsgesetze herangezogen werden. Auch hier muss wieder differenziert werden: Alle allgemeinen Polizei- und Ordnungsgesetze unterscheiden zwischen General- und Spezialermächtigun-

1886 Schenke, Polizei- und Ordnungsrecht, 10. Aufl. 2018, Rn. 36f.; Schoch, in: Schoch, Besonderes Verwaltungsrecht, 2018, Kapitel 1 Rn. $187 \mathrm{f}$; Kingreen/Poscher, Polizei- und Ordnungsrecht mit Versammlungsrecht, 10. Aufl. 2018, § 2 Rn. 43.

1887 Sog. Trennung von Aufgabe, Zuständigkeit und Befugnis, näher dazu Schenke, Polizei- und Ordnungsrecht, 10. Aufl. 2018, Rn. 36; Schoch, in: Schoch, Besonderes Verwaltungsrecht, 2018, Kapitel 1 Rn. 189f.; Siegel/Waldhoff, Öffentliches Recht für Berlin, 2. Aufl. 2017, § 2 Rn. $131 \mathrm{ff}$. 1888 Kingreen/Poscher, Polizei- und Ordnungsrecht mit Versammlungsrecht, 10. Aufl. 2018, § 3 Rn. 25. 
gen. ${ }^{1889}$ Zur Erfüllung bestimmter Aufgaben der Gefahrenabwehr (den sog. Standardmaßnahmen) wurden spezielle Ermächtigungsgrundlagen geschaffen (sog. Standardbefugnisse). Als Auffangtatbestand findet sich daneben eine Generalklausel, die subsidiär zur Anwendung kommen kann, falls keine der Standardbefugnisse einschlägig ist.

1033 Schließlich kann schon im Rahmen der Suche nach der tauglichen Ermächtigungsgrundlage berücksichtigt werden, ob die Norm auch die konkret handelnde Behörde ermächtigt. In Ländern mit Trennungsprinzip (näher dazu Rn. 1066) stellt sich regelmäßig die Frage, ob die Befugnisnorm für die Polizei oder die Befugnisnorm für die Ordnungsbehörde einschlägig ist. ${ }^{1890}$

1034 Dieses „Nebeneinander“ macht es in polizeirechtlichen Klausuren oftmals erforderlich, sich zunächst genau mit der Frage auseinanderzusetzen, welche Ermächtigungsgrundlage eigentlich die Richtige ist. ${ }^{1891}$

1035 Examenswissen: Ausnahmsweise kann sich die Ermächtigungsgrundlage auch in einer Gefahrenabwehrverordnung finden. Denn auch Verordnungen genügen dem Vorbehalt des Gesetzes (s. Rn. 561). In Klausuren wäre eine solche regelmäßig als Annex zum Sachverhalt abgedruckt. Es kann dann erforderlich sein, die Verordnung selbst auf ihre Rechtmäßigkeit zu untersuchen (dazu noch näher $\S 7$ Rn. 109 ff.).

\section{aa) Abgrenzung gegenüber Befugnissen des besonderen Gefahrenabwehrrechts}

1036 Bevor die Ermächtigungsgrundlagen des allgemeinen Polizei- und Ordnungsrechts in Betracht gezogen werden, ist zunächst die Frage aufzuwerfen, ob speziellere Normen deren Anwendbarkeit sperren (sog. Spezialbefugnisse) ${ }^{1892}$

\section{(1) Versammlungsrecht}

1037 Besondere Bedeutung kommt dabei zunächst den Ermächtigungsgrundlagen des Versammlungsrechts zu (näher zum Versammlungsrecht Rn. 1141ff.). Die Sperrwirkung des Versammlungsrechts gegenüber dem allgemeinen Polizei- und Ordnungsrecht nennt man „Polizeifestigkeit des Versammlungsrechts“ (s. dazu auch Rn. 1162ff.). Dies bedeutet, dass den versammlungsrechtlichen Eingriffsbefugnissen Vorrang vor denen des allgemeinen Polizei- und Ordnungs-

1889 Schenke, Polizei- und Ordnungsrecht, 10. Aufl. 2018, Rn. 38.

1890 Poscher/Rustenberg, JuS 2011, 888 (890f.).

1891 Siegel, in: Siegel/Waldhoff, Öffentliches Recht für Berlin, 2. Aufl. 2017, § 2 Rn. 134.

1892 Schoch, in: Schoch, Besonderes Verwaltungsrecht, 2018, Kapitel 1 Rn. 196.

Nikolas Eisentraut 
rechts zukommt und letztere "gesperrt“ sind. ${ }^{1893}$ Die genaue Reichweite der Sperrwirkung ist jedoch umstritten: Auch wenn die Ermächtigungsgrundlagen des allgemeinen Polizei- und Ordnungsrechts durch das Versammlungsrecht gesperrt werden, können dessen Vorschriften nämlich lückenfüllend heranzuziehen sein, beispielsweise für die Frage der Bestimmung des richtigen Adressaten. ${ }^{1894}$ Die Abgrenzung ist auch deshalb wichtig, weil das Versammlungsrecht höhere Anforderungen an Eingriffe stellt, als dies die allgemeinen Polizeigesetze tun. ${ }^{1895}$

Die h.M. hält die Regelungen des Versammlungsrechts nur dann für ab- 1038 schließend, wenn es um „versammlungsspezifische Gefahren“ geht. ${ }^{1896}$ Im Einzelnen können drei Zeitpunkte unterschieden werden: 1. Maßnahmen im Vorfeld einer Versammlung, 2. Maßnahmen während einer Versammlung und 3. Maßnahmen nach der Versammlung.

1. Das VersG des Bundes enthält keine Regelungen für Vorfeldmaßnahmen. 1039 Die h.M. möchte daher den Rückgriff auf die allgemeinen Polizei- und Ordnungsgesetze erlauben, etwa um Personenkontrollen bei der Anreise zur Versammlung und Durchsuchungen sowie Beschlagnahmen $\mathrm{zu}$ ermöglichen; $\mathrm{Zu}$ Maßnahmen im Vorfeld einer Versammlung zählen auch die Meldeauflage und die Gefährderansprache (s. dazu die Rn. 1049, 1055, 1163 und § 5 Rn. 224, 234). ${ }^{1897}$ Soweit mit den Maßnahmen jedoch versammlungsspezifische Gefahren abgewehrt werden sollen, gerät der Rückgriff auf das allgemeine Polizei- und Ordnungsrecht in Konflikt mit dem Zitiergebot des Art. 19 I 2 GG, da ein Eingriff in Art. 8 I GG in Rede steht. Soweit man dennoch mit der h.M. von der Anwendbarkeit der allgemeinen Polizei- und Ordnungsgesetze ausgeht, müssen diese zumindest verfassungskonform ausgelegt werden. ${ }^{1898}$

2. Während der Versammlung ist der Rückgriff auf das allgemeine Polizei- 1040 und Ordnungsrecht gesperrt. Indes sollen nach h.M. unter Rückgriff auf die Ermächtigungsgrundlagen des Versammlungsrechts sog. Minusmaßnahmen möglich sein. ${ }^{1899} \S 15$ III VersG des Bundes ermöglicht danach nicht nur Versammlungsauflösungen, sondern im Sinne einer Generalklausel sämtliche weniger eingriffsintensiven Maßnahmen. ${ }^{1900}$

1893 Bünnigmann, JuS 2016, 695.

1894 Schoch, in: Schoch, Besonderes Verwaltungsrecht, 2018, Kapitel 1 Rn. 222; Siegel, in: Siegel/Waldhoff, Öffentliches Recht für Berlin, 2. Aufl. 2017, § 2 Rn. 135.

1895 Schoch, in: Schoch, Besonderes Verwaltungsrecht, 2018, Kapitel 1 Rn. 210.

1896 Schoch, in: Schoch, Besonderes Verwaltungsrecht, 2018, Kapitel 1 Rn. 217.

1897 Schoch, in: Schoch, Besonderes Verwaltungsrecht, 2018, Kapitel 1 Rn. $218 \mathrm{ff}$.

1898 Bünnigmann, JuS 2016, 695 (697).

1899 Schoch, in: Schoch, Besonderes Verwaltungsrecht, 2018, Kapitel 1 Rn. 221.

1900 Schoch, in: Schoch, Besonderes Verwaltungsrecht, 2018, Kapitel 1 Rn. 221.

Nikolas Eisentraut 
3. Bei Maßnahmen nach der Versammlung greift die Sperrwirkung des Versammlungsrechts nicht mehr, der Anwendungsbereich des allgemeinen Polizei- und Ordnungsrechts ist also wieder eröffnet; Dabei ist es unerheblich, ob die Versammlung durch die Polizei aufgelöst wurde oder ob sich die Teilnehmer`innen nach Durchführung einfach wieder zerstreuen. ${ }^{1901}$

\section{(2) Bauordnungsrecht}

1042 Speziellere Ermächtigungsgrundlagen finden sich zudem im Bauordnungsrecht. Die in den Bauordnungen enthaltenen Ermächtigungsgrundlagen für Abrissverfügungen, Nutzungsuntersagungen und Stilllegungsverfügungen (näher dazu Rn. 1234 ff.) gehen den Ermächtigungsgrundlagen des allgemeinen Polizei- und Ordnungsrechts vor.

\section{(3) Weitere Rechtsbereiche}

1043 In vielen weiteren Rechtsbereichen gibt es Beispiele für Spezialermächtigungen. ${ }^{1902}$ Auch das Gewerberecht sperrt in bestimmten Teilen die Ermächtigungsgrundlagen des allgemeinen Polizei- und Ordnungsrechts. § 1 I GewO sperrt die Gesetzgebungskompetenz der Länder (Art. 74 I Nr. 11, 72 I GG) für die Frage des „ob“ einer gewerblichen Tätigkeit; Im Bereich der Ausübung des Gewerbes („wie“) kann jedoch Landesordnungsrecht zum Tragen kommen. ${ }^{1903}$ Die Untersagung eines ohne erforderliche Zulassung betriebenen Gewerbes erfolgt daher auf Grundlage des § 15 I 2 GewO; da die Norm die Frage betrifft, „ob“ ein Gewerbe ausgeübt werden darf, sperrt sie den Rückgriff auf das landesrechtliche Gefahrenabwehrrecht. ${ }^{1904}$ Gleiches gilt für § 35 I 1 GewO bei der Gewerbeuntersagung wegen Unzuverlässigkeit. Ein Rückgriff auf das allgemeine Polizei- und Ordnungsrecht kommt hingegen bei Maßnahmen in Betracht, die die Ausübung des Gewerbes betreffen sowie bei eiligen bzw. vorläufigen Maßnahmen. ${ }^{1905}$

1901 Schoch, in: Schoch, Besonderes Verwaltungsrecht, 2018, Kapitel 1 Rn. 223.

1902 S. etwa § 24 BImSchG; weitere Beispiele bei Schoch, in: Schoch, Besonderes Verwaltungsrecht, 2018, Kapitel 1 Rn. $200 \mathrm{ff}$.

1903 Korte, in: Schmidt/Wollenschläger, Kompendium Öffentliches Wirtschaftsrecht, 4. Aufl. 2016, § 9 Rn. 39.

1904 Schoch, in: Schoch, Besonderes Verwaltungsrecht, 2018, Kapitel 1 Rn. 200 m.w. N.

1905 Korte, in: Schmidt/Wollenschläger, Kompendium Öffentliches Wirtschaftsrecht, 4. Aufl. 2016, § 9 Rn. 39. 


\section{bb) Abgrenzung zwischen Generalklausel(n) und Standardbefugnissen}

Ist keine Ermächtigungsgrundlage des besonderen Gefahrenabwehrrechts ein- 1044 schlägig, kommen die Ermächtigungsgrundlagen der allgemeinen Polizei- und Ordnungsgesetze in Betracht. Auch innerhalb des allgemeinen Polizei- und Ordnungsrechts bestehen Spezialitätsverhältnisse. Die sog. Generalklausel darf als Auffangtatbestand nur dann als Ermächtigungsgrundlage herangezogen werden, wenn nicht eine spezialgesetzliche Standardbefugnis die Voraussetzungen für den Eingriff normiert. ${ }^{1906}$

\section{(1) Die Standardbefugnisse}

Der Begriff der Standardbefugnisse bezeichnet häufig vorkommende und $\mathbf{1 0 4 5}$ deshalb vom Gesetzgeber in den allgemeinen Polizei- und Ordnungsgesetzen speziell geregelte Gefahrenabwehrmaßnahmen. ${ }^{1907}$

Unterschieden werden kann zwischen Gefahrenabwehrmaßnahmen, die auf 1046 eine Person oder Sache einwirken und Maßnahmen zur Datenerhebung und verarbeitung, die einen Bezug zu Daten aufweisen. Die Gruppierung der Standardbefugnisse variiert jedoch von Lehrbuch zu Lehrbuch.

\section{(a) Gefahrenabwehrmaßnahmen, die auf eine Person oder Sache einwirken} Für folgende auf eine Person oder Sache einwirkende Maßnahmen sind 1047 spezifische Ermächtigungsgrundlagen in den allgemeinen Polizei- und Ordnungsgesetzen kodifiziert worden:

- Platzverweisungen, ${ }^{1908}$ Aufenthaltsverbote ${ }^{1909}$ und Wohnungsverweisungen $^{1910}$, Kontaktverbote und elektronische Aufenthaltsüberwachung ${ }^{1911}$

- Ingewahrsamnahme ${ }^{1912}$

1906 Schoch, in: Schoch, Besonderes Verwaltungsrecht, 2018, Kapitel 1 Rn. 225 f.

1907 Schoch, in: Schoch, Besonderes Verwaltungsrecht, 2018, Kapitel 1 Rn. 225 spricht von wiederkehrenden, typisierbaren Handlungsmustern der Gefahrenabwehrbehörden; Kingreen/ Poscher, Polizei- und Ordnungsrecht mit Versammlungsrecht, 10. Aufl. 2018, § 11 Rn. 1 sprechen von Spezialbefugnissen.

1908 Näher Kingreen/Poscher, Polizei- und Ordnungsrecht mit Versammlungsrecht, 10. Aufl. 2018, § 15.

1909 Näher Kingreen/Poscher, Polizei- und Ordnungsrecht mit Versammlungsrecht, 10. Aufl. 2018, § 15; Benrath, DVBl 2017, 868; Eine Falllösung zu einem Aufenthaltsverbot findet sich bei Bretthauer, JURA 2018, 409 sowie bei Marxsen, JURA 2019, 105.

1910 Näher Kingreen/Poscher, Polizei- und Ordnungsrecht mit Versammlungsrecht, 10. Aufl. 2018, § 15; Seibert/Kohal, JURA 2019, 15. 
Examenswissen: Die Präventivhaft für Fußballhooligans war zuletzt Gegenstand einer Entscheidung des EGMR. ${ }^{1913}$

\section{- Sicherstellung und Beschlagnahme von Sachen ${ }^{1914}$}

Examenswissen: In Bremen und Hamburg ist die polizeiliche Unterbringung von Flüchtlingen spezialgesetzlich geregelt worden, während sie in anderen Bundesländern nur auf Grundlage der Generalklausel erfolgen kann. ${ }^{1915}$

- Verwertung, Einziehung und Vernichtung ${ }^{1916}$

- Durchsuchungen und Untersuchungen von Personen und Sachen ${ }^{1917}$ und das Betreten und die Durchsuchung von Wohnungen ${ }^{1918}$

\section{(b) Datenerhebung und Datenverarbeitung}

1048 Unter dem „Cluster“ Datenerhebung und Datenverarbeitung lässt sich eine Vielzahl an weiteren Standardbefugnissen zusammenfassen:

- Befragungen ${ }^{1919}$

- Identitätsfeststellungen ${ }^{1920}$

Examenswissen: Ein aktuell viel diskutiertes Thema im Kontext von Identitätsfeststellungen ist das sog. „racial profiling“, wenn beispielsweise der Eindruck entsteht, eine Identitätsfeststellung werde nur aufgrund der Hautfarbe durchgeführt. Die Anknüpfung an ein Merkmal des

1911 Näher Schenke, Polizei- und Ordnungsrecht, 10. Aufl. 2018, Rn. 139 f.; Guckelberger, DVBl 2017, 1121.

1912 Näher Schenke, Polizei- und Ordnungsrecht, 10. Aufl. 2018, Rn. 141 ff.; Kingreen/Poscher, Polizei- und Ordnungsrecht mit Versammlungsrecht, 10. Aufl. 2018, § 16.

1913 EGMR, Urt. v. 22.10.2018, Az.: 35553/12, 36678/12, 36711/12 (S, V u. A / Dänemark) = NVwZ 2019, 135 mit. Anm. Hoffmann.

1914 Näher Schenke, Polizei- und Ordnungsrecht, 10. Aufl. 2018, Rn. 158ff.; Kingreen/Poscher, Polizei- und Ordnungsrecht mit Versammlungsrecht, 10. Aufl. 2018, § 18.

1915 Dazu näher Guckelberger/Kollmann/Schmidt, DVBl. 2016, 1088; eine Fallösung zur Unterbringung geflüchteter Menschen auf Grundlage der polizeilichen Generalklausel findet sich bei Fontana/Klein, JA 2017, 846.

1916 Näher Schenke, Polizei- und Ordnungsrecht, 10. Aufl. 2018, Rn. $165 \mathrm{ff}$.

1917 Näher Schenke, Polizei- und Ordnungsrecht, 10. Aufl. 2018, Rn. 147 ff.; Kingreen/Poscher, Polizei- und Ordnungsrecht mit Versammlungsrecht, 10. Aufl. 2018, § 17.

1918 Näher Schenke, Polizei- und Ordnungsrecht, 10. Aufl. 2018, Rn. 152ff.; Kingreen/Poscher, Polizei- und Ordnungsrecht mit Versammlungsrecht, 10. Aufl. 2018, § 17 Rn. $19 \mathrm{ff}$.

1919 Näher Kingreen/Poscher, Polizei- und Ordnungsrecht mit Versammlungsrecht, 10. Aufl. 2018, § 13 Rn. $1 \mathrm{ff}$.

1920 Näher Schenke, Polizei- und Ordnungsrecht, 10. Aufl. 2018, Rn. 119 ff.; Kingreen/Poscher, Polizei- und Ordnungsrecht mit Versammlungsrecht, 10. Aufl. 2018, § 13 Rn. 30 ff.

Nikolas Eisentraut 
Art. 3 III 1 GG ist zwar grundsätzlich verboten, eine Anknüpfung kann jedoch als Teil eines Motivbündels unter strengen Voraussetzungen gerechtfertigt sein. ${ }^{1921}$

Examenswissen: Mit dem „racial profiling“ im Zusammenhang steht auch die Identitätsfeststellung an sog. „gefährlichen Orten“, weil die Standardbefugnisse hierfür weder ein verdächtiges Verhalten der kontrollierten Person noch eine konkrete Gefahr erfordern - Anknüpfungspunkt für Kontrollen sind daher oftmals an Art. 3 III 1 GG zu messende Kriterien. ${ }^{1922}$ Damit im Zusammenhang steht wiederum die sog. Schleierfahndung, bei der Identitätsfeststellungen ohne konkrete Gefahr ermöglicht werden. ${ }^{1923}$

\section{- $\quad$ erkennungsdienstliche Maßnahmen ${ }^{1924}$}

Examenswissen: Nicht nur die Polizei- und Ordnungsgesetze der Länder, sondern auch die StPO sieht eine Befugnisnorm für erkennungsdienstliche Maßnahmen vor. § 81b Alt. 2StPO ermöglicht die erkennungsdienstliche Behandlung von „Beschuldigten“. Obwohl in der StPO geregelt, wird die Vorschrift dem Gefahrenabwehrrecht zugeordnet; Da sie aber zugleich der Strafverfolgungsvorsorge zugeordnet wird, durfte der Bund eine Regelung in der StPO treffen. ${ }^{1925}$ Die Vorschrift beschränkt den Anwendungsbereich entsprechender landesrechtlicher Standardbefugnisse, soweit es um „Beschuldigte“ geht. Der Beschuldigtenbegriff wurde zuletzt vom BVerwG sehr weit ausgelegt. ${ }^{1926}$

\section{- Vorladung ${ }^{1927}$ \\ - Videoüberwachung ${ }^{1928}$}

Examenswissen: Im Kontext der Videoüberwachung spielen zurzeit sog. Body-Cams eine Rolle. Hierbei handelt es sich um von Polizeibeamten körpernah getragene Bild- und Tonaufzeichnungsgeräte. Immer mehr Länder schaffen Standardbefugnisse für den Einsatz solcher Bodycams. ${ }^{1929}$

1921 Dazu zuletzt OVG NRW, Urt.v. 7.8.2018, Az.: 5 A 294/16 = NVwZ 2018, 1497; Besprechung des Urteils von Hebeler, JA 2019, 237; eine Examensklausur zum Thema Racial Profiling findet sich bei Schneider/Olk, JURA 2018, 936.

1922 Kritisch Tomerius, DVBl 2017, 1399.

1923 Dazu Michl, DÖV 2018, 50.

1924 Näher Schenke, Polizei- und Ordnungsrecht, 10. Aufl. 2018, Rn. 125 ff.; Kingreen/Poscher, Polizei- und Ordnungsrecht mit Versammlungsrecht, 10. Aufl. 2018, § 13 Rn. 59 ff.

1925 Harnisch/Urbanek, DÖV 2018, 229 (229f.).

1926 BVerwG, Urt. v. 27.06.2018, Az. 6 C 39.16 = NJW 2018, 3194.

1927 Näher Schenke, Polizei- und Ordnungsrecht, 10. Aufl. 2018, Rn. 130 ff.; Kingreen/Poscher, Polizei- und Ordnungsrecht mit Versammlungsrecht, 10. Aufl. 2018, § 13 Rn. 76 ff.

1928 Näher Kingreen/Poscher, Polizei- und Ordnungsrecht mit Versammlungsrecht, 10. Aufl. 2018, § 13 Rn. 96 ff.; Ogorek, DÖV 2018, 688.

1929 Einen Überblick geben Köhler/Thielicke, NVwZ-Extra 13/2019, 1; s. auch Lachenmann, NVwZ 2017, 1424; Martini/Nink/Wenzel, NVwZ 2016, 1772; speziell zu §15c PolG NRW Arzt/ Schuster, DVBl 2018, 351. 
- $\quad$ Rasterfahndung ${ }^{1930}$ und weitere Verkehrskontrollen ${ }^{1931}$

Examenswissen: Zuletzt hat das BVerfG landesrechtliche Normen der Polizei- und Ordnungsgesetze zum Teil für verfassungswidrig erklärt, die automatische Kennzeichenerfassungen ermöglichten. ${ }^{1932}$

- Observationen ${ }^{1933}$

- verdeckte Datenerhebungen in oder aus Wohnungen ${ }^{1934}$

- Einsatz von verdeckten Ermittlern ${ }^{1935}$ und V-Leuten ${ }^{1936}$

- Datenerhebungen aus der Telekommunikation ${ }^{1937}$

- Online-Durchsuchungen ${ }^{1938}$

1049 Eine besondere Problematik stellt die Frage dar, ab wann der Gesetzgeber eine Gefahrenabwehrmaßnahme standardisieren muss und ein Rückgriff auf die Generalklausel deshalb unzulässig ist. Beispielsweise konnten bis 2007 Videoüberwachungen auf die allgemeinen Datenerhebungsklauseln gestützt werden; ein Urteil des BVerfG ${ }^{1939}$ hat jedoch dazu geführt, dass die Videoüberwachung nunmehr in allen Polizei- und Ordnungsgesetzen als Standardmaßnahme aufgenommen wurde. ${ }^{1940}$ Unter besonderen Umständen kann der Gesetzgeber also zur Schaffung einer Standardmaßnahme verpflichtet sein. ${ }^{1941}$

1930 Näher Schenke, Polizei- und Ordnungsrecht, 10. Aufl. 2018, Rn. $213 \mathrm{ff}$.

1931 Näher Kingreen/Poscher, Polizei- und Ordnungsrecht mit Versammlungsrecht, 10. Aufl. 2018, § 13 Rn. $14 \mathrm{ff}$.

1932 BVerfG, Beschluss v. 18.12.2018, Az.: 1 BvR 142/15 = NVwZ 2019, 381; dazu Roggan, NVwZ 2019, 344.

1933 Näher Kingreen/Poscher, Polizei- und Ordnungsrecht mit Versammlungsrecht, 10. Aufl. 2018, § 13 Rn. $105 \mathrm{ff}$.

1934 Näher Kingreen/Poscher, Polizei- und Ordnungsrecht mit Versammlungsrecht, 10. Aufl. 2018, § 13 Rn. $128 \mathrm{ff}$.

1935 Dazu Höhnerlein, NVwZ 2016, 511.

1936 Näher Schenke, Polizei- und Ordnungsrecht, 10. Aufl. 2018, Rn. $198 \mathrm{ff}$.

1937 Näher Kingreen/Poscher, Polizei- und Ordnungsrecht mit Versammlungsrecht, 10. Aufl. 2018, § 13 Rn. $137 \mathrm{ff}$.

1938 Näher Kingreen/Poscher, Polizei- und Ordnungsrecht mit Versammlungsrecht, 10. Aufl. 2018, § 13 Rn. $147 \mathrm{ff}$.

1939 BVerfG, Beschl. v. 23.2.2007, Az.: 1 BvR 2368/06 = DÖV 2007, 606.

1940 Siegel, in: Siegel/Waldhoff, Öffentliches Recht für Berlin, 2. Aufl. 2017, § 2 Rn. 138.

1941 Schoch, in: Schoch, Besonderes Verwaltungsrecht, 2018, Kapitel 1 Rn. 227.

Nikolas Eisentraut 
Beispiele: Ob die Landesgesetzgeber zur Schaffung von Standardbefugnissen verpflichtet sind, wird aktuell in Hinblick auf die sog. Meldeauflage, ${ }^{1942}$ die Gefährderansprache ${ }^{1943}$ und die Unterbringung von geflüchteten Menschen ${ }^{1944}$ diskutiert. Auch Gesichtserkennungssysteme, wie sie zuletzt am Berliner Bahnhof Südkreuz getestet wurden, sind in die Diskussion geraten. ${ }^{1945}$ Weiterhin wird die Schaffung von Standardbefugnissen für Body-Cams (s. Rn. 1048) diskutiert. ${ }^{1946}$ Schließlich kann sich die Frage auch bei auf die Generalklausel gestützten Stadionverboten für Hooligans stellen. ${ }^{1947}$

Der Gesetzgeber verfügt insoweit über eine Einschätzungsprärogative; eine Pflicht zur Standardisierung kann sich jedoch aus der Qualität des Grundrechtseingriffs ergeben: Je tiefgreifender eine Freiheitsbeeinträchtigung ist, desto eher bedarf es einer klar konturierten Eingriffsgrundlage (Bestimmtheitsgebot). 1948

Die Standardmaßnahmen genießen Vorrang vor der Generalklausel. Der 1050 Rückgriff auf die Generalklausel ist also immer dann gesperrt, wenn eine Maßnahme in den Anwendungsbereich einer Standardbefugnis fällt. Dafür ist auf das in der Standardbefugnis genannte Mittel abzustellen. ${ }^{1949}$ Erforderlich ist eine Auslegung, um die Reichweite der von der Standardbefugnis erfassten und damit für die Generalklausel gesperrten Sachverhalte zu ermitteln. ${ }^{1950}$

Examenswissen: Darüber hinaus wird diskutiert, ob die Sperrwirkung auch über den Anwendungsbereich einer Standardbefugnis hinaus zu erweitern ist, wenn eine Maßnahme, die auf die Generalklausel gestützt werden soll, von der Eingriffsintensität gleich oder höher als die der Standardmaßnahme ist. ${ }^{1951}$ Solange eine Maßnahme jedoch nicht typisiert werden muss (s. dazu Rn. 1049), spricht nichts gegen die Anwendung der Generalklausel. ${ }^{1952}$

1942 Die Meldeauflage wurde bisher nur in Rheinland-Pfalz standardisiert, während Meldeauflagen in anderen Bundesländern bisher auf die Generalklausel gestützt werden. Für eine Standardisierung Schoch, in: Schoch, Besonderes Verwaltungsrecht, 2018, Kapitel 1 Rn. 228.

1943 Die Forderung nach einer Standardisierung unterstützend Schoch, in: Schoch, Besonderes Verwaltungsrecht, 2018, Kapitel 1 Rn. 229.

1944 Offen lassend OVG Lüneburg, Beschl.v. 1.12.2015, Az.: 11 ME 230/15 = DVBl 2016, 116.

1945 Dazu näher Roggan, NVwZ 2019, 344 (346f.).

1946 Roggan, NVwZ 2019, 344 (346).

1947 Dazu näher Siegel, NJW 2013, 1035 (1037).

1948 Schoch, in: Schoch, Besonderes Verwaltungsrecht, 2018, Kapitel 1 Rn. 230.

1949 Kingreen/Poscher, Polizei- und Ordnungsrecht mit Versammlungsrecht, 10. Aufl. 2018, § 5 Rn. 14.

1950 Näher dazu Möstl, JURA 2011, 811 (842f.).

1951 Zum Streistand näher Roscher/Rustenberg, JuS 2011, 888 (892); s. auch Kingreen/Poscher, Polizei- und Ordnungsrecht mit Versammlungsrecht, 10. Aufl. 2018, § 5 Rn. $16 \mathrm{ff}$.

1952 In diesem Sinne auch Kingreen/Poscher, Polizei- und Ordnungsrecht mit Versammlungsrecht, 10. Aufl. 2018, § 5 Rn. 20. 


\section{(2) Die Generalklausel(n)}

1052 Ist weder eine Befugnis des besonderen Gefahrenabwehrrechts, noch eine Spezialbefugnis des Allgemeinen Polizei- und Ordnungsrechts einschlägig, ist der Weg zur Generalklausel frei. Die allgemeinen Polizei- und Ordnungsgesetze der Länder kennen mehrere generalklauselartige Eingriffsermächtigungen.

1053 Zentrale Bedeutung kommt der Generalklausel für Eingriffsmaßnahmen im Einzelfall zu. In allen Landesgesetzen findet sich eine Regelung, wonach die zuständige Behörde die notwendigen Maßnahmen treffen kann, um eine im einzelnen Falle bestehende Gefahr für die öffentliche Sicherheit (oder Ordnung) abzuwehren:

\begin{tabular}{|c|c|}
\hline Baden-Württemberg & $\S 3$ i.V.m. § 1 I 1 PolG BW \\
\hline Bayern & Art. 11 BayPAG / Art. 7 II i. V. m. Art. 6 BayLStVG \\
\hline Berlin & $\S 17$ I ASOG \\
\hline Brandenburg & $\S 10$ I BbgPolG / § 13 । BbgOBG \\
\hline Bremen & $\S 10 \mid 1$ BremPolG (ohne öffentliche Ordnung) \\
\hline Hamburg & $\S 3 \mathrm{I} \mathrm{HmbSOG}$ \\
\hline Hessen & $\S 11$ HessSOG \\
\hline Mecklenburg-Vorpommern & $\S 13$ SOG MV \\
\hline Niedersachsen & $\S 11$ i.V.m. § 2 Nr. 1 lit. a NdsSOG \\
\hline Nordrhein-Westfalen & § 8 I PolG NW / § 14 I OBG NW \\
\hline Rheinland-Pfalz & $\S 9$ I 1 POG RP \\
\hline Saarland & $\S 8$ I PolG SL \\
\hline Sachsen & § 3 I SächsPolG \\
\hline Sachsen-Anhalt & $\S 13$ i.V.m. § 3 Nr. 3 lit. a SOG LSA \\
\hline Schleswig-Holstein & $\S 174$ LVwG SH (ohne öffentliche Ordnung) \\
\hline Thüringen & $\S 12$ I und 2 ThürPAG / § 5 I ThürOBG \\
\hline BUND & $\S 14$ I und II 1 BPolG / § 38 BKAG \\
\hline
\end{tabular}

1054 Der Generalklausel kommt für das gesamte Gefahrenabwehrrecht eine zentrale Funktion als „Strukturierungsmodell“1953 $\mathrm{zu}$. Denn auch die überwiegenden Standard- und Spezialbefugnisse folgen in der Prüfungsstruktur der General-

1953 Schoch, in: Schoch, Besonderes Verwaltungsrecht, 2018, Kapitel 1 Rn. 240. 
klausel: Erforderlich ist regelmäßig, dass auf Tatbestandsseite eine Gefahr für eine Schutzgut vorliegt, woraufhin auf Rechtsfolgenseite Ermessen eröffnet wird. ${ }^{1954}$ Für Klausuren ist es daher unabdingbar, die Prüfungsstruktur der Generalklausel zu beherrschen. Diese wird - anders als die Standardbefugnisse deshalb auch vertieft dargestellt (s. sogleich Rn. 1081ff.).

Examenswissen: Ein aktuell besonders häufig diskutierter Anwendungsfall, bei dem gestützt auf die Generalklausel ein Verwaltungsakt ergeht, ist die sog. Meldeauflage. ${ }^{1955}$ Zuletzt ist zudem über die Zulässigkeit der Unterbringung von geflüchteten Menschen auf Grundlage der Generalklausel diskutiert worden. ${ }^{1956}$

Eine häufig diskutierte Frage ist, ob gegen Generalklauseln verfassungsrechtli- 1056 che Bedenken bestehen. Da die Generalklausel jedoch „in jahrzehntelanger Entwicklung durch Rechtsprechung und Lehre nach Inhalt, Zweck und Ausmaß hinreichend präzisiert, in ihrer Bedeutung geklärt und im juristischen Sprachgebrauch verfestigt“"1957 ist, wird sie als verfassungsmäßig angesehen. ${ }^{1958}$ Zweifel an der Verfassungsmäßigkeit des Tatbestandsmerkmals der „öffentlichen Ordnung“ stellen nicht die gesamte Generalklausel in Frage (näher noch zu diesem Tatbestandsmerkmal Rn. 1097 ff.). ${ }^{1959}$

Daneben enthalten die Polizeigesetze auch Generalklauseln für die Datenbzw. Informationserhebung und -verarbeitung. ${ }^{1960}$

Schließlich gibt es in den meisten Polizei- und Ordnungsgesetzen (mit Aus- 1058 nahme von Bayern) eine Generalklausel für die abstrakt-generelle Gefahrenabwehr mittels Erlasses von Rechtsverordnungen (s. näher zur Prüfung der Rechtmäßigkeit von Gefahrenabwehrverordnungen $\S 7$ Rn. 109ff.). ${ }^{1961}$

1954 Schoch, in: Schoch, Besonderes Verwaltungsrecht, 2018, Kapitel 1 Rn. 240.

1955 Näher zur Meldeauflage Benrath, DVBl 2017, 868; Siegel, NJW 2013, 1035 (1037 f.); Schucht, NVwZ 2011, 709; Falllösungen zur Meldeauflage finden sich bei Marxsen, JURA 2019, 105 und bei Schneider, ZJS 2008, 281.

1956 Näher Guckelberger/Kollmann/Schmidt, Polizeiliche Unterbringung von Flüchtlingen in privaten Immobilien, DVBl. 2016, 1088; eine Fallösung zur Unterbringung geflüchteter Menschen auf Grundlage der polizeilichen Generalklausel findet sich bei Fontana/Klein, JA 2017, 846.

1957 So BVerfG, Beschl. v. 23.5.1980, Az.: 2 BvR 854/79 = BVerfGE 54, 143 (144f.).

1958 Schoch, in: Schoch, Besonderes Verwaltungsrecht, 2018, Kapitel 1 Rn. 241; Schenke, Polizei- und Ordnungsrecht, 10. Aufl. 2018, Rn. 49.

1959 Kingreen/Poscher, Polizei- und Ordnungsrecht mit Versammlungsrecht, 10. Aufl. 2018, § 5 Rn. 5.

1960 Kingreen/Poscher, Polizei- und Ordnungsrecht mit Versammlungsrecht, 10. Aufl. 2018, § 5 Rn. 2 und näher $\S 12$.

1961 Schoch, in: Schoch, Besonderes Verwaltungsrecht, 2018, Kapitel 1 Rn. 232; Kingreen/Poscher, Polizei- und Ordnungsrecht mit Versammlungsrecht, 10. Aufl. 2018, § 23 Rn. 1.

Nikolas Eisentraut 
cc) Die zwangsweise Durchsetzung des allgemeinen Polizei- und Ordnungsrechts

1059 Eine Sonderkonstellation bilden Fälle, in denen es um die zwangsweise Durchsetzung von Maßnahmen der Polizei- und Ordnungsbehörden geht.

Beispiel: Ein Platzverweis wird vom Polizeibeamten ausgesprochen (= Verwaltungsakt). Der renitente R bewegt sich jedoch nicht von der Stelle. Daraufhin wird er vom Polizeibeamten vom Platz getragen.

1060 Als Ermächtigungsgrundlage für die Vollstreckung von Maßnahmen kommen teilweise die Standardbefugnisse selbst in Betracht. So liegt es bei der Ingewahrsamnahme, der Durchsuchung und der Sicherstellung: Die Ermächtigungsgrundlagen enthalten hier zugleich die Ermächtigung zu ihrer faktischen Durchsetzung. ${ }^{1962}$

1061 In der Regel bedarf die Vollstreckung aber einer eigenen Ermächtigungsgrundlage (zur Abgrenzung von Verwaltungsvollstreckungsrecht und polizeirechtlichen Standardmaßnahmen näher Rn. 1300). In Betracht kommt einerseits die Ermächtigungsgrundlage für die sog. unmittelbare Ausführung, die in den Polizei- und Ordnungsgesetzen zu finden ist; Andererseits kann die Vollstreckung auch auf Grundlage des VwVG erfolgen (näher zur Abgrenzung Rn. 1350 ff.).

\section{d) Formelle Rechtmäßigkeit}

1062 Bevor die materiellen Voraussetzungen und die Rechtsfolge der Ermächtigungsgrundlage geprüft werden, ist der Verwaltungsakt zunächst auf seine formelle Rechtmäßigkeit zu untersuchen.

\section{aa) Zuständigkeit}

1063 Unter der Überschrift „Zuständigkeit“ ist zu klären, ob die im Sachverhalt handelnde Behörde sachlich, örtlich und instantiell zuständig war, den Verwaltungsakt zu erlassen. ${ }^{1963}$

Ein Verstoß gegen die Zuständigkeitsregelungen führt im Grundsatz zur Rechtswidrigkeit, kann aber auch zur Nichtigkeit des Verwaltungsakts führen (s. näher § 6 Rn. 127).

1962 Kingreen/Poscher, Polizei- und Ordnungsrecht mit Versammlungsrecht, 10. Aufl. 2018, § 27 Rn. 19.

1963 Peine/Siegel, Allgemeines Verwaltungsrecht, 12. Aufl. 2018, Rn. 470.

Nikolas Eisentraut 
Sollte im Sachverhalt vorgegeben sein, dass die zuständige Behörde gehandelt hat, muss auf diese Frage nicht näher eingegangen werden (s. § 1 Rn. 25); es kann jedoch ergänzend kurz festgestellt werden, wer diese Behörde ist.

Die Frage der Zuständigkeit ist im Ausgangspunkt nach den allgemeinen 1064 Grundsätzen des Verwaltungsorganisationsrechts zu lösen (s. Rn. 580 ff.). Im Polizei- und Ordnungsrecht ist bei der Bestimmung der zuständigen Behörde darüber hinaus Folgendes zu beachten.

\section{(1) Sachliche Zuständigkeit}

Zunächst ist zu untersuchen, ob die sachlich zuständige Behörde gehandelt hat. 1065 Die Behörde ist sachlich zuständig, wenn sie berechtigt ist, den Aufgabenbereich wahrzunehmen. Untersucht werden sollte dafür die Frage, ob die Ordnungsbehörden oder die Polizei sachlich zuständig sind. Teilweise ist in den Bundesländern das sog. Trennsystem, teilweise das sog. Einheitssystem realisiert worden:

Beim Trennungssystem wird zwischen Ordnungsbehörden und Polizei un- 1066 terschieden. Während die Ordnungsbehörden Gefahrenabwehr „vom Schreibtisch aus“ betreiben, ist die Polizei „vor Ort“ tätig. ${ }^{1964}$ Teilweise wurden für Polizei und Ordnungsbehörden sogar jeweils eigene Gesetze erlassen (s. die Übersicht in Rn. 1012). In Bundesländern mit Trennungsprinzip ist daher zu untersuchen, ob die Polizei oder die Ordnungsbehörden sachlich zuständig sind. Während im Grundsatz die Ordnungsbehörden zuständig sind (Subsidiarität der Polizei gegenüber den Ordnungsbehörden), ${ }^{1965}$ kann aufgrund besonderer Regelung ausnahmsweise eine originäre oder Eilzuständigkeit der Polizei begründet sein. ${ }^{1966}$ An die Trennung anknüpfend muss im Einzelfall geprüft werden, ob die Ermächtigungsgrundlage die Zuständigkeit auf die Polizei oder die Ordnungsbehörden beschränkt oder ob beide Behörden parallel zuständig sind.

Beispiel: In Berlin darf die Ingewahrsamnahme von Personen nach $\S 30$ I ASOG Bln nur durch die Polizei vorgenommen werden.

1964 Siegel, in: Siegel/Waldhoff, Öffentliches Recht für Berlin, 2. Aufl. 2017, § 2 Rn. 28.

1965 Kingreen/Poscher, Polizei- und Ordnungsrecht mit Versammlungsrecht, 10. Aufl. 2018, § 3 Rn. 19.

1966 Für Berlin Siegel, in: Siegel/Waldhoff, Öffentliches Recht für Berlin, 2. Aufl. 2017, § 2 Rn. $29 \mathrm{ff}$. 
1067 In Bundesländern mit Einheitssystem erfolgt eine solche Trennung nicht. Innerhalb der Polizei wird aber auch in diesen Ländern zwischen den Polizeiverwaltungsbehörden und dem Polizeivollzugsdienst unterschieden. ${ }^{1967}$

1068 Weiterhin besteht nach den sog. Privatrechtsklauseln der Polizei- und Ordnungsgesetze eine Subsidiarität der Tätigkeit der Polizei- und Ordnungsbehörden gegenüber der ordentlichen Gerichtsbarkeit. ${ }^{1968}$ Die Privatrechtsklauseln ordnen dafür an, dass der Schutz privater Rechte nur dann den Polizei- und Ordnungsbehörden obliegt, wenn gerichtlicher Schutz nicht rechtzeitig zu erlangen ist und wenn ohne Hilfe durch die Polizei- oder Ordnungsbehörden eine Rechtsvereitelung drohte. ${ }^{1969}$ Auch wenn die Privatrechtsklausel teilweise dem Wortlaut nach nur auf die Polizei erstreckt wird, soll sie erst Recht für die Tätigkeit der Ordnungsbehörden gelten. ${ }^{1970}$ Die Privatrechtsklausel ist nur dann einschlägig, wenn es allein um den Schutz privater Rechte geht; die Klausel läuft daher bei den typischerweise betroffenen Rechtsgütern Leib, Leben, Freiheit, Ehre und Eigentum leer, weil Angriffe darauf auch straf- oder öffentlich-rechtlich sanktionsbewehrt sind (näher noch zu den Schutzgütern Rn. 1086 ff.). ${ }^{1971}$ Abzustellen sein soll jedoch auf die einfach-rechtliche Schutzstellung, nicht auf die Schutzfunktion der Grundrechte. ${ }^{1972}$

Beispiel: Leben und Gesundheit werden von $\S \S 223,212,211$ StGB als Teil der objektiven Rechtsordnung geschützt (nicht hingegen: Art. 2 II 1 GG).

1069 Teilweise finden sich in den allgemeinen Polizei- und Ordnungsgesetzen die sachliche Zuständigkeit näher regelnde Bestimmungen:

1967 Siegel, in: Siegel/Waldhoff, Öffentliches Recht für Berlin, 2. Aufl. 2017, § 2 Rn. 28.

1968 S. Art. 2 II BayPAG; § 1 II BBgPolG; § 1 IV ASOG Bln; § 1 II BremPolG; § 2 II PolG BW; § 3 III SOG Hamburg; § 1 III SOG Hessen; § 1 III SOG MV; § 1 III SOG Nds; § 1 II PolG NW; § 1 III POG RP; $\S 1$ III PolG Saarland; § 2 II PolG Sachsen; § 1 II SOG SA; § 162 II LVwG SH; § 2 II PAG Thüringen; § 2 II OBG Thüringen; § 1 IV BPolG.

1969 Kingreen/Poscher, Polizei- und Ordnungsrecht mit Versammlungsrecht, 10. Aufl. 2018, § 3 Rn. 41.

1970 Näher zu den einzelnen Voraussetzungen Kingreen/Poscher, Polizei- und Ordnungsrecht mit Versammlungsrecht, 10. Aufl. 2018, § 3 Rn. $41 \mathrm{ff}$.

1971 Kingreen/Poscher, Polizei- und Ordnungsrecht mit Versammlungsrecht, 10. Aufl. 2018, § 3 Rn. 42.

1972 Kingreen/Poscher, Polizei- und Ordnungsrecht mit Versammlungsrecht, 10. Aufl. 2018, § 3 Rn. 42. 
Beispiel: In Berlin richtet sich die sachliche Zuständigkeit nach den $\S \S 2 f f$. ASOG i.V.m. dem Zuständigkeitskatalog für Ordnungsaufgaben. ${ }^{1973}$ In Schleswig-Holstein ergibt sich die sachliche Zuständigkeit aus $§ 165$ LVwG. ${ }^{1974}$

\section{(2) Instantielle Zuständigkeit}

Die instantielle Zuständigkeit fragt danach, welche Hierarchieebene der Verwal- 1070 tung zuständig ist. Dieser Instanzenzug wird zumeist in den jeweiligen Polizeiund Ordnungsgesetzen näher geregelt. Ein Verstoß führt zur Rechtswidrigkeit des Verwaltungsakts, nicht jedoch zur Nichtigkeit. ${ }^{1975}$

Die Binnendifferenzierung innerhalb der jeweiligen Behörde ist hingegen ohne Belang. ${ }^{1976}$ Auch kommt es nicht darauf an, welcher Amtswalter, konkret: welche ${ }^{\star}$ r Polizeivollzugsbeamt`in gehandelt hat, weil ihr Handeln der Behörde zugerechnet wird. ${ }^{1977}$

\section{(3) Örtliche Zuständigkeit}

Die örtliche Zuständigkeit richtet sich in den Ländern mit Einheitssystem (s. be- 1072 reits Rn. 1067) nach sog. Polizeibezirken, die darauf abstellen, in welchem Bezirk eine polizeiliche Aufgabe wahrzunehmen ist; gleiches gilt im Grundsatz für die Ordnungsbehörden in Ländern mit Trennsystem. ${ }^{1978}$

Soweit sich die örtliche Zuständigkeit nicht aus dem jeweils einschlägigen 1073 Landesgesetz ergibt, kann hilfsweise auf $\S 3$ VwVfG zurückgegriffen werden.

\section{bb) Verfahren}

Die Frage etwaiger Verfahrensfehler ist im Ausgangspunkt nach den allgemeinen 1074 Grundsätzen des Verwaltungsverfahrensrechts zu lösen (s. hierzu Rn. 621 ff.), soweit sich aus den Polizeigesetzen keine spezifischen Verfahrensanforderungen ergeben. ${ }^{1979}$

1973 Siegel, in: Siegel/Waldhoff, Öffentliches Recht für Berlin, 2. Aufl. 2017, § 2 Rn. 131.

1974 Becker/Brüning, Öffentliches Recht in Schleswig-Holstein, 2014, § 3 Rn. 59.

1975 Schenke, Polizei- und Ordnungsrecht, 10. Aufl. 2018, Rn. 454.

1976 Kingreen/Poscher, Polizei- und Ordnungsrecht mit Versammlungsrecht, 10. Aufl. 2018, § 2 Rn. $28 \mathrm{f}$.

1977 Kingreen/Poscher, Polizei- und Ordnungsrecht mit Versammlungsrecht, 10. Aufl. 2018, § 5 Rn. 6.

1978 Schenke, Polizei- und Ordnungsrecht, 10. Aufl. 2018, Rn. 459.

1979 Schenke, Polizei- und Ordnungsrecht, 10. Aufl. 2018, Rn. 490; Kingreen/Poscher, Polizeiund Ordnungsrecht mit Versammlungsrecht, 10. Aufl. 2018, § 6 Rn. 19. 

VwVfG erforderlich. Davon kann jedoch - für das Polizei- und Ordnungsrecht besonders relevant - im Falle von Gefahr im Verzug nach $\S 28$ II Nr. 1 VwVfG abgewichen werden. Zudem ist sie nach § 28 III VwVfG entbehrlich, wenn ihr ein zwingendes öffentliches Interesse entgegensteht. Im Polizei- und Ordnungsrecht wird der Anhörung aus diesen Gründen keine große Bedeutung zugemessen. ${ }^{1980}$

1076 Spezifische Verfahrensanforderungen ergeben sich insbesondere im Bereich der Standardbefugnisse. ${ }^{1981}$

1077 Examenswissen: Bei Minderjährigen ergibt sich aufgrund der Regelung des §12 I VwVfG die Besonderheit, dass diesen die Handlungsfähigkeit im Verwaltungsverfahren fehlen kann (s. Rn. 641). Auf die Generalklausel gestützte Verwaltungsakte können dann nur wirksam gegenüber ihren gesetzlichen Vertretern bekannt gegeben werden. ${ }^{1982}$ Sind die gesetzlichen Vertreter nicht erreichbar, kann kein wirksamer Verwaltungsakt gegenüber dem Minderjährigen erlassen werden; in diesem Fall muss die Behörde ohne Grundverwaltungsakt im Wege der Verwaltungsvollstreckung vorgehen (näher zur Verwaltungsvollstreckung im Polizei- und Ordnungsrecht Rn. 1059 ff.). ${ }^{1983}$

\section{cc) Form}

1078 Auch die Frage etwaiger Formfehler ist im Ausgangspunkt nach den allgemeinen Grundsätzen des Verwaltungsverfahrensrechts $\mathrm{zu}$ lösen (s. hierzu näher Rn. 681ff.), soweit sich aus den Polizeigesetzen keine spezifischen Verfahrensanforderungen ergeben. ${ }^{1984}$ Teilweise müssen nach den Landesgesetzen Ordnungsverfügungen in Abweichung vom Regelfall des § 37 II 1 VwVfG schriftlich erlassen werden, soweit nicht Gefahr im Vollzug vorliegt (so in § 19 I BbgOBG und $\S 20$ I NWOBG). Schließlich kommt der Ausnahme vom Begründungserfordernis nach § 39 II Nr. 2 VwVfG im Polizei- und Ordnungsrecht Bedeutung zu. ${ }^{1985}$

1980 Kingreen/Poscher, Polizei- und Ordnungsrecht mit Versammlungsrecht, 10. Aufl. 2018, § 6 Rn. 21.

1981 Kingreen/Poscher, Polizei- und Ordnungsrecht mit Versammlungsrecht, 10. Aufl. 2018, § 6 Rn. 20.

1982 Kingreen/Poscher, Polizei- und Ordnungsrecht mit Versammlungsrecht, 10. Aufl. 2018, § 9 Rn. 5.

1983 Kingreen/Poscher, Polizei- und Ordnungsrecht mit Versammlungsrecht, 10. Aufl. 2018, § 9 Rn. 5.

1984 Schenke, Polizei- und Ordnungsrecht, 10. Aufl. 2018, Rn. 490.

1985 Kingreen/Poscher, Polizei- und Ordnungsrecht mit Versammlungsrecht, 10. Aufl. 2018, § 6 Rn. 22.

\section{Nikolas Eisentraut}




\section{e) Materielle Rechtmäßigkeit}

Im Anschluss an die formelle Rechtmäßigkeit ist in der materiellen Rechtmä- 1079 ßigkeit ist zu prüfen, ob die streitgegenständliche Maßnahme auch den materiellrechtlichen Anforderungen der Ermächtigungsgrundlage entspricht und ob sie von deren Rechtsfolge gedeckt ist. Unterschieden werden muss danach, ob eine Standardbefugnis oder die Generalklausel als Ermächtigungsgrundlage für einschlägig befunden wurde. Die Prüfung kann sodann entlang der für das Verwaltungsrecht typischen Einteilung in Tatbestand und Rechtsfolge erfolgen (s. zur Grundstruktur der Prüfung der materiellen Rechtmäßigkeit Rn. 526ff.; für vertiefende Ausführungen s. Rn. 712ff.; ein Überblick über weitere Möglichkeiten, die Prüfung aufzubauen, findet sich in Rn. $803 \mathrm{ff}$.).

\section{aa) Die Standardbefugnisse}

In ihrer Grundstruktur erfolgt die Prüfung der Standardbefugnisse dem Prü- 1080 fungsablauf für die Generalklausel. Diese wird deshalb sogleich umfassend dargestellt und muss beherrscht werden. Im Vergleich zur Generalklausel werden Tatbestand und Rechtsfolge bei Standardmaßnahmen jedoch vielfach modifiziert. ${ }^{1986}$ Alle diese Spezialregelungen auswendig zu lernen, macht keinen Sinn; vielmehr muss die Grundstruktur beherrscht und der Umgang mit den Besonderheiten innerhalb der Grundstruktur erlernt werden. ${ }^{1987}$ Die folgende Darstellung konzentriert sich daher auf die Prüfung der Generalklausel. Für eine tiefergreifende Auseinandersetzung mit den einzelnen Standardmaßnahmen wird auf die in Rn. 1140 genannte Vertiefungsliteratur hingewiesen.

\section{bb) Die Generalklausel}

Ist weder eine Ermächtigungsgrundlage des besonderen Gefahrenabwehrrechts, 1081 noch eine Standardbefugnis taugliche Ermächtigungsgrundlage (s. zur Abgrenzung soeben Rn. 1036 und Rn. 1044) und wurde deshalb die Generalklausel als „Auffang-Ermächtigungsgrundlage“ für einschlägig befunden, muss im Anschluss an die formelle Rechtmäßigkeit geprüft werden, ob die Maßnahme auch deren materiell-rechtlichen Anforderungen entspricht.

Die Generalklausel folgt in allen Bundesländern einer vergleichbaren 1082 Prüfungsstruktur (s. bereits die Normenübersicht in Rn. 1053). Wichtig ist es

1986 Siegel/Waldhoff, Öffentliches Recht für Berlin, 2. Aufl. 2017, § 2 Rn. 144.

1987 Kingreen/Poscher, Polizei- und Ordnungsrecht mit Versammlungsrecht, 10. Aufl. 2018, § 11 Rn. 28. 
auch bei der Prüfung der Generalklausel (wie stets im Verwaltungsrecht) klar zwischen Tatbestand und Rechtsfolge zu trennen. Auf Tatbestandsseite sind die Tatbestandsmerkmale der Ermächtigungsgrundlage zu prüfen. Sind sie erfüllt, ist zu untersuchen, ob die von der Behörde gewählte Rechtsfolge von der Ermächtigungsgrundlage gedeckt ist.

\section{(1) Tatbestandsmerkmale}

1083 Die Generalklausel kennt in der Regel 4 Tatbestandsmerkmale. Neben der in Klausuren schon im Rahmen des Prüfungspunktes „Ermächtigungsgrundlage“ zu klärenden Frage der Subsidiarität (a) bedarf es des Vorliegens einer Gefahr (c) für eines der polizeilichen Schutzgüter der öffentlichen Sicherheit oder Ordnung (b) und der taugliche Adressat der Maßnahme muss in Anspruch genommen worden sein (d).

1084 Die unbestimmten Tatbestandsmerkmale (öffentliche Sicherheit und Ordnung, Gefahr) sind vollständig gerichtlich überprüfbar. Der Behörde ist insofern kein Beurteilungsspielraum eingeräumt (s. zum Begriff des Beurteilungsspielraums näher Rn. 735). ${ }^{1988}$

\section{(a) Subsidiarität}

1085 Zur Subsidiarität der Generalklausel gegenüber Befugnissen des besonderen Gefahrenabwehrrechts s. Rn. 1036 ff. sowie zu den Standardbefugnissen s. Rn. $1044 \mathrm{ff}$.

\section{(b) Öffentliche Sicherheit und Ordnung}

1086 Zunächst müsste das Schutzgut der öffentlichen Sicherheit oder Ordnung betroffen sein. ${ }^{1989}$ Gegenüber dem Schutzgut der öffentlichen Sicherheit ist das Schutzgut der öffentlichen Ordnung subsidiär, es ist also nur dann zu prüfen, wenn das Schutzgut der öffentlichen Sicherheit nicht betroffen ist. ${ }^{1990}$

Das Schutzgut der öffentlichen Sicherheit umfasst 3 Elemente, auch Teilschutzgüter ${ }^{1991}$ genannt:

1988 Schenke, Polizei- und Ordnungsrecht, 10. Aufl. 2018, Rn. 51f.

1989 In den Bundesländern Bremen und Schleswig-Holstein beschränkt sich der Tatbestand allein auf die öffentliche Sicherheit.

1990 Schoch, in: Schoch, Besonderes Verwaltungsrecht, 2018, Kapitel 1 Rn. 243.

1991 Kingreen/Poscher, Polizei- und Ordnungsrecht mit Versammlungsrecht, 10. Aufl. 2018, § 7 Rn. 2.

\section{Nikolas Eisentraut}


1. die Unverletzlichkeit der Rechtsordnung,

2. die Unversehrtheit der Rechtsgüter und Rechte des Einzelnen und

3. den Bestand und die Funktionsfähigkeit des Staates und seiner Einrichtungen.

Soweit sich im einschlägigen Landesrecht keine Legaldefinition findet, ${ }^{1992}$ muss diese Definition auswendig gelernt werden.

Bei der Subsumtion unter die einzelnen Teilschutzgüter kann es zu Über- 1088 schneidungen derart kommen, dass eine Gefahr für mehrere der genannten Elemente bejaht werden kann. ${ }^{1993}$ Gegenüber den anderen Teilschutzgütern ist die Unverletzlichkeit der Rechtsordnung deshalb vorrangig zu prüfen, während den anderen Elementen eine Reservefunktion zukommt. ${ }^{1994}$

(1.) Das Element der Unverletzlichkeit der Rechtsordnung umfasst die 1089 gesamte Rechtsordnung und ermöglicht es so, drohende Verletzungen geltenden Rechts zu verhindern. ${ }^{1995}$ Aufgrund der Verrechtlichung weiter Lebensbereiche kommt dem ersten Element zentrale Bedeutung zu. ${ }^{1996}$

Erfasst werden zunächst drohende Verstöße gegen formelle Gesetze. Eine 1090 typische Fallgruppe bildet das Straf- und Ordnungswidrigkeitenrecht. Die Verhinderung von Verstößen gegen das StGB und das OWiG lassen sich häufig nur unter Rückgriff auf die Generalklausel unterbinden, beispielsweise wenn ein rechtsextremistisches Konzert wegen Volksverhetzung (§130 StGB) untersagt wird. ${ }^{1997} \mathrm{Zu}$ den gesetzlichen Vorschriften zählen weiterhin die Bestimmungen des Verwaltungs- wie auch des Privatrechts. ${ }^{1998}$ Letztere werden zwar auch vom Element der Unversehrtheit der Rechtgüter und Rechte des Einzelnen erfasst. Soweit sie jedoch beiden Teilschutzgütern unterfallen, greift die Privatrechtsklausel nicht (s. zur Privatrechtsklausel Rn. 1068).

Weiterhin erfasst die Generalklausel auch Verstöße gegen untergesetzliche 1091 Normen wie Gefahrenabwehrverordnungen. ${ }^{1999}$ In Klausuren bietet das Teil-

1992 So in § 2 Nr. 2 BremPolG, § 3 Nr. 1 SOG LSA sowie § 54 Nr. 1 ThürOBG.

1993 Zur historischen Begründung Kingreen/Poscher, Polizei- und Ordnungsrecht mit Versammlungsrecht, 10. Aufl. 2018, § 7 Rn. 4.

1994 Kingreen/Poscher, Polizei- und Ordnungsrecht mit Versammlungsrecht, 10. Aufl. 2018, § 7 Rn. 6.

1995 Schoch, in: Schoch, Besonderes Verwaltungsrecht, 2018, Kapitel 1 Rn. 245.

1996 Götz/Geis, Allgemeines Polizei- und Ordnungsrecht, 16. Aufl. 2017, §4 Rn. 7; Schoch, in: Schoch, Besonderes Verwaltungsrecht, 2018, Kapitel 1 Rn. 244.

1997 OVG Bremen Beschl.v. 26.11. 2011, Az.: 1 B 309/11 = BeckRS 2011, 56338; weitere Beispiele bei Schoch, Besonderes Verwaltungsrecht, 2018, Kapitel 1 Rn. 247.

1998 Schoch, in: Schoch, Besonderes Verwaltungsrecht, 2018, Kapitel 1 Rn. 248 und 252.

1999 Schoch, in: Schoch, Besonderes Verwaltungsrecht, 2018, Kapitel 1 Rn. 249.

Nikolas Eisentraut 
schutzgut der Unverletzlichkeit der Rechtsordnung daher auch das typische „Einfallstor“ in der Anfechtungsklage für die Prüfung der Rechtmäßigkeit einer Gefahrenabwehrverordnung (zur Rechtmäßigkeitsprüfung einer Gefahrenabwehrverordnung s. näher $\S 7$ Rn. 109 ff.). ${ }^{2000}$

1092 Auch das EU-Recht nimmt am Schutz der objektiven Rechtsordnung teil, etwa wenn aufgrund von Straßenblockaden eine Beeinträchtigung der Warenverkehrsfreiheit (Art. 34 AEUV) droht. ${ }^{2001}$

(2) Vom Element der Unversehrtheit der Rechtsgüter und Rechte des

Einzelnen erfasst werden insbesondere das Leben, die Gesundheit und Freiheit, sowie das Eigentum und Persönlichkeitsrechte. ${ }^{2002}$ In der Regel werden diese Rechtsgüter auch von der objektiven Rechtsordnung geschützt, sodass das zweite Element keine Anwendung findet. Es kann jedoch in zwei Fallgruppen zur Anwendung kommen: Einerseits spielt die Unversehrtheit der Rechtsgüter und Rechte des Einzelnen eine Rolle bei Naturereignissen, da das objektive Recht nur menschliches Verhalten regeln kann. ${ }^{2003}$

1094 Zum anderen greift das Element der Unversehrtheit der Rechtsgüter und Rechte des Einzelnen bei Selbstgefährdungen, da die objektive Rechtsordnung den Einzelnen nicht vor sich selbst schützt. ${ }^{2004}$ Bei einer vom freien Willen getragenen Selbstgefährdung, die zugleich unbeteiligte Dritte nicht gefährdet, wird aber regelmäßig aufgrund des Selbstbestimmungsrechts aus Art. 2 I, 2 II 1 GG auch dieses Teilschutzgut nicht als gefährdet angesehen. ${ }^{2005}$ Entsprechendes gilt für die Selbsttötung, auch wenn die Behörden hier regelmäßig einschreiten werden. ${ }^{2006}$ Die Rechtmäßigkeit des polizeilichen Einschreitens im Falle eines Selbsttötungsversuchs ergibt sich daraus, dass der Beamte in der ex ante Betrachtung nicht weiß, inwieweit der Selbsttötungsversuch von einem freien Willensentschluss getragen ist. Die Verhinderung wird deshalb als Gefahrerforschungsein-

2000 Kingreen/Poscher, Polizei- und Ordnungsrecht mit Versammlungsrecht, 10. Aufl. 2018, § 27 Rn. $15 \mathrm{ff}$.

2001 Schoch, in: Schoch, Besonderes Verwaltungsrecht, 2018, Kapitel 1 Rn. 251.

2002 Schoch, in: Schoch, Besonderes Verwaltungsrecht, 2018, Kapitel 1 Rn. 253.

2003 Kingreen/Poscher, Polizei- und Ordnungsrecht mit Versammlungsrecht, 10. Aufl. 2018, § 7 Rn. 6 und 21.

2004 Kingreen/Poscher, Polizei- und Ordnungsrecht mit Versammlungsrecht, 10. Aufl. 2018, § 7 Rn. 23.

2005 Kingreen/Poscher, Polizei- und Ordnungsrecht mit Versammlungsrecht, 10. Aufl. 2018, § 7 Rn. 25.

2006 Kingreen/Poscher, Polizei- und Ordnungsrecht mit Versammlungsrecht, 10. Aufl. 2018, § 7 Rn. $27 \mathrm{f}$.

Nikolas Eisentraut 
griff bzw. als Einschreiten wegen einer Anscheinsgefahr (zu diesen Begriffen Rn. 1107 und Rn. 1112ff.) qualifiziert. ${ }^{2007}$

Da die Durchsetzung privater Rechte und Rechtsgüter zunächst den Zivilgerichten vorbehalten ist, ist deren Schutz mittels der Polizei- und Ordnungsgesetze nur subsidiär möglich (s. bereits Rn. 1068). Die Landespolizeigesetze enthalten dementsprechend sog. Subsidiaritätsklauseln. ${ }^{2008}$ Danach können die Gefahrenabwehrbehörden zum Schutz privater Rechte und Rechtsgüter nur dann einschreiten, wenn gerichtlicher Schutz nicht rechtzeitig zu erlangen ist und wenn ohne behördliche Hilfe die Verwirklichung des Rechts vereitelt oder wesentlich erschwert würde. ${ }^{2009}$ Darüber hinaus ist teilweise auch ein Antragserfordernis des Berechtigten normiert worden. ${ }^{2010}$

(3.) Unter das Teilschutzgut des Bestands des Staates und seiner Einrichtungen und Veranstaltungen fällt zunächst die territoriale Unversehrtheit und politische Unabhängigkeit der Bundesrepublik Deutschland. Weiterhin erfasst werden vom Einrichtungsbegriff die Organe, Behörden, Körperschaften, Stiftungen, Anstalten und vergleichbare Sachkomplexe wie die öffentlichen Hochschulen, Kammern, Rundfunkanstalten und Schwimmbäder. Schließlich schützt der Begriff der Veranstaltung ad hoc gebildete Handlungskomplexe wie Staatsempfänge, Tage der offenen Tür und militärische Manöver. ${ }^{2011}$ Wiederum greift vorrangig das Teilschutzgut der objektiven Rechtsordnung, wenn eine Verletzung der Rechtsordnung in Rede steht, so etwa beim Widerstand gegen Vollstreckungsbeamte nach $\S 113$ StGB oder der Störung öffentlicher Betriebe nach $\S 316 \mathrm{~b}$ StGB. ${ }^{2012}$ Seine Auffangfunktion kann das Element dort erfüllen, wo nicht zugleich eine Verletzung der objektiven Rechtsordnung droht. ${ }^{2013}$ Dies gilt wie-

2007 Kingreen/Poscher, Polizei- und Ordnungsrecht mit Versammlungsrecht, 10. Aufl. 2018, § 7 Rn. 28.

2008 Näher dazu Schoch, in: Schoch, Besonderes Verwaltungsrecht, 2018, Kapitel 1 Rn. $254 \mathrm{ff}$. 2009 So in § 2 II PolG BW; Art. 2 II BayPAG; § 1 Abs. 4 ASOG Bln; § 1 II BbgPolG, § 1 II BremPolG; $\S 3$ Abs. 3 HmbSOG; § 1 Abs. 3 HessSOG; § 1 Abs. 3 SOG MW; § 1 Abs. 3 NdsSOG; § 1 II PolG NW; § 1 Abs. 3 POG RP; § 1 Abs. 3 PolG SL; § 2 II SächsPolG; § 1 II SOG LSA; § 162 II LVwG SH; § 2 II ThürPAG; $\S 2$ II ThürOBG; s. auch § 1 Abs. 4 BPolG.

2010 § 2 II PolG BW; § 2 II SächsPolG; in der Lit. wird teilweise generell ein Antrag gefordert, Nachweise zu dieser Ansicht bei Schoch, in: Schoch, Besonderes Verwaltungsrecht, 2018, Kapitel 1 Rn. 254 Fn. 724.

2011 Kingreen/Poscher, Polizei- und Ordnungsrecht mit Versammlungsrecht, 10. Aufl. 2018, § 7 Rn. 30.

2012 Schenke, Polizei- und Ordnungsrecht, 10. Aufl. 2018, Rn. 60; Kingreen/Poscher, Polizeiund Ordnungsrecht mit Versammlungsrecht, 10. Aufl. 2018, § 7 Rn. $32 \mathrm{f}$.

2013 Kingreen/Poscher, Polizei- und Ordnungsrecht mit Versammlungsrecht, 10. Aufl. 2018, § 7 Rn. 34. 
derum bei Naturereignissen, etwa wenn ein Gewitter einen Staatsempfang gefährdet. ${ }^{2014}$ Bloße Beeinträchtigungen der Funktionsfähigkeit der staatlichen Einrichtungen sollen hingegen nicht genügen, soweit sie nicht zugleich die Rechtsordnung verletzen; scharfe Kritik an einer staatlichen Einrichtung, das Fotografieren polizeilicher Einsätze und die Warnung vor polizeilichen Geschwindigkeitskontrollen sollen daher nicht tatbestandsmäßig sein. ${ }^{2015}$

Schließlich erfüllen auch Gefährdungen der öffentlichen Ordnung den Tatbestand der Generalklausel. Das Tatbestandsmerkmal der öffentlichen Ordnung ist jedoch hoch umstritten. In Bremen und Schleswig-Holstein wurde deshalb auch auf dieses Tatbestandsmerkmal verzichtet. In den meisten Bundesländern wird am Tatbestandsmerkmal der öffentlichen Ordnung jedoch bis heute festgehalten. Soweit sich keine Legaldefinition im Gesetz findet, ist folgende Definition auswendig zu lernen: „Die öffentliche Ordnung umfasst die Gesamtheit der im Rahmen der verfassungsmäßigen Ordnung liegenden ungeschriebenen Regeln für das Verhalten des einzelnen in der Öffentlichkeit, deren Beachtung nach den jeweils herrschenden Anschauungen unerlässliche Voraussetzung eins geordneten staatsbürgerlichen Zusammenlebens ist.“"2016

Als Gefahr für die öffentliche Ordnung wurde beispielsweise das Angebot von „DamenSchlamm-Catchen oben ohne“2017 angesehen.

1098 Problematisch am Tatbestandsmerkmal ist, dass auf „ungeschriebene Regeln“ abgestellt wird. Es geht also um außerrechtliche Sozialnormen. Wer bestimmt jedoch über die ,jeweils herrschende Anschauung“? In der Praxis wird dafür nicht etwa empirisch die Mehrheitsanschauung der Bevölkerung ermittelt; der unbestimmte Rechtsbegriff wird vielmehr von den Gerichten ausgelegt. ${ }^{2018}$ Zum vergleichbaren Fall des Tatbestandsmerkmals der Sittenwidrigkeit in § 33a GewO hat das VG Karlsruhe sehr anschaulich ausgeführt: „Gleichwohl bedarf es entgegen der Ansicht des Klägers nicht der Einholung eines demoskopischen Sachverständigengutachtens zur Ermittlung der vorherrschenden sozialethischen Überzeugungen. Abgesehen davon, dass demoskopische Umfragen, die einem solchen Gutachten zugrunde zu legen wären, schon wegen der Abhängigkeit des

2014 Weitere Beispiele bei Kingreen/Poscher, Polizei- und Ordnungsrecht mit Versammlungsrecht, 10. Aufl. 2018, § 7 Rn. 35.

2015 Str., s. näher Kingreen/Poscher, Polizei- und Ordnungsrecht mit Versammlungsrecht, 10. Aufl. 2018, § 7 Rn. $37 \mathrm{f}$.

2016 So legaldefiniert in $\S 3$ Nr. 2 SOG LSA und § 54 Nr. 2 OBG Thüringen.

2017 VGH München, Beschluss v. 9.12.1983, Az.: 22 CE 83 A/3074 = NVwZ 1984, 254.

2018 Kritisch dazu Kingreen/Poscher, Polizei- und Ordnungsrecht mit Versammlungsrecht, 10. Aufl. 2018, § 7 Rn. 44. 
Ergebnisses von der jeweiligen konkret gewählten Fragestellung und ihrer vielschichtig möglichen Interpretation durch die Befragten keine Gewähr für ein zutreffendes Meinungsbild bieten könnten, ist es - wie bei anderen unbestimmten Rechtsbegriffen auch - Aufgabe der Rechtsprechung, den Inhalt des unbestimmten Rechtsbegriffs der guten Sitten selbst festzustellen (...).“2019

Obwohl das Tatbestandsmerkmal deshalb ideologisch anfällig ist und mit 1099 dem vom Grundgesetz intendierten Minderheitenschutz in einer Spannungslage steht, ${ }^{2020}$ halten die Rechtsprechung und die überwiegende Literatur am Tatbestandsmerkmal der öffentlichen Ordnung fest. ${ }^{2021}$ Typischerweise wird das Tatbestandsmerkmal herangezogen, um Gefährdungen der Menschenwürde begegnen zu können. Indes zählt Art. 1 I GG genau genommen zur geschriebenen Rechtsordnung und unterfällt bereits dem Tatbestandsmerkmal der öffentlichen Sicherheit. Zudem kommt der öffentlichen Ordnung im Versammlungsrecht Bedeutung zu (s. näher Rn. 1182f.).

Hausarbeitswissen: Mit der öffentlichen Ordnung in engem Zusammenhang steht das Tatbestandsmerkmal der Sittenwidrigkeit, das im Gewerberecht eine bedeutende Rolle spielt. Auch hier stellen die Gerichte auf „außerrechtliche Sozialnormen“ ab. ${ }^{2022}$ Als sittenwidrig wurden durch die Gerichte insbesondere Peep-Shows ${ }^{2023}$ und Laserdrome-Spiele ${ }^{2024}$ angesehen.

\section{(c) Gefahr}

Gefahrenabwehr besteht klassischer Weise in der Abwehr von Gefahren für die 1101 polizeilichen Schutzgüter. ${ }^{2025}$ Dem Gefahrbegriff kommt daher im Polizei- und Ordnungsrecht zentrale Bedeutung zu. Für auf Grundlage der Generalklausel erlassene Verwaltungsakte verlangt diese deshalb, dass eine Gefahr für eines der vorstehend erörterten Schutzgüter vorliegen muss.

2019 VG Karlsruhe, Urt. v. 12.09.2013, Az.: 3 K 496/12, juris Rn. 36.

$2020 \mathrm{Zu}$ diesen Kritikpunkten Kingreen/Poscher, Polizei- und Ordnungsrecht mit Versammlungsrecht, 10. Aufl. 2018, § 7 Rn. $44 \mathrm{ff}$.

2021 Kingreen/Poscher, Polizei- und Ordnungsrecht mit Versammlungsrecht, 10. Aufl. 2018, § 7 Rn. 49 und 52.

2022 Dazu näher Öttinger, GewArch 2016, 365.

2023 BVerwG, Urt. v. 15.12.1981, Az.: 1 C 232.79 = BVerwGE 64, 274.

2024 BVerwG, Beschl. v. 24.10.2001, Az.: 6 C 3/01 = BVerwGE 115, 189.

2025 Schoch, in: Schoch, Besonderes Verwaltungsrecht, 2018, Kapitel 1 Rn. 10; zur Gefahrenabwehr als staatliche Aufgabe Schoch, in: Schoch, Besonderes Verwaltungsrecht, 2018, Kapitel 1 Rn. 65 ff.; zur Gefahrenabwehr durch Private Schoch, in: Schoch, Besonderes Verwaltungsrecht, 2018, Kapitel 1 Rn. 130 ff. 
Soweit sich im jeweils einschlägigen Polizeigesetz keine Legaldefinition findet, ${ }^{2026}$ muss folgende Definition beherrscht werden: „Eine Gefahr ist ein Zustand, der bei ungehindertem Ablauf des zu erwartenden Geschehens mit hinreichender Wahrscheinlichkeit ein geschütztes Rechtsgut schädigen wird.“ Die Generalklausel erfordert das Bestehen einer solchen Gefahr im Einzelfall (sog. konkrete Gefahr).

1103 Vom Begriff der konkreten Gefahr zu unterscheiden ist der Begriff der sog. abstrakten Gefahr. Eine abstrakte Gefahr liegt dann vor, wenn ein Verhalten abstrahiert vom konkreten Einzelfall typischerweise zu einer Rechtsgutsgefährdung führt. ${ }^{2027}$ Eine abstrakte Gefahr ist erforderlich, wenn die Behörde eine Gefahrenabwehrverordnung erlassen will (s. zur Gefahrenabwehrverordnung auch $\S 7$ Rn. 107).

1104 Auf Grundlage der Definition können mehrere Aspekte problematisiert werden:

1105 Zunächst kann zu problematisieren sein, ob das Vorliegen der Voraussetzungen des Gefahrbegriffs nach objektiven oder subjektiven Gesichtspunkten zu beurteilen ist:

1106 Nach dem sog. objektiven Gefahrbegriff käme es auf die im Nachhinein zweifelsfrei festgestellte Situation an (Beurteilung ,ex post“).

1107 Nach heute herrschender Meinung ist jedoch mit dem subjektiven Gefahrbegriff darauf abzustellen, ob der handelnde Beamte in der konkreten Situation vertretbar von einem Zustand ausgehen durfte, der die Voraussetzungen des Gefahrbegriffs erfüllt (sog. ex ante Beurteilung). ${ }^{2028}$ Dadurch kann der Gefahrbegriff auch dann erfüllt sein, wenn der Beamte nur ex ante von einer Gefahr ausgehen durfte, obwohl ex post gar keine Gefahr vorlag (sog. Anscheinsgefahr). ${ }^{2029}$

1108 Durfte der Beamte hingegen von keiner Gefahr ausgehen und tut dies trotzdem, wird von einer sog. Putativgefahr (oder auch Scheingefahr) gesprochen. ${ }^{2030}$ Sein Vorgehen war dann mangels Gefahr rechtswidrig.

2026 Legaldefiniert in $\S 2$ Nr. 3 a) BremPolG; § 2 Nr. 1 a) Nds. SOG; § 3 Nr. 3 a) SOG LSA; § 54 Nr. 3 a) ThürOBG.

2027 Schenke, Polizei- und Ordnungsrecht, 10. Aufl. 2018, Rn. 70; Kingreen/Poscher, Polizeiund Ordnungsrecht mit Versammlungsrecht, 10. Aufl. 2018, § 8 Rn. 9.

2028 Kingreen/Poscher, Polizei- und Ordnungsrecht mit Versammlungsrecht, 10. Aufl. 2018, § 8 Rn. 48.

2029 Kingreen/Poscher, Polizei- und Ordnungsrecht mit Versammlungsrecht, 10. Aufl. 2018, § 8 Rn. 49.

2030 Kingreen/Poscher, Polizei- und Ordnungsrecht mit Versammlungsrecht, 10. Aufl. 2018, § 8 Rn. 61.

\section{Nikolas Eisentraut}


Weiterhin können die einzelnen Definitionsmerkmale zu problematisieren 1109 sein:

So setzt die Definition voraus, dass eine Schädigung eines Rechtsguts 1110 droht. Nicht ausreichend sind demnach bloße Belästigungen. ${ }^{2031}$ Als Belästigungen werden Einwirkungen auf ein Rechtsgut qualifiziert, die zwar nachteilig, unangenehm, lästig oder unerfreulich sind, aber nicht darüber hinausgehen. ${ }^{2032}$ Unaufdringliches Betteln im öffentlichen Raum wird beispielsweise nicht als Gefahr, sondern bloß als Belästigung qualifiziert. ${ }^{2033}$

Weiterhin kommt es nach der Definition darauf an, dass die Gefahrenlage 1111 hinreichend wahrscheinlich ist. ${ }^{2034}$ Es reicht also nicht aus, dass eine Vermutung ohne tatsächliche Anhaltspunkte im Raum steht. ${ }^{2035}$ Auch ein reines Risiko reicht noch nicht, bei dem alles gegen die Wahrscheinlichkeit einer Schädigung spricht, diese aber nicht 100\%ig ausgeschlossen werden kann. ${ }^{2036}$ Dabei können die Anforderungen daran, wie wahrscheinlich ein Schadenseintritt sein muss, durchaus variieren: Umso höherrangig das Rechtsgut und der ihm drohende Schaden, desto geringere Anforderungen sind an die Wahrscheinlichkeit zu stellen. $^{2037}$

Eine besonders problematische Kategorie ist der sog. Gefahrenverdacht. Von 1112 einem Gefahrenverdacht wird gesprochen, wenn zwar die Möglichkeit einer Gefahr besteht, weil bereits Anhaltspunkte darauf hindeuten, der Beamte aber letztlich im Ungewissen darüber ist, die Anhaltspunkte also noch nicht für die Bejahung der hinreichenden Wahrscheinlichkeit des Schadenseintritts genügen. $^{2038}$

Umstritten ist, welche Befugnisse den Polizei- und Ordnungsbehörden im Falle eines Gefahrenverdachts zustehen:

2031 Schenke, Polizei- und Ordnungsrecht, 10. Aufl. 2018, Rn. 74.

2032 Kingreen/Poscher, Polizei- und Ordnungsrecht mit Versammlungsrecht, 10. Aufl. 2018, § 8 Rn. 3.

2033 Kingreen/Poscher, Polizei- und Ordnungsrecht mit Versammlungsrecht, 10. Aufl. 2018, § 8 Rn. 4.

2034 Schenke, Polizei- und Ordnungsrecht, 10. Aufl. 2018, Rn. 77.

2035 Kingreen/Poscher, Polizei- und Ordnungsrecht mit Versammlungsrecht, 10. Aufl. 2018, § 8 Rn. 6.

2036 Näher Kingreen/Poscher, Polizei- und Ordnungsrecht mit Versammlungsrecht, 10. Aufl. 2018, § 8 Rn. 6.

2037 Schenke, Polizei- und Ordnungsrecht, 10. Aufl. 2018, Rn. 77.

2038 Kingreen/Poscher, Polizei- und Ordnungsrecht mit Versammlungsrecht, 10. Aufl. 2018, § 8 Rn. 51; zu den unterschiedlichen Verständnissen und den daraus resultierenden Missverständnissen des Begriffs des Gefahrenverdachts näher Schenke, JuS 2018, 505 (508).

Nikolas Eisentraut 
Unproblematisch ist die Befugnisreichweite, wenn die Zulässigkeit eines Einschreitens bei Gefahrverdacht spezialgesetzlich normiert ist: Bestimmte Standardmaßnahmen lassen bereits einen Gefahrenverdacht ausreichen, so bei der Durchsuchung von Personen, Sachen und Wohnungen und dem Aufenthaltsverbot. ${ }^{2039}$ Die Ermächtigungsgrundlagen sprechen dabei meist von „Tatsachen, die die Annahme eines bestimmten Geschehens rechtfertigen“. ${ }^{2040}$

Problematisch wird es da, wo eine Maßnahme bei einem Gefahrenverdacht nur auf eine Ermächtigungsgrundlage gestützt werden könnte, die in tatbestandlicher Hinsicht das Vorliegen einer konkreten Gefahr verlangt (so insbesondere die Generalklausel). Nur wenn der Gefahrenverdacht zugleich als konkrete Gefahr qualifiziert werden kann, wäre ein Einschreiten möglich.

Ein Teil der Literatur sieht den Gefahrenverdacht deshalb als Unterform der konkreten Gefahr an. ${ }^{2041}$ Dagegen spricht jedoch, dass bei einem Gefahrenverdacht über die hinreichende Wahrscheinlichkeit eines Schadenseintritts gerade Unklarheit besteht.

Nach einer weiteren Ansicht soll es hingegen möglich sein, im Einzelfall zu untersuchen, ob ein Schaden mit hinreichender Wahrscheinlichkeit droht - nur dann könne der Gefahrenverdacht auch als konkrete Gefahr qualifiziert werden. ${ }^{2042}$ Dafür müsste dann jedoch ausnahmsweise der objektive Gefahrbegriff zugrunde gelegt werden, weil aus der ex ante Perspektive ja gerade Ungewissheit darüber besteht, ob eine konkrete Gefahr vorliegt. ${ }^{2043}$

Nach a.A. soll das Recht der Polizei- und Ordnungsbehörden zu Eingriffen nach der Generalklausel auch dann bestehen, wenn keine konkrete Gefahr vorliegt, weil der Generalklausel eine stillschweigende Ermächtigung dazu zu entnehmen sei. ${ }^{2044}$ Beschränkt seien Maßnahmen aus Verhältnismäßigkeitsgesichtspunkten aber auf Gefahrerforschungseingriffe. ${ }^{2045}$ Bei Gefahrerforschungseingriffen handelt es sich um der weiteren Erforschung des Sachverhalts dienende Maßnahmen, um herauszufinden, ob eine konkrete Gefahr besteht oder nicht. ${ }^{2046}$

2039 Kingreen/Poscher, Polizei- und Ordnungsrecht mit Versammlungsrecht, 10. Aufl. 2018, § 8 Rn. 53.

2040 Näher zu den möglichen Spezialermächtigungen Schenke, JuS 2018, 505 (509).

2041 Kingreen/Poscher, Polizei- und Ordnungsrecht mit Versammlungsrecht, 10. Aufl. 2018, § 9 Rn. 24.

2042 Schenke, JuS 2018, 505 (510).

2043 Meyer, JURA 2017, 1259 (1265); Schenke, Polizei- und Ordnungsrecht, 10. Aufl. 2018, Rn. 88a.

2044 Götz/Geis, Allgemeines Polizei- und Ordnungsrecht, 16. Aufl. 2017, § 6 Rn. 31.

2045 Vgl. Schenke, JuS 2018, 505 (510).

2046 Schenke, Polizei- und Ordnungsrecht, 10. Aufl. 2018, Rn. 86.

Nikolas Eisentraut 
Richtigerweise sollten bei bloßem Gefahrenverdacht, bei dem eine konkrete Gefahrensituation fehlt, allein Gefahrerforschungseingriffe zulässig sein, die nicht in die Rechte des Betroffenen eingreifen und deshalb auch keiner Ermächtigungsgrundlage bedürfen. ${ }^{2047}$ Solange keine Ermächtigungsnormen in den Polizei- und Ordnungsgesetzen geschaffen wurden, die eingreifende Maßnahmen im Falle eines Gefahrenverdachts ermöglichen, ${ }^{2048}$ sind sie mangels Gefahr als rechtwidrig zu qualifizieren. Dafür sprechen die ganz zentralen Grundsätze des Vorrangs und Vorbehalts des Gesetzes. ${ }^{2049}$

Die Wahrscheinlichkeit ist jedenfalls dann hinreichend konkret, wenn eine

\section{Schädigung bereits eingetreten ist oder jedenfalls mit Sicherheit zu erwar-} ten ist. ${ }^{2050} \mathrm{Im}$ Bereich darunter variieren die Anforderungen an die Wahrscheinlichkeit in Abhängigkeit vom Rechtsgut: Je gewichtiger das Rechtsgut ist, umso geringer sind die Anforderungen an die hinreichende Wahrscheinlichkeit. $^{2051}$

Hausarbeitswissen: Wie weit der Begriff der konkreten Gefahr in das Vorfeld der Tatbegehung reicht, ist zuletzt intensiv in die Diskussion geraten. Ausgangspunkt waren in Reaktion auf das BKAG-Urteil des BVerfG ${ }^{2052}$ vorgenommene Änderungen am Bayerischen Polizeiaufgabengesetz. ${ }^{2053}$ Mit der sog. „drohenden Gefahr" ${ }^{\text {“2054 }}$ wurde in $\S 11$ Abs. 3 PAG Bayern eine neue „Gefahrenkategorie“ eingeführt, mittels derer bereits die Entstehung einer Gefahr verhindert werden können soll. Unklar ist, ob es sich hierbei um einen Unterfall einer konkreten Gefahr handelt, bei der nur die Wahrscheinlichkeitsschwelle in Hinblick auf die zeitliche und sachliche Dimension gelockert wurde ${ }^{2055}$ oder ob es sich bei der drohenden Gefahr um eine Verlagerung der Eingriffsermächtigung in den einer Gefahr vorgelagerten Bereich handelt. Für Letzteres spricht, das es ansonsten gar keiner Normierung bedurft hätte. In seinem BKAG-Urteil hat das BVerfG jedenfalls nur Überwachungsmaßnahmen bei terroristischen Gefahren im Falle einer drohenden Gefahr für zulässig gehalten; insofern entspricht die

2047 Schenke, Polizei- und Ordnungsrecht, 10. Aufl. 2018, Rn. 88a.

$2048 \mathrm{Zu}$ dieser Forderung Schenke, JuS 2018, 505 (510).

2049 Schenke, Polizei- und Ordnungsrecht, 10. Aufl. 2018, Rn. 88a.

2050 Kingreen/Poscher, Polizei- und Ordnungsrecht mit Versammlungsrecht, 10. Aufl. 2018, § 8 Rn. 6.

2051 Kingreen/Poscher, Polizei- und Ordnungsrecht mit Versammlungsrecht, 10. Aufl. 2018, § 8 Rn. 6.

2052 BVerfG, Urt. v. 20.4.2016, Az.: 1 BvR 966/09 = BVerfGE 141, 220; dazu Kießling, VerwArch 2017, 282.

2053 Kingreen/Poscher, Polizei- und Ordnungsrecht mit Versammlungsrecht, 10. Aufl. 2018, § 8 Rn. 15.

2054 Umfassend zum Begriff Leisner-Egensperger, DÖV 2018, 677.

2055 So Kingreen/Poscher, Polizei- und Ordnungsrecht mit Versammlungsrecht, 10. Aufl. 2018, $\S 8$ Rn. 16. 
Kategorie der drohenden Gefahr der des Gefahrenverdachts. ${ }^{2056}$ Die weitergehenden Eingriffsbefugnisse nach der bayerischen Regelung werden deshalb für verfassungswidrig erachtet. ${ }^{2057}$

1117 Der Gefahrbegriff wird für die Standardmaßnahmen teilweise qualifiziert (sog. qualifizierte Gefahren), sodass über das Vorliegen einer konkreten Gefahr hinausgehende Voraussetzungen $\mathrm{zu}$ prüfen sind. ${ }^{2058}$ Die Normierung der Standardbefugnisse folgt insofern der Je-Desto-Formel: Je eingriffsintensiver eine polizeiliche Maßnahme ist, desto höher sind die Anforderungen an den Gefahrbegriff. ${ }^{2059}$ Die Begriffe der „Gefahr für Leib und Leben“, der „gemeinen Gefahr“ und der „erheblichen Gefahr“ zeigen an, dass ein besonderes Gewicht der drohenden Schädigung vorliegen muss. ${ }^{2060}$ Wenn eine besondere zeitliche Nähe verlangt wird, sprechen die Polizei- und Ordnungsgesetze von „gegenwärtiger Gefahr“, „unmittelbar bevorstehender Gefahr“ oder einer „Gefahr im Verzug“. 2061 Der Begriff der „dringenden Gefahr“ wird nicht einheitlich zwischen diesen Polen verortet. $^{2062}$

\section{(d) Polizei- und Ordnungspflichtigkeit}

1118 Auch wenn sich dies nicht unmittelbar aus dem Wortlaut der Generalklausel ergibt, dürfen auf die Generalklausel gestützte Verwaltungsakte rechtmäßiger Weise nur an die sog. Polizei- bzw. Ordnungspflichtigen adressiert werden. ${ }^{2063}$ Dies wird für alle Maßnahmen nach den Polizei- und Ordnungsgesetzen in eigenständigen Normen angeordnet. ${ }^{2064}$

1119 Teilweise wird die Polizei- und Ordnungspflichtigkeit nicht der Prüfung der Tatbestandsmerkmale zugeordnet, sondern als eigener Prüfungspunkt zwi-

2056 Trurnit, JURA 2019, 258 (265); Weiterentwicklung nach Shirvani, DVBl 2018, 1393 (1395). 2057 Kingreen/Poscher, Polizei- und Ordnungsrecht mit Versammlungsrecht, 10. Aufl. 2018, § 8 Rn. 18; Shirvani, DVBl 2018, 1393; a. A. Holzner, DÖV 2018, 946.

2058 Schenke, Polizei- und Ordnungsrecht, 10. Aufl. 2018, Rn. 78.

2059 Trurnit, JURA 2019, 258 (263).

2060 Kingreen/Poscher, Polizei- und Ordnungsrecht mit Versammlungsrecht, 10. Aufl. 2018, § 8 Rn. 21.

2061 Kingreen/Poscher, Polizei- und Ordnungsrecht mit Versammlungsrecht, 10. Aufl. 2018, § 8 Rn. 21.

2062 Kingreen/Poscher, Polizei- und Ordnungsrecht mit Versammlungsrecht, 10. Aufl. 2018, § 8 Rn. 21.

2063 Kingreen/Poscher, Polizei- und Ordnungsrecht mit Versammlungsrecht, 10. Aufl. 2018, § 9 Rn. 1.

2064 S. bspw. für Berlin die $\S \S 13,14$ und 16 ASOG.

Nikolas Eisentraut 
schen Tatbestand und Rechtsfolge geprüft. ${ }^{2065}$ Vorliegend wird die Prüfung, ob überhaupt ein Polizei- bzw. Ordnungspflichtiger in Anspruch genommen wurde, bereits als Aspekt der Tatbestandsmäßigkeit geprüft. Die Frage der richtigen Auswahl unter mehreren in Betracht kommenden Störern wird hingegen als Ermessensentscheidung der Rechtsfolgenseite zugeordnet.

In den Polizei- und Ordnungsgesetzen wird zwischen verschiedenen Polizei-/ 1120 Ordnungspflichtigen unterschieden:

(1.) dem Verhaltensstörer, (2.) dem Zustandsstörer und (3.) dem Nichtstörer.

(1.) Der Verhaltensstörer ist derjenige, dessen Handeln oder Unterlassen die $\mathbf{1 1 2 1}$ Gefahrenquelle darstellt (sog. Verhaltensverantwortlichkeit). ${ }^{2066}$ Bei der Verhaltensverantwortlichkeit kommt es weder darauf an, dass den Verhaltensstörer ein Verschulden trifft, noch darauf, ob der Störer einsichts- oder verschuldensfähig ist. $^{2067}$

Examenswissen: Für Kinder unter 14, teilweise auch unter 16 Jahren wird zudem eine sog. Zusatzverantwortlichkeit der aufsichtspflichtigen Personen angenommen, die neben die Verhaltensverantwortlichkeit tritt. ${ }^{2068}$

Wann ein Handeln oder Unterlassen für eine Gefahrenquelle ursächlich ist, wird 1123 im Polizei- und Ordnungsrecht nach der sog. Theorie der unmittelbaren Verursachung beurteilt. ${ }^{2069}$ Danach ist jedes Verhalten ursächlich, das die „Gefahrengrenze“ überschreitet. ${ }^{2070}$ Dafür erforderlich ist letztlich eine Wertung, welcher Beitrag noch als unmittelbare Verursachung gelten soll. ${ }^{2071}$ In Prüfungsarbeiten ist daher unter Auswertung der Sachverhaltsangaben eine vertretbare und mit Argumenten untermauerte Lösung zu finden, ob ein Beitrag eine Verhaltensverantwortlichkeit begründen kann oder nicht.

2065 Allgemein für die Adressatenstellung Peine/Siegel, Allgemeines Verwaltungsrecht, 12. Aufl. 2018, Rn. 526, 528.

2066 Kingreen/Poscher, Polizei- und Ordnungsrecht mit Versammlungsrecht, 10. Aufl. 2018, § 9 Rn. 2.

2067 Kingreen/Poscher, Polizei- und Ordnungsrecht mit Versammlungsrecht, 10. Aufl. 2018, § 9 Rn. 5.

2068 Näher Schenke, Polizei- und Ordnungsrecht, 10. Aufl. 2018, Rn. 265ff.; Kingreen/Poscher, Polizei- und Ordnungsrecht mit Versammlungsrecht, 10. Aufl. 2018, § 9 Rn. 5.

2069 Die aus dem Strafrecht bekannte Äquivalenztheorie findet keine Anwendung, s. näher Kingreen/Poscher, Polizei- und Ordnungsrecht mit Versammlungsrecht, 10. Aufl. 2018, § 9 Rn. 10 sowie auch Schenke, Polizei- und Ordnungsrecht, 10. Aufl. 2018, Rn. $241 \mathrm{ff}$.

2070 Kingreen/Poscher, Polizei- und Ordnungsrecht mit Versammlungsrecht, 10. Aufl. 2018, § 9 Rn. 15.

2071 Schenke, Polizei- und Ordnungsrecht, 10. Aufl. 2018, Rn. 243. 
Eine besondere und in Klausurlösungen als Standardproblem zu beherrschende Problematik stellt die Fallgruppe der sog. Zweckveranlasser dar. Zweckveranlasser ist derjenige, der das Verhalten eines Verhaltensstörers subjektiv oder objektiv bezweckt, anstatt selbst die Gefahrengrenze zu überschreiten. ${ }^{2072}$

Beispiel: Eine Schaufensterwerbung führt dazu, dass es zu Menschenansammlungen nicht nur auf dem Gehsteig, sondern auch auf der Straße kommt, sodass der Straßenverkehr behindert wird. Die Gefahrengrenze überschreiten die Passanten, die auf der Fahrbahn stehen. Fraglich ist jedoch, ob auch der das Schaufenster verantwortende Geschäftsinhaber polizeipflichtig ist.

Weiteres Beispiel: Auch der Veranstalter eines Fußballspiels kann als Zweckveranlasser polizeipflichtig sein, wenn es zu Ausschreitungen der Fans kommt. ${ }^{2073}$

1125 Die dogmatische Herleitung der Polizei- und Ordnungspflichtigkeit des Zweckveranlassers stellt die Literatur vor Herausforderungen. ${ }^{2074}$ Ob etwa objektive oder subjektive Kriterien zugrunde zu legen sind, ist umstritten, teilweise wird auch ein Nebeneinander der Theorien angenommen, weil beide Aspekte für die Frage der Zurechnung der Störereigenschaft von Belang sein könnten. ${ }^{2075}$ Teilweise wird die Figur für verzichtbar gehalten, soweit eine Inanspruchnahme als Nichtstörer in Betracht kommt (dazu sogleich Rn. 1128). ${ }^{2076}$ In Prüfungsarbeiten kommt es darauf an, unter Aufzeigung der in der Literatur zum Thema der Zweckveranlassung vertretenen Positionen $\mathrm{zu}$ einem vertretbaren Ergebnis zu gelangen, was wiederum eine gut begründete Wertung verlangt. ${ }^{2077}$

1126 (2.) Der Zustandsstörer ist derjenige, der für eine Sache verantwortlich ist, die die Gefahrenquelle darstellt (sog. Zustandsverantwortlichkeit). ${ }^{2078}$ Sowohl die tatsächliche Gewalt über eine Sache als auch das Eigentum daran können die Verantwortlichkeit begründen. ${ }^{2079}$ Die überwiegende Ansicht fordert auch für eine

2072 Kingreen/Poscher, Polizei- und Ordnungsrecht mit Versammlungsrecht, 10. Aufl. 2018, § 9 Rn. 27; Schoch, JURA 2009, 360.

2073 OVG Berlin-Brandenburg, Beschl. v. 27.9.2013, Az.: 1 S 245.13, juris Rn. 2, s. Kingreen/Poscher, Polizei- und Ordnungsrecht mit Versammlungsrecht, 10. Aufl. 2018, § 9 Rn. 28.

$2074 \mathrm{Zu}$ den Ansätzen Kingreen/Poscher, Polizei- und Ordnungsrecht mit Versammlungsrecht, 10. Aufl. 2018, § 9 Rn. 29.

2075 Näher Schenke, Polizei- und Ordnungsrecht, 10. Aufl. 2018, Rn. $244 \mathrm{f}$.

2076 In diese Richtung Kingreen/Poscher, Polizei- und Ordnungsrecht mit Versammlungsrecht, 10. Aufl. 2018, §9 Rn. 31.

2077 Die Figur des Zweckveranlassers präsentieren in einer Falllösung zu einer Original-Examensklausur Hebeler/Spitzlei, JA 2019, 282 (285f.).

2078 Kingreen/Poscher, Polizei- und Ordnungsrecht mit Versammlungsrecht, 10. Aufl. 2018, § 8 Rn. 2.

2079 Schenke, Polizei- und Ordnungsrecht, 10. Aufl. 2018, Rn. 268.

\section{Nikolas Eisentraut}


Sache das Überschreiten der Gefahrengrenze i.S.d. Theorie der unmittelbaren Verursachung. ${ }^{2080}$

Gibt es mehrere Zustands- und womöglich auch Verhaltensstörer, muss 1127 in der Klausur zunächst nur festgestellt werden, dass die Behörde jedenfalls eine als Störer zu qualifizierende Person in Anspruch genommen hat. Ob diese Auswahl auch richtig war, ist eine Frage der Ermessensausübung der Behörde und daher auf Rechtsfolgenseite zu erörtern (s. näher Rn. 1139).

(3.) Sollte weder der Verhaltensstörer, noch der Zustandsstörer in Anspruch 1128 genommen werden können, so können Polizei- und Ordnungsbehörden die Gefahr selbst beseitigen. ${ }^{2081}$ Sollte dies nicht möglich sein, kann schließlich der sog. Nicht-Störer in Anspruch genommen werden. ${ }^{2082}$ Die Voraussetzungen für ein Vorgehen gegen den Nichtstörer (auch polizeilicher Notstand genannt) sind in allen Polizei- und Ordnungsgesetzen der Länder konkretisiert worden. ${ }^{2083}$

Eine besondere Problematik bildet die Frage der Rechtsnachfolge in Polizei- 1129 und Ordnungspflichten. Eine Rechtsnachfolge wird beispielsweise im Todesfall durch die Erbfolge ausgelöst. In diesem Fall stellt sich die Frage, ob die Polizeibzw. Ordnungspflichtigkeit auf den Rechtsnachfolger übergehen kann. Es geht also darum, ob ein polizei- bzw. ordnungsrechtliches Vorgehen gegen den Rechtsnachfolger neu eingeleitet werden muss oder ob es fortgeführt werden kann (indem beispielsweise ein bestandskräftiger Verwaltungsakt auch gegen den Rechtsnachfolger vollstreckt wird). ${ }^{2084}$ Die Diskussion wird durch die Vielzahl an in der Literatur eingeführten Differenzierungskriterien noch erschwert. ${ }^{2085}$ Für eine erfolgreiche Klausurbearbeitung sollte die Kenntnis der folgenden Grundzüge reichen, um zu einer vertretbaren Lösung zu gelangen:

2080 Schenke, Polizei- und Ordnungsrecht, 10. Aufl. 2018, Rn. 268; Kingreen/Poscher, Polizeiund Ordnungsrecht mit Versammlungsrecht, 10. Aufl. 2018, § 9 Rn. 45.

2081 Kingreen/Poscher, Polizei- und Ordnungsrecht mit Versammlungsrecht, 10. Aufl. 2018, § 8 Rn. 2.

2082 Kingreen/Poscher, Polizei- und Ordnungsrecht mit Versammlungsrecht, 10. Aufl. 2018, § 8 Rn. 2.

2083 § 9 BWPolG; Art. 10 bayPAG; Art. 9 III BayLStVG; § 16 ASOG Bln; § 7 BbgPolG; § 18 BbgOBG; $\S 7$ BremPolG; § 10 I HambSOG; § 9 HSOG; § 71 I SOG SOG M-V; § 8 Nds.SOG; § 6 PolG NRW; § 19 NWOBG; § 7 RhPfPOG; § 6 SPolG; § 7 SächsPolG; § 10 SOG LSA; § 220 I SchlHLVwG; § 10 ThürPAG; $\S 13$ ThürOBG; § 20 I BPolG.

2084 Kingreen/Poscher, Polizei- und Ordnungsrecht mit Versammlungsrecht, 10. Aufl. 2018, § 9 Rn. 54.

2085 Die Modifikationen ablehnend Kingreen/Poscher, Polizei- und Ordnungsrecht mit Versammlungsrecht, 10. Aufl. 2018, § 9 Rn. 56.

Nikolas Eisentraut 
Bei höchstpersönlichen Pflichten, also solchen, die allein vom Rechtsvorgänger erfüllt werden können, scheidet eine Rechtsnachfolge aus. ${ }^{2086}$

Ansonsten ist zu differenzieren, ob es um die Rechtsnachfolge in eine $\mathrm{Zu}$ stands- oder Verhaltensverantwortlichkeit geht und ob sich die Verantwortlichkeit bereits konkretisiert hat.

1131 Eine Rechtsnachfolge in eine abstrakte (noch nicht konkretisierte) Zustandsverantwortlichkeit gibt es nicht. Gegen einen neuen Besitzer ergeht einfach eine neue polizei- bzw. ordnungsbehördliche Maßnahme.

Beispiel: A erbt von B ein Grundstück, auf dem ein Baum steht, der auf das Nachbarhaus zu stürzen droht. Gegenüber B wurde jedoch bisher noch keine Verfügung erlassen, wonach B zum Fällen des Baumes verpflichtet würde. Die Ordnungsbehörde kann auf Grundlage der polizeilichen Generalklausel gegenüber A nunmehr eine solche Anordnung treffen.

1132 Die Rechtsnachfolge in eine bereits konkretisierte Zustandsverantwortlichkeit wurde bisher für möglich gehalten. Die Pflichtigkeit „klebt“ sozusagen an der Sache, nicht am Verantwortlichen. Diese Ansicht ist jedoch in die Kritik geraten; vermehrt wird eine gesetzliche Regelung der Überleitung gefordert. ${ }^{2087}$

Beispiel: Bereits zu B's Lebzeiten hat die Behörde eine Fäll-Verfügung erlassen. Als B verstirbt, geht nach traditioneller Sichtweise mit dem Erbfall auch die mit der Verfügung begründete Pflicht, den Baum zu fällen, von B auf den Erben A über.

1133 Eine Rechtsnachfolge in eine abstrakte Verhaltensverantwortlichkeit scheidet aus, wenn sich der Rechtsnachfolger durch eigenes Verhalten der Polizeipflichtigkeit aussetzt. Eine Rechtsnachfolge kommt hier nur bei sog. „unfertigen Verpflichtungen“ in Betracht. ${ }^{2088}$

Beispiel (angelehnt an Kingreen/Poscher, Polizei- und Ordnungsrecht mit Versammlungsrecht, 10. Aufl. 2018, § 9 Rn. 51): Rockstar R spielt zur Nachtzeit regelmäßig und unter voller Verstärkung seine E-Gitarre. Damit gefährdet er die Gesundheit der Patienten im benachbarten Krankenhaus. Als $R$ verstirbt, setzt sein Sohn $S$ die Tätigkeit fort. Die Ordnungsbehörde kann nunmehr direkt gegenüber $S$ eine Ordnungsverfügung erlassen, die ihm das nächtliche Gitarrenspiel untersagt.

2086 Kingreen/Poscher, Polizei- und Ordnungsrecht mit Versammlungsrecht, 10. Aufl. 2018, § 9 Rn. 54.

2087 Siegel, in: Siegel/Waldhoff, Öffentliches Recht in Berlin, 2. Aufl. 2017, § 2 Rn. 115. 2088 Siegel, in: Siegel/Waldhoff, Öffentliches Recht in Berlin, 2. Aufl. 2017, § 2 Rn. 117.

Nikolas Eisentraut 
Die Rechtsnachfolge in eine konkretisierte Verhaltensverantwortlichkeit soll 1134 ohne Überleitungsregelung nicht zulässig sein. ${ }^{2089}$

Beispiel: Gegenüber R wird eine Ordnungsverfügung erlassen, bevor er verstirbt. Ohne Überleitungsvorschrift entfaltet die Ordnungsverfügung keine Wirkungen gegenüber $S$.

\section{(2) Rechtsfolge: Ermessen}

Die Generalklauseln der Polizei- und Ordnungsgesetze eröffnen der zuständi1135 gen Behörde auf Rechtsfolgenseite Ermessen (,kann“) (s. allgemein zum Ermessen Rn. 729 ff.). ${ }^{2090}$ Die behördliche Maßnahme ist daher auf Ermessensfehler zu untersuchen.

Untersucht werden muss einerseits, ob die Behörde ihr Entschließungser- 1136 messen und andererseits, ob sie ihr Auswahlermessen fehlerfrei ausgeübt hat. Folgende Fragen sind im allgemeinen Polizei- und Ordnungsrecht in diesem Kontext typischerweise zu thematisieren:

Im Rahmen der Prüfung des Auswahlermessens kann zunächst zu untersuchen sein, ob die Ermächtigungsgrundlage überhaupt die von der Behörde ergriffene Maßnahme deckt. ${ }^{2091}$ Da die Generalklausel dazu ermächtigt, die „erforderlichen Maßnahmen“ zu ergreifen, ist zu untersuchen, ob die Behörde ihr Ermessen überschritten und in Bezug auf die jeweils streitgegenständliche Maßnahme unverhältnismäßig gehandelt hat. ${ }^{2092}$

Aufbauhinweis: Teilweise wird die Verhältnismäßigkeit auch außerhalb der 1138 Ermessensfehler geprüft, weil die Polizei- und Ordnungsgesetze Verhältnismäßigkeit und Ermessen in jeweils eigenständigen Regelungen thematisieren. Nach überzeugender Ansicht handelt es sich bei der Verhältnismäßigkeit indes um einen Aspekt der Ermessensüberschreitung. ${ }^{2093}$

In die Prüfung des Auswahlermessens auf Ermessensfehler fällt auch die Frage, ob die Behörde die Auswahl unter mehreren Störern rechtsfehlerfrei getroffen hat. Diese Frage ist nur dann aufzuwerfen, wenn auch mehrere taugliche Adressaten für die Maßnahme in Betracht kommen. ${ }^{2094}$ Die Auswahl richtet sich stets zunächst nach dem Effektivitätsgebot, sodass die Behörde grundsätzlich den

2089 Siegel, in: Siegel/Waldhoff, Öffentliches Recht in Berlin, 2. Aufl. 2017, § 2 Rn. 117.

2090 Kingreen/Poscher, Polizei- und Ordnungsrecht mit Versammlungsrecht, 10. Aufl. 2018, § 10 Rn. 34.

2091 Peine/Siegel, Allgemeines Verwaltungsrecht, 12. Aufl. 2018, Rn. 530.

2092 Zum Verhältnismäßigkeitsgrundsatz im Polizei- und Ordnungsrecht näher Kingreen/Poscher, Polizei- und Ordnungsrecht mit Versammlungsrecht, 10. Aufl. 2018, § 10 Rn. $15 \mathrm{ff}$.

2093 Peine/Siegel, Allgemeines Verwaltungsrecht, 12. Aufl. 2018, Rn. $535 \mathrm{f}$.

2094 Peine/Siegel, Allgemeines Verwaltungsrecht, 12. Aufl. 2018, Rn. 529.

Nikolas Eisentraut 
Störer heranziehen darf, durch den sich die Gefahrenbeseitigung am wirksamsten realisieren lässt. ${ }^{2095}$ Bei gleicher Effektivität ist hilfsweise auf den Verhältnismäßigkeitsgrundsatz abzustellen. ${ }^{2096}$

\section{f) Literaturhinweise}

1140 Lehrbuchliteratur zum Polizei- und Ordnungsrecht: Kingreen/Poscher, Polizeiund Ordnungsrecht mit Versammlungsrecht, 10. Aufl. 2018; Schoch, Polizei- und Ordnungsrecht, in: Schoch, Besonderes Verwaltungsrecht, 2018; Schenke, Polizei- und Ordnungsrecht, 10. Aufl. 2018; Götz/Geis, Allgemeines Polizei- und Ordnungsrecht, 16. Aufl. 2017; Gusy, Polizei- und Ordnungsrecht, 10. Aufl. 2017; Lisken/Denninger, Handbuch des Polizeirechts, 6. Aufl. 2018

Lesenswerte Aufsätze: Poscher/Rusteberg, Die Klausur im Polizeirecht, JuS 2011, S. 888 ff., S. 984 ff., 1082ff.; Möstl, Standardmaßnahmen des Polizei- und Ordnungsrechts, JURA 2011, S. 840 ff.; Trurnit, JURA 2019, 258 - Eingriffsschwellen für polizeiliche Maßnahmen; Meyer, JURA 2017, 1259 - Subjektiver oder objektiver Gefahrbegriff, „Gefahrenverdacht“ und Vorfeldbefugnisse: Dauerbaustellen des Gefahrenabwehrrechts; Danne, JuS 2018, 434 - Doppelfunktionale Maßnahmen in der öffentlich-rechtlichen Klausur; Stückemann, JA 2015, 569 Die Rechtsnachfolge in die gefahrenabwehrrechtliche Verhalts- und Zustandsverantwortlichkeit

Falllösung: Fall 1 in: Eisentraut, Fälle zum Verwaltungsrecht, 2020

\section{Ermächtigungsgrundlagen des Versammlungsrechts (Sebastian Eickenjäger)}

1141 Das Versammlungsrecht ist eines der Kernrechtsgebiete des besonderen Verwaltungsrechts, in Studium und Examen stets klausurrelevant ${ }^{2097}$ und nicht zuletzt auch in der Praxis von erheblicher Bedeutung. In Theorie und Praxis stellen sich aktuell Herausforderungen z. B. im Hinblick auf Versammlungen im Rahmen von Großveranstaltungen (G 20), sog. „gemischten“ Veranstaltungen, ${ }^{2098}$

2095 Kingreen/Poscher, Polizei- und Ordnungsrecht mit Versammlungsrecht, 10. Aufl. 2018, § 9 Rn. 89.

2096 Kingreen/Poscher, Polizei- und Ordnungsrecht mit Versammlungsrecht, 10. Aufl. 2018, § 9 Rn. 90.

2097 S. hierzu die in Rn. 1221 angeführten Literaturhinweise.

2098 S. hierzu Petersen, DÖV 2019, 131.

Nikolas Eisentraut/Sebastian Eickenjäger 
Versammlungen im privaten Raum ${ }^{2099}$ (Fraport) sowie hinsichtlich neuer Protestformen (Protestcamps, ${ }^{2100}$ Blockupy Proteste, Flash- und Smartmobs, ${ }^{2101}$ virtuelle Versammlungen ${ }^{2102}$ etc.). $\mathrm{Zu}$ berücksichtigen ist zudem, dass die Versammlungsfreiheit aus Art. 8 GG in hohem Maße durch die Rechtsprechung des BVerfG geprägt wurde und zunehmend auch eine Überlagerung des nationalen Versammlungsrechts durch europäisches, internationales und transnationales Recht $^{2103} \mathrm{zu}$ beobachten ist. Seit die Länder durch die Föderalismusreform im Jahre 2006 die ausschließliche Gesetzgebungskompetenz im Bereich des Versammlungsrechts erlangt haben, sind zudem in Bayern, Niedersachsen, Sachsen, Sachsen-Anhalt und Schleswig-Holstein Landesversammlungsgesetze neben das Bundesversammlungsgesetz (VersammlG) getreten, die teilweise Eingriffsbefugnisse neu regeln. In den Ländern, die bisher kein eigenes Landesversammlungsgesetz erlassen haben, gilt das Versammlungsgesetz des Bundes (VersammlG) gemäß Art. 125a I 1 GG als Bundesrecht fort.

Die folgende Tabelle führt die Versammlungsgesetze des Bundes und der 1142 Länder auf:

\begin{tabular}{|c|c|}
\hline Bund & $\begin{array}{l}\text { Gesetz über Versammlungen und Aufzüge (VersammIG) vom 15. November } \\
1978 \text { (BGBl. I 1789), zuletzt geändert durch Art. } 2 \text { G vom 8. Dezember } 2008 \\
\text { (BGBI. I S. 2366) }\end{array}$ \\
\hline Bayern & $\begin{array}{l}\text { Bayerisches Versammlungsgesetz (BayVersG) vom 22. Juli } 2008 \text { (GVBI. } \\
\text { S. 421), ab 1.10.2008; zuletzt geändert durch § } 1 \text { ÄndG vom 23.11.2015 } \\
\text { (GVBI. S. 410) }\end{array}$ \\
\hline Niedersachsen & $\begin{array}{l}\text { Niedersächsisches Versammlungsgesetz (NdsVersG) vom 7. Oktober } 2010 \\
\text { ab 1.2.2011 (Nds. GVBI. S. 465, ber. S. 532) }\end{array}$ \\
\hline Sachsen & $\begin{array}{l}\text { Gesetz über Versammlungen und Aufzüge im Freistaat Sachsen (Sächs- } \\
\text { VersG) vom 25. Januar } 2012 \text { (SächsGVBI. S. 54); zuletzt geändert durch } \\
\text { Art. } 4 \text { ÄndG vom 17.12. } 2013 \text { (SächsGBI. S. 890) }\end{array}$ \\
\hline
\end{tabular}

2099 S. BVerfG, Urt. v. 22.2.2011, Az.: 1 BvR 699/06 = BVerfGE 128, 266 - Fraport sowie Scharlau, Schutz von Versammlungen auf privatem Grund, 2018.

2100 S. hierzu etwa Hartmann, NVwZ 2018, 200 und Friedrich, DÖV 2019, 55.

2101 S. hierzu Lenski, VerwArch 103 (2012), 539; Neumann, NVwZ 2011, 1171.

2102 S. hierzu etwa Kersten, JuS 2017, 193; Möhlen, MMR 2013, 221; Vogelsang, Kommunikationsformen des Internetzeitalters im Lichte der Kommunikationsfreiheiten des Grundgesetzes, 2017.

2103 S. hierzu Ripke, Europäische Versammlungsfreiheit, 2012; Eickenjäger/Fischer-Lescano, Transnationalisierung des Versammlungsrechts, in: Ridder/Breitbach/Deiseroth, Kommentar Versammlungsrecht, i.E. 
Sachsen-Anhalt Gesetz des Landes Sachsen-Anhalt über Versammlungen und Aufzüge (VersG LSA) vom 3. Dezember 2009 (GVBI. LSA S. 558), ab 12.12.2009

Schleswig-Holstein Versammlungsfreiheitsgesetz für das Land Schleswig-Holstein (VersFG SH) vom 18. Juni 2015 (GVOBI. Schlesw.-H. 135)

\section{a) Versammlungsrecht in der Klausurbearbeitung}

1143 In der Klausur wird es sich regelmäßig um Anfechtungssituationen im Hinblick auf Maßnahmen gegen (geplante) Versammlungen handeln. Da die Maßnahmen nach dem Versammlungsrecht typischerweise als Verwaltungsakte zu qualifizieren sind, ist damit im Grundsatz die Anfechtungsklage statthaft.

1144 In Abwandlung der Grundkonstellation der Anfechtungsklage treffen Studierende zudem auf die Konstellation, dass eine geplante Versammlung unmittelbar bevorsteht. Hier ist oftmals ein Antrag auf Eilrechtsschutz nach \$ 80 V VwGO, gerichtet auf die Wiederherstellung bzw. Anordnung der aufschiebenden Wirkung eines Rechtsbehelfs, gegen sofort vollziehbare Maßnahmen zu prüfen (zum Antrag nach $\S 80 \mathrm{~V}$ VwGO § 8).

1145 Außerdem ist in der Klausur häufig die Fortsetzungsfeststellungklage statthaft, etwa wenn es um bereits erledigte Maßnahmen im Rahmen einer Versammlung oder um eine Auflösung der Versammlung geht. Das erforderliche Fortsetzungsfeststellungsinteresse wird hierbei regelmäßig aufgrund schwerwiegender Eingriffe in Art. 8 GG, eines bestehenden Rehabilitationsinteresses oder aufgrund bestehender Wiederholungsgefahr gegeben sein (zur Fortsetzungsfeststellungsklage § 4).

1146 Die Feststellungsklage nach $\S 43$ I VwGO ist im Rahmen des Versammlungsrechts etwa bzgl. der Feststellung der Rechtswidrigkeit der Erhebung und Verarbeitung von Daten einschlägig. ${ }^{2104}$ An einem anfechtbaren Verwaltungsakt fehlt es auch bei den in Klausuren immer wieder relevanten Gefährder*innenansprachen (s. hierzu auch Rn. 224f. und 1003 (Polizeirecht)), mit denen einzelnen Personen empfohlen wird, von Veranstaltungen fernzubleiben und zugleich mitgeteilt wird, dass ihnen gegenüber ansonsten Maßnahmen nach dem Polizeioder Versammlungsrecht vorgenommen werden, soweit die Voraussetzungen hierfür vorliegen (zur Feststellungsklage näher § 6).

2104 S. BVerwG, Urt. v. 25.10.2017, Az.: 6 C 45.16 = BeckRS 2017, 138147, wo mit der Erhebung der Feststellungsklage u. a. die Feststellung der Rechtswidrigkeit der Anfertigung von Bildaufnahmen mittels des Einsatzes von Tornado-Kampfflugzeugen begehrt wurde. 
Examenswissen: Entsprechende Anschreiben oder Ansprachen enthalten hinweisende Elemente (Mitteilung des Kenntnisstandes der Behörde bezüglich der betreffenden Person), empfehlende Elemente (den Hinweis, bestimmte Dinge zu tun bzw. zu unterlassen) und auch warnende Elemente (es drohen bestimmte behördliche Maßnahmen, wenn die Person nicht wie empfohlen handelt), geben jedoch kein Tun, Dulden oder Unterlassen rechtsverbindlich auf. Da die Ansprachen damit nicht darauf gerichtet sind, eine verbindliche Rechtsfolge festzusetzen und es mithin an einer Regelung im Sinne des $§ 351$ VwVfG fehlt, sind sie nicht als Verwaltungsakt zu qualifizieren. Die statthafte Klageart wäre somit entweder die allgemeine Leistungsklage (wenn die Ansprache oder ein Anschreiben für gegenstandslos erklärt werden soll) oder die Feststellungsklage (wenn festgestellt werden soll, dass die Behörde nicht berechtigt war, eine entsprechende Ansprache vorzunehmen oder ein entsprechendes Schreiben aufzusetzen) (zur allgemeinen Leistungsklage näher §5).

Die genannten Klausurkonstellationen setzen jeweils voraus, dass die zentralen 1148

Eingriffsgrundlagen des Versammlungsrechts geprüft werden können. Im Folgenden werden daher die für die Fallbearbeitung wichtigsten Eingriffsgrundlagen vorgestellt. Hierbei werden zwei Unterscheidungen vorgenommen: Zum einen zwischen Ermächtigungsgrundlagen für Eingriffe in Versammlungen unter freiem Himmel und Versammlungen in geschlossenen Räumen und zum anderen zwischen den Eingriffsbefugnissen nach dem Bundesversammlungsgesetz (VersammlG) und den Landesversammlungsgesetzen.

\section{b) Ermächtigungsgrundlagen}

Bevor in der Klausur Eingriffsgrundlagen des Versammlungsrechts (hierzu unten dd) herangezogen werden, ist zunächst (zumindest gedanklich) zu prüfen, ob der Anwendungsbereich der Versammlungsgesetze des Bundes und der Länder überhaupt eröffnet ist. Dies kann verneint werden, wenn keine Versammlung im Sinne der jeweiligen Versammlungsgesetze vorliegt (aa), wenn das jeweilige Versammlungsgesetz nur auf öffentliche Versammlungen Anwendung findet, es sich jedoch um eine nichtöffentliche Versammlung handelt (bb), und zuletzt, wenn ausnahmsweise die Sperrwirkung des Versammlungsrechts (sogenannte Polizeirechtsfestigkeit des Versammlungsrechts, s. dazu auch Rn. 1037 ff.) nicht greift (cc).

\section{aa) Versammlungsbegriffe der Versammlungsgesetze}

Zunächst zu der Frage, wann eine Veranstaltung nach den der Versammlungs- 1150 gesetze jeweils zugrundeliegenden Versammlungsbegriffen als Versammlung zu qualifizieren ist: 
Versammlung vor. In der Literatur besteht deshalb Uneinigkeit bzgl. der Frage, ob zwischen dem Begriff des §1 VersammlG und dem des Art. 8 I GG zu unterscheiden oder von einem einheitlichen Versammlungsbegriff auszugehen ist. ${ }^{2105}$ Eine Unterscheidung ist jedenfalls dort vorzunehmen, wo der Schutzbereich des Art. 8 I GG und der Regelungsbereich des VersammlG auseinanderfallen. ${ }^{2106} \mathrm{Zu}$ beachten ist in diesem Zusammenhang zunächst, dass Art. 8 I GG die Versammlungsfreiheit dem Wortlaut nach als Bürgerrecht vorsieht, ${ }^{2107}$ nach $\S 1$ I VersammlG jedoch ,jedermann“ berechtigt ist. Außerdem schützt Art. 8 I GG öffentliche wie nichtöffentliche Versammlungen, während das VersammlG gemäß $\S 1 \mathrm{I}$ grds. nur öffentliche Versammlungen umfasst (s. hierzu Rn. 1157f.). Schließlich sind vom VersammlG auch unfriedliche Versammlungen umfasst, obwohl diese vom Schutzbereich des Art. 8 I GG ausgeschlossen sind. ${ }^{2108}$

Von diesen Unterschieden abgesehen ist auf den Versammlungsbegriff des Art. 8 I GG in der Ausprägung durch die Rechtsprechung des BVerfG abzustellen, wonach es sich bei Zusammenkünften mehrerer Personen zur gemeinschaftlichen, auf die Teilhabe an der öffentlichen Meinungsbildung gerichteten Erörterung oder Kundgebung um eine Versammlung handelt. ${ }^{2109}$ In der Literatur besteht im Hinblick auf diese Definition Uneinigkeit darüber, welche Mindestteilnehmer^innenzahl gegeben sein muss und welche materiellen Anforderungen an den Zweck einer Veranstaltung zu stellen sind.

1153 Bzgl. der erforderlichen Anzahl der Teilnehmer^innen geht die h.M. von einer Mindestanzahl von zwei Personen aus, während andere mindestens drei ${ }^{2110}$ oder - mit Verweis auf die Mindestpersonenzahl für die Gründung von Vereinen - sieben Personen fordern. ${ }^{2111}$

Im Hinblick auf die Anforderungen an den Zweck einer Veranstaltung besteht Einigkeit darüber, dass bloße Ansammlungen mangels innerer Verbindung nicht von der Versammlungsfreiheit geschützt werden. Davon abgesehen werden ein enger und ein weiter Versammlungsbegriff vertreten. Der weite Versamm-

2105 Laut BVerwG entspricht der Versammlungsbegriff des Versammlungsgesetzes demjenigen des Grundgesetzes, Urt. v. 16.05.2007, Az.: 6 C 23/06 = BVerwGE 129, 42 [45]. Zu dem Streitstand s. Kniesel/Braun/Keller, Besonderes Polizei- und Ordnungsrecht, 1. Aufl. 2018, Rn. 174 ff. m.w. N. 2106 Kniesel/Braun/Keller, Besonderes Polizei- und Ordnungsrecht, 1. Aufl. 2018, Rn. 174.

2107 S. hierzu Fischer-Lescano, Deutschengrundrechte: Ein Anachronismus, 2019, i.E. 2108 Kniesel/Braun/Keller, Besonderes Polizei- und Ordnungsrecht, 1. Aufl. 2018, Rn. 175. 2109 S. zuletzt BVerfG, Beschl. v. 27.10.2016, Az.: 1 BvR 458/10 = BVerfGE 143, 161 (210). 2110 OLG Saarbrücken, Beschl. v. 15.09.1998, Az.: Ss Z 225-98 (106-98) = NStZ-RR 1999, 119. 2111 S. hierzu Kniesel/Braun/Keller, Besonderes Polizei- und Ordnungsrecht, 1. Aufl. 2018, Rn. 62. 
lungsbegriff will eine Öffnung zugunsten von unpolitischen und privaten Formen des sich-versammelns umfassen, so dass auch ausschließlich genussorientierte Sport- und Musikveranstaltungen umfasst wären, solange kollektive Öffentlichkeit besteht. ${ }^{2112}$ Der enge Versammlungsbegriff, zu dem wohl auch das BVerfG tendiert, ${ }^{2113}$ verlangt, dass über das bloße Sich-Versammeln hinaus eine Meinungskundgabe erfolgen muss, die das Ziel hat, auf die Öffentlichkeit einzuwirken. ${ }^{2114}$

Examenswissen: Der EGMR hat zuletzt ausdrücklich davon abgesehen, den Versammlungsbegriff (des Art. 11 I EMRK) zu definieren oder Kriterien zur Bestimmung festzulegen, um die Gefahr einer restriktiven Interpretation zu vermeiden. ${ }^{2115}$ Im Anschluss daran wird in der Literatur für einen offenen Versammlungsbegriff plädiert, der sich von formellen (insbesondere körperliche Anwesenheit oder Mindestteilnehmer`innenzahl) und materiellen (bestimmter Zweck der Meinungsbildung) Kriterien freimacht und das Vorliegen einer Versammlung bejaht, wenn die Möglichkeit besteht, dass die Versammlung der kommunikativen Entfaltung in der Öffentlichkeit dient und es sich um einen Beitrag zur demokratischen Öffentlichkeit handelt. ${ }^{2116}$

Die Versammlungsgesetze Bayerns, Niedersachsens, Sachsens und Schleswig- 1156 Holsteins haben den engen Versammlungsbegriff des BVerfG übernommen. ${ }^{2117}$ In $\S 2$ I VersFG SH wurde eine Mindestteilnehmer^innenzahl von drei Personen und in Art. 2 I BayVersG, § 2 NdsVersG sowie § 1 III SächsVersG von zwei Personen bestimmt. §1 VersG LSA ist wortgleich mit § 1 VersammlG, womit diesbezüglich auf die Ausführungen zum Bundesversammlungsgesetz verwiesen werden kann.

\section{bb) Öffentliche und nichtöffentliche Versammlungen}

Die Versammlungsgesetze des Bundes und der Länder beantworten die Frage, ob 1157 sie sowohl auf öffentliche als auch auf nichtöffentliche Versammlungen anwendbar sind oder nicht, ganz unterschiedlich.

Bzgl. des VersammlG - dessen Eingriffsbefugnisse nicht auf nichtöffentliche Versammlungen anzuwenden sind - geht eine Ansicht davon aus, dass die

2112 So etwa Depenheuer in: Maunz/Dürig, GG, Art. 8, 48. EL 2006, Rn. 47.

2113 Petersen, DÖV 2019, 131 (132), m.w. N.

2114 BVerwG, Urt. v. 25.10.2017, Az.: 6 C 46/16 = NJW 2018, 716 (719).

2115 EGMR, Urt. v. 15.11.2018, Az.: 29580/12, 36847/12, 11252/13, 12317/13, 43746/14 (Navalnyy/ Russland), Rn. 98.

2116 S. hierzu Eickenjäger/Fischer-Lescano, Transnationalisierung des Versammlungsrechts, in: Ridder/Breitbach/Deiseroth, Kommentar Versammlungsrecht, i.E.

2117 Enders, in: Dürig-Friedel/Enders, Versammlungsrecht, 2016, § 1 VersammlG, Rn. 51 ff., 62 ff., 69f., 77 f. Vgl. auch Kniesel, in: Dietel/Kintzel/Kniesel, Versammlungsgesetze, 17. Aufl. 2016, § 1 VersammlG, Rn. 17 ff.; Petersen, DÖV 2019, 131 (132). 
Bestimmungen des VersammlG analog anzuwenden sind. ${ }^{2118}$ Hierfür spreche insbesondere, dass es sinn- und systemwidrig wäre, wenn die nichtöffentliche Versammlung - die weniger gefährdet und gefährlich sei als die öffentliche Versammlung - auf der Grundlage des allgemeinen Polizei- und Ordnungsrechts leichter eingeschränkt werden dürfte als eine öffentliche auf der Grundlage des Versammlungsrechts. Eine andere Ansicht geht von der Anwendbarkeit des allgemeinen Polizei- und Ordnungsrechts aus mit der Maßgabe, dass eine „verfassungsorientierte Interpretation“ der Ermächtigungsgrundlagen des allgemeinen Polizei- und Ordnungsrechts vorzunehmen sei, im Rahmen derer der besonderen Bedeutung des Art. 8 GG Rechnung zu tragen sei. ${ }^{2119}$

1159 Für das BayVersG gilt, dass dieses ausdrücklich gemäß Art. 2 III BayVersG im Hinblick auf die hier relevanten Eingriffsbefugnisse nur auf öffentliche Versammlungen Anwendung findet. Die Versammlungsgesetze in Sachsen (SächsVersG) und Sachsen-Anhalt (VersG LSA) beschränken sich ebenfalls (wie das VersammlG) auf öffentliche Versammlungen. Da hier eine analoge Anwendung des jeweiligen Landesversammlungsgesetzes offensichtlich mangels planwidriger Regelungslücke ausscheidet, kann in Bayern, Sachsen und Sachsen-Anhalt gegenüber nichtöffentlichen Versammlungen auf die allgemeinen Befugnisse nach dem allgemeinen Polizei- und Ordnungsrecht zurückgegriffen werden. ${ }^{2120}$ Da auch nichtöffentliche Versammlungen in den Schutzbereich der Versammlungsfreiheit fallen, sind hierbei jedoch stets die strengen Anforderungen des Art. 8 GG zu berücksichtigen. Dies gilt insbesondere im Hinblick auf nichtöffentliche Versammlungen in geschlossenen Räumen, bei denen ein Einschreiten nur bei Verstößen gegen das Waffenverbot, den Friedlichkeitsgrundsatz und zum Schutz gleichgewichtiger Verfassungsgüter zulässig ist. ${ }^{2121}$

1160 Anders verhält es sich beim NdsVersG, das gleichermaßen auf öffentliche und nichtöffentliche Versammlungen Anwendung findet und deshalb grds. Sperrwirkung gegenüber dem allgemeinen Polizei- und Ordnungsrecht entfaltet. ${ }^{2122}$ Das VersFG SH gilt grds. genauso wie das NdsVersG gemäß §§ 1 I und 2 III VersFG SH für öffentliche wie für nichtöffentliche Versammlungen.

1161 Folgende Tabelle stellt die vorherigen Ausführungen überblicksartig dar:

2118 S. etwa Rühl, NVwZ 1988, 577 (579, 581); Kingreen/Poscher, Polizei- und Ordnungsrecht, 10. Aufl. 2018, § 19 Rn. 16.

2119 S. BVerwG, Urt. v. 23.3.1999, Az.: 1 C 12/97 = NVwZ 1999, 991 (992); Kniesel/Poscher, in: Lisken/Denninger, Handbuch des Polizeirechts, 6. Aufl. 2018, K, Rn. $21 \mathrm{f}$.

2120 Kniesel, in: Dietel/Kintzel/Kniesel, Versammlungsgesetze, 17. Aufl. 2016, §1 VersammlG, Rn. 20, $27 \mathrm{f}$.

2121 Heinhold, in: Wöchtler/Heinhold/Merk, BayVersG, 1. Aufl. 2011, Art. 2, Rn. 36.

2122 Miller, in: Wefelmeier/Miller, NdsVersG, 1. Aufl. 2012, § 2, Rn. 4.

Sebastian Eickenjäger 


\begin{tabular}{ll}
\hline $\begin{array}{l}\text { Im Geltungsbereich der folgenden } \\
\text { Versammlungsgesetze ... }\end{array}$ & $\begin{array}{l}\text {... auf nichtöffentliche Versammlungen anwendbares } \\
\text { Recht. }\end{array}$ \\
\hline VersammIG & $\begin{array}{l}\text { E.A.: analoge Anwendung VersammlG } \\
\text { A.A.: verfassungskonform interpretierte Bestimmungen } \\
\text { des allgemeinen Polizeirechts }\end{array}$ \\
\hline BayVersG & Verfassungskonform interpretierte Bestimmungen \\
& BayPAG \\
\hline NdsVersG & NdsVersG \\
\hline SächsVersG & Verfassungskonform interpretierte Bestimmungen \\
\hline VersG LSA & SächsPolG \\
\hline VersFG SH & Verfassungskonform interpretierte Bestimmungen \\
\hline
\end{tabular}

\section{cc) Polizeirechtsfestigkeit des Versammlungsrechts}

Die Formel der Polizeirechtsfestigkeit des Versammlungsrechts (hierzu auch Rn. 1037 ff.) beschreibt die Abgrenzung des Versammlungsrechts (als lex specialis) vom allgemeinen Polizei- und Ordnungsrecht (als lex generali) und dient dem besonderen Schutz der in Art. 8 I GG garantierten Versammlungsfreiheit. ${ }^{2123}$ In Versammlungen soll grds. nur nach Maßgabe der strengen Vorgaben des Versammlungsrechts eingegriffen werden können. Zudem zeichnen sich die Steuerungskonzepte der Bundes- und Landesversammlungsgesetze dadurch aus, dass sie Veranstalter`innen und Leitung in hohem Maße die Verantwortung für die Einhaltung des gesetzlichen Rahmens der Versammlungsfreiheit übertragen. ${ }^{2124}$ Insofern dient die „Sperrwirkung“ des Versammlungsrechts auch der Sicherstellung der „Autonomie“ der Versammlung. Der Rückgriff auf das allgemeine Polizei- und Ordnungsrecht zur Einschränkung der Versammlungsfreiheit ist daher nur zulässig, wenn die Versammlungsgesetze selbst keine abschließenden Regelungen enthalten.

Im Vorfeld der Versammlung entfalten die Bestimmungen der Versamm1163 lungsgesetze gegenüber der Gesamtversammlung mangels Regelungslücke vollumfänglich Sperrwirkung. Ein Rückgriff auf das allgemeine Polizei- und Ordnungsrecht ist jedoch ausnahmsweise zulässig, soweit es sich um Maßnahmen

2123 Götz/Geis, Allgemeines Polizei- und Ordnungsrecht, 16. Aufl. 2017, § 23 Rn. 38.

2124 Kniesel/Poscher, in: Lisken/Denninger, Handbuch des Polizeirechts, 6. Aufl. 2018, K, Rn. 24. 
gegenüber einzelnen Teilnehmer*innen handelt. ${ }^{2125}$ Hierzu zählen etwa Gefährder*innenansprachen, Meldeauflagen, Personenkontrollen, Durchsuchungen, Beschlagnahmen sowie Teilnahmeuntersagungen. Das Bundesversammlungsgesetz sieht hierfür keine Ermächtigungsgrundlagen vor. Und da es der Versammlung (bzw. den Veranstalter`innen und der Leitung) auch an organisatorischen Möglichkeiten und der nötigen Infrastruktur fehlt, um selbst (d.h. autonom) im Hinblick auf anreisende Teilnehmer^innen für die Wahrung der öffentlichen Sicherheit und Ordnung zu sorgen, können die Behörden hier ausnahmsweise auf das allgemeine Polizei- und Ordnungsrecht zurückgreifen. ${ }^{2126} \mathrm{Zu}$ beachten ist jedoch, dass manche Landesversammlungsgesetze solche „Vorfeldmaßnahmen“ gegenüber einzelnen Teilnehmer`innen teilweise bereits gesetzlich geregelt haben (s. hierzu Rn. $1086 \mathrm{ff}$. und $1204 \mathrm{ff}$.).

Während der Versammlung können die Behörden nach der h.M. vermittelt über § 15 I VersammlG bzw. § 13 I 2 VersammlG Eingriffe auf das allgemeine Polizei- und Ordnungsrecht stützen, wenn hierdurch die eingriffsintensive Auflösung vermieden werden kann. ${ }^{2127}$ Als so genannte „Minusmaßnahmen“ (hierzu Rn. 1218ff.) kommen etwa die Sicherstellung gefährlicher Gegenstände, der Austausch von Leiter ${ }^{\star}$ innen und Ordner`innen, der Ausschluss von Teilnehmer^innen sowie das Verbot der Verwendung einzelner strafrechtlich relevanter Musikstücke oder Plakate in Betracht. Auch hier ist zu berücksichtigen, dass mittlerweile manche Landesversammlungsgesetze entsprechende Minusmaßnahmen ausdrücklich geregelt haben (hierzu Rn. $1186 \mathrm{ff}$. und $1204 \mathrm{ff}$.).

1165 Die h.M. in der Literatur und Rechtsprechung geht zudem davon aus, dass entgegen der Sperrwirkung bzw. der Polizeirechtsfestigkeit des Versammlungsrechts - bzgl. „nicht versammlungsspezifischer Gefahren“ (etwa bau-, feuer-, oder gesundheitspolizeilicher Art) auf die Regelungen des allgemeinen Polizeirechts zurückgegriffen werden kann. ${ }^{2128}$

2125 BVerwG, Urt. v. 25.10.2017, Az.: 6 C 45.16 = BeckRS 2017, 138147, Rn. 16.

2126 Kniesel/Poscher, in: Lisken/Denninger, Handbuch des Polizeirechts, 6. Aufl. 2018, K, Rn. $36 \mathrm{f}$.

2127 Götz/Geis, Allgemeines Polizei- und Ordnungsrecht, 16. Aufl. 2017, §23 Rn. 39. Hierzu kritisch: Kniesel/Poscher, in: Lisken/Denninger, Handbuch des Polizeirechts, 6. Aufl. 2018, K, Rn. $26 \mathrm{ff}$.

2128 S. etwa Enders, in: Dürig-Friedl/Enders, Versammlungsrecht, 1. Aufl. 2016, § 5 VersammlG, Rn. 4.; Götz/Geis, Allgemeines Polizei- und Ordnungsrecht, 16. Aufl. 2017, § 23 Rn. 39; Kniesel/ Braun/Keller, Besonderes Polizei- und Ordnungsrecht, 1. Aufl. 2018, Rn. 418ff.; kritisch hierzu Eickenjäger/Haerkötter/Vetter, in: Ridder/Breitbach/Deiseroth, Versammlungsrecht, i.E., §5 VersammlG, Rn. 54 und Eickenjäger/Ewering/Kohlmeier, in: Ridder/Breitbach/Deiseroth, Versammlungsrecht, i.E., § 13 VersammlG, Rn. $20 \mathrm{ff}$. 
Examenswissen: In diesem Zusammenhang von Bedeutung ist insbesondere das Urteil des VGH 1166 Mannheim zur Auflösung eines in geschlossenen Räumen abgehaltenen Konzerts einer rechtsextremistischen Skinhead-Band auf der Grundlage der polizeilichen Generalklausel aus feuerpolizeilichen Gründen zur Abwehr konkreter Gefahren für Leben und Gesundheit der Versammlungsteilnehmer*innen. ${ }^{2129}$ Die Entscheidung steht stellvertretend für Eingriffe aufgrund des Polizei- und Ordnungsrechts - egal ob Verbot oder Auflösung - aufgrund nicht versammlungsspezifischer Gefahren.

Mit der Beendigung einer Versammlung und nach einer Auflösung der Ver1167 sammlung entfällt auch der Vorrang der Versammlungsgesetze. ${ }^{2130}$ Auflösungen können dann durch die Behörden etwa mit Platzverweisen nach Maßgabe des allgemeinen Polizei- und Ordnungsrechts durchgesetzt werden.

$\mathrm{Zu}$ beachten ist jedoch, dass auch bei Vorfeldmaßnahmen, Minusmaßnahmen und Maßnahmen gegenüber Teilnehmer*innen im Rahmen der Abreise von der Versammlung der Schutz aus Art. 8 I GG greift und etwaige Maßnahmen auf der Grundlage des allgemeinen Polizei- und Ordnungsrechts den verfassungsrechtlichen Anforderungen des Art. 8 I GG genügen müssen. In diesem Sinne darf z. B. die Anreise nicht durch Kontrollen unzumutbar erschwert und das Recht auf einen geordneten Abzug nach Beendigung oder Auflösung der Versammlung nicht beeinträchtigt werden. ${ }^{2131}$

\section{dd) Die einzelnen Ermächtigungsgrundlagen der Versammlungsgesetze}

Für die Beschränkung von Versammlungen unter freiem Himmel und in geschlossenen Räumen sehen die Versammlungsgesetze des Bundes und der Länder eine Reihe von Eingriffsbefugnissen vor. Die wichtigsten Eingriffsmöglichkeiten stellen dabei Verbote, Beschränkungen (Auflagen) und die Auflösung dar. Darüber hinaus von Relevanz sind insbesondere die Ermächtigungen zu Maßnahmen gegenüber einzelnen Teilnehmer*innen.

In den folgenden zwei Tabellen werden die zentralen Ermächtigungsgrund- $\mathbf{1 1 7 0}$ lagen bzgl. Versammlungen unter freiem Himmel und in geschlossenen Räumen aufgeführt. Unter „d) Materielle Rechtmäßigkeit“ (Rn. 1177) erfolgt sodann eine systematische Darstellung der Ermächtigungsgrundlagen im Hinblick auf ihre materiell-rechtlichen Voraussetzungen.

2129 VGH Mannheim, Urt. v. 12.7.2010, Az.: 1 S 349/10 = BeckRS 2010, 52002.

2130 Götz/Geis, Allgemeines Polizei- und Ordnungsrecht, 16. Aufl. 2017, § 23 Rn. 39.

$2131 \mathrm{Zu}$ den verfassungsrechtlichen Anforderungen bei Vorfeldmaßnahmen s. Götz/Geis, Allgemeines Polizei- und Ordnungsrecht, 16. Aufl. 2017, § 23 Rn. 22. Zu der „Nachwirkung von Art. 8 I GG s. Kniesel/Braun/Keller, Besonderes Polizei- und Ordnungsrecht, 1. Aufl. 2018, Rn. 418 ff. 
1171 Die wichtigsten Eingriffsbefugnisse (Beschränkungen, Verbot und Auflösung) zu Versammlungen unter freiem Himmel im Überblick:

\begin{tabular}{ll}
\hline Versammlungsgesetze & Maßnahmen \\
\hline VersammlG & Beschränkungen: § 15 I \\
& Verbot: § 15 I \\
& Auflösung: § 15 III \\
\hline BayVersG & Beschränkungen: Art. 15 I und IV \\
& Verbot: Art. 15 I \\
& Auflösung: Art. 14 IV \\
\hline NdsVersG & Beschränkungen: § 8 I und IV \\
& Verbot: § 8 II 1 und IV \\
\hline SächsVersG & Auflösung: § 8 II \\
& Beschränkungen: § 15 I \\
& Verbot: § 15 I \\
\hline VersG LSA & Auflösung: § 15 III \\
& Beschränkungen: § 13 I \\
& Verbot: § 13 I \\
\hline VersFG SH & Auflösung: § 13 IV \\
& Beschränkungen: § 13 I \\
& Verbot: § 13 I \\
\hline
\end{tabular}

1172 Die wichtigsten Eingriffsbefugnisse zu Versammlungen in geschlossenen Räumen im Überblick:

\begin{tabular}{ll}
\hline Versammlungsgesetz & Maßnahmen \\
\hline VersammlG & Verbot: § 5 \\
& Auflösung: § 13 \\
\hline BayVersG & Verbot: Art. 12 I \\
& Auflösung: Art. 12 II \\
& Beschränkungen: Art. 12 \\
\hline NdsVersG & Verbot: § 14 II 1 \\
& Auflösung: § 14 II 1 \\
& Beschränkungen: § 14 I \\
& Besondere Maßnahmen (gegenüber einzelnen Personen): § 15 \\
\hline SächsVersG & Verbot: § 4 \\
& Auflösung: § 13 \\
\hline VersG LSA & Verbot: §4
\end{tabular}

\section{Sebastian Eickenjäger}


Fortsetzung

\begin{tabular}{ll}
\hline Versammlungsgesetz & Maßnahmen \\
\hline & Auflösung: § 11 \\
\hline VersFG SH & Verbot: § 20 I \\
& Auflösung: § 20 I \\
& Beschränkungen: § 20 I \\
& Maßnahmen gegenüber einzelnen Personen: § 9 I und II i. V. m. § 20 I \\
\hline
\end{tabular}

\section{c) Formelle Rechtmäßigkeit}

Die Prüfung der formellen Rechtmäßigkeit gliedert sich in die Prüfungspunkte 1173 Zuständigkeit, Verfahren und Form (zur Prüfung im Allgemeinen ausführlich Rn. 579 ff.). Folgende versammlungsrechtliche Besonderheiten bestehen:

\section{aa) Zuständigkeit}

Die Zuständigkeiten für die dargestellten Eingriffsbefugnisse ergeben sich aus $\mathbf{1 1 7 4}$ landesrechtlichen Bestimmungen und stellen sich danach in den einzelnen Bundesländern wie folgt dar:2132

\begin{tabular}{|c|c|c|}
\hline Bundesland & Landesrechtliche Bestimmungen & Zuständige Behörden \\
\hline $\begin{array}{l}\text { Baden-Würt- } \\
\text { temberg }\end{array}$ & $\begin{array}{l}\text { Verordnung des Innenministeriums } \\
\text { über Zuständigkeiten nach dem Ver- } \\
\text { sammlungsgesetz (VersGZuVO) v. } \\
\text { 25. 5.1977 (GBI. 196), zuletzt geändert } \\
\text { durch Art. } 1 \text { ÄndVO vom 17.12.2008 } \\
\text { (GBI. } 2009 \text { S. 5) }\end{array}$ & $\begin{array}{l}\text { - } \text { gem. § } 1 \text { I die Kreispolizeibehörden } \\
\text { als untere Verwaltungsbehörden } \\
\text { (also nach § } 15 \text { I Nr. } 1 \text { VwG BW in } \\
\text { den Landkreisen die Landratsämter, } \\
\text { in den Stadtkreisen gem. § } 15 \text { I Nr. } 2 \\
\text { VwG BW die Gemeinden) } \\
\text { - bei Maßnahmen „der Polizei“ } \\
\text { (§§ } 9 \text { II, 12, 12a, 13 I, 18, 19 IV, 19a } \\
\text { VersammIG): Polizeivollzugsdienst }\end{array}$ \\
\hline Bayern & Art. 24 BayVersG & $\begin{array}{l}\text { - II S. 1: Kreisverwaltungsbehörden } \\
\text { (gem. Art. } 37 \text { I } 1 \text { LKrO das Land- } \\
\text { ratsamt bzw. nach Art. } 9 \text { I } 1 \text { GO die } \\
\text { kreisfreie Gemeinde) } \\
\text { - II S. 2: ab Beginn der Versammlung } \\
\text { und in unaufschiebbaren Fällen }\end{array}$ \\
\hline
\end{tabular}

2132 S. hierzu ausführlich die Ausführungen unter „Landesrechtliche Zuständigkeits-, Verfahrens- und Kostenregelungen“ zu den einzelnen Bundesländern in: Ridder/Breitbach/Deiseroth, Versammlungsrecht, i.E. 
Fortsetzung

\begin{tabular}{|c|c|c|}
\hline Bundesland & Landesrechtliche Bestimmungen & Zuständige Behörden \\
\hline & & $\begin{array}{l}\text { kann auch die Polizei (Polizeivoll- } \\
\text { zugsdienst) Maßnahmen treffen }\end{array}$ \\
\hline Berlin & $\begin{array}{l}\text { Allgemeines Gesetz zum Schutz der } \\
\text { öffentlichen Sicherheit und Ordnung in } \\
\text { Berlin } \\
\text { (Allgemeines Sicherheits- und Ord- } \\
\text { nungsgesetz - ASOG Bln) in der Fas- } \\
\text { sung v. 11.10.2006 (GVBI. S. 930), } \\
\text { zuletzt geändert durch Art. } 5 \text { G zur } \\
\text { Umsetzung der Seveso-III-RL und zur } \\
\text { Änd. zuständigkeitsrechtlicher Vor- } \\
\text { schriften v. 16.3.2018 (GVBI. 186) }\end{array}$ & $\begin{array}{l}\text { - gem. § } 2 \text { IV } 1 \text { i. V. m. Nr. } 23 \text { II der } \\
\text { Anlage: Polizeipräsident*in Berlin }\end{array}$ \\
\hline Brandenburg & $\begin{array}{l}\text { Verordnung zur Übertragung der Zu- } \\
\text { ständigkeiten nach dem Versamm- } \\
\text { lungsgesetz (ZustVO VersamG), v. } \\
\text { 29.10.1991 (GVBl. S. 470), zuletzt } \\
\text { geändert durch Art. } 2 \text { G zur Ersetzung } \\
\text { von § } 16 \text { des VersammlungsG v. 26.10. } \\
2006 \text { (GVBl. I 114) }\end{array}$ & 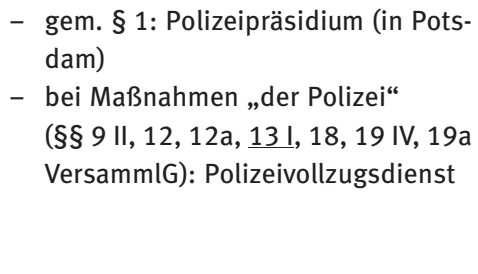 \\
\hline Bremen & $\begin{array}{l}\text { Verordnung über die Zuständigkeit der } \\
\text { Verwaltungsbehörden nach dem Ver- } \\
\text { sammlungsgesetz v. 9.2.1993 } \\
\text { (Brem.GBI. S. 63), zuletzt geändert } \\
\text { durch Nr. } 2.3 \text { i. V. m. Anl. } 3 \text { und Nr. } 2.4 \\
\text { i. V.m. Anl. } 4 \text { ÄndBek. V. 2. 8.2016 } \\
\text { (Brem.GBI. S. 434) }\end{array}$ & $\begin{array}{l}\text { - gem. § } 1 \text { I für Maßnahmen nach } \\
\S \S 14 \text { I, } 15 \text { I, } 17 \text { a III und IV, } 18 \text { II } \\
\text { VersammIG }{ }^{2133} \text { die Ortspolizeibe- } \\
\text { hörden (gem. } \S 65 \text { I Nr. 2, } 67 \text { II } \\
\text { BremPolG in der Stadtgemeinde } \\
\text { Bremen das Ordnungsamt und in } \\
\text { der Stadtgemeinde Bremerhaven } \\
\text { der Oberbürgermeister als Vertreter } \\
\text { des Magistrats) } \\
\text { - bei Maßnahmen „der Polizei“ } \\
\text { (§§ } 9 \text { II, 12, 12a, 13I, 18, 19 IV, 19a } \\
\text { VersammIG) sowie Maßnahmen }\end{array}$ \\
\hline
\end{tabular}

2133 Obwohl $\S 5$ VersammlG hier nicht genannt wird, ist davon auszugehen, dass für Verbote nach $\S 5$ VersammlG ebenfalls die Ortspolizeibehörden zuständig sind. Es ist jedenfalls nicht nachvollziehbar, warum die Zuständigkeit für Verbote von Versammlungen in geschlossenen Räumen anders ausfallen soll als die Zuständigkeit für Verbote von Versammlungen unter freiem Himmel.

2134 So jedenfalls VG Bremen, Urt. v. 4.9. 2014, Az.: 5 K 1145/13; kritisch hierzu Fischer-Lescano, Zuständigkeits-, Kosten und Verfahrensregeln Bremen, in: Ridder/Breitbach/Deiseroth, Kommentar Versammlungsrecht, i.E.

\section{Sebastian Eickenjäger}


Fortsetzung

\begin{tabular}{|c|c|c|}
\hline Bundesland & Landesrechtliche Bestimmungen & Zuständige Behörden \\
\hline & & $\begin{array}{l}\text { nach } \S 15 \text { III und IV VersammlG }{ }^{2134} \text { : } \\
\text { Polizeivollzugsdienst }\end{array}$ \\
\hline Hamburg & $\begin{array}{l}\text { Anordnung über Zuständigkeiten im } \\
\text { Versammlungsrecht und öffentlichen } \\
\text { Vereinsrecht v. 10.12.1968 (Amtl. } \\
\text { Anz. 1968, 1513), zuletzt geändert } \\
\text { durch Artikel } 37 \text { der Anordnung v. } \\
\text { 26.10.2010 (Amtl. Anz. S. 2129, 2132) }\end{array}$ & $\begin{array}{l}\text { - } \text { gem. Nr. I Abs. } 1 \text { Nr. } 1 \text { die Behörde } \\
\text { für Inneres und Sport } \\
\text { - } \text { bei Maßnahmen „der Polizei“ } \\
\text { (§§ } 9 \text { II, 12, 12a, 13 I, 18, } 19 \text { IV, 19a } \\
\text { VersammIG): Polizeivollzugsdienst }\end{array}$ \\
\hline Hessen & $\begin{array}{l}\text { Verordnung zur Durchführung des } \\
\text { Hessischen Gesetzes über die öffentli- } \\
\text { che Sicherheit und Ordnung und des } \\
\text { Hessischen Freiwilligen-Polizeidienst- } \\
\text { Gesetzes (HSOG-DVO) vom 12.6.2007 } \\
\text { (GVBI. I S. 323), zuletzt geändert durch } \\
\text { Art. } 1 \text { Vierte ÄndVO v. 23.10.2012 } \\
\text { (GVBI. S. 326) }\end{array}$ & $\begin{aligned} \text { - } & \text { gem. } § 11 \text { Nr. 2: allgemeine Ord- } \\
& \text { nungsbehörden } \\
\text { - } & \text { Gemeinde mit weniger als } 7.500 \\
& \text { Einwohner*innen: Kreisordnungs- } \\
& \text { behörde (also die/der Landrät*in) } \\
\text { - } & \text { bei Maßnahmen „der Polizei“ } \\
& \text { (§§ } 9 \text { II, 12, 12a, 13I, 18, } 19 \text { IV, 19a } \\
& \text { VersammlG): Polizeivollzugsdienst }\end{aligned}$ \\
\hline $\begin{array}{l}\text { Mecklenburg- } \\
\text { Vorpommern }\end{array}$ & $\begin{array}{l}\text { Landesverordnung über die zuständi- } \\
\text { gen Behörden nach dem Versamm- } \\
\text { lungsgesetz (VersG-ZustVO) v. } 21.7 \text {. } \\
1994 \text { (GVOBI. M-V S. 804), zuletzt ge- } \\
\text { ändert durch Erste ÄndVO vom 19.1. } \\
2007 \text { (GVOBl. M-V S. 30) }\end{array}$ & $\begin{array}{l}\text { - } \text { gem. } § 2 \text { die Landrät*innen und die } \\
\text { Oberbürgermeister*innen der kreis- } \\
\text { freien Städte als Kreisordnungsbe- } \\
\text { hörden } \\
\text { - } \text { bei Maßnahmen „der Polizei“ } \\
\text { (§§ } 9 \text { II, 12, 12a, 13 I, 18, } 19 \text { IV, 19a } \\
\text { VersammlG): Polizeivollzugsdienst }\end{array}$ \\
\hline Niedersachsen & $\S 24 \mathrm{NdsVersG}$ & $\begin{array}{l}\text { - vor Versammlungsbeginn (I } 1 \mathrm{Nr} \text {. 1): } \\
\text { untere Versammlungsbehörde } \\
\text { (Landkreise, kreisfreien Städte, } \\
\text { großen selbständigen Städte und } \\
\text { selbständigen Gemeinden wahr, auf } \\
\text { dem Gebiet der Landeshauptstadt } \\
\text { Hannover die Polizeidirektion Han- } \\
\text { nover) } \\
\text { - nach Versammlungsbeginn (I } 1 \\
\text { Nr. 2): die Polizei (Polizeivollzugs- } \\
\text { dienst) }\end{array}$ \\
\hline $\begin{array}{l}\text { Nordrhein- } \\
\text { Westfalen }\end{array}$ & $\begin{array}{l}\text { Verordnung über Zuständigkeiten } \\
\text { nach dem Versammlungsgesetz v. 2.2. } \\
1987 \text { (GV. NRW. S. 62), zuletzt geändert } \\
\text { durch Verordnung v. 9.9.2014 (GV. } \\
\text { NRW. S. 500) }\end{array}$ & $\begin{array}{l}\text { - gem. § 1: Kreispolizeibehörden } \\
\text { (gem. gem. § } 2 \text { I POG NRW die Poli- } \\
\text { zeipräsidien der kreisfreien Städte } \\
\text { und die Landrät*innen, soweit das } \\
\text { Kreisgebiet zu einem Polizeibezirk } \\
\text { erklärt wurde) }\end{array}$ \\
\hline
\end{tabular}


Fortsetzung

\begin{tabular}{|c|c|c|}
\hline Bundesland & Landesrechtliche Bestimmungen & Zuständige Behörden \\
\hline $\begin{array}{l}\text { Rheinland- } \\
\text { Pfalz }\end{array}$ & $\begin{array}{l}\text { Landesverordnung über die Zustän- } \\
\text { digkeit der allgemeinen Ordnungsbe- } \\
\text { hörden in der Fassung v. 31.10.1978 } \\
\text { (GVBl. S. 695), zuletzt geändert durch } \\
\text { Artikel } 9 \text { des Zweiten Landesgesetzes } \\
\text { zur Kommunal- und Verwaltungsreform } \\
\text { vom 28.9. } 2010 \text { (GVBl. } 2010 \text { S. 280) }\end{array}$ & $\begin{array}{l}\text { - } \text { gemäß } \S \S 1,2 \text { Nr. } 9 \text { die Kreisord- } \\
\text { nungsbehörde (in den Landkreisen } \\
\text { die Kreisverwaltungen und in kreis- } \\
\text { freien Städten die Stadtverwaltun- } \\
\text { gen); } \\
\text { - } \text { in der großen kreisangehörigen } \\
\text { Stadt: Stadtverwaltung (§ } 1 \mathrm{Nr} .9 \mathrm{HS} \\
\text { 2) } \\
\text { - bei Maßnahmen „der Polizei“ } \\
\text { (§§ } 9 \text { II, 12, 12a, 13 I, 18, } 19 \text { IV, 19a } \\
\text { VersammlG): Polizeipräsidien }\end{array}$ \\
\hline Saarland & $\begin{array}{l}\text { Verordnung zur Übertragung und Än- } \\
\text { derung von Zuständigkeiten v. 17.9. } \\
1991 \text { (Amtsblatt 1991, 1066), zuletzt } \\
\text { geändert durch das Gesetz v. 21.11. } \\
2007 \text { (Amtsbl. S. 2393) }\end{array}$ & $\begin{array}{l}\text { - gem. } § 11 \text { : die Landkreise, der Re- } \\
\text { gionalverband Saarbrücken, die } \\
\text { Landeshauptstadt Saarbrücken und } \\
\text { die kreisfreien Städte } \\
\text { - } \text { bei Maßnahmen „der Polizei“ } \\
\text { (§§ } 9 \text { II, 12, 12a, } 13 \text { I, 18, } 19 \text { IV, 19a } \\
\text { VersammlG): Polizeivollzugsdienst }\end{array}$ \\
\hline Sachsen & § 32 SächsVersG & $\begin{array}{l}\text { - gem. Abs. 1: Kreispolizeibehörden } \\
\text { (nach § } 64 \text { I Nr. } 3 \text { SächsPolG die } \\
\text { Landratsämter und die Kreisfreien } \\
\text { Städte) } \\
\text { - für die in Abs. } 2 \text { genannten Maß- } \\
\text { nahmen: Polizeivollzugsdienst }\end{array}$ \\
\hline
\end{tabular}

\begin{tabular}{|c|c|c|}
\hline $\begin{array}{l}\text { Sachsen-An- } \\
\text { halt }\end{array}$ & $\begin{array}{l}\text { Verordnung über die Zuständigkeiten } \\
\text { auf verschiedenen Gebieten der Ge- } \\
\text { fahrenabwehr (ZustVO SOG) } \\
\text { vom 31.7.2002 (GVBI. LSA S. 328), } \\
\text { zuletzt geändert durch Art. } 3 \text { Zweite } \\
\text { Polizeistrukturreformrerordnung v. } \\
\text { 18.12.2018 (GVBI. LSA S. 443). }\end{array}$ & $\begin{array}{l}\text { - } \text { gem. } § 1 \text { I Nr. } 1 \text { Landkreise bzw. die } \\
\text { kreisfreie Stadt Dessau-Roßlau; in } \\
\text { Halle und Magdeburg: gem. § } 1 \text { । } \\
\text { Nr. } 2 \text { die Polizeidirektion } \\
\text { - } \text { bei Maßnahmen „der Polizei“ } \\
\text { (§§ } 11 \text { I, } 16 \text { Abs. 3, } 17 \text { IV, } 18 \text { I Ver- } \\
\text { sammIG LSA): Polizeivollzugsdienst }\end{array}$ \\
\hline $\begin{array}{l}\text { Schleswig- } \\
\text { Holstein }\end{array}$ & $\S 27$ VersFG SH & $\begin{array}{l}\text { - gemäß Abs. } 1 \text { für Versammlungen } \\
\text { unter freiem Himmel: Landrät*innen } \\
\text { und die Bürgermeister^innen der } \\
\text { kreisfreien Städte als Kreisord- } \\
\text { nungsbehörden } \\
\text { - } \text { gemäß Abs. } 2 \text { für Versammlungen in } \\
\text { geschlossenen Räumen: Bürger- } \\
\text { meisterinnen der amtsfreien Ge- } \\
\text { meinden, die/der Amtsdirektor^in, }\end{array}$ \\
\hline
\end{tabular}


Fortsetzung

\begin{tabular}{|c|c|c|}
\hline Bundesland & Landesrechtliche Bestimmungen & Zuständige Behörden \\
\hline & & $\begin{array}{l}\text { in ehrenamtlich verwalteten Ämtern } \\
\text { die/der Amtsvorsteher*in }\end{array}$ \\
\hline Thüringen & $\begin{array}{l}\text { Thüringer Verordnung zur Bestimmung } \\
\text { von Zuständigkeiten im Geschäftsbe- } \\
\text { reich des Innenministeriums v. } 15.4 \text {. } \\
2008 \text { (GVBI. 2008, 102), zuletzt geän- } \\
\text { dert durch Verordnung v. } 8.10 .2013 \\
\text { (GVBl. S. 311) }\end{array}$ & 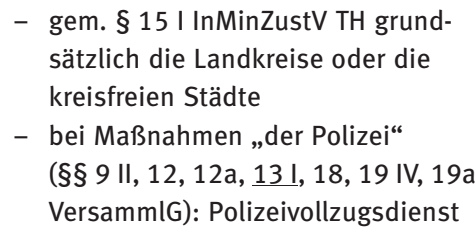 \\
\hline
\end{tabular}

\section{bb) Verfahren und Form}

Vor dem Erlass beschränkender Maßnahmen sind die Beteiligten anzuhören $\mathbf{1 1 7 5}$ (§ 28 I VwVfG) soweit nicht ein Fall des § 28 II VwVfG (bei Maßnahmen im Rahmen von laufenden Versammlungen insbesondere Gefahr im Verzug gemäß § 28 II Nr. 1 VwVfG) vorliegt. Die Anhörung erfolgt oftmals im Rahmen eines sogenannten Kooperationsgesprächs, ${ }^{2135}$ dessen Durchführung in Landesversammlungsgesetze teilweise ausdrücklich geregelt ist (s. § 3 III VersFG SH, Art. 14 I 1 BayVersG sowie § 6 NdsVersG).

Beschränkungen nach § 15 I und II VersammlG sowie $\S \S 5$ und 13 VersammlG 1176 können grds. mündlich oder schriftlich ergehen (§ 37 II VwVfG); mündliche Verwaltungsakte sind gemäß § 37 I 2 VwVfG schriftlich zu bestätigen, wenn hieran ein berechtigtes Interesse besteht und der_die Betroffene dies unverzüglich verlangt. Ein schriftlicher sowie ein schriftlich bestätigter Verwaltungsakt ist gemäß § 39 I 1 VwVfG mit einer Begründung zu versehen. Verfügungen nach $\S 13$ VersammlG sind im Hinblick auf dessen Wortlaut (,unter Angabe eines Grundes“) auch dann zu begründen, wenn sie mündlich erfolgen. Diese Anforderungen sind aufgrund der höheren Eingriffsintensität eines präventiven Verbots analog auf mündliche Verbote nach $\S 5$ VersammlG zu übertragen. ${ }^{2136}$ Verfügungen sind zudem gemäß $\S 41 \mathrm{VwVfG}$ bekannt zu geben.

2135 Hettich, Versammlungsrecht in der Praxis, 2. Aufl. 2018, S. 222, Rn. 211.

2136 Eickenjäger/Haerkötter/Vetter, in: Ridder/Breitbach/Deiseroth, Kommentar Versammlungsrecht, i.E., § 5 VersammlG, Rn. 63. 


\section{d) Materielle Rechtmäßigkeit}

1177 Bei der Prüfung der Voraussetzungen der Ermächtigungsgrundlage ist wiederum danach zu differenzieren, ob es sich um eine Versammlung unter freiem Himmel oder in geschlossenen Räumen handelt.

\section{aa) Versammlungen unter freiem Himmel}

1178 Bei Versammlungen unter freiem Himmel muss weiter differenziert werden, ob das VersammlG des Bundes oder ein Landesversammlungsgesetz einschlägig ist.

\section{(1) VersammlG des Bundes}

1179 Für die Beschränkung von öffentlichen Versammlungen unter freiem Himmel sieht das VersammlG des Bundes verschiedene Eingriffsbefugnissen vor, von denen die wichtigsten die Verbote und Beschränkungen (Auflagen) nach §15 I VersammlG und die Auflösung nach § 15 III VersammlG darstellen. §15 I VersammlG bestimmt für das Verbot und die Erteilung von Auflagen, dass diese nur zulässig sind, wenn nach den zur Zeit des Erlasses der Verfügung erkennbaren Umständen die öffentliche Sicherheit oder Ordnung bei Durchführung der Versammlung oder des Aufzuges unmittelbar gefährdet ist. §15 II VersammlG ermöglicht ein Verbot oder die Erteilung von Auflagen für Versammlungen an Orten, die als Gedenkstätten von historisch herausragender, überregionaler Bedeutung an die Opfer der menschenunwürdigen Behandlung unter der nationalsozialistischen Gewalt- und Willkürherrschaft erinnern. Die Auflösung nach § 15 III VersammlG ist zulässig, wenn Versammlungen nicht angemeldet sind, wenn von den Angaben der Anmeldung abgewichen oder den Auflagen zuwidergehandelt wird, oder wenn die Voraussetzungen zu einem Verbot gegeben sind.

1180 Gemäß Art. 8 II GG stehen Versammlungen unter freiem Himmel zwar unter einem allgemeinen Gesetzesvorbehalt. Das BVerfG verlangt seit der BrokdorfEntscheidung jedoch, dass aufgrund der grundlegenden Bedeutung der Versammlungsfreiheit für das Funktionieren der demokratischen Grundordnung die Auflösung und das Verbot nur zum Schutz gleichwertiger Rechtsgüter unter strikter Wahrung des Grundsatzes der Verhältnismäßigkeit und nur bei einer unmittelbaren, aus erkennbaren Umständen herleitbaren Gefährdung dieser Rechtsgüter erfolgen dürfen. ${ }^{2137}$

1181 Bzgl. der Anforderungen an beschränkende Maßnahmen ergibt sich aus der Rechtsprechung des BVerfG, dass eine Gefährdung der öffentlichen Sicherheit

2137 BVerfG, Beschl. v. 14.5.1985, Az.: 1 BvR 233, 341/81 = BVerfGE 69, 315 (348f., 353f.). 
grds. dann gegeben ist, wenn eine strafbare Verletzung der objektiven Rechtsordnung, der subjektiven Rechte und Rechtsgüter Dritter oder der Veranstaltungen des Staates und seiner Einrichtungen droht. ${ }^{2138}$ Die Rechtsgüter müssen dabei indes zum einen gleichwertig sein und zum anderen müssen die Versammlungsbehörden Maßnahmen auf das beschränken, was zum Schutze der Rechtsgüter erforderlich ist. ${ }^{2139}$

Dem Begriff der öffentlichen Ordnung kommt im Versammlungsrecht eine „Reservefunktion“ zu, um unvorhergesehenen und unerträglichen Störungen des öffentlichen Friedens begegnen zu können. ${ }^{2140}$ Öffentliche Ordnung meint dabei die Gesamtheit der ungeschriebenen Regeln, deren Befolgung nach den jeweils herrschenden sozialen und ethischen Anschauungen als unerlässliche Voraussetzung eines geordneten menschlichen Zusammenlebens innerhalb eines bestimmten Gebiets angesehen wird. ${ }^{2141} \mathrm{Zu}$ beachten ist, dass die öffentliche Ordnung regelmäßig nur zur Rechtfertigung von Auflagen herangezogen werden kann, da Verbote und Auflösungen im Wesentlichen nur zum Schutz elementarer Rechtsgüter in Betracht kommen. ${ }^{2142}$

Examenswissen: In der Praxis wurde die öffentliche Ordnung bisher insbesondere gegenüber rechtsextremen Versammlungen in Anschlag gebracht. ${ }^{2143}$ Das BVerfG ist dieser Rechtsprechung jedoch damit entgegengetreten, dass zur Abwehr von kommunikativen Angriffen auf Schutzgüter der Verfassung nur auf bereits geschaffene Strafrechtsnormen rekurriert werden darf und deshalb ein Rückgriff auf die in § 15 I VersammlG enthaltene Ermächtigung zum Schutz der öffentlichen Ordnung ausscheidet, soweit kein Straftatbestand erfüllt ist. ${ }^{2144}$ Die Versammlungsbehörden können gegenüber Versammlungen wegen einer Gefährdung der öffentlichen Ordnung deshalb nur dann einschreiten, wenn - über die Gefahr der Verwirklichung von Straftaten durch das Verbreiten nationalsozialistischen Gedankenguts hinaus - provokative oder aggressive Begleitumstände zu befürchten sind, von denen im konkreten Fall eine Einschüchterung der Bevölkerung sowie ein Klima der Gewaltdemonstration bzw. potentielle Gewaltbereitschaft

2138 S. Barczak, in: Ridder/Breitbach/Deiseroth, Versammlungsrecht, i.E., §15 VersammlG, Rn. $95 \mathrm{ff}$.

2139 BVerfG, Beschl. v. 14.5.1985, Az.: 1 BvR 233, 341/81 = BVerfGE 69, 315 (348f., 353 f.).

2140 S. hierzu Barczak, in: Ridder/Breitbach/Deiseroth, Kommentar Versammlungsrecht, i.E., $\S 15$ VersammlG, Rn. 162.

2141 BVerfG, Beschl. v. 14.5.1985, Az.: 1 BvR 233, 341/81 = BVerfGE 69, 315 (352).

2142 BVerfG, Beschl. v. 14.5.1985, Az.: 1 BvR 233, 341/81 = BVerfGE 69, 315 (352f.).

2143 S. hierzu die Rspr. des OVG Münster, etwa die Beschl.v. 23.3.2001, Az.: 5 B 395/01 = NJW 2001, 2111; v. 12.4.2001, Az.: 5 B 492/01 = NJW 2001, 2113; v. 29.6. 2001, Az.: 5 B 832/01 = NJW 2001, 2986 und v. 02.3.2004, Az.: 5 B 392/04 = BeckRS 2004, 21977.

2144 S. hierzu die Beschl. des BVerfG v. 24.3.2001, Az.: 1 BvQ 13/01 = NJW 2001, 2069; v. 7.4. 2001, Az.: 1 BvQ 17/01 u.a. = NJW 2001, 2072; v. 12.4.2001, Az.: 1 BvQ 19/01 = NJW 2001, 2075; v. 1.5. 2001, Az.: 1 BvQ 22/01 = NJW 2001, 2076; v. 1.5.2001, Az.: 1 BvQ 21/01 = NJW 2001, 2078. 
ausgeht. ${ }^{2145}$ Dies kann beispielsweise dann der Fall sein, wenn Personen uniformiert, mit bestimmten Gegenständen (Landsknechtstrommeln, Fahnen, Fackeln etc.) oder in Marschordnung in paramilitärischer Art und Weise auftreten. ${ }^{2146}$

1184 Eine unmittelbare Gefährdung nach § 15 I und III VersammlG setzt laut BVerfG eine Sachlage voraus, die bei ungehindertem Geschehensablauf mit hoher Wahrscheinlichkeit zu einem Schaden für die der Versammlungsfreiheit entgegenstehenden Interessen führt. ${ }^{2147}$ Auch bei der Gefahrenprognose müssen die Versammlungsbehörden die Bedeutung der Versammlungsfreiheit berücksichtigen. Hieraus folgt, dass als Grundlage der Gefahrenprognose nur konkrete und nachvollziehbare tatsächliche Anhaltspunkte zugrunde gelegt werden können und bloße Vermutungen damit nicht ausreichen. ${ }^{2148}$

1185 Über die Befugnisse des § 15 I und III VersammlG hinaus sieht das VersammlG weitere Eingriffsmöglichkeiten vor. $\mathrm{Zu}$ nennen sind hier die Ermächtigung zur Durchsetzung des Schutzwaffen- und Vermummungsverbots nach §17a IV VersammlG ${ }^{2149}$, zur Entsendung von Polizeibeamt^innen aus $\S 18$ I i.V.m. $§ 12$ VersammlG ${ }^{2150}$, zum Ausschluss von Teilnehmer^innen (bei Aufzügen) gemäß $\S \S 18$ III und 19 IV VersammlG ${ }^{2151}$ und zur Vornahme von Bild- und Tonaufzeichnungen nach $\S \S 19$ a i.V.m. 12a VersammlG ${ }^{2152}$.

2145 BVerfG, Beschl.v. 23.6.2004, Az.:1 BvQ 19/04 = NJW 2004, 2814 (2815f.) und Beschl.v. 19.12. 2007, Az.: 1 BvR 2793/04 = NVwZ 2008, 671 (673f.).

2146 S. hierzu Barczak, in: Ridder/Breitbach/Deiseroth, Kommentar Versammlungsrecht, i. E., $\S 15$ VersammlG, Rn. 168. Vgl. auch BVerfG, Beschl.v. 24.3.2001, Az.: 1 BvQ 13/01 = NJW 2001, 2069 (2071). Laut BVerfG kann die öffentliche Ordnung auch verletzt sein, wenn ein rechtsextremer Aufzug an einem speziell der Erinnerung an das Unrecht des Nationalsozialismus und den Holocaust dienenden Gedenktag so durchgeführt werden soll, dass von seiner Art und Weise Provokationen ausgehen, die das sittliche Empfinden der Bürgerinnen und Bürger erheblich beeinträchtigen, Beschl. v. 26.1.2006, Az.: 1 BvQ 3/06 = NVwZ 2006, 585.

2147 BVerfG, Beschl. v. 19.12.2007, Az.: 1 BvR 2793/04 = NVwZ 2008, 671 (672).

2148 BVerfG, Beschl. v. 19.12.2007, Az.: 1 BvR 2793/04 = NVwZ 2008, 671 (672).

2149 Näher hierzu Kniesel/Braun/Keller, Besonderes Polizei- und Ordnungsrecht, 1. Aufl. 2018, Rn. $248 \mathrm{ff}$.

2150 Näher hierzu Kniesel/Braun/Keller, Besonderes Polizei- und Ordnungsrecht, 1. Aufl. 2018, Rn. $350 \mathrm{ff}$.

2151 Näher hierzu Kniesel/Braun/Keller, Besonderes Polizei- und Ordnungsrecht, 1. Aufl. 2018, Rn. 376 ff.; Kingreen/Poscher, Polizei- und Ordnungsrecht mit Versammlungsrecht, 10. Aufl. 2018, $\S 21, \mathrm{Rn} .7 \mathrm{ff}$.

2152 Näher hierzu Kingreen/Poscher, Polizei- und Ordnungsrecht mit Versammlungsrecht, 10. Aufl. 2018, § 20, Rn. 46 ff. und § 21 Rn. 5f.; Kniesel/Braun/Keller, Besonderes Polizei- und Ordnungsrecht, 1. Aufl. 2018, Rn. 358ff.; Götz/Geis, Allgemeines Polizei- und Ordnungsrecht, 16. Aufl. 2017, § 23 Rn. $30 \mathrm{ff}$.

\section{Sebastian Eickenjäger}




\section{(2) Landesversammlungsgesetze}

Das BayVersG regelt in Art. 15 entsprechend der Regelung in $\S 15$ VersammlG 1186 Beschränkung, Verbot und Auflösung von Versammlungen (Abs. 1 bis 4). In Art. 15 V BayVersG findet sich eine Ermächtigung zum Ausschluss von Störer*innen (vgl. § 18 VersammlG).

Die zentrale Eingriffsnorm im NdsVersG stellt $\S 8$ dar. Hier sind Beschrän- 1187 kung (Abs. 1 und 4), Verbot (Abs. 2S. 1 und Abs. 4) und Auflösung (Abs. 2) geregelt. Im Gegensatz zum VersammlG unterschiedet die Regelung in § 8 NdsVersG bzgl. der Eingriffsbefugnisse nicht nach dem Zeitpunkt (vor oder während der Versammlung), sondern nach der Schwere der Gefahr. ${ }^{2153}$

$\S 10$ NdsVersG sieht die Möglichkeit der Vornahme „besonderer Maßnahmen“ vor. Nach Abs. 1 S. 2 kann die Versammlungsbehörde Leiter^innen ablehnen oder den Einsatz von Ordner*innen untersagen. Abs. 2 ermöglicht ein Vorgehen gegen einzelne Teilnehmer^innen im Vorfeld und während der Versammlung; Abs. 3 ermächtigt zum Ausschluss von Teilnehmer^innen.

§ 15 SächsVersG entspricht im Hinblick auf Beschränkungen (Abs. 1), Verbot (Abs. 1) und Auflösung (Abs. 3) § 15 VersammlG. ${ }^{2154}$

§ 13 VersammlG LSA regelt Beschränkungen, Verbote und die Auflösung von 1189 Versammlungen. Im Unterschied zu § 15 I VersammlG sieht § 13 I VersammlG LSA vor, dass Verbote und Beschränkungen nur bei dem Vorliegen einer unmittelbaren Gefahr für die öffentliche Sicherheit möglich sind, die öffentliche Ordnung mithin nicht umfasst ist. Abs. 2 und 3 regeln Verbote und Beschränkungen im Hinblick auf Gedenkstätten und Gedenktage. Die Regelungen zur Auflösung in Abs. 4 und 5 entsprechen den Regelungen in § 15 III und IV VersammlG.

Das VersFG SH sieht Eingriffsbefugnisse in den $\S \S 13$ bis 15 vor. Die zentrale 1190 Vorschrift ist $\S 13$ VersFG SH, welche Beschränkungen, das Verbot und die Auflösung regelt. Nach $\S 13$ I VersFG SH kann die zuständige Behörde die Durchführung einer Versammlung unter freiem Himmel beschränken oder verbieten, die Versammlung nach deren Beginn auch auflösen, wenn nach den zur Zeit des Erlasses der Maßnahmen erkennbaren Umständen die öffentliche Sicherheit bei Durchführung der Versammlung unmittelbar gefährdet ist. §13 IV regelt Beschränkungen, Verbote und die Auflösung im Hinblick auf Gedenkstätten. § 14 VersFG SH ermöglicht die Untersagung der Teilnahme einzelner Personen (Abs. 1)

2153 Enders, in: Dürig-Friedl/Enders, Versammlungsrecht, 1. Aufl. 2016, §15 VersammlG, Rn. 204.

2154 Allein die Regelung zu Verboten oder Beschränkungen im Zusammenhang mit Gedenktagen oder Gedenkstätten (Abs. 2) weist Abweichungen zu § 15 VersammlG auf, indem hier eine Gleichsetzung „der nationalsozialistischen und der kommunistischen Gewaltherrschaft“ vorgenommen wird. S. hierzu Scheidler, NVwZ 2011, 924. 
bzw. den Ausschluss einzelner Teilnehmer*innen und §15 VersFG SH die Durchsuchung, Sicherstellung und Identitätsfeststellung.

\section{bb) Versammlungen in geschlossenen Räumen}

1191 Bei Versammlungen in geschlossenen Räumen besteht die Besonderheit, dass diese gemäß Art. 8 II GG schrankenlos gewährleistet sind. In der Praxis sind die Einschränkungsmöglichkeiten besonders bei so genannten Skinhead-Konzerten von Relevanz. ${ }^{2155}$

\section{(1) VersammlG des Bundes}

1192 Das VersammlG des Bundes sieht für Versammlungen in geschlossenen Räumen das Verbot nach § 5 und die Auflösung nach § 13 VersammlG vor. Maßgebliches Kriterium für die Abgrenzung zwischen Verbot und Auflösung ist der Beginn der Versammlung. Auf der Grundlage des §5 VersammlG können Versammlungen bis zum Beginn der konkreten Versammlung verboten werden. Nach Beginn kommt nur die Auflösung gemäß § 13 VersammlG in Betracht.

1193 Examenswissen: Laut zutreffender Ansicht des VGH Mannheim hat eine Versammlung begonnen, wenn sie der im Versammlungsgesetz vorgesehenen Ordnungsgewalt der Versammlungsleiter^innen unterliegt. ${ }^{2156}$ Eine Ausnahme bzgl. der strengen Abgrenzung zwischen Verbot und Auflösung im Hinblick auf den Beginn der Versammlung ergibt sich aus dem Verhältnis zwischen $\S 5$ Nr. 2 und § 13 I 1 Nr. 3 VersammlG. Laut § 13 I 1 Nr. 3 VersammlG kommt eine Auflösung in Betracht, wenn die Leitung Personen, die Waffen oder sonstige Gegenstände im Sinne von § 2 III mit sich führen, nicht sofort ausschließt und für die Durchführung des Ausschlusses sorgt. Gemäß $\S 5$ Nr. 2 VersammlG kommt ein Verbot nach Beginn einer Versammlung (!) in Betracht, wenn weiteren Teilnehmer^innen, die Waffen oder Gegenstände im Sinne des § 2 III VersammlG mit sich führen, der Zutritt gewährt wird. § 5 Nr. 2 VersammlG regelt danach den Fall, dass bewaffneten Teilnehmerinnen (aktiv) Zutritt gewährt wird und § 13 I 1 Nr. 3 VersammlG den Fall, dass sich bewaffnete Teilnehmer^innen mangels Kontrolle Zugang verschaffen.

\section{(a) $\$ \mathbf{5}$ - Verbot von Versammlungen in geschlossenen Räumen}

$1194 \S 5$ VersammlG regelt insgesamt vier Verbotstatbestände, aufgrund derer bzgl. versammlungsspezifischer Gefahren gegenüber Versammlungen in geschlossenen Räumen vorgegangen werden kann.

2155 S. hierzu etwa VGH Mannheim, Urt. v. 12.7.2010, Az.: 1 S 349/10 = BeckRS 2010, 52002. 2156 VGH Mannheim, Urt. v. 26.1.1998, Az.: 1 S 3280/96 = NVwZ 1998, 761 (763); so auch Enders, in: Dürig-Friedl/Enders, Versammlungsrecht, 1. Aufl. 2016, § 5 VersammlG, Rn. 7. 
§ 5 Nr. 1 VersammlG sieht die Möglichkeit des Verbots vor, wenn Veranstalter^innen unter die Vorschriften des $\S 1$ II Nr. 1 bis 4 fallen und im Falle der Nummer 4 das Verbot durch die zuständige Verwaltungsbehörde festgestellt worden ist. $§ 5 \mathrm{Nr} .1$ VersammlG knüpft damit an den Ausschluss von der Versammlungsfreiheit nach $\S 1$ II Nr. 1 bis 4 VersammlG an. Gleichzeitig bezieht sich $\S 5$ Nr. 1 VersammlG nur auf die Person des/der jeweils betreffenden Veranstalters ${ }^{\star}$ in. Im Einzelnen regelt $\S 5$ Nr. 1 VersammlG folgende Konstellationen:

- Nr. 1 i.V.m. § 1 II Nr. 1 VersammlG regelt die Möglichkeit eines Verbots für den Fall, dass jemand (als natürliche oder juristische Person) gemäß Art. 18 GG das Grundrecht der Versammlungsfreiheit verwirkt hat.

- Nr. 1 i.V.m. §1 II Nr. 3 VersammlG ermöglicht ein Verbot gegenüber einer Partei, die nach Art. 21 II GG durch das BVerfG für verfassungswidrig erklärt worden ist.

- $\quad$ Für ein Verbot nach Nr. 1 i.V.m. § 1 II Nr. 2 VersammlG muss ebenfalls eine Feststellung der Verfassungswidrigkeit einer Partei gemäß Art. 21 II GG durch das BVerfG vorliegen; darüber hinaus ist hier jedoch auch ein Verbot gegenüber natürlichen Personen möglich.

- Laut Nr. 1 i.V.m. § 1 II Nr. 4 VersammlG kann eine Versammlung verboten werden, wenn der/die Veranstalter*in eine gemäß Art. 9 II GG verbotene Vereinigung ist.

Ein Verbot kann daneben auf $\mathbf{5}$ Nr. 2 VersammlG gestützt werden, wenn be1196 waffneten Personen der Zutritt zur Versammlung gewährt wird.

§ 5 Nr. 3 VersammlG ermöglicht ein Verbot für den Fall, dass Tatsachen 1197 festgestellt sind, aus denen sich ergibt, dass Veranstalter*innen oder ihr Anhang einen gewalttätigen oder aufrührerischen Verlauf der Versammlung anstreben. Die Voraussetzungen „gewalttätig“ und „aufrührerisch“ stellen eine Konkretisierung des Friedlichkeitsgebots aus Art. 8 I GG dar. Zu berücksichtigen ist hierbei, dass laut BVerfG eine Versammlung nicht schon dann unfriedlich ist, wenn von einzelnen Teilen oder Teilnehmer*innen der Versammlung Gewalt ausgeht. ${ }^{2157}$ Ein Verbot kommt vielmehr nur dann in Betracht, wenn eine Demonstration im Ganzen einen gewalttätigen oder aufrührerischen Verlauf nimmt ${ }^{2158} \mathrm{bzw}$. von der Versammlung insgesamt ein aggressives Verhalten ausgeht.

Der Verbotstatbestand des $\mathbf{\S} \mathbf{5}$ Nr. 4 VersammlG setzt voraus, dass Tatsachen festgestellt sind, aus denen sich ergibt, dass der/die Veranstalter`in oder sein/ihr Anhang Ansichten vertreten oder Äußerungen dulden werden, die ein Verbrechen

2157 BVerfG, Beschl. v. 14.5.1985, Az.: 1 BvR 233, 341/81 = BVerfGE 69, 315 (359ff.).

2158 BVerfG, Beschl. v. 14.5.1985, Az.: 1 BvR 233, 341/81 = BVerfGE 69, 315 (361). 
oder ein von Amts wegen zu verfolgendes Vergehen zum Gegenstand haben. Er zeichnet sich dadurch aus, dass er nicht auf Beschränkungen der Versammlungsfreiheit verweist, die sich bereits aus dem GG selbst ergeben, sondern vielmehr an strafbares Verhalten ${ }^{2159}$ der Veranstalter`innen selbst bzw. des Anhanges anknüpft. ${ }^{2160}$

\section{(b) $§ 13$ - Auflösung von Versammlungen in geschlossenen Räumen}

$1199 \S 13$ VersammlG enthält - ebenso wie $\S 5$ VersammlG - insgesamt vier Tatbestände, die eine Auflösung von Versammlungen in geschlossenen Räumen ermöglichen:

1200 § 13 I 1 Nr. 1 VersammlG ermöglicht eine Auflösung, wenn - genauso wie bei einem Verbot nach $\S 5$ Nr. 1 VersammlG - im Hinblick auf Veranstalter^innen die Voraussetzungen des $\S 1$ II VersammlG erfüllt sind (hierzu Rn. 1195).

1201 § 13 I 1 Nr. 2 Alt. 1 VersammlG ist vergleichbar mit § 5 Nr. 3 VersammlG und ermöglicht eine Auflösung, wenn die Versammlung einen gewalttätigen oder aufrührerischen Verlauf nimmt (hierzu Rn. 1197). ${ }^{2161}$ § 13 I 1 Nr. 2 Alt. 2 VersammlG ermöglicht zudem eine Auflösung bei unmittelbarer Gefahr für Leben und Gesundheit der Teilnehmer*innen.

1202 § 13 I 1 Nr. 3 VersammlG ist vergleichbar mit $\S 5$ Nr. 2 VersammlG und ermöglicht eine Auflösung für den Fall, dass die Leitung Personen, die Waffen oder sonstige Gegenstände im Sinne von § 2 III mit sich führen, nicht sofort ausschließt und für die Durchführung des Ausschlusses sorgt. Im Unterschied zu § 5 Nr. 3 VersammlG kommt es nicht darauf an, dass die Leitung bewaffneten Personen den Zutritt gewährt und selbst dafür verantwortlich ist, dass Waffen eingeführt werden. Es kommt vielmehr darauf an, ob die Leitung trotz der Kenntnis von bewaffneten Personen nicht für einen Ausschluss dieser sorgt. ${ }^{2162}$

$2159 \mathrm{Zu}$ einem Verbot führen können die folgenden Straftatbestände: $\S \S 80$ a, 81, 82, 90 a, 94, 95, 105, 106, 111, 126, 130, 140, 240, 241, 353 d StGB.

$2160 \mathrm{Zu}$ den verfassungsrechtlichen Bedenken gegenüber dieses Tatbestands s. Eickenjäger/ Haerkötter/Vetter, in: Ridder/Breitbach/Deiseroth, Versammlungsrecht, i.E., §5 VersammlG, Rn. $46 \mathrm{ff}$.

2161 Im Gegensatz zu $\S 5$ Nr. 3 VersammlG kommt es hier jedoch nicht darauf an, ob Veranstalter^innen oder deren Anhang einen gewalttätigen oder aufrührerischen Verlauf der Versammlung anstreben, sondern nur, ob tatsächlich die Versammlung einen entsprechenden Verlauf annimmt.

2162 S. Kniesel, in: Dietel/Kintzel/Kniesel, Versammlungsgesetze, 17. Aufl. 2016, § 13 VersammlG, Rn. 16; Eickenjäger/Ewering/Kohlmeier, in: Ridder/Breitbach/Deiseroth, Versammlungsrecht, i. E., § 13 VersammlG, Rn. 27. 
Auf der Grundlage des § 13 I 1 Nr. 4 VersammlG kommt eine Auflösung in 1203 Betracht, wenn durch den Verlauf der Versammlung gegen Strafgesetze verstoßen wird, die ein Verbrechen oder von Amts wegen zu verfolgendes Vergehen zum Gegenstand haben oder wenn in der Versammlung zu solchen Straftaten aufgefordert oder angereizt wird und die Leitung dies nicht unverzüglich unterbindet. Dieser Tatbestand geht über die Vorgaben des $\S 5$ Nr. 4 VersammlG hinaus und ist aufgrund seiner weiten Fassung in besonderem Maße im Lichte der verfassungsrechtlichen Vorgaben des Art. 8 GG zu betrachten. Im Hinblick auf die in Frage kommenden Straftaten sind in diesem Sinne einerseits Art. 8 I GG, der nur friedliche Versammlungen und Versammlungen ohne Waffen schützt und andererseits Art. 8 II GG, wonach Versammlungen in geschlossenen Räumen keinem Gesetzesvorbehalt unterliegen, zu berücksichtigen. ${ }^{2163}$ In diesem Sinne führt die Verwirklichung von Meinungsäußerungsdelikten einerseits nicht zur Unfriedlichkeit einer Versammlung, da es bei entsprechenden Straftaten an einer (physischen) Gefährlichkeit mangelt. Andererseits kann sich eine Auflösung nach § 13 I 1 Nr. 4 VersammlG auf Meinungsäußerungsdelikte stützen, die auf den Schutz von Verfassungsgütern und Grundrechten Dritter (verfassungsimmanente Schranken) abzielen. Allerdings erscheint die Möglichkeit einer Auflösung aufgrund jeglicher Verfassungsgüter und Grundrechte Dritter im Hinblick auf die Bedeutung des schrankenlos gewährleisteten Rechts auf Versammlungsfreiheit in geschlossenen Räumen zu weitgehend. In der Literatur wird vor diesem Hintergrund argumentiert, dass nur Verstöße gegen Strafgesetze, die auf den Schutz der Art. 1 und Art. 20 GG ${ }^{2164}$ gerichtet sind, zu einer Auflösung berechtigen. Eine andere Ansicht spricht sich dafür aus, eine Beschränkung auf den Schutz des Art. 1 GG vorzunehmen. ${ }^{2165}$

\section{(2) Landesversammlungsgesetze}

Die Eingriffsgrundlagen für Versammlungen in geschlossenen Räumen sind auf $\mathbf{1 2 0 4}$ Landesebene ganz unterschiedlich ausgestaltet worden.

Die Regelungen in Sachsen und Sachsen-Anhalt zum Verbot und der Auf- 1205 lösung (§§ 4 und 13 SächsVersG und $\S \S 4$ und 11 VersammlG LSA) entsprechen den

2163 S. hierzu ausführlich Eickenjäger/Ewering/Kohlmeier, in: Ridder/Breitbach/Deiseroth, Kommentar Versammlungsrecht, i.E., § 13 VersammlG, Rn. $28 \mathrm{ff}$.

2164 So Kniesel/Poscher, in: Lisken/Denninger, Handbuch des Polizeirechts, 6. Aufl. 2018, K, Rn. 131-133.

2165 So Eickenjäger/Ewering/Kohlmeier, in: Ridder/Breitbach/Deiseroth, Versammlungsrecht, i. E., § 13 VersammlG, Rn. $30 \mathrm{f}$. 
Regelungen des VersammlG. Insofern kann auf die Ausführungen zu §§ 5 und 13 VersammlG verwiesen werden.

1206

In Bayern sind die Eingriffsbefugnisse für Versammlungen in geschlossenen Räumen zusammenfassend in Art. 12 BayVersG geregelt. Art. 12 I BayVersG regelt das Verbot und Art. 12 II BayVersG die Auflösung. Die Verbots- und Auflösungstatbestände entsprechen weitgehend denen der $\S \S 5$ und 13 VersammlG. ${ }^{2166} \mathrm{Im}$ Gegensatz zum VersammlG ist in Art. 12 I und II BayVersG jeweils ausdrücklich die Möglichkeit vorgesehen, anstatt eines Verbots oder (nach Beginn der Versammlung) einer Auflösung sonstige Beschränkungen (insbesondere sogenannte „Minusmaßnahmen“) vorzunehmen. Art. 12 II 2 BayVersG bestimmt in diesem Sinne ausdrücklich für die Auflösung, dass diese in den Fällen von Satz 1 Nr. 2 bis 4 nur zulässig ist, wenn andere Maßnahmen der zuständigen Behörde, insbesondere eine Unterbrechung, nicht ausreichen. Insofern ist die Auflösung subsidiär gegenüber den Minusmaßnahmen.

Das NdsVersG fasst das Verbot und die Auflösung einer Versammlung in geschlossenen Räumen in § 14 II 1 NdsVersG zusammen. Im Gegensatz zu §§ 5 und 13 VersammlG gilt bzgl. beider Maßnahmen, dass diese verfügt werden können, wenn die Friedlichkeit der Versammlung unmittelbar gefährdet ist und die Gefahr nicht anders abgewehrt werden kann. § 14 NdsVersG orientiert sich mithin an Art. 8 II GG, wonach Versammlungen in geschlossenen Räumen ohne Gesetzesvorbehalt gewährleistet sind. § 14 I NdsVersG sieht zudem vor, dass die zuständige Behörde eine Versammlung in geschlossenen Räumen beschränken kann, also sogenannte „Minusmaßnahmen“ verfügen kann, wenn ihre Friedlichkeit unmittelbar gefährdet ist. Laut Abs. 2 S. 1 sind Verbote und Auflösungen ausdrücklich nur dann zulässig, wenn eine vorliegende Gefahr nicht anders, insbesondere durch Maßnahmen nach Abs. 1, abgewehrt werden kann. Über § 14 NdsVersG hinaus regelt $\S 15 \mathrm{NdsVersG}$ so genannte „besondere Maßnahmen“, die gegenüber einzelnen Personen erlassen werden können.

1208 Auch das VersFG SH fasst in $\S 20$ I das Verbot und die Auflösung in einer Norm zusammen. Die zuständige Behörde kann danach eine Versammlung in geschlossenen Räumen verbieten, oder nach Beginn der Versammlung auflösen, wenn nach den zur Zeit des Erlasses der Maßnahmen erkennbaren Umständen eine unmittelbare Gefahr (1.) eines unfriedlichen Verlaufs der Versammlung, (2.) für Leben oder Gesundheit von Personen oder (3.) dafür besteht, dass in der Versammlung Äußerungen erfolgen, die ein Verbrechen oder ein von Amts wegen

$2166 \mathrm{Zu}$ den Unterschieden s. Haerkötter/Kohlmeier, in: Ridder/Breitbach/Deiseroth, Versammlungsrecht, i.E., Art. 12 BayVersG, Rn. 2ff. sowie Heinhold, in: Wächtler/Heinhold/Merk, BayVersG, 1. Aufl. 2011, Art. 12. 
zu verfolgendes Vergehen darstellen. Neben dem Verbot und der Auflösung besteht unter denselben Voraussetzungen nach Abs. 1 die Möglichkeit, die Versammlung zu beschränken, d.h. so genannte „Minusmaßnahmen“ zu erlassen. Verbote und Auflösungen sind nach Abs. 2 subsidiär gegenüber Beschränkungen und demnach nur zulässig, wenn entsprechende Maßnahmen nicht ausreichen.

Neben den in $\S 20$ VersFG SH genannten Maßnahmen kommen nach $\S 9$ I und II i.V.m. § 20 I VersFG SH Maßnahmen gegenüber einzelnen Versammlungsteilnehmer*innen in Betracht. § 9 VersFG SH verweist hierzu auf Maßnahmen nach dem LVwG, d.h. dem allgemeinen Polizeirecht, sieht über den Verweis in II auf $\S 20$ VersFG SH für deren Anwendung jedoch vor, dass zusätzlich das Vorliegen einer Gefahr im Sinne von $§ 20$ I VersFG SH gegeben sein muss. Insofern handelt es sich bei dem Verweis auf $\S 20$ I VersFG SH um eine qualifizierte Rechtsgrundverweisung.

\section{cc) Adressat*innen und Pflichtigkeit im Versammlungsrecht}

Als Adressat*innen von Maßnahmen im Zusammenhang von Versammlungen 1209 kommen Teilnehmer^innen, Leiter^innen und Veranstalter^innen in Betracht.

Examenswissen: Veranstalter`innen sind diejenigen Personen, die zu der Versammlung einladen und für das Zustandekommen, Inhalt, Ausgestaltung und Durchführung der Versammlung zuständig sind. ${ }^{2167}$ Die Leiter`innen sind für die Organisation und Ordnung der laufenden Versammlung zuständig und bestimmen über Eröffnung, Unterbrechung und Beendigung der Versammlung. ${ }^{2168}$ Teilnehmer*innen sind alle Personen, die sich aktiv im Rahmen einer Versammlung beteiligen oder nur zuhören, nicht jedoch zufällig anwesende Passantinnen oder etwa unbeteiligtes Ausschankpersonal. ${ }^{2169}$

Soweit die Versammlungsgesetze des Bundes und der Länder selbst keine Stö- 1211 rer*innenbestimmungen enthalten, sind die entsprechenden Bestimmungen des allgemeinen Polizeirechts (hierzu Rn. $1118 \mathrm{ff}$.) heranzuziehen. ${ }^{2170}$

Vor der Versammlung sind Veranstalter*innen die richtigen Adressat*innen 1212 von Verbotsverfügungen oder Auflagen. Adressat^innen von Auflösungsverfügungen und nachträglichen bzw. während der Versammlung verfügten Beschränkungen sind die Leiter^innen und alle Teilnehmenden. (Potentielle) Teil-

2167 Kniesel/Braun/Keller, Besonderes Polizei- und Ordnungsrecht, 1. Aufl. 2018, Rn. 197.

2168 Kniesel/Braun/Keller, Besonderes Polizei- und Ordnungsrecht, 1. Aufl. 2018, Rn. 199.

2169 Kniesel/Braun/Keller, Besonderes Polizei- und Ordnungsrecht, 1. Aufl. 2018, Rn. $203 \mathrm{ff}$.

2170 Kniesel/Braun/Keller, Besonderes Polizei- und Ordnungsrecht, 1. Aufl. 2018, Rn. 428. 
nehmer`innen können vor der Versammlung Adressat*innen sein, wenn es sich um sogenannte Vorfeldmaßnahmen und dabei insbesondere um Teilnahmeuntersagungen ${ }^{2171}$ handelt. Gegen externe Störer ${ }^{\star}$ innen, $d$. h. solche Personen, die Versammlungen stören, nicht aber selbst an einer (Gegen)Versammlung teilnehmen, kann nach Maßgabe des allgemeinen Polizeirechts vorgegangen werden. ${ }^{2172}$

Soweit es zu Störungen durch Dritte kommt, ist unter den Voraussetzungen des polizeilichen Notstandes auch eine Inanspruchnahme von Nichtstörer`innen möglich. Der polizeiliche Notstand ist mittlerweile teilweise in den neuen Landesversammlungsgesetzen ausdrücklich geregelt:

- Niedersachsen: § 8 III NdsVersG (Versammlungen unter freiem Himmel) und $\S 14$ III NdsVersG (Versammlungen in geschlossenen Räumen)

- Schleswig-Holstein: § 13 II VersFG SH (Versammlungen unter freiem Himmel) und § 20 III VersFG SH (Versammlungen in geschlossenen Räumen)

1214 Wo es keine entsprechenden Regelungen gibt, sind die sich aus der Rspr. des BVerfG ergebenden Vorgaben zu berücksichtigen. Danach besteht grds. die dahingehende Schutzpflicht des Staates, die Durchführung einer rechtmäßigen Versammlung gegenüber Störungen durch Nichtteilnehmer`innen unter allen Umständen und unter Heranziehung aller zur Verfügung stehenden Mittel und Ressourcen sicherzustellen. ${ }^{2173}$ Behördliche Maßnahmen sind zudem primär gegen die Störer`innen zu richten. ${ }^{2174}$ Von diesem Grundsatz darf nur abgewichen werden, „wenn gravierende irreparable Schäden an den Rechtsgütern Leben und Gesundheit drohen, wenn die Polizei tatsächlich der Gewalt nicht mehr Herr werden und die Entwicklung der Gewalt durch eigene Mittel nicht mehr steuern oder begrenzen kann (echter polizeilicher Notstand), oder wenn die Polizei in eine Gewalteskalation hineingezogen wird, die durch Gefahren für Leben und Gesundheit höchsten Ausmaßes für Versammlungsteilnehmer, Polizei, Unbeteiligte und Störer führen, dann steht es im Ermessen der Polizei, den Nicht-Störer in Anspruch zu nehmen (unechter polizeilicher Notstand)،“2175 Die Darlegungsund Beweislast für das Vorliegen von Gründen für ein Vorgehen gegen Nichtstörer^innen auf der Grundlage des polizeilichen Notstands liegt bei der Behörde;

2171 Näher hierzu Kniesel/Braun/Keller, Besonderes Polizei- und Ordnungsrecht, 1. Aufl. 2018, Rn. $326 \mathrm{ff}$.

2172 VGH Mannheim, Urt. v. 12.02.1990, Az.: 1 S 1646/89 = NVwZ-RR 1990, 602 (603f.).

2173 St. Rspr. BVerfG. S. zuletzt etwa BVerfG, Beschl. v. 11.9.2015, Az.: 1 BvR 2211/15; BVerfG, Beschl. v. 20.12.2012, Az.: 1 BvR 2794/10 = NVwZ 2013, 570 (571).

2174 BVerfG, Beschl. v. 20.12.2012, Az.: 1 BvR 2794/10 = NVwZ 2013, 570 (571).

2175 Rühl, NVwZ 1988, 577 (584).

Sebastian Eickenjäger 
diese muss detailliert und substantiiert darlegen, welche Maßnahmen und Anstrengungen (insbesondere im Hinblick auf das Ersuchen um Amtshilfe) unternommen wurden, um die sichere Durchführung der Versammlung sicherzustellen. ${ }^{2176}$

\section{dd) Rechtsfolge: Ermessen}

Im Hinblick auf die zuvor dargestellten versammlungsrechtlichen Ermächti- 1215 gungsgrundlagen steht den zuständigen Behörden auf der Rechtsfolgenseite ein Ermessen zu (s. zum Ermessen Rn. 729ff.). Mithin sind die entsprechenden Maßnahmen auf Ermessensfehler hin zu untersuchen (s. zur Ermessensprüfung Rn. 744 ff.).

Bzgl. des Verhältnisses der genannten Maßnahmen untereinander gilt, dass 1216 Verbote und die Auflösung nur zulässig sind, wenn zuvor alle sinnvoll anwendbaren milderen Mittel, insbesondere die Erteilung von Auflagen (etwa nach § 15 I VersammlG), ausgeschöpft wurden, um friedliche Demonstrationen zu ermöglichen. ${ }^{2177}$

Gemäß § 13 I 2 VersammlG, Art. 12 II 2 BayVersG, § 13 I 2 SächsVersG, § 11 I 21217 VersG LSA gilt zudem für Versammlungen in geschlossenen Räumen ausdrücklich, dass eine Auflösung - im Sinne des Verhältnismäßigkeitsgrundsatzes - nur zulässig ist, wenn andere polizeiliche Maßnahmen, insbesondere eine Unterbrechung der Versammlung nicht ausreichen. Gemäß §§ 13 II und 20 II VersFG SH setzten (sowohl bei Versammlungen in geschlossenen Räumen als auch bei Versammlungen unter freiem Himmel) Verbote oder Auflösungen voraus, dass Beschränkungen nicht ausreichen.

Das BVerwG geht davon aus, dass neben dem Verbot oder der Auflösung der 1218 Erlass so genannter „Minusmaßnahmen“ zulässig und im Hinblick auf den Verhältnismäßigkeitsgrundsatz u.U. geboten ist. ${ }^{2178}$ Die zuständigen Behörden müssten im Rahmen der ihnen zustehenden Befugnisse ein milderes und angesichts der konkreten Sachlage angemesseneres Mittel zur Abwehr der von der Versammlung ausgehenden unmittelbaren Gefahren - wie z. B. die Sicherstellung eines beleidigenden Spruchbandes oder das Verbot von Musikstücken oder

2176 BVerfG, Beschl. v. 11.9.2015, Az.: 1 BvR 2211/15; BVerfG, Beschl. v. 20.12.2012, Az.: 1 BvR 2794/10 = NVwZ 2013, 570 (571).; BVerfG, Beschl.v. 10.5.2006, Az.: 1 BvQ 14/06, NVwZ 2006, 1049 (1049f.).

2177 BVerfG, Beschl. v. 14.5.1985, Az.: 1 BvR 233, 341/81 = BVerfGE 69, 315 (353).

2178 S. BVerwG, Urt. v. 8.9.1981, Az.: 1 C 88.77 = BVerwGE 64, 55 (58). S. auch BVerwG, Beschl.v. 14.01.1987, Az.: 1 B 219/86 = NVwZ 1988, 250; BVerwG, Beschl.v. 23.8.1991, Az.: 1 B 77/91 = BeckRS 1991, 31230188. 
Bands, wenn durch das Spielen der Stücke oder dem Auftritt einer Band zu erwarten ist, dass hierdurch Straftatbestände erfüllt werden - als mildere Maßnahme gegenüber der Auflösung einsetzen. ${ }^{2179}$

$1219 \mathrm{Zu}$ beachten ist hierbei, dass mehrere Landesversammlungsgesetze entsprechende Minusmaßnahmen ausdrücklich geregelt haben (hierzu Rn. 1186ff. und $1204 \mathrm{ff}$.).

1220 Examenswissen: In der Literatur wird dem Ansatz der Rspr. mit dem systematischen Argument entgegengetreten, dass es sich bei entsprechenden Maßnahmen um Aliud- und nicht um Minusmaßnahmen handelt und die Anwendung von Minusmaßnahmen das im VersammlG angelegte Konzept der versammlungsrechtlichen Selbstverantwortung (Grundsatz der Autonomie der Versammlung) unterminiere. ${ }^{2180}$ Hierfür wird angeführt, dass einerseits Behörden mit Auflagen unmittelbaren Gefahren begegnen könnten und andererseits Veranstalter^innen die Obliegenheit hätten, die Einhaltung der gesetzlichen und behördlichen Vorgaben sicherzustellen sowie mit den ihnen an die Hand gegebenen Mitteln die Teilnehmer*innen zu rechtskonformen Verhalten anzuhalten. ${ }^{2181}$ Soweit die Veranstalter^innen ihrer Obliegenheit nicht nachkämen oder sich zu einem Vorgehen gegenüber störenden Teilnehmer`innen nicht der Unterstützung der Ordnungsbehörden bedienen würden, stünde den Behörden nach der Konzeption des VersammlG das Mittel der Auflösung zur Verfügung. ${ }^{2182}$ Aufgrund des Grundsatzes der Autonomie der Versammlung dürften „Minusmaßnahmen“ danach nur angeregt, nicht aber unmittelbar angeordnet werden. ${ }^{2183}$

\section{e) Literaturhinweise}

1221 Lehrbücher: Götz/Geis, Allgemeines Polizei- und Ordnungsrecht, 16. Aufl. 2017, $\S 23$; Kingreen/Poscher, Polizei- und Ordnungsrecht mit Versammlungsrecht, 10. Aufl. 2018, §§ 19-22; Kniesel/Braun/Keller, Besonderes Polizei- und Ordnungsrecht, 1. Aufl. 2018, 1. Kapitel; Schenke, Polizei- und Ordnungsrecht, 10. Aufl. 2018, Rn. $360 \mathrm{ff}$.

2179 S. BVerwG, Urt. v. 8.9.1981, Az.: 1 C 88.77 = BVerwGE 64, 55 (58).

2180 Kniesel/Poscher, in: Lisken/Denninger, Handbuch des Polizeirechts, 6. Aufl. 2018, K, Rn. 24ff.; Wittmann, in: Ridder/Breitbach/Deiseroth, Kommentar Versammlungsrecht, i. E., § 15 VersammlG, Rn. $39 \mathrm{ff}$.

2181 Kniesel/Poscher, in: Lisken/Denninger, Handbuch des Polizeirechts, 6. Aufl. 2018, K, Rn. $24 \mathrm{ff}$; Wittmann, in: Ridder/Breitbach/Deiseroth, Kommentar Versammlungsrecht, i. E., § 15 VersammlG, Rn. $39 \mathrm{ff}$.

2182 Kniesel/Poscher, in: Lisken/Denninger, Handbuch des Polizeirechts, 6. Aufl. 2018, K, Rn. 24ff.; Wittmann, in: Ridder/Breitbach/Deiseroth, Versammlungsrecht, i. E., § 15 VersammlG, Rn. $39 \mathrm{ff}$.

2183 So Friedl, in: Friedl/Enders, Versammlungsrecht, 1. Aufl. 2016, §13 VersammlG, Rn. 15 und 17; Eickenjäger/Ewering/Kohlmeier, in: Ridder/Breitbach/Deiseroth, Versammlungsrecht, i.E., $\S 13$ VersammlG, Rn. $32 \mathrm{ff}$.

Sebastian Eickenjäger 
Aktuelle Beiträge aus der Ausbildungsliteratur: Bünnigmann, Polizeifestigkeit im Versammlungsrecht, JuS 2016, 695; Gröpl/Leinenbach, Examensschwerpunkte des Versammlungsrechts, JA 2018, 8

Aktuelle Fallbesprechungen: Buchholtz, Streit um missglückte „Hagida“Demo, JuS 2018, 889; Herrmann, Ärger am Bahndamm, JuS 2017, 1093; Lassahn, Unerwünschte Gesellschaft, JuS 2016, 730; Marxsen/Lehners, Camp in Gipfelnähe, JuS 2018, 701; Schmitz, Versammlungsfreiheit und Gegendemonstration, JuS 2017, 753; Spilker/Wenzel, Pro-Asyl-Demonstration mit Hindernissen, JuS 2016, 337

\section{Ermächtigungsgrundlagen des Bauordnungsrechts (Felix Steengrafe)}

Die Anfechtung eines Verwaltungsakts kann im öffentlichen Baurecht entweder durch den Vorhabenträger, in Form der Anfechtung einer Nebenbestimmung oder einer belastenden, bauordnungsrechtlichen Anordnung, oder durch einen Dritten erfolgen.

In Betracht kommt zunächst die Anfechtung von Nebenbestimmungen zur

Baugenehmigung. Die Erteilung der Baugenehmigung ist - sofern deren tatbestandliche Voraussetzungen vorliegen - eine gebundene Entscheidung, auf die ein Rechtsanspruch besteht (s. § 3 Rn. 155). Auch für die Frage der Zulässigkeit von Nebenbestimmungen ist diese rechtliche Einordnung beachtlich. Nebenbestimmungen sind bei einer gebundenen Entscheidung nur zulässig, wenn diese durch eine Rechtsvorschrift zugelassen werden oder wenn die Nebenbestimmung sicherstellen soll, dass die gesetzlichen Voraussetzungen der Baugenehmigung erfüllt werden, § 36 I VwVfG. Die Erteilung einer Baugenehmigung mit einer Nebenbestimmung ist gegenüber der Versagung das mildere Mittel und damit entsprechend des Grundsatzes der Verhältnismäßigkeit erforderlich. Hinsichtlich der isolierten Anfechtbarkeit von Nebenbestimmungen wird an dieser Stelle auf die Ausführungen in Rn. $249 \mathrm{ff}$. verwiesen.

In der zweiten Konstellation ficht der Adressat eine bauordnungsrechtliche Verfügung an.

Die Baugenehmigung bzw. das Anzeigeverfahren soll präventiv Verstöße gegen das Baurecht verhindern (präventive Kontrolle). Bauordnungsverfügungen sollen hingegen im Rahmen oder nach der Realisierung des Bauvorhabens auftretende bzw. bestehende Verstöße gegen das Baurecht beseitigen (repressive Kontrolle). ${ }^{2184}$

2184 Kahl/Dubber, ZJS 2015, 558 (558); Stollmann/Beaucamp, Öffentliches Baurecht, 11. Aufl. 2017, § 19, Rn. 1; Oldiges/Brinktrine, in: Steiner/Brinktrine, Besonderes Verwaltungsrecht, 9. Aufl. 2018, § 3, Rn. 298. 
Als bauordnungsrechtliche Verfügungen kommen die Stilllegungs- oder Beseitigungsverfügung oder die Nutzungsuntersagung in Betracht. Für die einzelnen Voraussetzungen der bauordnungsrechtlichen Anordnungen wird an dieser Stelle auf Rn. $1234 \mathrm{ff}$. verwiesen.

1226 Eine Baugenehmigung begünstigt den Bauherren, kann jedoch zugleich auch einen Dritten belasten und ist damit ein Verwaltungsakt mit Doppelwirkung. ${ }^{2185}$ In Betracht kommt daher auch die Anfechtung der Baugenehmigung durch einen Nachbarn. Bei der Anfechtungsklage eines Nachbarn ist insbesondere die Klagebefugnis nach $\S 42$ II VwGO - aufgrund der fehlenden Adressateneigenschaft - problematisch. Die Klagebefugnis eines Dritten erfordert nach der Schutznormtheorie die Möglichkeit der Verletzung einer nachbarschützenden Vorschrift. Ausgangspunkt ist damit die Bestimmung einer möglicherweise verletzten Rechtsnorm. Der nachbarschützende Charakter von Rechtsnormen ergibt sich aus deren Auslegung, vor allem nach deren Wortlaut sowie Sinn und Zweck. ${ }^{2186}$ Nach der Feststellung der nachbarschützenden Wirkung der Rechtsnorm ist zu prüfen, ob der Kläger in dem von der Rechtsnorm besonders geschützten Personenkreis umfasst ist. Nach dem materiellen Nachbarbegriff ist „Nachbar“ in diesem Sinne jede Person, die sich im Einwirkungsbereich des Vorhabens langfristig oder ständig aufhält. ${ }^{2187}$ Das Bauplanungsrecht ist grundstücksbezogen. Ein bauplanungsrechtlicher Nachbarschutz steht damit nur dem Grundstückseigentümer oder Inhaber vergleichbarer dinglicher Rechte und nicht obligatorisch Berechtigten zu. ${ }^{2188}$

\section{a) Einführung in das Baurecht}

1227 Das öffentliche Baurecht umfasst alle Rechtsvorschriften über die Zulässigkeit, Grenzen, Ordnung sowie Förderung der Nutzung von Boden, insbesondere hinsichtlich der Errichtung, Nutzung, Veränderung sowie Beseitigung von baulichen Anlagen. ${ }^{2189}$

2185 Wolf, NVwZ 2013, 247 (247); Erbguth/Mann/Schubert, Besonderes Verwaltungsrecht, 12 Aufl. 2015, Rn. 1322; Sperlich, JA 2017, 38 (38).

2186 Erbguth/Mann/Schubert, Besonderes Verwaltungsrecht, 12. Aufl. 2015, Rn. 1329; Stollmann/Beaucamp, Öffentliches Baurecht, 11 Aufl. 2017, § 21, Rn. 31.

2187 Erbguth/Mann/Schubert, Besonderes Verwaltungsrecht, 12 Aufl. 2015, Rn. 1334; Muckel/ Ogorek, Öffentliches Baurecht, 3. Aufl. 2018, § 10, Rn. 16.

2188 BVerwG, Beschl.v. 11.7.1989, Az.: 4 B 33/89, Rn. 4 = NJW 1989, 2766 (2766); VGH München, Beschl. v. 9.5.2017, Az.: 9 CS 16.1241, Rn. 19; VGH München, Beschl. v. 2.9.2016, Az.: 9 CS 16.1138, Rn. 16; VGH Mannheim, Beschl.v. 27.6.2006, Az.: 8 S 997/06, Rn. 2.

2189 Stollmann/Beaucamp, Öffentliches Baurecht, 11. Aufl. 2017, §1, Rn. 1.

Felix Steengrafe 


\section{aa) Unterscheidung zwischen Bauplanungs- und Bauordnungsrecht}

Im öffentlichen Baurecht ist zwischen dem Bauplanungs- und Bauordnungsrecht 1228 zu unterscheiden. Das Bauplanungsrecht umfasst insbesondere die Zulässigkeit von Vorhaben nach den Regelungen des BauGB sowie die Vorschriften über die Bauleitplanung und setzt sich aus dem BauGB und auf diesem Gesetz erlassenen Verordnungen (Baunutzungsverordnung, Wertermittlungsverordnung und Planzeichenverordnung) zusammen. Die Bauleitplanung ist wiederum in den Flächennutzungsplan sowie den Bebauungsplan zu unterscheiden. Der Flächennutzungsplan im Sinne des $\S \S 5$ BauGB ff. ist der vorbereitende Bauleitplan, während der Bebauungsplan gemäß $\S \S 8$ BauGB ff. verbindlich ist. Während das Bauplanungsrecht flächenbezogen ist und damit einem Interessenausgleich zwischen öffentlichen und privaten Interessen dient, ist das Bauordnungsrecht objektbezogen und damit primär der Gefahrenabwehr zuzuordnen. ${ }^{2190}$ Das Bauordnungsrecht regelt die Voraussetzungen sowie das Verfahren zur Erteilung einer Baugenehmigung oder für den Erlass bauordnungsrechtlicher Verfügungen. Eine wesentliche bauordnungsrechtliche Anforderung in der Form des Verunstaltungsverbotes liegt in der Gestaltung des Vorhabens. ${ }^{2191}$ Die Rechtsgrundlagen des Bauordnungsrechts finden sich in den Bauordnungen der Bundesländer. Alle 16 Bundesländer haben eine eigene Bauordnung erlassen. Als Orientierungspunkt für die Bundesländer wurde die Musterbauordnung (im Folgenden MBauO) erarbeitet, die selbst jedoch kein Gesetz ist. Die Bauordnungen der Bundesländer orientieren sich in vielen Punkten an der MBauO. Aus Gründen der Übersichtlichkeit wird im Folgenden auf die Vorschriften der MBauO verwiesen, wobei jeweils auf die besonders relevanten landesrechtlichen Normen hingewiesen wird.

\section{bb) Verfassungsrechtliche Anknüpfungspunkte des öffentlichen Baurechts}

Der Bund verfügt gemäß Art. 74 I Nr. 18 GG über die konkurrierende Gesetz- 1229

gebungskompetenz für das Bodenrecht. Als Bestandteil der konkurrierenden Gesetzgebungskompetenz haben die Länder nach Art. 72 I GG „die Befugnis zur Gesetzgebung solange und soweit der Bund von seiner Gesetzgebungszuständigkeit nicht durch Gesetz Gebrauch gemacht hat.“ Das BauGB ist eine ab-

2190 Erbguth/Mann/Schubert, Besonderes Verwaltungsrecht, 12. Aufl. 2015, Rn. 795 ff.; Battis, Öffentliches Baurecht und Raumordungsrecht, 7. Aufl. 2017, Rn. $3 \mathrm{f}$.

2191 BVerwG, Beschl.v. 27.6.1991, Az.: 4 B 138/90, Rn. 6 = NVwZ 1991, 983 (984); BVerwG, Urt. v. 11.10.2007, Az.: 4 C 8/06, Rn. 10 ff.; Schröer, NZBau 2008, 759 (760); Erbguth/Mann/Schubert, Besonderes Verwaltungsrecht, 12. Aufl. 2015, Rn. 802; Muckel/Ogorek, Öffentliches Baurecht, 3. Aufl. 2018, § 9, Rn. 91.

Felix Steengrafe 
schließende Entscheidung des Gesetzgebers, weshalb keine Befugnis der Bundesländer zur Gesetzgebung im Bereich des Bauplanungsrechts besteht. ${ }^{2192}$

1230

Art. 28 II 1 GG gewährleistet den Gemeinden „,alle Angelegenheiten der örtlichen Gemeinschaft im Rahmen der Gesetze in eigener Verantwortung zu regeln“, was das Recht der Bauleitplanung umfasst. ${ }^{2193}$ Einfachgesetzlich spiegelt sich die Planungshoheit in § 2 I 1 BauGB wider, ${ }^{2194}$ nach dem die Gemeinden Bauleitpläne in eigener Verantwortung aufstellen. Ebenfalls durch Art. 28 II 1 GG als Ausdruck der Planungshoheit verfassungsrechtlich abgesichert ist das Recht der Gemeinde auf Beteiligung an Planungen von anderen Hoheitsträgern, sofern sich diese für die Gemeinde auswirken können. ${ }^{2195}$ Als Beispiel für eine solche Beteiligung ist $§ 9$ ROG anzuführen.

1231 Ebenfalls zum Schutz der kommunalen Planungshoheit sieht $\S 36$ BauGB die Regelung zum gemeindlichen Einvernehmen vor. ${ }^{2196}$ Nach § 36 I 1 BauGB wird über „die Zulässigkeit von Vorhaben nach den $\S \S 31,33$ bis 35 im bauaufsichtlichen Verfahren von der Baugenehmigungsbehörde im Einvernehmen mit der Gemeinde entschieden. “ Das gemeindliche Einvernehmen darf gemäß § 36 II 1 BauGB nur aus den sich aus den $\S \S 31$, 33, 34 und 35 ergebenden Gründen versagt werden. Wird das gemeindliche Einvernehmen nicht binnen zwei Monaten nach Eingang des Ersuchens verweigert, gilt dieses gemäß § 36 II BauGB als erteilt. Die Berechnung der Frist erfolgt nach $\S \S 187$ I, 188 II BGB. ${ }^{2197}$ Ein rechtswidrig versagtes Einvernehmen der Gemeinde kann nach $\S 36$ II 3 BauGB ersetzt werden.

1232 Das Bauordnungsrecht bezieht sich aufgrund seines Objektbezuges in erster Linie auf die Sicherheit sowie Gestaltung des Einzelvorhabens und ist Bestandteil des Polizei- und Ordnungsrechts, weshalb nach Art. 70 I GG eine Gesetzge-

2192 Erbguth/Mann/Schubert, Besonderes Verwaltungsrecht, 12. Aufl. 2015, Rn. $807 \mathrm{f}$.

2193 Krüper/Herbolsheimer, ZJS 2016, 546 (546f.); Krüper, ZJS 2010, 582 (582); Stollmann/ Beaucamp, Öffentliches Baurecht, 11. Aufl. 2017, § 2, Rn. 15 f.; Muckel/Ogorek, Öffentliches Baurecht, 3. Aufl. 2018, § 4, Rn. 1; Jeromin, in: Kröninger/Aschke/Jeromin, BauGB, 4. Aufl. 2018, § 2, Rn. 1.

2194 Stollmann/Beaucamp, Öffentliches Baurecht, 11. Aufl. 2017, § 2, Rn. 17; Muckel/Ogorek, Öffentliches Baurecht, 3. Aufl. 2018, § 4, Rn. 1; Jeromin, in: Kröninger/Aschke/Jeromin, BauGB, 4. Aufl. 2018, § 2, Rn. 1.

2195 Erbguth/Mann/Schubert, Besonderes Verwaltungsrecht, 12. Aufl. 2015, Rn. 812; Stollmann/ Beaucamp, Öffentliches Baurecht, 11. Aufl. 2017, § 2, Rn. 19.

2196 Hofmeister, in: Spannowsky/Uechtritz, BauGB, 3. Aufl. 2018, § 36, Rn. 1; Jeromin, in: Kröninger/Aschke/Jeromin, BauGB, 4. Aufl. 2018, § 36, Rn. 1.

2197 Hofmeister, in: Spannowsky/Uechtritz, 3. Aufl. 2018, § 36, Rn. 26; Jeromin, in: Kröninger/ Aschke/Jeromin, BauGB, 4. Aufl. 2018, § 36, Rn. 7.

Felix Steengrafe 
bungskompetenz der Länder besteht. ${ }^{2198}$ Diese Kompetenz drückt sich in den 16 Bauordnungen der Länder aus.

Für das öffentliche Baurecht ist Art. 14 GG von wesentlicher Bedeutung. 1233 Art. 14 I 1 GG schützt verfassungsrechtlich das Eigentum, was das Recht der Nutzung des Eigentums nach der eigenen Vorstellung umfasst. ${ }^{2199}$ Inhalt und Schranken der Eigentumsfreiheit bestimmen (einfache) Gesetze. ${ }^{2200}$ Ein Grundstück darf im Rahmen der Gesetze bebaut werden. Ein Anspruch auf Erteilung einer Baugenehmigung besteht, wenn öffentlich-rechtliche Vorschriften dem nicht entgegenstehen. Darüber hinaus kann zugunsten einer Bebauung ein Bestandsschutz eintreten. Ein unbeschränktes Baurecht besteht hingegen nicht. ${ }^{2201}$

Hausarbeitswissen: Es ist umstritten, ob sich diese sog. Baufreiheit aus Art. 14 GG ${ }^{2202}$ oder aus verwaltungsrechtlichen Vorschriften ${ }^{2203}$ ergibt.

\section{b) Die Beseitigungsverfügung}

Eine Beseitigungsverfügung ist aufgrund ihrer erheblichen Folgen nur die ulti- 1234 ma ratio um einen baurechtskonformen Zustand wiederherzustellen. ${ }^{2204}$ Die Beseitigung eines Bauwerkes kann teilweise oder vollständig angeordnet werden.

\section{aa) Ermächtigungsgrundlagen}

$\S 80 \mathrm{MBauO}$ normiert die Ermächtigungsgrundlage für eine Beseitigungsverfügung. In den Ländern finden sich die Ermächtigungsgrundlagen in den folgenden Normen:

2198 BVerwG, Urt. v. 11.10.2007, Az.: 4 C 8/06, Rn. 10; Dirnberger, in: Spannowsky/Uechtritz, 3. Aufl. 2018, § 1, Rn. 2; Oldiges/Brinktrine, in: Steiner/Brinktrine, Besonderes Verwaltungsrecht, 9. Aufl. 2018, § 3, Rn. 14; Stollmann/Beaucamp, Öffentliches Baurecht, 11. Aufl. 2017, § 2, Rn. 25. 2199 Jarass, in: Jarass/Pieroth, GG, 15. Aufl. 2018, Art. 14, Rn. 16.

2200 BVerfG, Urt. v. 6.12.2016, 1 BvR 2821/11, 1 BvR 321/12, 1 BvR 1456/12 = NJW 2017, 217 (221); BVerfG, Beschl. v. 15.1.1969, 1 BvL 3/66; BVerwG, Urt. v. 18. 8.1960, I C 42/59 = NJW 1961, 793 (793); Jarass, in: Jarass/Pieroth, GG, 15. Aufl. 2018, Art. 14, Rn. 5.

2201 Stollmann/Beaucamp, Öffentliches Baurecht, 11. Aufl. 2017, § 2, Rn. 3 ff.; Erbguth/Mann/ Schubert, Besonderes Verwaltungsrecht, 12. Aufl. 2015, Rn. 816ff.; Art. 14 GG bejahend: Jarass, in: Jarass/Pieroth, GG, 15. Aufl. 2018, Art. 14, Rn. 20.

2202 VGH Mannheim, Beschl. v. 22.1.1996, Az.: 8 S 2964/95, Rn. 3.

2203 Lege, ZJS 2012, 44 (45).

2204 Kahl/Dubber, ZJS 2015, 558 (561). 


\begin{tabular}{|c|c|}
\hline Baden-Württemberg & $\S 65$ LBO BW \\
\hline Bayern & Art. 76 BayBO \\
\hline Berlin & $\S 80 \mathrm{BauO}$ Bln \\
\hline Brandenburg & $\S 80 \mathrm{BbgBO}$ \\
\hline Bremen & $\S 79$ BremLBO \\
\hline Hamburg & $\S 76 \mathrm{HmbBO}$ \\
\hline Hessen & $\S 82 \mathrm{HBO}$ \\
\hline Mecklenburg-Vorpommern & $\S 80 \mathrm{LBO} \mathrm{MV}$ \\
\hline Niedersachsen & $\S 79$ NBauO \\
\hline Nordrhein-Westfalen & $\S 82 \mathrm{BauO} N R W$ \\
\hline Rheinland-Pfalz & $\S 81 \mathrm{f}$. LBO RP \\
\hline Saarland & $\S 82$ LBO Saar \\
\hline Sachsen & $\S \S 80$ SächsBO \\
\hline Sachsen-Anhalt & $\S 79$ BauO LSA \\
\hline Schleswig-Holstein & $\S 59$ LBO SH \\
\hline Thüringen & $\S 79$ ThürBo \\
\hline
\end{tabular}

\section{bb) Formelle Rechtmäßigkeit}

1235 Für ein bauordnungsrechtliches Einschreiten müssen - wie bei jedem Verwaltungsakt - die formellen Anforderungen in der Gestalt der sich aus dem Bauordnungsrecht ergebenden Zuständigkeit, des Verfahrens, insbesondere der Anhörung nach $\S 28$ VwVfG bei einer Bauordnungsverfügung als belastenden Verwaltungsakt, und der Form gewahrt werden (s. Rn. 579ff.). Bei einem schriftlichen Verwaltungsakt sind die Anforderungen des $\S 39$ VwVfG zu berücksichtigen.

\section{cc) Materielle Rechtmäßigkeit}

1236 Ein genehmigungspflichtiges Vorhaben darf nur abgerissen werden, wenn dieses formell und materiell illegal ist. Diese Voraussetzungen müssen kumulativ vorliegen. ${ }^{2205}$ Formelle Illegalität bedeutet, dass die erforderliche Baugenehmi-

2205 VG Münster, Urt. v. 19.6.2018, Az.: 2 K 6704/17, Rn. 33; Kersten, in: Schoch, Besonderes Felix Steengrafe 
gung nicht vorliegt oder das Bauwerk wesentlich von der Genehmigung abweicht. ${ }^{2206}$ Materiell illegal ist ein Bauwerk, wenn dieses nicht mit den öffentlichrechtlichen Anforderungen vereinbar ist. ${ }^{2207}$

Sofern ein Bauwerk nicht mit den öffentlich-rechtlichen Vorgaben vereinbar 1237 und damit materiell illegal ist, dieses aber durch eine Baugenehmigung gedeckt und somit formell legal ist, darf eine Beseitigungsverfügung nicht ergehen. Vor einer solchen Verfügung müsste die Baugenehmigung bestandskräftig aufgehoben werden (zu Rücknahme und Widerruf näher Rn. 836 ff.). ${ }^{2208}$ Im Falle eines vereinfachten Genehmigungsverfahrens kann sich die Legalisierungswirkung der Baugenehmigung nicht auf die im vereinfachten Genehmigungsverfahren ungeprüften Bereiche erstrecken, weshalb die vorherige Aufhebung der Baugenehmigung in diesem Einzelfall nicht erforderlich ist. ${ }^{2209}$ Einer Beseitigungsverfügung steht der passive Bestandsschutz als Ausdruck von Art. 14 I GG entgegen. War die Errichtung des Bauwerkes materiell rechtmäßig, schützt der passive Bestandsschutz vor einer Veränderung der Sach- und Rechtslage. ${ }^{2210}$ Diese Rechtsauffassung ist allerdings nicht unumstritten. Ebenfalls nicht unumstritten ist die Konstellation, in der die materielle Rechtmäßigkeit für einen Zeitraum nach der Errichtung und vor der ordnungsrechtlichen Verfügung eingetreten ist. ${ }^{2211}$ Bei genehmigungsfreien Vorhaben ist mangels erforderlicher Baugenehmigung naturgemäß nur auf die materielle Illegalität abzustellen.

Verwaltungsrecht, 2018, Kap. 3, Rn. 449; Kahl/Dubber, ZJS 2015, 558 (561); Lindner, JuS 2014, 118 (120).

2206 Kahl/Dubber, ZJS 2015, 558 (561); Lindner, JuS 2014, 118 (119); Oldiges/Brinktrine, in: Steiner/Brinktrine, Besonderes Verwaltungsrecht, 9. Aufl. 2018, § 3, Rn. 331; Battis, Öffentliches Baurecht und Raumordungsrecht, 7. Aufl. 2017, Rn. 599.

2207 OVG Greifswald, Beschl.v. 2.11.1993, 3 M 89/93 = NVwZ 1995, 608 (608); Oldiges/Brinktrine, in: Steiner/Brinktrine, Besonderes Verwaltungsrecht, 9. Aufl. 2018, § 3, Rn. 331; Battis, Öffentliches Baurecht und Raumordungsrecht, 7. Aufl. 2017, Rn. 599.

2208 Lindner, JuS 2014, 118 (121); Oldiges/Brinktrine, in: Steiner/Brinktrine, Besonderes Verwaltungsrecht, 9. Aufl. 2018, § 3, Rn. 335; Erbguth/Mann/Schubert, Besonderes Verwaltungsrecht, 12. Aufl. 2015, Rn. 1305.

2209 OVG Berlin-Brandenburg, Beschl. v. 23.6.2010, Az.: 2 S 99/09 = NVwZ-RR 2010, 794 (795); Lindner, JuS 2014, 118 (121).

2210 Battis, Öffentliches Baurecht und Raumordungsrecht, 7. Aufl. 2017, Rn. 601; Kersten, in: Schoch, Besonderes Verwaltungsrecht, 2018, Kap. 3, Rn. 450.

2211 VG Münster, Urt. v. 19.6.2018, Az.: 2 K 6704/17, Rn. 70; Battis, Öffentliches Baurecht und Raumordungsrecht, 7. Aufl. 2017, Rn. 601; Kersten, in: Schoch, Besonderes Verwaltungsrecht, 2018, Kap. 3, Rn. 450; Mit einem Überblick: Kahl/Dubber, ZJS 2015, 558 (563).

Felix Steengrafe 
Adressaten einer bauordnungsrechtlichen Verfügung können entweder der Handlungs- oder Zustandsstörer sein (s. Rn. 1121ff.). Bei der Auswahl des Störers ist die Effektivität der Gefahrenabwehr zu berücksichtigen. ${ }^{2212}$

Examenswissen: Eine Ordnungsverfügung kann auch gegenüber einem Rechtsnachfolger wirken. Maßgeblich ist hierbei das Landesrecht. ${ }^{2213}$ Sofern das Landesrecht keine Regelung enthält, stellt sich die Frage, ob mit der Verfügung eine höchstpersönliche Pflicht eintrat. In der Regel dürfte die Ordnungsverfügung allerdings sachbezogen und damit nicht höchstpersönlich sein. Auch ein Gesamtrechtsnachfolger wird damit durch die Verfügung verpflichtet. ${ }^{2214}$

\section{dd) Ermessen}

1239 Die Beseitigungsverfügung steht im pflichtgemäßen Ermessen der Bauverwaltung. Das Ermessen erstreckt sich auf das Erschließungsermessen („ob“) und das Auswahlermessen (,wie). Das Auswahlermessen erstreckt sich sowohl auf die Maßnahme als auch auf den Adressaten. ${ }^{2215}$ Bei der Auswahl ist die Effektivität der Gefahrenabwehr zu berücksichtigen. Nach der Rechtsprechung ist im Regelfall eine Ordnungsverfügung zu erlassen, um einen baurechtskonformen Zustand wiederherzustellen. Nur in Ausnahmefällen soll die Bauverwaltung von einer Beseitigungsverfügung absehen. ${ }^{2216}$

1240 Bestehen mehrere formell und materiell illegale Bauwerke ist grundsätzlich der allgemeine Gleichheitssatz des Art. 3 I GG anzuwenden. ${ }^{2217}$ Trotz des Gleichheitssatzes ist nicht erforderlich, dass die Bauverwaltung gegen alle illegalen Bauwerke zeitgleich vorgeht. Bei sachlichen Gründen darf sich die Verwaltung auf die Abarbeitung von Einzelfällen festlegen. Sachliche Gründe in diesem Sinne können das Gefahrenpotenzial einzelner Bauwerke, Größe oder Lage der Bauwerke oder die Kapazitätsgrenze der Baubehörde sein. ${ }^{2218}$ Eine Ungleichbehandlung kann einer Beseitigungsverfügung nur dann erfolgreich entgegengehalten werden, wenn kein sachlicher Grund für das abschnittsweise Vorgehen besteht. ${ }^{2219}$

2212 Erbguth/Mann/Schubert, Besonderes Verwaltungsrecht, 12. Aufl. 2015, Rn. 1313.

2213 Erbguth/Mann/Schubert, Besonderes Verwaltungsrecht, 12. Aufl. 2015, Rn. 1313.

2214 Stollmann/Beaucamp, Öffentliches Baurecht, 11. Aufl. 2017, §19, Rn. 46 f.

$2215 \mathrm{Kahl} /$ Dubber, ZJS 2015, 558 (564).

2216 Kersten, in: Schoch, Besonderes Verwaltungsrecht, 2018, Kap. 3, Rn. 446; Kahl/Dubber, ZJS 2015, 558 (564).

2217 Kahl/Dubber, ZJS 2015, 558 (565); Stollmann/Beaucamp, Öffentliches Baurecht, 11. Aufl. 2017, § 19, Rn. 35; Kersten, in: Schoch, Besonderes Verwaltungsrecht, 2018, Kap. 3, Rn. 454.

$2218 \mathrm{Kahl} /$ Dubber, ZJS 2015, 558 (565).

2219 Kahl/Dubber, ZJS 2015, 558 (565).

Felix Steengrafe 
Bei Kenntnis der Bauverwaltung von einer rechtswidrigen Bebauung über 1241 einen längeren Zeitraum, kann beim Adressaten einer späteren Ordnungsverfügung die Vorstellung entstanden sein, dass sich die Verwaltung mit der Bebauung abgefunden habe. In einem solchen Fall stellt sich die Frage nach der Schutzwürdigkeit dieser Vorstellung. Nahm die Behörde die rechtswidrige Bebauung einfach hin (sog. faktische Duldung), begründet dies keinen Vertrauenstatbestand für die zukünftige Akzeptanz der rechtswidrigen Bebauung. Dies gilt selbst in den Fällen, in denen die faktische Duldung über einen langen Zeitraum bestand. ${ }^{2220}$ Ein Vertrauenstatbestand kann sich aus einer sog. aktiven Duldung ergeben. Für die Annahme dieser Form der Duldung muss die Behörde in unmissverständlicher Art und Weise erklären, ob, für welchen Zeitraum und in welchem Rahmen die Duldung des baurechtswidrigen Zustandes erfolgen soll. Eine solche Erklärung kann im Einzelfall einer bauaufsichtlichen Verfügung entgegengehalten werden. ${ }^{2221}$

Ein Ermessensfehler kann in der Gestalt der Ermessensüberschreitung 1242 durch eine unverhältnismäßige Entscheidung vorliegen. Die bauordnungsrechtlichen Verfügungen müssen - wie alle staatlichen Maßnahmen - verhältnismäßig sein, weshalb die Verhältnismäßigkeit zu prüfen ist. Der legitime Zweck ist die Schaffung von baurechtskonformen Zuständen. In der Regel ist die Beseitigungsverfügung zur Förderung des Ziels geeignet. Nicht erforderlich ist eine solche Verfügung, wenn durch ein milderes aber gleich effektives Mittel der baurechtskonforme Zustand hergestellt werden kann. Aufgrund des erheblichen Substanzeingriffes stellt die Beseitigung den gravierendsten Eingriff in das Eigentum dar. ${ }^{2222}$ Eine Nutzungsuntersagung oder eine Genehmigung mit erheblichen Nebenbestimmungen sowie ein Teilabriss sind in vielen Fällen ein milderes Mittel, dessen gleiche Effektivität im Einzelfall zu betrachten ist. ${ }^{2223}$ Bei der Angemessenheit ist zwischen der Schwere des Eingriffs und der Bedeutung des verfolgten Zieles abzuwägen. ${ }^{2224}$ Trotz des erheblichen Eingriffs mit dem hohen wirtschaftlichen Schaden und den Folgen für den Adressaten stehen diese Er-

2220 OVG Münster, Urt. v. 24.2.2016, Az.: 7 A 1623/14 = NVwZ-RR 2016, 851 (853); OVG Münster, Urt. v. 22.8.2005, 10 A 4694/03 = NJOZ 2005, 5183 (5190); Sommer, JA 2017, 567 (568).

2221 OVG Münster, Beschl. v. 16.3.2007, Az.: 7 B 134/07, Rn. 29 = NVwZ-RR 2007, 661 (662); OVG Münster, Urt. v. 22. 8. 2005, Az.: 10 A 4694/03, Rn. 95 ff. = NJOZ 2005, 5183 (5190); OVG Berlin, Urt. v. 14.5.1982, Az.: 2 B 57/79, Rn. 23 = NJW 1983, 777 (778); Sommer, JA 2017, 567 (568).

$2222 \mathrm{Kahl} /$ Dubber, ZJS 2015, 558 (565).

2223 Kahl/Dubber, ZJS 2015, 558 (565); Kersten, in: Schoch, Besonderes Verwaltungsrecht, 2018, Kap. 3, Rn. 453.

2224 Kahl/Dubber, ZJS 2015, 558 (565).

Felix Steengrafe 
wägungen nicht per se einer Beseitigungsverfügung entgegen, andernfalls würden baurechtswidrige Bauwerke privilegiert werden. ${ }^{2225}$

\section{c) Die Nutzungsuntersagung}

1243 Anders als bei der Beseitigungsverfügung zielt die Nutzungsuntersagung nicht auf eine Substanzbeeinträchtigung, sondern auf ein Unterlassen ab.

\section{aa) Ermächtigungsgrundlagen}

$1244 \S 80$ S. 2 MBauO ermächtigt eine Nutzung zu untersagen, wenn eine Anlage im Widerspruch zu öffentlich-rechtlichen Vorschriften genutzt wird. In den Ländern finden sich die Ermächtigungsgrundlagen in den folgenden Normen:

\begin{tabular}{|c|c|}
\hline Baden-Württemberg & $\S 65$ LBO BW \\
\hline Bayern & Art. 76 BayBO \\
\hline Berlin & $\S 80 \mathrm{BauO} \mathrm{Bln}$ \\
\hline Brandenburg & $\S 80 \mathrm{BbgBO}$ \\
\hline Bremen & $\S 79$ BremLBO \\
\hline Hamburg & $\S 76 \mathrm{HmbBO}$ \\
\hline Hessen & $\S 82 \mathrm{HBO}$ \\
\hline Mecklenburg-Vorpommern & $\S 80$ LBO MV \\
\hline Niedersachsen & $\S 79 \mathrm{NBauO}$ \\
\hline Nordrhein-Westfalen & $\S 82 \mathrm{BauO}$ NRW \\
\hline Rheinland-Pfalz & $\S 81 \mathrm{f}$. LBO RP \\
\hline Saarland & $\S 82$ LBO Saar \\
\hline Sachsen & $\S \S 80$ SächsBO \\
\hline Sachsen-Anhalt & $\S 79$ BauO LSA \\
\hline Schleswig-Holstein & $\S 59$ LBO SH \\
\hline Thüringen & $\S 79$ ThürBO \\
\hline
\end{tabular}

2225 OVG Berlin, Beschl. v. 27.11.2001, Az.: 2 N 27/01 = LKV 2002, 184 (185); Kahl/Dubber, ZJS 2015, 558 (565); Stollmann/Beaucamp, Öffentliches Baurecht, 11. Aufl. 2017, § 19, Rn. 34.

Felix Steengrafe 


\section{bb) Formelle Rechtmäßigkeit}

Die formellen Anforderungen an den Erlass einer Nutzungsuntersagung weichen 1245 nicht von den obigen Anforderungen ab (s. Rn. 1235).

\section{cc) Materielle Rechtmäßigkeit}

Bei der Nutzungsuntersagung steht die Nutzung des Bauwerkes nicht im Einklang 1246 mit den öffentlich-rechtlichen Vorgaben. Umstritten ist, ob für den Erlass einer Nutzungsuntersagung die formelle Illegalität ausreichend ist. Teilweise wird auch eine materielle Illegalität gefordert. Begründet wird diese weitgehende Forderung mit der Beeinträchtigung des Eigentums. ${ }^{2226}$ Für eine ausreichende formelle Illegalität spricht die geringe Eigentumsbeeinträchtigung. ${ }^{2227}$ Die Intensität ist wesentlich geringer als bei einer Beseitigungsverfügung. Besteht sowohl eine formelle als auch materielle Illegalität ist nach beiden Auffassungen eine Nutzungsuntersagung materiell rechtmäßig. Die Frage der Erforderlichkeit der materiellen Illegalität wirkt sich damit nur in den Fällen auf das Ergebnis aus, in denen eine formelle, aber keine materielle Illegalität besteht. Der Bestandsschutz endet bei einer Nutzungsänderung. ${ }^{2228}$ Die Bauverwaltung muss im Rahmen ihrer pflichtgemäßen Ermessensausübung - sofern ausschließlich eine formelle Illegalität gefordert werden sollte - eine mögliche (offensichtliche) materielle Rechtmäßigkeit berücksichtigen. ${ }^{2229}$ Ansonsten kann an dieser Stelle auf die vorherigen Ausführungen zum Ermessen bei der Beseitigungsverfügung verwiesen werden (s. Rn. 1239ff.).

\section{d) Die Stillegungsverfügung}

Anders als die Beseitigungsverfügung oder die Nutzungsuntersagung bezieht sich 1247 die Stilllegungsverfügung zeitlich auf die Errichtungsphase des Bauwerkes.

2226 VGH Mannheim, Beschl. v. 22.1.1996, Az.: 8 S 2964/95, Rn. 3.

2227 VGH München, Urt. v. 5.12.2005, 1 B 03.2608 = NVwZ-RR 2006, 754 (755); OVG Bautzen, Beschl.v. 25.6.2001, Az.: B 67/01 = LKV 2002, 180 (180); Kahl/Dubber, ZJS 2015, 558 (567); Kersten, in: Schoch, Besonderes Verwaltungsrecht, 2018, Kap. 3, Rn. 446.

2228 BVerfG, Beschl. v. 15.12.1995, Az.: 1 BvR 1713/92 = NVwZ-RR 1996, 483 (483); BVerwG, Beschl. v. 9.9.2002, Az.: 4 B 52/02; BVerwG, Beschl. v. 27.2.1993, 4 B 5/93, Rn. 3.

2229 VGH München, Urt. v. 5.12.2005, Az.: 1 B 03.2608 = NVwZ-RR 2006, 754 (755); OVG Bautzen, Beschl. v. 25.6.2001, Az.: 1 B 67/01 = LKV 2002, 180 (180); Kahl/Dubber, ZJS 2015, 558 (568).

Felix Steengrafe 


\section{aa) Ermächtigungsgrundlagen}

1248 Die Ermächtigungsgrundlage für die Anordnung des Einstellens von Arbeiten ergibt sich aus $\S 79$ MBauO. In den Ländern finden sich die Ermächtigungsgrundlagen in den folgenden Normen:

\begin{tabular}{|c|c|}
\hline Baden-Württemberg & $\S 64$ LBO BW \\
\hline Bayern & Art. 75 BayBO \\
\hline Berlin & $\S 79$ BauO Bln \\
\hline Brandenburg & $\S 79 \mathrm{BbgBO}$ \\
\hline Bremen & $\S 78$ BremLBO \\
\hline Hamburg & $\S 75 \mathrm{HmbBO}$ \\
\hline Hessen & $\S 81 \mathrm{HBO}$ \\
\hline Mecklenburg-Vorpommern & $\S 79$ LBO MV \\
\hline Niedersachsen & $\S 79$ NBauO \\
\hline Nordrhein-Westfalen & $\S 81 \mathrm{BauO}$ NRW \\
\hline Rheinland-Pfalz & $\S 80$ LBO RP \\
\hline Saarland & $\S 81$ LBO Saar \\
\hline Sachsen & $\S \S 79$ SächsBO \\
\hline Sachsen-Anhalt & $\S 78$ BauO LSA \\
\hline Schleswig-Holstein & $\S 59$ LBO SH \\
\hline Thüringen & $\S 78$ ThürBO \\
\hline
\end{tabular}

\section{bb) Formelle Rechtmäßigkeit}

1249 Bezüglich der formellen Anforderungen kann auf die vorherigen Ausführungen verwiesen werden (s. Rn. 1235).

\section{cc) Materielle Rechtmäßigkeit}

1250 Das Einstellen von Arbeiten kann angeordnet werden, wenn Anlagen im Widerspruch zu öffentlich-rechtlichen Vorschriften errichtet, geändert oder beseitigt 
werden. Ausreichend ist die formelle Illegalität. ${ }^{2230}$ Die Legalisierungswirkung einer (materiell illegalen) Baugenehmigung steht einer Stilllegungsverfügung entgegen (s. Rn. 1237). ${ }^{2231}$ Bei genehmigungsfreien Vorhaben ist ausschließlich auf die materielle Illegalität abzustellen. ${ }^{2232}$ Auch für diese Verfügung steht der Bauverwaltung ein Ermessensspielraum zu. Für die Anforderungen an die pflichtgemäße Ermessensausübung wird auf die vorherigen Ausführungen verwiesen (s. Rn. 1239ff.).

\section{e) Literaturhinweise}

Lehrbücher: Battis, Öffentliches Baurecht und Raumordnungsrecht, 7. Aufl., 2017; 1251 Muckel/Ogorek, Öffentliches Baurecht, 3. Aufl. 2018; Stollmann/Beaucamp, Öffentliches Baurecht, 11. Aufl. 2017

Aufsätze: Schröer, Das Spannungsverhältnis zwischen bauordnungsrechtlichem Verunstaltungsverbot und bauplanungsrechtlichem Genehmigungsanspruch, NZBau 2008, 759; Krüper, Das Einvernehmen der Gemeinde nach § 36 BauGB - Materiell-, verfahrens- und prozessrechtliche Aspekte, ZJS 2010, 582; Krüper/Herbolsheimer, Die Veränderungssperre im Kontext gemeindlicher Planungshoheit, ZJS 2016, 546; Kahl/Dubber, Die repressive Bauaufsicht, ZJS 2015, 558; Wolf, Drittschutz im Bauplanungsrecht - Zur Weiterentwicklung eines stagnierenden Prozesses, NVwZ 2013, 247; Sperlich, Ein Meilenstein des Verwaltungsrechts: 40 Jahre „Schweinemästerfall“ - zur nachbarschützenden Wirkung des Rücksichtnahmegebotes, JA 2017, 38; Lindner, Formelle und materielle Illegalität bei bauordnungsrechtlichen Eingriffen - Zur dogmatischen Struktur von Baubeseitigungsanordnung und Nutzungsuntersagung, JuS 2014, 118; Sommer, Zur behördlichen Duldung im öffentlichen Baurecht, JA 2017, 567; Lege, Art. 14 für Fortgeschrittene - 45 Fragen zum Eigentum, die Sie nicht überall finden. Unter besonderer Berücksichtigung des Baurechts, ZJS 2012, 44

\section{Ermächtigungsgrundlagen des Kommunalrechts (Sebastian Piecha)}

Die Anfechtungsklage ist im besonderen Verwaltungsrecht eine häufige Konstel- 1252 lation in Prüfungsarbeiten. Sie spielt daher auch im Bereich des Kommunalrechts eine Rolle, wenngleich Fallgestaltungen im Bereich der Leistungs- und Feststel-

2230 Kahl/Dubber, ZJS 2015, 558 (568); Kersten, in: Schoch, Besonderes Verwaltungsrecht, 2018, Kap. 3, Rn. 445; Stollman/Beaucamp, Öffentliches Baurecht, 11. Aufl. 2017, § 19, Rn. 14.

$2231 \mathrm{Kahl} /$ Dubber, ZJS 2015, 558 (568).

2232 Kahl/Dubber, ZJS 2015, 558 (568).

Felix Steengrafe/Sebastian Piecha 
lungsklage hier eine noch größere Relevanz aufweisen (s. dazu $§ 5$ Rn. 235 ff. und $\S 6$ Rn. $186 \mathrm{ff}$.$) .$

1253 Voraussetzung ist stets das Vorliegen eines Verwaltungsakts (dazu Rn. $38 \mathrm{ff}$.). Im Kommunalrecht kommen dabei mehrere Konstellationen in Betracht: Zunächst könnte sich ein Bürger gegen einen Verwaltungsakt der Kommune wehren. Dann ist inzident, also innerhalb der Prüfung der Ermächtigungsgrundlage des Verwaltungsakts möglicherweise das nach den Regelungen des jeweiligen Kommunalrechts ordnungsgemäße Zustandekommen der als Ermächtigungsgrundlage dienenden Satzung oder Verordnung zu prüfen. Diese Konstellation wird an gegebener Stelle erwähnt. Es erscheint jedoch insbesondere denkbar, dass die Kommune selbst Adressatin eines Verwaltungsakts ist, etwa wenn die Aufsichtsbehörde Maßnahmen gegen sie ergreift. Diese Konstellation wird ausführlich im Folgenden erläutert (s. Rn. 1271ff.). Schließlich scheint es auch möglich, dass ein Verwaltungsakt an ein Rats- bzw. Kreistagsmitglied gerichtet wird. Ob und warum es sich hierbei um einen Verwaltungsakt handelt, muss dann ebenfalls geprüft werden. Dies wird im Folgenden ebenfalls erörtert (s. ebenfalls Rn. 1271ff.).

1254 Bei den letzten beiden soeben genannten Konstellationen ist im Einzelfall teilweise sehr umstritten, ob es sich bei der Maßnahme um einen Verwaltungsakt handelt oder nicht. Hierbei sind dann die Voraussetzungen des §35 S. 1 VwVfG schon im Rahmen der statthaften Klageart genau zu untersuchen (s. Rn. $38 \mathrm{ff}$.). Wann und wo die strittigen Punkte liegen, wird in diesem Abschnitt diskutiert.

\section{a) Einführung in das Kommunalrecht}

1255 Bevor jedoch die relevanten Ermächtigungsgrundlagen und Konstellation der Anfechtungsklage im Kommunalrecht beschrieben werden, wird im Folgenden nun zunächst ein einführender Überblick über die wesentlichen Grundlagen des Kommunalrechts gegeben, um dieses Rechtsgebiet für die Klausur- und Hausarbeitspraxis einordnen zu können.

\section{aa) Begriff des Kommunalrechts}

1256 Auch das Kommunalrecht hält zahlreiche Fallgestaltungen bereit, die Gegenstand einer Klausur sein können. ${ }^{2233}$ Dabei ist in den Anfangssemestern eine

2233 Die Prüfungsordnungen definieren das Kommunalrecht ausdrücklich als Teil des besonderen Verwaltungsrechts zu Pflichtfachstoff für die Erste Prüfung, etwa § 11 II Nr. 13 lit. b) JAG NRW, § 18 II Nr. 5 lit. c) JAPO Bayern; auch für die Zweite juristische Staatsprüfung werden die Inhalte des Kommunalrechts als Pflichtfachstoff in den meisten Bundesländern als bekannt 
isolierte Kommunalrechts-Abschlussklausur durchaus häufiger als in Fortgeschrittenenübungen oder gar Examensklausuren der ersten oder zweiten (Staats-) Prüfung. In den beiden letzteren Konstellationen werden kommunalrechtliche Aufgabenstellungen oft und gern mit solchen aus anderen Gebieten des besonderen Verwaltungsrechts, etwa dem Polizei- und Ordnungsrecht oder dem Baurecht verbunden. Eine auf den ersten Blick rein kommunalrechtliche und überschaubare Aufgabe kann so leicht im Schwierigkeitsgrad erhöht werden.

Unter dem Begriff „Kommunalrecht“ versteht man die Rechtssätze, die die 1257 Rechtsstellung der Kommunen innerhalb des Staates, die Grundordnung sowie Organisation der Kommune sowie ihre Aufgaben, Instrumente und Finanzen regeln (Innenrecht der Kommune). ${ }^{2234}$ Dabei spielt im Kommunalrecht auch das Verhältnis zu ihren Bürgern bzw. Einwohnern (Außenrecht) eine Rolle. Ähnlich dem Staatsrecht für die Grundordnung des Staates und das Verhältnis zu den dort lebenden Menschen regelt das Kommunalrecht Entsprechendes auf der untersten Ebene staatlicher Verwaltung, den Kommunen. Es wird daher auch von Kommunalverfassung gesprochen, da die Regelungen grundlegende Bestimmungen zur Ordnung der Kommunen festlegen. Im Wesentlichen ist der Begriff jedoch ein Synonym zu dem des Kommunalrechts. Der Begriff Kommune ist dabei der Oberbegriff insbesondere für die Gebietskörperschaften der Städte und Gemeinden sowie für Gemeindeverbände wie die (Land-)Kreise. ${ }^{2235}$

Das Kommunalrecht ist nicht bundeseinheitlich geregelt, seine Ausgestaltung obliegt den einzelnen Ländern (dazu Rn. 1268), die hierfür die Gesetzgebungskompetenz (Art. 70 I GG) haben. ${ }^{2236}$ Bundesrechtlich enthält das GG lediglich zwei, wesentlich grundlegende, übergeordnete Vorgaben: Art. 28 I 2 GG legt fest, dass in Gemeinden, Städten und Kreisen eine nach den Grundsätzen der allgemeinen, unmittelbaren, freien, gleichen und geheimen Wahl hervorgegangene Volksvertretung besteht. Ferner gewährleistet Art. 28 II 1, 2 GG die kommunale Selbstverwaltungsgarantie (dazu Rn. 1259ff.). Landesverfassungsrechtlich ist diese Selbstverwaltungsgarantie meist noch einmal festgeschrieben, wenngleich sich

vorausgesetzt und können daher Prüfungsgegenstand sein, vgl. § 52 I Nr. 1 JAG NRW und § 58 II Nr. 1 JAPO Bayern.

2234 Vgl. Burgi, Kommunalrecht, 6. Aufl. 2019, § 1 Rn. 10.

2235 Mit Ausnahme des Grundgesetzes und des Landesrechts Nordrhein-Westfalen, in welchem die KrO NRW grundsätzlich die Bezeichnung „Kreis“ festlegt, haben alle Flächenländer die Bezeichnung „Landkreis“ gewählt. Im Folgenden wird daher die Bezeichnung „Landkreis“ verwendet sowie der Begriff „Kommune“, wenn sowohl Gemeinden als auch Gemeindeverbände genannt sind.

2236 Vgl. Gern/Brüning, Deutsches Kommunalrecht, 4. Aufl. 2019, Rn. 52 m.w. N.; zu den Möglichkeiten der Mischverwaltung und weiteren kommunalrechtlichen Bezügen s. ebendort, Rn. $53 \mathrm{ff}$. 
die inhaltliche Ausgestaltung jeweils teilweise stark unterscheidet und über die im GG festgelegten Garantien hinausgehen kann. ${ }^{2237}$ Die Gewährleistung aus dem Grundgesetz bildet insoweit die inhaltliche Mindestgarantie. ${ }^{2238}$

\section{bb) Die kommunale Selbstverwaltungsgarantie}

1259 Die kommunale Selbstverwaltungsgarantie (Art. 28 II GG bzw. ggf. die jeweilige Landesverfassungsbestimmung) umfasst im Wesentlichen zweierlei:

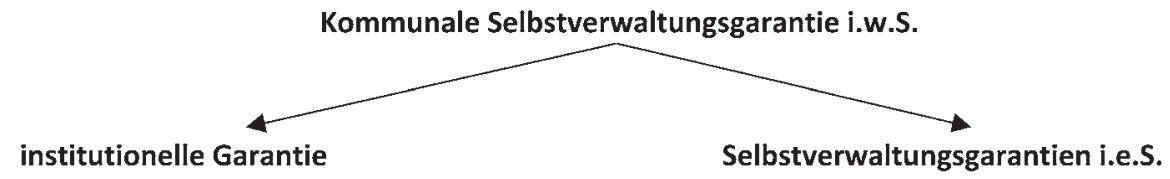

1260

Die institutionelle Garantie bedeutet, dass gewährleistet ist, dass es die Einrichtung (Institution) Kommune überhaupt als solche geben muss. ${ }^{2239}$ Dies meint jedoch nur allgemein die Einrichtung von Kommunen, nicht den Bestand einer einzelnen Kommune. ${ }^{2240}$

Die Selbstverwaltungsgarantie i.e.S. bedeutet, dass den Kommunen ein eigener Aufgabenbereich zugesprochen wird, innerhalb dessen sie sich eigenverantwortlich organisieren können bzw. müssen sowie die damit verbundenen Aufgaben auch wahrnehmen. ${ }^{2241}$ Grundsätzlich besitzen die Städte und Gemeinden danach die Allzuständigkeit für alle Aufgaben der örtlichen Gemeinschaft, d.h. die alleinige und umfassende Zuständigkeit für die öffentliche Verwaltung, sofern Gesetze nichts anderes bestimmen. ${ }^{2242}$ Für Gemeindeverbän-

2237 Art. 71 I VerfBW, Art. 11 II 2 BayVerf., Art. 97 I 1 BbgVerf., Art. 1442 BremVerf., Art. 4 II 1 HmbVerf., Art. 137 III 1 HV, Art. 72 I Verf. M-V, Art. 78 VerfNRW, Art. 57 I NdsVerf., Art. 49 I VerfRP, Art. 118 SVerf, Art. 82 II SächsVerf, Art. 87 VerfLSA, Art. 54 VerfSH, Art. 91 I ThürVerf.; dazu ausführlich Burgi, Kommunalrecht, 6. Aufl. 2019, § 7 Rn. $5 \mathrm{ff}$; Ritgen, NVwZ 2018, $114 \mathrm{ff}$.

2238 Burgi, Kommunalrecht, 6. Aufl. 2019, § 6 Rn. 2; vgl. dazu zuletzt BVerfG, Urt. v. 21.11.2017, Az.: 2 BvR 2177/16 = BVerfGE 147, 185.

2239 BVerfG, Beschl. v. 23.11.1988, Az. 2 BvR 1619, 1628/83 = BVerfGE 79, 127 (143) - Rastede. 2240 BVerfG, Beschl. v. 27.11.1978, Az. 2 BvR 165/75 = BVerfGE 50, 50; Beschl. v. 18.10.1994, Az. 2 BvR 611/91 = LKV 1995, 187.

2241 Vgl. Gern/Brüning, Deutsches Kommunalrecht, 4. Aufl. 2019, Rn. 99.

2242 Vgl. etwa § 2 GO NRW; grundlegend: BVerfG, Beschl.v. 23.11.1988, Az. 2 BvR 1619, 1628/83= BVerfGE 79, 127 (143) - Rastede. 
de, insbesondere Landkreise, gilt Entsprechendes für alle Aufgaben der überörtlichen Gemeinschaft. ${ }^{2243}$

Hausarbeitswissen: Aufgaben der örtlichen bzw. überörtlichen Gemeinschaft bilden den Grundstock der Selbstverwaltung in den Kommunen. Wie sich diese Aufgaben jedoch bestimmen und herleiten, ist durchaus nicht unumstritten. Das BVerfG verweist in ständiger Rechtsprechung darauf, dass dies auch die Kompetenz umfasst, bislang unbesetzte Aufgaben in ihrem Bereich an sich zu ziehen. ${ }^{2244}$ Zum einen müssen sie einen spezifisch örtlichen Bezug aufweisen. Zum anderen können es auch Aufgaben sein, die historisch den Kommunen zuwachsen und seit jeher eine kommunale Aufgabe gewesen sind. Schließlich war zeitweise auch in der Diskussion, dass sich einiges aus der finanziellen Leistungsfähigkeit der Kommunen ableite. ${ }^{2245}$

Daraus ergibt sich im Wesentlichen, dass eine Kommune aus der Selbstverwal- 1263 tungsgarantie bestimmte Gemeindehoheiten ableiten kann, die ihr zustehen: ${ }^{2246}$

\section{- Inhaltliche Bestimmung der Aufgabenerledigung}

Die Kommune hat die Befugnis selbst zu bestimmen, wie sie ihre Aufgaben erledigt.

\section{- Subjektsgarantie}

Die Kommunen als solches haben Subjektsqualität, müssen also im Verwaltungsbau als selbstständige Gebietskörperschaften vorgesehen sein. Das schützt jedoch nicht den Bestand einzelner Kommunen, sondern nur die Institution „Kommune“ an sich. ${ }^{2247}$

\section{- Organisationshoheit}

Die Kommune kann ihre innere Organisation sowie die Wahl der Organisationsform zur Erfüllung der ihr obliegenden Aufgaben eigenverantwortlich bestimmen. Hierzu gehört etwa die Gliederung nach Abteilungen, Wahl der Rechtsform bei wirtschaftlichem Tätigwerden, Organisation der Ratsarbeit. Dabei wird diese durch die zahlreichen materiell-rechtlichen Vorgaben eingeschränkt.

2243 Vgl. etwa § 3 KrO NRW.

2244 BVerfG, Beschl. v. 23.11.1988, Az. 2 BvR 1619, 1628/83 = BVerfGE 79, 127 (147) - Rastede. 2245 Kritisch Gern/Brüning, Deutsches Kommunalrecht, 4. Aufl. 2019, Rn. 83.

2246 Vgl. zum Ganzen Burgi, Kommunalrecht, 6. Aufl. 2019, § 6 Rn. 22ff.; Gern/Brüning, Deutsches Kommunalrecht, 4. Aufl. 2019, Rn. 99 ff.; Brüning, Jura 2015, 952 ff.; Magen, JuS 2006, 404 ff. 2247 BVerfG, Beschl. v. 12.5.1992, Az. 2 BvR 470, 650, 707/90 = BVerfGE 86, 90 (107). 


\section{- Kooperationshoheit}

Der Kommune steht es frei, mit anderen Kommunen oder Privaten zusammenzuarbeiten. Beeinträchtigt wird dies bei Zwangseingliederungen in eine Verwaltungsgemeinschaft, der pflichtigen Zuweisung von Aufgaben an einen Zweckverband oder die Pflicht zur Mitwirkung in einer ArGe (,Jobcenter“)2248.

\section{- Personalhoheit}

Die Kommune hat die Hoheit, über ihr Personal selbst zu entscheiden. Die beinhaltet die Auswahl, Einstellung und Ausgestaltung der Dienstverhältnisse sowie Zuweisung der Aufgaben. Sie hat Dienstherreneigenschaft und kann auch Beamte einstellen. Die Vorgaben des Beamten- oder Arbeitsrechts sind dabei einschränkend und rechtfertigungsbedürftig.

\section{- Finanzhoheit}

Die Kommune hat die Hoheit über ihre Finanzen und ihren Haushalt. Sie stellt eigenverantwortlich ihren Haushalt auf und verwaltet ihr Budget.

\section{- Freiheit der Wirtschaftsbetätigung}

Die Kommune hat das Recht zur Wahrnehmung von Aufgaben durch wirtschaftliche Betätigung.

\section{- Planungshoheit}

Die Kommune hat in ihrem Wirkungskreis die Hoheit, planerische Entscheidungen selbstständig zu fällen, etwa Bebauungspläne aufzustellen. Dies wird durch gesetzgeberische Vorgaben und mögliche überörtliche Planungen eingeschränkt.

\section{- Satzungshoheit}

Die Kommune hat die Hoheit, sich selbst eine Satzung zu geben und dort das Nähere zu regeln sowie die Hoheit, Satzungen im Rahmen ihres eigenen Wirkungskreises, oder wenn fachgesetzlich vorgesehen, zu bestimmen.

1264 Die kommunale Selbstverwaltungsgarantie kann man zwar inhaltlich als das „Grundrecht der Kommune“ verstehen, weil es den Gemeinden subjektive Rechte verleiht. Gleichwohl ist es dogmatisch gesehen kein Grundrecht, sondern eine

2248 BVerfG, Urt. v. 20.12.2007, Az. 2 BvR 2433, 2434/04 = BVerfGE 119, 331 (361 ff.). 
rein institutionelle Garantie. ${ }^{2249}$ Diese Garantie kennt mehrere Schutzrichtungen und Verpflichtete: Zum einen müssen sowohl Bund als auch die Länder sie gewährleisten und achten, zum anderen müssen auch die Kommunen selbst diese (insbesondere gegenseitig) berücksichtigen, etwa wenn diese sich wirtschaftlich betätigen oder Planungsentscheidungen treffen, die Nachbargemeinden berühren können. ${ }^{2250}$ Schließlich müssen die Gemeinden sich auch selbst an die Selbstverwaltungsgarantie halten, indem sie Maßnahmen vermeiden, welche auf die Aushöhlung oder Abschaffung der Selbstverwaltung innerhalb einer Kommune hinauslaufen, indem etwa nicht sämtliche Aufgaben der Leistungsverwaltung privatisieren. Ausdrücklich nicht verpflichtet sind hingegen Private, denn das sieht Art. 28 II GG weder ausdrücklich noch im Wege einer unmittelbaren Drittwirkung für diese vor.

Auf die Selbstverwaltungsgarantie kommt es etwa bei Eingriffen durch die $\mathbf{1 2 6 5}$ Aufsichtsbehörde oder durch den Gesetzgeber an. Die Kommune kann dieses Recht vor den Verwaltungsgerichten oder auch im Rahmen der Kommunalverfassungsbeschwerde nach Art.93 I Nr. 4b GG gerichtlich geltend machen. Insoweit ist der Begriff für Anfänger auch deshalb irreführend, da es dort nicht um die Geltendmachung eines Grundrechts, sondern einer institutionellen Garantie geht. Eingriffe in die kommunale Selbstverwaltungsgarantie können nur durch Gesetz erfolgen, denn sie ist nach Art. 28 II GG ausschließlich „im Rahmen der Gesetze“ gewährleistet. Das Recht der kommunalen Selbstverwaltung besteht somit nicht in unbegrenztem Umfang.

Eingriffe in die Selbstverwaltungsgarantie können durch sachliche Gründe des Gemeinwohls gerechtfertigt sein. Dies gilt jedoch nicht für jene, die den absolut geschützten Kernbereich oder Wesensgehalt berühren. Nach Rechtsprechung des BVerfG wird die kommunale Selbstverwaltungsgarantie nur dann gewährleistet, wenn die Kommune Gelegenheit zu kraftvoller Betätigung habe und nicht bloß ein Schattendasein führe. ${ }^{2251}$

Hausarbeitswissen: Was zum Kernbereich kommunaler Selbstverwaltung überhaupt gehört und wie dieser bestimmt wird, ist durchaus umstritten. ${ }^{2252}$ Die Rechtsprechung geht von einem historisch gewachsenen Kern des Selbstverwaltungsrechts aus (sog. Substanzmethode). ${ }^{2253}$ Teilweise wird in

2249 Dazu etwa BVerfG, Beschl. v. 23.11.1988, Az. 2 BvR 1619, 1628/83 = BVerfGE 79, 127 (143) Rastede; ausführlich Burgi, Kommunalrecht, 6. Aufl. 2019, § 6 Rn. 4; Gern/Brüning, Deutsches Kommunalrecht, 4. Aufl. 2019, Rn. 70 ff.

2250 Burgi, Kommunalrecht, 6. Aufl. 2019, § 6 Rn. 9 ff.; dort auch im Folgenden.

2251 BVerfG, Beschl. v. 23.11.1988, Az. 2 BvR 1619, 1628/83 = BVerfGE 79, 127 (143) - Rastede. 2252 Ausführlich Gern/Brüning, Deutsches Kommunalrecht, 4. Aufl. 2019, Rn. $119 \mathrm{ff}$.

2253 BVerfG, Beschl.v. 24.6.1969, Az. 2 BvR 446/64 = BVerfGE 26, 228 (238); BVerfG, Beschl.v. 7.2. 1992, Az. 2 BvL 24/84 = BVerfGE 83, 363 (381). 
der Literatur der Kernbereich danach bestimmt, was nach einem Eingriff in die Selbstverwaltungsgarantie noch übrig bleibt und inwieweit dies dem typischen Erscheinungsbild einer Kommune dann noch gerecht würde (sog. Substraktionsmethode). ${ }^{2254}$ Schließlich wird bei der Funktionalmethode noch ergänzend berücksichtigt, dass die kommunale Selbstverwaltung in das politische Gemeinwesen mit eigenen Aufgaben eingegliedert sei und ihr auch aus dem GG, etwa aus Art. 28 II GG spezifische Funktionen zugeordnet seien, die sie beibehalten müsse. ${ }^{2255}$

\section{cc) Landesrechtliche Ausgestaltung des Kommunalrechts}

1268 Den Ländern obliegt die Ausgestaltung des Kommunalrechts im Rahmen ihrer Gesetzgebungskompetenz. Man spricht bei den Regelungen, da sie die innere und äußere Verfassung der Kommunen zum Gegenstand haben, auch von „Kommunalverfassungsrecht“ (s. Rn. 1257). Grob unterschieden werden im Wesentlichen (Flächen-)Länder, ${ }^{2256}$ in denen es jeweils eigene Regelwerke für Gemeinden und Landkreise gibt und Länder, die sowohl für Gemeinden bzw. Städte als auch Landkreise geltende, gemeinsame Kommunalverfassungsgesetze vorweisen.

1269 Eine besondere Stellung nehmen die Stadtstaaten Berlin, Bremen und Hamburg ein, bei denen jeweils die Landesverfassung und weitere Landesgesetze die kommunale Ordnung festlegen. In Hamburg und Berlin besteht dabei gar eine Einheit zwischen Land und Stadt, wobei in Berlin und Hamburg etwa die Bezirksämter vergleichbare Funktionen wie in Flächenländern die Kommunen wahrnehmen. ${ }^{2257}$ Das Land Bremen besteht aus zwei Kommunen (Städte Bremen und Bremerhaven), wobei die Landesinstitutionen teilweise gleichzeitig als Organe der Stadt Bremen dienen (Art. 148 BremVerf), soweit die Stadt dies bestimmt, wohingegen die Stadt Bremerhaven jedoch weitgehend autonom selbstverwaltet wird. 2258

1270 Die Rechtsgrundlagen des Kommunal(verfassungs)rechts in den Ländern stellen sich wie folgt dar: ${ }^{2259}$

2254 BVerwG, Urt. v. 22.11. 957, Az. VII C 69/57= BVerwGE 6, 19 (25); Beschl. v. 20.5.1958, Az. I C 193.57 = BVerwGE 6, 342 (345f.).

2255 BayVerfGH, Entsch. v. 29. 8.1997, Az. 8-VII-96 u. a. = NVwZ-RR 1998, 82 (85).

2256 Als solche bezeichnet man alle Länder mit Ausnahme der „Stadtstaaten“ Berlin, Bremen und Hamburg.

2257 Dazu ausführlich Holland, in: Siegel/Waldhoff, Öffentliches Recht in Berlin, 2. Aufl. 2017, $\S 1$ F.; Art. 106 VI 3 GG geht (insbesondere für die Städte Hamburg und Berlin) davon aus, dass in einem Land nicht zwingend Gemeinden bestehen müssen.

2258 Dazu ausführlich Fischer-Lescano/Sperlich, Landesrecht Bremen: Studienbuch, 2018, §§ 2, 3.

2259 Vgl. im Einzelnen Gern/Brüning, Deutsches Kommunalrecht, 4. Aufl. 2019, Rn. 60; 197 ff. 


\begin{tabular}{ll}
\hline Land & Rechtsgrundlagen des Kommunalrechts (,Kommunalverfassung“) \\
\hline Baden-Württemberg & $\begin{array}{l}\text { Gemeindeordnung (GemO BW) } \\
\text { Landkreisordnung (LKrO BW) }\end{array}$ \\
\hline Bayern & $\begin{array}{l}\text { Gemeindeordnung (BayGO) } \\
\text { Landkreisordnung (BayLKrO) }\end{array}$ \\
\hline Berlin & $\begin{array}{l}\text { Verfassung von Berlin (BlnVerf) } \\
\text { Allgemeines Zuständigkeitengesetz (AZG) }\end{array}$ \\
\hline Brandenburg & Kommunalverfassung (BbgKVerf) \\
\hline Bremen & $\begin{array}{l}\text { Verfassung für die Stadt Bremerhaven (VerfBrhv) } \\
\text { Verfassung der Freien Hansestadt Bremen (VerfBrem) }\end{array}$ \\
\hline Hamburg & Verfassung der Freien und Hansestadt Hamburg (HmbVerf) \\
\hline Bezirksverwaltungsgesetz (BezVG)
\end{tabular}

\section{b) Die Anfechtungsklage im Kommunalrecht}

Es besteht im Kommunalrecht die Besonderheit, dass oft schon umstritten ist, ob die Anfechtungsklage in einer bestimmten Situation überhaupt statthaft ist oder nicht. Für die Darstellung in diesem Werk wird grundsätzlich die herrschende Literatur- bzw. Rechtsprechungsmeinung gewählt und an geeigneter Stelle dann auf diesen Streit eingegangen. 
Bei den Anfechtungssituationen kann dabei insbesondere zwischen zwei Arten unterschieden werden: Dabei kommt insbesondere die Kommune selbst als Adressatin von Verwaltungsakten nach $§ 35$ S. 1 VwVfG (zum Begriff des Verwaltungsakts ausführlich Rn. $38 \mathrm{ff}$.) in Betracht. Auch ist es möglich, dass ein Rats- oder Kreistagsmitglied in seiner Eigenschaft als Bürger Adressat eines Verwaltungsakts wird.

1272 Dabei muss stets zunächst eine Anfechtungssituation i.S.v. §42 I VwGO vorliegen, d. h. es muss der betreffende Verwaltungsakt mit dem Ziel der Aufhebung vor Gericht angegriffen werden. Dabei kommt es in kommunalrechtlichen Fragestellungen insbesondere auf eine saubere Subsumtion des Verwaltungsaktbegriffs (s. dazu näher in Rn. $38 \mathrm{ff}$.) an. In kommunalrechtlichen Sachverhalten dürften dabei i.d.R. die Merkmale „Außenwirkung“ sowie „Regelungswirkung“ problematisch sein:

1273 Herauszuarbeiten ist dann stets, ob tatsächlich ein Verwaltungsakt vorliegt oder nicht, denn danach richtet sich, ob mit der Anfechtungsklage die richtige Klageart gewählt wurde.

\section{aa) Maßnahmen der Kommunalaufsicht}

1274 Dabei sind hier im Wesentlichen Maßnahmen der Kommunalaufsicht problematisch. Die Aufsicht ist das notwendige Gegenstück zur Selbstverwaltungsgarantie. ${ }^{2260}$ Es soll ihre Erfüllung gesetzlicher Pflichten bzw. die Koordination innerhalb der staatlichen Grenzen gewährleisten und ihre Verwaltungstätigkeit schützen. ${ }^{2261}$ Man unterscheidet zwischen präventiver und repressiver Aufsicht: Die präventive Aufsicht erfolgt im Vorhinein etwa durch Anzeige- oder Vorlagepflichten gegenüber der Aufsichtsbehörde und Genehmigungsvorbehalte durch die Aufsichtsbehörde. Die repressive Aufsicht erfolgt im Nachhinein der kommunalen Maßnahme und beinhaltet i.d.R. inzident die Rechtmäßigkeitsprüfung der jeweiligen kommunalen Maßnahme (z. B. Beschluss des Rates). Dabei steht der Aufsichtsbehörde ein Entschließungs- (Ob) und Ausübungsermessen (Wie) in Bezug auf ihr Tätigwerden zu.

1275 Ob die Außenwirkung vorliegt, richtet sich nach dem jeweiligen Typ der wahrgenommenen Aufgabe: Eine Außenwirkung besteht regelmäßig, wenn es

2260 Etwa BVerfG, Urt. v. 23.1.1957, Az. 2 BvF 3/56 = BVerfGE 6, 104 (118); Beschl. v. 21.6.1988, Az. 2 BvR 602/83, 2 BvR 974/83 = BVerfGE 78, 331 (341).

2261 Burgi, Kommunalrecht, 6. Aufl. 2019, § 8 Rn. 27; Gern/Brüning, Deutsches Kommunalrecht, 4. Aufl. 2019, Rn. 303. 
sich um freiwillige oder pflichtige Selbstverwaltungsaufgaben handelt. Bei staatlichen Aufgaben dürfte diese Außenwirkung jedoch grundsätzlich fehlen. Bei Aufgaben, die im Wege der Organleihe wahrgenommen werden, ist dies im Einzelfall zu prüfen.

Hausarbeits-/Examenswissen: Dabei kommt es auch darauf an, ob das jeweilige Kommunalrecht eher dem dualistischen oder monistischen Modell folgt: ${ }^{2262}$ Nach dem dualistischen Modell ${ }^{2263}$ unterscheidet man klassische Selbstverwaltungsaufgaben und staatliche Aufgaben, die den Kommunen insbesondere als Auftragsangelegenheiten übertragen wurden. Das monistische Modell $^{2264}$ folgt einem einheitlichen Begriff für öffentliche Aufgaben, die grundsätzlich allein und in eigener Verantwortung von den Kommunen wahrgenommen werden, sofern die Gesetze nichts anderes bestimmen. Aber auch dieses Modell kennt die Unterscheidung von Aufgaben nach Selbstverwaltungs- und staatlichen (Weisungs-)Aufgaben.

Die Reichweite der Kommunalaufsicht ist dabei unterschiedlich. Sie lässt sich grundlegend in zwei Kategorien einteilen:

\section{(1) Rechtsaufsicht}

Es erfolgt ausschließlich eine Kontrolle der Rechtmäßigkeit des kommunalen Handelns.

\section{(2) Fachaufsicht bzw. Sonderaufsicht}

Das kommunale Handeln wird sowohl hinsichtlich seiner Rechtmäßigkeit sowie Zweckmäßigkeit kontrolliert.

Maßnahmen der Rechtsaufsicht sind unter bestimmten Voraussetzungen 1278 Verwaltungsakte und daher ggf. im Wege der Anfechtungsklage angreifbar (s. Rn. 1284), da sie in Selbstverwaltungsangelegenheiten i.d. R. zumindest Außen- bzw. Regelungswirkung aufweisen. Maßnahmen der Fach- oder Sonderaufsicht sind mangels Außenwirkung regelmäßig keine Verwaltungsakte. Die Kommune wird dabei als verlängerter Arm des Staates tätig, womit auch keine subjektive Rechtsposition berührt wird..$^{2265}$

Eine Aufsichtsbehörde hat dann je nach landesrechtlicher Ausgestaltung eine Vielzahl von Möglichkeiten, einer Kommune mit Maßnahmen zu begegnen:

2262 Dazu etwa: Gern/Brüning, Deutsches Kommunalrecht, 4. Aufl. 2019, Rn. 265; Röhl, in: Schoch, Besonderes Verwaltungsrecht, 15. Aufl. 2013, Rn. $61 \mathrm{ff}$.

2263 Bayern, Niedersachsen, Rheinland-Pfalz, Saarland, Sachsen-Anhalt, Thüringen.

2264 Baden-Württemberg, Brandenburg, Hessen, Mecklenburg-Vorpommern, Nordrhein-Westfalen, Sachsen, Schleswig-Holstein.

2265 Vgl. etwa BVerwG, Urt. v. 16.3.1995, Az. 4 C 3/94 = NVwZ 1995, 899 (900). 


\section{- Informations-/Unterrichtungsrechte}

Die Aufsichtsbehörde ist umfassend über einzelne kommunale Selbstverwaltungsangelegenheiten zu informieren, wobei ihr hinsichtlich der Wahl der Mittel ein Ermessen zusteht (Akteneinsicht, Besichtigung etc.). Hierbei handelt es sich regelmäßig nicht um einen Verwaltungsakt, da hier die Regelungswirkung fehlt.

\section{- Beanstandungs-/Aufhebungsrechte}

Die Aufsichtsbehörde kann gefasste Beschlüsse, Anordnungen usw. beanstanden und gibt der Kommune somit die Möglichkeit zur Selbstkorrektur. Auch kann sie Handlungen aufheben oder rückgängig machen. Bei letzterem handelt es sich regelmäßig um Verwaltungsakte.

\section{- Anordnungs-/Anweisungsrechte}

Ist die Kommune zur Handlung verpflichtet und unterlässt diese, so kann die Aufsichtsbehörde diese Handlung anordnen bzw. anweisen. Bei Aufgaben im Selbstverwaltungsbereich ist dies ein Verwaltungsakt, gegen den die Anfechtungsklage statthaft wäre.

\section{- Ersatzvornahme}

Kommt die Kommune einer Beanstandung oder Anordnung nicht nach, so kann die Aufsichtsbehörde die geforderte Handlung selbst vornehmen oder einen Dritten hiermit beauftragen. Dies ist ebenfalls ein beklagbarer Verwaltungsakt. Dieser besitzt sogar ggf. eine Doppelnatur, da er auch gegen Bürger wirken kann, etwa wenn eine Satzung oder Verwaltungsakt ersatzweise erlassen wird.

\section{- Bestellung von Beauftragten}

Teilweise ${ }^{2266}$ wird die Bestellung eines Beauftragten ermöglicht, wenn die Kommune ihren Aufgaben in erheblichem Maße nicht oder nicht richtig nachkommt (etwa bzgl. des Haushalts). Dies stellt ebenfalls einen Verwaltungsakt dar.

\section{- Auflösung des Rates}

Als allerletztes Mittel, wenn keine Aufsichtsmaßnahme erfolgreich war, sehen einige Kommunalverfassungsgesetze auch die Auflösung des Rates unter engen Voraussetzungen vor. 2267 


\section{- Amtsenthebung des Bürgermeisters}

Schließlich kann in einigen Ländern ${ }^{2268}$ auch der Bürgermeister vorzeitig des Amtes enthoben werden.

\section{(1) Ermächtigungsgrundlagen}

Die Rechtsgrundlagen für die Maßnahmen der Kommunalaufsicht finden sich $\mathbf{1 2 8 0}$ hier:

\begin{tabular}{|c|c|}
\hline Land & Kommunalaufsicht \\
\hline Baden-Württemberg & $\begin{array}{l}\S \S 118 \mathrm{ff} . \text { GemO BW } \\
\S 51 \text { LKrO BW i.V.m. } \S \S 118 \mathrm{ff} . \text { GemO BW }\end{array}$ \\
\hline Bayern & $\begin{array}{l}\text { Art. } 108 \text { ff. BayGO } \\
\text { Art. } 94 \text { ff. BayLKrO }\end{array}$ \\
\hline Brandenburg & $\S \S 108 \mathrm{ff}$. BbgKVerf \\
\hline Bremen & $\begin{array}{l}\S \S 74 \mathrm{ff} . \text { VerfBrhv } \\
\text { Art. } 147 \text { VerfBrem }\end{array}$ \\
\hline Hessen & $\begin{array}{l}\S \S 135 \text { ff. HGO } \\
\S 54 \text { I HKO i.V. m. §§ } 135 \text { ff. HGO }\end{array}$ \\
\hline Mecklenburg-Vorpommern & $\S \S 78 \mathrm{ff} ., 123 \mathrm{KV} \mathrm{M}-\mathrm{V}$ \\
\hline Niedersachsen & $\S \S 170 \mathrm{ff}$. NKomVG \\
\hline Nordrhein-Westfalen & $\begin{array}{l}\S \S 119 \mathrm{ff} . \mathrm{GO} \text { NRW } \\
\S \S 57 \mathrm{KrO} \text { NRW i.V.m. §§ } 119 \mathrm{ff} . \mathrm{GO} \text { NRW }\end{array}$ \\
\hline Rheinland-Pfalz & $\begin{array}{l}\S \S 117 \mathrm{ff} . \text { GemO RP } \\
\S \S 60 \mathrm{ff} . \text { LKO RP }\end{array}$ \\
\hline Saarland & $\S \S 127 \mathrm{ff} . \mathrm{KSVG}$ \\
\hline Sachsen & $\begin{array}{l}\S \S 111 \text { ff. SächsGem0 } \\
\S 65 \text { SächsLKrO i. V. m. §§ } 111 \text { ff. SächsGem0 }\end{array}$ \\
\hline Sachsen-Anhalt & $\S \S 143 \mathrm{ff}$. KVG LSA \\
\hline Schleswig-Holstein & $\begin{array}{l}\S \S 120 \mathrm{ff} . \mathrm{GO} \mathrm{S}-\mathrm{H} \\
\S \S 59 \mathrm{ff} . \mathrm{KrO} \mathrm{S}-\mathrm{H}\end{array}$ \\
\hline Thüringen & $\S \S 116 \mathrm{ff}$. ThürKo \\
\hline
\end{tabular}

$2268 \S 128$ GO BW, § 118 SächsGemO, § 153 KVG LSA. 
1281 Bei der Klagebefugnis nach $\S 42$ II VwGO ist dann die Möglichkeit der Verletzung der kommunalen Selbstverwaltungsgarantie aus Art. 28 II GG (bzw. Landesverfassung) zu erwähnen. Dies gilt jedoch nicht, wenn es sich um staatliche Auftragsangelegenheiten handelt, denn dann ist die Selbstverwaltungsgarantie regelmäßig nicht betroffen. Es ist dann anhand der Schutznormtheorie zu untersuchen, ob sich die Kommune ausnahmsweise hierauf berufen kann. Bei Pflichtaufgaben nach Weisung im monistischen System kann sich die Klagebefugnis aus der landesrechtlich normierten kommunalen Selbstverwaltungsgarantie ergeben. ${ }^{2269}$

\section{(2) Formelle Rechtmäßigkeit}

1282 Bei der formellen Rechtmäßigkeit der Aufsichtsmaßnahme sind die Zuständigkeit, das Aufsichtsverfahren (Anhörung, Ablauf usw.) sowie mögliche Formvorschriften (etwa Schriftform) zu erörtern, die je nach Land unterschiedlich sein können.

1283 Die Zuständigkeit für die Aufsicht ist landesrechtlich höchst unterschiedlich geregelt, die in der Regel von der Größe oder Selbstständigkeit der Kommune abhängt: Meist nimmt diese Aufgabe bei kreisangehörigen Gemeinden jedoch der Landkreis und bei kreisfreien Städten eine staatliche Behörde (z. B. in NRW: Bezirksregierung) wahr. ${ }^{2270}$ Es kann jedoch auch sein, dass Fachgesetze aus dem besonderen Verwaltungsrecht eine spezielle Aufsichtsstruktur oder die Zuständigkeit für einzelne Bereiche besonderen Behörden zuweisen. Hier ist unbedingt auf die jeweiligen Gegebenheiten des Landes zu achten. Die in Rn. 1280 erwähnten Regelungen des Kommunal(verfassungs)rechts geben im Regelfall den genauen Rahmen für diese Verfahren vor. Gemein ist dem, dass unterschiedliche Maßnahmen (Aufhebung) etwa nur dann zulässig sind, wenn vorher eine andere Maßnahme (Beanstandung) erfolgt ist.

\section{(3) Materielle Rechtmäßigkeit}

1284 Im Rahmen der materiellen Rechtmäßigkeit sind sodann die inhaltlichen Voraussetzungen der Norm für die Kommunalaufsichtsmaßnahme zu prüfen. Regelmäßig wird eine Voraussetzung für ein Eingreifen sein, dass die Kommune rechtswidrig gehandelt hat, ob das Ermessen korrekt ausgeübt wurde und die Kommune hierdurch in ihren Selbstverwaltungsrechten verletzt wurde (subjektive

2269 Zum Ganzen: Burgi, Kommunalrecht, 6. Aufl. 2019, § 9 Rn. $13 \mathrm{ff}$.

2270 Übersicht bei Gern/Brüning, Deutsches Kommunalrecht, 4. Aufl. 2019, Rn. 308 ff.

Sebastian Piecha 
Rechtsverletzung). Dabei muss i.d.R. inzident die Maßnahme der Kommune geprüft werden. Das kann zu einem verschachtelten Aufbau führen und ermöglicht dem Aufgabensteller eine unterschiedliche Differenzierung des Schwierigkeitsgrades.

Vorschriften hinsichtlich des Ablaufs oder der Rechtmäßigkeit einer Rats-/ 1285 Kreistagssitzung können hier auch inzident zu prüfen sein. Folgende Normen sind dabei auf ihre Einhaltung zu prüfen:

\begin{tabular}{|c|c|}
\hline Land & Ablauf der Rats-/Kreistagssitzung \\
\hline Baden-Württemberg & $\begin{array}{l}\S \S 34 \mathrm{ff} . \text { GemO BW } \\
\S \S 29 \mathrm{ff} . \text { LKrO BW }\end{array}$ \\
\hline Bayern & $\begin{array}{l}\text { Art. } 45 \text { ff. BayGO } \\
\text { Art. } 40 \text { ff. BayLKrO }\end{array}$ \\
\hline Berlin & Art. $42 \mathrm{ff}$. BlnVerf \\
\hline Brandenburg & $\S \S 34 \mathrm{ff}$. BbgKVerf \\
\hline Bremen & $\begin{array}{l}\S \S 30 \mathrm{ff} . \text { VerfBrhv } \\
\text { Art. } 88 \mathrm{ff} . \text { VerfBrem }\end{array}$ \\
\hline Hamburg & Art. $19 f f$. VerfHH \\
\hline Hessen & $\begin{array}{l}\S \S 52 \text { ff. HGO } \\
\S \S 32 \text { ff. HKO i.V.m. HGO }\end{array}$ \\
\hline Mecklenburg-Vorpommern & $\S \S 29 \mathrm{ff.}$ KV M-V \\
\hline Niedersachsen & $\S \S 59$ ff. NKomVG \\
\hline Nordrhein-Westfalen & $\begin{array}{l}\S \S 47 \mathrm{ff} . \mathrm{GO} \text { NRW } \\
\S \S 32 \mathrm{ff} . \mathrm{KrO} \text { NRW }\end{array}$ \\
\hline Rheinland-Pfalz & $\begin{array}{l}\S \S 34 \mathrm{ff} . \text { GemO RP } \\
\S \S 27 \mathrm{ff} . \text { LKO RP }\end{array}$ \\
\hline Saarland & $\S \S 40 \mathrm{ff} . \mathrm{KSVG}$ \\
\hline Sachsen & $\begin{array}{l}\S \S 36 \text { ff. SächsGem0 } \\
\S \S 32 \text { ff. SächsLKrO }\end{array}$ \\
\hline Sachsen-Anhalt & $\S \S 52 \mathrm{ff}$. KVG LSA \\
\hline Schleswig-Holstein & $\begin{array}{l}\S \S 34 \mathrm{ff} . \mathrm{GO} \mathrm{S}-\mathrm{H} \\
\S \S 29 \mathrm{ff} . \mathrm{KrO} \mathrm{S}-\mathrm{H}\end{array}$ \\
\hline Thüringen & $\S \S 35 \mathrm{ff}$. ThürKO \\
\hline
\end{tabular}


1286 Ob ein Ratsbeschluss rechtmäßig war, kann anhand des folgenden groben Prüfungsschemas erörtert werden, wobei jeweils die landesrechtlichen Besonderheiten zu beachten sind:

\section{Rechtmäßigkeit eines Ratsbeschlusses ${ }^{2271}$}

A. Formelle Rechtmäßigkeit

I. Zuständigkeit

1. Verbandskompetenz der Kommune

2. Organkompetenz des Rates/Kreistages

II. Verfahren und Form

1. Ordnungsgemäße Einberufung der Sitzung

2. Festsetzung der Tagesordnung

3. Rechtzeitige Bekanntmachung der Tagesordnung

4. Form- und fristgerechte Einladung

5. Beschlussfähigkeit der Sitzung

6. Ordnungsgemäße Sitzungsleitung

7. Öffentlichkeit der Ratssitzung

8. Ordnungsgemäße Abstimmung

a) Mehrheitserfordernisse

b) Modalitäten (geheim/offen)

c) Berechnung des Abstimmungsergebnisses

9. Kein Verstoß gegen Mitwirkungsverbote

a) Vor- oder Nachteil für Ratsmitglied, Angehörige oder juristische Person, bei der es beschäftigt ist

b) Unmittelbarkeit des Vor- oder Nachteils (kein Hinzutreten weiterer Umstände durch die betreffende Entscheidung selbst hervorgerufen)

c) Kein Ausschlussgrund

10. Kein Verstoß gegen das freie Mandat

III. Rechtsfolge formeller Fehler (Nichtigkeit, wenn keine Ausnahme)

1. Bloßer Geschäftsordnungs-Verstoß

2. Mangelnde Entscheidungserheblichkeit bei Verstoß gegen Mitwirkungsverbot

3. Unbeachtlichkeit wegen Fristablauf

B. Materielle Rechtmäßigkeit

I. Spezialgesetzliche Voraussetzungen

2271 Bätge, Kommunalrecht NRW, 5. Aufl. 2019, Rn. 253. 
II. Kein Verstoß gegen höherrangiges Recht

III. Allgemeine Rechtmäßigkeitsvoraussetzungen

IV. Keine Ermessensfehler, sofern Ermessen eröffnet

Auch die Verhältnismäßigkeit der Maßnahme ist zu prüfen, insbesondere kommt $\mathbf{1 2 8 7}$ eine schwerwiegendere Maßnahme (z. B. Auflösung des Rates) erst dann in Betracht, wenn mildere Aufsichtsmaßnahmen (z.B. Beanstandung) erfolglos blieben. ${ }^{2272}$

\section{bb) Maßnahmen der Kommune gegen Einzelne}

Neben den Kommunalaufsichtsmaßnahmen kommen noch Maßnahmen gegen 1288

Einzelne in Betracht. Dabei sind insbesondere Konstellationen möglich, bei denen ein Ehrenamtler bzw. Rats-/Kreistagsmitglied Adressat des Verwaltungsakts ist. In den folgenden beiden Konstellationen muss auch schon im Rahmen der statthaften Klageart erörtert werden, weshalb es sich bei der jeweiligen Maßnahme überhaupt um einen Verwaltungsakt handelt.

\section{(1) Vertretungsverbote Ehrenamtlicher}

Ein häufiger Fall ist hier die Prüfung eines Vertretungsverbotes. In den meisten 1289 Kommunalverfassungsgesetzen sind nämlich umfassende Vertretungsverbote vorgesehen, die die Vertretung Ehrenamtlicher von Ansprüchen gegen die Kommune verbieten. ${ }^{2273}$ Stellen Rat oder Kreistag dann fest, dass ein solches Vertretungsverbot gegen einen Einzelnen (Ehrenamtlicher, Rats-/Kreistagsmitglied) besteht, so handelt es sich hierbei regelmäßig um einen mit der Anfechtungsklage anzugreifenden Verwaltungsakt i.S.v. § 35 S. 1 VwVfG.

\section{(2) Sanktionen gegen Ratsmitglieder}

Ein weiterer Fall im Kommunalrecht ist die Verhängung eines Ordnungsgeldes. 1290 Wird gegen ein Ratsmitglied oder einen Bürger ein Ordnungsgeld verhängt, so verlässt dies den innerorganisatorischen Bereich und es handelt sich um einen Verwaltungsakt i.S.v. §35 S. 1 VwVfG gegen die natürliche Person, da dieser Außenwirkung entfaltet, die auch eine verbindliche Rechtsfolge (Ordnungsgeld-

2272 S. etwa Rennert, JuS 2008, 119 (120).

2273 §17 III GemO BW; Art.50 BayGO; §23 i.V. m. §20, §33 II BbgKVerf; §26 GO; §26 KV M-V; §42 NKomVG; §32 i.V.m. §43 II GO NRW; §21 GemO RP; §26 II KSVG; §19 III SächsGemO; §32 III 2 KVG LSA; §23 i.V.m. §32 III GO SH. 
festsetzung ${ }^{2274}$ ) trifft. $^{2275}$ Im Übrigen sind solche Feststellungen des Rates eine rein innerorganisatorische Maßnahme, gegen die im Rahmen eines Kommunalverfassungsstreits geltend gemacht werden muss. Die Festsetzung ist nur dann rechtmäßig, wenn eine Verletzung des Kommunalrechts durch das Ratsmitglied erfolgt ist. Inzident ist diese Verletzung (etwa der Verschwiegenheitspflicht) durch das Ratsmitglied dann zu prüfen.

\section{c) Literaturhinweise}

1291 Lehrbuchliteratur zum Kommunalrecht: Burgi, Kommunalrecht, 6. Aufl. 2019; Ehlers/Fehling/Pünder (Hrsg.), Besonderes Verwaltungsrecht, Band III, 3. Aufl. 2013 (§ 64: Brüning, Kommunalverfassung, § 65: T. I. Schmidt: Kommunale Zusammenarbeit); Geis, Kommunalrecht, 4. Aufl. 2016; Gern/Brüning, Deutsches Kommunalrecht, 4. Aufl. 2019; Röhl, Kommunalrecht, in: Schoch, (Hrsg.), Besonderes Verwaltungsrecht, 15. Aufl. 2013; Schmidt, Kommunalrecht, 2. Aufl. 2014; Wolff/Bachof/Stober/Kluth, Verwaltungsrecht, Band II, 7. Aufl. 2010 (§§ 97-98); Lissack, Bayerisches Kommunalrecht, 4. Aufl. 2019

Landesspezifische Darstellungen des Kommunalrechts: Birkenfeld, Kommunalrecht Hessen, 6. Aufl. 2016; Pautsch, Kommunalrecht Niedersachsen, 2014; Bätge, Kommunalrecht Nordrhein-Westfalen, 5. Aufl. 2019; Ipsen, Niedersächsisches Kommunalrecht, 4. Aufl. 2011; Nauheim-Skrobek/Schmitz/Schmorleiz, Kommunalrecht Rheinland-Pfalz, 2. Aufl. 2017; Faßbender/König/Musall, Sächsisches Kommunalrecht, 2019

Aufsätze zum Kommunalrecht: Brüning, Die Verfassungsgarantie der kommunalen Selbstverwaltung aus Art. 28 II GG, Jura 2015, 592; Geis/Madeja, Kommunales Wirtschafts- und Finanzrecht (Teil I: JA 2013, 248; Teil II: JA 2013, 321); Knemeyer, Staatsaufsicht über die Kommunen, JuS 2000, 521; Lenski, Der öffentliche Raum als kommunale Einrichtung, JuS 2012, 984; Magen, Die Garantie kommunaler Selbstverwaltung, JuS 2006, 404; Otto, Der Kommunalverfassungsstreit in der Fallbearbeitung, ZJS 2015, 382; Pielow/Groneberg, Die deutschen Landkreise, JuS 2014, 794; Rennert, Die Klausur im Kommunalrecht (Teil 1: JuS 2008, 29; Teil 2: JuS 2008, 119; Teil 3: JuS 2008, 211); Schmitz, Der Öffentlichkeitsgrundsatz in der Kommunalverwaltung - Der Ausschluss der Öffentlichkeit in Grundstücksangelegenheiten im Gemeinderat, JuS 2017, 31; Starke, Grundfälle zur Kommunalverfassungsbeschwerde, JuS 2008, 319; Voßkuhle/Kaufhold,

2274 Z. B. § 29 III GO NRW.

2275 Vgl. OVG Münster, Beschl. v. 23.12.2009, Az. 15 A 2126/09 = DÖV 2010, 325; Bätge, Kommunalrecht NRW, 5. Aufl. 2019, Rn. 229. 
Grundwissen - Öffentliches Recht: Die verfassungsrechtliche Garantie der kommunalen Selbstverwaltung, JuS 2017, 728

Fallbearbeitungen: Bäcker, Fortgeschrittenenhausarbeit - Öffentliches Recht: Kommunalrecht - Zeichenkontingent im Amtsblatt, JuS 2018, 784; Bickenbach, Fortgeschrittenen-Hausarbeit - Öffentliches Recht: Städtisches Messezentrum, JuS 2006, 1091; v. Coelln, (Original-)Referendarexamensklausur Öffentliches Recht: Streit um die Entschädigung des Bürgermeisters, JuS 2008, 351; Everts, Assessorexamensklausur - Öffentliches Recht: Zulässigkeit einer kommunalen Bürgerbefragung, JuS 2004, 899; Ferreau, Fortgeschrittenenklausur - Öffentliches Recht: Staatsorganisations-, Kommunal-, Verwaltungsprozessrecht - Disharmonie im Kommunalwahlkampf, JuS 2017, 758; Janson/Blenk, Referendarexamensklausur - Öffentliches Recht: Verfassungsrecht und Kommunalrecht - Kein Geld mehr für die Gemeinderatsfraktion?, JuS 2018, 461; Jürgensen/Laude, Referendarexamensklausur - Öffentliches Recht: Allgemeines Verwaltungsrecht und Kommunalrecht - Grenzenlose Kommunalwirtschaft, JuS 2018, 635; Meickmann, Fortgeschrittenenklausur - Öffentliches Recht: Verwaltungsrecht - Die verschwiegene Bürgermeisterin, JuS 2017, 663; Sauer, Referendarexamensklausur - Öffentliches Recht: Zulassung zu einem Volksfest, JuS 2004, 1085; Towfigh/Schönfeldt, Eine Stadt in Aufruhr, JA 2018, 521; Winkler, Gelbengrün GmbH, JA 2004, 144; Wollenschläger/Lippstreu, Referendarexamensklausur - Öffentliches Recht: Zweitwohnungsteuer, JuS 2008, 529; Bätge, (Original-)Referendarexamensklausur - Öffentliches Recht: Verwaltungsrecht und Kommunalrecht - Sanktionen gegen ein Ratsmitglied, JuS 2018, 562

\section{Ermächtigungsgrundlagen des Verwaltungsvollstreckungsrechts (Mariamo Katharina Ilal)}

Das Verwaltungsvollstreckungsrecht ist bei Prüfern ${ }^{2276}$ vor allem als Einkleidung gefahrenabwehrrechtlicher Fallkonstellationen beliebt. Dies liegt einerseits daran, dass viele dieser Fallkonstellationen ohne weiteres um eine kostenrechtliche Ebene angereichert werden können. Andererseits liegt dies auch an der Affinität des Vollstreckungsrechts für Inzidenzprüfungen. Diese verlangen von den Bearbeiterinnen und Bearbeitern ein stark strukturiertes und sauberes Arbeiten anhand der verschiedenen Ebenen. Nicht selten stellt bereits das Erkennen einer vollstreckungsrechtlichen Konstellation einen ersten Fallstrick dar. Zudem

2276 Aus Gründen der besseren Lesbarkeit wird im Text an mehreren Stellen verallgemeinernd das generische Maskulinum verwendet. Diese Formulierungen umfassen gleichermaßen weibliche und männliche Personen; alle sind damit selbstverständlich gleichberechtigt angesprochen. 
lassen sich vollstreckungsrechtliche Klausurfälle meist ohne großen Aufwand um eine ganze Bandbreite verwaltungsprozessualer Fragestellungen erweitern.

Der folgende Beitrag möchte einen Überblick über die in Anfechtungskonstellationen relevanten Ermächtigungsgrundlagen des Verwaltungsvollstreckungsrechts geben. ${ }^{2277}$ Dafür wird nach einer Einführung (Rn. 1293ff.) das Verwaltungsvollstreckungsrecht in typischen Klausurkonstellationen verortet (Rn. 1299 ff.). Dem schließen sich Ausführungen zur Rechtmäßigkeitsprüfung von Vollstreckungsmaßnahmen im gestreckten Vollstreckungsverfahren nach § 6 I VwVG (Rn. 1317 ff.), mittels sofortigem Vollzug nach § 6 II VwVG (Rn. 1345ff.) und zur kostenrechtlichen Sekundärebene (Rn. 1366ff.) an.

\section{a) Überblick und Einführung in das Verwaltungsvollstreckungsrecht}

1293 „Verwaltungsvollstreckung ist die zwangsweise Durchsetzung öffentlich-rechtlicher Verpflichtungen des Bürgers [...] durch die Behörde in einem verwaltungseigenen Verfahren.“22278 Das Verwaltungsvollstreckungsrecht umschreibt die Gesamtheit der Rechtssätze, die die Rechtsdurchsetzung öffentlich-rechtlicher Pflichten durch die Verwaltung betreffen. Im weiteren Sinne umfasst der Begriff aber auch die der Vollstreckung nachgelagerte Sekundärebene, auf welcher es um Fragen der Kostenverteilung und Entschädigungsansprüche geht.

\section{aa) Das Recht zur Selbsttitulierung und Selbstvollstreckung}

1294 Während Private für die Rechtsdurchsetzung auf die Inanspruchnahme staatlicher Institutionen, namentlich Gerichte und staatliche Vollstreckungsorgane, angewiesen sind, bedarf es für die Vollstreckung öffentlich-rechtlicher Pflichten durch die Verwaltung keiner vorherigen gerichtlichen Titulierung. Anders als der Bürger wird die Verwaltung also nicht auf die Gerichte verwiesen, wenn sie Recht durchsetzen möchte. Vielmehr besitzt sie das Recht zur Selbsttitulierung und Selbstvollstreckung. ${ }^{2279}$ Erlässt eine Behörde einen Verwaltungsakt, der dem Adressaten ein Ge- oder Verbot auferlegt, so schafft sie sich dadurch

$2277 \mathrm{Zu}$ den in Feststellungskonstellationen relevanten Ermächtigungsgrundlagen des Verwaltungsvollstreckungsrechts s. § $6 \mathrm{Rn}$. $193 \mathrm{ff}$.

2278 Maurer/Waldhoff, Allgemeines Verwaltungsrecht, 19. Aufl. 2017, § 20 Rn. 1.

2279 Kingreen/Poscher, Polizei- und Ordnungsrecht, 10. Aufl. 2018, § 24 Rn. 36; Voßkuhle/ Wischmeyer, JuS 2016, 698 (699); ausführlich Lemke, Verwaltungsvollstreckungsrecht des Bundes und der Länder, 1997, S. 43 ff.

Mariamo Katharina Ilal 
gleichzeitig einen Vollstreckungstitel. Durch seine Titelfunktion ist der Verwaltungsakt „Zentralbegriff des Verwaltungsvollstreckungsrechts“2280. Kommt der Adressat der auferlegten Verpflichtung nicht nach, so kann die Behörde die Erfüllung der Verpflichtung unter den jeweiligen vollstreckungsrechtlichen Voraussetzungen (d.h. insbesondere unabhängig von der Rechtmäßigkeit des Verwaltungsakts, dazu sogleich unter Rn. 1327) selbst erzwingen.

\begin{abstract}
Beispiele: Ein Zwangsgeld wird zur Durchsetzung einer Wohnungsverweisung mit zehntätigem Rückkehrverbot verhängt. ${ }^{2281}$ Ein Dritter wird von der Behörde beauftragt, eine baurechtliche Gefahrenquelle zu beseitigen, nachdem der Adressat der ursprünglichen Verfügung seiner Pflicht nicht nachgekommen ist. ${ }^{2282}$ Ein im Halteverbot parkendes Fahrzeug wird durch einen beauftragten Dritten abgeschleppt. ${ }^{2283}$ Die Polizei setzt Wasserwerfer ein, um den Platzverweis gegenüber Teilnehmern einer aufgelösten Versammlung durchzusetzen. ${ }^{2284}$
\end{abstract}

\title{
bb) Normativer Rahmen
}

Das Verwaltungsvollstreckungsrecht kennt eine Vielzahl von spezialgesetzlichen Regelungen. ${ }^{2285}$ Den grundlegenden normativen Rahmen auf Bundesebene bilden aber das VwVG ${ }^{2286}$ und - soweit das Zwangsmittel des unmittelbaren Zwangs betroffen ist - das $\mathbf{U Z \mathbf { Z } \mathbf { w } ^ { 2 2 8 7 }}{ }^{\mathbf{2}}$. Sie gelten unmittelbar nur für die Verwaltungsvollstreckung durch Bundesbehörden (bzw. im Falle des UZwG für Vollzugsbeamte des Bundes). Auf Landesebene existieren verschiedene Regelungsansätze ${ }^{2288}$ : In Brandenburg beispielsweise gilt ein eigenes VwVG Bbg. In Berlin wiederum verweist § 8 VwVfG Bln dynamisch auf das VwVG des Bundes. Wieder anders ist es in Niedersachsen: Dort gilt zwar ein landeseigenes VwVG Nds. Jedoch finden sich die Regelungen zur Vollstreckung von Handlungs-, Duldungs- und Unterlassungspflichten im niedersächsischen Sicherheits- und Ordnungsgesetz.

2280 Baumeister, in: Schenke/Graulich/Ruthig, Sicherheitsrecht des Bundes, VwVG, 2. Aufl. 2019, Vorb. §§ 6-18 Rn. 18; Maurer/Waldhoff, Allgemeines Verwaltungsrecht, 19. Aufl. 2017, § 20 Rn. 2.

2281 OVG Münster, Urt. v. 9. 2.2012, Az.: 5 A 2152/10 = JuS 2012, 1151 (Anm. Walfhoff).

2282 BVerwG, Urt. v. 13.4.1984 - 4 C 31/81 = NJW 1984, 2591; BVerwG, Urt. v. 25.89.2008 - 7 C 5/ $08=$ NVwZ 2009, 122.

2283 BVerwG, Urt. v. 25.5.2018, Az.: 3 C 25/16 = NJW 2018, 2910.

2284 BVerfG, Beschl. v. 7.12.1998, Az.: 1 BvR 831/89 = NVwZ 1999, 290.

2285 Beispielsweise $\S \S 57 \mathrm{ff}$. AufenthG, $\S \S 34 \mathrm{ff}$. AsylG, §§ $249 \mathrm{ff}$. AO.

2286 v. 27.4.1953 (BGBl. I S. 15), zuletzt geändert durch Art. 1 des Gesetzes vom 30.6. 2017 (BGBl. I S. 1770).

2287 v. 10.3.1961 (BGBl. I, S. 165), zuletzt geändert durch Art. 4 des Gesetzes vom 24.5.2016 (BGBl. I S. 1217).

2288 Detaillierter Überblick über die verschiedenen Regelungsansätze der Länder bei Troidl, in: Engelhardt/App/Schlatmann, VwVG VwZG, 11. Aufl. 2017, Einf. Rn. 3. 
Die folgenden Ausführungen beziehen sich auf das VwVG des Bundes. Auf einige landesrechtliche Spezifika wird hingewiesen. Im Übrigen ist das grundlegende Prüfungsprogramm für vollstreckungsrechtliche Konstellationen auf Bundes- und Landesebene inhaltlich weitgehend parallel ausgestaltet.

\section{cc) Verwaltungszwang}

1296 Spricht man über Verwaltungsvollstreckung, so ist zwischen der Vollstreckung wegen Geldforderungen einerseits und der Erzwingung von Handlungen, Duldungen und Unterlassungen andererseits zu unterscheiden. Ersteres wird auch Beitreibung genannt. Letzteres wird unter dem Begriff des Verwaltungszwangs zusammengefasst. Diese Unterscheidung lässt sich auch anhand der Systematik des VwVG nachvollziehen: $\S \S 1-5 b$ VwVG regeln die Beitreibung, $\S \S 6-18$ VwVG den Verwaltungszwang. Der dritte Abschnitt des Gesetzes regelt die Kostenverteilung, §§ 19f. VwVG.

Wie auch in der juristischen Ausbildung liegt der Fokus dieses Beitrags auf dem Verwaltungszwang und den sich daran anschließenden Kostenfragen. ${ }^{2289}$

\section{dd) Pflichtiger}

1297 Gegen wen die Verwaltungsvollstreckung durchgeführt werden kann, ist im VwVG nicht ausdrücklich geregelt. Dies ist zunächst der durch den Verwaltungsakt Verpflichtete. ${ }^{2290}$ In Fällen des sofortigen Vollzugs (dazu unter Rn. $1345 \mathrm{ff}$.) ist dies derjenige, gegen den eine Grundverfügung hätte ergehen können. Bei objektbezogenen Verwaltungsakten kann Verpflichteter auch der Rechtsnachfolger sein. Die Durchsetzung einer baurechtlichen oder naturschutzrechtlichen Beseitigungsanordnung kann daher auch gegenüber einem neuen Grundstückseigentümer erfolgen. Bei mehreren in Betracht kommenden Pflichtigen muss die Behörde ihr Auswahlermessen ordnungsgemäß betätigen.

1298 Examenswissen: Der Verwaltungszwang gegen Behörden ist grundsätzlich unzulässig, § 17 VwVG. Dies ist Ausdruck des zwischenbehördlichen koordinationsrechtlichen Verhältnisses. Das Gesetz geht davon aus, dass die Behörde ein besonderes Ansehen genießt, aufgrund dessen es eines Verwaltungszwangs gegen sie grundsätzlich gar nicht bedarf. Vielmehr könne von der Behörde erwartet werden, dass sie ihren Verpflichtungen auch ohne die Anwendung von Zwangsmitteln

2289 Übersichtlich zur Vollstreckung wegen Geldforderungen Maurer/Waldhoff, Allgemeines Verwaltungsrecht, 19. Aufl. 2017, § 20 Rn. 9 ff.

2290 Baumeister, in: Schenke/Graulich/Ruthig, Sicherheitsrecht des Bundes, VwVG, 2. Aufl. 2019, Vorb. $\S \S 6-18$ Rn. $26 \mathrm{f}$. 
nachkommt. ${ }^{2291}$ Der Verwaltungszwang gegen Behörden ist daher nur zulässig, wenn er spezialgesetzlich zugelassen ist.

\section{b) Das Verwaltungsvollstreckungsrecht in der Klausur}

Typischer Ausgangspunkt einer vollstreckungsrechtlich eingekleideten Klausur ist die kostenrechtliche Sekundärebene (s. Rn. $1366 \mathrm{ff}$.). Die Prüfung eines Kostenbescheids setzt fundierte Kenntnisse der Verwaltungsvollstreckungsmaßnahmen und ihrer Rechtmäßigkeitsvoraussetzungen nach § 6 I und § 6 II VwVG voraus, auf die deshalb gesondert in Rn. $1317 \mathrm{ff}$. und Rn. $1345 \mathrm{ff}$. eingegangen wird.

Bevor jedoch die für das Verwaltungsvollstreckungsrecht typischen Ermächtigungsgrundlagen (Rn. 1302ff.), Zwangsmittel (Rn. 1306ff.) und Rechtsschutzkonstellationen (Rn. 1311ff.) im Überblick dargestellt werden, muss zunächst auf eine der häufigsten Fehlerquellen eingegangen werden: Die Verkennung vollstreckungsrechtlicher Konstellationen.

\section{aa) Erkennen einer vollstreckungsrechtlichen Konstellation, insbesondere Abgrenzung zu polizeirechtlichen Standardmaßnahmen}

Eine der größten Fehlerquellen in Klausurbearbeitungen ist das Verkennen vollstreckungsrechtlicher Konstellationen. Dies führt meist dazu, dass die Bearbeiterinnen und Bearbeiter versuchen, den Fall über die polizei- und ordnungsrechtlichen Generalklauseln zu lösen. Auslöser dieser Fehlerquelle ist, dass es nicht selten Parallelitäten zu den polizeirechtlichen Standardmaßnahmen gibt (s. dazu näher Rn. 1045ff.). Auch diese beinhalten teilweise Vollzugselemente, sodass hier die Abgrenzung zum Vollstreckungsrecht von besonderer Bedeutung ist.

Dabei ist zwischen Standardmaßnahmen mit Vollzugselement und Standardmaßnahmen ohne Vollzugselement zu differenzieren. ${ }^{2292}$

Erstere umfassen neben dem Ge- oder Verbot auch eine Befugnis zur Ausführung der Maßnahme durch die Polizei. Der Vollzug der Verfügung ist hier Teil der Standardmaßnahme. Beispiele für Standardmaßnahmen mit Vollzugselement sind das Festhalten zur Prüfung der Identität, die erkennungsdienstliche Behandlung, die Durchsuchung von Personen, Sachen und Wohnungen und die Inge-

2291 Deusch/Burr, in: Bader/Ronellenfitsch, VwVG, 43. Ed., Stand: 1.4. 2019, § 17 Rn. 1.

2292 Hierzu auch Muckel, JA 2012, 272 (274); Poscher/Rusteberg, JuS 2012, 26 (27f.); teilweise findet sich auch die Bezeichnung „Standardmaßnahme mit/ohne Ausführungsermächtigung“, vgl. Baumeister, in: Schenke/Graulich/Ruthig, Sicherheitsrecht des Bundes, VwVG, 2. Aufl. 2019, Vorb. §§ 6-18 Rn. 14. 
wahrsamnahme. ${ }^{2293}$ Eines Rückgriffs auf das Verwaltungsvollstreckungsrecht bedarf es in diesen Fällen nicht. Etwas anderes gilt aber dann, wenn das polizeiliche Handeln „überschießende vollstreckungsrechtliche Elemente“ beinhaltet. Das ist dann der Fall, wenn die Polizei über das standardisierte Verfahren hinaus Zwang anwenden muss. Tritt also eine Polizistin die Wohnungstür zum Zwecke der Wohnungsdurchsuchung ein und muss eine andere Polizistin den wütenden Mieter festhalten, damit die Wohnungsdurchsuchung stattfinden kann, so müssen beide Maßnahmen anhand der vollstreckungsrechtlichen Ermächtigungsgrundlagen bewertet werden.

Bei Standardmaßnahmen ohne Vollzugselement stellt die Durchführung der Grundverfügung stets eine Vollstreckungsmaßnahme dar. Dies ist beispielsweise bei der Vorladung oder dem Platzverweis der Fall. ${ }^{2294}$

1301 Examenswissen (Die Abgrenzung von Standardmaßnahme und Vollstreckungsmaßnahme bei der Sicherstellung): Es ist umstritten, ob im Rahmen einer Sicherstellung die Ansichnahme des Gegenstandes noch von der polizeigesetzlichen Ermächtigungsgrundlage (Standardmaßnahme) gedeckt ist oder nach Vollstreckungsrecht zu bewerten ist. ${ }^{2295}$ Sieht man in der Ermächtigungsgrundlage zur Sicherstellung allein die Befugnis zum Erlass eines Verwaltungsakts, der auf die Herausgabe einer Sache gerichtet ist, so bedürfte es für die Ansichnahme der Sache eines Rückgriffs auf das Vollstreckungsrecht. ${ }^{2296}$ Andererseits wird vertreten, dass die Ermächtigungsgrundlage zur Sicherstellung bereits die Ansichnahme der Sache als Vollzugselement beinhaltet. ${ }^{2297}$ Muss die Herausgabe der Sache aber durch Anwendung von Zwang vollzogen werden, so handelt es sich um ein „überschießendes Element“, sodass jedenfalls in diesen Fällen Einigkeit über den vollstreckungsrechtlichen Charakter der Maßnahme besteht.

\section{bb) Überblick über die typischen Ermächtigungsgrundlagen im Verwaltungsvollstreckungsrecht}

1302 Das VwVG geht in § 6 I VwVG als Regelfall davon aus, dass der Verwaltungszwang auf der Grundlage eines vollziehbaren Verwaltungsakts erfolgt. Der Zwangsmittelanwendung gehen dabei regelmäßig noch zwei Verfahrensschritte voraus: die Androhung und die Festsetzung. Aus dieser Mehraktigkeit gewinnt die

2293 Beispiele aus: Mosbacher, in: Engelhardt/App/Schlatmann, VwVG VwZG, 11. Aufl. 2017, Vorb. §§ 6-18 Rn. 1 a.

2294 Beispiele aus: Mosbacher, in: Engelhardt/App/Schlatmann, VwVG VwZG, 11. Aufl. 2017, Vorb. §§ 6-18 Rn. 1a.

2295 Muckel, JA 2012, 272 (274).

2296 Gusy, Polizei- und Ordnungsrecht, 10. Aufl. 2017, Rn. 286.

2297 Graulich, in: Lisken/Denninger, Handbuch des Polizeirechts, 6. Aufl. 2018, E Rn. 643; Kingreen/Poscher, Polizei- und Ordnungsrecht, 10. Aufl. 2018, § 18 Rn. 1, 15; W.-R. Schenke, in: Schenke/Graulich/Ruthig, Sicherheitsrecht des Bundes, BPolG, 2. Aufl. 2018, §47 Rn. 6; Wehr, in: Wehr, NK-BPolG, § 47 Rn. 2. 
Literatur den Namen „gestrecktes Verfahren“2298, welcher auch in diesem Beitrag Verwendung finden soll.

Examenswissen (Verwaltungszwang nach § 6 I VwVG auf Grundlage eines öffentlich-rechtlichen 1303 Vertrages): Auch ein öffentlich-rechtlicher Vertrag kann Vollstreckungsgrundlage sein (zum öffentlich-rechtlichen Vertrag s. ausführlich $\S 5$ Rn. 65 ff.). Dafür muss es sich zunächst um einen subordinationsrechtlichen Vertrag handeln ( 54 S. 2 VwVfG). Darüber hinaus muss sich der vertragsschließende Bürger der sofortigen Vollstreckung unterworfen haben (§ 61 I VwVfG). Sind diese Voraussetzungen erfüllt, so tritt in diesen Fällen im Rahmen des § 6 I VwVG der öffentliche Vertrag an die Stelle des dort genannten Verwaltungsakts.

Verwaltungszwang kann in dringenden Fällen auch ohne vorausgehenden Verwaltungsakt angewendet werden. Wenngleich es also nicht um den „Vollzug“ eines Verwaltungsakts geht, wird in diesen Fällen vom sog. sofortigen Vollzug ${ }^{2299}$ gesprochen. Ermächtigungsgrundlage ist \$ 6 II VwVG. Teilweise findet sich auch die

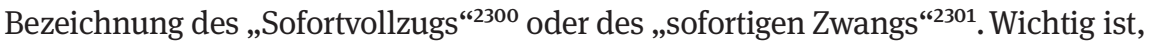
dass - unabhängig von dem in diesem Bereich anzutreffenden „besonders undurchsichtigen Begriffswirrwarr“2302 - die vollstreckungsrechtliche Problematik des sofortigen Vollzugs nicht mit der Anordnung der sofortigen Vollziehbarkeit i.S.d. $\S 80$ II 1 Nr. 4 VwGO verwechselt wird. Das eine lässt die aufschiebende Wirkung von Rechtsbehelfen, die gegen einen Verwaltungsakt eingelegt werden können, entfallen. Das andere bezeichnet die sofortige zwangsweise Durchsetzung einer Rechtspflicht.

Wie bereits eingangs angemerkt, nehmen vollstreckungsrechtlich eingekleidete Klausuren nicht selten ihren Ausgangspunkt auf der Kostenebene. Hierbei geht es um die Frage, wer die Kosten für eine Vollstreckungsmaßnahme zu tragen hat. Ermächtigungsgrundlage für die Kostenerhebung ist § 19 I VwVG.

\section{cc) Überblick über die Zwangsmittel}

$\S 9$ VwVG normiert die Mittel, mit denen der Verwaltungszwang angewendet wer- 1306 den kann, abschließend (sog. numerus clausus der Zwangsmittel). Als Zwangsmittel

2298 S. nur Kingreen/Poscher, Polizei- und Ordnungsrecht, 10. Aufl. 2018, § 24 Rn. 21; Muckel, JA 2012, 272 (275); Schweikert, Der Rechtswidrigkeitszusammenhang, 2013, S. 42.

2299 S. nur Kingreen/Poscher, Polizei- und Ordnungsrecht, 10. Aufl. 2018, § 24 Rn. 37; Maurer/ Waldhoff, Allgemeines Verwaltungsrecht, 19. Aufl. 2017, § 20 Rn. 25; Muckel, JA 2012, 354 (355). 2300 Baumeister, in: Schenke/Graulich/Ruthig, Sicherheitsrecht des Bundes, VwVG, 2. Aufl. 2019, Vorb. $\S \S 6-18$ Rn. 5.

2301 Schweikert, Der Rechtswidrigkeitszusammenhang, 2013, S. 47.

2302 Mosbacher, in: Engelhardt/App/Schlatmann, VwVG VwZG, 11. Aufl. 2017, § 6 Rn. 22. 
kommt je nach Fallkonstellation die Ersatzvornahme (§10 VwVG), das Zwangsgeld (§ 11 VwVG) oder der unmittelbare Zwang (§ 12 VwVG) in Betracht.

Bei der Ersatzvornahme wird ein beauftragter Dritter anstelle des Pflichtigen tätig. ${ }^{2303}$ Voraussetzung ist, dass die zu erzwingende Handlung eine vertretbare ist, d.h. dass sie nicht höchstpersönlich vorgenommen werden muss. Da Duldungs- und Unterlassungspflichten stets allein durch den Verpflichteten erfüllbar und damit höchstpersönlicher Natur sind, kommt die Ersatzvornahme als Zwangsmittel nur bei positiven Handlungspflichten in Betracht. Typisches Beispiel für vertretbare Handlungen ist die Beseitigung baurechtlicher Gefahrenquellen oder das Wegfahren eines Fahrzeugs aus dem Halteverbot.

1308 Mit dem Zwangsgeld soll der Betroffene durch die in Aussicht gestellte finanzielle Einbuße dazu gebracht werden, dem Grundverwaltungsakt Folge zu leisten. Nach § 11 I 1 VwVG geht das Gesetz davon aus, dass das Zwangsgeld regelmäßig bei unvertretbaren Pflichten verhängt werden kann. Typisches Beispiel dafür ist die Zwangsgeldverhängung für die Erzwingung von Auskünften oder Erklärungen. ${ }^{2304}$ Auch die Erzwingung von Duldungs- und Unterlassungspflichten (beispielsweise eine Wohnungsverweisung mit Rückkehrverbot) ist in diesem Zusammenhang zu nennen, §11 II VwVG. Das Zwangsgeld kann nach § 11 I 2 VwVG aber auch bei vertretbaren Handlungen verhängt werden. Voraussetzung ist, dass die Ersatzvornahme untunlich ist. Als Regelbeispiel nennt das Gesetz die finanzielle Überforderung des Pflichtigen in Bezug auf die Kosten der Ersatzvornahme. Damit soll das Risiko verringert werden, dass die Kosten der Ersatzvornahme im Nachhinein nicht beigetrieben werden können. Der Rekurs auf das Zwangsgeld bietet dann den Vorteil, dass das Zwangsgeld die Höhe der Kosten der Ersatzvornahme nicht unbedingt erreichen muss, der Betroffene aber dennoch durch Inaussichtstellung finanzieller Einbußen (und ggf. der Ersatzzwanghaft) zur Rechtstreue angehalten wird.

1309 Examenswissen (Ersatzzwangshaft nach § 16 VwVG): Die Ersatzzwangshaft ist kein selbständiges Zwangsmittel, sondern ein Surrogat für das Zwangsgeld, wenn dessen Beitreibung uneinbringlich ist. Sie soll denjenigen Pflichtigen, dem gegenüber die Inaussichtstellung finanzieller Einbußen (regelmäßig mangels Zahlungsfähigkeit) kein ausreichendes Beugemittel darstellt, durch den

2303 Nicht von § 10 VwVG umfasst ist die Selbstvornahme durch die Vollzugsbehörde. Anders ist dies auf landesrechtlicher Ebene: Die meisten Länder sehen sowohl in der Beauftragung eines Dritten als auch in der Selbstvornahme durch die Behörde eine Ersatzvornahme (z. B. § 25 VwVG BW; Überblick bei Mosbacher, in: Engelhardt/App/Schlatmann, VwVG VwZG, 11. Aufl. 2017, § 10 Rn. 2, 17). Auf Bundesebene hingegen stellt die Selbstvornahme einen Unterfall des unmittelbaren Zwangs dar, s. §12 Var. 2. VwVG.

2304 Beispiele aus App, JuS 2004, 7786 (789).

Mariamo Katharina Ilal 
Eingriff in die persönliche Freiheit zur Befolgung seiner Rechtspflicht bewegen. ${ }^{2305}$ Die Zwangshaft bedarf der richterlichen Anordnung.

Unmittelbarer Zwang ist die Einwirkung auf Personen oder Sachen durch 1310 körperliche Gewalt, ihre Hilfsmittel oder Waffen (so die Legaldefinition des § 2 I UZwG) sowie die behördliche Selbstvornahme. Aufgrund des Verhältnismäßigkeitsprinzips ist der unmittelbare Zwang „das an letzter Stelle stehende Zwangsmittel“2306. Wegen dieses Grundsatzes der Subsidiarität ist der unmittelbare Zwang nur zulässig, wenn Ersatzvornahme und Zwangsgeld nicht zum Ziel führen oder sie untunlich sind. ${ }^{2307}$ Ersteres ist der Fall, wenn Ersatzvornahme und Zwangsgeld entweder bereits erfolglos angewendet worden sind oder aber bereits vor ihrer Anwendung feststeht, dass sie erfolglos sein werden. ${ }^{2308}$ Nicht ausreichend ist die vermutliche Uneinbringlichkeit eines Zwangsgeldes aufgrund bescheidener Einkommensverhältnisse des Pflichtigen. ${ }^{2309}$ Ersatzvornahme und Zwangsgeld sind untunlich, wenn ihr Einsatz zwar Erfolg versprechend ist, der unmittelbare Zwang sich aber im konkreten Fall als wirksamer darstellt. ${ }^{2310}$ Liegt unmittelbarer Zwang in der Form der Einwirkung auf Personen oder Sachen durch körperliche Gewalt, ihre Hilfsmittel oder Waffen vor, so müssen zusätzlich die Voraussetzungen des UZwG beachtet werden.

\section{dd) Typische Rechtsschutzkonstellationen}

Für die Bearbeitung einer verwaltungsvollstreckungsrechtlichen Klausur ist es 1311 essentiell, die verschiedenen rechtlichen Ebenen eines Sachverhalts zu erfassen und auseinanderzuhalten. Nicht selten müssen die Bearbeiterinnen und Bearbeiter in umfangreiche Inzidenzprüfungen einsteigen. Von ihnen wird verlangt, trotz der vielen Verschachtelungen den Überblick zu behalten und das rechtlich Relevante an den jeweils richtigen Stellen einzuordnen und darzustellen.

2305 Lemke, Verwaltungsvollstreckungsrecht des Bundes und der Länder, 1997, S. 276.

2306 Wacke, JZ 1962, 138 zitiert nach Mosbacher, in: Engelhardt/App/Schlatmann, VwVG VwZG, 11. Aufl. 2017, § 12 Rn. 7.

2307 Anderes gilt freilich, wenn Spezialgesetze den unmittelbaren Zwang als einziges Zwangsmittel bestimmen, z. B. $\S 58$ AufenthG.

2308 OVG Berlin-Brandenburg, Beschl. v. 5.6.2014, Az.: OVG 3 S 71.13.

2309 OVG Berlin-Brandenburg, Beschl.v. 23.8.2013, Az.: OVG 3 S 41.13.

2310 Dies ist beispielsweise der Fall, wenn die Vollzugbehörde einen Gegenstand, den der Pflichtige herausgeben muss, bei dem Pflichtigen findet. Hier könnte auch das Zwangsgeld zum Erfolg führen, jedoch ist es effizienter dem unwilligen Pflichtigen die Sache wegzunehmen, Beispiel aus Lemke, Verwaltungsvollstreckungsrecht des Bundes und der Länder, 1997, S. 290. 
Die erste Ebene betrifft die Grundverfügung. Soweit sie nicht unanfechtbar ist, sind gegen sie Widerspruch und Anfechtungsklage statthafte Rechtsbehelfe. Kommt den eingelegten Rechtsbehelfen aufschiebende Wirkung zu, so ist die Behörde aufgrund des Suspensiveffekts grundsätzlich daran gehindert, den Verwaltungsakt zu vollstrecken (zum Suspensiveffekt s. § 8 Rn. $4 \mathrm{ff}$.). Gleiches gilt im Falle eines erfolgreichen Antrags nach $\S 80 \mathrm{~V} 1 \mathrm{VwGO}$ (s. § 8 Rn. 1ff.). Einen Einblick in die typischen Ermächtigungsgrundlagen, die auf dieser Ebene eine Rolle spielen, finden sich in den Beiträgen zum allgemeinen Verwaltungsrecht (s. Rn. 832 ff.), Polizeirecht (s. Rn. 1000 ff.) und Versammlungsrecht (s. Rn. 1141 ff.) und Bauordnungsrecht (s. Rn. 1222ff.). Der Fokus dieses Beitrags liegt auf den anderen beiden Ebenen.

Zunächst ist dies die Ebene der Vollstreckungsmaßnahme. ${ }^{2311}$ Will der Kläger unmittelbar gegen eine Vollstreckungsmaßnahme vorgehen, so gilt es in der Klausur zunächst den statthaften Rechtsbehelf zu ermitteln und sodann in der Begründetheit in die Prüfung der Rechtmäßigkeit der Vollstreckungsmaßnahme einzusteigen (zu den Voraussetzungen sogleich unter Rn. $1317 \mathrm{ff}$. und Rn. $1345 \mathrm{ff}$.).

Handelt es sich um eine Maßnahme im gestreckten Verfahren, so ist entscheidend gegen welche Vollstreckungsmaßnahme sich der Kläger wendet: Gegen Androhung (vgl. § 18 I VwVG) und Festsetzung sind Widerspruch und Anfechtungsklage statthafte Rechtsbehelfe. Da diesen Rechtsbehelfen gegen Maßnahmen in der Verwaltungsvollstreckung aufgrund von § 80 II 1 Nr. 3, S. 2 VwGO i.V.m. landesrechtlichen Vorschriften ${ }^{2312}$ regelmäßig keine aufschiebende Wirkung zukommt, kann hier auch einmal eine Rechtsschutzkonstellation nach $\S 80 \mathrm{~V} 1$ Fall 1 VwGO in Betracht kommen (Näheres hierzu in § 8). Die Anwendung der Zwangsmittel Ersatzvornahme und unmittelbarer Zwang ist indes ein Realakt, sodass hier die Feststellungsklage (u.U. in Verbindung mit Leistungsklage auf Rückgängigmachung der Vollzugsfolgen) statthafter Rechtsbehelf ist (näheres hierzu in $\S 6$ Rn. 193ff.). ${ }^{2313}$ Geht es dem Betroffenen um die Abwendung einer bevorstehen Zwangsmittelanwendung, so ist die vorbeugende Unterlassungsklage - hier aufgrund der Eilbedürftigkeit in Form des Antrags nach $\S 123$ VwGO (Näheres hierzu in §10) - statthaft.

2311 Ausführlich Lemke, Verwaltungsvollstreckungsrecht des Bundes und der Länder, 1997, S. $445 \mathrm{ff}$.

2312 Beispielsweise § 4 AGVwGO Berlin.

2313 Die Zwangsmittelanwendung im Falle eines Zwangsgeldes besteht in der Beitreibung des Zwangsgeld nach §§ 1-5b VwVG. Zu den Rechtsschutzkonstellationen in diesen Fällen s. Deusch/ Burr, in: Bader/Ronellenfitsch, VwVG, 43. Ed., Stand: 1.4.2019, § 5 Rn. $6 \mathrm{ff.;}$ Maurer/Waldhoff, Allgemeines Verwaltungsrecht, 19. Aufl. 2017, § 20 Rn. 11. 
Für Maßnahmen des sofortigen Vollzugs ordnet § $18 \mathrm{II}$ VwVG - obschon es 1315 sich um Realakte handelt ${ }^{2314}$ - Widerspruch und Anfechtungsklage als statthafte Rechtsbehelfe an.

Die dritte Ebene stellt die sog. Kostenebene dar. Es ist weitaus typischer, dass 1316 eine Klausur ihren Ausgangspunkt auf der Kostenebene nimmt als dass sie direkt auf Ebene der Vollstreckungsmaßnahme ansetzt. Statthafter Rechtsbehelf gegen einen Kostenbescheid sind Widerspruch und Anfechtungsklage. Die Rechtmäßigkeit des Kostenbescheids setzt die Rechtmäßigkeit der Maßnahme, für die die Kosten erhoben werden, voraus (Näheres dazu unter Rn. 1366ff.). Dies ist Einfallstor für die inzidente Überprüfung der Vollstreckungsmaßnahme nach § 6 I oder § 6 II VwVG. Deren Rechtmäßigkeitsvoraussetzungen sollen nun im Einzelnen unter Rn. 1317 ff. für das gestreckte Verfahren und Rn. 1345 ff. für den sofortigen Vollzug dargestellt werden.

\section{c) Gestrecktes Verfahren, § 6 I VwVG}

Den Regelfall des Verwaltungszwangs stellt das sog. gestreckte Verfahren nach 1317 § 6 I VwVG dar. Demnach kann ein Verwaltungsakt, der auf die Herausgabe einer Sache oder auf die Vornahme einer Handlung oder auf Duldung oder Unterlassung gerichtet ist, mit den in §9 VwVG genannten Zwangsmitteln durchgesetzt werden, wenn er unanfechtbar ist oder wenn sein sofortiger Vollzug angeordnet oder wenn dem Rechtmittel keine aufschiebende Wirkung beigelegt ist.

Der Anwendung von Verwaltungszwang auf Grundlage eines vollziehbaren 1318 Verwaltungsakts gehen spezielle vollstreckungsrechtliche Verfahrensschritte voraus: Zunächst ist das von der Vollstreckungsbehörde ausgewählte Zwangsmittel anzudrohen, $\S 13$ VwVG. Dadurch soll der Adressat der Grundverfügung zur Rechtstreue angehalten werden, während gleichzeitig durch die Festlegung auf ein bestimmtes Zwangsmittel auch eine Warnung, was im Falle der Zuwiderhandlung an Konsequenzen droht, ergeht. ${ }^{2315}$ Wird die Verpflichtung innerhalb der Frist, die in der Androhung bestimmt ist, nicht erfüllt, so setzt die Vollzugsbehörde das Zwangsmittel fest, § $14 \mathrm{I}$ VwVG. ${ }^{2316}$ Die Festsetzung soll

2314 So die herrschende Meinung, s. nur Deusch/Burr, in: Bader/Ronellenfitsch, VwVG, 43. Ed., Stand: 1.4.2019, § 18 Rn. 9.

2315 Deusch/Burr, in: Bader/Ronellenfitsch, VwVG, 43. Ed., Stand: 1.4. 2019, § 13 Rn. 1

2316 Viele landesrechtlichen Vollstreckungsvorschriften hingegen kennen die Festsetzung als Verfahrensstufe nicht, Überblick bei Troidl, in: Engelhardt/App/Schlatmann, VwVG VwZG, 11. Aufl. 2017, § 14 Rn. 7. 
dem Pflichtigen als letzte Warnung vor der Zwangsmittelanwendung dienen. ${ }^{2317}$ Erst dann kann das Zwangsmittel auch angewendet werden, § 15 VwVG.

Für die Klausurbearbeitung folgt aus eben dieser Mehraktigkeit des gestreckten Verfahrens nicht selten ein Aufbauproblem. Denn es bestehen regelmäßig gleich drei mögliche „Angriffspunkte“ im Rechtsschutzverfahren (Androhung, Festsetzung und Anwendung), die in ihren Voraussetzungen freilich ähnlich, in der Klausur jedoch dennoch auseinander zu halten sind.

Androhung und Festsetzung sind Verwaltungsakte. Will der Betroffene gegen sie vorgehen, so sind Widerspruch und Anfechtungsklage statthafte Rechtsbehelfe, vgl. § 18 I VwVG. Bei der Zwangsmittelanwendung handelt es sich indes um einen Realakt, gegen den Rechtsschutz im Rahmen der Feststellungsklage gewährt wird. Diesen Unterschieden in der prozessualen Verarbeitung der verschiedenen Vollstreckungsmaßnahmen wird in diesem Beitrag dadurch Rechnung getragen, dass Rechtmäßigkeitsvoraussetzungen von Androhung und Festsetzung im Lehrbuchkapitel der Anfechtungsklage, der Zwangsmittelanwendung indes im Kapitel der Feststellungsklage (s. § 5 Rn. 193ff.) dargestellt werden.

1321 Die Rechtmäßigkeit von Androhung und Festsetzung ist in dem typischen verwaltungsrechtlichen Grundmuster Ermächtigungsgrundlage - formelle Rechtmäßigkeit - materielle Rechtmäßigkeit zu prüfen. Auf allen drei Stufen finden sich Voraussetzungen, die beiden Vollstreckungsvoraussetzungen gemein sind. Sie werden im Folgenden unter Rn. $1322 \mathrm{ff}$. auch gemeinsam dargestellt. Dem schließen sich Ausführungen zu Rechtmäßigkeitsvoraussetzungen an, die spezifisch für die Androhung (Rn. 1337 ff.) bzw. Festsetzung gelten (Rn. 1342ff.).

\section{aa) Gemeinsame Rechtmäßigkeitsvoraussetzungen von Androhung und Festsetzung}

1322 Androhung und Festsetzung müssen wie jedes verwaltungsrechtliche Eingriffshandeln auf einer Ermächtigungsgrundlage beruhen (s. Rn. $554 \mathrm{ff}$.) sowie bestimmten formellen und materiellen Voraussetzungen Genüge tun.

\section{(1) Ermächtigungsgrundlage}

1323 Ermächtigungsgrundlage von Androhung und Festsetzung ist § 6 I VwVG. Optional kann auch das jeweilige Zwangsmittel (§§ 9 lit. x, 10-12 VwVG) und die

2317 Instruktiv zu den Rechtswirkungen der Festsetzung BVerwG, Beschl.v. 21.8.1996-4 B 100/ $96=$ NVwZ 1997, 381.

Mariamo Katharina Ilal 
Verfahrensstufe (für die Androhung § 13 VwVG, für die Festsetzung $§ 14$ VwVG) mit hinzu zitiert werden.

\section{(2) Formelle Rechtmäßigkeit}

Nach § 7 VwVG ist zuständige Vollzugsbehörde diejenige, die den zu vollziehen- 1324 den Verwaltungsakt erlassen hat (Grundsatz der Selbstvollstreckung durch die Ausgangsbehörde). ${ }^{2318} \mathrm{Da}$ Androhung und Festsetzung „Maßnahmen in der Verwaltungsvollstreckung“ sind, ist die Anhörung des Betroffenen nach § 28 II Nr. 5 VwVfG entbehrlich. ${ }^{2319}$

\section{(3) Materielle Rechtmäßigkeit: Allgemeine Vollstreckungsvoraussetzungen}

Die materielle Rechtmäßigkeit von Androhung und Festsetzung hängt zunächst vom Vorliegen der allgemeinen Vollstreckungsvoraussetzungen ab. Dafür muss den Vollstreckungsmaßnahmen ein wirksamer, bestimmter und vollstreckbarer Grundverwaltungsakt zugrunde liegen (Rn. $1326 \mathrm{ff}$.). Die Vollstreckungsbehörde muss das richtige Zwangsmittel gewählt haben (Rn. 1333). Es dürfen keine Vollstreckungshindernisse vorliegen (Rn. 1334) und die Maßnahme muss ermessensfehlerfrei und insbesondere verhältnismäßig sein (Rn. 1335f.).

\section{(a) Wirksamer, bestimmter und vollstreckbarer Grundverwaltungsakt}

Grundlage für den Verwaltungszwang nach §6 I VwVG ist ein wirksamer, be- 1326 stimmter und vollstreckbarer Grundverwaltungsakt. ${ }^{2320}$ Dabei sei vorausgeschickt, dass nur befehlende Verwaltungsakte, nicht aber feststellende oder rechtsgestaltende Verwaltungsakte überhaupt vollstreckungsfähig sind (vgl. Wortlaut § 6 I VwVG: „Verwaltungsakt, der auf die Herausgabe einer Sache oder

2318 Abweichendes kann sich teilweise aus den landesrechtlichen Vorschriften ergeben, so beispielsweise die Zuständigkeitserweiterung in § 8 I S. 3 VwVfG Bln.

2319 Für den Spezialfall der Festsetzung eines Zwangsgeldes vertritt eine Mindermeinung, dass die Festsetzung im Vorfeld der Beitreibung des Zwangsgeldes (§§ 1-5a VwVG) ergeht und deshalb eine Maßnahme vor (und eben nicht in) der Verwaltungsvollstreckung sei. Deshalb sei in diesen Fällen eine Anhörung eben doch erforderlich. Dem ist jedoch zu entgegen, dass dies zu einer künstlichen Aufspaltung eines einheitlichen Vollstreckungsvorgangs führte. Es ist nicht ersichtlich, weshalb die Androhung eines Zwangsgeldes eine Maßnahme im Vollstreckungsverfahren sein sollte, während die darauffolgende Festsetzung sodann als Maßnahme vor dem Vollstreckungsverfahren behandelt wird.

2320 Die Begriffe des Grundverwaltungsakts und der Grundverfügung werden in diesem Beitrag synonym verwendet. 
auf die Vornahme einer Handlung oder auf Duldung oder Unterlassung gerichtet ist").

\section{(aa) Wirksamkeit des Grundverwaltungsakts}

1327 Voraussetzung ist zunächst, dass ein wirksamer Grundverwaltungsakt vorliegt. Dies bestimmt sich nach den allgemeinen Vorschriften \$§ 43, 44 VwVfG (Näheres hierzu unter Rn. $98 \mathrm{ff}$.). Auf die Rechtmäßigkeit des Verwaltungsakts kommt es (soweit die Rechtswidrigkeit nicht zur Nichtigkeit führt) hingegen nicht an. Nicht selten firmiert dieser Grundsatz unter dem Schlagwort des fehlenden Rechtswidrigkeitszusammenhangs ${ }^{2321}$. Dahinter verbirgt sich der ,tragende Grundsatz des Verwaltungsvollstreckungsrechts, dass die Wirksamkeit und nicht die Rechtmäßigkeit vorausgegangener Verwaltungsakte Bedingung für die Rechtmäßigkeit der folgenden Akte und letztlich der Anwendung des Zwangsmittels ist“2322. Der fehlende Rechtswidrigkeitszusammenhang zwischen Grundverfügung und Vollstreckungsmaßnahme ist Ausdruck der Titelfunktion des Verwaltungsakts.

1328 Examenswissen (Vertiefende Herleitung des fehlenden Rechtswidrigkeitszusammenhangs): Bei unanfechtbaren Verwaltungsakten ergibt sich der fehlende Rechtswidrigkeitszusammenhang bereits aus der materieller Bestandskraft: Solange die Grundverfügung wirksam ist, kommt es für die Beurteilung der Rechtmäßigkeit der Vollstreckungsmaßnahme auf die Rechtmäßigkeit der Grundverfügung nicht an. ${ }^{2323}$ Hin und wieder finden sich in der Ausbildungsliteratur Verweise darauf, dass die Frage des Rechtswidrigkeitszusammenhangs bei Vollstreckungsmaßnahmen aufgrund sofort vollziehbarer Verwaltungsakte angesichts des Grundsatzes der Gesetzmäßigkeit der Verwaltung streitig sei. ${ }^{2324}$ Jedoch finden sich heute kaum ${ }^{2325}$ noch Stimmen, die einen sol-

2321 Schweikert, Der Rechtswidrigkeitszusammenhang, 2013; Voßkuhle/Wischmeyer, JuS 2016, 698 (700).

2322 So das OVG Lüneburg hier zitiert durch BVerfG, Beschl.v. 7.12.1998 - 1 BvR 831/89 = NVwZ 1999, 290 (292).

2323 Deusch/Burr, in: Bader/Ronellenfitsch, VwVG, 43. Ed., Stand: 1.4.2019, § 6 Rn. 20; Muckel, JA 2012, 272 (277).

2324 Streitübersicht bei Poscher/Rusteberg, JuS 2012, 26 (28); Auslöser des Streits ist, dass bei sauberer Differenzierung zwischen der Vollstreckung unanfechtbarer und sofortig vollziehbarer Grundverfügungen die Titelfunktion streng genommen nur für erstere Fallgruppe zur Begründung des fehlenden Rechtswidrigkeitszusammenhangs herangezogen werden kann und sich deshalb eigenständig mit dem Grundsatz der Gesetzmäßigkeit der Verwaltung für die zweite Fallgruppe auseinander gesetzt werden muss. Diese dogmatisch sehr interessante Frage hat indes keinen Raum in der Klausurbearbeitung, weshalb in diesem Beitrag lediglich auf die ausführliche Diskussion bei Schweikert, Der Rechtswidrigkeitszusammenhang, 2013, S. 100, 140 ff. hingewiesen wird.

2325 So noch Schoch, in: Schoch, Besonderes Verwaltungsrecht, 2018, Kap. 1 Rn. 916.

Mariamo Katharina Ilal 
chen Rechtswidrigkeitszusammenhang für Fälle sofort vollziehbarer Verwaltungsakte fordern. Vielmehr ist auch hier die ganz herrschende Meinung, dass die Rechtmäßigkeit des sofort vollziehbaren Grundverwaltungsakts keine Rechtmäßigkeitsvoraussetzung für die Vollstreckungsmaßnahme ist. ${ }^{2326}$ Auch das BVerfG hat diese Rechtsauffassung als ,verfassungsrechtlich unbedenklich“2327 bestätigt. In der Klausur sollte dieser Meinungsstreit daher nicht geführt und höchstens mit einem Satz angedeutet werden.

Der Einwand der Gesetzmäßigkeit der Verwaltung bleibt indes auch von der herrschenden Meinung nicht gänzlich ungehört. Vollzieht eine Behörde „sehenden Auges“ einen rechtswidrigen Grundverwaltungsakt, so kann dies im Einzelfall zur Unverhältnismäßigkeit und damit zur Rechtswidrigkeit der Vollzugsmaßnahme führen (Näheres Rn. 1336). Das ändert aber nichts daran, dass im Prüfungspunkt Grundverwaltungsakt auch in diesen Fällen allein dessen Wirksamkeit ausschlaggebend ist. Sollte es in der Klausur einmal um den Vollzug trotz erkannter Rechtswidrigkeit gehen, so ist diese Problematik daher nicht unter „Wirksamkeit des Grundverwaltungsaktes“, sondern an späterer Stelle im Rahmen der Verhältnismäßigkeit zu diskutieren.

\section{(bb) Bestimmtheit des Grundverwaltungsakts}

Damit der Adressat der Verfügung erkennen kann, was von ihm verlangt wird und sein Verhalten daran anpassen kann, muss der Inhalt des erlassenen Grundverwaltungsaktes „vollständig, klar und unzweideutig erkennbar sein“2328. Der der Vollstreckungsmaßnahme zugrunde liegende Grundverwaltungsakt muss deshalb bestimmt sein, vgl. §37 I VwVfG.

Examenswissen (Prüfung der Bestimmtheit als Ausnahme vom sonst fehlenden Rechtswidrigkeitszusammenhang): Die Unbestimmtheit des zu vollziehenden Verwaltungsakts führt dazu, dass dieser - obwohl lediglich rechtswidrig - nicht vollstreckbar ist. Es bietet sich daher an, das Bestimmtheitserfordernis systematisch als Ausnahme zum sonst geltenden Grundsatz des fehlenden Rechtswidrigkeitszusammenhangs zu begreifen. So wird es auch in der Rechtsprechung gesehen: „Insoweit erfährt der tragende Grundsatz des Verwaltungsvollstreckungsrechts, dass es für die Beurteilung einer Vollstreckungsmaßnahme auf die Rechtmäßigkeit der Grundverfügung nicht ankommt, eine Ausnahme. Die Unbestimmtheit der Grundverfügung infiziert eine zu ihrer Durchsetzung ergehende Vollstreckungsmaßnahme“2329.

2326 Stellvertretend für alle Poscher/Rusteberg, JuS 2012, 26 (28); ebenso der Konsens in der Rechtsprechung: BVerfG, Beschl. v. 7.12.1998, Az.: 1 BvR 831/89 = NVwZ 1999, 290 (292); OVG Lüneburg, Beschl.v. 23.4.2009, Az.: 11 ME 478/08; OVG Münster, Urt. v. 9.2.2012, Az.: 5 A 2152/10 = JuS 2012, 1151 (Anm. Waldhoff).

2327 BVerfG, Beschl. v. 7.12.1998, Az.: 1 BvR 831/89 = NVwZ 1999, 290 (292).

2328 Deusch/Burr, in: Bader/Ronellenfitsch, VwVG, 43. Ed., Stand: 1.4. 2019, Vorb § 6 Rn. 10.

2329 VGH Mannheim, Urt. v. 10.1.2013, Az.: 8 S 2919/11 = NVwZ-RR 2013, 451 (452): In diesem Fall hatte die Behörde dem Adressaten ohne weitere Präzisierung aufgegeben, innerhalb einer bestimmten Frist die Außenwände seines Hauses „,in einem landschaftlich unauffälligen Farbton zu gestalten" und nachdem der Adressat das Haus grün angestrichen hatte (und die Verfügung in Bestandskraft gewachsen war) ein Zwangsgeld angedroht. Das Gericht gab der dagegen gerichteten Anfechtungsklage mangels bestimmten Grundverwaltungsakts statt. 


\section{(cc) Vollstreckbarkeit des Grundverwaltungsakts}

1331 Der Verwaltungszwang ist nur zulässig, wenn der Grundverwaltungsakt unanfechtbar oder sofort vollziehbar ist. Die Unanfechtbarkeit tritt mit Ablauf der Rechtsbehelfsfristen ( $\S \S 70,73$ VwGO) ohne Einlegung eines Rechtsbehelfs oder aber mit einer rechtkräftigen ablehnenden Entscheidung über den eingelegten Rechtsbehelf ein. Ein Verwaltungsakt ist sofort vollziehbar, wenn Widerspruch und Anfechtungsklage keine aufschiebende Wirkung haben, vgl. § 80 I 1 VwGO. Die aufschiebende Wirkung kann dabei gesetzlich (§ 80 II 1 Nr. 1-3, S.2 VwGO) oder aber qua behördlicher Anordnung (sog. Anordnung der sofortigen Vollziehbarkeit, § 80 II 1 Nr. 4 VwGO) entfallen (Näheres hierzu in § 8 Rn. 14 ff.).

1332 Examenswissen (Abschleppfälle I): Nicht selten sind Abschleppmaßnahmen Ausgangspunkt vollstreckungsrechtlicher Klausurkonstellationen. Häufig geht es hier um den Wechsel vom gestreckten Verfahren in den sofortigen Vollzug (dazu später unter Rn. 1355). Einstiegstor ist aber die Erkenntnis, dass Verkehrszeichen Allgemeinverfügungen ( $335 \mathrm{~S} .2 \mathrm{VwVfG}$ ) sind, die wirksam werden, sobald sie so aufgestellt sind, dass sie „ein durchschnittlicher Kraftfahrer bei Einhaltung der nach § 1 StVO erforderlichen Sorgfalt schon mit einem raschen und beiläufigen Blick erfassen kann“²330 (s. hierzu auch Rn. 85, 165). Nach $\S 80$ II 1 Nr. 2 VwGO analog sind sie auch sofort vollziehbar (s. auch § 8 Rn. 17). ${ }^{2331}$

\section{(b) Richtiges Zwangsmittel}

1333 Die Vollzugsbehörde muss das richtige Zwangsmittel gewählt haben (zu den Unterschieden und Voraussetzungen s. oben Rn. 1306ff.). Bei mehreren in Betracht kommenden Zwangsmitteln muss sie ihr Ermessen ordnungsgemäß ausüben. $^{2332}$

\section{(c) Keine Vollstreckungshindernisse}

1334 Vollstreckungshindernisse stehen einer Vollstreckungsmaßnahme entgegen. Sie sind im VwVG nur in Ansätzen geregelt. Allein die Zweckerreichung ist ausdrücklich in $\S 15$ III VwVG normiert. Dies ist beispielsweise der Fall, wenn der Pflichtige zwischenzeitlich seiner Verpflichtung nachgekommen ist. Die Vollstreckung ist dann einzustellen. Gleiches gilt im Falle des Zweckfortfalls wegen Veränderung der tatsächlichen Umstände oder einer neuen Rechtslage ${ }^{2333}$, der

2330 BVerwG, Urt. v. 25.5.2018, Az.: 3 C 25/16 = NJW 2018, 2910.

2331 Schoch, in: Schoch/Schneider/Bier, VwGO, 36. EL Februar 2019, § 80 Rn. 150 f.

2332 Dieser Punkt kann freilich auch erst im Rahmen des Ermessens geprüft werden.

2333 Das Haus, das Gegenstand einer Abrissverfügung war, weil es sich nach alter Rechtslage im Landschaftsschutzgebiet befunden hat, befindet sich nach einer Gesetzesänderung nicht mehr im 
Unmöglichkeit der Zweckerreichung ${ }^{2334}$ oder des durch die Vollzugsbehörde erklärten Vollstreckungsverzichts.

\section{(d) Ermessen, insbesondere Verhältnismäßigkeit}

Die Anwendung des Verwaltungszwangs liegt im Ermessen der Vollzugsbehörde, 1335 welches jedoch gerichtlich auf Ermessensfehler hin überprüfbar ist, § 114 VwGO (Näheres zum Ermessen allgemein unter Rn. 729 ff., 739 ff.). Fehler können sowohl auf Ebene des Entschließungsermessens als auch des Auswahlermessens (bei mehreren Pflichtigen oder mehreren möglichen Zwangsmitteln) bestehen. Insbesondere der in § 9 II VwVG einfach-rechtlich konkretisierte Verhältnismäßigkeitsgrundsatz ist ein wichtiges Korrektiv, an dem sich die Vollstreckungsmaßnahme messen lassen muss.

Examenswissen (Unverhältnismäßigkeit der Vollstreckungsmaßnahme bei erkannter Rechtswidrigkeit der Grundverfügung) ${ }^{2335}$ : Wie bereits an früherer Stelle angedeutet (s. Rn. 1328), kann die Rechtswidrigkeit einer Grundverfügung im Ausnahmefall doch einmal auf die Rechtmäßigkeit der Vollstreckungsmaßnahme durchschlagen. Dies ist dann der Fall, wenn die Behörde einen Grundverwaltungsakt in Kenntnis ihrer Rechtswidrigkeit vollzieht und damit ,sehenden Auges Unrecht vollstreckt“2336. Teilweise findet sich diese Problematik unter dem Schlagwort der „rechtsmissbräuchlichen oder sittenwidrigen Vollstreckung“2337. Eine solche Vollstreckungsmaßnahme ist unverhältnismäßig und damit rechtswidrig. In diesen Fällen muss in der Fallbearbeitung doch einmal ausnahmsweise inzident die Rechtswidrigkeit der Grundverfügung geprüft werden. Dies allein reicht für das Durchschlagen der Rechtswidrigkeit auf die Vollstreckungsebene jedoch noch nicht aus. Hinzukommen muss auf behördlicher Seite ein subjektives Element, auf welches im Sachverhalt hingewiesen werden muss.

\section{bb) Besondere Rechtmäßigkeitsvoraussetzungen der Androhung}

Zwangsmittel müssen im gestreckten Verfahren schriftlich angedroht werden. Die 1337 Androhung ist ein von der Grundverfügung getrennter Verwaltungsakt, der dieser zeitlich nachgehen kann (sog. selbstständige Androhung). Die Androhung kann aber auch mit der Grundverfügung verbunden werden, § 13 II 1 VwVG; sie soll mit ihr verbunden werden, wenn den Rechtsbehelfen gegen die Grundverfügung

Landschaftsschutzgebiet, Beispiel aus: Troidl, in: Engelhardt/App/Schlatmann, VwVG VwZG, 11. Aufl. 2017, § 15 Rn. 9.

2334 Das Haus, das Objekt einer Abrissverfügung war, brennt ab.

2335 Ausführlich Schweikert, Der Rechtswidrigkeitszusammenhang, 2013, S. $196 \mathrm{f}$.

2336 Kingreen/Poscher, Polizei- und Ordnungsrecht, 10. Aufl. 2018, § 24 Rn. 33; Muckel, JA 2012, 272 (277).

2337 Sadler, VwVG VwZG, 9. Aufl. 2014, § 18 Rn. 6; Schweikert, Der Rechtswidrigkeitszusammenhang, 2013, S. 196. 
keine aufschiebende Wirkung zukommt, § 13 II 2 VwVG (sog. unselbstständige Androhung).

1338 Examenswissen (Einwendungen gegen die Grundverfügung im Rahmen der Anfechtung der Zwangsmittelandrohung): Ist die Androhung mit dem Grundverwaltungsakt verbunden (sog. unselbstständige Androhung, §13 II 2 VwVG), so erstreckt sich der Rechtsbehelf gegen die Zwangsmittelandrohung nach § 18 I 2 VwVG auch auf den Grundverwaltungsakt. Es kommt also zu einer gerichtlichen Überprüfung aller möglichen Einwendungen in einem Rechtsschutzverfahren. Prozessual wird dies über die objektive Klagehäufung nach § 44 VwGO erreicht (hierzu $\S 1$ Rn. 251). Freilich steht es dem Betroffenen frei, seinen Rechtsbehelf ausdrücklich auf die Zwangsmittelandrohung zu beschränken. Hat der Betroffene bereits einen Rechtsbehelf gegen den Grundverwaltungsakt eingelegt, so wird dieser durch die spätere Einlegung eines Rechtsbehelfs gegen die Zwangsmittelandrohung nicht berührt. ${ }^{2338}$ Es handelt sich dann um zwei selbstständige Rechtsschutzverfahren.

Ist die Androhung nicht mit dem Grundverwaltungsakt verbunden (sog. selbständige Androhung) und ist dieser unanfechtbar geworden, so sind Einwendungen des Betroffenen, die die Rechtmäßigkeit des Grundverwaltungsaktes betreffen, präkludiert. Der Betroffene kann in diesen Fällen lediglich geltend machen, durch die Androhung selbst in seinen Rechten verletzt zu sein, vgl. $\S 18$ I 3 VwVG. Dies umfasst beispielsweise Einwendungen gegen die Länge der Fristbemessung oder das Fehlen eines wirksamen Grundverwaltungsakts.

\section{(1) Besonderheiten innerhalb der formellen Rechtmäßigkeit}

1339 Die Androhung bedarf zu ihrer Rechtmäßigkeit der Schriftform, § 13 I 1 VwVG. Dies ist innerhalb der formellen Rechtmäßigkeit der Androhung zu prüfen.

\section{(2) Besonderheiten innerhalb der materiellen Rechtmäßigkeit}

1340 In materieller Hinsicht müssen neben den allgemeinen Vollstreckungsvoraussetzungen (oben Rn. 1325 ff.) die Voraussetzungen des $\S 13$ VwVG geprüft werden. So muss für die Erfüllung der Verpflichtung eine angemessene Frist bestimmt werden, § 13 I 2 VwVG. Für Duldungs- und Unterlassungspflichten ist eine Fristsetzung regelmäßig entbehrlich, weil deren Erfüllung kein zeitbezogenes Tätigwerden des Adressaten voraussetzt. Nach § 13 III VwVG muss sich die Androhung auf ein bestimmtes Zwangsmittel beziehen. Die gleichzeitige Androhung mehrerer

2338 Deusch/Burr, in: Bader/Ronellenfitsch, VwVG, 43. Ed., Stand: 1.4.2019, VwVG, § 18 Rn. 5. 
möglicher Zwangsmittel ist nach § 13 III 2 VwVG unzulässig (Kumulationsverbot). ${ }^{2339}$

Entscheidet sich die Vollstreckungsbehörde für die Ersatzvornahme, so ist in der Androhung der Kostenbetrag vorläufig zu veranschlagen, § 13 IV 1 VwVG. Entscheidet sich die Vollstreckungsbehörde für das Zwangsgeld, so ist dieses in einer bestimmten Höhe anzudrohen, § 13 V VwVG.

Examenswissen (Androhung „für jeden Fall der Zuwiderhandlung“ gegen ein Verbot zulässig?): Es ist umstritten, ob eine Androhung für ,jeden Fall der Zuwiderhandlung“ gegen ein Verbot ergehen darf. Sieht man darin die Androhung eines Zwangsmittels für jede einzelne Zuwiderhandlung, so lässt sich vertreten, dass eine solche Androhung „für jeden Fall der Zuwiderhandlung“ zulässig ist. Der Schutzzweck des Kumulationsverbots greife hier nicht ein, denn der Betroffene könne erkennen, was ihm drohe. ${ }^{2340}$ Andere wiederum verneinen die Zulässigkeit einer solchen Androhung, denn darin liege eine gleichzeitige Androhung mehrerer Zwangsmittel ,auf Vorrat“. ${ }^{2341}$ Zulässig sei dies nur, wenn das Gesetz eine solche Androhung „für jeden Fall der Zuwiderhandlung“" vorsehe. Entsprechende gesetzliche Vorgaben finden sich z. B. in § 17 FinDAG, $\S 332$ III 2 AO oder manchen landesrechtlichen Vollstreckungsgesetzen ${ }^{2342}$. Wo eine solche gesetzliche Grundlage fehle, würde eine Androhung „für jeden Fall der Zuwiderhandlung“ gegen den verfassungsrechtlichen Grundsatz des Vorbehalts des Gesetzes verstoßen.

\section{cc) Besondere Rechtmäßigkeitsvoraussetzungen der Festsetzung}

Innerhalb der materiellen Rechtmäßigkeit sind neben den allgemeinen Vollstre- 1342 ckungsvoraussetzung (oben Rn. 1325ff.) folgende Voraussetzungen zu prüfen: Der Festsetzung muss eine wirksame, vollstreckbare Androhung vorausgehen. Auch hier gilt der tragende Grundsatz des Verwaltungsvollstreckungsrechts: Die Rechtmäßigkeit der Festsetzung hängt allein von der Wirksamkeit und Vollstreckbarkeit der Androhung ab, nicht aber von deren Rechtmäßigkeit. ${ }^{2343}$ In der Klausur sind an dieser Stelle daher nur die Wirksamkeitsvoraussetzungen der Androhung (keine Nichtigkeit nach § 44 VwVfG sowie ordnungsgemäße Zustel-

2339 Manche landesrechtlichen Vorschriften lassen hingegen die Androhung mehrerer Zwangsmittel zu, Übersicht bei Troidl, in: Engelhardt/App/Schlatmann, VwVG VwZG, 11. Aufl. 2017, § 13 Rn. 17.

2340 Troidl, in: Engelhardt/App/Schlatmann, VwVG VwZG, 11. Aufl. 2017, §13 Rn. 4.

2341 Deusch/Burr, in: Bader/Ronellenfitsch, VwVG, 43. Ed., Stand: 1.4. 2019, VwVG, § 13 Rn. 22 ff; Sadler, VwVG VwZG, 9. Aufl. 2014, § 13 Rn. 87; BVerwG, Gerichtsbescheid v. 26.6.1997-1 A 10/95 = NVwZ 1998, 393; OVG Berlin-Brandenburg, Beschl.v. 8.6.2011, Az.: OVG 1 B 31/08 = BeckRS 2011, 51745 .

2342 Beispielsweise § 17 VI 2 VwVG Bremen; § 57 III 2 VwVG NRW, § 63 III 2 VwVG RheinlandPfalz.

2343 VGH Kassel, Beschl. v. 4.10.1995, Az.: 4 TG 2043/95 = NVwZ-RR 1996, 715; Troidl, in: Engelhardt/App/Schlatmann, VwVG VwZG, 11. Aufl. 2017, § 14 Rn. 1. 
lung nach $\S 13$ VII VwVG i.V.m. VwZG) zu prüfen. Auf die unter Rn. 1337 ff. dargestellten Rechtmäßigkeitsvoraussetzungen der Androhung kommt es nicht an.

Darüber hinaus darf die Festsetzung erst nach Ablauf der in der Androhung benannten Frist ergehen. Sodann ist zu prüfen, ob sich die Festsetzung im Rahmen der zeitlich vorausgegangenen Androhung bewegt. So darf beispielsweise im Falle eines angedrohten Zwangsgeldes i.H.v. $500 €$ dieses später nicht i.H.v. $750 €$ festgesetzt werden.

1344 Examenswissen (Festsetzung von Zwangsgeld bei Unmöglichkeit eines weiteren Verstoßes gegen die Unterlassungsverfügung?): „Eines der umstrittensten Probleme des Verwaltungsvollstreckungsrechts “2344 betrifft die Frage, ob eine Behörde ein Zwangsgeld auch dann festsetzen darf, wenn zwar gegen die Unterlassungsverfügung verstoßen wurde, ein weiterer Verstoß jedoch nicht (mehr) möglich ist. Regelmäßig wird diese Streitfrage innerhalb der Verhältnismäßigkeit der Festsetzung verortet.

Als Beispielsfall sei folgende Konstellation skizziert: ${ }^{2345}$ Gegen den B ergeht eine sofort vollziehbare Wohnungsverweisung mit einem Rückkehrverbot für zehn Tage unter gleichzeitiger Androhung eines Zwangsgelds i.H.v. $500 €$ für den Fall der Zuwiderhandlung. Drei Tage vor Ablauf des Rückkehrverbots hält sich B verbotswidrig in der Wohnung auf. Einen Monat später setzt die Behörde ein Zwangsgeld von $500 €$ fest. Ist die Zwangsgeldfestsetzung rechtmäßig?

Problematisch ist hier allein die Tatsache, dass B zwar gegen das Verbot verstoßen hat, jedoch zum Zeitpunkt der Festsetzung ein weiterer Verstoß unmöglich war, da das Rückkehrverbot zeitlich befristet war.

Nach einer Ansicht ist eine Zwangsgeldfestsetzung in diesem Falle unzulässig. Denn wenn gegen ein Verbot nicht mehr verstoßen werden könne, so könne der Festsetzung auch keine Beugewirkung zukommen. ${ }^{2346}$ Es ginge dann nicht mehr darum, den Pflichtigen zur Rechtstreue anzuhalten, sondern seinen vorherigen Rechtsbruch abzustrafen. Ein solcher Strafcharakter sei dem Verwaltungsvollstreckungsrecht jedoch fremd, weshalb eine Zwangsgeldfestsetzung in diesen Fällen rechtswidrig sei.

Eine andere Ansicht stell die Festsetzung in einen weiteren Zusammenhang mit der ihr vorausgegangen Androhung. ${ }^{2347}$ Wäre dem Betroffenen im Zeitpunkt der Androhung klar, dass im Falle der Zuwiderhandlung gegen das Unterlassungsgebot ein Zwangsgeld gar nicht festgesetzt werden könne, so würde die Androhung ihrer Beugewirkung verlustig gehen. Gerade bei zeitlich eng begrenzten Verboten wie im Falle eines zehntätigen Rückkehrverbots würde die Androhung von Zwangsgeld nicht mehr geeignet sein, den Betroffenen zur Rechtstreue anzu-

2344 App, JuS 2004, 786 (791).

2345 So der Ausgangsfall in OVG Münster, Urt. v. 9.2.2012, Az.: 5 A 2151/10.

2346 OVG Lüneburg, Beschl. v. 23.4.2009, Az.: 11 ME 478/08; Dünchheim, NVwZ 1996, 117.

2347 OVG Münster, Urt. v. 9.2.2012, Az.: 5 A 2151/10; App, JuS 2004, 786 (791); Baumeister, in: Schenke/Graulich/Ruthig, Sicherheitsrecht des Bundes, VwVG, 2. Aufl. 2019, § 15 Rn. 16; Graulich, in: Lisken/Denninger, Handbuch des Polizeirechts, 6. Aufl. 2018, E Rn. 912 ff.; Muckel, JA 2012, 272 (278). Teilweise wird die Problematik auch innerhalb der Vollstreckungshindernisse (insbesondere unter der Zweckerreichung bzw. des Zweckfortfalls) diskutiert, s. Lemke, Verwaltungsvollstreckungsrecht des Bundes und der Länder, 1997, S. $232 \mathrm{ff}$. 
mahnen und ihm Konsequenzen für den Fall der Zuwiderhandlung in Aussicht stellen. Dies hätte zur Folge, dass zur effektiven Durchsetzung des Verwaltungsakts nicht mehr das Zwangsgeld, sondern nur noch die Anwendung unmittelbaren Zwangs zum Ziel führte. Dies wiederum verkehre aber das vom Gesetzgeber vorgezeichnete Subsidiaritätsverhältnis des unmittelbaren Zwangs zu den anderen Zwangsmitteln in sein Gegenteil, vgl. § 12 VwVG. Der nachträglichen Zwangsgeldfestsetzung käme daher aufgrund ihres Zusammenwirkens mit der Androhung eine „fortbestehende mittelbare Beugefunktion ${ }^{\text {“2348 }} \mathrm{zu}$. Ohne die daraus folgende nachträgliche Festsetzungsbefugnis könne der Betroffene nahezu risikolos gegen Unterlassungspflichten verstoßen. Dies zeigt sich insbesondere dann, wenn der Betroffene durch den Verstoß Fakten schafft und dadurch die Fortgeltung der Unterlassungspflicht selbst beendet (z.B. pflichtwidriger Abriss eines denkmalgeschützten Hauses oder verbotswidrige Fällung eines Baumes). ${ }^{2349}$

\section{d) Sofortiger Vollzug, § 6 II VwVG}

Nach § 6 II VwVG kann Verwaltungszwang auch ohne vorausgehenden Verwal- 1345 tungsakt angewendet werden, wenn der sofortige Vollzug zur Verhinderung einer rechtswidrigen Tat, die einen Straf- oder Bußgeldtatbestand verwirklicht oder zur Abwendung einer drohenden Gefahr notwendig ist und die Behörde hierbei innerhalb ihrer gesetzlichen Befugnisse handelt. Der sofortige Vollzug findet vor allem im Gefahrenabwehrrecht Anwendung, denn hier besteht nicht selten ein zeitlicher Handlungsdruck für die Behörde, dem das mehraktige gestreckte Verfahren nicht angemessen Rechnung tragen kann.

Beispiel: Ein Baum auf dem Grundstück des S droht jeden Augenblick auf die Straße zu stürzen. Die Behörde lässt ihn durch einen beauftragten Dritten fällen. ${ }^{2350}$

Für den sofortigen Vollzug nicht untypisch ist auch, dass der Verpflichtete nicht $\mathbf{1 3 4 6}$ rechtzeitig ermittelt oder erreicht werden kann, sodass ihm gegenüber gar kein Grundverwaltungsakt ergehen kann.

Beispiel: Die Behörde lässt einen Verstorbenen, dessen bestattungspflichtige Angehörige zunächst nicht bekannt sind, durch ein Bestattungsunternehmen beisetzen. ${ }^{2351}$

Die Anwendung von Zwangsmitteln im sofortigen Vollzug ist ein Realakt. Pro- 1347 zessual wird der sofortige Vollzug aber wie ein Verwaltungsakt behandelt, denn

2348 OVG Münster, Urt. v. 9.2.2012, Az.: 5 A 2152/10, Rn. 38.

2349 Beispiele aus OVG Münster, Urt. v. 9.2.2012, Az.: 5 A 2152/10, Rn. 35.

2350 Beispiel aus Muckel, JA 2012, 355 (347).

2351 Beispiel aus Sadler, VwVG VwZG, 9. Aufl. 2014, § 6 Rn. 337. 
$\S 18$ II VwVG ordnet als Rechtsbehelfe Widerspruch und Anfechtungsklage an. ${ }^{2352}$

1348 Auch der sofortige Vollzug ist in dem für das Verwaltungsrecht typischen Dreischritt Ermächtigungsgrundlage - formelle Rechtmäßigkeit - materielle Rechtmäßigkeit zu prüfen.

\section{aa) Ermächtigungsgrundlage}

1349 Ermächtigungsgrundlage für den sofortigen Vollzug ist § 6 II VwVG. Optional kann auch hier das jeweils einschlägige Zwangsmittel mitzitiert werden (§§ 9 I lit. x, $10-12$ VwVG).

1350 An dieser Stelle kann in der Fallbearbeitung die Abgrenzung zwischen sofortigem Vollzug und der polizeirechtlichen unmittelbaren Ausführung verlangt werden. Die unmittelbare Ausführung ist in mehreren Bundesländern im Sicherheits- und Ordnungsgesetz normiert und erlaubt der Polizei eine Maßnahme selbst oder durch einen Beauftragten unmittelbar auszuführen, wenn der Zweck der Maßnahme durch Inanspruchnahme der Verantwortlichen nicht oder nicht rechtzeitig erreicht werden kann. ${ }^{2353}$ Die Ähnlichkeit beider Institute basiert auf der Dringlichkeit, mit der die jeweilige Maßnahme auszuführen ist. Wenig verwunderlich ist es daher, dass der sofortige Vollzug und die unmittelbare Ausführung in ihren Rechtsmäßigkeitsvoraussetzungen nahezu deckungsgleich sind. ${ }^{2354}$ Dennoch darf nicht übersehen werden, dass der sofortige Vollzug Verwaltungsvollstreckungsrecht, die unmittelbare Ausführung hingegen materielles Polizeirecht ist.

1351 Deshalb ist in Ländern, die beide Institute vorsehen, das eine vom anderen abzugrenzen. ${ }^{2355}$ Teilweise wird diese Abgrenzung über den Vorrang der unmittelbaren Ausführung vorgenommen. ${ }^{2356}$ Eine andere Ansicht tritt diesem lex specialis-Verhältnis mit Verweis auf die Unterschiedlichkeit der Regelungsgebiete

2352 Sadler, VwVG VwZG, 9. Aufl. 2014, § 6 Rn. 279, § 18 Rn. 12; da regelmäßig keine Rechtsbehelfsbelehrung erfolgt ist, gilt die Jahresfrist nach $\S 58$ II VwGO.

2353 Baden-Württemberg: § 8 PolG; Bayern: Art. 9 PAG; Berlin: § 15 ASOG; Hamburg: § 7 SOG; Hessen: § 8 HSOG; Rheinland-Pfalz: § 6 POG; Sachsen: § 6 PolG; Sachsen-Anhalt: § 9 SOG; Thüringen: § 9 PAG.

2354 Poscher/Rusteberg, JuS 2012, 26 (29).

2355 Ausführlich Lemke, Verwaltungsvollstreckungsrecht des Bundes und der Länder, 1997, S. $200 \mathrm{ff}$.

2356 Kaniess, LKV 2013, 401; Kingreen/Poscher, Polizei- und Ordnungsrecht, 10. Aufl. 2018, § 24 Rn. 43; Muckel, JA 2012, 272, (275); Poscher/Rusteberg, JuS 2012, 26 (29); Schoch, in: Schoch, Besonderes Verwaltungsrecht, 2018, Kap. 1 Rn. 936.

Mariamo Katharina Ilal 
(einerseits Vollstreckungsrecht, andererseits Polizeirecht) entgegen. ${ }^{2357}$ Während das Vollstreckungsrecht davon ausgehe, dass es bei dem Verpflichteten zu einer Willensbeugung kommt, solle die unmittelbare Ausführung darauf aufbauen, dass der Verantwortliche an sich seiner Pflicht nachkommen möchte und die Behörde lediglich anstelle seiner tätig wird, ohne dass es einer Willensbeugung bedarf. Ist der Verantwortliche nicht vor Ort und sein tatsächlicher Wille nicht ermittelbar, so soll nach dieser Ansicht auf die mutmaßliche Willensbeugung abzustellen sein. Wird der (mutmaßliche) Wille des Verpflichteten durch die Maßnahme gebeugt, handele es sich um eine Maßnahme nach § 6 II VwVG; andernfalls sei die landesrechtliche Vorschrift zur unmittelbaren Ausführung einschlägig.

In der Klausur wird von den Bearbeiterinnen und Bearbeitern verlangt, dass sie das Abgrenzungsproblem erkennen (freilich nur, wenn das jeweilige Landesrecht neben dem sofortigen Vollzug auch die unmittelbare Ausführung normiert), sich je nach Argumentationslinie für das eine oder das andere Institut entscheiden und dieses dann in seinen Voraussetzungen konsequent durchprüfen.

\section{bb) Formelle Rechtmäßigkeit}

Nach § 7 VwVG gilt der Grundsatz der Selbstvollstreckung durch die Ausgangs-

behörde. Da im Falle des sofortigen Vollzugs regelmäßig kein Grundverwaltungsakt erlassen wurde, ist $\S 7$ VwVG dahingehend zu modifizieren, dass diejenige Behörde zuständig ist, die einen entsprechenden Grundverwaltungsakt hätte erlassen können. Da der sofortige Vollzug ein Realakt ist, bedarf es schon nach § 28 I VwVfG keiner Anhörung.

\section{cc) Materielle Rechtmäßigkeit}

Der Wortlaut des § 6 II VwVG geht davon aus, dass dem sofortigen Vollzug kein 1354 Grundverwaltungsakt vorausgeht. Dennoch gibt es Konstellationen, in denen ein Zwangsmittel trotz vorhandener Grundverfügung sofort und mithin ohne Durchlaufen des gestreckten Verfahrens angewendet wird (s. Rn. 1355). Der sofortige Vollzug setzt einen Dringlichkeitstatbestand voraus (s. Rn. 1357 ff.). Zudem muss die hypothetische Grundverfügung rechtmäßig sein, die Behörde also innerhalb ihrer gesetzlichen Befugnisse handeln (s. Rn. 1361). Darüber hinaus muss das

2357 Schenke, Polizei- und Ordnungsrecht, 10. Aufl. 2018, Rn. 564; VG Berlin, Urt. v. 19.6.2013, Az.: 14 K 34.13. 
richtige Zwangsmittel gewählt worden sein (Rn. 1362ff.) und die Maßnahme ermessensfehlerfrei und insbesondere verhältnismäßig sein (Rn. 1365).

\section{(1) Ohne vorausgehenden Verwaltungsakt}

1355 Wie bereits angedeutet, geht der Wortlaut des §6 II VwVG davon aus, dass der sofortige Vollzug ohne vorausgehenden Verwaltungsakt ergeht. Dem Gesetzgeber standen hierbei Fallkonstellationen vor Augen, in denen der Verpflichtete nicht (rechtzeitig) ermittelbar oder erreichbar ist und deshalb der Handlungsdruck der Behörde ausgelöst wird. Es sei an das oben genannte Beispiel (s. Rn. 1346) des zu bestattenden Verstorbenen gedacht, dessen Angehörige zunächst nicht bekannt sind.

Indes gibt es auch Fallkonstellationen, in denen „der Grundverwaltungsakt zwar bereits erlassen wurde, aber die weiteren Voraussetzungen des gestuften Vollstreckungsverfahrens wegen plötzlich auftretender Eilbedürftigkeit nicht eingehalten werden können“2358. Hier kann das oben genannte Beispiel des umsturzgefährdeten Baumes (s. Rn. 1345) unter leichter Modifikation bemüht werden: ${ }^{2359}$ Der Baum auf dem Grundstück des S droht langsam auf die Straße zu kippen. Die Behörde gibt dem S daher unter Anordnung der sofortigen Vollziehbarkeit und unter Androhung eines Zwangsgeldes auf, den Baum innerhalb von 2 Wochen $\mathrm{zu}$ fällen. Noch vor Fristablauf weht ein starker Orkan über die Stadt, welcher den Baum fast vollständig entwurzelt. Er droht nun jeden Augenblick auf die Straße zu kippen. Die Behörde lässt ihn durch einen Dritten fällen. In einem solchen Fall besteht ein dringlicher Handlungsdruck, dem das mehraktige gestreckte Verfahren nicht gerecht wird. Im Sinne einer effektiven Gefahrenabwehr muss es der Vollzugsbehörde möglich sein, die Verpflichtung trotz vorausgehenden Verwaltungsakts sofort $\mathrm{zu}$ vollziehen. Ein solcher Übergang vom gestreckten Verfahren in den sofortigen Vollzug ist nach § 6 II VwVG analog möglich (sog. abgekürztes Verfahren). ${ }^{2360}$ Freilich muss sich die Vollstreckungsmaßnahme dann auch an den Rechtmäßigkeitsvoraussetzungen des sofortigen Vollzuges

2358 Deusch/Burr, in: Bader/Ronellenfitsch, VwVG, 43. Ed., Stand: 1.4. 2019, § 6 Rn. 25.

2359 Beispiel aus Muckel, JA 2012, 355, (358).

2360 Alternative Bezeichnungen und Herleitungen in Maurer/Waldhoff, Allgemeines Verwaltungsrecht, 19. Aufl. 2017, § 20 Rn. 27: „verkürztes Verfahren“, in Schweikert, Der Rechtswidrigkeitszusammenhang, 2013, S. 49: „abgekürztes Verfahren“, in Lemke, Verwaltungsvollstreckungsrecht des Bundes und der Länder, 1997, S. 125: „erleichtertes Verfahren“. 
messen lassen. Insbesondere muss hier die Grundverfügung (anders als im gestreckten Verfahren) rechtmäßig sein (dazu sogleich unter Rn. 1361). ${ }^{2361}$

Examenswissen (Abschleppfälle II): Auch die Abschleppfälle laufen häufig - sofern sie sich nach Vollstreckungsrecht richten - über § 6 II VwVG in analoger Anwendung. Denn regelmäßig wird ein Abschleppvorgang dadurch ausgelöst, dass ein Fahrzeug in einem durch ein Verkehrsschild ausgewiesenem Halteverbot steht. Soweit das Schild sichtbar aufgestellt ist, liegt eine wirksame Grundverfügung vor, die nach § 80 II 1 Nr. 2 VwGO analog sofort vollziehbar ist (dazu bereits oben Rn. 1332). Dennoch bietet sich ein Vorgehen im gestreckten Verfahren meist nicht an, beispielsweise weil das Fahrzeug eine Feuerwehreinfahrt blockiert oder den Straßenverkehr oder anstehende Baumarbeiten behindert und deshalb umgehend entfernt werden muss. Auch hier wird daher häufig trotz vorhandener Grundverfügung nicht im gestreckten Verfahren, sondern unter den Voraussetzungen des $§ 6$ II VwVG analog vollstreckt.

\section{(2) Dringlichkeitstatbestand}

Die Voraussetzung der Dringlichkeit erklärt sich vor dem bereits angesprochenen zeitlichen Hintergrund des sofortigen Vollzugs. Er umfasst Fallkonstellationen, aber eben auch nur solche Fallkonstellationen, in denen die mit dem gestreckten Verfahren einhergehende zeitliche Verzögerung zur Durchsetzung der Rechtspflicht nicht in Kauf genommen werden kann.

Nach § 6 II Fall 1 VwVG muss der sofortige Vollzug zur Verhinderung einer rechtswidrigen Tat, die einen Straf- oder Bußgeldtatbestand verwirklicht, notwendig sein. Maßgeblich ist, dass die Verwirklichung des objektiven Tatbestandes unmittelbar und mit an Sicherheit grenzender Wahrscheinlichkeit bevorsteht. Ein schuldhaftes Handeln ist nicht erforderlich.

Nach § 6 II Fall 2 VwVG muss der sofortige Vollzug zur Abwendung einer 1359 drohenden Gefahr notwendig sein. „Unter Gefahr ist eine Sachlage zu verstehen, die bei ungehindertem Ablauf des Geschehens mit hinreichender Wahrscheinlichkeit zu einem Schaden für die Schutzgüter der öffentlichen Sicherheit oder

2361 Lemke, Verwaltungsvollstreckungsrecht des Bundes und der Länder, 1997, S. 223f.; anders Schweikert, die bereits die analoge Anwendbarkeit des § 6 II VwVG auf Fallkonstellationen mit ergangener Grundverfügung in Frage stellt: Schweikert, Der Rechtswidrigkeitszusammenhang, 2013, S. 193 f. Interessanterweise schweigt die Ausbildungsliteratur zur Frage, ob das abgekürzte Verfahren einen Rechtswidrigkeitszusammenhang voraussetzt oder nicht. Vertiefende Ausführungen sind daher auf rechtswissenschaftlicher Ebene von großem Interesse, sollten jedoch nicht Eingang in eine Fallbearbeitung finden. Vielmehr lässt sich sehr gut vertreten, dass eine analoge Anwendung des § 6 II VwVG auch eine analoge Anwendung all seiner Rechtmäßigkeitsvoraussetzungen (inklusive der Rechtmäßigkeit der Grundverfügung) nach sich zieht, sodass die Erforderlichkeit eines Rechtswidrigkeitszusammenhangs zu bejahen ist. Diese Herangehensweise bringt zudem den Vorteil, dass durch die nun folgende inzidente Prüfung der Grundverfügung keine Punkte vergeben werden. 
Ordnung führen würde.“2362 Dies ist jedenfalls dann nicht der Fall, wenn der Erlass einer Ordnungsverfügung gegen den der Behörde bekannten Ordnungspflichtigen unter Anordnung der sofortigen Vollziehung und gleichzeitiger Androhung der Ersatzvornahme zwar zu kurzfristigen Verzögerungen führte, diese aber die Wirksamkeit der erforderlichen Maßnahme weder aufheben noch wesentlich beeinträchtigen würde. ${ }^{2363}$ Die Vollzugsbehörde ist also dazu angehalten, das vom Gesetz vorgegebene Regel-Ausnahme-Verhältnis zwischen § 6 I und § 6 II VwVG ernst zu nehmen. Justiziabel wird dies durch das Dringlichkeitserfordernis, welches gerichtlich voll überprüfbar ist. Der Vollzugsbehörde kommt insofern kein Beurteilungsspielraum zu.

1360 Wie im materiellen Polizeirecht bedeutet Gefahr i.S.d. § 6 II VwVG nicht allein die objektiv vorliegende Gefahr bei ex post-Betrachtung (ausführlich zum Gefahrbegriff unter Rn. 1101ff.). Auch die sog. Anscheinsgefahr, also eine Gefahrenlage, die zwar nicht objektiv vorliegt, aber aus der ex-ante-Sicht eines Betrachters, der die „Sorgfalt, Klugheit und Besonnenheit eines typischen Beamten an den Tag legt“2364 gegeben ist, berechtigt die Behörde zum Einschreiten nach $\S 6$ II VwVG. ${ }^{2365}$ Gleiches gilt für den Gefahrenverdacht: Auch hier darf die Behörde Maßnahmen zur Gefahrenerforschung nach § 6 II VwVG vornehmen. ${ }^{2366}$ Die Frage, ob die Anscheinsgefahr oder der Gefahrenverdacht von dem Verpflichteten in zurechenbarer Weise gesetzt worden ist, spielt für die Frage der Rechtmäßigkeit der Vollzugsmaßnahme keine Rolle. Anderes gilt auf Kostenebene (hierzu sogleich unter Rn. 1382). Von Anscheinsgefahr und Gefahrenverdacht ist freilich die Scheingefahr zu unterscheiden (s. auch Rn. 1108). ${ }^{2367}$ Hierbei liegt weder objektiv eine Gefahrenlage vor, noch würde ein Betrachter mit den Fähigkeiten eines ty-

2362 Deusch/Burr, in: Bader/Ronellenfitsch, VwVG, 43. Ed., Stand: 1.4. 2019, § 6 Rn. 23.

2363 OVG Münster, Beschl.v. 9.4.2008 - 11 A 1386/05 = NVwZ-RR 2008, 437: Im vorliegenden Fall ließ die Behörde einen nicht akut einsturzgefährdeten Wetterschacht auf dem Grundstück der Betroffenen im Wege der Ersatzvornahme im sofortigen Vollzug sichern. Dass der Wetterschacht sicherungsbedürftig war, wenngleich keine akute Gefahr eines Einsturzes bestand, hatte die Behörde erkannt. Das Gericht gab der Klage der Betroffenen gegen den daraufhin ergangenen Kostenbescheid statt und urteilte, dass der sofortige Vollzug in diesem Fall nicht dringlich gewesen ist. Die Behörde hätte vielmehr Zeit gehabt, der Betroffenen durch sofort vollziehbaren Verwaltungsakt aufzugeben, den Schacht zu sichern und gleichzeitig die Ersatzvornahme anzudrohen. Die damit einhergehende zeitliche Verzögerung hätte die Wirksamkeit der zu vollziehenden Pflicht nicht beeinträchtigt, da der Schacht nicht akut einsturzgefährdet war.

2364 Kingreen/Poscher, Polizei- und Ordnungsrecht, 10. Aufl. 2018, § 8 Rn. 48.

2365 Sadler, VwVG VwZG, 9. Aufl. 2014, § 6 Rn. 315.

2366 Sadler, VwVG VwZG, 9. Aufl. 2014, § 6 Rn. 316.

2367 Kingreen/Poscher, Polizei- und Ordnungsrecht, 10. Aufl. 2018, § 8 Rn. 63; Sadler, VwVG VwZG, 9. Aufl. 2014, § 6 Rn. 322. 
pischen Beamten von einer solchen ausgehen. Eine dagegen gerichtete Maßnahme ist mangels Dringlichkeit rechtswidrig und kann ggf. zu Folgeansprüchen des Betroffenen gegen die Vollzugsbehörde führen.

\section{(3) Rechtmäßigkeit der hypothetischen Grundverfügung}

Ausweislich des Wortlauts von § 6 II VwVG muss die Vollzugsbehörde innerhalb ihrer gesetzlichen Befugnisse handeln. Dies tut sie nur dann, wenn die hypothetisch zu erlassene Grundverfügung rechtmäßig ist. Anders als im gestreckten Verfahren gibt es im sofortigen Vollzug also einen Rechtswidrigkeitszusammenhang: Ist die hypothetische Grundverfügung rechtswidrig, so ist es auch die entsprechende Vollzugsmaßnahme. Mangels vorausgehendem Grundverwaltungsakt gibt es auch keine Titelfunktion, die zum Entfall des Rechtswidrigkeitszusammenhangs führen könnte. Diese Rechtmäßigkeitsvoraussetzung des sofortigen Vollzugs dient in der Fallbearbeitung häufig als Einstiegstor in eine nicht selten umfangreiche Inzidentprüfung der hypothetischen Grundverfügung. Die Prüfung erfolgt im bekannten Dreischritt Ermächtigungsgrundlage - formelle Rechtmäßigkeit - materielle Rechtmäßigkeit. Dabei gilt es, den Überblick über den Aufbau zu behalten und dem Korrektor oder der Korrektorin zu zeigen, dass man die Ebenen auseinanderhalten kann.

\section{(4) Zwangsmittel}

Die Behörde muss das richtige Zwangsmittel gewählt haben. Während § 6 II VwVG diesbezüglich keine Einschränkungen vorsieht, kommen in der Praxis als Zwangsmittel nur die Ersatzvornahme und der unmittelbare Zwang in Betracht. ${ }^{2368}$ Dies liegt daran, dass der sofortige Vollzug auf die unmittelbare Herbeiführung des Erfolges gerichtet ist, das Zwangsgeld und dessen Beitreibung jedoch durch seine Beugewirkung auf ein Tätigwerden des Verpflichteten abzielt.

Unter Umständen müssen an dieser Stelle besondere Voraussetzungen des Zwangsmittels geprüft werden. Beispielsweise muss der Einsatz von Schusswaffen, Explosivmitteln und Wasserwerfern - auch wenn er im sofortigen Vollzug geschieht - angedroht werden, vgl. § 13 UZwG..$^{2369}$

2368 Deusch/Burr, in: Bader/Ronellenfitsch,VwVG, 43. Ed., Stand:1.4. 2019, § 6 Rn. 26; Erichsen/ Rauschenberg, JURA 1998, 31 (41); Sadler, VwVG VwZG, 9. Aufl. 2014, § 6 Rn. 301.

2369 Ausführlich zum Schusswaffengebrauch Graulich, in: Lisken/Denninger, Handbuch des Polizeirechts, 6. Aufl. 2018, E Rn. $916 \mathrm{ff.}$ 
1364 Examenswissen (Zulässigkeit des finalen Rettungsschusses): Die Frage nach der Zulässigkeit des finalen Rettungsschusses als Fall einer Anwendung unmittelbaren Zwangs ist umstritten. ${ }^{2370}$ Der finale Rettungsschuss ist ein Schuss, der mit an Sicherheit grenzender Wahrscheinlichkeit tödlich wirken wird.

Uneinigkeit besteht bereits hinsichtlich seiner verfassungsrechtlichen Zulässigkeit. Ankerpunkte der verfassungsrechtlichen Diskussion sind dabei die Menschenwürde aus Art. 1 I GG, das Verbot der Todesstrafe nach Art. 102 GG sowie die Wesensgehaltgarantie gem. § 19 II GG in Bezug auf das Recht aus Leben aus Art. 2 II 1 GG. Diskussionswürdig ist auch die Zulässigkeit des finalen Rettungsschuss mit Blick auf Art. 2 EMRK. Geht man - wie die wohl herrschende Meinung - von der verfassungsrechtlichen Zulässigkeit des finalen Rettungsschusses aus, so stellt sich die Folgefrage über die Notwendigkeit einer expliziten gesetzlichen Grundlage. Mittlerweise ist der finale Rettungsschuss in fast allen Bundesländern normiert. Eine entsprechende Ermächtigungsgrundlage fehlt jedoch in Berlin, Mecklenburg-Vorpommern und Schleswig-Holstein sowie auf Bundesebene. Hier dürfen Schusswaffen nur eingesetzt werden, um Personen angriffs- oder fluchtunfähig zu machen. Teilweise wird vertreten, dass die Tötung eines Angreifers die schwerwiegendste Form der „Angriffsunfähigkeit“ darstelle und der finale Rettungsschuss deshalb auch ohne explizite gesetzliche Regelung zulässig sei. ${ }^{2371}$ Dem wird jedoch entgegengehalten, dass die in Rede stehenden Gesetze Art. 2 II 1 GG nicht als durch eben jenes Gesetz eingeschränktes Grundrecht nennen und somit ein Verstoß gegen das Zitiergebot nach Art. 19 I 2 GG vorläge. Zudem setze die „Angriffs- und Fluchtunfähigkeit“ eine lebende Person voraus. ${ }^{2372}$ Auch würde die Subsumtion des finalen Rettungsschuss unter die Ermächtigungsgrundlagen zur „Angriffs- und Fluchtunfähigkeit“ dem verfassungsrechtlichen Grundsatz des Vorbehalts des Gesetzes nicht Genüge tun. ${ }^{2373}$ Nach letztgenannter Ansicht ist der finale Rettungsschuss in Ländern ohne explizite Regelung sowie auf Bundesebene unzulässig. Dies lässt freilich die Möglichkeit des Entfalls der strafrechtlichen Verantwortlichkeit des Beamten nach §§ 32, 34 StGB unberührt. ${ }^{2374}$

\section{(5) Ermessen, insbesondere Verhältnismäßigkeit}

1365 Auch die Zwangsmittelanwendung im Rahmen des sofortigen Vollzuges darf keine Ermessensfehler enthalten. Insbesondere muss sie verhältnismäßig sein. Steht beispielsweise ein Auto verbotswidrig im Halteverbot, liegt an der Frontscheibe aber ein gut sichtbarer Hinweis mit Namen und Handynummer des

2370 Ausführlich Graulich, in: Lisken/Denninger, Handbuch des Polizeirechts, 6. Aufl. 2018, E Rn. $950 \mathrm{ff}$.

2371 Zum Meinungsstand und für weitere Nachweise wird auf Thiel, in: Möstl/Kugelmann, Polizei- und Ordnungsrecht NRW, 11. Ed., Stand: 1.11.2018, § 63 Rn. 13 verwiesen.

2372 Schenke, Polizei- und Ordnungsrecht, 10. Aufl. 2018, Rn. 561; ähnlich Graulich, in: Lisken/ Denninger, Handbuch des Polizeirechts, 6. Aufl. 2018, E Rn. 971; Ruthig, in: Schenke/Graulich/ Ruthig, Sicherheitsrecht des Bundes, UZwG, 2. Aufl. 2019, § 12 Rn. 6.

2373 Schenke, Polizei- und Ordnungsrecht, 10. Aufl. 2018, Rn. 561.

2374 Dies gilt jedenfalls, soweit man dem Hoheitsträger ein Notwehrrecht zubilligt; detailliert zum Streitstand Erb, in: MüKO-StGB, 3. Aufl. 2017, § 32 Rn. $186 \mathrm{ff}$.

\section{Mariamo Katharina Ilal}


Fahrers, so muss die Vollzugsbehörde jedenfalls versuchen, den Fahrer zu kontaktieren, bevor sie das Auto abschleppen lässt. ${ }^{2375}$

\section{e) Sekundärebene, insbesondere Kosten}

Regelmäßig ist nicht die Vollstreckungsmaßnahme selbst, sondern der daraufhin 1366 ergehende Kostenbescheid Ausgangspunkt der Fallbearbeitung. Die Frage, wer die Kosten für die erfolgte Vollstreckungsmaßnahme zu tragen hat, ist auf der sog. Sekundärebene ${ }^{2376}$ verankert. Für die Fallbearbeitung ist entscheidend, dass die Ebenen Grundverfügung - Vollstreckungsmaßnahme - Kosten innerhalb des Aufbaus und der Prüfung strikt auseinandergehalten werden. Darin besteht meist schon die erste Hürde einer vollstreckungsrechtlich eingekleideten Klausur.

Neben den Kostenansprüchen der Behörde gegen den Pflichtigen umfasst 1367 die Sekundärebene auch die ggf. bestehenden Entschädigungsansprüche des Pflichtigen oder Dritter gegen die Vollzugsbehörde. Diese stellen die „Kehrseite der Kostenansprüche“ ${ }^{2377}$ dar und werden ausführlich in $\S 5$ Rn. 153 ff. dargestellt.

Kostenansprüche der Vollzugsbehörde sind das „Surrogat für die dem Ver- 1368 antwortlichen eigentlich obliegende Pflicht zur Gefahrenbeseitigung auf eigene Rechnung“2378. Die wichtigsten Kosten sind die bei der Durchführung der Vollstreckung entstandenen Kosten (sog. Auslagen, vgl. §344 AO). Dies sind insbesondere Aufwendungen, die die Behörde gegenüber Dritten getätigt hat. ${ }^{2379}$ Die Kosten werden durch schriftlichen Verwaltungsakt in Form eines Kostenbescheids geltend gemacht. Dieser kann dann wiederum im Wege der Beitreibung nach $\S \S 1-5 b$ VwVG vollstreckt werden.

Gegen den Kostenbescheid sind Widerspruch und Anfechtungsklage statthafte Rechtsbehelfe.

Examenswissen (Aufschiebende Wirkung der Rechtsbehelfe gegen den Kostenbescheid?): Mitunter wird diskutiert, ob Rechtsbehelfe gegen den Kostenbescheid nach erfolgter Verwaltungsvollstreckung aufschiebende Wirkung haben. Dem Wortlaut nach unterfallen sie § 80 II 1 Nr. 1 VwGO (Anforderungen von öffentlichen Abgaben und Kosten), sodass von einem Entfall der aufschiebenden Wirkung qua Gesetz auszugehen wäre. Sinn und Zweck des § 80 II 1 Nr. 1 VwGO ist

2375 Beispiel aus Erichsen/Rauschenberg, JURA 1998, 31 (41); anderes kann freilich wiederum gelten, wenn das Auto die Feuerwehrzufahrt zu einem brennenden Haus blockiert. Es muss wie immer eine Einzelfallbetrachtung vorgenommen werden.

2376 Je nachdem, wie die vorausgehenden Ebenen gezählt werden, findet sich auch der Begriff der „Tertiärebene“, vgl. Voßkuhle/Wischmeyer, JuS 2016, 698 (700).

2377 Poscher/Rusteberg, JuS 2012, 26 (32).

2378 Werner, JA 2000, 902 (908).

2379 Poscher/Rusteberg, JuS 2012, 26 (30).

Mariamo Katharina Ilal 
die Sicherung einer ordnungsgemäßen Haushaltsführung und eines stetigen Finanzmittelflusses an die Verwaltung. Die ihr zufließenden Mittel sollen für die Verwaltung kalkulierbar sein. Wann die Verwaltung im Wege des Verwaltungszwangs vorgehen muss, ist jedoch nicht vorhersehbar. Das Gleiche gilt für die dadurch entstehenden Kostenansprüche, weshalb sie für die Verwaltung sowieso nicht kalkulierbar sind und damit auch nicht die ratio der Haushaltssicherung treffen. Deshalb ist $\S 80$ II 1 Nr. 1 VwGO nach herrschender Meinung dahingehend teleologisch zu reduzieren, dass Kostenansprüche infolge von Vollstreckungsmaßnahmen nicht unter den Tatbestand fallen. ${ }^{2380}$ Auch unter $\S 80$ II S. 2 VwGO i.V.m. den landesrechtlichen Vorschriften, die die aufschiebende Wirkung für Maßnahmen in der Verwaltungsvollstreckung entfallen lassen, können die kostenrechtlichen Verfügungen nicht subsumiert werden. Denn es handelt sich hier um Maßnahmen die nach und nicht in der Verwaltungsvollstreckung ergehen. Somit haben Rechtsbehelfe gegen die Kostenbescheide regelmäßig aufschiebende Wirkung. Etwas anderes gilt freilich, wenn die Behörde die sofortige Vollziehbarkeit nach § 80 II 1 Nr. 4 VwGO anordnet.

\section{aa) Ermächtigungsgrundlage}

1371 Für die Erhebung von Kosten für durchgeführte Vollstreckungsmaßnahmen bedarf es einer gesetzlichen Grundlage. In der Klausur wird hier regelmäßig auf § 19 I VwVG abzustellen sein. ${ }^{2381}$ Danach können für Amtshandlungen nach dem VwVG (mithin Vollstreckungsmaßnahmen) Kosten erhoben werden. Das Gesetz enthält hier auch die Befugnis zur Geltendmachung der Kosten im Wege des Verwaltungsakts (vgl. § 19 I VwVG: werden erhoben), sodass sich die Vollzugsbehörde nicht auf den Klageweg verweisen lassen muss. ${ }^{2382}$

1372 Auch innerhalb der Ermächtigungsgrundlage des Kostenbescheids kann die oben besprochene Abgrenzung von unmittelbarer Ausführung und sofortigem Vollzug relevant werden (s. Rn. 1350 ff.). Hier setzt sich die Parallelität beider Institute fort. So ist für den Kostenbescheid nach sofortigem Vollzug auf § 19 I VwVG abzustellen, während die landesrechtlichen Polizeigesetze eigene Ermächtigungsgrundlagen für die Kostenerhebung nach der unmittelbaren Ausführung vorsehen. ${ }^{2383}$

1373 Examenswissen (Parallelität zu den polizeirechtlichen Kostenerhebungsnormen): Zu beachten ist in diesem Zusammenhang, dass vor allem auch die landesrechtlichen Sicherheits- und Ordnungsgesetze die Verwaltung zur Erhebung von Kosten für verschiedene Maßnahmen (bei-

2380 Gersdorf, in: Posser/Wolff VwGO, 49. Ed., Stand:1.7.2018, § 80 Rn. 54.1; Schoch, in: Schoch/ Schneider/Bier, VwGO, 36. EL Februar 2019, § 80 Rn. 144 m.w. N.

2381 Freilich sind auch hier spezialgesetzliche Ermächtigungsgrundlagen wie z.B. §§ 66, 67 AufenthG zu beachten.

2382 Näheres bei Muckel, JA 2012, 355 (360).

2383 Baden-Württemberg: § 8 II PolG; Bayern: Art. 9 II PAG; Berlin: § 15 II ASOG; Hamburg: § 7 III SOG; Hessen: § 8 II HSOG; Rheinland-Pfalz: § 6 II POG; Sachsen: § 6 II PolG; Sachsen-Anhalt: § 9 II SOG; Thüringen: §9 PAG II. 
spielsweise Kosten der unmittelbaren Ausführung; Sicherstellungs- und Verwahrungskosten) befugen. ${ }^{2384}$ Diese Normen gehören freilich nicht zum Verwaltungsvollstreckungsrecht, jedoch ist es aufgrund ihres parallel gelagerten Prüfungsprogramms sinnvoll, sie sich im Zusammenhang mit den vollstreckungsrechtlichen Kostengesetzen zu erschließen.

\section{bb) Formelle Rechtmäßigkeit}

In formeller Hinsicht gelten die üblichen Anforderungen. Überwiegend wird die 1374 Kostenerhebung als Annexkompetenz des Vollzuges gesehen, sodass danach die Vollzugsbehörde auch die für den Kostenbescheid zuständige Behörde ist, vgl. § 7 VwVG. ${ }^{2385}$ Zudem ist der Adressat des Verwaltungsakts nach § 28 I VwVfG anzuhören. Da die Kostenerhebung keine Maßnahme in der Verwaltungsvollstreckung ist, ist die Anhörung auch nicht nach $§ 28$ II Nr. 5 VwVfG entbehrlich.

\section{cc) Materielle Rechtmäßigkeit}

In materieller Hinsicht muss der Kostenerhebung eine rechtmäßige Vollstre1375 ckungsmaßnahme zugrunde liegen (Rn. 1376) und an den richtigen Kostenschuldner (Rn. 1379) in richtiger Höhe (Rn. 1380 f.) gerichtet sein. Darüber hinaus gilt auch hier der Verhältnismäßigkeitsgrundsatz (Rn. 1382ff.).

\section{(1) Rechtmäßige Vollstreckungsmaßnahme}

Kosten können nur für rechtmäßige Vollstreckungsmaßnahmen erhoben wer- 1376 den (vgl. Amtshandlungen nach diesem Gesetz in § 19 I VwVG). Für rechtswidriges Verhalten muss die Behörde die Kosten selbst tragen. ${ }^{2386}$ Was als „rechtsstaatliche Selbstverständlichkeit““2387 aufgefasst werden kann, bedarf inhaltlich in der Klausur einer eingehenden Erläuterung und ist regelmäßig Einfallstor in die Prüfung der Vollstreckungsmaßnahme. Hier kommt es also darauf an, die Vollstreckungsmaßnahme anhand des § 6 I oder II VwVG inzident zu prüfen. Für die inhaltlichen Ausführungen wird auf die Rn. 1317 ff. und Rn. 1345 ff. verwiesen.

Examenswissen (Keine Kostenerhebung nach rechtswidriger Vollstreckung): Kommt ein Kostenanspruch mangels rechtmäßiger Vollstreckungsmaßnahme aus § 19 I VwVG nicht in Betracht, so scheiden auch Ansprüche aus öffentlich-rechtlicher Geschäftsführung ohne Auftrag (Näheres dazu in $\S 11$ Rn. 50 ff.) sowie der öffentlich-rechtliche Erstattungsanspruch (Näheres dazu in

2384 Beispielsweise $\S \$ 15$ II, 41 III ASOG Berlin.

2385 Muckel, JA 2012, 355 (360); Sadler, VwVG VwZG, 9. Aufl. 2014, § 7 Rn. 1.

2386 Poscher/Rusteberg, JuS 2012, 26 (31); Sadler, VwVG VwZG, 9. Aufl. 2014, § 19 Rn. 8.

2387 Muckel, JA 2012, 355 (360). 
$\S 5$ Rn. 189ff.) aus. Die vollstreckungsrechtliche Kostenerhebungsnorm ist insofern abschließend. ${ }^{2388}$

1378 Examenswissen (Ist die Rechtmäßigkeit der Grundverfügung Rechtmäßigkeitsvoraussetzung für den Kostenbescheid?): Die Frage nach dem Rechtswidrigkeitszusammenhang, die bereits auf Ebene der Überprüfung der Rechtmäßigkeit der Vollstreckungsmaßnahme behandelt wurde (s. Rn. 1328), findet sich auch auf Kostenebene wieder. ${ }^{2389}$

Es sei daran erinnert, dass die Rechtmäßigkeit der Grundverfügung für die Rechtmäßigkeit von Vollstreckungsmaßnahmen im gestreckten Verfahren keine Rolle spielt (zum insofern fehlenden Rechtswidrigkeitszusammenhang s. oben Rn. 1327). Auf Kostenebene besteht ebenfalls jedenfalls dann kein Rechtswidrigkeitszusammenhang, wenn die Kostenerhebung auf dem Vollzug eines bestandskräftigen Verwaltungsakts basiert. Für den Fall des Vollzugs eines sofort vollziehbaren Verwaltungsakts wird vereinzelt vertreten, dass in diesen Fällen der Kostenbescheid von der Rechtmäßigkeit des Verwaltungsakts abhängt. ${ }^{2390}$ Dem tritt jedoch die herrschende Meinung mit Bezug auf die Titelfunktion des Verwaltungsakts entgegen. ${ }^{2391}$ In diesen Fällen sei gesondert gegen die Grundverfügung im Wege der Anfechtungsklage vorzugehen. Dies sei auch immer noch möglich, denn weder der Vollzug noch der Kostenbescheid führen zur Erledigung des Grundverwaltungsakts. ${ }^{2392}$ Ist diese Anfechtungsklage begründet, so wird das Gericht nach § 113 I 2 VwGO (bei einem entsprechend vom Kläger zu stellenden Antrag) auch den Kostenbescheid aufheben. ${ }^{2393}$ Geht der Kläger aber isoliert gegen den Kostenbescheid vor, so kann er Einwendungen gegen die Grundverfügung nicht geltend machen.

Anderes gilt freilich für den sofortigen Vollzug. Hier ist die Rechtmäßigkeit der hypothetischen Grundverfügung ja aber auch bereits Rechtmäßigkeitsvoraussetzung der Vollstreckungsmaßnahme, welche wiederum Rechtmäßigkeitsvoraussetzung des Kostenbescheids ist.

\section{(2) Richtiger Kostenschuldner}

1379 Richtiger Kostenschuldner ist der Vollstreckungsschuldner. Bei mehreren in Betracht kommenden Schuldnern hat die Behörde nach pflichtgemäßem Ermessen auszuwählen.

2388 OVG Münster, Beschl. v. 9.4.2008 - 11 A 1386/05 = NVwZ-RR 2008, 437; Kingreen/Poscher, Polizei- und Ordnungsrecht, 10. Aufl. 2018, § 25 Rn. 10.

2389 Details bei Poscher/Rusteberg, JuS 2012, 26 (31) sowie Voßkuhle/Wischmeyer, JuS 2016, 689 (700).

2390 Enders, NVwZ 2009, 958 (959).

2391 Lemke, Verwaltungsvollstreckungsrecht des Bundes und der Länder, 1997, S. 446; Poscher/ Rusteberg, JuS 2012, 26 (31); BVerwG, Urt. v. 25.9.2008 - 7 C 5/08 = NVwZ 2009, 122.

2392 BVerwG, Urt. v. 25.9.2008 - 7 C 5/08 = NVwZ 2009, 122.

2393 Poscher/Rusteberg, JuS 2012, 26 (32); Voßkuhle/Wischmeyer, JuS 2016, 689 (700).

\section{Mariamo Katharina Ilal}




\section{(3) Richtige Höhe}

Die erhobenen Kosten dürfen den gesetzlich vorgegeben Rahmen nicht über- $\mathbf{1 3 8 0}$ steigen. Bei der Kostenerhebung nach erfolgter Ersatzvornahme ist es unschädlich, wenn die erhobenen Kosten die in der Androhung aufgeführten Kosten übersteigen, s. § 13 IV VwVG (sog. Recht zur Nachforderung).

Examenswissen: In diesen Fällen ist der Pflichtige jedoch über die Kostenüberschreitung, sofern sie wesentlich ist, zu unterrichten. Eine unterlassene Unterrichtung führt zwar nicht zur Rechtswidrigkeit der Kostenerhebung, kann jedoch ggf. Amtshaftungsansprüche auslösen. ${ }^{2394}$

\section{(4) Verhältnismäßigkeit}

Die Kostenforderung muss verhältnismäßig sein.

Von besonderer Klausurrelevanz ist in diesem Punkt die Kostenerhebung gegenüber einem Anscheins- oder Verdachtsstörer. Wie bereits unter Rn. 1360 besprochen, können Vollstreckungsmaßnahmen auch dann rechtmäßig sein, wenn zwar objektiv keine Gefahrenlage vorliegt, aber ein Fall der Anscheinsgefahr oder des Gefahrverdachts gegeben ist. Für die Rechtmäßigkeit der Vollstreckungsmaßname spielt es keine Rolle, ob der Anscheins- oder Verdachtsstörer den Rechtsschein einer Gefahr zurechenbar verursacht hat. Entscheidend ist im Sinne einer effektiven Gefahrenabwehr allein die ex-ante-Betrachtung. Anders ist dies aber auf der nachgelagerten Kostenebene. Es geht hier nicht mehr um die Abwendung einer (Anscheins-)Gefahr, sondern um die Verteilung der Kostenlast für das Tätigwerden der Vollzugsbehörde. Das Argument der effektiven Gefahrenabwehr, das eine ex-ante-Betrachtung auf Vollzugsebene stützt, überzeugt in dieser Situation, in der die Gefahr bereits abgewehrt ist, nicht. Auf Kostenebene gilt daher eine ex-post-Betrachtung und zwar dergestalt, dass sie in Fällen der Anscheinsgefahr oder des Gefahrverdachts die Kostenlast nach dem Zurechnungsprinzip verteilt. ${ }^{2395}$

Hat also der Kostenschuldner, den Anschein der Gefahr bzw. den Gefahrverdacht in zurechenbarer Weise verursacht, so muss er auch für die Kosten aufkommen.

2394 BVerwG, Urt. v. 13.4.1984 - 4 C 31/81 = NJW 1984, 2591; Troidl, in: Engelhardt/App/ Schlatmann, VwVG VwZG, 11. Aufl. 2017, § 13 Rn. 6.

2395 OVG Hamburg, Urt. v. 24.9.1985, Az.: Bf VI 3/85 = NJW 1986, 2005; VGH Mannheim, Urt. v. 17.3. 2011 - 1 S 2513/10; Ob es darüber hinaus auch auf ein Vertretenmüssen ankommt, ist streitig: bejahend Stammberger, in: Engelhardt/App/Schlatmann VwVG VwZG, 11. Aufl. 2017, § 19 Rn. 5, verneinend VG Berlin, Urt. v. 28.11.1990 -1 A 154/89. 
Beispiel nach VG Berlin, Urt. v. 28.11.1990 - 1 A 154/89: Nachdem der Mieter auf mehrmaliges Klingeln der Polizei nicht reagierte, sich aber aufgrund zutreffender Angaben eines Nachbarn noch kurze Zeit vorher in der Wohnung die Lichtverhältnisse geändert hatten, vermutet die Polizei einen Unglücksfall und tritt die Wohnungstür ein. Im Nachhinein stellt sich heraus, dass der sich tatsächlich im Urlaub befindliche Mieter eine Zeitschaltuhr installiert hatte. Dies rechnete ihm das Gericht als zurechenbare Setzung des Gefahrverdachts an.

Fehlt ein solcher Zurechnungszusammenhang, so ist die Kostenforderung unverhältnismäßig.

Beispiel nach OVG Berlin, Beschl. v. 28.11.2001 - 1 N 45/00: Nachdem ein Nachbar der Polizei mitgeteilt hatte, dass der Mieter einer anliegenden Wohnung konkrete Suizidgedanken geäußert hatte und dieser auf ein Klingeln der Polizei nicht reagierte, tritt diese die Wohnungstür ein. Nachträglich kann nicht geklärt werden, ob der Mieter, der sich zum Zeitpunkt des Eintretens nicht in der Wohnung befunden hatte, dem Nachbarn gegenüber tatsächlich Suizidgedanken geäußert hatte. Die Unaufklärbarkeit ging zulasten der Polizei, sodass das Gericht zugunsten des Mieters annahm, er habe den Gefahrverdacht nicht zurechenbar verursacht.

Beispiel nach OVG Hamburg, NJW 1986, 2005: Nachdem angeblich ein herumstreunender junger Löwe von einem Anwohner gesichtet worden war, kommt es zu einem Polizeieinsatz. Später stellt sich heraus, dass der Löwe tatsächlich an der Leine seines Besitzers für nur wenige Minuten ausgeführt worden und später zurück in dessen Wohnung verbracht worden war. Das Gericht verneinte auch hier einen Zurechnungszusammenhang.

1383 Examenswissen (Abschleppfälle III): Auch in Abschleppfällen (s. bereits Rn. 1332 und Rn. 1356) kann die Verhältnismäßigkeit der Kostenforderung in Frage stehen. Hier geht es vor allem um Fälle, in denen ein Fahrzeug aus einer nachträglich eingerichteten Halteverbotszone abgeschleppt wird und die Kosten später vom Halter verlangt werden. ${ }^{2396}$ Auf Vollstreckungsebene ist zunächst wichtig zu erkennen, dass ein nachträglich per Verkehrsschild eingerichtetes Halteverbot eine Allgemeinverfügung ist, die - sofern das Verkehrsschild ordnungsgemäß aufgestellt ist - auch abwesenden Haltern gegenüber wirksam wird und sofort vollziehbar ist. Liegt ein Dringlichkeitstatbestand vor, so kann die Behörde auch in den sofortigen Vollzug nach § 6 II VwVG analog wechseln. Das Abschleppen des Fahrzeugs ist insbesondere dann verhältnismäßig, wenn die Behörde vorher versucht hat, den Halter zu kontaktieren, dies aber fruchtlos geblieben ist (z. B. weil der Halter im Urlaub war). Eine solche Abschleppmaßnahme kann also auch dann rechtmäßig sein, wenn zum Zeitpunkt des Parkens noch kein Halteverbot bestand, ein solches aber später eingerichtet wurde. Fraglich ist dann aber, ob die Kosten für die Abschleppmaßnahme vom Halter verlangt werden können. Das BVerwG geht in diesen Fällen davon aus, dass ein Verkehrsteilnehmer zwar „stets mit Situationen rechnen [muss], die eine kurzfristige Änderung der bestehenden Verkehrsregelungen erforderlich machen“2397 und damit nicht uneingeschränkt darauf vertrauen darf, dass ein ursprünglich ordnungsgemäß abgestelltes Fahrzeug dies auch bleibt. Ihn trifft daher eine Obliegenheit, in regelmäßigen Abständen nach dem abgestellten Fahrzeug zu sehen (oder ggf. einen Dritten damit zu beauftragen). Daraus leitet das Gericht eine

2396 So die Ausgangssituation in BVerwG, Urt. 24.5.2018 - 3 C 25/16 = NJW 2018, 2910.

2397 BVerwG, Urt. v. 24.05.2018, Az.: 3 C 25/16, Rn. 22 = NJW 2018, 2910 (2911).

\section{Mariamo Katharina Ilal}


„Mindestvorlaufzeit von drei vollen Tagen“2398 zugunsten des Halters ab, denn „nur ein solcher Vorlauf deckt auch eine typische Wochenendabwesenheit ab“2339. Daraus ergibt sich, dass „eine Kostenpflicht [...] erst für eine Abschleppmaßnahme am vierten Tag nach Aufstellung der Halteverbotsschilder den Anforderungen des Verhältnismäßigkeitsgrundsatzes“2400 entspricht.

\section{(5) Verjährung}

$\mathrm{Zu}$ guter Letzt kann in der Klausur auch einmal die Verjährung der Kostenforde- $\mathbf{1 3 8 4}$ rung relevant werden. Da § 19 I VwVG auch auf § 346 II AO verweist, gilt für die Kostenforderung die einjährige Festsetzungsfrist nach § 346 II 1 AO. Sie beginnt mit Ablauf des Kalenderjahrs, in dem die Kosten entstanden sind, § 346 II 2 AO. Anhaltspunkte für den Ablauf der Frist müssen sich jedoch aus dem Sachverhalt ergeben; ebenso kann wohl erwartet werden, dass - sofern zur Prüfung keine AO zugelassen ist - die relevante Norm im Sachverhalt abgedruckt wird. Regelmäßig wird dieser Punkt jedoch derart problemarm sein, dass er auch übergangen werden kann.

\section{dd) Überblick über die Entschädigungsansprüche}

Ebenfalls Gegenstand der Sekundärebene sind die ggf. bestehenden Ansprüche 1385 des durch den Verwaltungsvollzug Betroffenen gegen die Vollzugsbehörde (dazu bereits kurz in Rn. 1367; ausführlich zu den öffentlich-rechtlichen Ersatzleistungen $\S 5 \mathrm{Rn}$. $153 \mathrm{ff}$. sowie $\S 11){ }^{2401}$ Als Entschädigungsansprüche kommen für rechtswidriges Vollstreckungshandeln der allgemeine Amtshaftungsanspruch (§ 11 Rn. 2ff.) bzw. der allgemeine Aufopferungsanspruch in Betracht (§ 11 Rn. $61 \mathrm{ff}$.). ${ }^{2402}$ Ein Anspruch auf Entschädigung des Sonderopfers besteht auch bei einer rechtmäßigen, aber übermäßigen Inanspruchnahme (es sei an das Beispiel des Nichtstörers gedacht; Näheres auch in $\S 11$ Rn. 61 ff.). ${ }^{2403}$ Diese Ansprüche gelten in analoger Anwendung auch für den Anscheins- und Verdachtsstörer, sofern er den Anschein bzw. den Gefahrverdacht nicht zurechenbar gesetzt hat.

2398 BVerwG, Urt. v. 24.5.2018, Az.: 3 C 25/16, Rn. 24 = NJW 2018, 2910 (2911).

2399 BVerwG, Urt. v. 24.5.2018, Az.: 3 C 25/16, Rn. 28 = NJW 2018, 2910 (2912).

2400 BVerwG, Urt. v. 24.5.2018, Az.: 3 C 25/16, Rn. 31 = NJW 2018, 2910 (2912).

2401 Übersichtliche Darstellung bei Poscher/Rusteberg, JuS 2012, 26 (32).

2402 Für Entschädigungen nach rechtswidrigem Polizeihandeln normieren die landesrechtlichen Gesetze diesen Anspruch teilweise explizit, beispielsweise in §59 II ASOG Berlin.

2403 Auch insofern ist der Aufopferungsanspruch häufig spezialgesetzlich kodifiziert, beispielsweise in §59 I ASOG Berlin. 


\section{f) Literaturhinweise}

1386 Kingreen/Poscher, Polizei- und Ordnungsrecht, 10. Aufl. 2018, § 24; Lemke, Verwaltungsvollstreckungsrecht des Bundes und der Länder, 1997; Maurer/Waldhoff, Allgemeines Verwaltungsrecht, 19. Aufl. 2017, § 20; Muckel, Verwaltungsvollstreckung in der Klausur, JA 2012, $272 \mathrm{ff}$. und 355 ff.; Poscher/Rusteberg, Die Klausur im Polizeirecht, JuS 2012, 26; Voßkuhle/Wischmeyer, Grundwissen - Öffentliches Recht: Verwaltungsvollstreckung, JuS 2016, 698

\section{Der Vollzugsfolgenbeseitigungsanspruch (Jana Himstedt)}

1387 Eine besondere Klausurkonstellation stellt es dar, wenn der Kläger nicht nur die Aufhebung eines Verwaltungsakts begehrt, sondern zugleich auch die Beseitigung der durch dessen Vollzug eingetretenen Folgen. Materiell-rechtlich lässt sich das letztere Klageziel auf den Folgenbeseitigungsanspruch stützen (sog. Vollzugsfolgenbeseitigungsanspruch, s. §5 Rn. 174). Dessen prozessuale Durchsetzung erfordert nicht die Erhebung einer gesonderten Leistungsklage, sondern kann mithilfe eines Annexantrags nach § 113 I 2, 3 VwG0 direkt im Zuge der Anfechtungsklage erfolgen. § 113 I 2, 3 VwGO gewährt insofern eine spezielle objektive Klagehäufung (§44 VwGO, s. zur objektiven Klagehäufung näher $\S 1$ Rn. $231 \mathrm{ff}.)^{2404}$, die eine vereinfachte Geltendmachung der Folgenbeseitigung gemeinsam mit dem Primärrechtsschutz (Anfechtung) ermöglichen soll.

Examenswissen: Die Statthaftigkeit eines solchen Antrags erfordert, dass die in § 113 I 2, 3 VwGO genannten Kriterien vorliegen, insbesondere also die Möglichkeit der Folgenbeseitigung und die Spruchreife der Sache. Einer Wiederherstellung des status quo ante dürfen mithin keine unüberwindbaren rechtlichen oder tatsächlichen Hindernisse entgegenstehen (Unmöglichkeit); auch darf ihr „Ob“ oder „Wie“ nicht im behördlichen Ermessen stehen und keine weitere Sachverhaltsaufklärung notwendig sein (fehlende Spruchreife)..$^{2405}$

Konsequenz für die Begründetheitsprüfung in solchen Konstellationen ist, dass diese einem zweistufigen Aufbau folgen muss: So wird sie zunächst hinsichtlich des Aufhebungsantrags (gerichtlicher Prüfungsmaßstab: § 113 I 1 VwGO) und sodann hinsichtlich des Annexantrags (Prüfungsmaßstab: § 113 I 2, 3 VwGO) vorgenommen. Für den Erfolg des Annexantrags müssen die materiell-rechtlichen Voraussetzungen des Folgenbeseitigungsanspruchs gegeben sein (s. §5 Rn. 176ff.), sofern keine vorrangige spezialgesetzliche Anspruchsgrundlage

2404 Riese in: Schoch/Schneider/Bier, VwGO, 36. EL Februar 2019 § 113 Rn. 81.

2405 Riese in: Schoch/Schneider/Bier, VwGO, 36. EL Februar 2019, § 113 Rn. 86, 89.

Mariamo Katharina Ilal/Jana Himstedt 
existiert. Die Vorschrift des $\S 113$ I 2, 3 VwGO selbst ist hingegen rein prozessrechtlicher Natur und stellt keine materiell-rechtliche Grundlage für eine Rückgängigmachung der Vollzugsfolgen eines Verwaltungsakts dar. ${ }^{2406}$

Die Prüfung der Begründetheit der Anfechtungsklage kann somit nach folgendem Schema erfolgen:

I. Begründetheit des Aufhebungsantrags (§ 113 I 1 VwGO)

II. Begründetheit des Annexantrags auf Vollzugsfolgenbeseitigung (§ 113 I 2, 3 VwGO):

$\rightarrow$ Prüfung des allgemeinen Folgenbeseitigungsanspruchs nach dem unter

$\S 5$ Rn. 187 dargestellten Schema, sofern keine vorrangige, spezialgesetzliche Anspruchsgrundlage besteht.

\section{Die Begründetheitsprüfung bei der Anfechtung von Nebenbestimmungen (Christian Kaerkes)}

Nach der herrschenden Meinung (s. ausführlich zur statthaften Klageart gegen $\mathbf{1 3 8 8}$ Nebenbestimmungen die Rn. 249ff.) ist gegen belastende Nebenbestimmungen die Anfechtungsklage statthaft. Die Klage ist dann begründet, wenn die Nebenbestimmung rechtswidrig ist und den Kläger in seinen Rechten verletzt, vgl. § 113 I 1 VwGO. Der Bürger möchte aber nur die Nebenbestimmung beseitigen, während der begünstigende Hauptverwaltungsakt (meist eine Genehmigung) bestehen bleiben soll. Dieses Ziel kann nur erreicht werden, wenn es denn möglich ist, die Nebenbestimmung von dem Hauptverwaltungsakt zu trennen („Teilbarkeit“).

Nach der Ansicht der Rechtsprechung ist für die Begründetheit der Anfechtungsklage gegen eine Nebenbestimmung deshalb zusätzlich erforderlich, dass der Hauptverwaltungsakt „sinnvoller- und rechtmäßiger Weise bestehen bleiben kann.“2407 Diese ungeschriebenen Voraussetzungen können auf die Bindung des Gerichtes an das Gesetz zurückgeführt werden, vgl. Art. 20 III GG.

Nach der materiellen Rechtmäßigkeit der Nebenbestimmung ist daher zusätzlich zu prüfen, ob der Hauptverwaltungsakt ohne die Nebenbestimmung „sinnvoll und rechtmäßig“، ist. Die Begründetheit der Anfechtungsklage setzt demnach voraus:

2406 Ahrens, Staatshaftungsrecht, 3. Aufl. 2018, Rn. 302; Detterbeck, NVwZ 2019, 97 (98).

2407 BVerwG, Urt. v. 22.11.2000, Az.: 11 C 2.00 = BVerwGE 112, 221 (224). 
- Rechtswidrigkeit der Nebenbestimmung,

- Verletzung des Klägers in dessen Rechten und

- Sinnvoller und rechtmäßiger Rest-Verwaltungsakt

1390 Für die Klausur bietet sich deshalb etwa der folgende Obersatz an: „Die Klage ist begründet, soweit die Nebenbestimmung rechtswidrig ist, der Betroffene dadurch in seinen Rechten verletzt wird und der Hauptverwaltungsakt noch rechtmäßig und sinnvollerweise bestehen bleiben kann, vgl. § 113 I 1 VwGO.“

\section{Rechtswidrigkeit der Nebenbestimmung}

1391 Die Prüfung der Rechtswidrigkeit einer Nebenbestimmung orientiert sich an dem allgemeinen Schema, das schon von der Prüfung eines normalen Verwaltungsakts bekannt ist (s. Rn. $507 \mathrm{ff}$.; $553 \mathrm{ff}$.):

- Ermächtigungsgrundlage,

- Formelle Rechtmäßigkeit und

- Materielle Rechtmäßigkeit.

Einige wichtige Besonderheiten sind aber bei den einzelnen Prüfungspunkten zu beachten: ${ }^{2408}$

\section{a) Ermächtigungsgrundlage}

1392 Nebenbestimmungen können die Freiheit des Bürgers beschränken und bedürfen daher einer gesetzlichen Grundlage (Vorbehalt des Gesetzes - s. Rn. $555 \mathrm{ff}$.). Ermächtigungsgrundlage für den Erlass einer Nebenbestimmung wird regelmäßig § 36 I VwVfG oder § 36 II VwVfG sein. Seltener kann auch eine spezialgesetzliche Regelung in Betracht kommen.

\section{b) Formelle Rechtmäßigkeit}

1393 Im Rahmen der formellen Rechtmäßigkeit ist zu prüfen, ob die Anhörung (s. Rn. 631 ff.) gem. § 28 I VwVfG ordnungsgemäß erfolgt ist. Weil Nebenbestimmungen den Bürger belasten, muss der Bürger richtigerweise auch die Möglichkeit haben, sich rechtzeitig gegenüber der Behörde zu äußern.

2408 Hufen/Bickenbach, JuS 2004, 966 ff. 
Examenswissen: Diese Ansicht ist nicht unumstritten. ${ }^{2409}$ Dahinter steht meist 1394 die Überlegung, dass die Anhörung nur für belastende Hauptverwaltungsakte notwendig sei, Nebenbestimmungen aber öfters zu begünstigenden Verwaltungsakten hinzugefügt werden.

Fehlt es an der erforderlichen Anhörung, ist die Nebenbestimmung formell $\mathbf{1 3 9 5}$ rechtswidrig. Allerdings kann der Fehler nach allgemeinen Regeln (s. Rn. 693 ff.) geheilt werden (§ $45 \mathrm{VwVfG}$ ) oder unbeachtlich sein (§ $46 \mathrm{VwVfG}$ ).

Im Übrigen richtet sich die formelle Rechtmäßigkeit nach dem bekannten 1396 Schema (s. Rn. 579ff.):

- Zuständigkeit,

- Verfahren und

- Form.

\section{c) Materielle Rechtmäßigkeit}

Die materielle Rechtmäßigkeit erfordert, dass die Anforderungen der Ermäch- 1397 tigungsgrundlage eingehalten werden.

\section{aa) Spezialgesetzliche Ermächtigung}

Kommt ausnahmsweise nicht $§ 36$ VwVfG, sondern eine andere Rechtsgrundlage 1398 in Betracht, ist diese als spezialgesetzliche Regelung vorrangig zu prüfen. Es müssen dann nur die Voraussetzungen dieser Rechtsgrundlage gegeben sein. Hingegen kommt es auf $\S 36$ VwVfG und dessen Voraussetzungen nicht mehr an.

\section{bb) Regelfall des $§ 36$ VwVfG}

In der überwiegenden Anzahl der Fälle wird es allerdings auf $\S 36$ VwVfG an- 1399 kommen. Dabei ist danach zu unterscheiden, ob die Behörde beim Erlass des Hauptverwaltungsaktes über Ermessen verfügt oder nicht (s. Rn. 729ff.).

\section{(1) Gebundene Entscheidung}

Im Anwendungsbereich des § 36 I VwVfG - für einen gebundenen Hauptver- 1400 waltungsakt - ist zunächst zu prüfen, ob die Nebenbestimmung ,durch Rechts-

2409 Vgl. näher Stelkens, in: Stelkens/Bonk/Sachs, VwVfG, 9. Aufl. 2018, § 36 Rn. 25 und § 28 Rn. $31 \mathrm{ff}$. 
vorschrift zugelassen ist oder [...] sie sicherstellen soll, dass die gesetzlichen Voraussetzungen des Verwaltungsakts erfüllt werden.“

In der Klausur ist insbesondere die Sicherstellung der gesetzlichen Voraussetzungen bedeutsam. Hier ist zu begutachten, ob erstens der Bürger derzeit keinen Anspruch auf den Hauptverwaltungsakt hat, weil nicht alle gesetzlichen Voraussetzungen erfüllt sind, und zweitens, ob die Nebenbestimmung die fehlende(n) Voraussetzung(en) „ersetzt“ (d.h. deren Erfüllung sicherstellt). Sind hingegen bereits alle gesetzlichen Voraussetzungen erfüllt, muss der Bürger den begehrten Hauptverwaltungsakt auch ohne Nebenbestimmungen erhalten.

\section{(2) Ermessensentscheidung}

1402 Liegt der Hauptverwaltungsakt im Ermessen der Behörde, dann sind auch Nebenbestimmungen ohne weitere Voraussetzungen grundsätzlich zulässig, vgl. § 36 II VwVfG. Es kommt insbesondere nicht darauf an, dass die gesetzlichen Voraussetzungen des Verwaltungsakts sichergestellt werden. Daher muss sehr deutlich zwischen den beiden Absätzen des $§ 36 \mathrm{VwVfG}$ unterschieden werden:

- Falls ein Anspruch auf den Hauptverwaltungsakt besteht, dann I.

- Falls der Hauptverwaltungsakt im Ermessen steht, dann II.

\section{(3) Weitere Voraussetzungen}

1403 Der Erlass von Nebenbestimmungen ist eine Ermessensentscheidung der Behörde („,darf“, „nach pflichtgemäßem Ermessen“, vgl. §36 I, II VwVfG). Die Behörde kann zwar Nebenbestimmungen erlassen, muss es aber nicht. Diese Ausübung des Ermessens darf nicht mit dem Ermessen zum Erlass des Hauptverwaltungsaktes verwechselt werden. In der Klausur ist die Entscheidung der Behörde auf Ermessensfehler zu überprüfen (s. zur Ermessensfehlerlehre Rn. 739 ff.). Dabei sind auch die Grundrechte und der Grundsatz der Verhältnismäßigkeit zu berücksichtigen.

1404 Soweit entsprechende Anhaltspunkte bestehen, ist auch auf § 36 III VwVfG einzugehen. Das Kopplungsverbot (s. Rn. $243 \mathrm{ff}$.) ist dann nicht verletzt, wenn ein sachlicher Zusammenhang zwischen der Nebenbestimmung und dem Hauptverwaltungsakt besteht.

1405 Im Ergebnis setzt sich also die Prüfung der materiellen Rechtmäßigkeit zusammen aus:

- Einhaltung der gesetzlichen Voraussetzungen des § 36 VwVfG,

- Ordnungsgemäße Ausübung des Ermessens und

- Ggf. Beachtung des Kopplungsverbotes. 


\section{Verletzung subjektiver Rechte}

Voraussetzung für den Erfolg der Anfechtungsklage ist weiterhin, dass der Kläger 1406 in seinen Rechten verletzt wird, vgl. § 113 I 1 VwGO (s. ausführlich § 2 Rn. 828 ff.). Für Nebenbestimmungen gilt, dass für rechtswidrige, belastende Nebenbestimmungen eine solche Rechtsverletzung anzunehmen ist. Der Kläger hat nämlich entweder einen Anspruch auf einen nebenbestimmungsfreien Verwaltungsakt oder einen Anspruch auf ermessensfehlerfreie Entscheidung über den Erlass der Nebenbestimmungen. ${ }^{2410}$

Im Gutachten reicht deshalb regelmäßig die Feststellung aus, dass die rechtswidrigen Nebenbestimmungen den Kläger auch in dessen Rechten verletzen, vgl. § 113 I 1 VwGO.

\section{Sinnvoller und rechtmäßiger Rest-Verwaltungsakt}

Der verbleibende Verwaltungsakt wird regelmäßig sinnvoll sein. Der Rest-Ver- 1407 waltungsakt wäre dann sinnlos, wenn entweder „der verbleibende Teil keine selbstständige Bedeutung hat oder der Verwaltungsakt bei Wegfall der Nebenbestimmung einen anderen Sinn erhalten und dadurch seinen Zweck verfehlen würde.“2411 Da Verwaltungsakte ohne Nebenbestimmungen erlassen werden können, ist aber kaum einzusehen, wann die Aufhebung einer Nebenbestimmung den Verwaltungsakt einmal sinnlos werden lassen sollte. ${ }^{2412}$

Wichtiger ist das Kriterium der Rechtmäßigkeit des Rest-Verwaltungsakts. 1408 Dieser wird insbesondere rechtswidrig sein, wenn die Nebenbestimmung erst die Rechtmäßigkeit des Hauptverwaltungsaktes herbeiführen sollte, vgl. §36 I VwVfG. ${ }^{2413}$ Ohne die Nebenbestimmung wäre die Erfüllung der gesetzlichen Voraussetzungen nicht mehr sichergestellt.

Beispiel: Baugenehmigung mit der Auflage, den Brandschutz zu gewährleisten

Eine Baugenehmigung darf regelmäßig nur dann erteilt werden, wenn das Vorhaben mit allen öffentlich-rechtlichen Vorschriften im Einklang steht. Zu diesen Vorschriften gehört auch der Brandschutz, sodass das Vorhaben eigentlich nicht genehmigungsfähig wäre. Die Rechtmäßigkeit der Baugenehmigung kann nur dadurch herbeigeführt werden, dass eine Nebenbestimmung erlassen wird.

2410 Hufen/Bickenbach, JuS 2004, 966 (968).

2411 Sproll, NJW 2002, 3221 (3222).

2412 Vgl. Bumke, in: Festschrift für Battis, 2014, 177 (194).

2413 Vgl. Bumke, in: Festschrift für Battis, 2014, 177 (187). 
Entfällt die Nebenbestimmung, dann kann die Baugenehmigung nicht mehr rechtmäßiger Weise bestehen bleiben. Es stünden dem Vorhaben wieder öffentlich-rechtliche Vorschriften entgegen. In einem solchen Fall kann die Nebenbestimmung nicht aufgehoben werden. Die Anfechtungsklage wäre zwar zulässig, aber unbegründet.

1409 Der Rest-Verwaltungsakt kann schließlich deshalb rechtswidrig sein, weil die Behörde ihr Ermessen einheitlich ausgeübt hat (Hauptverwaltungsakt und Nebenbestimmung). Wird die Nebenbestimmung aufgehoben, konnte die Behörde zuvor noch keine selbstständige Ermessensentscheidung über den verbleibenden Rest-Verwaltungsakt treffen. ${ }^{2414}$

Beispiele: Entscheidung über eine Subvention mit einer (belastenden) Auflage; Befristete Sondernutzungserlaubnis für eine künstlerische Darbietung

Die Behörde hat über Hauptverwaltungsakt und Nebenbestimmung bisher ausschließlich gemeinsam „nachgedacht“. Das ihr zustehende Ermessen hat die Behörde nicht für den Fall einer Subvention ohne Auflage (oder Sondernutzungserlaubnis ohne Befristung) ausgeübt. Deshalb könnte man den Rest-Verwaltungsakt für rechtswidrig und die Anfechtungsklage für unbegründet erachten.

Zusammengefasst existieren also verschiedene Fallgruppen, wann ein Hauptverwaltungsakt nicht „rechtmäßiger Weise bestehen bleiben“ kann:

- Herbeiführung der Rechtmäßigkeit gerade durch die Nebenbestimmung,

- Einheitliche Ermessensausübung der Behörde und

- Sonstige Fälle der Rechtswidrigkeit.

Erweist sich der verbleibende Verwaltungsakt nicht als „rechtmäßig und sinnvoll“, dann ist die Anfechtungsklage zulässig, aber unbegründet.

Dem Bürger steht allerdings immer noch die Verpflichtungsklage zur Verfügung. Wenn der begehrte Verwaltungsakt rechtswidrig ist, weil die gesetzlichen Voraussetzungen ohne die Nebenbestimmung nicht sichergestellt sind, kann auch die Verpflichtungsklage keinen Erfolg haben. Der Bürger hat keinen Anspruch auf den Erlass eines rechtswidrigen Verwaltungsakts. Denkbar ist aber ein Anspruch auf den Verwaltungsakt mit einer rechtmäßigen Nebenbestimmung. 1412 Der Rest-Verwaltungsakt kann außerdem deshalb rechtswidrig sein, weil die Ermessensausübung nur einheitlich erfolgt ist. Da der Verwaltungsakt in diesem Fall im Ermessen der Behörde liegt, steht dem Bürger nach allgemeinen Regeln

2414 Schenke, in: Festschrift für Roellecke, 1997, 281 (295).

Christian Kaerkes 
nur ein Anspruch auf eine ermessensfehlerfreie Entscheidung zu. Im Ergebnis erreicht der Bürger regelmäßig ein „Bescheidungsurteil“, vgl. § 113 V 2 VwGO.

In der Klausur darf daher die Prüfung der Verpflichtungsklage nicht vergessen werden, wenn die Anfechtungsklage daran scheitert, dass der Rest-Verwaltungsakt nicht „rechtmäßig und sinnvoll“ wäre (zur Prüfung der Verpflichtungsklage ausführlich $\S 3$ ).

Examenswissen: Die zusätzliche Voraussetzung, dass der Verwaltungsakt rechtmäßig bestehen bleiben können muss, ist in der Literatur nicht unumstritten. Die Bindung an Gesetz und Recht (Art. 20 III GG) hilft in diesem Fall nicht weiter („Rechtsstaatsklemme“ $)^{2415}$, weil entweder die rechtswidrige Nebenbestimmung hingenommen werden muss oder ein rechtswidriger Verwaltungsakt geschaffen wird.

Letztendlich geht es um die Frage, ob die Nachteile durch den Bürger oder die Verwaltung getragen werden sollten. Hierauf sind zwei Antworten möglich:

Widersprüchliches Verhalten des Bürgers oder Verantwortung der Behörde: Der Bürger muss sich vorhalten lassen, dass er die Aufhebung des rechtswidrigen Zustandes nur insoweit begehrt, als er belastet ist. Die rechtswidrige Begünstigung möchte er weiterhin in Anspruch nehmen können. Darin kann ein widersprüchliches Verhalten erblickt werden. ${ }^{2416}$ Der Bürger verlangt nicht, den rechtswidrigen Zustand zu beenden, sondern nur, ihn zu seinen Gunsten zu verändern und zu perpetuieren.

Der Behörde ist hingegen der Vorwurf zu machen, dass sie für die anfängliche Rechtswidrigkeit verantwortlich ist. Immerhin hat die Behörde den Verwaltungsakt mit der rechtswidrigen Nebenbestimmung überhaupt erlassen. Weil rechtswidrige Verwaltungsakte aufgehoben werden können (§§ 48, 49 VwVfG), könnte man es der Behörde auch anlasten, wenn sie von dieser Möglichkeit keinen Gebrauch macht.

Wer diese Verantwortung der Behörde betont, kann die in der Rechtsprechung aufgestellte Voraussetzung („Rechtmäßigkeit des Rest-Verwaltungsakts“) ablehnen. Zu prüfen sind dann „nur“ die Voraussetzungen des § 113 I 1 VwGO. Die Anfechtungsklage ist begründet, soweit die Nebenbestimmung rechtswidrig ist und den Kläger in seinen Rechten verletzt.

\section{Literaturhinweise}

Hufen/Bickenbach, JuS 2004, 966: „Der Rechtsschutz gegen Nebenbestimmungen 1415 zum Verwaltungsakt“; Im Übrigen s. bereits Rn. 279

2415 Hufen/Bickenbach, JuS 2004, 966 (967).

2416 Schenke, JuS 1983, 182 (185). 